\title{
Jan Stehle
}

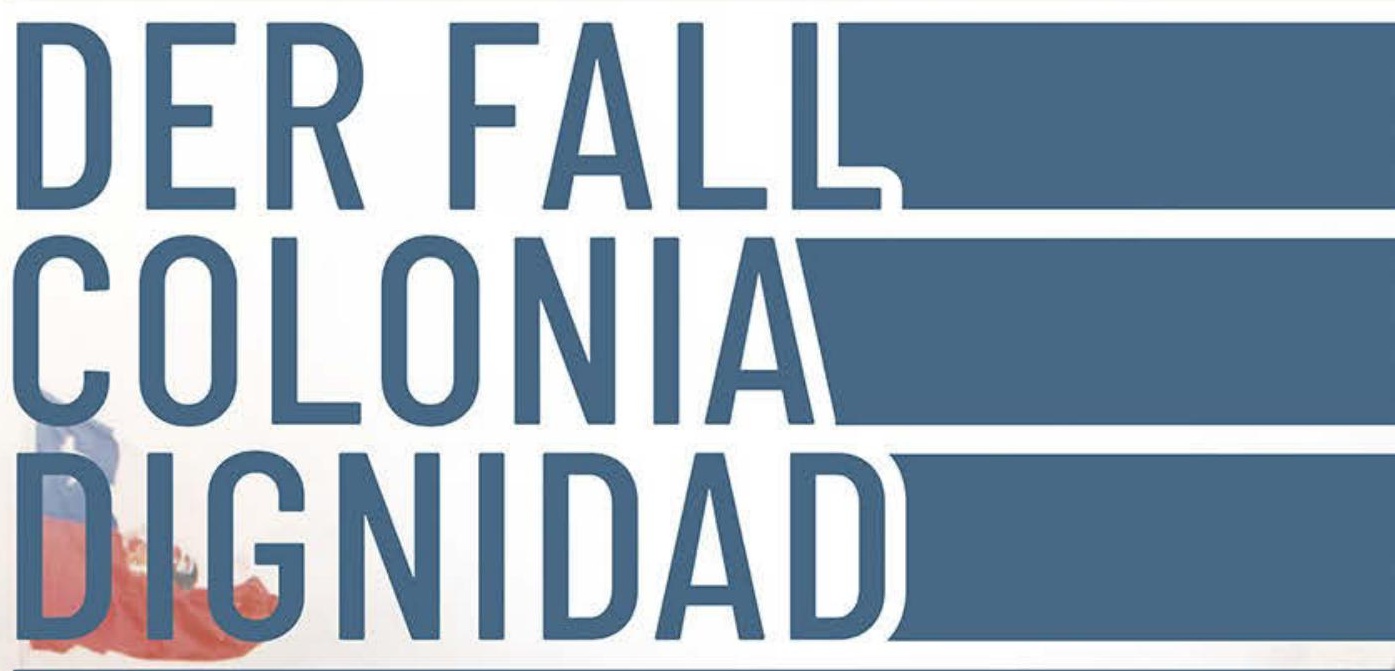

Zum Umgang bundesdeutscher Außenpolitik und Justiz mit Menschenrechtsverletzungen 1961-2020

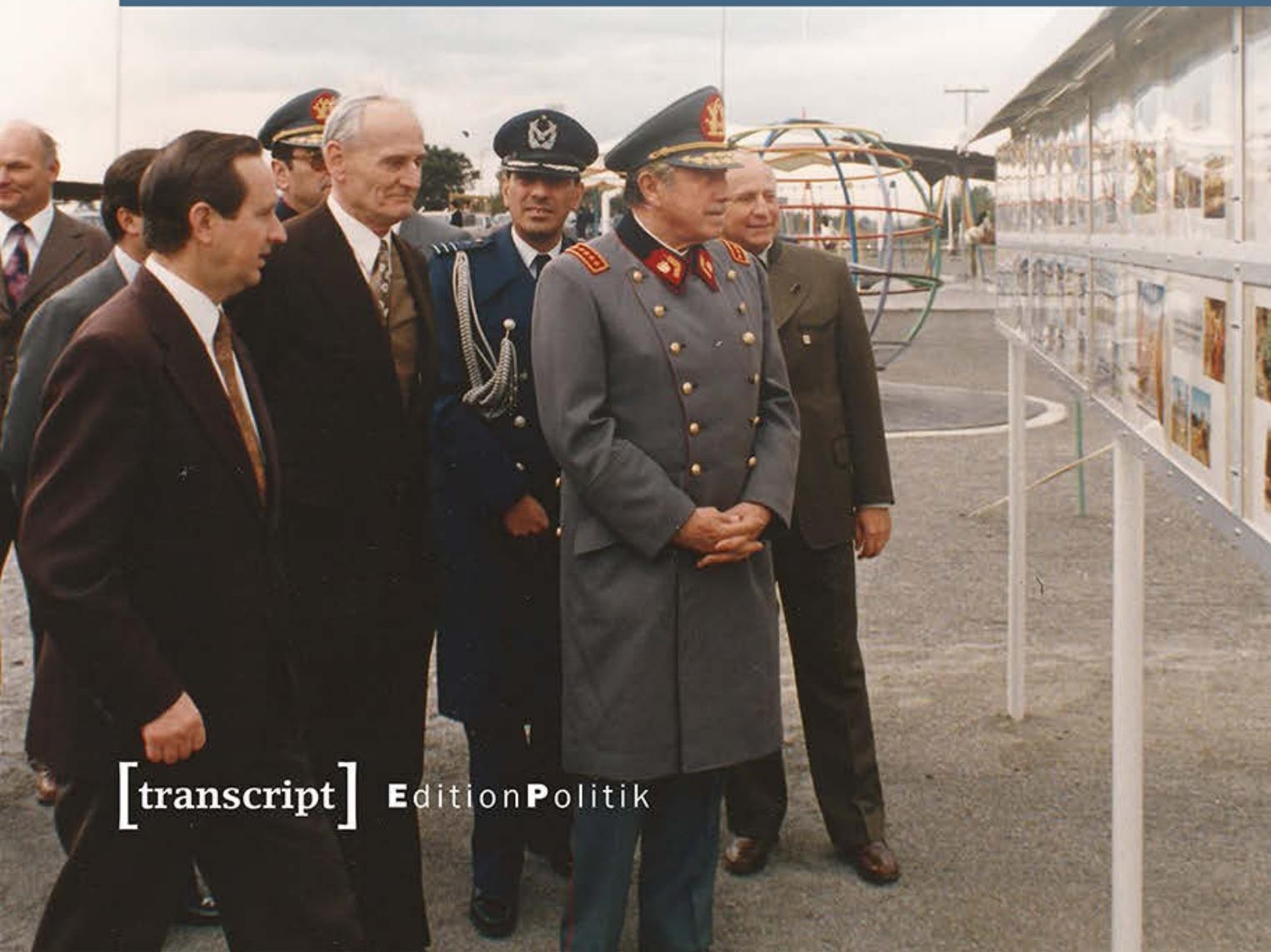


Jan Stehle

Der Fall Colonia Dignidad

Edition Politik | Band 125 
Die freie Verfügbarkeit der E-Book-Ausgabe dieser Publikation wurde ermöglicht durch den Fachinformationsdienst Politikwissenschaft POLLUX

P OLLUX Informationsdienst

und ein Netzwerk wissenschaftlicher Bibliotheken zur Förderung von Open Access in den Sozial- und Geisteswissenschaften (transcript, Politikwissenschaft 2021)

Die Publikation beachtet die Qualitätsstandards für die Open-Access-Publikation von Büchern (Nationaler Open-Access-Kontaktpunkt et al. 2018), Phase 1 https://oa2020-de.org/blog/2018/07/31/empfehlungen_qualitätsstandards_oabücher/

Hauptsponsor: Staats- und Universitätsbibliothek Bremen (POLLUX - Informationsdienst Politikwissenschaft)

Vollsponsoren: Universitätsbibliothek Bayreuth | Universitätsbibliothek der HumboldtUniversität zu Berlin | Freie Universität Berlin - Universitätsbibliothek| Staatsbibliothek zu Berlin | Universitätsbibliothek Bielefeld | Universitätsbibliothek der Ruhr-Universität Bochum (RUB) | Universitäts- und Landesbibliothek Bonn | Vorarlberger Landesbibliothek | Universitätsbibliothek der Technischen Universität Chemnitz | Universitäts- und Landesbibliothek Darmstadt | Sächsische Landesbibliothek Staats- und Universitätsbibliothek Dresden (SLUB) | Universitätsbibliothek Duisburg-Essen | Universitäts- und Landesbibliothek Düsseldorf | Universitätsbibliothek Erlangen-Nürnberg | Universitätsbibliothek Frankfurt/M. | Niedersächsische Staats- und Universitätsbibliothek Göttingen | Universitätsbibliothek Greifswald | Universitätsbibliothek der FernUniversität in Hagen | Staats- und Universitätsbibliothek Carl von Ossietzky, Hamburg | TIB - Leibniz-Informationszentrum Technik und Naturwissen- schaften und Universitätsbibliothek | Gottfried Wilhelm Leibniz Bibliothek - Niedersächsische Landesbibliothek | Universitätsbibliothek Heidelberg | Universitätsbibliothek Kassel | Universitätsbibliothek Kiel (CAU) | Universitätsbibliothek Koblenz - Landau | Universitäts- und Stadtbibliothek Köln | Universitätsbibliothek Leipzig | Zentral- und Hochschulbibliothek Luzern | Universitätsbibliothek Otto-von-Guericke-Universität Magdeburg | Universitätsbibliothek Marburg | Max Planck Digital Library (MPDL) | Universitäts- und Landesbibliothek Münster | Universitätsbibliothek der Carl von Ossietzky-Universität, Oldenburg | Universitätsbibliothek Osnabrück | Universitätsbibliothek Passau | Universitätsbibliothek St. Gallen | Universitätsbibliothek Vechta | Universitätsbibliothek Wien | Universitätsbibliothek Wuppertal | Zentralbibliothek Zürich

Sponsoring Light: Bundesministerium der Verteidigung | Landesbibliothek Oldenburg Mikrosponsoring: Stiftung Wissenschaft und Politik (SWP) - Deutsches Institut für Internationale Politik und Sicherheit | Leibniz-Institut für Europäische Geschichte, Mainz

Jan Stehle, geb. 1974, lebt in Berlin, wo er am Forschungs- und Dokumentationszentrum Chile-Lateinamerika (FDCL) tätig ist. Der Politikwissenschaftler, Ökonom und Menschenrechtsaktivist forscht seit Jahren zum Thema Colonia Dignidad und setzt sich auf verschiedenen Ebenen für die Aufarbeitung der dort begangenen Verbrechen ein. 
Jan Stehle

\section{Der Fall Colonia Dignidad}

Zum Umgang bundesdeutscher Außenpolitik und Justiz mit

Menschenrechtsverletzungen 1961-2020 
Dissertation am Fachbereich Politik- und Sozialwissenschaften der Freien Universität Berlin, Einreichung und Disputation 2020.

\section{Bibliografische Information der Deutschen Nationalbibliothek}

Die Deutsche Nationalbibliothek verzeichnet diese Publikation in der Deutschen Nationalbibliografie; detaillierte bibliografische Daten sind im Internet über http://dnb.dnb.de abrufbar.

\section{(c) $(1)(\Theta)$}

Dieses Werk ist lizenziert unter der Creative Commons Attribution-NonCommercial-NoDerivs 4.0 Lizenz (BY-NC-ND). Diese Lizenz erlaubt die private Nutzung, gestattet aber keine Bearbeitung und keine kommerzielle Nutzung. Weitere Informationen finden Sie unter https://creativecommons.org/licenses/by-nc-nd/4.o/deed.de Um Genehmigungen für Adaptionen, Übersetzungen, Derivate oder Wiederverwendung zu kommerziellen Zwecken einzuholen, wenden Sie sich bitte an rights@transcript-publishing.com Die Bedingungen der Creative-Commons-Lizenz gelten nur für Originalmaterial. Die Wiederverwendung von Material aus anderen Quellen (gekennzeichnet mit Quellenangabe) wie z.B. Schaubilder, Abbildungen, Fotos und Textauszüge erfordert ggf. weitere Nutzungsgenehmigungen durch den jeweiligen Rechteinhaber.

\section{(c) 2021 transcript Verlag, Bielefeld}

Umschlaggestaltung: Maria Arndt, Bielefeld

Umschlagabbildung: Winfried Hempel. Dargestellt ist Augusto Pinochet bei einem Besuch des Casino Familiar der Colonia Dignidad in Bulnes mit Paul Schäfer (re.) und weiteren Führungsmitgliedern der Gruppierung. [Jahr unbekannt]

Druck: Majuskel Medienproduktion GmbH, Wetzlar

Print-ISBN 978-3-8376-5871-2

PDF-ISBN 978-3-8394-5871-6

EPUB-ISBN 978-3-7328-5871-2

https://doi.org/10.14361/9783839458716

Buchreihen-ISSN: 2702-9050

Buchreihen-eISSN: 2702-9069

Gedruckt auf alterungsbeständigem Papier mit chlorfrei gebleichtem Zellstoff. Besuchen Sie uns im Internet: https://www.transcript-verlag.de Unsere aktuelle Vorschau finden Sie unter www.transcript-verlag.de/vorschau-download 


\section{Inhalt}

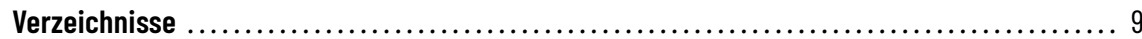

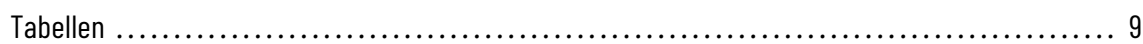

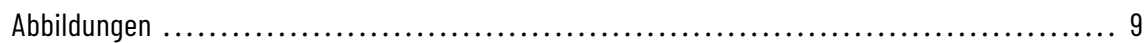

Archivsiglen ...................................................... 10

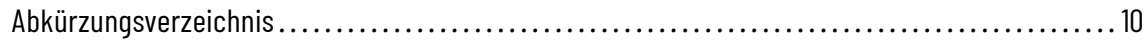

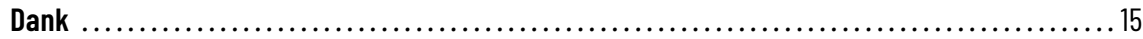

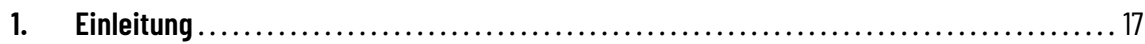

2. Der Fall Colonia Dignidad: Akteur_innen, Quellen und Vorgehen ................... 27

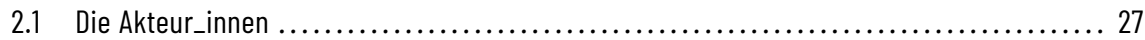

2.2 Die vorhandenen Quellen und mein Umgang mit ihnen ........................... 38

2.2.1 Literatur ..................................................... 39

2.2.2 Presseberichterstattung .......................................... 42

2.2 .3 Archive ........................................................ 45

2.2.4 Akten aus juristischen Verfahren..................................... 47

2.2.5 Das Geheimarchiv und andere Quellen der Colonia Dignidad ................... 51

2.3 Wissenschaftliche Aufarbeitung von Menschenrechtsverbrechen...................... 61

2.3.1 Das Amt und der Aktenzugang: Informationsfreiheit und Behördentransparenz .... 62

2.3.2 Gesetzliche Regelungen des Aktenzugangs zu Forschungszwecken.............6 63

2.3.3 Meine eigenen Bemühungen um Aktenzugang für die Forschung zu dieser Arbeit ... 68

3. Entstehungsgeschichte und Struktur der Colonia Dignidad ...................... 85

3.1 Die pseudoreligiöse kriminelle Gemeinschaft - Genese und Struktur ................. 87

3.1.1 Paul Schäfer und die Entstehung der Gruppierung in den 1950er Jahren .......... 88

3.1.2 Interne Struktur und Hierarchieebenen ................................ 106

3.1.3 Die pseudoreligiöse kriminelle Gemeinschaft - innere Struktur ................. 111

3.1.4 Die kriminelle Vereinigung - Wirken nach außen ....................... 116

3.2 Colonia Dignidad - Ort, Rechtspersonen und Eigentumsstruktur ......................... 119

3.2.1 Rechtspersonen und Dependancen in der Bundesrepublik ................... 120 
3.2.2 Niederlassungen der Colonia Dignidad in Chile 123

3.2.3 Rechtspersonen und Eigentumsstruktur der Colonia Dignidad in Chile ........... 127

4. Der bisherige Kenntnisstand über die Verbrechen der Colonia Dignidad .............. 149

4.1 Die internen Verbrechen der kriminellen Gemeinschaft Colonia Dignidad ................ 152

4.1 .1 Sexueller Missbrauch ............................................... 152

4.1.2 Kindesentführung nach Chile, Adoptionsbetrug ............................ 159

4.1.3 Freiheitsberaubung - Fluchtfälle und Hilferufe......................... 180

4.1.4 Postzensur und -überwachung ..................................... 197

4.1.5 Missachtung des Rechts auf Schulbildung ............................. 202

4.1.6 Arbeitsverhältnisse .............................................. 205

4.1.7 Unfälle und andere Vorfälle, teilweise mit Todesfolge ...................... 211

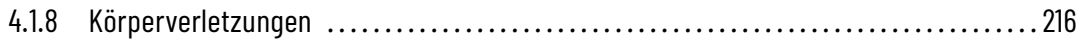

4.2 Die externen Verbrechen der kriminellen Organisation Colonia Dignidad ............... 232

4.2.1 Kindesaneignungen - Betrügerische Adoption von chilenischen Kindern.......... 232

4.2.2 Waffenbau und Waffenhandel .................................... 241

4.2.3 Menschenrechtsverbrechen im Kontext der chilenischen Diktatur .............. 258

4.2.4 Sexualverbrechen gegen chilenische Kinder ........................... 299

4.2 .5 Ungeklärte Todesfälle....................................... 303

5. Die juristische und parlamentarische Aufarbeitung der Verbrechen

der Colonia Dignidad ................................................ 311

5.1 Juristische Aufarbeitung der Verbrechen in Chile .............................. 314

5.1.1 Verfahren nach der Flucht von Wolfgang Müller (1966-1969)................... 324

5.1.2 Untersuchung der Ermordung von Juan René Muñoz Alarcón (1978).............. 329

5.1.3 Untersuchungen durch die Richter Navas und Robert (1989) .................. 336

5.1.4 Verfahren wegen sexuellen Missbrauchs an Chilenen (1996-2013) ................ 354

5.1.5 Verfahren wegen Menschenrechtsverbrechen (seit 2005) ..................... 357

5.2 Parlamentarische Vorgänge in Chile ................................. 360

5.2.1 Aberkennung der Immunität von Héctor Taricco und Claudio Fuentes 1968 ...... 360

5.2.2 Untersuchungsausschuss der Cámara de Diputados 1968 .................... 364

5.2.3 Besuch des Menschenrechtsausschusses in der Colonia Dignidad 1990 .......... 367

5.2.4 Untersuchungsausschuss der Cámara de Diputados 1995 ..................... 368

5.2.5 Untersuchungsausschuss der Cámara de Diputados 1997 .................... 374

5.2.6 Untersuchung der Ausschüsse für Menschenrechte und Familie 1999 ...............381

5.3 Juristische Aufarbeitung der Verbrechen in der Bundesrepublik .................... 387

5.3.1 Zivilverfahren gegen Amnesty International vor dem LG Bonn (1977-1997) ......... 394

5.3.2 Zivilverfahren gegen Hugo Baar vor dem LG Köln (1988-1995) ................... 405

5.3.3 Ermittlungen der StA Siegen und Bonn (1977) .............................. 408

5.3.4 Ermittlungen der StA Bonn (1985-2010) ................................... 411

5.3.5 Ermittlungen der StA Bonn wegen Diktaturverbrechen in der Colonia Dignidad $(1991-2010)$................................. 436

5.3.6 Ermittlungen der StA Bonn wegen sexuellen Missbrauchs (1997-2010) ............. 441

5.3.7 Ermittlungen der StA Memmingen, Krefeld und Bonn (2005-2008) .............. 442

5.3.8 Ermittlungen der StA Krefeld (2011-2019) .............................. 443 
5.3.9 Chilenisches Vollstreckungsersuchen zu Hartmut Hopp (2014-2018).............. 451

5.3.10 Ermittlungen der StA Münster (2016-2019)............................ 454

5.4 Der Fall Colonia Dignidad im Deutschen Bundestag .......................... 456

5.4.1 Anhörung im Unterausschuss für Menschenrechte und humanitäre Hilfe 1988 .... 460

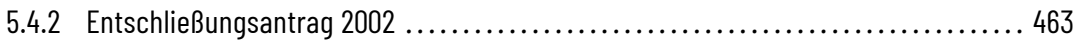

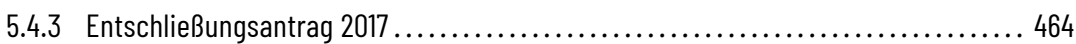

5.4 .4 Weitere Aktivitäten des Bundestages .............................. 467

6. Fünf historische Phasen des Falls Colonia Dignidad ......................... 475

6.1 Phase I (bis 1961): Die Genese einer totalitären Gruppierung .......................... 481

6.2 Phase II (1961-1973): Aufbau in Chile, erste Skandale und Allende-Regierung ............. 486

6.2.1 1961-1966: Aufbau der Siedlung und Vernetzung mit lokalen Eliten .............. 487

6.2.2 1966-1968: juristische und politische Erfolge der CD-Strategie.................. 490

6.2.3 1968-1973: Die zahnlose Botschaft und die Allianz der Colonia Dignidad mit den Putschisten ........................................... 492

6.3 Phase III (1973-1990): Die Colonia Dignidad während der chilenischen Militärdiktatur ..... 495

6.3.1 1973-1979: Die »harte Phase« der Diktatur - Kalter Krieg und Unterstützung für die Colonia Dignidad ................................. 497

6.3.2 1979-1984: Jahre des Schweigens - Bekannte Fakten und mächtige Netzwerke .....515

6.3.3 1985-1987: Die allmähliche Sensibilisierung der bundesdeutschen Diplomatie ...... 515

6.3.4 1988-1990: Der ergebnislose Einsatz Genschers ......................... 530

6.4 Phase IV (1990-2005): Die chilenische Transición bis zur Festnahme Schäfers .......... 542

6.4.1 1990-1996: Verwaltungshandeln in Chile und deutsche Passivität .............. 542

6.4.2 1997-2005: Schäfers Ende durch Aufklärer_innen im Alleingang ................ 548

6.5 Phase V (2005 bis heute): Die verspätete Transición der Colonia Dignidad .............. 553

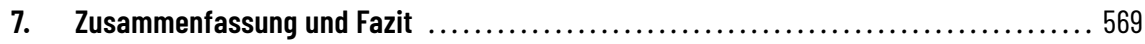

7.1 Akteur_innen des Falls Colonia Dignidad, Literatur und Quellen (Kapitel 2) .............. 569

7.2 Entstehung und Struktur der Colonia Dignidad (Kapitel 3) ............................ 571

7.3 Interne und externe Verbrechen der Colonia Dignidad (Kapitel 4) .................... 574

7.4 Juristische und parlamentarische Aufarbeitung der Verbrechen der Colonia Dignidad (Kapitel 5) ...................................... 578

7.5 Fünf historische Phasen des Falls Colonia Dignidad (Kapitel 6) ....................... 590

7.6 Fazit und Ausblick ............................................... 605

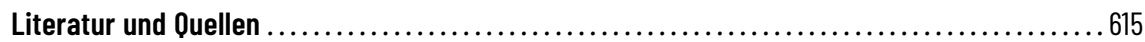

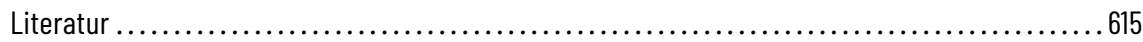

Archivbestände ....................................................... 640 



\section{Verzeichnisse}

\section{Tabellen}

Seite 43 | Tabelle 1: Phasen der Presseberichterstattung über den Fall Colonia Dignidad

Seite 46 | Tabelle 2: Recherche in deutschen, chilenischen und US-amerikanischen Archiven

Seite 87 | Tabelle 3: Die Verbrechen der Colonia Dignidad

Seite 107 | Tabelle 4: Gruppen und Alterssegmente

Seite 144 | Tabelle 5: Chronologie der Rechtspersonen, Unternehmen und Vermögenstransaktionen der Colonia Dignidad

Seite 148 | Tabelle 6: Rechtspersonen und Unternehmen der Colonia Dignidad

Seite 193 Tabelle 7: Fluchtversuche und Hilfsersuchen aus der Colonia Dignidad

Seite 194 | Tabelle 8: Weitere in Quellen erwähnte Fluchtversuche

Seite 281 | Tabelle 9: Übersicht der chilenischen Strafverfahren wegen Verschwundenen

Seite 317 Tabelle 10: Übersicht der wichtigsten Justizverfahren in Chile seit 1966

Seite 358 | Tabelle 11: An Richter Jorge Zepeda übertragene bzw. von ihm eröffnete Verfahren

Seite 390| Tabelle 12: Strafrechtliche Ermittlungsverfahren in der Bundesrepublik Deutschland

Seite 391 | Tabelle 13: Von der CD angestrengte Gerichtsverfahren in der Bundesrepublik

Seite 431 | Tabelle 14: Auflistung der Zeug_innenaussagen im Verfahren StA Bonn, AZ 50 Js $285 / 85$

Seite 468 | Tabelle 15: Aktivitäten des Deutschen Bundestages mit Bezug zur Colonia Dignidad

\section{Abbildungen}

Seite 56 | Abbildung 1: Ficha Fernando Gómez Segovia

Seite 57 Abbildung 2: Ficha Alvaro Vallejos Villagrán (2)

Seite 58 | Abbildung 3: Ficha Eduardo Fernando Soto Henríquez (1) 
Seite 58 | Abbildung 4: Ficha Eduardo Fernando Soto Henríquez (2)

Seite 59 | Abbildung 5: Auszug der Ficha Luis Enrique Peebles Skarnic (3)

Seite 60 Abbildung 6: Ficha Hernán Larraín Fernández (1)

Seite 60 Abbildung 7: Ficha Hernán Larraín Fernández (2)

Seite 244 | Abbildung 8: Schild an der Zufahrtstraße zur ehemaligen Colonia Dignidad, das vor Sprengstoff warnt

Seite 293 | Abbildung 9: Ficha Pedro Castro C

\section{Archivsiglen}

$\begin{array}{ll}\text { A MMDH } & \text { Archivo Museo de la Memoria y los Derechos Humanos } \\ \text { AdsD } & \text { Archiv der sozialen Demokratie (Archiv der Friedrich-Ebert-Stiftung) } \\ \text { AGH } & \begin{array}{l}\text { Archivo General Histórico (Archiv des chilenischen Außenministe- } \\ \text { riums) }\end{array} \\ \text { Archiv AI } & \text { Archiv von Amnesty International Deutschland } \\ \text { Archiv BPA } & \text { Archiv des Bundespresseamts } \\ \text { Archiv FDCL } & \text { Archiv des Forschungs- und Dokumentationszentrums Chile- } \\ & \text { Lateinamerika } \\ \text { Archiv FUNVISOL Fundación de Documentación y Archivo Vicaría de la Solidaridad } \\ \\ \text { BArch } & \text { (Archiv der Nachfolgestiftung der katholischen Menschenrechtsor- } \\ \text { HISArch } & \text { ganisation Vicaría de la Solidaridad) } \\ \text { PA AA } & \text { Bundesarchiv } \\ \text { PA-DBT } & \text { Archiv des Hamburger Instituts für Sozialforschung } \\ \text { PDM } & \text { Politisches Archiv des Auswärtigen Amts } \\ \text { PHF } & \text { Parlamentsarchiv des Deutschen Bundestags } \\ \text { PJD } & \text { Privatarchiv Dieter Maier } \\ \text { PJK } & \text { Privatarchiv Hernán Fernández } \\ \text { PJS } & \text { Privatarchiv John Dinges } \\ \text { PWH } & \text { Privatarchiv Jürgen Karwelat } \\ & \text { Privatarchiv Jan Stehle }\end{array}$

\section{Abkürzungsverzeichnis}

AA Auswärtiges Amt

ABC Agripalma, Bardana, Cinoglosa (1988-1990 gegründete Aktiengesellschaften der Colonia Dignidad)

ACDP Archiv für Christlich-Demokratische Politik (Archiv der Konrad-AdenauerStiftung)

ACSP Archiv für Christlich-Soziale Politik (Archiv der Hanns-Seidel-Stiftung)

AFDD Agrupación de Familiares de Detenidos Desaparecidos (Verband der während der chil. Diktatur [1973-1990] durch Verschwindenlassen ermordeten Personen) Amtsgericht 
AI Amnesty International

AM Außenminister

AV NA Auslandsvertretung Neues Amt (Aktenbestand der Auslandsvertretungen im PA AA)

AZ Aktenzeichen

BArchG Bundesarchivgesetz

BfDI Bundesbeauftragte(r) für den Datenschutz und die Informationsfreiheit

BIR-Sur Brigada de Inteligencia Regional Sur (Brigade der DINA [1974-1977], zuständig für einige Regionen südlich von Santiago)

BKA Bundeskriminalamt

BM Bundesminister(-ium)

BMI Bundesministerium des Inneren

BND Bundesnachrichtendienst

BMJ(V) Bundesministerium der Justiz (und Verbraucherschutz)

BSG Bundessozialgericht

BT-DS Bundestagsdrucksache

BVA Bundesversicherungsamt (Bundesbehörde mit Rechtsaufsicht über Rententräger, seit 2019 Bundesamt für Soziale Sicherung [BAS])

BVerfG Bundesverfassungsgericht

BVerwG Bundesverwaltungsgericht

CA Corte de Apelaciones (Berufungsgericht)

CD Colonia Dignidad

CDE Consejo de Defensa del Estado de Chile (Vertretung des chilenischen Staates auf juristischer Ebene)

CF Cerro Florido Sociedad Colectiva Civil (Untergesellschaft des ABC-Aktienholdings)

CINTRAS Centro de Salud Mental y Derechos Humanos (Chilenische Menschenrechtsorganisation)

CIPER Centro de Investigación Periodística (Chilenisches Internetportal für Investigativjournalismus)

CIRE Centro de Inteligencia Regional (Geheimdienst-Einheit in der Region Biobío)

CMN Consejo de Monumentos Nacionales (Chilenische Denkmalschutzbehörde)

CNI Central Nacional de Inteligencia (Geheimdienst der chilenischen Diktatur [1977-1990], Nachfolgeorganisation der DINA)

CORFO Corporación de Fomento de la Producción (Verband zur Produktionsförderung [chilenische Behörde])

DB Drahtbericht (Verschlüsseltes Telegramm einer Auslandsvertretung an das AA)

DC Democracia Cristiana (Christdemokratische Partei in Chile)

DDHH Derechos Humanos (Menschenrechte)

DE Drahterlass (Verschlüsseltes Telegramm des AA an eine Auslandsvertretung)

DINA Dirección Nacional de Inteligencia (Geheimdienst der chilenischen Diktatur [1973-1977])

ECCHR European Center for Constitutional and Human Rights

FDCL Forschungs- und Dokumentationszentrum Chile-Lateinamerika 
FITAL Feria Internacional de Talca (Internationale Messe von Talca [hier war die $C D$ regelmäßig vertreten])

FS Fernschreiben

FUNVISOL Fundación de Documentación y Archivo Vicaría de la Solidaridad (Nachfolgestiftung der katholischen Menschenrechtsorganisation Vicaría de la Solidaridad)

GG Grundgesetz

GGO Gemeinsame Geschäftsordnung der Bundesministerien

GIZ Deutsche Gesellschaft für Internationale Zusammenarbeit $\mathrm{GmbH}$

GO-BT Geschäftsordnung des Deutschen Bundestages

GOPE Grupo de Operaciones Especiales (Spezialkräfte der chilenischen uniformierten Polizei [Carabineros])

GZ Geschäftszeichen

HISArch Archiv des Hamburger Instituts für Sozialforschung

IFG Informationsfreiheitsgesetz

IGFM Internationale Gesellschaft für Menschenrechte

INDH Instituto Nacional de Derechos Humanos (Nationales Menschenrechtsinstitut)

IRG Internationales Rechtshilfegesetz

JIPOL Jefatura de Inteligencia Policial (Geheimdienstliche Abteilung der PDI)

LG Landgericht

LMJ Landesministerium der Justiz

MdB Mitglied des Deutschen Bundestages

MIR Movimiento de Izquierda Revolucionaria (Bewegung der Revolutionären Linken)

MR- Menschenrechts-

NIG Not-und Interessengemeinschaft der Geschädigten der Colonia Dignidad

NL Nachlass

OHG Offene Handelsgesellschaft (Personenhandelsgesellschaft nach bundesdeutschem Gesellschaftsrecht)

OLG Oberlandesgericht

PA AA Politisches Archiv des Auswärtigen Amts

PA-DBT Parlamentsarchiv des Deutschen Bundestags

PC Partido Comunista (Chilenische Partei)

PDI Policía de Investigaciones (Chilenische Kriminalpolizei)

PDM Privatarchiv Dieter Maier

PHF Privatarchiv Hernán Fernández

PJD Privatarchiv John Dinges

PJK Privatarchiv Jürgen Karwelat

PJS Privatarchiv Jan Stehle

PPD Partido por la Democracia (Chilenische Partei)

PS Partido Socialista (Chilenische Partei)

PSM Private Sociale Mission

PWK Privatarchiv Wolfgang Kneese

RA Rechtsanwalt

RDA República Democrática Alemana (Deutsche Demokratische Republik) 
RFA República Federal de Alemania (Bundesrepublik Deutschland)

RHE Rechtshilfeersuchen

RiStBV Richtlinien für das Strafverfahren und das Bußgeldverfahren

RK Rechts- und Konsular- (Bezeichnung für die Zuständigkeit von Abteilungen oder Personen beim AA für Rechts- und Konsularangelegenheiten)

SA Sociedad anónima (Aktiengesellschaft)

SBED Sociedad Benefactora y Educacional Dignidad (Rechtsperson der CD in Chile)

SENAME Servicio Nacional de Menores (Staatliche Kinder- und Jugendbehörde)

SES Senior Experten Service e. V.

SII Servicio de Impuestos Internos (Staatliche chilenische Steuerbehörde)

SIM Servicio de Inteligencia Militar (Geheimdienst des Heeres)

SNS Servicio Nacional de Salud (Staatlicher Gesundheitsdienst)

StA Staatsanwaltschaft

StGB Strafgesetzbuch

StPO Strafprozessordnung

StS Staatssekretär

SÜG Sicherheitsüberprüfungsgesetz

UDI Unión Demócrata Independiente (Chilenische Partei)

UP Unidad Popular (Wahlbündnis Salvador Allendes)

VB Villa Baviera (Bayern-Dorf, Eigenname der CD seit 1980er)

VG Verwaltungsgericht

VLR Vortragender Legationsrat (Amtsbezeichnung im Auswärtigen Dienst)

VS Verschlusssache

VSA Verschlusssachenanweisung

VS-NfD Verschlusssache - Nur für den Dienstgebrauch

VS-V Verschlusssache - Vertraulich

VwGO Verwaltungsgerichtsordnung

ZW Zwischenarchiv 



\section{Dank}

Dieses Buch stellt meine Dissertationsschrift dar, die ich am Fachbereich Politik- und Sozialwissenschaften der Freien Universität Berlin verfasst habe. Auf dem langen Weg der Beschäftigung mit den politischen und juristischen, aber auch den menschlichen Dimensionen des Themas Colonia Dignidad bin ich unzähligen Personen aus den diversesten Sphären begegnet. Viele dieser Begegnungen haben nicht nur diese Arbeit, sondern auch mein Leben bereichert. Insbesondere das Leid vieler Betroffener ist mir dabei sehr nahe gegangen.

Die Liste der Menschen, die mich in diesen Jahren unterstützt hat, ist lang und ich möchte daher an dieser Stelle keine einzelnen Danksagungen vornehmen, sondern mich zu gegebener Zeit bei Euch/Ihnen persönlich bedanken. Nennen möchte ich lediglich einige für den formalen Prozess dieser Arbeit grundlegende Personen und Institutionen. Ihren Ausgang nahm dieses Forschungsvorhaben durch die bestärkende und inspirierende Unterstützung durch Wolf-Dieter Narr (R.I.P.). Bettina Engels (FU Berlin) und Olaf Kaltmeier (Uni Bielefeld) bin ich für die hervorragende Betreuung dieser Arbeit überaus dankbar. Der Rosa-Luxemburg-Stiftung danke ich für die Gewährung eines Promotionsstipendiums, ebenso der Hamburger Stiftung zur Förderung von Wissenschaft und Kultur für die Bereitstellung eines Druckkostenzuschusses. Dank gilt auch Lars Breuer für das Gesamtlektorat der Dissertation sowie Ute Löhning für das Endlektorat für diese Buchveröffentlichung.

Ich widme dieses Buch allen »Aufklärer_innen« und Betroffenen, besonders erwähnen möchte ich stellvertretend für viele andere Hernán Fernández und Dieter Maier, die sich eine Aufklärung und Aufarbeitung der Verbrechen der Colonia Dignidad zur Lebensaufgabe gemacht haben. 



\section{Einleitung}

Die Colonia Dignidad (kurz CD) war eine auslandsdeutsche Siedlung, die 1961 in einer abgelegenen Gegend Zentralchiles gegründet wurde. Die Gruppierung um den Laienprediger Paul Schäfer umfasste etwa 300 Personen, die für das Projekt nach Chile ausgewandert waren. Die CD verübte etwa fünf Jahrzehnte lang - von ihrer Entstehung bis zur Festnahme Schäfers 2005 - systematisch Verbrechen. Die Gruppe war streng hierarchisch organisiert. An der Spitze stand Schäfer, umgeben von einer Gruppe ihm absolut loyaler Führungsmitglieder, den sogenannten Jerarcas (Hierarchen). Durch ein System der ständigen gegenseitigen Überwachung, Denunziation und Bestrafung waren aber die meisten Colonos $^{1}$, also Mitglieder der Gruppierung, an Verbrechen beteiligt. Schäfer missbrauchte über all die Jahre systematisch Minderjährige, vor allem Jungen, sexuell. Dieser sexuelle Missbrauch ${ }^{2}$ kann als Primärverbrechen der CD bezeichnet werden. Die Struktur der CD diente von Anfang an dazu, diese Taten zu ermöglichen und Schäfer vor Strafverfolgung zu schützen. Die anderen, sekundären Verbrechen lassen sich unterteilen in interne und externe Verbrechen. Die internen Verbrechen richteten sich gegen die Colonos. Diese wurden - von anderen Colonos - ihrer Freiheit beraubt sowie körperlich und seelisch misshandelt. An den externen Verbrechen waren einzelne Colonos, insbesondere Führungsmitglieder, beteiligt. Diese Verbrechen beging die CD vor allem in Zusammenarbeit mit Militär und Geheimdiensten während der chilenischen Diktatur von 1973 bis 1990. Unter anderem wurden politische Gefangene in der CD eingesperrt, verhört, gefoltert, vielfach ermordet und ihre Leichen beseitigt. $\mathrm{Zu}$ den externen Verbrechen gehörte auch der systematisch organisierte sexuelle Missbrauch chilenischer Kinder aus der Umgebung der CD.

In Medien in Chile und der Bundesrepublik wurde seit den 1960er Jahren immer wieder über die CD, ihre Verbrechen und die Vorgänge rund um sie herum berich-

Da der Begriff Colono eine Eigenbezeichnung der Bewohner_innen der CD war, wird er in dieser Arbeit nicht gegendert. Einzelne Bewohnerinnen werden jedoch als Colonas bezeichnet.

2

Der Begriff sexueller Missbrauch wird teilweise kritisiert, da er sprachlich impliziert, es könne legitime Formen des »sexuellen Gebrauchs « anderer Personen, speziell auch von Kindern geben. Zur Erklärung möchte ich daher betonen, dass Schäfers Taten klarer Ausdruck von Machtmissbrauch und sexualisierter Cewalt waren. Dennoch verwende ich den Begriff sexueller Missbrauch in dieser Arbeit, da er weit verbreitet ist, speziell auch im Kontext der Colonia Dignidad. 
tet. Dies erfolgte meist in relativ kurzen Phasen starker öffentlicher Aufmerksamkeit, die von längeren Phasen eher geringen Interesses abgelöst wurden. Zumindest theoretisch waren die CD-Verbrechen also der Öffentlichkeit in beiden Ländern bekannt. Der Fall Colonia Dignidad, also der Umgang mit diesen Verbrechen, war phasenweise auch Gegenstand innenpolitischer Debatten - sowohl in Chile als auch in der Bundesrepublik. In den diplomatischen deutsch-chilenischen Beziehungen ist das Thema seit über 50 Jahren nahezu dauerhaft präsent - wenn auch in unterschiedlicher Intensität. Auch Staatsanwaltschaften und Gerichte in beiden Ländern befassen sich seit über fünf Jahrzehnten mit dem Fall CD.

Auch nach Schäfers Festnahme 2005 und seinem Tod 2010 besteht die Siedlung weiterhin fort - nun als Touristenattraktion unter dem Namen Villa Baviera (BayernDorf). Dort leben heute noch etwa 100 Colonos, die meisten haben den Ort verlassen, viele sind nach Deutschland gegangen.

\section{Persönliche Motivation und Feldzugang}

Mein Interesse für den Fall CD hat biographische Gründe. Im Februar 1990 - dem letzten Monat der chilenischen Diktatur - ging ich für ein Jahr als Austauschschüler nach Coronel, eine Stadt mit 120.000 Einwohner_innen in der südchilenischen Provinz Concepción. Ich nahm die Spaltung der chilenischen Gesellschaft in Gegner_innen und Anhänger_innen der Diktatur wahr, aber auch die besondere Rolle, die deutsche Immigrant_innen in der chilenischen Gesellschaft spielten. Mein erster Kontakt mit dem Fall CD war ein Besuch mit meiner Gastfamilie im Casino Familiar, einem von der CD betriebenen Restaurant in Bulnes.

Auch nach meiner Rückkehr nach Deutschland verfolgte ich das Thema weiter. Im Februar 1991 veröffentlichte die sogenannte Rettig-Kommission - die von der ersten demokratisch gewählten Regierung nach der Diktatur eingesetzte Wahrheits- und Versöhnungskommission - ihren Abschlussbericht über die Menschenrechtsverbrechen der Diktatur. Dieser bestätigte offiziell, dass es während der Diktatur in der Colonia Dignidad Fälle von Folterungen und »Verschwindenlassen $\aleph^{3}$ politischer Gefangener gegeben hatte.

1994/1995 nutzte ich die Möglichkeit, anstelle meines Zivildienstes den sogenannten Anderen Dienst im Ausland, in Chile abzuleisten. Dabei lernte ich die Arbeit der Agrupación de Familiares de Detenidos Desaparecidos (Organisation der Angehörigen von Verhaftet-Verschwundenen, AFDD) kennen, einer Vereinigung von Angehörigen von Menschen, die zwischen 1973 und 1990 verhaftet wurden und seitdem als verschwunden gelten. Viele der AFDD-Mitglieder aus der Gegend zwischen Santiago ${ }^{4}$ und Concepción

3 Der Begriff beschreibt eine Praxis der Entführung, Ermordung und Beseitigung der Leiche durch Bedienstete des Staates ohne jegliche Dokumentation, was eine nachträgliche Strafverfolgung dieser Taten besonders erschwert. Für eine genaue Definition siehe United Nations Office of the High Commissioner for Human Rights (OHCHR). International Convention for the Protection of All Persons from Enforced Disappearance, online unter https://www.ohchr.org/EN/HRBodies/CED/ Pages/ConventionCED.aspx. 
vermuteten, dass ihre Angehörigen in die CD verschleppt und dort ermordet worden waren.

Erste Ergebnisse der zaghaften Aufarbeitung der Diktaturverbrechen waren 1995 die Verurteilung und Inhaftierung von Manuel Contreras, dem ehemaligen Chef der Dirección de Inteligencia Nacional (des Diktaturgeheimdienstes, DINA), und seines Stellvertreters. Das System Colonia Dignidad funktionierte zu diesem Zeitpunkt jedoch noch immer und innerhalb der Siedlung wurden weiterhin interne Verbrechen begangen. Die von der Rettig-Kommission festgestellten Verbindungen der CD mit Diktaturverbrechen wurden nicht strafrechtlich untersucht oder gar verfolgt. Chilenische Menschenrechtsaktivist_innen, mit denen ich sprach, aber auch progressive chilenische Medien erklärten dies mit der Existenz nicht näher beschriebener Unterstützungsnetzwerke der CD. Auch von Seiten der bundesdeutschen Diplomatie - so hieß es - erhalte die CD Schutz. Insgesamt, so die Wahrnehmung, sei die CD eine Art Staat im Staate, für den die Regeln der chilenischen Politik und Justiz nicht gelten. Dies werde auch von der Bundesregierung gedeckt. Von chilenischen Gesprächspartner_innen wurde ich regelmäßig gefragt, wie ich als deutscher Staatsbürger mir dies erklären könne. Dies verstärkte meine Motivation, Antworten auf diese Frage zu suchen.

2008 begann ich mit meinen Recherchen, zunächst im Archiv des Forschungsund Dokumentationszentrums Chile-Lateinamerika (FDCL). ${ }^{5}$ Ich fand umfangreiche Sammlungen von Presseartikeln und Zeitzeug_innenberichten, eine Broschüre von Amnesty International (AI) von 1977 sowie einige journalistische Monografien. Diese beschrieben die Vorgänge um die CD sowie ihre Verbrechen detailliert. Allerdings basierten die Darstellungen im Wesentlichen auf Aussagen von Betroffenen sowie auf Quellen aus Menschenrechtskreisen. Offizielle Dokumente, etwa von Regierungsoder Justizbehörden wurden kaum angeführt, da sie - so die Darstellung von Journalist_innen und Aktivist_innen - der Geheimhaltung unterlägen. Aus den wenigen verfügbaren Quellen war kaum ersichtlich, dass sich die Bundesregierung oder die bundesdeutsche Justiz dafür eingesetzt hätten, die CD-Verbrechen zu beenden oder diese auch nur zu untersuchen. Gerade für die Jahre während und nach der Diktatur, als eine Aufarbeitung der Diktaturverbrechen in Chile einsetzte, erschien mir dieses Verhalten erklärungsbedürftig. So entstand meine Idee, die Reaktionen bundesdeutscher Behörden im Rahmen einer Promotion wissenschaftlich zu untersuchen. Dabei wollte ich auch dem Gerücht nachgehen, Bundesbehörden hätten die Verbrechen der CD gedeckt.

Beim Politischen Archiv des Auswärtigen Amts (PA AA) erhielt ich Einblick in einige dutzend Bände zur CD, die Vorgänge des Auswärtigen Amtes (im Folgenden AA) und der Botschaft ${ }^{6}$ zur CD aus dem Zeitraum bis 1977 dokumentierten. Laut Findbüchern sollte es im PA AA noch mindestens 177 weitere Bände zum Thema geben - die jedoch

Die Nichtregierungsorganisation FDCL bearbeitet Menschenrechtsthemen in Lateinamerika. Sie entstand in der Solidaritätsarbeit mit politisch Verfolgten nach dem chilenischen Militärputsch 1973. In denselben Räumlichkeiten wie das FDCL arbeiten auch die Lateinamerika Nachrichten, eine Monatszeitschrift zu Lateinamerika.

6 Wenn in dieser Arbeit nur von Botschaft die Rede ist, ist damit stets die bundesdeutsche Auslandsvertretung in Santiago de Chile gemeint. 
nicht einsehbar waren. Sie unterlagen einer sogenannten Schutzfrist, durch die vorgeblich sowohl das Staatswohl als auch Persönlichkeitsrechte geschützt werden sollen. Diese Begründung erschien mir auch in Anbetracht der im Raum stehenden Verbrechen nicht nachvollziehbar und verstärkte meine Skepsis bezüglich der Rechtmäßigkeit der Geheimhaltung. Ich klagte daraufhin auf Zugang zu sämtlichen die CD betreffenden Akten des AA.

\section{Fragestellung}

Die vorliegende Arbeit beschäftigt sich mit der Frage, wie bundesdeutsche Behörden auf die Verbrechen der Colonia Dignidad reagierten, d.h. wann und in welchem Umfang sie von ihnen wussten, aber vor allem wie sie mit diesem Wissen umgegangen sind. Für diese systematische Rekonstruktion und Analyse des bundesdeutschen staatlichen Handelns im Fall Colonia Dignidad müssen zunächst die Verbrechen der CD selbst bestimmt bzw. der diesbezügliche Kenntnisstand zusammengetragen werden.

Meine Ausgangsthese lautet, dass bundesdeutsche Behörden von den menschenrechtswidrigen Verhältnisse in der CD sowie von ihren Verbrechen wussten, aber nicht adäquat reagiert haben. Gemessen am Ziel des Schutzes von Menschenrechten haben sie versagt. Sie unternahmen keine ausreichenden Maßnahmen, um eine Fortsetzung der ihnen bekannten Verbrechen zu verhindern. Auch zu einer Aufklärung und Sanktionierung vergangener Verbrechen trugen bundesdeutsche Behörden nur wenig bei.

Mein Ansatz war dabei, behördliche Quellen und Dokumente auszuwerten und auf dieser Grundlage zu ergründen, inwieweit bundesdeutsche Behörden Kenntnisse von dem besaßen, was Betroffene und Medien an Beobachtungen, Feststellungen und Vorwürfen zu Verbrechen der CD geäußert haben. Ausgangspunkt für meine Erschließung behördlicher Quellen waren die bereits verfügbaren Quellen, die vornehmlich von aufklärerischen Akteur_innen stammen. Die Beantwortung meiner Fragestellung setzt eine solide Kenntnis der eigentlichen Verbrechen voraus. Daher ist ein Ziel meiner Arbeit eine umfangreiche, wissenschaftlich fundierte Darstellung der CD-Verbrechen.

Der Fall Colonia Dignidad war und ist eine zwischenstaatliche Angelegenheit. Eine Untersuchung des Agierens deutscher Behörden im Fall CD kann sich keineswegs ausschließlich auf deutsche Quellen stützen. Die Auswertung chilenischer Quellen etwa der umfangreichen Aktenbestände aus chilenischen Gerichtsverfahren zur CD ist hierfür unverzichtbar. Auch wenn eine Bearbeitung meiner Fragestellung es oftmals erforderlich macht, den Blick auf andere Akteur_innen zu richten, bleibt mein Fokus doch das Handeln bundesdeutscher Behörden im Fall CD.

\section{Relevanz der Arbeit}

Für Betroffene, Angehörige und aufklärerische Akteur_innen, aber auch für die Gesellschaft im Allgemeinen steht angesichts der über 50-jährigen Verbrechensgeschichte der CD die Frage im Raum: Wie war das möglich? Wer trägt die Verantwortung dafür, dass die CD ihre Verbrechen so lange ungehindert begehen konnte und was folgt heute daraus? Die wenigen vorhandenen wissenschaftlichen Arbeiten zur Colonia Dignidad un- 
tersuchen bestimmte Teilaspekte des Systems CD oder des Falls CD. ${ }^{7}$ Diese Studien basieren vorwiegend auf Medienberichten sowie auf Quellen von aufklärerischen Akteur_innen.

Eine systematische wissenschaftliche Darstellung der CD-Verbrechen, vor allem aber eine Analyse der Reaktionen staatlicher Behörden im Fall CD liegt bisher nicht vor. Der Hauptgrund hierfür ist der schwierige bis unmögliche Zugang zu den entsprechenden Quellen. Viele Dokumente lagen zu Beginn meines Forschungsvorhabens zudem noch gar nicht vor, wie z.B. zahlreiche chilenische Gerichtsurteile. Viele private Archive von aufklärerischen Anwält_innen und Aktivist_innen waren ebenfalls schwer zugänglich, da diese aus verständlichen Gründen vorsichtig waren und viele Verfahren noch anhängig waren. Meinem Zugang gingen oft lange Prozesse der Vertrauensbildung voraus. Durch meine Bemühungen bei der Erschließung von Quellen bekam ich rasch Kontakt zu vielen aufklärerischen Akteur_innen. Mit vielen von ihnen verbinden mich heute enge und vertrauensvolle Kontakte. Bei staatlichen Akteur_innen sowie Vertreter_innen des Systems CD wurden meine Gesprächsanfragen hingegen häufig ablehnend beschieden. Einige sprachen zwar mit mir, bestanden aber auf der Vertraulichkeit der Gespräche. Auch mein Zugang zu behördlichen Quellen folgte nur in manchen Fällen einem geregelten Verfahren, wie etwa bei meinen juristischen Auseinandersetzungen mit dem Auswärtigen Amt (AA). Vielfach erhielt ich Zugang zu Akten auf irregulärem Wege - also nicht indem Behörden oder Institutionen diese offiziell verfügbar machten, sondern weil Einzelpersonen - die zum Teil in diesen Behörden oder Institutionen tätig waren - sie mir zukommen ließen, da sie selbst eine Aufarbeitung des Falls CD für geboten hielten.

Die Relevanz dieser Arbeit besteht daher in der Identifikation relevanter Quellenbestände, deren bestmöglicher Erschließung und deren systematischer Auswertung als Grundlage einer wissenschaftlichen Untersuchung des Umgangs bundesdeutscher Behörden mit dem Fall CD.

\section{Die Dynamik des Forschungsfeldes}

Seit Beginn meiner Forschungstätigkeit 2008 hat sich das Forschungsfeld zum Teil sehr dynamisch entwickelt. In Chile war das öffentliche und mediale Interesse am Fall CD zunächst sehr hoch. Nach der Festnahme Paul Schäfers 2005 intensivierten sich die strafrechtlichen Untersuchungen in Chile. Über die nachfolgenden Ermittlungserfolge, wie etwa das Auffinden eines Waffenarsenals oder des Geheimarchivs auf dem Gelände der $C D$, berichteten chilenische Medien intensiv. In der Bundesrepublik hatte das Medieninteresse am Fall CD nach 2005 hingegen schrittweise abgenommen. $\mathrm{Zu}$ Beginn meiner Forschungen war das Thema in der Öffentlichkeit kaum präsent.

7 Vgl. z.B Rückert, Horst. Vom Folterzentrum der Militärdiktatur zum Ferienort. Die Geschichte der „Villa Baviera« in Chile. [Dissertation], Stuttgart 2017; Douglas, Marcela. Hopes and Horror - An ethnographic study of a Cerman community in Chile. [Dissertation] Troms $\varnothing$ 2013; online unter: https://munin.uit.no/handle/10037/5810; Künz, Bärbel. Die Colonia Dignidad zwischen kollektiver Freistatt und instrumentalisiertem Zwangskollektiv. [unveröffentlichte Diplomarbeit], Köln 2010; Mazuré Loos, Lorena. Perspektiven der deutsch-chilenischen Minderheit in Chile auf Colonia Dignidad. [Diplomarbeit], Wien 2009, online unter http://othes.univie.ac.at/4235/1/2009-03-16_044 8041.pdf. 
Nach Schäfers Tod 2010, wurden alle noch anhängigen strafrechtlichen Ermittlungen in der Bundesrepublik zum Fall CD eingestellt. Erst die Flucht des in Chile verurteilten Hartmut Hopp nach Deutschland löste eine neue Welle medialer Aufmerksamkeit hierzulande aus. In deren Folge gab es zahlreiche neue Entwicklungen in der strafrechtlichen Aufarbeitung, der politischen Thematisierung des Falls CD, aber auch in der Erinnerung an die CD-Verbrechen. Viele dieser Entwicklungen habe ich parallel zu meiner Forschungstätigkeit mit begleitet und teilweise sogar mitgestaltet. Strafanzeigen von Menschenrechtsanwält_innen führten ab 2011 zu neuen Ermittlungen gegen Hartmut Hopp. Ab 2014 finanzierte das AA von zivilgesellschaftlichen Akteur_innen initiierte Veranstaltungen und Dialogseminare in Chile und der Bundesrepublik mit dem Ziel der Errichtung einer Gedenk- und Bildungsstätte in der ehemaligen CD. 2016 hielt der damalige Außenminister Frank-Walter Steinmeier eine Rede, in der er die Rolle der bundesdeutschen Diplomatie im Fall CD kritisch würdigte und eine moralische Mitverantwortung der Bundesregierung für die CD-Verbrechen einräumte. Eine politische Verantwortung wies er jedoch zurück. 2017 führten parlamentarische Initiativen zu einer einstimmigen Entschließung des Bundestags. Darin fordern die Abgeordneten die Bundesregierung zu diversen Maßnahmen zur Aufarbeitung der CD-Verbrechen auf. Die Begleitung dieser Erfahrungen ermöglichten mir Einblicke und Erkenntnisse, die nicht unmittelbar, jedoch in den Kontext dieser Arbeit einfließen.

\section{Aufbau der Arbeit}

Kapitel 2 beschreibt im ersten Abschnitt (2.1) die unterschiedlichen Gruppen von Akteur_innen im Fall CD. Dies sind neben dem System CD die aufklärerischen Akteur_innen und die staatlichen Akteur_innen. Im nächsten Abschnitt (2.2) stelle ich die vorhandene Literatur und Presseberichterstattung zum Thema vor und berichte, welche Archive ich für mein Vorhaben konsultiert habe und welche Akten - insbesondere aus juristischen Verfahren - ich zum Fall CD einsehen und auswerten konnte. Daran schließt sich eine Übersicht der von der CD erstellten Quellen an, zu denen etwa das 2005 beschlagnahmte Geheimarchiv der CD gehört. Dieses ist heute einer der wichtigsten verfügbaren Quellenbestände zur Repression der chilenischen Militärdiktatur. Ein kleinerer Teil der für dieses Vorhaben ausgewerteten Aktenbestände stammt aus Privatarchiven und Archiven von Institutionen und Nichtregierungsorganisationen. Die Mehrzahl hingegen sind Aktenbestände politischer Behörden und der Justiz. Die Akten der Justizverfahren enthalten unter anderem hunderte von Aussagen von CD-Mitgliedern, in denen sie Verbrechen beschreiben oder auch ihr Mitwirken an Verbrechen einräumen. Ebenfalls enthalten sind beispielsweise Vernehmungen externer Opfer und Akteur_innen, Polizeiberichte und Anklageschriften. Den Zugang zu vielen dieser Quellen erhielt ich wie geschildert nicht auf formellem Weg.

Im letzten Abschnitt des Kapitels (2.3) schildere ich meine Bemühungen um einen regulären Aktenzugang bei deutschen Regierungs- und Justizbehörden. Diese fanden im Spannungsfeld zwischen meinem Interesse an Transparenz und wissenschaftlicher Forschung sowie dem Interesse der Behörden an der Geheimhaltung ihrer Unterlagen statt. Dabei nehme ich insbesondere Bezug auf die gesetzlichen Grundlagen des Aktenzugangs: das Bundesarchivgesetz und das Informationsfreiheitsgesetz. Diese räumen 
den Behörden einen starken Ermessensspielraum bei der Freigabe von Akten ein. Ich schildere, wie ich beim AA oder beim Bundeskanzleramt mit unterschiedlichem Erfolg zunächst auf dem Verwaltungsweg und später auf dem Rechtsweg versucht habe, Zugang zu Akten zu erhalten. Dieser Abschnitt soll anderen Forscher_innen Erkenntnisse über die verfügbaren Verfahren und die von den Behörden verfolgten Argumentationsund Handlungsmuster zur Durchsetzung ihrer Interessen zur Verfügung stellen.

Kapitel 3 beschreibt die Entstehungsgeschichte der CD und charakterisiert die CD einerseits als Gruppierung und andererseits als physischen Ort. Dabei beschreibe ich auch die unterschiedlichen Rechtspersonen der CD in Chile und der Bundesrepublik sowie die Eigentumsstruktur der CD, inklusive ihrer zahlreichen Unternehmen. Im ersten Abschnitt (3.1) gehe ich neben der Entwicklung der Gruppierung bis zur Auswanderung nach Chile auch auf die Herausbildung der hierarchischen Struktur und der Zwangsmechanismen in der CD ein, insbesondere auf die Rolle der CD-Führungsgruppe. Die $C D$ verstehe ich dabei einerseits als nach innen wirkende kriminelle Gemeinschaft und andererseits als nach außen wirkende kriminelle Vereinigung. Der zweite Abschnitt des Kapitels (3.2) beschreibt die CD als physischen Ort, also das Kerngelände der Siedlung in der Gemeinde Parral sowie die verschiedenen Niederlassungen der CD in Chile und der Bundesrepublik. In diesem Abschnitt stelle ich auch die Rechtspersonen und Eigentumsstrukturen der CD vor.

Die Darstellung und Analyse der Reaktionen bundesdeutscher Behörden setzt eine umfassende Kenntnis über die Verbrechen der CD voraus. Das Wissen über Ausmaß, Art und Dimensionen der CD-Verbrechen wuchs im Verlaufe meines Forschungsvorhabens beständig. Kapitel 4 widmet sich daher einer systematischen Zusammenstellung des derzeitigen Kenntnisstands über die unterschiedlichen Verbrechenskomplexe sowie dessen Genese. Da sich meine Darstellung vielfach auf behördliche Quellen bezieht, gehe ich auch darauf ein, was Behörden wie das AA oder Staatsanwaltschaften zu welchem Zeitpunkt zumindest theoretisch über die Verbrechen hätten wissen können und was sie - laut den mir vorliegenden Akten - tatsächlich darüber wussten. Neben Behördenakten ziehe ich für meine Darstellung auch Quellen aufklärerischer Akteur_innen sowie öffentlich zugängliche Quellen heran, wie beispielsweise Medienberichte oder Berichte der Vereinten Nationen. Bei meiner Darstellung unterscheide ich zwischen den internen Verbrechen der kriminellen Gemeinschaft CD, die sich gegen Colonos richteten (Abschnitt 4.1) und den externen Verbrechen der kriminellen Vereinigung CD, die oftmals im Kontext der chilenischen Diktatur verübt wurden (Abschnitt 4.2). Beide Unterkapitel gliedern sich in unterschiedliche Verbrechenskomplexe bzw. Tatbestände, wie sexueller Missbrauch oder Waffenhandel. Für jede dieser Kategorien beschreibe ich jeweils, welche Belege für welche Verbrechen zu welchem Zeitpunkt zugänglich waren, wann welchen Behörden erste Anhaltspunkte oder auch konkretere Informationen zu diesen Verbrechen vorlagen und wie diese gegebenenfalls darauf reagierten. Zur Veranschaulichung schildere ich in vielen Kategorien exemplarisch einzelne Fälle. Eine umfassende Darstellung sämtlicher bekannter Einzelfälle würde den Rahmen dieser Arbeit bei weitem sprengen.

Im Kapitel 5 liegt der Schwerpunkt nicht auf den Verbrechen selbst, sondern auf der politischen und juristischen Aufarbeitung der CD-Verbrechen in Deutschland und Chile. Basis der Darstellung sind wiederum vor allem die mir zugänglichen behörd- 
lichen Quellen. In Abschnitt 5.1 untersuche ich die juristische Aufarbeitung in Chile. Abschnitt 5.2 widmet sich der Behandlung des Themas CD im chilenischen Parlament. In Abschnitt 5.3 stelle ich die juristische Aufarbeitung in der Bundesrepublik dar. In Abschnitt 5.4 behandle ich schließlich die Befassung des Deutschen Bundestags mit der CD und ihren Verbrechen.

In beiden Ländern gab es seit den 1960er Jahren zahlreiche staatsanwaltliche Ermittlungen sowie gerichtliche Straf- und Zivilverfahren mit Bezug zur CD. Während sich die strafrechtlichen Verfahren meist gegen Colonos richteten, entstand ein Großteil der zivilrechtlichen Verfahren durch Klagen der CD. Diese reagierte auf aufklärerische Initiativen als Teil ihrer Verteidigungsstrategie systematisch mit Unterlassungsund Verleumdungsklagen gegen Kritiker_innen. In diesem Kapitel zeichne ich - meist exemplarisch - bestimmte Verfahren nach und stelle dar, welche Verbrechenskomplexe thematisiert wurden und welchen Ausgang die Verfahren jeweils hatten. Zusätzlich diskutiere ich, welche Auswirkungen die parallele Zuständigkeit von bzw. die Kooperation zwischen Behörden beider Länder jeweils auf das Verfahren hatte und welche Wechselwirkungen zwischen Justizbehörden, politischen Behörden und zivilgesellschaftlichen Akteur_innen es jeweils gab. Viele weitere Verfahren beispielsweise im Verwaltungs-, Sozial-, Steuer- und Arbeitsrecht kann ich dabei aufgrund ihrer großen Anzahl nur anschneiden.

Auch die Parlamente bzw. einzelne Abgeordnete in beiden Ländern befassten sich seit den 1960ern mit dem Fall CD. So gab es im chilenischen Parlament in den 1960er und 1990er Jahren diverse Untersuchungsausschüsse zur CD. In der Bundesrepublik beschränkte sich die parlamentarische Beschäftigung mit der CD lange Zeit auf Fragen einzelner Abgeordneter oder Fraktionen an die Bundesregierung. 1988 fand eine öffentliche Anhörung des Bundestags-Unterausschusses für Menschenrechte und humanitäre Hilfe statt. Erst in den $2000 e r$ Jahren gab es größere parlamentarische Initiativen: 2002 verabschiedete der Bundestag erstmals einen Entschließungsantrag mit Forderungen an die Bundesregierung, der jedoch folgenlos blieb. 2017 folgte ein weiterer, diesmal einstimmig beschlossener, Entschließungsantrag.

Kapitel 6 beschreibt den Umgang bundesdeutscher Behörden mit dem Fall CD in fünf historischen Phasen. Der Fokus liegt dabei auf dem Agieren des Auswärtigen Amtes und der Botschaft. Starke Berücksichtigung findet aber auch das Verhalten der Justizbehörden, besonders in Nordrhein-Westfalen. Dabei synthetisiere ich zahlreiche Erkenntnisse aus den vorherigen Kapiteln zu Leitlinien, die das Handeln der Behörden in den jeweiligen historischen Phasen bestimmten.

Drei grundlegende Aspekte des Falls CD stelle ich der Beschreibung der einzelnen Phasen voran: Dies sind erstens die Bilateralität des Falls und die - je nach Ansicht doppelte oder ungeklärte Verantwortung Deutschlands und Chiles. Zweitens schildere ich die Wechselwirkungen zwischen der politischen und der juristischen Ebene in beiden Staaten. Drittens gehe ich auf das Bild der Deutschstämmigen in Chile sowie auf die Asymmetrie der deutsch-chilenischen Beziehungen ein.

Abschnitt 6.1 beschreibt Phase I (bis 1961), die Entstehung der Gruppierung um Paul Schäfer, die Herausbildung der pseudoreligiösen Gemeinschaft und ihres internen Zwangssystems bis zur Auswanderung eines Großteils der Gruppe nach Chile. Da- 
zu gehören auch die ersten unscharfen Eindrücke, die Behörden von der Gruppierung erhalten.

Abschnitt 6.2 zeichnet Phase II (1961-1973) nach, also den Aufbau der CD in Chile bis zum Militärputsch im September 1973. Während die CD sich in den ersten fünf Jahren mehr oder weniger unbekannt in der Region etabliert, ereignen sich ab 1966 erste Fluchtfälle und Skandale, durch die der Fall CD erstmals öffentlich bekannt wird und die auch Reaktionen von Politik und Justiz nach sich ziehen. Gegen Ende der 1960er Jahre festigt sich das System CD schließlich. Während der sozialistischen Regierung unter Salvador Allende ab 1970 fürchtet die CD um ihren Fortbestand und sucht die Allianz mit militanten rechten Gruppen. Die CD unterstützt diese mit Infrastruktur, Waffen und Know-how und wird so zu einem wichtigen Teil jener, die auf einen Sturz der Allende-Regierung durch einen Staatsstreich hinarbeiten.

Abschnitt 6.3 behandelt die Jahre der Militärdiktatur (Phase III, 1973-1990). Diese können als Epoque d'Or der CD bezeichnet werden. Die CD geht eine enge Allianz mit Militär und Geheimdienst ein, sie unterhält direkte Verbindungen zu Diktator Pinochet und Geheimdienstchef Contreras und ist aktiv an der Zerschlagung der Opposition beteiligt. Im Gegenzug genießt die CD während der Diktatur den Schutz Pinochets und agiert vollkommen straflos. In den ersten Jahren der Diktatur dient die CD als Haftort, an dem (politische) Gefangene gefoltert und ermordet werden, aber auch als Schulungs- und Trainingsstätte für Angehörige des Geheimdienstes. Nachdem Berichte von Folterüberlebenden öffentlich bekannt werden, verteidigt die Botschaft die CD, das AA schweigt unter Verweis auf schwebende juristische Verfahren. Erst Mitte der 1980er Jahre rückt die bundesdeutsche Diplomatie schrittweise von dieser Linie ab. Bundesdeutsche Staatsanwaltschaften beginnen wegen der internen Verbrechen der CD zu ermitteln.

Abschnitt 6.4 beschreibt Phase IV vom Ende der Diktatur 1990 bis zur Festnahme Paul Schäfers 2005. Dieser Zeitraum ist geprägt von der Transición, dem ausgehandelten Übergang zur Demokratie. Die neue chilenische Regierung ist um Aufklärung des Falls CD bemüht, jedoch durch personelle und strukturelle Kontinuitäten in den Behörden in ihrem Handeln stark eingeschränkt. Die bundesdeutschen Behörden verhalten sich vornehmlich abwartend bis passiv und schreiben die Verantwortung für die Aufklärung des Falls CD den chilenischen Behörden zu. Ab 1996 führen Strafanzeigen von Familien chilenischer Missbrauchsopfer in Chile zu engagierteren Strafermittlungen. Die offene Unterstützung der CD durch rechte Kreise schwindet. 1997 verlässt Schäfer die CD und geht in Argentinien in den Untergrund.

Abschnitt 6.5 beschreibt die Phase V des Falls CD seit 2005. Bemühungen aufklärerischer Akteur_innen führen 2005 zur Festnahme Schäfers. Diese führt nicht zu einem Zusammenbruch oder einer Schließung der CD, sondern zu einem allmählichen Öffnungsprozess, gewissermaßen einer verspäteten Transición der CD, die ebenfalls von vielen personellen und strukturellen Kontinuitäten begleitet ist. Die strafrechtliche Aufarbeitung der CD-Verbrechen in Chile trifft immer noch auf zahlreiche Widerstände, dennoch können in einer Reihe von Gerichtsverfahren zahlreiche Verbrechenskomplexe zumindest exemplarisch aufgeklärt werden. Der Großteil der einzelnen Taten wird jedoch nicht untersucht. Nur wenige Täter_innen werden verurteilt und erhalten meist niedrige Strafen. Mehrere Beschuldigte entziehen sich der chilenischen Justiz durch 
ihre Flucht nach Deutschland. In Deutschland werden noch anhängige Ermittlungsverfahren nach Schäfers Tod 2010 eingestellt. Nach Hartmut Hopps Flucht in die Bundesrepublik 2011 werden neue Verfahren eröffnet, auch diese werden jedoch 2019 wegen mangelnden Tatverdachts eingestellt. Außenminister Frank-Walter Steinmeier erkennt in einer Rede 2016 zwar eine moralische Verantwortung der bundesdeutschen Diplomatie für die CD-Verbrechen an - eine Anerkennung politischer Schuld bleibt indes aus. Die CD besteht bis heute fort und entwickelte sich als Villa Baviera (Bayern-Dorf) zur Touristenattraktion. Wirtschaftlich fußt sie noch immer auf den ABC-Gesellschaften der CD, die Ende der 1980er Jahre auf betrügerische Art und Weise gegründet worden waren. Bestrebungen zur Errichtung einer Gedenkstätte in der CD sind bisher nicht erfolgreich.

Das letzte Kapitel (7) fasst die wichtigsten Ergebnisse der Arbeit noch einmal zusammen und formuliert einen Ausblick für den zukünftigen Umgang mit der CD sowie für die zukünftige Forschung zum Fall CD. 


\section{Der Fall Colonia Dignidad: Akteur_innen, Quellen und Vorgehen}

Als Fall Colonia Dignidad bezeichne ich in dieser Arbeit die Summe aller Vorgänge, inklusive der Verbrechen, die sich im Zusammenhang mit der ab 1961 von Siegburg nach Chile emigrierten Personengruppe um Paul Schäfer ereignet haben. Dazu gehören auch die Reaktionen diverser Behörden auf diese Vorgänge sowie die Auseinandersetzung mit diesen in der Öffentlichkeit. Zu einem noch nicht abgeschlossenen Fall wird die Colonia Dignidad (kurz CD) dadurch, dass viele dieser Vorgänge, insbesondere Straftaten, bisher weder von den zuständigen Behörden noch von der Justiz ausreichend aufgeklärt bzw. aufgearbeitet wurden. Auch die Auseinandersetzung über die Geschichtsschreibung der $C D$ dauert bis heute an. Eine wissenschaftliche Auseinandersetzung mit dem Fall Colonia Dignidad erfolgte bisher nur spärlich. Das liegt zum großen Teil daran, dass der Zugang zu vielen Akteur_innen, Quellen und Informationen bislang nicht oder nur schwer möglich war. In diesem Kapitel beschreibe ich die zunächst die wesentlichen Akteur_innen des Falls Colonia Dignidad (2.1). Anschließend gehe ich auf die vorhandene Literatur und Presseberichterstattung zur Colonia Dignidad sowie auf die unterschiedlichen vorhandenen Quellen ein und referiere den Stand der wissenschaftlichen Forschung (2.2). Im dritten Teil des Kapitels (2.3) gehe ich auf die Problematik des Zugangs zu unterschiedlichen Quellen ein.

\subsection{Die Akteur_innen}

Als Colonia Dignidad bezeichne ich die Personengruppe um Paul Schäfer und deren Niederlassungen, von der Auswanderung nach Chile ab 1961 bis zur Festnahme Schäfers 2005. Die Bewohner_innen der CD bezeichne ich als Colonos. Für die Zeit nach März 2005 spreche ich auch von der Ex-Colonia Dignidad bzw. von Ex-Colonos. Der Fall Colonia Dignidad - wie eben definiert - beginnt in den 1950er Jahren in der Bundesrepublik Deutschland und dauert dort sowie in Chile bis heute an. Im Folgenden soll es um die Akteur_innen in diesem Fall gehen. Deren wichtigste Gruppen sind: 
- Das System Colonia Dignidad mit der Colonia Dignidad selbst sowie ihren Ableger_innen in Chile und der Bundesrepublik sowie den von der CD in beiden Ländern geschaffenen Unterstützungsnetzwerken. Dazu gehören auch Rechtsanwält_innen, die die CD oder einzelne ihrer Mitglieder vertreten bzw. vertraten und Medien, die überwiegend positiv über die CD berichteten.

- Die Aufklärer_innen: Dazu gehören aus der CD geflüchtete Personen, Verbände von Opfern und Angehörigen, Menschenrechtsorganisationen sowie Rechtsanwält_innen und Aktivist_innen, die sich im Sinne der Menschenrechte engagieren. Dazu zählen Medien, die überwiegend kritisch über die CD berichten bzw. berichteten.

- Staatliche Akteure - wie Regierungen, Staatsanwaltschaften, Gerichte, Militär, Polizei und Geheimdienste - werden gesondert betrachtet, da sie oft eine ambivalente Rolle einnehmen bzw. nicht eindeutig dem System CD oder den Aufklärer_innen zugerechnet werden können.

Im Folgenden werden die drei Gruppen von Akteur_innen ausführlicher vorgestellt.

\section{Das System Colonia Dignidad}

Die Colonia Dignidad war nach innen eine kriminelle Gemeinschaft und nach außen eine international agierende kriminelle Vereinigung. Sie verfügte über Niederlassungen in der Bundesrepublik (1956-1995) und in Chile (ab 1961). Sie führte geschäftliche und finanzielle Transaktionen in zahlreichen weiteren Staaten durch. Ihre offiziell wohltätigen formalen Rechtspersonen waren der Verein Private Sociale Mission (im Folgenden kurz PSM) in Deutschland und der Verein Sociedad Benefactora y Educacional Dignidad (im Folgenden kurz SBED) in Chile. Seit 1988 übertrug die CD große Teile ihres Vermögens in Chile auf die aus den geschlossenen Aktiengesellschaften Agripalma, Bardana und Cinoglosa bestehende sogenannte ABC-Holding.

Nach außen wurde die CD nur durch eine Handvoll Personen vertreten. Aushängeschild in Chile war Hermann Schmidt, Präsident der SBED. Ab Mitte der 1970er Jahre kam Hartmut Hopp hinzu, der mit den Jahren immer mehr zum Sprecher oder »Außenminister ${ }^{1}$ der CD wurde. Im Unterschied zu Schmidt ging Hopp einer intensiven Reisetätigkeit nach. Weitere Außenkontakte nahmen auch Kurt Schnellenkamp, Albert Schreiber, Hans-Jürgen Blanck und Alfred Matthusen wahr. In der Bundesrepublik war Hugo Baar bis 1975 als Vereinsvorsitzender der PSM für die Öffentlichkeitsarbeit verantwortlich. Später leiteten Alfred Schaak und Alfred Matthusen die PSM, hielten sich aber mit öffentlichen Äußerungen eher zurück. Paul Schäfer selbst trat nur äußerst selten in der Öffentlichkeit auf und bekleidete keine formellen Ämter. ${ }^{2}$

1 European Center for Constitutional and Human Rights (ECCHR). Stellungnahme zu der Rolle von Hartmut W. Hopp innerhalb der Colonia Dignidad - Seine Kollaboration mit dem PinochetRegime und Verbrechen an Bewohnern der Colonia Dignidad. Berlin, Oktober 2011. S. 11, online unter https://www.ecchr.eu/fileadmin/Pressemitteilungen_deutsch/Stellungnahme_Colonia_Dignida d_Hopp_-_2011-10-06.pdf. Bei Online-Ressourcen wird im Folgenden ein Abrufdatum nur angegeben, wenn die entsprechende Web-Adresse am 01.03.2020 nicht mehr erreichbar war.

2 Lediglich in den ersten Jahren der PSM hatte Schäfer das Amt des Treuhänders inne. PA AA, B 85 , Bd. 598, Bericht Botschaft an AA vom 25.01.1963, 502-81.05-124/63. 
Seit den 1960er Jahren schuf die CD formalisierte wie informelle Lobby- und Unterstützungsnetzwerke, unter anderem um Aktivitäten der Aufklärer_innen entgegenzuwirken. Auf regionaler Ebene vernetzte sich die CD in der ländlichen Umgebung der Siedlung in Chile mit benachbarten Grundbesitzer_innen. In der nächstgelegenen Ortschaft Catillo wurden enge Beziehungen zu Beamt_innen des Registro Civil (Standesamt) und des Retén de Carabineros (Wache der uniformierten Polizei) gepflegt. Die CD lag in der ländlichen Gemeinde sowie im Gerichtsbezirk von Parral, entsprechend wichtig war die Stadt für die CD. Daneben pflegte die CD Kontakte in die wichtigsten Städte der Región del Maule (mit der Hauptstadt Talca) sowie der Región del Biobío (mit der Hauptstadt Concepción). Auch zu den Militärregimentern in Concepción (III. División del Ejército) und Linares (Escuela de Artillería) gab es enge Kontakte. Während der Diktatur, also von 1973 bis 1990, bildete die CD eine sogenannte Repressionsallianz ${ }^{3}$ mit der DINA 4 und anderen Repressionsorganen. Dazu gehörte auch der direkte Draht zu Diktator Pinochet und DINA-Chef Manuel Contreras.

$\mathrm{Zu}$ den formalisierten und öffentlich agierenden Unterstützungsstrukturen gehörten sogenannte Freundeskreise, darunter die Asociación de Amigos de Dignidad oder die Comités de Pacientes (Patientenkomitees), die ins Leben gerufen wurden, um das Krankenhaus der CD gegen eine drohende Schließung zu verteidigen. Nach Auflösung der SBED gründete die CD den Verein Organización Comunitaria de Desarrollo Social Perquilauquén (kurz Perquilauquén) ${ }^{5}$. Er übernahm die Trägerschaft von Krankenhaus und Schule. Dem Verein gehörten auch Personen außerhalb der CD an, darunter Politiker_innen wie Ignacio Urrutia Bonilla ${ }^{6}$. Der Verein Perquilauquén besteht bis heute, ebenso wie die ABC-Holding mit ihren zahlreichen Tochtergesellschaften. Neben diesen formalisierten Strukturen suchte sich die CD von Beginn an Unterstützer_innen in allen Sphären der Gesellschaft. Diese waren für die Aufrechterhaltung der CD von strategischer Bedeutung. ${ }^{7}$ Um ihre Gunst zu erlangen, wurden die Unterstützer_innen in die CD eingeladen, erhielten Geschenke wie Torten oder Essenspakete oder aber Freundschaftsdienste, wie unentgeltliche handwerkliche Dienstleistungen, medizinische Behandlungen sowie vorteilhafte Geschäftsbeziehungen. $\mathrm{Zu}$ diesen Unterstützer_innen gehörten lokale, regionale und nationale Politiker_innen, Militär- und Polizeiangehörige, Richter_innen, Unternehmer_innen, Zollbeamt_innen, Diplomat_innen, Verwaltungsbedienstete, Ärzt_innen, Musiker_innen sowie Nachbar_innen. Die Kontinuität

Maier, Dieter/Jan Stehle. Colonia Dignidad - pieza clave en el aparato represor de la dictadura cívico-militar. Orígenes, historia criminal y preguntas abiertas, in: Hevia, Evelyn/Jan Stehle (Hg.). Colonia Dignidad: diálogos sobre verdad, justicia y memoria, Santiago 2015, S. 27-70.

4 Die DINA existierte von 1973 bis 1977 und unterstand Diktator Pinochet persönlich. Nach ihrer Auflösung im Jahr 1977 entstand die Central Nacional de Inteligencia (CNI), die bis zum Ende der Diktatur Bestand hatte.

5 Perquilauquén ist der Name des Flusses, der durch die CD fließt.

6 La Nación vom 06.07.2005. »Diputado UDI Ignacio Urrutia, socio de sucesora de Colonia Dignidad«. Ignacio Urrutia Bonilla ist seit 2002 Mitglied der Cámara de Diputados. Er gehört seit 2019 der rechtsextremen Partei Partido Republicano an. Zuvor war er Mitglied der Unión Demócrata Independiente (UDI) und von Renovación Nacional (RN).

7 Salinas, Claudio/Hans Stange. Los amigos del »Dr.«Schäfer: La complicidad entre el Estado chileno y Colonia Dignidad, Santiago 2006. 
der CD nach dem Ende der Diktatur war nur aufgrund der Unterstützung durch breite Kreise der rechten Opposition möglich. Diese sabotierten die Versuche der neuen demokratischen Regierung, der CD auf administrativem Wege beizukommen. So legten etwa rechte Mitglieder von Senat und Abgeordnetenhaus, insbesondere der rechten Parteien Renovación Nacional (Nationale Erneuerung, RN) und Unión Demócrata Independiente (Unabhängige Demokratische Union, UDI) Beschwerde beim Verfassungsgericht gegen die Auflösung der SBED ein, ${ }^{8}$ unterstützten inszenierte Hungerstreiks der CD gegen die Schließung des Krankenhauses ${ }^{9}$ und kritisierten öffentlich die von der Justiz im Rahmen der Fahndung nach Schäfer durchgeführten Razzien in der CD. Eine besonders prominente Rolle nahm hierbei der Senator Hernán Larraín Fernán$\mathrm{dez}^{10}$ ein. Vereinzelt erhielt die CD auch Unterstützung aus Kreisen des regierenden Mitte-Links-Bündnisses, der sogenannten Concertación ${ }^{11}$, etwa vom Abgeordneten Felipe Letelier von der Partido por la Democracia (Partei für die Demokratie, PPD).

Unterstützend wirkten auch einige rechtskonservative Medien, die jahrelang positiv über die CD berichteten. Diese Unterstützer_innen handelten teils aus Bewunderung für die »Deutschen « und ihre soziale Fassade ${ }^{12}$, teils aus ideologischer Überzeugung und teils aus Eigennutz. Zum Unterstützungsnetzwerk der CD gehörten zudem dutzende Rechtsanwält_innen, die die CD bei juristischen Verfahren verteidigten und meist eine offensive Strategie verfolgten: Personen oder Institutionen, die Verbrechen der CD zur Anzeige gebracht oder Untersuchungen angeregt hatten, sollten durch Verleumdungsklagen und diverse Rechtsmittel zum Schweigen gebracht werden.

\section{Unterstützungsnetzwerke in der Bundesrepublik}

Während die Unterstützungsnetzwerke in Chile teilweise öffentlich agierten, verhielten sie sich in der Bundesrepublik eher diskret. Die PSM in Siegburg beschränkte sich vorwiegend auf die Akquise von Sachspenden sowie von in Chile benötigten Maschinen, Fahrzeugen und Ersatzteilen. Lobbyarbeit wurde bis Ende der 1980er Jahre vor allem beim Auswärtigen Amt und bei der chilenischen Botschaft betrieben sowie bei rechtskonservativen Einzelpersonen, die mit der chilenischen Diktatur oder der CD

8 Tribunal Constitucional, AZ124-1991. Eingereicht am 18.03.1991 von 17 Senatoren. Vgl. Larraín Cruz, Rafael (Hg.). Fallos del Tribunal Constitucional pronunciados entre el 23 de diciembre 1985 y el 23 de junio 1992. Santiago 1993, S. $379 \mathrm{ff}$.

9 PHF, Declaración Pública Senado de Chile vom September 1994. Erklärung zum Hungerstreik der CD unterzeichnet von 15 Senatoren und zahlreichen Abgeordneten.

10 Hernán Larraín Fernández ist Mitglied der Partei UDI und seit 2018 chilenischer Minister für Justiz und Menschenrechte. Zuvor war er Senator für die Region Maule (1994-2018). Er war Präsident der Partei UDI in den Jahren 2006-2008 sowie 2015-2017.

11 Als Concertación de Partidos por la Democracia wird das Mitte-Links-Bündnis bezeichnet, das während der Transición, also des Übergangs zur Demokratie, von 1990-2010 die Regierung stellte. Ein ähnliches Parteienbündnis während der zweiten Amtszeit von Präsidentin Michelle Bachelet (2014-2018) trug den Namen Nueva Mayoría.

12 Als soziale Fassade der CD bezeichne ich die auf wohltätige Arbeit ausgerichteten Vereine PSM, SBED und Perquilauquén und ihre Einrichtungen wie das Jugendheim Heide (Lohmar), das Krankenhaus und die private Schule. 
sympathisierten und diese etwa als "Musterbeispiel deutscher Aufbauleistung ${ }^{13}$ bezeichneten. Während das Unterstützungsnetzwerk in Chile breiter war, konzentrierte sich die CD in der BRD strategisch auf einige wenige Unterstützer, die politisch am rechten Rand der CDU und vor allem der CSU standen. Diese wurden hofiert, etwa mit Einladungen in die Siedlung, wo sie wie Staatsgäste behandelt wurden. ${ }^{14}$ Diese Unterstützer nutzten ihre Kontakte in der Bundesrepublik meist diskret. So traten etwa Hartmut Hopp und seine Frau Dorothea Witthahn ${ }^{15}$ in den 1980er Jahren in die CSU ein. Sie waren polizeilich gemeldet am Wohnsitz eines CSU-Ortsvorsitzenden. ${ }^{16}$

Hinzu kamen Geschäftsbeziehungen zwischen bayrischen Unternehmen und der chilenischen Diktatur, auch im Rüstungsbereich. Da das chilenische Regime aufgrund seiner Menschenrechtsverletzungen zeitweise Schwierigkeiten hatte, Waffen auf dem freien Markt zu erwerben, dürften diese Geschäfte eine hohe Bedeutung gehabt haben. $\mathrm{Zu}$ diesen Rüstungsdeals gibt es einige journalistische Recherchen, ${ }^{17}$ aber bislang nur wenige Quellen. Eine wichtige Rolle bei diesen Geschäftsbeziehungen spielte der Waffenhändler und BND-Informant Gerhard Mertins. Er pflegte engen Kontakt zu DINAChef Manuel Contreras. Die CD unterstützte die DINA bei ihren Auslandsoperationen in Europa. Sie half der DINA auch, Laborbestandteile für die Herstellung chemischer

13 Sudetendeutsche Zeitung vom 09.11.1979. »Augenschein in Chile: die Colonia Dignidad am Fuß der Anden ein Musterbeispiel deutscher Aufbauleistung. «Autor des Artikels ist der Münchner CSUStadtrat Wolfgang Vogelsgesang.

14 Beispielsweise besuchte 1978 Dieter Huber, damaliger Auslandsreferent der CSU und Vertrauter von Franz Josef Strauß, mit einer Gruppe von 35 CSU-Mitgliedern die CD. Ein wichtiges Verbindungsglied zwischen der CSU und der chilenischen Diktatur war Malte Radmann Puffe, der Repräsentant der Hanns-Seidel-Stiftung in Chile. Vgl. El Mercurio vom 25.11.1978. »Apreciaciones de 35 Alemanes sobre la Realidad Chilena «. Auch der Siegburger Bundestagsabgeordnete Adolf Herkenrath (CDU) besuchte die CD und verteidigte sie öffentlich. General-Anzeiger, Rhein-Sieg Zeitung vom 30.12.1987. »Colonia Dignidad-Anhängern ist nichts vorzuwerfen«.

15 In Chile tragen alle Personen offiziell zwei Nachnamen - den Vatersnamen (Patronym) und den Muttersnamen (Matronym). Diese Nachnamen ändern sich auch nach Heirat nicht. Im Alltag wird häufig nur ein Nachname verwendet, normalerweise der erste. Personen, deren erster Nachname sehr häufig ist, werden zur besseren Unterscheidung mit beiden Nachnamen bezeichnet. In dieser Arbeit wird in der Regel nur der erste Nachname verwendet. Bei verheirateten Colonas wird die chilenische Namensgebung verwendet, mit Ausnahme von einzelnen verheirateten Colonas, bei denen die Verwendung des Nachnamens des Ehemanns auch in Chile geläufig war (beispielsweise bei Gisela Seewald, Ehefrau von Gerd Seewald - die laut chilenischer Namensgebung Gisela Gruhlke Hahn hieß). Der zweite Nachname wird genannt, wenn es die Identifikation im Verlauf der Arbeit wesentlich erleichtert. So gab es beispielsweise in der CD insgesamt drei Personen mit dem Namen Wolfgang Müller.

16 PJS, Sammlung CD. Schreiben Konrad Niedermeier, Bürgermeister von Rottach-Egern, an CSUGeneralsekretär Gerold Tandler vom 28.11.1987.

17 Vgl. Hoffmann, Wolfgang, »Waffen aus Deutschland«, in: Die Zeit Nr. 09/1984 vom 24.02.1984, S. 17, online unter https://www.zeit.de/1984/09/waffen-aus-deutschland/. Der Artikel erwähnt die Lieferung des Waffensystems Kormoran durch Messerschmidt-Bölkow-Blohm (MBB), für die sich der bayrische Ministerpräsident Franz Josef Strauß persönlich eingesetzt haben soll. Die chilenische Journalistin Mónica González berichtete in der Zeitschrift Análisis einige Jahre später ebenfalls über von Strauß geförderte Waffenverkäufe von MBB an Chile. Diese seien über den in Bayern und Österreich lebenden DINA-Agenten Antal Lipthay eingefädelt worden. VgI. Análisis vom 03.08.1987, S. 14-16. »Proyecto Kormoran: El plan secreto alemán«. 
Waffen nach Chile zu schmuggeln. Die DINA verfügte über ein Verbindungsbüro am Starnberger See sowie mit Wolff von Arnswaldt über einen Kontaktmann am Flughafen Frankfurt. Dieser leitete die Frachtabteilung der chilenischen Fluggesellschaft Línea Aérea Nacional (LAN) und stand im Kontakt mit CD-Mitgliedern in Siegburg.

Nur wenige Unterstützer, wie der Münchner Stadtrat Wolfgang Vogelsgesang (CSU), der Waffenhändler Gerhard Mertins oder der Siegburger Bürgermeister und spätere Bundestagsabgeordnete Adolf Herkenrath (CDU) unterstützten in der Bundesrepublik öffentlich die $\mathrm{CD}$. Das bundesdeutsche Unterstützungsnetzwerk war nur bis Ende der 1980er Jahre aktiv.

\section{Die Aufklärer_innen}

In aufklärerischer Weise beschäftigten sich mit der $C D$ vor allem Einzelpersonen, in der Bundesrepublik ebenso wie in Chile. Erstmals öffentlich bekannt wurde der Fall CD in der BRD mit der erfolgreichen Flucht von Wolfgang Müller (heute Kneese) 1966. Diese löste eine Welle der Medienberichterstattung aus. Die Angehörigen der nach Chile Ausgewanderten waren zu diesem Zeitpunkt nicht systematisch untereinander vernetzt. In Reaktion auf die Presseberichte wandten sich daher einzelne Angehörige häufig an das AA sowie an andere Behörden, um Aufklärung über das Schicksal der ausgewanderten Personen zu erhalten. 1976 erwähnten die Vereinten Nationen die CD in Berichten erstmals als Haft- und Folterort der DINA. ${ }^{18}$ Einige Überlebende der Folter in der CD wandten sich an Amnesty International (AI) in der Bundesrepublik. Die Frankfurter AI-Gruppe nahm sich des Themas an und veröffentlichte 1977 eine Broschüre über die CD. ${ }^{19}$ Die beiden Autoren waren Dieter Maier und Jürgen Karwelat. Vor allem Maier recherchiert und veröffentlicht bis heute zu diesem Thema. Die CD ging juristisch gegen die AI-Broschüre vor und erwirkte vor dem LG Bonn eine einstweilige Verfügung, die eine weitere Verbreitung untersagte. Das daraus resultierende juristische Verfahren dauerte 20 Jahre an (bis 1997). Die Spitze der deutschen AI-Sektion um die Generalsekretäre Helmut Frenz und Walter Rövekamp nahm sich des Themas CD an. Unterstützung bekam sie von einzelnen Bundestagsabgeordneten wie Ernst Waltemathe (SPD). Die Chile-Solidaritätsbewegung griff das Thema in den 1980er Jahren nur vereinzelt auf. Lediglich Einzelpersonen recherchierten und veröffentlichten regelmäßig zur CD, beispielsweise in der Zeitschrift Lateinamerika Nachrichten. ${ }^{20}$ Ende der

18 United Nations Economic and Social Council (ECOSOC). Bericht E/CN.4/1188 vom 04.02.1976. Report of the ad hoc working group established under resolution 8 (XXXI) of the Commission On Human Rights to inquire into the present situation of human rights in Chile, online unter https://documents-dds-ny.un.org/doc/UNDOC/GEN/G76/021/02/PDF/G7602102.pdf?OpenEle ment(Englisch), https://documents-dds-ny.un.org/doc/UNDOC/GEN/G76/021/05/PDF/G7602105.pd f?OpenElement(Spanisch) sowie United Nations Economic and Social Council (ECOSOC). Bericht A/31/253 vom 08.10.1976. Protection of Human Rights in Chile. Note by the Secretary-General, online unter https://documents-dds-ny.un.org/doc/UNDOC/CEN/N76/193/25/PDF/N7619325.pdf?Open Element(Englisch), https://documents-dds-ny.un.org/doc/UNDOC/CEN/N76/193/27/PDF/N7619327. pdf?OpenElement(Spanisch).

19 Amnesty International. Colonia Dignidad: deutsches Mustergut in Chile - ein Folterlager der DINA, Frankfurt a.M. 1977.

20 Vgl. Lateinamerika Nachrichten. Colonia Dignidad - Der doppelte Skandal: Der Prozeß vor dem Bonner Landgericht - eine Dokumentation. Sondernummer, September 1980; Lateinamerika Na- 
1980er Jahre gründete sich die Angehörigengruppe Not- und Interessengemeinschaft der Geschädigten der Colonia Dignidad (NIG). Jürgen Karwelat ist bis heute einer ihrer Sprecher_innen. Aus einer Spaltung der NIG entstand der von Wolfgang und Heike Kneese geleitete Verein Flügelschlag. Mit Hilfe der Hamburger Stiftung zur Förderung von Wissenschaft und Kultur unterstützte der Verein in den 1990er und 2000er Jahren Bemühungen um strafrechtliche Aufklärung in Chile.

$\mathrm{Zu}$ den Aufklärer_innen gehörten auch eine Handvoll Personen, die aus der CD fliehen konnten, darunter die Ehepaare Georg und Lotti Packmor sowie Hugo und Waltraud Baar. Die Genannten traten nur selten öffentlich auf, ihre Berichte an das AA wurden jedoch zur Grundlage für politische Maßnahmen sowie ab 1985 für ein Ermittlungsverfahren der StA Bonn. ${ }^{21}$ Ein wichtiges öffentliches Ereignis war eine Anhörung im Bundestag im Februar 1988. ${ }^{22}$ Dabei kam neben aufklärerischen Stimmen (Wolfgang Kneese, Helmut Frenz, Hugo Baar, Lotti Packmor u.a.) auch Hartmut Hopp für die CD zu Wort.

In den 1990er und 2000er Jahren beschränkte sich die Aufklärung über die CD in der Bundesrepublik auf Recherchen von wenigen, mit dem Thema vertrauten Journalist_innen und Menschenrechtsaktivist_innen. Diese regten auch eine Reihe von Kleinen Anfragen und Initiativen einzelner Bundestagsabgeordneter verschiedener Fraktionen an. Dazu gehörten Ernst Waltemathe und Lothar Mark von der SPD, Ludger Vollmer von Bündnis 90/Die Grünen sowie Ulla Jelpke von der Linken bzw. PDS. 2002 verabschiedete der Bundestag auf Initiative von Lothar Mark einen Entschließungsantrag, ${ }^{23}$ der allerdings weitgehend ohne Folgen blieb, ${ }^{24}$ ebenso wie ein von Lothar Mark initiierter einmaliger Runder Tisch ${ }^{25}$ im Bundestag 2005, nach der Festnahme von Paul Schäfer. Erst als Hartmut Hopp 2011 vor der chilenischen Justiz nach Deutschland floh, er-

chrichten. Colonia Dignidad. Sociedad benefactora y educacional dignidad. Cesellschaft für Wohlfahrt und Erziehung...und Freiheitsberaubung und Folter und Ceheimdienstkontakte. Lateinamerika Nachrichten, Nr. 166/1988, online unter https://lateinamerika-nachrichten.de/wp-content/up loads/2014/12/LN166_Web.pdf sowie Lateinamerika Nachrichten. Colonia Dignidad. Der Skandal geht weiter, Sonderheft, Dezember 1989.

21 StA Bonn, AZ 50 ]s 285/85.

22 Öffentliche Anhörung im Unterausschuss für Menschenrechte und humanitäre Hilfe am 22.02.1988 zum Thema »Befinden sich deutsche Staatsangehörige unfreiwillig und unter menschenrechtsverletzenden Bedingungen in der Colonia Dignidad in Chile?«. PA-DBT 3127, 712 - UA 2 - 2451. Stenographisches Protokoll der 10. Sitzung des Unterausschusses für Menschenrechte und Humanitäre Hilfe vom 22.02.1988. Auch online unter http://coloniadignidad-prot.blogspot.co $\mathrm{m} /$.

23 Deutscher Bundestag. Drucksache 14/7444 vom 13.11.2001. Antrag der Fraktionen von SPD, BÜNDNIS 90/DIE GRÜNEN und FDP. Hilfe für die Opfer der Colonia Dignidad. Der Antrag wurde bei Enthaltung der CDU/CSU einstimmig angenommen. Deutscher Bundestag. Plenarprotokoll 14/236 vom 16.05.2002, S. 23616B.

24 Der in Punkt II.6 des Entschließungsantrags vorgesehene Bericht der Bundesregierung über die Umsetzung der verabschiedeten Maßnahmen, der für Mai 2003 angekündigt war, erfolgte nicht. Vgl. Verwaltung des Deutschen Bundestags (Hg.). Datenhandbuch zur Geschichte des Deutschen Bundestags 1994-2003, erstellt von Michael F. Feldkamp unter Mitarbeit von Birgit Ströbel, Berlin, 2005, S. 346, online unter: https://www.bundestag.de/resource/blob/189498/4b3f91ce2dfodf2fc96b 28172930e5f1/Datenhandbuch1994_2003-data.pdf. 
reichte das Thema CD wieder die deutsche Öffentlichkeit. Verschiedene Opfer stellten, vertreten von der Menschenrechtsanwältin Petra Schlagenhauf, Strafanzeigen gegen Hartmut Hopp. Die Menschenrechtsorganisationen European Center for Constitutional and Human Rights (ECCHR) und das Forschungs- und Dokumentationszentrum Chile-Lateinamerika (FDCL) begleiteten diese Bemühungen um strafrechtliche Aufarbeitung. 2014 begann das AA, seine einseitige Unterstützung der Colonos sowie der CD-Unternehmen aufzugeben und Expert_innen sowie Opfer(-verbände) in Chile und Deutschland bei ihren Bemühungen um die Einrichtung einer Gedenkstätte in der CD zu unterstützen. Die erste in diesem Sinne vom AA geförderte Aktivität war ein internationales Seminar im Museo de la Memoria y los Derechos Humanos (MMDH) in Santiago im Dezember 2014. ${ }^{26}$ Seitdem fanden jährlich Dialogseminare und Workshops mit Betroffenengruppen statt, die von der stellvertretenden Leiterin der Gedenk- und Bildungsstätte Haus der Wannseekonferenz, Elke Gryglewski, federführend organisiert wurden. Im Februar 2016 kam in Deutschland ein Spielfilm über die Colonia Dignidad in die Kinos, der auch die Rolle der deutschen Botschaft thematisierte. ${ }^{27}$ Daraufhin lud der damalige Außenminister Frank-Walter Steinmeier im April 2016 diverse Akteur_innen und Betroffene zur einer Vorführung des Films sowie zu einer Rede in das AA ein, in der er die Rolle des AA im Fall CD kritisch beleuchtete und sich vor den Opfern verneigte. ${ }^{28}$ Die Rede war ein Meilenstein, auch wenn die Worte des Ministers sorgfältig abgewogen waren, um Entschädigungsansprüche zu vermeiden. 2017 verabschiedete der Bundestag einstimmig einen Entschließungsantrag, ${ }^{29}$ der die Bemühungen um Aufarbeitung wieder auf die politische Agenda setzte. Konkrete Folgen dieses Beschlusses sind bislang die Durchführung eines wissenschaftlichen Oral-History-Projekts an der FU Berlin ${ }^{30}$ sowie die Einrichtung eines Hilfsfonds für Opfer der CD. ${ }^{31}$ Deutschland und Chile unterzeichneten 2017 eine Erklärung zur Gründung einer Gemischten Kommission, um gemeinsam die Aufklärung zu befördern. Vereinbart wurde unter anderem die Einrichtung eines Dokumentationszentrums und eines Gedenkorts, die $\mathrm{Zu}$ sammenarbeit bei der Feststellung, Sicherung und Auswertung von Spuren und Dokumenten der auf dem CD-Gelände begangenen Verbrechen sowie die Überprüfung der

26 Vgl. den Tagungsband: Hevia, Evelyn/Jan Stehle (Hg.). Colonia Dignidad: diálogos sobre verdad, justicia y memoria, Santiago 2015.

27 Gallenberger, Florian (Regie). Colonia Dignidad - Es gibt kein Zurück. Deutschland, Frankreich, Luxemburg 2015, $110 \mathrm{~min}$.

28 Auswärtiges Amt, Rede des Bundesministers des Auswärtigen Dr. Frank-Walter Steinmeier »Zum Thema Colonia Dignidad « und Paneldiskussion »Ein Tag der uns aufatmen lässt« vom 26.04.2016, Berlin, 2016, online unter: https://www.auswaertiges-amt.de/de/newsroom/160426-colonia-dignid $\mathrm{ad} / 280124$.

29 Deutscher Bundestag. Drucksache 18/12943 vom 27.06.2017. Antrag der Fraktionen CDU/CSU, SPD und BÜNDNIS 90/DIE GRÜNEN. Aufarbeitung der Verbrechen in der Colonia Dignidad. Der Antrag wurde vom Bundestag einstimmig angenommen. Deutscher Bundestag. Plenarprotokoll 18/243 vom 29.06.2017, S. 25049A.

30 Colonia Dignidad. Ein chilenisch-deutsches Oral History-Archiv, online unter https://www.cdoh.n et/.

31 Deutscher Bundestag. Drucksache 19/10410 vom 21.05.2019. Unterrichtung durch die Bundesregierung. Hilfskonzept für die Opfer der Colonia Dignidad der Gemeinsamen Kommission von Deutschem Bundestag und Bundesregierung. 
Vermögenswerte und der aus der CD hervorgegangenen Gesellschaften und Unternehmen. ${ }^{32}$

In Chile bemühten sich in den 1960er Jahren nur wenige Einzelpersonen in der Region um eine Aufklärung über die CD. Landesweit wurde die CD durch die Presseberichterstattung zum Thema. Dabei mischten sich die vielen kritischen Beiträge mit Sensationsberichterstattung und CD-freundlichen Beiträgen. Wenige Monate nach dem Militärputsch vom 11. September 1973 schlossen sich Angehörige von Verschwundenen in der Agrupación de Familiares de Detenidos Desaparecidos (AFDD) zusammen. Die Organisation suchte nach entführten und seitdem verschwundenen Familienmitgliedern. Insbesondere in der Región del Maule, in der die CD liegt, erlangte sie Informationen über die Verschleppung von Personen in die CD. ${ }^{33}$ Unterstützt wurden sie dabei von kirchlichen Organisationen wie der Vicaría de la Solidaridad sowie von Menschenrechtsorganisationen wie dem Centro de Salud Mental y Derechos Humanos (Zentrum für psychische Gesundheit und Menschenrechte, CINTRAS). Seit den 1980er Jahren protestierten Angehörige von Verschwundenen auch vor den Toren der CD und wurden gewaltsam verscheucht. Ebenso wie in der Bundesrepublik griff die Menschenrechtsbewegung das Thema CD jedoch nur punktuell auf. Einzelne Menschenrechtsanwält_innen nahmen sich des Falls CD an, darunter in den 1980er Jahren Guillermo Ceroni, Sergio Corvalán und Máximo Pacheco. Diese vertraten zunächst Amnesty International und später die Bundesregierung. Ab 1984 wandte sich Heinz Kuhn, der 1968 die $C D$ verlassen hatte und in Los Angeles (Chile) lebte, von der CD-Führung ab und unterstützte die Ehepaare Baar und Packmor bei ihrer Flucht aus der Siedlung. Kuhn sagte in verschiedenen Verfahren gegen die CD aus und arbeitete mit aufklärerischen Journalist_innen zusammen. Ab 1996 stellte der Rechtsanwalt Hernán Fernández zahlreiche Strafanzeigen wegen sexuellen Missbrauchs von chilenischen Kindern gegen Paul Schäfer und mehrerer seiner Kompliz_innen. Nach der Festnahme von Paul Schäfer 2005 wurden diverse Ermittlungsverfahren zu CD-Verbrechen bei Richter Jorge Zepeda Arancibia gebündelt. Als »Ministro en Visita extraordinaria «, d.h. besonderer Richter für den Komplex CD an der Corte de Apelaciones (Berufungsgericht, im Folgenden kurz CA) Santiago eröffnete Zepeda dort noch weitere Verfahren. Opfervertreter_innen kritisierten immer wieder Zepedas Rolle. Allerdings lobten sie auch die Ermittlungsarbeit einer Reihe von Beamt_innen der Policía de Investigaciones (chilenische Kriminalpolizei, PDI), allen voran aus deren Departamento Quinto - Asuntos Internos (Abteilung Fünf - Interne Angelegeheiten) und ihrer Brigada de Derechos Humanos (Menschenrechtsbrigade). ${ }^{34}$

PJS, Sammlung AA. Absprache zwischen der Regierung der Republik Chile und der Regierung der Bundesrepublik Deutschland über die Einsetzung einer Chilenisch-deutschen Cemischten Kommission zur Aufarbeitung der »Colonia Dignidad« und Integration der Opfer in die Cesellschaft, unterzeichnet am 12.07.2017 vom Lateinamerikabeauftragten des AA, Dieter Lamlé und dem chilenischen Botschafter Patricio Pradel.

33 Zum Wirken der Menschenrechtsorganisationen in der Región del Maule vgl. Museo de la Memoria y los Derechos Humanos. Archivos de la Memoria en Chile, Region del Maule. Santiago, 2017.

34 Zur Arbeit dieser Abteilungen der PDI im Rahmen der strafrechtlichen Aufarbeitung der Verbrechen der Militärdiktatur siehe: Bonnefoy, Pascale. Cazar al cazador-detectives tras criminales de lesa humanidad, Santiago 2018. 


\section{Staatliche Akteur_innen}

Unterschiedliche staatliche Akteure in Chile und der Bundesrepublik befassten sich mit den Vorgängen in der Colonia Dignidad. In der Bundesrepublik war dies vor allem das Auswärtige Amt und Staatsanwaltschaften in Nordrhein-Westfalen, insbesondere die Staatsanwaltschaft Bonn. Phasenweise befassten sich auch weitere Behörden und Bundesministerien mit der CD. Die Akten zur Übersiedlung und Einrichtung der CD in Chile enthalten zahlreiche Empfehlungsschreiben von staatlichen Stellen in Chile, aber auch in der Bundesrepublik. Der früheste aktenkundige Beleg ist ein Schreiben des Bundesfamilienministeriums an die Botschaft in Santiago vom Mai 1961, in dem um Unterstützung für die Übersiedlung der CD nach Chile gebeten wird:

»Der Eindruck, der anläßlich der Einweihungsfeier von der Arbeit der Privaten Sozialen Mission gewonnen wurde, war gut. Das soziale Anliegen steht im Vordergrund. Aus diesen Cründen ist zu erwarten, daß das neue Vorhaben des Vereins in Chile unterstützungswürdig ist. Ich wäre Ihnen, sehr geehrter Herr Botschafter, dankbar, wenn Sie den Vertretern der Privaten Sozialen Mission Ihre Hilfe und Ihren Schutz gewähren könnten. 35

Das Bundesverwaltungsamt befasste sich Anfang der 1960er Jahre mit der Auswanderung der Gruppe nach Chile.

Das Bundesverteidigungsministerium wertete 1977 Luftbilder der CD aus, die der bundesdeutsche Botschafter Erich Strätling in Auftrag gegeben und von der chilenischen Luftwaffe hatte anfertigen lassen. Es bestätigte Strätlings Aussage, dass auf dem Gelände keine "versteckten Gebäude oder Bewachungsmaßnahmen « bestünden. ${ }^{36}$ Bundesdeutsche Rentenversicherungsträger begannen ab Ende der 1980er Jahre, Rentenzahlungen an Berechtigte in der CD zu suspendieren, nachdem bekannt geworden war, dass die Zahlungen nicht den Berechtigten zugutegekommen waren.

Auch juristische Verfahren lieferten wichtige Einblicke in das kriminelle Wirken der CD, insbesondere das Zivilverfahren der CD gegen Amnesty International (AI) vor dem Landgericht Bonn ${ }^{37}$ sowie die strafrechtlichen Ermittlungsverfahren der Staatsanwaltschaften Bonn ${ }^{38}$ und Krefeld. ${ }^{39}$ Keines der in der Bundesrepublik in den Jahren 1961 bis 2016 eröffneten Ermittlungsverfahren führte zu einer Anklageerhebung. Alle Verfahren wurden eingestellt. Begründet wurde dies mit dem Fehlen eines hinreichenden Tatverdachts. Im Rahmen der in Nordrhein-Westfalen geführten strafrechtlichen Ermittlungsverfahren und zivilrechtlichen Auseinandersetzungen wurden zahlreiche Rechtshilfeersuchen nach Chile übermittelt, die diverse Behörden durchliefen.

Der Bundesnachrichtendienst (BND) spielte ebenfalls eine Rolle im Fall CD. Deren genaues Ausmaß kann jedoch aufgrund fehlenden Aktenzugangs noch nicht umfassend

PA AA, B 85, Bd. 598. Abschrift, Schreiben des Bundesministers für Familien- und Jugendfragen an Botschafter Dr. Strack vom 16.05.1961. 
beurteilt werden. Bislang hat der BND dem Bundesarchiv lediglich ein Dutzend Seiten Akten zum Thema CD übergeben. ${ }^{40}$ Auch im Bundeskanzleramt lagert eine Reihe von Unterlagen des BND zur CD, die dem Geheimschutz unterliegen und nicht zugänglich sind. ${ }^{41}$

Auch in Chile befasste sich eine große Zahl staatlicher Behörden und Institutionen mit der CD. Die früheste aktenkundige Intervention zugunsten der CD geschah, als die PSM-Mitglieder Hermann und Ursula Schmidt im November 1960 beim chilenischen Konsulat in Bad Godesberg für sich sowie den minderjährigen Peter Schmidt und Heinrich Kuhr-Schiwon Einreisevisa beantragten. Der Konsul Carlos Guillermo Osorio beschrieb dem chilenischen Außenminister das Jugendheim der PSM als »WirksamkeitOrdnung- und Sauberkeitsvorbild $\aleph^{42}$. Er und fuhr fort:

»Das Stammhaus Heide wurde von Herrn Botschafter in Begleitung des Ministerrates besucht; die beiden genannten Herren empfingen einen großartigen Eindruck der Organisation. Andererseits ist der Plan des Verlegens des Heimes nach Chile vom Deutschen Roten Kreuz weitgehend unterstützt. « ${ }^{43}$

Nationale und regionale Behörden in Chile unterstützten das Einwanderungsvorhaben sowie die Gründung der SBED. Der SBED wurde Steuer- und Zollfreiheit gewährt. In der Folgezeit baute sich die CD ein Netzwerk von Unterstützer_innen bei diversen Behörden und Institutionen auf. Diese hofierte sie, lud sie sein und bat sie bei Bedarf um Gefälligkeiten und Unterstützung. Dabei konnte die CD auf die Unterstützung zahlreicher Deutschstämmiger rechnen, die in einflussreichen Positionen waren. Zudem konnte die $\mathrm{CD}$ auf eine generell deutschenfreundliche Haltung in der chilenischen Gesellschaft zählen. Während der Diktatur von 1973 bis 1990 erfuhr die CD die uneingeschränkte Unterstützung sämtlicher staatlicher Stellen. Sie ging eine offene Allianz mit den chilenischen Repressionsorganen ein und wurde von Diktator Pinochet persönlich protegiert. Die Justiz, in der die CD bereits in den 1960er Jahren Fürsprecher gewonnen hatte, hielt während der Diktatur ebenfalls ihre schützende Hand über die Siedlung. Dies änderte sich auch mit dem Übergang zur Demokratie ab 1990 nicht schlagartig. Viele der Diktatur wohlgesonnene Beamte behielten zunächst ihre Posten. Die ersten demokratischen Regierungen in den 1990er Jahren versuchten, die CD auf administrativem Wege aufzulösen, was aufgrund der weitreichenden offenen oder verdeckten Unterstützung durch staatliche Behörden und vor allem durch rechte Parlamentarier_innen misslang. Die Cámara de Diputados (das chilenische Abgeordnetenhaus) setzte daraufhin mehrere Untersuchungsausschüsse ein, deren Empfehlungen jedoch weitgehend folgenlos blieben.

41 Siehe dazu ausführlicher Abschnitt 2.3.3.

42 PJK, Ordner Hummel, Hefter Auslandsdeutsche Siedlungs $\mathrm{CmbH}$ 1960-1961. Schreiben von Konsul Osorio an den chilenischen Außenminister vom 29.11.1960. 


\subsection{Die vorhandenen Quellen und mein Umgang mit ihnen}

Die Quellen zum Fall Colonia Dignidad sind vielfältig und umfangreich, jedoch nur zum Teil öffentlich zugänglich. Daher wurde die öffentliche Diskussion über den Fall jahrzehntelang auf der Grundlage unvollständiger Information geführt. In der Folge zirkulierten in der Öffentlichkeit zahlreiche Spekulationen und Mythen über die Colonia Dignidad, die sich zum Teil verselbstständigten. Um dem entgegenzuwirken, habe ich versucht, für mein Forschungsvorhaben Zugang zu einer größtmöglichen Anzahl von Primärquellen zu erhalten. Meine Motivation war, auf möglichst breiter Quellengrundlage die Frage beantworten zu können, welche Verbrechen in der Colonia Dignidad genau begangen wurden. Dies wiederum ist die Voraussetzung für die Frage danach, wie sich Behörden zu diesen Verbrechen verhalten haben. $\mathrm{Zu}$ den Quellen, die ich erschließen wollte, gehören

- Quellen von politischen Behörden (Regierungen, Botschaften und Parlamenten) in Chile und der Bundesrepublik

- Quellen von Justizbehörden (Gerichte, Staatsanwaltschaften) in Chile und der Bundesrepublik

- Quellen von der Colonia Dignidad selbst

- Quellen von Aufklärer_innen, Zeitzeug_innen und Betroffenen

- Presseberichterstattung aus unterschiedlichen Zeiträumen in Chile und der Bundesrepublik

Bis 2005, als dem Jahr der Festnahme Paul Schäfers, war die CD eine weitgehend geschlossene Siedlung, in der jahrzehntelang Verbrechen begangen worden waren, die zum allergrößten Teil bis heute nicht aufgeklärt, geschweige denn geahndet wurden. Daher hatten zahlreiche Akteur_innen ein Motiv, Informationen zurückzuhalten oder den Zugang zu Quellen restriktiv zu handhaben: Täter_innen, um für ihre Taten nicht bestraft zu werden; die (ehemalige) Colonia Dignidad, um nicht zivilrechtlich für diese Taten in Haftung genommen zu werden; staatliche Akteur_innen in der Bundesrepublik Deutschland und Chile, um nicht mitverantwortlich gemacht zu werden (etwa wegen unterlassener Hilfe) und so schlechter Presse oder gar Entschädigungsforderungen zu entgehen.

Während meiner Forschungsarbeit veränderte sich die Quellenlage zum Teil erheblich: So wurden etwa in Chile sehr viele Quellen neu verfügbar, die Richter Zepeda bei Razzien 2000 und 2005 in der CD gefunden und jahrelang geheim gehalten hatte. Darunter ist auch ein Archiv mit über 45.000 Karteikarten (spanisch fichas), das als Geheimarchiv der CD oder auch als Ficha-Archiv bezeichnet wird (vgl. dazu ausführlich Abschnitt 2.2.5). Ab 2014 wurden Teile dieses Archivs im Internet verbreitet. Die Jefatura de Inteligencia Policial (Geheimdienstabteilung der der chilenischen Kriminalpolizei (PDI), im Folgenden kurz JIPOL) gab daraufhin viele Dokumente, die sie jahrelang verwahrt hatte, an das Archivo Nacional (chilenisches Nationalarchiv) ab. Dieses machte 
die Dokumente teilweise zugänglich. ${ }^{44}$ Zudem übergab Dieter Maier ab 2013 Teile seines umfangreichen Privatarchivs an das Museo de la Memoria y los Derechos Humanos $(\mathrm{MMDH})$ in Santiago, wo es seitdem öffentlich zugänglich ist. Auch in Deutschland wurde schlagartig eine Vielzahl zusätzlicher Quellen zugänglich: Nach seiner Rede im Auswärtigen Amt 2016 verkürzte der damalige Bundesaußenministers Steinmeier die Schutzfristen für Akten zur CD in Beständen des Politischen Archivs des Auswärtigen Amts (PA AA) um zehn Jahre. Dadurch wurden über 100 Aktenbände aus den Jahren 1986-1996 allgemein zugänglich - allerdings mit einer Reihe von Auflagen (vgl. dazu Abschnitt 2.3.3).

Trotz entsprechender Hinweise auf weitere versteckte Bestände wurde die (ehemalige) CD niemals systematisch nach relevanten Dokumenten und Quellen durchsucht. Es ist davon auszugehen, dass Vieles inzwischen vernichtet wurde. Andere Quellen befinden sich möglicherweise heute noch in der Siedlung, ob offen oder versteckt. Immer wieder werden in Medienberichten Quellen erwähnt, die von einzelnen Colonos geleakt werden. Beispielsweise erhielt der chilenische Regisseur und Drehbuchautor Cristián Leighton 2016 von CD-Führungsmitgliedern hunderte Videokassetten und Tonbänder sowie Tausende Fotos. ${ }^{45}$ Das Material brachte er in ein gemeinsames Dokumentarfilmprojekt seiner Produktionsfirma Surreal mit der Leipziger Produktionsfirma LOOKS Film ein. Im Auftrag von WDR, SWR, arte und Netflix entstand ein mehrteiliger Dokumentarfilm zur Colonia Dignidad, der im März 2020 erstmals ausgestrahlt wurde. ${ }^{46}$ Unklar ist, was anschließend mit dem Material geschehen wird. ${ }^{47}$

\subsubsection{Literatur}

Vor der Festnahme Schäfers 2005 trugen nur wenige Autor_innen aus menschenrechtlicher Motivation Wissen über die Colonia Dignidad systematisch zusammen. Dennoch bilden diese Informationen bis heute die Grundlage dessen, was über das kriminelle Wirken der CD bekannt ist. In der Bundesrepublik war die erste umfangreichere Publikation zur CD eine Broschüre von Amnesty International von $1977 .{ }^{48}$ Die CD erwirkte eine einstweilige Verfügung, aufgrund derer der Vertrieb dieser Broschüre bis 1997 verboten blieb. ${ }^{49}$

Vgl. https://www.archivonacional.gob.cl/sitio/Contenido/Noticias/89326:AN-pone-a-disposicion-de -la-ciudadania-archivos-de-Colonia-Dignidad. Zugangsrestriktionen gelten insbesondere für Patient_innenakten des CD-Krankenhauses, die mit dem Datenschutz begründet werden. Vgl. Burghardt, Peter, »Folklore und Folter«, in: Süddeutsche Zeitung vom 16.03.2020, S. 25. Baumeister, Annette/Huismann, Wilfried. »Colonia Dignidad - Aus dem Innern einer deutschen Sekte«. Dokumentation [arte], Erstausstrahlung am 10.03.2020.

Da die Urheberschaft des Materials ungeklärt ist, suchte LOOKS Film nahezu alle ehemaligen und gegenwärtigen Colonos auf und bot ihnen jeweils einmalig 80.000 chilenische Pesos bzw. 100 Euro für die pauschale Abtretung jeglicher Bildverwertungsrechte an. Auf diesem Weg sollten mögliche Klagen aufgrund der möglicherweise widerrechtlichen Entwendung oder Verwendung des Materials abgewendet werden. Die Mehrzahl der (Ex-)Colonos unterzeichnete die Abtretungsvereinbarung.

Amnesty International, Colonia Dignidad: deutsches Mustergut.

LC Bonn, AZ 3 O 103/77. 
Den ersten Teil der Broschüre verfasste Dieter Maier. Er beschrieb das Folterlager für politische Gefangene in der CD. Die Darstellung basierte auf den Aussagen mehrerer Folter-Überlebender, die sich ins Exil gerettet hatten. Maier sammelte seitdem jahrzehntelang sämtliche Hinweise über die CD, ihr Innenleben und ihre Verbindungen zur chilenischen Militärdiktatur. Er reiste selten nach Chile, hielt jedoch eine enge Verbindung zu im Exil lebenden Chilen_innen und insbesondere zu seinem Freund Carlos Liberona. ${ }^{50}$ Liberona war Mitglied der Bewegung der Revolutionären Linken (Movimiento de Izquierda Revolucionaria kurz: MIR) und gelangte nach politischer Gefangenschaft in Chile 1977 ins Exil in die Bundesrepublik. Er hatte die CD bereits seit Ende der 1960er Jahre beobachtet. Sein Bruder Lorenzo Liberona, ein Mitglied der Democracia Cristiana (christdemokratischen Partei, DC), hatte die CD besucht. Zu Beginn der AllendeRegierung (1970-1973) hatte Carlos Liberona innerhalb des MIR ein Netz aufgebaut, das rechtsextreme, mit der CD kooperierende Gruppen beobachtete und infiltrierte. Darunter war auch die militante Frente Nacionalista Patria y Libertad ${ }^{51}$ (Nationalistische Front Vaterland und Freiheit). Die vom Netzwerk ${ }^{52}$ gesammelten Information flossen in diverse Veröffentlichungen in Chile und Deutschland ein. Maier schrieb lange Zeit unter Pseudonym, etwa als Friedrich Paul Heller. ${ }^{53}$ In Chile publizierte Maier als Paul Friedrich Violenstein, das Pseudonym von Liberona war Jaime Lagos. ${ }^{54}$ Für einzelne Aufsätze wählte Maier zusätzliche Pseudonyme. ${ }^{55}$ Gemeinsam mit einem Kollegen publizierte er auch zu rechtsextremistischen Netzwerken und deren Verbindungen nach Lateinamerika. ${ }^{56}$ Ende der $2000 e r$ Jahre begann Maier auch unter seinem Klarnamen zu veröffentlichen. ${ }^{57}$

Neben Maier veröffentlichte vor $2005 \mathrm{zu}$ den Verbrechen der CD in deutscher Sprache lediglich der Journalist Gero Gemballa. Dieser befasste sich ab 1987 intensiv mit

50 PJS, Sammlung Dieter Maier. »Don Carlos de la Mancha« von Dieter Maier, 2011 [unveröffentlichtes Manuskript]. Vgl. auch: Liberona, Carlos/Lucía Sepúlveda Ruiz. Memorias de un labrador de futuro. Carlos Liberona, el amor y la lucha, Santiago 2010.

51 Zum Frente Nacionalista Patria y Libertad vgl. Schwarz, Simone. Chile im Schatten faschistischer Bewegungen. Frankfurt a.M., 1997, S. 81-112.

52 Liberona nannte das Netzwerk »la orquestita (das Orchesterchen), offenbar in Anspielung auf die »Rote Kapelle«, die Bezeichnung für ein Widerstandsnetzwerk in Deutschland zur Zeit des Nationalsozialismus.

53 Vgl. u.a. Heller, Friedrich Paul. Colonia Dignidad: von der Psychosekte zum Folterlager, Stuttgart 1993; Heller, Friedrich Paul. Lederhosen, Dutt und Giftgas: Die Hintergründe der Colonia Dignidad, Stuttgart 2011; Heller, Friedrich Paul. Pinochet - Eine Täterbiografie in Chile, Stuttgart 2012.

54 Lagos, Jaime/Paul Friedrich Violenstein. Colonia Dignidad - Buscando la salida del laberinto, Santiago 1988.

55 Vgl. Berggur, Bernd. Colonia Dignidad - Umrisse eines deutschen Kolonisationsprojekts in Chile, in: Babylon. Beiträge zur jüdischen Gegenwart, Heft 5/1989, S. 126-132; Kletten, Ingo. Durch Terror zum modernen Staat. Der chilenische Geheimdienst DINA, in: Reemtsma, Jan Phillipp (Hg.). Folter: zur Analyse eines Herrschaftsmittels, Hamburg 1991, S. 37-72.

56 Vgl. u.a. Heller, Friedrich Paul/Anton Maegerle. Die Sprache des Hasses. Rechtsextremismus und völkische Esoterik - Jan van Helsing, Horst Mahler..., Stuttgart 2001.

57 Vgl. u.a. Maier, Dieter. »Äußerste Zurückhaltung«-die Colonia Dignidad und die deutsche Diplomatie 1961-1978. Nürnberg 2008, online verfügbar unter: https://www.menschenrechte.org/wp-co ntent/uploads/2009/11/Colonia_dignidad.pdf und Maier, Dieter. Colonia Dignidad - Auf den Spuren eines deutschen Verbrechens in Chile, Stuttgart 2016. 
der $C D$, reiste mehrfach nach Chile und versuchte selbst in die CD zu gelangen. Neben seinen Monographien von 1988 und $1998^{58}$ produzierte Gemballa im Auftrag des WDR einen Dokumentarfilm ${ }^{59}$ und mehre kürzere Reportagen und schrieb für die Zeitschrift Stern. ${ }^{60} 2002$ verstarb Gemballa im Alter von nur 40 Jahren. Wichtige deutschsprachige Informationen lieferte auch die Monatszeitschrift Lateinamerika Nachrichten, insbesondere mit zwei Sonderheften 1980 und $1989^{61}$ sowie einem Schwerpunktheft $1988 .{ }^{62}$

Der US-amerikanische Journalist John Dinges recherchierte ausführlich zum chilenischen Geheimdienst DINA und dessen Verbindungen. Dinges untersuchte beispielsweise die Rolle des US-amerikanischen DINA-Agenten Michael Townley, der an verschiedenen Attentaten im Ausland beteiligt war und bei Europareisen auch Kontakt zur CD hatte. ${ }^{63}$ Auch zu den Verbindungen zwischen CD und DINA publizierte Dinges. ${ }^{64}$

In Chile gab es vor der Festnahme Schäfers zwar eine umfangreiche Presseberichterstattung zur CD, jedoch nur wenige andere auf eigenen Recherchen basierende Veröffentlichungen. Eine wichtige Ausnahme war ein Buch, das ein Mitglied der christdemokratischen Jugend in Parral bereits 1968 verfasste, ${ }^{65}$ das viele Details über das Innenleben der CD enthielt, die auch noch Jahrzehnte später als gesichert gelten. Neuere Informationen brachte erst Herman Schwember, den die chilenische Regierung unter Präsidentin Michelle Bachelet 2006 als Regierungsbeauftragten für die CD einsetzte. ${ }^{66}$ Schwember erstellte ein Übergangsprogramm für die $(E x-) C D^{67}$, das Einblicke in die Firmen- und Produktionsstruktur der (ehemaligen) CD gibt und verschiedene $\mathrm{Zu}$ kunftsszenarien für sie entwirft.

Wissenschaftliche Veröffentlichungen zur CD, etwa aus der Religionswissenschaft oder der Psychologie, gab es etwa von Niels Biedermann ${ }^{68}$ und Susanne Bauer ${ }^{69}$, die

58 Cemballa, Gero. Colonia Dignidad. Ein deutsches Lager in Chile, Reinbek 1988; Cemballa, Gero. Colonia Dignidad: ein Reporter auf den Spuren eines deutschen Skandals, Frankfurt a.M. 1998.

59 Gemballa, Gero. »Das Dorf der Würde, die Colonia Dignidad in Chile«, Reportage in der ARDSendereihe »Unter Deutschen Dächern«, 90 min, Erstausstrahlung am 30.07.1989.

60 Vgl. u.a. Cemballa, Gero. »Munition für das Folterlager«, in: Der Stern Nr. 8/1988 vom 18.02.1988, S. 236-239.

61 Lateinamerika Nachrichten. Colonia Dignidad - Der doppelte Skandal.

62 Lateinamerika Nachrichten. Colonia Dignidad. Sociedad benefactora y educacional dignidad.

63 Dinges, John. The Condor Years: How Pinochet and his Allies brought Terrorism to Three Continents, New York 2004.

64 Dinges, John. »Colonia Dignidad«, in: The Rebel vom 06.02.1984, S. 26-35.

65 Rodríguez, Quezada/Hugo Manuel. Colonia Dignidad-¿Enigma o desafío?, Santiago 1968.

66 Schwember, Herman. Delirios e Indignidad. El Estéril Mundo de Paul Schäfer, Santiago 2009.

67 PJS, Sammlung CD. Delegado de Gobierno (Herman Schwember) Programa Integral de Transición Comunidad Villa Baviera (ex-Colonia Dignidad), März 2006.

68 Biedermann, Niels/Judith Strasser/Julian Poluda. »Colonia Dignidad« - Psychotherapie im ehemaligen Folterlager einer deutschen Sekte, in: Zeitschrift für Politische Psychologie, 14 (2006) Nr. $1+2$, S. 111-127.

69 Bauer, Susanne (2009). The Meaning of Music in a German Sect in Chile: Colonia Dignidad. Voices: A World Forum for Music Therapy, online unter https://www.voices.no/columnist/colbauer200409.php (zuletzt abgerufen am 26.05.2009) sowie Bauer, Susanne. Psychologische Behandlungsmöglichkeiten für religiös traumatisierte Menschen am Beispiel der Sekte Colonia Dignidad, in: Utsch, Michael (Hg.). Pathologische Religiosität-Cenese, Beispiele, Behandlungsansätze, Stuttgart 2012, S. 67-105. 
nach Schäfers Festnahme im Auftrag des AA therapeutisch in der CD tätig waren, aber auch von Henning Freund. ${ }^{70}$ Ein Tagungsband zu dem bereits erwähnten Seminar am MMDH in Santiago 2014 enthält Beiträge diverser Akteur_innen zur Geschichte der $\mathrm{CD}$, der von ihr begangenen Menschenrechtsverletzungen und den dazugehörigen Bemühungen um Aufarbeitung. ${ }^{71}$ Marcela Douglas betrachtet in ihrer ethnographischen Dissertation $^{72}$ die CD als utopistische Gemeinschaft und untersucht deren Beziehung zu totalitären Strukturen. Horst Rückert untersucht in seiner geschichtswissenschaftlichen Dissertation ${ }^{73}$ die Wandlung der CD von einem Ort schwerer Menschenrechtsverletzungen zu einem Touristenziel. Demnächst fertiggestellt werden geschichtswissenschaftliche Dissertationen von Evelyn Hevia zur Rolle des Krankenhauses in der CD sowie von Meike Dreckmann zu Geschichtsbildern in der heutigen Villa Baviera. ${ }^{74}$

\subsubsection{Presseberichterstattung}

Seit den Ursprüngen der Gruppierung im Rhein-Sieg-Kreis in den 1950er Jahren sind in Deutschland, Chile sowie der gesamten Welt zehntausende Presseartikel über die CD erschienen. Die bundesdeutsche Medienberichterstattung ist zu großen Teilen über die Pressedokumentation des Bundespresseamts zugänglich, die chilenische ist weitgehend in der Biblioteca del Congreso Nacional (BCN) in Santiago einsehbar. Meine Recherchen in den beiden umfangreichen und dennoch unvollständigen Archiven habe ich ergänzt durch Recherchen in weiteren institutionellen und privaten Archiven, insbesondere des Hamburger Instituts für Sozialforschung, der Friedrich Ebert Stiftung (AdsD), der Konrad-Adenauer-Stiftung (ACDP), von Amnesty International sowie des Berliner Forschungs- und Dokumentationszentrums Chile-Lateinamerika (FDCL). Außerdem habe ich in den Privatarchiven von Dieter Maier und Jürgen Karwelat in Deutschland sowie in den Archiven Fundación de Documentación y Archivo Vicaría de la Solidaridad (FUNVISOL) und des Zentrums für psychische Gesundheit und Menschenrechte (CINTRAS) in Santiago nach Presseartikeln recherchiert.

70 Freund, Henning. Religion als Trauma und Bewältigungshilfe am Beispiel der totalitären religiösen Cemeinschaft Colonia Dignidad, in: Utsch, Michael (Hg.). Pathologische Religiosität-Cenese, Beispiele, Behandlungsansätze, Stuttgart 2012, S. 107-136.

71 Hevia/Stehle (Hg.). Colonia Dignidad: diálogos sobre verdad, justicia y memoria.

72 Douglas, Marcela. Hopes and Horror - An ethnographic study of a German community in Chile. [Dissertation]. Troms $\varnothing$ 2013, online unter: https://munin.uit.no/handle/10037/5810.

73 Rückert, Horst. Vom Folterzentrum der Militärdiktatur zum Ferienort. Die Geschichte der »Villa Baviera« in Chile, Stuttgart 2017.

74 Mit Ausnahme von Douglas (Universität Troms $\emptyset$, Norwegen) entstehen/entstanden alle diese Dissertationen an der FU Berlin. 
Tabelle 1: Phasen der Presseberichterstattung über den Fall Colonia Dignidad

\begin{tabular}{|c|c|}
\hline 1966 & Flucht Wolfgang Müllers (heute Wolfgang Kneese) und Wilhelmine Lindemanns \\
\hline 1968 & Untersuchung der CD durch die chilenische Zollbehörde \\
\hline 1977 & Berichte von Amnesty International u.a. über die Zusammenarbeit zwischen CD und DINA \\
\hline $\begin{array}{l}1987- \\
1989\end{array}$ & $\begin{array}{l}\text { Drei Jahre nach Flucht der Ehepaare Baar und Packmor aus der CD erhöhtes Engage- } \\
\text { ment der Bundesregierung. Sogenannte »Hubschrauber«-Untersuchungsmission. Unter- } \\
\text { suchungsverfahren durch die Richter Navas und Robert }\end{array}$ \\
\hline $\begin{array}{l}1990- \\
1991\end{array}$ & Ende der Diktatur in Chile. Versuch der Auflösung der SBED \\
\hline $\begin{array}{l}1996- \\
1998\end{array}$ & $\begin{array}{l}\text { Strafanzeigen chilenischer Eltern wegen sexuellen Missbrauchs. Flucht Tobias Müllers und } \\
\text { Salo Lunas. Razzien in der CD und Flucht Paul Schäfers }\end{array}$ \\
\hline $\begin{array}{l}2005 \\
2006\end{array}$ & Festnahme Schäfers. Enthüllungen in chilenischen Cerichtsverfahren \\
\hline 2011 & Flucht Hartmut Hopps vor der chilenischen Justiz nach Deutschland \\
\hline 2016 & Rede von Bundesaußenminister Steinmeier zur Colonia Dignidad \\
\hline
\end{tabular}

Die Presseberichterstattung zur Colonia Dignidad erfolgte meist in Zyklen. Auf eine Welle der Berichterstattung mit Hunderten oder gar Tausenden Berichten folgten Phasen, in denen nur wenige Beiträge erschienen (Tabelle 1). Ausgangspunkt der frühesten breiteren Berichterstattung über die CD war die Flucht von Wolfgang Müller (heute Kneese) im März 1966. Die chilenische Wochenzeitschrift Ercilla veröffentlichte in den darauffolgenden Wochen eine Reihe von Artikeln zur $C^{75}$ sowie zur Flucht von Müller und Wilhelmine Lindemann. Medien in Chile und der Bundesrepublik, aber auch weltweit griffen die Berichterstattung von Ercilla auf. ${ }^{76}$ Viele der heute allgemein bekannten Tatsachen über die Verhältnisse in der CD und die von der CD begangenen Verbrechen, die noch Jahre später in chilenischen Gerichtsurteilen bestätigt wurden, waren bereits Gegenstand dieser Presseberichte in den 1960er Jahren. Dazu gehören Berichte über Freiheitsberaubung und Fluchtfälle, über sexuellen Missbrauch, sklavenähnliche Arbeitsverhältnisse, schwere Körperverletzungen sowie die Verabreichung von Elektroschocks und Psychopharmaka. Neben ihrer aufklärerischen Funktion trugen die frühen Presseberichte jedoch auch zur Verbreitung von Mythen und Spekulationen bei, insbesondere über die angeblichen Verbindungen der CD zu hochrangigen ehemali-

75 Ercilla vom 23.03.1966. »Alemanes nazis y antinazis luchan en Chile«; Ercilla vom 30.03.1966. »Tras los muros de la misteriosa colonia alemana«; Ercilla vom 13.04.1966. »La justicia tras el misterio de >Dignidad««; Ercilla vom 20.04.1966. »Colonia >Dignidad - Siembra de recelos«; Ercilla vom 27.04.1966. »Wolfgang Müller: ১Solo contra todos««; Ercilla vom 04.05.1966. »Ante la justicia austríaca denuncian: diabólicos métodos de >Dignidad««; Ercilla vom 11.05.1966. »Extradición de Paul Schäfer pide Alemania«; Ercilla vom 01.06.1966. »Nueva etapa en proceso a >Dignidad«; Ercilla vom 20.07.1966. »Las 600 fojas del proceso a >Dignidad ««.

76 Vgl. u.a. Süddeutsche Zeitung vom 08.07.1966, S. 3, »Zucht und Unzucht in der Siedlung >Würde«« sowie Le Monde vom 14.04.1966. »Une colonie agricole allemande aurait été transformée en camp de concentration $\ll$. 
gen Nazis. So bebilderte Ercilla den ersten Artikel über die Flucht Wolfgang Müllers ${ }^{77}$ mit Fotos von Adolf Eichmann, Martin Bormann und einem Stacheldrahtzaun des KZ Auschwitz. Zugleich spekulierte die Zeitschrift, dass Mengele und Bormann sich in Chile aufhielten. Aus sicherer diplomatischer Quelle habe man erfahren, so Ercilla, dass Wolfgang Müller den Aufenthaltsort Bormanns kenne. Die Spekulationen wurden innerhalb weniger Tage von weiteren Medien übernommen, ohne dass es konkrete Belege für die Thesen gab. ${ }^{78}$ Selbst ein interner Bericht der deutschen Botschaft in Tel Aviv von 1966 erwähnte eine Agenturmeldung über ein "privates deutsches Konzentrationslager in Chile«, bei dessen Leitern es sich »um frühere deutsche Offiziere, darunter auch SS-Offiziere « handeln sollte. ${ }^{79}$ Viele Medien in unterschiedlichen Ländern übernahmen die Behauptung eines »Nazi-Lagers ${ }^{80}$ ungeprüft. Auch DDR-Zeitungen griffen diese Darstellung auf. ${ }^{81}$ Das AA reagierte umgehend darauf und bat die Botschaft, "Behauptungen entgegenzutreten, die deutschem Ansehen abträglich « ${ }^{82}$ seien. Auf einer Pressekonferenz der Bundesregierung teilte der Sprecher des AA mit, es lägen keinerlei Anhaltspunkte dafür vor, dass sich »prominente frühere Nazis« in der Siedlung befänden. »Bisherige Untersuchungen « hätten gezeigt, dass die Siedlung »positive landwirtschaftliche Arbeit« leiste, die auch »von chilenischer Seite anerkannt « würde. ${ }^{83}$ Nichtsdestotrotz wird das Bild von der CD als einer »Nazi-Sekte« sowie von Paul Schäfer als SS-Offizier von einigen Medien bis heute reproduziert.

Während Menschenrechtsaktivist_innen versuchten, Informationen über die CD und ihre Verbrechen zu verbreiten, betrieb die Colonia Dignidad intensive Lobbyarbeit bei Redaktionen und Journalist_innen, um entlastende oder positive Berichte über die Siedlung zu lancieren. In der Bundesrepublik gelang ihr das nur vereinzelt und meist in regionalen oder sehr konservativen Medien. So veröffentlichte der Münchner CSU-Stadtrat Wolfgang Vogelsgesang nach mehreren Besuchen in der Siedlung einige CD-freundliche Artikel in rechtskonservativen Medien. ${ }^{84}$ Auch der ZDF-Moderator Gerd Löwenthal besuchte die Siedlung und äußerte sich anschließend positiv über die CD. Der Waffenhändler Gerhard Mertins versuchte 1988, einen CD-freundlichen Arti-

77 Ercilla vom 23.03.1966, S. 20-21. »Policía frustró sensacional rapto. Exclusivo: Comandos alemanes en acción en calles de Santiago«.

78 Vgl. u.a. La Tarde vom 12.04.1966, S 1. »Nazis se tomaron Colonia >Dignidad««.

79 PA AA, B 85, Bd. 598. Fernschreiben Nr. 250 Botschaft Tel Aviv an AA vom 15.04.1966.

80 Vgl. u.a. Le Figaro vom 14.04.1966. »Un >camp nazi< aurait été découvert au Chili«.

81 Vgl. u.a. Neues Deutschland vom 15.04.1966, »Nazi-KZ in Chile«; Berliner Zeitung vom 16.04.1966, »Oase für Nazimörder« sowie Neues Deutschland vom 04.05.1966. »Bonner Vertretung duldete KZ-Skandal«.

82 PA AA, B 33, Bd. 465. Fernschreiben Dr. Meyer-Lohse an Botschaft Santiago vom 20.04.1966.

83 PA AA, B 33, Bd. 465. Durchdruck vom 20.04.1966 LR I Dr. Ruhfus.

84 Vgl. u.a. Vogelsgesang, Wolfgang. »Augenschein in Chile: die Colonia Dignidad am Fuß der Anden ein Musterbeispiel deutscher Aufbauleistung.«, in: Sudetendeutsche Zeitung vom 09.11.1979; Deutschland-Magazin Nr. 3/1980, S. 32f. »Anatomie einer Hetzkampagne« sowie Bayernkurier vom 05.01.1980. »Eine deutsche Siedlung am Fuße der Anden - Zu Besuch in der sozialen >Colonia Dignidad««. Für weitere Artikeln von Vogelsgesang vgl. Lateinamerika Nachrichten. Colonia Dignidad-Der doppelte Skandal, S. 50. 
kel in der Zeitschrift Quick zu platzieren und vermittelte entsprechende Kontakte. Das Ergebnis war jedoch ein CD-kritischer Artikel. ${ }^{85}$

In Chile war die CD mit ihrer Lobbyarbeit weit erfolgreicher. Sie lud regelmäßig ausgewählte Journalist_innen in die CD ein, schaltete Anzeigen und schrieb Leser_innenbriefe. Die Berichterstattung verlief lange Zeit entlang einer politisch-ideologischen Polarisierung: Rechte bzw. diktaturnahe Medien, wie beispielsweise die Tageszeitungen der Medienkonsortien El Mercurio S.A.P. ${ }^{86}$ und Grupo COPESA ${ }^{87}$, die bis heute einen großen Teil des chilenischen Medienmarktes dominieren, verfolgten bis Ende der 1990er Jahre größtenteils eine CD-freundliche Linie. Publikationen der demokratischen Opposition gegen die Diktatur, wie die der Christdemokratie nahestehenden Tageszeitungen La Epoca und Fortín Mapocho, die Zeitschriften Análisis, Hoy, Apsi und Cauce sowie die kommunistische Wochenzeitung El Siglo und die MIR-nahe Punto Final berichteten durchgehend kritisch über die CD. Dasselbe galt ab 1990 auch für die regierungseigene La Nación.

Regelmäßig versuchte die CD-Führung in der Bundesrepublik kritische Berichterstattung auf juristischem Wege zu unterbinden. So erwirkte die CD bereits 1967 eine einstweilige Verfügung gegen den Stern, ${ }^{88}$ weitere einstweilige Verfügungen richteten sich 1977 wiederum gegen den Stern sowie gegen Amnesty International. ${ }^{89}$ In den 1980er Jahren führte die CD einen Rechtsstreit gegen den WDR und den Journalisten Gero Gemballa. ${ }^{90}$

\subsubsection{Archive}

Für diese Arbeit habe ich in den folgenden Archiven in der Bundesrepublik, in Chile und in den USA recherchiert (Tabelle 2):

85 Quick Nr. 18/1988 vom 27.04.1988, S. 20-27. »Die geheime Kolonie«. Mertins berichtete der Bonner Staatsanwaltschaft bei seiner Vernehmung am 01.03.1989, der Artikel sei auf seine Veranlassung hin entstanden. StA Bonn, AZ 50 ]s 285/85, Bd. XI, BI. 68ff. Vernehmung von Gerhard Mertins am 01.03.1989.

86 Zu El Mercurio Sociedad Anónima Periodística gehören u.a. die Tageszeitungen El Mercurio, La Segunda, Las Últimas Noticias, El Sur.

87 Zu Grupo COPESA gehören u.a. die Tageszeitungen La Tercera und La Cuarta, sowie die Zeitschrift Qué Pasa.

88 Stern Nr. 40/1967 vom 01.10.1967. »Angst vor der Sekte. Eine verzweifelte Mutter tötete sich und ihre drei Kinder.«

89 Die einstweilige Verfügung wandte sich gegen die AI-Broschüre (Amnesty International, Colonia Dignidad: deutsches Mustergut) sowie gegen den Verlag Gruner und Jahr wegen eines zeitgleich erschienenen Artikels im Stern (Stern Nr. 13/1977 vom 17.03.1977, S. 26-33. »Das Folterlager der Deutschen «).

90 Dokumente zu diesen Vorgängen finden sich im Bestand Colonia Dignidad des Archivs im Hamburger Institut für Sozialforschung (künftig HISArch, Bestand CD). 
Tabelle 2: Recherche in deutschen, chilenischen und US-amerikanischen Archiven

\section{1: Bundesrepublik Deutschland}

\begin{tabular}{|c|c|}
\hline Archiv und Abkürzung & Besonders relevante Bestände \\
\hline $\begin{array}{l}\text { Politisches Archiv des } \\
\text { Auswärtigen Amts (PA } \\
\text { AA) }\end{array}$ & $\begin{array}{l}\text { Lateinamerikareferat (B 33), Rechtsreferat (B 83), Auslandsvertretung in } \\
\text { Santiago (AV NA) }\end{array}$ \\
\hline Archiv BStU & Berichte der Hauptverwaltung Aufklärung der DDR-Staatssicherheit zur CD \\
\hline Bundesarchiv (BArch) & Bestände von BM], BND, Bundeskanzleramt, BMI, Bundesverwaltungsamt \\
\hline $\begin{array}{l}\text { Archiv des Bundespres- } \\
\text { seamts (Archiv BPA) }\end{array}$ & Presseberichterstattung \\
\hline $\begin{array}{l}\text { Parlamentsarchiv Bun- } \\
\text { destag (PBT) }\end{array}$ & $\begin{array}{l}\text { Unterausschuss Menschenrechte und humanitäre Hilfe und Auswärtiger } \\
\text { Ausschuss in den Jahren 1987-1989 }\end{array}$ \\
\hline $\begin{array}{l}\text { Archiv der sozialen De- } \\
\text { mokratie (AdsD) }\end{array}$ & Nachlass Ernst Waltemathe (SPD, MdB) \\
\hline $\begin{array}{l}\text { Archiv für Christlich } \\
\text { Demokratische Politik } \\
\text { (ACDP) }\end{array}$ & Presseberichterstattung \\
\hline $\begin{array}{l}\text { Archiv für Christlich- } \\
\text { Soziale Politik (ACSP) }\end{array}$ & Nachlass Franz-Josef Strauß, Protokolle der CSU-Landesgruppe \\
\hline $\begin{array}{l}\text { Archiv Hamburger } \\
\text { Institut für Sozialfor- } \\
\text { schung (HISArch) }\end{array}$ & $\begin{array}{l}\text { Umfangreicher Bestand, der Teilweise aus einem Überfall auf die PSM im } \\
\text { November } 1988 \text { stammt }^{\mathrm{a}}\end{array}$ \\
\hline $\begin{array}{l}\text { Archiv Amnesty Inter- } \\
\text { national (Archiv Al) }\end{array}$ & $\begin{array}{l}\text { Akten zum Gerichtsverfahren der SBED gegen Amnesty International (1977- } \\
\text { 1997) sowie Akten aus weiteren juristischen Verfahren }\end{array}$ \\
\hline Archiv FDCL & NL Reinhold Freitag (NIG), Teile des Privatarchivs von Jürgen Karwelat (PJK) \\
\hline $\begin{array}{l}\text { Privatarchiv John Din- } \\
\text { ges (PJD) }\end{array}$ & Juristische Verfahren und Dokumente zum Mord an Orlando Letelier \\
\hline $\begin{array}{l}\text { Privatarchiv Hernán } \\
\text { Fernández (PHF) }\end{array}$ & Juristische Verfahren in Chile \\
\hline $\begin{array}{l}\text { Privatarchiv Winfried } \\
\text { Hempel (PWH) }\end{array}$ & In der CD gefundene Audioaufnahmen \\
\hline $\begin{array}{l}\text { Privatarchiv Wolfgang } \\
\text { Kneese (PWK) }\end{array}$ & $\begin{array}{l}\text { Juristische Verfahren gegen Wolfgang Kneese aus den1960er Jahren, Verein } \\
\text { Flügelschlag, Presseberichterstattung }\end{array}$ \\
\hline $\begin{array}{l}\text { Privatarchiv Jürgen } \\
\text { Karwelat (PJK) }\end{array}$ & PSM inkl. deren Auswanderung nach Chile, NIG. \\
\hline $\begin{array}{l}\text { Privatarchiv Dieter } \\
\text { Maier (PDM) }\end{array}$ & $\begin{array}{l}\text { Verbindungen zwischen CD und DINA während der Diktatur. Teilweise ab- } \\
\text { gegeben an das Archiv des Museo de la Memoria y los Derechos Humanos } \\
\text { in Santiago. }\end{array}$ \\
\hline
\end{tabular}

a Am 30.11.1988 drangen Unbekannte in das Haus der PSM in Hennef-Heisterschoß ein, sperrten die Bewohner_innen ein und entwendeten umfangreiches Aktenmaterial. Vgl. StA Bonn, AZ 50 Js 285/85, Bd. X, Bl. 223-225. Presseerklärung zu dem Überfall auf Mitglieder der Privaten Socialen Mission e.V. in deren Wohnhaus in Hennef-Heisterschoß von Rechtsanwalt Gatzweiler, o.D. 
2.2: Chile

\begin{tabular}{|c|c|}
\hline Archiv und Abkürzung & Besonders relevante Bestände \\
\hline $\begin{array}{l}\text { Archivo General Histór- } \\
\text { ico (AGH) (chilenisches } \\
\text { Außenministerium) }\end{array}$ & Korrespondenz zwischen Zentrale und der chilenischen Botschaft in Bonn. \\
\hline $\begin{array}{l}\text { Biblioteca del Congre- } \\
\text { so Nacional (BCN) }\end{array}$ & Presseberichterstattung \\
\hline $\begin{array}{l}\text { Fundación de Docu- } \\
\text { mentación y Archivo } \\
\text { Vicaría de la Soli- } \\
\text { daridad (FUNVISOL) }\end{array}$ & $\begin{array}{l}\text { Aussagen von Folterüberlebenden und Zeitzeug_innen sowie Berichte von } \\
\text { chilenischen Menschenrechtsgruppen. Presseberichterstattung }\end{array}$ \\
\hline Archivo CINTRAS & Presseberichterstattung \\
\hline $\begin{array}{l}\text { Archivo Museo de la } \\
\text { Memoria y los erechos } \\
\text { Humanos (AMMDH) }\end{array}$ & Teile des Privatarchivs Dieter Maier (siehe Tabelle 2.1) \\
\hline $\begin{array}{l}\text { Privatarchiv Hernán } \\
\text { Fernández (PHF) }\end{array}$ & $\begin{array}{l}\text { Akten chilenischer Verfahren und Berichte der Untersuchungskommissio- } \\
\text { nen des chilenischen Parlaments. }\end{array}$ \\
\hline
\end{tabular}

2.3: USA

\begin{tabular}{|l|l|}
\hline Archiv und Abkürzung & Besonders relevante Bestände \\
\hline $\begin{array}{l}\text { National Archives, } \\
\text { College Park, Maryland } \\
\text { (NA-CP) }\end{array}$ & State Department, CIA \\
\hline $\begin{array}{l}\text { United Nations Archi- } \\
\text { ves, New York (A UN) }\end{array}$ & Dokumente zu Menschenrechtsverletzungen in Chile während der Diktatur \\
\hline $\begin{array}{l}\text { Privatarchiv John Din- } \\
\text { ges (PJD) }\end{array}$ & Verbindungen zwischen CD und DINA während der Diktatur \\
\hline
\end{tabular}

Der umfangreichste Teil meiner Archivrecherchen fand im Politischen Archiv des Auswärtigen Amts sowie in Privatarchiven statt.

\subsubsection{Akten aus juristischen Verfahren}

Neben den Archivrecherchen war ein wichtiger Teil meiner Forschungsarbeit die Auswertung von Akten aus bundesdeutschen und chilenischen Justizverfahren. In Deutschland und Chile fand seit den 1960er Jahren eine Vielzahl juristischer Verfahren mit Bezug zur CD statt. Die Akten dieser Verfahren sind wichtig bei der Rekonstruktion des Falls Colonia Dignidad, da in ihnen verschiedene Akteur_innen zu Wort kommen, teilweise sogar zeitnah zu den untersuchten Vorgängen. Zudem wurden oftmals wichtige Dokumente oder Berichte zum Stand der Ermittlungen als Beweismittel zu den Akten genommen. Relevant sind diese Akten auch, da seitens der Bundesregierung in verschiedenen Phasen des Falls Colonia Dignidad argumentiert wurde, man befände sich 
in einem »schwebenden Verfahren «, dessen Ende man abwarten müsse, bevor Maßnahmen getroffen werden könnten. Insbesondere in der Bunderepublik gab es bislang zwar zum Teil jahrzehntelange Verfahren, jedoch keine einzige Anklage oder gar rechtskräftige Verurteilung. Nur anhand der vorhandenen Akten lässt sich analysieren, warum dies so ist.

\section{Akten von Verfahren zur Colonia Dignidad in der Bundesrepublik}

Der Zugang zu Justizakten bewegt sich - wie auch bei anderen Archivalien - im Spannungsfeld zwischen dem öffentlichen bzw. wissenschaftlichen Interesse auf der einen Seite und Schutz von Persönlichkeitsrechten auf der anderen Seite. Akten juristischer Verfahren in der Bundesrepublik werden nach Abgabe durch die entsprechende Behörde (Gericht oder Staatsanwaltschaft) in den jeweils zuständigen Landesarchiven aufbewahrt, sofern sie als archivwürdig erachtet werden. Dort unterliegen sie den jeweiligen Landesarchivgesetzen sowie den darin festgelegten Sperrfristen. In der Regel beträgt diese Frist 30 Jahre - wenn die Akten persönliche Daten enthalten oder einer Geheimhaltungsvorschrift unterliegen sogar deutlich länger. Vor Ablauf dieser Frist erhalten ausschließlich Beteiligte des Verfahrens Kenntnis von den Akten - und dies auch nur während der Dauer des Verfahrens. Die Sperrfrist beginnt grundsätzlich mit der Entstehung eines Dokuments. Bei Aktenbänden oder Verfahren mit mehreren Aktenbänden beginnt die Sperrfrist in der Regel mit der Entstehung des jüngsten Dokuments. Ein Beispiel: Das wichtigste strafrechtliche Ermittlungsverfahren zur CD lief von 1985 bis 2010. ${ }^{91}$ Ein Großteil der Ermittlungen fand vermutlich in den ersten fünf bis acht Jahren des Verfahrens statt. Seit 1994 wollte die Staatsanwaltschaft das Verfahren einstellen, benötigte hierzu jedoch eine Bestätigung des AA. ${ }^{92}$ Das AA wiederum war gegen eine Einstellung, ${ }^{93}$ weshalb das Verfahren formal weiter lief. Allem Anschein nach wurde jedoch nicht mehr umfangreich ermittelt. Dennoch stammt das jüngste Dokument von 2010. In einem Archiv wären die Akten somit erst ab 2041 einsehbar - nach Ablauf der 30-jährigen Sperrfrist - obwohl ein Großteil der Akten aus den 1980er Jahren stammt. Drei der vier Beschuldigten des Verfahrens sind bereits heute verstorben und es ist anzunehmen, dass bis 2041 sämtliche Beschuldigte, aber auch ein Großteil der Opfer und der am Verfahren beteiligten Amtsträger_innen nicht mehr am Leben ist. Den (mutmaßlich) an Verbrechen beteiligten Personen bleibt damit zu Lebzeiten eine öffentliche Diskussion über diese Taten erspart. Den Opfern und der Öffentlichkeit wird gleichzeitig die Möglichkeit einer zeitnahen Aufarbeitung genommen.

In der Bundesrepublik wurden bis heute sämtliche strafrechtlichen Ermittlungsverfahren mit Bezug zur CD wegen mangelnden Tatverdachts ( $\$ 170$ II StPO) eingestellt. Allerdings werden Akten aus eingestellten Ermittlungsverfahren in der Regel nicht für

91 StA Bonn, AZ 50 Js 285/85, Strafrechtliches Ermittlungsverfahren gegen Paul Schäfer, Hartmut Hopp, Gisela Seewald und Hugo Baar, wegen des Vorwurfs der Freiheitsberaubung, Körperverletzung usw.

92 Artikel 90 I der Richtlinien für das Strafverfahren und das Bußgeldverfahren (RiStBV) sehen vor, dass einer Behörde oder Körperschaft des öffentlichen Rechts, die Strafanzeige erstattet hat oder auf andere Weise am Ausgang des Verfahrens interessiert ist, vor einer Einstellung Gelegenheit zu einer Stellungnahme gegeben werden soll. 
archivwürdig erachtet. Die meisten dieser Verfahren fanden in Nordrhein-Westfalen statt. Mir ist kein Fall bekannt, in dem Akten aus solch einem Verfahren im Landesarchiv Nordrhein-Westfalen zugänglich wären. Die Staatsanwaltschaft Bonn teilte mir bei einem Gespräch $2009^{94}$ mit, dass die Akten der Bonner Ermittlungen ab 1985 nach Abschluss des Verfahrens ans zuständige Landesarchiv abgegeben werden sollen, da es sich um einen emblematischen Fall handle. ${ }^{95}$ Die Akten des ersten Ermittlungsverfahrens gegen Paul Schäfer 1961 sowie eines weiteren Verfahrens von 1965 wurden nach Einstellung des Verfahrens vernichtet. ${ }^{96}$ Ob auch die Akten des Bonner Ermittlungsverfahrens von $1977^{97}$ vernichtet wurden, ist nicht bekannt. In den Beständeübersichten des Landesarchivs sind sie nicht vermerkt. Möglicherweise wurden sie zu den Akten der Ermittlungsverfahren ab 1985 genommen. Große Mengen staatsanwaltlicher Ermittlungsakten lagern vermutlich noch bei den zuständigen Staatsanwaltschaften, insbesondere in Bonn und Krefeld.

Obwohl also Justizbehörden und Archive in Deutschland keinerlei Einsicht in Akten aus Justizverfahren zur Colonia Dignidad bieten, konnte ich für diese Arbeit dennoch eine große Anzahl dieser Akten auswerten. Oftmals konnte ich diese allerdings nicht auf offiziellem Wege einsehen, sondern über Archive von Menschenrechtsorganisationen, über Privatpersonen, Rechtsanwält_innen sowie Personen in Behörden. Teilweise war die Überlassung der Aktenkopien an die Bedingung geknüpft, Vertraulichkeit über die Herkunft des Materials zu wahren. Konkret konnte ich folgende Akten auswerten:

- Einige Bände des strafrechtlichen Ermittlungsverfahrens, das die StA Bonn ab 1985 führte, aus Beständen des Archivs von Amnesty International. ${ }^{98}$

- Akten des Zivilverfahrens der CD gegen Amnesty International und den Verlag Gruner \& Jahr am Landgericht Bonn ab 1977 aus Beständen des Archivs von Amnesty International sowie aus Privatarchiven. ${ }^{99}$

- Diverse Einstellungsverfügungen der Bonner Staatsanwaltschaft, Korrespondenz zu Verfahren zwischen dem AA und den Justizministerien des Bundes und Nordrhein-Westfalens sowie Urteile von Verfahren vor Verwaltungs- und Sozialgerichten mit Bezug zur CD, allesamt aus Beständen des PA AA. Hier lagern auch diverse Bände des von den Richtern Guillermo Navas und Hernán Robert 1989 in Chile geleiteten Untersuchungsverfahrens sowie Auszüge aus diversen anderen Verfahren. Diese Akten wurden dem AA von den Rechtsanwälten Máximo Pacheco, Sergio Corvalán und Guillermo Ceroni zugeleitet, die in den 1980er und 1990er

PJS, Sammlung Gesprächsnotizen. Notiz eines Gesprächs mit dem für die CD-Verfahren zuständigen StA, Martin Diesterheft, vom 09.12.2009.

95 Ob dies inzwischen geschehen ist, ist nicht bekannt. In den Beständeübersichten des Landesarchivs werden diese Akten bislang nicht aufgeführt (Stand: November 2019).

96 StA Bonn, AZ 14 ]s 173/61 jug. Ermittlungsverfahren gegen Paul Schäfer wegen Verdachts des sexuellen Missbrauchs von drei noch nicht 14-jährigen Jungen sowie StA Bonn, AZ 14 ]s 1940/65. Ermittlungsverfahren wegen Verdachts der Kindesentziehung. Erwähnt in: PA AA, AV NA 31577. Schreiben von Oberstaatsanwalt Irsfeld an den Justizminister von Nordrhein-Westfalen vom 19.07.1985. 
Jahren für die Botschaft in verschiedenen Verfahren und Vorgängen mit CD-Bezug tätig waren.

- Einzelne Schriftsätze und Aktenauszüge aus diversen deutschen Verfahren und Unterlagen, die 2000 und 2005 von der chilenischen Kriminalpolizei beschlagnahmt wurden. Diese befinden sich in den Beständen des Archivo Nacional in Santiago.

\section{Akten von Verfahren zur Colonia Dignidad in Chile}

In Chile gelten nach Abschluss eines Gerichtsverfahrens die entsprechenden Akten als öffentlich. In der Regel werden sie im Archiv des erstinstanzlichen Gerichts verwahrt und zugänglich gemacht. Oftmals werden die Akten dem Archiv jedoch nicht unmittelbar nach Ende des Verfahrens zugeleitet. Meist bleiben sie in den Händen der zuständigen Richter_innen, bis auch eventuelle Parallelverfahren abgeschlossen und die gegebenenfalls verhängten Strafen verbüßt wurden. Im Fall Colonia Dignidad gab es diverse Verfahren bereits in den 1960er Jahren, die vornehmlich beim Juzgado de Parral (Amtsgericht) geführt wurden. 1996 begannen die strafrechtlichen Ermittlungen, die zur Festnahme Schäfers führten. 2013 wurde das Verfahren mit rechtskräftigen Urteilen der Corte Suprema abgeschlossen.

Die Mehrzahl der Verfahren wegen Menschenrechtsverbrechen in der CD wurde nach der Festnahme Schäfers im März 2005 bei Untersuchungsrichter Jorge Zepeda an der CA Santiago gebündelt. Zepeda sprach seine Urteile in den Jahren 2008 bis 2015 . Die Verfahrensakten gab er anschließend nicht an das Gerichtsarchiv ab, sondern bewahrte sie in seinem Büro auf. Nach intensiven Bemühungen konnte ich die Akten von zwei der vielen Verfahren für wenige Stunden einsehen. Eine weitere Einsichtnahme wurde mir versagt. Wann die Akten dem Archiv zugeleitet werden, liegt vollständig im Ermessen des Richters. Daher bestehen keinerlei rechtliche Mittel, um weiteren Aktenzugang zu erlangen.

Da die Regelungen zum Schutz persönlicher Daten in Chile weniger ausgeprägt sind als hierzulande und Regelungen zur Informationsfreiheit hingegen sehr weitreichend sind, kann ein Zugang zu Akten auch über diesen Weg erlangt werden. ${ }^{100}$

Trotz der genannten Zugangshindernisse konnte ich auf informellem Wege, d.h. über Kontakte zu Rechtsanwält_innen und anderen Verfahrensbeteiligten, Einblick in viele zehntausend Seiten Verfahrensakten erhalten. Dazu gehören die folgenden Verfahren:

- Mehrere Verfahren am CA Santiago, AZ 2182-98, darunter die episodios (Einzelverfahren) »Ley de Control de Armas« (Waffenherstellung u. -handel durch die CD)

100 Beispielsweise erreichte der Journalist Luis Narváez 2013 die Herausgabe digitalisierter Aktenkopien eines CD-Verfahrens (CA Santiago AZ 2182-98 »Ley de Control de Armas«) seitens des Consejo de Defensa del Estado (CDE) (Vgl. Corte Suprema, AZ 4380-2012). Das Verfahren über die Waffenproduktion und -lagerung in der CD war im Jahr 2008 mit Verurteilungen von Paul Schäfer, Kurt Schnellenkamp, Karl van den Berg und Hartmut Hopp abgeschlossen worden. Die Akten zu diesem des Verfahrens befanden sich jedoch weiterhin bei Richter Jorge Zepeda, der keinen Zugang erlaubte. 
»Asociación Ilícita (Colonia Dignidad)«; »Lesiones Graves« (Schwere Körperverletzung durch Elektroschocks und Medikamente), sowie folgende Verfahren wegen sogenannter Verschwundener: »Juan Maino«, »Alvaro Vallejos Villagrán«, »Pedro Merino«, »Boris Weisfeiler«, »Alfonso Chanfreau« sowie »Parral« (27 Verschwundene).

- Verfahren wegen des Verschwindenlassens von Adán Valdebenito Olavarría, Juzgado del Crimen de Lota, AZ 28.888-1975 (dann: Richter Carlos Aldana, CA Concepción)

- Abusos sexuales y otros, Juzgado de Parral, AZ 53.015 u.a. (dann: Richter Hernán González, CA Talca)

- Adriana Bórquez (Entführung und Folter), Juzgado del Crimen de Talca, AZ 10-2004 (dann: Richter Jorge Zepeda, CA Santiago)

- Miguel Becerra (Mord) CA Santiago, AZ 12.293-2005 (Richter Jorge Zepeda)

- Osvaldo Heyder (Mord) Juzgado del Crimen de Talca, AZ 38.720-2005 (dann: Richter Jorge Zepeda, CA Santiago)

- Infracción a Ley de Adopción, Juzgado de Parral, AZ 55.070 M

- Miguel Rojas Rojas, Gilberto Rojas Vásquez y Ruperto Torres Aravena (Verschwundene) CA Santiago, AZ 8.710-2005 (Richter Jorge Zepeda)

- Asociación Ilícita (Franz Baar und Ingrid Szurgelies) Juzgado del Crimen de Parral, AZ 66.122. (dann: Richter Jorge Zepeda, CA Santiago)

- Asociación Ilícita (Efraín Vedder) Juzgado del Crimen de Parral, AZ 66.124

- Investigación a Colonia Dignidad 1989, CA Talca, AZ 43.210-1989 (Richter Roberto Navas/Hernán Robert Arias) ${ }^{101}$

Aus den Justizakten konnte ich zahlreiche relevante Informationen über die CD und ihre Verbrechen gewinnen.

\subsubsection{Das Geheimarchiv und andere Quellen der Colonia Dignidad}

Nahezu seit Bestehen der Colonia Dignidad gab es Spekulationen darüber, dass die Gruppierung systematisch Informationen über Personen und Institutionen sammelte, um damit Gegner_innen einzuschüchtern oder ggf. zu erpressen. Tatsächlich begriff die CD die Kontrolle über Kommunikation und Informationen stets als strategisches Mittel $\mathrm{zu}$ ihrem Machterhalt. Innerhalb der Siedlung wurden Information nur sehr selektiv weitergegeben, so dass viele Gesamtvorgänge nur wenigen Personen bekannt waren. Zudem bespitzelten die Colonos sich gegenseitig. Über versteckte Mikrophone hörten Mitglieder der Sicherheitsgruppe sie ab und ihre Beichten wurden in Seelsorgeakten akribisch erfasst. Informationen von außen, aus offenen und geschlossenen Quellen, sowie Korrespondenz wurden im von Gerd Seewald geleiteten Büro gesammelt, klassifiziert und archiviert. Die CD legte ein Geheimarchiv mit umfangreichen Informationen über Einzelpersonen an. Dieses umfasste Zehntausende Karteikarten (sogenannte Fichas). Andere Sektionen des Büros befassten sich mit der Wirtschaftstätigkeit und 
der Buchhaltung der $\mathrm{CD}^{102}$ sowie mit den juristischen Verfahren, die die $\mathrm{CD}$ in Chile und in der Bundesrepublik führte. ${ }^{103}$

Information über das Leben außerhalb der CD erhielten die Colonos nur in vorgefilterter Form. In einer Foto- und Videowerkstatt wurden bereits in den 1960er Jahren Videos für die Colonos sowie für die Außenwelt produziert. ${ }^{104}$ Um die CD nach außen als wohltätige Einrichtung zu präsentieren, wurden auch Propagandavideos und -schriften erstellt. ${ }^{105}$ Wichtige Freund_innen der CD bekamen nach ihren Besuchen in der Siedlung jeweils Videos von ihrem Aufenthalt geschenkt. Die Besucher_innen wurden ebenfalls überwacht und heimlich gefilmt bzw. aufgenommen. Auch außerhalb der Siedlung fertigte die CD heimlich Aufnahmen von Gesprächen oder Gerichtsverhandlungen an. Auch der interne Funkverkehr wurde teilweise aufgezeichnet und archiviert. $^{106}$

Nachdem Paul Schäfers und einige weitere Führungspersonen der CD 1997 untergetaucht waren, wurden die von der CD gesammelten Informationen teilweise verbrannt oder vergraben. ${ }^{107}$ Andere Dokumente und Materialien wurden bei Durchsuchungen von Polizei und Justiz beschlagnahmt und wieder andere blieben unbehelligt und liegen heute in privaten Händen innerhalb oder außerhalb der Siedlung. Unbekannt ist die Anzahl der Dokumente, die bis heute vergraben oder versteckt bleiben. Dadurch bleiben

102 Für diesen Bereich waren in Chile unter anderem Erika Heimann und Cesa Kunde verantwortlich, später auch Hans Schreiber und der externe Buchhalter Luis Lamas Zarricueta. In Siegburg führte Rita Seelbach die Bücher.

103 Für juristische Angelegenheiten war in der CD Hans-]ürgen Blanck verantwortlich. Nach seinem Tod 2004 übernahm Hans Schreiber diese Aufgabe.

104 Einige dieser Videos werden von Marcela Douglas (2013) besprochen und sind hier einsehbar: htt ps://munin.uit.no/handle/10037/5810.

105 Beispielsweise erstellte die CD im Jahr 1976 eine Hochglanzbroschüre in spanisch- und deutschsprachiger Version ohne Angaben zu Verfasser_innen, Erscheinungsort und -jahr, vgl. o. A. [SBED]. »Festschrift 15 Jahre in Chile 1961-1976«, o. O. [Parral], o.]. [1976] sowie o. A. [SBED]. »15 años Sociedad Benefactora y Educacional Dignidad. 1961-1976«, o. O. [Parral], o.]. [1976]. Von dieser Broschüre erschien 2011 eine kuriose Neuauflage, vgl. o. A. [Johannes Wieske]. »Festschrift 50 ]ahre in Chile 1961-2011«, O. O. [Parral], 0.]. [2011]. Bereits in den 1990er Jahren waren mehrere Ausgaben des Mensajero de Dignidad erschienen, vgl. u.a. Asociación Nacional de Miembros y Amigos de la Sociedad Benefactora y Educacional Dignidad. »Mensajero de Dignidad: 30 años Dignidad en Chile«, Santiago 1990

106 Der Rechtsanwalt (und Ex-Colono) Winfried Hempel ließ eine Reihe von Tonbändern aus der CD digitalisieren. Darunter befinden sich beispielsweise Predigten von Paul Schäfer, Berichte von Spionagereisen führender CD-Mitglieder nach Bolivien und Mitschnitte des Zivilverfahrens der CD gegen Amnesty International. Vgl. The Clinic vom 04.07.2014, S. 24-25. »Aparecen las grabaciones secretas de Paul Schaefer al interior de Colonia Dignidad«. 2018 zeigte die Künstlerin María Verónica San Martín eine auf diesen Audioquellen basierende Performance, vgl. Archivo Nacional de Chile. Exposición + performance »Dignidad«, September 2018, online unter: https://www.archi vonacional.gob.cl/sitio/Contenido/Cartelera/87473:Dignidad.

107 Gerd Seewald gab an, dass er und weitere Personen auf Anweisung Schäfers Dokumentenbestände zu verhafteten und verschwundenen Personen verbrannt hätten. CA Santiago, AZ 2182-98 (») uan Maino«), Bd. 4b, Bl. 1786. Polizeiliche Vernehmung von Gerd Seewald vom 07.06.2005. 
wichtige Kenntnisse über Vorgänge einer strafrechtlichen und historischen Aufarbeitung vorenthalten. ${ }^{108}$

\section{Das Geheimarchiv der Colonia Dignidad}

2000 und 2005 beschlagnahmte die Policía de Investigaciones (PDI) bei richterlich angeordneten Durchsuchungen in der CD umfangreiche Aktenbestände. Bei einer von Richter Ricardo Riquelme geleiteten Razzia ${ }^{109} 2000$ beschlagnahmte die PDI Talca zahlreiche Aktenmappen und Aktenordner mit Materialsammlungen zu Einzelpersonen und Institutionen. ${ }^{110}$ Die Mappen waren beschriftet mit den Namen von Führungspersonen aus Politik, Militär, Kirche, Parteien, Bewegungen und Gewerkschaften aus Chile, Deutschland und anderen Staaten. Sie enthielten vor allem Dokumente aus offenen Quellen, insbesondere ausgeschnittene Presseartikel, einige Briefe, juristische Schriftsätze und Fotos. Viele der beschrifteten Mappen und Umschläge waren leer, darunter auch solche, die mit "freigelassene Gefangene«, »Extremisten« oder »Verschwundene« beschriftet waren. Mir gegenüber äußerten Gesprächspartner_innen die Vermutung, dass diese Dokumente bewusst in gut sichtbaren Regalen auf dem Flur des CD-Verwaltungsgebäudes platziert worden waren, um die Verantwortlichen in Justiz und Politik vor weiteren Ermittlungen zu warnen, sprich mit der Preisgabe kompromittierender Informationen zu drohen. Gerd Seewald gab an, die Materialsammlungen allein angefertigt zu haben. Die Dokumente aus den Mappen, die leer gefunden wurden, habe er verbrannt, da sie nicht mehr von Interesse gewesen seien. ${ }^{111}$

\section{Die Beschlagnahme der Fichas und der Bolsa im Juni 2005}

Im Juni 2005 führte die PDI eine weitere, von Ermittlungsrichter Jorge Zepeda angeordnete und nach einem Bibelvers öffentlichkeitswirksam »Jeremia 33:3 «112 genannte

108 So berichtete beispielsweise 2014 ein Zeuge dem Ermittlungsrichter Mario Carroza, er habe 1998 zwei Pickup-Ladungen Dokumente in einem 4-5 Meter tiefen Loch auf einem Acker der CD vergraben, vgl. Narváez, Luis. »Testigo Clave vuelve a ex Colonia Dignidad«, in: Televisión Nacional de Chile, edición central, ausgestrahlt am 22.10.2014. Der Richter ordnete Ausgrabungen an, stellte diese kurze Zeit später jedoch ergebnislos wieder ein. Vgl. La Tercera vom 23.10.2014, S. 18. »PDI busca documentos en Villa Baviera.«

109 Die Razzia fand statt im Rahmen eines Verfahrens wegen Bildung einer kriminellen Vereinigung (Juzgado de Parral, AZ 62.577) und erfolgte auf Anordnung von Richter Juan Guzmán, der den Fall des Verschwundenen Alvaro Vallejos Villagrán untersuchte (CA Santiago, AZ 2182-98 (»Alvaro Vallejos Villagrán«)).

110 CA Santiago, AZ 2182-98 (»Alvaro Vallejos Villgagrán«), Bd. 5, Bl.1440ff. Acta de Incautación, Policía de Investigaciones de Talca vom 19.09.2000. Vgl. auch Diario El Centro vom 09.10.2000, S. 2-3. »Dignidad: La verdad del caso archivos«. Zur kriminalpolizeilichen Bewertung der Akten vgl. CA Santiago, AZ 2182-98 (»Asociación Ilícita«), Bd. I (Parral), BI. 467ff. PDI de Talca, Informe Policial Nro. 01/00510 vom 08.12.2001.

111 CA Santiago, AZ 2182-98 (»Asociación Ilícita«), Bd. I (Parral), BI. 209ff. Richterliche Vernehmung von Gerd Seewald vom 03.10.2000.

112 Der Vers lautet: »Rufe mich an, so will ich dir antworten und will dir anzeigen große und gewaltige Dinge, die du nicht weißt.«(Lutherbibel 1912, Jeremia 33:3). 
Großrazzia in der (Ex-)CD durch. Dabei wurden große Mengen von Waffen und Dokumenten gefunden. ${ }^{113}$ Die in drei großen Containern vergrabenen Materialien waren laut Innenstaatssekretär Jorge Correa Sutil das größte jemals in privaten Händen aufgefundene Waffenarsenal in Chile. Daneben fanden die Ermittler_innen drei große Regale und eine große Anzahl von Kisten mit Karteikarten und Dokumenten. ${ }^{114}$

Zepeda stufte die Dokumente als geheim ein. Die JIPOL wertete sie im richterlichen Auftrag aus und bewahrte sie auf. ${ }^{115}$ Das Herzstück des Fundes waren 46.308 personenbezogene Karteikarten (spanisch: fichas), auf denen Informationen aus unterschiedlichen Quellen gesammelt waren. Lediglich um die 500 Karteikarten gab Zepeda weiter an andere Richter_innen, die mit Menschenrechtsfällen aus der Diktaturzeit befasst waren. ${ }^{116}$ Auf diesem Wege gelangten einzelne Karteikarten und polizeiliche Auswertungsberichte in die Ermittlungsakten sowie an die Medien, die fortan über die Gründe für die Geheimhaltung spekulierten. Opferverbände drängten jahrelang auf eine Offenlegung des Geheimarchivs, bis Zepeda 2014 schließlich einwilligte und dem Instituto Nacional de Derechos Humanos (Nationales Institut für Menschenrechte, kurz INDH) eine DVD mit den digitalisierten Karteikartenblättern übergab. Der Fernsehsender Chilevisión gelangte an eine Kopie der DVD und strahlte einen 90-minütigen Dokumentarfilm dazu aus. ${ }^{117}$ Später überreichte er die DVD an verschiedene Menschenrechtsorganisationen. Da sich das INDH unter Verweis auf den Datenschutz weigerte, das gesamte Geheimarchiv zu veröffentlichen (lediglich Betroffenen wurde auf Antrag die eigene Ficha übermittelt), entschloss sich der Gedenkort Londres $38,{ }^{118}$ das gesamte Material auf seiner Webseite zu veröffentlichen. ${ }^{119}$ Ebenfalls veröffentlicht wurde ein vorher als geheim eingestufter, 1082 Seiten umfassender Bericht der JIPOL über die Aktenordner und Einzeldokumente, die zusammen mit den Karteikarten gefunden worden waren. ${ }^{120}$ Dieser zusätzliche Dokumentenbestand wird als »bolsa« (Tasche) bezeichnet.

Gerd Seewald sagte bei seinen späteren Vernehmungen durch Zepeda umfangreich über das Geheimarchiv aus. Er gab an, ab 1974 alleinverantwortlich sämtliche Informationen, die er von Schäfer und anderen erhalten hatte, systematisiert auf Karteikarten

113 La Nación vom 15.06.2005, S. 7. »Zepeda encontró archivo secreto de Dignidad«.

114 CA Santiago, AZ 2182-98 (»Antonio Llidó«), Bd. 4b, Bl. 1806ff. Polizeibericht (PDI, Brigada de Asuntos especiales y DDHH) Nr. 115 vom 23.06.2005.

115 CA Santiago, AZ 2182-98 (»Asociación Ilícita«), Bd I (2) (Ministro), Bl. 587ff. Geheimer Polizeibericht (PDI, JIPOL) Nr. 263 vom 28.12.2005.

116 La Nación vom 29.03.2006, S. 6. »Abren archivos secretos de la Colonia Dignidad a jueces de $\mathrm{DDHH}$.

117 Narváez, Luis. Las fichas del horror. Reihe En la Mira. Chilevisión, 87 min, ausgestrahlt am 09.07.2014, online unter https://www.youtube.com/watch?v=eBW-tQOjwol.

118 Das Haus in der Straße Londres Nr. 38, gelegen in der Innenstadt von Santiago, war einer der irregulären Haftorte der DINA, an dem Gefangene festgehalten und gefoltert wurden. Heute ist Londres 38 ein Cedenkort (espacio de memoria). Siehe https://www.londres38.cl.

119 Londres 38 (Website), »Archivo de la Colonia Dignidad: ¿Dónde están las piezas que faltan?«, 2014, online unter http://londres38.cl/1934/w3-article-96548.html. Eine verschlagwortete Datenbank der fichas findet sich unter https://www. fichas-chile.com.

120 Bericht der JIPOL an Richter Jorge Zepeda vom 24.01.2006. »Procesamiento y análisis de la información remitida por el ministro Jorge Zepeda Arancibia el 14 de septiembre de 2005 «, online unter: http://londres38.cl/1934/w3-article-97390.html. 
festgehalten zu haben. Er sagte: »Paul Schäfer era mi jefe, él quiso tener un archivo de gran envergadura de gente de izquierda. Me dijo que había que hacer un archivo completo de toda la gente de izquierda. ${ }^{121}$ Die CD habe zum Zweck der Informationsgewinnung mit Informant_innen in Concepción, Coronel, Lota, Los Angeles, Linares, Parral und Santiago zusammengearbeitet. Auch die unmittelbare Umgebung der CD wurde mit Hilfe von Spitzeln intensiv beobachtet. Als Begründung gab Seewald an: »[N]os interesaba saber quienes eran nuestros vecinos, por si eran politicamente sospechosos. ${ }^{122}$ Auch wenn Gefangene in die CD gebracht wurden, habe er des Öfteren deren Verhöre transkribiert und die Information auf die Karteikarten übertragen. In Santiago seien Alfred Matthusen und Albert Schreiber für Kontakte zu Behörden sowie für die Informationsgewinnung zuständig gewesen. Kurt Schnellenkamp habe die Verbindungen zu Militärregimentern gepflegt. Auch Fernando Gómez Segovia, der Kommandant der Brigada de Inteligencia Regional Sur der DINA (BIRSur), die ihren Sitz in einem Haus der CD in Parral hatte, versorgte Schäfer und Seewald mit Informationen zu politischen Aktivist_innen, Angehörigen des Militärs und der Polizei. Diese Angaben wurden mithilfe weiterer Spitzel vervollständigt. Gómez Segovia, so Seewald, habe auch von der Existenz des CD-Geheimarchivs gewusst. Damit warf Seewald eine Frage auf, die er in seinen Vernehmungen nicht beantwortete und die bis heute nicht abschließend untersucht ist: In welcher Form hatten die DINA und andere Teile der Repressionallianz Zugang zu den Informationen des CD-Geheimarchivs? Der weitaus größte Teil des Ficha-Archivs ist in spanischer Sprache verfasst, was nur für den internen Gebrauch innerhalb der CD unnötig gewesen wäre. Zudem geht ein wichtiger Teil der Information direkt auf Mitglieder der DINA-Spitze zurück. Dazu gehören Manuel Contreras (Ficha-Deckname: »Mamo«), Pedro Espinoza (»Schlosser«), Fernando Gómez Segovia (»Gu«) und Eduardo Neckelmann Schütz (»NS«). Allerdings gibt es auch Fichas mit privaten Informationen über diese Personen. Das legt nahe, dass selbst die DINASpitze nicht ohne weiteres Zugang zum Geheimarchiv hatte.

Nur ein kleiner Teil, einige Hundert Fichas, haben ausschließlich deutschsprachige Eintragungen. Meist handelt es sich dabei um Berichte von Mitgliedern der PSM in Deutschland. Auch diese verfügten über ein Netzwerk von Informanten_innen, das insbesondere zur Beobachtung der exilchilenischen Community in der Bundesrepublik diente. Aus meiner vorläufigen Analyse der Fichas ergibt sich, dass das Archiv nicht ausschließlich der Beobachtung und Verfolgung linker Aktivist_innen diente, sondern ein Mittel war, um Angehörige von Militär-, Polizei- und Geheimdiensten auf ihre bedingungslose Loyalität zu Pinochet hin zu durchleuchten.

Laut Seewald konzentrierte sich die Informationsgewinnung und -verarbeitung vornehmlich auf die »schlimmsten Jahre« der chilenischen Diktatur von 1973 bis 1978. Damit stützt Seewald die These, dass die CD und die Militärjunta eine direkte Repressionsallianz bildeten, welche die Machtposition Pinochets absicherte. ${ }^{123}$ Nach 1978, so Seewald, seien lediglich Informationen vervollständigt und aktualisiert worden, und

CA Santiago, AZ 2182-98 (»]uan Maino«), Bd. 4b, Bl. 1682ff. Richterliche Vernehmungen von Gerd Seewald am 18./19. 08.2005.

Ebd. 
zwar bis 1996, also bis kurz bevor Schäfer die Siedlung verließ. Allerdings sollten auch danach von sämtlichen Personen, die in die CD kamen, Fotos angefertigt und abgelegt werden. Das betraf auch Gäste des CD-Restaurants in Bulnes. ${ }^{124}$

Im Folgenden möchte ich anhand einiger prägnanter Beispiele die Charakteristika und Relevanz der Fichas aufzeigen (Abbildungen 1 bis 7):

Hauptmann Fernando Gómez Segovia war von 1974 bis 1977 Kommandant der Regionalen DINA-Brigade BIRSur. Diese hatte ab 1974 ihr Hauptquartier in einem Haus in Parral, das der CD gehörte. Die Ficha enthält ein Kryptogramm, das vermutlich zur Verschlüsselung der Kommunikation zwischen Gómez Segovia und der CD verwendet wurde. Auf der Karte ist vermerkt, dass Gómez Segovia an einer geheimdienstlichen Schulung in Brasilien teilgenommen hat. Der letzte Eintrag handelt von Eheproblemen Gómez Segovias. Als Quelle für diese Information ist »Alh« angegeben, die Kurzform von "Alharaco«, was umgangssprachlich Großmaul bedeutet. Dies war der Deckname des CD-Führungsmitglieds Albert Schreiber. Zum Zeitpunkt des Eintrags 1986 war Gómez Segovia nicht mehr für den Geheimdienst tätig, sondern für die chilenische Post.

\section{Abbildung 1: Ficha Fernando Gómez Segovia}

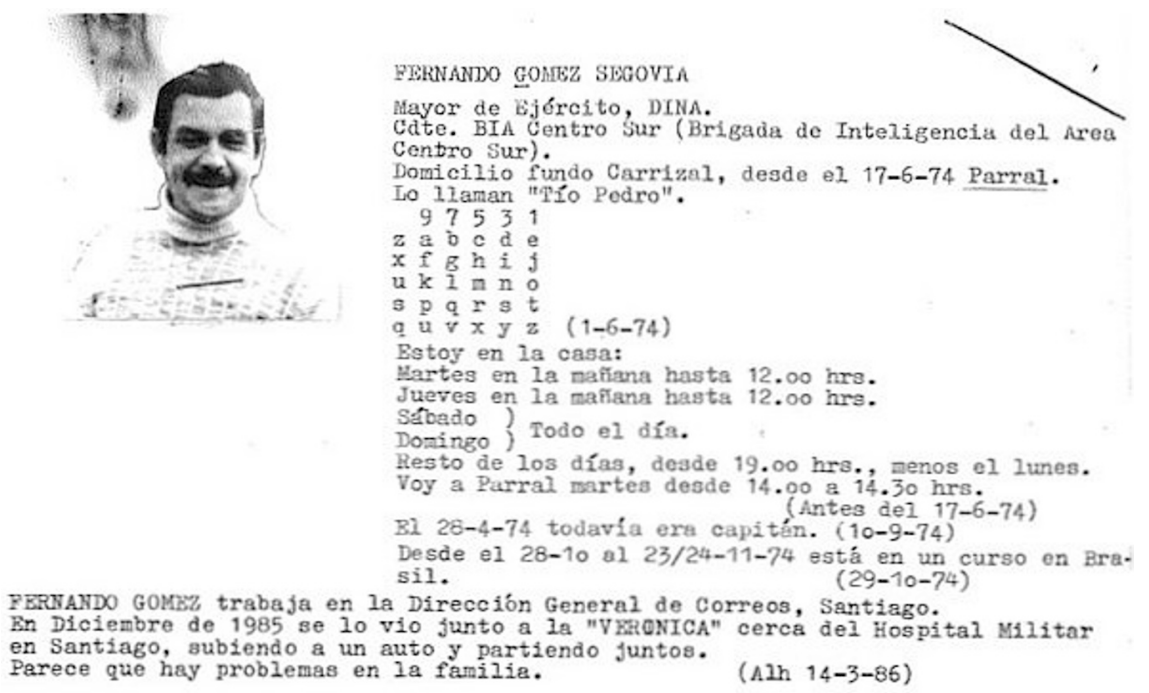

124 Sowohl die Fichas als auch die weiteren 2005 beschlagnahmten Dokumente (»Bolsa«) enthalten eine große Anzahl von Fotografien von Gästen des CD-Restaurants in Bulnes. Diese sind in den Beständen des Archivo Nacional zur CD einsehbar. 
Alvaro Vallejos Villagrán war Mitglied der MIR. Er wurde im Juli 1974 in Santiago entführt, in die Colonia Dignidad verschleppt und ist seitdem verschwunden. Das Urteil wegen seiner Entführung ${ }^{125}$ ist bislang das einzige rechtskräftige Urteil eines chilenischen Gerichts mit Bezug zu Verschwundenen, das die Verurteilung eines Colonos zur Folge hatte (in diesem Fall Gerhard Mücke). Die Ficha ist mit einem handschriftlichen »D« markiert, das für »Desaparecido« (Verschwundener) steht. Zudem enthält die Karte Auszüge aus Verhören im Juli und September 1974, die vermutlich unter Anwendung von Folter durchgeführt wurden.

\section{Abbildung 2: Ficha Alvaro Vallejos Villagrán (2)}

\section{ALVARO MODESTO VALILBJOS VILLAGRAN (2)}

Su nonbro político es Matias, posteriornente se 11 amb Polo.

Hiega todo contacto con el MiR de Curico, la Tita, Pablo Pallamar, el Toro, Juan Carlos.

Se conectaba con su jefe através del enlace con punto fijo a la bemana. La urltima vez fue uno, dos o tres días antes del $1^{\circ}$ de mayo. Se juntaron regularmen
te dos veces a la semana.

Ia soflora es cómplice.

Irunca habla reuniones en su casa.

Para contacto en las calles, desde la mitad de enero hasta la mitad de marzo,

1a. zona: Gran Avenida - Santa Rosa - San Joaquín - Paralelo líuevo.

Semanalmente hacian un punto, por ejemplo, calle La Pirfmide; caminando El de

Santa Rosa hacia Gran Avenida $y$ el enlace'le contesto. Bso duraba una semana.

Después pasaron a la Brigadier de la Cruz, etc.

Bra estudiante de Medicina, hasta el $4^{\circ}$ affo.

Como clave conoce el sistema de libros.

Había contacto con Argentina por intormedio de una mujer en los primeros días de enero de este aflo.

A "Lucas" lo conoce solamente asi.

BI HIR tiene prohibido asilarse.

(Hatias 3o-7-74)

Botuve dos días en Concepeión, como nirista, fui a una conferenoia sindical.

Alojé en un pensionado universitaria que se lians "Iuciano Cruz", a 5 cuadras

de 1 a Univeraidad.

Local FTR, Agustinas esq. Meturana.

(Iatías 6-9-7í)

Local PER, Bellavista, entre Loreto $y$ Recoleta.

(Yatias 30-7-74)

Eduardo Fernando Soto Henríquez war ein einfacher DINA-Agent, der im August 1974 in der CD stationiert war. Laut dem auf der Ficha wiedergegebenen Bericht vom August 1974 beklagte sich die CD darüber, dass Soto Henríquez zu neugierig gewesen sei und eigenmächtig gehandelt habe. Der Bericht endet mit der Feststellung, »don Mamo« (DINA-Chef Contreras) solle entscheiden, ob der Agent bleiben oder abberufen werden solle. Laut einer darauffolgenden Information eines Spitzels namens »Vilches« wurde Soto Henríquez daraufhin aus der CD abberufen und für sein Verhalten sanktioniert. Die Karte gilt als erster dokumentarischer Beleg dafür, dass DINA-Agenten fest in der CD stationiert waren. 
Abbildung 3: Ficha Eduardo Fernando Soto Henríquez (1)

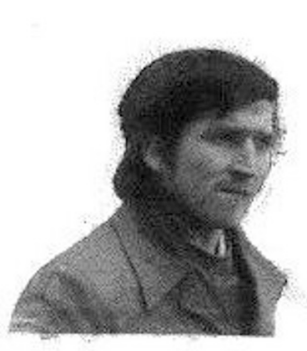

EINAARDO FERMAYID WX SOTO HEIRIQUEZ

Cabo (?) de Ejército, DINA, Santiago.

Sirvió en la Escuela de Suboficiales y Escuela de Infa tería de San Barnardo.

3 años trabajo como instructor.

El 11-9-73 particips en $2 a$ acción en puente laipo (pue te de los mineros).

Desde el 27-8-74 guardaespalda.

$(30-8-74)$

Informe: Este funcionario ha demostrado hasta la fechs un excesivo interés en averiguar o indagar actividades que son netamente privadas en la Colonia, con lo que $h$ causado la desconfianza $y$ el temor por parte de sus ha bitantes. Bntre otras se puede decir:

1.- Habiendo pasado por una puerta que se encuentra co candado, cuya chapa opera con clave, se mostró viv mente interesado en conocer la clave correspondien te. Como le fuera negado lo anterior, insistió en hacerlo tratando de mirar directamente la operació correspondiente.

2.- Preguntó a dos personas diferentes cuál era la pro cedencia de $10 s$ fusiles.

3.- Preguntó insistentemente quién habia hecho el puen te de concreto que se encuentra ubicado en la cancha de aterrizaje.

4.- Comenzó a abrir cajones, de un equipo de emergenci mirando $\mathrm{su}$ contenido,

5.- Pese a que su acompanante le manifestó que iban a continuar viaje de inmediato, se bajó del vehiculo entrue viajaban p leyantó 19 carpa en una puerta d

Abbildung 4: Ficha Eduardo Fernando Soto Henríquez (2)

EDUARDO BERHANDO SOTO HERRIQUEZ (2)

Por suerto que las cosas que ja conoce don Mamo, no se encontraban ahl on ose momento.

6.- Hizo preguntas indiscretas referidas a vida privada a uno de los fóvenes de la Colonia.

7.- Se le pidí coplar los contenidos de algunos alcro-filas, a lo que el pre guntó de donde hablon sacedo esos aicro-filas.

8.- Bn Parrel, se le pidis esperar unos mozentos en la Bstación de Bencina Bs so, toaarse alguna bebida $y$ nientras tanto alrar $y$ escucher. Contestó en foraa prepotente, que él habia sido enviado sólo como guaräaspaldas $\mathrm{y}$ qu en el sjercito cada uno tieme un trabajo especifico.

9.- 5o le interesa asyormente el trabajo. Se lovanta diarianente a las 13 hro

10.- Pinalaente ea un hoabre de cará́cter discolo, diffeil de poder trabajar con él.

11.- Se deja a criterio de con Keao, si debe continuar trabajando con la Colo. nia o deba ser caabiado. (fin szosto 74 )

Preguata a un joven: Si sus pedres estén en Alezania\} si a su nedre le gustar' ilegar aca; por sus heraanos; sí está vivo su padre; Cuento tiempo li eva en Cinile; si tiene la posibilided de viajar a fleaopis para visitg a aus padres:

K1. 10-9-74 se 10 mandó a Santízo.

Dorbre F telbbo de su polola: Kilisa Cruz, 250004.

Cabo Bduardo Fornando Soto Eenríguez, salis de la Bscuela de Infanteria hace

un aWo, ahora trabaja en DISA, exy intranquilo, slgo vivo, inteligente en algunas cosas. Se 10 sancionó por su comportaniento en el fundo.

(vilches $4-9-74$ ) 
Luis Enrique Peebles Skarnic und Erick Zott Chuecas, beides Mitglieder der MIR, wurden 1975 von DINA-Agenten in die CD verschleppt und dort mehrere Tage lang unter Folter verhört. Nach ihrer Verlegung in andere Haftzentren gelang es ihnen, nach Europa auszureisen, wo sie den Vereinten Nationen und Amnesty International von ihrer Verschleppung in die CD berichteten. Vor dem LG Bonn sagten Peebles und Zott 1978 über ihre Foltererfahrungen in der CD aus. ${ }^{126}$ Die Ficha zu Peebles enthält eine Information des bundesdeutschen Botschafters Erich Strätling. Dieser berichtet über einen Ausreiseversuch von Peebles und Zott über die deutsche Botschaft und deren später schließlich geglückte Ausreise mithilfe der belgischen Botschaft. Vermutlich hatte Strätling diese Information einem CD-Führungsmitglied bei einem persönlichen Gespräch übermittelt.

Abbildung 5: Auszug der Ficha Luis Enrique Peebles Skarnic (3)

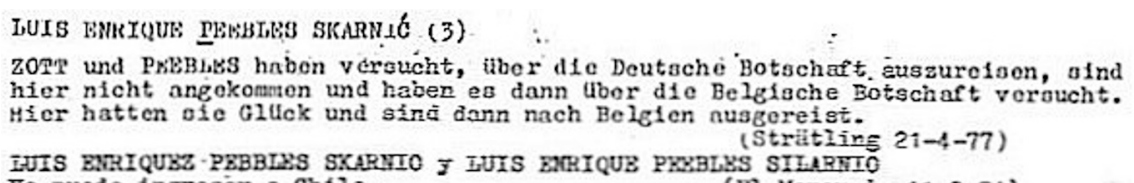

Hernán Larraín ist seit 2018 chilenischer Minister für Justiz und Menschenrechte. Er gehört der extrem rechten UDI an, die zumindest in ihren Ursprüngen pinochetistisch war. Von 2006-2008 und von 2015-2017 war er Präsident der UDI. Von 1994 bis 2018 war er Senator für die Region Maule, in der die CD liegt. Zwischen 1991 und 1997 verteidigte er diese energisch. Larraín trat auf Solidaritätskundgebungen für die CD auf und wandte sich gegen den Versuch der christdemokratischen Regierung unter Patricio Aylwin, die SBED aufzulösen. Der deutschsprachige Bericht auf der Fichas entstammt einem Brief des CD-Führungsmitglieds Hans-Jürgen Blanck, der sich zu diesem Zeitpunkt in der Bundesrepublik aufhielt. Blanck berichtet über Vorträge, die Larraín und Jaime del Valle (der später während der Diktatur chilenischer Justiz- und Außenminister war) 1982 an der Universität Würzburg hielten. Dort lehrten damals die Professoren Lothar Bossle (Soziologie) und Dieter Blumenwitz (Jura). Beide waren Besucher und Unterstützer der Colonia Dignidad. Bossle war ein Vertrauter von Franz Josef Strauß. Er hatte direkten Zugang zu Pinochet und soll in Chile Geschäfte für bundesdeutsche Unternehmen angebahnt haben. ${ }^{127}$ Blumenwitz verfasste ein juristisches Gutachten für die $C D^{128}$ und wirkte an der Ausarbeitung der chilenischen Verfassung von 1980 mit.

126 Zum Zivilverfahren der CD gegen Amnesty International vgl. LC Bonn, AZ 3 O 123/77.

127 PA AA, AV NA 31577. Vermerk des Botschaftsmitarbeiters DB über ein Telefonat mit Lothar Bossle vom 20.03.1985 sowie PJS, Sammlung Luis Narváez. Bericht der JIPOL/PDI vom 13.10.2006: Procesamiento y Análisis de la información en idioma alemán remitida por el Ministro Jorge Zepeda Arancibia el 14 de septiembre de 2005. Documento 69. Protokoll eines Telefonats zwischen »Struppi« (Hartmut Hopp) und »Rettich« (Gerhard Mertins) vom 15.11.1987.

128 StA Bonn AZ 50 ]s 285/85, Bd. IV. Von der SBED im Verfahren LC Bonn AZ 3 O 123/77 eingereichtes Gutachten von Dieter Blumenwitz vom 24.10.1980. Das Gutachten kommt zu dem Ergebnis, dass eine Teilnahme der Bonner Richter_innen an der Beweiserhebung in Chile im Rahmen eines Rechtshilfeersuchens nicht möglich ist. 
Abbildung 6: Ficha Hernán Larraín Fernández (1)

\section{HERNAN LARRAIN JWRNAWDFE}

Symposion dos Lehratuhle fllr Soziologie $x$ und des Inst1tute fur Demokratieforgohung, wurzburg:

"Die Bedeutung der Institutionen und der Autoritat fur die Bntwioklung und don Bestand einer Demokratie."

23. 4. 1982, 16.15 Uhr:

"Die sutoritäre Demokratie im lateinamerikanisohen Kontext und die soziale Doktrin der katholisohen Kirchen

PrOf. HBRNAN LARRATN

Prorektor dor papstlichen Universitüt, Sant1ago de Chile.

Das Thems des Vortrags von Prof. HBRNaN LARRAIN wurde kurzfristig geändert. Er sprach ther die chtistdemokrabischen Partelen in Sudamerike und die politioohe Rolle der katholischen Kirche. Sein Vortrag ondote mit einer vermichtenden Beurteilung der $D C$ besonders in Chile. Br stellte klar, daB die z.r. in der katholis schen Kirche Lateinanerikas vertretene "Theologie der Befreiung nichts mit den eigentlichen Auftrag der Kirche su tun habe; wenn die Bibel von Befreiung spreche sei die Befreiung des Menschen von seiner sunde geneint, aber nicht die politische Befroiung aus seinen sozialen Verhultnissen.

Beide Chilenen, JAING DBL VALIS und LARRAIN, nahsen ke in Blatt vor den Lynd, als es um die gezielte Desinformation uber Chile ging, fur die allein die marxistische Unterwanderung der Medien in den westlichen Denokratien verantwortlioh ist, das habe sogar in Spanien unter Pranco schon angefangen.

In einer kurzen Kaffeepause am zweiten Tag setzten wir uns zu diesen beiden ohilenischon Professoren an den Tisch (Prof. Bóssle hatte uns schon am ersten Tag den beiden vorgestelit und gesagt, daB wir aus Chile kommen). IARRAIN war vehr aufgeschlosen und erzahlte uns, $\mathrm{daB}$ or sohon dreimal-mit JAILE (GUZMAN bei una auf dem Fundo, war, einmal, in der UP-Zeit, einmal 1974 und einmal 1975. Er oohkitat unsere Arbelt ehr hoch, wie er sagte. Er hat auf dem Fundo den Präsident on Sohmidt und seine Frau, den Doktor und einen Albert kennengelernt, und er kennt

Abbildung 7: Ficha Hernán Larraín Fernández (2)

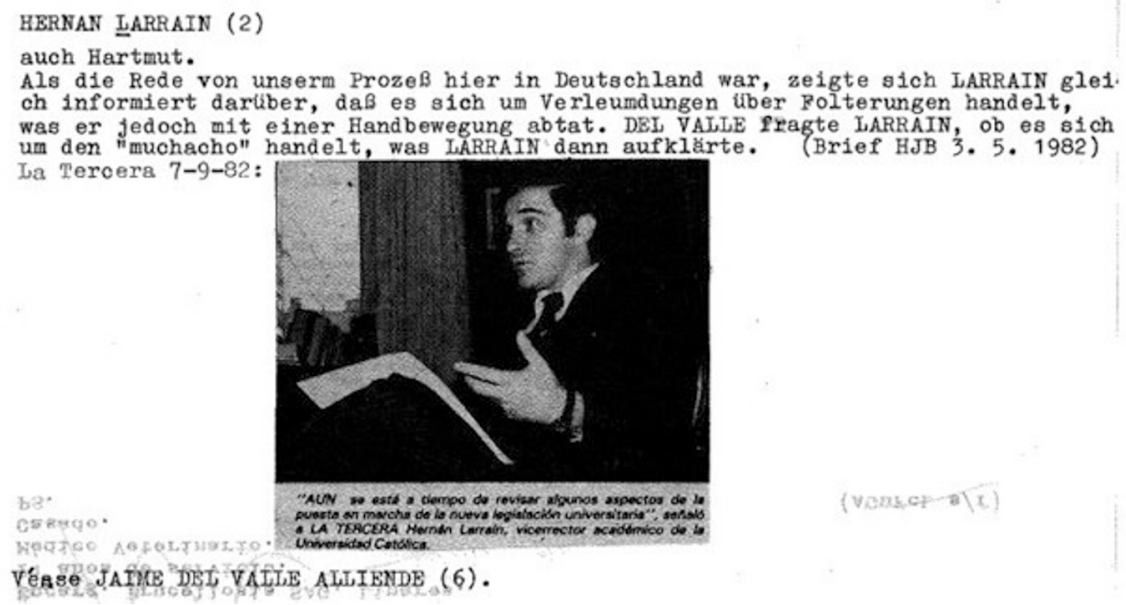

Das Geheimarchiv der CD ist der umfangreichste Aktenbestand zur Repression während der Diktatur, der bislang in Chile gefunden wurde. Es handelt sich nicht nur um ein Archiv einer kriminellen Gemeinschaft über ihre Freund_innen und Feind_innen, sondern um ein geheimdienstliches Archiv über eine Diktatur und ihre Repres- 
sionsorgane. Als solches ist es einzigartig und in Lateinamerika lediglich vergleichbar mit den 1992 in Paraguay aufgefundenen Archivos del Terror. ${ }^{129}$ Die Bedeutung des CDGeheimarchivs für die Aufarbeitung der CD- und Diktaturgeschichte wird von Dieter Maier und mir wie folgt eingeschätzt: »Su estudio permite dibujar una arqueología de la represión en Chile y entender el factor clave que jugó la asociación >público-privada entre la policía secreta DINA y los alemanes de la Colonia Dignidad en la reafirmación en el poder de Pinochet. «130

Das chilenische Bildungsministerium stellte den Dokumentenbestand 2016 unter Denkmalschutz. ${ }^{131}$ Seit Januar 2019 sind die 2000 und 2005 sichergestellten Unterlagen im Archivo Nacional in Santiago einsehbar. ${ }^{132}$ Dazu gehören neben den Fichas noch 23.000 weitere Dokumente der CD.

\subsection{Wissenschaftliche Aufarbeitung von Menschenrechtsverbrechen}

Für eine unabhängige Erforschung von Behördenhandeln ist der weitreichende Zugang zum entsprechenden Aktenmaterial notwendig. ${ }^{133}$ Dieser kollidiert jedoch häufig mit dem Interesse von Institutionen, die sie betreffenden Verwaltungsprozesse möglichst vertraulich zu handhaben. In der Regel entscheiden Behörden bei Anträgen auf Einsicht in ihre Archiv- und Verwaltungsakten äußerst restriktiv, erst recht, wenn ihnen das Forschungsthema sensibel erscheint. Bei Bundesbehörden ist der Zugang zu Dokumenten gesetzlich geregelt. Bei bereits archivierten Dokumenten greift das Bundesarchivgesetz (BArchG), während das Informationsfreiheitsgesetz (IFG) den Zugang zu Akten regelt, die sich noch in den jeweiligen Behörden befinden. Dabei hat der Gesetzgeber den Behörden einen breiten Ermessensspielraum eingeräumt und eine Reihe von Gründen festgelegt, die eine Nichtherausgabe von Akten für Forschungszwecke rechtfertigen.

Im Zuge verschiedener Debatten über personelle Kontinuitäten in bundesdeutschen Behörden nach 1945 wurde in den vergangenen Jahren verstärkt eine wissenschaftliche Untersuchung dieser Behörden eingefordert, die u.a. der zu sehr eingeschränkte $\mathrm{Zu}$ gang zu Akten bis dahin verhindert hatte. Die Reaktion auf diese Forderungen war allerdings keine generelle Öffnung der Archive, sondern die Einberufung sogenannter

129 Maier/Stehle, Colonia Dignidad, S. 53.

130 Ebd.

131 Diario Oficial 41.626 vom 06.12.2016. Declara Monumento Nacional en la categoría de Monumento Histórico al »Archivo de Colonia Dignidad«.

132 Eine Übersicht über die Bestände findet sich hier: Archivo Nacional de Chile. AN pone a disposición de la ciudadanía archivos de Colonia Dignidad vom 31.12.2018, online unter https://www.archivonacional.gob.cl/sitio/Contenido/Noticias/89326:AN-pone-a-disposicion-dela-ciudadania-archivos-de-Colonia-Dignidad.

133 Teile dieses Abschnitts sind eine Ausarbeitung von: Jan Stehle. Das Amt und der Aktenzugang. Meine Bemühungen um Aktenfreigabe beim Auswärtigen Amt im Kontext des Berichts der Historikerkommission sowie der Archivierungspraxis des Auswärtigen Amts, in: Hawel, Markus (Hg.). Work in progress. Work on progress. Doktorand_innen-Jahrbuch der Rosa-Luxemburg-Stiftung, Bd.1, Berlin 2011, S. 119-133, online unter https://www.rosalux.de/fileadmin/rls_uploads/pdfs/sonst _publikationen/JB2011_studienwerk.pdf. 
Unabhängiger Historikerkommissionen (UHK), deren Auftrag und personelle Zusammensetzung die Behörden jeweils bestimmten. »Unabhängig« bedeutet also lediglich, dass die Kommissionsmitglieder keine Behördenangehörigen sind. Sie unterliegen jedoch sehr wohl den zum Teil recht strikten vertraglich festgelegten Bedingungen der Behörden. ${ }^{134}$ Vorreiter war hierbei das Auswärtige Amt mit einer 2010 veröffentlichten Studie über seinen Umgang mit der NS-Vergangenheit nach 1945, die kurz als Das Amt zitiert wird. ${ }^{135}$ Dem Beispiel des AA folgten weitere Behörden diesem Beispiel. In den letzten Jahren erschienen ähnliche Studien im Auftrag des Bundesarbeitsministeriums (BMAS) $)^{136}$, des Bundesjustizministeriums (BMJ) ${ }^{137}$, des Bundesfinanzministeriums $(\mathrm{BMF})^{138}$, des Bundesnachrichtendienstes $(\mathrm{BND})^{139}$ und des Bundesamtes für Verfassungsschutz (BfV) ${ }^{140}$. Die Veröffentlichungen befassen sich dabei einerseits mit der Geschichte der jeweiligen Behörde während des Nationalsozialismus und thematisieren andererseits den Umgang mit dieser Vergangenheit während der Nachkriegsjahrzehnte.

\subsubsection{Das Amt und der Aktenzugang: Informationsfreiheit und Behördentransparenz}

Auch die Debatte um Informationsfreiheit und Behördentransparenz bekam durch die Veröffentlichung dieser Studien neuen Schwung. So übte etwa die vom AA beauftragte Unabhängige Historikerkommission scharfe Kritik an der Archivpolitik der Behörde. Diese habe sich "jahrzehntelang nicht nur faktisch bedeckt gehalten, sondern durch eine ausgesprochen restriktive Archivpolitik unabhängige Bemühungen um eine kritische Erforschung seiner Geschichte immer wieder konterkariert «. ${ }^{141}$ Auch für die Kommission selbst habe sich die Benutzung mancher Archivbestände in der Praxis schwierig gestaltet:

134 So beschränkt sich der Auftrag der im Februar 2011 berufenen Historikerkommission des BND auf die Aufarbeitung der Jahre bis 1968. Vgl. Unabhängige Historikerkommission zur Erforschung der Geschichte des BND. Projektbeschreibung (o. D.), online unter https://www.uhk-bnd.de/?page_id=17.

135 Conze, Eckart/Norbert Frei/Peter Hayes/Moshe Zimmermann. Das Amt und die Vergangenheit. Deutsche Diplomaten im Dritten Reich und in der Bundesrepublik, München 2010.

136 Vgl. Nützenadel, Alexander (Hg.). Das Reichsarbeitsministerium im Nationalsozialismus: Verwaltung - Politik - Verbrechen. [Unabhängige Historikerkommission zur Ceschichte des Reichsarbeitsministeriums 1933-1945], Göttingen 2017.

137 Vgl. Cörtemaker, Manfred/Christoph Safferling. Die Akte Rosenburg: das Bundesministerium der Justiz und die NS-Zeit, München 2016.

138 Vgl. Kuller, Christiane. Bürokratie und Verbrechen. Antisemitische Finanzpolitik und Verwaltungspraxis im nationalsozialistischen Deutschland, Berlin u.a. 2013; Kilian, Jürgen. Krieg auf Kosten anderer. Das Reichsministerium der Finanzen und die wirtschaftliche Mobilisierung Europas für Hitlers Krieg, Berlin u.a. 2017 sowie Banken, Ralf. Hitlers Steuerstaat. Die Steuerpolitik im Dritten Reich, Berlin u.a. 2018.

139 Vgl. Unabhängige Historikerkommission zur Erforschung der Geschichte des Bundesnachrichtendienstes. Veröffentlichungen [o. D.], online unter https://www.uhk-bnd.de/?page_id=340.

140 Vgl. Coschler, Constantin/Michael Wala. »Keine neue Gestapo«: Das Bundesamt für Verfassungsschutz und die NS-Vergangenheit, Reinbek 2015.

141 Conze et al., Das Amt, S. 716. 
»Neben evidenten individuellen Vorbehalten einzelner Mitarbeiter gegen den an die Kommission ergangenen Auftrag dürften die Cründe dafür vor allem in den eingeschliffenen strukturellen Sonderbedingungen zu suchen sein, unter denen das PA AA seit Langem operiert und die einem demokratisch transparenten Archivzugang, wie ihn das Bundesarchiv auf der Crundlage des Bundesarchivgesetzes erfolgreich praktiziert, zuwiderlaufen. [...] All dies hat zur Konsequenz, dass die Kommission [...] letztlich nicht sicher sein kann, wirklich alle für ihre Arbeit wesentlichen Unterlagen zu Gesicht bekommen zu haben; dies gilt insbesondere für die erst zu einem sehr späten Zeitpunkt zugänglich gewordenen und noch nicht deklassifizierten VS-Sachen. ${ }^{142}$

Der Bericht der Historikerkommission kommt zu dem Schluss, dass das über Jahrzehnte gepflegte Selbst- und Geschichtsbild des AA ein Mythos ist. ${ }^{143}$

Hierbei kommt eine Besonderheit zum Tragen: Als einzige oberste Bundesbehörde gibt das AA seine Akten nicht ans Bundesarchiv ab, sondern verwaltet sie im eigenen Hause, im sogenannten Politischen Archiv (PA AA). Damit ist das AA bei Anträgen auf Akteneinsicht Richter und Beteiligter zugleich. Nach der Veröffentlichung von Das Amt forderten zahlreiche Stimmen eine Überführung des PA AA in das Bundesarchiv, darunter auch der ehemalige Außenminister Fischer, der die UHK 2005 eingesetzt hatte, sowie Hartmut Weber, bis 2011 Präsident des Bundesarchivs.

\subsubsection{Gesetzliche Regelungen des Aktenzugangs zu Forschungszwecken}

Seit über 200 Jahren ist der Zugang zu Behördeninformationen gesetzlich geregelt. ${ }^{144}$ Seit der Novellierung des Freedom of Information Act (FOIA) in den USA 1974 - einer Folge des Watergate-Skandals - öffnen sich Verwaltungen weltweit zunehmend für die Informationsbedürfnisse von Bürger_innen. Die Debatte um eine Ausweitung der Informationsfreiheit ist dabei meist eine Diskussion über die Grenzen der notwendigen Geheimhaltung. Im Folgenden möchte ich darstellen, wie diese Grenzen, aber auch der Zugang zu Akten der obersten Bundesbehörden derzeit gesetzlich geregelt sind.

\section{Das Bundesarchivgesetz}

Das Bundesarchivgesetz (BArchG) $)^{145}$ definiert als Rolle des Bundesarchivs, die schriftlich dokumentierten Amtsvorgänge des Bundes »auf Dauer zu sichern, nutzbar zu ma-

142 Ebd., S. $718 f$.

143 Ebd., S. 12.

144 Scholz, Michael. Die Öffnung der Archive für Jedermann. Zur Geschichte der öffentlichen Benutzung, in: Brandenburgisches Landeshauptarchiv ( $\mathrm{Hg}$.). Brandenburgische Archive - Mitteilungen aus dem Archivwesen des Landes Brandenburg Nr. 10/1997, S. 4-9, online unter http://blha.brande nburg.de/wp-content/uploads/2017/06/Brandenburgische_Archive_10_1997.pdf.

145 Gesetz über die Sicherung und Nutzung von Archivgut des Bundes (Bundesarchivgesetz-BArchG) vom 06.01.1988, in: Bundesgesetzblatt, 1988 Teil I, Nr. 2 vom 14.01.1988, S. 62ff. Im Folgenden zitiert als BArchC. Am 19. Januar 2017 verabschiedete der Bundestag mit den Stimmen der Großen Koalition eine Novellierung des BArchG. Allerdings haben die Änderungen aus meiner Sicht wenig Einfluss auf Akteneinsichtsbegehren wie etwa zu dieser Untersuchung. Insbesondere bei Verschlusssachen ändert sich wenig am Ermessensspielraum der Behörden bei der Gewährung von Aktenzugang. 
chen und wissenschaftlich zu verwerten« ( $\$$ I BArchG) und somit eine »rückblickende Kontrolle von Regierung und Verwaltung « zu ermöglichen, wie das Leitbild des Archivs besagt. ${ }^{146}$ Das Auswärtige Amt (AA) archiviert seine Akten hingegen im hauseigenen Politischen Archiv (PAAA), da es diese Bestände »regelmäßig zur Erfüllung unterschiedlichster Aufgaben [...] benötigt « ${ }^{147}$ Die Unterschiede zwischen beiden Archiven haben durchaus Auswirkungen auf die Verwaltung und die Freigabe von Akten. Mit Ausnahme des AA müssen also sämtliche Verfassungsorgane, Behörden und Gerichte des Bundes alle Dokumente, die sie nicht mehr zur Erfüllung ihrer Aufgaben benötigen, dem Bundesarchiv zur Übernahme anbieten (\$2 I BArchG).

Sind Dokumente beim Bundesarchiv archiviert, so regelt das BArchG, dass sie 30 Jahre nach ihrer Entstehung auf Antrag für jede Person einsehbar sind. Ausgenommen davon ist personenbezogenes Schriftgut sowie Dokumente, die einer Geheimhaltungseinstufung unterliegen. Die sogenannte Schutzfrist von 30 Jahren kann jedoch auf Antrag verkürzt werden, »wenn die Benutzung für ein wissenschaftliches Forschungsvorhaben oder zur Wahrnehmung berechtigter Belange unerlässlich ist ( $\$ 5 \mathrm{~V}$ BArchG). Die Fristverkürzung liegt in erster Linie im Ermessen der Behörde. Diese befindet darüber, ob ein sogenanntes Ausschlusskriterium vorliegt. Nach $\$ 5$ VI ist dies unter anderem der Fall, wenn:

»1. Grund zu der Annahme besteht, dass das Wohl der Bundesrepublik Deutschland oder eines ihrer Länder gefährdet würde, oder

2. Grund zu der Annahme besteht, dass schutzwürdige Belange Dritter entgegenstehen, [...]

5. die Ceheimhaltungspflicht nach $\S 203$ Abs. 1 bis 3 des Strafgesetzbuches oder anderen Rechtsvorschriften des Bundes über Ceheimhaltung verletzt würde.« ( $(5 \mathrm{VI}$ BArchC)

Wird ein Antrag auf Herabsetzung der Schutzfrist abgelehnt, so kann dagegen beim zuständigen Verwaltungsgericht Klage erhoben werden. Seit Inkrafttreten des BArchG 1988 gab es zwei entsprechende Klagen gegen das AA, ${ }^{148}$ darunter meine eigene. ${ }^{149}$

\section{Das Informationsfreiheitsgesetz}

Das AA bewahrt - wie auch andere Ministerien - Akten aus der »laufenden Verwaltung « in den hierfür zuständigen Fachreferaten auf. ${ }^{150}$ Wie sämtliche amtlichen Informationen der obersten Bundesbehörden (mit Ausnahme der Nachrichtendienste) un-

146 Bundesarchiv. Leitbild [o. D.], online unter https://www.bundesarchiv.de/bundesarchiv/leitbild/ind ex.html.de, zuletzt abgerufen am 17.02.2011.

147 Deutscher Bundestag. Drucksache 17/4339 vom 21.12.2010. Antwort der Bundesregierung auf die Kleine Anfrage der Fraktion BÜNDNIS 90/DIE GRÜNEN - Drucksache 17/3804 - Erleichterung des Forschungszugangs zu Archiven des Auswärtigen Amts und anderer Bundesministerien, S. 2.

148 Deutscher Bundestag. Drucksache 17/4339 vom 21.12.2010, S. 7.

149 Bei dem anderen Fall handelt es sich um eine Klage Dieter Maiers auf Einsicht von Akten zur argentinischen Militärdiktatur. Vgl. VG Berlin, AZ VG 1 K 1.10.

150 Deutscher Bundestag. Drucksache 17/4339 vom 21.12.2010, S. 3. 
terliegen diese Unterlagen seit 2006 dem Informationsfreiheitsgesetz (IFC). ${ }^{151}$ Mit Inkrafttreten des IFG sollte ein »Paradigmenwechsel von der generellen Amtsverschwiegenheit zu einer offenen Verwaltung « eingeleitet werden. ${ }^{152}$ Das Cesetz begründet für jede Person "gegenüber den Behörden des Bundes einen Anspruch auf Zugang zu amtlichen Informationen « ( $(1$ IFC). Jedoch nennt das Cesetz zugleich eine Reihe von Ausnahmen, etwa zum »Schutz von öffentlichen Belangen « ( $($ I IFG), zum »Schutz des behördlichen Entscheidungsprozesses« ( $(4$ IFG) sowie zum »Schutz personenbezogener Daten « (§ 5 IFG). Die Auslegung dieser Ausnahmen liegt - wie auch beim BArchG - vollständig im Ermessen der entscheidenden Behörde. Seit Inkrafttreten des IFC wird kritisiert, dass die Auslegungspraxis der Behörden sehr restriktiv ist. ${ }^{153}$ Der Ausnahmenkatalog des IFC stelle eine »Ceneralklausel zur Verweigerung von Informationen « ${ }^{154}$ dar. Er sei zu weit und zu unbestimmt gefasst und gebe dadurch den Behörden die Möglichkeit, durch eine pauschale Anführung abstrakter Gefahren Informationsgesuche im Widerspruch zur Intention des Cesetzes vollständig zu blockieren.

Immerhin kann bei Auseinandersetzungen mit Behörden bezüglich der Anwendung des IFG vermittelnd der Bundesbeauftragte für den Datenschutz und die Informationsfreiheit (BfDI) angerufen werden. Die Einflussmöglichkeiten des BfDI sind als nachgeordnete Behörde des Bundesministeriums des Innern (BMI) jedoch begrenzt. So besitzt der BfDI keinerlei Weisungsbefugnis.

\section{Verschlusssachen}

Sowohl BArchC als auch IFC sehen vor, dass ein Antrag auf Akteneinsicht abgelehnt werden kann, falls für die entsprechenden Dokumente eine Geheimhaltungseinstufung vorliegt. Rechtsgrundlagen für die Einstufung eines Schriftstücks als »streng geheim«, »geheim«, als »Verschlusssache Vertraulich« (VS-V) oder »Verschlusssache nur für den Dienstgebrauch« (VS-NfD) sind zum einen die Verschlusssachenanwei-

151 Gesetz zur Regelung des Zugangs zu Informationen des Bundes (Informationsfreiheitsgesetz, IFG) vom 05.09.2005, in: Bundesgesetzblatt, 2005 Teil I, Nr. 57, S. 2722ff. vom 13.09.2005. Im Folgenden zitiert als IFG. Das IFG gilt für die Bundesebene. Auf Länderebene haben inzwischen 13 Bundesländer eigene Informationsfreiheitsgesetze verabschiedet. Es fehlen noch Bayern, Niedersachsen und Sachsen (Stand Januar 2020). Eine entsprechende Übersicht ist online verfügbar unter https: //transparenzranking.de/.

152 Bundesbeauftragter für den Datenschutz und die Informationsfreiheit. 2. Tätigkeitsbericht zur Informationsfreiheit für die Jahre 2008 und 2009, Bonn 2010, online unter https://www.bfdi.bu nd.de/SharedDocs/Publikationen/Taetigkeitsberichte/TB_IFC/2TB08_09.pdf, S. 9.

153 Vgl. Redelfs, Manfred. Erfahrungen mit dem Informationsfreiheitsgesetz: Transparenz für Hartnäckige, in: BBE Newsletter Nr. 16/2007 vom 09.08.2007, online unter https://www.b-b-e.de/filea dmin/inhalte/PDF/newsletter/nl-2018-16.pdf, (zuletzt abgerufen am 11.02.2011).

154 Bräutigam, Thomas. Rechtsvergleichung als Konfliktvergleich. Das deutsche Informationsfreiheitsgesetz aus Perspektive des US-amerikanischen und finnischen Rechts. [Dissertation] Universität Helsinki, 2008. https://www.doria.fi/bitstream/handle/10024/42586/rechtsve.pdf; (zuletzt aufgerufen am 24.02.2011). 
sung des BMI (VSA) $)^{155}$ und zum anderen das Sicherheitsüberprüfungsgesetz (SÜG) ${ }^{156}$. $\S 2$ der VSA definiert Verschlusssachen als »im öffentlichen Interesse, insbesondere zum Schutz des Wohles des Bundes oder eines Landes, geheimhaltungsbedürftige Tatsachen, Gegenstände oder Erkenntnisse« begründet. Bis vor kurzem war wenig über die Anzahl, Charakteristika und Archivierung von Verschlusssachen in Geheimarchiven der obersten Bundesbehörden sowie in staatlichen Archiven bekannt. Im Zuge der Debatten über Informationsfreiheit und Verwaltungstransparenz wird seit einigen Jahren jedoch auch verstärkt über den Umgang mit Verschlusssachen diskutiert u.a. in Publikationen ${ }^{157}$ und Parlamenten. ${ }^{158}$

Laut Bundesregierung fällt der überwiegende Teil der als vertraulich eingestuften Akten in die Kategorie »VS-NfD «. ${ }^{159}$ Der Historiker Josef Foschepoth schätzt die Anzahl von Verschlusssachen bei Bundesministerien, Nachrichtendiensten, obersten Gerichten sowie dem Bundestag auf einen zweistelligen Millionenbereich. ${ }^{160}$ Angesichts von »Millionen bislang nicht zugänglicher VS-Akten«, so Foschepoth, sei »die Geschichte der Bundesrepublik noch nicht geschrieben $« .{ }^{161}$ Meine eigene Durchsicht inzwischen freigegebener Akten im PA AA ergab, dass viele Dokumente ursprünglich den Stempel »SS-NfD« trugen, bei denen nicht recht ersichtlich ist, weshalb eine Geheimhaltung erforderlich gewesen sein soll. Die Vermutung, dass das Prädikat »VS-NfD« sehr freigiebig verwendet wurde, bestätigen auch interne Schreiben des AA. So heißt es etwa im Hauserlass eines Staatssekretärs von 1968:

»Der VS-Verkehr hat im Auswärtigen Amt einen Umfang angenommen, der die vorschriftsmäßige Behandlung der VS außerordentlich erschwert. Ich habe festgestellt,

155 Allgemeine Verwaltungsvorschrift zum materiellen Geheimschutz (Verschlusssachenanweisung, VSA) vom 10.08.2018, in: Cemeinsames Ministerialblatt 2018, Nr. 44-47, S. 826ff. Im Folgenden zitiert als VSA.

156 Gesetz über die Voraussetzungen und das Verfahren von Sicherheitsüberprüfungen des Bundes (Sicherheitsüberprüfungsgesetz, SÜG) vom 20.03.1994, in: Bundesgesetzblatt 1994 Teil 1, Nr. 25. S. 687ff. Im Folgenden zitiert als SÜG.

157 Vgl. Jens Niederhut/Uwe Zuber (Hg.). Geheimschutz Transparent? Verschlusssachen in staatlichen Archiven, Essen 2010. Der Sammelband diskutiert umfassend die Behandlung von Verschlusssachen in Archiven sowie die Zugangsmöglichkeiten für Forscher_innen.

158 Vgl. Deutscher Bundestag. Drucksache 16/11354 vom 12.12.2008. Antwort der Bundesregierung auf die Kleine Anfrage der Fraktion der FDP (Drucksache 16/11079). Freigabe von Akten der Bundesregierung sowie Deutscher Bundestag. Drucksache 17/4339 vom 21.12.2010.

159 Deutscher Bundestag. Drucksache 16/11354 vom 12.12.2008, S. 2 f.

160 Foschepoth, Josef. Die Bedeutung der Bundesakten für einen neuen Blick auf die Geschichte der Bundesrepublik Deutschland, in: Mitteilungen aus dem Bundesarchiv 21 (2013), Heft 1, S. 74-79, hier S. 73. Die VS-Bestände in den Landesarchiven betragen noch einmal weitere 1,4 Regalkilometer, vgl. Foschepoth, Josef. Staatsschutz und Grundrechte in der Adenauerzeit, in: Jens Niederhut/Uwe Zuber ( $\mathrm{Hg}$.). Geheimschutz Transparent? Verschlusssachen in staatlichen Archiven, Essen 2010, S. 27-58, hier S. 29. Im PA AA werden ca. 8.000 Archivbände mit Verschlusssachen von 1949 bis 1975 verwahrt, vgl. Deutscher Bundestag. Drucksache 17/4339 vom 21.12.2010, S. 4.

161 Foschepoth, Josef. Staatsschutz und Grundrechte in der Adenauerzeit, in: Jens Niederhut/Uwe Zuber (Hg.). Geheimschutz Transparent? Verschlusssachen in staatlichen Archiven, Essen 2010, S. 2758 , hier S. 27. 
dass in Abweichung von den Bestimmungen der VS-Anweisung Schriftstücke in erheblichem Umfange höher eingestuft werden, als es nach den Vorschriften des $§ 4$ der VSAnweisung erforderlich wäre. Ich bitte daher, bei der Einstufung der VS einen wesentlich strengeren Maßstab als bisher anzulegen. Die Arbeitseinheiten sind verpflichtet, laufend [...] für die weitgehende Herabstufung des VS-Schriftgutes zu sorgen. « ${ }^{162}$

Formal sieht die VSA vor, dass die Notwendigkeit zur Geheimhaltung ständig überprüft wird. Laut Michael Hollmann, Präsident des Bundesarchivs, ist dies jedoch »in den vergangenen 60 Jahren seit der Gründung der Bundesrepublik Deutschland nur in sehr unzureichendem Maße tatsächlich umgesetzt worden «. ${ }^{163}$ Laut VSA entfällt die Einstufung als Verschlusssache nach 30 Jahren, sofern die Abteilung, die das Dokument erstellt hat, diese nicht explizit verlängert. ${ }^{164}$

Unklar ist, wie viele der als geheim eingestuften Akten überhaupt in Archive gelangen und wie viele dort auch einsehbar werden. 2008 bestätigte die Bundesregierung die Vernichtung von VS-Dokumenten. Allein seit Oktober 2005 seien 3181 VS-Sachen vernichtet worden. ${ }^{165}$ Jens Niederhut und Uwe Zuber vom Landesarchiv NRW schreiben dazu: »Nur gute und vertrauensvolle Beziehungen zu den entsprechenden Behörden gewährleisten, dass überhaupt geheime Akten in die Archive kommen und nicht etwa unkontrolliert vernichtet werden. $" 166$ Eine Rechtsgrundlage für die Vernichtung von sensiblem Aktenmaterial ist mir nicht bekannt. ${ }^{167}$ Dennoch gibt es Indizien, die vermuten lassen, dass die Vernichtung brisanter Akten bei verschiedenen Bundesbehörden zumindest lange Zeit gängige Praxis war: So heißt es beispielsweise in einem Hauserlass des AA von 1977:

»Auf die Notwendigkeit der Vernichtung entbehrlicher VS wird hingewiesen. Auch hier sollte möglichst schon bei Fertigung, bzw. beim Eingang einer VS festgelegt werden,

162 PA AA, ZW 125131. Staatssekretär im AA an die Herren Leiter der Arbeitseinheiten im Hause, Betr.: Behandlung von Verschlusssachen (VS) im Auswärtigen Amt, 27.03.1968. GZ ZB 9 -82.00/0 - Ein ähnlicher Hauserlass vom 28.12.1977 klingt nur unwesentlich anders.

163 Hollmann Michael. Verschlusssachen im Bundesarchiv, in: Jens Niederhut/Uwe Zuber (Hg.). Geheimschutz Transparent? Verschlusssachen in staatlichen Archiven, Essen 2010, S. 113-118, hier S. 114.

164 Laut § 19 II VSA lauten die Fristen für eine Aufhebung der VS-Einstufung wie folgt: »Einstufungen sind aufgehoben, sofern auf der Verschlusssache keine längere oder kürzere Frist bestimmt ist (vergleiche $\S \S 16$ und 17) 1. für die Vorgänge der Jahre 1949 bis 1959 mit Ablauf des 31. Dezember 2012, 2. für die Vorgänge der Jahre 1960 bis 1994 bis zum 1. Januar 2025 - dabei sind beginnend mit dem Ablauf des Jahres 2013 mindestens drei Jahrgänge je Kalenderjahr in chronologischer Reihenfolge auf Offenlegung zu prüfen, 3. für die Vorgänge der Jahre ab 1995 nach 30 Jahren.«

165 Deutscher Bundestag. Drucksache 16/11354 vom 12.12.2008, S. 8.

166 Jens Niederhut/Uwe Zuber. Einleitung, in: Jens Niederhut/Uwe Zuber (Hg.). Ceheimschutz Transparent? Verschlusssachen in staatlichen Archiven, Essen 2010, S. 9-16, hier S. 15.

$167 \S 32$ VSA regelt zwar die Vernichtung von VS-Sachen, dort sind jedoch lediglich Verschlusssachen gemeint, »die das zuständige Archiv nicht übernimmt«. Der Aktenplan des AA (Stand: 14.07.2008) enthält das APZ 262.05 »Aufbewahrung, Verwaltung, Archivierung und Vernichtung von VS, §§ 20-30, jährl. Prüfungen«. Vgl. Auswärtiges Amt. Aktenplan 2008, online unter: https://www.auswaertiges-amt.de/cae/servlet/contentblob/382696/publicationFile/4259/Aktenplan-Download.pdf (zuletzt abgerufen am 06.01.2013). 
dass sie nach Bearbeitung oder nach Eintreten eines bestimmten Ereignisses vernichtet werden kann. ${ }^{168}$

\subsubsection{Meine eigenen Bemühungen um Aktenzugang für die Forschung zu dieser Arbeit}

In diesem Abschnitt möchte ich exemplarisch beschreiben, wie sich meine eigenen Bemühungen um Akteneinsicht beim Auswärtigen Amt, beim Bundeskanzleramt, beim BMI, beim BND sowie bei der Staatsanwaltschaft Bonn gestaltet haben. Einige dieser Bemühungen waren vergeblich. Andere führten erst nach langwierigen Rechtstreitigkeiten zu einem Aktenzugang.

\section{Auswärtiges Amt}

$\mathrm{Zu}$ Beginn meiner Recherchen, im Herbst 2008, besuchte ich das PA AA, um die dortigen Bestände zu eruieren. Über die Findbücher konnte ich etwa 200 Aktenbände $^{169}$ identifizieren, die schon im Titel einen direkten Bezug zur Colonia Dignidad aufweisen. Das Archivpersonal teilte mir sogleich mit, dass ich davon gemäß BArchG nur jene Akten einsehen dürfe, die älter als 30 Jahre seien. Das war nur bei ca. 25 von den $200 \mathrm{Ar}-$ chivbänden der Fall. ${ }^{170}$ Für jüngere Unterlagen, so teilte mir das PA AA mit, müsse ich mich »auf die Sekundärliteratur einschließlich Presseberichterstattung stützen. « ${ }^{171} \mathrm{Als}$ ich mich erkundigte, ob bei Akten, die jünger als 30 Jahre sind, das IFG zur Anwendung kommen könne, antwortete mir das AA:

»Das IFG ist [...] auf neue, noch nicht archivierte Aktenbestände anwendbar. Dies ist jedoch mit Einschränkungen verbunden [...] Cemäß § 3 Nr. 4 IFC besteht ein Anspruch auf Informationszugang nicht, wenn die Information einer [...] Ceheimhaltungs- oder Vertraulichkeitspflicht oder einem Berufs- oder besonderen Amtsgeheimnis unterliegt. Dies ist bei Unterlagen zur Villa Baviera, die noch nicht archiviert sind, der Fall. ${ }^{172}$

Die Behörde behauptete also, dass sämtliche Akten zur Colonia Dignidad, die noch nicht ans Archiv abgegeben wurden, per se geheimhaltungsbedürftig seien. Nach Beratung mit meiner Rechtsanwältin Petra Schlagenhauf stellte ich daraufhin den Antrag auf Einsicht »in alle Akten des AA zur Colonia Dignidad (Villa Baviera), die den Untersuchungszeitraum meines Forschungsvorhabens betreffen (1961-2008)«. ${ }^{173}$ Ich stützte mich dabei u.a. auf die Möglichkeit zur Verkürzung von Schutzfristen in $\$ 5$ V BArchG.

168 PA AA, ZW, Bd. 125.131. Der Staatssekretär des AA an die Herren Leiter der Arbeitseinheiten im Hause, Betr.: Behandlung von Verschlusssachen (VS) im Auswärtigen Amt, 28.12.1977. CZ ZB 9 $82.00 / 0$.

169 Ein Aktenband im PA AA umfasst, gemäß den Erfahrungen des Verfassers, durchschnittlich 200400 Seiten.

170 Die übrigen etwa 175 Aktenbände reichen von 1981-1998, waren zu Beginn der Recherchen also mindestens zehn Jahre alt.

171 PJS, E-Mail vom PA AA an den Verfasser vom 12.09.2008.

172 PJS, Schreiben des AA an den Verfasser vom 27.01.2009.

173 PJS, Schreiben des Verfassers an das AA vom 03.03.2009. 
Ich wies zudem vorsorglich darauf hin, dass eine wissenschaftliche Auswertung der Akten das Wohl der Bundesrepublik nicht gefährden könne. Vielmehr, so argumentierte ich, läge die wissenschaftliche Aufarbeitung der dort begangenen Menschenrechtsverbrechen im Interesse von Öffentlichkeit und Wissenschaft - und damit eigentlich auch im Interesse des AA selbst. BArchG und IFG sähen beide eine gerichtliche Überprüfung der VS-Einstufung vor. Etwaigen Persönlichkeitsrechten Dritter könne durch eine Verpflichtung zur Anonymisierung Rechnung getragen werden, so meine Argumentation.

Entweder war mein Antrag beim AA eine Seltenheit oder mein Promotionsthema war von besonderer Brisanz. Jedenfalls lud das PA AA nur wenige Tage nach Eingang meines Schreibens elf Referate des AA zu einer internen Besprechung ein. Das Thema lautete: »Zugang zu den Unterlagen über die Colonia Dignidad nach IFG und Archivrecht $\ll .{ }^{174}$

Mein Antrag wurde aufgeteilt: Meine Anfrage zum Archivgut wurde vom PA AA beantwortet, für die noch nicht archivierten Aktenbestände war die Arbeitseinheit Informationsfreiheitsgesetz des AA zuständig. Beide Stellen lehnten meinen Antrag ab.

\section{Der Verwaltungsweg auf der Grundlage des Bundesarchivgesetzes}

Das PA AA argumentierte, der Inhalt des Schriftgutes sei geeignet, die Beziehungen der Bundesrepublik zu Chile zu belasten:

»Entgegen der von Ihnen in o.g. Antrag vorgetragenen Auffassung besteht somit Grund zu der Annahme, dass das Wohl der Bundesrepublik durch die vorzeitige Benutzung des Schriftgutes gefährdet würde [...] Ein Interesse an der wissenschaftlichen Aufarbeitung der Colonia Dignidad/Villa Baviera in Teilen der Öffentlichkeit steht der Einschlägigkeit dieses Ausschlusstatbestandes nicht entgegen. Ein amtliches Interesse an ihrem wissenschaftlichen Vorhaben [...] ist vor diesem Hintergrund nicht gegeben. « ${ }^{175}$

Gegen diese Entscheidung legte ich Widerspruch ein. Ich argumentierte, dass das BArchG zwar die Möglichkeit nachteiliger Auswirkungen eines Archivzugangs auf internationale Beziehungen vorsieht. Allerdings müssten diese im Einzelfall schlüssig dargelegt werden. Eine pauschale Prognose wie hier im Falle des PA AA sei jedoch nicht ausreichend. Zudem sehe die Gemeinsame Geschäftsordnung der Bundesministerien (GGO) die Möglichkeit einer Genehmigung unter gewissen Auflagen vor. ${ }^{176}$ Ferner wies ich darauf hin, dass ich bei einem Forschungsaufenthalt in Chile im Archiv des dortigen Außenministeriums Bestände zu Deutschland und CD bis zum Jahr 2005 einsehen durfte, was darauf hinweise, dass Chile die Befürchtung einer Schädigung der bilateralen Beziehungen nicht teilte.

Auch in seinem Widerspruchsbescheid ${ }^{177}$ argumentierte das PA AA, dass das »Wohl der Bundesrepublik Deutschland« in Gefahr sei. Die Aufarbeitung des Gesamtkomplexes Colonia Dignidad sei ein »hochgradig sensibles Thema«. Falls durch die Veröffent-

Von der Besprechung am 26.03.2009 erhielt ich Kenntnis über die Akteneinsicht in einem späteren Klageverfahren. Der Inhalt der Besprechung ist mir nicht bekannt. 
lichung meiner Dissertation Informationen aus den Akten an derzeitige Bewohner_innen der Villa Baviera gelangten, seien schutzwürdige Interessen von Opfern, Zeug_innen und Beteiligten bedroht. Das PA AA schrieb weiter:

»Die Bewältigung des Komplexes CD/VB ist für die Beziehungen der Bundesrepublik Deutschland zur Republik Chile von essentieller Bedeutung. Angesichts der Sensibilität des Themas ist hierfür unbedingte Vertraulichkeit insbesondere hinsichtlich personenbezogener Daten und interner Entscheidungsprozesse im Auswärtigen Amt Voraussetzung. Eine Einsichtnahme in die Archivakten und die anschließende Verwendung gewonnener Informationen zu einem anderen als dem vorbestimmten Zweck der Verwaltungsaufzeichnungen ist geeignet, diese Vertraulichkeit zu gefährden und damit der deutsch-chilenischen Zusammenarbeit schweren, möglicherweise irreparablen Schaden zuzufügen. § 5 Abs. 6 Nr. 1 BArchG steht einer Benutzung der begehrten Akten daher entgegen. ${ }^{178}$

Das PA AA berief sich auf seinen Ermessensspielraum nach $\$ 5$ BArchG, sowie auf die dort genannten Ausnahmegründe, namentlich die schutzwürdigen Daten Dritter sowie die Einstufung eines Großteils der Akten als »VS-NfD«. Gegen diesen Bescheid erhob ich Klage beim VG Berlin. ${ }^{179}$

\section{Das Klageverfahren auf Grundlage des Bundesarchivgesetzes}

In der Klagebegründung argumentierte meine Rechtsanwältin, ein Ermessensspielraum nach $\$ 5$ BArchG sei nicht vorhanden, da die dort angeführten Ausnahmen im konkreten Fall nicht erfüllt seien: Die Beziehungen zu Chile seien 20 Jahre nach Ende der dortigen Diktatur nicht gefährdet und der Fall CD werde seit über 40 Jahren in der Presse thematisiert. Zudem sei für eine wissenschaftliche Bearbeitung meiner Fragestellung eine Einsicht in die Akten des AA unerlässlich.

Das AA entgegnete in seiner Klageerwiderung, es sei unerheblich, ob eine Gefährdung der bilateralen Beziehungen tatsächlich vorliege, hierfür genüge die Prognose des AA. ${ }^{180}$ Auch sei eine Anonymisierung der persönlichen Daten Dritter durch Schwärzen bei 131 Archivbänden mit geschätzt 26.000 Blatt »aus verwaltungsökonomischer Sicht nicht zu bewerkstelligen. ${ }^{181}$ Das AA behauptete auch weiterhin, die persönlichen Opferdaten seien in höchstem Maße schutzwürdig - ganz im Gegensatz zu Aussagen von

178 Ebd.

179 Klageerhebung am 26.10.2009. Aktenzeichen des Verfahrens: VG 1 K 892.09. Das AA hatte mich im Ablehnungsbescheids darauf hingewiesen, dass ein Widerspruchsverfahren bei einer obersten Bundesbehörde nach § 68 Verwaltungsgerichtsordnung (VwCO) nicht vorgesehen ist. Daher sei direkt Klage zu erheben.

180 PJS, Klageerwiderung AA vom 20.05.2010.

181 Ebd. Bei Rechtsstreitigkeiten über von Behörden geheimgehaltenes Aktenmaterial besteht ein Problem in der Bestimmung des Streitgegenstandes, also der tatsächlichen Menge der Akten. Während das AA in seiner Klageerwiderung von 131 Aktenbänden spricht, habe ich (später) aus Findbüchern eine Tabelle mit 177 Aktenbänden mit direktem Bezug zur CD erstellt. Noch undurchsichtiger ist die Lage bei der Akteneinsicht nach IFG, da zu (noch) nicht archivierten Behördenakten keinerlei Findmittel eingesehen werden können. Auch hier macht das AA widersprüchliche Angaben über die Größe des relevanten Aktenbestandes. 
Opfer-Organisationen. ${ }^{182}$ Das AA beharrte darauf, dass ein Zugang zu den Akten nach \$ 5 BArchG »ausgeschlossen« sei und »das Transparenzgebot und das Interesse des Klägers an der Forschung zurückzutreten « hätten. ${ }^{183}$

Auch bei einer vom Gericht angesetzten Güteverhandlung bot das AA keine generelle Herabstufung der Schutzfrist an. Auf Vorschlag des Richters wurde Folgendes vereinbart:

»Das AA ist bereit, auf konkrete Anfragen des Klägers zu bestimmten Ereignissen, die nach Möglichkeit nach Datum und Cegenstand präzisiert sind, das Archivmaterial durchzusehen und zu prüfen, ob dort Bestände sind, die insbesondere den politischen Meinungsbildungsprozess widerspiegeln. Diese Dokumente werden sodann geprüft, ob einer Herausgabe Cründe entgegenstehen. Falls das nicht der Fall ist, wird das Material dem Kläger in Kopie zugänglich gemacht. «184

Ich übergab dem AA daraufhin eine Liste mit etwa 60 zeitlich eingegrenzten Ereignissen ab 1980 und bat um Einsicht in die betreffenden Aktenvorgänge. Nach zehnwöchiger Prüfung teilte mir das AA mit, die Liste sei »bedauerlicherweise nicht geeignet «, um die angestrebte »sinnvolle Eingrenzung tatsächlich zu erreichen ${ }^{185}{ }^{15}$ Die Liste sei zu umfangreich, zu unbestimmt und solle daher »reduziert und konkretisiert « werden. ${ }^{186} \mathrm{Un}$ ter dem Eindruck der Diskussionen über die Ergebnisse der Historikerkommission ${ }^{187}$ und um das Verfahren abzukürzen schlug ich dem AA eine generelle Herabsetzung der Schutzfrist für Unterlagen bis zum Jahr 1998 vor - inklusive einer Einsicht in die VSVerzeichnisse. ${ }^{188}$ Eine präzisere Eingrenzung sei mir ohne Kenntnis über den Inhalt der Akten nicht möglich. Für den Ablehnungsfall drohte ich, eine Wiederaufnahme des Gerichtsverfahrens zu beantragen. ${ }^{189}$

Das AA antwortete, zwar weiterhin zu einem Vergleich bereit zu sein, beharrte jedoch auf einer Eingrenzung der Bestände, vor allem um den Verwaltungsaufwand zu reduzieren. Eine Anfertigung detaillierter Inhaltsverzeichnisse entspräche fachlich einer »vertieften Erschließung«bzw. einer »Gesamtsichtung des Aktenbestands« und wäre daher vom Arbeitsaufwand her »unvertretbar. ${ }^{190}$ Das AA schlug mir vor, mich auf Akten eines »Registraturbildners « zu beschränken, also beispielsweise auf die Akten der Botschaft in Santiago im Bestand der Auslandsvertretungen. ${ }^{191}$

182 Die fordern schon lange eine Öffnung der Aktenbestände zur CD. Die Not- und Interessengemeinschaft der Geschädigten der Colonia Dignidad (NIG) wandte sich etwa 2010 in einem offenen Brief an den damaligen Außenminister Westerwelle. Darin beklagte sie die nicht stattfindende Aufarbeitung und forderte auch konkret eine Aktenfreigabe für mein Forschungsvorhaben. Ähnliche Forderungen an das AA stellt die NIC seit ihrer Cründung 1988. PJS, Klageerwiderung AA vom 20.05.2010.

VG Berlin, AZ VG 1 K 892.09. Abschrift der nichtöffentlichen Sitzung vom 11.06.2010.

PJS, Schreiben der Rechtsabteilung des AA an den Verfasser vom 06.10.2010.

PJS, Schreiben der Rechtsabteilung des AA an den Verfasser vom 06.10.2010.

Conze et al., Das Amt und die Vergangenheit.

Das Jahr 1998 wurde in Anlehnung an ein ähnliches Verfahren gewählt, in welchem dem Kläger 2011 Akteneinsicht gewährt worden war.

PJS, Schreiben des Verfassers an das AA vom 22.02.2011.

PJS, Schreiben des AA an RAin Schlagenhauf vom 08.03.2011.

Ebd. 
Die im Vorschlag genannten Akten machen mehr als ein Drittel aller im PA AA archivierten Akten zum Fall CD aus der Zeit von 1980 bis 1998 aus. Zudem nahm ich an, dass sie einen Großteil der Vorgänge um die CD abdecken. Daher signalisierte ich dem AA meine Bereitschaft, auf diesen Vorschlag einzugehen. ${ }^{192}$ Ich fügte eine Liste von 85 Aktenbänden bei und verwies dabei auch auf die Entwicklungen im parallel stattfindenden IFG-Verfahren. Das AA reagierte relativ umgehend:

»In diesem Sinne sind wir bereit, im Lesesaal des Politischen Archivs die Einsichtnahme der gewünschten Akten der Botschaft Santiago im Archivbestand >Auslandsvertretungen ab 1949/51<, entsprechend einer Schutzfristverkürzung nach § 5 Abs. 5 BArchC zu gewährleisten. Kopien können nicht gefertigt werden. Ihr Mandant wird gebeten, eine Verpflichtung zum Schutz personenbezogener Daten zu unterzeichnen und seine Dissertation nach Fertigstellung zur Prüfung vorzulegen. ${ }^{193}$

Die Plötzlichkeit, mit der das AA bereit war, sich auf diesen Vergleich einzulassen, nachdem bereits über zwei Jahre seit meinem Antrag auf Akteneinsicht vergangen waren, überraschte mich. Möglicherweise gab es einen Zusammenhang mit aktuellen Entwicklungen im Fall CD: Nur wenige Tage vor dem Schreiben des AA war bekannt geworden, dass Hartmut Hopp sich der chilenischen Justiz entzogen hatte und nach Deutschland geflüchtet war. Damit war das Thema CD einmal mehr in den Medien präsent. Im Juli 2011 wurde der von beiden Seiten ausformulierte und abgestimmte Vergleich zwischen dem AA und mir schließlich beim VG Berlin protokolliert. ${ }^{194}$

\section{Das Verwaltungsverfahren auf Grundlage des IFG}

Im April 2009 hatte ich parallel zum eben geschilderten Verfahren auch einen Ablehnungsbescheid von der Arbeitseinheit Informationsfreiheitsgesetz des AA erhalten. ${ }^{195}$ Darin ging es um meinen Antrag auf Einsicht von Akten, die sich noch in der »laufenden Verwaltung « des AA befinden. Das AA entschied, dass sämtliche 17 Aktenbände des Länderreferates Chile zum Thema Colonia Dignidad aus dem Zeitraum Januar 2005 bis April 2009 komplett als »VS-NfD« eingestuft seien und daher nicht eingesehen werden könnten. Zudem könne eine Freigabe der Akten »bilaterale Beziehungen belasten und Gesprächspartner desavouieren«, womit das Amt auf eine entsprechende Ausnahmeregelung in \$ 3 IFG anspielte. Allerdings gäbe es noch weitere Aktenbände zum Thema $\mathrm{CD}$ in anderen Referaten. Sollte ich auch an diesen interessiert sein, so solle ich »eine neue, zeitlich oder thematisch konkretisierte Anfrage« stellen, um »eine detaillierte Prüfung des Zugangsanspruches zu diesem Aktenbestand « zu ermöglichen. ${ }^{196}$ Ich legte Widerspruch gegen diesen Bescheid ein und dehnte zudem meinen Antrag auf alle neu benannten Unterthemen und Aktenbände aus. Im Juli 2009 erhielt ich ein Schreiben des AA mit einer Auflistung der »Unterlagen der Rechtsabteilung des Auswärtigen Amts betreffend `Colonia Dignidad««. Darin waren 90 Aktenbände aufgelistet, davon 77 aus dem

\footnotetext{
192 PJS, Schreiben des Verfassers an AA vom 27.05.2011

193 PJS, Schreiben des AA an RAin Schlagenhauf vom 10.06.2011.

194 VG Berlin, VG 1 K 892.09. Abschrift des Protokolls vom 29.07.2011.

195 PJS, Schreiben AA an den Verfasser vom 06.04.2009.

196 Ebd.
} 
Fachreferat 511 (Nothilfe für Deutsche im Ausland). Die Laufzeit der Akten reichte bis ins Jahr 1967 zurück. Auch für diese Akten machte das AA erneut Ausnahmeregelungen wie Geheimschutz, den Schutz bilateraler Beziehungen oder Persönlichkeitsrechte geltend. Im Oktober 2009 wurde dem AA mein Wunsch mitgeteilt, Einsicht in sämtliche aufgeführten Akten zu nehmen und zu prüfen, ob in anderen Referaten des AA noch weitere Akten zur CD vorlägen. In Absprache mit meiner Anwältin und dem AA warteten wir eine Entscheidung des Bundesverwaltungsgerichts in einer ähnlichen Sache ab. ${ }^{197}$ Im November 2009, nach der Entscheidung, fragte das AA an, ob ich »im Falle einer Herausgabe dieser Akten mit der Schwärzung der personenbezogenen Daten Dritter« einverstanden wäre, was ich bejahte. ${ }^{198}$ Das AA kündigte daraufhin eine längere Prüfung an und stellte mir schließlich im Mai 2010 seinen Widerspruchsbescheid aus. Darin hieß es:

»Das Auswärtige Amt ist bei erneuter Prüfung unter Berücksichtigung Ihrer Argumente zu dem Schluss gekommen, dass Ihrem Mandanten ein Informationszugang nicht gewährt werden kann. Der Anspruch auf Informationszugang nach §1 Abs. I IFC ist nach $\S 3$ Nr. I a), 3 Nr. 4, 5 Abs. I, 3 Nr. 7 IFG ausgeschlossen. « ${ }^{199}$

Unter anderem fürte das Amt aus:

»Die laufenden Cerichtsverfahren in Sachen Colonia Dignidad könnten durch das Bekanntwerden von Informationen beeinflusst und gefährdet werden und dadurch die Beziehungen zu Chile nachteilig beeinflusst werden. Das diplomatische Vertrauensverhältnis zu Chile könnte ferner gefährdet werden, da die Akten Informationen enthalten, die die chilenischen Behörden der deutschen Botschaft unter der Voraussetzung der vertraulichen Behandlung übermittelt hat [...] Das Auswärtige Amt hat im Rahmen der ihm zustehenden Entscheidungsprärogative befunden, dass der Informationszugang wegen einer möglichen Belastung der deutsch-chilenischen Beziehungen nicht der geeignete Weg für die grundsätzlich förderungswürdige Aufklärung der Ceschehnisse in der Colonia Dignidad ist [...]. ${ }^{200}$

Das AA argumentierte, die Akten seien vollständig als »VS-NfD« eingestuft. Zudem müsse man die Privatsphäre der Opfer schützen. Hierzu bemühte das Amt sogar das Grundgesetz:

»Die Akten beinhalten viele Aufzeichnungen zu Einzelschicksalen von Bewohnern, ohne dass die Betroffenen in eine Weitergabe der Informationen über sie eingewilligt

197 BVerwG 7 C 21.08. Entscheidung vom 29.10.2009. In diesem Verfahren urteilte das Bundesverwaltungsgericht, dass der Anspruch auf Zugang zu einer Information nach §3 Nr. 4 IFC nicht alleine dadurch ausgeschlossen sei, dass die Information formal als Verschlusssache eingestuft wurde. Vielmehr komme es darauf an, ob die materiellen Gründe für eine solche Einstufung noch immer vorlägen.

198 PJS, Schreiben AA an den Verfasser, 19.11.2009. und Schreiben des Verfassers an das AA vom 23.11.2009.

199 PJS, Widerspruchsbescheid des AA an den Verfasser vom 10.05.2010.

200 Ebd. 
haben. Enthalten sind ferner detaillierte Informationen zu laufenden Ermittlungsverfahren gegen die Mitglieder der ehemaligen Führungsriege. Es ist ein schutzwürdiges Interesse der Opfer, dass ihre Namen und die Einzelheiten der zu ihren Lasten begangenen Taten nicht an die Öffentlichkeit gelangen. Die schutzwürdigen Interessen der Betroffenen am Ausschluss des Informationszugangs überwiegen gegenüber dem Informationszugangsinteresse Ihres Mandanten. Bei einer Einsichtnahme in die hier betroffenen Akten zum Zwecke der Erstellung einer später zu veröffentlichenden wissenschaftlichen Dissertation wäre zu befürchten, dass, selbst wenn Namen unkenntlich gemacht würden, in die durch das Persönlichkeitsrecht nach Art.2 Abs. I i. V. m. Art. 1 Abs. I GG geschützte Privatsphäre der Opfer eingegriffen würde. Dabei ist zu berücksichtigen, dass es mit den hier betroffenen Taten besonders schwere Verletzungen der Menschenwürde der Betroffenen einhergegangen sind, vor allem Folter und sexueller Kindesmissbrauch sind Cegenstand. Vor diesem Hintergrund ist zu befürchten, dass die Benutzung zu einem anderen als dem ursprünglichen Verwaltungszweck der Unterlagen und die Auswertung besonders schutzwürdige Interessen Dritter verletzen würde. Demgegenüber haben das Transparenzgebot und das Interesse Ihres Mandanten an der Forschung ausnahmsweise zurückzutreten. « ${ }^{201}$

Gegen diesen Bescheid des AA reichte ich im Juni 2010 Klage ein. ${ }^{202}$

\section{Das Klageverfahren auf Grundlage des Informationsfreiheitsgesetzes}

In meiner Klagebegründung und der Klageerwiderung des AA waren die Argumente denen im Verwaltungsverfahren sehr ähnlich. Das AA argumentierte, die Aufarbeitung der Geschichte der CD sei zwar im Grundsatz unumstritten, berge aber

»in der Umsetzung insoweit innenpolitisches Konfliktpotenzial, als diese Aufarbeitung ihre Zusammenarbeit mit der Militärdiktatur betreffe. Eine vorzeitige Freigabe der beantragten Akten mit dem Bekanntwerden deutscher interner Informationen, Überlegungen, Bewertungen, Entscheidungsprozesse und nicht für die Öffentlichkeit bestimmter Mitteilungen an chilenische Regierungsmitglieder und sonstige chilenische Akteure zur Colonia Dignidad/Villa Baviera würde vor diesem Hintergrund einen solchen Anlass für neue Konflikte und Vorwürfe zum (damit verbundenen) Umgang mit der Militärdiktatur schaffen - nicht nur zwischen den politischen Richtungen in Chile, sondern vor allem auch zwischen Chile und Deutschland. ${ }^{203}$

In Chile, so das AA weiter, werde ausländische Kritik aufgrund des Nationalstolzes über Parteigrenzen hinweg nicht geschätzt. Zudem betreffe mein Informationsbegehren aktuelle Geschehnisse: »Die laufenden Gerichtsverfahren in Sachen Colonia Dignidad könnten durch das Bekanntwerden von Informationen beeinflusst und gefährdet

201 Ebd.

202 VG Berlin, AZ VG 2 K 80.10.

203 PJS, Klageerwiderung des AA (»Stellungnahme«) vom 30.11.2010, GZ: 505-511 E 2010-035 (IFG VC 2 K 80.10 1196). 
und dadurch die Beziehungen zu Chile nachteilig beeinflusst werden. ${ }^{204}$ Zusammenfassend stellte das AA fest:

»Das Auswärtige Amt hat im Rahmen der ihm zustehenden Entscheidungsprärogative befunden, dass der Informationszugang wegen einer möglichen Belastung der deutsch-chilenischen Beziehungen nicht der geeignete Weg für die grundsätzlich förderungswürdige Aufklärung der Ceschehnisse in Colonia Dignidad ist und hält an dieser Einschätzung fest. «" 205

Ein Unterschied zum BArchG-Verfahren (siehe oben) war die pauschale Einstufung vieler Akten als Verschlusssache. In einem ähnlichen Verfahren war eine solche pauschale Einstufung 2010 als rechtswidrig erachtet worden. ${ }^{206}$ In meinem Klageverfahren schien der berichterstattende Richter eine ähnliche Haltung einzunehmen. Im Januar 2011 forderte er das AA zur »Übersendung eines mit (paginierten) Blattzahlen spezifizierten Inhaltsverzeichnisses [...] mit abstrakter Umschreibung der jeweiligen Inhalte« der strittigen Akten auf. ${ }^{207}$ In seiner Antwort vom Februar $2011^{208}$ listete das AA auf 34 Seiten 115 Bände zur Colonia Dignidad aus der politischen Abteilung und der Rechtsabteilung des AA mit Aktenzeichen, Aktenbetreff und Zeitraum auf. ${ }^{209}$ Diese Akten seien teilweise vollständig und teilweise zum großen Teil als Verschlusssache eingestuft. Der Aktenbetreff war sehr allgemein gehalten mit Titeln wie »Berichterstattung«, »Weisung« oder »letzte Entwicklungen«. Gleichzeitig enthielt die Aufstellung aber auch Inhaltsbezeichnungen wie »Artikel aus der Frankfurter Allgemeinen Sonntagszeitung« oder »Der Spiegel«. Auch diese Inhalte gehörten zu Aktenbänden, die komplett als »VS$\mathrm{NfD}$ « klassifiziert waren. Dies veranlasste den berichterstattenden Richter, dem AA Folgendes $\mathrm{zu}$ antworten:

»Das übersandte Inhaltsverzeichnis lässt es zweifelhaft erscheinen, dass der Aktenbestand ausschließlich aus derlei [als VS eingestufte, vertrauliche] Informationen besteht. Beispielsweise der Zeitungsbericht »Der Spiegel« dürfte nicht hierunter fallen. Ich bitte daher im Hinblick auf $\S 7$ Abs. 2 Satz 1 IFC um substantiierte Mitteilung, an welcher Stelle des Aktenbestands genau (Blatt für Blatt) es um Informationen der genannten Art geht und welcher Ausschlussgrund dem Informationsbegehren des Klägers im Übrigen entgegengehalten wird. Hierbei bitte ich zu berücksichtigen, dass der Kläger sich damit einverstanden erklärt haben dürfte, die Informationen in anonymisierter (geschwärzter) Form einzusehen, soweit es um personenbezogene Daten geht. «10 $^{210}$

204 Ebd. Diese Argumentationslinie führt jegliche Menschenrechtspolitik des AA ad absurdum. Im Umkehrschluss hieße das, dass Menschenrechtsverletzungen nur gegenüber Staaten angesprochen werden sollten, die dies auch wünschen.

205 Ebd.

206 BVerwG, AZ 20 F 13.09. Urteil vom 19.04.2010. In diesem Fall hatte das Bundeskanzleramt sogar versucht, eine Vorlage der eingestuften Akten ans Gericht durch eine Sperrerklärung zu verhindern.

207 PJS. Schreiben des VG an das AA vom 27.01.2011, GZ: 505-511 E 2010-035 (IFG VG 2 K 80.10 1196).

208 PJS. Schreiben des AA an das VG vom 25.02.2011, GZ: 505-511 E 2010-035 (IFC VG 2 K 80.10 1196).

209 Die aufgeführten Bestände umfassten die Jahre 1967-2010. Ein Großteil stammte jedoch - sofern aufgeführt - aus den Jahren 2005-2010.

PJS. Schreiben des VG an das AA vom 01.03.2011, GZ: 505-511 E 2010-035 (IFG VG 2 K 80.10 1196). 
Das AA stellte daraufhin fest, dass eine blattgenaue Aufstellung und Überprüfung der ca. 33.000 Blatt wegen begrenzter Personalressourcen sehr langwierig sei. Das AA sei daher bereit, mir einen Teileinblick in das Material zu gewähren. Allerdings solle ich mein Ersuchen hierzu »in zeitlicher und sachlicher Hinsicht « eingrenzen. ${ }^{211}$ Zudem enthalte die überwiegende Zahl der strittigen Unterlagen "personenbezogene Daten von Dritten im Sinne des $\$ 5$ Abs. I IFG«. In diese könne »aufgrund der teilweise schwerwiegenden Menschenrechtsverletzungen« keine Einsicht gewährt werden, es sei denn die Betroffenen stimmten dem »ausdrücklich « $\mathrm{zu}^{212}$

Meine Rechtsanwältin entgegnete darauf, dass ich ohne Kenntnis der genauen Inhalte der Aktenbände keine Eingrenzung vornehmen könne. Stattdessen solle das AA mir mitteilen, welche Aktenteile sie im Vergleichswege anbieten könne. Ferner seien "schwerwiegende Menschenrechtsverletzungen« kein Ausschlussgrund im Sinne des IFG. Müssten Opfer kontaktiert werden, so sei dies Aufgabe des AA, da der Kläger die betreffenden Namen nicht kenne. Zudem bot sie erneut an, persönliche Opferdaten zu schwärzen, bzw. anonym zu behandeln und regte ein Treffen zur gemeinsamen Aktendurchsicht an. ${ }^{213}$ Nur wenige Tage später ging das AA auf diesen Vorschlag ein. Ich könne mir in den Räumen des AA einen Überblick über die Akten verschaffen, dürfe jedoch keine Kopien anfertigen. Zudem solle ich die Endfassung dieser Arbeit vorab zur Prüfung übersenden. ${ }^{214}$ Im August 2010 wurde der abgestimmte Vergleich vom Gericht protokolliert und von beiden Seiten akzeptiert. ${ }^{215}$

\section{Bundeskanzleramt}

Als ich in Beständen des Bundeskanzleramts im Bundesarchiv recherchierte, wies mich eine Archivarin auf Aktenbände hin, die möglicherweise für meine Forschung interessant seien, die aber aufgrund ihrer Laufzeit teilweise dem IFG unterlägen. Daraufhin stellte ich beim Bundeskanzleramt einen Antrag auf Herabsetzung der Frist nach BArchG und IFG. ${ }^{216}$ Auch diese Anträge wurden abgelehnt, es kam erst zu einem Verwaltungs- und später zu einem Klageverfahren auf Grundlage des IFG. Die Argumentation des Bundeskanzleramtes ähnelte jener des AA.

\section{Das Verwaltungsverfahren auf Grundlage von Bundesarchivgesetz und Informationsfreiheitsgesetz}

Das Bundeskanzleramt teilte mir im Mai 2011 mit, dass sich in den Akten Verschlusssachen befänden, deren Prüfung einige Zeit in Anspruch nehmen werde. ${ }^{217}$ Im Am 7.

211 PJS. Schreiben des AA an das VG vom 05.04.2011, GZ: 505-511 E 2010-035 (IFC VG 2 K 80.10 1196).

212 Ebd.

213 PJS. Schreiben RAin Schlagenhauf an VG vom 14.05.2011.

214 PJS. Schreiben AA an VG vom 06.06.2011, GZ: 505-511 E 2010-035 (IFC VG 2 K 80.10 1196).

215 PJS. Vollständiger Text des Vergleiches vom 10.08.2010.

216 PJS. Schreiben des Verfassers an das Bundesarchiv vom 21.03.2011 (BArchC) sowie Schreiben des Verfassers ans Bundesarchiv vom 09.05.2011 (IFG). Das Bundesarchiv leitete die Schreiben an das Bundeskanzleramt weiter.

217 PJS. Schreiben des Bundeskanzleramts an den Verfasser vom 12.05.2011, AZ 13 IFC IN1/NA 87/2001. Am 15.08.2011 teilte das Bundeskanzleramt mir mit, dass die Akten personenbezogene Daten enthalten und forderte mich auf, mein Informationsinteresse gemäß IFC zu begründen. PJS, Schrei- 
Oktober 2011 erhielt ich einen Bescheid, der mir einen partiellen Zugang zu zwölf Aktenbänden zusagte. ${ }^{218} 14$ Dokumente darin enthielten jedoch private Daten. Um diese einzusehen, müsste ich zuvor eine entsprechende Erklärung zum Datenschutz abgeben. Weitere 18 Dokumente dürften nicht eingesehen werden. $\mathrm{Zu}$ jedem einzelnen dieser Dokumente wurde ein Ausschlussgrund genannt (meist VS-Einstufung oder Schutzes internationaler Beziehungen). Obwohl einige Dokumente bereits 1977 entstanden, wurde bei allen zwölf Aktenbänden eine Beurteilung nach IFG zugrunde gelegt. Noch im selben Monat legte ich gegen diesen Bescheid Widerspruch ein. ${ }^{219}$ Im März 2012 erreichte mich der Widerspruchsbescheid des Bundeskanzleramts. Darin wurde mir Zugang zu einem Teil der ursprünglich verweigerten Dokumente gewährt. Das Schreiben erwähnte außerdem eine Reihe zusätzlicher Dokumente, insbesondere die Korrespondenz zwischen Bundeskanzleramt und BND zum Thema CD. In diese dürfe jedoch zum großen Teil aus Gründen des Geheimschutzes kein Einblick genommen werden. Einige Aktenkopien, die mir als Anlage zum Bescheid übersandt wurden, enthielten Zwischenblätter mit entsprechenden Hinweisen:

»Dieses Leerblatt ersetzt ein Schriftstück [...] des BND. Cegenüber dem Bundesnachrichtendienst besteht kein Anspruch auf Informationszugang nach dem IFC (§ 3 Nr. 8 IFG). $\ll^{220}$

Mein erneuter Widerspruch wurde abgelehnt. ${ }^{221}$ Der 14-seitige Widerspruchsbescheid des Bundeskanzleramts vom Juli 2012 erläutert Dokument für Dokument, aus welchen Gründen ein Zugang jeweils nicht gewährt werden könne. So heißt es beispielsweise:

»Schreiben Nr. 2 vom 26.05.1988 enthält Angaben zu mutmaßlichen Verbindungen der Colonia Dignidad zu Nachbarstaaten. Dies könnte auch nach der Auflösung der Colonia Dignidad die Beziehungen des genannten Landes zu Chile beeinflussen und für die Interessen der Bundesrepublik schädlich sein [...].

Schreiben Nr. 4 vom 25.03.1997 enthält Aussagen über die Verbindung der Colonia Dignidad in ausländische Sicherheitsbehörden (und Angaben zum Funkverkehr). Das Offenlegen der Informationen würde die Zusammenarbeit mit Sicherheitsbehörden gefährden, die diese Informationen im Vertrauen auf die Verschwiegenheit übermittelten.

Das Schreiben Nr. 5 vom 23.04.1997 enthält Angaben zu den Sicherungsanlagen der Colonia Dignidad. [...].

Schreiben Nr. 6 vom 04.09.1997 beantwortet eine Anfrage des Auswärtigen Amtes an

ben des Bundeskanzleramts an den Verfasser vom 15.08.2011. Dem kam ich nach und sicherte zudem zu, persönliche Daten durch Anonymisierung o.Ä. zu schützen. PJS, Schreiben des Verfassers an das Bundeskanzleramt vom 23.08.2011.

218 PJS, Schreiben des Bundeskanzleramts an den Verfasser vom 07.10.2012 (Bescheid).

219 PJS, Schreiben des Verfassers an das Bundeskanzleramt vom 25.10.2011 (Widerspruch). Darin verwies ich auf das Ende der chilenische Diktatur 1990, weshalb § 3 Nr. 1 IFC (Schutz internationaler Beziehungen) nicht greife. Zudem verwies ich zur VS-Einstufung auf meinen Vergleich mit dem AA.

220 PJS, Schreiben des Bundeskanzleramts an den Verfasser vom 09.03.2012 (Bescheid) mit Übersendung von Kopien. PJS, Schreiben des Bundeskanzleramts an den Verfasser vom 11.07.2012 (Bescheid). 
den Bundesnachrichtendienst (BND). Es geht um die Bewertung von Cerüchten im Zusammenhang mit der Colonia Dignidad. Das Dokument enthält Aussagen zu einem anderen Nachrichtendienst.«

Die Kosten meiner Anfrage nach dem IFC wurden mit 896,20 Euro beziffert. Cegen diesen zweiten Widerspruchsbescheid reichte ich im August 2012 Klage beim VG Berlin ein. ${ }^{222}$ Das Klageverfahren ruht derzeit, da vereinbart worden war, Präzedenzurteile abzuwarten. Letztere sind unterdessen zwar ergangen. Da ich inzwischen jedoch umfangreiche andere Quellenzugänge erschlossen hatte, habe ich meinerseits noch keine Wiederaufnahme des Verfahrens beantragt.

\section{Das Klageverfahren auf Grundlage des Informationsfreiheitsgesetzes}

Meine Klagebegründung ${ }^{223}$ nahm Bezug auf die weiter oben beschriebenen Vergleiche mit dem AA. ${ }^{224}$ Meine Rechtsanwältin führte aus, dass das Bundeskanzleramt die streitbefangenen Unterlagen nicht dem Gericht vorgelegt habe. Sie bezog sich auf einen ähnlichen Fall, in dem ein solches Vorgehen vom Bundesverwaltungsgericht als rechtswidrig angesehen wurde. ${ }^{225}$ Die pauschale Behauptung einer möglichen Schädigung der deutsch-chilenischen Beziehungen sei angesichts des zeitlichen Abstands zum Ende der chilenischen Militärdiktatur nicht nachvollziehbar, so die Begründung weiter. Vielmehr sei von chilenischer Seite in den letzten Jahren mehrfach der Wille zur Aufarbeitung des Falls CD bekundet worden. So habe mir etwa das Archiv des chilenischen Außenministeriums Dokumente zum Fall Colonia Dignidad bis einschließlich 2005 vorgelegt.

In seiner Klageerwiderung vom März $2013^{226}$ argumentierte das Bundeskanzleramt, es sei der falsche Anspruchsgegner, da die Mehrzahl der fraglichen Dokumente vom BND erstellt wurden. Für diese Dokumente greife zudem der generelle Ausschluss von Geheimdienstdokumenten nach $\$ 3$ Nr. 8 IFG. Als Dienst- und Fachaufsicht des BND sei das Bundeskanzleramt dabei »ebenso schutzwürdig wie der BND selbst«. ${ }^{227}$ Zudem seien neben den deutsch-chilenischen Beziehungen insbesondere die vertraulichen Beziehungen des BND zu befreundeten Nachrichtendiensten gefährdet. Man habe bereits ausgeführt,

»dass sämtliche Dokumente Rückschlüsse auf die Informationsquelle ermöglichen. Es lassen sich entweder Rückschlüsse auf die Informationsherkunft herleiten oder es handelt sich um Informationen anderer Dienste zur Thematik. Auch mutmaßliche Bezie-

222 VG Berlin, AZ 2 K 190.12. Klage vom 12.08.2012 (Schreiben).

223 PJS, Schreiben RAin Schlagenhauf an VG Berlin vom 04.01.2013 (Klagebegründung).

224 VG Berlin, AZ 1 K 892.09. Vergleich vom 29.7.2011 (BArch) und VG Berlin, AZ 2 K 80.10. Vergleich vom 10.08.2011 (IFG).

225 BVerwG, AZ 20 F 13.09. Entscheidung vom 19.04.2010. Die RAin kündigte einen Antrag nach § 99 Abs. 2 VwCO an, und bezog sich dabei auf eine Entscheidung des BVerwG von 2010. Die Klägerin Gaby Weber hatte die Einsicht in die BND-Akten zu Adolph Eichmann beantragt. Das Gericht entschied, dass eine generelle Sperrerklärung des Bundeskanzleramtes rechtswidrig sei und dass die Akten dem Gericht vorgelegt werden müssen, damit dieses die Ceheimhaltungsbedürftigkeit überprüfen kann. PJS, Schreiben Bundeskanzleramt an VG Berlin vom 28.03.2013 (Klageerwiderung). Ebd. 
hungen der Colonia Dignidad zu Nachbarstaaten werden beschrieben und Aussagen über Sicherheitsbehörden gemacht. Die Bekanntgabe der Information birgt nach Einschätzung der Bundesregierung für Chile innenpolitisches Konfliktpotential bzgl. der Zusammenarbeit der Colonia Dignidad mit der Militärdiktatur (1973-1990). Sollte aufgrund der Bekanntgabe der Informationen ein innenpolitischer Konflikt in Chile ausbrechen, hat dies möglicherweise negative Auswirkungen auf die derzeitigen außenpolitischen Beziehungen der Bundesrepublik Deutschland zu Chile.»

Auch das Klageverfahren ruht derzeit, da vereinbart wurde, einschlägige Präzedenzurteile abzuwarten.

\section{Bundesministerium des Inneren (BMI)}

Im Juni 2011 beantragte ich auf Grundlage des IFG beim Bundesministerium des Inneren (BMI) Einsicht in Aktenbestände zur Colonia Dignidad. ${ }^{228}$ Im Oktober 2011 wurde dem Antrag zugestimmt, mit der Einschränkung, dass persönliche Daten geschwärzt würden. ${ }^{229}$. Ich erhielt eine Aufstellung der vorliegenden Dokumente aus den Jahren 1989 bis 2007 zusammen mit dem Hinweis, dass ich meine Anfrage zur Kostensenkung weiter eingrenzen oder nur einen Teil der Akten einsehen könne. Im Juni 2012 erhielt ich sämtliche Aktenkopien - insgesamt 53 Seiten - per Post zugeschickt, zusammen mit einer Zahlungsaufforderung über 168,74 Euro zzgl. Kopierkosten. ${ }^{230}$

\section{Bundesnachrichtendienst (BND)}

Im Januar 2009 schrieb ich an den BND mit der Bitte um Mitteilung über die dort vorhandenen Aktenbestände zum Thema $\mathrm{CD}^{231}$ Der BND teilte mir daraufhin mit, dass er mein Anliegen nicht unterstützen könne, da sämtliche Unterlagen des BND als Verschlusssache eingestuft seien, in die grundsätzlich keine Einsicht genommen werden könne. ${ }^{232}$ Sämtliche BND-Unterlagen seien Verschlusssachen im Sinne von $\$$ 2 I VSA. »Eine Einsichtnahme durch Außenstehende oder eine Auskunftserteilung aus diesen Unterlagen ist deshalb grundsätzlich nicht möglich, « hieß es. Nicht mehr geheimhaltungsbedürftige und archivwürdige Unterlagen würde der BND regelmäßig an das Bundesarchiv abgeben, wo sie im Bestand B 206 zugänglich gemacht würden. Etwa zwei Jahre später stellte ich einen erneuten Antrag auf Akteneinsicht beim BND. ${ }^{233}$ Ich verwies auf die vielfältigen Bezugspunkte meiner bisherigen Recherchen zum BND und auf die Tatsache, dass der genannte Bestand des Bundesarchivs lediglich ca. 20 Seiten umfasse. Ich erwähnte auch, dass der BND anderen Wissenschaftler_innen einen selektiven und thematisch begrenzten Aktenzugang ermöglicht hatte. ${ }^{234}$ Im April

228 PJS, Schreiben des Verfassers an das BMI vom 09.06.2011. recherchieren, vgl. Hammerschmidt, Peter. Deckname Adler. Klaus Barbie und die westlichen Ceheimdienste. Frankfurt a.M. 2014. 
2011 antwortete mir der Leiter der Arbeitsgruppe Archiv des BND, dass in der letzten Zeit keine neuen Unterlagen zur Abgabe an das Bundesarchiv angefallen seien. In dem Schreiben hieß es weiter:

»Der BND betreibt allerdings permanent die systematische archivische Erschließung seiner Altunterlagen, die noch nicht abgeschlossen ist. Daher ist nicht auszuschließen, dass sich in Zukunft doch noch weitere Unterlagen zur Colonia Digndiad ergeben könnten. Ich vermag insoweit lediglich anheim zu stellen, nach ca. einem Jahr mit Ihren Anliegen erneut an den BND heranzutreten [...]. Soweit Sie die Überzeugung äußern, dass eine wissenschaftliche Aufarbeitung des Falls Colonia Dignidad geboten sei und im wissenschaftlichen Interesse liege, darf ich anmerken, dass eine Aufarbeitung des Falls >Colonia Dignidad « durch den BND aktuell nicht vorgesehen ist. « ${ }^{235}$

Auf eine erneute Anfrage im Juli 2012 erhielt ich eine ähnliche Antwort. ${ }^{236}$ Schließlich wurde mir der Zugang zu einer Auswahl von Dokumenten zu Georg Mertins in Aussicht gestellt, die sich allerdings als nicht relevant erwiesen. ${ }^{237}$

\section{Staatsanwaltschaft Bonn}

Die StA Bonn führte ab 1961 und besonders von 1985 bis 2010 diverse strafrechtliche Ermittlungsverfahren gegen Führungsmitglieder der CD. Laut $\$ 476 \mathrm{StPO}^{238}$ ist eine Einsichtnahme in Ermittlungsakten zu Forschungszwecken unter bestimmten Voraussetzungen möglich, insbesondere wenn

»das öffentliche Interesse an der Forschungsarbeit das schutzwürdige Interesse des Betroffenen an dem Ausschluss der Übermittlung erheblich überwiegt. Bei der Abwägung [...] ist im Rahmen des öffentlichen Interesses das wissenschaftliche Interesse an dem Forschungsvorhaben besonders zu berücksichtigen.« (§ 476 I StPO)

Als besonders schützenswert gelten dabei personenbezogene Daten, die erst nach einer Geheimhaltungsverpflichtung übermittelt werden, sofern sie nicht zuvor anonymisiert werden können.

Im April 2009 nahm ich Kontakt zur StA Bonn auf, im Dezember 2009 führte ich ein Gespräch mit dem für die Ermittlungen zuständigen Staatsanwalt Martin Diesterheft.

235 PJS, Schreiben des BND an den Verfasser vom 15.04.2011.

236 PJS, Schreiben des Verfassers an den BND vom 04.07.2012 und Schreiben BND an den Verfasser vom 23.07.2012. Allerdings hatte ich diesmal meine Anfrage um eine Namensliste erweitert.

237 In dem Schreiben vom 23.07.2012 war mir in Aussicht gestellt worden, in Pullach Bände zu Georg Mertins einsehen zu können. 2013 und 2014 erhielt ich erneute Schreiben, in denen mir mitgeteilt wurde, dass weitere Signaturen zu Mertins nun endbearbeitet seien und von mir eingesehen werden könnten. PJS, Schreiben BND an den Verfasser vom 01.02.2013 und Schreiben BND an den Verfasser vom 11.09.2014. Ein Kollege, der diese Bestände tatsächlich einsehen durfte, teilte mir jedoch mit, dass diese für mein Forschungsthema nicht relevant seien, weshalb ich von einer Einsichtnahme absah.

238 Strafprozessordnung (StPO), in der Fassung vom 02.08.2000. Geändert durch das Gesetz zur Änderung und Ergänzung des Strafverfahrensrechts (Strafverfahrensänderungsgesetz 1999) vom 02.08.2000, in: Bundesgesetzblatt 2000 Teil I, Nr. 38 vom 11.08.2000, S. $1256 \mathrm{f}$. 
Bereits im Vorfeld hatte ich mein Interesse bekundet, Einsicht in Ermittlungs- und Gerichtsakten, Gerichtsurteile, Rechtshilfeersuchen zwischen Deutschland und Chile sowie die Haftbefehle gegen Führungsmitglieder der CD zu erhalten. Bei dem Gespräch stellte mir der Staatsanwalt die Einsichtnahme nach Erklärung meiner Verpflichtung zur Geheimhaltung ${ }^{239}$ in Aussicht. ${ }^{240}$ Kurz darauf übersandte er mir eine entsprechende Verpflichtungserklärung, zusammen mit der Ankündigung, dass mir in den nächsten Tagen Übersichten über die Dokumente per E-Mail zugehen würden. ${ }^{241}$ Doch dazu kam es leider nicht. Auf meine Nachfrage im Februar 2010 teilte mir der Staatsanwalt mit:

»Nach Rücksprache mit der Behördenleitung bestehen aus Cründen des Persönlichkeitsschutzes, insbesondere der vernommenen Zeugen, Bedenken gegen eine Übersendung umfassender Inhaltsübersichten. Um Ihr Promotionsvorhaben dennoch zu unterstützen, wird um Konkretisierung der Auskunftserteilung gebeten, die im Einzelfall entschieden werden muss. $\ll^{242}$

Auf meinen Hinweis, ich sei auch mit geschwärzten Inhaltsübersichten einverstanden, antwortete mir der Staatsanwalt erneut:

»Nach erneuter Rücksprache mit meinem Dienstvorgesetzten wird derzeit keine Möglichkeit gesehen, Ihnen die benannten Inhaltsübersichten zu übersenden, die nach Schwärzen der relevanten Teile praktisch nutzlos erscheinen. ${ }^{243}$

Ein weiteres Insistieren erschien mir an dieser Stelle nicht aussichtsreich. Wenig später erhielt ich auf anderem Wege Einblick in die Bände I-XII des wohl wichtigsten Bonner Ermittlungsverfahrens. ${ }^{244}$ Obwohl mir bei einem Gespräch mit dem ermittelnden Staatsanwalt ${ }^{245}$ mitgeteilt wurde, dass diese Akten nach Abschluss des Verfahrens sicherlich als geschichtlich relevant erachtet und an das Landesarchiv abgegeben werden würden, gibt es bislang keinen Eintrag dazu in den Beständeübersichten des Landesarchivs.

\section{Fazit}

Die genannten Bundesbehörden handhaben den Umgang mit ihren Akten aus der Nachkriegszeit bisher restriktiv, es sei denn, besondere Transparenz wurde ihnen verordnet, war politisch gewollt oder lag in ihrem Interesse. Die Entscheidung über Ausnahmen von dieser restriktiven Praxis lag dabei immer im Ermessen der Behörde selbst. Die entsprechenden Gesetze gestehen der Behörde einen Ermessensspielraum

239 Gemäß §353b StCB und § 476 Abs. 3 StPO.

240 PJS, Notiz eines Gesprächs mit dem für die CD-Verfahren zuständigen StA, Martin Diesterheft, vom 09.12.2009.

241 PJS, Schreiben von Staatsanwalt Martin Diesterheft vom 11.12.2009.

242 PJS, E-Mail von StA Martin Diesterheft an den Verfasser vom 24.02.2010.

243 PJS, E-Mail von StA Martin Diesterheft an den Verfasser vom 24.03.2010.

244 StA Bonn, SZ 50 ]s 285/85. Das Verfahren wurde im September 2010 eingestellt. Ich erhielt Einblick in diese Bände über das Archiv von Al.

245 PJS, Notiz eines Cesprächs mit dem für die CD-Verfahren zuständigen StA, Martin Diesterheft, vom 09.12.2009. 
zu. Konkret überprüfbar ist dieser nur durch Gerichte, d.h. in der Regel durch langwierige und kostspielige Klageverfahren. Das zeigen exemplarisch meine eigenen Bemühungen um Aktenzugang. In einem Fall gab es erst zwei Jahre nach Antragstellung einen Erörterungstermin beim Gericht. Zwischen erster Antragsstellung und dem tatsächlichen Zugang zu den Akten nach den Vergleichen mit dem AA vergingen mehr als zweieinhalb Jahre. Da es bei Gerichtsverfahren nach BArchG und IFG um die Auslegung von Ermessensspielräumen und Prognosen geht, können sie aber auch gänzlich anders ausfallen. Der Ausgang eines solchen Verfahrens hängt stark vom Interesse, der Überzeugung und dem Engagement der zuständigen Kammer ab. Hinzu kommen Einflüsse von politischen Entwicklungen und medialen Aufmerksamkeitsökonomien: Die Vergleiche, die das AA mir schließlich vorschlug, dürften im Zusammenhang stehen einerseits mit der Debatte um Das Amt und andererseits mit der Flucht der CD-Führungsfigur Hartmut Hopp von Chile nach Deutschland im Mai 2011, die medial große Beachtung fand.

Wegen der Verfahrensdauer und -kosten sind solche Anträge auf Akteneinsicht im Sinne einer individuellen Kosten-Nutzen-Abwägung nicht sinnvoll. Daher haben in den letzten Jahrzehnten nur wenige Wissenschaftler_innen diesen Weg beschritten. Allerdings gibt es auch Beispiele, die hoffnungsvoll stimmen. So erreichte Dieter Maier durch eine Klage beim VG Berlin 2010 Zugang zu Akten des PA AA zu Argentinien mit Laufzeit bis 1999. ${ }^{246}$ Für den Historiker Peter Hammerschmidt hat das PA AA Bestände zum Fall Klaus Barbie freigegeben (Laufzeit bis 1988). Die Journalistin Gaby Weber erhielt Einblick in Verzeichnisse von VS-Beständen beim BND zu Adolf Eichmann. ${ }^{247}$ $\mathrm{Ob}$ diese Einzelfälle sich mittelfristig zu einem generell großzügigeren Aktenzugang ausweiten, bleibt abzuwarten. Das AA wird seine Ermessensspielräume und Einschätzungsprärogativen sicherlich nicht freiwillig, also ohne politischen oder juristischen Druck, aus der Hand geben.

Um diese politische Debatte zu flankieren und mittelfristig einen Wandel in der Grundhaltung des PA AA und anderer Archive einzuleiten, müssen jedoch Präzedenzentscheidungen auf der juristischen Ebene bis hoch zum Bundesverwaltungsgericht erklagt werden. Da Kosten und Aufwand solcher Klageverfahren das Forschungsbudget einzelner Promotionsprojekte bei weitem übersteigen, sind hier wissenschaftliche und politische Institutionen gefragt, eigene Klagen $\mathrm{zu}$ führen oder Klagen einzelner Forscher_innen gezielt zu unterstützen. Nur so kann auch der eklatanten Ungleichheit der juristischen und ökonomischen Mittel entgegengetreten werden, denn Behörden treten bei solchen Rechtsstreitigkeiten mit großen - steuerfinanzierten - Rechtsabteilungen an.

Letztlich geht es hierbei generell um die politische Frage ob, und wenn ja in welchen Fällen, eine wissenschaftliche Aufarbeitung von Menschenrechtsfragen dem Wohl der Bundesrepublik zuwiderlaufen kann. Noch 2010 antwortete die Bundesregierung auf eine Kleine Anfrage im Bundestag:

246 Dieter Maier klagte im November 2009 auf Benutzung von Archivgut zu den deutsch-argentinischen Beziehungen 1998/1999 im PA AA in Bezug auf den argentinischen Geheimdienstler Carlos Antonio Españadero alias »Major Peirano«. VG Berlin, AZ VG 1 K 1.10. 
»Die wissenschaftliche Aufarbeitung von Menschenrechtsfragen und das >Wohl der Bundesrepublikıschließen sich nicht aus. Die Abwägung unterliegt einer Einzelfallprüfung. « 248

Solange dieselbe Behörde, die die Akten erstellt hat, auch diese Einzelfallprüfung durchführt, kann vor dem Hintergrund der dargestellten Erfahrungen angenommen werden, dass bei dieser Einzelfallprüfung ausschlaggebend ist, ob sich die Behörde von dem Aufarbeitungsvorhaben politische Vorteile verspricht oder nicht. Auffallend ist aus meiner Erfahrung zudem, dass zur Begründung einer Ablehnung des Aktenzugangs häufig die Notwendigkeit des Schutzes persönlicher Opferdaten angeführt wird. Von der Möglichkeit den Schutz privater Daten durch Anonymisierungsauflagen zu gewährleisten, wird hingegen nur selten Gebrauch gemacht. Aus vielen Gesprächen mit Opfern habe ich jedoch den Eindruck, dass diese meist selbst Transparenz einfordern. 



\section{Entstehungsgeschichte und Struktur der Colonia Dignidad}

Der Name Colonia Dignidad steht einerseits für den physischen Ort in Chile, an dem sich die Gruppierung um Paul Schäfer 1961 niederließ, sowie für deren weitere Niederlassungen in Chile und der Bundesrepublik. Andererseits bezeichnet er die Personengruppe bzw. die kriminelle Gemeinschaft, deren Verbrechen sich gegen die eigenen Mitglieder richteten. Schließlich ist Colonia Dignidad ein Synonym für die kriminelle Vereinigung, die aus einigen Mitgliedern der Gruppe bestand, deren Verbrechen sich nach außen richteten.

Dabei ist Colonia Dignidad kein neutraler Begriff. Die heutigen Bewohner_innen bezeichnen die Siedlung in ihrer Kommunikation nach innen als »Fundo« (Landgut) oder »Villa« (Dorf). Nach außen sprechen sie von »Villa Baviera« (Bayern-Dorf). Sie sprechen nur selten von der »Colonia«, wenn sie sich auf die Vergangenheit unter Paul Schäfer beziehen. Da diese Vergangenheit mit Verbrechen verknüpft ist, und die heutigen Bewohner_innen sich ein Leben ohne diese historische Belastung wünschen, vermeiden sie es weitgehend, von »Colonia Dignidad« zu sprechen.

Menschenrechtsaktivist_innen hingegen betrachten die Umbenennung des Ortes als Versuch einer Reinwaschung der verbrecherischen Geschichte. Sie benutzen ausschließlich den Ausdruck »Colonia Dignidad«, um damit die Notwendigkeit einer Aufarbeitung zu betonen. Die Verwendung des Begriffs soll auch aufzeigen, dass zwischen der alten Colonia Dignidad - vor der Festnahme Paul Schäfers im Jahr 2005 - und der neuen Colonia Dignidad Kontinuitäten bestehen, die einer Aufarbeitung im Wege stehen. Auch in der Presseberichterstattung steht »Villa Baviera « meist für eine affirmative oder empathische Perspektive, während »Colonia Dignidad« eher die Verbrechensgeschichte des Ortes betont.

»Colonia Dignidad« (Kolonie Würde) ist kein formal existierender Name eines Ortes oder einer Institution. Der Begriff fand im Zuge der Berichterstattung über die dritte und erfolgreiche Flucht Wolfgang Müller Lilischkies aus der Siedlung 1966 erstmals Verwendung. ${ }^{1}$ Bis dahin wurde die Gruppe von bundesdeutschen Behörden als 
»Private Sozialmission-Parral« bezeichnet, danach fand auch die Bezeichnung »Kolonie >Dignidad« « Eingang in den bundesdeutschen Sprachgebrauch. Mitunter ist auch in abgekürzter Form von »La Colonia« die Rede. Die Bewohner_innen werden, auch in dieser Arbeit als »Colonos (Siedler_innen) bezeichnet. ${ }^{2}$ Colonia Dignidad ist eine Zusammensetzung der Wörter Kolonie und Würde. Letzteres geht auf die offizielle Bezeichnung der 1961 in Chile eingetragenen Rechtsperson zurück, die Sociedad Benefactora y Educacional Dignidad (Wohltätigkeits- und Bildungsgesellschaft Würde). Auch früher hat die Gruppierung sich nur selten selbst als Colonia Dignidad bezeichnet. In der Kommunikation mit der Außenwelt verwendeten sie eher den vollen bzw. abgekürzten Namen der Rechtsperson. ${ }^{3}$ Der Verwendung des Namens Colonia Dignidad durch Behörden und Öffentlichkeit widersprach die Gruppierung lange Jahre nicht. Seit Ende der 1980er Jahre wurde er von den Führungsmitgliedern jedoch zunehmend als »Erfindung der Presse ${ }^{4}$ zurückgewiesen - vermutlich als Reaktion auf die jahrzehntelangen Skandale. Etwa zeitgleich ${ }^{5}$ entstand die Bezeichnung Villa Baviera. Familiäre Verbindungen nach Bayern oder eine bayrische Herkunft wiesen die Colonos nicht auf. ${ }^{6}$ Der Bezug zu Bayern könnte mit der Ähnlichkeit der Landschaft zu tun haben, sollte aber mit Sicherheit eine politische Sympathie für die Bayrische Staatsregierung unter Franz-Josef Strauß ausdrücken. ${ }^{7}$ Der Name sollte die Lobbyarbeit der Colonia Dignidad in Kreisen

2 Die Bewohner_innen selbst bezeichnen sich gelegentlich auch eingedeutscht als Kolonisten.

3 Als Abkürzungen fanden »Sociedad Dignidad « oder einfach »Dignidad « Verwendung. Intern sprachen die Bewohner_innen von der »Cemeinschaft«, den physischen Ort nennen sie meist »Fundo« (Landgut).

4 PA-DBT, Anlage zum Sitzungsprotokoll Nr. 10 des Unterausschusses für Menschenrechte und Humanitäre Hilfe vom 22.02.1988, Bericht Dr. Hopp zu Colonia Dignidad, Chile. S. 1.

5 Ein Bericht über die Geschichte der Colonia Dignidad nennt den 01.10.1986 als das Datum an dem »die 17 Grundstücke der Colonia Dignidad in Villa Baviera umbenannt werden.«CA Santiago, AZ 2182-98 (»Asociación Ilícita«), Bd. III (Ministro), Bl. 1325f. An anderer Stelle wird 1985 als das Jahr genannt, in dem sich CD in Villa Baviera umbenannte, vgl. Heller, Colonia Dignidad: von der Psychosekte zum Folterlager, S. 211.

6 Künz hat die Herkunftsorte der Colonos untersucht: Keine der vor 1945 geborenen Personen stammte aus Bayern. Vgl. Künz, Bärbel. Die Colonia Dignidad zwischen kollektiver Freistatt und instrumentalisiertem Zwangskollektiv. [unveröffentlichte Diplomarbeit], Köln 2010, S. 2off. Laut Cemballa wurde lediglich Hermann Schmidt in Bayern geboren. Cemballa, Cero. Colonia Dignidad. Ein deutsches Lager in Chile, Reinbek 1988, S. 114.

7 SBED-Präsident Hermann Schmidt sagte in einem Interview, nach Franz-Josef Strauß gefragt: »Yo soy bávaro, pero todos le tenemos un especial aprecio porque es un hombre de verdad y de valor. Es como Pinochet. «El Mercurio vom 06.12.1987, S. D 4-5. Manuel Contreras Valdebenito, Sohn des Direktors der DINA Manuel Contreras Sepúlveda, sagte, dass sein Vater Paul Schäfer die Umbenennung der Colonia in »Villa Baviera« vorgeschlagen habe, anlässlich eines geplanten Besuchs von Franz-Josef Strauß, vgl. Revista Cosas vom 01.04.2005, S. 84ff. »Manuel Contreras Valdebenito: Mis días en Colonia Dignidad«. Cemballa berichtet, dass er an der Toreinfahrt zur CD am 28.08.1987 »ein Grenzschild >Freistaat Bayern<, [...] ergänzt um die Aufschrift >Villa Baviera« antraf. Cemballa, Gero. Colonia Dignidad. Ein deutsches Lager in Chile, Reinbek 1988, S. 18. Im Gästehaus der CD hing ein offizielles von der Bayrischen Staatskanzlei angefertigtes bayrisches Wappen. Ebd. S. 158. Die Besucher des CD-Restaurants »Casino-Familiar « in Bulnes wurden von einem handsignierten Portrait des bayrischen Ministerpräsidenten empfangen. Cemballa, Cero. Colonia Dignidad: ein Reporter auf den Spuren eines deutschen Skandals, Frankfurt a.M. 1998, S. 163. 
der CSU begünstigen. ${ }^{8}$ Auf jeden Fall dient der Name Villa Baviera bis heute dazu, ein Distanz zu jenen Zeiten auszudrücken, die mit den Verbrechen der Gruppe assoziiert werden. ${ }^{9}$

\subsection{Die pseudoreligiöse kriminelle Gemeinschaft - Genese und Struktur}

Als Personengruppe kann die Colonia Dignidad einerseits als pseudoreligiöse kriminelle Gemeinschaft betrachtet werden und andererseits als kriminelle Vereinigung. Als kriminelle Gemeinschaft umfasst die Colonia Dignidad alle Gruppenmitglieder, während die kriminelle Vereinigung nur diejenigen Colonos umfasst, die direkt an der Begehung von Verbrechen beteiligt waren.

\section{Tabelle 3: Die Verbrechen der Colonia Dignidad}

\begin{tabular}{|l|l|}
\hline $\begin{array}{l}\text { Die pseudoreligiöse kriminelle Gemein- } \\
\text { schaft CD interne Verbrechen }\end{array}$ & $\begin{array}{l}\text { Die internationale kriminelle Vereinigung CD exter- } \\
\text { ne Verbrechen }\end{array}$ \\
\hline Sexueller Missbrauch & Sexueller Missbrauch \\
\hline Kindesentführung und Adoptionsbetrug & Waffenherstellung und -handel \\
\hline Freiheitsberaubung & Wirtschaftsverbrechen \\
\hline $\begin{array}{l}\text { Körperverletzung (durch körperliche Stra- } \\
\text { fen, Medikamentenverabreichung, Elektro- } \\
\text { schocks) }\end{array}$ & $\begin{array}{l}\text { Menschenrechtsverbrechen als Teil des Repressions- } \\
\text { apparates der chilenischen Diktatur }\end{array}$ \\
\hline Postzensur und-überwachung & $\begin{array}{l}\text { Missachtung des Rechtes auf Bildung/Schul- } \\
\text { plicht }\end{array}$ \\
\hline Sklavenähnliche Arbeitsverhältnisse & \\
\hline
\end{tabular}

Nach Maier/Stehle, Colonia Dignidad, S. 30.

Eine offizielle Auflistung aller Gruppenmitglieder der CD in den Jahren von der Ankunft in Chile 1961 bis zur Festnahme Paul Schäfers in Argentinien 2005 existiert nicht. Eine exakte Erfassung der Gruppenmitglieder wird auch durch die Tatsache erschwert, dass die Gruppe über mehrere Standorte in Chile und der Bundesrepublik verfügte und gegenüber Behörden oftmals falsche Angaben machte. Selbst nach dem Ende der Diktatur in Chile weigerte sich die CD, chilenischen Verwaltungsbeamt_innen im Rahmen von Volkszählungen Zugang zur Siedlung zu gewähren. Sie erreichten, dass sie die Zählungen selbstständig durchführen konnten. ${ }^{10}$

8 Heller, Colonia Dignidad, von der Psychosekte, S. 211 schreibt: »Bossles und seiner Parteifreunde wegen nannte sich die Colonia Dignidad 1985 um in >Villa Baviera (dt.: Bayerndorf).«

9 Bauer, Susanne. Psychologische Behandlungsmöglichkeiten für religiös traumatisierte Menschen am Beispiel der Sekte Colonia Dignidad, in: Utsch, Michael (Hg.). Pathologische Religiosität - Genese, Beispiele, Behandlungsansätze, Stuttgart 2012, S. 67-105, hier S. 74.

10 Vgl. El Mercurio vom 23.04.1992, S. C7. »Cuatro colonos empadronaron a alemanes en Villa Baviera«. 
Eine augenscheinlich weitgehend vollständige Liste von 1989, die vermutlich von der Deutschen Botschaft in Santiago erstellt wurde, umfasst 311 Namen. ${ }^{11}$ Lediglich die zu diesem Zeitpunkt in Deutschland lebenden CD-Mitglieder (wie z.B. Rita Seelbach) und die vor der Erstellung der Liste verstorbenen Personen sind hier nicht erfasst. Eine 2003 von der CD angefertigte Statistik ${ }^{12}$ spricht von 292 aus der Bundesrepublik eingewanderten Colonos (darunter 117 Männer und 175 Frauen). Danach sind 78 Colonos in Chile geboren, 13 Chilen_innen adoptiert und weitere sechs ohne Adoption Mitglieder der Gruppe geworden. 74 Colonos sind dem Dokument zufolge zwischen 1961 und 2003 verstorben, 14 lebten außerhalb und 35 hätten die Gruppe verlassen. Zum 21. Juli 2003 zähle Villa Baviera daher 266 Bewohner_innen. 2006 erstellte der Beauftragte der chilenischen Regierung für die CD, Herman Schwember, aus verschiedenen Daten der chilenischen Kriminalpolizei, des Registro Civil und der CD eine weitere Liste. Er sprach von 404 Personen, die bis dahin Teil der Gruppierung gewesen waren. ${ }^{13}$

\subsubsection{Paul Schäfer und die Entstehung der Gruppierung in den 1950er Jahren}

Die Geschichte der CD ist eng mit der Person Paul Schäfer verknüpft. ${ }^{14}$ Auch wenn viele wichtige Entscheidungen von einer Gruppe von Führungspersonen mitgetragen wurden, war es doch Schäfer, der die Regeln, Leitlinien und Richtungsentscheidungen der $C D$ prägte und in allen wichtigen Fragen konsultiert wurde. Bis zu seiner Festnahme im Jahr 2005 gab es in der CD keinerlei Planungen für eine Zeit nach Schäfer. In gewisser Weise begann und endete die Colonia Dignidad also mit Paul Schäfer. Keine Analyse der Colonia Dignidad kommt daher daran vorbei, sich mit seiner Person zu befassen.

Paul Schäfer wurde am 4. Dezember 1921 in Bonn geboren. Er war der dritte Sohn von Anna Schmitz aus Troisdorf. ${ }^{15}$ Der Vater, Jakob Schäfer, verschwand nach der Schei-

11 FUNVISOL, Bestand CD. Verzeichnis der in der Sociedad »Dignidad« lebenden Personen, Februar 1989.

12 PJS, Sammlung Seewald. »Statistik Habitantes«.

13 PJS, Sammlung CD. Herman Schwember. Programa Integral de Transición Comunidad de Villa Baviera (ex Colonia Dignidad). Delegado de Gobierno, März 2006, S. 21.

14 Biedermann (2006: 113) schreibt: »Die ১Colonia Dignidad ‘ war eines der verschiedenen düsteren Kapitel der jüngsten chilenischen Geschichte. Fast vier Jahrzehnte lang hatte sich auf chilenischem Boden ein Staat im Staate etablieren können. Eine ganze Generation von Kindern wuchs hier in einem fortschreitend repressiver werdenden System heran, das wohl in erster Linie darauf ausgerichtet war, dem Sektenführer Paul Schäfer uneingeschränkte Herrschaft sowie das Ausleben seiner pädophilen Neigungen zu ermöglichen.«

15 Troisdorf ist die größte Stadt des Rhein-Sieg-Kreises in Nordrhein-Westfalen. Die Daten stammen von der Meldekarte Paul Schäfers beim Einwohnermeldeamt Siegburg, vgl. Künz, Bärbel. Die CoIonia Dignidad zwischen kollektiver Freistatt und instrumentalisiertem Zwangskollektiv. [unveröffentlichte Diplomarbeit], Köln 2010. [Darin enthalten: Dokumentenanhang, Nr. 1: Meldekarte Paul Schäfer] Eine Veröffentlichung der Evangelischen Kirchengemeinde Troisdorf, in der Schäfer 1936 konfirmiert wurde, berichtet, dieser sei im Stadtteil Spich aufgewachsen. Später sei die Mutter in die Frankfurter Straße und dann in die Wilhelmstrasse 5 gezogen. Vgl. Groß, Heike/Ingo Zöllich. »Es gibt kein Zurück« - Paul Schäfer als Jugendgruppenleiter in Troisdorf, in: Evangelische Kirchengemeinde Troisdorf, Kompass Nr. 677, März-Mai 2018, S. 8-11, hier S. 8. 
dung von der Mutter 1932. Paul Schäfer war damals zehn Jahre alt. ${ }^{16}$ Die Mutter heiratete 1933 erneut. Laut Schäfer starb sein Vater im Krieg, ${ }^{17}$ ebenso wie seine beiden älteren Brüder Walter und Hans. ${ }^{18}$

Im Alter von sechs Jahren verletzte sich Paul Schäfer schwer am Auge - unklar ist, ob durch eine Gabel ${ }^{19}$ oder eine Schere ${ }^{20}$ - und trug fortan ein Glasauge. Er musste zwei Jahrgangsstufen wiederholen und verließ 1936, im Alter von 14 Jahren, die Schule nach der sechsten Klasse ohne Abschluss. ${ }^{21}$ Sein ehemaliger Schulfreund Willi Georg berichtet: »Wir dienten in der ersten Zeit zwei Herren. Wir waren verpflichtet, am Hitlerjugend-Dienst teilzunehmen, hielten aber auf der anderen Seite treu zu unserer Jugendgruppe, die dem evangelischen »Eichenkreuz angeschlossen war. « ${ }^{22}$ Schäfer, so Georg, habe die Hitlerjugend abgelehnt, sei deswegen jedoch nicht verfolgt worden. Auf lokaler Ebene habe er Schutz durch den »Kraftmenschen« Danilo erhalten, der auf Jahrmärkten auftrat: »Danilo hasste die Nationalsozialisten und versprach, daß jeder, der Paul Schäfer anrührte, es mit ihm zu tun bekäme. « ${ }^{23}$ Nach dem Schulabgang begann Schäfer in Troisdorf bei der Dynamit Aktiengesellschaft (DAG - der ehemaligen Alfred Nobel AG) in der Munitionsproduktion zu arbeiten. ${ }^{24}$

Im Alter von 18 Jahren zog Schäfer nach Siegburg. Ab Oktober 1940 wurde er einige Monate zum Reichsarbeitsdienst in Aachen eingeberufen. Aufgrund seiner Augenverletzung wurde er nicht an der Front eingesetzt. ${ }^{25}$ Am 6. Februar 1941 wurde er zum Kriegsdienst eingezogen und in Münster stationiert, vermutlich als Sanitäter. ${ }^{26} \mathrm{Als} \mathrm{Be-}$

Schäfers Meldekarte vermerkt über seinen Vater: »Aufenthalt unbekannt«. Künz, Bärbel. Die Colonia Dignidad zwischen kollektiver Freistatt und instrumentalisiertem Zwangskollektiv. [unveröffentlichte Diplomarbeit], Köln 2010. Darin enthalten: Dokumentenanhang, Nr. 1: Meldekarte Paul Schäfer.

17 CA Santiago, AZ 2182-98 (»Alfonso Chanfreau«), Bd. 9a, BI. 3042. Servicio Médico Legal. Informe Psicológico Paul Schäfer Schneider vom 16.01.2006. Schäfer gab im Rahmen dieser gerichtspsychologischen Begutachtung nach seiner Festnahme an, er habe keinerlei Erinnerungen an den Vater, dieser sei im Krieg gestorben. Heller schreibt, Schäfers Eltern hätten sich getrennt, als dieser zehn Jahre alt war. Vgl. Heller, Friedrich Paul. Lederhosen, Dutt und Giftgas: Die Hintergründe der Colonia Dignidad, 4. erweiterte und aktualisierte Aufl., Stuttgart 2011, S. 13. PJS, Sammlung NIC, Not- und Interessengemeinschaft der Geschädigten der Colonia Dignidad, Materialdienst 1989 [Bericht von Willi Georg], S. 12.

19 Willi Georg, zitiert in La Tercera vom 30.06.1997, S. 6f. »Las andanzas de Paul Schäfer«. Vgl. Kölner Stadtanzeiger. Sonderdruck »Kolonie der Qualen«, August/September 1997, S. 7 sowie PJS, Sammlung NIG, Not- und Interessengemeinschaft der Geschädigten der Colonia Dignidad, Materialdienst 1989 [Bericht von Willi Georg], S. 13 Groß/Zöllich, »Es gibt kein Zurück«, S. 19.

21 Ebd.

22 PJS, Sammlung NIG, Not- und Interessengemeinschaft der Geschädigten der Colonia Dignidad, Materialdienst 1989 [Bericht von Willi Georg], S. 14.

23 Ebd.

24 CA Santiago, AZ 2182-98 (»Alfonso Chanfreau«), Bd. 9a, Bl. 3042. Servicio Médico Legal. Informe Psicológico Paul Schäfer Schneider vom 16.01.2006. burg, die 1940 mit dem Auszug aus der mütterlichen Wohnung im Alter von 18 Jahren angelegt wurde. Künz, Bärbel. Die Colonia Dignidad zwischen kollektiver Freistatt und instrumentalisiertem Zwangskollektiv. [unveröffentlichte Diplomarbeit], Köln 2010. Darin enthalten: Dokumenten- 
ruf ist auf seiner Meldekarte »Krankenwärter« angegeben (ebd.). Als Sanitäter war er u.a. in Frankreich stationiert. ${ }^{27}$ Aufgrund der spärlichen Information über Schäfers Rolle während des Zweiten Weltkrieges wurde später verschiedentlich über seine Beteiligung an nationalsozialistischen Verbrechen spekuliert. Konkret genannt wurden mögliche Einsätze in Zwangsarbeiterlagern der Dynamit Aktiengesellschaft in Troisdorf ${ }^{28}$ sowie in einem Außenlager des KZ Buchenwald der HASAG in Meuselwitz. Beides konnte bislang nicht verifiziert werden. ${ }^{29}$

Wie es scheint, absolvierte Schäfer keinerlei berufliche Ausbildung und hatte auch keinerlei akademischen Grad. ${ }^{30}$ Nach dem Krieg soll Schäfer weitgehend arbeitslos gewesen sein. Er war ohne Wohnsitzeintrag und lebte in der Wohnung seiner Mutter und seines Stiefvaters. ${ }^{31}$ Als Assistent des Jahrmarktkünstlers Danilo zog Schäfer zeitweise von Schaubude zu Schaubude. ${ }^{32}$

anhang, Nr. 1: Meldekarte Paul Schäfer. Die Eintragung der Wohnsitzverlegung am 06.02.1941 nach Münster lautet »[unleserlich] Ers. Abt. 6«, vermutlich handelt es sich bei der unleserlichen Stelle um die Abkürzung »San.«. Fröhling schreibt, Schäfer sei Sanitäter der Luftwaffe gewesen. Vgl. Fröhling, Ulla. Unser geraubtes Leben - Die wahre Ceschichte von Liebe und Hoffnung in einer grausamen Sekte, Köln 2012, S. 41.

27 CA Santiago, AZ 2182-98 (»Alfonso Chanfreau«), Bd. 9a, Bl. 3042. Servicio Médico Legal. Informe Psicológico Paul Schäfer Schneider vom 16.01.2006. Schäfer selbst sagt darin, er sei als Sanitäter in »Deutschland, Russland, Frankreich, Belgien, Mittlerer Orient und Dänemark« gewesen.

28 Schäfer war ab 1936 für die Dynamit Aktiengesellschaft (DAG) in Troisdorf tätig. VgI. PDM. Schreiben Martin Andresen an Dieter Maier vom 12.10.1994. Die DAC (später: Dynamit Nobel AG) beschäftigte mehrere Tausend Zwangsarbeiter, darunter etwa 500 in Troisdorf. Vgl. Guerra, Tonino/Roland Günter. Aufbruch in Troisdorf. Essen, 1992. S. 35.). Ob Schäfer Kontakt zu ihnen hatte, ist ungeklärt.

29 Ein ehemaliger jüdischer Zwangsarbeiter des HASAG-Außenlagers in Meuselwitz teilte Amnesty International (Al) mit, Schäfer als seinen Aufseher erkannt zu haben. Der deutsche AlCeneralsekretär Walter Rövekamp schrieb daraufhin an das Chile-Team der Al-Zentrale in London: »A witness, a very credible old jewish man, told us that he was in the labour camp of Meuselwitz [...] between september or october of 1944 and april 1945. The camp was a part of the HASAG-Werke, an ammunition factory and outpost of either the concentration camp Birkenau or Buchenwald [...] Two SS-officers had the command in the camp of Meuselwitz. They were both very young. [...] The other had only one eye and was called Otschka (eye). Otschka was a very violent man and a choleric. One officers name was SCHÄFER. [...] After he had read the newspaper reports about Paul Schäfer, he was convinced that this man is Otschka.«Archiv AI, Bestand CD. Schreiben Walter Rövekamp an Lia Dover vom 05.07.1988.

30 Dennoch ließ Schäfer sich später in Chile gerne mit fiktiven Titeln wie »Doktor«, »Professor« oder »Ceneral« anreden. Hugo Baar berichtet, er habe auf Anweisung von Hartmut Hopp in den USA einen gefälschten Doktortitel für Schäfer gekauft. Vgl. PA AA, B 83, Bd. 2384. Bericht von Hugo Baar an die deutsche Botschaft vom 02.04.1985, S. 26.

31 Groß/Zöllich, »Es gibt kein Zurück«, S. 8.

32 Danilo war in Kleinkunstkreisen bekannt für seine »Amboß-Brückenkonstruktion« mit dessen Hilfe er einen Amboß auf seinen Bauchmuskeln bewegen konnte. PJK, Ordner Schäfer. Schreiben Helmut Schulte an Helmut Frenz vom 20.09.1980. Fröhling schreibt, dass Schäfer und Danilo gemeinsam Jungen missbrauchten: »An Schäfers Geburtstag werden sie [die Jungen] zusammen mit Schäfer zu Danilo eingeladen, der wohnt auch in Siegburg, hat Katzen und Hunde. Den Jungen führt er allerlei Zirkustricks vor. Und an ihnen vergnügen darf er sich auch.« Fröhling, Unser geraubtes Leben, S. $136 f$. 
1946 übernahm Paul Schäfer auf ehrenamtlicher Basis die Leitung der Gruppe »Leubelfing - einer von vier Jungsgruppen der Evangelischen Jugend Troisdorf. Schäfers im Krieg gefallener Bruder Walter war zuvor einer der wesentlichen Leiter dieser Gruppen gewesen. Paul Schäfer organisierte Treffen im Keller des evangelischen Gemeindehauses, Theaterprojekte sowie Zeltfreizeiten an den Wochenenden. Bei einem CVJMZeltlager in Leuscheid Ende 1946 soll er mit evangelikalen Kreisen in Kontakt gekommen sein. Fortan soll er in seiner Gruppe evangelikales Liedgut (sogenannte Reichslieder) angestimmt haben. ${ }^{33}$ Aus den Gruppenstunden wurden Bibelstunden, dabei lud er auch einzelne Jungen zum »persönlichen Gebet « in die Wohnung seiner Mutter. 1947 soll Schäfers Wohnsitz die Nothelferschule Benroth bei Waldbröl gewesen sein. ${ }^{34}$ Diese befand sich auf dem Waldgut von Friedrich Baron von der Ropp. ${ }^{35} 1949$ verließ Schäfer Troisdorf in Richtung Gartow im Landkreis Lüchow-Dannenberg. Dort arbeitete er in einem Altersheim der Diakonie. Zusätzlich war er als Jugendwart bei der St. GeorgsKirche im Kirchspiel Gartow angestellt. Im Oktober 1950 wurde er von beiden Anstellungen entlassen. wegen "Beeinflussung der Jugendlichen und Sektenverhalten $"{ }^{36}$ Nach seiner Entlassung lebte Schäfer einige Tage im Wald, wo ihm, wie er gegenüber einem Zeitzeugen behauptete, Christus begegnet sei. ${ }^{37}$ In den folgenden zwei Jahren hielt er sich weiter in der Gegend um Gartow auf. Trotz seiner Entlassung leitete er selbstständig weiter seine Jugendgruppen. Im Frühjahr 1951 trat er bei einem Treffen der Pfingstbewegung in Holtdorf als Redner auf. Im Sommer 1952 verließ Schäfer die Gartower Gegend. ${ }^{38}$

Es folgte eine Reihe von Anstellungen als Jugendleiter bei verschiedenen evangelischen Kirchengemeinden, die jeweils mit Entlassungen endeten, ${ }^{39}$ nachdem Kritik an seinen Erziehungsmethoden laut geworden war. Vermutlich gab es wiederholt auch Hinweise auf sexuellen Missbrauch an ihm anvertrauten Jugendlichen. Von 1952 bis 1953 war Schäfer als Erzieher im Fürsorgeheim »Gotthilf-Vöhringer-Haus« der Diakonie in Heidenheim beschäftigt. Dort wurde er, »nachdem er bei sexuellen Übergriffen auf Jungen erwischt worden war «, ${ }^{40}$ entlassen. Strafanzeige wurde jedoch nicht gestellt. Nach seiner Entlassung am 1. August $1953^{41}$ absolvierte Schäfer eine sechsmonatige Ausbildung als Jugendheimleiter in der Jugendherberge Brilon im Sauerland. Anschließend

Groß/Zöllich, »Es gibt kein Zurück«, S. 9.

Gemballa, Gero. Colonia Dignidad: ein Reporter auf den Spuren eines deutschen Skandals, Frankfurt a.M. 1998, S. 61.

Vgl. ebd. Friedrich Baron von der Ropp (1879-1964) war ein evangelikaler Missionar, der während der Weimarer Republik u.a. eine »Schule für die Seelsorge der Arbeiterschaft« und eine »Christliche Kampfschar « gründete. Vgl.: »Ropp, Friedrich Baron von der« in: Kulturportal West-Ost, online unter http://kulturportal-west-ost.eu/biographien/ropp-friedrich-baron-von-der-2. Paul Schäfers Bruder Walter, soll als »Diakon« einer solchen »Christlichen Kampfschar« angehört haben. Groß/Zöllich, »Es gibt kein Zurück«, S. 11.

Ebd.

Ebd.

Laut Fröhling, Unser geraubtes Leben, S. 25 wurden Schäfers Anstellungsverhältnisse in Bethel, Gartow, Heidenheim, Mönchengladbach durch Entlassung (vorzeitig) beendet.

Ebd.

Vgl. StA Bonn, AZ 50 ]s 285/85, Bd VII, Bl 135.-Vernehmung von Ida Gatz vom 06.07.1988. 
wurde er 1954 stellvertretender Leiter des Paul-Gerhard-Heims, eines Männerwohnheims in Mönchengladbach. Dort war er für den Bereich nicht-sesshafte Jugendliche verantwortlich. ${ }^{42}$

Nach seinen Entlassungen betrieb Schäfer seine Jugendgruppen autonom weiter. Seine Anziehungskraft schien so stark zu sein, dass sich viele Jugendliche über die Verbote ihrer Eltern und die Kritik der Kirchengemeinden hinwegsetzten, um weiterhin Schäfers Gruppen anzugehören. Das Protokoll einer Sitzung des Sport- und Jugendausschusses der Gemeinde Gartow vom Juni 1951 gibt Aufschluss über die Anziehungskraft, die Schäfer auf die Jugendlichen ausübte und über die Hilflosigkeit der Behörden angesichts seiner Methoden. In der Sitzung berichteten mehrere Eltern, wie sie durch Schäfers Einwirken sukzessive ihre Autorität gegenüber ihren Kindern verloren hätten. Ein Vater zweier 13-jähriger Jungen berichtet:

»Sie kommen oft des nachts gegen 3 oder 4 Uhr erst zurück, haben einen ständigen Cewichtsverlust zu verzeichnen und lassen sich weder durch Drohung noch durch Schläge davon abhalten, auch aus der verschlossenen Wohnung heraus durch das Fenster zu den von Schäfer allabendlich, besser allnächtlich, veranstalteten Zusammenkünften zu gehen.

Da Schäfer tagsüber schläft (er kann dies ja, da er nicht arbeitet, Arbeiten auch nie gelernt hat, sondern Arbeitslosenunterstützung bezieht) ist er nachts ausgeruht, die Kinder aber durch die Schule oder Lehre körperlich und geistig ermüdet. Wie es Schäfer nun möglich ist, durch suggestive Cewalt das Interesse der Kinder an seinen sektischen Betstunden, die wahrlich mit Religion nichts mehr zu tun haben, wach zu halten, ist unerklärlich. In wieweit irgendwelche hypnotische Einflüsse auf die Kinder ausgeübt werden, ist vollkommen unbekannt, da die Kinder den Eltern gegenüber verschlossen sind. «3 $^{43}$

Ein weiterer Vater bezeichnet es

»als unerhört von Schäfer, daß er mit den im Alter zwischen 11 und 20 Jahren stehenden Jungens bis nachts früh 3 und $4 \mathrm{Uhr}$ betend und singend durch Wald und Flur zieht. Den Kindern fehlt dadurch der erforderliche Nachtschlaf und ihre Cesundheit wird dadurch untergraben und ihr Nervensystem zerrüttet. Er befürchtet, daß sein Junge, wenn es noch eine Weile so weitergeht, bald im Irrenhaus landet. Aber Schelten und Schläge fruchten nichts; der Junge verharrt unentwegt in seinem Widerstand gegen die väterlichen Anordnungen. ${ }^{44}$

Das Protokoll enthält auch einen Hinweis darauf, dass in Gartow Gerüchte über sexuellen Missbrauch an Jugendlichen durch Schäfer die Runde machten: Einer der Väter, so

42 Vgl. Fröhling, Unser geraubtes Leben, S. 78 sowie PJK, Ordner Schäfer. Ida Catz, o.]., »Stationen im Leben des Paul Schäfer«.

43 Künz, Bärbel. Die Colonia Dignidad zwischen kollektiver Freistatt und instrumentalisiertem Zwangskollektiv. [unveröffentlichte Diplomarbeit], Köln 2010. Darin enthalten: Dokumentenanhang Nr. 2: Landeskirchliches Archiv Hannover, E 50 Nr. 334. Niederschrift über die Sitzung des Sport- und Jugendausschusses der Gemeinde Gartow vom 20.06.1951. 
heißt es, »widersprach dem Verdacht, daß Schäfer sich in sittlicher Beziehung an den Kindern vergehe. ${ }^{45}$

Auf Schäfers Geheiß gingen die Jugendlichen nicht mehr zu den Gottesdiensten der evangelischen Kirche. Er lud auch Prediger von auswärts ein, einer von ihnen habe z.B. auf eine direkte Frage den Jugendlichen geantwortet: »Man muss Gott mehr gehorchen als den Menschen, den Eltern. ${ }^{46}$ Der Laienprediger ${ }^{47}$ Schäfer entwickelte einen von urchristlichen Ideen geprägten Diskurs und suchte in baptistisch-freikirchlichen Gemeinden nach Anhänger_innen. »In seinen Predigten betonte er besonders die Beichte und die entschiedene bedingungslose Nachfolge, d.h. die Übergabe des ganzen Lebens an Gott durch Jesus Christus. ${ }^{48}$ Bei den Menschen, die Schäfer folgten, handelte es sich vorwiegend um Handwerker- und Arbeiterfamilien aus einfachen Verhältnissen. Viele von ihnen kamen aus Gebieten, die vor $1945 \mathrm{zu}$ Deutschland gehört hatten bzw. aus ehemaligen deutschen Siedlungsgebieten in Polen, Russland, Litauen, der Ukraine etc. ${ }^{49}$

Von Jahr zu Jahr weitete Schäfer die Schar seiner Anhänger_innen aus, indem er an verschiedenen Orten »Gemeinschafts- bzw. Bibelstunden« durchführte, bei denen er predigte. ${ }^{50}$ In regelmäßigen Abständen verschickte er Rundbriefe $\mathrm{e}^{51}$ und organisierte alljährlich an verschiedenen Orten Zeltfreizeiten, ${ }^{52}$ die eine wichtige Rolle bei der Konstituierung seiner »Gemeinde« spielten. $\mathrm{Zu}$ diesen Freizeiten lud Schäfer weitere Prediger ein, wie Willi Georg berichtet:

»Unser Kreis war noch klein. Er bestand aus einigen Jungen, die Mitglieder des evangelischen Jugendbundes waren. Unter anderem Cerhard Mücke, eine Familie Marquard und Klunk aus München-Gladbach. Dazu kamen später Herbert und Horst Münch, Alfred Schaak und Frau, Brigitte Baak, die ich aus der Baptistengemeinde Siegburg mitbrachte. Durch eigene Jugendstunden, die in der Gärtnerei Willy Schieferstein began-

45 Ebd.

46 Ebd.

47 Schäfer selbst bezeichnete sich laut Hugo Baar als »Evangelist«. Vgl. PA AA, B 83, Bd. 2384. Bericht von Hugo Baar an die deutsche Botschaft vom 02.04.1985, S. 3.

48 Ebd.

49 Künz untersuchte die Herkunft der vor 1945 geborenen Gruppenmitglieder anhand ihrer Geburtsorte. Sie kommt zu dem Schluss, dass 44 der 65 identifizierten Ceburtsorte in den ehemaligen deutschen Ost- und Siedlungsgebieten liegen. Diese bilden jedoch keinen geographisch zusammenhängenden Raum. Künz, Bärbel. Die Colonia Dignidad zwischen kollektiver Freistatt und instrumentalisiertem Zwangskollektiv. [unveröffentlichte Diplomarbeit], Köln 2010, S. 23.

Willi Ceorg berichtet, er habe 1950 seinen alten Schulfreund Paul Schäfer erstmals nach dem Krieg wiedergetroffen. Etwa zwei Jahre später habe er nach Einladung Gerhard Mückes an einer Bibelstunde in der Wohnung von Paul Schäfers Mutter Anna in Troisdorf in der Wilhelmstraße teilgenommen »und erlebte dort, dass er versuchte junge Menschen zu Christus zu bringen. Von diesem Tage an kamen wir öfters zusammen und hielten Bibelstunden.«PJK, Ordner Schäfer. Bericht Willi Georg vom 21.07.1966, »Abschrift«.

51 PJK, Ordner Schäfer. Zusammenstellung einiger dieser Rundbriefe von Ida Catz.

52 In August 1954 in Groß-Schwülper in der Nähe von Braunschweig, 1955 auf dem Hof der Familie Böckler in Zang (Heidenheim), April 1956 im Haus Heimatruh in Wuppertal, im Sommer 1956 in Groß-Schwülper, 1957 in Hanstett bei Hamburg, 1958 im Bergischen Land. Vgl. PJK, Ordner Schäfer. Ida Gatz, o.]., »Stationen im Leben des Paul Schäfer« sowie Fröhling, »Unser geraubtes Leben«. 
nen und später teils in Brigitte Baaks bzw. meiner eigenen Wohnung fortgesetzt wurden, kam Brigitte Krahm dazu. Es bestanden damals zwei getrennte Kreise, der erste war unser Kreis in Troisdorf und der zweite war der Kreis um Paul Schäfer mit Hilde und Ida Ritz [...] Diese Gruppe zusammen mit Cerhard Mücke, gingen überall dort mit, wo P. Schäfer arbeitete.

Es war uns eine Selbstverständlichkeit, dass Sündenbekenntnis und Wiedergutmachen einer völligen Bekehrung vorausging, bzw. Teil der Bekehrung war. Im Falle Alfred Schaak spürte ich, wie Schäfer geradezu fanatisch darauf ausging als alleiniger Seelsorger zu gelten. Nicht selten hörte man in seinen Reden, wenn er davon sprach, dass wir dem Herr Jesus dienten »der Herr Jesus bin ich.« Ich glaubte damals es müsste so sein [...]. Durch das regelmäßige Sündenbekennen zu ihm allein, blieb es später nicht aus, dass Schäfer um die tiefsten innersten Gedanken eines jeden Einzelnen wusste. Dadurch war er in der Lage, eines jeden Leben zu kontrollieren. [...] In einem unserer Zusammenkünfte besprachen wir das Wachsen und die finanzielle Seite unserer Cemeinschaft. Wir wurden uns klar, dass uns das Zehntengeben zum Segen werden würde. Herr Schaak, der Kaufmann war, übernahm die geschäftlichen Dinge. [...] Ich habe nie erlebt, [...] dass irgendjemand recht gewusst hat, wie es um die finanzielle Lage der Gemeinde gestanden hat. Schaak war im geschäftlichen sowie Schäfer im geistlichen despotisch veranlagt. [...] Seit dieser Zeit lief alles auf gemeinsamer Basis. «" ${ }^{53}$

Neben persönlichen Beichten verlangte Schäfer von den Gruppenmitgliedern auch, ihm ihre Beichten schriftlich zu übergeben. Ergänzt wurde dieser Kontrollmechanismus durch ein ausgeklügeltes technisches Überwachungssystem:

»Für besondere Gespräche war ein Zimmer mit einer Abhöranlage eingerichtet. Die Telefon-Anlage der Post war angezapft und ein Lautsprecher, sowie ein Tonbandgerät waren in einem anderen Zimmer angeschlossen. So z.B. wurde immer bespitzelt und eventuell öffentlich zur Rechenschaft gezogen. $\ll^{54}$

Bei Verstößen gegen Schäfers Vorstellungen von Moral, Gehorsam und Disziplin drohten strenge körperliche Strafen, die in seltenen Fällen von Schäfer selbst ausgeführt wurden:

»Paul Schäfer hat nie selber geschlagen; aber er hat die Stärksten, Kurt Schnellenkamp und Cerhard Mücke dazu bestimmt z.B. Jugendliche zu schlagen, wenn sie frech gewesen waren. Das geschah dann im Keller, und wir mussten oben tüchtig laut singen und Gitarre spielen, damit man das Schreien nicht hörte. [...] Das Prinzip bei Paul Schäfer ist nur gehorchen und nochmals gehorchen um jeden Preis. Die Weiber haben nichts zu melden und haben zu schweigen. ${ }^{55}$

Romantische oder gar sexuelle Begegnungen wurden von Schäfer als »Fleischeslust « und »Teufelszeug« bezeichnet und mit drakonischen Maßnahmen bestraft. Bereits in

53 PJK, Ordner Schäfer. Bericht von Willi Georg vom 21.07.1966, »Abschrift«.

54 PJK, Ordner Schäfer. Bericht von Getrude Krafft vom 16.05.1966. Krafft war von 1956 bis 1960 »Hausmutter, Oberschwester und Büroleiterin der Privaten Sozialen Mission.« Vor der Auswanderung eines Großteils der Gruppe sagte sie sich von der Gruppierung los. 
jenen Jahren wurde Jugendlichen mit Medikamenten und Elektroschocks »der Teufel ausgetrieben«, wie Schäfer es nannte. ${ }^{56}$ Psychopharmaka dienten dazu, die Willenskraft zu brechen. Hinzu kamen rituelle Prügelorgien, bei denen mehrere Personen auf die zu bestrafende Person einredeten, bzw. einschrien und dann minutenlang auf sie einprügelten. ${ }^{57}$ Als Bestrafungsmechanismus ordnete Schäfer auch mehrtägiges Fasten an. ${ }^{58}$

Schäfers Beziehung zu Frauen war von Misogynie bestimmt. Er behandelte Frauen herablassend, bezeichnete sie öffentlich als "Sauweiber « und hielt sie aus allen wichtigen Vertrauens- und Entscheidungsstrukturen heraus - es sei denn, es war ihm von Nutzen. ${ }^{59}$ Liebesbeziehungen Schäfers mit Frauen sind nicht bekannt. ${ }^{60}$ Gelegentlich berichtete Schäfer, er sei verheiratet - möglicherweise um mit dieser Fassade scheinbarer heterosexueller Normalität den Vorwürfen des als Homosexualität bezeichneten Missbrauchs von Jungen entgegenzuwirken. ${ }^{61}$ Das engste Vertrauensverhältnis mit einer Frau führte Schäfer in der Colonia Dignidad mit der Krankenschwester Maria Strebe, die Schäfer ebenfalls nach Argentinien begleitete. ${ }^{62}$

56 Vgl. Fröhling, Unser geraubtes Leben, S. 84f.

57 Vgl. ebd., S. 140.

58 Vgl. ebd., S. 84f. Das Fasten bzw. der Essensentzug war darüber hinaus wohl auch ein religiös begründetes Ritual. So schreibt der Colono Johannes Wieske: »Als ich hörte, dass es einige gab, die sehr lange gefastet hatten, begann auch ich, nur mit Wasser zu leben und habe das einundzwanzig Tage und Nächte lang durchgehalten« PJS, Sammlung CD. Unveröffentlichtes Buchmanuskript von Johannes Wieske, o.T., o. O. [Parral], o.]. [2011], S. 56.

59 Frauen besetzten in der CD Schlüsselpositionen, die ein hohes Vertrauen von Schäfer erforderten: im Krankenhaus, in der Buchhaltung, am Eingangstor und an Wachtürmen sowie zeitweise in Niederlassungen der CD in Santiago, Parral und Bulnes. Sie nahmen jedoch nicht an den rein männlich besetzten Führungsgremien, wie z.B. dem »Herrenabend « teil.

60 Ein besonderes Vertrauensverhältnis führte Schäfer mit der Krankenschwester Maria Strebe, die ihn auch in den Untergrund nach Argentinien begleitete, wo sie am 25.10.2002 verstarb. CA Santiago, AZ 2182-98 (»]uan Maino«), Bd. 2a, Bl. 766. Es gibt Spekulationen über eine Liebesbeziehung zwischen den beiden, die jedoch nicht belegt sind.

61 Gegenüber einem chilenischen Gefängnispsychologen erwähnte Schäfer im November 2005 eine Ehe mit »Herta Schmit«, ohne weitere Einzelheiten zu nennen. CA Santiago, AZ 2182-98 (»Alfonso Chanfreau«), Bd. 9a, Bl. 3043. Servicio Médico Legal. Informe Psicológico Paul Schäfer Schneider vom 16.01.2006. Helmut Schulte schildert, dass Schäfer Mitte der 1950er Jahre mit einer »Cemeinde« aus Lüchow-Dannenberg nach Siegburg zurückkehrte. »Eine entscheidende Person dabei war eine Frau Schmidt, genannt »Schmidtchen«. PJK, Ordner Schäfer. Schulte an Helmut Frenz vom 20.09.1980. Im Rahmen einer Vernehmung durch die Staatsanwaltschaft Bonn äußerte sich der Waffenhändler Cerhard Mertins folgendermaßen: „Die aus dem Raume Siegburg stammenden Behauptungen, daß Schäfer homosexuell veranlagt sei, habe ich erst bei meinem zweiten oder dritten Besuch angeschnitten. Er versicherte mir ehrenwörtlich, daß diese Behauptung als Racheakt von irgendwelchen früheren Interessenten, die mit nach Chile wollten, sei. Er sei völlig normal veranlagt, wäre verheiratet gewesen, hatte ein Kind und hat jetzt eine kleine Chilenin adoptiert." StA Bonn, 50 ]s 285/85, Bd. 11, Bl. 72, Zeugenvernehmung Gerhard Mertins vom 01.03.1989. Willi Georg berichtet, Paul Schäfer habe Ende der 1950er Jahre der Krefelder Krankenschwester Helene Hormes die Heirat versprochen. Auch sei er mit Brigitte Baak, der späteren Ehefrau von Gerhard Mücke, verlobt gewesen. PJK, Ordner Schäfer. Bericht von F.W. Georg vom 21.07.1966.

62 Vgl. die Aussage von Friedhelm Zeitner, der Schäfer ebenfalls in Argentinien begleitete. Villarubia, Gustavo. »Mi vida bajo el régimen de Paul Schäfer«. La historia de uno de los guardaespaldas del lí- 
Zu einer Zeltfreizeit in Groß-Schwülper im August 1954 lud Schäfer die Familie des Predigers Hugo Baar ein. Dieser stand seitdem mit Schäfer in ständiger Verbindung. ${ }^{63}$ Baar hatte von 1944 bis 1949 das Predigerseminar des Bundes evangelisch-freikirchlicher Gemeinden absolviert und war danach bei verschiedenen Gemeinden als Prediger tätig gewesen. Teile der freikirchlichen Gemeinden in Salzgitter-Bad und Gronau, wo Baar predigte, schlossen sich der Schäfer'schen Gruppierung an. Bei einer Bibelwoche in der evangelisch-freikirchlichen Gemeinde Eimsbüttel in Hamburg 1957 lernte Baar den Prediger Hermann Schmidt kennen. Schäfer, Baar und Schmidt waren später die Gründungsväter der Colonia Dignidad. ${ }^{64}$ Eine große Zahl der ausgewanderten Deutschen in der späteren CD stammte ursprünglich aus den Gemeinden Schmidts und Baars in Hamburg-Eimsbüttel ${ }^{65}$ und Gronau ${ }^{66}$.

Schäfer dominierte die Beziehungen zu Baar und Schmidt vollständig. Fröhling berichtet von einem Besuch Schäfers bei Baar in Salzgitter im Januar 1955. Dabei habe sich Schäfer mehrere Tage lang mit Baar eingeschlossen und über religiöse Fragen diskutiert. Anschließend habe Baar sich Schäfer »untergeordnet«. ${ }^{67}$

Am 19. August 1955 soll es in Karlsruhe zu einer Begegnung gekommen sein, die bis in die heutige Zeit nachwirkt: Auf einer Großveranstaltung des Heilungsevangelisten William Branham, auf der dieser ein blindes Mädchen angeblich durch eine Wunderheilung wieder zum Sehen brachte, begegneten sich Paul Schäfer und Ewald Frank. ${ }^{68}$ Frank, Gründer und Prediger der Freien Volksmission Krefeld, bezieht sich bis heute auf Branhams Lehre. Einige Personen aus dem Umfeld der Colonia Dignidad in Deutsch-

der de Colonia Dignidad [Interview mit Friedhelm Zeitner], in: CIPER (Website), 23.09.2013, online unter https://www.ciperchile.cl/2013/09/23/"mi-vida-bajo-el-regimen-de-paul-schafer". Maria Strebe soll Schäfer bereits zu Beginn der $1950 e r$ Jahre in Gartow kennengelernt haben (vgl. Fröhling, Unser geraubtes Leben, S. 123). Sie war später leitende Krankenschwester des Krankenhauses der Colonia Dignidad und soll laut Zeugenaussagen für Elektroschockfolter verantwortlich sein.

63 Baar selbst gab bei einem Gespräch beim Oberkreisdirektor Siegburg an, seit 1953 »nebenbei ehrenamtlich bei der Privaten Sozialen Mission « mitgewirkt zu haben, bis er 1960 vollständig zur PSM übergetreten sei. PA AA, B85, Bd. 598. Vermerk vom 19.03.1963 über ein Cespräch Hugo Baars beim Oberkreisdirektor Siegburg am 15.03.1963, das stattfand, um »ergänzend zur kriminalpolizeilichen Vernehmung einige Fragen zu klären.«

64 Hermann Schmidt wurde erster Leiter des Jugendheims in Heide (Lohmar). Die drei bereisten 1960 gemeinsam mit dem Auto drei Monate lang mehrere arabische Länder und Israel. Im Januar 1961 schließlich reiste Schäfer mit Schmidt nach Chile während Baar bis 1975 in Siegburg »die Stellung hielt«. Schmidt wurde in Chile der Präsident der Sociedad Benefactora y Educacional Dignidad während Baar den Vorsitz der Privaten Socialen Mission innehatte.

65 Wieske beziffert die Zahl der Personen, die 1958 aus der Gemeinde in Elmsbüttel nach Heide (Lohmar) kamen mit 15. Vgl. PJS, Sammlung CD. Unveröffentlichtes Buchmanuskript von Johannes Wieske, o.T., o. O. [Parral], o.]. [2011], S. 56.

66 PA AA, B 83, Bd. 2384. Bericht von Hugo Baar an die deutsche Botschaft vom 02.04.1985, S. 3.

67 Fröhling, Unser geraubtes Leben, S. 78.

68 Ebd., S. 39. Während Fröhling auf Basis ihrer Cespräche mit Ex-Colonos schreibt, Schäfer und Frank seien sich bei der Veranstaltung in Karlsruhe begegnet, leugnet Frank, dass es zu einer Begegnung gekommen sei. PJS, Sammlung Volksmission/Frank. Pressemitteilung Freie Volksmission e.V. vom 15.12.2011. »Colonia Dignidad: Landgericht verhandelte über Klagen der Freien Volksmission Az. 12 O 478/11 Az. 12 O 473/11«. 
land und Österreich besuchten später Franks Gottesdienste. ${ }^{69} 2004$, wenige Monate vor Schäfer Festnahme in Argentinien, besuchte Frank die Colonia Dignidad. Er predigte in der Siedlung und führte Massentaufen durch. ${ }^{70}$ Nach Schäfers Festnahme verhängte das chilenische Innenministerium eine Einreisesperre gegen Frank, aus Angst, er könne eine Art Nachfolger Schäfers werden. ${ }^{71}$ Gegen das Einreiseverbot wehrte sich Frank vehement. ${ }^{72}$ Andere Prediger der Freien Volksmission besuchten seitdem die CD. 2014 erreichte Frank eine Aufhebung der Einreisesperre. ${ }^{73}$ Viele der nach Deutschland zurückgekehrten oder justizflüchtigen CD-Mitglieder besuchen bis heute Franks Versammlungen. ${ }^{74}$

Willi Georg berichtet, dass die Sommerfreizeit 1955 in Zang

»damit endete, dass eine gemeinsame Arbeit in der Zeltmission mit dem Amerikanischen Evangelisten William Branham uns die Tür öffnete nach Österreich. Bemerkenswert an dieser Freizeit war, dass der Vater von Ingrid Klunk, [...] Herbert Klunk, zweimal durch Handauflegen von zwei Schlaganfällen geheilt wurde. ${ }^{75}$

Ebenfalls 1955 reiste Schäfer ins österreichische Graz, wo er die Familien Wagner und Wöhri »eingemeindete « ${ }^{76} 1956$ festigte sich die Gruppe entscheidend. Am 9. Juni 1956 berief Schäfer in Mönchengladbach eine »Brüderkonferenz« ein, bei der er die Regeln

69 So gab die in Deutschland lebende Mutter von Brigitte Mücke (geb. Baak) 1983 an, die Freie Volksmission zu frequentieren. PJK, Ordner Paul Schäfer. Vermerk Jürgen Karwelat vom 08.03.1983 über Gespräch mit Maria Baak in Troisdorf am 01/02.03.1983. Auch Teile der Familien Wagner und Wöhri, die Ende der 1960er Jahre aus der CD nach Österreich zurückgekehrt waren, sollen Teil der Frank-Gemeinde gewesen sein. Vgl. PJS, Sammlung Volksmission/Frank. Vermerk über Gespräch mit Gudrun Müller (geb. Wagner) vom 17.07.2018.

70 La Segunda vom 22.03.2005, S. 7. »Predicador apocalíptico convence a parte de los colonos de Villa Baviera«.

$71 \mathrm{AGH}$, Bestand RFA, Embajada de Chile en la RF de Alemania 2005. Resolución $N^{\circ} 5020$ del Departamento Extranjería y Migración del Ministerio del Interior vom 17.10.2005.

72 Ebd., Schreiben Ewald Frank an die chilenische Botschaft vom 21.10.2005 [traducción no oficial]. Ewald Franks Sohn Werner suchte am 09.10.2005 die chilenische Botschaft in Berlin auf und sprach gegenüber Botschaftsrat Barriga Drohungen aus. Die chilenische Botschaft berichtete darüber nach Santiago »[Werner Frank] indicó en tono cortés pero amenazador que llegarían hasta las últimas consecuencias si no se levanta la prohibición de ingreso que pesa sobre su padre. [...] Indicó que en el día de ayer su padre [...] había telefoneado al excanciller Federal Helmut Schmidt (197482), para ver >que se podía hacer < [...] Aludió que su padre también conocía al ex Presidente Federal Johannes Rau (1999-2002). Señaló que su padre conocía >muchas historias de Colonia Dignidad y que hasta ahora había callado. Preguntó qué pasaría si esto se da a conocer? Señaló que no deseaba crearle un >bochorno internacional a Chiles, pero que esperaba que se hiciera justicia con su padre«. Ebd. Chilenische Botschaft Berlin an das chilenische Außenministerium, Oficio reservado vom 10.10.2005.

73 CA Santiago, AZ 2209-2014, Beschluss vom 12.12.2014 sowie Bestätigung durch Corte Suprema, AZ 32.430-2014, Beschluss vom 29.12.2014.

74 Darunter sind auch viele ehemalige Führungsmitglieder der CD, wie Hartmut Hopp und Dorothea Witthahn, Albert Schreiber (2008 verstorben), seine Frau Lilli und Sohn Ernst, Erika Heimann sowie Manfred Skrabs. PJK, Ordner Schäfer. Bericht von Willi Georg vom 21.07.1966. »Abschrift«.

76 Vgl. Fröhling, Unser geraubtes Leben, S. 86. In Salzburg verfügt die Freie Volksmission Krefeld bis heute über einen Ableger. Einige CD-Rückkehrer_innen leben in der Gegend. 
und Strukturen der »Gemeinschaft « umriss. Gegenüber den »Herren« und den »ledigen Schwestern « sprach er über biblische Lebensgemeinschaften. "Alle die dazu bereit sind, ihr persönliches Leben aufzugeben und ihre Arbeitskraft und ihr verdientes Geld der Gemeinschaft zu überlassen, sollen >Kreuzler genannt werden und sind die tragende Säule der Gemeinschaft. «"

Die sogenannten Kreuzler arbeiteten unentgeltlich. Die weiteren Anhänger_innen der Gruppe zahlten einen »Zehnten« in die Kasse ein, die Alfred Schaak verwaltete. So stand die Gruppe schnell auf soliden finanziellen Beinen und konnte eine entsprechende Infrastruktur aufbauen. Willi Georg erinnert sich:

»Die erste Anschaffung, mit diesem von uns gegebenen Zehntengeldes war ein Volkswagenbus [...] Beim Kauf zugegen waren Alfred Schaak, Paul Schäfer, Rita Seelbach und ich selbst. [...] Durch diesen Kauf hatten wir die Gelegenheit gemeinsam wegzufahren $[\ldots] . \ll^{78}$

Das Fahrzeug erlaubte es Schäfer, an verschiedenen Orten Deutschlands und Österreichs neue Anhänger_innen zu werben. Das Vorgehen bei der »Eingemeindung« neuer Mitglieder war hart: Wollte beispielsweise ein Ehepartner nicht Teil der Gruppe werden, so wurde mit allen Mitteln eine Scheidung forciert. Dabei wurden vermeintlich religiöse Gründe angeführt und auch vor kriminellen Methoden - wie sie später in Chile weiterentwickelt wurden - schreckte die Gemeinde nicht zurück:

Bereits Anfang 1956 hatte Schäfer zwölf seiner »Getreuen« zu sich gerufen und ihnen von seinem Plan berichtet, eine »bleibende Stätte« für die Gruppe zu schaffen:

»Er schlug vor, das Einkommen eines ganzen Jahres einzubringen, um das Geld für den Kauf eines Hauses zu ermöglichen, und sagte zu gleicher Zeit, sollte man aus der Cruppe ausscheiden wollen, hätte man keinen Anspruch auf die Rückzahlung der Einlage. Er legte ein vorgefertigtes Schreiben vor, das von allen unterschrieben wurde. ${ }^{79}$

Diese Grundidee von der Gruppe als einer Gütergemeinschaft, in die alle Mitglieder ihre Arbeit und ihr Vermögen einbringen und die im Gegenzug für ihre Mitglieder sorgt, übertrug Schäfer später auch auf die CD. ${ }^{80}$ Einige Mitglieder überwiesen ihren gesamten Lohn auf ein Konto, für das Schaak verfügungsberechtigt war. ${ }^{81}$

Zit. n. ebd., S. 87. Das Kreuzler-Dasein wurde vertraglich festgehalten (v. Willi Georg, Alfred Schaak, Herbert und Horst Münch, Gerhard Mücke, und den Schwestern Brigitte Baak, Brigitte Kram, Helga Habeck, Ida und Gertrud Ritz).

79 StA Bonn, 50 ]s 285/85, Bd. VII, BI. 136. StA-Vernehmung von Ida Gatz vom 06.07.1988.

80 Schäfer betonte dies immer wieder. 1998 als er die CD bereits verlassen hatte, schrieb er den Colonos einen Brief, in dem es hieß: »Es muß eine menschliche und juristische Alternative, Möglichkeit beschlossen werden, welche einen Weggang ohne Forderung und Erpressung von seiten der Vergeßlichen erlaubt, denn ein juristisches Recht auf Auszahlung oder Entschädigung besteht nicht für die Einzelnen, die ihr Kreuz auf sich genommen hatten. [.] Zu der juristischen Betrachtung muß noch gesagt werden, daß es hunderte von Zeugen gibt, die vor Gott und Menschen und Behörden dies freiwillige Verhältnis bestätigen. Und das ist die Grundlage gegen die wenigen Abtrünnigen und Untreuen und Unreifen. «PJS, Sammlung CD. Brief Schäfers an die Colonos vom Oktober 1998. 
Im August 1956 zogen erste »Geschwister« der Gruppe nach Heide (Lohmar) im nordrhein-westfälischen Rhein-Sieg-Kreis. Hier erwarb die Gruppierung ein Grundstück, entsumpfte das Gelände, riss eine alte Holzbaracke ab und begann mit dem Bau eines Jugendheims, das 1959 fertiggestellt wurde. Tagsüber arbeiteten die Kreuzler unentgeltlich in den Läden der von Alfred Schaak und Heinz Kuhn gegründeten Schaak und Kuhn oHG und anderen Unternehmen von Gruppenmitgliedern. Vorwiegend in ihrer Freizeit errichten sie das neue Gebäude. ${ }^{82}$ Ein Kreis von inzwischen schon etwa 200 Personen spendete für das Bauvorhaben. ${ }^{83}$ Unter anderem als offizieller Träger des Bauvorhabens wurde am 31. Dezember $1956^{84}$ der Verein Private Sociale Mission (PSM) gegründet. Dieser bestand bis in die 1990er Jahre und fungierte als Rechtsperson des deutschen Ablegers der Colonia Dignidad. Vereinszweck der PSM war laut Satzung:

»a.) Minderbemittelten und Erholungsbedürftigen äußere und innere Hilfe zu leisten;

b.) Aufnahme von gefährdeten und bedürftigen Jugendlichen ins Missionshaus;

c.) Jugendlichen und Erwachsenen Ferien- und Freizeitaufenthalt zu vermitteln.

Die Arbeit ist international, überkonfessionell und politisch unabhängig. [...] Weil das Anliegen eine soziale Missionsarbeit ist, gehören zu ihm Freunde aus allen Kreisen, die in ihrer Kirche oder Cemeinschaft Mitglied bleiben. Der Verein will keine neue Glaubensgemeinschaft bilden. ${ }^{85}$

Der Verweis auf den internationalen Charakter der Arbeit war möglicherweise bereits ein Hinweis auf die von Schäfer beabsichtige Auswanderung.

Schäfers Auftreten war herrisch, selbstgerecht und egozentrisch, sein Umgangston rau und vulgär. ${ }^{86}$ Obwohl dies im Widerspruch zum strengen, prüden und keuschen Diskurs freikirchlicher Kreise steht, vermochte es Schäfer, seine Getreuen von seiner vermeintlichen Gottesnähe zu überzeugen, die ihm als einzigem Gruppenmitglied eine Aura der Unfehlbarkeit verlieh. Der Architekt Johannes Wieske berichtet:

82 Amnesty International, Colonia Dignidad: deutsches Mustergut, S. 34.

83 StA Bonn, 50 ]s 285/85, Bd. VII, BI. 136. StA-Vernehmung von Ida Catz vom 06.07.1988.

84 Dieses Datum nennt Fröhling, »Unser geraubtes Leben«, S. 92. Auch Hugo Baar nennt 1956 als Gründungsjahr der PSM. PA AA, B 83, Bd. 2384. Bericht von Hugo Baar an die deutsche Botschaft vom 02.04.1985, S. 3. Die früheste bekannte Satzung datiert auf den 02.01.1958. Vgl. AGH, Bestand RFA, Oficios ordinarios y confidenciales 1968, Abschrift Satzung PSM, Heide, vom 02.01.1958. Der Verein wurde erst am 6. August 1968 ins Vereinsregister Siegburg eingetragen (VR 637, Amtsgericht Siegburg), als gemeinnützig anerkannt und rückwirkend bis 1965 von der Körperschaftssteuer befreit. PDM, Bestand PSM, Finanzamt Siegburg, Körperschaftssteuer-Freistellungsbescheid für 1965 für die PSM vom 27.03.1968. Der erste Vorstand bestand aus: Hugo Baar (Vorsitzender), Wilhelm Zeitner (stv. Vorsitzender), Gerhard Schmidtke (Geschäftsführer), Alfred Schaak (Schatzmeister) und Erika Heimann (Schriftführerin).

$85 \mathrm{ACH}$, Bestand RFA, Oficios ordinarios y confidenciales 1968, Abschrift Satzung PSM, Heide, vom 02.01.1958.

86 PJS, Sammlung CD. Unveröffentlichtes Buchmanuskript von Johannes Wieske, o.T., o. O. [Parral], o.]. [2011], S. 56. 
»Paul Schäfer hat immer darauf losgeredet, gehandelt, gepredigt. Er fühlte sich offenbar so auserwählt und begnadet, dass er nie Fehler machte, weil Cottes Ceist ihn erfüllte und leitete und deshalb, wieder rückschlüssig, er keine Fehler machen konnte. ${ }^{87}$

Vielen Colonos gab Paul Schäfer komische oder herablassende Spitznamen wie Pfuscher, Klops, Hering oder Dickback. Sich selber ließ er hingegen mit Werkstattmeister, General, Doktor oder Pius ansprechen, sein bekanntester Spitzname lautete tío (permanente), auf Deutsch: (ewiger) Onkel. ${ }^{88}$

Schäfer inszenierte sogenannte »Scherbengerichte« die dazu dienen sollten, Fehler $\mathrm{zu}$ erkennen und in Zukunft zu unterlassen. Laut Wieske »[e]ine gute Einrichtung, die aber in der Hauptsache dazu bestimmt war, den Hauptakteur als fehlerlos zu glorifizieren und Nebensächliches als Hauptursachen für Fehler hervorzuheben. ${ }^{89}$

1957 führte Baar eine Missionswoche in zwei evangelisch-freikirchlichen Baptistengemeinden in Hamburg durch. Dabei überzeugte er einen Teil der Gemeindemitglieder davon, ihr Leben von Grund auf zu ändern und zur Verwirklichung ihres christlichen Glaubens Mitglieder der Gruppe in Heide (Lohmar) zu werden. Die beiden Gemeinden spalteten sich daraufhin. Etwa 30 Personen, darunter der Prediger aus der Eimsbütteler Gemeinde, Hermann Schmidt, schlossen sich der Schäfer-Gruppe an. ${ }^{90}$

Am 29. Juli 1957 wurden dem Kreisjugendamt 17 Minderjährige als Bewohner des Hauses in Heide (Lohmar) gemeldet. ${ }^{91}$ Es waren allesamt Kinder von Gruppenmitgliedern, die allerdings nicht in dem Haus lebten. Nach dem Gesetz waren sie Pflegekinder, die unter Aufsicht des Jugendamtes standen. Am 20. Dezember 1957 besuchte erstmals eine Kreisfürsorgerin das Heim, das einen guten Eindruck auf sie machte. ${ }^{92}$ Sie berichtete: »In der Hausgemeinschaft mit Prediger Baar und Evangelist Schäfer würden Kinder mit Gästen und Vereinsmitgliedern, die am Gemeinschaftshaus bauten, zusammen leben. ${ }^{93}$ Auch im Folgejahr war der Bericht des Jugendamtes positiv und vermerkte: »[D]ie Kinder fühlten sich wie zu Hause «. ${ }^{94}$

Bereits in diesen Jahren konzipierte Schäfer ein System, das seine Herrschaft über die Gruppe perfektionieren und ihm den Zugang zu Opfern für seine Sexualverbrechen sichern sollte: Durch seinen pseudoreligiösen Diskurs legitimierte er das Aufbrechen von Familienstrukturen sowie von jeglichen auf familiärer oder freundschaftlicher Bande basierenden Vertrauensstrukturen. Johannes Bechtloff, ein Mitglied der Gruppe, das noch vor der Ausreise nach Chile den Absprung schaffte, berichtet:

87 Ebd., S. 54.

88 Ebd., S. 87.

89 Ebd., S. 54f.

$90 \mathrm{Vgl}$. Amnesty, Colonia Dignidad, S. 34. Wieske spricht hingegen von dem »Abschied von uns etwa fünfzehn scheinbaren Ketzern aus der Baptistengemeinde«. P]S, Sammlung CD. Unveröffentlichtes Buchmanuskript von Johannes Wieske, o.T., o. O. [Parral], 0.]. [2011], S. 56.

91 Vgl. Kölner Stadtanzeiger, »Kolonie der Qualen«, S. 12. Unter den 17 Kindern seien auch Wolfgang Kneese, Helmut Baar und Hartmut Hopp gewesen. Die Liste sei Teil einer Akte über die Private Sociale Mission, die vom Leiter des Kreisjugendamtes Siegburg im Archiv der Stadtverwaltung gefunden worden sei.

92 Ebd.

93 Ebd.

94 Ebd. 
»Auf diese Weise kam ich ganz nach Heide, wo ich getrennt von meiner Familie lebte. Die Familie wurde auseinander gerissen. Unsere Kinder wohnten bei fremden Menschen in Gronau und meine Frau und ich in Heide, aber getrennt. Das war die Lebensweise für alle, die in Heide wohnten.

Diese Lebensweise ist nur zu begreifen, wenn man weiß, daß der Hintergrund ein irreligiöser ist. Der eigentliche Cründer und Leiter dieser Bewegung ist Paul Schäfer, ein Junggeselle. Er galt und gilt als der Geistliche, bei dem wir fast alle in der Seelsorge waren. Damit waren wir diesem Mann praktisch ausgeliefert. Durch das Aussprechen all der Gedanken, die gegen die Sache waren, wurde die Abhängigkeit noch größer. Mit der Zeit wuchs diese religiöse Meinung im eigenen Herzen und man glaubte, dieser Weg sei der einzig richtige, um ewiges Leben zu bekommen. Mit dieser Cewissheit im Herzen wuchs auch die Angst vor dem Verlorengehen, wenn man diese Gruppe verlassen würde. Die Gefangenschaft des Geistes und der Seele führten zur Gefangenschaft des Leibes. Wollte einer von uns seine Kinder oder die Kinder die Eltern besuchen, dann konnte man dies nicht ohne weiteres: Es bedurfte der Zustimmung eines Paul Schäfers. Und bei ihm war dieses Anliegen nicht selten als fleischlich abgetan worden. Dem Anliegen zweier Eheleute wurde in keiner Weise Rechnung getragen. Z. B. ist meine Frau seelisch fast kaputt gegangen unter dieser Trennung, aber sie fand kein Verständnis. Ich war mehrere Monate in Graz, von der Leitung des »Missionshauses« ausgesandt. In der Zeit ging es meiner Frau körperlich und seelisch sehr schlecht. Sie wollte die Cruppe verlassen. Man glaubte mich sicher und so verlangte man von ihr schriftlich, sie sollte unterschreiben, daß sie nichts mehr mit Cott und den Menschen dieser Gruppe zu tun haben wolle. Damit hätte sie ja unterschrieben, daß sie auch mit mir nichts mehr zu tun haben will. Dieses Beispiel soll zeigen, mit welchen Mitteln die Menschen dort festgehalten werden. Und diese Machtmittel können gar nicht in die Öffentlichkeit kommen, weil die Bindung durch die Seelsorge zu fest ist. Selbst wenn ein Jugendl[icher] einmal weggelaufen ist, das taten einige, dann wurden sie wieder eingefangen. ${ }^{95}$

Ein weiterer Bericht zeigt, wie Schäfer selbst führende Mitglieder der Gruppe von Beginn an dominierte:

»In diese Zeit fiel der Anschluss des Hamburger Personenkreises - größtenteils aus der Baptistengemeinde kommend - mit ihren Predigern Johannes Bechtloff und Hermann Schmidt. Die Ankunft Hermann Schmidts ging folgendermaßen vonstatten. Noch nicht ganz angekommen, forderte Paul Schäfer Schmidt in meiner Gegenwart auf, seiner Frau Ursula Schmidt mitzuteilen, dass sie ihren Sohn von nun ab der Heimerziehung überlassen müsse. Das heißt, sie müsste ihr Erziehungsrecht abgeben. Nach einigen hin und her geführten Cesprächen, gab Frau Schmidt diesem Ansinnen nach, da Schäfer Hermann Schmidt den Auftrag gab, seiner Frau die Scheidung anzudrohen, falls sie nicht willig sei. Frau Schmidt gestand mir noch Monate später, dass sie gerne wieder einmal ihren Sohn für sich gehabt hätte und ihn geherzt und geküsst hätte, aber aus Angst vor den leitenden Brüdern hätte sie es nicht gewagt. Es war wie bei 
so vielen, sie sehnten sich nach etwas Herzlichkeit und einem Familienleben. Durch das Wesen und seiner Despotie wurde etwas Kaltes, Unpersönliches, ja sogar innere Regungen und normales menschliches Fühlen und Denken zerstört. «"96

Aus heutiger Sicht erscheint die im Zitat erwähnte Übertragung des Sorgerechts für die Kinder der Gruppe als geplanter Akt innerhalb eines Systems, das zum Ziel hatte, die Verfügbarkeit von Jungen für die permanente Begehung seiner Sexualverbrechen zu gewährleisten. Die Kinder wurden systematisch von ihren Eltern entfremdet und waren Schäfer somit schutzlos ausgeliefert. Durch die Übertragung des Sorgerechts auf andere Gruppenmitglieder wurden Familienstrukturen zerschlagen. Damit verfolgte Schäfer das Ziel, selbst die Kontrolle über jedes Individuum der Gruppe ausüben zu können. ${ }^{97}$ Der religiöse Aspekt entpuppte sich dabei immer mehr als Deckmantel, wie aus einem Bericht von Willi Georg hervorgeht:

»Unsere Gottesdienste und Gebetsstunden wurden seltener - die neue Parole hieß>Arbeit ist Cottesdienst. < Unser Vorsatz nach dem Urchristentum machte langsam einem sozialen Gedanken Platz. [...] Die Handlungen in Heide und heute in Dignidad entsprachen nicht mehr dem geistlich biblischen wie am Anfang, sondern dem rein menschlichen. Dieser Wandel ließ auch Gerichtsprozesse zu, die nicht in der Einzahl geführt wurden. "98 $^{98}$

Menschen, die sich gegen Schäfer und die Gruppe stellten, wurden mit Verleumdungsklagen bedrängt. Dieses Vorgehen wurde im Laufe des Bestehens der Colonia Dignidad perfektioniert und massenhaft angewandt. Gegner_innen der Gruppe wurden dadurch ausgeschaltet und ihre Unterstützer_innen gleichzeitig von der angeblichen und gerichtlich bestätigten Tadellosigkeit der Gruppe überzeugt. Die Planung dieser juristischen »Angriffs- und Verteidigungsstrategie« der Gruppe oblag in der CD weitgehend Hans-Jürgen Blanck. Dieser hatte Jura studiert, ohne das Studium allerdings abzuschließen.

Auch ein anderes Ritual der CD stammt bereits aus der Gründungszeit der Gruppe: die öffentlichkeitswirksame Inszenierung von Festlichkeiten. Mit dem Ziel Unterstützer_innen zu gewinnen, wurden Gäste hofiert und ihnen das soziale Engagement der Gruppe präsentiert. Am 23. September 1960 wurde das Jugendheim in Heide (Lohmar)

96 PJK, Ordner Schäfer. Bericht von Willi Georg vom 21.07.1966, »Abschrift«.

97 Susanne Bauer schreibt dazu: » Für die Mitglieder wurde das Selbstbild der >Auserlesenen ‘ geschaffen. Man geht davon aus, dass es Schäfer bereits zu diesem Zeitpunkt gelungen war, seine erwachsenen Anhänger durch systematische Manipulation, d.h. lobende und strafende Maßnahmen zur Kontrolle von Gedanken, Verhalten und Emotionen, in eine sZwangsabhängigkeit'[...]versetzt zu haben [...]. Jugendliche wurden dazu überredet, sich von ihren Eltern, deren Besuche immer mehr reduziert wurden, zu trennen. Man verschickte gefälschte `Es-geht-mir-gut Briefes, in denen die Minderjährigen erklärten, dass sie ihren Weg zu Cott gefunden hatten, dankbar seien und ihre Eltern fortan nicht mehr brauchten. «Bauer, Susanne. Psychologische Behandlungsmöglichkeiten für religiös traumatisierte Menschen am Beispiel der Sekte Colonia Dignidad, in: Utsch, Michael (Hg.). Pathologische Religiosität - Cenese, Beispiele, Behandlungsansätze, Stuttgart 2012, S. 67105, hier S. 75. 
mit einer Feier offiziell eingeweiht. Neben lokalen Persönlichkeiten war auch Bundespräsident Heinrich Lübke eingeladen, der sich jedoch entschuldigen ließ (möglicherweise machten bereits Informationen über den Sektencharakter der Gruppe die Runde). Als Vertreterin der Bundesregierung nahm Frau Dr. Friesecke vom Bundesministerium für Familien- und Jugendfragen an der Feier teil. ${ }^{99}$

Im Sommer $1960^{100}$ reisten Baar, Schmidt und Schäfer mehrere Monate lang nach Spanien, Marokko, Algerien, Libyen, Ägypten, Jordanien, Israel und in die Türkei. ${ }^{101}$ Laut Baar diente die Reise dazu, »die sozialen Verhältnisse und die Waisenkinderarbeit kennenzulernen. ${ }^{102}$ Vermutlich sollte auf der Reise eine Auswanderung sondiert werden. Aufgrund der zunehmenden Bekanntheit von Schäfers Missbrauchstaten war eine Strafverfolgung immer wahrscheinlicher geworden. Gegenüber seinen Anhängern redete Schäfer nun offen über seine Ausreisepläne und begründete diese mit der Angst vor einem Überfall der Sowjets: »Schaefer preached one day that he had had a dream: In his dream, the Russian troops had poured over the border into West Germany. He said that to save us we had to get out of Germany. «103

Gemeinsam mit Hermann Schmidt reiste Schäfer am 3. Januar 1961 nach Chile, wo er am Folgetag ankam. ${ }^{104}$ Am 27. Januar zeigte Hermann Altevogt Paul Schäfer wegen sexuellen Missbrauchs an. ${ }^{105}$ Daraufhin erließ das Amtsgericht Siegburg am 21. Februar

99 Ossendorf, Karlheinz. Colonia Dignidad - Die »Würde« gab es nur im Namen. Die Sekte Private Sociale Mission im Raum Siegburg, in: Ceschichts- und Altertumsverein für Siegburg und den Rhein-Sieg-Kreis e. V. (Hg.). Heimatblätter des Rhein-Sieg-Kreises 2009, 77. Jahrgang, Siegburg 2009, S. 240-269, hier S. 243.

100 Laut Jamil Siam, Sohn von Hussein Siam, waren Schäfer, Baar und Schmidt im Juni 1960 in Jerusalem. Vgl. Fröhling, Ulla. »Hussain Siam«, in: Unser geraubtes Leben [Website zum Buch], zuletzt geändert 08.11.2016, online unter https://www.unser-geraubtes-leben.de/die-betroffenen/hussain-siam/index.php. Aus Israel brachten Schäfer, Schmidt und Baar den 15-jährigen Hussein Siam in die Bundesrepublik mit. Seinem Vater, einem Postbeamten in Ost-Jerusalem, versprachen sie eine gute Ausbildung für den Sohn. Hussein Siam wurde auch nach Chile mitgenommen und 1970 gemeinsam mit Hartmut Hopp und Cünther Reiss zum Studium in die USA geschickt. Während Hopp in die CD zurückkehrte, nutzten Reiss und Siam den Auslandsaufenthalt zum Ausstieg aus der CD.

101 CA Santiago, AZ 2182-98 (»Asociación Ilícita«), Bd. I, BI. 296. Schriftsatz der CD-Anwälte Cesar Valero, Mario Ruiz und Gonzalo Ruiz vom 20.10.2000.

102 PA AA, B 83, Bd. 2384. Bericht von Hugo Baar an die deutsche Botschaft vom 02.04.1985, S. 4.

103 Dinges, John. Colonia Dignidad in: The Rebel vom 06.02.1984, S. 26-35, hier S. 30.

104 Am 15.08.1977 teilte das BMI dem AA mit: »Am 3. Januar 1961 reisten Sch. und eine weitere Person nach Chile und gründeten dort das Missionslager »La Dignidad«. PA AA, AV NA 31580. Schreiben Der Bundesminister des Inneren an das AA vom 15.08.1977. CZ ÖS 6 - 625312 II Schäfer. Bei der weiteren Person dürfte es sich um Hermann Schmidt gehandelt haben. Auf seinen 1975 und 1980 im deutschen Konsulat in Chile eingereichten Antragsformularen zur Ausstellung/Verlängerung seines Reisepasses hatte Schäfer auf die Frage »Wann haben sie Deutschland verlassen « den 04.01.1961, bzw. den 05.01.1961 angegeben. PA AA, AV NA 31582. Antrag auf Ausstellung eines Reisepasses von Paul Schäfer vom 24.04.1975 sowie ebd. Antrag auf Verlängerung eines Reisepasses von Paul Schäfer vom 29.10.1980.

105 PJS, Sammlung Luis Narváez. Bericht der JIPOL/PDI vom 13.10.2006: Procesamiento y Análisis de la información en idioma alemán remitida por el Ministro Jorge Zepeda Arancibia el 14 de septiembre de 2005. Archivador 13, Documento 10, S. 175.Vgl. auch Heller, Colonia Dignidad, von der Psychosekte, S. 28. 
einen Haftbefehl gegen Schäfer. Dieser reiste daraufhin noch einmal von Chile nach Brüssel. Er ließ eine Gruppe von Kindern, die er in Heide (Lohmar) missbraucht hatte, zu ihm bringen und instruierte sie, im Fall einer Befragung durch Ermittler, die Taten von Schäfer zu leugnen. Willi Malessa sagte dazu aus:

»El caso es que a los meses después de haber desaparecido Paul SCHAFER, uno de sus hombres de confianza, Kurt SCHNELLENKAMP, nos llevó a varios niños en un furgón hasta cruzar la frontera con Bélgica, donde en forma sorpresiva nos encontramos con SCHAFER, quién tomó contacto con cada uno de los niños y nos dio instrucciones. por separado sobre lo que teníamos que decir si la policía nos interrogaba respecto a abusos sexuales por parte de él. (nunca fui entrevistado por la policía) «. ${ }^{106}$ (Hervorhebung im Original)

Den ebenfalls bei diesem Treffen anwesenden Heinz Kuhn soll Schäfer angewiesen haben, die sogenannten Seelsorgeakten der Gruppe - also die von Schäfer stets eingeforderten schriftlichen Sündenbekenntnisse - zu verbrennen, was dieser daraufhin auch tat. $^{107}$

Unterdessen bereiteten Schäfers Vertrauensleute die Ausreise der Gruppe nach Chile vor. Dass die Wahl auf das südamerikanische Land fiel, erklärt sich durch die Verbindungen der Führungsgruppe um Schäfer zum chilenischen Botschafter in der BRD, Arturo Maschke, sowie zum chilenischen Konsul Guillermo Osorio. ${ }^{108}$ Der Kontakt soll zustande gekommen sein, als Handwerker der Gruppe in der chilenischen Botschaft in Bonn Reparaturarbeiten durchführten. ${ }^{109}$ Der Botschafter und einige seiner Mitarbeiter sollen daraufhin mehrfach das Jugendheim in Heide (Lohmar) besucht haben und empfohlen haben, die soziale Arbeit der Gruppe nach Chile auszuweiten. ${ }^{110}$ Guillermo

106 CA Santiago, AZ 2182-98 (»]uan Maino«), Bd. 5a, BI. 2173. Polizeiliche Vernehmung von Willi Malessa vom 29.09.2005.

107 PA AA, AV NA 31645, Gedächtnisprotokoll von Heinz Kuhn über seine Vernehmung bei Richter Navas am Vortag (01.02.1989).

108 Heller, Colonia Dignidad, von der Psychosekte, S. 181, schreibt dazu: »Ausschlaggebend für die Wahl Chiles als Fluchtland dürften diejenigen Personen gewesen sein, die die Ausreise sympathisierend arrangierten. Es waren der damalige chilenische Botschafter Arturo Maschke und der Botschaftsangestellte Guillermo Osario. Beide waren Nazis. Maschke, der sunsere [die chilenische] Rasse « gerne durch deutsches Blut aufgefrischt sehen mochte, hatte die Private Sociale Mission gekannt und empfahl Chile für die Auswanderung. Später verhalf er der Colonia Dignidad als Chef der chilenischen Nationalbank und Finanzminister zu ihren Zoll- und Steuerprivilegien. >Willk Osorio hatte während seiner diplomatischen Karriere Kontakte mit Naziorganisationen in Deutschland und arbeitete nach dem Putsch mit der DINA.«Als Konsulardirektor des chilenischen Außenministeriums verantwortete Osorio 1976 die Ausstellung falscher Pässe für Michael Townley und Armando Fernández Larios, die an der Ermordung des ehemaligen chilenischen Außen- und Verteidigungsministers Orlando Letelier am 21.09.1976 beteiligt gewesen waren. Osorio starb unter ungeklärten Umständen am 22.10.1977 als Protokollchef des chilenischen Außenministeriums. Eine strafrechtliche Untersuchung seines Todes ist derzeit noch anhängig.

109 CA Santiago, AZ 2182-98 (»Asociación Ilícita«), Bd. Ministro I (2), Bl. 661. Curriculum Vitae Dr. Gerd Seewald Lefèvre vom 17.09.2005.

110 Vgl. Gästebuch der CD von 1965, wiedergegeben in: Mercurio vom 15.05.1977. S. S9ff. »El Remezón Dignidad - diálogo con dudas«. 
Osorio bat am 29. November 1960 das chilenische Außenministerium um die schnelle Gewährung eines Einwanderungsvisums für Hermann Schmidt Georgi, seine Frau Ursula Spinti de Schmidt sowie ihre Kinder Peter Schmidt Spinti und den adoptierten Heinrich Kuhr-Schiwon.

»Hinsichtlich dieses Gesuches erlaube ich mir, der zuständigen Abteilung anzugeben, dass der Cenannte eine ehrenhafte Person ist, der in Zusammenarbeit mit anderen ein Jugend-Heim errichtet hat, das ein Wirksamkeit-, Ordnung- und Sauberkeitsvorbild ist. Das Direktorium dieses Heimes hat beschlossen, Herrn Schmidt als Bevollmächtigten nach Chile zu entsenden, um ein Grundstück zu kaufen, da man vorhat, ein gleichartiges Heim dort zu errichten und in späterer Zeit die ganze Einrichtung, Anlagen und sogar das Personal und die Jugend von hier nach dort zu verlegen. Das Stammhaus `Heide w wurde von Herrn Botschafter in Begleitung des Ministerrates besucht; die beiden genannten Herren empfingen einen großartigen Eindruck der Organisation. Andererseits ist der Plan des Verlegens des Heimes nach Chile vom Deutschen Roten Kreuz weitgehend unterstützt. «111

Auch bei bundesdeutschen Behörden wurden Führungsmitglieder von Schäfers Gruppe vorstellig: Am 3. Dezember 1960 sprachen Kurt Schnellenkamp und Hans-Jürgen Blanck im Amt für Auswanderung des Bundesverwaltungsamts vor und berichteten über die Auswanderungspläne einer etwa 30-köpfigen Gruppe nach Chile, wo sie ein Stück Land erwerben wolle. $^{112}$

Nach außen wurde die Wahl Chiles mit dem schweren Erdbeben im Süden des Landes vom 22. Mai 1960 begründet: ${ }^{113}$ Dort wolle man Jugendliche unterstützen, die durch das Beben ihre Eltern verloren hatten. Eltern von Kindern, die ohne ihre Sorgeberechtigten nach Chile reisten, soll gesagt worden sein, es handele sich lediglich um eine Chorfahrt. ${ }^{114}$ Viele Gruppenmitglieder gaben ihre Arbeitsstellen auf und brachten ihr Vermögen in das Auswanderungsvorhaben der Gruppe ein. Wieske berichtet:

»Wir gaben unsere gut bezahlten Berufe auf als Statiker und Oberpostsekretärin, wir gaben meinen Bausparvertrag und ihren Anteil an der Eigentumswohnung auf, wir verließen alle sehr lieben Verwandten und Bekannten, und wir gingen bewusst in eine unbekannte Zukunft. ${ }^{115}$

111 PJK, Ordner Hummel. Schreiben Konsul Osorio an den Außenminister, No. 105/65 vom 29.11.1960. Gesuch Einwanderungsvisum Hermann Schmidt, Ursula Schmidt und Heinrich Kuhr-Schiwon.

112 PJK, Ordner Hummel. Schreiben Bundesverwaltungsamt an das Zwischenstaatliche Komitee für europäische Auswanderung vom 12.07.1961. CZ 292-01-205061.

113 Das Erbeben beim südchilenischen Valdivia 1960 ist bis heute das schwerste, das jemals gemessen wurde. Über 1.600 Personen starben, Zehntausende wurden verletzt und Hunderttausende wurden obdachlos.

114 Vgl. Heller, Friedrich Paul. Lederhosen, Dutt und Giftgas: Die Hintergründe der Colonia Dignidad, 4. erweiterte und aktualisierte Aufl., Stuttgart 2011, S. 16.

115 PJS, Sammlung CD. Unveröffentlichtes Buchmanuskript von Johannes Wieske, o.T., o. O. [Parral], o.]. [2011], S. 55. 


\subsubsection{Interne Struktur und Hierarchieebenen}

Innerhalb der Colonia Dignidad gab es zwei parallele Strukturen - Männer und Frauen waren strikt voneinander getrennt und wussten kaum voneinander. Beide Geschlechter waren jeweils in Gruppen eingeteilt, vor allem nach Alterskohorten. Diese verfügten, Pfadfinder_innen ähnlich, über altertümliche Bezeichnungen und Kennzeichen (wie z.B. Wimpel). Die Einteilung der Gruppen soll bereits in den 1950er Jahren in Siegburg entstanden sein. ${ }^{116}$ Der Aufstieg von einer Gruppe in die nächste war anfangs vom Alter abhängig, später jedoch allein von Schäfers Gunst. Daher blieben die Gruppen nach dessen Abtauchen 1997 konstant. ${ }^{117}$

Geschlafen wurde in nach Geschlechtern getrennten Schlafsälen. Auch die Ehepaare lebten im Alltag weitgehend getrennt voneinander. Für gemeinsame Sexualität blieben nur geheime Treffen, beispielsweise nachts im Wald. ${ }^{118}$ Obwohl Schäfer das Eheleben als »Fleischespest « verteufelte, fanden in allen Phasen der CD Eheschließungen statt. Diese mussten jedoch von Schäfer autorisiert werden. Dies erfolgte meist erst nach langer Wartezeit und auch nur bei besonders loyalen Personen. Die Hochzeitszeremonien fanden außerhalb des Geländes statt - ein Großteil der Gruppe durfte nichts davon erfahren. ${ }^{119}$ Nach Schäfers Abtauchen nahm die Zahl der Hochzeiten deutlich zu. ${ }^{120}$ Noch im Oktober 1998 hatte Schäfer aus seinem Versteck in Argentinien von der »Heiratswut « gewarnt, die der »Gemeinschaft« schade. ${ }^{121}$

116 Ebd., S. 80.

117 Heller, Lederhosen, S. 27.

118 Dies galt auch für die 15 Ehepaare, die bereits in Deutschland geheiratet hatten. Erst 17 Jahre nach Ankunft in Chile erhielten elf dieser Paare ein eigenes Schlafzimmer. Archiv AI, Bestand CD. Bericht Waltraud Baar an die deutsche Botschaft Santiago vom 09.02.1989.

1191968 und 1969 durften jeweils vier Paare heiraten. In den $1970 e r$ und 1980er Jahren heirateten mindestens jeweils sechs Paare und in den 1990ern - vor dem Untertauchen Schäfers - mindestens vier Paare. Vgl. Aufstellungen von Eheschließungen in: Archiv Al, Bestand CD. Bericht Waltraud Baar an die deutsche Botschaft Santiago vom 09.02.1989 sowie PA AA, AV NA 31666. Liste zum Anschreiben des chilenischen Innenministeriums vom 10.05.1994. Deutsche Bewohner der CD, hier: Personenstand.

120 Zwischen 1999 und Schäfers Festnahme kam es zu 57 Eheschließungen. Dies verdeutlicht Schäfers sinkenden Einfluss nach seinem Untertauchen. PJS, Sammlung Seewald. »70 matrimonios nuevos 1995-2008 e hijos«. PJS, Sammlung CD. Brief Paul Schäfer an die CD-Bewohner_innen vom Oktober 1998. 
Tabelle 4: Gruppen und Alterssegmente*

4.1: Bezeichnungen der männlichen Mitglieder, Gruppen und Alterssegmente

\begin{tabular}{|l|l|l|}
\hline Edelweiser (0-5 ].) & & »kleine Jungen« \\
\hline Keile (6-12 ].) & geboren ab 1969 & »kleine Jungen« \\
\hline $\begin{array}{l}\text { Heilsarmee und Moritze } \\
\text { (ab 13 J.) }\end{array}$ & geboren 1955-1968 & Darunter »die Grünen« \\
\hline Askaris & geboren 1954-1957 & Auch »die Crauen« \\
\hline Mittlere Knappen & geboren 1948-1953 & \\
\hline Große Knappen & geboren 1940-1947 & Bereits in Deutschland verhei- \\
\hline Komalos & geboren 1927-1940 Männer \\
\hline Herren und Opas & & rate \\
\hline
\end{tabular}

4.2: Bezeichnungen der weiblichen Mitglieder, Gruppen und Alterssegmente

\begin{tabular}{|l|l|l|}
\hline Falken & geboren ab 1968 & \\
\hline Kleine Mädchen -Vögel & geboren 1958-1968 & $\begin{array}{l}\text { unterteilt in Singvögel und } \\
\text { Wandervögel }\end{array}$ \\
\hline $\begin{array}{l}\text { Wasserflöhe } \\
\text { (später Feuerwache) }\end{array}$ & geboren 1953-1959 & \\
\hline Feldmäuse & geboren 1954-1956 & Bei Rittel nicht erwähnt \\
\hline Halalis & geboren 1948-1953 & \\
\hline Schranzen & geboren 1940-1947 & \\
\hline Dragoner & geboren 1925-1940 & Dragoner \\
\hline Frauen & bereits in D verheiratet & Frauen \\
\hline Omas & geboren vor 1900 & Omas \\
\hline
\end{tabular}

* Nach CA Santiago, AZ 2182-98 (»Juan Maino«), Bd. IVb, Bl. 1684. Richterliche Aussage von Gerd Seewald vom 18.08.2005 sowie Rittel, Heike/Jürgen Karwelat. Lasst uns reden. Frauenprotokolle aus der Colonia Dignidad, Stuttgart 2018, S. 266.

Sämtliche CD-Mitglieder hatten klar umrissene Verantwortungsbereiche. Heller beschreibt dies folgendermaßen:

»Die Colonia Dignidad war nach dem Muster eines Ständestaates mit Elementen einer Sklavenhaltergesellschaft aufgebaut. Nur Schäfer hatte kein formales Amt inne. Seine Macht war gleichsam in sich selbst begründet: >Alle Fäden laufen beim tío zusammen, weil sie ja auch von dort kommen<, schreibt ein Mitglied in beredter Unlogik. « ${ }^{122}$

122 Heller, Colonia Dignidad, von der Psychosekte, S. 12. 
Gerd Seewald zählte bei einer Vernehmung im August $2005^{123}$ folgende Arbeitsbereiche der CD auf: Krankenhaus, Schule (intern/extern), Steinbruch (in Bulnes), Büro, Archiv, Werkstätten (Möbelwerkstatt, Schreinerei, Schlosserei, Maschinenwerkstatt) und Landwirtschaft (Getreide, Obst, Viehzucht, Geflügelzucht, Imkerei). In dieser Aufzählung fehlt eine Reihe von Bereichen, wie Küche, Wäscherei, Schneiderei, Schusterei, Mühle, Bäckerei/Konditorei, Restaurant in Bulnes, Warenvertrieb, Überwachung/Sicherheit.

Die verschiedenen Arbeitsbereiche in der CD waren weitgehend geschlechtergetrennt. Lotti Packmor beschrieb dies nach ihrer Flucht in ihrem Bericht an die deutsche Botschaft so:

»In der Mühle, Hühnerstall, Kuhstall, Hospital, Großküche, arbeitet nur weibliches Personal. Lediglich in der Metzgerei arbeitet ein Metzgermeister namens Siegmund Busse und Frau Elli Matthusen, die Frau des Alfred Matthusen, gemeinsam. In den Werkstätten arbeitet nur männliches Personal. Allen weiblichen Fundobewohnern ist es verboten, die Schreinerei, die Elektrowerkstatt, die Dreherei, die Schlosserei, die Vulkanisation usw. zu betreten. Schäfer selber hat's verboten. Vor versammelter Dorfgemeinde sagte er: »Wenn ich ein Weib in irgendeiner Werkstatt antreffe, die schlage ich zusammen, wenn Ihr Euch nicht an meine Anordnungen haltet. ${ }^{124}$

Im Krankenhaus waren beispielsweise bis auf den Leiter (Hartmut Hopp) ausschließlich Frauen tätig. Dasselbe galt für die Küche, die Wäscherei, die Buchhaltung sowie Teile der Vieh- und Geflügelzucht. Männer arbeiteten in den Werkstätten und in der Landwirtschaft. Paul Schäfer war ein erklärter Misogynist - dementsprechend war die $C D$ von patriarchalen Strukturen geprägt. In den Entscheidungsinstanzen der CD waren Frauen nicht vertreten. Männer sprachen von Frauen herablassend als »die Langhaarigen ${ }^{125}$ Dennoch waren einige Schlüsselpositionen mit Frauen besetzt, etwa im Krankenhaus (Gisela Seewald, Maria Strebe), in der Buchhaltung (Erika Heimann, Gesa Kunde, Rita Seelbach), am Eingangstor (»Galpón«) und bei den Wachposten. Auch die Misshandlungen mit Elektroschocks und Medikamenten wurden maßgeblich von Frauen durchgeführt. Selbst eine bewaffnete Einheit von Frauen für die geplante militärische Verteidigung der CD gab es - die sogenannte Dornbuschgruppe. Der Colono Franz Baar beschrieb diese Gruppe folgendermaßen:

»Hildegard Möhring era la jefa de todas las mujeres, encargada de entregar vestimentas y organizar el trabajo y distribución del personal femenino, ella tenía conocimiento de los maltratos físicos que aplicaban Katharina Pöhlchen, Erika Heimann, Esther Tymm, Rita Seelbach, Anna Maschke. Este grupo de mujeres era denominado como

CA Santiago, AZ 2182-98 (»]uan Maino), Bd. 4b, Bl. 1682ff. Richterliche Vernehmung von Cerd Seewald am 18/19.08.2005.

124 StA Bonn, AZ 50 ]s 285/85, Bd. 1, Bl. 6-35. Transkription des Tonbandberichts von von Lotti Packmor an die Deutsche Botschaft vom 17.03.1985, S. 21f.

125 PJS, Sammlung CD. Unveröffentlichtes Buchmanuskript von Johannes Wieske, o.T., o. O. [Parral], o.]. [2011], S. 80. 
>DORNBUSCH $<$, correspondiente al nombre de un grupo de alemanes de la Segunda Guerra Mundial, ya que estas mujeres portaban armas de fuego. ${ }^{126}$

\section{Die Führungsstruktur der CD}

Über die Hierarchie innerhalb der CD entschied allein Schäfer. Er verteilte Aufgaben und gewährte Einzelnen Privilegien, um seine eigene Sicherheit und den Fortbestand seiner Gruppierung zu gewährleisten. Schäfer hatte also von allen relevanten Vorgängen und Verbrechen in der CD Kenntnis. Zur Durchführung von Verbrechen sowie zur Aufrechterhaltung des Systems war er allerdings auf die Hilfe seiner Führungsgruppe angewiesen. Dabei weihte er seine Helfer meist nur in Teilbereiche einzelner Vorgänge ein. Je höher der Grad der Verantwortung, desto umfangreicher war meist das Wissen. Sämtliche Aufgaben, bei denen Fluchtgefahr bestand (wie etwa Reisen außerhalb des Siedlungsgeländes) oder bei denen Geheimnisse bewahrt werden mussten (z.B. über die Kooperation mit dem Geheimdienst oder über geheime Konten im Ausland) wurden ausschließlich an bedingungslos loyale Personen übertragen. Tätigkeiten außerhalb der Siedlung wurden wegen der gegenseitigen Überwachung in der Regel gemeinschaftlich ausgeführt. Längere unbegleitete Reisen oder Aufenthalte außerhalb der CD unternahm nur eine Handvoll Personen (darunter Hartmut Hopp, Kurt Schnellenkamp und Albert Schreiber). Zu den besonders vertrauensvollen Tätigkeiten gehörte auch die Leitung der CD-Außenstellen in Bulnes, Santiago und Siegburg sowie die Tätigkeit in der Sicherheitsgruppe. Letztere war in die Funktionsweise der Überwachungstechnologie eingeweiht und hätte somit theoretisch die Möglichkeit gehabt, die Siedlung unbemerkt zu verlassen.

Will man analysieren, weshalb Einzelne das System der CD gestützt oder gar an konkreten Verbrechen mitgewirkt haben, so müssen dabei sicherlich die verschiedenen Alterskohorten betrachtet werden. Zudem ist zu unterscheiden zwischen jenen, die als Jugendliche oder Erwachsene außerhalb der CD gelebt haben - also einen Vergleich mit dem Rest der Welt ziehen konnten - und jenen, die als Kinder in die CD gekommen oder dort geboren worden waren. Freund unterscheidet diesbezüglich vier Gruppen von Colonos: $:^{127}$

- Die als Erwachsene mit Paul Schäfer nach Chile Ausgewanderten

- Die als (größere) Kinder nach Chile gereisten, die in der Bundesrepublik noch Erfahrungen mit »normalen Strukturen von Familie und Sexualität « ${ }^{128}$ machen konnten

- Die in der CD Geborenen

- In die CD verschleppte chilenische Kinder von Franz Baar vom 28.04.2005.

127 Vgl. Freund, Henning. Religion als Trauma und Bewältigungshilfe am Beispiel der totalitären religiösen Gemeinschaft Colonia Dignidad, in: Utsch, Michael (Hg.). Pathologische Religiosität - Genese, Beispiele, Behandlungsansätze, Stuttgart 2012, S. 107-136, hier S. 108. 
Seit den 1990er Jahren verwenden Ermittler_innen, Menschenrechtsorganisationen und kritische (ehemalige) Colonos das Wort Jerarca (Hierarch), um Personen zu beschreiben, die innerhalb der CD eine Führungsposition innehatten und dementsprechend Verantwortung tragen. Personen, die in der ehemaligen CD seit 2005 das Sagen haben, werden als nuevos Jerarcas (neue Hierarchen) bezeichnet. Im juristischen Sinne könnte Jerarca als Mittäter oder Komplize übersetzt werden. Da die hierarchische Struktur der CD nicht formalisiert war und viele der Verbrechen bis heute strafrechtlich nicht geahndet wurden, handelt es sich jedoch vorrangig um eine moralische Beurteilung. Die Anzahl der Jerarcas wird auf zwischen 10 und 70 Personen geschätzt. Heller etwa schreibt 2011:

»Zehn bis fünfzehn Männer um Schäfer hatten mit ihm zusammen die reale Macht inne. Sie waren eine informelle Gruppe innerhalb der >Herren < ohne besonderen Namen. Sie waren für die Verhängung der Strafen, die Sicherheitssysteme, die Waffen und die oft in Crauzonen der Legalität oder der Illegalität operierenden Ceschäftsführung zuständig. ${ }^{129}$

Belisario Velasco, von 1990 bis 1999 Staatssekretär im chilenischen Innenministerium, schätzte hingegen 1999: „Serían unas 25 personas las que manejarían todo lo referido a la ex Colonia Dignidad y los 250 alemanes aproximadamente que están en el país y que se encuentran en el predio son más víctimas que victimarios. « ${ }^{130}$ Ein Bericht der chilenischen Kriminalpolizei von 2001 zählt 41 Personen auf und schreibt dazu: »al interior de la Ex Colonia Dignidad existe un claro ordenamiento jerárquico y piramidal, ubicándose en la cabeza de esta organización precisamente su líder Paul Schäfer Schneider ${ }^{131}$

Ein unveröffentlichter Bericht Erick Zotts von $2007^{132}$ enthält eine differenziertere Auflistung der "supuestos autores (materiales y/o intelectuales), cómplices, encubridores y testigos de los delitos«. 26 Personen seien Teil der »Jerarquía de la Colonia Dignidad« gewesen (darunter mit Gisela Seewald und Erika Heimann zwei Frauen). Des Weiteren werden unter der Rubrik "paramilitares de la Colonia Dignidad« 30 Personen aufgeführt, »que fueron seleccionados por PS para asumir funciones de seguridad, protección de personas, vigilancias, castigos y ejecutar misiones de alta confidencialidad (criminales). "Die Auflistung »victimarios y asistentes para la aplicación de torturas« enthält weitere 12 Namen von Personen, die insbesondere an Misshandlungen mit Medikamenten und Elektroschocks im Krankenhaus beteiligt gewesen sein sollen.

129 Heller, Friedrich Paul. Lederhosen, Dutt und Giftgas: Die Hintergründe der Colonia Dignidad, 4. erweiterte und aktualisierte Aufl., Stuttgart 2011, S. 26.

130 Cámara de Diputados, Diarios de Sesiones, Legislatura 340 a , Sesión $27^{a}$ vom 10.08.1999, S. 124169. Informe de las Comisiones Unidas de Derechos Humanos, Nacionalidad y Ciudadanía, y de Familia, encargadas de estudiar y fiscalizar cómo los distintos órganos públicos competentes han colaborado para el éxito de las investigaciones judiciales relativas a la ex Colonia Dignidad, hier S. 131.

131 CA Santiago, AZ 2182-98 (»Asociación llícita«), Bd. I (Parral), BI. 391ff. PDI Prefectura Regional Talca, Informe Policial No. 02/00510 vom 08.01.2001.

132 Vgl. für den gesamten Absatz: PJS, Sammlung Dieter Maier. Zott, Erick. Colonia Dignidad. Propuestas para apoyar una estrategia juridica actualizada en Chile. Unveröffentlichtes Arbeitspapier für ein Treffen in Wien, Wien 2007. 
Letztlich listet Zott in der Rubrik »Responsables e implicados en supestos delitos económicos« 19 Namen auf. Interessanterweise enthält Zotts Bericht auch die Namen sieben externer Personen.

\subsubsection{Die pseudoreligiöse kriminelle Gemeinschaft - innere Struktur}

Der Begriff Sekte wird umgangssprachlich meist mit religiösen Gruppierungen assoziiert, die eine eigenständige religiöse Linie verfolgen und sich von den großen, anerkannten Glaubensrichtungen abgrenzen. Der Begriff Sekte ist eindeutig negativ konnotiert und wird meist mit Unfreiheit, Gehirnwäsche und anderen negativen Auswirkungen auf Individuen in Verbindung gebracht. Da es oftmals keinen wissenschaftlichen Nachweis für einen kausalen Zusammenhang zwischen der Zugehörigkeit zu einer solchen Gruppierung einerseits und negativen Auswirkungen auf die psychische Gesundheit Einzelner anderseits gibt, ${ }^{133}$ bemüht sich die Religionswissenschaft zunehmend um eine neutralere Terminologie. Viele Gruppierungen werden heute als »neureligiöse Bewegungen« bezeichnet. Für diejenigen Gruppen, die offensichtlich nach innen oder außen eine zerstörerische bzw. verbrecherische Wirkung entfalten, hat sich der Begriff destructive cult etabliert. ${ }^{134}$ Freund betrachtet auch die Colonia Dignidad als einen solchen destructive cult. ${ }^{135}$

Trotz der Unschärfe des Begriffs wird die Colonia Dignidad seit Jahrzehnten nicht nur in der Berichterstattung, sondern auch in wissenschaftlichen Veröffentlichungen vielfach als Sekte bezeichnet. ${ }^{136}$ Auch bundesdeutsche Behörden verwendeten früh diese Bezeichnung, wie beispielsweise 1962 das Bundesverwaltungsamt:

Freund, Henning. Religion als Trauma und Bewältigungshilfe am Beispiel der totalitären religiösen Gemeinschaft Colonia Dignidad, in: Utsch, Michael (Hg.). Pathologische Religiosität-Cenese, Beispiele, Behandlungsansätze, Stuttgart 2012, S. 106-136. Hier: S. 106.

Ein Beispiel für eine solche zerstörerische Claubensgemeinschaft ist die Cruppierung Peoples Temple des US-amerikanischen Predigers Jim Jones. 1978 starben in Guyana 918 Mitglieder dieser Gruppe durch einen Massen(selbst-)mord. Das Auswärtige Amt sah Parallelen zwischen der Cruppe Peoples Temple und CD und telegraphierte an die Botschaft in Santiago: „Da mit einem wachsenden Interesse der deutschen Öffentlichkeit an der Tätigkeit von Sekten und damit auch an der COLONIA DIGNIDAD zu rechnen ist, wird um Bericht über die gegenwärtige Situation dieses Lagers gebeten.«PA AA, ZW 111130. Erlass vom 24.11.1978. CZ 331-383.25 CHL. Ein weiteres Beispiel für einen »destructive cult« ist die japanische Gruppierung Alpha (früher Omu Shinrikyo). Diese verübte am 20.03.1995 einen Ciftgas-Anschlag auf die U-Bahn in Tokyo, bei dem 13 Menschen starben und Hunderte verletzt wurden.

135 Freund, Henning. Religion als Trauma und Bewältigungshilfe am Beispiel der totalitären religiösen Cemeinschaft Colonia Dignidad, S. 107.

136 Vgl u.a. Biedermann, Niels/Judith Strasser/Julian Poluda.»Colonia Dignidad«-Psychotherapie im ehemaligen Folterlager einer deutschen Sekte, in: Zeitschrift für Politische Psychologie, 14 (2006) Nr. 1+2, S. 111-127 sowie Bauer, Susanne. Psychologische Behandlungsmöglichkeiten für religiös traumatisierte Menschen am Beispiel der Sekte Colonia Dignidad, in: Utsch, Michael (Hg.). Pathologische Religiosität - Cenese, Beispiele, Behandlungsansätze, Stuttgart 2012, S. 67-105. Freund selbst verwendete den Begriff Sekte in früheren Publikationen zur CD, vgl. Freund, Henning. »Colonia Dignidad« - Der Öffnungsprozess einer »geschlossenen Cemeinschaft«, in: EZW Materialdienst - Zeitschrift für Religions- und Weltanschauungsfragen Nr. 5/2008, S. 180-185. 
»Nachforschungen haben ergeben, dass es sich mit großer Wahrscheinlichkeit bei der Privaten Sozialmission um eine Sekte handelt, deren Angehörige zwar im Berufsleben stehen, jedoch persönlich keinen Kontakt mit anderen der Sekte nicht angehörenden Menschen haben. Vorhaben und Absichten der Privaten Sozialmission sind daher nicht klar durchschaubar. «137

Korrekter wäre es, die CD als eine geschlossene totalitäre Gruppierung zu bezeichnen, deren religiöse Ursprünge teilweise in freikirchlich-baptistischen Glaubensrichtungen liegen, ${ }^{138}$ deren religiöse Praxis jedoch eine "pseudo-urchristliche Privatreligion « ${ }^{139}$ war, die maßgeblich durch den Laienprediger Paul Schäfer geprägt wurde. ${ }^{140}$ Schäfer und die CD-Führungsriege bezeichneten die Gruppe als »Brautgemeinde Christi ${ }^{141}$.

Nachdem sich die freikirchlichen Prediger Hugo Baar und Hermann Schmidt mit Teilen ihrer Gemeindemitglieder der Gruppe um Schäfer anschlossen hatten, suchte die CD niemals aktiv die Nähe zu anderen religiösen Gemeinschaften und isolierte sich zunehmend. Nach außen inszenierte ${ }^{142}$ sich die CD von Beginn an selbst als eine aus

137 PA AA, B 85, Bd. 598. Schreiben des Bundesverwaltungsamts, Amt für Auswanderung an die Botschaft vom 16.01.1962.

138 Zwei der engsten Begleiter Paul Schäfers, Hermann Schmidt und Hugo Baar, waren Prediger in freikirchlich-baptistischen Gemeinden gewesen.

139 Freund, Henning. »Colonia Dignidad« - Der Öffnungsprozess einer »geschlossenen Gemeinschaft«, in: EZW Materialdienst - Zeitschrift für Religions- und Weltanschauungsfragen Nr. 5/2008, S. 180-185, hier S. 180.

140 Heller, Friedrich Paul. Lederhosen, Dutt und Giftgas: Die Hintergründe der Colonia Dignidad, 4. erweiterte und aktualisierte Aufl., Stuttgart 2011, S. 14, formuliert dies folgendermaßen: »Die Sekte hing einem fundamentalistischen, theologisch unreflektierten, formlos-unmittelbaren Christentum an, das viel vom muffigen protestantischen Milieu der 1950er Jahre hatte. Diese diffuse Sektiererei formte sich im Laufe der Jahre zu Schäfers Privatreligion. «Über die Schäfer'sche Privatreligion schreibt Heller: »Schäfers Privatreligion und seine amoralische Praxis gewährte keine psychische Sicherheit. Alles war ambivalent. Unter diesen Umständen konnten sich keine zuverlässigen moralischen Maßstäbe herausbilden. Wer dort aufgewachsen war, kannte nur die Moral der Führungsclique. Schäfers Predigten gaben die Normen vor. Den Widerspruch, dass der Ursprung der Moral gleichzeitig ein Schmutzfink war, spürten Einzelne, die Sekte als ganze konnte ihn nicht auflösen. Einzelne ballten die Faust in der Tasche, aber sie hallen gebrochen mit den Maßstäben vor ihrem Eintritt in die Schäfer-Sekte, und die Jüngeren hallen keine Vergleichsmöglichkeiten. Im Rückblick konnte sich die Colonia Dignidad als Feldversuch der Morallehre erweisen: Menschen wir Efrain Vedder, die 35 Jahre lang nur die Colonia Dignidad kannten, hatten noch ein Gewissen.« Ebd., S. 40.

141 Freund, Henning. »Colonia Dignidad« - Der Öffnungsprozess einer »geschlossenen Cemeinschaft«, in: EZW Materialdienst - Zeitschrift für Religions- und Weltanschauungsfragen Nr. 5/2008, S. 180-185, hier S. 181.

142 Heller, Lederhosen, S. 39, schreibt über die Selbstinszenierung Schäfers: „Schäfer war ein Meister der Inszenierung. In Deutschland inszenierte er gerne Aufführungen van Laientheatern [...] In Chile organisierte er Musik- und Turnfeste, Demonstrationen und Staatsbesuche. Er inszenierte sich selbst vor der Presse als »schwarzes Schaf«, das dirigierte statt Fragen zu beantworten [...]; er inszenierte 1966 seinen eigenen Selbstmord und letztendlich die ganze Colonia Dignidad als Folklore und Bayerndorf. Efrain Vedder musste mit anderen Kindern in Lederhosen und mit Tirolerhut Schuhplattler tanzen, wenn die Bayern kamen. Waren es chilenische Offiziere, bediente Schäfer deren Erwartung an deutsche Kriegsveteranen des Zweiten Weltkriegs und gab den Helden [...]. Jeder bekam die Antwort, die er hören wollte.« 
Mitgliedern aller christlichen Konfessionen zusammengesetzte Gruppierung mit wohltätigen Motiven. Hermann Schmidt schrieb 1961 dazu: „Das Werk und seine Ideen fußen auf christlichen Grundlagen, ohne eine bestimmte Konfession zu verfolgen und ist völlig unpolitisch. «"143

Die CD bildete ein geschlossenes System, in dem nur noch die Gruppe zählte und die einzelnen Mitglieder ihrer Individualität beraubt wurden. ${ }^{144}$ Aus Sicht der »Auserlesenen ${ }^{145}$ - also im Inneren der Gruppe - war die Gruppierung permanent von außen bedroht. Diese konstruierte Bedrohung, die Schäfer oftmals als »kommunistisch« beschrieb, diente als Legitimation für die Verlegung der Gruppe von Deutschland nach Chile, ${ }^{146}$ aber auch für die dortige Abschottung, Überwachung und Militarisierung. ${ }^{147}$ Dahinter stand Schäfers Furcht. Schäfer war charakterisiert durch seine panische Angst vor äußeren und inneren Gegner_innen, die sein Projekt in Frage stellen oder seine Verbrechen aufdecken könnten. Aus dieser Furcht heraus baute er ein umfangreiches Überwachungssystem auf, das auf gegenseitiger Bespitzelung und technischer Überwachung (z.B. Abhörsysteme) basierte. Schäfer verstand schnell, dass der kontrollierte Zugang zu Informationen ein Schlüssel für die Überlebenssicherung der CD, aber auch für seine eigene Machtstellung innerhalb der Gruppe war.

\section{Das Schäfer'sche Kontrollkollektiv}

Nach Außen inszenierte sich die CD gerne als demokratisch geprägte Organisation mit einer "Generalversammlung « als höchster Entscheidungsinstanz. Stand unerwünschter Besuch an, wurde dieser meist mit der Begründung abgelehnt, die Generalversammlung müsse erst darüber befinden. ${ }^{148}$ Zur Diskreditierung von Personen, die aus der CD geflüchtet waren, wurden »außerordentliche Generalversammlungen« inszeniert. Diese setzten dann eine »Untersuchungskommission« ein, die über außereheliche Affären und vermeintliche Sucht- oder Persönlichkeitsprobleme der Geflüchteten berichtete. In eidesstattlichen Versicherungen beschrieben einzelne Colonos akribisch die »Auswüchse bis ins Pervers-Monströse« der Abtrünnigen. ${ }^{149}$ Tatsächlich war aber allein der Wille Schäfers und seiner Führungsgruppe entscheidend. Dieser wurde

143 PJK, Ordner Hummel. Schreiben Hermann Schmidt an den chilenischen Innenminister Sótero del Río vom 15.05.1961.

144 Bauer, Susanne. Psychologische Behandlungsmöglichkeiten, S. 69.

145 Ebd., S. 75.

146 Bauer, Susanne. Psychologische Behandlungsmöglichkeiten, S. 75, schreibt dazu: »Schäfer verbreitete das Gerücht eines bevorstehenden Einmarschs der Kommunisten, und die Mitglieder der Siegburger Cemeinde fühlten sich erneut als die Auserlesenen und Gerettete. Sie stimmten den Ausreiseplänen ohne Einwände zu.«

147 Die Colona Ingrid Szurgelies erklärte bspw. bei ihrer richterlichen Vernehmung: »En el tiempo de Allende yo también ayudé a fabricar armas [...] pensaba que eran para defender los campos de los comunistas«. CA Santiago, AZ 2182-98 (»Asociación Ilícita«), Bd. II (Parral), Bl. 1230. Richterliche Vernehmung Ingrid Szurgelies vom 22.11.2004.

148 So z.B. im März 1985, als die Botschaft der CD die Abhaltung eines Konsularsprechtags anbot. Vgl. PA AA, AV NA 31577. Schreiben SBED (gez. Hermann Schmidt) an Konsul Haller vom 11.04.1985.

149 AdsD, NL Waltemathe, Bestand CD, Box/Mappe Nr. 31. Übersetzung, Protokoll der außerordentlichen Generalversammlung vom 26.10.1985. 
als kollektiver Wille der Gruppe und als objektive Wahrheit deklariert. Die Gruppenversammlung war also nicht Ausdruck eines demokratischen Prozesses, sondern dessen Gegenteil: Eine Kontrollinstanz, die Ausdruck der uneingeschränkten Herrschaft Schäfers und seiner Führungsclique war. ${ }^{150}$ Den Ablauf einer Gruppenversammlung beschrieb ein Colono folgendermaßen:

»In schmerzhafter Erinnerung sind mir die vielen harten Gruppenversammlungen geblieben, wo die einzelnen so in die Enge getrieben und angeschrien wurden, bis sie sich in Widersprüche verwickelten und dann der Lüge bezichtigt wurden. Daraufhin wurde derjenige von der ganzen Cruppe zusammen- und blutig geschlagen. Alle Vorfälle wurden fast immer öffentlich ausgetragen, so dass sich alle von dieser Person zurückzogen und sich selber fürchteten Widerstand zu leisten. Auf diese Weise wurde einer nach dem anderen isoliert. Meistens waren es solche Personen, die Schäfer die Wahrheit gesagt hatten und sich ihm nicht beugten. ${ }^{151}$

Jegliche Interessen von Individuen waren verpönt - diese mussten sich der »Gemeinschaft « unterordnen, die den Weg der »Wahrheit und des Rechts« beschritt. Die bedingungslose Unterordnung jedes Einzelnen wurde von Schäfer vorgegeben und von den Führungsmitgliedern umgesetzt, vorgeblich zum Wohle der Gruppe. Wer sich dieser Logik nicht unterwarf, galt als gemeinschaftsschädigender Egoist. Jegliche Kritik an Schäfer und der Führungs wurde daher als Kritik an der gesamten Gruppe aufgefasst. Dies galt schon vor der Übersiedlung nach Chile, in Siegburg, wie Willi Georg 1966 berichtete:

»Vor jedem Gespräch oder Besprechung wurde den entsprechenden Männern schon vorher einsuggestiert, wie sie sich zu verhalten hatten. Entweder laut oder leise. Je nach der Person. Bei Cesinnungseinstellungen gegen Schäfer wurde der Entsprechende niedergeschrien. Nicht nur im Kleinen, sondern auch im Gesamtkreis nach dem Abendessen. Man frug nicht nach männlicher oder nach fraulicher Würde. Man nannte es Demut, wenn man es ertrug, oftmals ungerecht einer Schuld bezichtigt zu werden. Man nannte es Hochmut, wenn man sein Recht forderte. Und als geisteskrank wurde man bezeichnet, wenn man Schäfer einer Schuld überführte oder offen über Misszustände klagte. Eine alte Taktik Schäfers, war die, manchmal zwei, manchmal mehr, manchmal alle zu Gesprächen heranzuziehen. Somit wußte keiner was eigentlich recht anlag und kein zu enger Kontakt entstehen konnte untereinander und er mit ruhigem Cewissen seine Meinung ändern konnte, da keiner vom anderen wußte. Es wurde ebenso eine unbedingte Hörigkeit auf die sogenannten leitenden Brüder verlangt. Niemand hatte seine eigene Meinung. Es wurde solange herumgeredet, bis am Schluss Schäfers Meinung doch die rechte war. Nach sonntäglichen Cottesdiensten wurden oftmals Predigten von anderen so zerrissen, dass die einzige von Schäfer als

So ein Bericht des deutschen Psychologen David Becker im Auftrag des chilenischen Innenministeriums. CA Santiago, AZ 2182-98 (»Asociación Ilícita«), Bd. I (2) (Parral), Bl. 785ff. David Becker, informe acerca de las condiciones de vida de los habitantes de Villa Baviera desde una perspectiva de Salud Mental, 14.10.1997.

151 StA Krefeld Az 3 ]s 753/11, Bl. 122of. Bernd Schaffrik: »Einige Zeugnisse über mein Vergangenes Leben in der >Colonia Dignidad«, September 2010. 
gut übrigblieb. Niemand wagte recht zu reden oder zu beten, aus Angst etwas Falsches zu sagen. Das verschloss jedem den Mund und führte dazu, dass Schäfer als kleiner »Papst « ein unbedingtes Herrscherrecht besaß. ${ }^{152}$

Unabhängig von tatsächlichen Ereignissen galt Schäfers Wort als die Wahrheit. Die Unterordnung unter seinen Willen war absolutes Prinzip. Wer diesem nicht folgte und etwa eigene Wahrheitsmaßstäbe ansetzte, konnte drakonisch bestraft werden. Die Strafen erfolgten aufgrund der hierarchisierten Gruppenstruktur auch ohne die Präsenz Schäfers, wie Gero Gemballa in seinem Bericht über die CD darlegt:

»Die >Colonia Dignidad ist eine Gemeinschaft ohne Kommunikation. Immer noch ist die schriftliche Beichte Pflicht. Die »Gruppentanten« führen zudem ein Gruppenbuch, in dem detailliert auch kleinste Verfehlungen festgehalten werden:

Sieglinde Baar beichtet als Zwölfährige: >lch habe ohne Erlaubnis einen Schluck Wasser aus der Waschküche getrunken.<Ein Kind beichtet, es habe eine Emailleschüssel zu fest auf die Erde gestellt, und Ulrike Mysliwitz hat sich mit dem Kamm eines anderen Kindes frisiert. Gruppentante Ruth teilt Paul Schäfer im Gruppenbuch schriftlich mit, das Mädchen habe den Vorfall erst geleugnet. Zitat aus dem Gruppenbuch:

,Ulrike wurde von der Cruppe gefragt: Wer lügt? Ulrike: Ich lüge nicht. Sie wurde geohrfeigt. Gleiche Frage. Antwort: Ich lüge nicht. Sie wurde auf die Bank gelegt und der Hintern versohlt. Cleiche Frage. Antwort: Ich lüge nicht. Und dann ging es erbarmungslos rund, erst dann sagte sie: Ich lüge. « ${ }^{153}$

Wer auf seiner oder ihrer Wahrheit insistierte, wurde niedergemacht, gedemütigt, körperlichen Strafen ausgesetzt oder gar jahrelang von der Gruppe isoliert und mit Medikamenten ruhiggestellt. Wer solche Strafen verhindern wollte, ordnete sich unter, führte Befehle aus, widersprach nicht und denunzierte andere, um nicht selbst denunziert zu werden.

Seine Machtstellung innerhalb der Gruppe sicherte Schäfer auch durch die Zerschlagung jeglicher familiären oder freundschaftlichen Bindungen sowie durch die Vergötterung seiner Person. Von den Colonos wurde die vollständige Aufgabe alles Privaten sowie die exklusive und uneingeschränkte Loyalität Schäfer gegenüber erwartet. Jegliche Kommunikation unter Gruppenmitgliedern, auch über private Themen, war hingegen untersagt. Hugo Baar berichtete nach seiner Flucht aus der CD 1984:

»Ein weiterer, in das Cewissen jedes Einzelnen hineingehämmerter Satz des Herrn Schäfer lautet: Niemand darf ein Geheimnis haben! Alles muß ans Licht. Jesus ist das Licht, Jesus ist auch die Wahrheit. Wer an Jesus glaubt, ihm gehört, redet und tut die Wahrheit. Alle Heimlichkeit und Lüge ist vom Teufel. Auch alle Heuchelei hat nichts mit Cott und der Wahrheit zu tun usw. Nun, das sind alles klare biblische Aussagen. Was aber Herr Schäfer in fast 30 Jahren aus diesen biblischen Aussagen gemacht hat und macht, hat fast nichts mehr mit der Bibel zu tun. Hier werden immer nur einige

152 PJK, Ordner Schäfer. Bericht Willi Georg vom 21.07.1966, »Abschrift«, S. $5 f$.

153 Gemballa, Gero. Colonia Dignidad. Ein deutsches Lager in Chile, Reinbek 1988, S. 54. 
Wahrheiten aus der Bibel aus dem Cesamtzusammenhang herausgenommen, dann noch überbetont und schließlich sogar von Herrn Schäfer mißbraucht. « ${ }^{154}$

Nach Gutdünken urteilte Schäfer über Gut oder Böse und ordnete Bestrafungen an. Zudem baute er sich ein Informationsmonopol auf, indem er Colonos dazu anregte, sich gegenseitig zu bespitzeln. Bei den regelmäßigen Einzelgesprächen mit Beichtcharakter forderte er Berichte über vermeintliche Verfehlungen der Befragten selbst, aber auch anderer Personen ein. ${ }^{155} \mathrm{Zu}$ solchen Berichten gehörten auch vermeintliche Regelverstöße in Form von bloßen Gedanken oder gar Träumen. Ergänzt wurde dies durch ein ausgeklügeltes System der Überwachung durch versteckte Mikrofone an unterschiedlichen Orten. Die so zusammengetragenen Informationen sammelte Schäfer in sogenannten Seelsorgeakten. Diese dienten ihm als Machtmittel, das er bei Bedarf gegen die betreffenden Personen einsetzen konnte. So wurden z.B. bei aus der Kolonie Geflüchteten umgehend »Informationsdossiers« zusammengestellt, die die Abkehr von der CD mit den akribisch aufgelisteten vermeintlichen Verfehlungen der Abtrünnigen begründete. ${ }^{156}$

\subsubsection{Die kriminelle Vereinigung - Wirken nach außen}

Die Colonia Dignidad als kriminelle Vereinigung ging zahlreiche Allianzen mit zivilen und staatlichen Akteur_innen ein. Sie beging Verbrechen, um ihre Macht zu erhalten und den Fortbestand der Gruppe zu sichern. Die Verbrechen, von denen nun die Rede ist, richteten sich nicht gegen Gruppenmitglieder, sondern gegen Dritte. Dazu gehört insbesondere die Kooperation mit dem chilenischen Geheimdienst zur Zeit der Militärdiktatur, der Dirección de Inteligencia Nacional (DINA) sowie mit anderen Institutionen zur Bekämpfung des Widerstandes gegen die Diktatur.

Während ihrer gesamten Existenz war die CD intensiv damit beschäftigt, Versuche abzuwehren, über die Verbrechen der Gruppe und die in ihr herrschenden Zustände aufzuklären. Aus ihrer eigenen Sicht befand sie sich in einem ständigen Überlebenskampf. Sie wandte daher alle ihr zur Verfügung stehenden legalen und illegalen Mittel an, um diese vermeintliche Bedrohung abzuwehren. Damit setze sie auch jeglichen Aufklärungsbemühungen von außen - in Deutschland wie in Chile - ihre gesamte Macht entgegen: Sie betrieb eine umfangreiche Lobby- und Medienarbeit, bildete offene und

154 PA AA, B 83, Bd. 2384. Bericht von Hugo Baar an die deutsche Botschaft vom 02.04.1985, S. 10.

155 Vgl. Bauer, Susanne. Psychologische Behandlungsmöglichkeiten, S. 80.

156 AdsD, NL Waltemathe, Bestand CD, Box/Mappe Nr. 31. Übersetzung, Protokoll der außerordentlichen Generalversammlung vom 26.10.1985. Das Dokument listet auf exemplarische Weise detailliert vermeintliche Liebschaften, Drogen- und Alkoholkonsum und »gemeinschaftsschädigendes Verhalten« der geflüchteten Colonos Hugo Baar, Georg Packmor und Lotti Packmor auf. Dieses vermutlich in weiten Teilen erfundene Protokoll sollte die Claubwürdigkeit der Berichte der Ceflüchteten an die deutsche Botschaft und ihre Aussagen vor der bundesdeutschen Justiz in Frage stellen. Nach Heinz Kuhns endgültiger Abkehr von der CD wurde ein Dossier über seine vermeintlichen betrügerischen Machenschaften erstellt. Dieses wurde von der CD zu den Verfahrensakten der Untersuchung 1989 von Richter Navas und Robert (Juzgado de Parral AZ 43.210 - Vgl. Kap 5.1.3) gereicht. PA AA, AV NA 31693. Dokumente »Heinz Kuhn, betrügerischer Konkurs« und »Anklageschrift SBED Heinz Kuhn, 11.März 1933«, beide o.D. 
verdeckte Unterstützungsnetzwerke, sprach gezielte Einladungen in die Siedlung aus und beschenkte loyale Unterstützer_innen u.a. mit Essenspaketen. Gegner_innen begegnete die CD mit Dienstaufsichtsbeschwerden oder Verleumdungsklagen. Führten solche legalen Mittel nicht zum gewünschten Erfolg, griff die Gruppe zu drastischeren Maßnahmen wie Morddrohungen gegen Journalist_innen ${ }^{157}$ oder der Beschuss des Wohnhauses eines Rechtsanwalts ${ }^{158}$ zeigen.

Die CD bediente sich auch Maßnahmen, die eigentlich eher bei ihren Gegner_innen vermutet werden könnten und mit denen sie sich als Opfer angeblicher Kampagnen inszenierte, wie Demonstrationen, offene Briefe, Unterschriftenlisten, Petitionen ${ }^{159}$ und sogar Hungerstreiks. ${ }^{160}$

Gegen Ende der 1960er Jahre begann sich die CD zu bewaffnen und Kontakt zu Militärs und rechtsextremen Kreisen zu suchen. Seit Amtsantritt der sozialistischen Regierung unter Salvador Allende Ende 1970 arbeitete die CD konkret mit militanten rechtsextremen Gruppen sowie den Putschisten von 1973 zusammen. Die CD begann mit der Erstellung eines Archivs, in dem während der Militärdiktatur Informationen zu über 30.000 Personen gesammelt und ausgewertet wurden. Die CD erfüllte dabei als parastaatlicher Akteur, sozusagen als Dienstleister für die Diktatur, eine wichtige Funktion für den Repressionsapparat der Diktatur, wahrte aber gleichzeitig ihre Eigenständigkeit. Die CD als kriminelle Vereinigung war international organisiert. Das meint nicht nur die offiziellen Sitze in Chile und der Bundesrepublik, sondern vor allem die Netzwerke, Geschäfte und Immobilien in den USA, Argentinien, Belgien, Venezuela und dem Karibikstaat St. Kitts und Nevis. Tonbänder, die in der CD gefunden wurden, belegen, dass CD-Mitglieder Mitte der 1970er Jahre nach Peru und Bolivien reisten, um die dortigen Streitkräfte auszuspionieren. ${ }^{161}$

\section{Das chilenische Gerichtsurteil wegen Bildung einer kriminellen Vereinigung}

Am 25. März 1999 reichte der Consejo de Defensa del Estado de Chile (chilenischer Staatsverteidigungsrat, CDE) Strafanzeige gegen 19 Mitglieder der CD sowie vier chilenische Unterstützer der CD wegen Bildung einer kriminellen Vereinigung ein. Am

157 Die Journalistin Erika Vexler, die für die Zeitschrift Ercilla 1966 über die Flucht von Wolfgang Müller (heute: Wolfgang Kneese) berichtete, wurde mit dem Tode bedroht und erhielt daraufhin Polizeischutz. Vgl. Le Figaro vom 16.04.1966, »Le >camp de concentration< chilien - L'un des dirigeants Hermann Schmidt arrêté et écroué."

158 Am 09.04.1991 wurde das Haus von Guillermo Ceroni, Rechtsanwalt der Botschaft, mit einem Cewehr beschossen. Die festgenommenen Täter sind Mitglieder der »Amigos de Colonia Dignidad «. PA AA, AV NA 31603. DB 246 vom 09.04.1991.

159 Deutscher Bundestag. Drucksache 12/683 vom 06.06.1991. Bericht des Petitionsausschusses, S 14.

160 Über die Medien angekündigte Hungerstreiks von Colonos gab es beispielsweise im April 1968 (gegen die Beschlagnahmung der Steinbrecheranlage durch den chil. Zoll), im April 1977 (im Zuge der Berichte von Al und Stern), im Januar 1989 (gegen die Untersuchung der CD durch Richter Navas) und im Januar 1991 (gegen das Auflösungsdekret der chil. Regierung).

161 PWH, Tonband Nr. 48. Vgl. auch Becerra, Abril. »Colonia Dignidad al descubierto: Artista revela las conversaciones telefónicas de Paul Schäfer«, in: RadioUChile (Website), 07.10.2018, online unter https://radio.uchile.cl/2018/10/07/colonia-dignidad-al-descubierto-artista-revela-las-conv ersaciones-telefonicas-de-paul-schafer/. 
10. April 2006 erhob Richter Jorge Zepeda Anklage ${ }^{162}$ gegen 14 CD-Mitglieder und vier Agenten der DINA. Am 9. April 2014 sprach er sein Urteil: Die vier Führungsmitglieder der CD, Kurt Schnellenkamp, Gerd Seewald, Gerhard Mücke und Karl van den Berg sowie die drei DINA-Agenten Manuel Contreras, Pedro Espinoza und Fernando Gómez Segovia wurden zu jeweils vier Jahren Haft verurteilt. Vier angeklagte CDMitglieder wurden freigesprochen. ${ }^{163}$ Vier Angeklagte waren während des Prozesses verstorben, ${ }^{164}$ weitere vier hatten sich durch Flucht ins Ausland einer möglichen Verurteilung entzogen. ${ }^{165}$ Die Corte Suprema (Oberster Gerichtshof) bestätigte das Urteil am 29. Dezember 2016 und hob das Strafmaß auf fünf Jahre und einen Tag Haft an. Das Urteil wurde nur gegen fünf Verurteilte vollstreckt - auch Manuel Contreras und Gerd Seewald waren inzwischen verstorben.

In seinem Urteil fasste Zepeda Erkenntnisse aus einer Reihe vorangegangener Urteile zusammen. Diese betrafen die Straftatbestände Entführung (bis heute verschwundener Personen), Verstoß gegen das Waffengesetz, Körperverletzung (durch Elektroschock- und Psychopharmaka-Vergabe) und sexueller Missbrauch. Der Richter folgerte, dass die Beschuldigten Teil einer nach militärischem Muster hierarchisch aufgebauten Organisation waren, die spätestens seit 1970 eine große Anzahl von Verbrechen geplant und ausgeführt hatte. Diese Organisation hatte sich nach dem Militärputsch vom 11. September 1973 mit dem Geheimdienst DINA verbündet und auf dem Gelände der CD ein Haftzentrum errichtet, in dem Verbrechen gegen Gegner_innen der Diktatur begangen wurden, deren Spuren später verwischt wurden.

Die Bedeutung dieses Urteilsspruchs lag insbesondere darin, dass Zepeda die Taten der CD als Verbrechen gegen die Menschheit wertete, obwohl es sich bei den verurteilten Colonos formal nicht um staatliche, sondern um zivile Akteure handelte. Er befand:

»De acuerdo al contexto en que se ha cometido el delito de asociación ilícita de autos, se concluye que éste es de lesa humanidad o contra la humanidad; delito en el que, además de los acusados agentes del Estado de Chile, fue cometido por acusados civiles cuya participación culpable ha sido analizada anteriormente en este fallo, los que, si bien no formaban parte de la organización militar regular de la época, colaboran con ésta activamente y aprovechan de dicha colaboración y del poder de dirección sobre un grupo de colonos alemanes, actuando en interés de los servicios de seguridad, también denominados >de inteligencia< de aquel entonces. ${ }^{166}$

162 CA Santiago, AZ 2182-98 (»Asociación Ilícita«), Bd. Il (Ministro), Bl. 677ff. Auto de procesamiento.

163 Dabei handelte es sich um Rebeca Schäfer, Peter Schmidt, Matthias Gerlach und Friedhelm Zeitner. Alle vier hatten Schäfer bei seinem Leben im Untergrund in Argentinien von 1997-2005 begleitet. Bei Rebeca Schäfer und Matthias Gerlach handelt es sich um adoptierte Chilenen.

Dies betrifft Paul Schäfer (†2010), Renate Freitag (†2013), Gisela Seewald (†2013) und Albert Schreiber (†2008).

165 Dies waren Hartmut Hopp, Hans-Jürgen Riesland und Albert Schreiber (alle CD) sowie Armando Fernandez Larios (DINA). 


\subsection{Colonia Dignidad - Ort, Rechtspersonen und Eigentumsstruktur}

Die Colonia Dignidad war in der Bundesrepublik Deutschland entstanden und hatte hierzulande eine Niederlassung, die bis 1995 existierte. Zwischen 1961 und 1963 siedelte ein Großteil der Gruppe nach Chile über. Ihren Fortbestand sicherte die CD durch eingebrachtes Vermögen von Gruppenmitgliedern sowie durch umfangreiche wirtschaftliche Tätigkeiten, die vor allem aufgrund der sklavenähnlichen, nicht entlohnten Arbeit der Gruppenmitglieder profitabel waren. Dazu gehörten auch illegale Aktivitäten wie Waffenhandel. Über Vereine, die in der Bundesrepublik (PSM) und in Chile (SBED und Organización Comunitaria de Desarrollo Social Perquilauquén) als gemeinnützig anerkannt waren, erhielt die CD von beiden Staaten jahrzehntelang steuerliche Vergünstigungen. In Chile kamen Zollfreiheit sowie staatliche Subventionen in Millionenhöhe für Schule und Krankenhaus hinzu. Von deutscher Seite flossen durch Rentenzahlungen für Gruppenmitglieder weitere Millionen direkt in die Kassen der CD-Führung. Eine Aufklärung dieser Vermögenssituation fand durch die chilenische Justiz nur partiell und durch die bundesdeutsche Justiz noch überhaupt nicht statt. Auch die Festnahme Schäfers 2005 führte nicht zu einer Auflösung der Gruppe. Vielmehr wurden die wirtschaftlichen Aktivitäten der Siedlung in Chile Ende der 1980er/Anfang der 1990er Jahre auf ein komplexes Netz geschlossener Aktiengesellschaften mit dutzenden Tochtergesellschaften übertragen. Diese werden von verbliebenen Mitgliedern der ehemaligen CD in derselben Siedlung - nun unter dem Namen Villa Baviera - bis heute weitergeführt.

2017 forderte der Deutsche Bundestag die Bundesregierung einstimmig auf, »die Klärung der Besitzverhältnisse der CD/Villa Baviera voranzutreiben, auch mit dem Ziel, dass Mittel aus dem Vermögen konkret den Opfern zugutekommen «. ${ }^{167}$ Am 12. Juli 2017 unterzeichneten Vertreter_innen der chilenischen und der Bundesregierung eine Absprache über die Einsetzung einer »chilenisch-deutschen Gemischten Kommission zur Aufarbeitung der >Colonia Dignidad « und Integration der Opfer in die Gesellschaft«. Diese soll sich u.a. mit »Überprüfung der Vermögenswerte sowie der aus der >Villa Baviera</'Colonia Dignidad hervorgegangenen Gesellschaften und Unternehmen « 168 befassen. Eine von der Gemischten Kommission beauftragte und von der Deutschen Gesellschaft für Internationale Zusammenarbeit (GIZ) angefertigte Machbarkeitsstudie zur Überprüfung der Vermögenssituation liegt seit 2018 vor. Die GIZ gab gegen-

167 Deutscher Bundestag. Drucksache 18/12943 vom 27.06.2017. Antrag der Fraktionen CDU/CSU, SPD und BÜNDNIS 90/DIE GRÜNEN. Aufarbeitung der Verbrechen in der Colonia Dignidad, S. 4 sowie Deutscher Bundestag. Plenarprotokoll 18/243 vom 29.06.2017, S. 25049A. 
über dem Rechtsanwalt der ABC-Firmen ${ }^{169}$ Juan Pablo Guzmán Giesen ${ }^{170}$ eine Verschwiegenheitsverpflichtung ab im Gegenzug für den Einblick in die Firmenbuchhaltung. ${ }^{171}$ Die Studie wurde vom AA als Verschlusssache eingestuft. Bundestagsabgeordnete konnten sie in der Geheimschutzstelle des Bundestages einsehen, dürfen jedoch nicht darüber sprechen.

\subsubsection{Rechtspersonen und Dependancen in der Bundesrepublik}

Ab 1955 errichtete die Gruppe um Paul Schäfer ein »Jugendheim« in Heide (Lohmar) bei Siegburg. Hierfür wurde Ende 1956 als offizieller Träger der Verein PSM gegründet. In der ersten bekannte Satzung vom 2. Januar 1958 wird auch Paul Schäfer als Mitglied des Vereinsvorstands aufgeführt. ${ }^{172}$ Soweit mir bekannt ist, war dies das letzte Mal, das Paul Schäfer innerhalb der CD-Struktur ein formales Amt innehatte. Erst 1968 wurde der Verein beim Amtsgericht Siegburg offiziell eingetragen und als gemeinnützig anerkannt. ${ }^{173}$ Vorsitzender der PSM war von 1956-1980 Hugo Baar. Mehrere Vereinsmitglieder waren Beschäftigte der Schaak und Kuhn oHG, die eine Reihe von Einzelhandelsgeschäften betrieb. ${ }^{174}$ Zudem gab es einen Transportbetrieb mit LKWs, der auf Kurt

169 Die Aktiengesellschaften Agripalma, Bardana und Cinoglosa (»ABC«) bilden seit 1989/1990 und bis heute die wirtschaftliche Struktur der CD. Sie wurden gegründet, um die Auflösung des gemeinnützigen Vereins Sociedad Benefactora y Educacional Dignidad (SBED) durch die chilenische Regierung im Jahr 1991 zu umgehen. (Vgl. Kap. 3.2.3).

170 Juan Pablo Guzmán war gemeinsam mit seinem Vater Cirilo Guzmán an der Gründung der ABCFirmen Ende der 1980er Jahre beteiligt. Vgl. PA AA, AV NA 32986. Schreiben Botschaft an das Sozialgericht Berlin vom 26.11.1996, Betr.: Beteiligung am Vermögen der ehemaligen Colonia Dignidad (CD).

171 Deutscher Bundestag. Drucksache 19/3380 vom 11.07.2018. Antwort der Bundesregierung auf die Kleine Anfrage der Fraktion DIE LINKE - Drucksache 19/2955 - Stand der Aufarbeitung der Verbrechen der Colonia Dignidad. Antworten auf Fragen 11-14.

172 Vgl. PA AA, B85, Bd. 598, Bericht 124/63 der Botschaft Santiago an das AA vom 25.01.1963.

173 Die Eintragung ins Vereinsregister erfolgte am 06.06.1968 unter der Nr. VR 637. Grundlage hierfür war die Vereinssatzung vom 04.11.1967. Darin werden als Vorstandsmitglieder genannt: Hugo Baar/Vorsitzender, Wilhelm Zeitner/stv. Vorsitzender, Gerhard Schmidtke/Geschäftsführer, Alfred Schaak/Schatzmeister und Erika Heimann/Schriftführerin. Kurioserweise bescheinigte das Siegburger Finanzamt dem Verein bereits am 27.03.1968 die Gemeinnützigkeit-und zwar rückwirkend für das Jahr 1965 (Steuernummer 132/442). PDM. Amtsgericht Siegburg, Vereinsregisterauszug VR 637 sowie PDM, Finanzamt Siegburg. Freistellungsbescheid vom 27.03.1968. Vgl. auch StA Bonn, 50 ]s 285/85, Bd. IX, BI. 59. Vernehmung Rita Seelbachs vom 06.09.1988.

174 Die am 1.10.1959 begonnene »Schaak und Kuhn ESKA oHG «, gegründet von Heinz Kuhn und Alfred Schaak, eingetragen im Handelsregister beim Amtsgericht Siegburg unter HR A 1026, hatte zum Zweck den »Einzel- und Großhandel mit Lebensmitteln, Obst- und Südfrüchten, Einzelhandel mit Textilien, Möbeln und Elektrogeräten, sowie eine Drogerie. « Heinz Kuhn schied am 31.07.1962 aus dem Handelsgeschäft aus, da er nach Chile reiste. Die Gesellschaft hieß fortan »Schaak oHC«. Die Cesellschaft soll 9 Lebensmittelgeschäfte und Drogerien in Siegburg und Umgebung betrieben haben. 1976 war jedoch nur noch ein Lebensmittelgeschäft feststellbar, in der Mühlenstr. 54 in Siegburg. PDM, Bestand PSM. »Bericht über die Private Sociale Mission e.V., Siegburg Michaelstr. 2 « von Jürgen Karwelat, 1976, S. 6. 
Schnellenkamp eingetragen war. ${ }^{175}$ Nach der Ausreise der Gruppe nach Chile führten Vertrauenspersonen Schäfers sowohl PSM als auch Schaak oHG bis in die 1990er Jahre weiter. ${ }^{176}$ Amnesty International schätzte 1977 die Größe der in Deutschland verbliebenen Gruppe auf 15 Personen. ${ }^{177}$ Als 1987 und 1988 die Medienberichterstattung über die CD zunahm, sanken die Gewinne der Schaak oHG. Gleichzeitig stieg durch das gesteigerte öffentliche Interesse der Druck auf die Staatsanwaltschaft Bonn, die bereits 1985 ein Ermittlungsverfahren gegen Paul Schäfer eröffnet hatte, das aber bisher erfolglos geblieben war. Am 26. April 1988 ließ die StA Bonn die Räumlichkeiten von PSM und Schaak oHG durchsuchen. Unter den dabei sichergestellten Akten befand sich auch die Korrespondenz mit der CD in Chile. In einem Brief des Leiters der PSM Alfred Matthusen an Schäfer heißt es:

»Da der Baarsatan unsere Arbeitsweise kennt, hier mit Geldern von drüben einkaufen und die Teile als Geschenksendung rüberschicken, wird er nicht locker lassen, bis sie auch da nachforschen [...] Lieber Tio, ich glaube, die Zeit rückt näher um hier das Meiste aufzulösen. ${ }^{178}$

Matthusens Brief schließt mit den Worten: »Viele Grüße aus dem immer fieser werdenden Deutschland «. ${ }^{179} 1995$ löste die PSM sich formell auf. ${ }^{180}$

\section{Das Jugendheim Heide (Lohmar)}

Das erste Domizil der Gruppe, das Jugendheim in Heide (Lohmar) war ab 1955 errichtet worden. Paul Schäfer hatte das Grundstück vom Kölner Rechtsanwalt Dr. Dr. Otto Nelte gekauft, der in Nürnberg den NS-Kriegsverbrecher Wilhelm Keitel verteidigt hatte.$^{181}$ Architekt war Hans Wieske, der später auch den Bau der Gebäude auf dem CD-Gelände in Chile anleitete. ${ }^{182}$ Am 23. September 1960 wurde das Jugendheim in Heide (Lohmar)

CA Santiago, AZ 2182-98 (»Ley de Control de Armas«), Bd. II, BI. 703. Informe Médico Legal 5025-05 de Kurt Herbert Schnellenkamp Nelaimischkies vom 05.01.2006.

Die Schaak oHC wurde im Mai 1992 aus dem Handelsregister gestrichen (vgl. Kölner Stadtanzeiger, »Kolonie der Qualen«, S. 17), der PSM e.V. wurde am 19.08.1995 vom Siegburger Amtsgericht die Rechtsfähigkeit entzogen (vgl. LG Bonn, Pressemitteilung des vom 18.11.1997 zur Beendigung des Verfahrens 30 123/77.). Als wichtigste Vertreter der CD in der Bundesrepublik fungierten Hugo Baar (bis 1975), Alfred Schaak (bis 1985), Alfred Matthusen (ab 1985) sowie Rita Seelbach. Amnesty International, Colonia Dignidad: deutsches Mustergut, S. 50.

178 StA Bonn, 50 ]s 285/85, Bd. 9, Bl. 142ff. Schreiben Alfred (Matthusen) »Crüß Cott Tio« (Schäfer) vom 20.03.1988.

179 Ebd.

180 Auf eigenen Antrag entzog das Amtsgericht Siegburg der PSM am 16.08.1995 die Rechtsfähigkeit, da die Mitgliederzahl auf unter drei gefallen sei. Vgl. Cesterkamp, Harald. »Ein Ende des unendlichen Prozesses« in: Al-Journal 10/1997, S. 6-12, hier S. 12.

181 Kölner Stadtanzeiger. Sonderdruck »Kolonie der Qualen«, August/September 1997, S. 9 und Ossendorf, Karlheinz. Colonia Dignidad - Die »Würde« gab es nur im Namen. Die Sekte Private Sociale Mission im Raum Siegburg, in: Ceschichts- und Altertumsverein für Siegburg und den RheinSieg-Kreis e. V. (Hg.). Heimatblätter des Rhein-Sieg-Kreises 2009, 77. Jahrgang, Siegburg 2009, S. 240-269, hier S. 241. Karwelat berichtet ebenfalls, das Grundstück in Heide (Lohmar) sei auf Paul Schäfer eingetragen gewesen. PDM, Bestand PSM. »Bericht über die Private Sociale Mission e.V., Siegburg Michaelstr. 2« von ]ürgen Karwelat, 1976, S. 1.

182 Vgl. Amnesty International, Colonia Dignidad: deutsches Mustergut, S. 34. 
offiziell eingeweiht. Im Oktober 1961 waren dort 65 Erwachsene und Kinder polizeilich gemeldet. ${ }^{183}$ Am 13. Dezember 1961 wurde das Heim an die Bundeswehr verkauft und am 15. Januar 1962 übergeben. ${ }^{184}$ Teile eines Wachbataillons aus Bonn zogen dort ein, später betrieb der Generalarzt der Luftwaffe dort ein Untersuchungszentrum. Der Kaufpreis soll 900.000 DM betragen haben. ${ }^{185}$ Hugo Baar betrieb sein Missionsbüro nun in der Wolsdorfer Straße 83 in Siegburg. ${ }^{186}$

\section{Lebensmittelläden der Schaak und Kuhn $\mathrm{oHG}^{187}$}

Ein wichtiges wirtschaftliches Standbein der CD waren die von Heinz Kuhn und Alfred Schaak geführten Lebensmittelgeschäfte in Siegburg. Die Läden verkauften u.a. Lebensmittelprodukte aus der Colonia Dignidad. Eine Reihe junger Frauen aus der Gruppierung arbeitete dort unentgeltlich, bzw. für ein Taschengeld. In den 1960er Jahren wurden insgesamt neun Läden betrieben, 1977 war es nur noch ein einziger (Mühlenstraße 54). Dieser existierte bis 1989. ${ }^{188}$ Hugo Baar berichte im Jahr 1985 darüber:

»Im Erdgeschoß befindet sich ein Lebensmittelgeschäft. [...] In der 1. und 2. Etage wohnen die Verkäuferinnen. Insgesamt sind außer Herrn Schaak und einem pensionierten Herrn, dessen 3 Kinder in Chile sind, noch ca. 11 weibliche Personen, die zur Privaten Socialen Mission gehören. ${ }^{189}$

\section{Südweg 32, Hennef-Heisterschoß}

Bis 1990 hatten PSM und Schaak oHG ihren Sitz in einem zweistöckigen Haus in Hennef-Heisterschoß, unweit von Siegburg. Laut Nachbar_innen wohnten dort vier bis sechs Personen, auffällig sei eine 15 Meter hohe Kurzwellenantenne gewesen. Nach einem Überfall $1988^{190}$ wurden Kameras und Bewegungsmelder installiert, zwei Schä-

183 Kölner Stadtanzeiger. Sonderdruck »Kolonie der Qualen«, August/September 1997, S. 15.

184 PA AA, B85, Bd. 598. Polizeiliche Vernehmung Hugo Baars vom 15.02.1963.

185 Vgl. Colonia Dignidad - Der doppelte Skandal: Der Prozeß vor dem Bonner Landgericht - eine Dokumentation. Lateinamerika Nachrichten, Sondernummer September 1980, S. 8 sowie Heller, Friedrich Paul. Lederhosen, Dutt und Giftgas: Die Hintergründe der Colonia Dignidad, 4. erweiterte und aktualisierte Aufl., Stuttgart 2011, S. 16.

186 PA AA, B85, Bd. 598. Polizeiliche Vernehmung Hugo Baars vom 15.02.1963.

187 In Kölner Stadtanzeiger, »Kolonie der Qualen«, S. 6, heißt es: »In Siegburg und Umgebung unterhielt die PSM noch bis Ende der achtziger Jahre eine Kette von Lebensmittelgeschäften unter dem Namen »Schaak OHG «. Dort wurden auch landwirtschaftliche Produkte der Colonia Dignidad verkauft [...] Nachdem 1977 die Menschenrechtsorganisation Amnesty International Zeugen benennen konnte, wurde sogar zum Boykott der Lebensmittelläden aufgerufen. 1989 wurden die Siegburger Geschäfte endgültig geschlossen.«

188 Vgl. Amnesty International, Colonia Dignidad: deutsches Mustergut, S. 50.

189 PA AA, B 83, Bd. 2384. Bericht von Hugo Baar an die deutsche Botschaft vom 02.04.1985, S. 7.

190 Vgl. A MMDH, Bestand Dieter Maier, Carpeta 16. Pressemitteilung von RA Gatzweiler und Presseartikel. Bei dem Überfall am 30.11.1988 sollen die Hausbewohner im Keller gefesselt und umfangreiches Akten- und Filmmaterial gestohlen worden sein. Gatzweiler beschwerte sich beim Fernsehsender RTL: Spiegel-TV habe in seiner Sendung vom 19.06.1989 Filmmaterial ausgestrahlt, das am 30.11.1988 entwendet worden sei. PA AA, AV NA 31675. Schreiben von RA Gatzweiler an den Chefredakteur der Fernsehanstalt RTL Plus, den Verantwortlichen für Spiegel TV sowie den Re- 
ferhunde bewachten den Garten. In Berichten wird auch ein Haus in der Michaelstraße 2 in Siegburg erwähnt, auf dem »hohe Antennen standen ${ }^{191}$

\subsubsection{Niederlassungen der Colonia Dignidad in Chile}

Nach ihrer Ankunft in Santiago im Januar 1961 begaben sich Paul Schäfer und Hermann Schmidt auf die Suche nach einem geeigneten Grundstück. Schon nach wenigen Tagen trafen sie auf den deutschstämmigen Juden Rudi Cohn Baden, mit dem sie sich anfreundeten. ${ }^{192}$ Er stellte ihnen für einige Jahre sein Wohnhaus in der Calle Villalobos 666 in Santiago als Anlaufstelle zur Verfügung. Zudem wurde er Vizepräsident des CD-Vereins SBED. ${ }^{193}$

\section{Das Kerngelände der Colonia Dignidad}

Im Oktober 1961 wurde von einer italienischen Kolonisationsgesellschaft das Landgut El Lavadero in Südchile erworben. ${ }^{194}$ In den Folgejahren kamen die benachbarten Landgüter El Pasto (1966) und El Peumo (1968) hinzu. ${ }^{195}$ Das entlegene Gut liegt in der Vorkordillere der Anden, etwa 350 Kilometer südlich von Santiago. Ausgehend von der Kleinstadt Parral erreichte man die Colonia Dignidad nach 40 Kilometern Fahrt über eine nicht-asphaltierte Schotterstraße. ${ }^{196}$ Über die Jahre hinweg vergrößerte sich das Gelän-

dakteur Warner Poelchau, Betr: Spiegel TV am 19.06.1989 Die entwendeten Akten wurden später dem HIS-Archiv übergeben.

Kölner Stadtanzeiger, »Kolonie der Qualen«, S. 11.

192 StA Bonn, AZ 50 ]s 285/85, Bd. 7, Bl. 247ff. Transkription eines Radiointerviews mit Rudi Cohn Baden bei Radio FFN, Frankfurt a.M., April 1988. Vgl. auch Juzgado del Crimen de Talca, AZ 10-2004 (»Tortura, detención ilegal y secuestro de Adriana Bórquez Adriazola), Bl. 480. Vernehmung von Heinz Kuhn am 16.06.2004.

193 Rudi Cohn gab an, mit Schäfer und der CD-Führung gebrochen zu haben, als er nach der Flucht Wolfgang Müllers (Kneese) 1966 erfahren hatte, dass Schäfer Kinder in seinem direkten Umfeld missbraucht hatte. Vgl. StA Bonn, AZ 50 Js 285/85, Bd. 7, Bl. 247ff. Transkription eines Radiointerviews mit Rudi Cohn Baden bei Radio FFN, Frankfurt a.M., April 1988.

194 Hermann Schmidt und Rudolph Cöllen erwarben am 9.10.1961 den Fundo El Lavadero, hijuela parcela 3 (3062 Hektar plus Wasserrechte) von der Compañia Chileno-Italiana de Colonización S.A. (CITAL). Diese war mit ihrem Vorhaben, das Gelände für die Landwirtschaft urbar zu machen, gescheitert. Der SBED wurde eine Nutznießung für 30 Jahre eingeräumt. PA AA, AV NA 31576. Vorgänge um die ehem. Colonia Dignidad, hier: Grundbuchauszüge. Zuvor hatte die CD-Führung in Erwägung gezogen, ein Stück Land bei Catemu zu erwerben, das Rudi Cohn veräußern wollte. Das Land war den Colonos jedoch zu klein. Cohn half der CD jedoch fortan bei der Grundstücksuche und wurde auch Vorstandsmitglied der im Oktober 1961 gegründeten Rechtsperson SBED. Auch der Kauf des Landgutes El Huaro bei Concepción war zuvor gescheitert (Vgl. La Segunda 10.06.1997, Sonderbeilage »36 años de »Dignidad« en Chile«, S. 4). Bei der Abwicklung der ersten Rechtsgeschäfte wurde die CD von Rechtsanwältin Sofia Mayanz de Zahler unterstützt, der Mutter des ehemaligen Präsidenten der chilenischen Zentralbank.

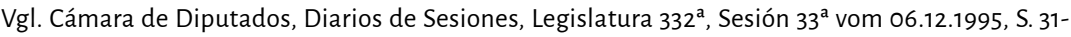
88. Informe de la Comisión Especial Investigadora de la Cancelación de la Personalidad Jurídica de Colonia Dignidad, creada con el objeto de verificar la forma como se dio cumplimiento al decreto supremo que disolvió esa institución, S. 45. El Pasto wurde von der SBED gekauft, während El Peumo auf Walter Laube eingetragen wurde. 1973 wurde El Peumo an Cerhard Mücke übertragen. Heute ist die Straße vollständig asphaltiert. 
de durch Zukäufe anliegender Ländereien auf eine Gesamtfläche von zwischen 14.000 und 17.000 Hektar. ${ }^{197}$ Ein Teil dieses Geländes war ab den 1960er Jahren mit einem etwa 2,80m hohen Zaun umgeben. Die anfänglichen Holzpfeiler wurden später durch etwa 8.000 Betonpfeiler ersetzt.${ }^{198}$ Bereits in den 1960er Jahren wurde eine Flugzeuglandepiste errichtet. Diese soll in den 1970er Jahren verlängert worden sein, um Flugzeugen der chilenischen Luftwaffe die Landung zu ermöglichen. ${ }^{199}$ Die Siedlung der CD besteht aus etwa 50 Gebäuden - Wohnhäusern, Werkstätten und Schuppen, die relativ kompakt auf einer Fläche von etwa 183 Hektar angeordnet sind. ${ }^{200} 2016$ wurde diese Fläche unter Denkmalschutz gestellt. ${ }^{201}$ Um das Dorf herum liegen landwirtschaftliche Nutzflächen. Vor allem in Osten befinden sich weitläufige, hügelige Waldstücke, die teilweise forstwirtschaftlich genutzt werden. Neben diesem Kerngelände, das die Colonos als Fundo (Landgut) bezeichnen, erwarb die CD folgende weitere Ländereien und Immobilien in Chile:

\section{Restaurant und Steinbrecheranlage in Bulnes}

Das knapp 300 Hektar große Landgut El Litral in Bulnes, etwa 100 Kilometer südlich der CD gelegen, beherbergt bis zum heutigen Tage das 1984 eröffnete Restaurant "Casino Familiar « sowie eine bereits seit den $1960 e r$ Jahren betriebene Steinbrechanlage. ${ }^{202}$ Das Restaurant war und ist als einzige öffentliche Dependance wichtig für das Außenbild der Colonia Dignidad. Der Steinbruch war bis zu seinem Verkauf 2015 ein wichtiges wirtschaftliches Standbein der CD dar. El Litral verfügt über eine nicht-asphaltierte Start- und Landepiste für Kleinflugzeuge.

\section{Stadthäuser in Santiago}

Die CD verfügte stets über eine Anlaufstelle in Santiago. Diese diente als Übernachtungsstätte für Colonos, zum Vertrieb für in der CD produzierte Waren, als Lager für Warenlieferungen aus Siegburg sowie als Ort für Empfänge und Besprechungen. Bis

197 Im Jahr 2006 gab der chilenische Regierungsbeauftragte für die CD, Herman Schwember, die Cesamtfläche des CD-Grundeigentums in den Cemeinden Parral und Bulnes mit 15.738,7 Hektar an. VgI. PJS, Sammlung CD. Delegado de Cobierno (Herman Schwember) - Programa Integral de Transición Comunidad de Villa Baviera (ex Colonia Dignidad), März 2006, S. 32.

198 Rittel, Heike/Jürgen Karwelat. Lasst uns reden. Frauenprotokolle aus der Colonia Dignidad, Stuttgart 2018, S. 24.

199 CA Santiago, AZ 2182-98 (»Asociación Ilícita«), Bd. IV (Ministro), Bl. 1789. Richterliche Vernehmung von Eduardo Guy Neckelmann Schütz vom 18.10.2006.

200 Die Angabe von etwa 183 Hektar verwendete der chilenische Staat, der das Celände 2016 als historisches Monument unter Denkmalschutz stellte. Vgl. Diario Oficial N 41.530 vom 10.08.2016. Ministerio de Educación. Decreto 208 vom 18.07.2016. »Declara Monumento Nacional en la Categoría de Monumento Histórico al >Conjunto de Inmuebles y Sitios Correspondientes a la Ex Colonia Dignidad, ubicados en la comuna de Parral, provincia de Linares, Región del Maule«.

201 Vgl. ebd. Das Dekret besagt, dass ohne Erlaubnis des Consejo de Monumentos Nacionales (CMN) keinerlei Veränderung an den historischen Stätten vorgenommen werden darf.

202 Die zur Aktiengesellschaft Abratec S.A. gehörende Steinbrechanlage wurde am 26.05.2015 veräußert. 2019 stellte der Käufer Antrag auf Rückabwicklung des Kaufes wegen Betrugs. Vgl. Séptimo Juzgado Civil de Santiago, AZ C 16102-2019 (»Olavarría/Schreiber«), Klageschrift Felix Orlando Olavarría Vergara vom 05.07.2019, »Demanda nulidad relativa de actos y contratos por dolo.« 
mindestens 1975 verfügte die CD über eine Wohnung in der Calle Román Díaz 512 im Stadtteil Providencia. ${ }^{203}$ Dort sollen nach dem Putsch von 1973 auch Treffen zwischen Schäfer und dem DINA-Chef Manuel Contreras stattgefunden haben. ${ }^{204}$ Am 15. Januar $1975^{205}$ erwarb die SBED ein großes zweistöckiges Haus in der Calle Campo de Deportes 817 im Stadtteil Nuñoa, nur wenig Meter vom Haupttor des Estadio Nacional de Chile (Nationalstadion) entfernt. Das Haus wurde mit Funk- und Überwachungstechnologie sowie mit einer hydraulischen Rampe versehen, mit der Autos und Lastwagen unter der Erde geparkt und so versteckt werden konnten. Hohe DINA-Funktionäre gingen in dem Haus ein und aus. ${ }^{206} 1975$ fand dort ein Empfang für die Ehefrau Pinochets, Lucía Hiriart de Pinochet, statt. Auch der Geheimdienstchef und die Justizministerin waren bei diesem Treffen anwesend. ${ }^{207}$ Möglicherweise wurde das Haus auch als Folterstätte genutzt. ${ }^{208}$ Jahrelang fungierte Alfred Matthusen als »Leiter des Hauses. Er pflegte auch den regelmäßigen Kontakt zur deutschen Botschaft. Die Botschaft bezeichnete ihn als »ständige[n] Vertreter ${ }^{209}$ oder »Verbindungsmann ${ }^{210}$ der CD. Am 18. Januar 1988 explodierte im Garten des Hauses eine Bombe. ${ }^{211}$ Nach Ende der Diktatur demons-

203 PA AA, AV NA 31582. Passantrag Paul Schäfer vom 24.04.1975.

204 PJS, Sammlung Gesprächsnotizen. Notiz des Gesprächs von Dieter Maier mit Bernd Schaffrik und Waltraud Schaak vom 11.11.2011. Auch der Pressesprecher der Militärjunta, Federico Willoughby berichtete in seiner Aussage bei Richter Zepeda von einem Treffen mit Alfred Matthusen in der Wohnung in der Calle Román Díaz (Vgl. CA Santiago, AZ 12.293.2005 »homicidio Miguel Becerra Hidalgo«. Urteil vom 27.11.2008. S. $6 f$.

205 PJS, Sammlung Seewald. »historia de predios y entidades«.

206 CA Santiago, AZ 2182-98 (»]uan Maino«), Bd. 5a, BI. 2168. Richterliche Vernehmung von Siegfried Hoffmann vom 04.10.2005. Darin heißt es: »cuando realizaba labores en Santiago, residiendo en la casa de Campo de Deportes, se realizaron reuniones y almuerzos con militares, concurriendo entre otros Manuel CONTRERAS, pero en esas ocasiones viajaban a ser de anfitriones Paul SCHÄFER, Albert SCHREIBER o Alfred MATTHUSEN, manteniéndome SCHÄFER, siempre al margen de estas actividades."

207 Willoughby berichtet über diesen Empfang: »En 1975 y con ocasión de una recepción en honor de la señora Lucía Hiriart, de unas 50 personas, fuimos invitados a la casa de Campos de Deportes. Les facilité recetas inglesas para preparar venado. La comida, muy formal, fue una de las últimas ocasiones en que vi a Schneider, que aparecía disimulado entre el personal que atendía las mesas. « Willoughby-MacDonald, Federico. La Guerra. Historia íntima del poder en los últimos 55 años de política chilena 1957-2012, Santiago 2012, S. 143. Die Nummer 2 der DINA, Pedro Espinoza, war ebenfalls bei diesem Empfang anwesend und sagte darüber bei Richter Zepeda aus: »concurrí en una oportunidad a una recepción que se hizo en la casa que tenían los colonos en la calle Campos de Deportes, donde asistió la señora Lucía Hiriart de Pinochet, una hija de ésta, el coronel Contreras, la señora Mónica Madariaga y otras personalidades. «CA Santiago, AZ 2182-98 (»Asociación Ilícita«), Urteil vom 09.04.2014, S. 73.

208 Die ehemalige sozialistische Gefangene und spätere Kollaborateurin der DINA, Luz Arce Sandoval, gab an, 1974 in einem Haus gefoltert worden zu sein, das nicht der DINA gehörte. Möglicherweise handelte es sich dabei um das Haus Calle Campo de Deportes 817. Bei ihrem Folterer mit dem Decknamen »]avier « handelte es sich möglicherweise um Hartmut Hopp. CA Santiago, AZ 2182-98 (»Alvaro Vallejos Villagrán«), Bd 4a, BI. 1280. Aussage von Luz Arce vom 09.06.2000.

209 PA AA, AV NA 31581, Vermerk von Petersmann (RK 543) vom 30.09.1976, Betr: Kolonie »Dignidad «.

210 PA AA, ZW 111130. Bericht Nr. 1322/78 Botschafter Strätling an AA vom 15.12.1978.

211 Laut Albert Schreiber und Erna Hühne, die sich im Haus aufhielten wurde ein Sprengsatz über die Mauer geworfen. VgI. PJK. Bundestagsanhörung, Eidesstattliche Erklärungen Schreiber und Hüh- 
trierten vor dem Haus mehrfach Angehörige von Verschwundenen. ${ }^{212} 1997$ fanden in dem Haus gleich drei Razzien statt, da es als möglicher Fluchtort Schäfers galt. ${ }^{213}$ Seit 1985 existierte eine private Telefon-Direktleitung zur Colonia Dignidad. ${ }^{214} 1990$ erfolgte eine weitere Verbindung zu einer Dependance des Heeres. ${ }^{215}$ Nach Schäfers Festnahme war vereinzelt gefordert worden, das Haus in eine Gedenkstätte zu verwandeln und dort ein Museum einzurichten. ${ }^{216}$. Die CD verkaufte das Haus jedoch 2010 an die Reinigungsfirma Maclean. ${ }^{217}$

\section{Das Haus der Colonia Dignidad in Parral}

1974 stellte die Colonia Dignidad dem Geheimdienst DINA ein Haus in Parral zur Verfügung. Die SBED hatte das Gebäude zuvor von der Witwe des Parraler Arztes und CD-Freundes Mario Mujica erworben. Solange die DINA bestand (1974-1977), befand sich dort das Hauptquartier der BIR-Sur, ${ }^{218}$ der einzige Brigade der DINA, die außerhalb von Santiago stationiert war. Sie war zuständig für die Informationsgewinnung und Repression in der Region zwischen Rancagua und Concepción. Die BIR-Sur verfügte über etwa 50 Agent_innen in verschiedenen Städten, die von 1974 bis 1976 von Fernando Gómez Segovia sowie 1976/1977 von Eduardo Guy Neckelmann Schütz befehligt wurden. Nach dem Auszug der DINA renovierten Colonos das Haus. Sie installierten Bewegungsmelder, die automatisch Alarm auslösten und Fotos machten, sobald sich jemand dem Haus auf einige Meter näherte. ${ }^{219} 1986$ verkaufte die SBED das Haus an Estela del Carmen Espinoza Hernández. Auf Antrag einiger Sektionen der Angehörigenorganisation der Verschwundenen (AFDD) stellte der Consejo de Monumentos Nacionales (chilenischer Denkmalrat, CMN) das Haus 2018 unter Denkmalschutz. ${ }^{220}$

ne vom 18.02.1988. Der Journalist Cero Cemballa berichtete, der ehemalige DINA Chef Contreras habe das Haus 3 Wochen zuvor besucht. Es sei unklar, ob es sich bei dieser Bombe tatsächlich um einen Angriff handelte, oder ob es sich, wie Gemballa andeutete, um eine Selbstinszenierung der CD handelte, um sich zum Opfer stilisieren zu können. Cemballa, Gero. »Munition für das Folterlager«, in: Der Stern Nr. 8/1988 vom 18.02.1988, S. 236-238. Gemballa.

212 Vgl. La Nación vom 17.08.1997, S. 10. »Querella criminal contra Dignidad«, sowie La Epoca vom 03.05.1998, S. 14. »Dignidad: Terminó ocupación policial«.

213 Vgl. El Mercurio vom 08.12.1997, S. C1. »Allanan por tercera vez inmueble de ex-Colonia«.

214 Vgl. El Metropolitano vom 04.08.2000, S. 10. »Denuncian que Ejército protegería a Colonia Dignidad«. Die Heeresdependance liege in der Calle San Ignacio 242.

215 Ebd.

216 Bericht der Kongressabgeordneten Nelson Avila und Guillermo Ceroni vom August 2000. Vgl. La Tercera vom 08.01.2006, S. 20. »Ex-colonos buscan transformar casa en museo de la tortura«.

217 Vgl. Moya, Laura. La represión en el barrio de José Domingo Cañas durante la dictadura (1973-1990). Memoria de los vecinos. Santiago 2013.

218 Das Haus befindet sich in der Calle Ignacio Carrera Pinto (ehemals Calle La Unión) 262 im Zentrum von Parral.

219 Vgl. PJS, Sammlung CD. Protokoll der Anhörung von Waltraud und Hugo Baar vor der Comisión Nacional de Verdad y Reconciliación vom 02.11.1990.

220 Vgl. Consejo de Monumentos Nacionales (CMN). Noticia: »El CMN aprueba solicitud de declaratoria del sitio de memoria Cuartel de la DINA en Parral como monumento histórico«, 27.12.2018, online unter https://www.monumentos.gob.cl/prensa/noticias/cmn-aprueba-solicitud-declaratoria -sitio-memoria-cuartel-dina-parral-como-monumento. 


\section{Weiteres Grund- und Immobilienvermögen der Colonia Dignidad}

Im Untergrund in Argentinien lebte Paul Schäfer in Immobilien, die Peter Schmidt erworben haben soll. Es handelt sich um die Finca La Solita in Chivilcoy (Provinz Buenos Aires) sowie um ein weiteres Anwesen in Tortuguitas, einem Vorort von Buenos Aires. ${ }^{221}$ Schmidt selbst sagte 2007 aus, dass er die Finca La Solita erworben habe, das Geld hierfür habe jedoch nicht von der CD gestammt. ${ }^{222} 1995$ erwarb die von Colonos gegründete Gesellschaft Transportes y Rentas La Esperanza Limitada zwei Wohnungen in Concepción. ${ }^{223} 1997$ oder 1998 reisten Rebeca Schäfer, Peter Schmidt und Hartmut Hopp nach St. Kitts und Nevis. Dort erwarben sie eine Wohnung in einer Feriensiedlung. Paul und Rebeca Schäfer erhielten für diese Investition Reisepässe des Karibikstaates auf den Namen Paul und Rebeca Berger. ${ }^{224}$ Was nach Schäfers Festnahme aus den genannten Immobilien in Argentinien, Chile sowie St. Kitts und Nevis wurde, ist nicht bekannt.

\subsubsection{Rechtspersonen und Eigentumsstruktur der Colonia Dignidad in Chile}

Ab 1961 übertrug die CD große Teile ihres zuvor in Deutschland angehäuften Vermögens nach Chile. Dazu gehörten auch Erlöse aus Verkäufen der Privathäuser von Gruppenmitgliedern. ${ }^{225}$ Aufstellungen der CD zufolge summierten sich allein die Einnahmen aus etwa zehn Hausverkäufen Anfang der 1960er Jahre auf rund 400.000 DM. ${ }^{226} \mathrm{Hinzu}$ kamen die erwähnten 900.000 DM für das Jugendheim in Heide (Lohmar). Wenige Monate nach Ankunft der ersten Colonos in Chile, im Juli 1961, wurde der Verein Sociedad

221 CA Santiago, AZ 2182-98 (»Asociacion Ilícita«), Bd. IV (Ministro), BI. 1661f. Richterliche Vernehmung von Rebeca Schäfer vom 20.10.2006 sowie ebd., Bl. 186of. Richterliche Vernehmung von Peter Schmidt vom 25.01.2007

222 CA Santiago, AZ 2182-98 (»Asociacion llícita«), Bd. IV (Ministro), BI. 1861. Richterliche Vernehmung von Peter Schmidt vom 25.01.2007.

223 PJS, Sammlung CD. Delegado de Gobierno (Herman Schwember) - Programa Integral de Transición Comunidad de Villa Baviera (ex Colonia Dignidad), März 2006, S. 32

224 CA Santiago, AZ 2182-98 (»Asociación llícita«), Bd. I (Ministro), BI. 247. Schreiben (oficio reservado) PDI - Fuerza de Tarea Dignidad an das Jugzado de Parral vom 28.04.2005. Subprefecto Rojas teilt in diesen Schreiben mit, er habe vom deutschen Konsul Fischer erfahren, dass der Reisepass des Staates St. Kitts and Nevis von Rebeca Schäfer, Nr 0077021, am 09.09.1998 auf den Namen Rebeca Carmen Berger ausgestellt wurde. Zuvor hatte Rebeca Schäfer am 15.07.1998 bei dem Registro Civil in St. Kitts eine Namensänderung beantragt. Vgl. auch: CA Santiago, AZ 2182-98 (»Armas«), Bd. II, Bl. 434ff. Richterliche Vernehmung von Hartmut Hopp vom 29.09.2005.

225 CA Santiago, AZ 2182-98 (»Asociación Ilícita«), Bd. I (Parral), BI. 330. Polizeiliche Aussage von Erich Fege vom 14.10.2000. Darin berichtet Fege: »En el mes de octubre del año 1961 llegué a este país [...] Para viajar hasta acá tuve que vender mi casa y mi automóvil, aportando a la Sociedad Benefactora aproximadamente veinticinco mil marcos." PJS, Sammlung Seewald. Dokumente »Aufstellung« und »Antecedentes«, o.D. 
Benefactora y Educacional Dignidad (SBED) gegründet. ${ }^{227}$ Ziel des Vereins war es laut Satzung,

»der bedürftigen Jugend Hilfe zu leisten; den obdachlosen und hilflosen Kindern und Jugendlichen im Allgemeinen und im Besonderen jenen in den vom Erdbeben des Jahres 1960 betroffenen Provinzen, durch körperliche und geistige Ertüchtigung sowie sittlicher, schulischer, technischer und landwirtschaftlicher Erziehung, um ihnen ein würdiges Leben zu ermöglichen. ${ }^{228}$

$\mathrm{Zu}$ diesem Zwecke sollte im Süden Chiles Land erworben und darauf ein Jugendheim, eine Schule und Werkstätten errichtet werden. Präsident der SBED war von der Gründung bis zur Auflösung 1994 Hermann Schmidt Georgi. ${ }^{229}$ Weitere Vorstandsposten rotierten über die Jahre, waren aber stets mit absoluten Vertrauensleuten Schäfers besetzt. ${ }^{230}$ Schäfer selbst war nie Mitglied des Vorstands.

Die Ländereien und Firmen der CD wurden von Beginn an auf Privatleute eingetragen - allesamt führungstreue Colonos ${ }^{231}$ - sie waren meist nicht Eigentum der SBED. ${ }^{232}$ Die formellen Eigentümer übertrugen der SBED daraufhin ein Nießbrauchrecht. Eine 1968 von der Cámara de Diputados eingesetzte Untersuchungskommission rügte dieses Vorgehen in ihrem Bericht ${ }^{233}$ und forderte eine umgehende Übertragung der Grundstücke und Vermögenswerte an die SBED, was jedoch nicht geschah. Ein Grund für das Vorgehen der CD war möglicherweise die Angst vor einem Vermögensverlust im Falle einer Vereinsauflösung oder einer Landreform. Das Eigentum am bis zu 17.000 Hektar umfassenden Kerngelände der CD wurde mehrfach unter führungstreuen Colonos umgeschichtet. Insbesondere 1977 und 1986 fanden Parzellierungen statt.

227 Die Vereinsgründung und Verabschiedung der Satzung erfolgten am 25.06.1961, am nächsten Tag erfolgte im Notariat von Fernando Escobar die Beurkundung. Über die Rechtsanwältin Sofia Mayanz de Zahler beantragten Hermann Schmidt Georgi, Rudi Cohn Baden und Erhard Eidner Herold schließlich beim Staatspräsidenten die Eintragung als Rechtsperson. Die Eintragung erfolgte per Dekret. CA Santiago, AZ 2182-98 (»Alvaro Vallejos Villagrán«), Bd. 6a, Bl. 2170f. Dekret Nº 3949 des Justizministers vom 21.09.1961.

228 Ebd., Bl. 2177.

229 Die Auflösung der SBED erfolgte per Dekret. Vgl. Diario Oficial Nº 33.896 vom 16.02.1991. Ministerio de Justicia, Decreto $N^{\circ} 143$ vom 31.01.1991. Declara disuelta y cancela personalidad jurídica y destina bienes de entidad que indica. Die CD klagte durch alle Instanzen gegen diese Entscheidung, so dass die Auflösung erst 1994 rechtskräftig wurde.

230 StA Bonn, 50 ]s 285/85, Bd. 1, BI. 128. Der Vorstand bestand am 19.05.1985 aus Hermann Schmidt (Präsident), Hans-Jürgen Blanck (Vizepräsident), Dr. Hartmut Hopp (Sekretär), Albert Schreiber (Schatzmeister) und Rudolf Cöllen (Stv. Schatzmeister).

231 PA AA, AV NA 31576. Vorgänge um die ehem. Colonia Dignidad, hier: Crundbuchauszüge. Das Dokument führt folgende Colonos als Eigentümer der diversen Grundstücksparzellen der CD auf: Hermann Schmidt, Rudolf Cöllen, Erwin Bohnau, Kurt Schnellenkamp, Johan Spatz, Walter Laube, Erich Fege, Karl van den Berg, Alfred Matthusen, Gerhard Mücke.

232 Lediglich ein kleiner Teil des Crundbesitzes der Colonia Dignidad war zeitweise auf die SBED eingetragen. AdsD, NL Ernst Waltemathe, Ordner/Box Nr. 12. Informe »Sociedad Benefica y Educacional Dignidad«, o. A. [vermutlich CDE], O. P. N 3 , S. 32.

233 Cámara de Diputados, Diarios de Sesiones, Legislatura extraordinaria periodo 1968-1969, Sesión $12^{\text {a }}$ vom 26.11.1968, S. 1131-1161. Informe de la Comisión Especial designada para investigar las actividades de la Sociedad Benefactora y Educacional »Dignidad«, de Parral. 
Die 1977 in »Dignidad« umbenannten Einzelgrundstücke wurden 1986 in »Villa Baviera« umbenannt. ${ }^{234}$

Die ersten Jahre der CD in Chile standen im Zeichen der »Aufbauarbeit ${ }^{235}$ - Gebäude wurden errichtet, Wege gebaut und Felder urbar gemacht. Dabei entwickelte sich schnell eine rege Geschäftstätigkeit. Nach außen hin beteuerte die CD stets, dass alle Einnahmen in die soziale Arbeit flössen. Dies führte dazu, dass die SBED als gemeinnützige Organisation von der Zahlung von Körperschaftssteuern befreit wurde. ${ }^{236}$ Verschiedene Quellen legen jedoch nahe, dass die SBED den chilenischen Behörden bis Ende der 1980er Jahre keinerlei oder nur prekäre Nachweise über ihre Geschäftstätigkeit erbrachte. Selbst auf Nachfrage behauptete sie pauschal, alle Überschüsse flössen in die soziale Arbeit, insbesondere in das Krankenhaus. Bereits bei einer Inspektion 1968 hatte der CDE eine umfangreiche wirtschaftliche Tätigkeit der SBED festgestellt. ${ }^{237}$ Der Verein verfüge über eine umfangreiche industrielle Landwirtschaft, Handwerksbetriebe, Kraftwerke zur Stromerzeugung, eine Fliesenfabrik, eine Fertigung von Zementrohren, eine Mühle, Bäckerei und Konditorei, Geflügel- und Schweinezucht, moderne Werkstätten sowie einen umfangreichen Fuhrpark. Diese Betriebe, so das CDE, leisteten auch Dienstleistungen für Dritte, die nicht - wie von der SBED behauptet - zum Selbstkostenpreis erbracht würden. SBED-Präsident Hermann Schmidt habe gegenüber dem CDE dargelegt, dass alle Einkünfte aus dem Steinbruch und der Aktivität der zahlreichen zollfrei eingeführten Lastwagen vollständig in die soziale Arbeit der SBED geflossen seien. Auch der Kauf des Landguts El Pasto 1966 sei nur durch diese Einkünfte möglich gewesen. Die Gruppe führe - wie schon zuvor in Deutschland - ein gemeinschaftliches Leben,

»trabajando todos para todos sin sueldos ni salarios y disponiendo cada uno del dinero, ropas y alimentación que requieren sus necesidades, sin haber tenido nunca una dificultad al respecto, sostienen, igualmente un perfecto y libre entendimiento en materia de libertad personal y de distribución del trabajo. «38

234 PA AA, AV NA 31576, Vorgänge um die ehem. Colonia Dignidad, hier: Grundbuchauszüge.

235 In einer bezahlten Anzeige im Jahr 1968 in der Zeitung El Mercurio beschrieb das unterzeichnende Direktorium der SBED die »Aufbauleistung « folgendermaßen: »Al comprar el fundo >El Lavadero< en Parral, no había allí edificio utilizable y solo 40 hectareas de terreno cultivado. Hasta ahora se cultivaron 700 hectareas; se construyeron más de 45 kilómetros de caminos, con numerosos puentes; se levantaron viviendas para 236 personas. [...] Se han construido una maestranza, talleres completos y modernos de carpintería, electricidad, de producción de tubos, tejas, baldosas de cemento y ladrillos. Se han construido una escuela primaria y un Hospital gratuito que recibe hasta 60 pacientes y que al 31 de diciembre de 1967 tiene bajo control médico a 3000 campesinos.«El Mercurio vom 25.02.1968, S. 37. Inserción - La Colonia »Dignidad« a la opinión pública.

236 AdsD, NL Ernst Waltemathe, Ordner/Box 12. Consejo de Defensa del Estado, O. P. 3 vom 19.10.1990. »Informe Sociedad Benéfica y Educacional Dignidad«, S. 15 sowie Dekret N 4250 des Finanzministeriums vom 03.10.1962.

237 CA Santiago, AZ 2182-98 (»Asociación Ilícita«), Bd. I (2) (Parral), BI. 935-954. Consejo de Defensa del Estado, Informe No 378 referente a la posibilidad de cancelar la personalidad jurídica de la Corporación »Sociedad Benefactora y Educacional Dignidad« vom 25.06.1968. 
Der CDE schlussfolgerte, dass die SBED zwar formell (nach ihrer juristischen Person) eine Mischform aus Corporación und Stiftung sei, mit dem Zweck, Hilfe für bedürftige Kinder und Jugendliche zu leisten. Faktisch aber sei sie eine Art Produktionsgenossenschaft:

»La actividad principal de los miembros de la entidad está concentrada en la explotación agrícola-industrial de los fundos El Lavadero y el Pasto; en la explotación a considerable escala de la planta chancadora; y también en la explotación commercial de los camiones y camionetas de que es dueña. $^{239}$

Damit, so die CDE, habe die SBED ihren Satzungszweck bislang nicht erfüllt, was aber die rechtliche Grundlage für eine steuerliche Vorzugsbehandlung sei. Dass die Grundstücke der CD auf Einzelpersonen eingetragen seien und nicht auf die SBED, sei eine schwere Unregelmäßigkeit. Zwar könne die SBED nicht insgesamt als gesetzeswidrig bezeichnet werden, es sei jedoch durchaus möglich, sie aufzulösen. In diesem Fall fiele ihr Vermögen an den chilenischen Staat.

Der Bericht des erwähnten Untersuchungsausschusses vom 27. November $1968^{240}$ entlastete die SBED jedoch von den meisten Vorwürfen des CDE. Ohne genauer auf Zahlen und Fakten einzugehen, behauptete er, es sei plausibel, dass die Einnahmen aus der wirtschaftlichen Tätigkeit der SBED vollständig in die wohltätige Arbeit der Gesellschaft flössen. Letztlich monierte der Ausschuss, wie erwähnt, nur die Eintragung der Grundstücke auf Einzelpersonen. Der Bericht verwies auch auf eine Stellungnahme der Arbeitsbehörde (Dirección del Trabajo), die in ihrem Bericht 3598 an den Untersuchungsausschuss festgestellt hatte, dass

»Las personas que prestan servicios en la corporación de derecho privado sSociedad Benefactora y Educacional Dignidad ‘ tienen calidad de trabajadores y debe cumplirse a su respecto con la legislación social y previsional chilena. ${ }^{241}$

Dies - so der Untersuchungsausschuss - gelte jedoch nicht rückwirkend. Doch auch diese Anweisung hatte keine Änderung an den Arbeitsverhältnissen innerhalb der CD zur Folge.

Der bundesdeutsche Botschaftsrat Kaufmann-Bühler bemerkte 1972 nach einem Besuch in der CD in seinem Bericht an das Auswärtige Amt, dass der Wettbewerbsvorteil der SBED letztlich auf nicht entlohnter Arbeit beruhe:

»Fragt man sich nach der Zukunft der Kolonie, so bleiben viele Fragen offen. Wirtschaftliche Probleme scheinen auf absehbare Zeit nicht zu bestehen. Die Produktion an landwirtschaftlichen Gütern deckt den Eigenbedarf einschließlich des Bedarfs für das Krankenhaus bei weitem. Ein erheblicher Teil dürfte verkauft werden. Haupteinnahmequelle - die Leitung bezeichnet sie als einzige Einnahmequelle der Kolonie ist ein Steinbruch, in dem Schotter für den Straßenbau gewonnen wird. Ferner setzt die Kolonie aus zuverlässigen Mitgliedern bestehende Bautrupps auf Großbaustellen

239 Ebd. Bl. 950.

240 Cámara de Diputados, Diarios de Sesiones, Legislatura extraordinaria periodo 1968-1969, Sesión $12^{\mathrm{a}}$ vom 26.11.1968, S. 1131-1161.

241 Ebd., S. $1138 f$. 
in Santiago ein. Der Lohn fließt der Leitung zu. Überhaupt arbeiten alle Mitglieder der Kolonie, ohne Lohn zu empfangen. Die Produktivität der Kolonie beruht nicht zuletzt auf dem Fehlen des Lohnkostenfaktors. « ${ }^{242}$

Diese »Produktivität« genoss die CD bis mindestens 2005, als die CD-Unternehmen begannen, tatsächlich Löhne auszuzahlen. Seit 1990 hatten die CD-Firmen zwar formell begonnen, reguläre Arbeitsverhältnisse anzumelden, Löhne zahlten sie jedoch nur auf dem Papier aus. Den Colonos wurde ein Großteil des nominalen Gehalts für Unterkunft und Verpflegung oder als »Spende« für das Krankenhaus abgezogen - nur ein Taschengeld wurde tatsächlich ausbezahlt. ${ }^{243}$ Da die meisten Colonos die CD bis 2005 nicht verlassen durften, hatte Geld für sie ohnehin kaum eine reale Funktion.

Mit der Machtübernahme der Militärs 1973 begannen für die CD auch in wirtschaftlicher Hinsicht "goldene Jahre«, in denen ihre Geschäftspraktiken, die auch vorher keiner rigorosen Kontrolle unterlegen hatten, überhaupt nicht mehr hinterfragt wurden. Auch die Aktivitäten des Steinbruchs - der Abbau und Verkauf von Schotter für die Bauwirtschaft - weiteten sich aus. Ramírez beschrieb 2009 den Umfang dieses Geschäftsbetriebs:

»Durante dos décadas fue un verdadero monopolio que abastecía la construcción desde Los Ángeles a Talca. Era imposible competir con sus precios, por un factor tan simple como ilegal: a los alemanes no les pagaban sueldos ni leyes sociales.

A mediados de los '80, Abratec se consolidó en las ligas mayores de la construcción al asumir dos tareas monumentales en las obras de la represa Colbún Machicura: la perforación de un túnel y la excavación del canal que va de Machicura a Talca.« ${ }^{244}$

Dazu kamen Waffengeschäfte (vgl. Abschnitt 4.2.2) und Minenprojekte. Mehrere Colonos berichten von monatelangen Goldschürfaktivitäten Ende der 1970er/Anfang der 1980er Jahre. Der Colono Dieter Malessa berichtete 2005 im Rahmen einer richterlichen Vernehmung:

»Debo señalar que desde el año 1979 a 1984 trabajé en la mina de oro de Tirua, yo estaba trabajando en todo lo que fuese relativo a la maquinaria pesada, dicho trabajo se realizaba en los meses de noviembre a marzo lo que se hizo durante cinco años, respecto a la producción de la mina, yo nunca supe la cantidad de oro que era sacada, ya que todo era secreto y nadie se atrevió a consultar la ganancia del producto, el único

242 PA AA, ZW 111129. Bericht Botschaftsrat Werner Kaufmann-Bühler an das AA vom 19.02.1972 »Aufzeichnung des RK-Referenten der Botschaft Santiago über den Besuch der deutschen Kolonie »Dignidad« am 19.06.1972, S. 22.

243 CA Santiago, AZ 2182-98 (»Asociación Ilícita«), Bd. III (Parral), BI. 1836. Richterliche Vernehmung von Michael Müller vom 02.09.2005 sowie CA Santiago, AZ 66.124 (»Asociación Ilícita-Efrain Vedder«), BI. 719. Polizeiliche Vernehmung von Efrain Vedder vom 23.09.2005.

244 Ramírez, Pedro. »Crisis en la ex Colonia Dignidad desata pugna por la fortuna que ocultó Schäfer.» in: CIPER (Website), 24.03.2009, online unter: https://ciperchile.cl/2009/03/24/crisis-en-la-ex-colo nia-dignidad-desata-pugna-por-la-fortuna-que-oculto-schafer/. Das Unternehmen Abratec wurde erst 1988 gegründet. Vermutlich bezieht sich der Autor auf den Steinbruch der CD, der 1988 in das neugegründete Unternehmen überführt wurde. 
que sabía eso era Schäfer, creo que la mina tenía producción ya que se hizo por cinco años. $\ll^{245}$

Der Colono Gerd Schaffrik berichtete von Schürfaktivitäten an drei anderen Orten und einer umfangreichen Goldproduktion:

»Entre 1978 y 1979, en el verano, estuve en la Villa limpiando el oro que se obtuvo en gran cantidad desde`Carahue «. Del segundo al quinto año me correspondió estar en las minas ubicadas en >Allinco<, >Colico<y en el río >Loncotripay< [...]. En la Villa se fundía el oro en barritas de 200 gramos y también limpiábamos en baños con electrolito y química también. Hermann Schmidt y yo eramos los encargados de estas tareas. Eugen Böckler construyó el aparato eléctrico para los baños electrolíticos. «"246

Die Schürferlaubnis wurde formell beantragt ${ }^{247}$ und genehmigt. ${ }^{248}$ Etwa zur selben Zeit kritisierte der Leiter des geographischen Labors der Universidad de Chile in Temuco, Eduardo Pino Zapata, in einem Interview die Pläne der CD, in der Provinz Cautín Titaneisenerz abzubauen. ${ }^{249}$ In dem betreffenden Gebiet befänden sich die größten Vorkommen dieses wertvollen Minerals, das besonders wichtig für die Rüstungsindustrie sei. Der Rohstoff sollte, so der Wissenschaftler, der Entwicklung Chiles dienen und nicht an ausländische Unternehmen verschenkt werden. Laut Pino hielten sich Mitglieder der CD in der Region auf, die mit modernen Maschinen Prospektionsarbeiten durchführten. 250

Die Vorkommen lägen zwar in der Nähe der drei von der SBED beantragten Gebiete, sie seien aber nicht mit diesen identisch. Die CD wies diese Darstellung zurück. Aus heutiger Sicht erscheint es unwahrscheinlich, dass die CD tatsächlich Titaneisenerz abgebaut hat. Außer der Erteilung der Schürflizenzen gibt es auch keine Belege hierfür. Jedoch sagte ein Ex-Colono aus, die Goldminen hätten den Zweck gehabt, den lukrativen Export von Titan zu verschleiern: Man habe überhöhte Produktionsziffern für das Gold ausgewiesen und den Titanexport als Goldexport getarnt. ${ }^{251}$ Geschäftspartner bei den Bergbauvorhaben der CD soll der deutsche Waffenhändler Gerhard Mertins gewe-

245 CA Santiago, AZ 2182-98 (»Asociación llícita«), Bd. II (2) (Parral), Bl. 1413f. Richterliche Vernehmung von Dieter Malessa vom 22.03.2005.

246 CA Santiago, AZ 2182-98 (»Armas«), Bd. II, BI. 421. Richterliche Vernehmung von Helmut Schaffrik vom 22.09.2005.

247 Das staatliche Bergbaublatt veröffentlichte im August 1979 drei Anträge der SBED auf Erteilung von Explorationslizenzen in den Cemeinden Carahue und Teodoro Schmidt in der Provinz Cautín (9. Region). Der Antrag bezog sich nicht nur auf die Erlaubnis Cold zu schürfen, sondern lautete: »Que hemos descubierto un yacimiento de placeres metalíferos que contienen titanio, tantalio, zirconio, plata y oro.«Boletín Oficial de Minería de Santiago vom 16.08.1979.

248 Diario Oficial Nº 30.634 vom 08.04.1980. Ministerio de Minería, Decretos $N^{0} 13,14,15$. Otorga concesión a la Sociedad Benefactora y Educacional Dignidad.

249 La Tercera vom 23.03.1980, S. 13. »Denuncia científico de U. de Chile->Colonia Dignidad pretende explotar mineral de titanio«".

250 Ebd.

251 PJS, Sammlung Dieter Maier. Vermerk Maier über Gespräche mit einem Ex-Colono an den Tagen 26-29.06.2006. 
sen sein. Alfred Gerlach, einer der Piloten der CD, berichtete, die Goldmine in Carahue sei ein gemeinschaftliches Unternehmen von Schäfer und Mertins gewesen:

»Efectivamente en una oportunidad volé junto a Hermann Schmidt, trasladando a Mertins desde Villa [Baviera] hasta Nueva Imperial, donde aterrizamos en una pista particular muy mala, este señor se dirigía hasta Carahue, lugar en que estaba ubicada una mina donde extraían oro en un negocio que tenía con Schäfer. « ${ }^{252}$

Der Ex-Colono Franz Baar berichtete zudem, er habe den Vizechef der (damals bereits aufgelösten) DINA, Pedro Espinoza Bravo, bei den Schürfarbeiten angetroffen. ${ }^{253}$

Neben den Schürfungen gibt es noch einen weiteren Beleg für geschäftliche Verbindungen zwischen der CD und (ehemaligen) Angehörigen der DINA: Im August 1986 kauften die beiden Colonos Alfred Gerlach und Erna Brock zwei an die CD angrenzende Grundstücke des ehemaligen Fundo San Manuel. ${ }^{254}$ Verkäuferin war die S. A. La Chola Corporation, eine von sechs Aktiengesellschaften, die der panamaische Rechtsanwalt und spätere Staatspräsident Guillermo Endara für DINA-Chef Manuel Contreras gegründet hatte. Die La Chola Corporation wurde einer breiteren Öffentlichkeit erstmals 1976 bekannt, im Zuge von Ermittlungen zur Ermordung Orlando Leteliers (Außenminister der Allende-Regierung) durch die DINA. ${ }^{255}$ Contreras soll mithilfe der von Endara gegründeten Gesellschaften Gelder für Auslandsoperationen der DINA-Exterior (internationale Abteilung der DINA) finanziert haben. ${ }^{256}$ Die Eintragung des Kaufs der Grundstücke ins Grundbuch ${ }^{257}$ ist bisher der einzig bekannte Beleg für diese wirtschaftliche Verbindung zwischen CD und (Ex-)DINA.

Eine wichtige Einnahmequelle für die CD-Führung waren Rentenzahlungen und Versorgungsleistungen aus Deutschland. Diese wurden von Beginn an nicht individuell an die berechtigten Gruppenmitglieder ausgezahlt, sondern flossen direkt in die Kasse der CD-Führung: Hugo Baar, ehemals Mitglied der Führungsriege der CD und 1984 von dort geflüchtet, sagte aus: »Niemand von den Rentenempfängern hat, seit er in Chile ist, seine Rente je gesehen oder bekommen. ${ }^{258}$ Aussagen weiterer Colonos bestätigen dies. ${ }^{259}$ Alfred Schaak hatte zwar in der Bundesrepublik für alle Rentenempfänger_in-

252 CA Santiago, AZ 2182-98 (»Asociación Ilícita«), Bd. I (2) (Ministro), BI. 399. Richterliche Vernehmung von Alfred Gerlach vom 22.03.2006.

253 Basso, Carlos, »El escalofriante testimonio del conejillo de Indias de Colonia Dignidad«, in: El Mostrador vom 27.08.2015, online unter https://www.elmostrador.cl/noticias/pais/2015/08/27/el-escalo friante-testimonio-del-conejillo-de-indias-de-colonia-dignidad-i/.

254 PJS, Sammlung Seewald. »historia predios y entidades«.

255 Vgl. Calloni, Stella. Operación Condor. Pacto Criminal, La Habana 2006, S. 336.

256 Vgl. Washington Post vom 28.07.1991. »Panama: Dirty business as usual« sowie El País vom 17.11.1992. »La rotunda derrota de Endara confirma la falta de liderazgo en Panama«.

257 Conservador de Bienes Raices Parral, AZ 1254-18 und AZ 1254-19.

258 PA-DBT 3127, 712 - UA 2 - 2451. Stenographisches Protokoll der 10. Sitzung des Unterausschusses für Menschenrechte und Humanitäre Hilfe vom 22.02.1988, S. 10/154. Auch online unter http://col oniadignidad-prot.blogspot.com/.

259 CA Santiago, AZ 2182-98 (»Asociación llícita«), Bd. I (Parral), BI. 330. Polizeiliche Aussage von Erich Fege vom 14.10.2000. Darin berichtet Fege: »Además debo indicar que desde el año 1949 a 1961, recibí una pension especial otorgada por el Cobierno Alemán por invalidez de Guerra y otra de vejez, las que perdí debido a que una vez en Chile, esos dineros los percibió Villa Baviera.« 
nen eigene Bankkonten eingerichtet, auf die die Renten überwiesen wurden. Zugleich verfügte er aber über Vollmachten für all diese Konten. ${ }^{260}$ Laut Baar entschied jedoch allein Paul Schäfer über die Verwendung der so zur Verfügung stehenden Gelder. ${ }^{261}$ Bereits 1962 sprach Hermann Schmidt in der Botschaft in Santiago vor, legte Briefe der Konsularstelle der Botschaft an einzelne Colonos vor, und fragte an, »ob er nicht selbst die Angelegenheit dieser Leute bei der Botschaft erledigen könne. « ${ }^{262}$ In der Folge wickelten Schmidt und andere Führungspersonen der CD diese Angelegenheiten im Sammelverfahren in der Botschaft (bzw. im Konsulat) ab. Ohne dass die in Deutschland Rentenberechtigten Colonos persönlich vorsprechen mussten, stellte das Konsulat für sie sogenannte Lebensbescheinigungen zur jährlichen Vorlage bei den Rententrägern aus. Eine interne Vorlage des Auswärtigen Amts beschrieb dieses Vorgehen 1987 so:

»Die konsularische Betreuung der deutschen Staatsangehörigen in der CD erstreckt sich im Wesentlichen auf Paßverlängerungen, Rentenauszahlungen und Lebensbescheinigungen. Sie wurden bis in das Jahr 1986 im Sammelverfahren über einen Beauftragten der CD in der Botschaft abgewickelt, ein Geschäftsablauf, der sich bei der Abgelegenheit der Kolonie als der praktikabelste erwiesen hatte. ${ }^{263}$

1968 waren bereits 20 in Deutschland rentenberechtigte Colonos über 60 Jahre alt. Eine Aufstellung des Bundesversicherungsamtes von $1988^{264}$ spricht von insgesamt 28 Rentenempfänger_innen. Durch diese habe die CD von verschiedenen deutschen Rententrägern bis dahin Rentenzahlungen in Höhe von 3,1 Millionen DM erhalten. Diese Aufstellung war vermutlich nicht vollständig. Nach 1988 verweigerten einige Rententräger aufgrund der Medienberichterstattung über die CD eine weitere Auszahlung von Renten ohne persönliches Vorsprechen der Berechtigten in der Botschaft. Sie hatten berechtigte Zweifel daran, dass die Zahlungen auch tatsächlich den Berechtigten zugutekämen. Die CD klagte daraufhin (im Namen der Betroffenen) gegen verschiedene Rententräger. Das erste Verfahren beim Bremer Sozialgericht ${ }^{265}$ ging 1988 zu Ungunsten der CD aus, die jedoch umgehend Berufung einlegte. 1995 entschied das Bundessozialgericht (BSG) in Kassel, ${ }^{266}$ dass die Rententräger die Zahlungen einstellen dürfen, wenn die Rentenempfänger_innen der CD ihre Mitwirkungspflichten verletzen. Dies sei der Fall, wenn diese nicht persönlich in der Botschaft oder bei Rentensprechtagen der Bundesversicherungsanstalt für Angestellte (BfA) erschienen. In zwei etwas anders

260 Vgl. z.B. PA AA, B85, Bd. 598. Wanda Schaffrik an den Oberkreisdirektor des Landkreises Stade, Abt. Lastenausgleich vom 02.01.1963.

261 PA-DBT 3127, 712 - UA 2 - 2451. Stenographisches Protokoll der 10. Sitzung des Unterausschusses für Menschenrechte und Humanitäre Hilfe vom 22.02.1988, S. 10/154. Auch online unter http://col oniadignidad-prot.blogspot.com/.

262 PA AA, B85, Bd. 598. Bericht 124/63 der Botschaft Santiago an das AA vom 25.01.1963.

263 PA AA, AV NA 31583. Vorlage Referat 330 an den Staatssekretär vom 10.09.1987.

264 PA AA, AV NA 31679. Schreiben BVA (Herr Hassa) an das BM für Arbeit und Sozialordnung (z. Hd. Herr Clever) vom 08.11.1988.

265 PA AA, AV NA 31596. Bremer Sozialgericht, AZ 6 C 61/1988. Urteil vom 03.08.1988. Hermann Schmidt und andere vs. Bremer Landesbank Kreditanstalt.

266 BSC, AZ 4 RA 54/93. Entscheidung vom 22.02.1995. Klägerin war hier Katharina Seelbach Ewig. 
gelagerten Fällen 2000 und 2001 ordnete das BSG jedoch eine Auszahlung an die Kläger an. ${ }^{267}$ Auch eine weitere BSG-Entscheidung 2003 fiel zugunsten der CD aus. ${ }^{268}$ Die beklagten Rententräger konnten somit einige Male die Auszahlung der Renten aufschieben, letztlich wurden diese jedoch immer ausgezahlt und kamen so der CD zugute. Eine Fernsehdokumentation der $\mathrm{ARD}^{269}$ schätzte im Jahr 2016, dass über die Rentenzahlungen ein zweistelliger Millionenbetrag in die CD geflossen sei. Norbert Blüm, zu Zeit der Einstellung der Rentenzahlungen Bundesarbeitsminister, bestätigte, dass die Rentenzahlungen der CD-Führungsriege zugutegekommen waren. Er kommentierte: »Das war ein saftiges Einkommen für einen Folterapparat, mitfinanziert von der Deutschen Rentenversicherung - ohne ihr Wissen. « ${ }^{270}$ Das Auswärtige Amt wollte 2016 diese Vorwürfe weder bestätigen noch dementieren und erklärte: „Die Vorgänge um die Colonia Dignidad und die Rolle der deutschen Botschaft zu der Zeit sind Teil umfangreicher wissenschaftlicher Untersuchungen, die das Auswärtige Amt begrüßt und unterstützt. « ${ }^{271}$ Auf welche wissenschaftlichen Untersuchungen sich das Auswärtige Amt hierbei bezieht und wie diese unterstützt wurden, ist nicht bekannt.

Vermutlich flossen auch umfangreiche staatliche chilenische Zahlungen in die CDKassen. Auch wenn die SBED stets betonte, insbesondere in ihrer Schule und ihrem Krankenhaus unentgeltliche soziale Arbeit für die arme Landbevölkerung der Region $\mathrm{zu}$ leisten, ist es eher wahrscheinlich, dass beide Institutionen für die CD wichtige Einnahmequellen waren: Die Schule erhielt staatliche Subventionen und das Krankenhaus wurde vom chilenischen Staat jahrzehntelang umfangreich für medizinische Leistungen finanziert. Hinzu kamen Sachleistungen wie Medikamente. ${ }^{272}$

Die private, aber staatlich subventionierte externe Schule der CD existiert unter dem Namen Escuela Villa Baviera bis zum heutigen Tage. Die Schule wurde am 22. März 1985 von Lucía Hiriart, der Ehefrau von Diktator Pinochet, eingeweiht. Sie befindet sich auf dem Anfahrtsweg zur CD, wenige Kilometer vor dem Eingangstor und wird von etwa 70 Kindern aus der Region besucht. Kinder der Colonos besuchen diese Schule erst seit der Festnahme von Paul Schäfer. Vorher besuchten sie die interne Schule der CD (vgl. Abschnitt 4.1.5). Von Beginn an erhielt die externe Schule staatliche Subventionen. 1990 betrugen diese etwas mehr als 3 Millionen Pesos pro Jahr. ${ }^{273}$ Zusätzlich stellte die

267 BSG, AZ B5 R] 38/99. Entscheidung vom 05.04.2000 und BSC, AZ B 13 R] 67/99 R. Entscheidung vom 13.12. 2001.

268 BSC, AZ B 13 R] 39/02 R. Entscheidung vom 03.04.2003.

269 Neuhoff, Ulrich/Klaus Weidmann. »Die Sekte der Folterer«, Reportage der ARD-Sendereihe »Die Story im Ersten«, 45 min, Erstausstrahlung am 14.11.2016.

270 Tagesschau.de. »Colonia Dignidad - Deutsche Renten für die Sekte«, 18.11.2016, online unter https ://www.tagesschau.de/ausland/colonia-dignidad-deutsche-renten-101.html (zuletzt abgerufen am 26.11.2016).

271 Bonner Ceneralanzeiger vom 15.11.2016. »Colonia Dignidad « mit Rentengeld illegal finanziert?«, online unter https://ga.de/news/politik/ausland/colonia-dignidad-mit-rentengeld-illegal-finanzier t_aid-43115355.

272 La Epoca vom 18.08.1997, S. 14. »Los 36 años de historia del centro asistencial«.

273 PHF, SBED, Consideraciones acerca de la Labor de Beneficencia realizada por la Sociedad Dignidad en el Hospital Villa Baviera y la Escuela Villa Baviera, o. D., S. 11. Vgl. auch Juzgado de Letras de Parral, AZ 43.210. Informe sobre Investigación a Colonia Dignidad, Ministro en Visita Extraordinaria Hernán Robert Arias, Ministro I. CA Talca, o. D. Von Richter Robert am 31.07.1989 der Corte 
staatliche Agentur Junta Nacional de Auxilio Escolar y Becas (JUNAEB) Frühstück und Mittagessen zur Verfügung.

Das in den frühen 1960er Jahren in der CD errichtete Krankenhaus El Lavadero wurde 1968 vom Servicio Nacional de Salud (Nationaler Gesundheitsdienst, kurz SNS) als Privatkrankenhaus anerkannt. ${ }^{274}$ Durch einen Vertrag mit dem SNS erhielt das Krankenhaus vom Staat spätestens ab 1972 Medikamente, medizinische Verbrauchsgüter und Milch sowie ab 1979 zusätzlich monatliche Subventionen. ${ }^{275}$ Diese ersetzten ab 1985 teilweise und ab 1989 vollständig den Wert der erbrachten Gesundheitsleistungen. 1988 wurde das Krankenhaus in Hospital Villa Baviera umbenannt. 1990 beliefen sich die staatlichen Zahlung auf durchschnittlich knapp 7 Millionen Pesos pro Monat. ${ }^{276}$

\section{Die Umstrukturierung des CD-Vermögens ab 1988}

Die 1980 verabschiedete chilenische Verfassung sah vor, dass nach acht Jahren Präsidentschaft Pinochets ein Plebiszit über die Fortführung der Regierung stattfinden müsse. Als Anfang 1988 die Abstimmung absehbar und damit auch ein Ende der Diktatur denkbar wurde, begann die CD eine Reihe von Maßnahmen, um ihr Vermögen umzustrukturieren. Vor allem wollte sie verhindern, dass eine künftige, möglicherweise der CD nicht mehr freundlich gesinnte Regierung auf das Gruppenvermögen zugreifen konnte. Mitte des Jahres 1988 schrieb Gerd Seewald an Alfred Matthusen, den Leiter der PSM in Siegburg. In dem Brief ging es um die Gründung einer neuen Gesellschaft:

»Seit Anfang April d. J. haben wir die Generalvertretung für Elektroden von ABRACOR, Belgien, übernommen. Zu diesem Zweck haben wir eigens eine Aktiengesellschaft, ABRATEC S.A.C.I. gegründet. Die Chefs von ABRACOR wissen, daß ABRATEC praktisch nichts Anderes ist, als die Sociedad. [...] Wir haben uns mit ABRATEC neben unserer Landwirtschaft, unserer Steinbrecherei und unserm Kasino ein viertes Bein zugelegt. ${ }^{277}$

Die Übernahme der Vertretung von Abracor hatte der CD-Freund Heinz Euteneier vermittelt. Die Abratec S. A. C. I. ist eine geschlossene Aktiengesellschaft. Erstzeichner der Aktien waren vier Colonos. ${ }^{278}$ In den Folgejahren übertrugen die formellen Eigentümer des Steinbruchs, des Restaurants und großer Teile des beweglichen Vermögens (darunter u.a. der 42 Lastwagen umfassende Fuhrpark, industrielle und landwirtschaftli-

Suprema übergeben. Enthalten in: CA Santiago, AZ 2182-98 (»Asociación Ilícita«) Bd. I (2) (Parral), Bl. 585-676, hier BI. 668.

274 CA Santiago, AZ 2182-98 (»Asociación Ilícita«), Bd. III (Ministro), BI. 1323. Resolución No. 1015 des Servicio Nacional de Salud (VII Zona) vom 11.07.1968.

275 Cámara de Diputados, Diarios de Sesiones, Legislatura 332ª , Sesión 33ª vom 06.12.1995, S. 31-88. Informe de la Comisión Especial Investigadora de la Cancelación de la Personalidad Jurídica de Colonia Dignidad, creada con el objeto de verificar la forma como se dio cumplimiento al decreto supremo que disolvió esa institución, S. $47 f$.

276 PHF, Oficio Reservado 270 des Cesundheitsministers Jorge Jimenez de la Jara an Staatspräsident Aylwin vom 30.01.1991.

277 PJS, Sammlung CD. Schreiben Gerd Seewald (»Dr.) an Alfred Matthusen o.D. [vermutlich 1988].

278 Dies waren Karl van den Berg, Willi Malessa, Helmut Seelbach und Siegfried Hoffmann. 
che Maschinen sowie die medizinischen Geräte des CD-Krankenhauses ${ }^{279}$ ) ihre Vermögenswerte an Abratec - im Gegenzug erhielten sie Abratec-Aktien. Im Januar 1990 wurde die Gesellschaft Cerro Florido Sociedad Colectiva Civil (CF) gegründet. An diese wurden große Teile der CD-Grundstücke übertragen. Bereits im November 1989 hatte Cirilo Guzmán de la Fuente, Rechtsanwalt der CD, gemeinsam mit seinem Sohn Juan Pablo Guzmán Giessen ${ }^{280}$ drei neue geschlossene Aktiengesellschaften gegründet: Agripalma S. A., Bardana S. A. und Cinoglosa S. A. Diese bildeten zusammen die sogenannte ABC-Holding. ${ }^{281}$ Die drei AGs übernahmen in der Folge die Aktien von Abratec und CF. Durch sukzessive Kapitalerhöhungen erwarben viele Colonos formal unterschiedlich viele der insgesamt 99.000 Aktien der ABC-Gesellschaften. Diese drei Gesellschaften existieren bis heute und bis vor kurzem waren ausschließlich Colonos Aktionär_innen. ${ }^{282}$ Interessanterweise wurden jedoch nicht alle Colonos zu Aktionär_innen: Viele der chilenischen Adoptivkinder erhielten keine Aktien. Auch viele Führungspersonen erhielten keine Aktien, bzw. übertrugen diese weiter an ihre Kinder. Dies geschah vermutlich, um im Falle zivilrechtlicher Schadenersatzansprüche von Opfern Beschlagnahmen zu verhindern. 2006 sollen insgesamt 197 Colonos verschiedene Mengen von Aktien der drei $\mathrm{ABC}$-Gesellschaften gehalten haben. ${ }^{283}$

Im Januar 1991 erkannte die Regierung der Übergangsphase nach der Diktatur unter Präsident Patricio Aylwin Azócar der SBED per Dekret den Status als Rechtsperson $a b .{ }^{284} \mathrm{Zu}$ diesem Zeitpunkt befand sich das gesamte Vermögen der CD bereits nicht mehr in den Händen der SBED, sondern in Form von Anteilen an den ABCGesellschaften formal im Privatbesitz zahlreicher Colonos. Die Auflösung der SBED

279 La Epoca vom 05.02.1991, S. 11: „Cuatro sociedades anónimas de colonos son dueñas de los bienes de Dignidad«.

280 Beide veräußerten kurz darauf ihre Aktien an verschiedene Colonos.

281 PA AA, AV NA 32986. Bericht der Botschaft an das Sozialgericht Berlin vom 26.11.1996, Betr.: Beteiligung am Vermögen der ehemaligen Colonia Dignidad (CD). Der Bericht enthält eine chronologische Aufstellung der Firmengründungen, Kapitalerhöhungen etc. Als Anlagen sind eine Reihe notarieller Verträge über Firmengründungen, Kapitalerhöhungen etc. aus dem Diario Oficial und von DICOM S. A. beigefügt.

282 Der chilenische Investigativjournalist Pedro Ramirez vom Centro de Investigación Periodística (ClPER) hat im Jahr 2009 eine Reihe von Artikeln zur Übertragung des CD-Vermögens auf das ABC Aktienholding veröffentlicht und dazu eine Reihe von Hintergrunddokumenten zugänglich gemacht. Vgl. Ramírez, Pedro. „Crisis en la ex Colonia Dignidad desata pugna por la fortuna que ocultó Schäfer, in: CIPER (Website), 24.03.2009, online unter http://ciperchile.cl/2009/03/24/crisis -en-la-ex-colonia-dignidad-desata-pugna-por-la-fortuna-que-oculto-schafer/, Ramírez, Pedro. »Los secretos del código moral que se desplomó en Colonia Dignidad«, in: CIPER (Website), 26.03.2009, online unter http://ciperchile.cl/2009/03/26/los-secretos-del-codigo-moral-que-se-desplomo-en-co lonia-dignidad/ sowie Ramírez, Pedro. »La negociación que entrega US\$6 millones para indemnizar a las víctimas de Schäfer«, in: CIPER (Website), 28.08.2009, online unter http://ciperchile.cl/20 09/08/28/la-negociacion-que-entrega-us6-millones-para-indemnizar-a-las-victimas-de-schafer/.

283 PJS, Sammlung CD. Delegado de Gobierno (Herman Schwember) - Programa Integral de Transición Comunidad de Villa Baviera (ex Colonia Dignidad), März 2006, S. 26. Ein Großteil der Aktionär_innen hielt zwischen 360 und 410 Aktien. Einige Colonos hielten aber auch nur 50 Aktien, Peter Schmidt hingegen 2.443 Aktien.

284 Diario Oficial N³3.896 vom 16.02.1991. Ministerio de Justicia, Decreto 143 vom 31.01.1991. »Declara disuelta y cancela personalidad jurídica y destina bienes de entidad que indica.« 
lief damit ins Leere. Nichtsdestotrotz wehrte sich die CD dagegen juristisch, aber auch mit einer umfangreichen medialen Kampagne. Dabei erhielt sie auch erhebliche politische Unterstützung von rechter Seite. Während die SBED verschiedene Rechtsmittel gegen die Entscheidung der Regierung einlegte einlegte, ${ }^{285}$ reichten 17 rechte Senatoren im März 1991 eine Verfassungsbeschwerde ein. ${ }^{286}$ Wie erwähnt verzögerten die diversen Rechtsmittel die Auflösung der SBED bis Ende $1994{ }^{287} \mathrm{Da}$ die CD für den Erhalt der staatlichen Subventionen für Krankenhaus und Schule eine nicht auf Gewinnerwirtschaftung ausgelegte Rechtsperson benötigte, wurde umgehend ein neuer Verein gegründet, die Organización Comunitaria de Desarrollo Social Perquilauquén. Diese wurde im Mai 1995 von der Gemeinde Parral anerkannt wurde und fungiert bis heute als Trägerin der Schule und des Krankenhauses, bzw. der Gesundheitsstation.

Aufgrund der Berichte der aus der CD geflüchteten Ehepaare Baar und Packmor sowie des zunehmenden Drucks der Bundesregierung führte die chilenische Justiz ab Januar 1989 eine Untersuchung der CD durch. Für diese war zuerst Richter Guillermo Navas von der CA Chillán und später Richter Hernán Robert Arias von der CA Talca zuständig. Am 31. Juli 1989 übergab Robert seinen Bericht an die Corte Suprema. ${ }^{288}$ Darin bemängelte er, dass die SBED ihm trotz Aufforderung keine vollständige Buchhaltung vorgelegt habe, obwohl sie gesetzlich zu einer exakten Buchführung verpflichtet sei. Robert stellte fest, dass die SBED für die Arbeit von Schule und Krankenhaus hohe staatliche Zahlungen erhalten habe, jedoch nicht darlegen könne, welcher Anteil der Einnahmen der SBED für soziale Arbeit aufgewendet werde. Die vorgelegten aggregierten Zahlen der SBED wiesen Jahr für Jahr einen Gewinn aus, ${ }^{289}$ ohne dass dessen Zustandekommen nachvollzogen werden könne. Da die SBED vom chilenischen Gesundheitsdienst SNS jede medizinische Dienstleistung bis zu einem Maximum von knapp 69 Millionen Pesos pro Jahr vollständig erstattet bekomme, könne man aus den vorgelegten Zahlen nicht schließen, dass die SBED einen wohltätigen Einsatz für Kranke oder Arme leiste. Richter Robert stellte fest:

»De lo anteriormente expuesto se desprende que no es efectiva la afirmación uniforme de los directivos e integrantes de la Colonia en el sentido de que el referido Estableci-

285 Vgl. dazu von Pottstock Molina, Edmundo Maximilano Carlos. Cancelación de la personalidad jurídica de la corporación sociedad benefactora y educacional Dignidad. [Unveröffentlichte Lizenziatsarbeit], Universidad de Chile, Santiago 1999.

286 Vgl. La Epoca vom 20.03.1991, S. 15. »17 senadores de derecha llevan el caso Dignidad al Tribunal Constitucional«. Die Verfassungsbeschwerde wurde am 18.06.1991 zurückgewiesen. Tribunal Constitucional, AZ 124-1991. Vgl. auch Larraín Cruz, Rafael (Hg.). Fallos del Tribunal Constitucional pronunciados entre el 23 de diciembre 1985 y el 23 de junio 1992. Santiago 1993, S. $379 f f$.

287 Am 29.11.1994 entschied die Corste Suprema endgültig, dass die Auflösung der SBED rechtmäßig war. Vgl. El Mercurio vom 03.12.1994, S. C1. »Colonia Dignidad anunció el cierre de su hospital y escuela.

288 Juzgado de Letras de Parral, AZ 43.210. Informe sobre Investigación a Colonia Dignidad, Ministro en Visita Extraordinaria Hernán Robert Arias, Ministro I. CA Talca. o. D. Von Richter Robert am 31.07.1989 der Corte Suprema übergeben. Enthalten in: CA Santiago, AZ 2182-98 (»Asociación Ilícita《) Bd. I (2) (Parral), Bl. 585-676.

289 Vgl. ebd., Bl. 653. Der ausgewiesene Cewinn betrug 1984 gut 32.474 .499 Pesos (\$), für 1985 \$ 95.939.820, für $1986 \$ 103.758 .716$, für $1987 \$ 166.904 .913$ und für $1988 \$ 168.982 .416$. 
miento Hospitalario preste una atención gratuita a los campesinos y a la gente pobre que vive en las cercanías de Villa Baviera. « 290

Auch die Grundstücke der SBED, so Robert, befänden sich nicht im Besitz des Vereins, sondern gehörten einzelnen Colonos. Diese hätten ihm erzählt, dass sie aufgrund des ihnen entgegengebrachten Vertrauens als Grundstückseigentümer ausgewählt worden wären, jedoch keinen Kaufpreis entrichtet hätten. ${ }^{291}$ Der Richter erinnerte daran, dass bereits 1968 eine Untersuchungskommission der Cámara de Diputados die Überführung der Grundstücke in den Besitz der SBED angemahnt hatte, was jedoch nie geschehen sei. Die befragten Colonos hätten zum Teil gar nicht gewusst, wem die Grundstücke gehörten. Im September 1989 ordnete Robert die Eröffnung eines Strafverfahrens gegen die SBED wegen Betruges an. ${ }^{292}$ ordnete. Dieses wurde jedoch kurze Zeit später ergebnislos eingestellt.

Nach ihrem Amtsantritt am 11. März 1990 griff die neue Regierung unter Aylwin Roberts Bericht wieder auf. Sein Inhalt wurde zur Grundlage für die bereits erwähnte Auflösung der SBED. In ihrem Dekret vom 31. Januar 1991 argumentierte die Regierung, die SBED habe ihren satzungsgemäßen Vereinszweck nicht erfüllt und stattdessen ihre Mitglieder begünstigt. Anstelle armen Kinder und Jugendlichen zu helfen, habe die SBED den Lebensunterhalt der eigenen Gruppe finanziert. Durch ihre wirtschaftlichen Aktivitäten habe die SBED hohe Gewinne erzielt, gleichzeitig aber für Schule und Krankenhaus Subventionen erhalten und andere Vergünstigungen wie z.B. Zollfreiheit genossen, die eigentlich gemeinnützigen Organisationen vorbehalten sind. Zudem seien selbst laut den Zahlen der SBED für 1989 nur gut $9 \%$ der Einnahmen in die soziale Arbeit in Krankenhaus und Schule geflossen. Das chilenische Innen- und Justizministerium schrieben in einer gemeinsamen Pressemitteilung:

»La cancelación de la personalidad jurídica de Colonia Dignidad pone término a un enclave que durante 29 años ha intentado constituirse en un Estado dentro de otro Estado, imponiéndole a sus integrantes un sistema de vida completamente reñido con nuestra concepción cristiano-occidental de la familia y eludiendo, además, el cumplimiento de las leyes que rigen a todos los habitantes de la República.«"293

Zur Vermögenssituation führten sie aus:

»La realidad de hecho de la corporación es muy diferente de la establecida en sus estatutos, pues se ha organizado bajo el amparo de la personalidad jurídica cancelada, un núcleo humano cerrado, no integrado a la comunidad chilena, compuesto por aproximadamente 312 personas que habitan en la denominada Villa Baviera en forma permanente, dirigidos por un pequeño grupo de lideres, bajo un régimen de vida y de trabajo no exento de graves arbitrariedades, con el cual tienden a satisfacer de manera regular y continua sus necesidades vitales de habitación, alimentación, vestuario etc., siendo

290 Ebd., BI. 670.

291 Ebd., Bl. $663 \mathrm{ff}$.

292 Juzgado del Crímen de Parral, AZ 43899.

293 PA AA, AV NA 31605. Ministerio del Interior und Ministerio de Justicia, Declaración Pública vom 01.02.1991. 
de este modo, los asociados los beneficiarios principales de la obra en común.

Las utilidades que la sociedad obtiene de sus explotaciones agrícolas, forestales, mineras, industriales y comerciales, son todas lucrativas, las que no solo no se destinaron al cumplimiento de los fines benéficos contemplados en sus estatutos, sino que tampoco se consumen en las dos únicas actividades sociales que realiza, y que son el Hospital y la Escuela Básica, las que, por otra parte, principalmente funcionan por los aportes estatales entregados que suman más de $\$ 83.000 .000$.- anuales.

El patrimonio de Colonia Dignidad llega a estar en un momento compuesto por más de 15.000 hectáreas de propiedades raíces, complejos industriales, Comerciales, mineros, y un nutrido conjunto de bienes muebles, ello fortalecido gracias a las franquicias aduaneras y exenciones tributarias. Todo este patrimonio en el ultimo tiempo ha sido transferido a sociedades comerciales de propiedad de un reducido grupo de dirigentes de la Colonia. ${ }^{294}$

Das Dekret verfügte, dass sämtliche Vermögenswerte der SBED der Corporación Metodista de Chile, einer kirchlichen Institution, übertragen werden sollten.

Der deutsche Botschafter Wiegand Pabsch berichtete citissime nach Bonn, er habe von der Entscheidung der chilenischen Regierung erst zeitgleich mit den Pressebereichten erfahren. Er habe daraufhin umgehend ein Gespräch mit Belisario Velasco, Staatssekretär im Innenministerium, geführt und darin seine Besorgnis formuliert:

»Ich wies auf die wiederholten Versicherungen verschiedener Minister hin, die wirtschaftliche Crundlage der Fortexistenz der Bewohner der CD, von denen wohl die Mehrheit eher Opfer als Täter seien, solle nicht angetastet werden. Man dürfe auch dieses Ziel nicht aus den Augen verlieren. Velasco entgegnete das chilenische Recht kenne keine Alternativen. Wenn die Bewohner der >Villa Baviera durch unberechtigte Ausnutzung der der CD gewährten Steuer- und sonstigen Vorteile sich ungerechtfertigt bereichert oder sonstige Rechtsverstöße begangen hätten, müssten sie dafür haften.

Es ist davon auszugehen, dass die jetzt eingeleiteten Maßnahmen noch einige Zeit in Anspruch nehmen werden, da mit der Anfechtung aller dieser Maßnahmen durch Rechtsmittel und der vollen Ausschöpfung des Rechtswegs durch die Führungsclique der Kolonie zu rechnen ist. Nichts wird so heiß gegessen, wie es gekocht wird. Es lässt sich aber nicht ausschließen, dass Mitglieder der Kolonie - u.U. gegen den Willen ihrer Führer - sich eines Tages an die deutsche Öffentlichkeit und deutsche Behörden mit der Bitte um Schutz gegen einen Entzug ihrer in 30 Jahren erarbeiteten wirtschaftlichen Lebensgrundlagen durch einen enteignungsgleichen Eingriff wenden werden. ${ }^{295}$

Während die CD juristisch gegen die Auflösungsverfügung vorging, initiierte die chilenische Regierung eine Reihe von Strafverfahren wegen Wirtschaftsdelikten gegen die CD. Im März 1991 eröffnete der Servicio de Impuestos Internos (oberste chilenische 
Steuerbehörde, SII) ein Strafverfahren gegen Hermann Schmidt und Kurt Schnellenkamp wegen Steuerhinterziehung. ${ }^{296}$ Am 29. September 1995 erhob das 13. Juzgado del Crimen de Santiago Anklage. Schmidt und Schnellenkamp wurde vorgeworfen, Gewinne aus Anlagen in Investmentfonds nicht versteuert zu haben und so den Fiskus 1986 bis 1989 um 152 Millionen Pesos geprellt zu haben. ${ }^{297}$ Am 21. März 2003 wurde Schnellenkamp - Hermann Schmidt war inzwischen verstorben - zu drei Jahren Haft auf Bewährung sowie zur Begleichung der Steuerschuld verurteilt. Das Urteil wurde erst Ende 2007 rechtskräftig. Da der Verurteilte über keinerlei Vermögen verfügte, konnte die Steuerschuld nicht eingetrieben werden. Ein weiteres Strafverfahren gegen SBEDVorstände wegen Zollbetrugs wurde ebenfalls 1991 initiiert und später vermutlich eingestellt. ${ }^{298}$

Neben den genannten Strafverfahren wurde auf Betreiben des CDE wegen der Übertragung des CD-Vermögens auf die ABC-Gesellschaften 1988-1990 ein weiteres Strafverfahren wegen Betrugs (»contratos simulados«) eröffnet. ${ }^{299}$ Im November 1997 beantragte die Cámara de Diputados bei der Corte Suprema die Bündelung der bei verschiedenen Gerichten anhängigen Strafverfahren wegen Wirtschaftsverbrechen gegen die CD. Die Corte Suprema lehnte dies ab. ${ }^{300}$

Das Betrugsverfahren wurde für die ABC-Gesellschaften der CD jedoch durchaus relevant. Der CDE erreichte 1996, dass große Teile der Ländereien der CD mit Pfandrechten belegt wurden, was eine Art von Beschlagnahme darstellte. Für die CD-Unternehmen bedeutete dies, dass sie keine Hypotheken auf diese Grundstücke mehr aufnehmen konnten, was sie in eine zunehmend prekäre finanzielle Situation brachte. Die deutsche Botschaft setzte sich bei der chilenischen Regierung für eine Aufhebung der Beschlagnahme ein. Sie beauftragte 2008 den Insolvenzverwalter Herman Chadwick, eine Studie über die finanzielle Situation der Aktiengesellschaften zu erstellen. Diese bescheinigte den Gesellschaften eine desolate Finanzsituation und betonte die Notwendigkeit neuer Kredite. ${ }^{301}$ Der CDE bot den CD-Unternehmen 2009 einen Deal an: Die Beschlagnahme würde aufgehoben, wenn die Gesellschaften garantieren, dass sie die Forderungen mittels Veräußerung von CD-Ländereien beglichen, sollten einzelne CD-Mitglieder $\mathrm{zu}$ Entschädigungszahlungen verurteilt werden. Am 21. August 2009 unterzeichneten der CDE einen entsprechenden Vertrag mit den $\mathrm{CD}$-Firmen Abratec und $\mathrm{CF}^{302}$ Darin verpflichteten sich die Unternehmen für vier Parzellen der Villa Baviera (mit ca. 3.500 Hektar), eine Hypothek zugunsten

296 13. Juzgado del Crímen de Santiago, AZ 96.447. Das Verfahren richtete sich gegen Schmidt und Schnellenkamp als Repräsentanten der SBED.

297 PA AA, AV NA 31666. Anklageschrift, als Anlage zu einem Schreiben von RA Máximo Pacheco an Botschafter Reichenbaum vom 09.10.1995.

298 Juzgado de Bulnes, AZ 34.422-3.

299 14. Juzgado del Crímen de Santiago, AZ 136.414.

300 Vgl. El Mercurio vom 18.11.1997, S. C1. »Ex-Colonia Dignidad: Suprema rechazó petición de Cámara«.

301 Vgl. Ramírez, »Crisis en la ex Colonia Dignidad «.

302 PJS, Sammlung CD. Vertrag »Transacción e Hipotecas Fisco de Chile - Consejo de Defensa del Estado e Inmobiliaria e Inversiones Cerro Florido Limitada y Abratec S.A.«, unterzeichnet am 21.08.2009 im Notariat Osvaldo Pereira Conzález, Repertorio Nº 11.335 - 09, Online unter: http: //ciperchile.cl/wp-content/uploads/escritura-publica.pdf. 
des chilenischen Fiskus einzutragen. ${ }^{303}$ Den Verkehrswert dieser Grundstücke hatten Sachverständige der CA Talca zuvor auf über 6 Millionen US-Dollar geschätzt. Bei 40 einzeln im Vertrag aufgeführten Strafverfahren verpflichteten sich die CDUnternehmen, im Falle rechtskräftiger Entschädigungsurteile bis zum 31. Dezember 2017 die Entschädigungssummen zu begleichen oder ggf. mit ihren Ländereien dafür $\mathrm{zu}$ haften. Bis heute (Stand März 2020) wurden jedoch keinerlei Entschädigungen von CD-Unternehmen an die Opfer gezahlt. Die im Vertrag genannten Verfahren führten nur in wenigen Fällen vor dem genannten Stichtag zu vollstreckbaren zivilrechtlichen Titeln für die Geschädigten. Selbst in jenen Fällen, die vor Ablauf dieser Frist rechtskräftige zivilrechtliche Ansprüche begründeten, verweigern die CD-Unternehmen bislang jegliche Zahlung. Die Geschädigten, bzw. der CDE, beantragten daraufhin im Juni 2017 die Vollstreckung der Ansprüche gegen die aktuelle Eigentümerin der betreffenden Parzellen, die Inmobiliaria Bergneustadt Limitada. ${ }^{304}$

Seit 1995 haben einzelne Colonos eine Reihe von Unternehmen gegründet, die formalrechtlich nicht Teil der ABC-Holding sind, jedoch teilweise Dienstleistungen für diese erbringen (vgl. Tabelle 6). Ziel dieser Gründungen war offensichtlich die Umgehung der Beschlagnahme. Zudem sollten einzelnen Colonos Vermögensvorteile verschafft werden. ${ }^{305}$ Zusätzlich wurde eine große Anzahl von Tochterunternehmen der ABC-Gesellschaften gegründet (vgl. Tabelle 6). Zudem erhielt die CD Unterstützung durch verschiedene (semi-)staatliche Akteur_innen: Zwischen 2008 und 2013 führte die GIZ Beratungen und Coachings für einige der $\mathrm{ABC}$-Gesellschaften und ihre Töchter durch. ${ }^{306}$ Der Senior Experten Service e. V. (SES), eine Stiftung der deutschen Wirtschaft für internationale Zusammenarbeit, entsandte Fachkräfte in die CD. ${ }^{307}$ Auch die Corporación de Fomento de la Producción (staatliche Wirtschaftsförderungsgesellschaft, kurz CORFO) unterstützte Unternehmen der CD. ${ }^{308}$

303 Vgl. Ramírez, »La negociación«.

304 Juzgado de Parral, AZ C391-2017.

305 PJS, Sammlung CD. Delegado de Cobierno (Herman Schwember) - Programa Integral de Transición Comunidad de Villa Baviera (ex Colonia Dignidad), März 2006, S. 26.

306 Zwischen 2008 und 2013 waren im Bundeshaushalt Mittel von ca. 250.000 Euro pro Jahr eingestellt für »Projekte zur Förderung der Integration der Villa Baviera (soziale und wirtschaftliche Anbindung) in die Region und in die chilenische Gesellschaft«. Ein Großteil dieser Mittel floss in Maßnahmen der Wirtschaftsförderung und -beratung, die von der GIZ durchgeführt wurden. Vgl. z.B. Deutscher Bundestag, Drucksache 16/9900 vom 08.08.2008. Entwurf eines Cesetzes über die Feststellung des Bundeshaushaltsplans für das Haushaltsjahr 2009 (Haushaltsgesetz 2009), S. 40, online unter http://dip21.bundestag.de/dip21/btd/16/099/1609900.pdf. Bei dem Haushaltstitel handelt es sich um Kapitel 0502, Titel 687-29.

307 Die Bundesregierung antwortete 2001 auf eine Anfrage: »SES-Experten unterstützen vor Ort die Ceriatrie und Krankenpflege, die Milchproduktion und -verarbeitung, die Produktionsprozesse in einer Bäckerei und Fleischerei, die Modernisierung der Landwirtschaft, den Ausbau eines Gasthofes und die teilweise Umgestaltung der Siedlung für touristische Zwecke.« Deutscher Bundestag. Plenarprotokoll 17/132 vom 19.10.2011, S. 15630D.

308 Die CORFO unterstützte beispielsweise den Bau des Hotels Baviera in der CD von 2011-2012. Vgl. Villa Baviera (Website). Hotel. [o.].], online unter https://www.villabaviera.cl/hotel/. »Hotel Baviera [...] es una construcción masiva de 3 pisos, que se construyó y modificó mediante apoyo Corfo en el año 2011-2012." 
Seit Anfang der 1990er Jahre versteckte die CD auch einen Teil ihres Vermögens im Ausland. Vermutlich sollten diese Gelder einer möglichen Verlegung der Gruppe ins Ausland dienen bzw. eine mögliche Flucht von Führungsmitgliedern ins Ausland sowie ein darauffolgendes Leben im Untergrund absichern. Die entsprechenden Geldbewegungen wurden bislang von der chilenischen Justiz nur ansatzweise untersucht insbesondere im Kontext der Ermittlungen wegen Bildung einer kriminellen Vereinigung. Die bundesdeutsche Justiz hat sich mit dieser Thematik bisher noch überhaupt nicht befasst.

CD-Arzt und -Führungsmitglied Hartmut Hopp sagte 2005 in chilenischer Untersuchungshaft umfangreich über die versteckten Gelder der CD aus. Er nannte verschiedene Länder und Banken, über die mithilfe Dritter Gelder geflossen seien. So habe Albert Schreiber Mitte der 1980er Jahre begonnen, Anteile von Investmentfonds in Chile zu kaufen. Dieses Geld sei später auf ein Konto der Chemical Bank in New York und von dort aus weiter in andere Länder transferiert worden u.a. nach Kanada, Uruguay, Argentinien und in Karibikstaaten. Schäfer habe vor seiner Flucht von Ersparnissen in Höhe von über 3 Millionen US-Dollar gesprochen (das entspricht 10.000 US-Dollar pro Bewohner_in der CD). Diese stünden für Notfälle wie eine Flucht zur Verfügung. Für das Leben Schäfers und seiner Begleiter_innen im Untergrund in Argentinien von 1997 bis 2005 seien Immobilien erworben worden. Um Schäfer und seiner Adoptivtochter Rebeca Pässe des Karibikstaates St. Kitts und Nevis zu verschaffen, so Hopp, sei er mit ihr dorthin gereist und habe dort ein Ferienapartment erworben. Es habe Auslandskonten gegeben, die ursprünglich von Albert Schreiber und Alfred Matthusen eröffnet worden seien und später auf andere Kontoinhaber übertragen worden seien. Teile dieser Gelder seien später nach Chile zurückgeflossen und von den mit der CD befreundeten Großgrundbesitzern José Miguel Stegmeier, Enrique Veloso und Edgardo Neumann verwaltet worden. Unter anderem sei mit Geldern aus Kanada das Landgut Tierra Negra in der Nähe von Los Angeles (Chile) gekauft worden. ${ }^{309}$

Laut mehrerer Aussagen war auch der Colono und Elektronikfachmann Winfried Schmidtke an Geldtransaktionen auf ausländischen Konten beteiligt. ${ }^{310}$ Schmidtke soll mehrfach mit Hopp für Transaktionen nach Miami gereist sein. Chilenische Medien berichteten, diese Reisen hätten haben dazu gedient, Geld von Konten des ehemaligen DINA-Chefs Manuel Conteras nach Chile zu transferieren. ${ }^{311}$ Nach Schäfers Flucht lebte Schmidtke in der Schweiz und soll auch dort an Geldtransaktionen beteiligt gewesen sein. Auch Albert Schreiber, Peter Schmidt und Hans-Jürgen Riesland seien während Schäfers Aufenthalt in Argentinien regelmäßig in die Schweiz gereist. Eine wichtige Rolle bei der Verwaltung der CD-Gelder sollen zudem die Buchhalterinnen Brigitte Krahm, Gesa Kunde und Erika Heimann gespielt haben. ${ }^{312}$

309 Vgl. CA Santiago, AZ 2182-98 (»Lesiones graves«), Bd. I, Bl. 47ff. Richterliche Vernehmung von Hartmut Hopp vom 29.09.2005 sowie CA Santiago, AZ 2182-98 (»Asociación ilícita«), Band IV, BI. 1856ff. Richterliche Vernehmung von Hartmut Hopp vom 23.01.2007. von Willi Malessa vom 10.05.2005. 
Wie viel von dem versteckten Vermögen der CD heute noch vorhanden ist und wer gegenwärtig darauf Zugriff hat, ist nicht bekannt. Die Unternehmen der CD zweigten jahrzehntelang Einnahmen aus ihren Kassen ab, die sie direkt an Schäfer übergaben. Der Colono und Vertrauensmann von Paul Schäfer Willi Malessa sagte 2005 gegenüber Ermittler_innen der PDI aus, Heimann habe ihm berichtet, sie habe von 1985 bis 2002 alle vier bis sechs Wochen jeweils 10 Millionen Pesos aus der Firmenkasse von Abratec entnommen und Schäfer zugeleitet. ${ }^{313}$ Das Leben diverser Colonos im Untergrund zwischen 1997 und 2005 war sicherlich kostspielig. Hohe Ausgaben für die CD verursachten über die Jahre sicherlich auch die Honorare für dutzende Rechtsanwält_innen in Deutschland und Chile. Nach 1990 wurden die chilenischen Anwälte Hinweisen zufolge zu großen Teilen aus dem Vermögen der ABC-Gesellschaften gezahlt.

Die beiden folgenden Tabellen widmen sich zusammenfassend einer Chronologie der Rechtspersonen, Unternehmen und Vermögenstransaktionen der CD (Tabelle 5) sowie einer Auflistung der Rechtspersonen und Unternehmen der CD (Tabelle 6).

\section{Tabelle 5: Chronologie der Rechtspersonen, Unternehmen und Vermögenstransaktionen der CD}

\begin{tabular}{|c|c|}
\hline 26.06 .1961 & $\begin{array}{l}\text { Eintragung des Vereins Sociedad Benefactora y Educacional Dignidad (SBED) als } \\
\text { corporación de derecho privado. }\end{array}$ \\
\hline 21.09.1961 & Per Regierungsdekret ${ }^{\mathrm{a}}$ wird die SBED als juristischen Person eingetragen. \\
\hline 09.10 .1961 & $\begin{array}{l}\text { Hermann Schmidt und Rudolf Cöllen erwerben für } 35.000 \text { Escudos von der Com- } \\
\text { pañia Italiana de Colonización (CITAL) den Fundo El Lavadero (hijuela Nr } 3 \text { der Ex- } \\
\text { Hacienda San Manuel, } 3000 \text { Hektar). Am 19.06.1963 wird das Nießbrauchrecht für } \\
\text { das Grundstück für } 15 \text { Jahre an die SBED übertragen. }\end{array}$ \\
\hline 24.07 .1962 & $\begin{array}{l}\text { Die Einfuhr von Schäfers Mercedes wurde per Dekret № } 3619 \text { des Finanzministers } \\
\text { Luis Mackenna vom } 24.07 .1962 \text { von der Zollzahlung befreit. Die Begründung laute- } \\
\text { te, die SBED führe »labores educacionales en favor de la niñez abandonada y des- } \\
\text { válida «durch. }{ }^{b}\end{array}$ \\
\hline 03.10 .1962 & $\begin{array}{l}\text { Per Dekret } N^{\circ} 4250 \text { des Finanzministeriums }{ }^{\mathrm{C}} \text { vom } 03.10 .1962 \text { wird die SBED mit Ver- } \\
\text { weis auf ihre Gemeinnützigkeit von der Körperschaftssteuer (Impuesto a la Renta } \\
\text { de Tercera Categoría) befreit. }\end{array}$ \\
\hline 14.05.1966 & $\begin{array}{l}\text { Die SBED erwirbt für } 115.000 \text { Escudos von Enrique Peragallo und Alberto Bardavid } \\
\text { den großen Fundo El Pasto (hijuela N }{ }^{\circ} 4 \text { der Ex-Hacienda San Manuel, über } 2000 \\
\text { Hektar). }\end{array}$ \\
\hline 17.11.1966 & $\begin{array}{l}\text { El Pasto wird parzelliert und an Gerhard Mücke, Karl van den Berg und Erwin Boh- } \\
\text { nau übertragen. }\end{array}$ \\
\hline
\end{tabular}

313 CA Santiago, AZ 2182-98 (»]uan Maino«), Bd. 5a, Bl. 2170ff. Polizeiliche Vernehmung von Willi Malessa vom 29.09.2005. Geht man von zehn Entnahmen á 10 Millionen Pesos pro Jahr über einen Zeitraum von 17 Jahren aus, so ergibt sich eine Gesamtsumme 1,7 Milliarden Pesos. Der Wechselkurs des chilenischen Pesos hat sich im genannten Zeitraum stark verändert. Entsprachen 10 Millionen Pesos 1985 noch etwa 91.000 Euro, so waren es 2002 nur noch rund 15.000 Euro. Legt man jedoch rechnerisch einen durchschnittlichen Wechselkurs von 450 chilenischen Pesos pro Euro zugrunde, so ergibt die genannte Summe von 1,7 Milliarden Pesos umgerechnet knapp 3,8 Millionen Euro. 


\begin{tabular}{|c|c|}
\hline 15.03 .1968 & $\begin{array}{l}\text { Walter Laube erwirbt von Italo Lapi und Alberto Liberati den Fundo El Peumo (Ex- } \\
\text { Hacienda San Manuel). }\end{array}$ \\
\hline 23.03 .1968 & $\begin{array}{l}\text { El Peumo wird parzelliert und an Walter Laube, Kurt Schnellenkamp und Erich Fege } \\
\text { übertragen. }\end{array}$ \\
\hline 27.03 .1968 & $\begin{array}{l}\text { Die Superintendencia de Aduanas (Zollaufsichtsbehörde) untersucht einen mögli- } \\
\text { chen Zollbetrug in Höhe von } 2 \text { Millionen Escudos in den Jahren 1963-1967. Die Zoll- } \\
\text { behörde beschlagnahmt vorläufig die Steinbrechanlage in Bulnes sowie verschie- } \\
\text { dene Fahrzeuge. } 119 \text { Erwachsene treten daraufhin in einen »unbefristeten Hun- } \\
\text { gerstreik«, der nach dem Besuch des Innenministers und der Ankündigung, die } \\
\text { Beschlagnahme aufzuheben, abgebrochen wird. Die Zollbehörde stellt dennoch } \\
\text { Strafanzeige wegen Zollbetruges. Das Juzgado de Parral leitet ein Strafverfahren } \\
\text { ein, }{ }^{d} \text { das am } 04.11 .1969 \text { eingestellt wird. }\end{array}$ \\
\hline 10.06 .1968 & $\begin{array}{l}\text { Die Dirección de Trabajo (Arbeitsbehörde) stellt in einem Bericht } 3598 \text { an den Un- } \\
\text { tersuchungsausschuss der Cámara de Diputados fest, dass die Personen, die Diens- } \\
\text { te für die SBED verrichten, Arbeitnehmerstatus haben und die Sozial- und Sozi- } \\
\text { alversicherungsgesetzgebung für sie eingehalten werden muss. Dies gelte jedoch } \\
\text { nicht rückwirkend. Die Direktorin der Superintendencia de Seguridad Social (Sozi- } \\
\text { alversicherungsaufsicht) stimmt mit dieser Einschätzung überein. }\end{array}$ \\
\hline 13.12 .1969 & $\begin{array}{l}\text { Der Colono Friedrich Pöhlchen erwirbt von Roberto Cerra den } 84 \text { Hektar großen Po- } \\
\text { trero El Litral des Fundo Los Peumos in Bulnes (heute Fundo El Aromo). }\end{array}$ \\
\hline 07.04.1971 & $\begin{array}{l}\text { Friedrich Pöhlchen erwirbt von Gustavo Schleyer sechs Parzellen mit Bergbaulizen- } \\
\text { zen im Fundo Libuy in Bulnes zum Steinbruch bzw. Sand- und Schotterabbau (Litral } \\
1 \text { bis 6). Insgesamt besitzt Friedrich Pöhlchen in Bulnes nun } 300 \text { Hektar Land. }\end{array}$ \\
\hline 15.01 .1975 & $\begin{array}{l}\text { Die SBED erwirbt von María Torm Tohá und anderen das Haus in der Calle Campos } \\
\text { de Deporte } 817 \text { in Santiago. Am 22.09.1989 wird das Anwesen an die Colonos Peter } \\
\text { Schmidt und Ulrich Schmidtke verkauft. }\end{array}$ \\
\hline bis 1990 & $\begin{array}{l}\text { Einzelne Colonos erwerben sieben weitere Grundstücke und überlassen das Nieß- } \\
\text { brauchrecht für15 oder } 30 \text { Jahre der SBED. }{ }^{f} \text { Formell sind folgende } 30 \text { Colonos Eigen- } \\
\text { tümer_innen der Grundstücke in Parral, Bulnes und Santiago: Hermann Schmidt, } \\
\text { Rudolf Cöllen, Alfred Matthusen, Johan Spatz, Gerhard Mücke, Karl van den Berg, } \\
\text { Erwin Bohnau, Walter Laube, Kurt Schnellenkamp, Erich Fege, Willi Malessa, Man- } \\
\text { fred Skrabs, Hartmut Hopp, Reinhard Döring, Marlies Döring, Hildegard Möhring, } \\
\text { Erika Heimann, Maria Strebe, Alfred Cerlach, Erna Brock, Helmut Seelbach, Ceorg } \\
\text { Schmidtke, Friedhelm Bensch, Siegmar Wellnitz, Brigitte Malessa, Edith Malessa, } \\
\text { Wolfgang Zeitner, Erwin Fege, Siegfried Laube, Peter Schmidt, Ulrich Schmidtke. }\end{array}$ \\
\hline 26.04 .1988 & $\begin{array}{l}\text { Eintragung der geschlossenen Aktiengesellschaft Abratec S. A.C. I. mit einem } \\
\text { Gründungskapital von } 10 \text { Mio. Pesos. Erst-Aktionäre sind Karl van den Berg, Willi } \\
\text { Malessa, Helmut Seelbach und Siegfried Hoffmann. }\end{array}$ \\
\hline $\begin{array}{l}13.11 .1989 \\
(25.11 .1989)\end{array}$ & $\begin{array}{l}\text { Gründung der drei Aktiengesellschaften Agripalma S. A., Bardana S. A. und Ci- } \\
\text { noglosa S. A. durch die Rechtsanwälte Cirilo und Juan Pablo Guzmán. Cründungs- } \\
\text { kapital je } 3 \text { Millionen Pesos. Durch sukzessive Kapitalerhöhungen wird das Stamm- } \\
\text { kapital jeder der drei Cesellschaften aufjeweils } 99 \text { Millionen Pesos angehoben, ver- } \\
\text { teilt aufjeweils } 33.000 \text { Aktien. Ab Januar } 1990 \text { schließen die CD-Firmen Arbeitsver- } \\
\text { träge mit den Colonos ab. }\end{array}$ \\
\hline
\end{tabular}




\begin{tabular}{|c|c|}
\hline 06.01.1990 & $\begin{array}{l}\text { Erste Aktienübertragung: } 60 \text { Colonos erwerben jeweils } 50 \text { Aktien der drei ABC- } \\
\text { Gesellschaften. }\end{array}$ \\
\hline 10.01 .1990 & $\begin{array}{l}\text { Gründung der Cesellschaft Sociedad Colectiva Civil Cerro Florido (CF). Gründungs- } \\
\text { mitglieder sind die } 30 \text { genannten Colonos, die formal die Crundstücke in Parral, } \\
\text { Bulnes und Santiago besitzen. Sie übertragen die insgesamt ca. 13.00o Hektar an } \\
\text { die CF. Das Nießbrauchrecht behält die SBED. Das Direktorium der CF setzt sich aus } \\
\text { je } 2 \text { Mitgliedern der drei ABC-Cesellschaften zusammen. Als Schiedsperson im Fal- } \\
\text { le einer Abwicklung wird Waldo Ortuzar benannt, der langjährige Rechtanwalt der } \\
\text { CD und Mitglied der Corte Suprema (abogado integrante). }\end{array}$ \\
\hline 26.03 .1990 & $\begin{array}{l}\text { Die } 30 \text { Cesellschafter_innen der CF (die formalen Crundstückseigner_innen) über- } \\
\text { tragen ihre CF-Anteile an die ABC-Cesellschaften und erhalten dafür im Cegenzug } \\
\text { ABC-Aktien. }\end{array}$ \\
\hline 01.04 .1990 & $\begin{array}{l}\text { Die SBED erkennt gegenüber einer Reihe von Mitgliedern Schulden in Höhe von } \\
\text { knapp } 386 \text { Mio. Pesos an, die diese angeblich in den 1960er Jahren der SBED gelie- } \\
\text { hen hätten.g }\end{array}$ \\
\hline 18.05 .1990 & $\begin{array}{l}\text { Aktionärsversammlungen der ABC-Gesellschaften beschließen eine Kapitalerhö- } \\
\text { hung durch die Ausgabe von jeweils } 27.000 \text { neuen Aktien á } 3000 \text { Pesos. Insgesamt } \\
\text { verfügt jede der drei Gesellschaften nun über ein Kapital von } 99 \text { Mio. Pesos, aufge- } \\
\text { teilt auf jeweils } 33.000 \text { Aktien. } 75 \text { Colonos zeichnen jeweils } 360 \text { Aktien. }\end{array}$ \\
\hline 24.05 .1990 & $\begin{array}{l}\text { Die geschlossene Aktiengesellschaft Abratec S. A. C. I. benennt sich um in Abratec } \\
\text { S. A. }\end{array}$ \\
\hline 20.07 .1990 & $\begin{array}{l}\text { Kapitalerhöhung bei Abratec S.A. von gut } 10 \text { Mio. auf gut } 248 \text { Mio. Pesos. Dazu } \\
\text { zeichnen } 225 \text { Colonos jeweils } 360 \text { Aktien der drei ABC-Cesellschaften, die wieder- } \\
\text { um jeweils } 7500 \text { Aktien von Abratec zeichnen. } 75 \text { von Abratec erworbene Vermö- } \\
\text { gensgegenstände (Maschinen, Lastwagen etc.) werden an die ABC-Cesellschaften } \\
\text { vermietet. }\end{array}$ \\
\hline 31.01 .1991 & $\begin{array}{l}\text { Umbenennung der Sociedad Colectiva Civil Cerro Florido in Inmobiliaria e Inversio- } \\
\text { nes Cerro Florido Ltda. } \\
\text { Per Dekret } N^{\circ} 143 \text { des Justizministeriums wird die SBED aufgelöst. }{ }^{\text {h }} \text { Die Rechtsan- } \\
\text { wälte der CD fechten die Entscheidung an. }\end{array}$ \\
\hline 04.02 .1991 & Die SBED tritt von allen Nießbrauchrechten an Grundstücken zurück. \\
\hline 15.02 .1991 & $\begin{array}{l}\text { Abratec S. A. übernimmt die Bewirtschaftung des Steinbruchs und des Casino Fa- } \\
\text { miliar in Bulnes sowie die Landwirtschaft der CD. Im April } 2002 \text { übernimmt Cerro } \\
\text { Florido Ltda. die Landwirtschaft. }\end{array}$ \\
\hline 22.02 .1991 & $\begin{array}{l}\text { CD-Anwalt Reyes übergibt der amtierenden Justizministerin Wörner das Vermö- } \\
\text { gensinventar der CD. Danach stehen Aktiva in Höhe von } 400.000 \text { Pesos Passiva in } \\
\text { Höhe } 180 \text { Mio. Pesos gegenüber. Die CD hinterlässt also eine Mio. DM Schulden. Die } \\
\text { Passiva werden mit steuer- und arbeitsrechtlichen Verpflichtungen begründet. In- } \\
\text { nenminister Krauss erklärt, die Regierung werde dieses Vermögensinventar nicht } \\
\text { anerkennen. }\end{array}$ \\
\hline 1991 & $\begin{array}{l}\text { Der Servicio de Impuestos Internos (Steuerbehörde) leitet ein Strafverfahren ge- } \\
\text { gen Kurt Schnellenkamp und Hermann Schmidt wegen Steuerhinterziehung durch } \\
\text { die SBED zwischen } 1986 \text { und } 1989 \text { ein. }{ }^{j} 1995 \text { werden beide angeklagt. Hermann } \\
\text { Schmidt verstirbt 1996, Kurt Schnellenkamp wird } 2003 \text { zu drei Jahren Haft sowie } \\
\text { einer Steuernachzahlung verurteilt. Die CA Santiago bestätigt das Urteil 2007. }\end{array}$ \\
\hline 1993 & $\begin{array}{l}\text { Cerro Florido Ltda. kauft weitere Grundstücke, die an die CD angrenzen, sowie in } \\
\text { Trabuncura. }\end{array}$ \\
\hline
\end{tabular}




\begin{tabular}{|c|c|}
\hline 08.09.1994 & $\begin{array}{l}\text { Die Rechtsanwälte Fernando Saenger und Roberto Cotelli verklagen die SBED im } \\
\text { Namen von } 66 \text { Colonos beim Arbeitsgericht in Parral wegen nicht bezahlter Löhne. } \\
\text { Der Anwalt der CD, Roberto Saldías, erkennt eine Schuld in Höhe von } 80 \text { Mio. Pesos } \\
\text { an. }\end{array}$ \\
\hline 06.12.1994 & $\begin{array}{l}\text { Die SBED stellt nach der Übertragung aller Grundstücke und Vermögenswerte ihre } \\
\text { Aktivitäten ein. }\end{array}$ \\
\hline 03.02 .1995 & $\begin{array}{l}\text { Eintragung der Organización Comunitaria de Desarrollo Social Perquilauquén als } \\
\text { juristische Person. Perquilauquén wird Träger des Krankenhauses und der Schule } \\
\text { der CD. }\end{array}$ \\
\hline 22.12.1995 & $\begin{array}{l}\text { Eintragung des Unternehmens Transportes y Rentas la Esperanza Ltda. Am } \\
\text { 31.07.2000 übertragen Katharina und Ingrid Pöhlchen ihre Erbrechte am Crund- } \\
\text { stück Potrero El Litral del fundo El Aromo (Los Peumos-Litral) an die Firma. }\end{array}$ \\
\hline 19.05.1998 & $\begin{array}{l}\text { Eintragung des Unternehmens Sociedad Agrícola e Industrial Tierra Negra Ltda. } \\
\text { in Los Angeles durch die Cesellschafter José Miguel Stegmeier, Edgardo Neumann } \\
\text { und Enrique Veloso. }\end{array}$ \\
\hline 06.06 .2000 & $\begin{array}{l}\text { Eintragung des Unternehmens Agrícola Rarinco Limitada durch die Gesellschafter } \\
\text { Horst Laube Laib, Georg Laube Laib, Jörg Traugott Seewald Cruhlke, Dirk Collen Cert } \\
\text { und Hans Jürgen Riesland Bollmann. Am } 31.10 .2000 \text { kommt als weiterer Gesell- } \\
\text { schafter Luis Ernesto Lamas Zarricueta hinzu. }\end{array}$ \\
\hline 31.07 .2001 & Eintragung des Unternehmens Productos Alimenticios Prodal Ltda. \\
\hline 22.07 .2005 & Internehmens Industrializados y Prefabricados Induval Ltda. \\
\hline
\end{tabular}

a Diario Oficial No 25.059 vom 02.10.1961. Dekret No 3949 des Ministerio de Justicia vom 21.09.1961. „Concede personalidad jurídica y aprueba los estatutos a la >Sociedad Benefactora y Educacional Dignidad, de Santiago«.

b Cámara de Diputados, Diarios de Sesiones, Legislatura extraordinaria periodo 1968-1969, Sesión $12^{\text {a }}$ vom 26.11.1968, S. 1131-1161. Informe de la Comisión Especial designada para investigar las actividades de la Sociedad Benefactora y Educacional »Dignidad«, de Parral, hier S. 1144 .

c Dekret $\mathrm{N}^{\circ} 4250$ des Finanzministeriums vom 03.10.1961. Zitiert in: 13. Juzgado del Crimen de Santiago, AZ 96.447, Urteil vom 21.04.2003, S. 7 und 9.

d Juzgado de Parral, AZ 25.097.

e Cámara de Diputados, Diarios de Sesiones, Legislatura extraordinaria periodo 1968-1969, Sesión $12^{\text {a }}$ vom 26.11.1968, S. 1131-1161. Informe de la Comisión Especial designada para investigar las actividades de la Sociedad Benefactora y Educacional »Dignidad«, de Parral, hier S. 1138f. f uzgado de Letras de Parral, AZ 43.210. Informe sobre Investigación a Colonia Dignidad, Ministro en Visita Extraordinaria Hernán Robert Arias, Ministro I. CA Talca, o. D. Von Richter Robert am 31.07.1989 der Corte Suprema übergeben. Enthalten in: CA Santiago, AZ 2182-98 (»Asociación Ilícita«) Bd. I (2) (Parral), Bl. 585-676, hier Bl. 664.

g CA Santiago, AZ 2182-98 (»Asociación Ilícita«), Bd. I (Parral), Bl. 450f. Informe Policial 02/00510 vom 08.01.2001.

h Diario Oficial N³3.896 vom 16.02.1991. Ministerio de Justicia, Decreto 143 vom 31.01.1991. »Declara disuelta y cancela personalidad jurídica y destina bienes de entidad que indica.«

i PA AA, AV NA 31604, DB 139 vom 25.02.1991.

j 13. Juzgado del Crimen de Santiago, AZ 96447-91.

k CA Staniago, AZ 13.519-2003. Urteil vom 18.07.2007. 
Tabelle 6: Rechtspersonen und Unternehmen der Colonia Dignidad

\begin{tabular}{|c|c|}
\hline Agripalma S.A. & $\begin{array}{l}\text { Representante Legal (Cesetzliche_rVertreter_in, kurz: Rep.): Tho- } \\
\text { mas Schnellenkamp, Friedhelm Bensch, Erika Tymm }\end{array}$ \\
\hline Bardana S.A. & Rep.: Udo Hopp, Thomas Schnellenkamp \\
\hline Cinoglosa S.A. & Rep.: Hans Schreiber, Günther Schaak, Lilian Schaffrik \\
\hline $\begin{array}{l}\text { Inmobiliaria e Inversiones Cerro } \\
\text { Florido (CF) }\end{array}$ & Eigentümer_in: Agripalma S. A., Bardana S.A., Cinoglosa S.A. \\
\hline Abratec S.A. & $\begin{array}{l}\text { Eigentümer_in: Agripalma, Bardana, Cinoglosa, Transportes y } \\
\text { Rentas La Esperanza, Karl van den Berg. Verkauft im Mai } 2015 \text { an } \\
\text { Inversiones e Inmobiliaria Cepaemil S.A. - Diese klagt derzeit auf } \\
\text { Rückabwicklung des Kaufvertrags (7. Juzgado Civil de Santiago, } \\
\text { AZ C-16102-2019) }\end{array}$ \\
\hline Inmobiliaria Bamberg Ltda. & $\begin{array}{l}\text { Eigentümer_in: CF, Abratec-Rep.: Thomas Schnellenkamp, Hans } \\
\text { Schreiber, Markus Blanck, Wolfgang Müller A., Martin Matthu- } \\
\text { sen, Günter Schaffrik, Siegfried Laube }\end{array}$ \\
\hline Inmobiliaria Bergneustadt Ltda. & Eigentümer_in: wie Inmobiliaria Bamberg Ltda. \\
\hline Inmobiliaria Breslau Ltda. & Eigentümer_in: wie Inmobiliaria Bamberg Ltda. \\
\hline Inmobiliaria Heidenheim Ltda. & Eigentümer_in: wie Inmobiliaria Bamberg Ltda. \\
\hline Inmobiliaria Küstrin Ltda. & Eigentümer_in: wie Inmobiliaria Bamberg Ltda. \\
\hline Inmobiliaria Neidenburg Ltda. & Eigentümer_in: wie Inmobiliaria Bamberg Ltda. \\
\hline Inmobiliaria Marienburg Ltda. & Eigentümer_in: wie Inmobiliaria Bamberg Ltda. \\
\hline $\begin{array}{l}\text { Inversiones y Rentas Electricas } \\
\text { Villa Baviera Ltda. }\end{array}$ & $\begin{array}{l}\text { Eigentümer_in: CF, Abratec - Rep.: Wolfgang Müller A., Günter } \\
\text { Schaffrik }\end{array}$ \\
\hline $\begin{array}{l}\text { Avícola Villa Baviera } \\
\text { (razón social: El Quilén) }\end{array}$ & $\begin{array}{l}\text { Eigentümer_in: CF, Inversiones Itata Ltda. - Rep.: Thomas Schnel- } \\
\text { lenkamp, Markus Blanck }\end{array}$ \\
\hline $\begin{array}{l}\text { Restaurant Villa Baviera Ltda. } \\
\text { (Bulnes) }\end{array}$ & $\begin{array}{l}\text { Eigentümer_in: Abratec, Inversiones Itata Ltda. - Rep.: Siegfried } \\
\text { Hoffmann, Cünther Schaffrik, Siegfried Laube }\end{array}$ \\
\hline $\begin{array}{l}\text { Agrícola Valle Florido Ltda. } \\
\text { (razón social: Inmobiliaria Bay- } \\
\text { reuth Ltda.) }\end{array}$ & $\begin{array}{l}\text { Eigentümer_in: CF, Inversiones Itata Ltda. - Rep.: Thomas Schnel- } \\
\text { lenkamp, Markus Blanck }\end{array}$ \\
\hline $\begin{array}{l}\text { Turismo y Casino Villa Baviera } \\
\text { Ltda. }\end{array}$ & $\begin{array}{l}\text { Eigentümer_in: Abratec, Inversiones Itata Ltda. - Rep.: Siegfried } \\
\text { Hoffmann, Cünther Schaffrik, Siegfried Laube }\end{array}$ \\
\hline $\begin{array}{l}\text { Talleres y Maquinarias Abratec } \\
\text { Ltda. }\end{array}$ & $\begin{array}{l}\text { Eigentümer_in: Abratec, Inversiones Itata Ltda. - Rep.: Siegfried } \\
\text { Hoffmann, Cünther Schaffrik, Siegfried Laube }\end{array}$ \\
\hline Inversiones Itata Ltda. & $\begin{array}{l}\text { Eigentümer_in: CF, Agricola Valle Florido, Erika Tymm, Waltraud } \\
\text { Tymm, Lilian Schaffrik (alle } 3 \text { Eigentümer_innen und Rep.) }\end{array}$ \\
\hline Transportesy Rentas La Esperanza & $\begin{array}{l}\text { Eigentümer_in: Sociedad e Inmobiliaria Santa Regina, Edgardo } \\
\text { Alonoso Escalona Aedo (Eigentümer und Rep.) }\end{array}$ \\
\hline $\begin{array}{l}\text { Industrializados y Prefabricados } \\
\text { Induval Ltda. }\end{array}$ & unbekannt \\
\hline $\begin{array}{l}\text { Rarinco Sociedad Agricultora } \\
\text { Comercial/Agrícola Rarinco Ltda. }\end{array}$ & unbekannt \\
\hline $\begin{array}{l}\text { Agroindustrial Tierra Nueva, } \\
\text { Purranque }\end{array}$ & Erwin Fege \\
\hline
\end{tabular}




\section{Der bisherige Kenntnisstand über die Verbrechen der Colonia Dignidad}

Die Colonia Dignidad als System (vgl. Abschnitt 2.1) beging seit ihrem Bestehen kontinuierlich eine große Anzahl von Verbrechen bzw. Straftaten. In allen Phasen des Falls Colonia Dignidad drangen Informationen über diese Verbrechen nach außen, meist verbreitet durch Journalist_innen und Menschenrechtsaktivist_innen. Allerdings stammten die Informationen nicht immer aus erster Hand. Zeitnahe juristische oder behördliche Untersuchungen blieben oft aus. Nur ein Teil der Taten wurden daher bislang von der Justiz in Chile oder in Deutschland untersucht bzw. auch geahndet. Untersuchungen, die tatsächlich stattfanden, wurden zudem häufig nicht mit der gebotenen Gründlichkeit und Konsequenz durchgeführt. Nicht zuletzt besteht selbst bei den Untersuchungsergebnissen, die vorliegen, oftmals bis heute kein vollständiger Zugang zu den Akten. All diese Umstände haben vielfach zu einer Art unbestätigtem Wissen über den Fall CD geführt, das mitunter durch Hypothesen oder Spekulationen angereichert wird. Bisherige Darstellungen der CD-Verbrechen sind daher oft lückenhaft oder konzentrieren sich auf einzelne Aspekte.

Ziel dieses Kapitels ist es daher, den heutigen Kenntnisstand über die Verbrechen der Colonia Dignidad anhand der verfügbaren Quellen möglichst umfassend zusammenzutragen und zu systematisieren. Dabei hat die Einordnung in bestimmte Verbrechenskomplexe Vorrang vor einer rein chronologischen Struktur. Dennoch soll auch der Wissensstand rekonstruiert werden, der sich bereits vor der Festnahme Schäfers 2005 entwickelt hatte. Mit Primärinformationen von Behörden und anderen Akteur_innen soll dabei stets auch der Frage nachgegangen werden, wer zu welchem Zeitpunkt welche Kenntnisse von den jeweiligen Verbrechen besaß.

Die folgende Darstellung basiert auf der Auswertung einer Vielzahl inzwischen verfügbarer Dokumente aus Justizverfahren oder Behörden sowie auf Aussagen von Betroffenen. Sie enthält viele, zum Teil ausführliche Originalzitate von Betroffenen. Diese stammen aus Vernehmungsakten und anderen Dokumenten. Diese Art der Darstellung soll eine möglichst wort- und detailgenaue Schilderung der Verbrechen ermöglichen. Dies erscheint mir erforderlich, weil viele Verbrechen, aber vor allem die Sichtweise der Betroffenen in vielen öffentlichen Darstellungen der CD nur verkürzt wiedergegeben 
werden. Zudem ist vielfach nicht ersichtlich, ob es sich um quellengestützte Aussagen handelt oder um eine Reproduktion von Kenntnissen aus zweiter oder dritter Hand. Außerdem sollen wortgetreue Schilderungen eine Analyse des jeweiligen Zeitgeistes in der Colonia Dignidad ermöglichen, ohne die die Frage, wie die CD so lange bestehen konnte, meines Erachtens nicht beantwortet werden kann.

Dabei betrachte ich die CD als ein System (vgl. Abschnitt 2.1), das sich nach innen und nach außen absicherte, um seine im Kern kriminelle Struktur erhalten zu können. Die Strategie zur Erreichung dieses Dauerzustandes einer »verbrecherischen Kontinuität « hatte dabei mehrere Bestandteile oder Sphären. ${ }^{1}$ Schäfers Sexualverbrechen sind in diesem Sinne das Primärverbrechen der CD. Damit ist gemeint, dass Entstehung und Wirken der CD Schäfer von Beginn an dazu dienten, diese Verbrechen kontinuierlich ausüben zu können, ohne dafür strafrechtlich belangt zu werden. Die CD als Gruppe bot den notwendigen Rahmen und Schutz zur straflosen Perpetuierung dieser Primärverbrechen. Daher war es stets das zentrale Ziel Schäfers und der Führungsgruppe der CD, den Fortbestand der Gruppe zu sichern. Hierzu diente der Aufbau sowohl einer internen als auch einer externen Fassade, die zu konstruieren und aufrechtzuerhalten kompliziert und aufwändig war. Als interne Fassade diente das gruppeninterne Gemeinschaftsnarrativ, das auf dem pseudoreligiösen Diskurs einer Gemeinschaft von Auserlesenen, die in entbehrungsreicher Arbeit ein großes Werk vollbringen, fußte. Dieses fand ihren Ausdruck einerseits in der rigiden Trennung von Geschlechtern und der Unterbindung von Familien- oder sonstigen Vertrauensstrukturen und andererseits in der Konstruktion einer individuellen und exklusiven Rechenschaftspflicht gegenüber Schäfer. Diese Fassade wirkte nach innen als diskursives Gerüst. Indem die Eltern ihre elterlichen Sorgepflichten für in der CD lebende Kinder faktisch an Paul Schäfer und seine Führungsgruppe übertrugen, verschaffte dieser sich Zugang zu Opfern für seine Sexualverbrechen. Die Außendarstellung der CD als vermeintlich wohltätige Organisation war Kern der externen Fassade. Mit diesem Image betrieb die CD zur Absicherung ihrer Existenz eine intensive Lobbyarbeit, baute verlässliche Unterstützungsnetzwerke auf und bekämpfte jegliche Aufklärungsversuche mit juristischen Mitteln.

Neben Schäfers Sexualverbrechen als dem Primärverbrechen, gab es auch zahlreiche Sekundärverbrechen (siehe Tabelle 3). Dabei unterscheide ich zwischen internen Verbrechen, die an Gruppenmitgliedern verübt wurden und externen Verbrechen, die über die CD hinauswirkten, wie beispielsweise die im Rahmen der Allianz der CD mit der Diktatur und dem Geheimdienst DINA begangenen Taten. Zur Durchführung sowohl der internen als auch der externen Verbrechen war Paul Schäfer auf einen bedingungslos loyalen Führungszirkel angewiesen, dem er im Gegenzug Privilegien und Einfluss innerhalb der Gruppe einräumte. Diese Verbrechen waren sekundär insofern, als sie einem bestimmten Zweck dienten, nämlich den Fortbestand der Gruppierung zu gewährleisten, und damit den Rahmen für Schäfers Sexualverbrechen bzw. die Privilegien seiner Führungsriege abzusichern. Damit dieses System fortbestehen konnte, musste sichergestellt werden, dass möglichst wenig Informationen bekannt wurden. Gelangten doch einmal unerwünschte Informationen nach außen, etwa durch Fluchtfälle oder 
Zeugnisse von Folterüberlebenden, so musste verhindert werden, dass Behörden gegen die CD vorgingen.

Die internen Verbrechen (Abschnitt 4.1) dienten dazu, die Autorität und Führungsrolle Schäfers sowie das innere Machtgefüge der Gruppe aufrechtzuerhalten. Diese Verbrechen wurden nach innen pseudoreligiös legitimiert. Von allen Gruppenmitgliedern wurde die vollständige Unterwerfung unter den Willen Schäfers verlangt. Schäfer selbst verstand sich als Inbegriff der kollektiven Wahrheit. Ihm $\mathrm{zu}$ widersprechen war daher gleichbedeutend mit einem Angriff auf die Gruppe als Ganzes, der unterbunden und sanktioniert werden musste. Jeglicher Anflug von Opposition gegen diese internen Verhältnisse, aber auch Fluchtversuche wurden u.a. durch drakonische Prügelstrafen, Einsperren, Ruhigstellung und Brechen der Willenskraft (durch Medikamente oder eine "Auslöschung« des Gedächtnisses durch Elektroschocks) unterbunden. Diese Verbrechen wurden gegenüber der Gruppe - soweit sie anderen Gruppenmitgliedern überhaupt bekannt wurden - als notwendige Strafen für gruppenschädigendes Verhalten bzw. Verstöße gegen die Normen der Gruppe legitimiert. Neben den körperlichen und psychischen Schäden, die die Opfer dieser Verbrechen erleiden mussten, hatten diese Zwangsmaßnahmen auch einen abschreckenden Effekt für den Rest der Gruppe. Den Gruppenmitgliedern wurde so signalisiert, dass sie sich den herrschen Verhältnissen $\mathrm{zu}$ fügen oder schwerwiegende Konsequenzen zu befürchten hatten. In diese Kategorie der internen Verbrechen fällt auch Schäfers systematischer sexueller Missbrauch an Gruppenmitgliedern. In der Regel wurden all diese Taten von den Betroffenen niemals zur Anzeige gebracht. Selbst aus der CD geflohene Colonos wagten diesen Schritt aus Angst vor Repressalien und »den langen Arm der $C D$ «meist nicht.

Die externen Verbrechen (Abschnitt 4.2) dienten vornehmlich zur Festigung der Macht der CD nach außen. Wichtigstes Beispiel hierfür ist die Beteiligung der CD an den Menschenrechtsverbrechen der chilenischen Militärdiktatur in den Jahren 1973-1990, die ihr im Gegenzug eine bedingungslose Unterstützung durch die Militärregierung bis zu Diktator Pinochet persönlich einbrachte. Während sich die externen Menschenrechtsverbrechen der CD im Kontext der Diktatur auf die Jahre 1973 bis 1990 konzentrierten, beging die CD viele weitere externe Verbrechen seit dem Jahr der Ankunft in Chile (1961) bis zur Festnahme Paul Schäfers 2005. Hierzu zählt auch der systematische sexuelle Missbrauch chilenischer Kinder durch Paul Schäfer und die Aneignung von chilenischen Kindern durch betrügerisch herbeigeführte Adoptionen. ${ }^{2}$

2 Aufgrund dieser Kategorisierung kommt es zum Teil zu inhaltlichen Überschneidungen. So war z.B. der systematische sexuelle Missbrauch von Kindern von Colonos ein internes Verbrechen (4.1.1), während der Missbrauch chilenischer Kinder aus der Umgebung der CD eher als externes Verbrechen zu werten ist (4.2.4). Auch die betrügerischen Adoptionen (4.1.2) stellten externe Verbrechen dar, deren Opfer später Opfer interner Verbrechen wurden. 


\subsection{Die internen Verbrechen der kriminellen Gemeinschaft Colonia Dignidad}

\subsubsection{Sexueller Missbrauch}

Berichten von Opfern zufolge verübte Paul Schäfer während seines Lebens Tausende von Missbrauchs- und Vergewaltigungsverbrechen. ${ }^{3}$ Er beging diese Taten über einen Zeitraum von mindestens fünf Jahrzehnten, an Mitgliedern der Gruppe ebenso wie an externen Personen - ungehindert von der Justiz. In diesem Abschnitt geht es um die sexuellen Verbrechen Schäfers an Gruppenmitgliedern. ${ }^{4}$ In gewisser Hinsicht markieren die sexuellen Verbrechen Paul Schäfers den Anfang und das Ende der Colonia Dignidad. Schäfers Entscheidung, nach Chile überzusiedeln, lag darin begründet, dass er in der Bundesrepublik eine strafrechtliche Verfolgung seiner Taten und damit seine Festnahme fürchtete. Ebenfalls aus Angst vor Strafverfolgung in Chile floh Schäfer 1997 nach Argentinien. Zudem stellen Schäfers Sexualstraftaten die Primärverbrechen der CD dar. Während andere Verbrechen einem bestimmten Zweck dienten (z.B. der Bestand der CD zu sichern oder Einnahmen zu generieren), waren diese Verbrechen Selbstzweck. Schon allein deshalb ziehen sie sich wie ein roter Faden durch die Geschichte der CD. Bereits in Heide (Lohmar) war das Ziel der Gruppe, Schäfer Opfer für seine Missbrauchstaten zuzuführen. Die gesamte pseudoreligiöse Gruppierung war nur ein Mittel, um diesen Zweck zu legitimieren. Und immer wenn dieser Zweck gefährdet war, änderte die $C D$ ihre Strategie.

Erste Hinweise auf Schäfers Missbrauchstaten gab es bereits in den frühen 1950er Jahren. Von der Gründung der Gruppe in den 1950er Jahren bis mindestens zu seiner Flucht nach Argentinien 1997 beging Schäfer kontinuierlich, in der Regel vermutlich mehrmals täglich, sexuelle Verbrechen. Seine bevorzugten Opfer waren männliche Kinder und Jugendliche im Alter von etwa 6 bis 18 Jahren. Es gibt jedoch auch eine Reihe von Berichten und Hinweisen über einen Missbrauch Schäfers an erwachsenen Männern ${ }^{5}$ sowie an Mädchen und Frauen. Noch bis vor Kurzem galt sexualisierte Gewalt gegen Frauen in der CD als Tabuthema. Erst seit 2017 wurden erste Berichte darüber bekannt. ${ }^{6}$ Der Rechtsanwalt und Ex-Colono Winfried Hempel berichtete, unter den etwa 120 von ihm rechtlich vertretenen Ex-Colonos seien etwa 15 Frauen, die berichteten,

Laut Wolfgang Kneese »handelt [es] sich bei dem Kindesmissbrauch in der Ära Schäfer um 30.000 bis 35.000 Kindesvergewaltigungen. Vgl. PJS, Sammlung AA. Auswärtiges Amt, Rede des Bundesministers des Auswärtigen Dr. Frank-Walter Steinmeier »Zum Thema Colonia Dignidad « und Paneldiskussion »Ein Tag der uns aufatmen läßt«vom 26.04.2016, Berlin 2016 [unveröffentlichte Broschüre], S. 37.

4 Die Sexualverbrechen Schäfers an externen chilenischen Kindern werden in Abschnitt 4.2.4 erörtert.

$5 \quad$ Hier handelte es sich wohl um Männer, die schon seit ihrer Kindheit von Schäfer missbraucht wurden. Der Colono Cerd Schaffrik berichtet beispielsweise, dass er bis zur Flucht von Schäfer 1997 - als C.S. bereits 45 Jahre alt war - von diesem missbraucht wurde. VgI. CA Santiago, AZ 2182-98 (»Ley de Control de Armas«), Bd. II, BI. 420. Vernehmung von Gerd Schaffrik am 22.09.2005.

6 Dazu gehört ein Bericht der Zeitzeugin Iris Leiva Arévalo, vgl. Rittel, Heike/Jürgen Karwelat. Lasst uns reden. Frauenprotokolle aus der Colonia Dignidad, Stuttgart 2018, S. 119-132. 
von Schäfer missbraucht worden zu sein. ${ }^{7}$ Die vom AA eingesetzte Psychiaterin Karin Hinzner berichtete 2018 von Therapiesitzungen mit Colonas, dass der sexuelle Missbrauch von Frauen unter massiven Drohungen und mit besonderer Gewalt stattfand. ${ }^{8}$

Verübte Schäfer seinen Missbrauch in den 1950er Jahren noch vorwiegend in Privatwohnungen, auf Jugendfreizeiten oder im Jugendheim der Gruppe in Heide (Lohmar), fanden die Missbrauchs- und Vergewaltigungshandlungen in Chile mit den Jahren zunehmend systematischer und organisierter statt. Ein immer größerer Kreis von CDMitgliedern und externen Personen war Teil eines ausgeklügelten Systems, das dazu diente, Schäfer Opfer für seine Sexualverbrechen zuzuführen. Der Missbrauch fand in Schäfers Schlafzimmer im Freihaus, in den Duschen oder an anderen Orten innerhalb der Siedlung statt. Auch Colonos, die selbst nicht Missbrauchsopfer wurden, bekamen die Taten mit. Diese waren vermutlich einer Mehrzahl der Colonos (zumindest den männlichen) bekannt. Während viele Colonos bei Vernehmungen nach der Festnahme Schäfers behaupteten, erst nach dessen Flucht aus der CD von seinen Sexualverbrechen erfahren zu haben, berichteten andere bereits frühzeitig davon. Franz Baar etwa antwortete bei seiner richterlichen Vernehmung im Juli 2004 auf entsprechende Fragen, alle Deutschen hätten über den Missbrauch Minderjähriger gewusst: »Todos los alemanes sabían de los abusos deshonestos que sufrían los menores. « Das vernehmende Gericht bestätigte diese Aussage und führte als Beleg einen entsprechenden Polizeibericht an:

»Del relato efectuado por los menores abusados sexualmente por Schäfer, queda claramente establecido que hay muchos miembros de la >Colonia< que saben y conocen las desviaciones y gustos sexuales de su líder, pues son ellos mismos los que llevan a la habitación de éste a los menores agredidos. ${ }^{10}$

Die Taten wurden jedoch aus verschiedenen Gründen geduldet, etwa aus Angst vor Schäfer, der den Opfern drohte für den Fall, dass sie über die erlebten Misshandlungen sprächen. Wolfgang Müller Ahrend etwa berichtete von mehrfachen Todesdrohungen: »Tres veces, en distintas ocasiones, Schäfer me amenazó con la pistola apuntándome a la cabeza me dijo: 'Si hablas, serás hombre muerto. «" ${ }^{11}$ Ein anderer Grund war religiöse Verblendung bzw. der Glaube an die Unfehlbarkeit Schäfers. Insbesondere die

Löhning, Ute. »Dahinten, da ist was rot« - Frauen in der Colonia Dignidad, in: Nachrichtenpool Lateinamerika (npla), 30.12.2017, online unter https://www.npla.de/thema/memoria-justicia/dahi nten-da-ist-was-rot-frauen-in-der-colonia-dignidad/.

Penjean, Lorena. „Niels Biedermann, psiquiatra de los sobrevivientes de Colonia Dignidad: sNunca, en los trece años que llevo trabajando con los colonos he oído mencionar el nombre del doctor Dörr« [Interview mit Niels Biedermann und Karin Hinzner], in: The Clinic (Website), 02.05.2018, online unter https://www.theclinic.cl/2018/05/02/niels-biedermann-psiquiatra-los-sob revivientes-colonia-dignidad-nunca-los-trece-anos-llevo-trabajando-los-colonos-he-oido-mencion ar-nombre-del-doctor-dorr/.

9 CA Santiago, AZ 2182-98 (»Asociación Ilícita«), Bd. II (Parral), BI. 1207 (R). Richterliche Vernehmung von Franz Baar am 07.07.2004.

10 CA Santiago, AZ 2182-98 (»Asociación Ilícita«). Erstinstanzliches Urteil vom 09.04.2014, S. 12.

11 CA Santiago, AZ 2182-98 (»Lesiones graves«), Bd. I, BI. 66. Testimonio Wolfgang Müller Ahrend vom 25.10.2005. 
jüngeren Opfer, die schon als Kleinkinder in die CD gekommen oder gar dort geboren wurden, waren ihrem Peiniger schutzlos ausgeliefert. Denn ihnen fehlte jegliches Wissen über Sexualität und das Recht auf (körperliche) Selbstbestimmung, wie der Aussage des Colono Michael Hühne aus dem Jahr $2005 \mathrm{zu}$ entnehmen ist:

»Fui criado desde chico desde los cinco años que llegué a Chile de una manera como todos los niños de Villa Baviera [...] yo no sabía nada de sexo ya que estaba prohibido saberlo y que alguien lo enseñara, desde los siete años hasta los dieciocho años, fui abusado por Paul Schäfer de una forma constante con penetración [...], lo que a mí me pasaba era para mi normal ya que no sabía cómo era la vida en el exterior de la villa. « ${ }^{12}$

Die folgende Aussage des Colonos Willi Malessa von 2005 über den vom ihm erlittenen Missbrauch verdeutlicht das Vorgehen Schäfers im Hinblick auf die Auswahl seiner Opfer. Sie zeigt zudem die breite Struktur von Unterstützern, die Schäfers Taten erst ermöglichten:

»En mi familia en Alemania éramos 8 hermanos por lo que a mis padres se les tornó muy difícil el poder mantenernos a todos, es así como mi madre a través de la religión conoció a Paul SCHAFER, quien era pastor evangélico, y como era sabido que SCHAFER, estaba construyendo un hogar de menores y a raíz de los problemas económicos mi madre optó por enviar a mi hermano mayor [...] al hogar de SCHAFER, todo esto en los años 1959. Como siguieron los problemas económicos mi madre al año siguiente me envió a mí al hogar de menores, donde conocí a Paul SCHAFER, quien el mismo día que llegué comenzó a abusar de mí, cuando yo recién había cumplido 10 años de edad. En este lugar estuve aproximadamente un año donde no volví a ver a SCHAFER, ya que este tuvo problemas judiciales por abusos de menores y desapareció de Alemania. El caso es que a los meses después de haber desaparecido Paul SCHAFER, uno de sus hombres de confianza Kurt SCHNELLENKAMP, nos llevó a varios niños en un furgón hasta cruzar la frontera con Bélgica, donde en forma sorpresiva nos encontramos con SCHAFER, quién tomó contacto con cada uno de los niños y nos dio instrucciones por separado sobre lo que teníamos que decir si la policía nos interrogaba respecto a abusos sexuales por parte de él (nunca fui entrevistado por la policía). En el mes de julio del año 1961 desde el mismo internado que me encontraba en Alemania fui trasladado junto a tres menores por Cerd SEEWALD y Erwin BOHNAU, a Chile específicamente al Fundo EI Lavadero de la comuna de Parral donde me encontré nuevamente con Paul SCHAFER, quién nuevamente comenzó a abusar sexualmente de mí, esto ocurrió hasta cuando cumplí 16 años de edad. Debo dejar en claro que como yo me encontraba solo frente al mundo, nunca comenté a nadie lo que me estaba ocurriendo con Paul SCHAFER, básicamente por miedo a las represalias que podría tomar éste si se enteraba que lo había delatado. $\ll^{13}$

12 CA Santiago, AZ 2182-98 (»Asociación Ilícita«), Bd. II (Parral), BI. 1395. Richterliche Vernehmung Michael Hühne am 18.04.2005.

13 CA Santiago, AZ 2182-98 (»]uan Maino«), Bd. 5a, BI. 2172f. Polizeiliche Vernehmung von Willi Malessa am 29.09.2005. Hervorhebung im Original. Eine detaillierte Schilderung des Missbrauchs durch Schäfer ist in folgendem Interview mit Friedhelm Zeitner enthalten: Villarubia, Gustavo. »Mi vida bajo el régimen de Paul Schäfer«. La historia de uno de los guardaespaldas del líder de 
Kein einziger Colono hat je in Chile Strafanzeige wegen der in der CD an ihm/ihr begangenen Sexualverbrechen gestellt. Bis zu Schäfers Festnahme 2005 schwiegen die meisten Betroffenen auch bei offiziellen Vernehmungen weitgehend darüber. Das einzige chilenische Gerichtsurteil zu Schäfers Sexualverbrechen behandelt den Missbrauch und die Vergewaltigung von 26 chilenischen Jungen aus der Umgebung der Colonia Dignidad zwischen 1993 und 1997 (vgl. Abschnitt 4.2.4). Auch in der Bundesrepublik wurden sämtliche Strafermittlungen, die seit 1961 wegen des Verdachts des sexuellen Missbrauchs gegen Paul Schäfer geführt wurden, wegen »fehlendem hinreichenden Tatverdacht« nach \$ 170 II StPO eingestellt. Hinweise auf die Sexualverbrechen Schäfers lagen den Ermittlungsbehörden spätestens seit Anfang 1961 vor. Damals nahm die Staatsanwaltschaft Bonn nach Strafanzeigen ein Ermittlungsverfahren gegen Schäfer auf. Von diesen Ermittlungen nahmen wenig später diverse Behörden Kenntnis. ${ }^{14}$ Seit 1966 waren Schäfers Taten sogar Gegenstand einer regelmäßigen breiteren Medienberichterstattung. ${ }^{15}$

Erste Hinweise von Institutionen oder Behörden auf sexuellen Missbrauch durch Schäfer stammen jedoch bereits aus den späten 1940er und frühen 1950er Jahren. Damals arbeitete Schäfer in verschiedenen Jugendheimen der Evangelischen Kirche in der Bundesrepublik. Nach Hinweisen auf Missbrauchstaten wurde er aus mehreren dieser Einrichtungen entlassen. Im Oktober 1950 beispielsweise wurde Paul Schäfer von der evangelischen Kirche im Landkreis Lüchow-Dannenberg wegen »Beeinflussung der Jugendlichen und Sektenverhalten « aus zwei Anstellungsverhältnissen ${ }^{16}$ entlassen. Schäfer führte seine Jugendgruppe daraufhin selbstständig weiter. Das Protokoll einer Sitzung des Sport- und Jugendausschusses der Gemeinde Gartow vom Juni $1951^{17}$ belegt, dass Gerüchte über Schäfers sexuellen Missbrauch an Jugendlichen bereits damals die Runde machten. ${ }^{18}$

Im August 1953 wurde Paul Schäfer vom Gotthilf-Vöhringer-Haus in Heidenheim entlassen, nachdem er bei sexuellen Übergriffen auf Jungen erwischt worden war. ${ }^{19} \mathrm{Al}-$ lerdings wurde der Grund für seine Entlassung nie öffentlich mitgeteilt, sondern ledig-

Colonia Dignidad, in: CIPER (Website), 23.09.2013, online unter https://www.ciperchile.cl/2013/09/ 23/"mi-vida-bajo-el-regimen-de-paul-schafer".

14 Vgl. u.a. PJK, Ordner Hummel. Schreiben des Innenministers in NRW an das Bundesverwaltungsamt vom 25.05.1961.

15 Vgl. u.a. Widmann, Carlos, »Zucht und Unzucht in der Siedlung,Würde«, in: Süddeutsche Zeitung vom 08.07.1966, S. 3 .

16 Im Landkreis Lüchow-Dannenberg war Schäfer in einem Altersheim der Diakonie und als Jugendwart bei der St. Georgs-Kirche im Kirchspiel Gartow angestellt.

17 Künz, Bärbel. Die Colonia Dignidad zwischen kollektiver Freistatt und instrumentalisiertem Zwangskollektiv. [unveröffentlichte Diplomarbeit], Köln 2010. Darin enthalten: Dokumentenanhang, Nr. 2: Niederschrift über die Sitzung des Sport- und Jugendausschusses der Cemeinde Gartow vom 20.06.1951.

18 Ebd. Laut Sitzungsprotokoll widersprach einer der Väter »dem Verdacht, daß Schäfer sich in sittlicher Beziehung an den Kindern vergehe« Dies belegt, dass Cerüchte über Missbrauch im Raum standen und diskutiert wurden.

19 Vgl. Fröhling, Ulla. Unser geraubtes Leben, S. 75f. sowie Groß, Heike/Ingo Zöllich. »Es gibt kein Zurück«, S. 11. 
lich intern unter Gemeindemitgliedern kommentiert. Es wurde auch keine Strafanzeige gestellt oder entsprechende Hinweise an Strafverfolgungsbehörden gegeben.

Selbstorganisierte Zeltfreizeiten und Zusammenkünfte mit Jugendlichen sowie später die Errichtung des Jugendheims in Heide (Lohmar) boten Schäfer neue Möglichkeiten für seine Taten. Diverse männliche Gruppenmitglieder berichteten in jenen Jahren, von Schäfer missbraucht worden zu sein, oftmals sogar bereits am ersten Tag des Zusammentreffens. ${ }^{20}$ Als sich im Umfeld der Gruppe um Paul Schäfer die Hinweise auf dessen Sexualverbrechen verdichteten und dieser damit rechnen musste, früher oder später belangt zu werden, entschied sich die Gruppe zur Auswanderung nach Chile.

Schon bald nach seiner Übersiedlung nach Chile erhielten bundesdeutsche politische Behörden Kenntnis von den Missbrauchsvorwürfen gegen Schäfer, die ab 1961 Gegenstand der Ermittlungen der Staatsanwaltschaft Bonn waren.

Die folgenden Zitate aus unterschiedlichen Phasen der CD belegen, über welche Kenntnisse AA und die Botschaft in Santiago zu dem sexuellen Missbrauch in der CD verfügten:

Bereits im Januar 1963 berichtete die Botschaft dem AA vom Verein »Private Soziale Mission, Parral/Chile«:

»Nach einer vertraulichen Mitteilung des Direktors des Landesverbandes Rheinland Landesjugendamt - vom 19. Februar 1962 soll gegen den Treuhänder Schäfer ein Ermittlungsverfahren wegen Unzucht mit einem Kind (\$176 Abs. 1 Ziff. 3 StCB) anhängig sein. Das Ermittlungsverfahren könne jedoch zur Zeit nicht vorangetrieben werden, da sich Schäfer in den USA aufhalten soll. Schäfer ist im Fahndungsbuch des Bundeskriminalamts mit »Sternchen« aufgeführt. ${ }^{21}$

1966 erkundigte sich der in der Bundesrepublik lebende Vater zweier Jungen, die mit ihrer Mutter in die CD ausgewandert waren, über einen Rechtsanwalt bei der Botschaft nach dem Wohlergehen seiner Söhne Wolfgang und Michael Hühne. Er war durch die Presseberichte nach der Flucht von Wolfgang Müller (heute: Kneese) beunruhigt. Die Botschaft antwortete ihm:

»Es ist richtig, daß einer der früher leitenden Männer der Mission, der in Deutschland wegen Unzucht mit Minderjährigen gesucht wird, auch in der Kolonie gelegentlich abartige Beziehungen zu Kinder[n] unterhalten haben soll, - nach den Informationen der Botschaft aber nicht zu den Söhnen Ihres Herren Mandanten-. Dieser Mann ist Anfang dieses Jahres entflohen. Sein Treiben wurde von der Mission mißbilligt, aber wegen seiner starken persönlichen Ausstrahlungskraft nicht unterdrückt. Zur Zeit dürfte für Herrn Hühne insoweit kein Anlaß zur Sorge mehr bestehen.

Die Meldungen in Presse und Fernsehen waren oft stark übertrieben und teilweise unrichtig. Viele Koloniemitglieder, denen von deutschen Angehörigen die Möglichkeit

20 Vgl. u.a. CA Santiago, AZ 2182-98 (»]uan Maino«), Bd. 5a, BI. 2172f. Polizeiliche Vernehmung von Willi Malessa am 29.09.2005 sowie Fröhling, Ulla. Unser geraubtes Leben, S. 108. 
gegeben wurde, nach Deutschland zurückzukehren, entschieden sich nach einem Cespräch mit dem chilenischen Sonderrichter unter vier Augen, in der Kolonie zu bleiben, in der es Ihnen gut gehe und in der sie eine wertwolle, uneigennützige Sozialarbeit leisten. ${ }^{22}$

Die Antwort verdeutlicht, dass die Botschaft sich die ihr von der CD zugetragenen Informationen zu eigen machte. Denn es erschließt sich nicht, aus welcher anderen Quelle die Informationen über Schäfers vermeintliche Missbrauchsopfer in der CD stammen sollten.

Nachdem das Ehepaar Lotti und Georg Packmor im Februar 1985 aus der CD fliehen konnte, berichteten sie der Botschaft ausführlich von den Vorgängen innerhalb der Siedlung und auch über die Sexualstraftaten Schäfers. Der damalige Botschafter Holzheimer leitete den Bericht der Packmors an das AA weiter. Er regte an, »unsere Erkenntnisse über die Lebensverhältnisse in der $C D$ « auch der chilenischen Regierung zur Verfügung zu stellen und fügte an:

»Wichtiger wäre allerdings, daß die in vielem an ein Konzentrationslager gemahnenden Lebensbedingungen wie die Behandlungen mit Psychopharmaka und Elektroschocks geändert werden und Herrn Schäfer nicht weiter Gelegenheit gelassen wird, Kinder bei sich schlafen zu lassen (siehe Fahndungsersuchen in der Vergangenheit). ${ }^{23}$

Tatsächlich nahm die Staatsanwaltschaft Bonn aufgrund dieses Schreibens sowie des beigefügten Berichts des Ehepaares Packmor 1985 Ermittlungen gegen Paul Schäfer auf - allerdings nicht explizit wegen sexuellen Missbrauchs, sondern wegen »Freiheitsberaubung, Körperverletzung usw. «. ${ }^{24}$ Auf eine Anfrage der Botschaft zur Person Schäfers antwortete die nordrhein-westfälische Justiz im Juli 1985:

»Cegen den am 4.12.1921 in Bonn geborenen Paul Schäfer bestand seiner Zeit der Verdacht, sich an drei noch nicht 14-jährigen Jungen in sexueller Hinsicht vergangen zu haben. Deswegen war bei der Staatsanwaltschaft Bonn unter dem Aktenzeichen 14 ]s 173/61 jug. ein Ermittlungsverfahren anhängig. Die aufgrund eines gegen Paul Schäfer erwirkten Haftbefehls eingeleiteten Fahndungsmaßnahmen blieben jedoch ohne Erfolg. Da in der Zwischenzeit neue Erkenntnisse nicht gewonnen werden konnten, wurde die Ausschreibung des Beschuldigten zur Festnahme am 23. Juli 1970 gelöscht, weil sie im Hinblick auf Verschlechterung der Beweislage (nur auf Kinderaussagen gestützter Tatverdacht) unverhältnismäßig erschien. Der Haftbefehl wurde auf Antrag der Staatsanwaltschaft Bonn am 13.10.1970 aufgehoben. Mit Verfügung vom 14.5.1974 wurde das Verfahren wegen zwischenzeitlich eingetretener Verfolgungsverjährung eingestellt und der noch niedergelegte Suchvermerk zurückgenommen. Ein aus dem Verfahren 14 JS 173/61 jug. Ausgetrennter Vorgang - 14 Js 1940/65 StA Bonn an die Rechtsanwälte des Vaters von Michael und Wolfgang Hühne vom 03.11.1966. RK V3 SK 9230. PA AA, B 83, Bd. 2384. Bericht Botschafter Holzheimer an AA 330 vom 27.03.1985, Ber. 352/85 rk 543.00 . 
ist am 9.12.1966 gemäß §170 II StPO eingestellt worden. Die Akten beider Verfahren sind bereits seit längerem vernichtet. ${ }^{25}$

Bei dem »ausgetrennten Vorgang « handelte es sich um ein Verfahren wegen Verdachts der Kindesentziehung. ${ }^{26}$ Der erwähnte Haftbefehl vom Amtsgericht Siegburg erging am 21. Februar $1961^{27}$ Er ging auf eine Strafanzeige von Hermann Altevogt bei der Kriminalpolizei in Gronau vom 27. Januar 1961 und der darauffolgenden Vernehmung der jugendlichen Missbrauchsopfer zurück. ${ }^{28}$ Schäfer war jedoch bereits am 3. Januar 1961 nach Chile ausgereist ${ }^{29}$ und hatte sich so einer drohenden Verhaftung entzogen. $\mathrm{Hu}$ go Baar, der nach der Auswanderung des Großteils der Gruppe weiter für die CD in Deutschland blieb, berichtete ebenfalls 1985:

»Anfang 1961 flogen dann Herr Schmidt und Herr Schäfer nach Chile [...] Ich ging jetzt ganz ins Jugendheim Heide bei Siegburg und übernahm dort auch die Heimleitung. Einige Wochen später kamen 2 Beamte der Siegburger Kriminalpolizei (ein Herr und eine Frau) und erklärten mir, daß 3 Jungen in Cronau bei der dortigen Kriminalpolizei ausgesagt hätten, daß Herr Schäfer im Jugendheim sich an ihnen vergangen hätte. « ${ }^{30}$

Fortan wurde Schäfer im Fahndungsbuch der Botschaft in Santiago aufgeführt. Damit begannen ein Versteckspiel und eine gezielte Desinformationskampagne zu seinem Aufenthaltsort. Im Januar 1963 teilte Botschafter Strack dem AA mit, Schäfer sei im Fahndungsbuch des Bundeskriminalamts aufgeführt, der Haftbefehl könne jedoch nicht vollstreckt werden, da sich Schäfer in den USA aufhalte. ${ }^{31}$ Im Juni 1963 berichtete die Botschaft dann, Schäfer halte sich in Buenos Aires auf. "Die genaue Anschrift dürfte das Landgericht Bonn kennen, bei dem unter dem Aktenzeichen 3 0 66/1962 ein Rechtsstreit gegen Paul Schäfer schwebt. ${ }^{32}$ Tatsächlich hatten die chilenischen Grenzbehörden am 08. November 1961 eine Ausreise Schäfers nach Argentinien vermerkt, jedoch keine Wiedereinreise. ${ }^{33}$ Laut Willi Georg, der bis zur Ausreise nach Chile Teil der Gruppe um Schäfer gewesen war, hätte Schäfers Flucht durch eine schnellere Ausstellung des Haftbefehls verhindert werden können. Zu dem Zeitpunkt, als die miss-

PA AA, AV NA 31577. Schreiben von Oberstaatsanwalt Irsfeld an das Justizministerium NRW vom 19.07.1985, »Betr. Ermittlungsverfahren gegen Verantwortliche der Sekte >Christliche Soziale Mission in Siegburg wegen des Verdachts auf Freiheitsberaubung u.a.«.

Es handelt sich hier um ein Verfahren, das nach einer Strafanzeige von Minna Wagner wegen Kindesentziehung eingeleitet wurde. Zu diesem Vorgang, siehe Abschnitt 4.1.2.

PA AA, B 83, Bd. 1177. Einstellungsverfügung der StA Bonn zum Ermittlungsverfahren 31 U]s 4856/77 vom 22.07.1977. Naranjo nennt als Aktenzeichen des Haftbefehls 13 CS 165/61. Vgl. Naranjo, Jaime. Colonia Dignidad en los debates parlamentarios, in: Hevia/Stehle (Hg.). Hevia/Stehle (Hg.). Colonia Dignidad: diálogos sobre verdad, justicia y memoria, S. 153-161, hier S. 154. PJS, Sammlung Luis Narváez. Bericht der JIPOL/PDI vom 13.10.2006: Procesamiento y Análisis de la información en idioma alemán remitida por el Ministro Jorge Zepeda Arancibia el 14 de septiembre de 2005. Archivador 13, Documento 10, S. 175. PA AA, AV NA 31580. Schreiben des BMI an AA vom 15.08.1977, Betr.: Paul Schäfer in Chile. PA AA, B 83, Bd. 2384. Bericht von Hugo Baar an die deutsche Botschaft vom 02.04.1985, S. 4. PA AA, B 85, Bd. 598. Schreiben Botschafter Strack an AA vom 25.01.1963, CZ 502-81.05-124/63. Becerra, Gonzalo. »Hace agua la galera de Paul Schäfer?«, in: Qué Pasa vom 10.03.1988, S. 13-15. 
brauchten Kinder in Gronau vernommen wurden, deren Eltern später Strafanzeige erstatteten, sei Schäfer noch in der Bundesrepublik gewesen. ${ }^{34}$ Nachdem die StA Bonn ihr Ermittlungsverfahren eingestellt hatte, reiste Paul Schäfer 1975 in die Bundesrepublik und beantragte in Siegburg einen neuen Reisepass. Er gab als Wohnort "Siegburg« und als bisherigen Wohnort »El Mallín/Esquel, Argentinien« an. ${ }^{35}$

Erst 1997, nachdem der aus der CD geflüchtete Colono Tobias Müller und der in der CD missbrauchte Chilene Salo Luna in die Bundesrepublik gereist waren, eröffnete die Staatsanwaltschaft Bonn erneut ein Ermittlungsverfahren gegen Schäfer wegen sexuellen Missbrauchs. ${ }^{36}$ Auch dieses Verfahren wurde eingestellt, und zwar 2010 nach Schäfers Tod.

\subsubsection{Kindesentführung nach Chile, Adoptionsbetrug}

Im Zusammenhang mit der Übersiedlung der Gruppe um Schäfer wird oftmals von einer systematischen Kindesentführung nach Chile gesprochen. Dieter Maier spricht gar von der "größten Massenentführung in der Geschichte der BRD «. ${ }^{37}$ Diese These soll im Folgenden anhand der verfügbaren Dokumente und Zeugnisse überprüft werden.

Insbesondere in den Anfangsjahren der Gruppe (1961-1963), aber auch später, wanderte eine Reihe von Kindern ohne Begleitung ihrer Eltern nach Chile aus. Hermann Schmidt und Hugo Baar hatten sich hierfür von den Sorgeberechtigten der Kinder Einwilligungserklärungen für eine Reise nach Chile unterzeichnen und notariell beglaubigen lassen. Rita Seelbach, die Buchhalterin der PSM, erklärte dazu 1988:

»Über die Umstände der Überwechslung der Jugendlichen nach Chile ist mir bekannt, daß Herr Baar Cespräche mit Eltern, bzw. Elternteilen geführt hatte, inwieweit diese mit der Übersiedlung ihrer Kinder einverstanden seien. Es hat in diesem Zusammenhang Einwilligungserklärungen gegeben betr. jedes einzelnen Kindes. Diese Erklärungen sind notariell beglaubigt worden. $\ll^{38}$

Diese Erklärungen konnten später auch als unbefristete Abtretungen des Sorgerechts zugunsten von Baar und Schmidt interpretiert werden. Die CD ließ sich von den jeweiligen Amtsgerichten formale Bestallungsurkunden ausstellen, also Urkunden über die formelle Vormundschaft. In einem Fall adoptierte Hermann Schmidt auch ein Kind, das mit nach Chile ausgereist war. ${ }^{39}$ Mehrere dokumentierte Beispiele verdeutlichen,

PJS, Sammlung NIC. Not- und Interessengemeinschaft der Geschädigten der Colonia Dignidad, Materialdienst 1989. Bericht eines Ehemaligen [Willi Georg], S. 9. Diese Aussage deckt sich jedoch nicht mit den zuvor aufgeführten Quellen laut denen die Strafanzeige erst am 27.01.1961 gestellt wurde, als Schäfer bereits ausgereist war. PJS, Sammlung Luis Narváez. Bericht der JIPOL/PDI vom 13.10.2006: Procesamiento y Análisis de la información en idioma alemán remitida por el Ministro Jorge Zepeda Arancibia el 14 de septiembre de 2005.

35 Künz, Die Colonia Dignidad, darin enthalten: Dokumentenanhang Nr. 26. Antrag auf Ausstellung eines Reisepasses von Paul Schäfer vom 09.06.1975, Siegburg. 
dass die ursprünglichen Sorgeberechtigten der Kinder oftmals darüber im Unklaren gelassen wurden, dass es sich nicht nur um eine Reise nach Chile, sondern um eine endgültige Übersiedlung handelte. Auch war den Betreffenden häufig nicht bewusst, dass die Einwilligungserklärungen zur Grundlage für eine dauerhafte Übertragung des Sorgerechts bzw. für eine endgültige Adoption werden würden. Diverse Berichte verdeutlichen aber auch, dass den Eltern keine einheitliche Legende für die dauerhafte Übersiedlung gegeben wurde. Einigen wurde erzählt, es handele sich um eine Urlaubsreise nach Dänemark, ${ }^{40}$ andere erfuhren von einer Chorfahrt nach Chile. ${ }^{41}$ Einige Sorgeberechtige versuchten später, ihre Kinder zurückzubekommen, was allerdings in allen Fällen scheiterte. Die Botschaft und das AA nahmen mehrere dieser Fälle direkt zur Kenntnis, weitere Fälle wurden ihnen durch Presseberichte bekannt. In keinem einzigen Fall unternahmen Botschaft oder AA jedoch Schritte, die unmittelbar zu einer Rückholung von Minderjährigen aus der CD führten. Im Folgenden werden einige Fälle ausführlicher dargestellt, die besonders gut dokumentiert sind und die exemplarisch das Verhalten der CD, der Angehörigen und des AA darlegen.

\section{Der Fall Wolfgang Müller (heute Kneese)}

Wolfgang Müller Lilischkies (heute Kneese) war eines der ersten Kinder der Gruppe, das im Juli 1961 ohne seine Eltern nach Chile verbracht wurde. Am 29. April 1961 hatte seine Mutter Vera Müller folgende Erklärung unterzeichnet:

»Ich [...] erkläre mich als Sorgeberechtigte für meinen Sohn Wolfgang Müller [...] damit einverstanden, dass dieser eine Reise nach Chile antritt und gestatte ihm dort Aufenthalt zu nehmen.

Herr Hermann Schmidt oder Herr Hugo Baar [...] sollen berechtigt sein, während der Überfahrt und während des Aufenthaltes meines Sohnes in Chile dort seine Rechte, die mir als der Sorgeberechtigten meinem minderjährigen Sohn gegenüber zustehen, voll wahrzunehmen. ${ }^{42}$

Auf Grundlage dieser notariellen Erklärung stellte das Amtsgericht Hamburg-Altona am 22. Oktober 1962 eine Bestallungsurkunde aus, welche Hugo Baars Vormundschaft bescheinigte. ${ }^{43}$ Baar wiederum erteilte Hermann Schmidt eine Untervollmacht.

Noch 1962 gingen bei der Botschaft die ersten Anfragen von Eltern ein, die sich nach ihren Kindern erkundigten. Im Januar 1963 berichtete die Botschaft dem AA unter dem Betreff "Auswanderung nach Chile hier: >Private Sociale Mission` Parral/Chile « ${ }^{44}$. Am 16. Mai 1961 sei die Botschaft erstmalig auf die Auswanderungsbewegung der PSM aufmerksam gemacht worden, und zwar durch ein Schreiben des Bundesministers für Familien- und Jugendfragen (BMFJ). ${ }^{45}$ Der Minister habe die Ziele der PSM als unterstützungswürdig bezeichnet und die Botschaft gebeten, den Vertretern der PSM in

Dies geschah im Fall von Wolfgang Müller Ahrend. Vgl. Fröhling, »Unser geraubtes Leben«, S. 149.

Vgl. u.a. Heller, Lederhosen, Dutt und Giftgas, S. 16.

Archiv Al, Bestand CD. Erklärung Vera Müller (geb. Lilischkies) vom 29.04.1961.

PA AA, B 85, Bd. 598. Bericht Botschaft an AA vom 06.11.1963, GZ V 3 81.05-1382/63.

PA AA, B 85, Bd. 598. Bericht Botschaft an AA vom 25.01.1963, GZ 502-81.05-124/63.

PA AA, B 85, Bd. 598. Abschrift des Schreibens vom BMF] an Botschafter Strack vom 16.05.1961. 
Chile Hilfe und Schutz zu gewähren. Später, so die Botschaft, habe sie erfahren, dass laut einer vertraulichen Mitteilung des Direktors des Landesverbandes Rheinland des Landesjugendamtes vom Februar 1962 ein Ermittlungsverfahren gegen Paul Schäfer wegen Unzucht mit einem Kind anhängig sein soll. Die Ermittlungen hätten jedoch nicht vorangetrieben werden können, da sich Schäfer in den USA aufhalte. Die Botschaft berichtete weiter, sie habe bereits mehrere Anfragen von in Deutschland lebenden Müttern erhalten, deren Kinder nach Chile ausgewandert sein sollen und die nichts mehr von sich hätten hören lassen. In einer längeren Unterredung mit dem Präsidenten der SBED, Hermann Schmidt, in den Räumen der Botschaft habe dieser geäußert:

»Die Zahl derjenigen Kinder, deren Eltern in Deutschland seien, betrage 10-11. Außerdem seien 4-5 Waisen oder Halbwaisen auf dem Fundo. Er sei im Besitz schriftlicher Einwilligungen der Eltern bzw. Vormünder zur Erziehung dieser Kinder.« 46

Im März 1963 legte das Bundesverwaltungsamt dem AA in einem Schreiben nahe, die CD bald durch Beamte der Botschaft besuchen zu lassen. Dabei sollte insbesondere festgestellt werden, ob sich dort Minderjährige ohne elterliche Begleitung befänden. In diesem Fall könnten die Eltern in der Bundesrepublik kontaktiert werden, um zu klären, ob das erforderliche Einverständnis zur Auswanderung vorliege. ${ }^{47}$ Daraufhin besuchten Rechts- und Konsular-Referent (RK) Wasserberg sowie Konsularsekretär Rick von der Botschaft am 25. April 1963 die CD. Über diesen vermutlich ersten Besuch von Botschaftsangehörigen in der CD berichtete Botschafter Dr. Strack nach Bonn:

»Sie wurden von der Heimleitung zwar mit ausgesuchter Höflichkeit behandelt, aber bewusst daran gehindert, nähere Kontakte mit den Mitgliedern der Mission aufzunehmen, von denen sie etwa nur die Hälfte zu Cesicht bekommen haben. Es ist daher auch der Botschaft nicht gelungen, den Schleier des Ceheimnisses der Privaten Sozialen Mission zu lüften. $^{48}$

Es sei laut Strack offensichtlich gewesen, dass die Mitglieder der Mission etwas zu verbergen gehabt hätten. Die Vermutung liege nahe, dass es sich um eine Sekte handle, die ihren Mitgliedern den Abbruch jeglicher familiären Beziehungen zur Pflicht gemacht hätte. Doch zeigte Strack sich auch beeindruckt: »Unzutreffend dürfte dagegen die Annahme sein, auf dem Gut herrschten unsittliche Zustände. Eine derart mustergültige Ordnung und Disziplin [...] wäre in diesem Fall nicht zu erreichen. ${ }^{49}$ Laut Angaben des »Heimleiters« Hermann Schmidt lebten etwa 20 Minderjährige in der Siedlung, für die er über Einwilligungserklärungen der gesetzlichen Vertreter verfüge, »die ihm die Erziehungsgewalt übertragen hätten. Einige der Kinder habe er adoptiert. $\aleph^{50} \mathrm{Dazu}$ erklärte die Botschaft, bisher keine Anfragen von Eltern Minderjähriger aus der Bun-

PA AA, B 85, Bd. 598. Bericht Botschaft an AA vom 25.01.1963, CZ 502-81.05-124/63. 
desrepublik erhalten zu haben. ${ }^{51}$ Lediglich aus der chilenischen Tagespresse sei der Fall des 17-jährigen Wolfgang Müller bekannt, der vor etwa acht Monaten aus dem Heim entflohen und dann angeblich reumütig wieder zurückgekehrt sei. Die Botschaft fügte ihrem Bericht ein Empfehlungsschreiben des BMFJ an Botschafter Strack bei. ${ }^{52}$ Darin heißt es, das Ministerium habe anlässlich der Einweihung des Jugendheimes in Heide (Lohmar) einen guten Eindruck von der Gruppe gewonnen. Etwa 25 Jungen hätten dort ein ständiges Zuhause gefunden.

»Das soziale Anliegen steht im Vordergrund. Aus diesen Gründen ist zu erwarten, daß das neue Vorhaben des Vereins in Chile unterstützungswürdig ist. Ich wäre Ihnen, sehr geehrter Herr Botschafter, dankbar, wenn sie den Vertretern der Privaten Sozialen Mission Ihre Hilfe und Ihren Schutz gewähren könnten. «53

Es erscheint fragwürdig, warum die Botschaft nach ihrem Besuch in der CD keine weiteren Schritte zur Aufklärung unternahm. Schließlich hatte die CD-Führung just bei diesem Besuch, der unter anderem dazu dienen sollte, die Situation von Minderjährigen in der Siedlung zu klären, eine Kontaktaufnahme des Botschaftspersonals zu den Minderjährigen bewusst verhindert. Auch Schmidts Aussage, ihm sei für etwa 20 Minderjährige das Sorgerecht übertragen worden und er habe einige Kinder adoptiert, erscheint angesichts der hohen Zahl aus heutiger Sicht zumindesten sehr auffällig.

Etwa ein halbes Jahr später wurde die Sorgerechtsabtretung im Fall Wolfgang Müller für die Botschaft wieder aktuell. Der 17-Jährige war zum zweiten Mal aus der Siedlung geflüchtet und mithilfe eines Polizisten zu Bekannten in die Stadt Temuco, etwa 350 Kilometer südlich der CD, gelangt. Arturo Meissner, der deutsche Honorarkonsul in Temuco, führte ein Gespräch mit Müller, der schwere Anschuldigungen gegen die CD-Führung erhob und von Misshandlungen und Zwangsarbeit berichtete. Meissner schrieb in seinem Bericht an die Botschaft: "Der Junge macht den Eindruck eines Psychopathen, er verleumdet mit vollendeter Sicherheit ${ }^{54}$. Zudem seien die Chilenen, die Müller in Temuco aufgenommen hätten, »lasterhaft « und führten einen »berüchtigten Lebenswandel.«Gegenüber der Botschaft regte Meissner an, Müller nach Deutschland »heimzuschaffen«. Er fürchtete eine erneute Flucht Müllers und eine mögliche Rufschädigung durch Müller, konkret, dass er "seine Schule verleumdet und dadurch den Ruf aller deutschen Schulen des Landes in Mitleidenschaft zieht. Zu leicht wird geglaubt, dass wieder Nazimethoden angewandt werden. ${ }^{55}$ Müller gehöre zwar, so Meissner, in eine strenge Schule, er werde jedoch über kurz oder lang wieder fliehen. Meissner forderte die Bekannten von Müller auf, diesen an die Polizei zu übergeben, was auch geschah. Die Polizei wiederum übergab Müller den eilig herbeigereisten Mitgliedern der CD-Führung, darunter Hermann Schmidt und Gisela Seewald.

51 In der Tat handelte es sich bei den Anfragen von Eltern, die bis dato aktenkundig geworden waren, um zu diesem Zeitpunkt bereits volljährige Kinder. PA AA, B 85, Bd. 598. Schreiben des BMF] an Botschafter Strack vom 16.05.1961.

53 Ebd.

54 PA AA, B 85, Bd. 598. Schreiben von Honorarkonsul Meissner (Temuco) an Botschaft vom 05.10.1963. 
Daraufhin ließ sich die Botschaft von der CD-Führung die Bestallungsurkunde für Müller vorlegen. ${ }^{56}$ Diese wies Hugo Baar als Sorgeberechtigten und Hermann Schmidt als Bevollmächtigten aus. Die Botschaft berichtete dem AA, laut Angaben der PSM zeige Müller psychopathische Neigungen - ebenso wie seine Mutter, die inzwischen auch in der CD lebe und »wegen Geistesschwäche entmündigt " ${ }^{57}$ sei. Angesichts des »besonders delikaten « Falles bat die Botschaft das AA um Weisung für das weitere Vorgehen. Nachdem eine Antwort aus Bonn ausblieb, insistierte die Botschaft und regte eine »Heimschaffung « von Müller an. ${ }^{58}$ Die Botschaft argumentierte, sie müsse die Konsulate anweisen, was in einem erneuten Fluchtfall zu tun sei. »Rechtlich besteht nach Ansicht der Botschaft zur Zeit keine Möglichkeit, den Minderjährigen bei seinen angeblichen Bedrängern zu schützen. ${ }^{59}$ Als Nachtrag zur ihrem bisherigen Bericht bat die Botschaft das AA jedoch um Prüfung, ob vormundschaftsgerichtliche Maßnahmen in Frage kämen.

»Es besteht eine grosse Wahrscheinlichkeit dafür, dass Wolfgang Müller von seinem Vormund gezwungen wird, einer religiösen Sekte anzugehören. Dies bedeutet für ihn gleichzeitig einen vollständigen Entzug seiner persönlichen Freiheit. Ein einwandfreier Nachweis lässt sich allerdings insoweit nicht führen. ${ }^{60}$

Trotz der schwerwiegenden Vorwürfe, die im Raum standen, war dies für längere Zeit der letzte Vorgang in den Botschaftsakten zum Fall Müller. Knapp zweieinhalb Jahre später, Anfang März 1966, floh Wolfgang Müller zum dritten Mal aus der CD. Der entsprechende Bericht der Botschaft an das AA ist das nächste aktenkundige Dokument zu diesem Fall. ${ }^{61}$ Botschafter Nostitz bat, diesen Bericht an das Amtsgericht HamburgAltona weiterzuleiten. Wolfgang Müller sei nach seiner Flucht in die Botschaft gekommen und habe eine Volljährigkeitserklärung sowie eine Rückführung in die Bundesrepublik beantragt. Gleichzeitig habe Hermann Schmidt unter Vorlage der Vormundschaftserklärung die Herausgabe von Müller gefordert und behauptet, dieser sei schizophren. Müller erhebe schwere Anschuldigungen gegen die Leitung der Siedlung und behaupte, dass sich dort der in der BRD zur Fahndung ausgeschriebene Paul Schäfer aufhalte. Die Botschaft plane, Müller im deutschen Altersheim in Santiago unterzubringen, seinen Aufenthaltsort aber geheim zu halten. Sollte dieser bekannt werden, sei damit zu rechnen, dass er von CD-Mitgliedern gewaltsam abgeholt werde. Die Botschaft bat das AA um Mitteilung, ob Bedenken gegen eine »Heimschaffung« bestünden und gegebenenfalls um Einleitung der Volljährigkeitserklärung. ${ }^{62}$ Die Haltung der Botschaft schien nun, sicherlich auch aufgrund des persönlichen Berichts durch den geflohenen Müller, gänzlich kritisch gegenüber der CD.

PA AA, B 85, Bd. 598. Bericht Botschaft an AA vom 06.11.1963, GZ 502-81.05-1382/63. Ebd.

PA AA, B 85, Bd. 598. Bericht Botschaft an AA vom 02.12.1963, CZ 502-81.05-1467/63.

Ebd.

Ebd.

PA AA, B 85, Bd. 598. DB Nr. 59 vom 01.03.1966 zur Weiterleitung an das AC Hamburg-Altona. Der DB nimmt Bezug auf einen DE vom 15.01.1964, der sich allerdings nicht in der Akte befindet.

Wolfgang Müller war zu diesem Zeitpunkt 20 Jahre alt, das Volljährigkeitsalter betrug damals 21 Jahre. 
Die Botschaft konsultierte auch Friedrich-Wilhelm Kroll, einen ihr vertrauten Psychiater. Dieser konnte bei Wolfgang Müller keine psychische Erkrankung feststellen, sondern urteilte: "Seine Hass-erfüllte Einstellung der gesamten Umgebung der Sekte gegenüber, bei der er arbeiten mußte ist eine normale Reaktion auf alles das, was er an schrecklichen Dingen ertragen musste, sowohl körperlich wie seelisch. « ${ }^{63}$ Aus psychiatrischer Sicht empfehle er dringend, Müller von »der Sekte« fernzuhalten und ihn nach Deutschland zu bringen. Eine vorzeitige Volljährigkeitserklärung könne daher vom psychiatrischen Standpunkt aus befürwortet werden. Die nun vorliegende Expertenmeinung stützte das Rückführungsvorhaben der Botschaft.

Das Amtsgericht Hamburg-Altona antwortete jedoch zwei Tage später, Hugo Baar als Müllers Vormund sei angehört worden. Entgegen der Darstellung der Botschaft sei Wolfgang Müller offenbar doch schizophren und behandlungsbedürftig. Rückführung und Volljährigkeitserklärung würden daher nicht in Erwägung gezogen. ${ }^{64}$ Die CD hatte unterdessen ein psychiatrisches Gutachten von einem Dr. Auersperg vorgelegt, das Müller eine Schizophrenie attestierte. Ein Telefonat der Botschaft mit Auersperg ergab jedoch, dass dieser Müller niemals gesehen, geschweige denn untersucht hatte. ${ }^{65}$ Zudem stammte sein Gutachten von 1964. Gisela Seewald, die Ärztin der Siedlung, sei Schülerin von Auersperg gewesen. Daher, so vermutete die Botschaft, habe er sich vermutlich "auf deren Angaben zu sehr verlassen ${ }^{66}$ Botschafter Nostitz gab daher ein weiteres psychiatrisches Gutachten bei Dr. Fink in Auftrag. ${ }^{67}$ Auch dies ergab keinerlei psychische Erkrankung Müllers, schloss jedoch mit der Aussage:

»Der einzige Punkt, der nicht klar liegt, ist der Inhalt seiner Erlebnisse. Die ganze Geschichte seiner Erlebnisse auf dem Gut `El Lavadero erscheint beinahe als etwas Phantastisches, was man nur glaubt, in Kriminalromanen zu finden. Man könnte vermuten, dass Herr Müller ein Pseudologe (chronischer krankhafter Lügner) sei. Aber um diese Vermutung zu beweisen oder auszuschließen, wird eine polizeiliche Untersuchung benötigt, die außerhalb des Bereiches dieser gutachtlichen Untersuchung steht. Trotzdem muss man betonen, dass der Bericht des Patienten, durch seine semiologischen Züge, klinisch nicht als eine Fabulation erscheint. « ${ }^{68}$

Die Botschaft blieb bei ihrer Linie und informierte das Hamburger Amtsgericht von dem neuen Gutachten. Die Botschaft könne nicht verantworten, dass Müller in die CD zurückgebracht werde. Sie halte »eine Heimschaffung in die BRD für die einzige mögliche Lösung «. ${ }^{69}$ Zwei Tage später folgte ein weiteres Botschaftstelegramm an das

PA AA, B 85, Bd. 598. Nervenfachärtzliches Gutachten Dr. Kroll über Wolfgang Müller vom 02.03.1966.

64 PA AA, B 85, Bd. 598. FS AC Hamburg-Altona (Dr. Prudlo) an AA mit der Bitte um Weiterleitung an Botschaft vom 03.03.1966.

65 PA AA, B 85, Bd. 598. Durchdruck des Schreibens der Botschaft an das AC Hamburg-Altona vom 07.03.1966.

66 Ebd.

67 PA AA, B 85, Bd. 598. Psychiatrisches Gutachten Dr. Fink über Wolfgang Müller vom 06.03.1966.

68 Ebd.

69 PA AA, B 85, Bd. 598. Verschlüsseltes Telegramm Botschafter Nostitz an AA für AC Hamburg-Altona vom 07.03.1966, CZ V 6 - SK/593/66. 
Gericht. Die Botschaft habe ein Telegramm von Hugo Baar mit folgendem Text erhalten: »Mit Wissen und Zustimmung des Vormundschaftsrichters bitte ich mein Mündel Wolfgang Müller dem Bevollmächtigten Hermann Schmidt unverzüglich zu übergeben. ${ }^{70}$ Ohne einen förmlichen Beschluss des Vormundschaftsgerichts könne die Botschaft es bei der geschilderten Sachlage jedoch nicht verantworten, Baars Bitte nachzukommen. Der Botschafter verwies erneut auf das Gutachten von Dr. Fink sowie auf die Mitteilung von Dr. Auersperg, Müller nie untersucht zu haben. Das Botschaftstelegramm erwähnt auch zwei Schreiben des nordrhein-westfälischen Innenministers von $1961^{71}$, in denen die persönliche Zuverlässigkeit von CD-Führungsmitgliedern in Zweifel gezogen und betont wird, die Pläne der Gruppe um Schäfer müssten weiterhin mit Vorbehalt betrachtet werden. So sei das PSM-Vorstandsmitglied Kurt Schnellenkamp vorbestraft. Die übereifrigen Bemühungen »der hier dauernd vorsprechenden Vertreter der Gemeinschaft, Müller wieder unter ihren ausschließlichen Einfluss zu bringen« seien sehr auffällig. Das Telegramm endete mit den recht dramatischen Worten:

»Soeben erhält Botschaft Telefonanruf Altersheim, dass dieses von 15 Leuten umstellt sei. Leiter Heims befürchtet, dass gewaltsame Entführung Müllers beabsichtigt. Bei dieser Aktion wurde Kurt Schnellenkamp von Polizei festgenommen. Botschaft bittet dringend, vor Eingang obiger Unterlagen keine endgültige Entscheidung zu treffen. $\aleph^{72}$

Am 24. März 1966 schrieb die Botschaft erneut an das AA und legte einen Artikel der »vielgelesenen Illustrierten« Ercilla bei. Auf der Titelseite der chilenischen Zeitschrift prangt die Schlagzeile »Alemanes Nazis y Anti-Nazis luchan en Chile«. Der doppelseitige Artikel berichtet vom Versuch eines 15-köpfigen deutschen »Kommandos«, Wolfgang Müller aus dem deutschen Altersheim in Santiago zu entführen. Er stellt Spekulationen über Schäfer an und kommt zu dem Schluss, dieser könnte ein wichtiger Nazi-Kriegsverbrecher sein. Laut einer diplomatischen Quelle kenne Wolfgang Müller Martin Bormann. Der Artikel ist mit Aufnahmen Adolf Eichmanns, Martin Bormanns und des Zauns des KZ Auschwitz bebildert. ${ }^{73}$

Gegenüber dem AA formulierte die Botschaft ihre Befürchtung, dass die Angelegenheit in der chilenischen Öffentlichkeit weitere Kreise ziehen werde und bat das AA darum, beim Vormundschaftsgericht in Hamburg erneut auf die Erteilung einer Erlaubnis für eine Rückverbringung von Müller in die Bundesrepublik zu drängen. Gut eine Woche später antwortete das AA. ${ }^{74}$ Man könne die Botschaft nicht dazu ermächtigen den Minderjährigen Müller auf dem Luftwege heimzuschaffen. Ein Vertreter des AA habe mit Dr. Prudlo, dem Direktor des Amtsgerichts Hamburg-Altona, gesprochen. Dieser sehe sich nicht in der Lage, Müller in Kürze für volljährig zu erklären, da dem PA AA, B 85, Bd. 598. Telegramm Bots
vom 09.03.1966, GZ V 6-SK/593/66

71 Das Botschaftstelegramm erwähnt Schreiben des Innenministers von Nordrhein-Westfalen vom 25.05.1961 und 26.10.1961. Das Schreiben des Innenministers von Nordrhein-Westfalen an das Bundesverwaltungsamt vom 25.05.1961 ist enthalten in: PJK, Ordner Hummel. Ebd.

Ercilla vom 23.03.1966, S. 20-21. »Policía frustró sensacional rapto. Exclusivo: Comandos alemanes en acción en calles de Santiago«.

PA AA, B 85, Bd. 598. Schreiben AA an Botschaft vom 01.04.1966, GZ V 6-86.SH/2565. 
diverse formale Hindernisse entgegenstünden. In die Rechte des Vormunds könne er nur eingreifen, wenn das Wohl des Minderjährigen durch die Ausübung der Vormundschaftsrechte gefährdet sei, wofür er keine Anhaltspunkte habe. Die Haltung von Prudlo gegenüber der $\mathrm{CD}$ resümierte das AA folgendermaßen:

»Bei der Gemeinde in Chile handele es sich - entgegen der Annahme der Botschaft nicht um eine Sekte. Der Cemeinschaft gehörten vielmehr Personen aller christlichen Bekenntnisse an. Sie genieße in Chile ein hohes Ansehen, weshalb eine Cefährdung des Jugendlichen durch die Cemeinschaft nicht erkennbar sei. « ${ }^{75}$

Im Übrigen, so Prudlo (wiedergegeben vom AA), lebten auch Müllers Mutter und seine Tante in der CD, seine Versorgung sei dort sichergestellt. In Deutschland kenne er hingegen niemanden und würde sich aufgrund des 4-5-jährigen Aufenthalts in Chile vermutlich nur sehr schwer zurechtfinden. Es sei auch möglich, dass die von den Ärzten Kroll und Fink erstellten psychiatrischen Gutachten nicht richtig seien, da sich eine schizophrene Erkrankung häufig in Schüben zeige. Die beiden Ärzte hätten Müller möglicherweise zu einem Zeitpunkt untersucht, an dem Anzeichen von Geisteskrankheit nicht sichtbar waren.

Diese deutliche Positionierung Prudlos zugunsten der CD kann nur dadurch erklärt werden, dass Hugo Baar beim Direktor des Amtsgerichts eindringliche Überzeugungsarbeit geleistet hatte. Nach dieser Einschätzung, in der die Botschaft von dem Amtsgerichtsdirektor regelrecht zurechtgewiesen wurde, kam das AA zu folgendem Schluss:

»Das Auswärtige Amt hat nach dem Cespräch mit Amtsgerichtsdirektor Prudlo den Eindruck gewonnen, daß eine Mitwirkung des Vormundschaftsgerichts bei der Heimschaffung Müllers nicht erreichbar ist. [...] Die Botschaft wird daher gebeten, nach Möglichkeit einer Unterbringung des Minderjährigen bis zu seiner Volljährigkeit zu suchen und hierüber zu berichten. « $^{76}$

Nur wenige Tage danach erfuhr die Botschaft, dass sich - entgegen der Beteuerungen verschiedener CD-Mitglieder - Paul Schäfer sehr wohl in der Siedlung aufgehalten habe. ${ }^{77}$ Der deutschstämmige Chef der chilenischen Kriminalpolizei, Emilio Oelckers, berichtete Botschaftsangehörigen von den Ermittlungen seiner Behörde. Die Botschaft meldete dem AA:

»Demnach war der im Fahndungsbuch ausgeschriebene Paul Schäfer der eigentliche Leiter der Kolonie. Ihn hält Herr Oelckers Hollstein für die treibende Kraft des Unternehmens. Schäfer ist seit einer Woche flüchtig. Gegen ihn ist Haftbefehl ergangen. ${ }^{78}$

Nun gab es einen bundesdeutschen und einen chilenischen Haftbefehl gegen Paul Schäfer. Unter diesem Druck konstruierte die CD eine weitere Legende: Hermann Schmidt erklärte gegenüber der Presse, Schäfer sei einige Tage zuvor verschwunden, er habe 
eine geladene Pistole mitgenommen. Aus einem Abschiedsbrief könne abgeleitet werden, er hege die Absicht, Selbstmord zu begehen, sofern dies nicht schon geschehen sei. Schmidt machte hierfür die Anschuldigungen Müllers und die der inzwischen ebenfalls aus der CD geflohenen Wilhelmine Lindemann verantwortlich. ${ }^{79}$

Dass Wolfgang Müller nicht in die Bundesrepublik gebracht wurde, hatte weitreichende Folgen für ihn. Mitte April 1966 wurde er auf Anordnung eines chilenischen Untersuchungsrichters wegen des Verdachts der Unzucht mit Minderjährigen verhaftet. ${ }^{80}$ Die CD hatte Strafanzeigen gegen Müller wegen »Sodomie«, Pferdediebstahl und Verleumdung gestellt. Am 25. Februar 1967 wurde Müller wegen Beleidigung (abuso de publicidad) zu fünf Jahren Haft verurteilt. ${ }^{81}$ Zwischenzeitlich auf freiem Fuße, tauchte der inzwischen volljährige Müller unter und entzog sich seiner Haftstrafe durch Flucht in die Bundesrepublik. Am 13. April 1967 berichtete die Botschaft, Müller habe sich »inzwischen vermutlich mit Hilfe von Gönnern, nach Argentinien abgesetzt«. Von der dortigen Botschaft sei er "nach Deutschland heimgeschafft « worden. ${ }^{82}$

Während seiner Untersuchungshaft schrieb Wolfgang Müller einen Leserbrief, der den Fall CD auf kuriose Weise charakterisiert, an die chilenische Zeitschrift Ercilla. In dem Brief bedankt sich Müller bei den Gefängnisaufsehern dafür, dass diese ihm einen solch angenehmen Aufenthalt ermöglichten, sowie beim Gefängnisdirektor, der zu einem spirituellen Vater für ihn geworden sei. So sei seine Zeit in chilenischer Haft für ihn angenehmer gewesen als die an jenem düsteren Ort in der Kordillere, so Müller. ${ }^{83}$

\section{Der Fall Heinz Kuhr (später Schmidt, heute Wagner)}

In den Akten des AA ist auch der Fall von Heinz Kuhr (offiziell Heinrich Kuhr, später Schmidt, heute Wagner) umfassend dokumentiert. Kuhr wurde 1962 als 15-Jähriger ohne Begleitung seiner leiblichen Eltern in die CD gebracht. Hermann Schmidt hatte ihn 1959 adoptiert, ohne dass sich dessen leibliche Mutter, Elisabeth Schüring (geb. Kuhr), dessen bewusst war. 1965 äußerte diese gegenüber dem Jugendamt Bocholt den Wunsch, ihren Sohn Heinz aus Chile zurückholen zu lassen. Dabei erläuterte sie, wie ihr Sohn ihr entzogen worden war:

»Im Jahre 1955 trat in Cronau eine religiöse Sekte auf. Celeitet wurde diese von einem Mann namens Paul Schäfer aus Siegburg und Hermann Schmidt aus Siegburg. [...] Ich habe also meinen Sohn Heinrich 1955 nach Heide gegeben. Soweit ich mich erinnern kann heißt die Stelle: Private Soziale Mission, Heide bei Siegburg. Mir wurde erklärt, daß er in Bonn die Schule besuchen und dort Sprachen erlernen würde. Ich habe den Jungen auch öfter besucht und wurde dort gut bewirtet. Wenn ich es heute überlege, fällt mir auf, daß ich damals nie allein mit dem Jungen reden konnte. Immer war

El Mercurio vom 11.04.1966, S. 25. »Misterioso desaparecimiento de Paul Schäfer Schneider«. El Diario Ilustrado vom 16.04.1966, S. 1. »Ordenan detener a todos los jefes de Colonia Dignidad«. Juzgado de Parral, AZ 23.919. Erstinstanzliches Urteil vom 28.02.1967. Im Urteil der zweiten Instanz wurde das Strafmaß auf drei Jahre und einen Tag herabgesetzt: CA Chillán, AZ 75.818, Urteil vom 28.10.1969.

PA AA, B 85, Bd. 540. Schreiben Botschaft an AA vom 13.04.1967.

Ercilla vom 01.06.1966, S. 2. Leserbrief von Wolfgang Müller. »Müller agradece«. 
ein Betreuer dabei oder man schickte den Jungen fort. Der Schäfer wußte, daß ich geschieden war und daß ich den Namen meines gesch. Mannes nicht mehr gerne trug. Er schlug mir dann vor, den Namen zu ändern. Ich war im Jahre 1960 in Lüdenscheid beschäftigt. Des öfteren hat man mich von Lüdenscheid mit dem Auto abgeholt und immer versucht, daß ich in eine Namensänderung einwilligen sollte. Zunächst habe ich mich dagegen gesträubt. Am 05.01.1960 holte man mich wieder mit einem Auto in Lüdenscheid ab und brachte mich zu dem Rechtsanwalt Hans Depiereux, Siegburg, Bahnofstr 23a. Dort waren mehrere Leute anwesend: die Eheleute Hermann Schmidt, Herr Peter Ludwig und angeblich ein Rechtsanwalt. Dort hat man mir von einer Namensänderung etwas vorgelesen. Ich habe dann auch ein Schriftstück unterschrieben. Von einer Adoption hat man mir nichts gesagt. Später hat man mich dann zu einem Rechtsanwalt nach Bonn gebracht. Dort mußte ich eine Reisegenehmigung für meinen Sohn nach Chile unterschreiben. Man hat mir dort auch nicht gesagt, daß Heinrich für immer nach Chile fahren sollte, sondern man erklärte mir, daß vielleicht mal ein Ausflug nach dort erfolgen könnte und dass es richtiger wäre, wenn ich vorher unterschreiben würde. Nachdem ich bei diesem Rechtsanwalt in Bonn gewesen war, bin ich wohl ziemlich aufgeregt gewesen und habe gesagt: >Was soll das alles bedeuten, dieses Unterschreiben? Daraufhin wollte man mich ins Kino schicken, damit ich auf andere Gedanken käme. Ich habe geantwortet: >lch verzichte darauf, ich will meinen Jungen zurückhaben.く Man hat mich dann nach Lüdenscheid zurückgebracht.

Am 13.7.1962 kam ein Mann namens Hugo B a a r aus Heide bei Siegburg mit meinem Sohn zu mir, damit Heinz sich verabschieden sollte. Ich wollte gar nicht, daß er mitfuhr und fragte Heinz auch entsprechend, aber man ließ ihn gar nicht zu Worte kommen.

Als mein Sohn dann schon längere Zeit in Chile war, schickte man mir die Adoptionsurkunde vom 04.12.1959 und die Verhandlungsniederschrift vom 31.12.1959 sowie die vormundschaftsgerichtliche Cenehmigung des AC Siegburg vom 19.01.1962, Az. 6 VII $23632 \mathrm{zu}$. Ich war ganz erstaunt, daß ich jetzt auf einmal von einem Adoptionsvertrag las. [...]

Ich lebe in großer Sorge um meinen Sohn und wünsche, daß er schnellstens zu mir zurückkehrt. $^{84}$

Zumindest laut den Akten des AA ist das Jugendamt daraufhin nicht aktiv geworden. Erst über vierzig Jahre später, 2004, konnte Heinz Schmidt, wie er nun aufgrund der Adoption hieß, die CD verlassen und nach Deutschland zurückkehren. In den 1960er Jahren hatte er zwei Mal versucht, aus der CD zu fliehen. Beide Male gelangte er bis zur deutschen Botschaft in Santiago. Beim ersten Mal soll er es bis zum Pförtner geschafft haben, wo ihn seine Adoptiveltern Hermann und Ursel Schmidt abgefangen und in die CD zurückgebracht haben sollen. ${ }^{85}$ Beim zweiten Mal, im Februar 1969, sprach Heinz

84 PA AA, AV NA 31596. Jugendamt Bocholt 51/K/C. Protokoll der Vorsprache von Elisabeth Schüring (geb. Kuhr, gesch. Schiwon) vom 26.07.1965. Dieser Aktenband enthält auch eine Ausfertigung der von Frau Schüring bei Notar Depiereux in Siegburg am 04.12.1959 unterzeichneten »Einwilligung zur Kindesannahme« durch Hermann Schmidt sowie der vormundschaftsgerichtlichen Genehmigung des Kindesannahmevertrages durch das Amtsgericht Siegburg vom 19.01.1962.

85 PA-DBT 3127, 712 - UA 2 - 2451. Stenographisches Protokoll der 10. Sitzung des Unterausschusses für Menschenrechte und Humanitäre Hilfe vom 22.02.1988, S. 10/37. 
Schmidt in der Botschaft vor, dennoch gelang es seinen Adoptiveltern, ihn wieder in die CD zu bringen. ${ }^{86}$ Peter Packmor, der wenig später die CD verließ, berichtete, Heinz Schmidt sei nach seiner Rückkehr »sofort in das Koloniekrankenhaus gesteckt« worden, obwohl jeder in der Kolonie gewusst habe, dass er völlig gesund war. ${ }^{87}$ In den folgenden Jahren sprach die Botschaft Hermann Schmidt bei mehreren Gelegenheiten auf seinen inzwischen volljährigen Adoptivsohn an und bat darum, mit diesem sprechen zu können. 1972 besuchte Botschaftsrat Werner Kaufmann-Bühler die CD. In seinem ausführlichen Bericht erwähnte er auch Heinz Schmidt:

»[D]er jetzt 26-jährige Adoptivsohn des Leiters der Kolonie, der schon 1969 aus der Kolonie ausbrechen und bis zur Botschaft gelangen konnte, dort aber von seinen Adoptiveltern eingeholt und zur Rückkehr bewogen worden war, hatte jetzt in 2 Briefen um Hilfe gebeten. $\ll^{88}$

Die erwähnten Briefe richteten sich an seine leibliche Mutter in der Bundesrepublik (Brief vom 16. März 1972) und an die Botschaft (Brief vom 14. Mai 1972). ${ }^{89}$ Darin bat er um Hilfe für seine Rückkehr nach Deutschland.

Nachdem Kaufmann-Bühler bei seinem Besuch in der CD am 19. Juni 1972 Hermann Schmidt gebeten hatte, mit Heinz sprechen zu dürfen, erschien zunächst die Ärztin Gisela Seewald und legte ihm ein dickes Dossier vor. Es enthielt zahlreiche Aussagen und Beobachtungen anderer Colonos über Heinz Schmidt, insbesondere von Kindern. Laut Kaufmann-Bühler war es

»eine regelrechte staatsanwaltschaftliche Ermittlungsakte. Die Vorwürfe bestehen meist aus Betätigungen mit sexuellem Einschlag, wie sie dem Sittlichkeitsdezernenten einer jeden Großstadt nicht fremd sind. Sie erreichen kaum die Stufe der kleinen Sittlichkeitskriminalität. Aber in der Kolonie schien so etwas unfaßbar zu sein. «o

Daraufhin sprach Kaufmann-Bühler mit Heinz Schmidt im Beisein von dessen Adoptiveltern. Schmidt habe dabei »übermüdet, schweigsam, gezwungen und geschoben« gewirkt, er habe zögernd und einsilbig gesprochen und wirkte »älter als seine 26 Jahre, beinahe ausgemergelt « und sehe »für einen Menschen, der ständig auf dem Lande lebt, auffallend bleich, beinahe ungesund « aus. Bei dem Treffen übergab Heinz Schmidt dem Botschaftsrat ein Schreiben, in dem er die Aussagen aus seinem vorherigen Brief an die Botschaft widerrief. ${ }^{91}$ Kaufmann-Bühler vermutete, dass dieses Widerrufsschreiben nicht seinem wahren Willen entsprach und schlussfolgerte: „Einiges spricht dafür,

StA Bonn, AZ 50 ]s 285/85, Bd. VIII. Aufzeichnung der Botschaft vom 16.5.1969, Betr.: Kolonie »Dignidad« hier: Heimschaffung des Herrn Peter Packmor.

Ebd.

PA AA, ZW 111129. Bericht Botschaftsrat Werner Kaufmann-Bühler vom 10.05.1972. Aufzeichnung des RK-Referenten der Botschaft über den Besuch der deutschen Kolonie »Dignidad« am 19.06.1972

Die Briefe selbst konnte ich in den Akten des PA AA nicht ausfindig machen.

PA AA, ZW 111129. Bericht Botschaftsrat Werner Kaufmann-Bühler vom 10.05.1972. Aufzeichnung des RK-Referenten der Botschaft über den Besuch der deutschen Kolonie »Dignidad« am 19.06.1972.

91 Auch dieses Widerrufsschreiben konnte ich in den Akten des PA AA nicht ausfindig machen. 
daß er gegen seinen Willen am Verlassen der Kolonie gehindert wird. " ${ }^{92}$ Die Botschaft leitete den gesamten Bericht Kaufmann-Bühlers an das AA weiter und wies noch einmal explizit auf Schmidt hin:

»Wegen des Falles Heinz Schmidt verweise ich insbesondere auf Teil XII der Aufzeichnung. Daraus ergibt sich, daß die Behauptung Frau Schürings, Heinz Schmidt werde in der Kolonie > praktisch gefangen< gehalten, nicht völlig von der Hand zu weisen ist. «"93

Trotz dieser eindeutigen Schlussfolgerung wurden jedoch weder die Botschaft selbst, noch das AA aktiv - zumindest ist hierüber in den Akten nichts zu finden. Auch die chilenische Polizei wurde nicht kontaktiert, um dem Vorwurf der Freiheitsberaubung nachzugehen.

Am 6. April 1973 lud die Botschaft Hermann Schmidt aufgrund eines Amtshilfeersuchens des Finanzministeriums Nordrhein-Westfalen vor. ${ }^{94}$ Schmidt erschien am 25. Juli in der Botschaft. Über seinen Adoptivsohn sprach er mit Botschaftsrat Platz, dem Amtsnachfolger von Kaufmann-Bühler. Platz berichtete später:

»Er habe Heinz Schmidt vor Jahren adoptiert, nachdem er von seiner leiblichen Mutter der >Privaten Sozialen Mission « in Siegburg praktisch aufgedrängt worden sei. Der Junge habe in einem für seine Entwicklung sehr ungünstigen familiären Milieu gelebt. Seine Mutter sei geschieden gewesen, habe als Kellnerin in einer Schankwirtschaft gearbeitet und nacheinander mit verschiedenen Männern eine Wohngemeinschaft unterhalten. [...] Um ihm eine konkrete Aufgabe zu geben, habe man Heinz Schmidt als Krankenpfleger im Hospital der Kolonie beschäftigt. Hier habe er sich mehrfach sexuelle Verfehlungen zuschulden kommen lassen, was es erforderlich gemacht habe, sihm den Kopf etwas zurecht zu setzen<. [...] Hermann Schmidt äußerte, daß sich sein Adoptivsohn nicht zuletzt auf Anraten von LR I [Legationsrat I. Klasse] Dr. KaufmannBühler in fach-psychiatrischer Behandlung befinde und durchaus eine Besserung seines Zustandes zu verzeichnen sei. Wahrscheinlich leide Heinz Schmidt an einer Art von Geisteskrankheit [...] Am Ende unseres Cesprächs sprach ich Herrn Hermann Schmidt darauf an, daß sein Adoptivsohn mehreren Vorladungen der Botschaft nicht nachgekommen sei. [...] Ich machte ihn darauf aufmerksam, daß sein Adoptivsohn volljährig sei und es in seinem Interesse als Adoptivvater liege, von Heinz Schmidt nicht eines Tages wegen Freiheitsberaubung angezeigt zu werden. Ein Cespräch in der Botschaft, auf dem ich den Eindruck gewinnen würde, daß Heinz Schmidt nicht die Absicht habe, die Kolonie zu verlassen, könne der Gefahr einer späteren Strafanzeige gegen Hermann Schmidt vorbeugen. Dieser sagte mir zu, sich die Angelegenheit zu überlegen. « 95

92 PA AA, ZW 111129. Bericht Botschaftsrat Werner Kaufmann-Bühler vom 10.05.1972. Aufzeichnung des RK-Referenten der Botschaft Santiago über den Besuch der deutschen Kolonie »Dignidad« am 19.06.1972. 
Trotz der starken Vorbehalte von Botschaftsrat Platz, gab dieser Hermann Schmidt lediglich Verhaltenshinweise statt die Polizei zu kontaktieren. Ein Vier-Augen-Gespräch zwischen Heinz Schmidt und einem Angehörigen der Botschaft kam niemals zu Stande. Etwa anderthalb Jahre später, Ende 1974, besuchte Platz die CD und äußerte gegenüber Gisela Seewald und Hermann Schmidt erneut den Wunsch, Heinz Schmidt zu sprechen. Seine Bitte um ein Gespräch unter vier Augen wurde »höflich, aber bestimmt abgelehnt. ${ }^{96}$ Das Gespräch im Krankenhaus fand in Anwesenheit von Ursula und Hermann Schmidt, Kurt Schnellenkamp sowie Hans-Jürgen Blanck statt. Heinz Schmidt machte dabei auf Platz einen »heiteren, ausgeglichenen und freundlichen Eindruck«. Er gab an, wegen einer psychiatrischen Behandlung durch Frau Dr. Seewald und einen Santiaguiner Psychiater namens Dr. Barros derzeit nicht arbeiten zu können. Platz fuhr in seinem Bericht fort: "Auf entsprechende Fragen meinerseits erklärte er mehrfach klar und offen, daß es ihm in >La Dignidad gefalle und er nicht den Wunsch habe, nach Deutschland zurückzukehren.« Platz zog folgendes Fazit seines Besuchs in der CD:

»Mein Cesamteindruck ist der, daß in »La Dignidad « effektiv wertvolle humanitäre Arbeit für die arme Landbevölkerung der Umgegend von Parral geleistet wird. [...] Was an Arbeiten zur Selbstversorgung der Kolonie auf praktisch allen Cebieten geleistet wird, erscheint bewundernswert. [...] Ich glaube, daß die Kolonie in der Vergangenheit zum Opfer mindestens teilweise ungerechtfertigter Beschuldigungen und Verleumdungen geworden ist. Er erscheint mir jedoch andererseits keineswegs ausgeschlossen, daß es in »La Dignidad « zu Vorfällen kam, die hart an den strafrechtlichen Tatbestand der Freiheitsberaubung grenzen. Vieles in der Kolonie bleibt nach wie vor undurchsichtig, was jedenfalls zum Teil an dem Schleier der Ceheimnistuerei liegen mag, mit dem sie sich umgibt und wodurch sie natürlicherweise Argwohn erregt. «" ${ }^{97}$

Auf den ersten Blick fällt sofort auf, dass Platz' Einschätzung der CD von 1974 sehr viel positiver und wohlwollender klingt als der Bericht Kaufmann-Bühlers von 1972. Doch hier handelt es sich nicht nur um Unterschiede der persönlichen Meinung. Ausschlaggebender dürfte der Militärputsch vom 11. September 1973 gewesen sein, nach dem jegliche kritische Berichterstattung der Botschaft über die CD unterblieb. Auf den zweiten Blick wird allerdings deutlich, dass in beiden Berichten - also bereits bei KaufmannBühler - jegliche Bezugnahme auf Vorgänge in der CD fehlt, die bei der Botschaft damals bereits aktenkundig waren. Insbesondere die Tatsache, dass die Botschaft sich bereits umfangreich mit anderen Fluchtfällen und Hilferufen anderer Colonos beschäftigt hatte, wurde hier an keiner Stelle berücksichtigt. Doch auch im Fall Heinz Schmidt für sich allein betrachtet hätte die Botschaft sich stärker und konkreter um Aufklärung bemühen müssen.

Nach 1974 geriet der Fall Heinz Schmidt in Vergessenheit. Der Name fand erst wieder Erwähnung in den Berichten von Lotti und Georg Packmor, nachdem diesen 1985 die Flucht aus der CD gelungen war. Georg Packmor nannte in seinem in der Botschaft 
auf Tonband gesprochenen Bericht Heinz Schmidt als Beispiel für zahlreiche Colonos, die im Krankenhaus der CD mit Elektroschocks und Medikamenten malträtiert wurden: „Einige dieser Kinder sind zeitlebens geschädigt. Da wäre z.B. zu erwähnen Heinz Schmidt. ${ }^{98}$

Der Stern griff die Aussagen des Ehepaars Packmor auf und berichtete im November und Dezember 1987 über den Fall Heinz Schmidt. ${ }^{99}$ Als Reaktion darauf forderte das AA die Botschaft auf, über die Fälle Peter Rahl, Heinz Schüring [Heinz Schmidt] sowie Johannes und Wolfgang Hühne zu berichten. Dass AA schrieb, dem Amterde vorgeworfen, auf Anfragen von in der Bundesrepublik lebenden Angehörigen

»nichts veranlasst, z. t. nicht einmal geantwortet, geschweige denn etwas erreicht zu haben. Aus hiesigen Akten lassen sich keine Erkenntnisse gewinnen. Botschaft wird gebeten, in dortigen Archiven nachzuforschen und ggf. über das seinerseits von der Botschaft veranlasste zu berichten. ${ }^{100}$

Eine Woche später, Ende Dezember 1987, antwortete die Botschaft:

»Ende der 6oer Jahre wurde Botschaft Heinz Schmidts Wunsch zum Verlassen der CD bekannt. 1969 gelang ihm die Flucht. Ausweislich eines Aktenvermerks aus 1972 gelangte er bis zur Botschaft, wurde jedoch von seinen Adoptiveltern zur Rückkehr bewogen. Hinweise zu den näheren Umständen des Vorfalls finden sich in den Akten nicht. Im März 1972 gelang es Heinz Schmidt, der als Krankenpfleger im CD-Krankenhaus eingesetzt war, einen Brief an seine leibliche Mutter aus CD herauszuschmuggeln. Darin bat er um Hilfe zur Rückführung nach Deutschland. Im Mai 1972 richtete er schriftlich die gleiche Bitte an Botschaft. Diese Bitte wiederrief er kurze Zeit danach. Widerruf-Schreiben wurde - ausweislich eines Aktenvermerks - mit Bericht Nr. 824'72 vom 23.06.72 AA vorgelegt.

Botschaft bemühte sich in der Folgezeit, Kontakt zu Heinz Schmidt aufrecht zu erhalten. Bei Besuchen des RK-Referenten [Kaufmann Bühler, bzw. Platz] am 19.06.1972 sowie am 21.11.1974 in CD kam es jeweils zu Gesprächen mit ihm. Bei diesen Anlässen warfen Adoptiveltern ihrem Sohn ,Verlogenheit, abartige Veranlagungen und sexuelle Verfehlungen vor (Anmerkung: Das Muster, rückkehrwillige bzw. Rückkehr bereite CD-Mitglieder zu kriminalisieren und/oder für geisteskrank zu erklären, wiederholte sich durch die Jahre hindurch). Gleichzeitig erfolgte seitens der Adoptiveltern stets der Hinweis auf die svollkommene Lebensuntüchtigkeit ihres Sohnes, den es vom Abgleiten in die Gosse zu retten gelte. « Botschaft forderte dennoch hartnäckig Heinz Schmidt wiederholt zu Vorsprachen in Santiago auf. Dieser Aufforderung konnte - vermutlich: durfte - er jedoch nicht nachkommen. Weitere Hinweise oder aussagekräftige Unterlagen finden sich in Akten nicht. ${ }^{101}$

PA AA, B 83, Bd. 2384. Transkription des Tonbandberichts von Georg Packmor an die deutsche Botschaft vom 15.03.1985, S. 6.

Vgl. Cemballa, Gero/Kai Hermann. »Leben wie im KZ«, in: Stern Nr. 49/1987 vom 26.11.1987, sowie Hermann, Kai. »Helft, helft bitte. Lasst mich nicht allein«, in: Stern Nr. 53/1987 vom 22.12.1987. 
Die Anmerkung zu einem sich wiederholenden Muster lässt an Deutlichkeit wenig zu wünschen übrig. Zugleich war diese Antwort der Botschaft aber ein Eingeständnis, dass man trotz der klaren Hinweise auf systematische Freiheitsberaubungen in der CD nichts unternommen hatte.

1988 kam Lotti Packmor auch bei einer Anhörung im Deutschen Bundestag auf Schmidt zu sprechen:

»Seitdem lebt er im Hospital; als völliges Wrack läuft er herum. Ich würde sagen, er kann gar nicht mehr klar denken. Er ist ständig in der Behandlung des Hospitals und hat entsprechende Kleidung. [...] Er wird eben als geistig umnachtet von Schäfer verschlissen nach all den Jahren der Behandlung. Er steht immer unter Medikamenten. ${ }^{102}$

Im April 1989 schrieb Untersuchungsrichter Hernán Robert Arias, der die CD untersuchte (vgl. Abschnitt 5.1.3) der Botschaft und fragte, ob folgende Aussage von Georg Packmor richtig sei:

»Heinz Schmidt war ungefähr 35 Jahre alt, als er in den 70er Jahren auf seiner Flucht bis nach Santiago und dort zur Botschaft gelangt war. Aufgrund der seinerzeit guten Beziehungen zwischen der Botschaft und der CD wurde die CD von der Botschaft per Telefon davon unterrichtet, die CD schickte Leute, die offenbar Heinz Schmidt zur Rückkehr bewegen konnten. ${ }^{103}$

Einen Monat später hakte Arias noch einmal nach und bat um eine baldige Beantwortung seines Schreibens. ${ }^{104}$ Erst einen Monat danach schrieb die Botschaft dem AA. Aus dem Bericht Kaufmann-Bühlers von 1972 gehe hervor, dass Heinz Schmidt 1969 bis zur Botschaft gelangen konnte, dort aber von seinen Adoptiveltern eingeholt und zur Rückkehr bewogen worden sei. Eine Präzisierung dieser Angaben sei der Botschaft jedoch nicht möglich, da die entsprechenden Unterlagen ${ }^{105}$ nicht auffindbar seien. Die Botschaft bat daher das AA um Übermittlung eventuell dort archivierter Vorgänge von 1969. Des Weiteren baten die chilenischen Anwälte, die im Auftrag der Botschaft das Untersuchungsverfahren begleiteten, das AA, Elisabeth Schüring, die leibliche Mutter, $\mathrm{zu}$ kontaktieren und sie zu fragen, wann und wo sie der Adoption ihres Sohnes Heinz zugestimmt habe. ${ }^{106}$

Knapp zwei Wochen später schrieb die Botschaft Rechtsanwalt Sergio Corvalán, dass das AA über keinerlei Dokumente zum Fluchtversuch von Heinz Schmidt von 1969 mehr verfüge. Frau Schüring sei kontaktiert worden, könne sich aber nicht mehr genau erinnern, in welchem Jahr die Adoption durchgeführt worden sei. Ihre Angaben schwankten zwischen 1959 und 1967. ${ }^{107}$ Am 30. Mai 1989 übersandte Elisabeth Schüring

PA-DBT 3127, 712 - UA 2 - 2451. Stenographisches Protokoll der 10. Sitzung des Unterausschusses für Menschenrechte und Humanitäre Hilfe vom 22.02.1988, S. 10/37. 
dann dem AA die oben bereits erwähnten Dokumente. Das AA leitete diese in Kopie an die Botschaft weiter. Ob die Botschaft die Dokumente an den Untersuchungsrichter weiterleitete, der gerade kurz vor Abschluss seiner Untersuchung stand, geht aus den Akten nicht hervor. Im Abschlussbericht des Untersuchungsrichters ${ }^{108}$ findet der Fall keine Erwähnung.

2002 heiratete Heinz Schmidt die Colona Irmgard Wagner und nahm ihren Nachnamen an. Bis dahin hatte er im Krankenhaus der CD gelebt. Er wurde jahrelang mit Medikamenten und Spritzen ruhiggestellt und trug schwere körperliche und seelische Leiden davon. 2005 siedelten Heinz und Irmgard Wagner in die Bundesrepublik über und schlossen sich der Freien Volksmission Krefeld des Predigers Ewald Frank an. 2006 verfassten beide Eheleute lange Briefe ans AA, in denen sie ihr erlittenes Leid darlegten und um Unterstützung baten. Pietro Merlo, ein Mitarbeiter des AA, überreichte diese Briefe Vertreter_innen der chilenischen Kriminalpolizei, als diese 2006 in der Bundesrepublik Gespräche zu den CD-Verfahren führten. Diese übergaben die Briefe an Richter Zepeda, der sie zu seinen Ermittlungsakten nahm. ${ }^{109}$

Der Fall Heinz Schmidt zeigt, wie Botschaft und AA trotz deutlicher Hinweise auf Freiheitsberaubung und andere strafrechtlich relevante Vorgänge sich lediglich beobachtend verhielten und keine angemessenen Maßnahmen einleiteten, um Betroffene zu unterstützen und ihnen beim Verlassen der Siedlung zu helfen. Dies hatte schwerwiegende Folgen für Opfer wie Heinz Schmidt, die so jahrzehntelang schutzlos Verbrechen ausgesetzt waren.

\section{Der Fall Lindemann}

In den 1960er Jahren wurden diverse weitere Fälle von Kindern bekannt, die ohne ihre (leiblichen) Eltern in der CD lebten. Botschaft und AA gingen diesen Fällen jedoch gar nicht oder nur sehr begrenzt nach. Nur wenige Tage nach der erfolgreichen Flucht Wolfgang Müllers am 28. März 1966, flüchtete auch Wilhelmine Lindemann aus der CD. Sie fand am Folgetag Zuflucht bei einem Grundschullehrer im wenige Kilometer von der CD entfernt gelegenen Catillo. Daraufhin eilte Claudio Fuentes, der Gouverneur von Parral, nach Catillo. Laut einem Pressebericht teilte Wilhelmine Lindemann ihm mit:

»No me dejan ver a mis hijos. Me pegaban y maltrataban en forma brutal. Paul Schäfer me trajo engañada. Me aseguró que traería a mi marido. Han pasado los años y nada sé de él. Decidí fugarme para pedir protección a las autoridades chilenas. [...] Quiero irme a Alemania a reunirme con mi marido y rescatar a mis hijos. «"10

Juzgado de Letras de Parral, AZ 43.210. Informe sobre Investigación a Colonia Dignidad, Ministro en Visita Extraordinaria Hernán Robert Arias, Ministro I. CA Talca, o. D. Von Richter Robert am 31.07.1989 der Corte Suprema übergeben. Enthalten in: CA Santiago, AZ 2182-98 (»Asociación Ilícita«) Bd. I (2) (Parral), BI. 585-676. ama) an Richter Zepeda vom 03.06.2006. Als Anhang beigefügt diverse Briefe von Heinz Wagner, Irmgard Wagner und Elisabeth Schüring. 
Lindemann gab an, ihre drei Kinder Manfred (14), Karla (12) und Harald (7) seit zwei Jahren nicht mehr gesehen zu haben und selbst mit Medikamenten ruhiggestellt worden zu sein. ${ }^{111}$ Die Süddeutsche Zeitung berichtete einige Wochen später auf ihrer »Seite Drei« ausführlich über die Fälle Wolfgang Müller und Wilhelmine Lindemann. Dem Artikel zufolge hatte Lindemann zu den chilenischen Behörden gesagt: »Wir alle sind Gefangene, außer den 15 Leitern der Siedlung. «112

Chilenische Behörden holten Lindemanns drei Kinder aus der CD und brachten sie bei Hector Taricco, dem Intendenten (eine Art Regionalpräsident) von Linares, unter. Am 30. März 1966 erschien Hermann Schmidt in Catillo. Die Behörden erlegten ihm als SBED-Präsidenten auf, dass er die Ausreise von Wilhelmine Lindemann erlauben müsse. Nachdem Schmidt dies zugesichert hatte, kehrte Lindemann in seiner Begleitung in die CD zurück. Dort angekommen sei sie nach Aussagen der CD-Ärztin Gisela Seewald plötzlich erkrankt. Taricco bestand darauf, dass Lindemann ins Krankenhaus von Linares gebracht wird. Das geschah auch und sie wurde von der chilenischen Kriminalpolizei vernommen. Nur eine Woche nach ihrer Flucht reiste ihr in der Bundesrepublik lebender Ehemann Kurt auf Betreiben der CD-Führung nach Chile. Er bewegte seine Frau, mit ihm zusammen in die CD zurückzukehren.

Am 21. Juli 1966 bestiegen Kurt und Wilhelmine Lindemann in Valparaíso ein Schiff und kehrten nach Siegburg zurück. Ihre drei Kinder ließen sie in der CD zurück. Am 12. Juli 1966 hatten sie bei einem Notar in Parral das Sorgerecht für Manfred, Karla und Harald auf das Colono-Ehepaar Friedrich und Magdalena Pöhlchen übertragen. Diversen Aussagen zufolge behielt die CD-Führung die Kinder gewissermaßen als Faustpfand für die Erlaubnis zum Verlassen der Siedlung. Auch Intendent Taricco und Gouverneur Fuentes stützten diese Aussage in einem gemeinsamen Bericht an den chilenischen Senat von 1968:

"Sabemos cuanto amaba, como es natural, la señora Lindemann a sus niños, y nos manifestó que por ningún motivo quería separarse de ellos, y por eso nos pidió que los trajéramos a nuestra casa, para que no quedaran solos en Dignidad. Sin embargo, la madre ha desaparecido y sus hijos han quedado recluídos en la Colonia en manos de extrañas personas. Y como en estos casos no rige la ley chilena, ni el Juez de Menores de Parral es consultado para estos efectos; sucedió que - ¡admirémosnos! - los padres directamente confirieron la tutela de sus hijos al señor Friedrich Pöhlchen mediante un documento otorgado en la Notaría de Parral el 12 de Julio de $1966 . «^{113}$

Der Intendant und der Gouverneur erwähnen in ihrem Bericht noch zwei weitere Fälle von Minderjährigen, die ohne ihre Eltern in der CD lebten und für die laut ihrer eigenen Aussage Hermann Schmidt das Sorgerecht ausübte. Einer war Willi Malessa, dessen Sorgerechtsübertragung an Schmidt von chilenischen Gerichten nicht autorisiert worden sei und der andere Wilhelm Wagner, dessen Eltern ihr Sorgerecht in Österreich per

111 La Nación vom 15.03.1968, S. 2. »¿Dónde están Wilhelmine Erna Lindemann y sus tres hijitos?«.

112 Widmann, Carlos, »Zucht und Unzucht in der Siedlung >Würde«, in: Süddeutsche Zeitung vom 08.07.1966, S. 3 .

113 PJS, Sammlung CD. Informe al Senado de Hector Taricco Salazar y Claudio Fuentes Avello vom 14.02.1968, S. 8. 
Vollmacht an Schmidt übertragen haben sollen. Im folgenden Abschnitt geht es um den Fall von Wilhelm Wagner und seinen Schwestern.

\section{Der Fall der Kinder der Familie Wagner}

Wilhelm Wagner wurde 1961 im Alter von 12 Jahren ohne seine Eltern in die CD verbracht. 1962 folgten ihm seine 17-Jahre alten Schwestern Irmgard und Edith. Die Mutter, Minna Wagner, stellte am 11. Mai 1965 in Graz Strafanzeige und verlangte die Herausgabe ihrer Kinder. Die österreichische Justiz leitete den Fall über das Außenministerium an die chilenische Justiz weiter. Die Staatsanwaltschaft Bonn leitete - ebenfalls nach einer Anzeige von Minna Wagner - ein Ermittlungsverfahren gegen Paul Schäfer wegen Kindesentziehung ein. ${ }^{114}$ Dieses wurde jedoch schon im Dezember 1966 eingestellt. ${ }^{115}$ Etwa ein halbes Jahr vorher hatte die Botschaft nach Bonn gekabelt:

»Nach Auskunft hiesiger österreichischer Botschaft liegt Staatsanwaltschaft Siegburg Anzeige von Rechtsanwalt Dr. Max Kornberger, Graz [.] vom 11.05.1965 mit Protokollen über schwere Misshandlungen von Minderjährigen und Erwachsenen Mitgliedern des Heimes der Mission Heid bei Siegburg aus früheren Jahren vor. Österreichische Botschaft hat Unterlagen chilenischer Polizei übergeben. « ${ }^{116}$

Die Strafanzeige nebst Anlagen gelangte zur Zeitschrift Ercilla. Diese veröffentlichte am 4. Mai 1966 eine Titelgeschichte dazu. ${ }^{117}$ Daraufhin meldete die Botschaft ans AA:

»Die genannte Anzeige des österreichischen Anwalts, [...] die Aussagen des Wolfgang Müller und seiner Mutter, die beide von den Leitern der Kolonie >Dignidad für schizophren erklärt und nach eingehenden psychiatrischen Untersuchungen für normal befunden wurden, lassen den Verdacht nicht von der Hand weisen, daß in der Kolonie deutsche Staatsangehörige unter irgendwie verbrämten Versprechungen wirtschaftlich ausgenutzt werden. ${ }^{118}$

Der wachsende Verdacht der Botschaft über die wahren Zustände in der CD sei auch dadurch genährt worden, dass sich Schäfer entgegen aller Beteuerungen von Hugo Baar (siehe oben) in der CD aufgehalten habe und nun erneut verschwunden sei. Daher, so der Bericht, sei nun das Ergebnis der Untersuchungen des chilenischen Sonderrichters abzuwarten. Das chilenische Außenministerium scheine wenig interessiert zu sein an der Angelegenheit und behandle die Anfrage der Botschaft, welche minderjährigen deutschen Staatsangehörigen sich ohne ihre Eltern in der CD aufhalten, sehr zögerlich. Dies wolle die Botschaft nun per Verbalnote anmahnen.

Auch im Fall Wagner konnte die Mutter die Herausgabe der minderjährigen Kinder nicht erreichen. Die CD verzögerte das Verfahren durch juristische Schritte und politische Lobbyarbeit, bis es eingestellt wurde. 


\section{Der Fall Tobias Müller}

Auch noch nach den 1960er Jahren kam es zu ähnlichen Fällen der Kindesentziehung innerhalb der CD. Beispielsweise unterzeichnete Renate Greißner 1983 bei Notar Depiereux in Siegburg eine Vollmacht, in der sie ihrem 10-jährigen Sohn Tobias Müller erlaubte, nach Chile zu reisen. Derselbe Notar hatte bereits 1960/61die Vollmachten zur Ausreise von Wolfgang Müller und Heinz Schmidt beglaubigt. Renate Greißner übertrug das Sorgerecht für ihren Sohn Tobias an ihre Mutter Margret Müller, die in der CD lebte. In dem Dokument wurde auch die Möglichkeit einer späteren Adoption durch die Großmutter erwähnt. Renate Greißner hatte einer späteren Aussage zufolge damals den Plan, in die CD nachzureisen. Jedoch wandte sie sich von der Gruppierung ab - u.a. als Folge der breiten Berichterstattung in der Presse 1987/1988 - und schloss sich dem Angehörigenverband Not- und Interessengemeinschaft der Geschädigten der Colonia Dignidad (NIG) an. Bei einem Gesprächstermin der NIG im AA im Juni 1988 bekräftigte Renate Greißner den Wunsch, ihren Sohn aus der CD nach Deutschland zurückzuholen. ${ }^{119}$ Vom AA um eine Stellungnahme gebeten, riet die Botschaft dazu, zunächst den Herausgabeanspruch für Tobias Müller vor dem Juzgado de Parral geltend zu machen. ${ }^{120}$ Botschaftsanwalt Máximo Pacheco hingegen empfahl, zur Geltendmachung dieses Anspruchs an das zuständige deutsche Vormundschaftsgericht heranzutreten. Dieses könne dann auf Antrag der Mutter ein Rechtshilfeersuchen an die chilenische Justiz stellen. Gleichzeitig könne präventiv ein Schutzantrag ${ }^{121}$ gestellt werden, um den Gesundheitszustand des Jungen überprüfen zu lassen. ${ }^{122}$ Einige Tage später teilte das AA Renate Greißner mit, dass beim örtlichen Standesamt keine Adoption ihres Sohnes Tobias verzeichnet sei. Das AA empfahl ihr, an ihre Mutter in der CD zu schreiben und die Herausgabe ihres Sohnes zu »erbitten ${ }^{123}$

\footnotetext{
119 PA AA, AV NA 31592. Protokoll vom Gespräch der NIG beim AA vom 15.06.1988.

120 PA AA, AV NA 31592. DB Nr. 318 vom 23.06.1988.
}

121 Schutzanträge (recursos de protección bzw. recursos de amparo) sind spezielle, in der chilenischen Verfassung verankerte Rechtsmittel, die dazu dienen sollen, individuelle Rechte unmittelbar zu schützen. So können Personen, deren Grundrechte beeinträchtigt sind, bei der zuständigen CA beantragen, dass die Rechtsstaatlichkeit wiederhergestellt wird. In Artikel 20 der chilenischen Verfassung von 1980 heißt es zum recurso de protección: „El que por causa de actos u omisiones arbitrarios o ilegales sufra privación, perturbación o amenaza en el legítimo ejercicio de los derechos y garantías establecidos [...] podrá recurrir por sí o por cualquiera a su nombre, a la Corte de Apelaciones respectiva, la que adoptará de inmediato las providencias que juzgue necesarias para restablecer el imperio del Derecho y asegurar la debida protección del afectado, sin perjuicio de los demás derechos que pueda hacer valer ante la autoridad o los tribunales correspondientes. «Diario Oficial de la República de Chile, Núm 30.798 vom 24.10.1980. Texto de la Constitución Política de la República de Chile. Artículo 20. Zum recursos de amparo heißt es in In Artikel 21 der Verfassung: »Todo individuo que se hallare arrestado, detenido o preso con infracción de lo dispuesto en la Constitución o en las leyes, podrá ocurrir por sí, o por cualquiera a su nombre, a la magistratura que señale la ley, a fin de que ésta ordene se guarden las formalidades legales y adopte de inmediato las providencias que juzgue necesarias para restablecer el imperio del derecho y asegurar la debida protección del afectado. «Ebd. 
Renate Greißner scheute allerdings davor zurück, sich an die CD Führung zu wenden, da sie Repressalien gegen ihren Sohn befürchtete. ${ }^{124}$ Sie stellte jedoch beim Amtsgericht Siegburg einen Antrag auf Rückübertragung der Vormundschaft und Herausgabe ihres Sohnes. Das Verfahren wurde an ein Berliner Amtsgericht weitergeleitet. ${ }^{125}$ Der Ausgang dieses Verfahrens ist nicht bekannt, aber ein Jahr später teilte das AA der Botschaft mit, Greißner habe sich nun entschlossen, in Chile auf Herausgabe ihres Sohnes zu klagen. ${ }^{126}$ Sie erwarte dafür eine Kostenübernahme durch das AA. Botschaftsanwalt Pacheco erklärte daraufhin, dass Greißner die Klage zwingend persönlich beim Gericht in Parral einreichen müsse. ${ }^{127}$ Die Botschaft war der Meinung, dass einer Klage "zunächst die persönliche Vorsprache von Frau Greißner bei der CD vorausgehen [sollte] um - persönlich - und - überraschend für die Leitung der CD den Herausgabeanspruch - vor Ort - geltend zu machen. ${ }^{128}$ In einem Gespräch mit dem AA vom 20. Juni 1989 wies Renate Greißner dieses Ansinnen vehement zurück und erklärte laut $\mathrm{AA}$,

»daß sie auf keinen Fall bereit sei, das Gelände der Colonia Dignidad selbst zu betreten. Nach dem langen Zeitraum, in dem sie ihren Sohn nicht mehr gesehen habe (seit 1983!) und den psychologischen Pressionen, denen er in der CD ausgesetzt sei, nehme sie an, daß er ihr vorerst derart entfremdet sei, daß ein Cespräch in der CD nicht zum Erfolg führen könne. Allenfalls sei sie bereit, ihren Sohn außerhalb der Colonia Dignidad zu treffen und mit ihm über einen längeren Zeitraum (mindestens 1 Woche) zusammenzubleiben.

Sie selbst habe, nachdem es sich wegen der fehlenden Mittel als unmöglich erwiesen habe, eine Klage auf Herausgabe zu erheben, an ihre Mutter geschrieben und Tobias zu einem 4-wöchigen Aufenthalt nach Deutschland eingeladen. Nach diesem Zeitraum solle er sich selbst entscheiden können, ob er zurück nach Chile oder bei seiner Mutter bleiben wolle. Sie habe sich verpflichtet seine Entscheidung zu respektieren. Auf dieses Schreiben hat sie bislang keine Antwort erhalten.

Dg33 regte an, in einem weiteren Schreiben den Widerruf der Vollmacht, mit der die Personensorge übertragen wurde, anzudrohen. Dann sei eher mit einer Antwort zu rechnen.

Wenn beides nicht fruchte, bleibe tatsächlich nur noch die Klage auf Herausgabe übrig. Das Amt habe, wie bereits erklärt wurde, keine Mittel, es werde sich aber weiterhin bemühen zu versuchen, eine Finanzierung zu finden. Man solle auf alle Fälle weiter in Kontakt bleiben. "129 $^{129}$

Der damalige Außenminister Genscher hatte nach einer Ministervorlage vom 11. September 1989 an die zuständigen Referate des AA eine Weisung erteilt, ihm mögliche

PA AA, AV NA 31592. DB Nr. 318 vom 23.06.1988.

StA Bonn, AZ 50 ]s 285/85, Bd. IX. Vernehmung von Renate Greißner vom 04.11.1988.

PA AA, AV NA 31592. DE Nr. 121 vom 30.05.1989.

PA AA, AV NA 31592. Rechtsauskunft vom RA Máximo Pacheco an Botschaftsrat Spohn vom 12.06.1989.

PA AA, AV NA 31592. DB 304 vom 14.06.1989.

PA AA, AV NA 31592. Vermerk 330-504.00 vom 21.06.1989. 
weitere Schritte in Sachen Colonia Dignidad vorzuschlagen. Eine Woche später berichtete ihm das zuständige Länderreferat 330 und schlug als eine von vielen Möglichkeiten vor, Angehörige von Betroffenen könnten Anzeigen bei chilenischen Gerichten einreichen. Dies sei zu Beginn des Jahres bereits u.a. mit Frau Baar und Frau Schaffrik erörtert worden. Die Betroffenen würden jedoch eine Übernahme der Verfahrenskosten (in Höhe von 50.000 US-Dollar pro Fall) verlangen. Die zuständigen Abteilungen blieben mit den Angehörigen in Verbindung, um auf diese Möglichkeiten hinzuweisen, und »ebenso mit Frau Greißner wegen Klage auf Herausgabe ihres Sohnes. «130

Keine der hier anvisierten Strafanzeigen kam jemals zustande. Die Betroffenen fürchteten sich davor, nach Chile zu reisen, um die Anzeigen persönlich einzureichen, was zwingend erforderlich war. Neben dem psychischen Druck und den körperlichen Repressalien durch die CD-Führung fürchteten sie Verleumdungsklagen der CD, die sie möglicherweise an einer Wiederausreise aus Chile hätten hindern können. Hinzu kam das finanzielle Risiko, da das AA sich nicht zu einer weitreichenden Kostenübernahme hatte durchringen können.

Am 20. Oktober 1989 schrieb Renate Greißner ihrer Mutter Margret in der CD und teilte ihr mit, dass sie die Übertragung des Sorgerechts von 1983 sowie ihre Zustimmung zu einer späteren Adoption zurückziehe. ${ }^{131}$ Einige Wochen später erhielt sie ein Schreiben von Fernando Saenger, einem Rechtsanwalt der CD. ${ }^{132}$ Darin hieß es, ihr Brief sei gegenstandslos, da Margret Müller ihren Enkelsohn bereits im Dezember 1987 adoptiert habe und eine Adoption nach chilenischem Recht nicht unilateral von den leiblichen Eltern rückgängig gemacht werden könne. Das AA beauftrage daraufhin Botschaftsanwalt Sergio Corvalán mit der Erstellung eines Rechtsgutachtens über die Frage, ob die Adoption von Tobias Müller überhaupt rechtskräftig erfolgt sei. Corvalán bat um eine Reihe von Dokumenten, stellte aber bereits vorab fest: »Die Adoptionspraxis der $\mathrm{CD}$ habe jedoch bisher gezeigt, dass alle von ihr vollzogenen Adoptionen rrechtskräftig، und daher nur gerichtlich anfechtbar sind. «33

In seinem Gutachten kam Corvalán zu dem Schluss, dass die von Renate Greißner 1983 in Siegburg unterzeichnete Erklärung in Chile als einfaches privates Dokument gelte und daher keinerlei Rechtsgültigkeit habe. Zudem sei der Richter am Gericht von Parral verpflichtet gewesen, vor einem Adoptionsbeschluss die leibliche Mutter anzuhören. Damit deute alles darauf hin, dass die Adoption betrügerisch zustande gekommen sei. Nichtsdestotrotz sei der Adoptionsbeschluss ein formeller Richterspruch und die Adoption damit rechtsgültig. Sie könne nur durch einen erneuten richterlichen Beschluss desselben Gerichtes wieder aufgehoben werden. Daher bliebe Renate Greißner nichts anderes übrig, als vor Ort einen Antrag auf Aufhebung oder Annullierung der Adoption zu stellen und darin anzuführen, dass sie niemals angehört worden sei. ${ }^{134}$

130 PA AA, AV NA 31600. Ministervorlage Referat 330 vom 18.09.1989.

131 PA AA, AV NA 31592. Schreiben Renate Greißner an Margret Müller vom 20.10.1989.

132 PA AA, AV NA 31592. Schreiben RA Fernando Saenger an Renate Greißner vom 06.11.1989.

133 PA AA, AV NA 31592. Schreiben Sergio Corvalán an Botschaftsrat Daerr vom 10.01.1989.

134 PA AA, AV NA 31592. Rechtsgutachten Sergio Corvalán vom 15.01.1990. »Informe en derecho sobre la adopción del joven Tobías Müller«. 
Renate Greißner schrieb unterdessen ans AA. Sie sei traurig und habe nach drei Jahren ohne Lebenszeichen von ihrem Sohn das Gefühl, auf der Stelle zu treten und dass ihr die Zeit davonlaufe. Obwohl ihr die Botschaft 1988 mitgeteilt habe, dass weder in Parral noch in Santiago oder Catillo eine Adoption eingetragen sei, solle diese nach Auskunft der CD bereits 1987 erfolgt sein. Im März 1990 bat Botschaftsanwalt Corvalán das AA um eine Vollmacht von Frau Greißner, um eine »Überprüfung der Adoption« vornehmen zu können. Ob dies geschah und ob die Botschaft oder der Anwalt darüber hinaus etwas in der Sache unternahmen, geht aus den eingesehenen Akten nicht hervor.

Tobias Müller verblieb noch jahrelang in der CD. Er flüchtete im Juli 1997 gemeinsam mit dem Chilenen Salo Luna. Beide reisten nach Deutschland, wo sie von der Staatsanwaltschaft Bonn vernommen wurden. Diese eröffnete daraufhin ein Ermittlungsverfahren "gegen Paul S. wegen sexuellen Missbrauchs von Kindern zum Nachteil des ehemaligen Koloniebewohners Tobias M. « ${ }^{135}$ Das Verfahren wurde nach Schäfers Tod 2010 ergebnislos eingestellt.

\subsubsection{Freiheitsberaubung - Fluchtfälle und Hilferufe}

Dieser Abschnitt behandelt die bisher bekannten Fluchtversuche und Hilferufe aus der CD als Ausdruck der permanenten Freiheitsberaubung in der Siedlung. Von Beginn an gab es Berichte über Versuche von Colonos, aus der CD zu fliehen. Nur wenige dieser Versuche waren erfolgreich (vgl. Tabelle 7). Gründe dafür waren die abgelegene Lage der Siedlung, die hochtechnologischen Überwachungsanlagen sowie die Aktivitäten der Sicherheitsgruppe, die viele Fluchtversuche vereitelte. In einigen Fällen wurden Flüchtende von Vertreter_innen chilenischer Behörden aufgegriffen. Einige schafften es sogar, bis zur deutschen Botschaft in Santiago oder bis zu einem deutschen Konsulat in anderen Städten zu gelangen. Mehrere Colonos, die die CD verlassen wollten, richteten auch Hilfsersuchen an die deutsche Botschaft.

Darüber hinaus sind die Fluchtversuche und Hilferufe auch im Kontext der pseudoreligiösen kriminellen Gemeinschaft CD zu sehen, die nicht nur mit unmittelbarem Zwang, sondern auch mit Isolation, Einschüchterung und einer pseudoreligiösen Indoktrinierung operierte. Die volljährigen Mitglieder hatten sich der Gruppe aus eigener Entscheidung angeschlossen. Dennoch standen sie unter ständiger Beeinflussung durch die von der Führung vorgegebene Doktrin. Diese deklarierte unter anderem jegliche Kritik an der Gruppierung oder gar eine Entscheidung gegen diese als Sünde. Sie schaffte ein komplexes System aus ständiger Angst und (Selbst-)Kontrolle. Für viele Colonos war ein Verlassen der CD daher kaum vorstellbar. Diejenigen, die sich für einen Fluchtversuch entschieden, taten dies aus Verzweiflung und meist erst nach langem Ringen mit sich selbst. Hugo Baar beschrieb dies bei einer Vernehmung wenige Monate nach seiner eigenen Flucht aus der CD:

»Die Angehörigen der Cesellschaft bleiben im Fundo aus Angst, Druck und im Clauben, sie würden sich versündigen, wenn sie das Fundo verlassen. Dies wird ihnen von

135 StA Bonn, AZ 50 JS 211/1997. Vgl. Landtag Nordrhein-Westfalen. Drucksache 15/3025 vom 18.10.2011. Antwort JM zu KIAnfr 1110, Drs 15/2782. Ermittlungen der NRW-Justiz zur Colonia Dignidad (Teil 1). 
dem Beschuldigten [Paul Schäfer] eingeimpft. Aus diesen Gründen sind auch meine Kinder dort geblieben und schreiben uns nicht einmal. Die Mitglieder der Cesellschaft nehmen im Fundo um ihres Glauben Willens alles hin, sie fühlen sich aber trotzdem in ihrer Freiheit u. im Leben beschränkt [...]. Ich selbst konnte im Dezember 1984 es mit meinem Gewissen nicht mehr vereinbaren, dort zu bleiben und bin dann geflüchtet. Meine Frau ist im April 1985 nachgekommen. Unsere 9 Kinder sind noch im Fundo. « ${ }^{136}$

Fluchtversuche gab es in der CD von Anfang an. Am 5. Juli 1962 - als noch nicht einmal alle Auswanderer_innen der Gruppierung in Chile angekommen waren - meldeten chilenische Medien bereits den ersten Fluchtversuch aus der Siedlung. ${ }^{137}$ Suchtrupps der CD fanden den 16-jährigen Wolfgang Müller (heute: Wolfgang Kneese) in einem Privathaus in Chillán, in das sie gewaltsam eindrangen und den Jugendlichen letztlich in die CD zurückbrachten. Der Fall Wolfgang Müller wurde bereits in Abschnitt 4.1.2 ausführlich behandelt, da eine thematische Überschneidung zwischen Kindesentführung und Freiheitsberaubung vorliegt. Am 26. September 1963 gelang Müller erneut die Flucht, allerdings war dies nur von kurzer Dauer. Müllers dritter Fluchtversuch im Februar 1966 war schließlich erfolgreich und löste eine breite Berichterstattung in Chile, ${ }^{138}$ der Bundesrepublik ${ }^{139}$ und darüber hinaus aus. ${ }^{140}$ Auch Müllers Mutter, Vera Müller, gelang die Flucht aus der CD. Beide kehrten in die Bundesrepublik zurück. ${ }^{141}$ Seit diesem Zeitpunkt sah sich die Colonia-Führung öffentlich dem Vorwurf der Freiheitsberaubung ausgesetzt.

Trotz der geringen Erfolgsaussichten versuchten Dutzende Colonos, zwischen 1961 und 2005 aus der CD zu fliehen. Einige Gründe hierfür waren der Arbeitszwang, das Verbot von Liebesbeziehungen und Familienleben sowie die alltäglich wiederkehrenden körperlichen und seelischen Misshandlungen. Die meisten Fluchtversuche scheiterten allerdings und gelangten auch nur selten an die Öffentlichkeit. Dennoch hatten Behörden und Medien in jeder historischen Phase der CD Kenntnis von einer Reihe misslungener Fluchtversuche. Da Geflüchtete öffentlich Zeugnis über die realen Verhältnisse in der CD ablegen konnten, war jeder einzelne Fluchtversuch für die CD ein Risiko. Nur etwas mehr als einer Handvoll Colonos gelang es, die CD endgültig zu verlassen und

136 StA Bonn, AZ 50 Js 285/85, Bl. 94. Vernehmung von Hugo Baar durch das AC Biedenkopf, Zweigstelle Gladenbeck vom 29.08.1985.

137 Vgl. u.a. La Tribuna de Los Ángeles vom 05.07.1962. »]óven Alemán refugiado protagoniza espectacular escapada desde Parral« sowie La Tercera vom 05.07.1962. »Niño alemán se fugó de Parral misteriosamente - en acción >comandos`alemanes en nuestro país«. Einsehbar unter PA AA, B 85, Bd. 598.

138 Die Berichterstattung fand in allen chilenischen Medien statt, besonders hervorzuheben sind die ausführlichen Artikel in der Wochenzeitschrift Ercilla, die ab März 1966 intensiv berichtete.

139 Vgl. u.a. Widmann, Carlos, »Zucht und Unzucht in der Siedlung >Würde«", in: Süddeutsche Zeitung vom 08.07.1966, S. 3. Dieser Artikel behandelt neben der Flucht von Wolfgang Müller auch die Flucht von Wilhelmine Lindemann aus der Siedlung.

140 Vgl. u.a. Le Monde vom 19.04.1966. »L'affaire du camp de concentracion du Chili«.

141 Zur Flucht von Wolfgang Müller und seiner strafrechtlichen Verfolgung durch die CD vgl. Basso, Carlos. »Wolfgang Kneese: el joven que le ganó un partido de ajedrez al diablo«, in: CIPER (Website), 28.08.2017, online unter https://ciperchile.cl/2017/08/28/wolfgang-kneese-el-joven-que-le-ga no-un-partido-de-ajedrez-al-diablo/. 
anschließend ausführlich über die Verhältnisse im Inneren der Siedlung aufzuklären. Dies waren Wolfgang Müller (1966), Peter Packmor (1969), Hugo Baar (1984) und seine Ehefrau Waltraud (1985), Georg und Lotti Packmor (1985) sowie Tobias Müller und Salo Luna (1997). Vera Müller, die Mutter von Wolfgang Müller, konnte die CD im Zuge der Flucht ihres Sohnes verlassen. Wilhelmine Lindemann (1966) und die österreichische Familie Wöhri (1968) verließen die CD mit dem Einverständnis der CD-Führung, mussten jedoch als Faustpfand ihre Kinder in der CD zurücklassen und sprachen daher nicht mit Behörden oder Medien über ihre Erlebnisse in der CD. Ein Sonderfall ist Heinz Kuhn, der schon in der Bundesrepublik und bis Ende der 1960er Jahre auch in der CD der Führungsgruppe angehörte. Nach eigenen Angaben flüchtete er 1968 mit seiner damaligen Ehefrau Ursula Klemkow aus der CD. Er ließ sich als Geschäftsmann in der südchilenischen Stadt Los Ángeles nieder und pflegte bis in die 1980er Jahre Beziehungen zur CD. Ab 1984 stellte er sich jedoch gegen die CD. Er kooperierte mit Ermittler_innen und verhalf Hugo Baar sowie dem Ehepaar Packmor zur Flucht.

Bereits 1949 hatte Paul Schäfer gegenüber einer Teilnehmerin seiner kirchlichen Jugendgruppen in Gartow geäußert: »Ich brauche einen Ort, wo mir niemand reinriecht. ${ }^{142}$ Schäfer lebte in ständiger Angst, aufgrund seiner Sexualverbrechen entdeckt und festgenommen zu werden. Sein Ziel war daher ein eigenes »Reich ${ }^{143}$ an einem entlegenen Ort in einem fernen Land sowie Maßnahmen, die jegliches Bekanntwerden der dortigen Zwangs- und Missbrauchsstrukturen unmöglich machen sollten. Nur aus Schäfers Sicht absolut verlässliche Mitglieder der Gruppierung durften die Siedlung verlassen, um notwendige Anliegen für die CD zu erledigen. Meist erfolgte sogar dies in kleinen Gruppen, um eine gegenseitige Bewachung zu gewährleisten. Ein unbemerktes Entkommen aus der CD war bereits wegen der Abgelegenheit der Siedlung schwierig: Die nächste Kleinstadt, Parral, und die Panamericana-Autobahn sind etwa 40 Kilometer entfernt. In dem Gebiet verfügte die CD-Führung über viele Verbündete und Informant_innen. Erschwerend kam hinzu, dass die meisten Colonos kein Spanisch sprachen, kein Geld hatten und auch keine Ausweispapiere besaßen - diese wurden zentral im CD-Büro verwahrt. Darüber hinaus verfügte die CD-Spitze über gute Beziehungen zu den Carabineros, der uniformierten Polizei, in der Region.

Ein über die Jahre hinweg immer ausgeklügelteres Sicherheits- und Überwachungssystem sollte einerseits die Siedlung vor Eindringlingen schützen, andererseits aber vor allem dafür sorgen, daß niemand die Siedlung eigenmächtig verlassen und so aus erster Hand über die dortigen Verbrechen berichten konnte. In den 1960er Jahren errichteten Colonos einen kilometerlangen Holzzaun um den bewohnten Teil der Siedlung. Dieser wurde mit Bewegungsmeldern und Kameras versehen sowie mit Stolperdrähten umgeben. Ende der 1970er Jahre wurden die Holzpfeiler in mehrjähriger Arbeit durch Betonpfeiler ersetzt. Ein Bericht der chilenischen Kriminalpolizei von 2001 beschreibt die technologisch sehr ausgefeilten Sicherheits- und Überwachungsanlagen der CD ausführlich:

142 Fröhling, »Unser geraubtes Leben«, S. 61. Die Äußerung machte Schäfer gegenüber Ida Gatz.

143 Ebd. S. 62. 
»En los reiterados procedimientos adoptados al interior de Villa Baviera, los funcionarios policiales se han percatado personalmente de la existencia de extensas alambradas con sensores de movimiento y micrófonos, en anillos de protección, este intrincado diseño de vigilancia da la impresión de haber sido ideado, más que como una forma de protegerse de los extraños, sino con la finalidad de evitar que los colonos huyan del fundo.

Asimismo, un complicado trazado de senderos secundarios se despliega entre los bosques, conectándose con los caminos princípales, todos los cuales tienen portones metálicos y candados con claves, que permiten una rápida evacuación en vehículos [...]. Todas estas rutas poseen sensores de movimiento e incluso, en alguno de ellos, se han detectado trampas hidráulicas para impedir el tránsito vehicular. Complementan este sistema de seguridad, una intrincada red de túneles y construcciones subterráneas, utilizadas como vías de escape y comunicación; torres y miradores de vigilancia ubicados en puntos estratégicos de observación; un moderno sistema de comunicaciones, compuesto por central telefónica, teléfonos celulares digitales, antenas subterráneas que imposibilitan su detección, handies talkies y equipos móviles de telecomunicación instalados en la mayoría de los vehículos, algunos de los cuales fueron adaptados como repetidoras de la señal, lo que dificulta su ubicación; cámaras de video que forman parte de un circuito cerrado de vigía y cámaras móviles que filman y transmiten la imagen simultáneamente hasta una sala de recepción. Importante es destacar que, según algunas pruebas realizadas, todas las comunicaciones policiales realizadas posiblemente son interceptadas.

De igual forma. se pudo apreciar que un grupo de aproximadamente treinta colonos se dedica a desarrollar labores de vigilancia, con turnos de patrullajes en automóviles. camionetas, camiones, motocicletas, bicicletas que recorren todos los senderos que cuentan con lugares considerados como sensibles. ${ }^{144}$

Zusätzlich zu der Gruppe von rund dreißig Colonos der mobilen Sicherheitsgruppe waren etwa zehn weitere Colonos in Sicherheitszentralen mit der Überwachung der Telekommunikation, der Bewegungsmelder und den Übertragungen der Videokameras beschäftigt. ${ }^{145}$ Als Sicherheitschef der CD fungierte zunächst Dieter Malessa (1970-1975), dann Erwin Fege (1975-1997) und, nachdem dieser die Siedlung verlassen hatte, Dietmar Schmidtke. ${ }^{146}$ Meldete die Sicherheitszentrale einen Vorfall am Zaun, so ertönte über die Lautsprecheranlage der Kolonie der »Pito« (Signalton) und mehrere Dutzend Angehörige der Sicherheitsgruppen eilten mit abgerichteten Hunden an die angezeigte Stelle und nahmen die Verfolgung der flüchtigen Person auf. Erwin Fege berichtete bei einer polizeilichen Vernehmung im Jahr 2000 über die technische Ausstattung und über seine Rolle in der Sicherheitsstruktur:

144 CA Santiago, AZ 2182-98 («Asociación Ilícita«), Bd. I (Parral), Bl. 463ff. PDI Prefectura Regional Talca - Polizeibericht 02/00510/vom 08.01.2001.

145 CA Santiago, AZ 2174-18, Bd. I, BI. 258. Bericht der Brigada Investigadora de Delitos contra los Derechos Humanos der PDI Nr. 20190384043/03283/202 vom 09.07.2019, Aussage von Luis Henríquez Seguel.

146 CA Santiago, AZ 2182-98 (»]uan Maino«), Bd. 2a, Bl. 985. Polizeiliche Vernehmung von Harald Tymm am 25.05.2005. 
»El encargado de la seguridad desde 1980 era yo. La seguridad era para el ingreso y egreso de personas a la Villa y en esa función detecté en cuatro o cinco oportunidades a personas que querían fugarse. Para efectuar mi trabajo usábamos cámaras de televisión en varios lugares, sistema infrarrojo ubicado en las piedras, además sensores de movimiento. Toda la información obtenida se condensaba en una sala de operaciones ubicada en el tercer piso del edificio administrativo de la Villa, a fin de evitar las salidas de colonos al exterior y saber todo lo que ocurría en el desplazamiento de las personas. $\ll^{147}$

Eine große Anzahl von Fluchtversuchen endete daher mit der Ergreifung der Geflüchteten durch die Suchtrupps der CD, noch bevor diese Behörden um Hilfe hätten ersuchen können. Einige dieser Fluchtversuche wurden später durch Berichte erfolgreich Geflüchteter bekannt, etwa Georg und Lotti Packmor oder Waltraud und Hugo Baar. Nach der Festnahme Schäfers 2005 gab es zudem diverse Aussagen von Colonos über Fluchtversuche vor Gericht. Viele der wieder Eingefangenen gaben an, nach ihren Fluchtversuchen körperlich misshandelt oder durch Psychopharmaka ruhiggestellt worden zu sein.

Wurden Fluchtversuche bekannt, so setzte die CD alles daran, gegenüber Behörden und Medien zu leugnen, dass es sich überhaupt um eine Flucht gehandelt hatte. Die Menschen in der CD seien frei und glücklich - so die Argumentation der CD-Führung daher könne von einer Flucht keine Rede sein. Aufgrund ihres Mangels an Geld, Papieren und Spanischkenntnissen wandten sich viele Geflohene an die Botschaft in Santiago bzw. an die Konsulate in Concepción oder Temuco. Die CD-Führung wusste dies und schickte bei Fluchtversuchen umgehend Suchtrupps zu den bundesdeutschen Vertretungen. Dort versuchte sie, die Geflüchteten mit psychischem Druck zur Umkehr zu bewegen. War dies erfolgreich, so nötigten sie die Geflüchteten nach ihrer Rückkehr in die CD, einen Entschuldigungsbrief an die Botschaft zu schreiben, in dem sie beispielsweise schrieben, sie seien aufgrund gesundheitlicher Probleme an jenem Tag verwirrt gewesen, eigentlich gehe es ihnen jedoch in der CD gut und sie wollten dort bleiben.

\section{Der Fall Nathanael Bohnau}

Unbeobachtete Augenblicke während eines Arbeitseinsatzes außerhalb der CD waren für mehrere Colonos eine Gelegenheit, um bei bundesdeutschen Vertretungen um Hilfe zu ersuchen. So auch für Nathanael Bohnau, um den es im Folgenden ausführlicher gehen soll.

Bohnau erschien am 10. Februar 1968 in der Botschaft in Santiago und berichtete drei Botschaftsmitarbeitern über Freiheitsberaubung und Misshandlungen in der CD "glaubhaft«, wie ein Bericht der Botschaft es formuliert. ${ }^{148}$ Er gab an, dass er, seine Frau

147 CA Santiago, AZ 2182-98 (»Asociación Ilícita«), Bd. I (Parral), Bl. 319f. Polizeiliche Vernehmung von Erwin Fege am 31.10.2000. Die Jahreszahlen der Aussagen von Erwin Fege und Harald Tymm (vorige FN) divergieren zwar, widersprechen sich jedoch nicht gänzlich, da Fege bei seiner Aussage am 31.10.2000 an anderer Stelle sagt: »trabajé en seguridad y en 1980 me hice cargo de ésta«.

148 PA AA, AV NA 31581. Botschaftsaufzeichnung V6-85 vom 10.02.1968, Betr.: Kolonie Dignidad, hier: Hilfsersuchen des der Kolonie angehörenden Herrn Nathanael Bohnau und Schilderung einiger Aspekte der Zustände in der Kolonie. 
und seine Tochter seit Jahren die Absicht hätten, die CD zu verlassen. Männer, Frauen und Kinder müssten dort völlig getrennt voneinander leben, selbst die Kommunikation untereinander werde unterbunden. Entgegen anderslautender Information sei Schäfer in der CD anwesend und gebe sich als Paul Schneider aus. Schon geringfügigste Verstöße gegen die von Schäfer erzwungene Ordnung zögen drakonische Strafen nach sich, und zwar dergestalt, »dass die jeweiligen Angehörigen der gleichen Gruppe den `Schuldigen vor vielen anderen Kolonie-Angehörigen mit Stockschlägen derart züchtigten, dass diese blutende Körperverletzungen davontrügen. ${ }^{149}$ Scharfe Hunde griffen Kinder an und rissen ihnen die Kleider vom Leibe, bevor sie von Schäfer zurückgerufen würden. Unter Drohungen würden von Colonos Aussagen erpresst, zu denen sie freiwillig nicht bereit wären. Seine Frau, Helene Bohnau, sei 22 Monate lang im Frauenwohnhaus der CD eingesperrt gewesen und sei sogar auf der Toilette von zwei Frauen ihrer Gruppe bewacht worden. Gegenwärtig sei eine über 70-jährige Koloniebewohnerin, Frau Schiwon, bereits seit mehreren Wochen eingesperrt. Der CD-Bewohner Johannes Matthusen wolle ebenfalls die Siedlung verlassen.

Vor Botschaftsbeamten unterzeichnete Nathanael Bohnau ein schriftliches Hilfsersuchen zur Rückreise in die Bundesrepublik - gemeinsam mit seiner Frau Helene und seinen Kindern. ${ }^{150}$ Einige Tage später suchte Botschaftsrat End den deutschstämmigen Generaldirektor der Kriminalpolizei PDI, Emilio Oelckers, auf und schilderte ihm den Fall. Laut eines Gesprächsvermerk von End ${ }^{151}$ gab Oelckers an, eine großangelegte Polizeiaktion »nur wegen des Falles Bohnau« vermeiden zu wollen. Er schlug der Botschaft vor, an das chilenische Außenministerium heranzutreten, um eine gemeinsame Untersuchungskommission aus chilenischem Außenministerium, deutscher Botschaft und PDI anzuregen. Diese Kommission solle dann unangemeldet und unter Schutz eines umfangreichen Polizeikontingents die CD besuchen und sich dort Herrn Bohnau »vorführen lassen«. Bohnau solle dann vor den Beamten eine Erklärung unterzeichnen, dass er die CD verlassen wolle. Sollte sich die Kolonieleitung weigern, Bohnau gehen zu lassen, könne die Kriminalpolizei den Koloniepräsidenten Hermann Schmidt festnehmen lassen. End schlug in seinem Vermerk vor, der chilenischen Seite per Verbalnote die Bildung einer solchen Untersuchungskommission vorzuschlagen und fügte an: »Über die konkrete Durchführung der >Entlassung« Bohnaus aus Dignidad müsste dann noch mit dem Außenministerium, bzw. der Kriminalpolizei gesprochen werden. « ${ }^{152}$ Am 22. Februar 1968 leitete Botschafter Salat diesen Vorschlag ans AA weiter und bat »besonders im Interesse von Herrn Bohnau um möglichst umgehende Weisung «. ${ }^{153}$ Doch zwei Tage später, am 24. Februar, erschien Nathanael Bohnau erneut in der Botschaft und übergab eine schriftliche Widerrufserklärung:

\footnotetext{
149 Ebd.

150 StA Bonn, AZ 50 ]s 285/85, Bd. VIII, BI. 130. Erklärung Nathanael Bohnau vom 10.02.1968.

151 PA AA, AV NA 31581. Vermerk Botschaftsrat End über Gespräch mit dem Generaldirektor der PDI, Oelckers vom 15.02.1968.

152 Ebd.

153 PA AA, AV NA 31581. Schreiben Botschafter Salat an AA vom 22.02.1968. V6-85-408/68, Reinkonzept, abges. am 23.02.1968.
} 
»Vor einigen Tagen war ich bei Ihnen auf der Botschaft. Ich habe Dinge geschildert die nicht der Wahrheit entsprachen, diese Dinge standen damals nur in den Zeitungen. Auch meiner Frau und Kindern geht es hier in der Kolonie gut. Ich wiederrufe alle meine Aussagen sie sint nicht wahr. Ich habe bei ihnen so geredet um einen Grund zuhaben, weil ich glaubte, daß sie es gerne hören wollen auch die Sache mit den Hunden ist nicht wahr. Entschuldigen Sie daß ich soviel Moleste gemacht habe ich Bedaure alles sehr. Ich habe sehr oft Kopfschmerzen dadurch ist auch mein Geruch verlorengegangen deshalb brauchte ich auch kein Soldat zusein. Ich wollte dann schon öfter die Kolonie verlassen aber wen es mier dan wieder gut gin war ich froh daß ich hier mit meiner Frau und Kinder Zusammen leben darf wie auch jetzt. Meinen unterschribenen Antrag Erkläre ich ungültig. Nathanael Bohnau. «154

Botschaftsmitarbeiter Pyroth, der das Widerrufsschreiben entgegennahm, berichtete dies erst am 7. März ans AA. Er kommentierte:

»Herr Bohnau machte dabei einen verschreckten Eindruck und lehnte jede weitere Erklärung ab. Die Botschaft hat den Eindruck, daß der Widerruf zumindest unter psychologischem Druck zustande gekommen ist. $\ll^{155}$

Die Botschaft hatte ein konkretes Zeugnis aus erster Hand über Freiheitsberaubung und ein schriftliches Ersuchen zur Rückreise vorliegen. Sie durchschaute auch, dass der Widerruf dieser Erklärung unter Druck zustande gekommen war.

Unterdessen hatte die Botschaft versucht, am 29. Februar 1968 auf eigene Initiative einen »Informationsbesuch « in der CD durchzuführen. Dort wurde den Botschaftsangestellten End und Wagner jedoch mit Verweis auf die gespannten Beziehungen zwischen $C D$ und Botschaft der Zutritt verwehrt. Ihnen wurde lediglich ermöglicht, die Siedlung von einer eineinhalb Kilometer entfernten Anhöhe aus einzusehen. ${ }^{156}$

Auf die dringende Bitte des Botschafters vom 22. Februar antwortete das AA am 15. März 1968 und lehnte den Vorschlag der Bildung einer Untersuchungskommission ab. ${ }^{157}$ Stattdessen sollte die chilenische Seite unterrichtet werden, dass Koloniemitglieder die Siedlung verlassen wollten. Die chilenische Seite sollte in einer Niederschrift bestätigen, dass den Betreffenden Polizeischutz zugesichert werde. Der Generaldirektor der PDI, Oelckers, sollte daraufhin mit ihnen sprechen - in Abwesenheit der CDLeitung. Mitglieder der Botschaft sollten an dieser Maßnahme nicht teilnehmen, jedoch sollte die Botschaft eine Privatperson beauftragen, an den Befragungen teilzunehmen, ohne dass bekannt werde, dass diese Person im Zusammenhang mit der Botschaft stehe. Doch auch hierzu kam es nicht.

Im August 1968 bekam Günter Bohnau, der in Siegburg lebende Sohn von Nathanael Bohnau, einen Brief von seinem Vater. Darin heißt es:

PA AA, AV NA 31581. Handschriftliches Schreiben Nathanael Bohnau an Botschaft vom 24.02.1968. Fehler im Original. 
»Uns geht es hier sehr schlecht, wir werden hier sehr schlecht behandelt. Die Kinder werden auch furchtbar geschlagen, und wem das nicht passt und hier nicht bleiben will wird hier bewacht. Die Mama war auch schon 1 Jahr und 10 Monate eingesperrt, ich durfte in dieser Zeit unter Aufsicht ein paar Male mit ihr sprechen. Sie ist auch fast nur Haut und Knochen, bitte helft uns doch hier noch einmal heraus. Wendet Euch an die deutsche Botschaft in Santiago. [...] Ich war in der deutschen Botschaft um Hilfe zu bitten, und hatte den Antrag gestellt, um nach Deutschland zurück zu kommen. Dann hat mir Kurt Schnellenkamp versprochen, dass sie uns zurückschicken werden, und sollte doch den Antrag in der deutschen Botschaft zurücknehmen, und diktierten mir den Brief an die deutsche Botschaft. Nun sehe ich mich betrogen und komme nicht raus. Andere Namen die auch gerne rauswollen sind folgende: Peter Packmor, Willi Freitag, Hildegard Zeitner geb. Bohnau, Olga Bernd, Linde Fendros, Helene Bohnau geb. Stobbe und andere. $\ll^{158}$

Daraufhin wandte sich Günter Bohnau ans AA und bat um »Rechtsschutz und Mithilfe bei der Rückkehr meiner in Chile befindlichen Angehörigen «, ${ }^{159}$ namentlich Nathanael Bohnau, Helene Bohnau (geb. Stobbe) und Edeltraut Bohnau. Er bat darum, seinen Angehörigen

»bei der Rückreise in die Bundesrepublik Deutschland beizustehen, da sie an ihrem freien Entschluß dies durchzuführen behindert werden. Ich darf jedoch hier vorbringen, daß meine Angehörigen mit Repressalien zu rechnen haben, wenn der Leitung der Siedlungsgemeinschaft irgendwelche Pläne oder Vorbereitungen einer Rückreise vorzeitig bekannt würden. ${ }^{160}$

Den Brief seines Vaters fügte er in Kopie bei. Das AA leitete das Ersuchen an die Botschaft weiter mit dem Betreff »Gewährung von Unterstützung nach $\$ 26 \mathrm{KG}$, hier: Familie Nathanael Bohnau, Siedlung >La Dignidad mit der Bitte um weitere Veranlassung ${ }^{161}{ }^{161}$ Eine Antwort erhielt Günter Bohnau auf sein Hilfsersuchen nicht. ${ }^{162}$

Im Februar 1972 schrieb Günter Bohnau an den Polizeichef von Parral und bat diesen um Hilfe bei der Rückführung seiner Eltern. Die chilenischen Behörden sahen jedoch deutsche Stellen in der Zuständigkeit und leiteten Bohnaus Schreiben über das chilenische Außenministerium an die Botschaft weiter. ${ }^{163}$ Am 2. Juni 1972 besuchten daraufhin ein Sohn und eine Tochter von Nathanael Bohnau, die ebenfalls in der CD

158 StA Bonn, AZ 50 ]s 285/85, Bd. VIII. Schreiben Nathanael Bohnau an seinen Sohn Günter Bohnau vom August 1968.

159 StA Bonn, AZ 50 ]s 285/85, Bd. VIII. Schreiben Günter Bohnau an die Rechtsabteilung des AA vom 15.08.1968.

160 Ebd.

161 StA Bonn, AZ 50 ]s 285/85, Bd. VIII. Schreiben AA an die Botschaft Santiago vom 20.08.1968, V6$88 / 5571$

162 Vgl. Kaes, Wolfgang/Andreas Stanetschek. »Bitte hilf uns hier raus«, in: Bonner Generalanzeiger vom 12.03.2009, online unter https://www.general-anzeiger-bonn.de/region/bitte-hilf-uns-hier-ra us_aid-40531101.

163 PA AA, ZW 111129. Bericht Botschaftsrat Werner Kaufmann-Bühler vom 10.05.1972. Aufzeichnung des RK-Referenten der Botschaft Santiago über den Besuch der deutschen Kolonie »Dignidad« vom 19.06.1972. 
lebten, die Botschaft und trugen vor, ihr Vater habe ab und zu Heimweh nach Deutschland und wünsche dann zurückzukehren. In Wahrheit aber wolle er aber in der Kolonie bleiben. ${ }^{164}$ Die Eltern hätten ihre Rückkehrabsicht wieder aufgegeben und einen entsprechenden Brief nach Deutschland geschrieben. Eine Kopie dieses Briefes legten sie Botschaftsrat Kaufmann-Bühler vor. Sie seien zur Botschaft gekommen, damit keine offiziellen Schritte unternommen würden. Ihr Vater wisse aber nicht von ihrem Botschaftsbesuch. Kaufmann-Bühler erklärte daraufhin, dass ihr Vater in seiner Entscheidung frei sei und sprach die Erwartung aus, die Frage bei seinem bevorstehenden Besuch in der CD auch mit Hermann Schmidt zu besprechen. ${ }^{165}$

Am 19. Juni 1972 besuchte Kaufmann-Bühler die CD »[a]ufgrund von zwei Gesuchen von Mitgliedern der Kolonie [...], ihnen zur Rückkehr in die Bundesrepublik Deutschland zu verhelfen. ${ }^{166}$ Neben dem Fall Nathanel Bohnau handelte es sich um den Fall von Heinz Schmidt, dem Adoptivsohn von Hermann Schmidt, der ausführlich in Abschnitt 4.1.2 behandelt wurde. Der Botschaftsrat führte ein Gespräch mit Nathanael Bohnau, bei dem sein Sohn und seine Tochter, die zuvor in der Botschaft gewesen waren, ebenfalls anwesend waren, zudem einige Vorstandsmitglieder, »die sich nicht hatten abschütteln lassen«, so Kaufmann-Bühler. ${ }^{167}$ In dem Gespräch bestätigte Bohnau die Angaben seiner Kinder aus der Botschaft. Er habe ab und an Heimweh gehabt, nun wisse er aber, »daß sein Platz hier in Dignidad sei«. ${ }^{168}$ Kaufmann-Bühler scheint das überzeugt zu haben, er folgerte in seinem Bericht:

»Es ist kaum anzunehmen, daß Nathanael Bohnau sich in anderer Umgebung außerhalb der Reichweite des Vorstandes anders verhalten würde. Er ist der Emigrant, der nirgends mehr richtig zu Hause ist und sich sicher oft nach der Heimat zurücksehnt die aber für ihn nicht Deutschland ist-, der sich gegen die Abkapselung aufbäumt, zu der ihn das Leben in der Kolonie zwingt, aber der sich letztlich mit seinem Schicksal wohl abgefunden hat. ${ }^{169}$

Die Einschätzung von Kaufmann-Bühler verwundert angesichts der in den Botschaftsakten dokumentierten Vorgänge von 1968. Am Ende seines Berichts kritisiert Kaufmann-Bühler, die CD sei aus seiner Sicht wirtschaftlich nur lebensfähig, da alle Mitglieder der Siedlung arbeiteten, ohne Lohn zu empfangen. Als Paradebeispiel privater Entwicklungshilfe, als das sich die CD-Leitung gerne darstelle, könne sie sicher nicht gelten. Weiter schreibt er:

»Dem steht die Abkapselung entgegen, der wiederum von der abgrundtiefen Überzeugung der Kolonisten von der Untauglichkeit des Chilenen zugrundeliegt. Die An-

StA Bonn, AZ 50 ]s 285/85, Bd. VIII, Vermerk Botschaftsrat Kaufmann-Bühler vom 02.06.1972, beglaubigt von der Botschaft am 14.06.1988.

165 Ebd.

166 PA AA, ZW 111129. Bericht Botschaftsrat Werner Kaufmann-Bühler vom 05.10.1972. Aufzeichnung des RK-Referenten der Botschaft Santiago über den Besuch der deutschen Kolonie »Dignidad«vom 19.06.1972, S. 1.

167 Ebd., S. 17.

168 Ebd., S. 18.

169 Ebd., S. 18. 
erkennung, die die Kolonie in manchen Kreisen Chiles findet [...] ist Ausdruck der Bewunderung, die man der deutschen Arbeit und Perfektion entgegenbringt, und die, gerade weil sie in Abkapselung praktiziert wurde, chilenische Belange eigentlich nicht berührt. Die Haltung der chilenischen Seite gegenüber der Kolonie wäre in dem Augenblick völlig anders, in dem Chilenen in das Leben und die Zwänge der Kolonie einbezogen würden. So ist die Kolonie >Dignidad « ein Stück Auslandsdeutschtum, das uns auch weiterhin mehr belasten als nützen wird. ${ }^{170}$

Botschafter Lahn leitete den Bericht am 6. Oktober 1972 ans AA weiter. ${ }^{171}$ Es verstehe sich von selbst, so ergänzte er, dass die Aufzeichnung persönliche Eindrücke und Aussagen enthalte, die zur Weitergabe an Dritte nicht geeignet seien. Nathanael Bohnau blieb bis zu seinem Tod 1987 in der CD.

Der Fall von Nathanael Bohnau ist einer der am besten dokumentierten Fälle in den Akten des AA. Über die Jahre hinweg gab es jedoch diverse weitere Fluchtversuche und Hilfsersuchen, die ähnlichen Mustern folgten. Anfang Januar 1976 etwa sprach der Colono Horst Münch im bundesdeutschen Konsulat in Concepción vor und bat um Hilfe zur Rückkehr in die Bundesrepublik. Nach seiner Vorsprache im Konsulat kehrte er in die CD zurück und schrieb wenige Tage später an den Konsul:

»Ich hatte inzwischen ein längeres Cespräch mit meinem älteren Bruder, in dem ich zu der Überzeugung gekommen bin, daß mein Weggehen aus der deutschen Colonie Parral unkorrekt war. Seit 2 Jahren habe ich ein nervöses Leiden, welches Schlafstörungen und Angstgefühle zur Folge hat, wenn ich keine Beruhigungsmittel einnehme. Kleine Probleme erscheinen mir manchmal riesengroß. [...] Ich befinde mich seit Freitag abend (9.1.) wieder auf unserem Fundo in Parral und nehme von der Rückreise nach Deutschland Abstand. Die Sociedad hat mir fachärztliche Hilfe angeboten, die ich in Anspruch nehmen will. ${ }^{172}$

\section{Der Fall Brigitte Mücke}

Brigitte Mücke (geb. Baak) ist die Ehefrau des CD-Führungsmitglieds Gerhard Mücke. Im April 1978 schrieb ein Rechtsanwalt Schlimgen aus Troisdorf im Auftrag des Bruders und der Mutter von Brigitte Mücke ans AA. ${ }^{173}$ Seine Mandant_innen hätten mehrere Schreiben von Frau Mücke aus der CD erhalten, in denen diese ihren Wunsch geäußert habe, in die Bundesrepublik zurückzukehren. Man wolle sie jedoch nicht gehen lassen. Der Rechtsanwalt bat das AA, über die Botschaft Kontakt zu Frau Mücke aufzunehmen. Daraufhin lud die Botschaft Brigitte Mücke zu einem Gespräch. Am 27. April erschien sie in Begleitung ihres Ehemannes Gerhard Mücke in der Botschaft. ${ }^{174}$ Auf das RA-Schreiben angesprochen, sagte sie aus, lediglich gelegentlich Heimweh zu haben, ansonsten gehe es ihr jedoch in der CD gut. Erst im letzten Jahr sei sie zu Besuch in der 
Bundesrepublik gewesen und sei dort mit ihrem Bruder und ihrer Mutter zusammengetroffen. Sie beabsichtige auch in Zukunft in die Bundesrepublik zu reisen, woran sie niemand hindere. Die Botschaft schloss ihren Bericht an das AA mit den Worten:

»Nach dem hier im Beisein von zwei Beamten der Botschaft von Frau Mücke im persönlichen Cespräch gewonnenen Eindruck sieht die Botschaft keinerlei Cründe für Zweifel an dem Wahrheitsgehalt der von Frau Mücke abgegebenen Erklärungen. « ${ }^{175}$

Es erscheint verwunderlich, dass die Botschaft keinerlei Gründe für Zweifel an der Erklärung hatte, die einem sich bereits mehrfach wiederholten Muster folgte: Colonos richteten direkt oder über Umwege deutliche Hilferufe an die Botschaft, dannach erschienen sie in Begleitung anderer und widerriefen die geleistete Erklärung.

Am 29. Juni 1978 schrieb der Rechtsanwalt erneut ans AA und fügte Kopien von zwei Schreiben Brigitte Mückes an ihre Mutter an. ${ }^{176}$ In einem Brief vom Juni 1977 schrieb Brigitte Mücke ihrer Mutter: »lasse mich bitte durch die Deutsche Botschaft hier herausholen, anders ist es mir nicht mehr möglich zu kommen, alles andere mündlich. Gründe, die ich schriftlich nicht nennen will, zwingen mich zu diesem Schritt. « ${ }^{177} \mathrm{RA}$ Schlimgen führte dazu aus:

»Kurz nachdem dieses Schreiben bei Frau Baak eingegangen war, wurde Frau Baak von ihrer Tochter wiederholt angerufen und gebeten, diesen Brief zu vernichten. Anschließend ist Frau Mücke ausschließlich, um den Brief an sich zu bringen, aus Chile angereist und hat sogar noch eine Tante in Hannover aufgesucht, bei der sich nach Angaben von Frau Baak der Brief befinden sollte. Da die Tochter jedoch nicht abließ hat Frau Baak diesen Brief ihrer Tochter ausgehändigt, die den Brief sofort in deren Anwesenheit noch vernichtete. Vorher hatte sich glücklicher Weise Frau Baak hiervon eine Kopie gefertigt. Sobald der Brief vernichtet war, ist Frau Mücke unverzüglich wieder nach Chile gereist, ohne ihre Mutter über die Hintergründe aufzuklären. ${ }^{178}$

Auch im zweiten beigelegten Brief an ihre Tochter vom März $1978^{179}$ bekräftigte Brigitte Mücke ihren Wunsch, die CD zu verlassen und in die Bundesrepublik zurückzukehren. Dies werde ihr jedoch verwehrt. Sie müssten viel arbeiten und hätten kein gemeinsames Zimmer mit ihrem Ehemann. Andererseits habe die Gemeinschaft auch wieder gute Seiten und sie wolle auf keinen Fall einen Presseskandal heraufbeschwören. Sie wolle die CD-Führung nun erneut bitten, sie gehen zu lassen. Wenn ihre Mutter lang nichts von ihr höre, solle sie die Botschaft kontaktieren und sie vorladen lassen, dann werde sie dort sagen, dass sie nach Hause will. Der Brief schloss mit den Worten: »Mauk [Spitzname ihres Ehemannes Gerhard Mücke, JS] gefällt es hier auch nicht,

175 Ebd.

176 PA AA, AV NA 31580. Schreiben RA Schlimgen an AA vom 29.06.1978.

177 PA AA, AV NA 31580. Erste Anlage zum Schreiben von RA Schlimgen an AA vom 29.06.1978. Fotokopie des handschriftlichen Briefes von Brigitte Baak an ihre Mutter vom 24.06.1977.

178 PA AA, AV NA 31580. Schreiben RA Schlimgen an AA vom 29.06.1978.

179 PA AA, AV NA 31580. Zweite Anlage zum Schreiben von RA Schlimgen an AA vom 29.06.1978. Fotokopie des handschriftlichen Briefes von Brigitte Baak an ihre Mutter, bei dieser eingegangen am 30.03.1978. 
aber er traut sich nichts zu sagen! Wir möchten beide gerne wieder zurück. «" ${ }^{180}$ Der Rechtsanwalt bekräftige gegenüber dem AA die große Sorge seiner Mandantin um ihre Tochter in der CD und äußerte sein Befremden darüber, dass Brigitte Mücke in der Botschaft nur in Begleitung ihres Ehemannes befragt wurde. Er bat darum, sie erneut zu einem Gespräch in die Botschaft einzuladen, allerdings diesmal in Abwesenheit ihres Ehemannes. Das AA leitete das Schreiben weiter an die Botschaft. Botschafter Strätling meldete daraufhin zurück ans AA, es seien keine weiteren neuen Tatsachen ersichtlich, die eine erneute Vorladung von Frau Mücke rechtfertigten:

»Aus hiesiger Sicht besteht daher kein Anlaß zu der Vermutung, Frau Mücke werde, wie dies offenbar von interessierter Seite schon im Vorjahr unterstellt worden war, auch in diesem Jahr wieder an der Ausreise gehindert. [...] Die Botschaft ist der Ansicht, daß Frau Mücke ebenso wie die anderen in der Colonia Dignidad lebenden deutschen Staatsangehörigen die mehr als 400 km lange Anreise von Parral nach Santiago nur bei Vorliegen wichtiger Gründe zugemutet werden sollte. ${ }^{181}$

Allem Anschein nach glaubte Strätling, bei dem Vorwurf der Freiheitsberaubung handele es sich um eine Inszenierung »von interessierter Seite«, um der CD zu schaden. Er reproduzierte damit den Diskurs der CD, die alle Vorwürfe mit Verweis auf eine vermeintliche Verleumdungskampagne gegen sie abtaten. Wie eine solche Kampagne jedoch von Colonos, die die CD verlassen wollten, getragen werden sollte, erscheint nicht nachvollziehbar. Es scheint, dass Strätling aus Sympathie für die CD die Vorwürfe a priori nicht glauben wollte und ihnen die Legitmität absprach. Dies hatte zur Folge, dass Opfern von Freiheitsberaubung nicht geholfen wurde.

Auf einen weiteren Erlass des AA hin bekräftigte Strätling erneut, es gebe keinerlei Anlass zu der Vermutung, dass Brigitte Mücke in der CD gefangen gehalten werde. Die Botschaft habe sich wiederholt mit ähnlichen Vorwürfen befasst, »doch haben ihre Ermittlungen keinen Beweis für die Richtigkeit der Beschuldigungen erbringen können. ${ }^{182}$ Dennoch wurde Brigitte Mücke, um der Weisung aus dem AA Folge zu leisten, erneut in die Botschaft geladen, wo sie am 14. November 1978 wiederum in Begleitung ihres Ehemanns erschien und ihre Aussage wiederholte: Sie leide zwar öfters an Heimweh, sei jedoch im allgemeinen mit ihrem Leben in der CD zufrieden. ${ }^{183}$ Eine Woche später erschien Gerhard Mücke unangemeldet alleine in der Botschaft und bat um ein Gespräch. ${ }^{184}$ Er erklärte, dass er nach der Vorsprache seiner Frau nun zu der Überzeugung gekommen sei, dass er dem AA gegenüber die tatsächliche Situation und die privaten Familienverhältnisse der Familie Baak offenbaren müsse, um zu zeigen, dass es sich um eine rein persönliche Angelegenheit handele. Er übergab ein Schriftstück,

180 Ebd.

181 PA AA, AV NA 31580. Bericht Botschafter Strätling an AA vom 26.07.1978, RK-SK 13887, Ber. Nr. $775 / 78$.

182 PA AA, AV NA 31580. Bericht Botschafter Strätling an AA vom 08.09.1978, RK-SK 13887, Ber. Nr. $931 / 78$.

183 PA AA, AV NA 31580. Bericht Botschafter Strätling an AA vom 20.11.1978, RK-SK 13887, Ber. Nr. $1218 / 78$.

184 PA AA, AV NA 31580. Bericht Botschafter Strätling an AA vom 01.12.1978, RK-SK 13887, Ber. Nr. $1267 / 78$. 
das er bat vertraulich zu behandeln und nicht RA Schlimgen zugänglich zu machen. Darin unterstellt Gerhard Mücke diverse psychische Erkrankungen seiner Frau und ihrer Geschwister, an der ihre Ehe zu zerbrechen drohe. Der angeblich psychisch kranke Bruder seiner Frau habe RA Schlimgen eingeschaltet und nun wolle sogar der Generalsekretär von Amnesty International, Helmut Frenz, die privaten Ehe- und Familienprobleme Mückes mit in das Verfahren der SBED gegen AI vor dem Landgericht Bonn hineinziehen. Mücke bat die Botschaft:

»Vielleicht können Sie verstehen, dass ich ungern meine Frau erneut nach Deutschland reisen lasse. [...] Vielleicht können Sie mir, in meinen Schwierigkeiten, unsere Ehe vor dem Hineinziehen in den Skandal zu bewahren helfen durch eine entsprechende Antwort an das AA. Denn meine Frau wird hier von niemand festgehalten. Ich möchte Sie bitten, dieses Cespräch vertraulich zu behandeln. $^{185}$

Nach diesem Gespräch von Gerhard Mücke in der Botschaft, gab es noch lange Zeit weiteren Schriftverkehr zwischen allen Beteiligten, der jedoch nichts an der Situation änderte. Brigitte Mücke durfte die CD weiterhin nicht verlassen.

Auch andere Colonos gaben nach gescheiterten Fluchtversuchen oder Hilfsersuchen unter Druck Schutzerklärungen für die CD-Führung ab. Meist wurden sie gezwungen zu leugnen, dass sie überhaupt hatten fliehen wollen. Beispielsweise erklärte Jürgen Szurgelies, der dreimal erfolglos versucht hatte, aus der CD zu entkommen (1982, 1983 und 1988), im Februar 1989 gegenüber einem chilenischen Richter:

»Nein, ich bin in keinem Fall gegen meinen Willen zurückgebracht worden. Ich verließ die Kolonie, um einen Spaziergang zu machen. Ich wollte einen Ausflug unternehmen, da verirrte ich mich, weil ich alleine war, und ich gelangte zu einem fremden Haus und dort wartete ich und hoffte, daß sie mich suchen kämen. ${ }^{186}$

Tabelle 7 listet 20 Fluchtversuche von insgesamt 25 Personen auf, ${ }^{187}$ die in den Akten des AA bzw. der Botschaft erwähnt werden. Über die meisten dieser Fluchtversuche wurde zeitnah in den Medien berichtet. In acht Fällen gelangten die Geflüchteten bis in Vertretungen der Bundesrepublik, wo sie ihren Wunsch zur Rückkehr in die Bundesrepublik vortrugen.

185 PA AA, AV NA 31580. Formloses Schreiben, unterzeichnet von Gerhard Mücke. »lch danke Ihnen, Herr Hieman...", Anlage zum Bericht Botschafter Strätling an AA vom 01.12.1978, RK-SK 13887, Ber. Nr. 1267/78.

PA AA, AV NA 31606. StA Bonn, AZ 50 Js 285/85. Verfügung vom 26.01.1994 (beabsichtigte Einstellung des Verfahrens), S. 35.

187 An einigen dieser Fluchtversuche waren mehrere Personen beteiligt. 
Tabelle 7: Fluchtversuche und Hilfsersuchen aus der Colonia Dignidad

\begin{tabular}{|c|c|c|c|c|}
\hline Datum & Name & $\begin{array}{l}\text { (zeitnahe) Me- } \\
\text { dienberichte }\end{array}$ & $\begin{array}{l}\text { geflüchtet/vorgela- } \\
\text { den in dt. Vertretung }\end{array}$ & $\begin{array}{l}\text { Flucht } \\
\text { erfolgreich }\end{array}$ \\
\hline 18.06 .1962 & Wolfgang Müller L. & $\mathrm{Ja}$ & Nein & Nein \\
\hline 26.09 .1963 & Wolfgang Müller L. & Nein & Konsulat Temuco & Nein \\
\hline Februar 1966 & Wolfgang Müller L. & $\mathrm{Ja}$ & Botschaft & $\mathrm{Ja}$ \\
\hline März 1966 & $\begin{array}{l}\text { Wilhelmine } \\
\text { Lindemann }\end{array}$ & $\mathrm{Ja}$ & Nein & (Ja) \\
\hline Februar 1968 & Nathanael Bohnau & Nein & Botschaft & Nein \\
\hline März 1969 & Heinz Schmidt & Nein & Botschaft & Nein \\
\hline Mai 1969 & Peter Packmor & $\mathrm{Ja}$ & Botschaft & $\mathrm{Ja}$ \\
\hline 1971 & Johannes Matthusen & $\mathrm{Ja}$ & Nein & $\mathrm{Ja}$ \\
\hline 1976 & Horst Münch & Nein & Konsulat Concepción & Nein \\
\hline 1977 & Brigitte Mücke & Nein & Botschaft & Nein \\
\hline $\begin{array}{l}\text { Dezember } \\
1984\end{array}$ & $\begin{array}{l}\text { Hugo (und Waltraud) } \\
\text { Baar }\end{array}$ & (Jahre später) & Nein & $\mathrm{Ja}$ \\
\hline Februar 1985 & $\begin{array}{l}\text { Georg und Lotti } \\
\text { Packmor }\end{array}$ & (Jahre später) & Botschaft & $\mathrm{Ja}$ \\
\hline April 1988 & Jürgen Szurgelies & Ja & Nein & Nein \\
\hline Januar 1996 & Karl Stricker & $\mathrm{Ja}$ & Nein & Nein \\
\hline Januar 1997 & Miguel Becerra & $\mathrm{Ja}$ & Nein & Nein \\
\hline Juli 1997 & $\begin{array}{l}\text { Tobias Müller und } \\
\text { Salo Luna }\end{array}$ & Ja & Botschaft & $\mathrm{Ja}$ \\
\hline April 1999 & Reinhardt Schmidtke & Ja & Nein & Nein \\
\hline Februar 2001 & Doris Gert & $\mathrm{Ja}$ & Nein & Nein \\
\hline März 2001 & Hilde Ritz & $\mathrm{Ja}$ & Nein & $\mathrm{Ja}$ \\
\hline $\begin{array}{l}\text { Dezember } \\
2002\end{array}$ & Efraín Vedder & Ja & Nein & $\mathrm{Ja}$ \\
\hline April 2003 & $\begin{array}{l}\text { Walter und Mathilde } \\
\text { Szurgelies; Franz und } \\
\text { Ingrid Baar }\end{array}$ & $\mathrm{Ja}$ & Nein & $\mathrm{Ja}$ \\
\hline
\end{tabular}

Nur die Hälfte der bekannt gewordenen Fluchtversuche endete mit einer Rückkehr der Betreffenden in die Bundesrepublik. Nur bei fünf der erfolgreichen Fluchten war die Botschaft an der Rückkehr in die Bundesrepublik beteiligt. ${ }^{188}$ Eine große Anzahl weiterer Fluchtfälle scheiterte, ohne dass Behörden oder Medien zeitnah davon Kenntnis erlangten. Tabelle 8 zeigt eine Zusammenstellung verschiedener Fluchtversuche, die im Nachhinein durch spätere Aussagen und Berichte bekannt wurden:

188 Dies betrifft die Fluchten von Peter Packmor (1969), Georg und Lotti Packmor (1985) sowie Tobias Müller und Salo Luna (1997). 
Tabelle 8: Weitere in Quellen erwähnte Fluchtversuche

\begin{tabular}{|c|c|c|}
\hline Datum & Person & Quelle(n), Bemerkungen \\
\hline 1968 & $\begin{array}{l}\text { Heinz Kuhn und Ursula } \\
\text { Klemkow }\end{array}$ & Ursula Klemkow (eigene Aussage) ${ }^{\mathrm{a}}$ \\
\hline 1970 & Hartmut Hopp & Lotti Packmor ${ }^{b}$ \\
\hline 1970 & Hussein Siam/Günther Reis & $\begin{array}{l}\text { Die beiden wurden zum Studium in die USA geschickt } \\
\text { und kehrten nicht zurück. }\end{array}$ \\
\hline $1971 / 72$ & Ulrike Myslewicz & Lotti Packmorc \\
\hline 1974 & Winfried Schmidtke & $\begin{array}{l}\text { Lotti Packmor }{ }^{d} \text { Schmidtke selbst gab an, er sei wäh- } \\
\text { rend der Allende-Regierung geflüchtet und nach sei- } \\
\text { ner Festnahme durch die PDI in die CD zurückgebracht } \\
\text { worden. }^{\text {e }}\end{array}$ \\
\hline 1980 & Lotti Packmor & Lotti Packmor ${ }^{f}$ \\
\hline o. D. & Rainer Schmidtke & Lotti Packmorg \\
\hline 1982 & Jürgen Szurgelies & RA Máximo Pacheco ${ }^{\text {h }}$ \\
\hline 1983 & Jürgen Szurgelies & RA Máximo Pacheco ${ }^{i}$ \\
\hline o. D. & Alfred Matthusen & Lotti Packmor ${ }^{j}$ \\
\hline o. D. & Gudrun Wagner & Hugo Baark \\
\hline o. D. & Gerhard Laube & Hugo Baarl \\
\hline 19.02.1992 & Klaus Schnellenkamp & Eigene Aussage $^{\mathrm{m}}$ \\
\hline o. D. & Hannelore Bensch & Eigene Aussage ${ }^{n}$ \\
\hline
\end{tabular}

a HISArch, Bestand CD, Ordner 1. LG Köln, 28 O 160/88 Vernehmung von Ursula Kuhn (geb. Klemkow) durch das AG Eutin vom 07.11.

b 1988PA-DBT, Stenographisches Protokoll der 10. Sitzung des Unterausschusses für Menschenrechte und humanitäre Hilfe des Auswärtigen Ausschusses vom 22.02.1988, S. 10/122.

c PA AA, B 83, Bd. 2384. Transkription des Tonbandberichts von Lotti Packmor an die Botschaft vom 17.03.1985, S. 19

d Ebd., S. 20.

e PJS, Sammlung Gesprächsnotizen. Notiz des Gesprächs des Verfassers mit Winfried Schmidtke vom 17.11.2019.

f PA AA, B 83, Bd. 2384. Transkription des Tonbandberichts von Lotti Packmor an die Botschaft vom 17.03.1985, S. 12ff.

g Ebd., S. 20.

h PA AA, AV NA 31589. Schriftsatz von RA Máximo Pacheco vom 06.02.1989.

i Ebd.

j PA-DBT, Stenographisches Protokoll der 10. Sitzung des Unterausschusses für Menschenrechte und humanitäre Hilfe des Auswärtigen Ausschusses vom 22.02.1988, S. 10/19.

k Ebd., S. 10/21.

l Ebd., S. 10/19.

m PJS, Sammlung Lothar Mark. Text Klaus Schnellenkamp vom 03.10.2007. »41 deutsche Staatsbürger werden vom eigenen Staat ins Folterlager deportiert. Die Bundesregierung schweigt bis heute. Die Täter werden gedeckt und die Opfer bleiben allein.«

n Juzgado de Parral, AZ 66.124 (»Asociación Ilícita, Efraín Vedder«), Bd. I, Bl. 589. Richterliche Vernehmung von Hannelore Bensch am 27.05.2005. 
Bis Mitte der 1980er Jahre hatten sich die bundesdeutschen Behörden passiv und beobachtend verhalten und nur zaghafte Schritte in Richtung einer Untersuchung der Verhältnisse in der CD unternommen. Die erfolgreichen Fluchten von Hugo Baar im Dezember 1984 sowie des Ehepaars Lotti und Georg Packmor im Februar 1985 markierten in dieser Hinsicht eine Zäsur. Hugo Baar war einer der Mitgründer der CD und ein langjähriger enger Vertrauter Schäfers. Auch das Ehepaar Packmor war in Vertrauensstellungen tätig gewesen - Georg Packmor im Steinbruch der CD in Bulnes und Lotti Packmor am Eingangstor der CD. Alle drei verfügten aus erster Hand über umfangreiche und detaillierte Kenntnisse über die Verhältnisse innerhalb der CD. Beide Fluchten unterstützte der inzwischen im südchilenischen Los Ángeles lebende CD-Mitbegründer Heinz Kuhn tatkräftig. Sowohl Baar als auch die Packmors flüchteten nicht in die deutsche Botschaft, da sie fürchteten, die CD-Leitung könne so von ihrer Flucht erfahren und diese vereiteln. Hugo Baar reiste, ohne die Botschaft zu kontaktieren, im Dezember 1984 über Argentinien in die Bundesrepublik und schickte der Botschaft im April 1985 einen 34-seitigen Bericht über die CD. ${ }^{189}$ Das Ehepaar Packmor begab sich in die kanadische Vertretung in Santiago. Erst nach einem Telefonat des kanadischen Botschafters mit seinem bundesdeutschen Kollegen stimmten sie einem Besuch der deutschen Botschaft zu. Dort sprachen beide ihre Erfahrungen in der CD auf Tonband ein. ${ }^{190}$

Die CD reagierte auf die Fluchten mit verleumderischen Dossiers. Darin listete sie Aussagen anderer Colonos auf, mit denen die vermeintliche Charakterlosigkeit der Geflüchteten belegt werden sollte. ${ }^{191}$ Hugo Baar selbst berichtete bei einer Vernehmung von dieser Vorgehensweise, die er bereits kannte:

»Es ist üblich, wenn jemand durch Flucht die Kolonie verläßt, daß hinsichtlich dieser Person eine Akte angelegt wird. In dieser Akte wird alles, was an Wahrheiten, Teilwahrheiten und Lügen über diese Person seitens der übrigen Koloniemitglieder berichtet wird, zusammengetragen. Ziel des Ganzen ist es, die Person dann in einem äußerst ungünstigen Licht erscheinen zu lassen. Die Person wird als ein Mensch äußerst niedrigen und miesen Charakters dargestellt, zudem als kranke oder krankhaft veranlagte Person, deren Weggang von der Kolonie im übrigen kein Verlust darstellt. Dies beruht alles auf der Initiative des Paul Schäfer. Dieser mißbraucht auf diese Weise »als alleiniger Seelsorger aller in dieser Kolonie« das Beichtgeheimnis, zumal alle Koloniemitglieder sich ihm gegenüber verpflichtet haben, ihm alles anzuvertrauen, was sie über ein anderes Mitglied der Kolonie in Erfahrung gebracht haben, unabhängig davon, ob dies der Wahrheit entspricht. « ${ }^{192}$

Die Fluchtberichte von Hugo Baar und dem Ehepaar Packmor wurden dem Bundesjustizministerium übergeben und führten 1985 zur Eröffnung des Ermittlungsverfahrens

189 PA AA, B 83, Bd. 2384. Bericht von Hugo Baar an die deutsche Botschaft vom 02.04.1985.

190 PA AA, B 83, Bd. 2384. Transkription der Tonbandberichte von Georg und Lotti Packmor an die deutsche Botschaft vom 15/17.03.1985.

PA AA, AV NA 31578. SBED, Persönlichkeit und Lebensstil der Geliebten, Frau Packmor. Ebd., Aufzeichnungen zu Ceorg Packmor. Ebd., Streng vertraulicher Bericht über Hugo Baar und Lotte Packmor. 
der Staatsanwaltschaft Bonn wegen "Freiheitsberaubung, Körperverletzung usw.« gegen Paul Schäfer und ab 1988 gegen Hartmut Hopp, Gisela Seewald und Hugo Baar (vgl. Abschnitt 5.3.4).

\section{Der Fall Jürgen Szurgelies}

Im April 1988 erhielt die Botschaft Kenntnis von einem Fluchtversuch von Jürgen Szurgelies. Dies führte erstmals zu einer juristischen Initiative der Botschaft, die jedoch erfolglos und ein Einzelfall blieb. Am 30. April 1988 stellte Botschaftsrat Spohn bei der CA Chillán einen Schutzantrag zugunsten von Jürgen Szurgelies. ${ }^{193}$ Die CD reagierte mit einem eigenen Schutzantrag zugunsten des 24 -jährigen Szurgelies, gestellt durch seine ebenfalls in der CD lebenden Eltern. ${ }^{194}$ Jürgen Szurgelies schloss sich schließlich schriftlich dem Schutzantrag seiner Eltern an. Sie beantragten, den Schutzantrag der Botschaft zurückzuweisen und argumentierten, aufgrund von Komplikationen bei der Geburt leide ihr Sohn unter körperlichen und psychischen Störungen. Der Arzt der CD Hartmut Hopp unterstützte die juristische Gegenoffensive mit einer ausführlichen ärztlichen Bescheinigung über Szurgelies' psychischen Zustand:

»El facultativo que suscribe certifica que ]ürgen Szurgelies Selent [...] padece de retardo mental a raíz de un daño cerebral, producido por complicaciones gestionales: [...] A este cuadro de fondo, a los 15016 años, se agregó un franco deterioro del carácter, con manifestaciones psicóticas que se expresaron

- en el deseso obsesivo de querer morir, lo que lo motivó a varios intentos de suicidio;

- en el deseo irresistible de arrancar

- en ideas delirantes de índole religiosa. ${ }^{195}$

Das Gericht lehnte den Schutzantrag der Botschaft ab. Diese legte Berufung ein, scheiterte aber auch damit vor der Corte Suprema. ${ }^{196}$

Die erfolgreiche Flucht von Tobias Müller und Salo Luna im Juli 1997 hatte weitreichende Auswirkungen: Sie wurde zum Auslöser dafür, dass Schäfer die Siedlung verließ und in Argentinien untertauchte. Die Botschaft unterstützte Müller und Luna bei ihrer Ausreise nach Deutschland. ${ }^{197}$

\section{Nach Schäfers Abtauchen - der Fall Doris Gert}

Doch auch nach Schäfers Abtauchen wurden noch weitere Fluchtversuche vereitelt. Der letzte Fall dieser Art ereignete sich im Februar 2001, als die 32-jährige Doris Gert aus der CD flüchtete. Da die Suchtrupps der CD sie nicht unmittelbar auffinden konnten, stellte ihr Vater, der Colono Daniel Gert, bei der Polizei eine Vermisstenanzeige. Kurz darauf fanden die CD-Suchtrupps Doris Gert am Ufer des Perquilauquén-Flusses und brachten

193 PA AA, AV NA 31682. Der gesamte Aktenband behandelt den Schutzantrag CA Talca, AZ 659-1988. Der Schutzantrag von Walter Szurgelies und Matthilde Selent vom 11.05.1988, CA Talca, AZ 6641988, ist enthalten in PA AA, AV NA 31584.

195 PA AA, AV NA 31682. Ärztliche Bescheinigung unterzeichnet von Hartmut Hopp auf Briefkopf: Ministerio de Salud, Servicio de Salud del Maule, Hospital El Lavadero, vom 30.04.1988.

196 Corte Suprema, AZ 12.542-1988.

197 PJS, Sammlung AA. Vermerk »Ablauf einer Fluchthilfe« von Botschaftsrat Alexander Mühlen vom 05.08.1997. 
sie zurück in die Siedlung. Allerdings hatten die Medien inzwischen von dem Fluchtversuch erfahren und berichteten darüber. ${ }^{198}$ Rechtsanwalt Hernán Fernández, der seit 1996 die in der CD missbrauchten chilenischen Kinder vertrat, stellte einen Schutzantrag für Doris Gert. ${ }^{199}$ Dem Gericht gegenüber legte er dar, dass es sich bei ihrer Flucht nicht um einen Einzelfall handele und stellte den Vorgang in Zusammenhang mit einer Reihe vergangener Fluchtfälle. Fernández führte außerdem aus, das Kritierium zur Beurteilung der Freiheit (bzw. Freiwilligkeit eines Aufenthalts in der Siedlung) müsse in einem Kontext wie dem der CD nötigerweise die Existenz von Grundvoraussetzungen für eine freie Entscheidung sein, Erklärungen allein reichten nicht aus:

»No basta una simple declaración de voluntad o relato verbal o escrito para demostrar una condición de libertad. Es necesario que se demuestren las condiciones básicas de dicha libertad, particularmente cuando existen antecedentes históricos y presentes, que demuestran que en un determinado territorio, como ocurre en Colonia Dignidad, se restringe esta garantía constitucional, irrenunciable e indisponible. ${ }^{200}$

Der Schutzantrag wurde abgewiesen. Nach ihrer gescheiterten Flucht wurde Doris Gert ins CD-Krankenhaus verbracht und dort unter Tabletten gesetzt. In einem späteren Verfahren berichtete sie ausführlich über Art und Umfang der ihr dort verabreichten Medikamente:

»Era medicada con gran cantidad de pastillas que me mantenían durante todo el día adormecida, incluso llegué a tomar 20 pastillas al día, entre las que recuerdo OLANZAPINA, LUMINAL, DIAZEPAM, RAVOTRIL, ACIDO VALPROICO, NORMATOL (CABAPENTINA), AZULFIDINE, ALUMINIO HIDRATO. [...] por el estado en el que me encontraba con los medicamenteos, no intenté escaparme nuevamente. ${ }^{201}$

Freiheitsberaubung war das Kernverbrechen der internen Zwangsstruktur der CD. Fluchtfälle und Hilferufe fanden regelmäßig über vier Jahrzehnte hinweg (1962-2001) statt. Botschaft und AA wussten aus zahlreichen Vorgängen, dass Colonos gegen ihren Willen in der CD festgehalten wurden und häuften dutzende Aktenbände über diese Fälle an. Trotzdem wurde lange Zeit jeder Vorgang als Einzelfall betrachtet, ohne einen Bezug zu den vorangegangenen Fällen und ihrer Systematik herzustellen.

\subsubsection{Postzensur und -überwachung}

Mit ihrem Eintritt in die Gruppe um Paul Schäfer gaben die Colonos ihre individuellen Freiheiten auf. Sie unterwarfen sich dem von Schäfer und seinen Führungsmitgliedern definierten Gruppenwillen sowie dem dazugehörigen totalen Überwachungssystem. Dazu zählte auch der Verlust der Möglichkeit, unkontrolliert und unzensiert mit

198 Diario El Centro vom 07.02.2001, S. 1f. »Frustrada fuga desde Dignidad - joven mujer alemana fue recapturada por colonos«.

199 CA de Talca, AZ 336.906.

200 CA de Talca. AZ 336.906, Bd. I, Bl. 3ff. Schriftsatz RA Hernán Fernández. Interpone recurso de amparo.

201 Ministerio Público, Fiscalía Regional VII Región del Maule, AZ R.U.C. 1110006072-K. Polizeiliche Vernehmung Doris Cert vom 20.04.2011. Hervorhebungen im Original. 
der Außenwelt kommunizieren zu können. Die Führungsgruppe der CD wusste genau, dass jegliche Schilderungen der tatsächlichen Zustände in der Siedlung jederzeit zu einem Beweismittel werden konnten, das bei etwaigen Untersuchungen gegen sie hätte verwendet werden können.

Hugo Baar gestand nach seiner Flucht aus der CD 1984, Gerd Seewald und Ursula Schmidt bei der Postzensur unterstützt zu haben. ${ }^{202}$ Die Briefe der "nicht ganz $\mathrm{Zu}$ verlässigen« seien generell kontrolliert worden. Einschreiben seien zwar den Empfänger_innen ausgehändigt worden, allerdings zuvor geöffnet und »bei kritischem Inhalt« kopiert worden. Einfache Briefe (ohne Einschreiben) mit »kritischen« Inhalten seien gar nicht ausgehändigt, sondern lediglich »in der Akte des Betreffenden mit abgeheftet« worden.

Baar berichtete auch, wie sehr die Colonos die Überwachung internalisierten: »Weil die einzelnen wissen, daß ihre Briefe im Büro gelesen werden, womit im Fundo jeder einverstanden ist, gab es wenig Korrekturen.«Die Briefe seien nichtssagend gewesen und eine Qual für die Schreibenden. Er habe beispielsweise nicht den Angehörigen in Deutschland über seine Kinder schreiben dürfen, »weil wir durch das Getrenntleben nichts von unseren Kindern wußten, d.h. das Getrenntleben wurde auch allen Verwandten verschwiegen. «03

Lotti Packmor berichtete nach ihrer Flucht aus der CD 1985, wie Paul Schäfer die versammelte Gemeinde von der Notwendigkeit einer Überwachung der Korrespondenz überzeugte und diese durch eine pseudodemokratische Abstimmung legitimierte:

Verschiedene bundesdeutsche Behörden erhielten bereits sehr früh Hinweise auf die Überwachung und Zensur der eingehenden und ausgehenden Post in der CD, wie ein Beispiel von 1962 zeigt:

Ruth Rühl gehörte zu den Jugendlichen, die sich in Heide (Lohmar) der Gruppe um Schäfer angeschlossen hatte. Im Oktober 1962 schrieb ihre Mutter, Sidonie Rühl, einen Brief an das AA wegen der »Auswanderung « ihrer Tochter. ${ }^{204}$ Diese sei kürzlich, ohne sich zu verabschieden oder eine Anschrift zu hinterlassen, nach Chile ausgereist. Rühl fügte die Kopie eines Briefes ihrer Tochter Ruth bei. Diese hatte ihr im Juni 1962 geschrieben:

»Mutti, Du wirst erstaunt sein einen Luftpostbrief von mir zu erhalten. Ich bin bereits auf hoher See. Wenn Du in Zukunft keine Post mehr von mir bekommst, sieh es bitte als normal an. Es grüßt Dich, Ruth. ${ }^{205}$

Die Mutter bat das AA, die Auswanderung der Gruppe um Schäfer zu beobachten. Sie befürchte, »dass sich hinter dieser geheimnisvollen religiösen Organisation etwas anderes verbirgt. ${ }^{206}$ Die Gruppe fordere von ihren Mitgliedern eine Trennung von ihren Angehörigen. Rühl gab an, im Kontakt zu anderen Eltern zu sein, deren Kinder bei der

202 Für den gesamten Absatz: PA AA, B 83, Bd. 2384. Bericht von Hugo Baar an die deutsche Botschaft vom 02.04.1985, S. 15.

203 Ebd.

204 PJK, Ordner Hummel. Schreiben Sidonie Rühl ans AA vom 26.10.1962.

205 Ebd.

206 Ebd. 
Auswanderung ebenso verfahren seien. Aufgefallen sei ihr, dass auf dem Brief ihrer Tochter mit Siegburger Poststempel kein Absender vermerkt gewesen sei. Sie schrieb:

»Nach den verschiedenen letzten sehr netten Briefen meiner Tochter kommt mir dieser allerletzte und nicht einmal von ihr persönlich übermittelte, wie ein Schemabrief vor, den zu schreiben sie sie gezwungen werden, vielleicht sogar schon hier in Siegburg von ihrer Ausreise. Alle Post von drüben soll dem Vernehmen nach durch eine Zensur in Siegburg gehen, wo ein Herr Hugo Baar [...] sie in Empfang nimmt, öffnet, liest und evtl. weiterschickt, im übrigen aber die Auswanderung dieser Cruppe >)ugendheim Heide in Siegburg abwickelt, denn es sollen auch ganze Familien dabei sein, die noch ihre Haushalte auflösen müssen, was naturgemäß längere Zeit beansprucht. Wahrscheinlich hat meine Tochter nun, wie alle anderen schon seit 4 Jahren, endgültig ihre Angehörigen aufgeben müssen, um an der Auswanderung der Gruppe teilnehmen zu können. Ich kann es nicht glauben, daß der Text ihres letzten Briefes ihre eigenen Gedanken und Empfindungen ausdrückt und kann es einfach nicht fassen, ja finde es unmenschlich, daß sie nun in Zukunft nicht mehr an mich schreiben darf. ${ }^{207}$

Sidonie Rühl fügte ihrem Schreiben an das AA auch Kopien von vier weiteren Briefen ihrer Tochter bei, die in herzlichem Ton verfasst waren und persönliche Informationen enthielten.

Das für Auswanderungsfragen zuständige Bundesverwaltungsamt leitete Rühls Schreiben samt Anlagen wenig später an die Botschaft weiter, mit der Bitte, Näheres über die Gruppe in Erfahrung zu bringen, insbesondere »ob tatsächlich einzelne Mitglieder der >Privaten Sozialmission von jeder Verbindung mit ihren Familienangehörigen in der Heimat abgeschnitten werden «. ${ }^{208}$ Das Vorgehen, das Rühl schildere, gebe Anlass »zu erheblichen Bedenken«.

Botschafter Strack erstattete dem AA Anfang 1963 umfassend Bericht. Die Botschaft sei mehrfach vom Bundesverwaltungsamt sowie von Müttern angeschrieben worden, deren Kinder nach Chile ausgewandert seien und seitdem den Kontakt abgebrochen hätten. Strack schrieb: »Wie es sich nachher herausstellte, befanden sich alle Gesuchten auf dem Fundo der PSM bei Parral, etwa 300 Kilometer südlich von Santiago. ${ }^{209}$ Hermann Schmidt und Albert Schreiber (von der CD) seien mehrfach in der Botschaft gewesen und hätten über eine Verleumdungskampagne berichtet, die in der Bundesrepublik gegen die PSM im Gange sei. Schmidt habe beschrieben, dass in der Tat alle Briefe in der Siedlung gesammelt würden und dann von ihm persönlich in einem großen Umschlag an die PSM in Siegburg verschickt würden. Dort würden die einzelnen Briefe dann an die jeweiligen Empfänger_innen weitergeschickt. Strack schloss seinen Bericht mit den Worten, die Botschaft werde die Tätigkeit der PSM weiterhin beobachten.

Das AA leitete den Bericht des Botschafters an das Innen- und Justizministerium, das Ministerium für Familien- und Jugendfragen sowie das Bundesverwaltungsamt

207 Ebd.

208 Ebd., Schreiben des Bundesverwaltungsamts an die Botschaft vom 10.12.1962. Ein ähnliches Schreiben richtete das Bundesverwaltungsamt an den Innenminister von NRW. 
weiter - mit der Bitte um »Kenntnisnahme und Stellungnahme [...] und etwaige weitere Veranlassung «. ${ }^{210}$ Hugo Baar, der nicht mit nach Chile ausgewandert war und die PSM in Siegburg leitete, wurde daraufhin von der Kriminalpolizei vernommen. Er sagte aus, dass es sich beim Fall Rühl um eine innerfamiliäre Auseinandersetzung handele. Zwar sei es richtig, dass der Briefversand von und nach Chile gebündelt stattfände, dies geschehe jedoch lediglich aus Sicherheitsgründen, damit kein Schreiben verlorengehe. Er werde Ruth Rühl bitten, sich schriftlich an die Kriminalpolizei zu wenden, um die Sache aufzuklären. Wenige Tage später ging bei der Behörde ein Schreiben von Ruth Rühl an »Onkel Hugo« ein. Darin schrieb sie, sie sei entsetzt zu hören, dass sich ihre Mutter an das AA gewandt habe und fühle sich durch deren »heimliches Treiben« und ihre Lügen persönlich beleidigt. Sie habe den Kontakt zu ihrer Mutter aus freier Entscheidung abgebrochen, da sie sich hintergangen fühle. Ruth Rühl schrieb: „Meine Auswanderung und der Abbruch der Korrespondenz trafen zufällig zusammen. «Die Lebensweise ihrer Mutter sei beschämend und sie wolle nicht, dass ihr ihre Adresse mitgeteilt werde. ${ }^{211}$

Neben der polizeilichen Vernehmung kam es zu einem Gespräch zwischen Baar und dem Oberkreisdirektor des Rhein-Sieg-Kreises. Letzterer schrieb daraufhin an den Regierungspräsidenten in Köln, aufgrund der bisherigen Ermittlungen könne nicht mit Sicherheit festgestellt werden, dass die Angehörigen der PSM gezwungen worden seien, nach Chile auszuwandern. Ebenso sei nicht nachzuweisen, dass der Briefverkehr zwischen den Mitgliedern der PSM in Chile und ihren Angehörigen in Deutschland in unzulässiger Weise überwacht werde. Die Erklärung von Baar, dass es jedem selbst überlassen sei, unmittelbar mit seinen Angehörigen in Deutschland brieflich zu verkehren, erscheine glaubwürdig. ${ }^{212}$ Die Beobachtung der PSM wurde daraufhin eingestellt. Die Strategie der CD, die Postzensur als freiwillige Praxis zu beschreiben, war voll aufgegangen.

In den folgenden Jahren stellten verschiedene Bundesbehörden mehrfach eine Postzensur bei der CD fest. Dennoch unternahmen sie jahrelang nichts dagegen. So schrieb die Botschaft beispielsweise 1970 in einer Aufzeichnung an das AA:

»Die Vereinigung, die religiöses Sektierertum mit wohltätigen Bestrebungen verbin$\operatorname{det}[$ [...] ist nach außen hermetisch abgeschirmt.[...] Festzustehen scheint, daß die Freiheit der Mitglieder eingeengt ist, daß Briefkontrolle und ein Verbot, die Kolonie frei zu verlassen, besteht. «13

Trotz dieser deutlichen Feststellung über Straftaten unternahmen AA und Botschaft keine weiteren Schritte. Erst 1985 wurde der Vorwurf der Verletzung des Postgeheimnisses in der CD erstmals Bestandteil eines strafrechtlichen Ermittlungesverfahrens in der Bundesrepublik. Ausgangspunkt der Ermittlungen, die sich gegen Paul Schäfer

210 PA AA, B 82, Bd. 371. Schreiben AA (Dr. Werner) an das Innenministerium u.a. vom 08.02.1963, V 6 (505) $-88-4738$.

211 PA AA B 85, Bd. 598. Schreiben von Oberkreisdirektor Rhein-Sieg-Kreis an den Regierungspräs. Köln vom 19.03.1963 mit den Anlagen des Protokolls der Vernehmung von Hugo Baar durch die Kriminalpolizei vom 15.02.1963 und dem Vermerk über ein Gespräch des Oberkreisdirektors mit Hugo Baar vom 19.03.1963.

212 Ebd.

213 PA AA, AV NA 31581. Aufzeichnung Betr: Kolonie »Dignidad« vom 10.07.1970, AZ: RK V 4-88. 
richteten, ${ }^{214}$ waren die Berichte, die Hugo Baar und das Ehepaar Georg und Lotti Packmor nach ihrer jeweiligen Flucht aus der CD angefertigt hatten. Die CD nahm die Ermittlungen als staatlichen Angriff wahr und ging - wie häufig in solchen Fällen - sofort zum Gegenangriff über: Ihre Strategie bestand darin, die Glaubwürdigkeit der belastenden Zeug_innen Hugo Baar, Heinz Kuhn sowie Georg und Lotti Packmor zu untergraben. Sie wurden einer großen Bandbreite von Verfehlungen bezichtigt, die belegen sollten, dass die Geflüchteten die CD freiwillig verlassen hatten und diese nun aufgrund gekränkter Eitelkeit, Habgier und charakterlicher Schwächen verleumden würden. In einem »Protokoll der außerordentlichen Generalversammlung vom 26.10.1985« heißt es etwa zu Hugo Baar:

»Um seine Trunk- und Drogensucht in Deutschland vor dem Direktorium in Chile zu verbergen und seinen perversen Lebensstil abzusichern, den er durch Intrigen, Willkür und Cünstlingswirtschaft aufrechterhielt, übte HB [Hugo Baar, ]S] einen Psychoterror ohnegleichen gegen alle Mitarbeiter aus und bildete ein System der gegenseitigen Bespitzelung unter ihnen, wobei er über 16 Jahre lang Post- und Telefonkontrolle skrupellos manipulierte. [...]. Damit niemand die Zustande und den Psychoterror an das Direktorium nach Chile berichten konnte, hat $\mathrm{HB}$ allen Mitarbeitern die Postanschrift der Sociedad Dignidad in Chile vorenthalten und ihre Briefe nach Chile geöffnet, gelesen und zensiert, an die Schreiber zur Korrektur zurückgegeben oder gar nicht abgeschickt und das über die ganzen Jahre. (Delikt laut § 202 StCB.) Fast alle Mitarbeiter gaben es deshalb auf, an ihre Verwandten und Freunde nach Chile zu schreiben. ${ }^{215}$

Diese Strategie der Gegenbeschuldigung verfolgte auch Hartmut Hopp, der sie bei einer Anhörung im Deutschen Bundestag 1988 für die CD zu Protokoll gab. ${ }^{216}$ Das Ermittlungsverfahren wurde schließlich 1994 eingestellt, ohne dass die Staatsanwaltschaft Anklage erhoben hatte. In der Einstellungsverfügung ${ }^{217}$ greift die Staatsanwaltschaft die von der CD geschürten Zweifel an der Glaubwürdigkeit der Belastungszeug_innen auf. In der Verfügung heißt es zur Postzensur:

»Bezüglich der von Hugo Baar erwähnten Fälle der Verletzung des Briefgeheimnisses ist zu berücksichtigen, daß ein wirksamer Strafantrag gem. § 205 StCB nicht vorliegt. Zudem wären Straftaten in diesem Zusammenhang gleichfalls verjährt, zumal sich seine Angaben auf den Zeitraum bis zu seinem Ausscheiden im Jahre 1985 beziehen.«

Ähnlich wie die StA Bonn verfuhr auch die chilenische Justiz 1989, im letzten Jahr der Militärdiktatur. Auf Antrag des Außenministeriums wurde ein verwaltungsrechtliches Verfahren gegen die CD eingeleitet. ${ }^{218}$ Auch in diesem Verfahren wurden die Berichte von Baar und dem Ehepaar Packmor herangezogen. Der ehemalige Colono Heinz Kuhn

214 StA Bonn, AZ 50 ]s 285/85. Die Ermittlungen wurden im Februar 1988 auf Hartmut Hopp, Gisela Seewald und Hugo Baar ausgedehnt.

215 Zitiert nach Heller [Maier], Colonia Dignidad: von der Psychosekte, S. $241 f$.

216 PA-DBT 3127, 712 - UA 2 - 2451. Stenographisches Protokoll der 10. Sitzung des Unterausschusses für Menschenrechte und Humanitäre Hilfe vom 22.02.1988, Anlage Bericht Dr. Hopp. 
machte weitere belastende Aussagen. Er beschrieb beispielsweise, wie die eingehende Post in der CD mithilfe von Wasserdampf heimlich geöffnet wurde. Laut Angaben des Richters Hernán Robert Arias befragte das Gericht hierzu Hunderte CD-Mitglieder:

»Interrogados al efecto 255 colonos de la nombrada Villa, expresan uniformemente que pueden salir libremente del fundo, no teniendo limitaciones de ninguna especie. En cuanto a la correspondencia, deponen en forma conteste que no han tenido inconveniencia en su recepción o despacho. Añaden que no es efectivo que ellas sean controladas o leídas por las personas antes individualizadas. ${ }^{219}$

Im Rahmen der Ermittlungen wurde auch die Leiterin des Postamts von Parral befragt. Sie erklärte, dass die ans Postfach der SBED gerichtete Post nur von einigen wenigen CD-Mitgliedern abgeholt werden könne. Neben SBED-Präsident Hermann Schmidt seien dazu bevollmächtigt: Manfred Schmidtke, Helmut Seelbach, Hans Jürgen Blanck, Gerd Seewald, Kurt Schnellenkamp, Wolfgang Müller (Altevogt) und Hartmut Hopp. ${ }^{220}$

Welche Bedeutung Schäfer und seine Führungsgruppe der Postkontrolle beimaßen, belegt eine Aussage Heinz Kuhns gegenüber dem Richter Hernán Robert Arias. Demnach sei Hildegard Bohnau aus der CD nach Deutschland geschickt worden, um einen Brief zurückzuholen, den ihr Vater geschrieben und unkontrolliert aus der Siedlung an seinen Sohn in Deutschland geschickt hatte:

»En el año 1967 el sr. Bohnau escribió en forma oculta una carta la que despachó con una persona que estaba de visita, de esta carta supo Schäfer y él mando a la hija de Bohnau a rescatar esta carta, al domicilio de su hermano, esta nina se llamaba Hildegard Bohnau, la que fue a Alemania, y rescató dicha carta sin que su hermano se diera cuenta, volviendo con dicha carta al fundo. «221

\subsubsection{Missachtung des Rechts auf Schulbildung}

Das Grundrecht auf Schulbildung wurde für die in der CD lebenden Kinder systematisch missachtet. Die Colonia Dignidad verfügte über zwei Schulen: Eine interne Schule, die vom chilenischen Bildungsministerium nicht als Schule anerkannt war, sowie seit 1985 eine staatlich anerkannte und subventionierte Privatschule (»Escuela Particular Villa Baviera«), die für Kinder aus der Umgebung der Siedlung offen war. Letztere wurde zumindest bis 2005 nicht von Colonos besucht.

Die interne Schule der CD existierte seit 1962 als private Schule ohne staatliche Anerkennung. Am 08. Juli 1967 teilte die SBED den chilenischen Behörden deren Existenz formal mit. ${ }^{222}$ Dies führte jedoch nicht zu einer staatlichen Anerkennung durch

219 Juzgado de Letras de Parral, AZ 43.210. Informe sobre Investigación a Colonia Dignidad, Ministro en Visita Extraordinaria Hernán Robert Arias, Ministro I. CA Talca. o. D. Von Richter Robert am 31.07.1989 der Corte Suprema übergeben. Enthalten in: CA Santiago, AZ 2182-98 (»Asociación Ilícita«) Bd. I (2) (Parral), Bl. 585-676, hier Bl. 675f.

220 Ebd. BI. 615.

221 PA AA, Bd. AV NA 31690. Juzgado de Parral, AZ 43.210, Bd. 5, Bl. 2370f. Gerichtliche Vernehmung von Heinz Kuhn Fenster vom 21.06.1989.

222 Juzgado de Letras de Parral, AZ 43.210. Informe sobre Investigación a Colonia Dignidad, Ministro en Visita Extraordinaria Hernán Robert Arias, Ministro I. CA Talca. o. D. Von Richter Robert am 
das Bildungsministerium. Auch die deutschen Behörden wussten bereits früh von der Existenz dieser Schule. Dies geht u.a. aus dem Schreiben eines Botschaftsmitarbeiters von 1966 hervor:

»Die Botschaft hat [...] erfahren, daß die Söhne ihres Mandanten auf einer sSchuleく der Mission, die allerdings nicht von der chilenischen Behörde beaufsichtigt wird, in deutscher Sprache unterrichtet werden; ob diese Ausbildung regelmässig ist und deutschen Verhältnissen entspricht ist allerdings zweifelhaft. "223 $^{223}$

Das CD-Führungsmitglied Gerd Seewald fungierte jahrzehntelang als Direktor der Schule und gleichzeitig als Lehrer für Geschichte, Spanisch und Deutsch. ${ }^{224}$ Als einziger Colono seiner Generation nahm Seewald die chilenische Staatsbürgerschaft an, vermutlich zu dem Zweck, bei einer staatlichen Anerkennung der Schule offiziell als Schulleiter auftreten zu können. ${ }^{225}$ Während ihrer gesamten Existenz verfügte die Schule über keine einzige Lehrkraft mit staatlicher Lehrerlaubnis. Der Unterricht fand getrennt nach Geschlechtern statt. Gelehrt wurde nur, was in das vorgegebene Weltbild der CD-Führung passte. So berichten Colonos, dass Seewald »Anpassungen« der Lehrbücher vornahm, etwa in Geschichte ${ }^{226}$ oder bei den Themen Familie und Sexualität, ${ }^{227}$ die in der CD Tabu waren.

Während externen Besucher_innen gerne ein funktionierender Schulalltag präsentiert wurde, ${ }^{228}$ sah die Realität gänzlich anders aus: Der Schulunterricht fand nicht täglich statt und war nicht verpflichtend - entgegen der chilenische Verfassung, die Schulpflicht bis zum achten Jahrgang vorschrieb. Er fand nur statt, wenn keine für die Siedlung »wichtige Arbeit « anstand. Konsul Dieter Haller berichtete nach einem Besuch in der CD am 7. November 1987 über den Stellenwert der Schule in der CD:

»Das Leben in der CD wird um die Arbeit sherumorganisiert<. Sie steht im Mittelpunkt des Daseins. Es gibt zwar eine feste Aufgabenverteilung, diese wird, je nach Notwendigkeit, jedoch geändert. Der Arbeitstag beginnt um 7 Uhr morgens, er dauert im Sommer bis spät in die Dämmerung. Wochenende oder einen freien Tag gibt es nicht. Jeder ist gehalten, neben der ihm zugewiesenen Aufgabe dort anzupacken, wo gerade Not am Mann ist. Dies bedeutet: Ist am Wochenende im Restaurationsbetrieb in Bulnes ein überdurchschnittlicher Andrang zu erwarten, werden dorthin je nach Bedarf die benötigten Kräfte shinverlegt«. Der typische Wochenablauf eines jungen Mannes:

31.07.1989 der Corte Suprema übergeben. Enthalten in: CA Santiago, AZ 2182-98 (»Asociación Ilícita «) Bd. I (2) (Parral), Bl. 585-676, hier Bl. 650.

223 Archiv FDCL, Ordner misc 13. Schreiben der Botschaft Santiago (Attaché Woltmann) an die Rechtsanwälte des Vaters von Michael und Wolfgang Hühne vom 03.11.1966. RK V3 SK 9230.

224 CA Santiago, AZ 2182-98 (»Asociación llícita«), Bd. Ministro I (2), BI. 657. Curriculum Vitae Dr. Cerd Seewald Lefèvre.

225 PA AA, B 83, Bd. 2384. Bericht Hugo Baar an die Botschaft vom 02.04.1985, Anlage, S. 3.

226 CA Santiago, AZ 2182-98 (»Alvaro Vallejos Villagrán«), Bd. 8a, BI. 2764. Polizeiliche Vernehmung von Franz Baar vom 28.04.2005.

227 CA Santiago, AZ 2182-98 (»Alvaro Vallejos Villagrán«), Bd. 8a, BI. 2783. Polizeiliche Vernehmung von Harald Tymm vom 12.05.2005.

228 CA Santiago, AZ 10-2004 (»Adriana Bórquez«), BI. 481. Gerichtliche Vernehmung von Heinz Kuhn vom 16.06.2004. 
,Während der Woche bin ich Schneider, am Wochenende bin ich Kellner.< Wird die Ernte eingefahren, so werden Junge und Alte ebenfalls dort eingesetzt. >Man kann hier so lange zur Schule gehen, wie man wilk, sagt der 33-jährige Baar-Sohn Helmut. Auch 25-Jährige gingen noch zur Schule. Im Umkehrschluß: Schule ist dann, wenn es gerade keine Arbeit gibt. «229

Auch der 1989 von der Corte Suprema eingesetzte Sonderrichter Hernán Robert Arias stellte in seinem Abschlussbericht fest, dass er bei seinen diversen Inspektionen der CD keinen einzigen Schüler bzw. keine einzige Schülerin in der Schule angetroffen habe. Auch konnte ihm die Leitung der SBED kein einziges Schulabgangszeugnis vorlegen. Richter Hernán Robert Arias schloss daraus, dass das verfassungsmäßig garantierte Recht auf Bildung sowie die verpflichtende Teilnahme an der Grundschule in der CD nicht gewährleistet seien. ${ }^{230}$

Der Gouverneur der Region Maule, Francisco Meza Seco, beschrieb nach seiner Inspektion vom 31. Oktober $1990^{231}$ ähnliche Beobachtungen und Schlussfolgerungen:

»No existe formación religiosa, ni preparación para proseguir estudios secundarios, los profesores de la Escuela Alemana no poseen títulos de normalistas, básico o de Estado; los alumnos no revalidan títulos en escuelas alemanas o chilenas; no ha sido creado el Consejo de Profesores consultado en los estatutos. Concluye este informe que existe infracción al artículo 19, № 10 de la Constitución Política, sobre enseñanza básica obligatoria. ${ }^{232}$

Auch eine 1997 vom Familienausschuss der Cámara de Diputados durchgeführte Untersuchung zu Verletzung von Kinderrechten in der CD stellte Ähnliches fest: Die interne Schule der CD sei rechtlich nicht existent, das Recht der Kinder auf Bildung werde verletzt und die Grundschulpflicht missachtet. Zusätzlich führte der Bericht einige Fälle von Urkundenfälschung durch die CD auf: Chilenische Jungen, die das »Intensivinternat« der CD besucht hatten, erhielten von der CD erstellte, fiktive Schulzeugnisse der CD-Schule, die betrügerischerweise das Logo des Bildungsministeriums trugen. ${ }^{233}$

229 PA AA, AV NA 31583. Bericht Haller vom 10.11.1987, Betr: Besuch in der CD am 7.11.1987, RK 543.00, VS-V Anlage zum Bericht 1126/87 vom 11.11.1987 der Botschaft.

230 Juzgado de Letras de Parral, AZ 43.210. Informe sobre Investigación a Colonia Dignidad, Ministro en Visita Extraordinaria Hernán Robert Arias, Ministro I. CA Talca. o. D. Von Richter Robert am 31.07.1989 der Corte Suprema übergeben. Enthalten in: CA Santiago, AZ 2182-98 (»Asociación Ilícita $\ll$ Bd. I (2) (Parral), Bl. 585-676, hier Bl. 668.

231 PA AA Bd. AV NA 31597. DB Nr. 592 von Botschaftsrat Kliesow vom 07.11.1990.

232 Zitat aus dem 34-seitigen Inspektionsbericht von Mesa Seco wiedergegeben im Bericht des Untersuchungsausschusses vom 1995. Cámara de Diputados, Diarios de Sesiones, Legislatura 332, Sesión 33a, 06.12.1995a en miércoles 6 de diciembre de 1995, Informe de la Comisión Especial Investigadora de la Cancelación de la Personalidad Jurídica de Colonia Dignidad, creada con el objeto de verificar la forma como se dio cumplimiento al decreto supremo que disolvió esa institución, S. 41f.

233 Cámara de Diputados, Informe de la Comisión Investigadora encargada de velar por el cumplimiento de las recomendaciones aprobadas por la H. Cámara de Diputados, en relación con la ex Colonia Dignidad vom 13.08.1997, online unter https://www.camara.cl/camara/media/docs/colonia 102.pdf(zuletzt abgerufen am 12.02.2018), S. 56. 
Trotz mehrfacher Feststellungen unterschiedlicher Behörden über die Missachtung der verfassungsmäßig verankerten Schulpflicht in der CD, setzte sich dieser Rechtsbruch in der CD bis zur Festnahme Schäfers 2005 fort. Erst danach haben viele Colonos in externen Bildungseinrichtungen Anpassungskurse besucht, ganze Schuljahre nachgeholt und dabei Primar- und teilweise auch Sekundarschulabschlüsse absolviert.

Neben der internen Schule für die Kinder der Colonos betrieb die SBED ab 1985 eine staatlich anerkannte und subventionierte Privatschule, die von Kindern aus der Umgebung der CD besucht wurde. Diese Schule war Teil der sozialen Fassade der CD. Sie wurde am 20. März 1985 von Lucía Hiriart de Pinochet, der Ehefrau des Diktators, eingeweiht. ${ }^{234}$ An der Feier nahmen viele örtliche Vertreter deutscher Unternehmen und Verbände teil. Die CD-Führung hatte auch den Bayerischen Ministerpräsidenten Franz-Josef Strauß zur Einweihungsfeier eingeladen, der jedoch aus Termingründen absagte. ${ }^{235}$ Botschafter Holzheimer schrieb in einem Vermerk über ein Telefonat mit dem Strauß-Vertrauten Prof. Lothar Bossle:

»Zur Einweihung der selbstgebauten Schule am 20. März'85 werden Herr Rudek, Präsident des Deutschen Schulverbands Santiago, und Herr Thümmler, Vertreter der Deutschen Bank in Santiago die Colonia Dignidad besuchen. ${ }^{236}$

Seit dem 27. Februar 1986 war die Schule staatlich anerkannt und erhielt fortan staatliche Zuschüsse. ${ }^{237}$ Die Escuela Particular Villa Baviera, so der offizielle Titel, befindet sich auf dem Zufahrtsweg zur CD, einige Kilometer vom Eingangstor der Siedlung entfernt. Im Zuge der beabsichtigten Auflösung des Vereins SBED im Januar 1991 stellte die chilenische Regierung ihre gesetzlich festgelegten Unterstützungszahlungen an die Schule ein. Die CD betrieb die Schule jedoch dennoch weiter. 1995 übertrug die CD die Trägerschaft der Schule an den neu von ihr neugegründeten Verein Organización de Desarrollo Social Perquilauquén. Dieser betreibt die Schule bis heute. Viele der Kinder der Colonos besuchen die Escuela Particular Villa Baviera noch heute.

\subsubsection{Arbeitsverhältnisse}

Unentlohnte Arbeit war von Beginn an ein integraler Bestandteil und Grundvoraussetzung für das Fortbestehen der Colonia Dignidad. Für das Funktionieren der CDStrukturen hatte sie vielfältige Funktionen: Erstens diente sie der Disziplinierung der Colonos. Sie war Anlass für alltägliches Überwachen und Strafen und sollte die Colonos davon abhalten, auf »dumme Gedanken« zu kommen. Zweitens erwirtschaftete die CD mit der unbezahlten Arbeit der Colonos massive Profite. Die so generierten Einnahmen

234 Vgl. u.a. La Nación vom 21.03.1985, S. 6: »Primera Dama inauguró escuela en Dignidad«.

235 PJS, Sammlung Gesprächsnotizen. Notiz des Cesprächs des Verfassers mit Dr. Brügmann, Archiv der Hans Seidel Stiftung vom 05.12.2011.

236 PA AA, AV NA 31577. Vermerk des Botschafters Holzheimer vom 20.03.1985.

237 PA AA, AV NA 31620. O. A. [Vermutlich Bildungsministerium oder Consejo de Defensa del Estado] "Sociedad Benefica y Educacional Dignidad - Infracciones a las disposiciones legales vigentes en materia de educación « [vermutlich entstanden in der Vorbereitung auf das Dekrets zur Auflösung der SBED]. 
ermöglichten es der CD, ihr kriminelles System weiter auszubauen und nach innen und außen abzusichern.

Bereits in der Bundesrepublik hatte die Gruppe ein System der Arbeit jenseits des offiziellen Arbeitsmarktes etabliert. Die »Kreuzler« - also jene Vollmitglieder der Gruppierung, die in Siegburg lebten - stellten ihre Arbeitskraft ohne Lohn oder Sozialversicherung zur Verfügung: Einige arbeiteten in den Einzelhandelsgeschäften oder Transportunternehmen der Führungsmitglieder, andere errichteten das Jugendheim in Heide (Lohmar). Wieder andere führten externe Tätigkeiten und Dienstleistungen aus. Das Geld, das sie hierfür einnahmen, floss direkt in die von Paul Schäfer und Alfred Schaak verwaltete Gruppenkasse, wie im Falle von Ida Gatz:

»Ida wird nach Allenbüttel geschickt zur Familie Schmidt, die einen Laden besitzt und zu Schäfers Gemeinschaft gehört. Ida versorgt den Haushalt und hilft im Geschäft. Ihr Gehalt geht direkt an Paul Schäfer bzw. an Alfred Schaak. Wie hoch es ist, weiß sie nicht. ${ }^{238}$

»Arbeit ist Gottesdienst « ${ }^{239}$ lautete einer von Schäfers Leitsprüchen. Damit stellte er die sklavenähnlichen Arbeitsverhältnisse in der CD als eine Art religiösen Imperativ dar. ${ }^{240}$ Der Verweis auf Gott legitimierte das ausschließlich von Schäfer und der CDFührungsgruppe definierte, von Unfreiheit, Zwang und Willkür geprägte Arbeitsleben. Gleichzeitig rechtfertigte der pseudoreligiöse Bezug ein Arbeitsleben jenseits arbeitsrechtlicher Regeln und Gesetze. Die Colonos kannten keine Arbeitsverträge, erhielten keinen Lohn, führten keinerlei Beiträge $a b$ und erwarben auch keine Ansprüche auf Renten- oder Sozialleistungen. Das Arbeitsleben begann bereits im Kindesalter. Die Colonos wurden je nach Willkür der CD-Führung dort eingesetzt, wo diese es gerade für wichtig erachtete. Die Arbeitenden wurden von anderen Colonos angelernt und oftmals parallel in mehreren Arbeitsbereichen eingesetzt. Der Arbeitstag hatte keine feste zeitliche Begrenzung. In der Regel bemaß sich die Länge einer Arbeitsschicht nach den Erfordernissen der jeweiligen Tätigkeit, sprich: es musste gearbeitet werden, bis die Aufgabe erledigt war. Freie Tage waren nicht vorgesehen, »Ruhetage " gab es nur, wenn aus Sicht der CD-Führung keine Arbeit »erforderlich« war. Schon Kinder mussten in der CD hart arbeiten, wie der Colono Friedhelm Zeitner berichtete:

238 Fröhling, »Unser geraubtes Leben«, S. 89.

239 Die Colona Gudrun Müller (geb. Wagner) berichtet: »Er hat immer gesagt: Arbeit ist Cottesdienst, und wir haben gearbeitet von früh bis in die Nacht. «Vgl. Hollenbach, Michael. Das Leben nach der Sekte. Ehemalige Mitglieder der Colonia Dignidad in Deutschland, in: Deutschlandradio Kultur vom 24.05.2014, online unter: https://www.deutschlandfunkkultur.de/traumata-das-leben-nach-d er-sekte.1278.de.html?dram:article_id=287257.

240 Die Grundlagen für dieses pseudoreligiöse Verständnis von Arbeit wurden in der Anfangsphase der Cruppierung in den 1950er Jahren in Siegburg gelegt. Dort wurde die Arbeit zur Bedingung für eine Aufnahme in den engeren Kreis der Cruppe. Die »Kreuzler«, die im Missionshaus in Siegburg wohnten und arbeiteten, erhielten schon damals lediglich Unterkunft, Verpflegung und Kleidung. Wer außerhalb arbeitete, musste seinen oder ihren Lohn an die Gemeinschaft abtreten und durfte lediglich zehn Mark Taschengeld behalten. Bei der Neuaufnahme als »Kreuzler musste man unterschreiben, nach einem eventuellen Austritt aus der Gemeinschaft keinerlei finanzielle Forderungen zu stellen. Vgl. Cemballa, Gero. Colonia Dignidad: ein Reporter auf den Spuren eines deutschen Skandals, Frankfurt a.M. 1998, S. 72. 
»Debí trabajar duramente desde los 8 años y seguir el ritmo de otros jóvenes que tenían hasta 11 años más que yo. Trabajábamos con pala, chuzo, picota, haciendo canales de riego, cercos, caminos, juntando piedras y troncos en los campos. A los 18 años, en 1981, empecé a aprender un oficio: tornero mecánico, soldador y constructor. Trabajé en eso 14 ó 15 años, siempre con un maestro alemán: reparé herramientas y maquinarias agrícolas, camiones y maquinarias pesadas; construimos máquinas nuevas, como harneros y cintas para la planta chancadora. No existía un horario de trabajo. Trabajábamos desde las 8:00 hasta las 22:00 y a veces hasta la medianoche, todos los días, incluidos sábados y domingos. Desde 1985 fuimos todos los domingos a Bulnes, a trabajar de garzón, atendiendo a la gente en el restaurante de la colonia, sin contrato de trabajo. Nunca se nos pagó nada. ${ }^{241}$

Es gab auch keinerlei Ruhestand im Alter. Ein anderer Colono, Heinz Kuhn, berichtete, dass Alte, die keine schwere körperliche Arbeit mehr vollbringen konnten, in anderen Bereichen arbeiten mussten: »Los ancianos trabajaban hasta sus últimos días, como no podían trabajar en trabajos pesados, los mandaban a la cocina o a la sastrería, pero trabajan todos. $\ll^{242}$

Neben der Produktions- und Ertragsfunktion diente die Arbeit auch der Disziplinierung und Unterwerfung der Colonos. Aufgrund der langen und anstrengenden Arbeitstage in Verbindung mit systematischem Schlafentzug, befanden diese sich oftmals in einem Zustand extremer Erschöpfung, ${ }^{243}$ was ihre Unterwerfung unter die Regeln des Zwangskollektivs ${ }^{244}$ begünstigte.

Bereits in den 1960er Jahren stellten chilenische Behörden fest, dass die Arbeitsverhältnisse in der CD nicht im Einklang mit der chilenischen Gesetzgebung standen. Im Februar 1968 verglichen der Intentendent von Linares, Hector Taricco Salazar und der Gouverneur von Parral, Claudio Fuentes Avello die Arbeitsbedingungen in der CD mit denen beim Bau ägyptischer Pyramiden oder der chinesischen Mauer. Sie gaben im Senat zu Protokoll, in der CD müssten sogar Kinder arbeiten und gebe es weder Arbeitsrechte noch Löhne:

»Dentro de la Colonia, Ilámense colonos, socios o protegidos, no rigen las Leyes del trabajo. Alli no hay horario de trabajo conforme a nuestras leyes, ni los menores y mujeres están protegidos por las normas que gobiernan a los chilenos en materia laboral; alli no hay accidentes del trabajo, porque el que muere en el trabajo muere fortuitamente y a veces se les entierra sin autopsia: allí no hay salarios ni sueldos, pues todos, se dice,

241 Villarubia, Gustavo. »Mi vida bajo el régimen de Paul Schäfer«. La historia de uno de los guardaespaldas del líder de Colonia Dignidad [Interview mit Friedhelm Zeitner], in: CIPER (Website), 23.09.2013, online unter https://www.ciperchile.cl/2013/09/23/"mi-vida-bajo-el-regimen-de-paul-sc hafer".

242 CA Santiago, AZ10-2004 (»Adriana Bórquez«), Bd. II, BI. 480ff. Richterliche Vernehmung von Heinz Kuhn vom 16.06.2004.

243 Die Colona Irmgard Wagner berichtete: »Von morgens halb fünf bis nachts um zwölf, eins, dann hatten wir drei Stunden für uns und dann ging es wieder weiter. Da hat uns keiner gefragt, ob wir geschlafen haben oder nicht. Ich bin selber beim Gehen eingeschlafen. «Vgl. Hollenbach, Das Leben nach der Sekte.

Die Bezeichnung geht zurück auf Heller, Colonia Dignidad - ein stabiles Zwangskollektiv. 
trabajan en comunidad, y el presidente de la Sociedad, que al mismo tiempo es codueño del predio, distribuye a cado uno lo que necesita, le da habitación, vestuario, comida etc. Con el mismo sistema se construyeron las Pirámides de Egipto y la Muralla China. ${ }^{245}$

Chilenische Politiker_innen vermuteten, dass die CD oder genauer ihr Verein, die SBED, ihren gemeinnützigen Status ausnutze, um wirtschaftliche Gewinne zu erzielen ohne Steuern abzuführen. Daher sollte auch ein 1968 von der Cámara de Diputados eingesetzter Untersuchungsausschuss verschiedene Unregelmäßigkeiten in der CD klären. In seinem Abschlussbericht betonte der Ausschuss, auch die CDBewohner_innen seien als Arbeiter_innen einzustufen und zitierte dazu aus einem eigens angeforderten Bericht der Dirección del Trabajo (Arbeitsbehörde): »Las personas que prestan servicios en la corporación de derecho privado sSociedad Benefactora y Educacional Dignidad tienen la calidad de trabajadores y debe cumplirse a su respecto con la legislación social y previsional chilena.« ${ }^{246}$ Wenn auch nicht rückwirkend, so müssten aber zukünftig die chilenischen Arbeitgesetze eingehalten und das von den zuständigen Behörden kontrolliert werden. Allerdings geschah dies bis in die 1990er Jahre nicht.

Die CD begründete das Fehlen formalisierter Arbeitsverhältnisse mit der Selbstlosigkeit ihrer Mission. Deren Aufgabe bestünde darin, einer von Werteverfall geprägten Welt Würde und Anstand entgegenzuhalten. Auf die Frage eines Journalisten, ob der wirtschaftliche Erfolg der CD seine Ursache in der Sklavenarbeit habe, antwortete SBED-Präsident Hermann Schmidt 1979, die Siedlungsbewohner_innen seien freiwillig an jenem Ort, um Gutes zu tun und uneigennützig für die »Würde« des menschlichen Daseins zu arbeiten:

»Aquí nadie está a la fuerza. Todos se encuentran aquí porque quieren hacer el bien. Porque estiman que la vida mundana - después de todo lo que sufrieron - no tiene valor. Que hay valores más importantes en el ser humano. Y uno de ellos es la dignidad [...] Trabajamos por la dignidad del ser humano. No por la nuestra. $\ll^{247}$

Sämtliche Erträge der uneigennützigen sozialen Arbeit des Kollektivs - so die offizielle Version der CD - fließe in die wohltätige Arbeit der SBED. Die CD leugnete also nicht die Existenz ausbeuterischer Arbeitsverhältnisse, sondern beschrieb diese als frei gewählt und gemeinnützigen Zwecken dienend. Noch 1988 erklärte Hartmut Hopp bei einer Anhörung des Deutschen Bundestages:

245 PJS, Sammlung CD. Informe al Senado de Hector Taricco Salazar y Claudio Fuentes Avello, Verteidigungsrede des Intendenten von Linares, Hector Taricco Salazar und des Couverneurs von Parral, Claudio Fuentes Avello vor dem Senat in einem Verfahren um die Aberkennung ihrer Immunität vom 14.02 .1968 , S. 4.

246 Cámara de Diputados, Boletín de Sesiones, Legislatura Extraordinaria periodo 1968-1969, Sesión $12^{\mathrm{a}}$ vom 26.11.1968, S. 1133-1160. Informe de la Comisón Especial designada para investigar las actividades de la »Sociedad Benefactora y Educacional Dignidad« de Parral, hier S. 1138. Darin wird der Bericht $N^{\circ} 3598$ der Dirección del Trabajo vom 10.06.1968 zitiert. Eine Kopie dieses Berichts ist einsehbar in in PA AA, AV NA 31596.

247 La Segunda 22.08.1979, S. 25: »Hermann Schmidt: En Dignidad solo hacemos el bien«. 
»In der Presse wird von täglich 16 Stunden Zwangs- bzw. Sklavenarbeit gesprochen. Tatsächlich wird niemand zur Arbeit gezwungen, von niemand eine Ableistung bestimmter Arbeitszeit gefordert. Jeder erfüllt die von ihm übernommenen sachlichen Aufgaben nach besten Kräften in voller, eigener Verantwortung. Alle arbeiten im eigenen Betrieb, denn tatsächlich kommen die Früchte der Arbeit allen Mitgliedern und der gemeinsamen Aufgabe zugute. ${ }^{248}$

Die chilenische Arbeitsgesetzgebung fand in der CD faktisch keine Anwendung, wie eine von der Cámara de Diputados eingesetzte Untersuchungskomission 1995 feststellte. Aus deren Bericht geht auch hervor, dass die CD zur Begründung vorbrachte, die Bewohner_innen der Siedlung seien keine Arbeiter_innen oder Angestellte, sondern Mitglieder eines gemeinnützigen Vereins:

»Al momento de dictarse el Decreto Supremo $N^{0} 143$, la entonces Sociedad Benefactora y Educacional Dignidad, corporación de derecho privado, sin fines de lucro, se había acogido a las franquicias tributarias y aduaneras que la legislación contempla para las instituciones de beneficencia. Por ello no llevaba contabilidad técnica, no hacía declaraciones anuales de impuesto a la renta y realizaba importaciones exentas de derechos aduaneros, acogiéndose a la Partida 00.12 del Arancel Aduanero. Por otro lado la mayoría, por no decir todos los habitantes de Villa Baviera que trabajaban en los campos, talleres y empresas de la ex Colonia Dignidad, no tenían, a juicio de sus dirigentes, la calidad de trabajadores y, por consiguiente, no percibían remuneraciones ni estaban sujetos al pago de imposiciones previsionales ni a prestaciones de salud, bajo la interpretación de ser socios activos de la Corporación. En lugar de pagar sus cuotas, proporcionaban su trabajo personal a la Corporación, como miembros de ella. En consecuencia tampoco había constancia de que hicieran uso de vacaciones o feriado legal. En síntesis, no se aplicaba la legislación laboral.«²49

Dass es keinerlei Arbeitsverträge gab, bedeutete in der Praxis, dass sämtliche Erträge, die durch die Arbeit erwirtschaftet wurden, in die Kassen der CD-Führung flossen. Über diese Kassen legte die CD den Behörden gegenüber keinerlei Rechenschaft ab. Ein von Richter Hernán Robert Arias in Auftrag gegebener Bericht des Wirtschaftsprüfers Rodrigo Reyes Villagrán stellte 1989 fest, die CD führe keine interne Buchhaltung: »La Sociedad Dignidad no lleva ninguna contabilidad interna. ${ }^{250}$ Da Aussagen von Colonos jedoch die Existenz einer internen Buchhaltung belegten, stellte Robert Arias in seinem

248 StA Bonn, AZ 50 ]s 285/85, Bd. III, BI. 2ff. Stellungnahme Hartmut Hopps zur Anhörung des Unterauschusses für Menschenrechte und humanitäre Hilfe des Bundestags vom 22.02.1988.

249 Cámara de Diputados, Diarios de Sesiones, Legislatura 332 $2^{\mathrm{a}}$, Sesión 33 ${ }^{\mathrm{a}}$ vom 06.12.1995, S. 31-88. Informe de la Comisión Especial Investigadora de la Cancelación de la Personalidad Jurídica de Colonia Dignidad, creada con el objeto de verificar la forma como se dio cumplimiento al decreto supremo que disolvió esa institución, auch online unter https://www.camara.cl/camara/media/do cs/colonia/01.pdf, S. 60 (zuletzt abgerufen am 12.02.2018).

250 Juzgado de Letras de Parral, AZ 43.210. Informe sobre Investigación a Colonia Dignidad, Ministro en Visita Extraordinaria Hernán Robert Arias, Ministro I. CA Talca. o. D. Von Richter Robert am 31.07.1989 der Corte Suprema übergeben. Enthalten in: CA Santiago, AZ 2182-98 (»Asociación Ilícita«) Bd. I (2) (Parral), Bl. 585-676, hier S. 652ff. 
Abschlussbericht fest, die Buchhaltungsunterlagen seien ihm trotz seiner richterlichen Aufforderung nicht zur Verfügung gestellt worden. ${ }^{251}$

Noch vor dem offiziellen Ende der Militärdiktatur, ab 1988, übertrug die CD den Großteil ihres Vermögens auf eine Reihe von Aktiengesellschaften (vgl. dazu ausführlicher Abschnitt 3.2.3). Gleichzeitig wurde damit begonnen, formelle Arbeitsverhältnisse bei der chilenischen Sozialversicherung anzumelden. Fortan mussten Colonos regelmäßig Lohnzettel unterschreiben. Die Bezahlung entsprach meist dem gesetzlichen Mindestlohn. Die dadurch recht geringen Sozialversicherungsbeiträge wurden korrekt abgeführt, dennoch erhielten die Colonos keinen Lohn ausbezahlt. Sie kannten nicht einmal ihr fiktives Gehalt, das sie »freiwillig« in die CD-Kasse »zurückspendeten«, wie es offiziell hieß.252 Eine Anekdote zeigt, dass viele Colonos in jenen Jahren Geld überhaupt nicht kannten: Rechtsanwalt Daniel Martorell, der Ende der 1990er Jahre in dem Verfahren wegen sexuellen Missbrauchs an chilenischen Kindern den Staatsverteidigungsrat (CDE) vertrat, legte bei einer Zeugenvernehmung einem Colono einen Geldschein aus dem Spiel Monopoly vor. Er fragte den Zeugen, ob dies das Geld sei, mit dem er bezahlt werde, was der Colono bejahte. ${ }^{253}$ Eine tatsächliche Auszahlung der Löhne fand erst nach Schäfers Festnahme 2005 statt. Viele Colonos erhielten fortan den Mindestlohn, von dem Zahlungen, etwa Mitgliedsbeiträge für den Verein Perquilauquén abgezogen wurden. Die Vorstände der ABC-Aktiengesellschaften bekamen hingegen deutlich höhere Gehälter.

Während der ersten Jahre der Transición, also des Übergangs Chiles zur Demokratie, strengte der chilenische Staat eine Reihe von behördlichen Untersuchungen und Gerichtsverfahren gegen die CD wegen Steuerhinterziehung und Scheinverträgen (»contratos simulados«) an. ${ }^{254}$ Kurt Schnellenkamp wurde 2007 wegen Steuerhinterziehung in den Jahren 1986-1989 zu drei Jahren Haft auf Bewährung verurteilt. ${ }^{255}$ Das Verfahren wegen Scheinverträgen wurde eingestellt, nachdem der CDE 2009 mit den ABCUnternehmen eine Einigung getroffen hatte: ${ }^{256}$ Die Gesellschaften sollten Hypotheken

251 Ebd.

252 CA Santiago, AZ 2182-98 (»Asociación Ilícita«), Bd. III (Parral), BI. 1836. Richterliche Vernehmung von Michael Müller vom 02.09.2005.

253 Hevia/Stehle (Hg.). Colonia Dignidad: diálogos sobre verdad. Diálogo con el público, S. 148. (Antwort von Daniel Martorell auf eine Frage aus dem Publikum).

254 Innenstaatssekretär Belisario Velasco erklärte im Jahr 1999 vor einem Untersuchungsausschuss, dass seit dem Dekret zum Entzug der Rechtsperson der SBED im Jahr 199115 Behörden gemeinsam versuchten, eine lange Liste von Straftatbeständen aufzuklären und zu sanktionieren. In diesem Zusammenhang gebe es in jenem Moment 75 bei Cerichten anhängige Verfahren, darunter 27 Steuerdelikte sowie arbeitsrechtliche Verfahren und Verfahren wegen Scheinverträgen. Vgl. Cámara de Diputados, Boletín de Sesiones, Legislatura 340 a , Sesión $27^{\mathrm{a}}$ vom 10.08.1999, S. 124-169. Informe de las Comisiones Unidas de Derechos Humanos, Nacionalidad y Ciudadanía, y de Familia, encargadas de estudiar y fiscalizar cómo los distintos órganos públicos competentes han colaborado para el éxito de las investigaciones judiciales relativas a la ex Colonia Dignidad, auch online unter https://www.camara.cl/camara/media/docs/colonia/o4.pdf (zuletzt abgerufen am 12.02.2018).

255 13. Juzgado del Crimen de Santiago, AZ 96.447. Erstinstanzliches Urteil vom 21.04.2003. Bestätigung: CA Santiago, AZ 13.519-2007. Urteil vom 18.07.2007.

256 Ramírez, Pedro. "La negociación que entrega US\$6 millones para indemnizar a las víctimas de Schäfer«, in: CIPER (Website), 28.08.2009, online unter http://ciperchile.cl/2009/08/28/la-negocia 
auf einige ihrer Ländereien aufnehmen, um zukünftig Entschädigungen an Opfer zu zahlen. Bis heute (Stand: Mai 2021) sind jedoch trotz dieser Vereinbarung keine Gelder an Opfer geflossen, obwohl es diverse Urteile gibt, die entsprechende Entschädigungsansprüche festschreiben.

Nach Schäfers Festnahmen stellten mehrere Colonos im Rahmen des Verfahrens wegen Bildung einer kriminellen Vereinigung Strafanzeigen gegen Mitglieder der CD-Führung, die sich u.a. auf Sklavenarbeit in der CD bezogen. ${ }^{257}$ Der Rechtsanwalt und ehemalige Colono Winfried Hempel kündigte an, Chile und die Bundesrepublik Deutschland im Namen von 120 (Ex-)Colonos auf Schadenersatz zu verklagen. Auch diese Klage bezieht sich teilweise auf den Vorwurf der Sklavenarbeit. Eine weitergehende juristische Bearbeitung dieser Thematik ist bisher ausgeblieben. Die wenigen bisher existieren Untersuchungen belegen jedoch, dass die sklavenähnlichen Arbeitsverhältnisse in der $C D$ ein wichtiger ökonomischer Faktor für die kriminelle Organisation der CD waren.

\subsubsection{Unfälle und andere Vorfälle, teilweise mit Todesfolge}

Im Folgenden geht es im Wesentlichen um Unfälle und andere Vorfälle mit Todesfolge. In der Colonia Dignidad kam es zu einer großen Anzahl schwerer Unfälle, teilweise mit Todesfolge, über die zum Teil nur bruchstückhafte Informationen vorliegen. Einige von diesen ereigneten sich im Zusammenhang mit unter Zwang geleisteter, unentlohnter Arbeit in der CD, vor allem aufgrund unzureichender Sicherheitsstandards. $\mathrm{Zu}$ anderen Vorfällen kam es durch massive Überlastung, gezielte Überforderung oder extremen Druck, dem die Bewohner_innen ausgesetzt waren.

An dieser Stelle möchte ich einige Beispiele aus der langen Liste von Unfällen bzw. gruppeninternen Todesfällen vorstellen, die zum großen Teil nicht oder nur oberflächlich Gegenstand juristischer Ermittlungen oder sonstiger behördlicher Untersuchungen wurden. Dieser Umstand trug auch dazu bei, dass die Berichterstattung über diese Vorfälle von Spekulationen und falsch wiedergegebenen Details geprägt war. Den teilweise bis heute kursierenden und mitunter sich widersprechenden Erzählungen über diese Vorkommnisse möchte ich hier eine möglichst adäquate und quellengestützte Darstellung gegenüberstellen.

cion-que-entrega-us6-millones-para-indemnizar-a-las-victimas-de-schafer/ [Escritura pública zwischen dem CDE und den Vertretern von Cerro Florido und Abratec unterzeichnet am 21.08.2009]. für die Ehepaare Franz Baar und Ingrid Szurgelies sowie Andreas Schmidtke und Ruth Szurgelies (Juzgado de Parral, AZ 66.122). Richter Zepeda übernahm die Fälle an der CA Santiago, stellte sie dann aber ein. Am 16.04.2018 stellte RA Fernández erneut Strafanzeige für Franz Baar und Ingrid Szurgelies. Das Verfahren (CA Santiago, AZ 2174-2018) wegen »delitos de lesa humanidad de tortura, secuestro, lesiones, e imposición ilegitima de trabajos y contribuciones (esclavitud y prácticas análogas) y otros delitos de lesa humanidad que resulten acreditados durante el sumario penal« befindet sich derzeit noch im Stadium der Ermittlungen (Richter Mario Carroza, dann Richterin Paola Plaza). 
Am 30. Dezember 1963 starb der 18-jährige Colono Reinhard Mysliwietz. ${ }^{258}$ Die Zeitung El Diario Ilustrado berichtete am 13. April 1966, eine der fünf auf dem CDeigenen Friedhof begrabenen Personen sei »Reinhard Bedder«, der bei einem Arbeitsunfall ums Leben kam. Das Gericht in Parral, so die Zeitung, habe diesbezüglich eine Untersuchung »eingeleitet und abgeschlossen ${ }^{259}$ In der 1977 erschienenen Broschüre von Amnesty International werden auf Grundlage von Berichten der Geflüchteten Wolfgang Müller und Wilhelmine Lindemann Vermutungen angestellt, nach denen »Reinhard Weder (18 Jahre)« »Zu Tode geprügelt worden« sei. ${ }^{260}$ Viele Jahre später berichtete die chilenische Zeitung La Nación auf Basis von Gesprächen mit Reinhards Mysliwietz' Adoptivbruder Efraín Vedder, dass »Reiner Vedder Veuhoff starb als er von einem Stahlseil erschlagen wurde, das riss, als Holzstämme aus dem Wald geholt wurden. ${ }^{261}$

Die am 1948 geborene Ursula Schmidtke starb zu einem ungeklärten Zeitpunkt zwischen 1963 und 1965. Ihre Sterbeurkunde ${ }^{262}$ datierte der mit der CD befreundete Arzt Mario Mujica auf den 29. Mai 1965. Andere Quellen ${ }^{263}$ legen jedoch nahe, dass Ursula (»Ursel«) Schmidtke bereits früher starb und Mujica die Sterbeurkunde erst später ausstellte. Angeblich soll er die Leiche nie gesehen haben. ${ }^{264}$ Chilenische Medien berichteten 1966, nach Wolfgang Müllers Flucht aus der CD über Schmidtkes Tod. Laut Müller habe sie sich nicht an die Regeln der Gemeinschaft gehalten und sei daraufhin von Schäfer gegeißelt worden. ${ }^{265}$ Richter Bravo Ubilla ließ daraufhin die Leiche von Ursula Schmidtke exhumieren. ${ }^{266}$ Die Ergebnisse dieser Exhumierung sind nicht bekannt. Laut dem Bericht von Georg Packmor hatte Schäfer Ursel Schmidtke regelmäßig wegen vermeintlicher Verfehlungen bei Versammlungen bloßgestellt und verprügeln lassen. Eines Tages sei sie deshalb in Richtung des Flusses Perquilauquén gerannt, um zu fliehen. Später sei sie erschöpft am Flussufer aufgefunden worden und einige Tage darauf im Krankenhaus der CD an einer Lungenentzündung verstorben. ${ }^{267}$ Jüngere Berichte bekräftigen jedoch, dass Ursel Schmidtke direkt an den Folgen schwerer Prügelstrafen

258 Name und Daten laut Grabstein auf dem Friedhof der CD, Beobachtung des Verfassers vom Mai 2009. Er wird von diversen Quellen auch als Reinhard Vedder Veuhoff beichnet. Gründe für die unterschiedliche Nennung des Nachnamens sind mir nicht bekannt.

259 El Diario Ilustrado vom 13.04.1966, S. 6. »Aumenta el desconcierto en el caso de la Colonia >Dignidad««.

260 Amnesty International, Colonia Dignidad: deutsches Mustergut in Chile, S. 44 f.

261 La Nación vom 04.04.2004, S. 22. »Escapando del tío Paul«. Eigene Übersetzung.

262 Juzgado de Parral, AZ 66.124 (»Asociación Ilícita, Efraín Vedder«), Bd. I, BI. 485.

263 Heinz Kuhn berichte Richter Navas bei seiner Vernehmung im Jahr 1989 Ursel Schmidtke sei 1963 oder 1964 gestorben. PA AA, AV NA 31588. Richterliche Vernehmung von Heinz Kuhn Fenster vom 06.02.1989. Botschaftsanwalt Máximo Pacheco schrieb 1989 an Richter Navas: »no obstante haber fallecido en el año 1963, la inscripción de la muerte de la menor fue solicitada en 1965«. PA AA, AV NA 31589. Schriftsatz Pacheco vom 23.02.1989.

264 PA AA, B 83, Bd. 2384. Transkription des Tonbandberichts von Georg Packmor an die deutsche Botschaft vom 15.03.1985, S. 6.

265 VEA vom 14.04.1966, S. 8f. »Misterio y conjeturas en la colonia alemana de Parral« sowie El Diario Ilustrado vom 16.04.1966, S. 1. »Ordenan detener a todos los jefes de Colonia Dignidad«.

266 El Diario llustrado vom 23.04.1966, S. 6. »Exhumados cadaveres de cementerio de >Dignidad ««.

267 PA AA, B 83, Bd. 2384. Transkription des Tonbandberichts von Georg Packmor an die deutsche Botschaft vom 15.03.1985, S. 6 . 
gestorben sei, die angeordnet worden waren, um sie für ihr angebliches Fehlverhalten zu bestrafen. Im Anschluss sei im Krankenhaus eine Fieberkurve simuliert worden, um eine Lungenentzündung als Todesursache vorzuspiegeln. ${ }^{268}$ Der Colono Walter Laube habe in einer Versammlung zugegeben, Ursel Schmidtke zu Tode geprügelt zu haben. ${ }^{269}$ Da er dieses Eingeständnis jedoch erst kurz vor seinem Tod 2007 abgab, kann es sich auch um eine Schutzbehauptung handeln, um andere zu decken. Auch könnten weitere Colonos an der Tat beteiligt gewesen sein. Ein früherer Bericht nennt als »Augenzeugen« Heinz Kuhn, Rudolf Cöllen, Gerhard Mücke, Karl Stricker, Maria Strebe und Paul Schäfer. ${ }^{270}$

Am 10. Januar 1967 stürzte Wolfgang Müller Ahrend bei Bauarbeiten von einer Leiter und erlitt schwere Schädelverletzungen. Er wurde mit einem Hubschrauber der Luftwaffe nach Santiago geflogen und dort im J.-J.-Aguirre-Krankenhaus behandelt. ${ }^{271}$

Im August 1967 brachte Elfriede Gerlach in Gronau ihre drei Töchter Renate (13), Brigitte (9) und Gudrun (6) um und tötete sich anschließend selbst. ${ }^{272}$ Ihr Mann Helmut hatte sich der Gruppe um Hugo Baar angeschlossen. Elfriede Gerlach war dagegen und soll befürchtet haben, ihr Mann könnte die Kinder nach Chile bringen. Helmut Gerlach wanderte nach dem Tod seiner Familie in die CD aus.

Im Jahr 1973 erlitt Gerhard Laube schwere Verbrennungen bei einem Brand in einer Mühlenhalle in der CD. Laube hatte dort mit einer Hammermühle Magnesium und Salpeter für den Bau von Handgranaten zerkleinert. ${ }^{273}$

Im Jahr 1974 oder 1975 verunglückte der 13-jährige Gerhard Spatz bei einem Trampolinsprung und ist seitdem querschnittsgelähmt. ${ }^{274} \mathrm{Er}$ war gedrängt worden, für eine Vorführung auf der FITAL-Messe ${ }^{275}$ ohne Anleitung oder Hilfsmittel einen doppelten Salto einzü̈ben.

Am 2. September 1983 starb der 26-jährige Manfred Schaak. Er soll aus dem Dachstuhl der Schlosserei gestürzt sein. ${ }^{276}$

268 Die Sterbeurkunde gibt als Todesursache an: „Causa de desfallecimiento de corazón y de la circulación; neumonía de virus. «Juzgado de Parral, AZ 66.124 (»Asociación llícita Efraín Vedder«), Bd. 1, BI. 485. Registro Civil de Catillo. Certificado de defunción Ursula Schmidtke Zeitner.

269 PJS, Sammlung Gesprächsnotizen. Notiz des Gesprächs mit Werner Schmidtke vom 17.02.2017.

270 PA AA, B 83, Bd. 2384. Transkription des Tonbandberichts von Georg Packmor an die deutsche Botschaft vom 15.03.1985, S. 6.

271 La Nación vom 19.01.1967, S. 6. »No se han descubierto radios clandestinos en Colonia Dignidad« sowie El Siglo vom 19.01.1967, S. 4. »Periodistas a declarar por saffaire`Colonia Dignidad«.

272 Bild am Sonntag vom 16.08.1967. »Mutter tötete drei Kinder bei Camping-Spiel « sowie Stern Nr. 40/1967 vom 01.10.1967. »Angst vor der Sekte. Eine verzweifelte Mutter tötete sich und ihre drei Kinder.«

273 CA Santiago, AZ 10-2004 (»Adriana Bórquez«), BI. 482. Richterliche Vernehmung Heinz Kuhn vom 16.06.2004 sowie PJS, Sammlung CD. E-Mail eines Colonos an den Verfasser vom 24.04.2012.

274 Juzgado de Parral, AZ 66.124 (»Asociación Ilícita Efraín Vedder«), Bd. 1. Richterliche Vernehmung von Gerd Spatz vom 09.05.2005.

275 FITAL steht für Feria Internacional de Talca, Internationale Messe von Talca. Die CD hatte dort regelmäßig einen Stand.

276 PJS, Sammlung Dieter Maier. E-Mail von Dieter Maier an den Verfasser vom 06.09.2012 sowie PJS, Sammlung CD. Colonia Dignidad - die Opfer fordern Gerechtigkeit. Buch von Werner Schmidtke [unveröffentlicht], Ahaus 2016, S. 60. 
Am 2. Mai 1987 starb der 8-jährige Hartmut Münch bei einem nächtlichen Jagdausflug von Paul Schäfer und Manuel Contreras auf dem CD-Gelände. Richter Hernán González untersuchte den Fall ab 1997 im Rahmen eines Verfahrens wegen sexuellen Missbrauchs in der CD. ${ }^{277}$ Der von Gisela Seewald ausgestellte Totenschein nannte eine Gehirnblutung als Todesursache. Bei ihrer Vernehmung behauptete Seewald, die Blutung sei Folge eines Sturzes von einem Lastwagen gewesen. ${ }^{278}$ Die gerichtsmedizinische Untersuchung stellte jedoch Einschusslöcher im Schädel des Jungen fest. Andere Colonos, die an der Jagd teilgenommen hatten, bestätigten, dass ein »hoher Militär« bei der Jagd dabei gewesen sei. Dieser habe den Jungen erschossen, als er aufstand, um ein Rebhuhn aufzulesen. Richter González stellte das Verfahren gegen den untergetauchten Schäfer vorläufig ein, da die Fälschung des Totenscheins durch Gisela Seewald verjährt sei. Manuel Contreras leugnete, bei der Jagd anwesend gewesen zu sein. 2005 - die Tat war inzwischen verjährt - widersprach Hartmut Hopp der Darstellung von Contreras und erklärte:

»Acerca de Manuel Contreras [...] recuerdo haberlo visto en varias ocasiones, entre los años 1976 y 1980 en el fundo junto a otros militares con quienes y junto a Schäfer salían de caza al interior del fundo. Recuerdo que en una de esas cacerías, en el año 1985 [1988 ]S], Paul Schäfer me cuenta que durante la caza que efectuaba junto a Manuel Contreras se había producido un accidente en el cual resultó herido un menor. [...] me señaló que el Ceneral había asumido la responsabilidad y quería informar a la Policía pero él (Schäfer) lo convenció de que no lo hiciera. Schäfer ordenó a la doctora Gisela Seewald [...] que emitiera un certificado de defunción que indicara que la muerte del menor Hartmut Münch se debía a una caída accidental.« ${ }^{279}$

Hopp fügte hinzu, er habe bei seiner Vernehmung durch Richter González nicht darüber berichtet: »Este incidente no lo relaté al ministro González cuando me preguntó al respecto. ${ }^{280}$ Bei der Vernehmung von Hopp durch Richter González 1997 oder 1998 war die Tat noch nicht verjährt.

Am 11. Februar 1989 starb Horst Wöhri bei einem Flugzeugunfall in der CD, sein Kopilot Norbert Laube wurde schwer verletzt. Das Cessna-Kleinflugzeug der beiden geriet nach Angaben der CD bei einem Tiefflug über der Siedlung in ein Stahlseil und stürzte daraufhin ab. ${ }^{281}$ Die Botschaft berichtete am folgenden Tag nach Bonn, die Leitung der CD habe versucht, den Flugzeugabsturz zu vertuschen. Verdächtig sei, dass sie die Reste der Maschine sofort nach dem Absturz beseitigt hätte, noch bevor die von dritter Seite alarmierten Flugsicherungsbeamten vor Ort eingetroffen waren. Norbert Laube sei in ein Krankenhaus in Concepción gebracht worden und stehe unter ständiger Begleitung von Hartmut und Dorothea Hopp. Angehörige des Konsulats in Concepción hätten das Krankenblatt eingesehen und festgestellt, dass Laube erst ca. vier bis fünf

277 Juzgado de Parral, AZ 53.015 u.a.

278 Juzgado de Parral, AZ 53.015. Urteil vom 16.11.2004.

279 CA Santiago, AZ 2182-98 (»]uan Maino«), Bd. $2^{\text {a }}$, Bl. 989ff. Richterliche Vernehmung von Hartmut Hopp vom 26.05.2005.

280 Ebd.

281 El Mercurio vom 13.02.1989, S. A1 und A12. »Cayó avión de la Colonia Dignidad«. 
Stunden nach dem Unfall per Flugzeug eingeliefert worden war. Anscheinend sei also zunächst versucht worden, Wöhri und Laube in der CD zu behandeln. Wöhri sei nach dem Unfall noch am Leben gewesen, wie Zeugen der Presse berichteten. ${ }^{282}$ Die Zeitung El Mercurio berichtete, Wöhri habe noch in derselben Woche vor dem Untersuchungsrichter Guillermo Navas aussagen sollen. ${ }^{283}$ In den Verfahrensakten findet sich allerdings eine Aussage Wöhris gegenüber Richter Navas. Diese fand bereits drei Tage vor dem Absturz, am 8. Februar statt und ist wenig aufschlussreich. ${ }^{284}$ Unter den Colonos kursierten Gerüchte, vor dem Absturz sei ein Schuss zu hören gewesen. Allerdings gibt es hierfür bislang noch keine Belege. Eine andere These lautet, Wöhri habe viel über interne Vorgänge in der CD gewusst. Unter anderem fuhr er den Unimog bei der Jagd, bei der Hartmut Münch zu Tode kam (siehe oben). Im Oktober 1989 legte die Generalinspektion der chilenischen Luftwaffe einen Abschlussbericht zu dem Flugzeugabsturz vor. Sie belegte Rudolf Cöllen mit einem Bußgeld, da er durch die umgehende Beseitigung des Flugzeugwracks von der Unfallstelle die Ermittlungen behindert habe. Das Flugzeug sei in der Nähe der CD abgestürzt und die verstreut liegenden Flugzeugteile seien umgehend in die CD gebracht worden. Die Autopsie des Leichnams von Horst Wöhri ergab einen Blutalkoholwert von 0,96 Promille sowie Rückstände eines Diuretikums, das zur Behandlung von Bluthochdruck eingesetzt wird und möglicherweise seine Flugfähigkeit beeinträchtigt habe. Der überlebende Kopilot Norbert Laube wurde von Hartmut Hopp und seiner Frau aus Concepción wieder zurück in die CD gebracht und konnte nicht zu den Vorgängen befragt werden. Hopp stellte eine Bescheinigung aus, in der er Laube als vernehmungsunfähig einstufte. ${ }^{285}$

Am 13. Februar 2002 stürzte der 66-jährige Karl Stricker von einem Dach und starb. ${ }^{286}$ Obwohl er unter dem Einfluss starker Psychopharmaka stand, ${ }^{287}$ war er zu Dacharbeiten abkommandiert worden. Bei einem ähnlichen Unfall am darauffolgenden Tag stürzte Wolfgang Müller Ahrend und zog sich schwere Verletzungen $z u{ }^{288}$ Er wurde in das Unfallkrankenhaus (ACHS) nach Chillán verlegt, ohne dass ihm die Psychopharmaka mitgegeben wurden, an die er in hoher Dosierung gewöhnt war. Durch diesen »kalten Entzug« kam er in eine lebensbedrohliche Situation. Für die

282 PA AA, AV NA 31596. DB 72 vom 14.02.1989, Pol'Rk 543.00, Betr.: CD, hier: Flugzeugabsturz, Bezug: Tel. Durchgabe an Bereitschaftsdienst am 13.02.

283 El Mercurio vom 13.02.1989, S. A1 und A12. »Cayó avión de la Colonia Dignidad«.

284 PA AA, AV NA 31588. Juzgado de Parral, AZ 43.210, Bd. 1, BI. 752. Aussage von Horst Wöhri Wagner vom 08.02.89.

285 PA AA, AV NA 31637. Fuerza Aerea de Chile, Direccion General de Aeronautica Civil, Inspectoria General, Oficio No 902 vom [unlesbar] Oktober 1989, Obj: Accidente de Aviación que afecta al Piloto Sr. Horst Wohri Wagner.

286 El Mercurio vom 18.02.2002, S. C8. »Investigan muerte de colono alemán«. Vgl. auch Stehle, Jan. La muerte de Karl Stricker y la amnesia de Otto Dörr, in: CIPER (Website), 10.04.2018, online unter https://ciperchile.cl/2018/04/10/colonia-dignidad-la-muerte-de-karl-stricker-y-la-amnesia-de-ot to-dorr/sowie Narváez, Luis. »La profunda huella de Otto Dörr en Colonia Dignidad«, in: El Dinamo vom 10.04.2018, online unter https://www.eldinamo.cl/nacional/2018/04/10/la-profunda-huella-de -otto-dorr-en-colonia-dignidad/(zuletzt eingesehen am 10.05.2018).

287 Vgl. El Mercurio vom 19.12.2002, S. C11. »Colono que se cayó del techo estaba sedado - SML detectó hipnosedante en cuerpo de Karl Stricker«.

288 Vgl. Ercilla vom 04.03.2002, S. 32. »Extraños accidentes«. 
behandelnden Ärzte, die nichts von seiner Abhängigkeit wussten, war diese nicht erklärbar.

Am 15. März 2002 starb der 40-jährige Rolf Schaffrik bei einer Bergwanderung in der Nähe der Termas de Chillán an Unterkühlung, als eine plötzliche Schlechtwetterfront die 7-köpfige Gruppe überraschte. ${ }^{289}$

\subsubsection{Körperverletzungen}

Die ständige Ausübung physischer und psychischer Gewalt charakterisiert das Zwangssystem der CD, das der Aufrechterhaltung der internen Machtstrukturen diente. Die Gewalt wurde oftmals willkürlich eingesetzt - fast immer auf Anordnung Schäfers und folgte meist keiner rationalen Logik. Ziel war die Ausschaltung individueller Willenskraft und die vollständige Unterwerfung der Colonos unter das gemeinschaftsinterne Zwangssystem.

Prügelstrafen wirkten als alltägliches Mittel zur Disziplinierung Einzelner, und zugleich als abschreckende und einschüchternde Maßnahme gegenüber der Gruppe. Colonos, die eine »rebellische« Haltung an den Tag legten, sei es, dass sie zu fliehen versuchten oder aus irgendeinem anderen Grund bei Schäfer in Ungnade fielen, wurden missbräuchlicherweise und zwangsweise Psychopharmaka verabreicht - teilweise in sehr hoher Dosierung und über lange Zeiträume. Oftmals wurden sie gleichzeitig monate- oder gar jahrelang im Krankenhaus der CD eingesperrt. Misshandlungen mit Elektroschocks, oftmals in Verbindung mit dem Spritzen von Medikamenten, sollte die Sexualität der Colonos gewaltsam unterdrücken. $\mathrm{Zu}$ den grausamsten internen Verbrechen der CD gehören die Misshandlung von Jungen im sogenannten Neukra, dem »neuen Krankenhaus«, sowie die Misshandlung von Mädchen der sogenannten Vogelgruppe, bzw. lila Gruppe Ende der 1960er und Anfang der 1970er Jahre. Elektroschocks wurden auch zur Auslöschung von Erinnerungen eingesetzt. Der ab 2004 von der Bundesregierung zur Behandlung von Colonos eingesetzte Psychiater Niels Biedermann schreibt hierzu:

»Weiteres Mittel der Verhaltenskontrolle war die breit gestreute Verabreichung hoch dosierter Psychopharmaka, einschließlich Antipsychotika. Ohne jegliche psychiatrische Indikation und Begründung wurden diese oft über Jahre verabreicht, mitunter zur Strafe nach misslungenen Fluchtversuchen, vor allem jedoch anscheinend zur sozialen Kontrolle systemwidrigen Verhaltens. Sogar Elektrokrampftherapie wurde zu diesem Zweck eingesetzt. Es gibt viele Einwohner der Kolonie, unter ihnen vor allem Frauen, die als Kinder im Alter zwischen neun und zwölf Jahren Erinnerungslücken, amnestische Episoden, aufweisen. Hier liegt die Vermutung nahe, dass auch sie missbräuchlicher Elektrokrampfbehandlungen ausgesetzt wurden. « 290

289 Vgl. La Nación vom 16.03.2002, S. 8. „Congelado murió colono de Villa Baviera«.

290 Biedermann, Niels/Judith Strasser/Julian Poluda. »Colonia Dignidad« - Psychotherapie im ehemaligen Folterlager einer deutschen Sekte, in: Zeitschrift für Politische Psychologie, 14 (2006) Nr. 1+2, S. 111-127, hier S. 121. 
Im Folgenden beschreibe ich zunächst die Anwendung körperlicher Gewalt in der CD. Dann gehe ich auf die Misshandlungen mit Elektroschocks und Medikamenten ein, die vom Krankenhaus der CD ausgingen. Im Anschluss daran beschreibe ich die besonders brutale Episode von Gewalt, der Jungen und Mädchen Ende der 1960er und Anfang der 1970er Jahre ausgesetzt wurden. Zum Abschluss des Abschnitts gehe ich auf die bisher erfolgten Untersuchungen dieses Verbrechenskomplexes im Rahmen strafrechrechtlicher Verfahren ein.

\section{Körperliche Gewalt und Prügelstrafen}

Die systematische Anwendung physischer Gewalt z.B. als Bestrafung war in der CD alltäglich. Dies begann bereits in der Anfangszeit der Gruppierung in den 1950er Jahren in der Bundesrepublik. Das ehemalige CD-Mitglied Willi Georg schrieb dazu 1966:

»Herr Franz Schmidt aus Graz wurde, weil er aus dem Haus weggelaufen war, fast bewußtlos geschlagen mit abgeschnittenen Gummischläuchen. [...] In der Kinderfreizeit in der Jugendherberge Brilon i. Westf. wurden nicht nur Jungens, sondern auch Mädchen, weil sie angeblich Hurengeister hatten, geschlagen. [...] In Brilon gab Schäfer den sSchlägerauftrag` an die älteren Knappen ab und gab ihnen so den Weg frei zur Brutalität. ${ }^{291}$

Prügelstrafen waren fast immer die Konsequenz jeglicher (vermeintlicher) Missachtung der Gemeinschaftsregeln oder Moralvorstellungen, die allein Paul Schäfer definierte. Das Prügeln übernahm Schäfer selbst, die Herren ${ }^{292}$ oder die jeweiligen Gruppenoberen der Männer-, Frauen- und Kindergruppen. Manchmal kam es zu regelrechten Prügelritualen. Dabei wurden praktisch alle Colonos dazu gedrängt, auch selbst andere zu schlagen - so wurden sie Teil einer Kultur der Gewalt. Die 1985 aus der CD geflüchtete Waltraud Baar berichtete 1989:

»Es gehörte von Anfang an bis heute zur Erziehungsmethode SCHÄFERs, daß in den Cruppen geschlagen wird. In der Praxis sieht das so aus: Das Kind oder der Jugendliche, der z.B. gelogen hat, der unordentlich mit seinen Sachen umging, faul oder frech war usw., wird in die Mitte der Cruppe genommen und von den anderen Kindern zur Rede gestellt. Zwischendurch bekommt er immer wieder von den einzelnen Schlägen ins Gesicht, oder wo sie hintreffen. Bleibt diese Gruppenerziehung erfolglos ordnet SCHÄFER weitere >Sonderbehandlungen ‘ an: Harte Züchtigung von Älteren, Entfernen aus der Gruppe, bis hin zur Behandlung im Krankenhaus. «"293

Bereits ein Jahr zuvor hatte ihr ebenfalls aus der CD geflüchteter Ehemann Hugo Baar bei einer Anhörung im Deutschen Bundestag eine kollektive Prügelorgie gegen Peter Rahl geschildert:

291 PJK. Bericht von F. W. Georg vom 21.07.1966. »Abschrift«.

292 Als »Herren« wurden jene älteren Männer bezeichnet, die bereits verheiratet nach Chile kamen.

293 Archiv Al, Bestand CD. Bericht von Waltraud Baar an AA vom 09.02.1989. »Bericht über Freiheitsberaubung, Mißhandlung und Mißbrauch minderjähriger Jungen während meiner Jahre in der Sociedad Benefactora Dignidad in Chile«. 
»Dr. Hopp hat diesen Fall bis ins Einzelne miterlebt. Er hat, bevor der Junge gerufen wurde, noch eine kleine Einleitung gemacht, und zwar daß es sich bei Peter um einen erkrankten Mann handele. Dann wurde er vom Krankenhaus geholt, und als er einige Fragen gestellt bekam, ging es los unter dem Motto: Du lügst! Er hatte irgendeine Äußerung gemacht, und das ganze Drama der Schlägerei begann in fürchterlichster Weise, wie ich es nie vorher miterlebt hatte. Alle schlugen drauf und bis auf einige wenige Herren von den Älteren, die sitzenblieben, stand die ganze Gruppe um ihn herum. Wer ihn gerade dazwischen bekam, schlug ihn, ob ins Cesicht, oder aufs Kreuz, wohin auch immer. Er stürzte; er blutete. Schließlich hat man ihn dann hochgezerrt, ins Bad geführt, mit kaltem Wasser ein bißchen abgewaschen und versucht, die Blutspuren wegzuwischen. ${ }^{294}$

Die selektive Anwendung von Gewalt als Strafmaßnahme gehörte zu den vielen von Schäfer erfundenen Institutionen bzw. Mechanismen der Gruppierung. Regelverstöße führten zu einem vorübergehenden Ausschluss von Gemeinschaftsaktivitäten sowie zur kollektiven Bestrafung des/der »Schuldigen«. Hierfür wurden bestimme Bestrafungsregeln und -rituale festgelegt. Dazu gehörte das von Schäfer ersonnene »Bimmel und Bammel«-System: Danach hatte jeder kleine Junge (»Bimmel«) ab dem Alter von etwa acht Jahren einen eigenen Aufpasser, einen älteren Jugendlichen oder jungen Erwachsenen (»Bammel«) zur Seite. Diesen musste er ständig begleiten und dessen Anordnungen stets befolgen. Sogar um auf die Toilette zu gehen oder ein Glas Wasser zu trinken, mussten die »Bimmel« ihre jeweiligen »Bammel« um Erlaubnis bitten. Schon bei kleinsten Regelverstößen, etwa dem Nichtbefolgen von Anweisungen oder vermeintlich respektlosem Verhalten gegenüber Älteren, sollten die »Bammel« die »Bimmel« mit Schlägen bestrafen. Nach der erfolgten Bestrafung mussten die »Bammel« Paul Schäfer innerhalb von 15 Minuten persönlich den Grund der Bestrafung mitteilen. Allerdings konnten sich die »Bimmel« auch bei Schäfer über ihren »Bammel« beschweren, was mitunter zur Bestrafung der »Bammel « führen konnte. ${ }^{295}$

Innerhalb der Mädchen- und Frauenstrukturen kamen ähnliche Mechanismen zur Anwendung, über die es bislang jedoch weniger Quellen und Zeugnisse gibt. Alle Fäden des Netzwerks aus Überwachung und Strafen liefen bei Paul Schäfer zusammen. Die von ihm gewünschte Misstrauenskultur war nahezu total und führte zur vollständigen Vereinzelung der Individuen im Sinn von Verlust jeglicher Vertrauensbeziehungen, was letztlich Schäfers Herrschaftsstellung absicherte. Bei einer Vernehmung 2005 berichtete die Colona Edeltraut Baar darüber, dass Schäfer auch die Mädchen zu Prügelstrafen untereinander drängte:

294 PA-DBT 3127, 712 - UA 2 - 2451. Stenographisches Protokoll der 10. Sitzung des Unterausschusses für Menschenrechte und Humanitäre Hilfe vom 22.02.1988. Auch online unter http://coloniadigni dad-prot.blogspot.com/, S. 10/23f.

295 Vgl. Bericht von Friedhelm Zeitner wiedergegeben in: Villarubia, Gustavo. »Mi vida bajo el régimen de Paul Schäfer . La historia de uno de los guardaespaldas del líder de Colonia Dignidad«, in: CIPER (Website), 23.09.2013, online unter https://www.ciperchile.cl/2013/o9/23/"mi-vida-bajo-e I-regimen-de-paul-schafer"\%. 
»Respecto a los castigos físicos aplicados a los miembros de la villa [...] una vez creo que tenía cerca de 12 años de edad y entré de improviso a una habitación donde una niña de mi grupo que tenía un año menos se estaba cambiando de ropa, hecho que le conté a la tía que nos cuidaba, la cual le contó lo sucedido a Paul Schäfer quien me dió bofetadas. Además, por orden de Schäfer se me pegó por compañeras de grupo al igual que yo lo hice con otras. ${ }^{296}$

Schäfer inszenierte auch kollektive Bestrafungsrituale. Dabei wurden einzelne Colonos, denen Vergehen vorgeworfen wurden, vor den sogenannten »Herrenabend« oder vor andere Gruppen männlicher Colonos zitiert. Dort wurde ihr vermeintliches Fehlverhalten vorgetragen. Das Opfer wurde in einer inszenierten Verhörsituation mit seinen angeblichen Taten konfrontiert und anschließend von der Gruppe mit Schlägen misshandelt. Ein Colono beschrieb das System aus Angst und Isolation, zu dem diese Tribunale beitrugen:

»In schmerzhafter Erinnerung sind mir die vielen, harten Gruppenversammlungen geblieben, wo die einzelnen so in die Enge getrieben und angeschrien wurden, bis sie sich in Widersprüche verwickelten und dann der Lüge bezichtigt wurden. Daraufhin wurde derjenige von der ganzen Gruppe zusammen- und blutig geschlagen. Alle Vorfälle wurden fast immer öffentlich ausgetragen, so dass sich alle von dieser Person zurückzogen und sich selber fürchteten Widerstand zu leisten. Auf diese Weise wurde einer nach dem anderen isoliert. Meistens waren es solche Personen, die Schäfer die Wahrheit gesagt hatten und sich ihm nicht beugten. ${ }^{297}$

Bei einer richterlichen Vernehmung 1985 beschrieb Hugo Baar mehrere dieser Situationen, die er seit $1980^{298}$ erlebt hatte:

»Im Jahre 1981 befand sich Peter Rahl, ein Sohn der Schwester des Herrn Packmor, im Krankenhaus auf einem Einzelzimmer. Eines Tages wurde Peter Rahl auf Anweisung des Beschuldigten aus dem Krankenhaus zu einer Herrenversammlung geholt. Peter Rahl wurde dann von dem Beschuldigten [Paul Schäfer] und einigen Anderen Fragen gestellt. Dann schlugen sie unvermittelt auf ihn ein, d.h. sie traten mit den Füssen und schlugen mit den Fäusten ohne Rücksicht, wo die Treffer hingingen. Der Beschuldigte selbst beteiligte sich an den Mißhandlungen nicht, sondern heizte nur durch Worte die Atmosphäre noch an. Peter Rahl sah danach fürchterlich aus, er blutete stark und wurde dann zurück ins Krankenhaus gebracht. Einige Zeit später habe ich bei der Betreuung von Peter Rahl geholfen. Er befand sich in einem fürchterlichen Zustand. Ausgangspunkt für die Mißhandlung war ein Liebesverhältnis mit einer Krankenschwester. Im Krankenhaus ist Peter Rahl mit Medikamenten behandelt und auch geschockt worden. Dies konnte ich bei meinen wiederholten Besuchen feststellen. Er konnte nicht mehr alleine laufen. Wenn er im Bett lag, lief ihm der Speichel aus dem Mund.

296 CA Santiago, AZ 2182-98 (»Asociación Ilícita«), Bd. II (Parral), BI. 1661. Richterliche Vernehmung von Edeltraut Baar vom 09.06.2005.

297 StA Krefeld, AZ 3 Js 753/11, Bd. V, BI. 1225. Bericht eines Colonos: Einige Zeugnisse über mein vergangenes Leben in der »Colonia Dignidad«, September 2010.

298 Vermutlich hatte der vernehmende Richter Baar gebeten, nur von Misshandlungen seit $1980 \mathrm{zu}$ berichten, da diese noch nicht verjährt waren. 
Einige Zeit später wurde Wolfgang Müller aus Lutter am Barrenberg ebenfalls zur Herrenversammlung gerufen und nach kurzer Befragung ähnlich wie Peter Rahl geschlagen. Die Mißhandlung war lediglich noch viel schlimmer, da mit Gummiknüppeln auf ihn eingeschlagen wurde. Er stürzte bei der Mißhandlung mehrfach zu Boden, wurde wieder hochgerissen und weiter auf ihn eingeschlagen. Nach der Mißhandlung wurde Wolfgang Müller ebenfalls ins Krankenhaus gebracht. Wie ich einige Wochen später feststellte, war er offensichtlich geschockt und auch mit entsprechenden Medikamenten behandelt worden. Ein Elektroschockgerät ist im Krankenhaus vorhanden. [...]

Etwa 1980/81 hat ein chilenischer Junge namens Sergio Contreras sich in ein Mädchen verliebt. Solche Beziehungen wollte der Beschuldigte nicht haben, deshalb hat er angeordnet, daß Sergio ins Krankenhaus kommt. Dort wurde er geschockt und mit Medikamenten behandelt. Ich habe Sergio mehrfach im Krankenhaus besucht. Er lag völlig apathisch auf seinem Bett, der Speichel floß ihm aus dem Mund. Dies waren die typischen Zeichen für die vorerwähnte Behandlung.

Ebenso erging es Franz Baar. Er hatte sich ebenfalls in ein Mädchen verliebt und wurde auf Weisung des Beschuldigten zu einem Gespräch geholt. Danach ist er wieder in sein Zimmer ins Krankenhaus zurück und wurde ca. 2 Wochen nicht gesehen. In dieser Zeit sprang er plötzlich aus dem Fenster des 1. Stockes des Krankenhauses, um wohl den Behandlungen im Krankenhaus zu entgehen. In der Folgezeit stand er sichtbar unter dem Einfluß der Medikamente, wenn er zur Arbeit ging. Er wurde auf dem Weg vom Krankenhaus zur Arbeitsstätte und zurück auf Weisung des Beschuldigten überwacht. ${ }^{299}$

\section{Misshandlungen mit Elektroschocks und Medikamenten}

Wolfgang Müller (heute Kneese) berichtete nach seiner Flucht aus der CD 1966, in der CD täglich dazu gezwungen worden zu sein, große Mengen Schlaftabletten zu schlucken. Zudem habe er regelmäßig Spritzen verabreicht bekommen, die ihn müde machten. ${ }^{300}$ Über den hohen Konsum von Sedativa in der Siedlung berichteten verschiedene Medien bereits 1966, z.B. die Zeitschrift Ercilla:

»En un mes los colonos de >Dignidad consumieron veinte frascos de >Librium<, otros veinte de >Valium y todo tipo de sedantes cuya adquisición se puede hacer sin receta médica. Las compras hechas en la farmacia de Parral por Hermann Schmidt muestran el grado de >doping a que estaban sometidos los colonos. «01

Ohne jegliche medizinische Indikation wurden einer großen Anzahl von Colonos über Jahrzehnte hinweg regelmäßig Psychopharmaka verabreicht. Diese Misshandlung mit Medikamenten fand bei einzelnen Colonos bis zu Schäfers Festnahme 2005 statt. Bei einigen setzte sie sich wegen der durch die lange Einnahme entstandenen Abhängigkeit sogar noch darüber hinaus fort. Viele Colonos erlitten hierdurch schwere gesundheitliche Schäden. Die großen Mengen verschreibungspflichtiger Medikamente bezog die

299 StA Bonn, AZ 50 ]s 285/85, Bd. I, Bl. 91f. Richterliche Vernehmung von Hugo Baar vom 29.08.1985.

300 PA AA, B 85, Bd. 598. Bericht von Wolfgang Müller vom 19.03.1966.

301 Ercilla vom 04.05.1966, S. 5. »Proceso a la Ingenuidad«. 
CD teilweise direkt über den chilenischen Gesundheitsdienst (Servicio Nacional de Salud - SNS), indem sie Rezepte für chilenische Patient_innen fälschte. Dieses Vorgehen erläuterte Lotti Packmor bereits 1985:

»Für die Nachbehandlung der geschockten Patienten oder auch für die Dauerbehandlung, für die weitere, braucht Dra. Seewald und Schäfer >Luminal < und >Meprobamato<. Beide Medikamente vom Servicio de Salud, und darüber muß strengstens Buch geführt werden.

Man macht es dann so, daß diese Medikamente chilenischen Patienten verordnet werden mit Schrägstrich, d.h. in die ficha wird das Medikament getippt, es wird als Beleg ein Rezept geschrieben von Dra. Seewald unterschrieben, und wenn der Patient das nächste Mal kommt oder wenn je die ficha gebraucht wird zum Einsehen, sieht man sofort, der Schrägstrich vor >Mepro<, vor >Luminal< bedeutet, diese Medikamente gingen so ins Hospital, die hat der Patient selber nie bekommen. « ${ }^{302}$

Misshandlungen durch Elektroschocks sollten Sexualität unterdrücken und Erinnerungen »auslöschen«. Sie wurden eingesetzt, wenn sich eine Liebesbeziehung anbahnte, mit der Schäfer nicht einverstanden war, ${ }^{303}$ und auch bei sexuellen Gedanken, Regungen oder Handlungen einzelner Colonos oder Colonas. Gruppenmitglieder, die Schäfers Führungsanspruch in Frage stellten oder ihm auch nur öffentlich widersprachen, wurden ebenso mit Elektroschocks misshandelt. Schäfer begründete diese Maßnahmen damit, den Betroffenen müssten »Dämonen« ausgetrieben werden. Die Misshandlungen durch Elektroschocks fanden in der Regel im Krankenhaus statt, im Fall der Misshandlung von Jungen und Mädchen Ende der 1960er, Anfang der 1970er jahre auch im Neukra, was weiter ausführlich beschrieben wird. Misshandlungen durch Elektroschocks wurden meist von der Ärztin Gisela Seewald durchgeführt, mit Unterstützung einiger Krankenschwestern, die möglicherweise im Rahmen ihrer medizinischen Ausbildung an psychiatrischen Einrichtungen in der Bundesrepublik Kenntnisse über Elektrokrampftherapie erlangt hatten. ${ }^{304}$ Auch diese Art der Misshandlung fand laut Aussagen der daran beteiligten Personen stets auf Anordnung Schäfers statt. Die Krankenschwester Ursula Klemkow berichtete 1988 von Misshandlungen in den ersten Jahren nach der Ankunft der Gruppe in Chile:

»In den Jahren 1963/1964 oder 1964/1965 war das Krankenhaus dann in den Anfängen fertig. Ich habe generell in dem Krankenhaus gearbeitet, in der Kinderabteilung und

302 PA AA, B 83, Bd. 2384. Transkription des Tonbandberichts von Lotti Packmor an die Botschaft vom 17.03.1985, S. $23 f$.

303 Ursula Kuhn berichtete 1988: „Aus den Erzählungen meines Ehemannes weiß ich, daß er Elektroschocks erhalten hat, damit er sich von mir trennt. Ihm wurde dann gesagt, er müsse doch endlich einsehen, daß ich nicht die richtige Frau für ihn sei und daß er sich von mir trennen solle. «HISArch, Bestand CD, Ordner 1. LG Köln 28 O 160/88. Vernehmung von Ursula Kuhn durch das AC Eutin vom 07.11.1988.

304 Die Krankenschwester Dorothea Hopp beschrieb die missbräuchliche Elektroschock- und Medikamentenvergabe in der CD 2006 ausführlich. Unmittelbar im Anschluss daran gab sie an, vor ihrer Ankunft in Chile sechs Monate lang in einer psychiatrischen Klinik in der Bundesrepublik gearbeitet zu haben, wo sie »einige Kenntnisse erworben« habe. CA Santiago, AZ 2182-98 (»Asociación Ilícita«), Bd. III (Ministro), Bl. 1303f. Polizeiliche Vernehmung von Dorothea Hopp vom 20.04.2006. 
auch in der Poliklinik [...] Als das Krankenhaus dann so einigermaßen fertig war, kann ich mich noch daran erinnern, daß ich eines Tages in das Krankenhaus gerufen wurde. Es wurde dann ein Patient im Rollstuhl hereingefahren und auf ein vorbereitetes Bett gelegt. Das Bett hatte eine harte Unterlage und auch eine Gummiunterlage.

Dem Patienten wurde dann von der Ärztin eine Spritze gegeben. Es wurde ihm zuvor eine Erklärung gegeben, von der ich annahm, dass sie nicht richtig war. Nach der Spritze schlief der Patient ganz schnell ein. Als Helferin waren Schwester Maria Strebe, Frau Ingrid Böckler, damals noch Seelbach, und ich zugegen. Wir hatten die Aufgabe, die Celenke des Patienten zu fixieren, damit unter der Schockeinwirkung keine Luxation eintritt. Eine von uns dreien hatte die Knie heruntergedrückt und je eine von den anderen hielt die Ellbogen. Frau Dr. Seewald führte dann die Elektroschocktherapie durch. Herr Schäfer war während dieser Therapie mit dabei. Ich meine, dieser Patient war wohl der erste Patient, der mit Elektroschock behandelt wurde. Genau kann ich das allerdings nicht angeben, da die einzelnen Personen nicht darüber gesprochen haben, wenn sie an solchen Sachen teilgenommen haben. Was der Einzelne jeweils machte, wurde verschwiegen und nicht mit den anderen darüber gesprochen.

Ich kann jedoch generell sagen, daß der Elektroschocktherapie nur Patienten unterzogen wurden, bei denen Herr Schäfer die Anweisung dafür gab und bei denen Herr Schäfer es für notwendig hielt, dass diese Therapie durchgeführt wird. Notwendig hielt Herr Schäfer diese Therapie bei solchen Leuten, die nicht mit ihm einverstanden waren oder seinen Befehlen zuwider handelten. Ich weiß von Fallen, wo junge Leute, die sich mochten, sich kleine Zettelchen geschrieben hatten oder sich auch mal Blicke zuwarfen. Wenn Herr Schäfer mit dieser Verbindung nicht einverstanden war, wurden diese jungen Leute auch dieser Therapie unterzogen. Eine Therapie unterblieb nur dann, wenn der Herr Schäfer mit einer Verbindung zwischen zwei jungen Leuten einverstanden war. «O5 $^{305}$

Die Misshandlungen mit Elektroschocks fanden hinter verschlossenen Türen, in den "Schockkammern « 306 des Krankenhauses statt. Laut zahlreichen Aussagen wussten jedoch viele Colonos davon - entweder weil sie an den Misshandlungen beteiligt waren, diese selbst erleiden mussten oder weil sie deren körperliche Spuren bei anderen wahrnahmen. Wolfgang Kneese berichtete 1988 von der Misshandlung seiner Mutter in den Anfangsjahren der CD:

305 HISArch, Bestand CD, Ordner 1. LG Köln 28 O 160/88. Vernehmung von Ursula Kuhn durch das AG Eutin vom 07.11.1988. Bei dem Patienten, den Kuhn erwähnte, handelt es sich um den Colono Helmut Schaffrik. Die von ihm erlittenen Elektroschockmisshandlungen beschreibt auch Ulla Fröhling, vgl. Fröhling, »Unser geraubtes Leben«, S. 175f.

306 Georg Packmor sprach nach seiner Flucht 1985 dazu Folgendes auf Band: »Das bringt dann als Folge Auswüchse bis hin zu Folterungsmaßnahmen, oder, wie häufig vorkommt in den letzten Jahren, daß Menschen der Kolonie mit Brechdurchfall ins Krankenhaus eingeliefert werden, um dann in den Schockkammern Zimmer 14 oder 9 Monate lang oder sogar Jahre in einigen Fällen verbringen müssen, weil sie nicht mehr Schäfer hörig waren oder ihm gefährlich werden. Diese Menschen laufen heute herum wie geistige Vollinvaliden«. PA AA, B 83, Bd. 2384. Transkription des Tonbandberichts von Georg Packmor an die deutsche Botschaft vom 15.03.1985, S. 5. 
»Meine Mutter ist in der Zeit vom August 1963 bis zum 5. April 1966 [...], in einem Raum eingesperrt gewesen, in dem sie sich mehrerer Elektroschockbehandlungen unterziehen mußte - ebenfalls gegen ihren Willen. Selbst wenn man dieser Frau nicht ganz glauben will, daß das passiert ist, kann sie nachweislich heute noch die verbrannten Schläfen vorweisen, die auf eine unsachgemäße Behandlung mit Elektroschocks zurückzuführen sind. ${ }^{307}$

Die Führung der CD sicherte sich bei den Misshandlungen durch Elektroschocks, aber auch bei der missbräuchlichen Medikamentenvergabe teilweise durch externe ärztliche Gutachten ab, wie Gero Gemballa berichtete:

»Zweifel an der Claubwürdigkeit von Vera Müllers Aussagen konnten kaum aufkommen. Vera Müller hatte Brandmale an den Schläfen; war krank und abgemagert. Die Elektroschock-Behandlung wurde sogar noch medizinisch begründet. Am 17.März 1966 schrieb ein Professor Dr. Alfred Auersperg der $>$ Universität Concepcion, medizinische Fakultät, Psychiatrische Abteilung؛: >Da die schizophrene Symptomatologie der Patientin in außerordentlicher Weise die Sphäre ihres Bewusstseins betrifft scheint eine Elektroschockbehandlung dringend erforderlich،. Dieses Schreiben ging auch zu den Unterlagen der deutschen Botschaft in Santiago. Als Lehre aus dem `Fall Müller «schickte die >Colonia Dignidad ihre Mitglieder schon vorbeugend zum Psychiater Dr. Mario Mujica, um von ihm eine psychiatrische Behandlung im Krankenblatt eintragen zu lassen. Später stand auch ein Dr. [Marcelo] Varas aus Santiago für Gefälligkeitsgutachten zur Verfügung. Bei weiteren (wenig erfolgreichen) Fluchtversuchen von Mitgliedern konnte man dann darauf hinweisen, daß das betreffende Mitglied der Cemeinschaft leider >psychisch krankı sei, es habe schon in den sechziger Jahren einem Psychiater vorgestellt werden müssen. ${ }^{308}$

Hugo Baar, der zuvor in der Bundesrepublik das Gerät für die Elektroschocks erworben hatte, ${ }^{309}$ wurde im Januar 1975 selbst mit Elektroschocks und Medikamenten misshandelt. Nach seiner Flucht aus der CD 1985 berichtete er davon:

»Als ich völlig erschöpft im Fundo ankam, empfing mich Herr Schäfer im Empfangshaus mit einer Gruppe von Herren. [...] Dann wurde ich in eines der Gästezimmer im Waldhaus gebracht. Hier, völlig isoliert und bewacht, wurde ich geschockt und entsprechend mit Medikamenten behandelt. Dieses habe ich bis vor einer Woche nicht gewußt. Im Beisein ihres Mannes und ihrer Schwester aus Canada erzählte davon Frau Packmor, nicht ahnend, daß ich selbst nichts davon wußte. [...] Ich hatte mich nur gewundert, daß meine Erinnerung über den Aufenthalt im Waldhaus lückenhaft war.

307 PA-DBT 3127, 712 - UA 2 - 2451. Stenographisches Protokoll der 10. Sitzung des Unterausschusses für Menschenrechte und Humanitäre Hilfe vom 22.02.1988. Auch online unter http://coloniadigni dad-prot.blogspot.com/, S. 10/14.

308 Gemballa, Gero. Colonia Dignidad. Ein deutsches Lager in Chile, Reinbek 1988, S. 82f. Mehrere Berichte von Colonos nennen Dr. Varas als Verfasser von Gefälligkeitsgutachten, mit denen Colonos für psychisch krank erklärt wurden. PA AA, B 83, Bd. 2384. Transkription des Tonbandberichts von Lotti Packmor an die Botschaft vom 17.03.1985, S. 10 und PA AA, B 83, Bd. 2384. Bericht von Hugo Baar an die Botschaft vom 02.04.1985, S. 6. 
Rund um die Uhr waren bei mir abwechselnd Frau Dr. Seewald, die Oberschwester Maria und Frau Ingrid Böckler, geb. Seelbach sowie die Herren Kurt Schnellenkamp und Rudolph Cöllen, alle besondere Vertrauensleute von Herrn Schäfer. Die 3 Erstgenannten, hinzu kommt noch die Rote-Kreuz-Schwester Ingrid Klunk, sind, wie mir aus anderen Fällen bekannt ist, die 4 weiblichen Personen, die die Leute schocken und mit Medikamenten behandeln, wenn Paul Schäfer es anordnet. [...] Als ich schon aufstehen durfte, sagte mir Herr Schäfer, daß ein chilenischer Arzt da wäre, der mich sprechen wollte. Frau Dr. Seewald kam dann mit Dr. Varas aus Santiago zu mir. [...] Erst einige Jahre später erfuhr ich, daß es sich bei Dr. Varas um einen Psychiater handelt. Ich dachte damals, ohne zu wissen, daß ich auf Anweisung von Herrn Schäfer sogar geschockt worden bin, daß er Dr. Varas nur hatte kommen lassen, um später einmal, falls erforderlich, sich schriftlich von Dr. Varas bescheinigen zu lassen, daß ich schon 1975 bei ihm in Behandlung war. $\ll^{310}$

Die Ex-Colona Gudrun Müller berichtete, bereits in den 1950er Jahren, vor ihrer Abreise nach Chile, mit elektrischen Viehtreibern ${ }^{311}$ misshandelt worden zu sein. Gegenüber einem chilenischen Gericht machte sie Aussagen über ihre Misshandlung durch eine »Maßnahme« - vermutlich Elektroschocks - ebenfalls noch in der Bundesrepublik:

»Ich hatte schon in Graz Freundschaft mit Alfred Matthusen geschlossen, und wir behielten sie so weit es ging aufrecht, bis sie eines Tages von Herrn Schäfer abgebrochen, zerstört wurde.

Ich wurde vor einige Herren gerufen und zur Rechenschaft gezogen und als Maßnahme von Herrn Mücke zusammengeschlagen. Herr Mücke äußerte sich, indem er sich umdrehte und sagte: swill keiner schlagen außer mir? Dieser Vorfall, vor allem die Maßnahme wurde mir schon in Heide aus dem Cedächtnis genommen. Ich kam in das dortige Krankenzimmer und wurde behandelt. Das weiß ich jetzt, seit einigen Monaten aus zweier Zeugen Mund. Ich weiß nur noch den Vorfall ganz genau, was die Maßnahme war wußte ich nicht mehr, denn sonst wäre ich nicht in Heide geblieben und auch nicht nach Chile mitgegangen. ${ }^{312}$

Mit »behandelt« meint Müller Stromstöße über die am Kopf angesetzten Elektroden des Elektroschockgeräts. Colonos sprechen in diesem Zusammenhang von »schocken «. ${ }^{313}$ In der internen Sprache der Colonos gibt es eine Reihe spezieller Ausdrücke, die Misshandlungen meist in beschönigender Form ausdrücken: So wird »behandeln« oftmals im Kontext der Misshandlung mit Psychopharmaka und Elektroschocks verwendet. Beim sogenannten »Schinkenklopfen« handelt es sich um Prügel. Die pseudo-religiöse Legitimierung dieser Taten spiegelt sich in Formulierungen wie »den Teufel blamieren«

310 Ebd., S. 6.

311 Fröhling, »Unser geraubtes Leben«, S. 117.

312 CA Santiago, AZ 2182-98 (»Lesiones Graves«), Bl. 52f. Bericht von Gudrun Müller, geb. Wagner vom 12.10.2005. »Mein Lebensbericht seit ich Herrn Schäfer kenne!«.

313 Hugo Baar berichtete z.B. 1985: »Hier, völlig isoliert und bewacht, wurde ich geschockt und entsprechend mit Medikamenten behandelt.«PA AA, B 83, Bd. 2384, Bericht von Hugo Baar an die Botschaft vom 02.04.1985, S. 6. 
oder »die Hurengeister austreiben« wider. Ulla Fröhling schreibt zu diesem speziellen Gebrauch von Ausdrücken und Redewendungen:

»Es gibt viele solcher Wörter und Wendungen, die außerhalb der Gruppe nicht verstanden werden. >Entpesten ‘ gehört dazu und `den Teufel blamieren<. Manche erfindet Schäfer, manche entstehen aus der Gruppe heraus. Wie in allen Sekten und isolierten Gruppen entwickelt sich eine eigene Sprache. ${ }^{314}$

Auch die gezielte Verabreichung von Medikamenten und Spritzen über einen langen Zeitraum, sollten zahlreiche Colonos willenlos machen und ihren Sexualtrieb teils langanhaltend hemmen. Protokolle von Vernehmungen aus chilenischen Gerichtsverfahren enthalten zahlreiche Aussagen dazu. José Angel Schmidt Spinti berichtete 2005 beispielsweise darüber:

»Cuando tenía entre 12 a 15 años de edad, me hicieron entrega de medicamentos, los cuales tenía que tomármelas todos los días y tres veces al día, hasta el año 1995 aproximadamente, dichos remedios me reprimían el deseo sexual. A esto quiero decir, que hasta hoy no logro recuperar el deseo sexual, debido a los remedios que me suministraban durante tanto tiempo. ${ }^{315}$

Die Sedierung und gewaltsame Unterdrückung der Sexualität hat viele Colonos zeitlebens geschädigt. Bei einer gerichtsmedizinischen Untersuchung im Jahr 2007 berichtete ein Colono, der Mitte der 1960er Jahre in die Siedlung gekommen war, er habe ab seinem 14. Lebensjahr dauerhaft unter Einfluss von Psychopharmaka gestanden und wie betäubt gelebt. Ein Sexualleben habe er nicht leben können bis ins Jahr 2000, als er seine erste Beziehung hatte:

»Mi vida sexual no existió. A los 14 años - por los azotes que me dieron - entré al hospital y no salí nunca más de ahí. Siempre estuve con fármacos [...] Estaba como matado de mi cuerpo, como anestesiado. Me daban entre 9 y 12 pastillas tres veces al día y en la noche además me inyectaban. Por eso no tuve vida sexual y mi primera relación sexual fue en el 2000 . $\ll^{316}$

\section{Die Misshandlungen im »Neukra» (ca. 1969-1972)}

Von besonders schlimmen Misshandlungen betroffen war Ende der 1960er und Anfang der 1970er Jahre eine größere Gruppe von etwa 6-12-jährigen Mädchen und Jungen, die in einem Krankenhausneubau, dem sogenannten Neukra, jahrelang mit Stromstößen im Genitalbereich, Schlägen und Medikamenten gequält wurden. Die 16 Mädchen der sogenannten »Vogelgruppe« wurden zudem etwa zwanzig Jahre lang vollständig isoliert und von sämtlichen Gemeinschaftsaktivitäten ausgeschlossen. Viele der Frauen konnten später keine eigenen Kinder bekommen, was höchstwahrscheinlich auf die erlittenen Misshandlungen zurückzuführen ist. Waltraud Baar berichtete dem AA über diese Gruppe bereits 1989:

314 Fröhling, »Unser geraubtes Leben«, S. 116.

315 CA Santiago, AZ 2182-98 (»Asociación Ilícita«), Bd. III (Ministro), BI. 1290. Polizeiliche Vernehmung von José Angel Schmidt Spinti vom 17.03.2006.

316 Juzgado de Parral, AZ 66.122. Bd. 2, BI. 885. Servicio Médico Legal, Informe Médico Legal 1292-07. 
»Um eine besondere Art der Freiheitsberaubung handelt es sich bei der sogenannten »V̈gel«-Gruppe. 16 Mädchen im Alter von jetzt 23 bis 31 Jahren, zu der auch unsere beiden jüngsten Töchter gehören [...]. Diese Cruppe durfte auf Anordnung von Schäfer etwa 1970 bis zu meinem Fortgang, April '85, nie am gemeinsamen Essen oder irgendeiner der Veranstaltungen, auch nicht bei den verschiedensten Besuchen, teilnehmen. Sie müssen, wie keine andere Cruppe, isoliert im Kinderhaus leben. [...] Zu dieser Isolierung kam es, weil nach Schäfers Aussage bei einer Besprechung diese Mädchen, als sie etwa fünf bis acht Jahre alte waren angeblich mit gleichaltrigen Jungen heimlich Geschlechtsverkehr hatten. Es war damals große Aufregung. Die Mädchen- und Jungengruppen wurden sofort von allen Kindergruppen isoliert, bekamen bestimmte Behandlung, die Mädchen tägliche Sitzbäder, über die Behandlung der Jungen hat ja Frau Packmor berichtet. Während die Jungen später im Saal wieder erscheinen durften, gilt für die Mädchen bis heute, trotz ihres jetzigen Alters, seit jetzt fast 20 Jahren, die Isolierung innerhalb der Fundogemeinschaft. «17

Nach der Ankunft der Gruppierung in Chile 1961/62 wurden Jungen und Mädchen in zunehmendem Maße räumlich voneinander getrennt. Die Kleinsten durften jedoch noch miteinander spielen und auch gemeinsam die Schule besuchen. Etwa 1969 gab einen Einschnitt: Schäfer kündigte an, dass mehrere der kleinen Mädchen sexuelle Kontakte mit den kleinen Jungen gehabt hätten.

Als Konsequenz wurden Jungen und Mädchen fortan strikt voneinander getrennt. Sie wurden bereits im Alter von ca. 5-12 Jahren zu harter Feldarbeit gezwungen und Misshandlungen ausgesetzt. Zwischendurch wurden sie einzeln immer wieder hinter die Büsche gerufen, wo sie geschlagen und ihnen mit elektrischen Viehtreibern Stromstöße im Genitalbereich versetzt wurden. Eine Colona berichtet über die wiederholten nächtlichen Misshandlungen:

»Die traumatischsten Erlebnisse, die mir wiederholt angetan wurden, waren nachts; ungefähr 1969, als ich 7 Jahre alt war. Ich wurde von zwei Frauen gepackt und aus dem Bett gerissen und in ein anderes Zimmer gezerrt. Hier hielt man mir Mund und Augen zu, drückte mich gewaltsam in ein großes Federbett, damit ich nicht so laut Schreien konnte, während nun eine Folter mit Schlägen und Elektrostößen auf mein bloßes Gesäß erfolgte. Ich schrie und strampelte, weil die Schmerzen unerträglich waren. Doch ich wurde umso tiefer in das Federbett gepresst, so dass ich nun keine Luft mehr bekam und in Todesangst versetz war und um mein Leben rang, begleitet von Schlägen und elektrischen Stößen. [...] Ich habe so viel Prügel und Stubenarrest mit Sprechverbot bekommen. Immer wurde auf den nackten Unterleib geschlagen. Oftmals wurden mir auch Stromstöße mit dem Viehtreiber in den Intimbereich versetzt und am ganzen Körper apliziert. [...] Während einer langen Zeitspanne, die ich nicht mehr genau eingrenzen kann, mussten wir sehr viele Tabletten einnehmen, so dass wir oft wie benommen waren. Abends vor dem Schlafengehen bekamen wir noch besonders starke

317 Archiv Al, Bestand CD. Bericht von Waltraud Baar an das AA vom 09.02.1989, »Bericht über Freiheitsberaubung, Mißhandlung und Mißbrauch minderjähriger Jungen während meiner Jahre in der Sociedad Benefactora Dignidad in Chile«, S. 10. 
Schlafmittel [...]. Alle Gruppenmitglieder, die diese schlimmen Folterungen und Misshandlungen erleiden mussten und heute verheiratet sind, konnten auf natürlichem Wege keine Kinder bekommen. Auch können wir unser intimes Eheleben nicht natürlich ausleben, da ich dabei unter unerträglichen Schmerzen leide. Ich vermute, dass damals im Neukra eine Elektrode des Elektroschockgerätes im Vaginalbereich angesetzt wurde. An demselben Problem leidet auch eine Freundin aus meiner damaligen >Vogelgruppe $\ll \ll^{318}$

Über die Misshandlungen, die die Jungen im Neukra erleiden mussten, berichtete auch Lotti Packmor 1988 im Bundestag:

»Lotti Packmor: Als ich ankam, hat mich Herr Schäfer in die Kinderarbeit getan. [...] Tatsache war, daß ich ganz zu Anfang, im Februar 1970, in einer Jungengruppe war, von der mir Schäfer vertraulich sagte, die Kinder seien moralisch, sexuell belastet, und sie würden behandelt. Ich sollte helfen.

Die Kinder standen immer unter starken Medikamenten. Mit einigen Helfern und Herrn Dr. Hopp und Dr. Gisela Seewald wurden die Kinder Tag und Nacht beaufsichtigt. Am Tage mußten wir mit ihnen Wanderungen über Berg und Täler machen. Die Kinder sollten müde werden. Sie taumelten zwar, wurden vollgestopft mit Drogen. In der Nacht wurden die Kinder völlig nackt in einem großen Raum, der eigens dafür gemacht wurde - Das Haus wurde gebaut, als ich schon in Chile war, ein Haus für besondere Zwecke, - so hat mir Herr Schäfer selber gesagt.

Da wurden 12 Betten im Kreis aufgestellt. Wir standen in der Mitte und sollten diese nackten Körperchen der acht- bis zwölfjährigen Jungen beobachten. Regte sich ein Augenlid oder in der Intimgegend etwas, wurde das Kind aus dem Bett gerissen und von den betreffenden Personen geschlagen, als da sind: Manfred Schmidke, Hartmut Hopp.

Abg. Duve (SPD): Auch von Herrn Dr. Hopp?

Lotti Packmor: Jawohl. Es sind fünf Helfer. Ich kann sie Ihnen namentlich geben. Oder die Kinder wurden unter die kalte Dusche gestellt. Nach dem Prügeln wurden sie wieder ins Bett gebracht, und sie durften weiter so liegen. [...] Viehtreiber hat man benutzt und die Kinder damit bearbeitet, - Viehtreiber mit elektrischer Batterie. Ich wurde dann als untauglich aus dieser Gruppe getan, aus dieser Gruppe der Aufpasser. Ich war aber auch dabei, als Gisela Seewald diesen Jungen - ich sage es der Wahrheit entsprechend, wie ich es erlebt habe - Spritzen in die Hoden gab. Die lagen dann geschwollen im Unterleib da. Herr Hartmut Hopp wird es bestätigen müssen. « 319

Helmut Seelbach, der selbst an den Misshandlungen der Jungen beteiligt war, berichtete chilenischen Ermittler_innen 2006:

»Paul Schäfer [...] ordenó que se llevasen a todos los jóvenes y niños (varones) al Neukra, para que se controlara a estos su erección, ya que no podían pensar en el sexo, siendo

318 StA Krefeld, AZ 3 Js 753/11, Bd. V, BI. 1240f. Bericht einer Colona vom 25.02.2011.

319 PA-DBT 3127, 712-UA 2-2451. Stenographisches Protokoll der 10. Sitzung des Unterausschusses für Menschenrechte und Humanitäre Hilfe vom 22.02.1988. Auch online unter http://coloniadigni dad-prot.blogspot.com/, S. 117/10f. 
el caso que para Schäfer esto era un vicio y un pecado [...] Los controles de los cuales estoy hablando, eran generalmente en base a medicamentos proporcionados por las enfermeras Maria Strebe e Ingrid Seelbach [...] y la otra persona que participó en estos controles al parecer fue la doctora Gisela Gruhlke. [...] me pude percatar que los menores o jóvenes que se encontraban bajo estas vigilancias, siempre se veían desganados, con sueño y con signos de andar bajos los efectos de alguna droga. Lo anterior lo menciono, ya que participé en la custodia de dichos muchachos por orden de Schäfer en compañía de Klaus Scholz, Gerhard Mücke, Reinhard Döring Falkenberg (Alemania), Manfred Schmidtke (Alemania), Manfred Skrabs y Heinrich Hempel [...] Seguidamente, en una oportunidad, mientras cuidábamos a los jóvenes en el Neukra llegó Paul Schäfer, con un elemento de unos $20 \mathrm{cms}$. de largo aproximadamente [...], el que al contacto con su punta provocaba un golpe eléctrico, manifestándonos que había que combatir el pecado y para lo cual había que colocar dicho artefacto en los genitales de los jóvenes o en el cuerpo de los mismos, situación que yo también realicé al igual que las personas antes mencionadas.[...] Schäfer también nos ordenó que cuando alguno de estos menores no obedecían el castigo anterior, había que llevarlos a la ducha y mojarlos con agua helada o caliente, para también aplicarles golpes de electricidad con el instrumento que describí anteriormente. [...] en otra oportunidad, divisé a Schäfer inyectar medicamentos en el pene de algunos colonos que se encontraban recluidos en el Neukra. $\ll^{320}$

\section{Strafrechtliche Verfolgung der Taten}

Die Bundesregierung wusste von den genannten Methoden der Misshandlung spätestens seit dem Bericht von Lotti und Georg Packmor 1985. Wie eindrücklich der Bericht war, lässt sich auch aus den Worten des damaligen Botschafters Holzheimer im Schreiben zur Weiterleitung des Berichts an das AA ablesen:

»Wichtiger wäre allerdings, daß die in vielem an ein Konzentrationslager gemahnenden Lebensbedingungen wie die Behandlungen mit Psychopharmaka und Elektroschocks geändert werden und Herrn Schäfer nicht weiter Gelegenheit gelassen wird, Kinder bei sich übernachten zu lassen. «21

Die genannten Formen physischer Gewalt, die juristisch als Körperverletzung zu betrachten sind, wurden strafrechtlich sowohl in der Bundesrepublik als auch in Chile untersucht: Die Staatsanwaltschaft Bonn ermittelte ab 1985 im Rahmen eines Verfahrens gegen Schäfer sowie ab 1988 gegen Gisela Seewald, Hartmut Hopp und Hugo Baar wegen »Freiheitsberaubung, Körperverletzung usw.«. ${ }^{322}$ Das Verfahren wurde 2010 nach $\$ 170$ II StPO eingestellt. ${ }^{323}$ Nachdem Hartmut Hopp 2011 vor der chilenischen Justiz

320 CA Santiago, AZ 2182-98 (»Asociación Ilícita«), Bd. III (Ministro), Bl. 1265ff. Polizeiliche Vernehmung von Helmut Seelbach Ewig vom 05.01.2006.

PA AA, B 83, Bd. 2384. Bericht Botschafter Holzheimer an AA (330) vom 27.03.1985, Ber. 352/85 rk 543.00 .

322 StA Bonn, AZ 50 ]s 285/85.

323 Der Paragraf besagt, dass die Staatsanwaltschaft keinen »genügenden Anlass zur Erhebung der öffentlichen Klage«sah. 
nach Deutschland geflüchtet war, stellte die Berliner Rechtsanwältin Petra Schlagenhauf im Namen ehemaliger Colonos Strafanzeige gegen Hopp wegen gefährlicher Körperverletzung durch die medizinisch nicht indizierte Verabreichung von Psychopharmaka. Aufgrund von Verjährungsfristen konnten nur noch Taten nach 2002 berücksichtigt werden. Die Staatsanwaltschaft Krefeld ermittelte, ${ }^{324}$ stellte aber im Mai 2019 auch dieses Ermittlungsverfahren nach $\$ 170$ II StPO ein.

In Chile leitete Richter Jorge Zepeda Ende 2005 ein Verfahren ein, ${ }^{325}$ in dem die Körperverletzungen an acht Colonos in den 1970er und 1980er Jahren untersucht wurden. Im März 2008 sprach Zepeda das erstinstanzliche Urteil, das die beiden Folgeinstanzen $^{326}$ in Bezug auf das Strafmaß bestätigten. Zepeda stellte fest, dass:

»Gudrun Wagner, Waltraud Schaak, Wolfgang Muller Ahrend, Gerd Schaffrik, Hans Peter Schaffrik, Horst Schaffrik, Günter Schaffrik y Jürgen Szurgelies, todos ellos jóvenes colonos alemanes, [...] fueron sometidos durante un largo tiempo, el que abarcó los décadas de los años 70 y 80, a stratamientos de salud «, y no obstante estar sanos, se les suministró >sicotrópicos‘y aplicó corriente eléctrica en sus cuerpos, mediante `electroshockı, permaneciendo los jóvenes aislados en el shospitalı, como también en el anexo a éste denominado >Neukra<, ubicados al interior de la hoy ex Colonia Dignidad. 327 $^{327}$

Diese Taten hätten bei mindestens drei der Betroffenen irreversible Schäden verursacht. Sie seien von Paul Schäfer angeordnet und von der Ärztin Gisela Seewald ausgeführt worden. Zepeda stufte die Taten in seinem Urteil als Verbrechen gegen die Menschheit ein und verurteilte Schäfer zu drei Jahren und einem Tag Haft. Gisela Seewald und die Krankenschwester Dorothea Witthahn gaben gegenüber Zepeda ihre Beteiligung an diesen Taten zu und schilderten diese detailreich. Gisela Seewald berichtete bei ihrer Vernehmung:

»Efectivamente, hice tratamientos a colonos que sufrían esquizofrenia y psicosis, para lo cual lo debía internarlos en el hospital de la Villa para el control médico. El tratamiento consistía en suministrarles medicamentos, electroshock y atención psicológica. De los pacientes recuerdo a Helmut Schaffrik y a sus hijos Cerd, Hans Peter, Jürgen Szurgelies y Heinz Schmidt. Paul Schafer me ordenó practicarles tratamientos a todos los jóvenes que, según él, se distraían pensando en sexo o divergiéndose en otras cosas. A estos jóvenes se les daba medicamentos y aplicaciones de electroshock; de los medicamentos que se usaban mezclados, recuerdo que la Clorpromazina, Haldol y Valium. El tratamiento duraba aproximadamente un mes y se efectuaba tanto en el hospital como en el anexo de éste denominado >Neukra<, porque el hospital se hacía chico.

Las dosis que se suministraban a los pacientes eran los que médicamente se recomiendan. Schafer me señalaba que había que tratar a estos niños pues no hacían caso, eran rebeldes; habían problemas en las relaciones entre los jóvenes y las muchachas. Tenía 
la obsesión, Schafer, de que los niños tenían manifestaciones demoníacas, las que sanaban con electroshock que se aplicaba en la frente.

El equipo que me ayudó y que siempre lo constituyó las mismas personas, nunca hubo un extraño. Inicialmente se le aplicaba al paciente una inyección intravenosa, con un narcótico de efecto muy breve y, bajo ese estado se le aplicaba el electroshock. Para disminuir el dolor de cabeza que este tratamiento se le aplicaba un medicamento, creo que era Clorpromazina, no recuerdo bien, que le producía sueño y así se evitaba el dolor de cabeza posterior.

El equipo lo integraba Ingrid Seelbach y Maria Strebbe, ambas fallecidas, y a veces me ayudaba Dorothea Witthahn. [...]

Los fundamentos religiosos también eran motivo para la aplicación de electroshock a los jóvenes; en opinión de Schafer, estos jóvenes estaban poseídos por el demonio, por eso no obedecían. Schafer ordenaba hacer algunos trabajos y los jóvenes no obedecían, ellos querían casarse, lo que es comprensible; si bien recuerdo Gudrun esperó treinta años, más o menos, para casarse. También le fue aplicado el tratamiento al novio de ésta joven. [...] Visto hoy en día los tratamientos, ellos no tenían justificación, pero en ese entonces lo que Schafer decía acerca de la posesión demoníaca yo encontraba que eso era justo o no tenía idea de lo que pasaba realmente. [...] No podría contestar en forma precisa que número de jóvenes recibieron tratamientos, pero serían unos $10 \mathrm{a}$ 15 entre hombres y mujeres. [...]

Los medicamentos usados eran Clorpromazina, Valium, Haldol; conozco el >Modecates, se trata de un remedio de larga duración, el paciente se inyecta y permanece alrededor de un mes bajo esos efectos. Efectivamente se aplicó esta medicina a pacientes. El año 1978 queda a cargo del hospital el doctor Hartmut Hopp y se aplicaron posteriormente estos tratamientos, por lo que en algunos casos nos coordinábamos con él en la aplicación. $\ll^{328}$

Auch die in Seewalds Aussage erwähnte Krankenschwester Dorothea Hopp, die Ehefrau von Hartmut Hopp, räumte ihre Beteiligung an Misshandlungen ein und beschrieb diese gegenüber den Ermittlungsbehörden:

»Debo decir, que hubo varias personas que fueron inyectadas por mí, con la intención de sedarlas y posteriormente aplicarles electroshock, ya que este era el procedimiento al interior de Colonia dignidad, específicamente en el Hospital de este enclave. En estos momentos puedo recordar a Helmut Schaffrik, Heinz Schmidt, José Vedder, Wolfgang Müller y Gudrun Wagner, entre otros, personas que eran inyectadas para posteriormente aplicarle el respectivo electroshock. De los colonos, que tengo conocimiento y sufieron electroshock, recuerdo a José Angel Schmidt Spinti y Peter Rahl. [...] El nombre de las inyecciones que aplicaba a los colonos, correspondía a >EVIPAN (producto alemán). Debo hacer presente que la Doctora Gisela Gruhlke fue la Directora del Hosptial de Colonia Dignidad hasta el año 1977, siendo en ese año que asumió mi marido el Doctor Hartmut Hopp Miottel. Por otra parte, es necesario que indique, que antes de

328 CA Santiago, AZ 2182-98 (»Lesiones Graves«), Bd. I, BI. 36ff. Richterliche Vernehmung von Gisela Seewald (geb. Gruhlke) vom 26.12.2005. 
Ilegar a Chile, trabajé más de medio año en un Hospital Psiquiátrico ${ }^{329}$, donde adquirí algunos conocimientos. $\ll^{330}$

Auch einige der Opfer schilderten die an ihnen verübten Verbrechen im Rahmen der von Richter Zepeda angeleiteten Untersuchungen. Efraín Vedder Veuhoff, der als chilenischer Junge von der CD adoptiert wurde, Colono berichtete bei einer richterlichen Vernehmung im Jahr 2005, wie er bereits ab dem Alter von acht Jahren mit Medikamenten und Spritzen misshandelt wurde:

»También a los ocho años me empezaron a dar unas pastillas en la enfermería, eran nueve diarias [...] éstas causaban que yo estuviera con cansancio, dolor de pecho, mareos y sueño. Cuando me empezó a doler el cuello, pregunté para qué eran esas pastillas y me contestaron para mi salud, que me hacían bien y que, si no las seguía tomando, me iba a enfermar de nuevo. [...] Recuerdo que en algunas oportunidades no tomaba las pastillas que me eran administradas, por lo que me comportaba muy rebelde ya que no estaba drogado, pero al percatarse de tal situación, Paul Schäfer ordenaba en forma inmediata que me trasladaran hasta el Hospital de la Villa donde me inyectaban un líquido de color amarillo, el que me suministraba la enfermera Dorothea WITTHAHN, Dra. Gisela SEEWALD (o GRUHLKE), Dr. Hartmut HOPP MIOTTEL o la matrona Ingrid SEELBACH. 331 $^{331}$

Zepedas Untersuchung der Misshandlungen durch Elektroschock und medizinisch nicht indizierte Vergabe von Psychopharmaka im Rahmen der Ermittlungsverfahren wegen schwerer Körperverletzung und wegen Bildung einer Kriminellen Vereinigung war unvollständig und von einer Auswahl nach willkürlichen Kriterien geprägt, die er auch in seinem Urteil nicht begründete. So erstreckte sich der Untersuchungszeitraum lediglich auf zwei Jahrzehnte, obwohl davor und danach ähnliche Taten begangen wurden. Zudem untersuchte der Richter nur die Taten an acht Colonos, obwohl eine deutlich höhere Zahl von (Ex-)Colonos ähnliche Köperverletzungstaten hatten erleiden müssen. Schließlich wurde als einziger Täter Paul Schäfer angeklagt und verurteilt, obwohl die weiteren Verantwortlichen, allen voran Gisela Seewald, Hartmut Hopp und Dorothea Witthahn, umfangreich ausgesagt und bei ihren Vernehmungen ihre Beteiligung an einigen der Taten teilweise eingeräumt hatten. Bei einem Gespräch antwortete mir Zepeda auf meine Frage, weshalb die Untersuchung so unvollständig erfolgt sei, er habe unter Druck gestanden, ein schnelles Urteil zu fällen, da sich Paul Schäfer zum Zeitpunkt des Verfahrens in Untersuchungshaft befand, die nicht unbegrenzt verlängert werden konnte. ${ }^{332}$

329 Damit ist vermutlich die psychiatrische Klinik der Universität Bonn in Bonn-Venusberg gemeint.

330 CA Santiago AZ 2182-98 (»Asociación Ilícita«), Bd. III (Ministro), BI. 1303f. Polizeiliche Vernehmung von Dorothea Hopp vom 20.04.2006.

331 Juzgado de Parral, AZ 66.124, BI. 719. Polizeiliche Vernehmung von Efraín Vedder Veuhoff vom 23.09.2005.

332 PJS, Sammlung Gesprächsnotizen. Notiz eines Gesprächs mit Jorge Zepeda vom 16.10.2012. 


\subsection{Die externen Verbrechen der kriminellen Organisation Colonia Dignidad}

Im Folgenden geht es um die externen Verbrechen der CD, d.h. zum einen um Verbrechen, die außerhalb der CD begangen wurden oder die Personen außerhalb der CD geschädigt haben. Ein Großteil dieser Verbrechen bezieht sich auf die Periode der chilenischen Diktatur von 1973-1990, in der die CD eine sehr enge Machtallianz mit der regierenden Militärjunta pflegte. Aber auch in Zeiten demokratisch gewählter Regierungen schädigte die CD Personen, die außerhalb der Siedlung lebten, massiv. Am stärksten betroffen war die teilweise sehr arme Bevölkerung aus der ländlichen Umgebung der CD.

\subsubsection{Kindesaneignungen - Betrügerische Adoption von chilenischen Kindern}

Während es in Abschnitt 4.1.2 um Entführungen und Adoptionsbetrug bei Kindern aus dem Innern oder dem direkten Umfeld der Gruppierung in Deutschland ging, behandelt dieser Abschnitt die widerrechtliche Aneignung von chilenischen Kindern von Familien aus der Umgebung der Siedlung. Dies bezieht sich vornehmlich auf die 1960er und 1970er Jahre.

Mir sind 21 Fälle bekannt, in denen chilenische Kinder auf verschiedenen Wegen Teil der CD wurden. ${ }^{333} 15$ davon waren männlich und sechs weiblich In den meisten dieser Fälle wurden Adoptionsverfahren, oder bei bereits Volljährigen Namensänderungen durchgeführt. Das geschah großteils betrügerisch und gegen den Willen der jeweiligen Erziehungsberechtigten. Daher handelte es sich in den meisten Fällen faktisch um Kindesaneignungen. ${ }^{334}$ Oftmals wurden Kinder auch ohne den Beschluss eines Vormundschaftsgerichts einfach in der CD »einbehalten«. Die meisten betroffenen Kinder stammten aus sozial schwachen Familien aus der Umgebung der CD. So beschreibt es auch der evangelikale Pastor Adrian Bravo, 335 ein bis Mitte der 1990er Jahre enger Vertrauter Schäfers:

333 Vgl. PJS, Sammlung AA. Wer sind die Opfer der Colonia Dignidad und wie könnte ihnen geholfen werden. Stellungnahme von Jan Stehle für die Mitglieder der Gemeinsamen Kommission von Bundestag und Bundesregierung zur Umsetzung des Hilfskonzepts für die Opfer von Verbrechen in der ehemaligen Colonia Dignidad für die Anhörung am 20.11.2018 [unveröffentlicht]. Anlage Colonia Dignidad, Adoptivkinder. Die Zahl (21) beinhaltet nicht die chilenischen Jungen, die in den 1990er Jahren in der CD missbraucht wurden und die teilweise über mehrere Monate oder Jahre dort lebten, bzw. festgehalten wurden.

334 Zum Thema der Adoptionen/Kindesaneingungen, vgl. Cámara de Diputados, Boletín de Sesiones, Legislatura $336^{a}$, Sesión $10^{\text {a }}$ vom 21.10.1997. Informe de la Comisión de Familia recaido en el Proyecto de Acuerdo que le encomienda investigar situaciones de posibles violaciones a los derechos de los niños y niñas en la ex Colonia Dignidad vom 15.10.1997, auch online unter https://www.cam ara.cl/camara/media/docs/colonia/03.pdf, S. 67ff (zuletzt abgerufen am 12.02.2018). Vgl. auch Schwember, Herman. Delirios e Indignidad. El Estéril Mundo de Paul Schäfer, Santiago 2009, S. 126ff. sowie Salinas/Stange. Los amigos, S. $157 f$.

335 Adrián Bravo war in den 1990er Jahren Teil der lokalen Unterstützungkomitees der CD. Er war aktiv an der Anwerbung chilenischer Kinder und Jugendlicher aus der Region für Wochenendaktivitäten in der CD (»]uventud de Viligia Permanente«) sowie am »Internado Intensivo« beteiligt. Als er vom 
»hijos de familias pobres y mal constituidas, madres separadas o solteras, padres alcohólicos, analfabetos. > No el hijo del senador Larraín o del diputado Felipe Letelier, sino los hijos de personas a las que nadie creería en el caso en que intentaran atacar a la Colonia.«336

Oftmals handelte es sich um Kinder, die zuvor zur Behandlung ins Krankenhaus der CD eingeliefert worden waren. Dort wurde den Eltern beispielsweise eröffnet, die Kinder benötigten eine mehrmonatige stationäre Behandlung. Dafür sollten die - teilweise analfabetischen - Eltern Einverständniserklärungen vor Notaren oder Gerichten unterzeichnen. Diese Erklärungen wurden häufig mithilfe von Beamt_innen bei Verwaltung und Justiz erstellt, die gute Beziehnugen zur CD-Führung unterhielten, und entpuppten sich später erst als Sorgerechtsabtretungen. Daraus wurden, wiederum mithilfe von mit der CD-Führung befreundeten Beamt_innen bei Verwaltung und Justiz, Adoptionsvorgänge. Diese waren zwar betrügerisch herbeigeführt, jedoch formalrechtlich irreversibel. Bei späteren Besuchsversuchen bekamen die leiblichen Eltern ihre Kinder entweder gar nicht mehr zu Gesicht oder durften sie nur in Anwesenheit von CDFührungsmitgliedern sprechen.

Formell wurden die Kinder meist von Ehepaaren aus der CD-Führung wie Hermann und Ursula Schmidt, Hartmut und Dorothea Hopp oder Hans-Jürgen und Erika Blanck adoptiert. Auch der alleinstehende Schäfer adoptierte ein Kind: Rebeca del Carmen Valenzuela Soto. Praktisch hatten diese Kinder in der CD aber wenig bis gar keinen Kontakt zu ihren Adoptiveltern. Sie lebten in den Kindergruppen und standen in der gruppeninternen Hierarchie in der Regel ganz unten.

Einen großer Teil der offiziellen Adoptionsvorgänge wurden von Rechtsanwalt José Seda Navarrete, später Juez de Policía Local von Parral, bearbeitet und von Maria Cristina Alfaro, einer Standesbeamtin des Registro Civil in Catillo, eingetragen. ${ }^{337} \mathrm{Bei}$ den Adoptionen durch Schäfer und Hopp wurden auch die renommierten Rechtsanwält_innen Luis Ortíz Quiroga und Olga Feliú aktiv. ${ }^{338}$ Oftmals fanden die formalen Verfahren erst mehrere Jahre nach der faktischen Aneignung der Kinder statt. Waren die Betreffenden inzwischen bereits volljährig, so wurde anstelle der Adoption meist eine Namensänderung durchgeführt, wie etwa im Fall von Franz Baar. Zu der größten Anzahl an Adoptionsverfahren kam es 1975-1976. Ein Bericht der Kriminalpolizei von 2001 führt in diesem Zeitraum allein innerhalb eines Jahres elf Adoptionen beim Juzgado de Letras in Parral auf. ${ }^{339}$

sexuellen Missbrauch durch Schäfer erfuhr, wandelte er sich von einem Unterstützer zu einem Gegner der CD-Führung und kooperierte mit der Justiz.

336 Vgl. Salinas/Stange, Los Amigos, S. 164.

337 PA AA, AV NA 31596. Schreiben von RA Pacheco an Botschaftsrat Spohn vom 30.06.1989 sowie CA Santiago, AZ 2182-98 (»Asociación Ilícita«), Bd. I (Parral), BI. 450f. PDI, Informe Policial 02/00510 vom 08.01.2001. 
Botschaft und AA waren über diese Adoptionsvorgänge zeitnah im Bilde. Ein Botschaftsmitarbeiter schrieb hierzu in einem Bericht über seinen Besuch in der CD im Juli 1977:

»Es bleibt noch zu erwähnen, daß die Angehörigen der Kolonie bis zum heutigen Tage insgesamt 22 Personen, vom Babyalter bis zu 21 Jahren, nach chilenischem Recht adoptiert haben. Es besteht das Bestreben, die durchgeführten Adoptionen in der Bundesrepublik Deutschland anerkennen zu lassen. Eine solche Anerkennung hätte nach dem neuen Adoptionsrecht u.a. Auswirkungen auf die Staatsangehörigkeit der Angenommenen. $\ll^{340}$

In mehreren Fällen bemühten sich die leiblichen Eltern der adoptierten Kindern später bei den zuständigen Behörden um eine Rückkehr ihrer Kinder. Alle diese Bemühungen blieben erfolglos. Im Folgenden beschreibe ich exemplarisch drei Adoptionsvorgänge, die auch zum Gegenstand von Presseberichten wurden: Miguel Becerra Monsalve, Carlos González und Cristian Javier Godoy Godoy.

\section{Miguel Becerra Monsalve}

Miguel Becerra Monsalve kam im Dezember 1973 im Alter von 12 Jahren mit seinem Vater, Miguel Becerra Hidalgo, in die CD. Der Vater war als Agent der DINA in der CD stationiert. Nachdem CD-Führungsmitglieder erfahren hatten, dass der Vater beabsichtigte, die DINA zu verlassen, vergifteten ihn Colonos im Juli 1974. Seine Leiche wurde in einem Auto an der Panamericana-Autobahn abgelegt, dabei wurde ein Selbstmord fingiert. Als die Mutter des Kindes, Olivia Monsalve, ihren Sohn daraufhin in der CD abholen wollte, bat Schäfer sie, ihn noch bis zum Ende des Schuljahres in der CD zu lassen. Sie stimmte - vermutlich unter Druck - zu. Anschließend wurde ihr jedoch jeglicher Kontakt zu ihrem Sohn verweigert. Die Mutter suchte das Gericht in Parral auf und erstattete Anzeige. Der zuständige Richter teilte ihr jedoch nach einem Besuch in der CD mit, dass es ihrem Sohn dort gut gehe und dass er selbst geäußert habe, dort bleiben zu wollen. Dem stimme er zu. Der Richter gestattete der Mutter lediglich, ihren Sohn an einem Sonntag pro Monat besuchen zu dürfen. Doch selbst zu diesen Terminen verweigerte die CD ihr den Zutritt. ${ }^{341}$ Daraufhin begab sich die Mutter zum nahegelegenen Artillerieregiment in Linares. Dort wurde ihr geraten, »ruhig zu bleiben, sonst würden ihr ihre weiteren Kindern ebenfalls weggenommen. ${ }^{342} 1976$ sprach eine Tante des Kindes in der Botschaft vor und bat im Namen der Mutter um Hilfe bei der Zurückerlangung ihres Kindes. Botschaftsrat Petersmann fertigte hierüber einen Vermerk an und bat den "ständigen Vertreter der CD in Santiago«, Alfred Matthusen, in die Botschaft zu kommen. ${ }^{343}$ Matthusen erschien am nächsten Tag und wurde zu Botschafter Strätling vorgelassen. Er versprach, über den Fall zu unterrichten. Wenige Tage später erschien Matthusen erneut in der Botschaft. Petersmann vermerkte dazu:

340 PA AA, AV NA 31581. Bericht Hiemann vom 11.07.1977, Betr.: Dienstreise in die Kolonie »Dignidad «.

341 Las Ultimas Noticias vom 18.04.1997, S. 4. »La increíble historia del >Kito«.

342 Las Ultimas Noticias vom 12.09.1980, S. 20. »Qué devuelvan a mi sobrino los de la Colonia Dignidad«.

PA AA, AV NA 31581. Vermerk von Botschaftsrat Petersmann vom 30.09.1976. 
»Am 15.10 suchte mich Herr Matthusen auf. Er zeigte mir den Durchdruck eines Briefes, den der Junge unter dem Datum 30.09.76 (!) an Staatspräsident Pinochet gerichtet haben soll. Darin drückt der Junge seinen Wunsch aus, in der Kolonie >Dignidad < bleiben zu können, auch wenn seine Mutter, die svon schlechten Ratgebern beeinflußt « werde, die veralteten (100 Jahre alten) chilenischen Gesetze vielleicht auf ihrer Seite habe. Die schlechten Ratgeber wollten seiner Mutter einreden, daß ihr Mann, der Vater des Jungen, von Mitgliedern der Kolonie getötet worden wäre. Der Vater sei jedoch von den Marxisten getötet worden. ${ }^{344}$

Matthusen gab an, vermutlich werde schon in der Folgewoche eine Gerichtsentscheidung getroffen. Außerdem habe die Mutter inzwischen über einen Anwalt dem Verbleib ihres Sohnes in der CD zugestimmt. Botschaftsrat Petersmann entgegnete, man könne der CD zwar keine Weisungen erteilen, hätte aber ein Interesse daran, dass von der Gruppierung keine illegalen Handlungen ausgingen. Er wies Matthusen darauf hin, dass in Chile - ebenso wie in der Bundesrepublik - das Sorgerecht bei den leiblichen Eltern liege. Für den Fall, dass die Mutter ihre Zustimmung nicht erteilen würde, rate er daher, den Jungen herauszugeben. Petersmann bat Matthusen, ihn auf dem Laufenden zu halten. Sein Vermerk endet mit der Feststellung: "Frau Becerra hat mich am 14. Oktober erneut aufgesucht. Ich habe sie etwa für den 19. Oktober erneut einbestellt.« ${ }^{345}$ Weiteres zu dem Fall ist den Akten leider nicht zu entnehmen.

Die Presse berichtete während der Diktatur mehrfach sowohl über den Mord an Miguel Becerra als auch über das Festhalten seines gleichnamigen Sohnes in der CD. ${ }^{346}$ Im November 1987 schrieb Botschaftsrat Haller in einem Vermerk zum bevorstehenden Konsularsprechtag (Vgl. Abschnitt 6.3.4) in der CD: »Frau Becerra bat um Nachforschungen nach ihrem seit 1974 in CD lebenden Neffen Miguel Becerra Monsalve. Sie legte mir ausführliche Unterlagen und ein Foto vor. « ${ }^{347}$ Einen Monat später erkannte die Mutter ihren Sohn in einer Fernsehreportage über die CD wieder und wandte sich an die Zeitung Las Ultimas Noticias. Der Bruder des Vaters, Juan Carlos Becerra, sprach mit einem Journalisten dieser Zeitung. Er forderte, die von Bundesaußenminister Genscher eingerichtete Sonderkommission ${ }^{348}$, die sich zu dieser Zeit in Chile aufhielt, solle das Schicksal seines Bruders untersuchen. ${ }^{349}$ Vier Jahre später, im Oktober 1991, besuchte der damalige Bundeskanzler Helmut Kohl Chile. Wenige Wochen nach dem Besuch ging im Bundeskanzleramt ein Schreiben von Elena Becerra, der Schwester des ermordeten Vaters, ein. Darin bat sie den Bundeskanzler um Hilfe bei der Aufklä-

PA AA, AV NA 31581. Vermerk von Botschaftsrat Petersmann vom 19.10.1976.

Ebd.

Vgl. u.a. Revista Cauce vom 29.10.1984, S. 32-35. »Otra vez >Dignidad〈: >A mi hermano lo asesinaron «.sowie La Epoca vom 02.03.1988, S. 16. Interview mit Elena Becerra: »Pinochet debe intervenir en Dignidad.«

PA AA, AV NA 31583. Vermerk Konsul Haller vom 03.11.1987.

Zur von Genscher im Dezember 1987 nach Chile entsandten Delegation, die die CD untersuchten sollte, vgl. Abschnitt 6.3.3.

Las Últimas Noticias 19.12.1987, S. 4. »Mi hijo apareció en colonia Dignidad«. 
rung des Mordes und bei der Befreiung ihres Neffen aus der CD. ${ }^{350}$ Eine Antwort ist mir nicht bekannt.

Nach einem vermeintlichen Fluchtversuch im Januar 1997 stellte die Familie von Miguel Becerra Monsalve bei der CA in Talca einen Schutzantrag, dem jedoch nicht stattgegeben wurde. ${ }^{351} 2004$ berichtete Kurt Schnellenkamp Miguel Becerra Monsalve erstmals von der Ermordung seines Vaters. ${ }^{352}$ Im November 2008 verurteilte die CA Santiago Paul Schäfer, Kurt Schnellenkamp und Rudolph Cöllen wegen des Mordes an Miguel Becerra Hidalgo. ${ }^{353}$

\section{Carlos Antonio González Castillo/Matthias Gerlach}

Carlos González wurde 1971 geboren. Laut dem Colono Alfred Gerlach, seinem formal zweiten Adoptivvater, wurde er im Krankenhaus der CD geboren. ${ }^{354}$ Seine Mutter soll bei der Geburt gestorben sein, der Vater habe daraufhin die CD gebeten, den Sohn aufzunehmen und großzuziehen. ${ }^{355}$ Servando González, ein Bruder von Carlos, gab hingegen an, dass ihre Mutter Ester Castillo 1972 wegen einer Erkältung im Krankenhaus der CD behandelt wurde und dort daraufhin verstarb. Sein Bruder Carlos sei daraufhin von der CD „einbehalten“ worden, niemand aus seiner Familie habe in eine Adoption von Carlos eingewilligt. ${ }^{356} 1975$ wurde der Junge vom Ehepaar Lotti und Georg Packmor adoptiert. Fortan hieß er Matthias Packmor. Als das Ehepaar 1985 aus der CD flüchtete, musste es Matthias zurücklassen. Lotti und Georg Packmor baten daraufhin die deutsche Botschaft um Hilfe, um ihren 13-jährigen Adoptivsohn aus der CD zu holen. Sie bevollmächtigten die Botschaft schriftlich, alle dafür notwendigen Schritte einzuleiten. ${ }^{357}$ In ihrem Bericht für die Botschaft sagte Lotti Packmor aus:

»Noch heute ist es so, daß die Jungens von etwa 8 bis zu 15-16 Jahren allein in Schäfers Obhut sind, keine mütterliche Betreuung haben. Er allein badet sie, hat täglich einen als sogenannten >Sprinter bei sich, immer bei Fuß, [...] und dieser sogenannte Sprinter schläft auch bei ihm in der Nacht. In dieser Gruppe, die «Keile ‘ genannt, ist auch unser Matthias, sein ganz besonderer Liebling. Das weißjedermann im Fundo. [...] Wir wollen unser Kind aus Schäfers Händen haben. Wir wollen unser Kind unbedingt und unter allen Umständen zu uns nehmen und nicht länger bei diesem Tyrann wissen. «358

350 PA AA, AV NA 31602. Schreiben von Elena Becerra an Bundeskanzler Kohl vom 18.10.1991.

351 La Nación vom 14.03.1997, S. 14. »Hermetismo en caso de niños sustraidos«.

352 CA Santiago, AZ 12.293-2005. Erstinstanzliches Urteil vom 27.11.2008, S. 16.

353 Das letztinstanzliche Urteil in diesem Fall fällte die Corte Suprema erst nach dem Tode Schäfers, im Oktober 2010. Schnellenkamp und Cöllen wurden wegen Beihilfe zum Mord zu 541 Tagen Haft auf Bewährung verurteilt. Corte Suprema, AZ 6796-09, Urteil vom 27.10.2010.

354 CA Santiago, AZ 2182-98 (»Asociación Ilícita«), Bd. I (2) (Ministro), Bl. 400. Richterliche Vernehmung von Alfred Gerlach vom 22.03.2006. Ebd.

Vega, Pedro. »Revelan espeluznante caso. Niño fue apropiado por ex Colonia Dignidad«, in: La Nación vom 15.08.1997.

PA AA, AV NA 31596. Schreiben RA Máximo Pacheco an Botschaftsrat Spohn vom 30.06.1989. PA AA, B 83, Bd. 2384. Transkription des Tonbandberichts von Lotti Packmor an die Botschaft vom 17.03.1985, S. 5 f. 
Botschafter Holzheimer leitete die Berichte der beiden Geflohenen ans AA weiter. Im Begleitschreiben schrieb er zu Matthias Packmor:

»Ein die Abwicklung der Ausreise [von Lotti und Ceorg Packmor] aus Chile noch überlagerndes Problem konnte allerdings nicht mehr gelöst werden. Die Eheleute Packmor hinterließen in der Colonia Dignidad ihren 14-jährigen Adoptivsohn Matthias. Wie stark seitens der Eltern der Wunsch ist, ihren Sohn zu sich zu holen, vermochte die Botschaft nicht eindeutig festzustellen. Sie hat die Eheleute jedenfalls umfassend über die notwendigen juristischen Schritte unterrichtet, die sie ggf. ergreifen müssen. «359

Nach ihrer Ausreise in die Bundesrepublik bekräftigten die Packmors auch gegenüber hiesigen Strafverfolgungsbehörden ihren Wunsch ihren Sohn aus der Siedlung zu holen. Bei einer Vernehmung bei der Staatsanwaltschaft Gronau am 04.11.1985 äußerte Georg Packmor:

»Wir haben auch bei der Deutschen Botschaft in Chile eine Ermächtigung hinterlassen, die Herausgabe des Matthias zu betreiben. Obwohl wir auch im Besitz der Geburtsurkunde des Matthias sind usw., hat sich jedoch noch nichts getan. Das heißt also, daß sich der Matthias gegen unseren Willen im Fundo befindet. $^{360}$

Diese Ermächtigung, in der die Eheleute Packmor die Botschaft bitten, »alle Schritte zu unternehmen, damit unserem Adoptivsohn Matthias Packmor Peters [...] die Ausreise von obengenannten Fundo, auf dem er festgehalten wird, möglich gemacht wird «, befindet sich bei den Botschaftsakten. ${ }^{361}$ Konsul Haller sprach zwar daraufhin mit dem Chef von Interpol, der ihm erklärte, die Packmors müssten eine notarielle Erklärung abgeben und darin ihr Einverständnis zur Ausreise unter Angabe des Reiseziels geben. Ferner brauche der Sohn einen chilenischen Reisepass, den er unter Vorlage des Personalausweises und der notariellen Erklärung erhalten könne. Weitere konkrete Schritte der deutschen Vertretung, um die Herausgabe des Jugendlichen an seine Adoptiveltern zu erreichen, sind mir jedoch nicht bekannt.,

Erst 1989 erfuhr die Botschaft von Rechtsanwalt Pacheco, dass Matthias bereits im September 1985 erneut adoptiert worden war, diesmal durch Alfred und Anna Gerlach (geb. Maschke). Er trage nun den Namen Matthias Gerlach. Maria Cristina Alfaro, dieselbe Standesbeamtin am Registro Civil in Catillo, die schon die erste Adoption beurkundet hatte, unterzeichnete auch diese - offensichtlich betrügerische - zweite Adoption. ${ }^{362}$ Als Grund für die zweite Adoption wurde angeführt, die Eltern hätten ihr Kind verlassen und sich ins Ausland abgesetzt. Im Juli 1997 wurde Matthias Gerlach von Hartmut Hopp nach Mendoza in Argentinien gebracht. Er tauchte erst im März 2005 wieder auf, nachdem Paul Schäfer in der Nähe von Buenos Aires festgenommen worden war.

PA AA, B 83, Bd. 2384. Schreiben von Botschafter Herrmann Holzheimer an AA (Ref. 330) vom 27.03.1985.

StA Bonn, AZ 50 ]s 285/85, Bd. 1, Bl. 108. Vernehmung von Georg Packmor im AC Gronau vom 04.11.1985. 
Gerlach hatte fast acht Jahre mit Schäfer im Untergrund verbracht. ${ }^{363}$ In dem chilenischen Strafverfahren wegen sexuellen Missbrauchs an chilenischen Kindern ${ }^{364}$ wurde Matthias Gerlach zu drei Jahren und einem Tag Haft auf Bewährung verurteilt. Auch im Verfahren wegen Bildung einer kriminellen Vereinigung ${ }^{365}$ war er angeklagt, wurde aber in der letzten Instanz freigesprochen.

\section{Cristián Javier Godoy Godoy/Michael Hopp}

Die Adoption des 1983 geborenen Cristián Javier Godoy Godoy durch Hartmut Hopp und seine Ehefrau Dorothea Witthahn im Jahr 1988 ist der letzte bekannte Adoptionsfall durch die CD. Die Adoptionsformalitäten wurden durch die Rechtsanwältin Olga Feliú abgewickelt, die gemeinsam mit ihrem Ehemann Waldo Ortúzar - der zwischen 1963 und 1990 als Fiscal Nacional Económico wirkte - die CD in verschiedenen Verfahren vertrat. Nach dem Ende der Diktatur wurde Feliú von der Corte Suprema als designierte Senatorin ernannt (1990-1998). Die Eintragung des Kindes als Michael Hopp erfolgte beim Registro Civil Catillo wiederum durch die Standesbeamtin Maria Cristina Alfaro. Als 1996 chilenische Eltern, deren Kinder im »Intensivinternat « der CD lebten, die ersten Strafanzeigen wegen sexuellen Missbrauchs einreichten, wurde bekannt, dass auch Michael Hopp dort untergebracht war. Die biologische Mutter Michaels, Sonia Godoy, stellte daraufhin Strafanzeige. Sie erklärte, dass ihr der Sohn betrügerisch weggenommen worden war und forderte seine Herausgabe. ${ }^{366}$ Ihr sei gesagt worden, dass sie für eine wichtige Operation ihres Sohnes im Krankenhaus Einverständniserklärungen unterschreiben sollte. Später sei ihr jedoch verweigert worden ihren Sohn besuchen zu dürfen und sie erfuhr, dass dieser vom Ehepaar Hopp adoptiert worden war. Ein Bericht der ermittelnden Beamten der Kriminalpolizei im Rahmen des Verfahrens beschreibt die Umstände der Adoption Cristián Javiers:

»Asimismo en atención a la declaración del Asistente Social del Juzgado de Menores de Parral quedó de manifiesto una atencion muy especial al sr. Hartmut Hopp Miottel en la tramitación de la adopcion del menor Cristián Javier, toda vez, que en cada momento en que este concurría a dicho Tribunal en su comparecencia estaba presente la Sra. Magistrado Lidia Villagrán, quedando de manifiesto además, que entre ambas personas existió realmente un tipo de sociedad para llevar a cabo fraudulentamente la tramitación de adopción del menor en comento. Por otra parte, también queda claro a la luz de los antecedentes, que toda la tramitación de adopción de Cristián Javier, fue hecha abusando de la calidad de analfabeta de la madre del menor quien jamás de acuerdo a lo investigado pudo haber entregado voluntariamente a su hijo en adopción. « ${ }^{367}$

\footnotetext{
363 Vgl. Bericht von Friedhelm Zeitner wiedergegeben in: Villarubia, Gustavo. »Mi vida bajo el régimen de Paul Schäfer«. La historia de uno de los guardaespaldas del líder de Colonia Dignidad«, in: CIPER (Website), 23.09.2013, online unter https://www.ciperchile.cl/2013/o9/23/"mi-vida-bajo-e I-regimen-de-paul-schafer"/.

364 Juzgado de Parral, AZ 53015-1996.

365 CA Santiago, AZ 2182-98 (»Asociación Ilícita«).

366 Las Ultimas Noticias vom 09.07.1997, S. 5. »Investigan Adopción de hijo de Hopp«.

367 Juzgado de Parral, AZ 55070 M, BI. 168ff. Informe Policial 683 der PDI vom 15.05.1998.
} 
Das Verfahren wegen Verstoßes gegen das Adoptionsgesetz, ${ }^{368}$ an dem sich auch der Staatsverteidigungsrat (CDE) und die staatliche Kinder- und Jugendbehörde SENAME (Servicio Nacional de Menores) beteiligten, endete jedoch im Dezember 2000 mit einem Freispruch für das Ehepaar Hopp in erster Instanz, ${ }^{369}$ da der erstinstanzliche Richter Hernán González an der CA Talca keine Verletzung des Adoptionsgesetzes sah. Der Freispruch wurde 2002 von der CA Talca bestätigt und durch das letztinstanzliche Urteil der Corte Suprema rechtskräftig. ${ }^{370}$

Das Ehepaar Hopp hatte Michael unterdessen außer Landes gebracht, wohl weil Michael im Rahmen der Ermittlungen im Verfahren um den sexuellen Missbrauch Schäfers befragt und gerichtsmedizinisch untersucht werden sollte. Am 31. Juli 1997 reisten Hartmut Hopp und Dorothea Witthahn mit ihrem Adoptivsohn nach Mendoza/Argentinien, gemeinsam mit zwei weiteren von der CD durch Adoption angeeigneten Kindern: Rebeca Schäfer und Matthias Gerlach welche Paul Schäfer bis 2005 in seinem argentinischen Versteck begleiteten. Dorothea Hopp reiste unterdessen mit Michael, begleitet von Winfried Schmidtke über Brasilien nach Venezuela und schließlich in die USA ${ }^{371}$ und kehrte erst 2002 wieder nach Chile zurück - nachdem der Haftbefehl gegen sie erloschen und Michael volljährig war.

\section{Rebeca del Carmen Valenzuela Soto/Rebeca Schäfer}

Die 1967 geborene Rebeca del Carmen Valenzuela Soto wurde 1975 von Paul Schäfer adoptiert und hieß fortan Rebeca Schäfer. ${ }^{372}$ Vermutlich wollte Schäfer so eine »normale heterosexuelle« Fassade vorspiegeln. Beachtlich ist jedenfalls, dass er als alleinstehender Mann überhaupt ein Mädchen adoptieren konnte. Schäfer wurde im Adoptionsverfahren von dem christdemokratischen Rechtsanwalt Luis Ortíz Quiroga vertreten.

Diese drei Beispiele belegen exemplarisch, wie die Kindesaneignung durch Adoption in der CD funktionierte: Der Schlüssel lag in den Beziehungen der CD zu lokalen Justiz- und Verwaltungsmitarbeiter_innen wie der Richterin Lydia Villagrán in Parral oder der Standesbeamtin Maria Cristina Alfaro in Catillo. Die Kinder stammten alle aus armen ländlichen Familien, die weder über einen Zugang zur Justiz verfügten, noch die Mittel für jahrelange Rechtsstreitigkeiten durch mehrere Instanzen mit den renommierten Anwälten der CD aufbringen konnten. Oftmals waren die Eltern der Kinder

368 Juzgado del Crimen de Parral, AZ 55.070 M.

369 El Mercurio vom 15.12.2000, S. C9. „Dictó Ministro: Sentencias para Dr. Hopp y su Esposa«.

370 El Mercurio vom 23.09.2004, S. C10. »La Suprema absolvió a jerarca de la ex Colonia Dignidad«.

371 CA Santiago, AZ 2182-98 (»Asociación Ilícita«), Bd. Bd. I (Parral), Bl. 391ff. Informe Policial Nr. $02 / 00510$ vom 08.01.2001.

372 Die 1967 als Rebeca del Carmen Valenzuela Soto geborene Rebeca Schäfer wurde 1975 adoptiert. PA AA, AV NA 31601. Schreiben von RA Pacheco an Botschaftsrat Spohn vom 03.06.1989. Folgende Anlagen sind dort (in Kopie) angefügt: Escritura Publica de adopción de la menor Rebeca del Carmen Valenzuela Soto por parte de Paul Schäfer Schneider otorgado ante el notario de Talca don Eduaro Ramirez Letelier, con fecha 02.12.1975 und Escritura pública de ampliación de la escritura de adopción referida anteriormente, otorgada por don Roberto Valenzuela Chandía y Paul Schäfer Schneider ante el Notario de Talca Eduaro Ramirez Letelier el 19.01.1976. Vgl. auch Sanhueza, Ana María. »La enigmática Rebeca Schäfer«, in: Qué Pasa vom 30.04.2010, online unter https://www.la tercera.com/revista-que-pasa/1-3264-9-la-enigmatica-rebeca-schafer/. 
anfangs sehr froh über die Gesundheitsversorgung und die (vermeintliche) Ausbildung, die ihren Kinder in der CD zuteilwurden. Unter Vorspiegelung falscher Tatsachen wurden sie schließlich dazu gebracht, Adoptionserklärungen zu unterschreiben, die sie als Analfabet_innen oft nicht verstanden. Die chilenischen - und deutschen - Behörden verfügten über Informationen über diese Adoptionsvorgänge, schritten jedoch nicht ein. Das erlaubte der CD eine Reihe von Kindesaneignungen, die teilweise offensichtlich durch betrügerische Vorgänge zustande kamen. Formalrechtlich betrachtet stellten diese jedoch irreversible Adoptionsbeschlüsse dar, die nur durch einen Annullierungsbeschluss desselben Gerichts hätten rückgängig gemacht werden können. ${ }^{373}$ Die biologischen Eltern verfügten jedoch nicht über die für ein solches Verfahren nötigen Kenntnisse und finanziellen Mittel. Gegen die geballte Macht der CD in der Region mit ihren Kontakten zu Behörden und Gerichten und mit der Unterstützung renommierter Rechtsanwält_innen erschienen diese Unterfangen ohnehin aussichtslos.

Eltern, die versuchten ihre Kinder zurückzuerlangen, wurden oftmals bedroht und teilweise über diktaturtreue Medien offen beschimpft und verleumdet: So wurde Guillermina San Cristobal Rubilar, die 1977 ihren Sohn Hernán Escobar aus der CD zurückholen wollte, beschimpft, sie gebe nur vor, ihren Sohn zurück zu wollen, um eine marxistische, antichilenische Diffamierungskampagne gegen die CD zu unterstützen. ${ }^{374}$ Die Zeitung La Tercera berichtete, die Mutter sei während der Allende-Regierung Sekretärin und »Intimfreundin des Marxisten Javier Figueroa Aguirre « gewesen und fügte an, sie sei weniger von Sorge um ihren Sohn getrieben, sondern beabsichtige, die chilenische Regierung international zu diskreditieren:

»Averiguaciones confidenciales señalan que Guillermina San Cristóbal Rubilar no quiere tanto la tuición de su hijo como desacreditar al Gobierno en el exterior. El objetivo de su maniobra es que ello trascienda al extranjero y si es posible sea utilizado en la próxima reunión de la UNESCO a fin de demostrar que en nuestro país no existen libertades. «375

Es erscheint unklar, wieso es die CD in manchen Fällen nicht für notwendig erachtete, die Kindesaneignungen durch einen Adoptionsbeschluss formalisieren zu lassen. Im Bericht des Untersuchungsrichters Hernán Robert Arias von 1989 sind zwei Fälle aufgeführt, ${ }^{376}$ bei denen Jungen nach einer Behandlung im Krankenhaus in der CD verblieben. ${ }^{377}$ Die Eltern durften sie zwar danach noch sporadisch besuchen, jedoch nicht mehr ohne Anwesenheit eines »Bewachers« sprechen. Später kamen auch diese Besuche nicht mehr zustande. Die angereisten Eltern bekamen beispielsweise gesagt,

373 PA AA, AV NA 31592. Informe en derecho sobre la adopción del joven Tobías Müller. [Rechtsgutachten von RA Sergio Corvalán im Auftrag der Botschaft] vom 15.01.1990.

374 El Cronista vom 25.05.1977, S. 16. »Mientras el niño se recupera en Colonia Dignidad - Madre que Ilora por su hijo, sólo lo hace para sumarse a campaña antichilena«.

375 La Tercera vom 25.05.1977, S. 2. »Detectan una extraña maniobra antichilena«.

376 Hernán Escobar und Sergio Contreras.

377 Juzgado de Letras de Parral, AZ 43.210. Informe sobre Investigación a Colonia Dignidad, Ministro en Visita Extraordinaria Hernán Robert Arias, Ministro I. CA Talca. o. D. Von Richter Robert am 31.07.1989 der Corte Suprema übergeben. Enthalten in: CA Santiago, AZ 2182-98 (»Asociación Ilícita«) Bd. I (2) (Parral), Bl. 585-676, hier Bl. 676. 
ihre Kinder seien gerade verreist. ${ }^{378} \mathrm{Zu}$ dieser Personengruppe gehören auch Ricardo Dennys Alvear, und Victor Briones.

Alle Adoptionsverfahren fallen in die Zeit der Militärdiktatur. Der Rechtsanwalt Hernán Fernández erklärte bei einer Anhörung in der Cámara de Diputados 1999, wie später in den 1990er Jahren ein ähnlicher modus operandi seitens der CD-Führung genutzt wurde, um chilenische Jungen für das sogenannte Intensivinternat der CD zu gewinnen, wo sie dem Missbrauch durch Paul Schäfer ausgesetzt waren. Fernández betont, dass auch in den 1990er Jahren oft Kinder armer Familien in die Fänge der CD gerieten.

»comenta que los niños identificados como víctimas de violación sodomítica crónica, con lesiones anales eran niños que estaban en internado intensivo, con tutores nombrados por los alemanes. No tiene duda que se ha seguido la misma mecánica que históricamente se ha hecho, con la colaboración de jueces de menores de la zona de Parral, en que los menores ingresaban bajo el régimen de adopción a la ex Colonia. Aquí la simple pobreza era causal para perder vínculos legales y afectivos con su familia de origen. Muchos menores expresan que nunca conocieron a los tutores que aparecen en los procesos de adopción. «779

\subsubsection{Waffenbau und Waffenhandel}

Die CD stellte Waffen her und lagerte sie. Sie handelte mit Waffen und bahnte Waffengeschäfte zwischen Dritten an. Sie experimentierte mit Sprengstoffen und hantierte in einer sogenannten Giftküche mit gefährlichen Chemikalien. Es gibt Hinweise, dass die CD auch Teil des Projekts ANDREA war, eines Geheimprojekts der DINA und des chilenischen Heeres zur Herstellung chemischer und bakteriologischer Waffen (vgl. dazu Abschnitt 4.2.3). Mehrere Colonos legten im Zuge zahlreicher Gerichtsverfahren, insbesondere wegen Verstoßes gegen das Waffenkontrollgesetz ${ }^{380}$, Geständnisse über diese Taten $\mathrm{ab}$.

Im Juni 2005 barg die PDI auf dem Gelände der CD an drei verschiedenen Stellen Metallcontainer. ${ }^{381}$ Die Behälter waren jeweils fünf bis sechs Meter tief in der Erde vergraben. Sie enthielten große Menge Waffen, darunter Raketenwerfer, Mörsergranaten,

378 La Ultimas Noticias vom 26.05.1997, S. 6. »No ve a su hijo hace 23 años«. Der Artikel berichtet über den Fall von Sergio Contreras Muñoz und befragt die Mutter, Anna Muñoz.

379 Cámara de Diputados, Boletín de Sesiones, Legislatura 340ª Sesión 27 $7^{\mathrm{a}}$ vom 10.08.1999. Informe de las Comisiones Unidas de Derechos Humanos, Nacionalidad y Ciudadanía, y de Familia, encargadas de estudiar y fiscalizar cómo los distintos órganos públicos competentes han colaborado para el éxito de las investigaciones judiciales relativas a la ex Colonia Dignidad, auch online unter http s://www.camara.cl/camara/media/docs/colonia/04.pdf, S. 21 (zuletzt abgerufen am 12.02.2018).

380 CA Santiago, AZ 2182-98 (»Ley de Control de Armas«). Die Corte Suprema (AZ 4708-07) verurteilte am 02.07.2008 schließlich Paul Schäfer zu 3 Jahren und 300 Tagen Haft. Kurt Schnellenkamp und Karl van den Berg erhielten Bewährungsstrafen von 2 Jahren und 300 Tagen Haft. Hartmut Hopp wurde zu 90 Tagen Haft verurteilt, die durch die Untersuchungshaft bereits abgegolten waren.

381 Die Waffenfunde fanden im Rahmen des Verfahrens CA Santiago, AZ 2182-98 (»]uan Maino«) statt. Die Ermittlungen dazu wurden daraufhin in ein »Cuaderno separado sinfracción a la ley de control de armas« ausgegliedert und als eigenständiges Verfahren weitergeführt. 
Handgranaten, Nachtsichtgeräte und viele dutzende Revolver, Gewehre, Maschinenpistolen und Maschinengewehre sowie Chemikalien. ${ }^{382}$ In einem Container befanden sich zumindest Teile des CD-Geheimarchivs. ${ }^{383}$ Dieses beinhaltet zahlreiche Dokumente mit Bezügen zum Komplex Waffen. ${ }^{384}$ Im August 2005 fand die PDI auf dem Gelände der CD in Bulnes weitere Kriegswaffen, darunter etwa 1700 Handgranaten, mehrere Panzerabwehrraketen, 20.000 Initialsprengstoffpräparate, 9500 Zünder, Sprengstoffe, diverse Chemikalien sowie Schalldämpfer, Tränengasgranaten, Handschellen und eine Armbrust. ${ }^{385}$ Bei dieser Gelegenheit wurden angeblich auch Elektroschockgeräte (»Viehtreiber«) gefunden, mit denen Colonos gequält worden waren, sowie Fahnen der chilenischen PC sowie der MIR. ${ }^{386}$ Bei diesen Ausgrabungen handelte es sich um den zweitgrößten Waffenfund in der jüngeren chilenischen Geschichte. ${ }^{387}$ Tippgeber für beide Waffenfunde in der CD bzw. in Bulnes war laut eigener Aussage der Colono Michael Müller. ${ }^{388}$ Die Waffen sollen erst nach dem Abtauchen Schäfers, vermutlich 1998 oder 1999, an den späteren Fundorten vergraben worden sein. ${ }^{389}$

382 CA Santiago, AZ 2182-98 (»ley de control de armas«), Bd. III, BI. 771ff. Auto de Procesamiento (Anklageschrift) vom 03.10.2005 Darin ist eine Liste der gefundenen Waffen enthalten.

383 Laut Zeugenaussagen gibt es weitere Teile des Geheimarchivs, die immer noch vergraben liegen. Die PDI hat 2015 neue Ausgrabungen durchgeführt, um sie zu finden. Diese waren jedoch erfolglos.

384 Einige dieser Dokumente wurden als Beweismittel Teil der Ermittlungsakten in den Verfahren AZ 2182-98 (»Ley de Control de Armas«) sowie »Asociación Ilícita«.

385 CA Santiago, AZ 2182-98 (»Ley de Control de Armas«), Bd. II, BI. 255. Bericht des Departamento de Operaciones Especiales (GOPE) der Carabineros vom 22.08.2005. Informe Pericial sobre Diligencia Judicial de Búsqueda, Identificación y Destrucción de Artefactos Explosivos, Sustancias Químicas, Armamento y Accesorios Ocultos en el Interior del Fundo Denominado »El Litral«, Ubicado en la Localidad de Bulnes VIII. Región.

386 La Tercera vom 19.06.2005, S. 24. »Archivos hallados en ex Colonia Dignidad contienen antecedentes hasta 1987 «. Besonders kurios erschienen verschiedene gefundene sogenannte Fantasiewaffen: Eine Kamera, die Pfeile verschießen kann, ein Pistolenhalfter mit installierter Pistole, der beim Heben beider Arme automatisch Schüsse abgab, sowie Stifte, die $22 \mathrm{~mm}$-Kugeln verschossen. Kurt Schnellenkamp bestätigte 2005, einige Colonos hätten solche Waffen bei sich getragen: „Casi todos teniamos lapices, los que disparaban balas calibre $22 \mathrm{~mm}$, y otros con luz de bengala. Estos eran usados para defensa personal, en el viaje. «CA Santiago, AZ 2182-98 (»Asociación Ilícita«), Bd. I (2) (Ministro), Bl. 453ff. Richterliche Vernehmung von Kurt Schnellenkamp vom 23.06.2005. Ein weiterer skurriler Fund war eine Tüte mit zwei Patronenhülsen und einem Zettel mit der handschriftlichen Aufschrift »]ohn Kennedy«. Daraufhin soll geprüft worden sein, ob eines der aufgefundenen Cewehre möglicherweise die Tatwaffe des vermeintlichen Kennedy-Mörders Lee Harvey Oswald gewesen war. El Mercurio vom 20.06.2005, S. C 11. »]uez resolvería hoy destino de los archivos secretos de Villa Baviera«.

387 Das bislang größte Waffenarsenal wurde am 06.08.1986 von chilenischen Militärs im nordchilenischen Küstenort Carrizal Bajo gefunden. Die Frente Patriótico Manuel Rodríguez, der bewaffnete Arm der chilenischen kommunistischen Partei, hatte dies aus Kuba eingeschmuggelt, um die Pinochet-Diktatur zu bekämpfen.

388 CA Santiago, AZ 2182-98 (»Ley de Control de Armas«), Bd. II, BI. 531ff. Richterliche Vernehmung von Michael Müller vom 14.10.2005. Müller zufolge wurden die Verstecke verraten, da man von einem Regierungsprogramm profitieren wollte, das im Gegenzug für die Abgabe illegal erworbener Waffen Straflosigkeit zusicherte.

389 Ebd. und CA de Santiago, AZ 2182-98 (»Ley de Control de Armas«), Bd. II, BI. 524ff. Polizeiliche Vernehmung von Michael Müller vom 13.06.2005. Laut Müller wurden die Waffenverstecke in der 
Am 23. Januar 2006 bat der in Untersuchungshaft sitzende Colono Karl van den Berg Richter Jorge Zepeda, eine Aussage machen zu dürfen. In seiner Vernehmung gab er an, während der Allende-Regierung 12-15 Fässer mit Granatsplittern und dem Sprengstoff Nitrin befüllt zu haben. Nitrin sei hochgefährlich, da es ohne Zünder explodieren könne. Später habe er die Fässer gemeinsam mit Hugo Baar im Perquilauquén-Fluss versenkt. ${ }^{390}$ Am 29. März meldete die Tageszeitung El Mercurio, Spezialeinheiten der Kriminalpolizei hätten mit der Bergung der Fässer begonnen. ${ }^{391}$ Wenige Tage später habe Zepeda jedoch entschieden, die Bergung aus Sicherheitsgründen abzubrechen. ${ }^{392}$ Gerüchten zufolge war Zepeda das Risiko zu hoch, beim Bewegen der Fässer eine unvorhergesehene Explosion auszulösen. Stattdessen wurden auf dem Zufahrtsweg zur CD Schilder aufgestellt, die vor einem Betreten des Flussufers warnten (vgl. Abbildung 8).

Es folgten weitere Waffenfunde: Die Tageszeitung El Mercurio meldete im März 2006, Zepeda habe bei Ausgrabungen etwa 20 Panzerabwehrminen ausgraben lassen, zusammen mit Filmmaterial mit Aufnahmen über deren Produktionskette sowie von kontrollierten Explosionen der Minen. ${ }^{393}$

Vieles deutet darauf hin, dass die Bewaffnung der Colonia Dignidad in den Anfangsjahren vor allem der Selbstverteidigung der Gruppierung dienen sollte. Grund hierfür war die große Angst Schäfers, entdeckt und an der Fortsetzung seiner Sexualverbrechen gehindert zu werden. ${ }^{394}$ Schäfer und seine engsten Vertrauenspersonen in der CD verfügten schon früh über Schusswaffen. Colonos, die von Schäfer sexuell missbraucht wurden, berichten, dieser habe sie schon in den 1950er Jahren in Deutschland mit einer Pistole eingeschüchtert und gedroht sie umzubringen, falls sie Dritten von seinen Missbrauchshandlungen erzählten. ${ }^{395}$ Das vermutlich erste Opfer von Schusswaffen in der CD war Schäfer selbst. Am 23. Januar 1963 wurde er mit einer Schusswunde ins Krankenhaus von Parral eingeliefert und erst Anfang Juli 1963 wieder entlassen. Nach Angaben des behandelnden Arztes handelte es sich um einen Jagdunfall. ${ }^{396}$

CD ab 1998 geändert, da man befürchtete, der ehemalige Sicherheitschef Erwin Fege sowie Willi Malessa, die beide die CD 1998 verlassen hatten, könnten die Verstecke verraten. 1999 soll ein Teil der Waffen zum CD-Gelände in Bulnes verbracht und dort vergraben worden sein.

CA Santiago, AZ 2182-98 (»]uan Maino«), Bd. 6a, Bl. 2615. Richterliche Vernehmung von Karl van den Berg vom 23.01.2006.

391 El Mercurio vom 29.03.2006, S. C9. »Dignidad «.

392 La Tercera vom 01.04.2006, S. 26. »FBI apoya búsqueda de estadounidense desaparecido en exColonia Dignidad « [Kasten: »Finaliza búsqueda de explosivos«].

393 El Mercurio vom 11.03.2006, S. C15. »Hallazgo: Minas antitanques en Villa Baviera«.

394 Schäfer wurde seit dem 22.02.1961 per Haftbefehl vom AC Siegburg gesucht und lebte in ständiger Angst, entdeckt zu werden. Gleichzeitig fürchtete er eine Strafverfolgung durch die chilenischen Behörden aufgrund seiner Sexualverbrechen.

395 PJS, Sammlung CD. E-Mail der Ex-Colona Gudrun Müller an den Verfasser vom 11.02.2016.

396 Juzgado de Parral, AZ 53.015, BI. 1264ff. Ficha Clínica Paul Schäfer Schneider. Im Bericht von Dr. Prof. Armando Alonso zu Schäfers Entlassung am 03. Juli 1963 (nach Aufnahme am 08.02.1963) heißt es über »Paul Schneider Schafer«: »Enfermo de 41 años, educador de párvulos. Durante la caza, sufre a quemaropa una herida de bala (»rifle de salon«) escapular derecha subcutánea. Es operado en Parral de su proceso abdominal [...]. El 25 de marzo se extrae el proyectil.«. Die Nachwirkungen dieser Schusswunde begleiteten Paul Schäfer sein Leben lang. In der ersten Hälfte der 1990er Jah- 
Abbildung 8: Schild an der Zufahrtstraße zur ehemaligen Colonia Dignidad, das vor Sprengstoff warnt.

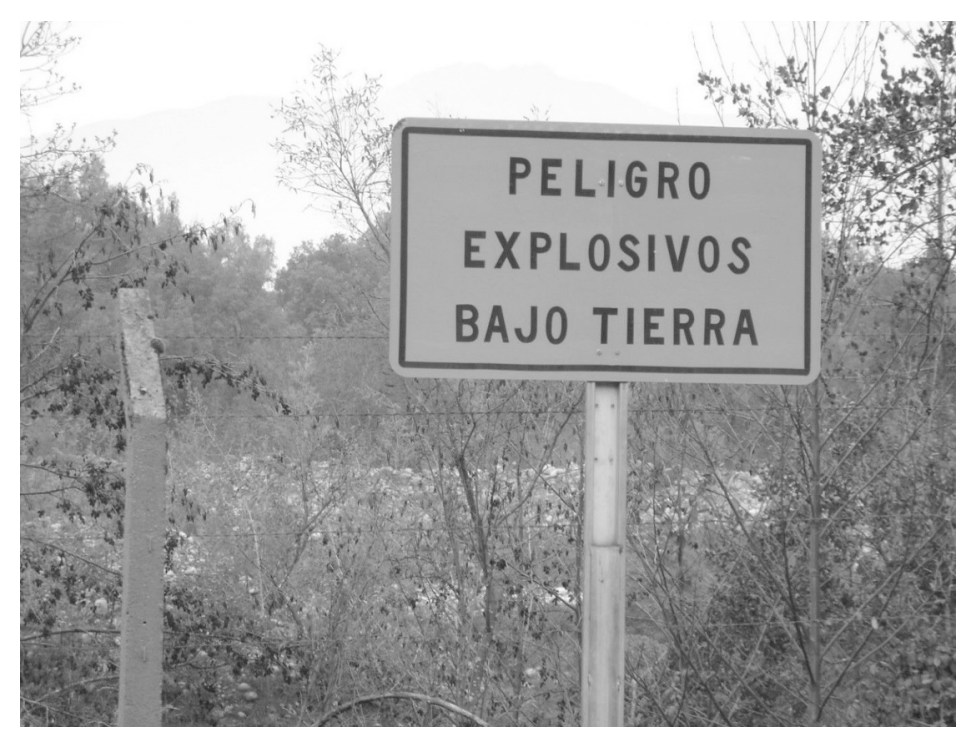

PJS, Sammlung CD. Fotografie des Warnschildes an der Zufahrtsstraße zur ehemaligen Colonia Dignidad, Mai 2009.

Der Wahlsieg Salvador Allendes 1970 löste bei der CD-Führung Ängste vor einer Enteignung ihres Grundbesitzes aus, hatte doch schon Allendes Amtsvorgänger, der Christdemokrat Eduardo Frei Montalva, eine Landreform angestoßen. Darüber hinaus befürchteten Schäfer und seine Vertrauten einen Angriff militanter linker Landreformaktivist_innen. ${ }^{397}$ Während der Allende-Regierung fanden in der CD regelmäßig militärische Trainings statt, an der viele Colonos teilnahmen. Unter den 2005 ausgegrabenen Dokumenten war auch ein detaillierter "Alarmplan«, der genaue Abläufe im Falle eines Angriffs festlegte, Colonos bestimmten Gruppen zuteilte und diesen jeweils Gefechtspositionen und Waffen zuwies. ${ }^{398}$ Außerdem wurden Funkverbindungen zwischen den verschiedenen bewaffneten Einheiten sowie Vorgehensweisen zur Versorgung von Verwundeten definiert. Potentielle Angreifer sollten durch Maschinengewehrfeuer, Tränengassalven, Flammenwerfer, Sprengladungen und diverse Fallen neutralisiert und zurückgeschlagen werden. Neben verschiedenen Männergruppen sollte auch eine Frauengruppe mit dem Namen »Dornbusch« an den Gefechten teilnehmen. Dieses Verteidigungsszenario wurde regelmäßig geprobt.

re ließ er sich in verschiedenen Krankenhäusern in Santiago mehrfach unter dem Namen eines Colonos, Walter Laube Wendland, behandeln.

397 CA Santiago, AZ 2182-98 (»Ley de control de Armas«), Bd. 2, BI. 451ff. Brief eines Mitglieds der CD-Führung an Hugo Baar vom 12.10.1970.

398 CA Santiago, AZ 2182-98 (»Asociación Ilícita«), Bd. I (2) (Ministro), Bl. 60off. Informe Secreto 263 der JIPOL an Richter Zepeda vom 28.12.2005. 
Unter den Dokumenten, die Ermittler_innen 2005 zusammen mit den Waffen fanden, waren mehrere Schreiben Schäfers und weiterer CD-Führungsmitglieder an Hugo Baar, der damals noch in Siegburg lebte und die PSM leitete. Baar wurde darin gebeten, Einzelteile und Materialien für die Anfertigung von 40-50 Maschinengewehren nach Chile zu schicken. Außerdem sollte er Waffen, Munition, Handgranaten, Tränengas und weitere chemische Substanzen auf dem Schwarzmarkt besorgen. ${ }^{399}$ Am 8. Oktober 1970 schickte Baar zwei Maschinengewehre als Ansichtsexemplare zum Nachbau, per Luftfracht nach Chile, eingeschweißt in Sauerstoffflaschen, die als medizinisches Gerät deklariert waren. ${ }^{400}$ Dies hatte Baar selbst bereits 1990 gegenüber der chilenischen Wahrheitskommission ${ }^{401}$ sowie zuvor bei einer Vernehmung durch das Finanzamt Siegburg 1988 eingeräumt:

»Ich habe auf dem Schwarzmarkt 1970/1971, nachdem ich im September 1970 von Schäfer im Beisein von Herrn Rudolf Cöllen Dollar in bar erhalten hatte, Pistolen, einige Cewehre, zwei Maschinengewehre und eine oder zwei Maschinenpistolen zuzüglich Munition gekauft und sie schwarz zusammen mit unseren caritativen Sendungen nach Chile geschafft. ${ }^{402}$

Weitere Waffen sollen auf dem Seeweg in Containern, in die Colonia gelangt sein. ${ }^{403}$ Sie wurden in einem Kellerraum verwahrt, von dem laut Hugo Baar nur folgende Personen wussten: Karl van den Berg, Rudi Cöllen, Johann Spatz, Heinrich Neufeld, Irenius Nikolai und Erwin Bohnau. Van den Berg und Spatz seien bezüglich der Waffen Schäfers Vertrauenspersonen gewesen. ${ }^{404}$ Sie errichteten eine Lagerhalle, in der oberirdisch Heuballen gelagert wurden. Darunter, im Keller, wurden Waffen ausprobiert und Schießübungen durchgeführt. ${ }^{405}$

399 CA Santiago, AZ 2182-98 (»Asociación Ilícita«), Bd. I (2) (Ministro), Bl. 611ff. Informe Secreto 263 der JIPOL an Richter Zepeda vom 28.12.2005 sowie PJS, Sammlung CD. Protokoll der Anhörung von Waltraud und Hugo Baar am 02/03.11.1990 durch Vertreter_innen der Comisión Nacional de Verdad y Reconciliación.

400 CA Santiago, AZ 2182-98 (»Ley de control de Armas«), Bd. II, BI. 440ff. Informe Secreto Nr. 212 der JIPOL an Richter Zepeda.

401 PJS, Sammlung CD. Protokoll der Anhörung von Waltraud und Hugo Baar am 02/03.11.1990 durch Vertreter_innen der Comisión Nacional de Verdad y Reconciliación vom 02.11.1990, S. 5. Hier sagte Baar, er habe 1970 auf dem Seeweg unter Missionsgut versteckt 20-40 Pistolen der Marke Walther, ein Maschinengewehr und Einzelteile eines zweiten Maschinengewehres, 20 Gewehre, 1-2 Maschinenpistolen und Munition nach Chile geschickt. Später in Chile habe er auch Waffen vorgefunden, die er nicht gekauft habe, wie beispielsweise ein sowjetisches Maschinengewehr

402 StA Bonn, AZ 50 ]s 285/85, Bd. IX, Bl. 132. Finanzamt Siegburg, Niederschrift über die am 21.April 1988 an Amtsstelle erteilten mündlichen Auskünfte [von Hugo Baar und Waltraud Baar] betreffend die Private Sociale Mission e. V., Siegburg. Das Siegburger Finanzamt prüfte im Nachgang der Bundestagsanhörung vom 22.02.1988 die Gemeinnützigkeit der PSM.

403 CA Santiago, AZ 2182-98 (»Ley de Control de Armas«), Erstinstanzliches Urteil vom 28.08.2006, S. 15 .

404 PJS, Sammlung CD. Protokoll der Anhörung von Waltraud und Hugo Baar am 02/03.11.1990 durch Vertreter_innen der Comisión Nacional de Verdad y Reconciliación vom 02.11.1990, S. 5. Baar spricht hier von fünf Personen, zählt jedoch dann sechs Namen auf.

405 CA Santiago, AZ 10-2004 (»Adriana Bórquez«), Bl. 186. Polizeiliche Vernehmung von Franz Baar vom 14.05.2004. Baar berichtet, dass diese mit unterirdischen Kelleranlagen versehene Lagerhalle 
Aussagen von Colonos belegen auch, dass die CD regelmäßig Waffen auf dem Seeweg einführte, als Missionsgut deklariert, unter Altkleidern in Containern versteckt. ${ }^{406}$ Vermutlich waren diese Waffen nicht für die CD selbst bestimmt, sondern zum Weiterverkauf. Albert Schreiber hatte Kontakte zu Beamt_innen des Zolls im Hafen von Valparaíso. Diese ließen die Waffen undeklariert passieren und erhielten im Gegenzug Geschenke sowie Einladungen in die CD. Dieser Waffenschmuggel wurde bereits in den 1980er Jahren bekannt und damals auch in der chilenischen ${ }^{407}$ und deutschen ${ }^{408}$ Presse thematisiert.

Im April 1987 legte das holländische Schiff »Nedloyd Manila« im Hafen der nordchilenischen Stadt Antofagasta an. In einem Container, der im mexikanischen Acapulco geladen worden war, wurden 82 Kartons mit 186.000 Schuss Munition verschiedenen Kalibers gefunden. Diese waren beim Anlaufen des chilenischen Hafens nicht deklariert. Daraufhin wurde der Kapitän des Schiffes verhaftet. Die Ladung soll für die CD bestimmt gewesen sein, und wurde in Valparaíso von einem Lastwagen der CD abgeholt. ${ }^{409}$

Eine weitere Waffenlieferung an die CD wurde durch ein »Behördenversehen« bekannt: Bei einer Routinekontrolle stoppte ein Polizist kurz nach dem Militärputsch einen mit Waffen beladenen Lastwagen, der auf dem Weg in die CD war. Am folgenden Tag erschien Schäfer entrüstet beim Vorgesetzten des Polizisten in Linares und legte eine von Pinochet unterzeichnete Karte vor, die sämtliche Mitglieder der Streitkräfte

hundert Meter von der Flugpiste und 200 Meter von dem Kanal mit Wasserkraftturbinen entfernt lag.

406 CA Santiago, AZ 2182-98 (»Ley de Control de Armas«). Erstinstanzlichen Urteil vom 28.08.2006, S. 13. Darin ist eine Aussage von Johann Spatz zitiert, in der dieser berichtet, dass Waffen in Containern unter Altkleidern versteckt in die CD gelangten.

407 Vgl. Análisis vom 30.07.1985, S. 24. „Colonia Dignidad - Qué abran las cajas!« Demnach sei beim Direktor der Nationalen Zollbehörde eine anonyme Anzeige eingegangen: Die CD erhalte regelmäßig auf dem Luft- und Seeweg Frachtgut, dass nicht von den Zollbehörden untersucht werde. Der Beamte Patricio Stillmann lasse das Frachtgut ungeöffnet passieren und bekomme im Cegenzug von der CD Geschenke sowie Einladungen, dort Urlaub zu machen. Alfred Matthusen bringe wöchentlich Geschenke zur Zollbehörde. Das Frachtgut sei deklariert als Medikamente und Verbrauchsgüter für das Krankenhaus der CD, oder aber als Altkleiderspende. Oftmals befänden sich in den Containern aber Mercedes-Fahrzeuge und Jeeps sowie Waffen. Der anonyme Anzeigenerstatter habe angeregt, die nächste Containerlieferung zu kontrollieren. Vgl. auch El Mercurio vom 06.12.1987, S. D4f. »Dignidad, puertas adentro«. Dort heißt es: »En dos ocasiones los han acusado de ingresar armas o maquinarias en los containers de ropa usada y, aunque la inspección es por sorteo, hace dos años Aduana anunció que lo revisaría todo.«

408 Gemballa, Gero. »Munition für das Folterlager«, in: Der Stern Nr. 8/1988 vom 18.02.1988, S. 236-238.

409 Ebd. Die CD reagierte auf Cemballas Stern-Artikel mit einer Unterlassungsklage gegen Autor und Verlag (OLG Köln, AZ 15 U 197/88). Der Ausgang dieses Verfahrens ist nicht bekannt. Im Verfahren wegen Bildung einer kriminellen Vereinigung in Chile finden sich die Frachtunterlagen über den Munitionstransport sowie der Einstellungsbeschluss aus einem zollrechtlichen Vorverfahren (Tribunal de Aduanas de Antofagasta, AZ 083/87). CA Santiago, AZ 2182-98 (»Asociación Ilícita«), Bd. I (2) (Ministro), Bl. 443ff. 
anwies, dem Inhaber dieser Karte vollste Unterstützung zukommen zu lassen. Damit war die Sache erledigt. ${ }^{410}$

Zudem begann die CD, selbst Waffen und Sprengstoffe zu produzieren. Der Colono Gerd Schaffrik berichtete, er selbst habe während der Regierungszeit Allendes Projektile mit Trinitrophenol befüllt. Davor habe auch Hopp mit Explosivstoffen gearbeitet:

»[D]urante el período del Allende, recibí la orden de hacer un tipo de explosivo con strinitrofenok [...] Sé que antes trabajó Hopp en estos explosivos, pero lo hice mejor que él y eso me gustó. Se rellenaron unas especies de proyectiles de barco con este explosivo. ${ }^{411}$

Karl van den Berg leitete die Produktion von Waffen an, an der teilweise 40 Colonos im Schichtbetrieb mitwirkten. ${ }^{412}$ Verschiedene Colonos bestätigten bei Vernehmungen 2005 ihre Beteiligung an der Produktion von Maschinengewehren, Maschinenpistolen, Handgranaten, Sprengstoffen, Schalldämpfern und Nachtsichtgeräten seit 1970 und teilweise bis ins Jahr $1994 .{ }^{413}$ Die Angaben über die Menge der gefertigten Waffen sind unzureichend. Ein Colono berichtete allerdings, er habe an der Produktion von etwa 100 Maschinengewehren und 500 Handgranaten mitgewirkt. ${ }^{414}$ Wie auch bei anderen Arbeitsprozessen in der CD, waren die Sicherheitsstandards im Produktionsverfahren gering, weshalb es zu einer Reihe von Unfällen kam. ${ }^{415}$

410 CA Santiago, AZ 12293-2005 (»homicidio Miguel Becerra Hidalgo«). Erstinstanzliches Urteil vom 27.11.2008, S. 8.

411 CA Santiago, AZ 2182-98 (»Ley de control de Armas«), Bd. II, BI. 421 Richterliche Vernehmung von Gerd Schaffrik vom 22.09.2005.

412 CA Santiago, AZ 2182-98 (»Maino«), Bd. 2a, Bl. 983ff. Polizeiliche Vernehmung von Harald Tymm vom 25.05.2005. Tymm berichtet, er sei ab dem Jahr 1970 unter der Leitung von Karl van den Berg und Johann Spatz an der Herstellung von Handgranaten und Maschinengewehren beteiligt gewesen. An der Waffenherstellung hätten außerdem Willi Malessa, Erwin Fege, Günther Schaak, Friedhelm Bensch, Ulrich Schmidtke, Gerd Machacek, Klaus-Dieter Schmidtke und Siegfried Laube mitgewirkt. Zwischen 1970 und 1976 habe er, Harald Tymm, an militärischen Trainings unter der Leitung von Paul Schäfer, Johann Spatz und zwei Chilenen teilgenommen. Sie seien für den Fall eines Angriffs auf die CD im Umgang mit langen und kurzen Waffen ausgebildet worden. Der Sohn von Manuel Contreras habe zudem Selbstverteidigung gelehrt. An der militärischen Ausbildung hätten Gerd Schaffrik, Friedhelm Bensch, Günther Schaak, Wolfgang Zeitner, Erwin Fege, Manfred Lindemann sowie Dietmar und Winfried Schmidtke teilgenommen.

413 CA de Santiago, AZ 2182-98 (»Ley de Control de Armas«), Bd. II, BI. 524ff. Polizeiliche Vernehmung von Michael Müller vom 13.06.2005. Ebd., Richterliche Vernehmung von Michael Müller vom 14.10.2005. Bei den Waffen, die nach dem Ende der Diktatur produziert wurden, soll es sich um Nachtsichtgeräte, Laser-Zielfernrohre und Schalldämpfer gehandelt haben. Die Schalldämpfer seien an Angehörige des Militärs verkauft worden.

414 CA Santiago, AZ 2182-98 (»Asociación Ilícita«), Bd. III (Ministro), BI. 1288. Polizeiliche Vernehmung von Rüdiger Schmidtke vom 17.03.2006.

415 So verletzte sich Eugen Böckler beim Ausprobieren einer Handgranate durch Metallsplitter an einer Hand. Vgl. CA Santiago, AZ 2182-98 (»Armas«), Bd. 4, Bl. 1381. Richterliche Vernehmung von Eugen Böckler vom 14.06.2005. Gerhard Laube zog sich bei der Herstellung von Sprengstoffen schwere Verbrennungen zu und soll zwei Jahre lang in Santiago im Krankenhaus behandelt worden sein. CA Santiago, AZ 10-2004 (»Adriana Bórquez«), BI. 482. Richterliche Vernehmung von Heinz Kuhn vom 16.06.2004. 
Den 50 Colonos, denen Schäfer am meisten vertraute, schenkte er je eine BrowningPistole, ${ }^{416}$ die diese ständig mit sich führten. In den Ermittlungsakten findet sich eine Liste der bei den Behörden eingetragenen Schusswaffen von Colonos. ${ }^{417}$ Diese umfasst 50 Pistolen und neun Gewehre, die auf CD-Führungsmitglieder und Vertrauenspersonen Schäfers eingetragen waren. Darunter waren auch vier Frauen. ${ }^{418}$

\title{
Vorbereitungen für den Militärputsch, Kooperation mit chilenischen Rechtsextremen
}

Zwischen 1970 und 1973 trafen sich verschiedene Gruppen militanter Allende-Gegner in der CD, um dort militärische Trainings und Kurse abzuhalten, Sabotageakte zu planen und von dort aus auszuführen. Der 1974 von der CD ermordete DINA-Agent Miguel Angel Becerra Hidalgo war vormals ein Mitglied der militanten rechtsextremen Organisation »Patria y Libertad« gewesen. Sein Bruder berichtete 1985 über die enge Zusammenarbeit von Patria y Libertad mit der Colonia Dignidad:

\begin{abstract}
»Miguel Angel Becerra Hidalgo en la época de la Unidad Popular, a partir de 1972 perteneció a un grupo de Patria y Libertad que realizaba trabajo de sabotaje. Trabajaba junto a Eugenio Martínez, Patricio Sotomayor y un señor de apellido Cardemil, mayor de ejército, ex director del Hospital de Linares entre otros. Este grupo operaba en la zona de Linares.

En una de las acciones este grupo tomó contacto con otro en que participaba un Teniente del Ejército y miembros de la Colonia Dignidad, se unieron y siguieron trabajando juntos. Los alemanes tenían más medios, ellos ofrecieron que el cuartel general funcionara en el interior de Colonia Dignidad. En uno de los operativos que tenía por objeto volar una torre de alta tensión en la zona de Longaví fueron sorprendidos por funcionarios de Cobierno de la época, tuvieron que arrancar, eran 506 personas, usaban una camioneta Peugeot de propiedad de Becerra, en la fuga chocaron con un camión estacionado, esto fue en la ciudad de Longaví. Becerra sufrió un golpe en la cabeza, con herida, los alemanes lo trasladaron al Hospital de la Colonia donde estuvo un buen tiempo hospitalizado. El grupo siguió actuando hasta septiembre de 1973, y en el recinto de la Colonia recibió entrenamiento militar.«19
\end{abstract}

Schon zu Allende-Zeiten kursierten Gerüchte darüber, dass Patria y Libertad die CD als paramilitärisches Trainingslager nutzte. ${ }^{420}$ In der CD gefundene Dokumente bele-

416 CA Santiago, AZ 2182-98 (»]uan Maino«), Bd. 2a, BI. 1021. Richterliche Vernehmung von Ulrich Schmidtke vom 31.05.2005.

417 CA Santiago, AZ 2182-98 (»Asociación Ilícita«), Bd. Parral I (2), Bl. 707ff. Resumen de Armas a Nombre de la Ex Sociedad Benefactora y Educacional Dignidad, sus Integrantes y Personas que han salido del Enclave Alemán [o. D.].

418 Dabei handelt es sich um Erika Heimann, Edith Malessa, Ingrid Klunk und Katharina Pöhlchen.

419 FUNVISOL, CD 2070, Rel 156-85. Testimonio Aristides Becerra Hidalgo, 1985.

420 So sagte z.B. Erick Zott, ein 1975 in der CD gefoltertes Mitglied der MIR, bei seiner Vernehmung 1978 durch das LG Bonn: »Ich erinnere mich auch noch an den Inhalt eines Informationsblattes der Studentenföderation der Universität Concepción aus dem Jahre 1972, in dem bekannt gemacht wurde, daß in der Colonia Dignidad eine Gruppe Rechtsextremer militärisch ausgebildet werde. 
gen nun, dass die CD militante Allende-Gegner mit Waffen versorgte. ${ }^{421}$ Eine wichtige Rolle spielte hierbei die Gruppe der sogenannten »pequeños agricultores « (»kleinen Landwirte«) - eine Reihe von Landbesitzern aus der Umgebung der CD, die sich in Anfang der 1970er Jahre regelmäßig in der CD trafen und Aktionen zur Destabilisierung der Allende-Regierung planten. Die CD verteilte und verkaufte an diese Gruppen u.a. Handfeuerwaffen, Munition, Sprengstoffe und Funkanlagen. ${ }^{422}$

Vieles deutet darauf hin, dass die Waffenproduktion in der CD nach dem Putsch vom 11. September 1973 ausgeweitet wurde, um chilenische Militärs mit Waffen zu versorgen. So veranstaltete die CD beispielsweise anlässlich eines Besuchs von Diktator Augusto Pinochet in der Siedlung am 20. August 1974 eine Waffenschau, worüber der damalige Pressesprecher Pinochets, Federico Willoughby, in einer Vernehmung ausführlich berichtete:

»[L]uego de las recepciones de rigor, se efectuó un stours< por el interior de la Colonia, siendo llevados en un momento a una habitación grande, con una gran mesa, donde se ubicaron todos; exhibiéndoseles una gran cantidad de elementos de defensa, armas de fuego diversas, visores nocturnos, etcétera; exhibiéndose además una metralleta sSterling ‘, que preguntando Pinochet de donde provenía esta arma, le respondieron que era del Ejército de Chile; luego, le mostraron otra arma similar, al preguntar de nuevo Pinochet por su procedencia, explicaron que esa arma había sido fabricada en la Colonia; precisa que ambas armas, al ser disparadas por los alemanes a través de una ventana de la habitación, pudieron darse cuenta que eran muy silenciosas; la gente que iba explicando esto, agrega, era gente de Contreras [...] asevera que tuvo la impresión que Pinochet conocía la existencia de todo esto. ${ }^{423}$

Willoughby berichtete auch von einem Kommentar des Generals Alfredo Canales. Dieser habe ihm gesagt, die CD verfüge über genügend Personal, Waffen und Artillerie, um etwa die Stadt Los Ángeles (mit damals gut 50.000 Einwohner_innen) einzunehmen. ${ }^{424}$

Der ehemalige DINA-Agent Michael Townley bestätigte in seinen Aussagen den Waffenbau in der CD. Allerdings erklärte er bei einer Vernehmung durch den chilenischen Richter Alejandro Madrid in den USA, die dort hergestellten Maschinengewehre seien von schlechter Qualität gewesen:

»El Ceneral Contreras...en 1976, a principios de 1977, por intermedio de Pedro Espinoza me dio o me había dado un par de metralletas fabricadas en Colonia Dignidad, basadas en un diseño alemán, me las dio para probarlas, básicamente para ver si... nadie en FAMAE o cualquier otro lugar había podido hacerlas funcionar en forma confiable. Y

Der Name dieser Rechtsextremisten ist Patria y Libertad«. LC Bonn, AZ 30 123/77, BI. 554. Vernehmung von Erick Zott vom 17.10.1978.

421 CA Santiago, AZ 2182-98 (»Asociación Ilícita«), Bd. I (2) (Ministro), Bl. 60off. Informe Secreto 263 der JIPOL an Richter Zepeda vom 28.12.2005.

422 Ebd., Bl. 604.

423 CA Santiago, AZ 12293-2005 (»homicidio Miguel Becerra Hidalgo«). Erstinstanzliches Urteil vom 27.11.2008, S. 8.

424 Ebd. Los Ángeles liegt etwa 180 Kilometer südlich der Colonia Dignidad und hat heute etwa 200.000 Einwohner_innen. 
luego de un mes o más jugando con ellas, tuve que conincidir totalmente con ellos, silenciadores sumamente buenos, armas increíblemente malas. « 425

In den Jahren nach dem Putsch vom 11. September 1973 bauten Kurt Schnellenkamp und Albert Schreiber die Kontakte der CD zu Offizieren verschiedener Militärregimenter aus, insbesondere in den Regionen Maule und Biobío. ${ }^{426}$ Auf diesem Wege besorgte die CD eine große Anzahl von Handfeuerwaffen, Munition, Mörsergranaten, Handgranaten und Sprengstoff. ${ }^{427}$ Schnellenkamp soll nach dem Putsch sogar im Hauptquartier der 3. Heeresdivision in Concepción tätig gewesen sein. ${ }^{428}$ Gleichzeitig stellte die CD einzelnen DINA-Agenten und Militärs Waffen und weitere Ausrüstung für Operationen gegen Oppositionelle zur Verfügung, lt. folgendem Eintrag auf einer Ficha, also einer Karteikarte aus dem CD-Geheimarchiv z.B. 1975 für eine Geheimdienstoperation gegen die Christdemokratische Partei:

»HIPOLITO SILVA ROJAS, teniente de Ejército, Escuela de Artillería de Linares, Jefe del CIRE de Linares. Tiene curso de inteligencia. (Hcp 30-9-75) El 2-10-75, llegó junto al Teniente Véjar, jefe del SIM, a la casa de recepción del fundo El Lavadero, para preguntar por gas paralizante, arma corta con silenciador, pelucas con barbas y bigotes. Querían pillar una red grande de la DC $(2-10-75) . \ll^{429}$

In der CD fanden Kurse für DINA-Agenten statt, bei denen diese von chilenischen Militärs und Colonos im Umgang mit Waffen und Sprengstoffen geschult wurden. Der ehemalige DINA-Agent Carlos Hernán Labarca Sanhueza berichtete Richter Jorge Zepeda 2007 von der wichtigen Rolle, der CD bei der Errichtung der Escuela Nacional de Inteligencia im Cajón del Maipo bei Santiago hatten. Die CD hatte hier u.a. die Funkanlagen installiert. Labarca berichtete auch von Sprengstofftrainings unter Leitung Gerhard Mückes in der CD, an denen er teilgenommen hatte:

»No recuerda bien la fecha en que, de la agrupación de `Casa de Piedra<, unas 6 a 7 personas, visitaron `Colonia Dignidadı, en grupos de 2 o 3 por el lapso de una semana, aproximadamente, acompañándolos [Armando] Fernández Larios. En dicho lugar

425 CA Santiago, AZ 7981-C (»homicidio Eugenio Berríos«), Bd. 7b, BI. 2298f. Richterliche Vernehmung von Michael Townley vom 13.07.2006.

426 Kurt Schnellenkamp hatte nach eigener Aussage insbesondere Kontakte zu Offizieren der 3. Heeresdivision in Concepción, wie Dante Iturriaga, Washington Carrasco und Luciano Díaz. CA Santiago, AZ 2182-98 (»]uan Maino«), Bd. $3^{\text {a }}$, Bl. 1299f. Polizeiliche Aussage Kurt Schnellenkamps vom 08.06 .2005

427 CA Santiago, AZ 2182-98 (»Asociación Ilícita«), Bd. I (2) (Ministro), BI. 453ff. Richterliche Vernehmung von Kurt Schnellenkamp vom 23.06.2005 sowie CA Santiago, AZ 2182-98 (»Asociación Ilícita«), Bd. I (2) Ministro, Bl. 60off. Informe Secreto 263 der JIPOL an Richter Zepeda vom 28.12.2005.

428 CD-Geheimarchiv. Ficha Amaya P. Gregorio. »Trabajó junto a Ku en el Cuartel General de la IIla. División en Concepción, después del 11«.

429 CD-Geheimarchiv. Ficha Hipólito Silva Rojas. CIRE steht für Centro de Inteligencia Regional, eine irregulares Kommando aus Mitgliedern von Marine und Heer zur Bekämpfung von linken Aktivist_innen. Dieses hatte seinen Sitz in der Marinebasis von Talcahuano. 
participó en un curso de `nociones de explosivos` dictado por el mismo colono gordo Ilamado >Mauk« [Gerhard Mücke], junto a otros colonos más jóvenes.« 430

Die ehemalige DINA-Agentin Maria Gómez Davis berichtete in einer Vernehmung von einem mehrtägigen Lehrgang mit Schießtraining in der CD:

»Hacíamos práctica de tiro, en una especie de cancha de tiro, que yo pienso que estaba cerca de la cancha de aterrizaje [...] Había apoyo para las metralletas que disparábamos, que eran sacos de arena. Se nos hacia instrucción con armas cortas, revólveres >Rossi< calibre 32, y pistolas, y también fusiles y metralletas con cargador circular. Los disparos los hacíamos dirigidos a blancos. $\ll^{431}$

Die »Grüne Gruppe«, eine paramilitärische Einheit der Colonos, absolvierte unter Leitung von Johann Spatz militärische Trainings. Der Sohn des DINA-Chefs, Manuel Contreras Valdebenito, unterrichtete die Gruppe in Karate. Auch eine weitere militärische Einheit von Colonos wurde von Chilenen instruiert. ${ }^{432}$

\section{Organisator des Waffenhandels im großen Stil: Gerhard Mertins}

Es gibt eine Reihe von Belegen und Indizien dafür, dass die CD ein wichtiger Umschlagplatz für Waffen war, die für das chilenische Militär bestimmt waren. In der CD wurden auch internationale Waffengeschäfte eingefädelt. Eine Reihe wichtiger Waffenhändler besuchte die Colonia Dignidad. Aussagen von Colonos bestätigen vor allem die zentrale Rolle, die »der berühmteste deutsche Waffenhändler der Nachkriegszeit «, ${ }^{433}$ Gerhard Mertins, ${ }^{434}$ dabei spielte. Mertins war während des Nationalsozialismus SS-Offizier gewesen und u.a. am »Unternehmen Eiche«, der Befreiung des italienischen Diktators Benito Mussolini 1943 beteiligt. Nach 1945 war Mertins in neonazistischen Organisationen aktiv. 1951 ging er als Militärberater nach Ägypten und in weitere Länder des Nahen Ostens, wo er als Vertreter großer bundesdeutscher Unternehmen Geschäfte vermittelte, aber auch für den US-Heeresgeheimdienst tätig war. ${ }^{435}$ Ab 1956 arbeitete Mertins unter dem Decknamen »Uranus« für den BND. 1963 gründete er gemeinsam mit Otto Skorzeny die Waffenfirma Merex AG, die hauptsächlich mit ausgesonderten Waffen der

430 CA Santiago, AZ 2182-98 (»Asociación llícita«), Bd. V (Ministro), BI. 2251. Richterliche Vernehmung von Carlos Hernán Labarca Sanhueza vom 25.04.2007.

431 CA Santiago, AZ 2182-98 (»Alvaro Vallejos Villagrán«), Bd. 4a, Bl. 1263f. Richterliche Vernehmung von Maria Antonieta Gómez Davis vom 21.03.2000.

432 CA Santiago, AZ 2182-98 (»Ley de Control de Armas«), Bd. 2, Bl. 531. Richterliche Vernehmung von Michael Müller vom 14.10.2005. Vgl. auch Revista Cosas vom 01.04.2005, S. 84ff. »Manuel Contreras Valdebenito: Mis días en Colonia Dignidad«.

433 Der SPIECEL Nr. 40/1990 vom 01.10.1990, S. 97-99, »Der Weg des Teufels«.

434 Zur Person Gerhard Mertins vgl. Silverstein, Ken. Private Warriors, New York 2000, S. 109-140; Hammerschmidt, Deckname Adler, S. 249-272 sowie Hammerschmidt, Peter. »With the Backing of the BND«. Die Waffengeschäfte des westdeutschen Auslandsnachrichtendienstes mit lateinamerikanischen Militärdiktaturen - das Beispiel »MEREX«, in: Journal of Intelligence, Propaganda and Security Studies (JIPSS), 6 (2012), S. 26-40.

435 Pérez Ricart, Carlos A. MEREX AG o la frontera de lo (i)legal en la política alemana de exportación de armamento. México vía Berlín Working Papers, Nr. 3, Berlin 2014, online unter https://www.sso ar.info/ssoar/handle/document/38508, S. 30. 
Bundeswehr handelte. Medienbekannt wurde Mertins Mitte der 1970er Jahre. Nach Anschuldigungen, er habe gesetzeswidrig Waffen in Spannungsgebiete geliefert, konnte Mertins vor Gericht belegen, dass der BND über diese Lieferungen Bescheid gewusst hatte. Daraufhin sprach ihm das Gericht wegen der erlittenen »Rufschädigung« eine Entschädigungszahlung in Höhe von 5 Millionen DM zu. ${ }^{436}$ Im April 1976 flog Mertins gemeinsam mit DINA-Chef Manuel Contreras und weiteren chilenischen Offizieren in den Iran, um beim Shah-Regime Unterstützung für die DINA und den »weltweiten Kampf gegen den Marxismus« zu suchen. ${ }^{437}$ Dem iranischen Regime soll Contreras angeboten haben, Ilich Ramirez Sánchez, besser bekannt als »Carlos«, zu ermorden. Dabei soll Contreras mit einem falschen Pass über die Bundesrepublik gereist sein, wo er sich mit Mertins traf, um dann gemeinsam mit ihm weiter in den Iran zu reisen. ${ }^{438}$

Der Ursprung der engen Verbindung zwischen Mertins und der CD ist angeblich, dass Hartmut Hopp bei einem Studienaufenthalt in den USA (1968-1970) Mertins' Sohn Helmut kennenlernte. ${ }^{439}$ Mertins besuchte wiederholt die $\mathrm{CD}^{440}$ und verteidigte diese öffentlich. ${ }^{441}$ Er lobbyierte bei Behörden und Institutionen für die CD und vermittelte ihr seinen Rechtsanwalt, Ludwig Klassen. Dieser vertrat die CD seit 1980 im Zivilverfahren gegen Amnesty International und den Verlag Gruner \& Jahr. ${ }^{442}$ Mertins gab sich mehrfach als Vorsitzender eines »Freundeskreises Colonia Dignidad « ${ }^{443}$ aus, der jedoch keinen formellen Status hatte, sondern eher ein loser Zusammenhang von Unterstützer_innen der CD in Deutschland war. Der damalige Botschafter Knackstedt berichtete dem AA 1989 zu den Beziehungen zwischen der CD und Mertins:

436 Vgl. das Buch eines Redakteurs der Tageszeitung Die Welt sowie Freundes von Mertins: Vielain, Heinz. Waffenhandel im Staatsauftrag. Was lange in Bonn geheim bleiben musste, Herford 1986.

437 Vgl. Gónzalez, Mónica. »El día en que Manuel Contreras le ofreció al Sha de Irán matar a >Carlos, El Chacal««, in: CIPER (Website), 29.08.2009, online unter https://www.ciperchile.cl/2009/08/06/el -dia-en-que-manuel-contreras-le-ofrecio-al-sha-de-iran-matar-a-"el-chacal"/.

438 Ebd.

439 Gemballa, Gero. Colonia Dignidad. Ein deutsches Lager in Chile, Reinbek 1988, S. 155.

440 Mertins selbst sagte aus, »5 bis $6 \mathrm{Mal}$ « in der CD gewesen zu sein. StA Bonn, AZ 50 ]s 285/85, Bd. XI, BI. 75. Vernehmung von Gerhard Mertins vom 01.03.1989. Es existiert ein Foto von 1981, auf dem Gerhard Mertins gemeinsam mit Paul Schäfer und Hugo Baar zu sehen ist. Das Foto beschlagnahmte Richter Zepeda 2005. CA Santiago, AZ 2182-98 (»]uan Maino«), Bd. 4b, Bl. 1935. Acta de Retiro de Especies vom 27.09.2005.

441 Vgl. Westfälische Rundschau vom 28.12.1979. »Waffenhändler: Colonia Dignidad kein Folterlager« sowie Kölner Stadtanzeiger vom 17.06.1980. »Waffenhändler und Bischof miteinander im Clinch«.

442 Heller, Colonia Dignidad: von der Psychosekte zum Folterlager, S. 185. Vgl. auch HISArch, Bestand CD, Ordner 2. Schreiben Cerhard Mertins an die Siegburger Presse vom 07.11.1979. Darin schreibt Mertins: »Rechtsanwalt Dr. Klassen vertritt in völliger Abstimmung die Interessen eines hier gebildeten Freundeskreises der Dignidad.«

443 Vgl. Lateinamerika Nachrichten. Colonia Dignidad - Der doppelte Skandal, S. 48. Dort ist die Rede von einem 120 Personen umfassenden Freundeskreis, dem neben Mertins u.a. der Münchner CSU-Stadtrat Wolfgang Vogelsgesang, der ZDF-Moderator Cerhard Löwenthal, die Würzburger Professoren Lothar Bossle und Dieter Blumenwitz, der Siegburger Bürgermeister und spätere Bundestagsabgeordnete Adolf Herkenrath (CDU) sowie der ehemalige deutsche Botschafter in Chile, Erich Strätling angehörten. 1989 erklärte Mertins jedoch bei der StA Bonn: »Ein Freundeskreis wurde geplant, kam aber organisatorisch nicht zur Durchführung. «StA Bonn 50 ]s 285/85, Bd. XI, BI. 93. Vernehmung von Gerhard Mertins vom 01.03.1989. 
»Mertins hat eine lange Beziehung mit der CD. Er bezeichnet sich Gespraechspartnern gegenüber als Vorsitzender der `Amigos de la Colonia Dignidad ‘. In der Vergangenheit war er oft Gast auf dem CD-Celaende. Die CD-Verantwortlichen haben ihm beim Aufbau seines meksikanischen Domizils und Neuen Ceschaefts fuer ein Jahr ein Mitglied der CD zur Verfuegung gestellt.

Mertins hat die CD unseres Wissens nach Anfang Januar d. J. Das letzte Mal besucht. Er tauchte damals ohne Vorankuendigung beim Militaer-Attache der Botschaft auf, um sich ueber die schlechte Behandlung der CD zu beklagen. Mil. Attache hat ihn nach kurzem Wortwechsel verabschiedet. « ${ }^{444}$

Dies war nicht das einzige Mal, dass Mertins Kontakt zu deutschen Diplomaten suchte, um sich für die CD einzusetzen: Nach eigenen Angaben besuchte er in den 1970er Jahren Botschafter Erich Strätling in Santiago. ${ }^{445}$ Botschafter Horst Kullak-Ublick, den er bereits kannte, habe er vor dessen Amtsantritt 1986 im AA besucht »und ihn in die Problematik der CD von meiner Warte eingeführt. Hierbei stellte ich ihm gleichzeitig Kurt Schnellenkamp vor, der gerade in Deutschland besuchsweise weilte. ${ }^{446} \mathrm{Als}$ Kullak-Ublick 1987 in Sachen CD von Außenminister Genscher zur Berichterstattung nach Bonn zitiert wurde, soll er sich am Flughafen mit Mertins getroffen haben. ${ }^{447}$ Im Dezember 1987 sprach Mertins im AA vor. Der Mitarbeiter der Rechtsabteilung Wasserberg berichtete hierüber:

»Herr Mertins, der mich am 3. Dezember aus anderem Anlaß besuchte, erzählte mir beiläufig, er habe seit Ende der 6oer Jahre im Auftrag des BND, der seinerseits einen Auftrag des Bundeskanzleramts gehabt habe, mehrmals die Colonia Dignidad in Chile besucht. Er habe festgestellt, und auch entsprechend berichtet, daß sämtlich gegen die Kolonie schon damals erhobenen Vorwürfe unzutreffend seien:

- Für Folterungen hätten die entsprechenden unterirdischen Räume gefehlt

- Auch die Vorwürfe gegen den Leiter der Kolonie (Unzucht mit minderjährigen Knaben) seien haltlos; Herr Schäfer sei völlig normal

- Es handele sich nicht einmal um eine Sekte

- Vielmehr seien die Koloniemitglieder auswanderungswillige deutsche Jungbauern gewesen.

Ich widersprach substantiiert unter Hinweis auf die aktenkundigen Tatsachen. Ich halte es durchaus für möglich, daß Herr Mertins, der auch im Stern als Freund der Kolonie bezeichnet wird, vom BND einen entsprechenden Auftrag hatte und diesen unzutreffend unterrichtet hat. Ich rege an, daß Referat 330, falls noch nicht geschehen, diese Frage mit dem BND aufnimmt. ${ }^{448}$

Ob dies danach geschah, geht aus den Akten leider nicht hervor.

1989 begab sich Mertins als einer der wichtigsten öffentlichen Fürsprecher der CD in der Bundesrepublik aus eigener Initiative zur Staatsanwaltschaft Bonn, um die CD

444 PA AA, AV NA 31589. Botschafter Knackstedt an Bonn AA 330, FS 115 vom 02.03.1989.

445 StA Bonn, AZ 50 ]s 285/85, Bd. XI, Bl. 69f. Vernehmung von Gerhard Mertins vom 01.03.1989.

446 Ebd., BI. 91.

447 Heller, Colonia Dignidad: von der Psychosekte zum Folterlager, S. 207.

448 PA AA, B 83, Bd. 2386. Vermerk von Wasserberg (Leiter Referat 512) vom 07.12.1987. 
beim dort geführten Ermittlungsverfahren zu entlasten. ${ }^{449}$ Er berichtete dem zuständigen Staatsanwalt, bereits 1972 den Polizeichef von Parral aufgesucht zu haben, da er von »entsprechenden deutschen Dienststellen« gebeten worden sei, Informationen über die CD einzuholen. Nach dem Putsch habe er DINA-Chef Manuel Contreras kennengelernt, der damals bereits mit Hartmut Hopp bekannt gewesen sei. ${ }^{450}$ Contreras selbst sagte bei einer Vernehmung 2006, er habe eine enge Beziehung zu Mertins gehabt. Dieser habe Waffen an das chilenische Heer verkauft und mehrfach die CD besucht:

»Respecto de Cerhard Mertins, lo conocí, fue muy amigo mío ya que era un proveedor de armas directo del ejército, tenía una enorme empresa en Bonn y vendía armas a través del mundo. Sé que visitó en algunas oportunidades la Colonia Dignidad.«451

Colonos bestätigten ebenfalls, dass Mertins an der Beschaffung von Waffen für die CD beteiligt war. ${ }^{452}$ Im Gegenzug nutzte er auch die Kontakte der CD zum chilenischen Militär, um Waffengeschäfte anzubahnen. Kurt Schnellenkamp berichtete über Mertins Beziehungen und Waffenlieferungen u.a. in den Irak:

»Sé que este señor vendía armamentos a diferentes gobiernos del lado oriental también a Irak. La empresa de Mertins se llamaba Merex. Mertins me solicitó en una oportunidad, a raíz de mis contactos con FAMAE, que consultara si esta empresa podía enviar 100.000 morteros a Irak. $\ll^{453}$

Auch Guy Eduardo Neckelmann, lokaler Chef der DINA in Parral von 1976 bis 1977, berichtete vor Gericht sogar von Mertins' Angebot einer Lieferung von Leopard-Panzern nach Chile:

»En materia de información obtenida desde la Colonia, sólo recuerdo que en una oportunidad, me sorprendí cuando Schäfer me aseguró que si tenía necesidad de obtener tanques >Leopard<, ellos me los podían armar. No le informé esto a Manuel Contreras porque para mí eso no era creíble [...] Muchos años después tomé conocimiento que los alemanes tomaron contacto con un traficante extranjero de armas y a partir de ello, estimé que era muy probable que ellos pudieran armar los tanques que me ofrecieron. ${ }^{454}$

Mertins arbeitete mit der CD auch beim Betrieb von Goldminen zusammen. Diese dienten möglicherweise zur Tarnung von Waffengeschäften (Vgl. Abschnitt 3.2.3).

Außerdem besaß Mertins eine Gold- und Silbermine im mexikanischen Bundesstaat Durango. 1981/82 hielten sich die CD-Führungsmitglieder Kurt Schnellenkamp,

449 StA Bonn, AZ 50 ]s 85/285.

450 Ebd., Bl. 68-98.

451 CA Santiago, AZ 2182-98 (»Asociación Ilícita«), Bd. I (2) (Ministro), BI. 384. Richterliche Vernehmung von Manuel Contreras Sepúlveda vom 02.03.2006.

452 CA Santiago, AZ 2182-98 (»]uan Maino«), Bd. 5a, BI. 2170ff. Polizeiliche Vernehmung von Willi Malessa vom 29.09.2005

453 CA Santiago, AZ 2182-98 (»Asociación Ilícita«), Bd. I (2) (Ministro), BI. 453ff. Richterliche Vernehmung von Kurt Schnellenkamp vom 23.06.2005.

454 CA Santiago, AZ 2182-98 (»Asociación Ilícita«), Bd. IV (Ministro), Bl. 1789. Richterliche Vernehmung von Eduardo Guy Neckelmann Schütz vom 18.10.2006. 
Helmut Seelbach und Rita Seelbach dort mehrere Monate auf. Laut Mertins sollte Schnellenkamp dort seine Kenntnisse der spanischen Sprache und seine Erfahrungen mit der Steinbrechanlage in Bulnes einbringen, Helmut Seelbach eine Funkanlage installieren und Rita Seelbach die Buchhaltung verbessern. ${ }^{455}$ Kurt Schnellenkamp bestätigte diese Angaben vor Gericht. ${ }^{456}$

Über die Verbindungen der CD zu anderen Waffenhändlern, wie Pedro Felix de Aguirre Lamas, ${ }^{457}$ Karel Honzik (alias Carlos Seibel) ${ }^{458}$ und Edgardo Bathich ${ }^{459}$ ist weitaus weniger bekannt. Nach Aussagen von Colonos ${ }^{460}$ sowie nach in der CD gefundenen Dokumenten besuchten sie die Siedlung ebenfalls mehrfach.

\section{Sprengstoff und die "Giftküche"}

Neben der Produktion von Waffen und dem Handel mit Waffen experimentierte die CD auch mit Chemikalien, Sprengstoffen und sogar Raketen. Im Gildehaus - dem Gebäude in dem sich auch der "Kartoffelkeller « befindet, in dem Gefangene gefoltert wurden gab es eine sogenannte Giftküche, in der jahrelang mit Chemikalien hantiert wurde. Dort sollen Hermann Schmidt und später Hartmut Hopp regelmäßig gearbeitet haben. ${ }^{461}$ Bei Durchsuchungen der CD im November 2005 wurden dort 454 Gefäße mit

455 StA Bonn, AZ 50 ]s 285/85, Bd. XI, Bl. 93f. Vernehmung von Gerhard Mertins vom 01.03.1989.

456 CA Santiago, AZ 2182-98 (»Asociación Ilícita«), Bd. I (2) (Ministro), BI. 453ff. Richterliche Vernehmung von Kurt Schnellenkamp vom 23.06.2005.

457 Pedro Felix de Aguirre Lamas war ein mit der Familie Pinochet befreundeter Waffenhändler (vgl. Beau, Nicolás/Laurent Léger. »Consejero de Pinochet cobró comisiones en Francia por los submarinos Scorpene«, in: CIPER (Website), 10.07.2008, online unter http://ciperchile.cl/2008/07/10/cons ejero-de-pinochet-cobro-comisiones-en-francia-por-los-submarinos-scorpene/. Er war mehrfach in der CD. Sein Klarname sowie sein CD-Spitzname »Croßer Fuchs « tauchen in den Unterlagen auf, die in der CD beschlagnahmt wurden. VgI. PJS, Bestand Luis Narváez. Bericht der JIPOL/PDI vom 13.10.2006: Procesamiento y Análisis de la información en idioma alemán remitida por el Ministro Jorge Zepeda Arancibia el 14 de septiembre de 2005. Archivador 13, Documento 10, S. 175 sowie CA Santiago, AZ 2182-98 (»Asociación Ilícita«), Bd. I (2) Parral, BI. 535. Bericht von »Struppi« (Hartmut Hopp) über den »Croßen Fuchs« (Pedro Felix de Aguirre Lamas).

458 Karel Honzik war Vertreter der Firmen Mowag und SIC und mit Gerhard Mertins befreundet. Bei seinen Besuchen in der CD verwendete er den Decknamen »Carlos Seibel«. Vgl. La Nación vom 22.06.2008. »Los otros secretos de Colonia Dignidad«.

459 Edgardo Bathich Villarroel ist ein chilenischer Unternehmer syrischer Abstammung, der mit dem Waffenhändler Monzer Al Kassar und dem argentinischen Ex-Präsidenten Carlos Menem verwandt ist. Vgl. La Nación vom 04.11.2007. „Los desconocidos vínculos de Edgardo Bathitch con la dictadura«. Bathich Villarroel war u.a. Geschäftspartner von Marco Antonio Pinochet (Sohn des Diktators). In einem Eintrag auf seiner Ficha im CD-Ceheimarchiv vom 29.08.1989 heißt es: „Empresa Bathitch Motoren [...] Tiene helicóptero propio, en que llegó al Casino de Bulnes. Amigo personal de Marcos Pinochet Hiriart [...] Regaló eje trasero para la micro escolar, y dejó trabajar a los mecánicos de ViIla Baviera en su taller con todas las facilidades posibles. Turco. «Der Eintrag stammt von »Schim«, Abkürzung für »Schimmel«, dem CD-Spitznamen von Ulrich Schmidtke. CD-Geheimarchiv, Ficha von Edgardo Bathich Villarroel.

460 PJS, Sammlung Dieter Maier. Notiz des Gesprächs von Dieter Maier mit Bernd Schaffrik und Waltraud Schaak vom 11.11.2011.

Heller, Lederhosen, Dutt und Giftgas, S. 140. 
Chemikalien ${ }^{462}$ sowie ein umfangreiches Foto- und Filmlabor beschlagnahmt. ${ }^{463}$ Laut Experten der Universidad de Chile, die Einblick in die Liste der aufgefundenen Stoffe hatten, eignen sich die Substanzen für ein breites Anwendungsspektrum, von der Entwicklung von Foto- und Videomaterial, bis zur Herstellung von Sprengstoffen. In den beschlagnahmten Behältern befanden sich jedoch auch eine Reihe schwer erhältlicher Substanzen, darunter gefährliche Nervengifte. ${ }^{464}$ Die CD setzte diese Gifte zur Eliminierung von Gegnern bzw. von in Ungnade gefallenen Personen ein. Gerichtlich bewiesen ist der Fall des DINA-Agenten Miguel Becerra Hidalgo, der im Juli 1974 vergiftet wurde. Die gerichtsmedizinische Untersuchung der Leiche ergab als Todesursache eine Vergiftung mit "pesticidas oxifosforados del tipo Bidrin, Tapona, DDVP etc. ${ }^{465}$ Auch bei weiteren Todesfällen gibt es Hinweise auf den Einsatz von Gift, etwa gegen Alfred Schaak (vgl. Abschnitt 4.2.5). Mehrere Personen äußerten den - bisher jedoch nicht nachgewiesenen -Verdacht, von der CD mit Kontaktgiften vergiftet worden $\mathrm{zu}$ sein. ${ }^{466}$

Diverse externe Personen verbrachten längere Zeit in der CD und arbeiteten dort an Waffenprojekten mit. Der Chemiker Francisco Lichnovsky (CD-Spitzname »Pancho«), der beim chilenischen Rüstungsproduzenten FAMAE sowie beim Unternehmen Tec Hartaim arbeitete, kannte sich besonders gut mit Sprengstoff aus. ${ }^{467}$ Er war gemeinsam mit Richard Roehling (CD-Spitzname »Knüsselböck«) aus Temuco an Experimenten mit Sprengstoffen und Raketen in der CD beteiligt. Roehling soll während des Nationalsozialismus als Assistent von Werner von Braun am Bau der V2-Raktete mitgewirkt haben. ${ }^{468}$ Außerdem war auch Cornelius Elmar Krieg (CD-Spitzname »Lindes«) an militärischen Trainings in der CD beteiligt. ${ }^{469}$

Die Waffenherstellung und der Waffenhandel der CD dienten mehreren Zwecken: Einerseits besänftigten sie die panische Angst Schäfers vor einem Angriff auf die Siedlung und damit auch vor seiner Entdeckung und Festnahme. Gegenüber den chileni-

462 CA Santiago, AZ 2182-98 (»Maino«), Bd. 6a, Bl. 2403ff. Acta de Incautación vom 25.11.2005.

463 El Mercurio vom 26.11.2005, S. C16. »Incautan químicos en Villa Baviera«.

464 La Nación vom 30.07.2006. »El arsenal químico de Colonia Dignidad«.

465 CA Santiago, AZ 12293-2005 (»homicidio Miguel Becerra Hidalgo«). Erstinstanzliches Urteil vom 27.11.2008.

466 Der erste dieser Berichte ist von 1965 und stammt vom Missionar Gerhard Krüger, der unangekündigt Angehörige in der CD besuchen wollte. Sein Besuchswunsch wurde abgelehnt. Nach einem Gespräch mit Führungspersonen fühlte er »dann plötzlich in der rechten Hand einen merkwürdigen Schmerz, verbunden mit Lähmungserscheinungen (später war an dieser Stelle für einige Zeit ein weißlicher Fleck zu sehen)«. PA AA, AV NA 31600. Schreiben Horst Krüger an Wolfgang Kneese vom 05.04.1989. Die Colona Gudrun Wagner berichtete mir, dass ein Führungsmitglied der CD bei einem Besuch in Deutschland 2010 zwei Familienmitgliedern zum Geburtstag je ein Deckchen und ein Taschentuch geschenkt habe. Beide seien kurz darauf schwer erkrankt. PJS, Sammlung Cesprächsnotizen. Notiz eines Gesprächs mit Gudrun Wagner vom 24.10.2010. Ob bei diesem Vorfall - der sich mit vielen ähnlichen Berichten deckt - Kontaktgift zum Einsatz kam, kann nicht zweifelsfrei nachgewiesen werden.

467 CA Santiago, AZ 2182-98 (»Asociación Ilícita«), Bd. I (2) (Ministro), Bl. 453ff. Richterliche Vernehmung von Kurt Schnellenkamp vom 23.06.2005.

468 CD-Geheimarchiv, Ficha Richard Roehling Vostarek.

469 CD-Geheimarchiv, Ficha Cornelius Elmar Krieg Marbecks. 
schen Militärs symbolisierten die Waffen die Macht der CD. Bei »speziellen Anlässen«, etwa wenn es darum ging, Regimegegner_innen zu eliminieren, ohne Spuren zu hinterlassen, konnte die Junta auf die Unterstützung der CD zurückgreifen. ${ }^{470} \mathrm{Im}$ Falle besonders vertrauter Militärs dienten Waffengeschenke auch als »kleine Aufmerksamkeit«. Oberst Juan Morales Salgado, damaliger Chef der DINA-Einheit »Brigada Lautaro « und heute wegen diverser Verbrechen gegen die Menschheit inhaftiert, soll nach Aufzeichnungen auf einer Ficha des CD-Geheimarchivs gegenüber anderen DINAAgenten mit seiner Beliebtheit in der CD geprahlt haben:

»El capitán Morales contó en una comida que ofreció en su casa al matrimonio del Cdte. Sotomayory su señora [...] que le habían hecho un regalo en la Colonia Dignidad, donde era el regalón y que consistía en una pistola con silenciador.« 471

Für die chilenische Militärjunta war die CD ein wichtiger Waffenumschlagplatz, über den auch das nach dem Putsch verhängte internationale Waffenembargo umgangen werden konnte. Das genaue Ausmaß des Waffenhandels kann nur vermutet werden ebenso wie der Profit, den die CD dadurch erzielte. Folgender Auszug aus einem Protokoll des Bundesinnenministeriums (BMI) über einen Besuch von zwei hochrangigen Beamten der PDI von 2006 belegt, dass die Ermittlungsbehörden möglicherweise über noch weiterführende Hinweise verfügen, die bislang nicht Gegenstand strafrechtlicher Verfahren waren:

»Auf Einladung der Abteilung Schwere und Organisierte Kriminalität (SO) besuchte vom 21.05.-23.05.06 eine zweiköpfige chilenische Delegation das BKA, um die bisherigen chilenischen Ermittlungen i. S. >Colonia Dignidad ‘ darzustellen und weitere Ermittlungen mit Deutschland abzustimmen.

Nach Schilderung von Herrn Castillo ist es aufgrund von Aussagen von Siedlern gelungen, die Waffendepots auf dem weitläufigen Gelände der >Colonia Dignidad` aufzufinden. Unter Pinochet wurden auf dem Gelände auch chemische Waffen für einen eventuellen Krieg mit Peru produziert und gelagert. Herr Castillo berichtete von umfangreichen Waffenlieferungen mit Flugzeugen von Miami nach Chile. Hierzu ist Filmmaterial vorhanden, das belegt, dass ca. 100.000 Handgranaten auf diesem Wege in die >Colonia gelangten. [...] Herr Klauer verwies auf die über den BKA-VB Buenos Aires übermittelten 663 Fotos von sichergestellten Waffen und Munition und stellte das Auswerteergebnis dar. Hiernach handelt es sich nicht nur um alte Weltkriegswaffen, sondern teilweise um neue Waffensysteme. 31 Waffen konnten durch SO 11 deutschen Herstellern zugeordnet werden. $\ll^{472}$

Vgl. den Fall Osvaldo Heyder, beschrieben in Abschnitt 5.3.5, sowie CD-Geheimarchiv, Ficha Hipólito Silva Rojas.

471 CD-Geheimarchiv, Ficha Juan Morales Salgado.

472 PJS, Sammlung IFC BMI. Schreiben des BKA an BMI vom 04.07.2006, AZ: SO 11 -107-218063105, Betr: Strafrechtliche Aufarbeitung der Ceschehnisse in der »Colonia Dignidad «-Bericht des BKA. Anlage: Protokoll des BKA, SO 11-107 vom 31.05.2006: Besuch einer chilenischen Delegation unter Leitung von Herrn Castillo vom 21.-23.05.2006 im BKA hier: Protokoll zu den Fachgesprächen bei SO. Bei Rafael Castillo Bustamante handelt es sich um den damaligen Leiter der Brigada de Asuntos Especiales y Derechos Humanos der PDI. 
Diese Schilderungen des hochrangingen chilenischen Ermittlers bestätigen die Verwicklungen der CD in massiven Waffenhandel und die Produktion von chemischen Kampfstoffen.

\subsubsection{Menschenrechtsverbrechen im Kontext der chilenischen Diktatur}

Die Colonia Dignidad war an den Vorbereitungen zum Militärputsch vom 11. September 1973 beteiligt und entwickelte sich nach diesem zu einem »Schlüsselelement des Repressionsapparates der Diktatur «. ${ }^{473}$ Die CD war geheimdienstlicher Akteur, sie diente als Schulungsstätte für chilenische DINA-Agent_innen sowie als Haft- und Tötungslager der Diktatur.

Zwischen 1973 und 1977 wurde eine große Anzahl politischer Gefangener in die CD verbracht, dort gefoltert und verhört. Das belegen Aussagen von ehemaligen politischen Gefangenen, Militärs und Geheimdienstagent_innen sowie von Colonos, die an den Verbrechen beteiligt waren. Aus Berichten und Vernehmungen von Colonos und ehemaligen Geheimdienstler_innen kann ebenfalls geschlossen werden, dass in der CD Dutzende Menschen - möglicherweise sogar über Hundert - ermordet wurden. Ihre sterblichen Überreste konnten jedoch bis zum heutigen Tage nicht gefunden werden. Eine Reihe von Quellen belegt zudem die Zusammenarbeit von Colonos mit DINA-Agent_innen bei Auslandsoperationen (DINA exterior) sowie die Unterstützung der CD für das geheime Projekt zur Entwicklung chemischer und bakteriologischer Waffen (Projekt ANDREA).

Darüber hinaus versorgte die CD die Repressionsorgane der Diktatur mit Waffen und Kommunikationstechnologie. Sie stellte ihr Gelände für Schulungen zur Verfügung, bei denen Colonos und Instrukteure des Militärapparats Unterricht in geheimdienstlichen Methoden, Foltertechniken sowie in der Handhabung von Waffen und Sprengstoff erteilten. Das beschlagnahmte CD-Geheimarchiv dokumentiert zudem die Rolle der CD als eine Art eigenständiger Geheimdienst. Die CD unterhielt als Teil einer zivil-militärischen Allianz mit der Diktatur ein Spionage- und Spitzelnetzwerk. Dessen Ziel war nicht nur die Bekämpfung des Widerstandes gegen die Diktatur, sondern auch eine Überprüfung von Angehörigen der Militärregierung, der verschiedenen Waffengattungen und ihrer jeweiligen Geheimdienste auf ihre individuelle Loyalität zu Augusto Pinochet. Die persönlichen Verbindungen zwischen der CD-Führung einerseits und der Spitze der DINA, insbesondere Manuel Contreras, sowie Diktator Pinochet andererseits, verdeutlichen diese Repressionsallianz, die über die gesamte Dauer der Militärregierung anhielt. Nach heutigem Stand hatte die CD für die DINA folgende Funktionen:

- Ausbildungs- und Trainingsstätte für DINA-Agent_innen

- Rückzugs- und Erholungsort für die DINA-Spitze

- Betreuung von Kindern von DINA-Agent_innen

- medizinische Versorgung für die DINA-Spitze (Contreras, Espinoza, u.a.)

- Bereitstellung/Installation von Funk- und Kommunikationstechnologie 
- Informationsbeschaffung und -austausch

- Haft- und Folterstätte zum Ziel der Informationsgewinnung

- Tötung von Gefangenen und Beseitigung ihrer sterblichen Überreste

Verschiedene Quellen, insbesondere Zeugnisse von Überlebenden, aber auch Aussagen aus juristischen Verfahren und Karteikarten (Fichas) aus dem beschlagnahmten CDGeheimarchiv zeichnen ein sicherlich unvollständiges, aber dennoch umfassendes Bild von der Dimension der Zusammenarbeit zwischen CD und DINA in den genannten Bereichen. 2016 stufte die chilenische Justiz die Verbindung zwischen CD und DINA im Nachhinein rechtskräftig als kriminelle Vereinigung ein. ${ }^{474}$

Die intensivste Zusammenarbeit zwischen CD und Diktatur fand in den Jahren 1973 bis 1977 statt, jener Phase der Diktatur, in der die DINA die brutalste Repression gegenüber Oppositionellen ausübte. Ein Großteil der Menschenrechtsverbrechen der Diktatur fällt in diese Periode. Im nächsten Abschnitt möchte ich beschreiben, wie sich der Wissensstand über die CD-Verbrechen während der Diktatur historisch entwickelte. In den darauffolgenden Abschnitten werde ich dann den heutigen Kenntnisstand darstellen, gegliedert in die Themenbereiche »Beziehungen zwischen der CD, Militär und Geheimdiensten «, »Haft und Folter in der CD«, »Mord und Verschwindenlassen« sowie »DINA exterior, Projekt ANDREA und die Rolle der CD«. Dieser Kenntnisstand geht zu großen Teilen auf Vernehmungsprotokolle und Erkenntnisse aus Ermittlungen der chilenischen Justiz nach 2005 zurück.

\section{Entwicklung des Kenntnisstands über die CD-Verbrechen im Kontext der Diktatur}

In Kreisen des chilenischen Widerstandes gegen die Diktatur wurde schon bald nach dem Putsch vom 11. September 1973 vermutet, dass die CD aktiv an der Repression beteiligt war. Eine geheimdienstähnliche Gruppe der MIR mit dem Namen »La Orquestita« (das Orchesterchen) hatte bereits während der Allende-Regierung die Verbindungen zwischen der militanten rechtsextremen Gruppe Patria y Libertad und der CD beobachtet. ${ }^{475}$ Im März 1974 soll Carlos Lorca, untergetauchter Anführer der Sozialistischen Partei und ehemaliger Kongressabgeordneter, einem Beamten der Botschaft bei einem

474 Verfahren CA Santiago, AZ 2182-98 (»Asociación Ilícita«).

475 Vgl. Maier, Dieter. Colonia Dignidad-Auf den Spuren eines deutschen Verbrechens in Chile, Stuttgart 2016, S. 184ff. sowie Liberona, Carlos/Lucía Sepúlveda Ruiz. Memorias de un labrador de futuro. Carlos Liberona, el amor y la lucha, Santiago 2010, S. $101 \mathrm{f}$. 
geheimen Treffen ${ }^{476}$ berichtet haben, die CD fungiere seines Wissens als Haft- und Folterlager:

»Lorca expuso al embajador [...] su convicción que la Colonia Dignidad ya estaba siendo ocupada como un centro de detención para prisioneros políticos de la zona, y que además la DINA estaba llevando detenidos desde Santiago para ser torturados por ciudadanos alemanes allá.«477

Botschafter Luedde-Neurath habe Lorca versprochen, den Hinweisen nachzugehen. In den Akten des PA AA finden sich allerdings keine Hinweise darauf, dass eine entsprechende Untersuchung tatsächlich stattgefunden hätte. Lorca wurde am 25. Juni 1975 von der DINA verhaftet und in das geheime Haftzentrum Villa Grimaldi gebracht. Seitdem gilt er als verschwunden. Der wenig später ermordete ehemalige DINA-Agent Juan Muñoz Alarcón sagte im Mai 1977 aus, dass Lorca zum damaligen Zeitpunkt in der CD inhaftiert und somit noch am Leben sei. ${ }^{478}$

1974 und 1975 war innerhalb der klandestin arbeitenden Reste linker Parteien und Bewegungen in Chile bereits bekannt, dass die CD vom Regime als Haft- und Folterstätte genutzt wurde. Einige Gefangene, die Haft und Folter in der CD überlebt hatten, berichteten nach ihrer Verlegung an andere Haftorte Mitgefangenen darüber. Der Journalist Alvaro Rojas etwa beschreibt, dass sich auf der Insel Quiriquina Gefangene darüber austauschen konnten:

»Así, cuando en el Campo de Prisioneros de Isla Quiriquina llegaron prisioneros del MIR que aseguraban haber sido torturados en la Colonia Dignidad y cuando se supo que la Colonia era un centro de detención y de interrogatorio de la DINA, no se sorprendió nadie. $« 79$

Gegen Ende des Jahres 1975 kam eine Reihe politischer Gefangener frei, die zuvor in der CD verhört und gefoltert worden und danach in andere Haftanstalten nach Santiago verbracht worden waren. Einigen von ihnen gelang es, Chile zu verlassen, und

476 Während Azócar (Azócar, Juan. Lorca - De la reforma universitaria a la lucha antidictatorial, Santiago 2011, S. 208) feststellt, dass Carlos Lorca das klandestine Gespräch im Küstenort Reñaca mit dem bundesdeutschen Botschafter Lüdde-Neurath führte, berichtet Sibylle Riedmiller, die Lorca nach Reñaca begleitete, es sei ein Vier-Augen-Gespräch zwischen Carlos Lorca mit einem Botschaftsmitarbeiter gewesen, bei dem es sich nicht um den Botschafter handelte: PJS, Sammlung CD. E-Mail von Sibylle Riedmiller an den Verfasser vom 16.09.2018. Riedmiller war eine von vier deutschen Mitarbeiter_innen bei internationalen Organisationen in Santiago, welche die klandestine Führung der Sozialistischen Partei im Untergrund unterstützten. Die Gruppe wurde als »los cuatro Alemanes « bekannt. Vgl. Frankfurter Rundschau vom 17.09.2018. »Sibylle Riedmiller in Frankfurt. Im Fluss trieben die Leichen«, online unter https://www.fr.de/frankfurt/sibylle-riedmiller-infrankfurt-im-fluss-trieben-die-leichen-a-1583178.

477 Azócar, Juan. Lorca - De la reforma universitaria a la lucha antidictatorial, Santiago 2011, S. 208. Der Autor zitiert hier einen engen Vertrauten Lorcas, der an dem Treffen teilgenommen haben soll, und zwar Jorge Sepúlveda. In den Akten des PA AA wird dieses Treffen nicht erwähnt.

478 11. Juzgado del Crímen, AZ 12.293, »Homicidio de Juan René Muñoz Alarcón«, BI. 14-26. Transkript der Erklärung von Juan René Muñoz Alarcón [o. D., Mai oder Juni 1977], aufgezeichnet im Solidaritätsvikariat in Santiago. Enthalten in PA AA, ZW 111131.

Rojas, Alvaro. Los secretos de la Colonia Dignidad, Santiago 1988, S. 27. 
ins Exil zu gehen, etwa nach Europa. Manche dieser Diktatur-Opfer wandten sich an verschiedene Institutionen der Vereinten Nationen in Genf, welche die Situation in der chilenischen Diktatur kritisch beobachteten. So hatte etwa die Kommission für Menschenrechte des UN-Wirtschafts- und Sozialrats (United Nations Economic and Social Council, ECOSOC) eine Ad-hoc-Arbeitsgruppe zur Situation der Menschenrechte in Chile eingerichtet. Im Februar 1976 erschien ein Bericht dieser Gruppe, in dem die CD erstmals offiziell in einer Liste von Haft- und Verhörzentren der chilenischen Diktatur aufgeführt wurde. Laut diesem Bericht sollen viele Verschwundene zwischenzeitlich oder zu diesem Zeitpunkt noch immer in der CD festgehalten worden sein:

"Según una fuente de información, muchas de las personas incluidas en la lista de 119 presos que han desaparecido se hallaban en la Colonia Dignidad y es posible que algunas estén todavía allá. ${ }^{480}$

Ein weiterer Bericht der Arbeitsgruppe vom Oktober 1976 beschreibt Folter und Experimente an Gefangenen in der CD, basierend auf Aussagen von Folter-Überlebenden aus Chile:

»Se sabe que existe otro centro de la DINA en Colonia Dignidad [...]. Se dice que en Colonia Dignidad se ha sometido a prisioneros a diferentes sexperimentos $<$ sin interrogatorio alguno: perros entrenados para cometer agresiones sexuales y para destruir los órganos sexuales de hombres y mujeres; >ensayos diferentes métodos de tortura (resistencia a las palizas, a las descargas eléctricas, a la posición colgante etc.); experimentos para volver locos a los detenidos mediante la administración de drogas, sometimiento a largos períodos de aislamiento y a otras condiciones infrahumanas. Es digno de señalar que, según se dice, en este campo lo único que los prisioneros oyen de sus aprehensores son las órdenes de tortura. En Colonia Dignidad parece haber un centro de tortura de índole especial en un lugar subterráneo especialmente equipado, donde existen celdas pequeñas, a prueba de sonido y herméticamente cerradas para presos. Les cubren la cabeza a los prisioneros con capuchones de cuero que les pegan a la cara con adhesivos químicos. Se dice que en esas celdas los torturadores Ilevan a cabo interrogatorios por un sistema de radio en circuito cerrado, mientras se tiene a los detenidos desnudos y atados a su litera y se les aplican descargas eléctricas. ${ }^{481}$

Der Bericht nennt in Verbindung mit der CD auch einen geheimen Haftort namens Monte Maravilla. Dieser Name wurde im April 1976 international bekannt: Damals organisierte Amnesty International eine Hilfsaktion für Edgardo Enriquez, einen der führenden Köpfe der MIR. Dieser war am 10. April in Buenos Aires verhaftet und von der DINA nach Chile gebracht worden, wo er, so AI, »in einem Verhörzentrum Monte Mara-

480 United Nations Economic and Social Council (ECOSOC). E/CN.4/1188 vom 04.02.1976. Report of the ad hoc working group established under resolution 8 (XXXI) of the Commission On Human Rights to inquire into the present situation of human rights in Chile, online unter http://daccess-ods.un.o rg/access.nsf/get?open\&DS=E/CN.4/1188\&Lang=S, S. 37. United Nations Economic and Social Council (ECOSOC). Bericht A/31/253 vom 08.10.1976, S. 96. 
villa festgehalten « werde. ${ }^{482} \mathrm{Ob}$ »Monte Maravilla« als Synonym für die CD stand oder einen anderen Haftort beschrieb, lässt sich bis heute nicht definitiv klären.

Im UN-Bericht wird auch der in der Nähe der CD liegende Berg Cerro Gallo als ein Ort beschrieben, an dem Gefangene festgehalten und möglicherweise getötet worden sein sollen. Im März 1974 führten Militäreinheiten aus verschiedenen Regimentern dort einen mehrtägigen Einsatz durch. ${ }^{483}$ Der Berg sollte durchkämmt und von »Extremisten « gesäubert werden. Dabei kam eine große Anzahl Militärs ${ }^{484}$ in die CD, wo sie von Schäfer und Hopp empfangen wurden. ${ }^{485}$ Sie übernachteten in der CD und brachen von dort aus zum Cerro Gallo auf, gemeinsam mit einigen Colonos in Lastwägen sowie unterstützt von Hubschraubern. Die Aussage eines ehemaligen Soldaten gegenüber einer AI-Mitarbeiterin aus dem Jahr 1984 legt nahe, dass es sich bei der Aktion um ein als Gefecht getarntes Massaker an politischen Gefangenen handelte, die in einem geheimen Lager in der Nähe der CD festgehalten wurden. ${ }^{486}$ Bestätigt ist bisher jedoch nur, dass bei dem Einsatz Landarbeiter festgenommen und in die CD verbracht wurden. ${ }^{487}$ Ein Landarbeiter aus Trabuncura, einem kleinen Dorf in der Nähe der CD, berichtete etwa, er sei im März 1974 von einer Militärpatrouille festgenommen und verhört worden und anschließend gemeinsam mit anderen zu einer "casa $\mathrm{N}^{\circ} 20$ de propiedad de los Alemanes ${ }^{488}$ gebracht worden. Am nächsten Tag sei ein Deutscher mit einem Lastwagen gekommen. Die Militärs hätten ihnen befohlen, auf den Lastwagen zu steigen, der sie dann ins Militärregiment von Chillán verbracht habe.

Ein Hinweis darauf, dass politische Gefangene möglicherweise noch jahrelang in der CD oder in deren Nähe festgehalten wurden, war die Aussage von Luis Arias Contreras. Der 1974 von den Carabineros entlassene Polizist, lebte seit 1978 im britischen Exil. 1979 sagte er gegenüber Amnesty International aus, ein Agent des Geheimdienstes der Carabineros (Servicio de Inteligencia de Carabineros, SICAR) habe ihm eine Liste von Gefangenen aus Chillán vom 21. Februar 1978 gezeigt. Als Ort der Inhaftierung war ein »campo de concentración ubicado al interior del fundo >Dignidad de Parral«

482 Vgl. Heller, Friedrich Paul. Die Colonia Dignidad: Ein politischer Skandal bis heute, in: Baer, Willi/Karl-Heinz Dellwo (Hg.). Chile - Salvador Allende und die Unidad Popular, Hamburg 2013, S. 215235, hier S. 234 (Anm. 4).

483 Maier/Stehle, Colonia Dignidad, S. 51f.

484 Der Hauptmann des Heeres, López Almarza, bestellte bei der CD über Funk 400 Essensrationen für die beteiligten Soldaten. CD-Geheimarchiv, Ficha Donato López Almarza.

485 CA Santiago, AZ 2182-98 (»Villa Baviera«), Bd. 8b, Bl. 2804. Polizeiliche Vernehmung von Iván Enrique Norambuena Arenas vom 15.06.2005. Weitere Colonos, die mit den Militärs bei diesem Einsatz in Kontakt standen waren und im Hubschrauber die Gegend inspizierten waren, Reinhard Döring und Manfred Schmidtke. CA Santiago, AZ 10-2004 (»Adriana Bórquez«), Bl. 186. Polizeiliche Vernehmung von Franz Baar vom 14.05.2004.

486 A MMDH, Bestand Dieter Maier. Entrevista [de Wendy Tindale] con Juan Miranda en Linares vom 11.07.1984.

487 Narváez, Luis. Las fichas del horror. Reihe En la Mira. Chilevisión, 87 min, ausgestrahlt am 09.07.2014, online unter https://www.youtube.com/watch?v=eBW-tQOjwol.

488 CA Santiago, AZ 2182-98 (»Alvaro Vallejos Villagrán«), Bd. 3a, Bl. 748. Polizeibericht PDI Parral Nr. 400 vom 12.04.1999, Aussage von Ernesto Pino Villalobos. 
genannt. ${ }^{489}$ Auf der Liste habe auch der Name von Arias' früherem Lehrer, Francisco Sánchez, gestanden. Dieser war im Oktober 1973 in Chillán festgenommen worden und gilt bis heute als verschwunden. ${ }^{490}$

Eine Reihe von Folterüberlebenden wandte sich 1976 an die Chile-Koordinationsgruppe von Amnesty International in Frankfurt a.M. Die AI-Mitarbeiter Dieter Maier und Jürgen Karwelat erstellten eine Broschüre, die eine Reihe von Berichten ehemaliger Gefangener zusammenführt ${ }^{491}$ und die Vorgeschichte der Sekte dokumentiert. Zeitgleich mit dem 60-seitigen Heft erschien im März 1977 ein Artikel über »Das Folterlager der Deutschen « von Kai Herrmann im Stern. ${ }^{492}$ In Reaktion darauf gab Botschafter Erich Strätling in Chile wenige Tage später folgende Erklärung ab:

»Angesichts von kürzlich in der Presse erschienenen Berichten über die angebliche Unterbringung chilenischer politischer Häftlinge in der von Deutschen bewohnten landwirtschaftlichen Niederlassung und wohltätigen Einrichtung >Colonia Dignidad ‘ bei Parral teilt der Botschafter der Bundesrepublik Deutschland folgendes mit: Nach der Veröffentlichung des Allana-Berichts der Ad-hoc Kommission der Vereinten Nationen Ende vergangenen Jahres habe ich der Siedlung Colonia Dignidad am 15. November 1976 einen Besuch abgestattet, um die im Bericht erhobenen Behauptungen zu prüfen. Bei diesem Besuch haben sich keine Anhaltspunkte für die Richtigkeit dieser Behauptungen ergeben. Auch eine Auswertung von Luftaufnahmen des gesamten Cebiets der $\mathrm{CD}$ durch deutsche Stellen hat keine Bestätigung der Behauptung erbracht, daß sich in oder bei der CD ein Lager mit sbesonders ausgestatteten unterirdischen Anlagen< befindet. $^{493}$

Die chilenische Tageszeitung El Mercurio zitierte diese Erklärung am 27. März und schrieb, es gebe keine chilenischen Gefangenen in der CD: »No hay chilenos detenidos en la Colonia >Dignidad« «. 494

Knapp einen Monat nach den Veröffentlichungen von AI und Stern reagierte die CD-Führung und startete eine Gegenoffensive. Hartmut und Dorothea Hopp besuchten den Botschafter und übergaben ihm ein Schreiben an Außenminister Genscher. Darin verkündeten sie, 225 Colonos würden in den Hungerstreik treten »wegen der gegen sie in der Bundesrepublik Deutschland gerichteten Pressegreuel und hemmungslosen

489 Archiv Al, Bestand CD. Declaración von Luis Arias Contreras, wohnhaft in Northampton, vom 18.02.1979. Übersandt von Al-Generalsekretär Helmut Frenz an den »CD«-Verteiler - Interna. Luis Arias hatte eine ähnliche Erklärung mit Datum vom 15.12.1978 an den UN-Ceneralsekretär geschickt.

490 Die Entführung und Ermordung von Francisco Sánchez wird gegenwärtig von Richter Aldana untersucht. CA Concepción, AZ 10-2017.

491 Amnesty International, Colonia Dignidad: deutsches Mustergut. Die Broschüre enthält u.a. die Zeugnisse von Erick Zott, Luis Peebles und Adriana Bórquez.

492 Herrmann, Kai. »Das Folterlager der Deutschen«, in: Stern Nr. 13/1977 vom 17.03.1977, S. 26-33.

493 PA AA, AV NA 31580. Schreiben Petersmann (RK-Referent) an die StA am LC Hamburg vom 28.07.1977.

494 El Mercurio vom 27.03.1977, S. 33. »Declaración del Embajador de la RFA: No hay chilenos detenidos en la Colonia >Dignidad««. 
Verleumdungen, angeführt durch Herrn H. Frenz, Generalsekretär von Amnesty International ${ }^{495}$ Gleichzeitig übergaben die Hopps ein 18-seitiges Dokument, das die Vorwürfe von Amnesty International bestritt. Strätling leitete dies ans AA weiter und schrieb dazu: »Eine erste Prüfung der Aufzeichnungen weisen diese als sorgfältige Arbeit aus, die sicherlich auch einen Beweiswert hat. «496

Kurz darauf, am 22. April 1977, beantragte die CD über ihre Rechtspersonen in Chile (SBED) und in der Bundesrepublik (PSM) beim Landgericht Bonn eine einstweilige Verfügung gegen Amnesty International und den Verlag Gruner \& Jahr. Das Gericht gab dem Antrag statt: Bis zur Klärung im Hauptverfahren untersagte es AI und dem Verlag, die Aussage zu wiederholen, die Colonia Dignidad sei ein Folterlager. ${ }^{497}$ Die strafrechtliche Aufklärung von Folter und Mord in der CD wurde damit de facto auf die Zeit nach dem Ende der Militärdiktatur verschoben. Denn die Militärdiktatur und ihr Justizapparat standen fest an der Seite der CD und letzterer behandelte Rechtshilfeersuchen aus Bonn nur zögerlich und abweisend. Aussagen diverser Zeug_innen, die AI im Rahmen des Verfahrens aufbot, ergaben ein umfangreiches Bild der Zusammenarbeit zwischen CD und DINA bei der Repression. Dies führte jedoch weder in Chile noch in Deutschland zu strafrechtlichen Ermittlungen.

Auch die Ermordung des DINA-Kollaborateurs Juan Muñoz Alarcón führte zu keiner weitergehenden Aufklärung. Er hatte kurz zuvor bei der kirchlichen Menschrechtsorganisation Vicaría de la Solidaridad Zeugnis abgelegt über die Zusammenarbeit zwischen DINA und CD bei der Folter und Ermordung politischer Häftlinge (Vgl. Abschnitt 5.1.2).

Die meisten Fälle von systematischer Folter und „Verschwindenlassen« während der chilenischen Diktatur fielen in die Jahre 1973 bis 1977, in denen auch die DINA existierte. 1977 wurde die DINA formell aufgelöst und ging in die CNI über. Nach der Auflösung der DINA hielt die CD weiterhin Kontakte zu den ehemaligen Führungskräften der DINA. Eine Beteiligung der CD an systematischen Menschenrechtsverbrechen wie Verschwindenlassen und Folter ist nach der Auflösung der DINA allerdings nicht mehr bekannt.

Die nach Ende der chilenischen Diktatur eingesetzte Wahrheitskommission hörte zahlreiche Zeug_innen und Betroffene an. In ihrem Bericht von 1991 (Rettig-Bericht) beschrieb sie die enge Zusammenarbeit von CD und DINA und wie diese Gefangene in die CD brachten, um sie dort zu foltern:

»Está comprobado que hubo diversas relaciones entre la DINA y Colonia Dignidad. Consta que una vez constituida la DINA como >Comisión DINA < a partir de noviembre de 1973, agentes de esta organización utilizaron predios como el fundo >El Lavadero < de la Colonia Dignidad y las hijuelas del antiguo fundo >San Manuel al interior de Parral para fines de la DINA, sea para la instrucción de sus agentes o con otros fines institucionales. Consta también que una casa ubicada en calle Ignacio Carrera Pinto, ex calle Unión, $N^{\circ} 262$ de Parral, y de la que se sabe que fue utilizada como recinto por la DINA, específicamente para una brigada de inteligencia regional, fue adquirida por la

495 PA AA, AV NA 31581. Schreiben der SBED an Botschafter Strätling vom 19.04.1977.

496 PA AA, B 83, Bd. 1177. DB 119 vom 22.04.1977.

497 Zum Verfahren LC Bonn, AZ 3 O 123/77 vgl. Abschnitt 5.3.1. 
Sociedad Benefactora y Educacional Dignidad por escritura pública del 24 de mayo de 1974, inscrita a su nombre el año siguiente y vendida en 1986. Se sabe también que el Director de la DINA y otros agentes de esa organización visitaron la Colonia Dignidad y parecían mantener cordiales relaciones con sus dirigentes.

La Comisión recibió un elevado número de declaraciones de personas que fueron detenidas por la DINA en Santiago y dicen haber sido llevadas en algún momento a Colonia Dignidad y mantenidas allí, cautivas, con la vista vendada, siendo además sometidas a torturas en ese lugar. También conoció declaraciones de personas que habrían sido detenidas en la zona de Parral o en ciudades no alejadas de esa zona y llevadas a Colonia Dignidad, donde fueron sometidas a similar trato. Un número significativo de estas declaraciones dan tal razón de sus dichos y son tan circunstanciadas y concordantes entre sí, así como con otros antecedentes, - entre ellos las declaraciones de algunos ex-agentes de la DINA y aún de ex-miembros de la propia Colonia Dignidad - que no cabe en conciencia dudar de su veracidad. La Comisión, por tanto, debe al menos concluir que un cierto número de personas detenidas por la DINA efectivamente fueron conducidas a Colonia Dignidad, mantenidas cautivas allí por un tiempo, y algunas de ellas sometidas a tortura, con la participación en estos hechos no sólo de agentes de la DINA sino también de personas que vivían en ese predio. « 498

Die staatliche Folterkommission beschrieb in ihrem Bericht 2004 verschiedene Foltermethoden in der CD detailliert:

»Numerosos declarantes ante esta Comisión dijeron haber estado en Colonia Dignidad entre los años 1974 y 1975 . Indicaron haber sido trasladados hasta ese lugar engrillados, vendados y esposados. Algunos testigos dijeron que fueron llevados inmediatamente después de ser detenidos. Otros señalaron que provenían de variados centros de reclusión de la región, de la Octava Región o de Santiago.

La Colonia, de acuerdo a lo señalado por quienes estuvieron allí, contaba con salas de tortura dotadas con instalaciones técnicas que permitían analizar, revisar y comparar las declaraciones de los detenidos. Algunos de los testimonios relataron que existía un centro de torturas en un lugar subterráneo especialmente equipado para ello y con pequeñas celdas a prueba de ruidos, herméticamente cerradas. En estas celdas se efectuaban los interrogatorios a través de un equipo electrónico con parlantes y micrófonos, mientras los detenidos permanecían desnudos, atados a rejillas metálicas y se les aplicaba corriente eléctrica.

Los testimonios de las mujeres y de los hombres que se presentaron ante la Comisión denunciaron que mientras eran torturados encendían unos grandes ventiladores durante horas, que producían un ruido ensordecedor y aire muy helado y fuerte. Afirman que también participaban en las torturas personas con acento extranjero. Todos los testigos coinciden en señalar que durante su detención sufrieron golpes, aplicación de electricidad, amenazas, simulacros de fusilamiento, vejaciones y violación sexual, utilización de perros entrenados para atacar a hombres y mujeres en los órganos sexuales,

498 Corporación Nacional de Reparación y Reconciliación. Informe de la Comisión Nacional de Verdad y Reconciliación. Bd. 2. Santiago 1996, online unter https://www.memoriachilena.gob.cl/archivos2/pdfs/MCo053680.pdf, hier S. $469 f$. 
privación de sueño, submarino en agua con inmundicias, submarino seco, colgamientos, largos períodos de aislamiento y, además, eran obligados a escuchar torturas a otros detenidos. « $^{499}$

Trotz deutlicher Feststellungen von Folter und Mord in der CD kam es erst nach 2005 $\mathrm{zu}$ einer nennenswerten strafrechtlichen Untersuchung. Inzwischen bestätigen einige chilenische Gerichtsurteile, dass es eine aus Mitgliedern von CD und DINA bestehende kriminelle Vereinigung gab, welche die CD als Haft- und Folterstätte nutzte. Mehrere Colonos machten gerichtliche Aussagen über Haft und Folter Hunderter sowie Erschießungen Dutzender Personen in der CD sowie über das Verscharren von Leichen in Massengräbern. Weiterhin liegen Aussagen von Colonos vor, die 1978 an der Ausgrabung und Verbrennung dieser Leichen beteiligt waren. Allerdings konnte bisher noch in keinem Fall die Identität eines in der CD ermordeten Menschen festgestellt und auch noch kein materieller Täter zweifelsfrei identifiziert werden. In den folgenden Abschnitten möchte ich den derzeitigen Kenntnisstand auf der Grundlage der von mir eingesehenen Quellen (u.a. Justizakten, Archivbestände und das CD-Geheimarchiv) zu bestimmten Themenkomplexen zusammengefasst darstellen. Den Anfang machen die Beziehungen der CD zu Militär und Geheimdiensten.

\section{Die Beziehungen der CD zu Militär und Geheimdiensten}

Vom Tag des Putsches an arbeitete die CD mit diversen Einheiten verschiedener Waffengattungen des Militärs zusammen. Dabei konnte sie auf Verbindungen zurückgreifen, die sie bereits in den Jahren zuvor geknüpft hatte: So bestanden bereits Beziehungen zu den Militärregimentern in der Region, insbesondere zur Artillerieschule in Linares und zur 3. Division des Heeres in Concepción. Aus dem CD-Geheimarchiv geht hervor, dass Kurt Schnellenkamp nach dem 11. September 1973 in der 3. Division des Heeres in Concepción gearbeitet haben soll. ${ }^{500}$ Verbindungen zur regionalen Polizei bestanden auch schon, vor allem aber existierten Kontakte zu zahlreichen Schlüsselpersonen der Militärjunta, die bereits zur Allende-Zeit Treffen und Schulungen in der CD abgehalten hatten. Die engen Verbindungen der CD zur DINA begannen ebenfalls schon vor dem Putsch, etwa zwischen Hartmut Hopp und DINA-Direktor Manuel Contreras. ${ }^{501}$ Auch der zweite Mann der DINA, Pedro Espinoza, stand bereits 1968 mit der $\mathrm{CD}$ in Kontakt, er war damals in der Artillerieschule in Linares stationiert. ${ }^{502}$

Federico Willoughby, der ehemalige Pressesprecher der Militärregierung schrieb 2012, er habe Hartmut Hopp in den Tagen vor dem Putsch darum gebeten, den konservativen Radiosender Radio Agricultura festungsmäßig auszubauen, um sicherzustel-

499 Comisión Nacional sobre Prisión Política y Tortura. Informe de la Comisión Nacional sobre Prisión Política y Tortura, Santiago 2004, S. 351. Für eine ausführliche Diskussion der chilenischen Wahrheitskommissionen vgl. Collins, Cath. Human Rights Trials in Chile during and after the >Pinochet Years<, in: The International Journal of Transitional Justice 4 (2009) No. 1, S. 67-86.

500 CD-Geheimarchiv, Ficha Gregorio Amaya P.

501 StA Bonn, AZ 50 ]s 285/85, Bd. XI, Bl. 68f. Vernehmung von Gerhard Mertins vom 01.03.1989.

502 CA Santiago, AZ 2182-98 (»Asociación Ilícita«) Bd. III (Ministro), BI. 1116. Richterliche Vernehmung von Pedro Espinoza vom 05.04.2006. 
len, dass am 11. September 1973 das Kommuniqué der Putschisten von dort verbreitet werden kann:

»A Schneider [Paul Schäfer, ]S] lo veía muy ocasionalmente en Santiago. Mi interlocutor directo era Hopp, quien vivía con Alfredo [Alfred Matthusen, JS] en un departamento en Providencia. Cuando ya se acercaba el golpe, les pedí si podían construir las defensas y blindaje de las instalaciones de radio Agricultura en la calle Teatinos, donde posiblemente se coordinarían las trasmisiones el día que se produjera la acción militar. Ellos, [...] trabajando entre 10 de la noche y 5 de la madrugada, colocaron los blindajes en escaleras, en el acceso al ascensor y en las ventanas entre el 9 y el 11 de septiembre. De manera cuando me levanté en la madrugada del martes 11 [...] comprobé que la radio estaba protegida. «03

Unmittelbar nach dem Putsch, so Willoughby, habe er einen Anruf des CD-Führungsmitglieds Alfred Matthusen erhalten. Dieser habe ihm angeboten, CD-Mitglieder zum Schutz seines Privathauses und seiner Familie abzustellen. Dies habe er, Willoughby, angenommen, woraufhin drei Colonos einige Tage sein Haus bewachten. ${ }^{504}$

Einige Wochen später, so Willoughby, habe er seine CD-Kontakte gebeten, in seinem Büro (also in einem Regierungsgebäude) Abhör- und Aufnahmetechnik zu installieren, damit er Gespräche mit Journalist_innen aufzeichnen könne. Zudem habe er den Kontakt zwischen der CD-Führung und der von Hauptmann Ewing koordinierten und von Hauptmann Pedro Espinoza Bravo geleiteten Präsidentengarde hergestellt. ${ }^{505}$

Einer der »Sprinter« - der Jungen, die Paul Schäfer begleiten mussten - berichtete, unmittelbar nach dem Putsch mit Schäfer nach Santiago gefahren zu sein. Dort habe dieser sich in der Wohnung der CD in der Calle Román Diaz 512 mit dem späteren DINA-Chef Manuel Contreras getroffen. ${ }^{506}$

Hartmut Hopp, der zu dieser Zeit formal Medizin an der Universidad Católica in Santiago studierte, hielt den direkten Draht zu den höchsten Repräsentanten von Militärregierung und DINA. Er verfügte über ein Büro im Regierungsgebäude Diego Portales $^{507}$ und eine Zugangskarte der höchsten Stufe für das DINA-Hauptquartier in der Calle Belgrado $11 .{ }^{508}$

Laut Zeugenaussagen spielte die CD auch eine wichtige Rolle bei der technischen Ausstattung der DINA: Sie installierte Kommunikations- und Funkanlagen an den wichtigsten DINA-Standorten und Haftzentren. So sagte DINA-Chef Contreras bei

503 Willoughby-MacDonald, Federico. La Guerra. Historia íntima del poder en los últimos 55 años de política chilena 1957-2012, Santiago 2012, S. 141.

504 CA Santiago, AZ 12.293.2005 »homicidio Miguel Becerra Hidalgo«. Urteil vom 27.11.2008. S. $6 f$.

505 Ebd., S. 142.

506 PJS, Sammlung Gesprächsnotizen. Notiz des Cesprächs von Dieter Maier mit Bernd Schaffrik und Waltraud Schaak vom 11.11.2011.

507 Vgl. Heller, Colonia Dignidad: von der Psychosekte zum Folterlager, S. 107.

508 PJS, Sammlung Gesprächsnotizen. Notiz eines Gesprächs von Petra Schlagenhauf und dem Verfasser mit dem ehemaligen DINA-Agenten Patricio Edgardo Roa Caballero vom 17.10.2012. Laut Roa Caballero verfügten nur wenige Besucher des DINA-Hauptquartiers über eine Zugangskarte der Stufe 4, die ohne weitere Nachfragen direkten Zugang zum Büro des DINA-Chefs Manuel Contreras ermöglichte. 
einer Vernehmung 2006, die DINA-Brigade BIR-Sur in Parral habe von Colonos Schulungen in Funk- und Telefonkommunikation erhalten, die auf diesem Gebiet versierter gewesen seien: "pues los alemanes estaban más avanzados al respecto« ${ }^{509}$ Im Mai 1974 wurde in der Casa de Piedra im Cajón del Maipo die Nationale Geheimdienstschule (Escuela Nacional de Inteligencia) eingerichtet. ${ }^{510}$ Ihr Direktor wurde Pedro Espinoza, die Nummer zwei der DINA. Dieser sagte 1974 vor Gericht aus, »einige Deutsche« hätten in der Casa de Piedra "Funkanlagen repariert «. ${ }^{511}$ Carlos Labarca, Espinozas Untergebener, beschrieb bei seiner Vernehmung 2007, Colonos hätten die Antenne und die Funkanlagen installiert, worüber DINA-Funktionäre in der Folge täglich verschlüsselten Funkkontakt mit der CD unterhielten:

»Es importante señalar que en la implementación de esta escuela tuvieron una destacada participación colonos de la llamada >Colonia Dignidadく, quienes instalaron la antena de transmisión y equipos de radio, de alta frecuencia, muy adelantados para la época, pues se comunicaban directamente y sin problemas a Parral y otras ciudades. Este equipo, desde Santiago, era operado por Fernández Larios y Pedro Espinoza, quienes se comunicaban diariamente con los colonos, en clave. Cuando los colonos venían a Santiago, concurrían a `Casa de Píedra< y ellos probaban los equipos y se comunicaban a Parral o a la casa que tenían cerca del Estadio Nacional. «12

Labarca berichtet ebenfalls, dass die Mitarbeiter der Geheimdienstschule in jener Zeit mit ihrem Führungsoffizier Fernández Larios gruppenweise jeweils eine Woche lang in der CD an Sprengstoffschulungen teilnahmen, die Gerhard Mücke mit weiteren Colonos leitete. Er führt aus, wie beeindruckt die DINA-Agenten von der technischen Ausstattung der CD waren und dass sie sich während der Schulungen dort selbst überwacht fühlten:

»Nos exhibían películas, fotos y documentos relacionados con la Segunda Guerra Mundial, donde se podía apreciar las destrucciones de tanques, puentes etc., además de las actuaciones de los Servicios de Inteligencia alemanes. Toda la clase era teórica, en una sala de reuniones habilitada para ello, no permitiéndosenos a los suboficiales, acceso a otras dependencias. [...] Quedé demasiado sorprendido, al igual que mis compañeros, por el nivel de avance de `Colonia Dignidad`a esa época. Tenían tecnología que nosotros no conocíamos, equipos de comunicación potentes, citófonos en todas las habitaciones, equipos de cámaras y videos, las puertas totalmente automatizadas, se abrían y cerraban solas. Tenía la impresión que éramos constantemente vigilados, pues siempre estábamos en las habitaciones que nos señalaban. ${ }^{513}$

509 CA Santiago, AZ 2182-98 (»Asociación llícita«), Bd. Ministro I (2), Bl. 384. Richterliche Vernehmung von Manuel Contreras vom 02.03.2006.

510 Skonic, Francisca. »Casa de Piedra: el secreto lugar de juerga y tortura de la DINA.«, in: CIPER (Website), 02.11.2007, online unter http://ciperchile.cl/2007/11/02/casa-de-piedra/.

511 CA Santiago, AZ 2182-98 (»Asociación Ilícita«), Bd. III (Ministro), Bl. 1120. Richterliche Vernehmung von Pedro Espinoza vom 05.04.2006.

512 CA Santiago, AZ 2182-98 (»Asociación Ilícita«), Bd. V (Ministro), BI. 2254. Richterliche Vernehmung von Carlos Hernán Labarca Sanhueza vom 25.04.2007. Ebd. 
Colonos installierten auch Funkantennen in der Villa Grimaldi, dem wichtigsten Haftund Folterzentrum der DINA in Santiago. ${ }^{514}$ Folterüberlebende berichteten, dass während ihrer Verhöre Funkverbindungen zwischen der Villa Grimaldi und der CD bestanden, um Gefangene mit den Aussagen anderer Gefangener konfrontieren zu können. ${ }^{515}$ Mitte 1974 erwarb die CD ein Haus in der Calle Union 262 in Parral, baute es zur Geheimdienstzentrale um und überließ es der DINA. Diese stationierte hier die BIR-Sur. ${ }^{516}$ Die CD richtete u.a. Funkanlagen ein und schulte das DINA-Personal. ${ }^{517}$. Colonos trafen sich regelmäßig zu Besprechungen mit BIR-Sur-Kommandant Gómez Segovia ${ }^{518}$ und unterstützten die DINA u.a. beim Transport von Gefangenen. ${ }^{519}$ Die Colonos Eva Schaak und Lotti Packmor arbeiteten als Köchinnen in dem Haus. ${ }^{520}$

Die dargestellten Vorgänge belegen die Zusammenarbeit der CD mit der DINA auf nationaler wie regionaler Ebene in verschiedenen für den Repressionsapparat der DINA relevanten Bereichen.

In den Provinzstädten Talca, Linares und Parral sollen Colonos in den Tagen unmittelbar nach dem Putsch vom 11. September 1973 an Verhaftungen beteiligt gewesen sein. Ein Augenzeuge aus Linares berichtete 1992:

»El día 11 andaban los militares en las calles, pero no hacían nada, después, tomaban gente presa. Junto con los milicos se veían alemanes, estamos seguros que eran los de la Colonia Dignidad. «21

Bereits zwei Tage nach dem Putsch, besuchte Hugo Cardemil, der neue Gouverneur von Linares, zusammen mit Guillermo Marín Estévez, dem Bürgermeister der Ortschaft Retiro, die CD. Sie wurden von Hermann Schmidt und Albert Schreiber empfangen,

514 Der ehemalige DINA-Agent Samuel Fuenzalida berichtet, beobachtet zu haben, wie CD-Mitglieder 1975 in der Villa Crimaldi Funkantennen installierten. CA Santiago, AZ 2182-98 (»Alvaro Vallejos Villagrán«), Bd. 1a, BI. 77 R. Richterliche Vernehmung von Samuel Fuenzalida Devia vom 02.06.1998. Vgl. auch PJS, Sammlung CD. Protokoll der Anhörung von Waltraud und Hugo Baar am 02/03.11.1990 durch Vertreter_innen der Comisión Nacional de Verdad y Reconciliación.

515 Erick Zott berichtet über sein Verhör in der CD: »Me atan a un catre de campaña con correas a los pies [...] Recuerdo que se sostuvo una comunicación radial con Villa Grimaldi y fueron interrogados los prisioneros Zaror y Sanzana. “CA Santiago, AZ 2182-98 (»Alvaro Vallejos Villagrán«), Bd. 8a, BI. 2608. Polizeiliche Vernehmung von Erick Zott vom 21.03.2005. Über die Funkverbindung zur Villa Grimaldi während seines Verhörs in der CD hatte Zott bereits 1978 berichtet. Archiv Al, Bestand CD. LC Bonn, AZ 3 O 123/77. Vernehmungsprotokoll des Zeugen Erick Zott vom 18.10.1978.

516 Die BIR-Sur trug DINA-intern den Namen »Brigada Michimalongo«.

517 CA Santiago, AZ 10-2004 (»Adriana Bórquez«), Bd. I, BI. 173ff. Polizeiliche Vernehmung von Fernando Gómez Segovia vom 15.05.2004.

518 Als regelmäßige Besucher des Hauses während der DINA-Jahre erkannten verschiedene DINAAgent_innen bei Vernehmungen auf Bildern Paul Schäfer, Albert Schreiber, Gerhard Mücke, Kurt Schnellenkamp und Manfred Schmidtke

519 CA Santiago, AZ 7981-E (»Muerte de Manuel Leyton«), Bd. 19a, BI. 5809. Polizeiliche Vernehmung der DINA-Agentin Zunilda de las Mercedes Robles Zuñiga vom 11.12.2007.

520 Archiv AI, Bestand CD. Aufzeichnung von Walter Rövekamp vom 11.01.1988 über Gespräch von Rövekamp mit Peter Clever über dessen Zusammenkunft mit dem Ehepaar Packmor.

521 Comité de Defensa de los Derechos del Pueblo. Labradores de la Esperanza. La región del Maule, Santiago 1992, S. 47. 
"quienes me manifestaron su entusiasmo por el gobierno militar«. ${ }^{522}$ Kurze Zeit später wurde Cardemil von Schäfer erneut in der CD empfangen. ${ }^{523}$

Unmittelbar nach dem Putsch nutzte die CD-Führung ihre neugewonnene Macht, um dutzende von Landarbeiter_innen, die nach Gewohnheitsreicht seit Jahrzehnten auf dem von der CD erworbenen Gelände lebten, zu vertreiben. ${ }^{524}$ Sie wurden mit Militärund CD-Fahrzeugen verschleppt und ausgesetzt, ihre Häuser wurden verbrannt. Ein damals 14-jähriger Betroffener berichtete Jahrzehnte später, von Colonos erst in die CD und später ins Kommissariat in Catillo gebracht worden zu sein, wo er anschließend von Carabineros gefoltert worden sei:

»[E]fectivamente fui detenido el día 13014 de septiembre de 1973 por los alemanes residentes de la Colonia Dignidad, cuando residía en el fundo San Manuel. En aquel tiempo yo tenía unos catorce años, cuando los Alemanes me llevaron hasta las oficinas de la Colonia sin explicar motivos. Recuerdo que estos andaban de civil y portaban armamento tipo ametralladora. [...] fui agredido por mis captores para luego ser subido al mismo camión en el que me detuvieron y ser conducido a la Comisaría de Carabineros de Catillo. En ese lugar fui entregado al carabinero Toledo, que era jefe de esa unidad [...] En ese cuartel fui mantenido durante toda la noche, siendo interrogado y torturado por Toledo y otros carabineros, con respecto al motivo por el cual no abandonaba el fundo. ${ }^{525}$

In den Tagen nach dem Putsch empfingen Schäfer und Hopp mehrfach Soldaten aus Parral. ${ }^{526}$ Von der CD aus patrouillierten die Soldaten gemeinsam mit Colonos in der Umgebung der Siedlung, insbesondere in den Wäldern in Richtung der Kordillere, um sie $\mathrm{zu}$ »durchkämmen « und von »Kommunisten« zu »säubern «. ${ }^{527}$ Dabei wurden Menschen festgenommen, geschlagen und schließlich außerhalb der Siedlung ausgesetzt. Auch in benachbarten Fundos, deren Eigentümer in enger Verbindung zur CD stan-

522 CA Santiago, AZ 2182-98 (»Asociación Ilícita«), Bd. II (Ministro), BI. 809ff. Richterliche Vernehmung von Hugo Cardemil vom 21.04.2006.

523 Ebd.

524 Die erste von vermutlich mehreren Vertreibungsaktionen soll bereits am 17.09.1973 stattgefunden gefunden haben. CA Santiago, AZ 8710-2005 (»ex-Colonia Dignidad, secuestro calificado de Miguel Rojas Rojas y otros«), Bd. I, BI. 1ff. Strafanzeige RA Hernán Quezada vom 31.03.2005. Insgesamt sollten mindestens 15 Familien betroffen gewesen sein, insgesamt 80 bis 100 Personen. Einige Betroffene und ihre Nachfahren trafen sich seit 2017 mehrfach, um ihre Erlebnisse miteinander auszutauschen. Mitorganisator der Treffen war der Rechtsanwalt und Ex-Colono Winfried Hempel.

525 CA Santiago, AZ 8710-2005 (»ex-Colonia Dignidad, secuestro calificado de Miguel Rojas Rojas y otros«), Bd. I, BI. 116. Polizeiliche Vernehmung von Rene Antonio Gómez González vom 26.01.2006.

526 CA Santiago, AZ 8710-2005 (»ex-Colonia Dignidad, secuestro calificado de Miguel Rojas Rojas y otros«), Bd. I, BI. 21f. und 131f. Polizeiliche Vernehmungen von Iván Enrique Norambuena Arenas vom 09.06.2005 und vom 26.01.2006. Norambuena spricht von einer Gruppe von 9o Soldaten, die Anfang Oktober 1973 etwa eine Woche in der CD verbrachten.

527 CA Santiago, AZ 8710-2005 (»ex-Colonia Dignidad, secuestro calificado de Miguel Rojas Rojas y otros«), Bd. I, BI. 19f. Polizeiliche Vernehmung von Daniel Enrique Zurita San Martin vom 02.06 .2005 
den, wurden Menschen festgenommen und zur Polizeiwache in Catillo gebracht. ${ }^{528}$ Die Gutsbesitzer beteiligten sich teilweise selbst an den Festnahmen. ${ }^{529}$

Die Zusammenarbeit zwischen der CD und den Beamt_innen der Polizeiwache in Catillo war bereits seit den $1960 e r$ Jahren eng. In den Wochen nach dem Putsch arbeiteten sie direkt zusammen bei der Repression gegen gemeinsame politische Gegner_innen in der Umgebung der CD: Angeführt von Feldwebel Toledo zogen uniformierte Colonos, gemeinsam mit Militärs aus Linares und Parral sowie Polizisten aus Catillo los und nahmen willkürlich Mitglieder linken Parteien oder Gewerkschaften fest. ${ }^{530}$ Ein ehemaliger Gefangener berichtete 2005 von seiner Festnahme durch Colonos und Carabineros, und davon, wie Colonos Gefangene mit Stricken um den Hals bei der Polizeiwache in Catillo ablieferten:

»[A]cerca de la cooperación entre personal de Carabineros o del Ejercito de Chile con los colonos alemanes de la `Villa Bavieraく, puedo señalar [...] en especial los del Retén Catillo comenzaron desde un principio a trabajar con los alemanes, procediendo estos a detener a los campesinos y hacerlos llegar a través de lazos que ponían en sus cuellos. El Sargento Toledo trabajaba de mutua cooperación con los alemanes, hasta el punto de facilitarle todos los medios a los Carabineros en relación al transporte. [...] Recuerdo que algunos alemanes andaban vestidos con uniformes militares y armados, siempre demostrando violencia. En una parcela que estaba ubicada al ingreso del predio, me percaté en muchas ocasiones de personas detenidas, ya que estas estaban custodiadas por militares y colonos. [...] Referente a lo que me correspondió vivir, puedo señar que fui detenido junto a mi hermano, a los días siguientes de ocurrido el golpe de Estado, Ilevándonos al interior de la `Colonia Dignidadı, lugar en el cual fuimos interrogados y golpeados por el Sargento TOLEDO, quien siempre nos dijo que él cumplía ordenes de la Colonia, como a manera de justificar el por qué estábamos detenidos, es decir los alemanes decían a quien la policía debía detener. [...] Respecto a los alemanes recuerdo a Paul Schäfer, el doctor Hopp, unos señores de apellidos Smith [Hermann Schmidt,

528 CA Santiago, AZ 8710-2005 (»ex-Colonia Dignidad, secuestro calificado de Miguel Rojas Rojas y otros«), Bd. I, BI. 1f. Strafanzeige RA Hernán Quezada vom 31.03.2005. Quezada führt darin aus: »Miguel Rojas Rojas, militante del Partido Socialista y su hijo Gilberto Rojas Vásquez, militante del Partido Comunista, fueron detenidos por efectivos de Carabineros y del Ejército en el ex fundo El Palomar [...] el día 13 de octubre de 1973. Ambos fueron trasladados al Retén de Catillo [...], recinto desde donde desaparecieron [...] Cabe señalar que el dueño del fundo >El Palomar «, Ignacio Urrutia de la Sotta, era un conocido samigo de la denominada >Colonia Dignidadı, y los miembros de ésta eran asiduos visitantes de su casa. Igualmente, el suboficial Diógenes Toledo concurría con frecuencia a dicho enclave alemán."

529 CA Santiago, AZ 8710-2005 (»ex-Colonia Dignidad, secuestro calificado de Miguel Rojas Rojas y otros«), Bd. I, BI. 119. Polizeiliche Vernehmung von Gustavo Torres vom 06.02.2006. Torres wurde gemeinsam mit seinem bis heute verschwundenen Vater Ruperto Torres am 16.09.1973 in Bajo las Torres festgenommen. An der Festnahme waren Militärs unter der Führung von Hugo Cardemil, Polizeibeamter der Wache von Catillo sowie der Gutsbesitzer Guillermo Marín Estévez beteiligt.

530 CA Santiago, AZ 2182-98 (»Alvaro Vallejos Villagrán«), Bd. 8b, Bl. 2813ff. Polizeiliche Vernehmung von Baltazar Castillo González vom 10.06.2005. 
JS] y Walter [Walter Laube, ]S] y otros de nombre Ursula [Schmidt, ]S] y Alberto [Albert Schreiber, ]S]. 531 $^{531}$

In der CD sowie auf der Wache wurden die Gefangenen geschlagen, verhört und dann meist wieder freigelassen. Fünf der im Oktober 1973 in Catillo Festgenommenen gelten jedoch bis heute als verschwunden. ${ }^{532}$ Die Beziehungen zwischen der CD und der Polizei in Catillo blieben auch in den Folgejahren eng. Ein Beamter, der 1981 seinen Dienst dort antrat, berichtete:

»Al llegar a esta unidad policial, me percaté que los funcionarios que allí se desempeñaban tenían una >relación< con la `Colonia Dignidadく, en el sentido de prestar colaboración a la comunidad, como asimismo de ser un lugar que debíamos visitar dentro de nuestros servicios de patrullaje. Asimismo quiero agregar que había un equipo radial facilitado por los colonos alemanes, el cual tenía un contacto directo con otro ubicado al interior del enclave alemán. «333

Der Beschluss zur Errichtung eines Folterlagers in der CD geht laut Gerd Seewald auf ein Treffen Schäfers mit Contreras in den Tagen nach dem Putsch zurück. ${ }^{534}$ Contreras kam im Oktober 1973 zusammen mit Juan Muñoz Alarcón in die CD. ${ }^{535}$ Dieser war Mitglied der Sozialistischen Partei und hatte zuvor als Sekretär des Bürgermeisters von Puente Alto gearbeitet. In den Monaten vor dem Putsch wandte er sich jedoch von der Sozialistischen Partei ab und arbeitete mit Gegner_innen der Allende-Regierung zusammen. Nach dem Putsch wurde er mehrfach verhaftet und kollaborierte daraufhin mit dem Geheimdienst. Er war der - oder einer der - Kapuzenmänner, die im Nationalstadion von Santiago Mitglieder linker Parteien und Bewegungen identifizierte und somit ihren Folterern und Mördern auslieferte. Ab Oktober 1973 arbeitete er in der CD für den Geheimdienst. Unter dem Decknamen »Molli« lieferte er Informationen an CD und DINA, die zum Teil im CD-Geheimarchiv festgehalten sind. Seine Frau und seine sechs Kinder lebten einige Zeit ebenfalls in der CD. Im Oktober 1977 wurde Muñoz Alarcón ermordet in Santiago aufgefunden. ${ }^{536}$ Zuvor hatte er der katholischen Menschenrechtsorganisation Vicaría de la Solidaridad ausführlich über seine Tätigkeit als DINA-Mitarbeiter berichtet. Unter anderem übergab er eine Liste mit den Namen 81

531 Ebd.

532 Alfredo Ricardo Durán Durán, Ramiro Antonio Romero González, Miguel Rojas Rojas, Gilberto Rojas Vásquez und Ruperto Torres Aravena wurden am 13.10.1973 festgenommen und sind seitdem verschwunden.

533 CA Santiago, AZ 8710-2005 (»ex-Colonia Dignidad, secuestro calificado de Miguel Rojas Rojas y otros«), Bd. I, Bl. 23. Polizeiliche Vernehmung von Orlando Antonio Calvo Hidalgo vom 09.06.2005.

534 CA Santiago, AZ 2182-98 (»Asociación llícita«), Bd. III (Ministro), BI. 1295f. Polizeiliche Vernehmung von Gerd Seewald vom 18.03.2006.

535 Ebd. sowie 11. Juzgado del Crímen, AZ 12.293 (»Homicidio de Juan René Muñoz Alarcón«), Bl. 87. Vernehmung der Ehefrau von Juan Muñoz Alarcón, Olivia Guajardo Barahona [o. D., vermutlich 1977 oder 1978].

536 Las Ultimas Noticias vom 25.10.1977, [Artikel zur Ermordung von Juan René Muñoz Alarcón] ohne Titel, einsehbar in PA AA, ZW 111131. 
Verschwundener, die nach seinen Angaben zu diesem Zeitpunkt noch lebten und in der CD inhaftiert seien. ${ }^{537}$

Auch der DINA-Agent Miguel Becerra Hidalgo alias »Uno« arbeitete in der CD. Die von ihm gelieferten Informationen sind ebenfalls im Geheimarchiv der CD erfasst. Becerra wurde im Juli 1974 von CD-Mitgliedern mit Pestizid ermordet ${ }^{538}$, nachdem er gegenüber seinem Bruder geäußert hatte, er wolle aus der DINA aussteigen.

Ein Bericht der 1985 geflüchteten CD-Bewohnerin Lotti Packmor gibt Anhaltspunkte über die Zusammenarbeit von CD-Mitgliedern und DINA-Agenten. Packmor arbeitete in Nachtschichten in der CD-Küche, bei der sie 1973/74 Essen verschiedener Qualitätsstufen zubereiten sollte: jeweils 5-6 »Besucheressen« [für DINA-Angehörige], Essen für die »Nachtarbeiter « [CD-Mitglieder, die an der Bewachung und Folter von Gefangenen beteiligt waren] und Essen für die »Schweine« [damit waren Gefangene gemeint]. 539

Im Geheimarchiv der CD finden sich Karteikarten über DINA-Agenten, die in der CD stationiert waren. In einem Bericht über den Agenten Eduardo Fernando Soto Henríquez an den Chef der DINA Manuel Contreras alias »Mamo « (siehe Abbildungen 3 und 4 in Abschnitt 2.2.5), beispielsweise, wird Soto als zu neugierig kritisiert. Er habe den Colonos Fragen zu privaten Dingen gestellt und unerlaubt die Ladefläche von Lastwägen kontrolliert. »Por suerte que las cosas que ya conoce don Mamo no se encontraban ahí en ese momento«, glücklicherweise hätten sich bestimmte sensible, dem DINA-Chef bekannte Dinge zu dem Zeitpunkt nicht dort befunden, so der Berichterstatter im August 1974. »Se deja a criterio de don Mamo si debe continuar trabajando con la Colonia o deba ser cambiado«, Contreras solle entscheiden, ob der betreffende DINA-Agent weiter in der CD arbeiten könne, hieß es weiter. Der Agent wurde daraufhin versetzt $t^{540}$. Dieser Bericht belegt, dass CD-Angehörige in Bezug auf die DINA-Aktivitäten in der Siedlung im direkten Kontakt mit Manuel Contreras standen.

Die CD pflegte Verbindungen zu Vertretern aller Waffengattungen des chilenischen Militärs sowie zu deren oftmals miteinander konkurrierenden Geheimdiensten. ${ }^{541}$ Die engsten Verbindungen bestanden jedoch zu Pinochet persönlich sowie zur DINA, dessen Machtbasis. Viele Colonos berichteten von regelmäßigen, teilweise wöchentlichen Besuchen des DINA-Chefs Contreras in der Siedlung. »Don Mamo«, wie er in der CD

Vgl. Abschnitt 5.1.2.

538 Im Verfahren wegen Mordes an Miguel Becerra Hidalgo (CA Santiago, AZ 12.293-2005) verurteilte Richter Zepeda im 2008 Paul Schäfer als Täter zu sieben Jahren Haft. Kurt Schnellenkamp und Rudolf Cöllen wurden wegen Verschleierung zu 541 Tagen Haft auf Bewährung verurteilt. Beim letztinstanzlichen Urteil der Corte Suprema war Schäfer bereits verstorben, die Urteile gegen Schnellenkamp und Cöllen wurden bestätigt.

539 Archiv Al, Bestand CD. Aufzeichnung von Walter Rövekamp vom 11.01.1988 über Gespräch von Rövekamp mit Peter Clever über dessen Zusammenkunft mit dem Ehepaar Packmor. Lotti Packmor nennt als »Nachtarbeiter« Gerhard Mücke, Karl van den Berg, Rudolf Cöllen und Johann Spatz.

540 CD-Geheimarchiv, Ficha Eduardo Fernando Soto Henríquez.

541 Die verschiedenen Waffengattungen des chilenischen Militärs hatten jeweils eigene Geheimdienste, wie den Servicio de Inteligencia Militar (SIM), den Servicio de Inteligencia de la Fuerza Aerea (SIFA), den Servicio de Inteligencia Naval (SIN) oder den Servicio de Inteligencia de Carabineros (SICAR). Zu deren Rivalitäten mit der DINA vgl. Heller, Friedrich Paul. Pinochet - Eine Täterbiografie in Chile, Stuttgart 2012, S. 69. 
genannt wurde, bewohnte dort ein Zimmer im »Waldhaus « mit CD-internem Telefonanschluss. Dieser ermöglichte beispielsweise die Kommunikation mit dem Haft- und Folterort Kartoffelkeller, wo Gefangene eingesperrt und gefoltert wurden, oder mit der Funkstation, die Verbindungen zum DINA-Hauptquartier in Santiago herstellte. ${ }^{542}$ Die enge Beziehung zwischen der CD-Führung und Contreras überdauerte die Auflösung der DINA 1977 und setzte sich bis zur Festnahme Contreras 1995 fort. Dieter Malessa, einer der Sicherheitschefs der CD, berichtete 2005, er habe im Jahr 1980 von Schäfer die Anweisung erhalten, das Auto der Ehefrau von Pedro Espinoza, ehemals 2. Mann der DINA, zu bergen, die auf der Panamericana einen Unfall hatte. Er habe das Auto auf einen Laster geladen und ins Haus der CD nach Santiago gebracht. ${ }^{543}$ Manuel Contreras Valdebenito, Contreras Sohn, berichtete, die Beziehung seines Vaters zur CD sei nach 1982 sogar noch enger geworden. Nach einem Anschlag auf das Auto von Contreras am 20. März 1984 hätten Colonos das Fahrzeug gepanzert und mit fünf Maschinenpistolen ausgerüstet. 1985 habe Contreras nach einer Krebserkrankung fünf Monate in der CD verbracht und sich einer Chemotherapie unterzogen. Hartmut Hopp habe ihn in allem versorgt, so der Sohn »lo atendió en todo«. 544

Auch weitere hohe Offiziere vertrauten sich dem CD Krankenhaus bzw. Hartmut Hopp als Arzt an: Pedro Espinoza berichtete, im Januar 1975 habe er seinen Vater wegen eines ernsten Gesundheitsproblems ins Krankenhaus der CD gebracht. Dies habe er bereits aus seiner Zeit als Chef der Artillerieschule in Linares ab 1969 gekannt. ${ }^{545}$ Federico Willoughby berichtete, Hopp habe ihn zu Untersuchungen wegen seines Nierenleidens in die USA begleitet. ${ }^{546}$

Das Vertrauen zwischen CD und DINA-Spitze ging so weit, dass die Siedlung führenden DINA-Offizieren und ihren Familien als Rückzugs- und Erholungsort diente. Manuel Contreras`Sohn berichtete von regelmäßigen Aufenthalten in der CD zwischen 1974 und 1977 und von Ausflügen mit der CD-Führung:

»Recuerdo un viaje que hicimos junto a todos los familiares de los miembros de la cúpula de la DINA. Éramos como 40 personas. Colonia Dignidad era como un lugar de veraneo para nosotros, un sitio para pasar los fines de semana. ${ }^{547}$

Die DINA-Kollaborateurin Luz Arce berichtete, sie sei von DINA-Offizieren eingeladen worden, in der CD Urlaub zu machen. Noch bis 1990 hätten Vertraute von Contreras, wie

542 PJS, Sammlung CD. Protokoll der Anhörung von Waltraud und Hugo Baar am 02/03.11.1990 durch Vertreter_innen der Comisión Nacional de Verdad y Reconciliación.

543 CA Santiago, AZ 2182-98 (»Asociación Ilícita«), Bd. II (2) Parral, Bl. 1413ff. Richterliche Vernehmung von Dieter Malessa vom 22.03.2005.

544 Revista Cosas vom 01.04.2005, S. 86. »Manuel Contreras Valdebenito: Mis días en Colonia Dignidad «.

545 StA Bonn, AZ 554 U]s 114/O6P, Bd. I, BI. 79. Polizeiliche Vernehmung von Pedro Espinoza Bravo vom 14.02.2005. Die chilenische Kriminalpolizei führte die Vernehmung durch und übermittelte sie im Rahmen eines Rechtshilfeersuchens an die StA Bonn.

546 Willoughby-MacDonald, Federico. La Guerra. Historia íntima del poder en los últimos 55 años de política chilena 1957-2012, Santiago 2012, S. 143.

547 Revista Cosas vom 01.04.2005, S. 85. »Manuel Contreras Valdebenito: Mis días en Colonia Dignidad«. 
Rolf Wenderoth Pozo oder Marcelo Moren Brito Urlaub in der CD gemacht. ${ }^{548}$ Weitere DINA-Offiziere verbrachten ihre Ferien mit ihren Familien in der CD. ${ }^{549}$ Manche Kinder von DINA-Angehörigen wurden in der CD betreut. Eduardo Guy Neckelmann, Chef der BIR-Sur, vertraute seine Kinder nach eigener Aussage sogar sieben Monate lang der CD an: »Mis niños estuvieron alrededor de 7 meses internados en la Colonia. «50

\section{Haft und Folter in der Colonia Dignidad}

In der Colonia Dignidad wurden nach dem 11. September 1973 politische Gefangene festgehalten, verhört und gefoltert. Bisher ist durch chilenische Gerichtsverfahren der Aufenthalt von Gefangenen in der CD für 1974 und 1975 belegt. ${ }^{551}$ Die Gefangenen wurden von Colonos, Militärs, DINA-Agent_innen oder Polizist_innen dorthin gebracht, entweder einzeln oder in Gruppen. In der CD wurden sie in der Regel unter Folter verhört. Bis heute ist unklar, welche Verbindungen bestanden einerseits zwischen dem Haft- und Verhörzentrum in der CD und andererseits dem Ort, an dem Verschwundene ermordet und ihre Leichen vergraben bzw. beseitigt werden. Vermutlich wurden die Gefangenen, die in der CD zum Zweck der Informationsgewinnung gefoltert wurden, strikt von denjenigen getrennt, die auf dem Gelände getötet oder deren Leichen beseitigt werden sollten. Jedenfalls konnten die Gefangenen, die ihre Haft und Folter in der CD überlebten, keine Angaben zu in der CD festgehaltenen Personen machen, die später zu Verschwundenen wurden.

Durch Gerichtsverfahren ist bislang dokumentiert, dass zwei größere Gruppen Gefangener zu Folterverhören in die CD verschleppt wurden.

Im September 1974 wurden 10-15 Mitglieder der Kommunistischen Partei aus Coronel und Lota in die CD gebracht, dort verhört und gefoltert. ${ }^{552}$ Mehrere der Verhöre

548 PA AA, AV NA 32992. Entwurf einer eidesstattlichen Erklärung von Luz Arce. Anlage zu einem Schreiben von Dieter Maier an die Botschaft (Herrn Kliesow) vom 20.07.1996.

549 Der DINA-Agent Osvaldo Pincetti berichtet, er habe dort nach 1976 einen Sommer lang auf Kinder von Militäroffizieren aufgepasst. CA Santiago, AZ 2182-98 (»Alvaro Vallejos Villagrán«), Bd. 3a, BI. 786. Polizeiliche Vernehmung von Osvaldo Pincetti vom 30.03.1999. Die DINA-Kollaborateurin Marcia Merino berichtet, dass auch Pedro Espinoza, zweiter Mann in der DINA hinter Contreras, dort seinen Urlaub verbrachte. CA Santiago, AZ 2182-98 (»Alvaro Vallejos Villagrán«), Bd. 1a, BI. 119. Richterliche Vernehmung von Marcia Merino vom 04.06.1998. Auch der Ex-Colono Willi Malessa berichtet, dass Contreras und Pedro Espinoza mit ihren Familien in der CD Urlaub machten. Juzgado de Parral, AZ 66.124 (»Asociación Ilícita Efraín Vedder«), Bd. 1, BI. 470. Richterliche Vernehmung von Willi Malessa vom 02.05.2005.

550 CA Santiago, AZ 2182-98 (»Asociación Ilícita«), Bd. IV (Ministro), Bl. 1788. Richterliche Vernehmung von Eduardo Guy Neckelmann Schütz vom 18.10.2006.

551 Auch der Colono Gerd Seewald behauptete, Militärs und Gefangene hätten sich nur 1974 und 1975 in der CD aufgehalten. CA Santiago, AZ 2182-98 (»]uan Maino«), Bd. IVb, BI. 1684. Richterliche Vernehmung von Gerd Seewald vom 18.08.2005.

552 Die Informationen in diesem Abschnitt stammen aus den Gerichtsverfahren zu den Verschwundenen Pedro Merino Molina (CA Santiago, AZ 3283-98 »Pedro Merino«) und Adán Valdebenito Olavarría (Juzgado de Lota, AZ 28.888). Die Verfahrensakten enthalten umfangreiche Aussagen mehrerer Cefangener aus Coronel, die in die CD verbracht wurden und dort Haft und Folter überlebt haben. Das Verfahren zu Pedro Merino endete mit einem Urteil der Corte Suprema vom 15.12.2014 (AZ 22266-2014). Drei Militärs bzw. DINA-Agenten, zwei Polizisten und ein Angehöriger der JustizPolizei (Gendarmería) wurden zu fünf Jahren und einem Tag Haft verurteilt. Das CD-Mitglied Gerd 
wurden im CD-Geheimarchiv festgehalten. ${ }^{553}$ Nach etwa drei bis vier Wochen wurden die Gefangenen in Kühllastwägen der DINA in das geheime Haftzentrum Cuatro Alamos in Santiago gebracht. Zwei der Gefangenen, Pedro Merino Molina und Adán Valdebenito Olavarría, gelten bis heute als verschwunden. Gerd Seewald, verantwortlich für das CD-Geheimarchiv, bestätigte bei Vernehmungen den Aufenthalt von etwa zehn Gefangenen aus Coronel in der CD. Paul Schäfer habe ihm über diese Gruppe gesagt: "Sie dürfen nicht überleben. «554

Im April und Mai 1975 wurden mindestens 50 Personen - größtenteils Mitglieder oder (vermeintliche) Sympathisant_innen der Kommunistischen Partei - in Talca und Umgebung festgenommen und in die CD verschleppt. Dort wurden sie zwischen drei und 24 Tagen festgehalten, verhört und gefoltert. Ein Teil wurde danach wieder freigelassen, andere wurden von DINA-Agenten in andere geheime Haftzentren nach Santiago verlegt. ${ }^{555} \mathrm{Zu}$ dieser Gruppe politischer Gefangener gehörten Adriana Bórquez, Iván Treskow, Manuel Bravo und Gerardo Sánchez, die später Zeugnisse über ihre Haft und Folter in der CD ablegten, etwa in der erwähnten Broschüre von Amnesty International Frankfurt im März 1977 und als Zeugen im Rahmen des Verfahrens AZ 3 O 123/77 vor dem Bonner Landgericht (Vgl. Abschnitt 5.3.1).

Bezüglich der beiden genannten Gruppen von Gefangenen wurden in Chile zwei Strafverfahren geführt. Im Verfahren wegen der Entführung von Adriana Bórquez Adriazola wurden Fernando Gómez Segovia, der DINA-Chef von Parral und der Colono Gerhard Mücke zu jeweils drei Jahren Haft auf Bewährung verurteilt. ${ }^{556}$ Das Verfahren wegen der Entführung der 50 Personen aus Talca und Umgebung endete mit der Verurteilung von Gómez Segovia zu fünf Jahren Haft auf Bewährung und von Gerhard Mücke zu drei Jahren und einem Tag Haft. ${ }^{557}$ Auch Kurt Schnellenkamp wurde zu 541 Tagen Haft verurteilt, verstarb aber, bevor das Urteil rechtskräftig wurde.

Seewald wurde freigesprochen. Das Verfahren zu Adán Valdebenito endete mit Urteil der Corte Suprema vom 11.01.2012 (AZ 7558-2011). Der DINA-Chef Manuel Contreras wurde zu 541 Tagen Haft verurteilt, der Polizist Orlando Manzo Durán zu 61 Tagen Haft.

553 CD-Geheimarchiv, Fichas von Pedro Merino, Adán Valdebenito, José Hilario San Martin, Ernesto David Tapia, Heriberto Toledo, Jose David Estrada, Vicente Pichott, Osvaldo de Dios Alarcón und Osvaldo Sempert. Die Fichas enthalten teilweise auch Kopien der Ausweisdokumente der Gefangenen. Besonders erschütternd sind die 28 Fichas umfassenden Protokolle der Verhöre von Pedro Merino.

554 CA Santiago, AZ 2182-98 (»Asociación Ilícita«), Bd. I (2) Ministro, BI. 563. Richterliche Vernehmung von Gerd Seewald vom 23.06.2005.

555 Darunter die Haft- und Folterzentren Cuatro Alamos, Villa Grimaldi und Irán 3033 (Venda Sexy). Ein DINA-Agent bestätigte bei seiner Vernehmung 2004, gemeinsam mit weiteren DINA-Agenten im Juni oder Juli 1975 20-25 Gefangene mit einem Bus aus der CD abgeholt und in die Villa Grimaldi nach Santiago verbracht zu haben. CA Santiago, AZ 2182-98 (»Pedro Merino«), Bd. VIla, BI. 2323. Richterliche Vernehmung von Amador Abraham Fuentes Salas vom 12.11.2004. Später sprach Fuentes Salas sogar von 40 verschleppten Gefangenen. CA Santiago, AZ 2182-98 (»]uan Maino«), Bd. Va, BI. 2381. Vernehmung von Amador Abraham Fuentes Salas vom 08.11.2005.

556 Verfahren CA Santiago, AZ 10-2004. Erstinstanzliches Urteil vom 15.04.2013 sowie CA Santiago, AZ 953-2013. Rechtskräftiges Urteil vom 29.10.2013.

557 Verfahren CA Santiago, AZ 49-2004. Erstinstanzliches Urteil vom 15.10.2015 sowie Corte Suprema, AZ 21614-2017. Urteil vom 22.05.2018. 
Neben den beiden genannten Gruppen sagten zahlreiche weitere Menschen aus, in der CD inhaftiert, verhört und gefoltert worden zu sein. Erick Zott und Luis Peebles, zwei Aktivisten der MIR, wurden Anfang Februar 1975 von der DINA in die CD gebracht und dort mehrere Tage lang gefoltert. ${ }^{558}$ Eduardo Garcés, ein Aktivist der Kommunistischen Partei, wurde ebenfalls im Februar 1975 in Coronel festgenommen und zusammen mit weiteren Gefangenen in einem Kühllastwagen in die CD gebracht. Dort wurde er von vier Personen, darunter einer Frau, in Arztkitteln gefoltert. Sowohl Peebles als auch Garcés wurden in Holzkisten gesteckt und mit Elektroschocks und Spritzen traktiert. Aus Peebles« Sicht war die Folter in der CD »systematischer und wissenschaftlicher « 559 als in anderen Haftzentren der DINA. Einer seiner Folterer, so Peebles, sei Paul Schäfer gewesen. ${ }^{560}$ Garcés wiederum hatte den Eindruck, das Objekt von (Folter-)Studien gewesen zu sein. Peebles, Zott und Garcés sagten bereits 1978 im Zivilverfahren vor dem Landgericht Bonn aus. ${ }^{561}$

Ein Gefangener wurde 1974 elf Monate lang in der CD festgehalten. Der aus Mazedonien eingewanderte Bestattungsunternehmer Mile Mavrosky Mileva wurde am 9. Januar 1974 in San Carlos festgenommen und einige Tage im Gefängnis von Chillán festgehalten. ${ }^{562}$ Ein Militärgericht verurteilte ihn zu 541 Tagen Haft. ${ }^{563}$ Von Chillán aus wurde er in die CD verschleppt und dort monatelang verhört und gefoltert. Aufgrund seiner Herkunft behauptete die Junta, er sei ein »kommunistischer Agent «. Während der Verhöre stellte man ihm Fragen auf Serbokroatisch und Russisch. Erst Ende Dezember 1974 wurde er zurück ins Gefängnis von Chillán gebracht und einige Tage später freigelassen. Mehrere Colonos bestätigten bei Vernehmungen den Aufenthalt Mavroskys in der CD. ${ }^{564}$ Das Besondere an diesem Fall ist, dass ein formell von der (Militär-)Justiz verurteilter Gefangener seine Haft überwiegend in der CD verbüßte.

Ein weiterer Fall ist der von Maria Isabel Romero. Sie wurde Anfang Juli 1975 von DINA-Agent_innen entführt und in die CD verschleppt. Dort verhörte sie Paul Schäfer. Am nächsten Tag brachte Hartmut Hopp sie in einem Fahrzeug aus der CD und

558 Die Kollaborateurin Marcia Merino (alias »la Flaca Alejandra«), die die DINA-Agenten begleitete, bestätigt dies. Vgl. Merino Vega, Marcia Alejandra. Mi verdad. Más allá del horror yo acuso, Santiago 2001, S. 72-77.

559 Vgl. La Epoca vom 23.02.1991, S. 12. »Eduardo Garcés, un condenado que sobrevivió«.

560 CA Santiago, AZ 2182-98 (»Alvaro Vallejos«), Bd. 5a, Bl. 1398ff. Richterliche Gegenüberstellung von Luis Peebles und Gerhard Mücke vom 11.09.2000.

561 PA AA, AV NA 31580. LG Bonn. AZ 3 O 123/77. Verlaufsprotokoll der Zeugenaussage von Eduardo Garcés vom 19.12.1978 sowie Archiv AI, Bestand CD. LC Bonn, AZ 3 O 123/77. Vernehmungsprotokoll der Zeugen Luis Peebles und Erick Zott vom 17.-18.10.1978.

562 CA Santiago, AZ 2182-98 (»]uan Maino«), Bd. 6a, BI. 2440f. Richterliche Vernehmung von Mile Mavrovsky Mileva vom 04.01.2006.

563 Tribunales de Justicia Militar en Tiempo de Guerra, Fiscalía Militar Letrada de Ejército y Carabineros Ñuble, AZ 3-1974. Das Urteil wurde von der Corte Suprema als Unrechtsurteil eingestuft und wieder aufgehoben. Corte Suprema, AZ 4177-2019. Urteil vom 04.09.2019.

564 CA Santiago, AZ 2182-98 (»]uan Maino«), Bd. 4b, Bl. 1678. Richterliche Vernehmung von Gerd Seewald vom 23.06.2005 sowie StA Bonn, AZ 555 ]s 315/06 K, Bd. I, BI. 292f. Vernehmung von Reinhard Döring vom 07.09.2009. Darin gibt Döring an, bei der Bewachung von Gefangenen mitgewirkt zu haben. »Ein Name war >Milovic - ein Pole. « Das CD-Geheimarchiv enthält 20 Fichas zu Mile Mavrosky. 
übergab sie dem DINA-Agenten Miguel Krassnoff, der sie wiederum in das Haft- und Folterzentrum Villa Grimaldi in Santiago bringen ließ.565 Ein Strafverfahren wegen der Entführung von Maria Isabel Romero ist derzeit noch anhängig. Gegen Miguel Krassnoff wurde 2018 Anklage erhoben. ${ }^{566}$

Verschiedene DINA-Angehörige bestätigten, dass es Transporte von Gefangenen zwischen der CD und anderen Haftorten gab. ${ }^{567}$ Der DINA-Arzt Osvaldo Pincetti Gac, der bei Verhören Hypnoseverfahren anwandte, gestand seine Beteiligung an mehreren Verhören in der CD:

»Efectivamente, estuve en la Colonia Dignidad en varias oportunidades en donde incluso alojaba en el hospital ya que habían operaciones en Chillán y como está cerca de Parral se llevaba a los detenidos a la colonia para ser interrogados y me tocaba hacer interrogatorios mediante hipnosis [...] Ahí conocí al comandante Gómez Segovia quién estaba a cargo de alguna unidad o enlace con los alemanes. «58

In einer weiteren Aussage berichtete er, dass die von ihm hypnotisierten Gefangenen auch gefoltert wurden und dass Schäfer, Hopp und Mücke auch bei Verhören anwesend waren:

»Respecto de las personas que interrogué en Colonia Dignidad, a ellas se les aplicaron torturas, los amenazaron, no ví que los tocaran, el señor Paul Schaffer estuvo presente en las interrogaciones, también el doctor Hopp y Gerhard Mücke. «569

Gerichtsakten ist zu entnehmen, Pincetti habe aus Talca stammende Gefangene in unterirdischen Kellerräumen hypnotisiert, wobei Mücke ihm Tabletten übergeben hätte, die er den Gefangenen verabreichen musste:

»cada dos días, Ilegaban detenidos procedentes de Talca, a los que dejaban en los subterráneos que estaban bajo dos galpones, a los cuales concurría durante la noche a los interrogatorios que efectuaba mediante hipnosis; recuerda a un capataz alemán, [...] de apellido Mücke, el cual le entregó un frasco con pastillas, las que debía suministrar a los detenidos, pues facilitaban la hipnosis ${ }^{570}$

565 CA Santiago, AZ 2182-98 (»]uan Maino«), Bd. 2a, Bl. 689ff. Schreiben von Maria Isabel Romero an Richter Zepeda vom 14.02.2005 und vom 07.04.2005 sowie Cooperativa.cl, »Miguel Krassnoff fue careado por víctima de torturas«, 05.01.2018, online unter https://www.cooperativa.cl/noticias/pais/dd-hh/judicial/miguel-krassnoff-fue-careado-por-victima-de-torturas/201801-05/112217.html.

566 CA Concepción, AZ 62.993, bzw. 05-2018. (Richterin Yolanda Mendez Mardones).

567 U. a. CA Santiago, AZ 2182-98 (»Pedro Merino«), Bd. $7^{\mathrm{a}}$, BI. 2332. Vernehmung von Silvio Antonio Concha González vom 08.03.2005. Concha González gibt an, gemeinsam mit weiteren DINAAgenten 10 bis 20 Cefangene von der CD zum Haftzentrum Cuatro Alamos in Santiago gebracht zu haben.

568 CA Santiago, AZ 2182-98 (»Alvaro Vallejos«), Bd. 8a, BI. 2568. Richterliche Vernehmung von Osvaldo Pincetti Gaci vom 15.01.2003.

569 CA Santiago, AZ 2182-98 (»Manuel Leyton«), Bd. 3a, Bl. 999. Richterliche Vernehmung von Osvaldo Pincetti Gaci vom 25.11.2004.

570 CA Santiago, AZ 47518 »Comité Central Partido Socialista« (Richter Miguel Vásquez). Erstinstanzliches Urteil vom 17.12.2018, S. 103. 
Mehrere Colonos, darunter Karl van den Berg, Rudolf Cöllen, Reinhard Döring und Johann Spatz, räumten ein, Gefangene bewacht zu haben. Eine Beteiligung an Folterhandlungen streiten sie jedoch ab. Auch Gerd Seewald bestätigte die Anwesenheit von Gefangenen in der CD. Paul Schäfer habe an den Verhören teilgenommen, berichtet Seewald, der die aus den Verhören stammenden Informationen in die Fichas im Geheimarchiv übertragen habe. ${ }^{571}$ Teile dieser Verhöre seien ihm in Papierform übergeben worden, andere als Aufnahme in Form von 20 Tonbändern, die Schäfer und DINAAgent_innen anhörten:

»Había unas 20 cintas grabadas con declaraciones de detenidos, que no recuerdo en detalles y no puedo identificar a que personas correspondían. Recuerdo que Paul Schäfer, junto a gente de la DINA, escucharon estas cintas. $\ll^{572}$

\section{Mord und Verschwindenlassen}

Einige Colonos waren partiell in das Verschwindenlassen von Gefangenen eingebunden, z.B. dadurch dass sie Gefangenen zum Exekutionsort transportierten, Gruben für Massengräber aushoben oder zuschütteten. Konkret sagte eine Reihe von Colonos aus, mehrmals gemeinsam mit Angehörigen von DINA oder Militär Gefangene in Fahrzeugen in ein Waldstück der CD transportiert zu haben. An einem gewissen Punkt seien sie, die Colonos, ausgestiegen und die Militärs seien mit den Gefangenen ein Stück weitergefahren. Anschließend hätten sie aus der Distanz Schusssalven gehört, dann seien sie gemeinsam mit den Militärs, aber ohne die Gefangenen wieder zurückgefahren. Zuvor hätten sie Löcher ausgehoben, die nach den Erschießungen von Colonos zugeschüttet wurden.

Mehrere Colonos sagten ebenfalls aus, im Rahmen der »Operación Retiro de Televisores ${ }^{573}$, auf deutsch »Abzug der Fernseher", (vermutlich 1978) dutzende Leichen ausgegraben und verbrannt zu haben.

Im Rahmen verschiedener Gerichtsverfahren seit $2005^{574}$ wegen Entführung und »Verschwindenlassens« von Oppositionellen konnten forensische Archäolog_innen an mehreren Stellen auf dem Gelände der CD leere Gräber auffinden, also Stellen, an denen in den betreffenden Jahren Erdbewegungen (Ein- oder Ausgrabungen) stattgefunden hatten. ${ }^{575}$ Dies deckt sich mit den Aussagen der Colonos. 2018 konnte der Ort iden-

571 CA Santiago, AZ 10-2004 (»Adriana Bórquez«), Bd. 6, BI. 2874. Richterliche Vernehmung von Cerd Seewald vom 11.09.2007.

572 CA Santiago, AZ 2182-98 (»Boris Weisfeiler«), Bd. Cuaderno Reservado, BI. 223ff. Richterliche Vernehmung von Gerd Seewald vom 13.04.2007.

573 Die von Diktator Pinochet angeordnete »Operación Retiro de Televisores« war ein Befehl an Militäreinheiten, um landesweit die Leichen der seit dem Putsch 1973 ermordeten politischen Aktivist_innen endgültig zu beseitigen.

574 Insbesondere im Verfahren CA Santiago, AZ 2182-98 (»]uan Maino«).

575 Vgl. Cáceres, Iván. Arqueología y Memoria en Colonia Dignidad: en busca de las materialidades de la represión y la violencia política, in: Evelyn Hevia/Jan Stehle (Hg.) Colonia Dignidad. Diálogos sobre verdad justicia y memoria. Santiago 2015, S. 130-145. 
tifiziert werden, an dem vermutlich die Leichen verbrannt wurden. ${ }^{576}$ Bislang wurden jedoch keinerlei sterbliche Überreste oder DNA-Spuren Ermordeter gefunden. Es konnte auch kein einziger materieller Täter der Erschießungen identifiziert werden.

Die Aussagen von Colonos lassen vermuten, dass zwischen 1973 und 1975 mehrere Dutzend Gefangene in der CD ermordet wurden. Über diese Fälle hinaus diente die CD vermutlich auch noch in anderen Fällen und Zeiträumen als »destino final« - so bezeichnen chilenische Menschenrechtsorganisationen den Ort, an dem Verschwundene ermordet und ihre Leichen vergraben bzw. beseitigt wurden. ${ }^{577}$ Tabelle 9 zeigt die relevanten Gerichtsverfahren wegen Verschleppung ${ }^{578}$ der Verschwundenen mit Bezug zur CD:

576 Narváez, Luis. »Descubren el lugar donde alemanes quemaron a fusilados de Colonia Dignidad«, in: El Dinamo vom 07.05.2018, online unter https://www.eldinamo.cl/nacional/2018/05/07/descubr en-lugar-donde-alemanes-quemaron-a-fusilados-de-colonia-dignidad/.

577 Bislang konnten in Chile lediglich Überreste von etwa 200 der offiziell 1100 Verschwundenen gefunden werden. Nur etwa 130 von ihnen konnten mithilfe von DNA-Analysen identifiziert werden. Vgl. Cáceres, Arqueología y Memoria, S. 143.

578 Da keine Leiche vorhanden ist, lautet im Falle der Verschwundenen der Tatvorwurf Entführung (»secuestro calificado«). 
Tabelle 9: Übersicht der chilenischen Strafverfahren wegen Verschwundenen

\begin{tabular}{|c|c|c|c|}
\hline $\begin{array}{l}\text { Gericht und erst- } \\
\text { instanzliches AZ }\end{array}$ & Opfer & $\begin{array}{l}\text { Corte Suprema: } \\
\text { Datum des } \\
\text { Urteils und AZ }\end{array}$ & Bezug zur CD \\
\hline $\begin{array}{l}\text { CA Santiago } \\
\text { AZ 2182-98 } \\
\text { (»Alvaro Vallejos } \\
\text { Villagrán«) }\end{array}$ & Alvaro Vallejos Villagrán & $\begin{array}{l}07.08 .2018 \\
A Z 19.127-2017\end{array}$ & $\begin{array}{l}\text { Urteil stellt Verschlep- } \\
\text { pung des Cefangenen in } \\
\text { die CD fest. }\end{array}$ \\
\hline $\begin{array}{l}\text { CA Santiago, } \\
\text { AZ 2182-98 } \\
\text { (»Pedro Merino })\end{array}$ & Pedro Merino Molina & $\begin{array}{l}15.12 .2014 \\
A Z 22.266-14\end{array}$ & $\begin{array}{l}\text { Urteil stellt Verschlep- } \\
\text { pung des Gefangenen in } \\
\text { die CD fest. }\end{array}$ \\
\hline $\begin{array}{l}\text { Juzgado del } \\
\text { Crímen de Lota, } \\
\text { AZ 28.888 }\end{array}$ & Adán Valdebenito Olavarría & $\begin{array}{l}11.01 .2012 \\
A Z 7558-11\end{array}$ & $\begin{array}{l}\text { Urteil stellt Verschlep- } \\
\text { pung des Cefangenen in } \\
\text { die CD fest. }\end{array}$ \\
\hline $\begin{array}{l}\text { CA Santiago } \\
\text { AZ 2182-98 } \\
\text { (»]uan Maino«) }\end{array}$ & $\begin{array}{l}\text { Juan Maino Canales, } \\
\text { Elizabeth Rekas Urra, } \\
\text { Antonio Elizondo } \\
\text { Ormaechea }\end{array}$ & $\begin{array}{l}13.11 .2014 \\
A Z 2931-14\end{array}$ & $\begin{array}{l}\text { Auffinden von Motoren- } \\
\text { teilen in der CD von Autos, } \\
\text { die möglicherweise den } \\
\text { Verschleppten gehörten. }\end{array}$ \\
\hline $\begin{array}{l}\text { CA Santiago } \\
\text { AZ 2182-98 } \\
\text { (»Alfonso } \\
\text { Chanfreau«) }\end{array}$ & Alfonso Chanfreau Oyarce & $\begin{array}{l}29.04 .2015 \\
A Z 24.558-14\end{array}$ & $\begin{array}{l}\text { Zeugnisse anderer Ge- } \\
\text { fangener und eines } \\
\text { DINA-Agenten über } \\
\text { die Verschleppung des } \\
\text { Gefangenen in die CD. }\end{array}$ \\
\hline $\begin{array}{l}\text { CA Santiago } \\
\text { AZ 2182-98 } \\
\text { (»Parral«) }\end{array}$ & $\begin{array}{l}27 \text { Personen aus Parral und } \\
\text { Umgebung, } 1973 \text { und } \\
1974^{*}\end{array}$ & $\begin{array}{l}27.12 .2007 \\
A Z 3587-05\end{array}$ & $\begin{array}{l}\text { Diverse Hinweise der An- } \\
\text { gehörigen aus der Region } \\
\text { über die Verschleppung in } \\
\text { die CD }\end{array}$ \\
\hline
\end{tabular}

* Dies sind: 1. Luis Evangelista Aguayo Fernández, 2. Manuel Eduardo Bascuñan Aravena, 3. José Ignacio Bustos Fuentes, 4. Enrique Ángel Carreño González,5. Rafael Alonso Díaz Meza, 6. Rolando Antonio Ibarra Ortega, 7. Aroldo Vivian Laurie Luengo, 8. Ireneo Alberto Méndez Hernández, 9. Armando Edelmiro Morales Morales, 10. José Luis Morales Ruiz, 11. Aurelio Clodomiro Peñaylillo Sepúlveda, 12. Luis Alcides Pereira Hernández, 13. Armando Aroldo Pereira Meriño, 14. Oscar Abdón Retamal Pérez, 15. Luis Enrique Rivera Cofré, 16. José Hernán Riveros Chávez, 17. Miguel Rojas Rojas, 18. Gilberto Antonio Rojas Vásquez, 19. Ramiro Antonio Romero González, 20. Roberto dei Carmen Romero Muñoz, 21. Oscar Eladio Saldías Daza. 22. Hernán Sarmiento Sabater, 23. Hugo Enrique Soto Campos, 24. Ruperto Oriol Torres Aravena, 25. Edelmiro Antonio Valdés Sepúlveda, 26. Víctor Julio Vivanco Vásquez und 27. Claudio Jesús Escanilla Escobar.

In den aufgeführten Verfahren (Tabelle 9) wurden Angehörige der DINA und anderer Waffengattungen verurteilt. In einigen Verfahren wurden auch Colonos angeklagt, etwa Paul Schäfer und Gerhard Mücke im Verfahren Alvaro Vallejos. Im Fall Juan Maino, Elizabeth Rekas und Antonio Elizondo, deren Aufenthalt in der CD nicht nachgewiesen werden konnte, ergingen Anklagen gegen Gerhard Mücke, Karl van den Berg und Hartmut Hopp. Jedoch wurden die in erster Instanz verurteilten Gerhard Mücke und Karl van den Berg letztinstanzlich freigesprochen. Hartmut Hopp entzog sich einer möglichen Verurteilung durch Flucht nach Deutschland. Die einzige rechtskräftige Verurteilung eines Colonos gab es im Fall Alvaro Vallejos Villagrán: Hier wurde Gerhard 
Mücke wegen Beihilfe zur Entführung zu drei Jahren und einem Tag Haft verurteilt. Paul Schäfer war zum Zeitpunkt der erstinstanzlichen Urteilssprüche bereits verstorben $^{579}$.

In drei der aufgeführten Verfahren stellte das Gericht fest, dass die betreffenden Gefangenen (Alvaro Vallejos Villagrán, Pedro Merino Molina und Adán Valdebenito Olavarría) 1974 in die CD verschleppt worden waren. Es konnte jedoch nicht eindeutig belegt werden, dass sie anschließend auch in der CD ermordet wurden.

In einigen der Verfahren wurden bereits während der Diktatur Schutzanträge oder Vermisstenanzeigen gestellt. Nach Ende der Diktatur stellten Angehörige häufig Strafanzeigen und die Verfahren wurden formal wieder aufgenommen. Aufgrund der $\mathrm{Zu}$ sammensetzung der zivilen Gerichte, der starken Rolle der Militärgerichte und der Anwendung des Amnestiegesetzes ${ }^{500}$ machten die Ermittlungen jedoch in der Praxis zunächst wenig Fortschritte. Erst 1998 entschied die Corte Suprema, das Amnestiegesetz bzgl. der Diktaturverbrechen zunächst zurückzustellen. Nach der Festnahme von Augusto Pinochet in London wuchs in der chilenischen Menschenrechtsbewegung die Hoffnung auf eine verstärkte strafrechtliche Aufarbeitung der Diktaturverbrechen. Weitere Strafanzeigen wurden gestellt, Ermittlungsrichter Juan Guzmán übernahm Hunderte von Verfahren an der CA Santiago, darunter auch das Verfahren wegen der Entführung und des Verschwindenlassens von Alvaro Villagrán. ${ }^{581}$ Nach der Pensionierung von Richter Guzmán 2005 lagen die Verfahren zu Verschwundenen mit Bezug zur CD bei verschiedenen Richter_innen, darunter Jorge Zepeda, der ab 2002 auch die erstinstanzlichen Ermittlungen zum Verschwinden von Juan Maino, Elizabeth Rekas und Antonio Elizondo übernahm. ${ }^{582}$ Nach der Festnahme Schäfers 2005 beschloss die Corte Suprema, alle Verfahren zu Diktaturverbrechen mit Verbindung zur CD an Zepeda zu übertragen..$^{583}$

579 Das erstinstanzliche Urteil im Verfahren um die Verschwundenen aus Parral und Umgebung erging bereits 2003. Damals befand sich Schäfer noch im Untergrund. Trotz zahlreicher Hinweise auf eine Beteiligung der CD wurde in diesem Verfahren kein einziger Colono angeklagt. Das mag auch daran gelegen haben, dass bei den Angehörigen der Streitkräfte, insbesondere in der Region, zu der Zeit große Angst vor Repressalien herrschte. Dies belegt die folgende Aussage eines Polizisten aus Parral vom Februar 2003: »Es efectivo que en la preparación del golpe me consta la participación de personas civiles y ciudadanos alemanes que aún desempeñan labores en la ciudad de Parral por lo cual no deseo comprometerme diciendo sus nombres, ni aún acogiéndome al beneficio que se me informa que tengo de reserva de identidad. Sin embargo, puedo agregar que algunos detenidos fueron vistos en una oficina que mantenían los alemanes de Colonia Dignidad en esta ciudad, en calle Unión.«CA Santiago, AZ 2182-98 (»Parral«), Bd. 12a, Bl. 3511f. Richterliche Vernehmung von Jorge Hernández Rocha vom 17.02.2003.

580 Das als Amnestiegesetz bekannte Dekret vom April 1978 sieht eine Amnestie für sämtliche während des Ausnahmezustandes (11.09.1973-10.03.1978) begangenen Verbrechen vor. Diario Oficial $\mathrm{N}^{\circ} 30.042$ vom 19.04.1978. Ministerio del Interior. Decreto 2191 vom 18.04.1978. »Concede amnistia a las personas que indica por los delitos que señala«.

581 CA Santiago, AZ 2182-98 (»Villa Baviera«).

582 Die Genannten waren allesamt Aktivist_innen der MAPU (Movimiento de Acción Popular Unitaria).

583 CA Santiago, AZ 2182-98 (»Conferencia«), Bd. 17ª Bl. 5751f. Corte Suprema, Oficio 932 vom 08.04.2005 》Transcribe resolución« zur Übertragung u.a. der Verfahren »Alvaro Vallejos« (Villa Baviera), »Boris Weisfeiler«, »Adriana Bórquez«, »Manuel Bravo y otros« an Richter Zepeda. In den 
Schäfers Festnahme führte zu einem großen öffentlichen Interesse an einer Aufklärung der CD-Verbrechen. Damit wuchs auch der Druck auf Zepeda, Verurteilungen herbeizuführen. 2005 und 2006 vernahm Zepeda eine große Anzahl Colonos. Er nahm einige CD-Führungsmitglieder in Untersuchungshaft, darunter Hartmut Hopp, Kurt Schnellenkamp und Gerhard Mücke. Anderen Colonos bot Zepeda vermutlich Deals oder Vergünstigungen an: So gab Willi Malessa gegenüber einem anderen Richter an, er wolle nichts zum Thema Verschwundene aussagen, da er bereits gegenüber Zepeda ausgesagt habe und dieser ihn als "testigo protegido y con reserva de identidad « behandle ${ }^{584}$, ihm also Zeugenschutz gewähre. Ein US-Diplomat berichtete 2005, Zepeda habe ihm gesagt, er arbeite mit einer Reihe von Informanten (»testigos reservados«) aus der CD zusammen. ${ }^{55}$ Dies erklärt möglicherweise, weshalb Zepeda Willi Malessa nicht anklagte.

Nach der Festnahme Schäfers änderten auch Colonos ihr Verhalten gegenüber der Justiz: Nachdem etwa Gerhard Mücke jahrelang geleugnet hatte, etwas über die Ermordung politischer Gefangener in der CD zu wissen, teilte er Zepeda im Juli 2005 mit, er wolle mit der Justiz zusammenarbeiten und seine Kenntnisse preisgeben. Bei seiner Vernehmung ${ }^{586}$ gab Mücke dann an, er sei dabei gewesen, als im Zeitraum eines Monats nachts vier bis fünf Mal drei oder vier Pick-Ups in die CD kamen, auf deren Ladefläche uniformierte Militärangehörige oder Polizisten mehrere Gefangene transportierten. Dass er von uniformierten Militär- oder Polizeiangehörigen spricht, legt nahe, dass es sich um Gefangene aus der Region handelte, die in den ersten Monaten nach dem Putsch verhaftet wurden. Die DINA, die üblicherweise in zivil agierte, existierte zu diesem Zeitpunkt noch nicht. Er habe die Anweisung erhalten, die Fahrzeuge mit einem Fahrzeug der CD zu begleiten, etwa vier bis fünf Kilometer weit auf einem Feldweg der CD. Dann sei er ausgestiegen und die Fahrzeuge seien noch etwa 200 Meter weitergefahren. Dann habe er Schüsse gehört. Daraufhin seien die Leichen der Erschossenen verscharrt worden, in Gruben, die zuvor vermutlich vom Baggerfahrer Erich Fege ausgehoben worden waren. Etwa 1978 habe Schäfer ihm dann befohlen, die »Gegend zu säubern«. Daraufhin habe er gemeinsam mit Rudolf Cöllen und Willi Malessa mit einem Bagger die verwesten Leichen wieder ausgegraben. Er könne sich an etwa 18 bis 21 Leichen erinnern, die sie gemeinsam in Säcke gesteckt und dann mit Phosphor oder anderen chemischen Substanzen verbrannt hätten. Diese Arbeit habe zwei bis drei Wochen gedauert.

Folgemonaten wurden Zepeda weitere Verfahren mit Bezug zur CD übertragen, darunter, »Pedro Merino«, »Alfonso Chanfreau«, »Asociación Ilícita Colonia Dignidad «, »Ley de Control de Armas«, »homicidio Miguel Becerra Hidalgo«. Zepeda führte auch das Verfahren »]uan Maino« weiter und eröffnete das Verfahren »lesiones graves«.

584 Juzgado de Parral, AZ 66.124 (»Asociación Ilícita (Efraín Vedder)«), Bd. 1, BI. 470. Richterliche Vernehmung von Willi Malessa vom 02.05.2005.

585 Der Bericht wurde über die Plattform Wikileaks bekannt, vgl. Bogolasky, Natalia. „Cables de Wikileaks mencionan polémicos stestigos reservados` en procesos de Colonia Dignidad, in: CIPER (Website), 20.10.2011, online unter https://ciperchile.cl/2011/10/20/cables-de-wikileaks-mencionan -polemicos-"testigos-reservados"-en-procesos-de-colonia-dignidad/.

586 CA Santiago, AZ 2182-98 (»]uan Maino«), Bd. 3a, Bl. 1353f. Richterliche Vernehmung von Gerhard Mücke vom 15.07.2005. 
Erich Fege, Rudolf Cöllen und Wilhelm Wagner bestätigten Mückes Darstellung und fügten ihr weitere Details hinzu. Fege bestätigte, die Gräber ausgehoben zu haben. ${ }^{587}$ Nachdem er aus der Ferne Schüsse vernommen habe, sei Mücke zu ihm gekommen und habe ihm aufgetragen, die Gräber wieder zuzuschütten. Wilhelm Wagner gab an, ${ }^{588}$ Ende 1974 oder Anfang 1975 gemeinsam mit Reinhard Döring von Schäfer den Auftrag bekommen zu haben, zwei Pick-Ups oder Jeeps in den Sektor Chenco, ein bewaldedes Gebiet der CD zu lotsen. Er vermutete, dass es sich bei den beiden Fahrern in zivil um DINA-Agenten handelte. Dazu sei er, Wagner, in ein Fahrzeug gestiegen, mit dem etwa fünf Gefangene transportiert wurden. In Chenco angekommen, seien Döring und er aus den Fahrzeugen ausgestiegen, welche dann noch ein Stück weiter in den Wald gefahren seien. Erst hätten sie, Wagner und Döring, die Geräusche des Baggers vernommen, den Fege fuhr. Dann sei eine Schusssalve zu hören gewesen und danach wieder der Bagger. Etwa eine halbe Stunde später seien die Fahrzeuge ohne die Gefangenen zurückgekehrt und hätten Döring und ihn wieder mitgenommen. Rudolf Cöllen gab an, ${ }^{589}$ er habe in den 1980er Jahren (sic!) von Schäfer den Auftrag erhalten, gemeinsam mit Mücke Leichen durch Verbrennen verschwinden zu lassen. Sie hätten die etwa 30 Leichen auf Gitterroste gelegt und mit Diesel und Holz verbrannt. Die Asche hätten sie daraufhin im nahegelegenen Fluss entsorgt. Zuvor hätte Mücke bei der Beseitigung der Leichen mit Willi Malessa zusammengearbeitet. Laut Mücke erkrankte Malessa nach einigen Tagen, weswegen Cöllen ihn ersetzte. Malessa sagte aus, er habe bis zu seiner Erkrankung gemeinsam mit Mücke, Karl van den Berg und Johann Spatz etwa 30 bis 40 Leichen exhumiert und verbrannt. ${ }^{590}$

Mehrere Colonos berichten, dass 1978 oder 1979 in der Chenco-Gegend etwa 25 Hektar Wald in Flammen standen. Schäfer habe ihnen erst nach drei Tagen erlaubt, das Feuer zu löschen. Im darauffolgenden Jahr sei das Gebiet wieder aufgeforstet worden. ${ }^{591}$ Möglicherweise wurde der Brand gelegt, um Spuren von Massengräbern zu verwischen. Laut Aussagen von Colonos, sei bei der Exhumierung der Leichen im Rahmen der »Operación de Retiro de Televisores« eines der Gräber von den beteiligten Colonos nicht wieder aufgefunden worden. ${ }^{592}$

Auch der für das CD-Geheimarchiv zuständige Gerd Seewald bestätigte die Ermordung verschiedener Personengruppen in der CD. Schäfer habe ihn und andere Colonos

587 CA Santiago, AZ 2182-98 (»]uan Maino«), Bd. 5a, Bl. 2200ff. Richterliche Vernehmung von Erich Fege vom 21.10.2005.

588 CA Santiago, AZ 2182-98 (»Lesiones graves«), Bd. 1, BI. 33ff. Richterliche Vernehmung von Wilhelm Wagener vom 22.09.2005.

589 CA Santiago, AZ 2182-98 (»]uan Maino«), Bd. 5a, Bl. 2204ff. Richterliche Vernehmung von Rudolf Cöllen vom 24.10.2005.

590 CA Santiago, AZ 683-2017 (»inhumación/exhumación ilegal Colonia Dignidad «), Bl. 1384. Polizeiliche Vernehmung von Willi Malessa vom 25.08.2017.

591 CA Santiago, AZ 2182-98 (»]uan Maino«), Bd. 5a, Bl. 2276ff. Richterliche Vernehmung von Manfred Lindemann vom 11.11.2005.

592 CA Santiago, AZ 683-2017 (»inhumación/exhumación ilegal Colonia Dignidad«). Polizeibericht (PDI) Nr. 2947 vom 08.06.2017. 
später angewiesen, die Informationen über Verschwundene im Archiv zu vernichten. ${ }^{593}$ Er erinnerte sich jedoch, von etwa 30 der MIR angehörenden Gefangenen gehört zu haben, die 1974 ermordet und im Chenco verscharrt worden seien:

»En el año 1974 murieron en Colonia varias personas que habían sido militantes del MIR. Escuché que eran unos 30 los muertos en esas circunstancias. No tengo más detaIles al respecto. Estas gentes fueron inhumadas en las fosas halladas en Chenco. Entre estos muertos podrían haber estado el >Loro Matías`, Sarmiento Sabater y Laurie, estos provenientes de Parral [...] Desconozco que mecanismo usaba Schäfer para eliminar a los detenidos. Alguna vez le escuché decir a éste: ১esos no deben sobrevivir. « ${ }^{594}$

Laut Seewald sollen Gefangene aus Parral und aus Coronel in der CD ermordet und ihre Leichen verscharrt worden sein, darunter vermutlich Alvaro Vallejos Villagrán, Hernán Sarmiento Sabater und Haroldo Laurie Luengo. ${ }^{595}$ Jedoch bleibt Seewald bei seinen Aussagen meist unpräzise und widersprüchlich.

Es gibt noch weitere Hinweise auf die Ermordung bzw. Beseitigung der Leichen von Gefangenen in der CD. Rudolf Cöllen berichtete, im Bereich des Weingartens habe es einen Verbrennungsofen gegeben, in dem er mehrfach Leichen ermordeter politischer Gefangener verbrannt habe. ${ }^{596}$

\section{Einsatz von Giftgas}

Ein Colono berichtete, es habe in der CD einen Sanitäts-Unimog (»Unimog-Sancar«) gegeben, der zu einem Gaswagen umgebaut worden sei. ${ }^{597}$ Das innere der Kabine sei hermetisch abgedichtet worden. Mit einem Rohr seien Abgase ins Innere der Kabine geleitet worden, um dadurch Gefangene zu ermorden. ${ }^{598}$ Paul Schäfer habe geprahlt, dass dies ein effizienterer Weg sei, um Gefangene umzubringen, als Erschießungen. Es gibt noch weitere Hinweise auf die Ermordung von Gefangenen durch Gas in der CD. Dennoch wurde dies nie gerichtlich untersucht. Dieter Maier gab 2011 an, von dem Psychiater Niels Biedermann erfahren zu haben, dass Colonos ihm gegenüber von Morden an Gefangenen durch Saringas berichtet hätten. ${ }^{599}$ Zudem gibt es Hinweise auf Besuche von Walter Rauff in der CD. Rauff war während des Nationalsozialismus maßgeblich am Einsatz von Gaswagen zur Ermordung von Jüd_innen und anderen KZ-Häftlingen

593 CA Santiago, AZ 2182-98 (»]uan Maino«), Bd. 4b, BI. 1786. Polizeiliche Vernehmung von Gerd Seewald vom 07.06.2005.

594 CA Santiago, AZ 10-2004 (»Adriana Bórquez«), Bd. 6, BI. 2874. Richterliche Vernehmung von Cerd Seewald vom 11.09.2007. »Loro Matías« war der Spitzname des MIR-Aktivisten Alvaro Vallejos Villagrán.

595 CA Santiago, AZ 2182-98 (»Boris Weisfeiler«), Bd. Cuaderno Reservado, Bl. 223ff. Richterliche Vernehmung von Gerd Seewald vom 13.04.2007.

596 CA Santiago, AZ 683-2017 (»inhumación/exhumación ilegal Colonia Dignidad«). Polizeibericht (PDI) Nr. 2947 vom 08.06.2017.

597 PJS, Sammlung Gesprächsnotizen. Notiz eines Gesprächs mit Georg Laube in Parral vom 27.11.2017

598 Ebd.

599 PJS, Sammlung Dieter Maier. Freiwille Vernehmung von Dieter Maier im chilenischen Generalkonsulat in Frankfurt a.M. vom 07.07.2011 durch die PDI-Beamten Patricio Sepúlveda und Paula Cortés. 
beteiligt. Nach einigen Jahren als Militärberater in Ecuador in den 1950er Jahren, wo er sich mit Augusto Pinochet anfreundete, ${ }^{600}$ ließ Rauff sich 1958 in Chile nieder und lebte dort bis zu seinem Tod 1984. Mindestens von 1958 bis 1962 war er für den BND tätig. ${ }^{601}$ Mehrere Quellen legen nahe, dass er als Berater für die DINA arbeitete. ${ }^{602}$ Laut Aussagen verschiedener Colonos besuchte Rauff mehrfach die CD. ${ }^{603}$

Ein weiteres Indiz für den Einsatz von Giftstoffen sind die Besuche von DINAAgent_innen, die an der Herstellung von Sarin und anderen tödlichen Substanzen beteiligt waren. ${ }^{604}$

\section{Ausgrabungen und Erkenntnisse}

Trotz einer großen Anzahl von Aussagen konnte die chilenische Justiz bisher keine Überreste der ermordeten und bis heute verschwundenen Personen auffinden. Auch die exakte Zahl der Opfer kann nicht festgestellt werden, ebenso wenig wie das genaue Datum der Taten, was Rückschlüsse auf mögliche Opfergruppen zulassen würde. Die von Richter Jorge Zepeda angeordneten Ausgrabungen konnten jedoch die Existenz leerer Gräber bestätigen. Die Hinweise auf die genauen Orte kamen dabei allesamt von Colonos. Einige der Fundstellen stellte das Consejo de Monumentos Nacionales 2016 unter Denkmalschutz. ${ }^{605}$ Der maßgeblich an den Ausgrabungen beteiligte forensische Archäologe Iván Cáceres kritisiert, die bisher aufgefundenen Gräber und Fundstellen seien vom dem ermittelnden Richter nicht angemessen stabilisiert und konserviert worden. Durch den langen Zeitablauf seit Mitte der 1970er Jahre seien wichtige Spuren oder Beweismittel inzwischen vermutlich zerstört. ${ }^{606}$ Nichtdestotrotz setzt Cáceres Hoffnung in weitere Ausgrabungen, da die bisherigen nur unvollständig durchgeführt worden seien. ${ }^{607}$ Die bisherigen forensischen Ausgrabungen in der $\mathrm{CD}^{608}$ fanden vor allem in den Jahren 2005, 2006, 2009, 2017 und 2018 statt. 2014 führte die PDI zusätzliche Grabungen durch. ${ }^{609}$

600 Von 1956 bis 1959 war Pinochet Mitglied einer Militärmission zum Aufbau der ecuadorianischen Kriegsakademie. Vgl. Heller, Pinochet, S. 18.

601 Bundesnachrichtendienst (2011), Mitteilungen der Forschungs- und Arbeitsgruppe Ceschichte des BND, Nr. 2, vom 23.09.2011. Walther Rauff und der Bundesnachrichtendienst.

602 Schneppen, Heinz. Walther Rauff: Organisator der Gaswagenmorde. Eine Biografie, Berlin 2011, S. $168 \mathrm{ff}$.

603 Vgl. Heller, Lederhosen, Dutt und Ciftgas, S. 142.

604 U. a. Besuche der DINA-Agenten Michael Townley und Eugenio Berríos, vgl. Abschnitt zum Projekt ANDREA.

605 Diario Oficial N` 41.530 vom 10.08.2016. Ministerio de Educación. Decreto 208 vom 18.07.2016.»Declara Monumento Nacional en la Categoría de Monumento Histórico al >Conjunto de Inmuebles y Sitios Correspondientes a la Ex Colonia Dignidadı, ubicados en la comuna de Parral, provincia de Linares, Región del Maule«.

606 Cáceres, Arqueología y Memoria, S. 143.

607 Ebd.

608 An allen diesen Ausgrabungen waren federführend die forensischen Archäologen Iván Cáceres und Kenneth Jensen beteiligt.

609 PJS, Sammlung CD. Präsentation von Iván Cáceres vor Angehörigen von Verschwundenen in Parral, April 2018. 
Bei Grabungsarbeiten wurden auch Teile von Automotoren gefunden, die möglicherweise aus Autos von Verschwundenen stammen, die mit ihren Fahrzeugen entführt wurden. So z.B. 2005 bei Ausgrabungen im Rahmen des Verfahrens wegen der Entführung der Verschwundenen Juan Maino, Elizabeth Rekas und Antonio Elizondo. Diese verschwanden 1976 mit ihren Fahrzeugen. ${ }^{610}$ Kurt Schnellenkamp sagte 2005 aus, er habe in Santiago in einem Militärregiment Autos abgeholt. Diese habe ihnen die Militärregierung als Dank dafür übergeben, dass Schäfer Augusto Pinochet einen Mercedes 600 geschenkt habe. ${ }^{611}$ Mehrere Colonos berichten davon, die Autos in der CD gesehen $\mathrm{zu}$ haben oder an der Verschleierung ihrer Herkunft beteiligt gewesen zu sein. So liegen seit Ende der 1980er Jahre Aussagen von Colonos vor, nach denen sie eine Reihe von Autos, die während der Diktatur in die CD gebracht wurden, umgespritzt und mit neuen Motornummern versehen hätten, um sie unkenntlich zu machen. ${ }^{612}$ Ulrich Schmidtke gab an, Jahre später gemeinsam mit Willi Malessa eine Reihe von Fahrzeugen auf dem Gelände der CD zerstört und vergraben zu haben. ${ }^{613}$ Es ist also wahrscheinlich, dass es sich tatsächlich um die Autos entführter politischer Gefangener handelte. Bis heute ist allerdings unklar, ob die Eigentümer der Fahrzeuge auch in die CD verbracht und dort ermordet wurden.

Sämtliche Ermittlungen zu den bisherigen konkret bekannten Fällen von Verschwindenlassen mit Bezug zur CD sind heute abgeschlossen. Sämtliche Urteile sind rechtskräftig. Richter Jorge Zepeda hat sein Mandat als besonderer Ermittlungsrichter für die CD-Verfahren 2017 an Mario Carroza abgegeben. In einem 2017 eröffneten Verfahren wegen »inhumación y exhumación ilegal « ${ }^{614}$ ermittelte dieser, mit dem Ziel, die Aufklärung über das Schicksal der in der CD Ermordeten voranzubringen. Im Rahmen dieses Verfahrens fanden weitere Ausgrabungen statt. Durch diese wurde 2018 der Ort aufgefunden, an dem möglicherweise Leichen verbrannt wurden. ${ }^{615} 2020$ wurden eine Reihe von Bodenproben entnommen und von einem schweitzer Labor untersucht. Hinweise auf menschliche Überreste oder Brandbeschleuniger konnten jedoch nicht festgestellt werden. Die Kosten für die Laboranalysen trug das AA im Rahmen der

610 Sowohl Juan Maino als auch das Paar Elizabeth Rekas und Antonio Elizondo besaßen PKWs der Marke Citroen, die nach ihrer Entführung nicht mehr auftauchten. Allerdings handelte es sich bei den im Rahmen von Grabungen in der CD gefundenen Motorenteilen um Modelle der Marke Renault.

611 CA Santiago, AZ 2182-98 (»Asociación Ilícita«), Bd. I (2) (Ministro), BI. 453ff. Richterliche Vernehmung von Kurt Schnellenkamp vom 23.06.2005.

612 González, Mónica. »Autos de detenidos desaparecidos en >Dignidad««, in: Análisis vom 28.08.1989, S. 1. Conzález berichtet von einer Liste, die Ceorg Packmor 1985 bei seiner Flucht aus der CD mitgenommen hatte. Diese führt 14 Fahrzeuge auf, die Verschwundenen bei ihrer Verhaftung entwendet wurden. Packmor hatte den Auftrag bekommen, Unfallfahrzeuge derselben Modelle zu kaufen, um Motor- und Karosserieteile auszutauschen, damit die Herkunft der Fahrzeuge verschleiert werden könne.

613 CA Santiago, AZ 2182-98 (»]uan Maino«), Bd. 2a, BI. 1021ff. Richterliche Vernehmung von Ulrich Schmidtke vom 31.05.2005.

614 CA Santiago, AZ 683-2017.

615 Narváez, Luis. »Descubren el lugar donde alemanes quemaron a fusilados de Colonia Dignidad«, in: El Dinamo vom 07.05.2018, online unter https://www.eldinamo.cl/nacional/2018/05/07/descubr en-lugar-donde-alemanes-quemaron-a-fusilados-de-colonia-dignidad/. 
deutsch-chilenischen Gemischten Kommission. ${ }^{616} 2021$ wurde Richter Carroza an den Obersten Gerichtshof berufen und gab das Verfahren an Richterin Paola Plaza ab. Diese führte im April 2021 eine Reihe von Vernehmungen in der ehemaligen CD durch. ${ }^{617}$

\section{Weitere Todesfälle im Kontext der Zusammenarbeit der CD mit der Diktatur}

Neben der Ermordung politischer Gefangener gab es eine Reihe weiterer Todesfälle, die zumindest mutmaßlich mit der Zusammenarbeit zwischen CD und Junta während der Militärdiktatur zusammenhängen, wie die bereits erwähnte Ermordung des DINAAgenten Miguel Becerra Hidalgo 1974 oder der Fall des DINA-Agenten Juan Muñoz Alarcón, der kurz vor seiner Ermordung über die Verbindungen der DINA zur CD berichtet hatte.

Am 5. Juni 1975 wurde Osvaldo Heyder Goycolea, Heeresoffizier und Mitarbeiter des Servicio de Inteligencia Militar (Militärgeheimdienst, SIM), in Talca erschossen in seinem Auto aufgefunden. Die offizielle Erklärung lautete, Heyder sei von der MIR ermordet worden. Tatsächlich deutet nichts auf eine Täterschaft der MIR, vieles jedoch auf einen Mord durch die DINA hin. Heyder soll im Januar 1975 in Valparaíso Meinungsverschiedenheiten mit anderen DINA-Agenten über die Folter von Gefangenen gehabt haben. ${ }^{618}$ Daraufhin wurde er nach Talca versetzt. Erick Zott, ein ehemaliger politischer Gefangene der MIR, der sowohl in Valparaíso als auch in der CD inhaftiert war, gab 2002 eine eidesstattliche Erklärung ab. Darin berichtete Zott von einem Gespräch mit Hugo Baar und dem AI-Generalsekretär Walter Rövekamp. Dabei habe Baar ihnen berichtet, 1975 hätten zwei CD-Angehörige in Talca an einem Attentat gegen einen Offizier des chilenischen Heeres teilgenommen. Er, Baar, der seinerzeit für die Verwaltung der Waffen der CD zuständig gewesen sei, habe die Waffe dann »zurück« bekommen und die beiden namentlich genannten $\mathrm{CD}$-Angehörigen hätten sich vorübergehend im Süden Chiles versteckt.

»que en aquel entonces (a mediados de los años 70) él estaba encargado de administrar la armería de la colonia y de esta manera se enteró que en el invierno chileno de 1975, dos miembros de la Colonia Dignidad, a quienes identificó y cuyos nombres no recuerdo, participaron en un atentado en contra de un oficial del ejército chileno en la ciudad de Talca. Hugo Baar recibió el arma de vuelta y estos dos miembros de la colonia se ocultaron temporalmente en el sur de Chile. ${ }^{619}$

616 PJS, Sammlung AA. Verbalnote des AA an die chilenische Regierung vom 08.10.2018, CZ 506-2226$77 \mathrm{CHL}$.

617 Dannemann, Victoria. Colonia Dignidad: »Es obligación de la judicatura lograr avances y dar respuesta a quienes esperan por tanto tiempo«, in: Deutsche Welle (Website), 10.05.2021, online unter https://p.dw.com/p/3tCWE.

618 El Periodista vom 25.11.2002, S. 22f. »La muerte de un capitán, la DINA y Colonia Dignidad«.

619 PJS, Sammlung CD. Declaración Jurada Erick Zott vom 23.10.2002 im chilenischen Konsulat in Wien. Dieses Dokument wird auch zitiert in: Basso Pietro, Carlos. »La extraña muerte del militar que enfrentó a la DINA«, in: El Mostrador vom 05.06.2015, online unter https://www.elmostra dor.cl/noticias/pais/2015/06/05/la-extrana-muerte-del-militar-que-enfrento-a-la-dina/. 
Das chilenische Gerichtsverfahren wegen Mordes an Osvaldo Heyder ${ }^{620}$ wurde eingestellt. Die in Deutschland wohnhafte Schwester von Osvaldo Heyer reichte 2006 Strafanzeige gegen unbekannt ein und es kam zu einem Ermittlungsverfahren. ${ }^{621}$ Die Staatsanwaltschaft Bonn vernahm u.a. Klaus Schnellenkamp. Dieser sagte aus, in der $C D$ sei verschiedentlich über eine Person mit dem Spitznamen »der Heide« gesprochen worden. Dieser habe mit einem Junta-General namens Leigh zusammengearbeitet, der wiederum einen Putschversuch gegen Pinochet geplant habe. ${ }^{622}$ Im Rahmen des chilenischen Verfahrens wegen der Ermordung Heyders stellte Chile ein Rechtshilfeersuchen an die Bundesrepublik. ${ }^{623}$ Das Verfahren der StA Bonn wurde 2008 nach $\$ 170$ II StPO eingestellt (vgl. Abschnitt 5.3.5).

Am 25. Dezember 1984 landete der russischstämmige US-Staatsbürger Boris Weisfeiler ${ }^{624}$ in Santiago. ${ }^{625}$ Der Mathematikprofessor an der Pennsylvania State University reiste ins südchilenische Los Ángeles und begann dort eine Wanderung in die Kordillere. ${ }^{626}$ Am 4. Januar 1985 wurde er letztmals gesehen, in der Nähe der Ortschaft San Fabián de Alico. Zu diesem Zeitpunkt befanden sich eine Einheit der Carabineros und eine Militärpatrouille in der Gegend. Als Weisfeiler nicht wieder auftauchte, meldete der Vizekonsul der USA in Chile den Fall am 25. Januar 1985 den chilenischen Ermittlungsbehörden. Schnell kamen Gerüchte auf, man habe Weisfeiler »verschwinden lassen« und die CD sei daran beteiligt. Für eine Beteiligung der CD gibt es bis heute keinerlei Beweise. Dennoch legen zwei Vorgänge eine Beteiligung der CD nahe: Ein anonymer Informant traf sich 1987 mehrmals mit dem Menschenrechtsanwalt Máximo Pacheco sowie Mitarbeiter_innen der US-Botschaft in Santiago. ${ }^{627}$ Er behauptete, damals Teil einer Militärpatrouille gewesen zu sein, die Weisfeiler festgenommen und in die CD gebracht habe. Ihm zufolge wurde Weisfeiler für einen »jüdischen Spion« gehalten. ${ }^{628}$ Der zweite Hinweise ist ein Funkgespräch zwischen Gerhard Mücke und

620 3. Juzgado del Crímen de Talca, AZ 38.720.

621 StA Bonn, AZ 554 UJs 114/06 P. Das Verfahren wurde am 04.01.2008 eingestellt. Vgl. Landtag Nordrhein-Westfalen. Drucksache 15/3025 vom 18.10.2011. Antwort ]M zu KIAnfr 1110, Drs 15/2782. Ermittlungen der NRW-Justiz zur Colonia Dignidad (Teil 1), S. 2.

622 StA Bonn, AZ 555 ]s 223/06P, Bl. 79ff. Vernehmung von Klaus Schnellenkamp vom 19.04.2007. In der Tat gab es heftige Konflikte und Diskussionen zwischen Pinochet und Leigh, unter anderem über die Führungsrolle innerhalb der Militärjunta. Vgl. Heller, Pinochet, S. $127 \mathrm{ff}$.

623 Corte Suprema, AZ 3737-2006. Deutsches AZ 663 AR 162-07.

624 Der in Moskau geborene Boris Weisfeiler verlies 1975 die Sowjetunion und bat in den USA um politisches Asyl. 1981 wurde er dort eingebürgert. Vgl. Washington Post vom 18.01.2003, S. A20. »Tracing a mystery of the missing in Chile«.

625 Zum Fall Boris Weisfeiler vgl. Basso Prieto, Carlos. El último secreto de Colonia Dignidad, Santiago 2002.

626 Der Abschnitt zu Boris Weisfeiler beruht auf der Durchsicht der Akten zum Verfahren CA Santiago, AZ 2182-98 (»Boris Weisfeiler«).

627 Die Gesprächsprotokolle befinden sich unter den von der U.S. Regierung im Rahmen des »Chile Declassification Projekt« freigegebenen Akten. U. S. Department of State. Freedom of Information Act (FOIA), Virtual Reading Room. Website, online unter: https://foia.state.gov/Search/Results.asp $\mathrm{x}$ ?collection=CHILE.

628 Lowy, Maxine. Memoria Latente: Una comunidad enfrentada por el desafío de los derechos humanos en Chile, Santiago 2016, S. 158-163. 
Kurt Schnellenkamp vom 2. April 1985, das Heinz Kuhn nach eigenen Angaben abgefangen hat. Es soll nahelegen, dass Weisfeiler zu diesem Zeitpunkt bereits tot war. In dem Gespräch geht es in verklausulierter Sprache um eine Person, die in der Gegend auf der Suche nach einer verschwundenen Person ist. Die gesuchte Person sei jedoch bereits auf dem Friedhof, »unter die Kartoffeln«, so das Gespräch zwischen Mücke und Schnellenkamp laut Kuhn. ${ }^{629}$ Die US-Regierung begann sich mit dem Verschwinden Weisfeilers verstärkt für die CD zu interessieren. Sie suchte unter anderem das Gespräch mit Lotti und Georg Packmor, die inzwischen in Kanada lebten. ${ }^{630}$ Die chilenische Wahrheitskommission stufte Weisfeiler 1991 nicht als Verschwundenen ein. ${ }^{631} \mathrm{Im}$ einem erstinstanzlichen Gerichtsverfahren hatte Richter Jorge Zepeda 2012 acht Angehörige von Heer und Carabineros angeklagt, diese jedoch wegen Verfolgungsverjährung freigesprochen. ${ }^{632}$ Die CA bestätigte dieses Urteil in zweiter Instanz 2018. ${ }^{633}$ Das letztinstanzliche Verfahren bei der Corte Suprema ist derzeit noch anhängig. ${ }^{634}$

Ebenfalls bis heute ungeklärt ist das Verschwinden des niederländischen Staatsbürgers Maarten Visser. Dieser brach am 12. Dezember 1985 von Puerto Montt aus zu einer Wanderung zum Vulkan Osorno auf und kehrte nicht mehr zurück. Seine Eltern reisten daraufhin regelmäßig nach Chile, um ihren Sohn zu suchen. 1987 wurde Marteens Vater, Paulus Visser, in Puerto Montt auf der Straße von einem Unbekannten angesprochen, der ihm sagte, sein Sohn werde in der CD festgehalten. Amnesty International arrangierte ein Treffen zwischen Paulus Visser und Hugo Baar in der Bundesrepublik. Dabei bezeichnete Baar es als möglich, dass sich zum damaligen Zeitpunkt CD-Mitglieder in der Gegend um Puerto Montt aufgehalten haben. Auch diesen Fall stufte die chilenische Wahrheitskommission als »sin convicción« ein, d.h. sie gelangte nicht zu der Überzeugung, dass Visser von Agenten der chilenischen Diktatur ermordet wurde. ${ }^{635}$ Im August 2005 stellte Paulus Visser Strafanzeige, die einem CD-Verfahren

629 Gemballa, Colonia Dignidad. Ein deutsches Lager in Chile, S. 108ff. sowie Heller, Lederhosen, Dutt und Giftgas, S. $88 \mathrm{ff}$.

630 Im Rahmen des »Chile Declassification Project«ab 1999 wurden eine Reihe von Berichten verschiedener US-Behörden zu Chile entsperrt und veröffentlicht. Darunter sind auch etwa 500 Dokumente zum Fall Boris Weisfeiler. Sie können auf einer Webseite des State Department eingesehen werden, vgl. U.S. Department of State. Freedom of Information Act. Chile Declassification Project: Final Release, online unter https://foia.state.gov/Search/PressRelease.aspx?q=state\&type2=20001113.

631 Vgl. Corporación Nacional de Reparación y Reconciliación. Informe de la Comisión Nacional de Verdad y Reconciliación. Bd. 2. Santiago 1996, online unter https://www.memoriachilena.gob.cl/archivos2/pdfs/MC0053680.pdf. Boris Weisfeiler wird im Abschnitt »Enumeración de otros casos sin convicción«, S. 820, aufgeführt. Die Kommission kam nicht zur zweifelsfreien Überzeugung, dass es sich beim Verschwinden Weisfeilers um einen durch staatliche Repressionsorgane ausgeführten politischen Mord handelte.

632 CA Santiago, AZ 2182-98 (»Boris Weisfeiler«). Urteil vom 04.03.2016. Richter Jorge Zepeda sah das Verschwinden Weisfeilers als Mord an, der nach chilenischem Strafgesetzbuch nach 15 Jahren verjährt, nicht aber um ein Verbrechen gegen die Menschheit, das nicht verjährt.

633 CA Santiago, AZ 361-2016.

634 Corte Suprema, AZ 36837-20.

635 Vgl. Corporación Nacional de Reparación y Reconciliación. Informe de la Comisión Nacional de Verdad y Reconciliación. Bd. 2. Santiago 1996, online unter https://www.memoriachilena.gob.cl/archivos2/pdfs/MCo053680.pdf. Maarten Melle Visser wird im Abschnitt »Enumeración de otros casos sin convicción«, S. 820, aufgeführt. 
zugeordnet wurde. ${ }^{636}$ Die Ermittlungen, die heute von Richter Alvaro Mesa Latorre geführt werden, sind noch nicht abgeschlossen. ${ }^{637}$

\section{DINA exterior, Projekt ANDREA und die Rolle der CD}

Es gibt eine Reihe von Hinweisen aus juristischen und publizistischen Quellen auf eine Beteiligung der CD an der Produktion und Lagerung chemischer Waffen im Kontext der Zusammenarbeit mit der chilenischen Militärdiktatur. Diese Waffen wurden einerseits zur Ermordung politischer Gegner_innen eingesetzt und sollten andererseits im Kriegsfall die chilenischen Streitkräfte gegen die Nachbarländer Peru und Argentinien stärken, denen Chile in puncto konventioneller Bewaffnung unterlegen war.

Die DINA hatte eine Auslandsabteilung (DINA exterior), die als militanter Auslandsgeheimdienst operierte. Ihr Rückgrat war ein Netz von als Diplomaten getarnten Agent_innen und Informant_innen in einer Reihe chilenischer Auslandsvertretungen. ${ }^{638}$ Geleitet wurde die DINA exterior von Raul Iturriaga Neumann in enger Koordination mit DINA-Chef Manuel Contreras. Ihr Ziel war neben der Informationsund Desinformationsarbeit die Überwachung und Bekämpfung des chilenischen Widerstandes im Exil, insbesondere in Lateinamerika und Westeuropa. Die DINA exterior pflegte Kontakte zu anderen Geheimdiensten, wie dem Bundesnachrichtendienst, und arbeitete bei Attentaten mit rechtsextremistischen Gruppen wie dem Movimiento Nacionalista Cubano oder der italienischen Avanguardia Nazionale zusammen. Die Koordination mit anderen Geheimdiensten im Cono Sur im Rahmen der Operation Condor ${ }^{639}$ ermöglichte die Entführung und Ermordung von Chilen_innen im Exil. Zwischen 1974 und 1976 führte die DINA exterior eine Reihe von Attentaten gegen wichtige chilenische Diktatur-Gegner_innen im Exil durch. Dazu gehören die Ermordung des ehemaligen chilenischen Heereschefs Carlos Prats in Buenos Aires 1974, der versuchte Mord am ehemaligen christdemokratischen chilenischen Innenminister Bernardo Leighton in Rom 1975 und die Ermordung des ehemaligen Verteidigungsministers der Allende-Regierung, Orlando Letelier und seiner Assistentin Ronni Moffit durch eine Autobombe in Washington $1976 .{ }^{640}$

Mit einer Strategie der »Entgrenzung « und Globalisierung des Staatsterrorismus ${ }^{641}$ suchte die DINA exterior den Kontakt zu befreundeten Geheimdiensten. Das gemeinsame Ziel war nicht selten die Bekämpfung »kommunistischer« Feinde, also insbesondere

636 CA Santiago, AZ 2182-98 (»Alvaro Vallejos Villagrán«), Bd. 8b, Bl. 2920ff. Strafanzeige von Paulus Visser vom 08.08.2005.

637 Poder Judicial. Noticias del Poder Judicial vom 03.07.2018. »Ministro Mesa realiza nuevas diligencias en el marco de causas por asesinatos, apremios y desaparición turista Holandés«, online unter https://www.somosnoticias.cl/2018/07/ministro-mesa-realiza-nuevas-diligencias-en-el-marco-d e-causas-por-asesinatos-apremios-y-desaparicion-turista-holandes/.

638 Vgl. Dinges, John. The Condor Years: How Pinochet and his Allies brought Terrorism to Three Continents, New York 2004 sowie Heller, Pinochet, S. $78 \mathrm{ff}$.

639 Die Operation Condor war eine Allianz der Geheimdienste der Militärdiktaturen von Chile, Uruguay, Paraguay, Bolivien, Brasilien und Argentinien. Vgl. Dinges, The Condor Years.

640 Vgl. Dinges, John/Saul Landau. Assassination on Embassy Row, New York 1982.

641 Vgl. Heller, Pinochet, S. 84. 
militant-linksradikaler Organisationen. ${ }^{642}$ Die DINA begann 1975 an der Entwicklung chemischer, biologischer und bakterieller Waffen zu arbeiten. Diese sollten einerseits zur Ermordung einzelner politischer Gegner_innen dienen und andererseits der Vorbereitung auf einen möglichen Krieg gegen Peru oder Argentinien dienen. Der Deckname für die Entwicklung nichtkonventioneller Waffen lautete Projekt ANDREA (Abkürzung für Alianza Nacionalista de Repúblicas Americanas). ${ }^{643}$ Dabei handelt es sich um ein 1975 vom chilenischen Geheimdienst initiiertes Bündnis lateinamerikanischer Nationalisten und Geheimdienstler, das - ähnlich wie die Operation Condor - die formalen staatlichen Strukturen unterlief. Letztlich gingen die Aktivitäten jedoch wohl nicht über Chile hinaus. ${ }^{644}$

Für die Herstellung und den Einsatz des Nervengases Sarin durch die DINA sowie des am Instituto Bacteriológico hergestellten Nervengiftes Botulin Toxin durch die DINA-Nachfolgerin Central Nacional de Inteligencia (CNI) gibt es inzwischen gerichtsfeste Beweise. Die Herstellung größerer Mengen nichtkonventioneller Waffen im Rahmen des Projekts ANDREA ist hingegen aufgrund der schwierigen Quellenlage bis heute nicht hinreichend erforscht. ${ }^{645}$ Im Folgenden möchte ich eine Reihe von Hinweisen zusammentragen, die eine Beteiligung der CD an diesen Aktivitäten nahelegen.

Die Aussage von DINA-Agent Juan Muñoz Alarcón wenige Wochen vor seiner Ermordung im Oktober 1977 zeigte erstmals eine mögliche Verbindung zwischen der CD und den Auslandsaktivitäten der DINA. Muñoz berichtete über das Vorgehen der DINA beim Verschwindenlassen von Personen in Santiago:

»[S]e les captura en Santiago, se los lleva a Tobalaba. Al lado de Grimaldi existe una casa bastante amplia donde se les detiene: se llama a Dignidad, en Dignidad existe una radio con la que puede comunicarse en segundos con cualquier lugar del mundoes la receptora central de toda la información del aparato exterior de la DINA. En estos momentos en Venezuela, en Colombia, en Suecia, Francia e Italia, está trabajando el $50 \%$ de la DINA.« ${ }^{646}$

Ob die Funkanlagen in der CD eigens für die DINA exterior errichtet wurden oder die CD bloß ihre eigenen Anlagen der DINA zur Verfügung stellte, ist nicht überliefert. Jedenfalls waren die Anlagen den chilenischen Militärs und auch der Botschaft bekannt:

642 Ebd. Laut Heller [Maier] hat die DINA Aktionen gegen die baskische ETA, die irische IRA und die deutsche RAF geplant. 1976 reiste DINA-ChefContreras unter anderem mit dem bundesdeutschen Waffenhändler Gerhard Mertins in den Iran. Er soll dem Schah angeboten haben, den Venezolaner Ilich Ramirez, alias Carlos, zu ermorden. Vgl. Gónzalez, Mónica. »El día en que Manuel Contreras le ofreció al Sha de Irán matar a >Carlos, El Chacal«, in: CIPER (Website), 29.08.2009, online unter https://www.ciperchile.cl/2009/08/06/el-dia-en-que-manuel-contreras-le-ofrecio-al-sha-d e-iran-matar-a-"el-chacal"/.

643 Vgl. Heller, Lederhosen, Dutt und Giftgas, S. 79.

644 Ebd.

645 Vgl. Heller, Pinochet, S. 146 sowie Conzález, Mónica. »Las armas químicas de Pinochet«, in: CIPER (Website), 22.08.2013, online unter http://ciperchile.cl/2013/08/22/las-armas-quimicas-de-pinoche $\mathrm{t} /$.

646 PA AA, ZW 111131. Transkript der Aussage von Juan Muñoz Alarcón vom Juni 1977 [in der Vicaría de la Solidaridad], S. 5. 
Am 20. Februar 1974 schrieb Militärattaché Weidhofer einen Vermerk an den Botschafter mit dem Betreff »Besuch von zwei Marineoffizieren in Dignidad«. ${ }^{647}$ Weidhofer habe vom Verbindungsoffizier der chilenischen Marine ein Mitteilung erhalten, am selben Tag seien zwei Marineoffiziere in die CD gereist seien, darunter Fregattenkapitän Pedro Castro,

»um eine Kommunikationsinspektion durchzuführen, da angeblich Schwierigkeiten bei Radio, Funk etc. -verbindungen bestehen. Information geschieht deshalb, da es sich in Dignidad um deutsches Interessensgebiet handelt. Auf Befehl-Weidhofer-Hauptfeldwebel. $\ll^{648}$

Auch die Ficha von Pedro Castro C. aus dem CD-Geheimarchiv bestätigt diese Inspektion:

Abbildung 9: Ficha Pedro Castro C.

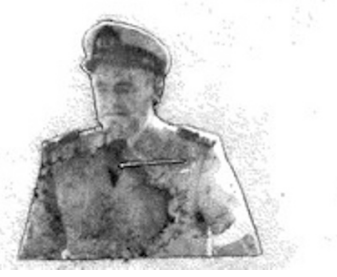

PEDRO CASTRO C.

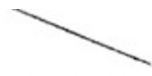

Capitán de corbeta, Ministerio de Delensa, Santiago.

Llegó el 2o-2-74 al fundo para hablar con el Dr. Soh

mandado por el jefe de la Armada. Desde noviembre de 1973 nabían escuchado y grabado nuestras frecuancias Hecibe todas las emisiones de numeros, habladas en a lemén, en el canal 1 (jueves, viernes y domzngo a ls

17 horas).

Llegó acompañado por el Teniente BOISSET (2-8-85)

Das erwähnte Attentat der DINA auf Orland Letelier in Washington im September 1976 läutete das Ende der DINA ein. Die USA bestanden auf einer Auslieferung zweier DINA-Agenten, die an dem Anschlag beteiligt waren: Armando Fernández Larios und Michael Townley, ein ziviler, US-amerikanischer Angestellter der DINA. Die Informationen, die das FBI zusammentrug, warfen ein Licht auf das Programm zur Herstellung von Saringas und anderer biochemischer Kampfstoffe im biochemischen Labor der DINA. Dieses befand sich in Townleys Haus in der Vía Naranja, Lo Curro in Santiago. Townley war 1975 mit mehreren Aufträgen nach Europa gereist und hatte seine Operationsbasis in Frankfurt a.M. Von dort aus kaufte er Waffen für das chilenische Heer in Belgien, observierte im Hafen von Genua den Bau von Fregatten für die peruanische Marine und bereitete in Rom das Attentat auf Bernardo Leighton vor. Kurz vor seiner Überstellung an die US-Behörden verfasste Townley eine Reihe von Dokumenten, in denen er Details seiner Tätigkeiten für die DINA preisgab. Darin beschrieb er u.a. die Einrichtung eines Chemielabors zur Herstellung von Saringas in seinem Haus und dass er bei seinen Europareisen benötigte Ausrüstung und Zusatzstoffe gekauft habe:

»[E]n Enero de 1975 [...] nos cambiamos a Via Naranja 4925, Lo Curro - una casa que ubicamos mi Sra. y yo y que [fue] comprado por orden de Col. M. Contreras S. y entregado a nosotros como casa habitación y lugar de trabajo para un proyecto en química

647 PA AA, AV NA 31581. Vermerk Militärattaché Weidhofer vom 20.02.1974.

648 Ebd. 
[...] Este proyecto era lo de encontrar una manera de producir »SARIN « un veneno de la familia Organo fosforados, desarrollado en la Segunda Guerra Mundial y utilizable como arma de defensa nacional o como un arma de eliminación clandestina (sus efectos pueden ser confundidos con un ataque cardíaco). Así que durante todos mis viajes posteriores en Europa se seguía trabajando este proyecto en mi ausencia y yo desde afuera compraba los equipos y materias primas necesarios [...] este proyecto dio resultados optimos durante Semana Santa de 1976. ${ }^{649}$

Kurz vor seiner Reise nach Europa, habe die DINA ihm Personen genannt, die er in Frankfurt kontaktieren sollte, darunter auch Kontaktpersonen zur CD, so Townley:

»Mientras estuve en Chile se me dieron algunos nombres de personas para que contactara en Francfort que eran amigos o tenían contacto con un lugar en Chile conocido como Colonia Dignidad. ${ }^{650}$

Auf Vermittlung von CD-Vertretern traf sich Townley in der Bundesrepublik auch mit Beamt_innen des BND. Auch der DINA-Agent Christoph Willeke unterhielt Kontakte zum BND. Mitte 1975 observierten Willeke und Townley den christdemokratischen Politiker (und späteren Präsidenten) Patricio Aylwin, der sich damals in der Bundesrepublik aufhielt. ${ }^{651}$

Der BND stand mit der DINA im Austausch zu Angehörigen der MIR, die in der Bundesrepublik politisches Asyl erhalten hatten. Der bundesdeutsche Auslandsgeheimdienst soll über mögliche Verbindungen von MIR-Aktivist_innen zu Mitgliedern der Rote-Arme-Fraktion (RAF) besorgt gewesen sein. ${ }^{652}$ Townley notierte, dazu es seien viele Listen hin- und hergeschickt worden. Der Austausch von Informationen habe oft über Wolf von Arnswaldt, den Leiter des Frankfurter Büros der chilenischen Fluglinie LAN, stattgefunden:

»[e]xistía un flujo de información que iba y venía. Mucha de esa información era transmitida - entregada a través de Wolf von Arnswaldt, gerente adjunto de la oficina de LAN-Chile en Francfort [...] nosotros enviábamos listas desde Chile, ellos nos enviaban listas a nosotros. Tenían algunas preguntas acerca de la gente que pensaban que estaba trabajando con la Badermeinhof. «653

Wolf von Arnswaldt stand wiederum in Kontakt mit dem DINA-Agenten Antal Lipthay, der in der Bundesrepublik im Auftrag der chilenischen Regierung das Büro der Presseagentur Orbe leitete. Orbe soll Gelder der chilenischen Regierung, die für Pressearbeit

649 CA Santiago, AZ 7981 (»homicidio Eugenio Berríos«), Bd. 23a, Bl. 8585. »Historia de Actuación en DINA« von Michael Townley, 14.03.1978.

650 PJD, Doc. 1-513/93. Vernehmung von Michael Townley durch den italienischen Richter Salvi in Washington vom 24./25.02.1993, S. 41.

651 PJD, Doc. 1-513/93. Vernehmung von Michael Townley durch den italienischen Richter Salvi in Washington vom 24./25.02.1993, S. 46.

652 Ebd., S. 41f. Vgl. auch Dinges, The Condor Years, S. 129.

653 PJD, Doc. I-513/93. Vernehmung von Michael Townley durch den italienischen Richter Salvi in Washington vom 24./25.02.1993, S. $42 \mathrm{ff}$. 
ausgewiesen waren, an die DINA weitergeleitet haben und so zu deren illegaler Finanzierung beigetragen haben. ${ }^{654}$ Mit von Arnswaldts Hilfe eröffnete Lipthay in Starnberg ein Büro. Dort arbeitete auch Angelika Radmann-Puffe, die Schwester von Malte Radmann-Puffe, dem Vertreter der CSU-nahen Hanns-Seidel-Stiftung in Santiago. Das Büro in Starnberg erfüllte die Funktion einer kommunikativen Schaltstelle. Laut Lipthay war es "ein Element zwischen dem Reise-Sekretariat des chilenischen Staates und der [bayrischen, JS] Staatskanzlei und der Hanns-Seidel-Stiftung der CSU«. ${ }^{655}$ Lipthays Kontakte zur bayrischen Staatsregierung sollen auch geschäftlicher Art gewesen sein: So soll er Dreiecksverkäufe des bayrischen Rüstungskonzerns Messerschmitt-BölkowBlohm an die chilenische Diktatur vermittelt haben, die mit Unterstützung von Franz Josef Strauß zustande gekommen seien. ${ }^{656}$

1993 wurde Wolf von Arnswaldt von einem chilenischen Richter vernommen. Auf die Frage, ob er Manuel Contreras persönlich kenne, antwortete von Arnswaldt, er habe als Übersetzer an einem Treffen mit Contreras zur Vorbereitung eines Deutschlandbesuches teilgenommen. Dabei gewesen sei auch der Chef der Technologieabteilung des chilenischen Heeres, Orlando Jorquera, der Geschäftsbeziehungen zu der deutschen Firma »M.B.B.« unterhalten habe:

»en cuanto al Ceneral Contreras, recuerdo que en una reunión social en el Departamento del Coronel en retiro don Orlando Jorquera, con motivo de una visita a Alemania, donde yo participaba como intérprete asistió el Ceneral Contreras [...] Jorquera era el Jefe de Centro de Investigaciones Tecnológicas de las FF.AA. y mantenía una relación comercial con la firma M.B.B. alemana. ${ }^{657}$

Weiterhin erklärte von Arnswaldt, er habe bei Linienflügen nach Santiago etwa 20 Koffer mit diversen Materialien in seinem Gepäck transportiert. Dort habe Alfred Matthusen, Teil der CD-Führungsgruppe, die Koffer in Empfang genommen und den Flughafen ohne Kontrollen verlassen:

»El contacto en Alemania fue de la siguiente manera, el Sr. Willeke me presentó al señor Schaak [...] cuando yo llegaba a Santiago, me esperaba don Alfredo Matthusen, quien retiraba esos paquetes y yo jamás pasaba por la Aduana con esa maleta [...] Calculo que a lo largo de los años traje desde Frankfurt, Alemania, a Santiago, en total, aproximadamente unas veinte maletas. [Townley] me pidió, además, que le hiciera de intermediario de una carga proveniente de la Empresa Gallenkamp que lo abastecía de este equipo de laboratorios y porcelanas y que esta carga se la redespachara desde Frankfort a Chile. « ${ }^{658}$

\section{Chemische Kampfstoffe und das Giftgaslabor der DINA}

Wolf von Arnswaldt bestätigte auch, dass Townley ihn beauftragt hatte, Material der Firma Gallenkamp entgegenzunehmen und ihm wiederum weiterzuleiten. Dabei handelte

654 Análisis vom 03.08.1987, S. 14ff. »Proyecto Kormoran: El plan secreto alemán«.

655 Archiv Al, Bestand CD. Notiz eines Gesprächs von Uli Herzog mit Antal Lipthay vom 22.01.1988.

656 Análisis vom 03.08.1987, S. 14ff. »Proyecto Kormoran: El plan secreto alemán«.

657 CA Santiago, AZ 7.981 (»homicidio Eugenio Berríos«),BI. $3865 f$.

658 Ebd., Bd. 10a, Bl. 3858. Richterliche Vernehmung von Wolf von Arnswaldt vom 25.02.1993. 
es sich vermutlich um Bestandteile für das Chemielabor der DINA, welche Townley 1975 bei der britischen Firma Gallenkamp kaufte.

Ab Anfang 1976 produzierte Michael Townley mit Hilfe der Chemiker Eugenio Berríos und Francisco Oyarzún Saringas. Die Effektivität der Substanz erprobte Townley bei einer »Vorführung« in dem geheimen Haftzentrum »Simón Bolívar« in Santiago. Dabei ermordete Townley zwei peruanische Gefangene vor den Augen von Contreras und weiteren Angehörigen der DINA. ${ }^{659}$ In den folgenden Monaten wurde das Nervengift bei diversen Attentaten eingesetzt. ${ }^{660}$ Nach dem Attentat auf Letelier in Washington wurde das Labor aufgelöst bzw. an einen unbekannten Ort gebracht. Im März 1977 wurde Townley der US-Justiz übergeben. Nach einem Deal mit den US-Behörden wurde er zu sechs Jahren Haft verurteilt. Dabei wurde ihm zugesagt, dass er nicht für außerhalb der USA begangene Verbrechen belangt würde. Seitdem wurde Townley mehrfach in den USA vom italienischen Richter Giovanni Salvi und dem chilenischen Richter Alejandro de la Madrid als Zeuge vernommen. Dabei gab er verschiedene Details über die Auslandsattentate der DINA und das Projekt ANDREA preis. Heute lebt Townley in den USA. Er bekam durch das US-Zeugenschutzprogramm eine neue Identität.

Seit 1977 wird spekuliert, dass Townleys Chemielabor nicht vernichtet, sondern in die CD gebracht wurde. Townley selbst vermutet das auch, wie er bei einer Vernehmung 2006 äußerte:

»Siempre me pregunté a dónde había enviado Contreras el equipo. Por muchos años sospeché que lo había enviado a Colonia Dignidad. No obstante, no tengo ninguna prueba de ello. ${ }^{661}$

Das Interesse der CD an dem Labor wunderte Townley nicht im Geringsten. Bei einer vorherigen Vernehmung soll er auch von biologischen Experimenten gesprochen haben, welche die CD an politischen Gefangenen vorgenommen habe. ${ }^{662}$ Townley gab bei seinen Vernehmungen stets an, die CD niemals selbst besucht zu haben. Es gibt jedoch Colonos, die bekräftigen, ihn dort gemeinsam mit seiner Ehefrau Mariana Callejas gesehen zu haben. ${ }^{663}$

Die so produzierten chemischen Kampfstoffe waren wie erwähnt auch im Kontext der Spannungen mit den Nachbarländern Peru und Argentinien relevant. Die CD soll

659 CA Santiago, AZ 2182-98 (»Conferencia«), Bd. Cuaderno Reservado 1, Bl. 12ff. Richterliche Aussage von Jorgelino del Carmen Vergara Bravo vom 20.01.2007. Vgl. dazu auch Rebolledo, Javier. La danza de los cuervos. El destino final de los detenidos desaparecidos, Santiago 2012, S. 165-174.

660 Townley gestand, das Sarin für die Morde am Mitarbeiter des Liegenschaftsregisters (conservador de bienes raíces), Renato Zenteno, sowie am DINA-Agenten Manuel Leyton bereitgestellt zu haben. Es gibt eine Reihe weiterer Attentate, bei denen das Nervengift mutmaßlich ebenfalls zum Einsatz gekommen ist.

661 CA Santiago, AZ 7.981 (»homicidio Eugenio Berríos«), Bd. 7b, BI. 2312. Richterliche Vernehmung von Michael Townley vom 13.07.2006.

662 Vgl. La Nación vom 30.03.2005, S. 11. »El secreto interrogatorio a Michael Townley«.

663 PJS, Sammlung Dieter Maier. Notiz des Cesprächs von Dieter Maier mit Bernd Schaffrik und Waltraud Schaak vom 11.11.2011, sowie PJS, Sammlung Gesprächsnotizen. Notiz des Gesprächs des Verfassers, Dieter Maier und Petra Schlagenhauf mit Bernd Schaffrik und Waltraud Schaak vom 04./05.02.2012. 
eine von mehreren geheimen Militärbasen gewesen sein, von denen im Falle eines Krieges Angriffe mit chemischen Waffen hätten ausgeführt werden können. ${ }^{664}$ In einem klandestin publizierten Buch von 1988 wurde erstmals ein Labor in der CD erwähnt, in dem mit Giftstoffen gearbeitet wurde: »Existe un laboratorio en Colonia Dignidad para pruebas de armas y análisis de gases. « ${ }^{665}$ Die Herstellung und Lagerung von Giftgas in der CD wurde in Chile nie ausführlich juristisch untersucht. Einzelne Ermittler, die sich ausführlich mit dem Fall CD beschäftigt haben, halten sie jedoch für belegbar: So berichteten hochrangige PDI-Beamt_innen ihren deutschen Kolleg_innen vom BKA bei einem Treffen in Wiesbaden 2006:

»Nach Schilderung von Herrn Castillo ist es aufgrund von Aussagen von Siedlern gelungen, die Waffendepots auf dem weitlaufigen Gelande der >Colonia Dignidad aufzufinden. Unter Pinochet wurden auf dem Gelande auch chemische Waffen für einen eventuellen Krieg mit Peru produziert und gelagert. « ${ }^{666}$

Der Besuch fand im Rahmen eines Austauschs zwischen deutschen und chilenischen Beamt_innen statt, die an Ermittlungen gegen Colonos beteiligt waren. Die chilenischen Beamt_innen führten auch Gespräche bei der Staatsanwaltschaft Memmingen, die damals gegen das nach Deutschland geflüchtete CD-Führungsmitglied Albert Schreiber ermittelte. ${ }^{667}$

In der CD gefundene Audioaufnahmen belegen, dass Colonos in den 1970er Jahren direkt an der Auslandsspionage beteiligt waren: So berichtete etwa Kurt Schnellenkamp der CD in einem Funk- oder Telefongespräch aus Bolivien von seinen Observationen einer Militärparade sowie von Installationen der bolivianischen Marine am TiticacaSee. ${ }^{668}$ Solche nachrichtendienstlichen Erhebungen über die militärische Infrastruktur von Nachbarländern können nur in Koordination mit hohen chilenischen Militärkreisen erfolgt sein.

Es gibt weitere Anhaltspunkte für die Herstellung und Lagerung von Giftstoffen und Nervengasen in der CD sowohl im Kontext ihrer Zusammenarbeit mit der Diktatur als auch für eigene Zwecke. Die Existenz der sogenannten Giftküche wurde bereits erläutert (Abschnitt 4.2.2).

Chilenische Medien spekulierten verschiedentlich über Verbindungen Hartmut Hopps zu Personen, die wegen Giftmorden während der Diktatur verurteilt wurden. ${ }^{669}$

664 Heller, Lederhosen, Dutt und Giftgas, S. 80.

665 Lagos, Jaime/Paul Friedrich Violenstein. Laberinto-Colonia Dignidad-una pista sobre los desaparecidos, Santiago 1988, S. 43. Jaime Lagos ist das Pseudonym des MIR-Aktivisten Carlos Liberona. Hinter Violenstein verbirgt sich Dieter Maier.

666 PJS, Sammlung IFC BMI.Vermerk BKA SO 11-107. Besuch einer chilenischen Delegation unter Leitung von Herrn Castillo vom 21.-23.05.2006 im BKA, hier: Protokoll zu den Fachgesprächen bei SO vom 30.05.2006.

667 Ebd.

668 PWH, Tonband Nr. 48. auch: https://radio.uchile.cl/2018/10/07/colonia-dignidad-al-descubierto-art ista-revela-las-conversaciones-telefonicas-de-paul-schafer/.

669 Vgl. El Mostrador vom 15.01.2010, »Médicos UC reconocen vínculos del Hospital con creador de venenos de la Colonia Dignidad«, online unter https://www.elmostrador.cl/noticias/pais/2010/01 /15/medicos-uc-reconocen-vinculos-del-hospital-con-creador-de-venenos-de-la-colonia-dignidad/ sowie El Mostrador vom 19.02.2019, »Las conexiones de Hartmut Hopp con los médicos de la UC 
Im Januar 2019 sprach Richter Alejandro de la Madrid sein erstinstanzliches Urteil im Verfahren um den Tod des ehemaligen christdemokratischen Präsidenten Eduardo Frei Montalva. Frei starb 1982 nach einer Reihe chirurgischer Eingriffe in der Clínica Santa María. Richter Madrid stufte den Tod als »homicidio simple« (in etwa vergleichbar mit Totschlag) ein und verurteilte sechs Personen für ihre Beteiligung an den Eingriffen und der Verschleierung der Vorgänge. Dem vorangegangen waren weitere Verfahren wegen der Ermordung von Eugenio Berríos, dem Chemiker der DINA, 1992 und wegen der Vergiftung von Gefangenen in der Haftanstalt Ex-Cárcel Pública mit Botulin-Toxin 1981. In all diesen Verfahren ${ }^{670}$ taucht der Name Hartmut Hopp in den Verfahrensakten auf. Der Grund dafür ist, dass Hopp mit einigen der im Fall Frei verurteilten Ärzte zusammen an der Universidad Católica studiert hatte und auch danach noch mit ihnen im Kontakt stand. So war Hopp ein Student des wegen des Mordes an Frei verurteilten Arztes Helmar Rosenberg gewesen. Er war ein Kommilitone des ebenfalls verurteilten Sergio González Bombardiere. Bei diesem im Pathologischen Institut der Universidad Católica ließ Hopp noch in seiner Funktion als Leiter des CD-Krankenhauses kostenfrei Biopsien durchführen. ${ }^{671}$ Im Verfahren um die (versuchten) Morde in der ehemaligen Cárcel Pública 1981 erklärte ein Arzt des Instituto Bacteriológico, Hartmut Hopp sei 1980 zwei Mal in das Institut gekommen, um weiße Laborkaninchen zu erwerben. ${ }^{672}$ Am 19. Januar 2006 vernahm de la Madrid Hartmut Hopp. ${ }^{673}$ Dieser berichtete, an der Universidad Católica u.a. bei den Professoren Barahona und Helmar Rosenberg studiert zu haben. Außerdem habe er in den 1970er Jahren in der CD eine Chemotherapie bei Manuel Contreras durchgeführt, nachdem dieser sich in Santiago einer Darmkrebsoperation durch Felix de Amesti unterzogen hatte. Contreras habe damals einen Monat lang in der CD gewohnt.

Möglicherweise verfügte die CD noch über das Ende der Militärdiktatur hinaus über Nervengifte. Ein Colono berichtet, dass er noch Ende der 1990er Jahre den Auftrag bekam, den Opferanwalt Hernán Fernández in Parral mit Saringas zu ermorden. ${ }^{674}$

Zusammenfassend lässt sich sagen, dass die bisher vorliegenden Hinweise über die Rolle der CD bei der Herstellung, Lagerung und dem Einsatz chemischer Kampfstoffe kein eindeutiges Bild ergeben. Der Eindruck bleibt, dass bislang keine umfassenden Anstrengungen unternommen wurden, um diesen Verbrechenskomplex aufzuklären.

condenados en el caso Frei«, online unter https://www.elmostrador.cl/noticias/pais/2019/02/19/las -conexiones-de-harmut-hopp-el-exjerarca-de-colonia-dignidad-con-los-medicos-de-la-uc-conden ados-en-el-caso-frei/.

670 Richter Alejandro Madrid an der CA Santiago führte die Ermittlungen zu verschiedenen Tötungsdelikten im Kontext der Giftproduktion der Diktatur. Sie trugen alle dasselbe Aktenzeichen 7981: »Ex Cárcel Pública« (7981-D), »Eduardo Frei Montalva« (7981-B) sowie »Manuel Leyton« (7.981-E).

671 CA Santiago, AZ 7.981. Polizeiliche Vernehmung von Sergio Conzález Bombardiere vom 27.03.2009, online unter https://www.elmostrador.cl/media/2019/02/Declaracion-del-Dr.Sergio-Go nzalez-caso-Frei-sobre-Colonia-Dignidad.pdf.

672 CA Santiago AZ 7.981-D (»Ex Cárcel Pública«). Urteil vom 16.02.2017, S. 73.

673 CA Santiago, AZ 7.981 (»Eugenio Berríos«), Bd. 19a, Bl. 7047ff. Richterliche Vernehmung von Hartmut Hopp vom 19.01.2006.

674 Heller, Lederhosen, Dutt und Giftgas, S. 85. 
Verwunderlich ist, dass Fragen zu diesem Themenkomplex bei Vernehmungen im Rahmen der zahlreichen CD-Verfahren meist ausblieben. Viele der aufgeführten Hinweise wurden von Privatpersonen recherchiert, sind aber in den eingesehenen Justizakten nicht vorhanden. Womöglich gibt es auch relevante Akten, die bis heute unter Verschluss gehalten werden. Das legt zumindest der Umstand nahe, dass hochrangige chilenische Ermittler_innen gegenüber ihren deutschen Kolleg_innen deutliche Aussagen über die Lagerung von Saringas in der CD machten, während die - mir bekannten Ermittlungsakten nichts dazu aufführen. Hier könnte eine Freigabe der Akten des Bundesnachrichtendienstes zur CD möglicherweise zur Aufklärung beitragen.

\subsubsection{Sexualverbrechen gegen chilenische Kinder}

Paul Schäfer kam im Januar 1961 in Chile an. Die ersten Jungen der Gruppierung, die er regelmäßig missbrauchte, erreichten das Land erst im Juli 1961. In der Zwischenzeit soll Schäfer eine Reihe chilenischer Kinder missbraucht haben. Rudi Cohn berichtete 1988 in einem Interview von drei Missbrauchsfällen in den ersten Monaten nach Schäfers Ankunft in Chile. ${ }^{675}$ Heinz Kuhn beschrieb dazu 1997 gegenüber einem Untersuchungsausschuss des chilenischen Abgeordnetenhauses, die Mutter eines so missbrauchten Jungen habe Anzeige gegen Schäfer erstattet, worauf dieser sich auf das Fundo Lavadero zurückgezogen habe:

»El senor Kohn(?) [Rudi Cohn, JS] ....acogió a Schäfer y a Schmidt. Schäfer abusó de los niños del senor Kohn (?) y abusó del niño del jardinero. Lo llevaron a Catemu, un lugar cerca de Santiago, y allí abusó del niño del administrador. Cuando llegué, Schäfer nos mandó al señor Schmidt y a mi a hacer diligencias por la nueva SBED. El recogió niños [...] en el paseo Ahumada, donde había una casa subterránea con juegos y se los llevó a la casa para lo que fuera. [...] Uno de esos niños vagos y huérfanos se robó un reloj de Schäfer, Schäfer y Schmidt fueron a buscar al niño, pero la mamá del niño habia hecho una denuncia, y cuando llegó la denuncia a la casa del señor Kohn (?), Schäfer se fue definitivamente al que hoy es el fundo Lavadero, o la CD. El señor Schmidt tuvo que dar la cara con el señor Kohn para tapar todos esos pecados en un juzgado de Santiago que hoy no existe. ${ }^{676}$

Aus den folgenden Jahrzehnten bis zu den 1990er Jahren kenne ich keine konkreten Belege für Missbrauchstaten von Schäfer an externen Kindern. Vermutlich beging er diese Taten ausschließlich an Gruppenmitgliedern. Ein inhärenter Widerspruch der Schäfer'schen Gemeinschaftsordnung sollte ihm schließlich selbst zum Verhängnis werden: Ein wichtiger Bestandteil von Schäfers Herrschaftskonzept lag in der Unterdrückung und Dämonisierung der Sexualität der Colonos. Nur die wenigen Ehepaare, die über ein eigenes Schlafzimmer verfügten, konnten im Verborgenen ihre Sexualität ausleben.

675 Rojas, Los secretos, S. 35. Interview mit Rudi Cohn.

676 PA AA, AV NA 32988. Cámara de Diputados, Sesión conjunta de las comisiones de Familia y Especial Investigadora de la ex Colonia Dignidad vom 06.08.1997, Diarios de Sesiones, BI. 137f. Preguntas de diputados a Heinz Kuhn, Bl. 137f. 
Die strikte Geschlechtertrennung, das Verbot enger zwischenmenschlicher Beziehungen und des Zusammenlebens in Familien führten zu einem Geburtenrückgang in der CD. ${ }^{677}$ Im Lauf der Jahre erlaubte die CD-Führung auch Eheschließungen immer seltener. In der Folge gab es weniger Kinder und somit auch weniger (potenzielle) Opfer für Schäfers Sexualverbrechen. In den 1970er Jahren versuchte Schäfer, vor allem durch die Aneignung chilenischer Kinder Zugang zu neuen Missbrauchsopfern zu bekommen, in der Regel durch betrügerisch herbeigeführte Adoptionen (vgl. Abschnitt 4.2.1). Aus den 1980er Jahren ist jedoch nur ein solcher Fall bekannt. ${ }^{678}$

Anfang der 1990er Jahre begann Schäfer, systematisch chilenische Kinder aus der Umgebung der CD in die Siedlung einzuladen. Dazu nutzte er die von der CD geschaffenen Unterstützungsstrukturen, die sogenannten Freundeskreise und Patientenkomitees. Dabei handelte es sich um Propagandainstrumente, welche die (vermeintliche) Unterstützung der CD durch die lokale Bevölkerung zum Ausdruck bringen und dadurch eine Art Schutzring um die CD legen sollten. Kontext dieser Bemühungen war der Versuch der chilenischen Regierung von 1991, die SBED aufzulösen. ${ }^{679}$ Als Reaktion darauf mobilisierte die $\mathrm{CD}$ die lokale Bevölkerung zu einer sogenannten »Mahnwache des Schmerzes« (»Vigilia del Dolor«) und einer sogenannten »ständigen Jugendwache« (»Juventud Vigilia Permanente«). ${ }^{680}$ Im Rahmen dieser Wachen wurden große Unterstützungsveranstaltungen an der Zufahrtsstraße zur CD inszeniert. ${ }^{681}$ An Wochenenden wurde eine große Anzahl von Kindern und Jugendlichen ${ }^{682}$ mit Bussen in die CD gebracht, wo sie gruppenweise an organisierten Freizeitaktivitäten und Wettbewerben

677 Am 19.06.1997 übersandte die Direktorin des Registro Civil (Personenstandsregister/Standesamt) dem Familienausschuss der Cámara de Diputados einen Bericht über Eheschließungen, Geburten und Adoptionen in der CD zwischen 1961 und 1997. Das Registro Civil zählt darin 22 Eheschließungen, 65 Ceburten und 12 Adoptionsfälle auf: Cámara de Diputados, Boletín de Sesiones, Legislatura 336 ${ }^{\mathrm{a}}$, Sesión $10^{\mathrm{a}}$ vom 21.10.1997, Informe de la Comisión de Familia recaido en el Proyecto de Acuerdo que le encomienda investigar situaciones de posibles violaciones a los derechos de los niños y niñas en la ex Colonia Dignidad, auch online unter https://www.camara.cl/camara/media/docs/col onia/03.pdf, S. 67ff (zuletzt abgerufen am 12.02.2018).

678 Gemeint ist die Adoption von Cristian Javier Godoy Godoy, heute Michael Hopp, vgl. Abschnitt 4.2.1.

679 Diario Oficial №33.896 vom 16.02.1991. Ministerio de Justicia, Decreto 143 vom 31.01.1991. »Declara disuelta y cancela personalidad jurídica y destina bienes de entidad que indica.«

680 Vgl. Salinas/Stange. Los amigos, S. 195ff sowie Douglas, Marcela. Hopes and Horror - An ethnographic study of a Cerman community in Chile. [Dissertation]. Troms $\varnothing 2013$, S. 189ff. Online unter: https://munin.uit.no/handle/10037/5810. Laut Douglas bestanden Vigilia del Dolor und Juventud Vigilia Permanente von 1991 bis 2001.

681 Viele dieser Veranstaltungen fanden in einer Art Amphitheater statt, dem sogenannten Arco del Dolor (Bogen des Schmerzes), das eigens dafür errichtet wurde. Es trug die Inschrift: »Vigilia del Dolor. Por Dignidad. Al supremo juez lo esperamos« (»Mahnwache des Schmerzes. Für Würde. Wir warten auf den obersten Richter«). Vgl. Douglas, Hopes and Horror, S. 191.

682 Laut Adrian Bravo, einem evangelikalen Pastor, der bis 1996 eng mit der CD zusammenarbeitete, und sich wegen der Missbrauchsvorwürfe abwandte, kamen an den Wochenenden anfangs 2000 Kinder in die CD. CA Santiago, AZ 2182-98 (»Asociación Ilícita«), Bd. I (Parral), BI. 283f. Richterliche Vernehmung von Adrian Bravo vom 20.11.1996. 
teilnahmen. In diesen Situationen missbrauchte Paul Schäfer viele der teilnehmenden Jungen. ${ }^{683}$

1995 wurde eine Gruppe chilenischer Jungen ausgewählt, Teil eines sogenannten »Intensivinternats« (»Internado Intensivo«) zu werden und dauerhaft in der CD zu leben. ${ }^{684}$ Den Eltern wurde eine kostenlose Ausbildung, Kost und Logis für ihre Kinder versprochen. Dazu mussten die Erziehungsberichtigten jeweils Betreuungsverträge mit Colono-Ehepaaren unterzeichnen. De facto durften sie ihre Kinder danach nur noch in Ausnahmefällen besuchen. Die chilenischen Jungen lebten gemeinsam mit ColonoKindern in Gruppenhäusern und wurden von »Tutoren« wie Günther Schaffrik, Jörg Schnellenkamp, Ernst Schreiber und Uwe Cöllen betreut. Abends wurden einzelne von ihnen von den »Sprintern « ${ }^{685}$ ausgewählt, um bei Paul Schäfer zu übernachten. Dieser missbrauchte und vergewaltigte sie regelmäßig. Die Opfer bekamen nach eigenen Aussagen Medikamente verabreicht, die sie gefügig machen und ihre Erinnerungen an die Taten auslöschen sollten. ${ }^{686}$

Im Juni 1996 gelang es Cristóbal Parada Pacheco, einem der chilenischen Jungen aus dem »Internat«, einen Kassiber an seine Großmutter aus der CD zu schmuggeln. Darin bat er sie, ihn aus der CD zu holen, und schrieb, Schäfer vergewaltige ihn. Der Mutter des Jungen gelang es, den Jungen unter einem Vorwand aus der CD zu holen. Da sie sich über die engen Beziehungen der CD zu den lokalen Behörden im Klaren war, reiste sie mit ihrem Sohn nach Santiago und stellte Strafanzeige bei der dortigen Kriminalpolizei. Rechtsanwalt Hernán Fernández Rojas, der u.a. für die staatliche Kinderschutzbehörde SENAME arbeitete, stellte kurz darauf einen Schutzantrag bei der CA Talca. Richter Jorge Norambuena nahm Ermittlungen auf und erließ am 14. August 1996 Haftbefehl gegen Paul Schäfer. ${ }^{67}$ Die CD-Anwälte legten daraufhin einen Schutzantrag zugunsten von Schäfer ein und argumentierten, die PDI versuche ihn einzuschüchtern. Die CA Talca sowie die Corte Suprema lehnten es jedoch ab, den Haftbefehl außer Kraft zu setzen. ${ }^{688}$ Wenig später übernahm an der CA Talca Sonderrichter (»Ministro en Visita«) ${ }^{689}$ Hernán González den Fall. Weitere Eltern von Jungen, die ebenso die CD besuchten oder im »Internat« der CD lebten, stellten Strafanzeigen, der Fall weitete sich schnell aus. Die CD versuchte die Ermittlungen zu behindern, versteckte Colono-Kinder

683 Vgl. Poder Judicial. Noticias del Poder Judicial vom 28.01.2013, „Corte Suprema dicta sentencia en investigación por abusos sexuales en la ex Colonia Dignidad«, übernommen von: https://www.lasegunda.com/Noticias/Nacional/2013/01/817731/Corte-Suprema-dicta-sentenci a-en-investigacion-por-abusos-sexuales-en-la-ex-Colonia-Dignidad.

684 Das »Internado Intensivo« bestand von etwa 1995 bis 1997. Vgl. CA Santiago, AZ 2182-98 (»Asociación Ilícita«), Bd. I (Parral), Bl. 283f. Richterliche Vernehmung von Adrian Bravo vom 20.11.1996.

685 Paul Schäfer suchte sich täglich zwei Jungen aus, die ihn begleiteten, denen er Anweisungen gab und die er missbrauchte. Diese bezeichnete er als »Sprinter«.

686 StA Krefeld, AZ3 Js 753/11, SB III, BI. 260ff. Richterliche Vernehmung von E. U. vom 02.03.2018 sowie StA Krefeld, AZ 3 ]s 753/11, SB III, BI. 256ff. Richterliche Vernehmung von ]. P. vom 20.02.2018.

687 PA AA, AV NA 31637. CA Talca, Urteil vom 14.10.1996 zum Schutzantrag von RA Saenger und RA Ortega Jarpa gegen Nelson Mery, Luis Henriquez sowie Richter Jorge Norambuena.

688 La Epoca vom 24.10.1996, S. 20. »Investigaciones podrá detener a líder de Dignidad Paul Schäfer«.

689 Ein »ministro en visita extraordinaria « ist ein Richter an einer Corte de Apelaciones (Berufungsgericht, CA), der bei Verfahren von großer Relevanz abgeordnet wird, um bei einem erstinstanzlichen Gericht Ermittlungen durchzuführen. 
außerhalb der $C D^{690}$ und entführte chilenische Kinder, vermutlich, um zu verhindern, dass sie aussagen oder gerichtsmedizinisch untersucht würden. Einer der Jungen, Rodrigo Salvo, ${ }^{691}$ wurde zwei Jahre lang an verschiedenen Orten in Chile festgehalten, bevor er im Juni 1999 im Büro des CD-Anwalts Fidel Reyes wieder auftauchte. Im Juni 2000 erhob González wegen dieser Entführung von Salvo Anklage gegen Albert, Lilli und Ernst Schreiber, Alfred Matthusen sowie vier chilenische Staatsbürger_innen. Die vier Colonos entzogen sich der Justiz durch Flucht in die Bundesrepublik. Sie blieben bis heute straflos. ${ }^{692}$

Um den Haftbefehl gegen Schäfer zu vollstrecken, führte die chilenische Polizei ab November 1996 mehrere Razzien auf dem Gelände der CD durch. Doch die CD erfuhr meist im Voraus davon. Paul Schäfer gelang es, sich in unterirdischen Einrichtungen auf dem Gelände zu verstecken. Im Juli 1997, nach der Flucht von Tobias Müller und Salo Luna aus der CD, die große mediale Aufmerksamkeit erregte, beschloss Paul Schäfer, die CD zu verlassen und sich in Argentinien zu verstecken. ${ }^{693}$ Sechs Colonos begleiteten

690 Beispielsweise wurde der Adoptivsohn von Hartmut Hopp im Juli 1997 nach Argentinien gebracht und reiste von dort mit seiner Adoptivmutter Dorothea Hopp nach Venezuela und weiter in die USA. Von dort kehrte er erst 2000 zurück. Die von Richter Conzález gesuchten Minderjährigen Georg und Siegfried Hempel wurden vier Jahre nach ihrem Untertauchen, im Mai 2001, in Santiago festgenommen. Vgl. Juzgado de Parral, AZ 53015. Urteil vom 16.11.2004.

691 Rodrigo Salvo verstarb im Jahr 2007 an Lymphdrüsenkrebs, er wurde nur 24 Jahre alt. Vgl. La Nacion vom 12.09.2007, S. 7. »Muere una de las víctimas de los abusos de Paul Schäfer«.

692 Die Bundesrepublik liefert eigene Staatsbürger grundsätzlich nicht an Drittstaaten aus (Ausnahmen bestehen auf EU-Ebene). Dies ergibt sich aus Artikel 16 GG. Im Fall von Albert Schreiber, der 2008 in Krefeld verstarb, stellte Chile ein Auslieferungsersuchen, das die Bundesrepublik ablehnte. Alfred Matthusen, gegen den ein chilenischer Interpol-Haftbefehl vorlag, war bereits im Jahr 2004 in der Bundesrepublik verstorben. Lilli und Ernst Schreiber leben heute in Krefeld. Gegen sie stellte Chile ebenfalls einen Interpol-Haftbefehl aus.

693 Laut einer Aussage von Erwin Fege verließ Schäfer die CD im August 1997: »En el año 1997, en el mes de agosto, recuerdo que según planificación de Hans ]ürgen Riesland y yo fui quien manejó el vehículo que los llevó afuera del fundo, especificamente al otro lado del río, al sector de Trabuncura, esto fue en la noche y en ese lugar habían dos vehículos más. Junto conmigo estaba Paul Schäfer, Mathias Gerlach y Peter Schmidt, siendo este último quien tenía todo claro respecto del lugar donde estaban esperando dos autos más, pudiendo divisiar a tres personas alrededor de estos, quienes eran Hans ]ürgen Riesland, pero los otros eran chilenos, de quienes ignoro mayores antecedentes, porque estos se quedaron en los vehículos. Una vez que bajaron a Schäfer del vehículo que yo manejaba y las cosas yo procedí a darme la vuelta y regresar a la Colonia.« CA Santiago, AZ 2182-98 (»Alvaro Vallejos«), Bd. 8a, BI. 2767. Polizeiliche Vernehmung von Erwin Fege vom 12.05.2005. Laut dem Journalisten Gustavo Villarubia, der am Auffinden von Schäfer durch ein Team des chilenischen Fernsehsenders Canal 13 beteiligt war, ist Schäfer folgendermaßen nach Argentinien geflohen: „Ellos cruzaron la cordillera en un avión de un particular. La salida fue por la Séptima Región. - Quien era ese particular? Era un empresario chileno de apellido Neumann, que tenía aviones y el pasó a Schäfer al otro lado de la frontera.« Vgl. PJS, Sammlung CD. Hayes Frabasile, Barbara. Colonia Dignidad: Una historia de horror, sexo y poder. [unveröffentlichtes Manuskript], Santiago 2005, S. 242. Anderen Angaben zufolge soll Schäfer von Bulnes aus mithilfe des befreundeten Piloten Maximilian Rudolph nach Argentinien geflogen sein. Vgl. PJS, Sammlung Gesprächsnotizen. Notiz eines Gesprächs des Verfassers mit Winfried Hempel vom 10.12.2017. 
ihn in den dortigen Untergrund. ${ }^{694}$ Erst 2005 wurde Schäfer von der argentinischen Polizei festgenommen und umgehend nach Chile ausgewiesen. Seine Begleiter_innen wurden nicht festgenommen und kehrten erst Jahre später nach Chile zurück.

Die Verfahren gegen Paul Schäfer und seine Beihelfer_innen und Kompliz_innen endeten erst nach Schäfers Tod 2013 mit der rechtskräftigen Verurteilung von 14 Colonos und 7 chilenischen Unterstützer_innen zu Haftstrafen zwischen 541 Tagen und 11 Jahren (vgl. Abschnitt 5.1.4).

Letztlich waren es diese externen Sexualverbrechen, die das Ende der CD einläuteten. Große Teile des Unterstützungsnetzwerks der CD in Chile brachen ab 1996 sukzessive weg, so dass es Ende der 1990er Jahre kaum noch öffentliche Fürsprecherinnen gab. ${ }^{695}$

\subsubsection{Ungeklärte Todesfälle}

In den vorangegangenen Abschnitten ist bereits eine große Anzahl von Todesfällen im Kontext der CD beschrieben, darunter viele Fälle, die juristisch bisher nicht vollständig aufgeklärt sind. Bei weiteren Todesfällen, die zum Teil ebenfalls bis heute nicht aufgeklärt wurden, liegen Vermutungen auf oder Indizien für eine mögliche Fremdeinwirkung durch Täter_innen der CD vor. Diese Hinweise sind unterschiedlich glaubwürdig. Das Fehlen umfassender juristischer Untersuchungen bzw. die fehlende Veröffentlichung vorhandener Ermittlungsergebnisse haben über die Jahre hinweg immer wieder Spekulationen über diese Tötungsdelikte genährt. In Zeiten intensiverer Medienberichterstattung über die CD boten die umfangreiche Verbrechensgeschichte der CD und die (vermeintlichen) Ungereimtheiten der Todesfälle insbesondere Anlass zu Spekulationen über eine Tatbeteiligung der CD. Einige dieser Todesfälle wurden mittlerweile aufklärt, bei anderen gab es nie stichhaltige Indizien, die Anlass für weiterführende Ermittlungen geboten hätten. Bei einigen Fällen konnte ein entsprechender Verdacht auf eine Beteiligung der CD jedoch bis heute nicht ausgeräumt werden.

694 Dies waren Renate Freitag, Matthias Gerlach, Rebeca Schäfer, Peter Schmidt, Maria Strebe und Friedhelm Zeitner. Strebe verstarb 2002 in Argentinien. Für Schilderungen des Lebens von Schäfer und seiner Begleiter_innen im argentinischen Untergrund vgl. Villarubia, Gustavo. »Mi vida bajo el régimen de Paul Schäfer«. La historia de uno de los guardaespaldas del líder de Colonia Dignidad [Interview mit Friedhelm Zeitner], in: CIPER (Website), 23.09.2013, online unter https://www.cipe rchile.cl/2013/09/23/"mi-vida-bajo-el-regimen-de-paul-schafer".

695 Einer der wenigen Personen, die sich noch Ende 2002 positiv über die CD äußerten, war der bekannte Psychiater Otto Dörr. Die New York Times berichte dazu: »Gen. Rodolfo Stange, a former commander of the national police and champion of the group, who is now a senator, declined a request for an interview, as did several lawyers who have represented the organization in court cases. But Otto Dorr Zegers, a prominent psychiatrist in Santiago who has served on the board of the Colonia Dignidad hospital, continues to defend the sect. He said the group had been the victim of > unjust attacks and treatment « that were part of sa curious hatred campaign > organized by the Chilean government. «Larry Rohter. »Chile sect thrives despite criminal charges«, in: New York Times vom 30.12.2002, S. A3. 


\section{Exhumierungen}

Am 13. Dezember 1962 verstarb Auguste Pöhlchen (geb. Friedrich) im Alter von 83 Jahren. Sie war die erste Colona, die in Chile angekommen war. Mario Mujica Bordali, ein mit der CD befreundeter Arzt aus Parral, bescheinigte als Todesursache Herzversagen. Pöhlchen wurde auf dem Friedhof des benachbarten Ortes Catillo beigesetzt.

Nur zwei Tage nach Auguste Pöhlchens Tod wurde ihre Leiche exhumiert, in die CD transportiert und auf dem neu eingerichteten Friedhof der CD erneut beerdigt. ${ }^{696}$ Der von den Behörden erst 1963 oder 1964 autorisierte Privatfriedhof der CD wurde in den nächsten Jahrzehnten zum Schauplatz diverser gerichtlich angeordneter Exhumierungen mit dem Ziel einer zweifelsfreien Feststellung der Todesursache. So wurden am 22. April 1966 auf Anordnung des Richters Enrique Bravo Ubilla die Leichen sämtlicher fünf bis dahin auf dem CD-Friedhof beerdigten Colonos exhumiert: Auguste Pöhlchen, Joanna Frieda Spinti (geb. Gruber, 80 Jahre), Anna Freitag (geb. Hartmann, 60 Jahre), Reinhard Vedder Mysliwietz (18 Jahre) und Ursula Schmidtke (17 Jahre). ${ }^{697}$ Wolfgang Müller (heute Kneese), der wenige Wochen zuvor aus der CD geflüchtet war, vermutete, einige dieser Personen könnten durch Gewalteinwirkung gestorben sein. Das Ergebnis der gerichtsmedizinischen Untersuchung der Leichen ist mir nicht bekannt.

Im Oktober 1997 wurden die sterblichen Überreste von Hartmut Münch exhumiert. Dieser war 1987 im Alter von 8 Jahren bei der Jagd erschossen worden, mutmaßlich von DINA-Chef Contreras (Vgl. Abschnitt 4.1.7). Bei Münchs Leiche konnten Einschussspuren festgestellt werden, die den Tod des Jungen verursacht hatten. ${ }^{698}$ Im September 1998 wurde die Leiche des 1996 verstorbenen, langjährigen SBED-Präsidenten Hermann Schmidt exhumiert, da es Spekulationen über die Ursache seines Ablebens gegeben hatte. ${ }^{699}$

Im Folgenden eine Reihe von weiteren Todesfällen, bei denen über eine gewaltsame Fremdeinwirkung im Zusammenhang mit der Colonia Dignidad spekuliert wurde:

\section{Winfried Kretzschmar}

Am 6. Dezember 1966 wurde Winfried Kretzschmar, 32-jähriger Presseattaché der Botschaft, im Keller seines Wohnhauses tot aufgefunden. Laut einem Bericht von Botschaftsrat Spang an das AA vom 13. Dezember soll der Polizeiarzt "unzweifelhaften Selbstmord durch Schuß in die Mundhöhle « festgestellt haben. ${ }^{700}$ Kretzschmar hatte sein Amt erst ein halbes Jahr vorher angetreten. Einige Medien aus Chile und der DDR spekulierten daraufhin über einen Zusammenhang zwischen dem Tod Kretschmars und dem Fall Colonia Dignidad. ${ }^{701}$ Unter Berufung auf chilenische Medien meldete der Deutschlandsender aus Ost-Berlin, »daß selbst in Kreisen der deutschen Kolonie

696 CA Santiago, AZ 2182-98 (»Conferencia«), Bd. 1ª Bl. 86ff. Aufstellung »Relación de colonos alemanes fallecidos y sepultados en el Cementerio de Villa Baviera, ordenados por su ubicación« o.D.

697 El Diario Ilustrado vom 23.04.1966, S. 6. »Exhumados cadaveres de cementerio de >Dignidad ««.

698 CA Santiago, AZ 2182-98 (»Asociación Ilícita«), Bd. I (Parral), BI. 409. Polizeibericht vom 08.01.2001.

699 Las Ultimas Noticias vom 26.08.1998, S. 5. »Restos exhumados son de Schmidt«.

700 PA AA, Personalakte Winfried Kretzschmar Z 51988, Bericht Botschaftsrat Spang an AA vom 13.12.1966.

701 PA AA, Personalakte Winfried Kretzschmar Z 51988, Aufzeichnung Abteilung Z, VLR I Heiperz vom 30.12.1966. 
in Chile die Version von einem Selbstmord Kretzschmars immer stärker angezweifelt werde. Zur fraglichen Zeit seien zwei Schüsse gehört worden. ${ }^{702}$ In der Botschaft, so das DDR-Organ, habe es tiefgehende politische Meinungsverschiedenheiten über »den Skandal in der Nazi-Kolonie Dignidad« sowie Konflikte »neonazistischer Elemente mit den übrigen Vertretern der Botschaft « gegeben. Botschafter von Nostitz habe eine »ausgesprochen neonazistische Atmosphäre in der Botschaft geschaffen, mit der Kretzschmar nicht einverstanden gewesen sein soll. Die Frage stellt sich: Wurde Kretzschmar in den Tod getrieben oder ermordet? ${ }^{703}$ Alle internen Aufzeichnungen des AA verweisen jedoch auf einen Selbstmord Kretzschmars aus persönlichen Motiven. Eine Aufzeichnung der Personalabteilung des AA zieht folgendes Fazit:

»Der beiliegende Bericht der Botschaft Santiago über den Selbstmord des Pressereferenten LS Dr. Winfried Kretzschmar am 6.12.1966 kann eine letzte Klärung über die Motive und Hintergründe nicht geben. [...] Es ist kein Grund zu verzeichnen, der darauf schließen lässt, dass sein Schritt auf mit dem Dienst zusammenhängende Umstände zurückzuführen ist.

Ganz abwegig sind die von dem ostberliner Deutschlandsender und linksorientierten chilenischen Blättern kolportierten Behauptungen, dass eine neo-nazistische Atmosphäre an der Botschaft zu seinem Selbstmord geführt hätte oder dass es sich gar um einen Mord gehandelt habe. [...]

Da die Angriffe und Verleumdungen des sowjetzonalen Deutschlandsenders im Zusammenhang mit dem Tod von Herrn Kretzschmar bisher in der freien Welt, ausser in einigen linksradikalen Blättern Chiles, keinen Widerhall gefunden haben, schlage ich vor, zu diesem bedauerlichen Ereignis nicht Stellung zu nehmen und keine Richtigstellung zu veranlassen. Durch eine solche Stellungnahme würde den Verleumdungen und Entstellungen sowjetzonaler Propaganda nur die gewünschte Publizität gegeben werden. ${ }^{704}$

\section{Homero Reyes Oñate}

Am 3. August 1967 wurde der Chef des Postamts von Parral, Homero Reyes Oñate, in einem Graben tot aufgefunden. ${ }^{705}$ Hugo Manuel Rodríguez Quezada, ein Mitarbeiter des Postamts und 1968 Autor des ersten kritischen Buches über die Colonia, ${ }^{706}$ behauptete daraufhin, Hinweise auf eine Beteiligung von Colonos an dem vermeintlichen Mord zu haben. Rodríguez war Mitglied der Christdemokratischen Partei von Parral und Teil einer Untersuchungskommission zur CD, die diese eingesetzt hatte. Am Vortag des Todes von Reyes hatte Rodríguez der Zeitschrift VEA ein umfangreiches Interview gegeben, in dem er selbst zahlreiche Vorwürfe gegen die CD erhob. ${ }^{707}$ Claudio Fuentes,

PA AA, B 33, Bd. 463, BPA/SBZ-Spiegel vom 20.12.1966: »Warum schweigt das Bonner Außenministerium zur Selbstmordserie?«.

PA AA, Personalakte Winfried Kretzschmar Z 51988, Aufzeichnung Abteilung Z, VLR I Heiperz vom 30.12.1966. 
Gouverneur von Parral, sagte wenige Tage nach dem Tod von Reyes Oñate dem Mercurio, die polizeilichen Ermittlungen hätten keinerlei Hinweise auf eine Verwicklung von Colonos ergeben. ${ }^{708}$ Die Botschaft berichtete dem AA über den Mercurio-Artikel: "Untersuchungen der Polizei haben ergeben, daß die in diesen Tagen gegen die Kolonie >Dignidad vorgebrachte Beschuldigung, sie sei in den unaufgeklaerten Tod des Buerovorstehers des Postamts von Parral verwickelt, unbegruendet sei.« Der Bericht schloss mit den Worten: »Die Vorfälle lassen darauf schließen, daß in gewissen Kreisen gegenüber der Kolonie Reserven bestehen. ${ }^{709}$ Ob der Fall juristisch endgültig aufgeklärt werden konnte, ist mir nicht bekannt.

\section{Alfred Schaak}

Alfred Schaak verstarb am 11. Oktober 1985 im Alter von 59 Jahren in einem Krankenhaus in Bonn-Beuel. ${ }^{710}$ Schaak hatte zu den Ersten gehört, die sich der Gruppierung um Paul Schäfer angeschlossen hatten. In den 1950er Jahren war er einer der Mitbegründer der Privaten Socialen Mission e. V. (PSM) in Siegburg. Während seine Frau und seine sieben Kinder Anfang der 1960er Jahre nach Chile auswanderten, verblieb der Kaufmann in der Bundesrepublik und leitete die Schaak und Kuhn oHG (vgl. Abschnitt 3.2.3). Nach Hugo Baars Ausreise nach Chile 1975 wurde Schaak Vorsitzender der PSM. Er war zuständig für die Kontakte der CD in der Bundesrepublik sowie für die Frachtsendungen an die CD auf dem See- und Luftweg. Schaaks Verbindungen zu Mitarbeiter_innen der DINA, seine Beteiligung am Transport von Waffen und Bestandteilen eines Chemielabors zur späteren Sarin-Gas-Produktion (vgl. Abschnitt 4.2.3) sind vielfältig belegt. Dieter Maier vermutete 2011, ${ }^{711}$ dass Schaak von der CD vergiftet wurde, da er plante auszusteigen, jedoch zu viel wusste. ${ }^{712}$ Am 5. Oktober 1985 soll Schaak zwei Personen aus Chile am Flughafen Frankfurt abgeholt haben. In den darauffolgenden Tagen bekam er hohes Fieber, bevor er knapp eine Woche später im Krankenhaus verstarb. Schnell wurde ein Leichenpass zur Überführung nach Chile beantragt. Hartmut Hopp reiste eigens aus Chile an und überführte die Leiche am 22. Oktober 1985. Einen Tag später traf er mit ihr in der CD ein. ${ }^{713}$ Schaak wurde auf dem CD-Friedhof beigesetzt. Sein Tod war Gegenstand von Ermittlungen der Staatsanwaltschaft Bonn, Ergebnisse dieser Untersuchungen wurden nicht bekannt. ${ }^{714}$ Laut einem Vermerk des damaligen AI-Generalsekretärs Walter Rövekamp ermittele die Kriminalpolizei den Tod Schaaks als »ungeklärte Todesursache«, was sowohl Mord als auch Selbstmord einschließt. ${ }^{715}$ Der Journalist Gero

708 El Mercurio vom 07.08.1967, S. 31: „Superado problema relacionado con la Colonia >Dignidad««.

709 PA AA, B 82, Bd. 991. Bericht Botschaft an AA vom 08.08.1967, AZ V3-85.05-1067/67.

710 HISArch, Bestand CD, Ordner Nr. 4, Leichenpass Alfred Karl Adolf Schaak, verstorben am 11.10.1985, ausgestellt am 17.10.1985 vom Standesamt Bonn III.

711 Heller, Lederhosen, Dutt und Giftgas, S. 91f. und S. 140.

712 Ebd., S. 35.

713 CA Santiago, AZ 2182-98 (»Conferencia«), Bd. 1a, Bl. 96. Aufstellung »Relación de colonos alemanes fallecidos y sepultados en el Cementerio de Villa Baviera, ordenados por su ubicación« o.D.

714 Zum Todesfall Alfred Schaak vgl. Gemballa, Colonia Dignidad. Ein deutsches Lager in Chile, S. 74f.

715 Archiv Al, Bestand CD. Vermerk von Walter Rövekamp vom 23.09.1987, Betr: Anruf von Hr. Matthusen, Kripomann in Brühl und Bruder des Colonia-Dignidad-Funktionärs. 
Gemballa berichtete in der Fernsehsendung "Aktuelle Stunde« des WDR vom 8. Oktober 1987, Schaak habe sich das Leben genommen. Die CD forderte Gemballa im Namen von Schaaks Witwe Eva über ihren RA Gatzweiler auf, diese Äußerung künftig zu unterlassen. In einem Schreiben vom 3. Dezember $1987^{716}$ berichtete Gemballa dem Anwalt der CD, vier Informant_innen hätten ihm gegenüber geäußert, Schaak habe sich ihrer Überzeugung nach das Leben genommen. Da der Freitod Schaaks »zum gegenwärtigen Zeitpunkt nicht zu beweisen « sei, verpflichtete Gemballa sich jedoch dazu, diese Aussage fortan zu unterlassen. ${ }^{717}$ Gegen einen natürlichen Tod Schaaks spricht, dass auch innerhalb der $C D$ verschiedene Erklärungen seines Ablebens verbreitet wurden. So berichtete Gudrun Müller:

»Alfred Schaak wurde angeblich umgebracht, so hat Helmut Seelbach es uns Mitgliedern erzählt, sogar wie es im Einzelnen passiert ist, vom russischen Ceheimdienst, bis in die Einzelheiten wie es passiert sein soll. Ich habe mich damals schon gewundert wie das genaue Wissen zustande gekommen sein kann. ${ }^{718}$

Dieter Maier schrieb 2006 an die Staatsanwaltschaft Bonn:

»Mir gegenüber hat Winfried Schmidtke die von Schäfer verbreitete Version angegeben, ein russischer Lastwagenfahrer habe wohl ein Kontaktgift benutzt, um Schaak umzubringen. «19 $^{719}$

\section{Raúl Berríos Herrera}

Am 14. April 1986 wurde der Marktverkäufer Raúl Berríos Herrera an einer Bushaltestelle in Santiago von einer Kugel des Kalibers 7,65mm in den Kopf getroffen und war sofort tot. Berríos war ein ehemaliger Arbeiter in der CD. ${ }^{720}$ Im Rahmen der Ermittlungen ${ }^{721}$ lud Richter Manuel Rojas Asejo 21 Colonos vor, auf deren Namen 7.65mm-Waffen registriert waren. Dieselben Colonos sollten mit ihren Waffen zu einem weiteren Termin beim Gericht in Bulnes erscheinen. ${ }^{722}$ Am 10. März 1987 kommentierte Botschafter Kullak-Ublick den Fall in einem Bericht ans AA:

»Der Ermittlungsrichter entschied im Rahmen der Untersuchungen auch die 7,5mmPistolen von 21 Angehörigen der Colonia Dignidad zu untersuchen, obwohl Anhaltspunkte für eine mögliche Tatbeteiligung offenbar nicht gegeben waren. CD-Mitglieder wehrten sich auf dem Rechtsweg gegen ballistische Untersuchung. Nach Angaben der chilenischen Presse sollen Carabineros, die mit der Untersuchung beauftragt wurden, drei Mal vom Haupttor der Colonia mit dem Hinweis, daß diese Leute nicht mehr hier

716 HISArch, Bestand CD, Ordner Nr. 4. Schreiben von Gero Gemballa an RA Gatzweiler vom 03.12.1987.

717 Ebd.

718 PJS, Sammlung CD. E-Mail Gudrun Müller an den Verfasser vom 12.02.2007.

719 StA Bonn, AZ 555 ]s 315/06, Bd. 1, Bl. 15. Schreiben von Dieter Maier an StA Bonn vom 06.09.2006.

720 Stern Nr. 50/1987 vom 03.12.1987. »Das Lager des Schreckens«.

721 3. Juzgado del Crímen de San Miguel, AZ 41.711-8.

722 La Segunda vom 09.12.1986, »Asesinato de Comerciante: 21 colonos de Colonia Dignidad declararán en juzgado de Santiago - sin sus armas - con ellas deberán presentarse en tribunal de Bulnes«. Einsehbar in PA AA, AV NA 31577. 
lebten, abgewiesen worden sein. Diese Episode hat erneut in das Bewußtsein gerückt, daß Angehörige der Colonia über Waffen in erheblichen Mengen verfügen. « ${ }^{723}$

\section{Hans-Karl Buss}

Am 19. Dezember 1989 bestieg der Kanzler der deutschen Botschaft in Santiago, HansKarl Buss, den Vulkan Casablanca bei Entrelagos, nahe der argentinischen Grenze. Nach einem etwa anderthalbstündigen Aufstieg trug er sich ins Gipfelbuch ein: "14.10 Uhr. Beste Sicht, Windstille, warm «. ${ }^{724}$ Buss kehrte jedoch nie von dieser Wanderung zurück. Gegen 21 Uhr am selben Tag kontaktierte seine Frau die Polizei. Eine tagelange Suchaktion, auch mit Hubschraubern, verlief erfolglos. Buss' Leiche wurde nie gefunden. Da die Besteigung des Casablanca als relativ einfach und ungefährlich gilt und das Terrain übersichtlich ist, spekulierte die Presse über ein mögliches Verbrechen. Dazu berichtete Botschafter Pabsch ans AA:

»Für ein Verschwinden durch Fremdeinwirkung (Entführung, Mord) fehlen jegliche Hinweise. Alle anderen möglichen Erklärungen (bis hin zu der von einem deutschen Journalisten verbreiteten These von der >Gefangennahme als Faustpfand c durch Angehörige der `Colonia Dignidad`) sind nach Überzeugung der Botschaft rein spekulativ und entbehren jeglicher Anhaltspunkte. [...] Unter diesen Umständen muß ich davon ausgehen, daß Herr Buss sich bei seiner Wanderung verirrt und mangels rechtzeitiger Rettung den Tod gefunden hat. $\ll^{725}$

Auch nach dem Untertauchen Schäfers 1997 gab es im Zuge der intensiven medialen Berichterstattung über die Verbrechen der CD zahlreiche Spekulationen über (vermeintlich) mysteriöse Todesfälle im Kontext der CD.

\section{Gero Gemballa}

Der Journalist Gero Gemballa, Autor zweier Bücher sowie zahlreicher Zeitschriftenartikel und Fernsehbeiträge zur CD, verstarb am 22. Februar 2002 in Stavelot (Belgien) im Alter von nur 40 Jahren. Offizielle Todesursache war ein Herzinfarkt. Klaus Schnellenkamp sagte aus, das CD-Führungsmitglied Hans-Jürgen Blanck habe Gemballas Tod mit folgenden Worten kommentiert: „[D]er Engel des Herrn hat ihn geschlagen, weil er sich an der Brautgemeinde Christi vergriffen hat. ${ }^{726}$ Gemballas früher Tod rief Spekulationen hervor, etwa über eine mögliche Ermordung durch Sarin-Gas. ${ }^{727}$ Belege gab es hierfür nicht.

Zusammenfassend kann zu den hier dargestellten ungeklärten Todesfällen gesagt werden, dass zumindest bei den meisten Fällen aus heutiger Sicht unwahrscheinlich ist, dass diese von der CD herbeigeführt oder beeinflusst wurden. Es scheint plausibler,

StA Bonn, AZ 50 ]s 285/85, Bd. IV, BI. 36ff. Bericht Botschafter Kullak-Ublick an AA (330) vom 10.03.1987, Betr: CD hier: Missglückter Konsularsprechtag am 18.02.1987.

PA AA, AV NA 33695. PVA Hans-Karl Buss 1987-1991. Der Zettel aus dem Gipfelbuch befindet sich in Buss' Personalakte.

725 PA AA, AV NA 33695. Botschaftsbericht vom 09.04.90, VW 110 SP WP/rcb, »Verschollenheit des Kzl. I KI. Hans-Karl Buss«.

726 Schnellenkamp, Geboren im Schatten der Angst, S. 236.

727 Burghardt, Peter, »Cebunkerte Ceheimnisse«, in: Süddeutsche Zeitung vom 05.02.2008, S. 8. 
dass die Macht der CD und ihr jahrzehntelanges strafloses kriminelles Wirken schnell Anlass für Spekulationen bot. Eine weitergehende Untersuchung der genannten Fälle dürfte mit hoher Wahrscheinlichkeit viele dieser Spekulationen entkräften und damit nicht nur zu einer Aufklärung, sondern auch zu einer Entmythologisierung der CD beitragen. Lediglich im Fall des plötzlichen Ablebens des langjährigen Vertreters der CD in der Bundesrepublik, Alfred Schaak, gibt es eine Reihe von Indizien und Ungereimtheiten, die einen gewaltsamen Tod zumindest möglich erscheinen lassen. 



\section{Die juristische und parlamentarische Aufarbeitung der Verbrechen der Colonia Dignidad}

Nachdem im letzten Kapitel die Verbrechen der CD systematisch dargelegt wurden, soll im Folgenden beschrieben und analysiert werden, wie Justiz und Parlamente in Chile und der Bundesrepublik diese Verbrechen bearbeitet haben.

Ein Großteil der Verbrechen der CD wurde von deutschen Staatsangehörigen auf chilenischem Staatsgebiet verübt und richtete sich gegen chilenische ebenso wie gegen deutsche Staatsangehörige. Aufgrund dieses grundsätzlich bistaatlichen Charakters dieser Taten stellt sich die Frage, wer für ihre strafrechtliche Verfolgung zuständig ist. Nach dem Territorialitätsprinzip war und ist die chilenische Justiz für die Untersuchung und Ahndung sämtlicher Verbrechen der CD zuständig, die auf chilenischem Staatsgebiet begangen wurden. Nach dem sogenannten Personalitätsprinzip kann bei Verbrechen, die von deutschen Staatsangehörigen oder gegen deutsche Staatsangehörige begangen wurden, jedoch das deutsche Strafrecht nach $\$ \$ 5$ und 7 StGB auch auf Taten im Ausland angewandt werden. Theoretisch haben wir es also bei vielen Verbrechen mit einer doppelten Zuständigkeit der chilenischen und der bundesdeutschen Strafverfolgungsbehörden zu tun. In der Praxis hat die Frage der Zuständigkeit den Fall CD in all seinen Phasen begleitet. Eine Kooperation zwischen den Justizapparaten beider Länder war durch das Fehlen eines Rechtshilfeabkommens erschwert. Die Folge waren langwierige und bürokratische Rechtshilfeersuchen in beide Richtungen. Diese brachten nur selten Fortschritte, führten jedoch oftmals zu einem jahrelangen Stillstand der Ermittlungen. Unterschiedliche Rechtskulturen führten zudem dazu, dass beide Seiten sich regelmäßig über die vermeintliche Untätigkeit der jeweils anderen Seite beschwerten. Auch Auseinandersetzungen über Formalia, etwa über die von Übersetzungen, zogen die Verfahren in die Länge.

Hinzu kamen auf beiden Seiten wechselnde politische Interessen und Allianzen. So war etwa in Chile zwischen 1973 und 1990 aufgrund der engen Zusammenarbeit zwischen der Militärdiktatur und der CD-Führung eine ernstzunehmende Untersuchung und Ahndung der Verbrechen kaum möglich. Pinochet hielt seine schützende Hand über die CD, wie u.a. der Bericht von einem Gespräch mit Diktator Pinochet von 1987 zeigt: 
»Das etwa einstündige Gespräch, das im wesentlichen zwischen Prof. Bossle und Pinochet geführt wurde, drehte sich um politische Fragen [...], aber auch um die Gefahr, daß die menschenrechtswidrigen Zustände in der Colonia Dignidad eine neue Kampagne gegen Chile auslösen könnten. Hierzu vertrat Pinochet die Ansicht, daß Menschenrechtsverletzungen in der Colonia Dignidad nicht erwiesen seien und daß es im übrigen Sache deutscher Cerichte wäre, die Täter zur Verantwortung zu ziehen.« ${ }^{1}$

Während in Chile die politischen Rahmenbedingungen die Möglichkeiten der juristischen Aufarbeitung bestimmten, zogen sich viele Stellen in der Bundesrepublik auf die Position zurück, dass in erster Linie Chile zuständig sei. So teilte die Bundesregierung noch 2016 in der Antwort auf eine schriftliche Frage mit: »Die Bundesregierung ist der Auffassung, dass der Schutz der Menschenrechte auf chilenischem Territorium vorrangig den dort zuständigen Stellen obliegt. $\ll^{2}$

Die CD betrieb von Anfang an einen großen Aufwand, um ihre Verbrechen zu verschleiern und deren strafrechtliche Aufklärung und Ahndung zu behindern. Dabei war sie äußerst erfolgreich. Eine große Anzahl von Rechtsanwält_innen überzog Kritiker_innen der CD systematisch mit Verleumdungsklagen. Bei Ermittlungen gegen Tatverdächtige aus der CD nutzten deren Rechtsanwält_innen mit hohem Einsatz sämtliche verfügbaren Rechtmittel, in der Regel durch alle möglichen Instanzen. Während die potenzielle Doppelzuständigkeit und die Bilateralität die Ermittlungen für die Justizbehörden eher behinderten, wusste die CD diesen Umstand zu ihrem Vorteil zu nutzen. Die mit rechtlichen Fragen befassten CD-Führungsmitglieder ${ }^{3}$ brachten beispielsweise Schriftstücke und andere Beweismittel aus Verfahren im jeweils anderen Land ein. Mehrfach kam es zu diplomatischen Verstimmungen, weil etwa Rechtsbeistände der CD in Chile aus vertraulichen Berichten des AA zitierten, die Bestandteil eines Ermittlungsverfahrens in der Bundesrepublik waren und im Rahmen der dortigen Akteneinsicht in die Hände der CD-Anwält_innen gelangt waren. ${ }^{4}$ Die juristische Strategie der CD beinhaltete auch die gezielte Lobbyarbeit bei Richter_innen und Justizmitarbeiter_innen. Ein prägnantes Beispiel hierfür ist ein Gesprächsvermerk des damaligen bundesdeutschen Botschafters Salat von 1968:

»Am 4. März erhielt ich unangemeldet den Besuch des Mitglieds des Höchsten Gerichtshofs (Ministro de la Corte Suprema) Don Ramiro Méndez Brañas. Er kam, um mir eingehend seine positiven Eindrücke von der Kolonie Dignidad zu schildern, die er deshalb gut kenne, weil er in der Nähe ein Fundo besitze und öfters Celegenheit gehabt habe, die Verdienste der Kolonie um die Entwicklung der Landwirtschaft festzustellen und die führenden Mitglieder der Kolonie zu besuchen.

PJK. Bericht Ludwig Martin über Chilereise 20-29.10.1987. Das von Ceneralbundesanwalt a. D. Ludwig Martin protokollierte Gespräch fand gemeinsam mit Lothar Bossle, einem Würzburger Soziologieprofessor und Vertrauten von Franz-Josef Strauß statt.

2 Deutscher Bundestag. Drucksache 18/8127 vom 15.04.2016. Schriftliche Fragen mit den in der Woche vom 11. April 2016 eingegangenen Antworten der Bundesregierung, S. 11f. Antwort von StM Maria Böhmer (AA) auf eine Frage des Abgeordneten Hans-Christian Ströbele (Crüne). 
Wenn Herr Méndez auch zugab, daß die Lebensformen der Kolonie jedenfalls für chilenische Auffassungen etwas ungewohnt seien, äußerte er doch die Meinung, die Opposition gegen die Kolonie sei zum großen Teil von einigen Gegnern organisiert, wobei wohl auch die Eifersucht mit eine Rolle spiele. [...] [Er] bat darum, den Inhalt unseres Gesprächs vertraulich zu behandeln. $\ll^{5}$

Da die Justizbehörden jahrzehntelang nur äußerst eingeschränkten Zugang zur CD hatten, konnte sie viele Verbrechen wegen Verjährung, verstorbener Täter_innen, vernichteter Beweismittel oder anderer Arten von Verschleierung (dazu gehört auch die gezielte "Auslöschung«, also Zerstörung von Erinnerungen von Colonos durch Elektroschocks) nicht untersuchen. Daneben war die Verfolgung der Verbrechen häufig dadurch besonders beschwert, dass die Opfer unter den Colonos die Täter_innen nicht anzeigten. Einerseits waren sie aufgrund der permanenten Freiheitsberaubung meist gar nicht in der Lage, sich unbeaufsichtigt an die Justiz zu wenden, andererseits wurden sie systematisch bedroht und eingeschüchtert, so dass sie für den Fall, dass ihr »Verrat« bekannt würde, brutale Strafen befürchteten. Aufgrund der Atmosphäre des Misstrauens und der gegenseitigen Bespitzelung konnten sich Opfer auch niemandem innerhalb der CD anvertrauen. Paul Schäfers Einfluss und Ausstrahlung waren so stark, dass es für viele Colonos zudem völlig undenkbar war, an der Richtigkeit seines Handelns zu zweifeln. Die CD-Führung verstärkte dieses mangelnde Unrechtsbewusstsein durch gezielte Manipulation und den selektiven Zugang zu Informationen. Da beispielsweise viele Kinder und Jugendliche in der CD keinerlei Informationen über die menschliche Sexualität hatten, konnten sie den an ihnen begangenen sexuellen Missbrauch gar nicht als solchen begreifen.

In der Bundesrepublik hat trotz jahrzehntelanger Ermittlungen niemals eine Staatsanwaltschaft Anklage gegen Täter_innen der CD beantragt. Ein Großteil der beschriebenen Taten sind inzwischen verjährt, lediglich Mord verjährt nach bundesdeutschem Recht nicht. Eine Verfolgung als Verbrechen gegen die Menschheit die ebenfalls nicht verjähren - ist hierzulande nur für Taten nach dem 1. Juli 2002 möglich. ${ }^{6}$

In Chile hat die Justiz insbesondere nach Schäfers Festnahme 2005, die Verbrechen der CD in einer Reihe von Strafverfahren, etwa aus dem Kontext der Militärdiktatur, als Verbrechen gegen die Menschheit eingestuft. Diese verjähren in Chile nicht. Einige dieser Verfahren endeten mit rechtskräftigen Verurteilungen. Diese Urteile decken ein breites Spektrum krimineller Handlungen ab, die Straftatbestände sind u.a. Mord, Entführung und Folter, schwere Körperverletzung, sexueller Missbrauch, Verstoß gegen das Waffengesetz und Bildung einer kriminellen Vereinigung. Die entsprechenden Urteile sind offen zugänglich, ${ }^{7}$ die jeweiligen Verfahrensakten sind - mit einigen Einschränkungen - für Forscher_innen in den zuständigen Gerichtsarchiven einsehbar. Aufgrund der Verurteilungen gibt es einen nachvollziehbaren juristischen Wissensstand. Die Vielschichtigkeit und Systematik der von der CD begangenen Verbre- 
chen wurde vielfach gerichtlich festgestellt, ohne dass allerdings die Mehrzahl der Einzeltaten bisher auch geahndet wurde. $\mathrm{Zu}$ vielen Einzelverbrechen existiert eine Reihe von Quellen unterschiedlicher Provenienz und Qualität. Deren Bewertung macht einen sorgfältigen Abgleich und eine fundierte Analyse erforderlich. So werden manche Taten in Akten zu anderen Untersuchungsgegenständen erwähnt, dann jedoch aus unterschiedlichen Gründen nicht weiterverfolgt, z.B. wegen Verjährung. Andere Taten wiederum wurden weder von Betroffenen angezeigt noch von Amts wegen verfolgt.

Im Folgenden betrachte ich, wie sich die chilenische Justiz mit den CD-Verbrechen auseinandergesetzt hat. Abschnitt 5.2. beschreibt und analysiert die Befassung des chilenischen Parlaments mit dem Fall CD. Die Abschnitte 5.3 und 5.4 widmen sich dem Umgang der bundesdeutschen Justiz und des Deutschen Bundestags mit den CD-Verbrechen.

\subsection{Juristische Aufarbeitung der Verbrechen in Chile}

Die chilenische Justiz ist seit Wolfgang Müllers (heute Kneeses) Flucht aus der CD 1966 bis zum heutigen Tage mit dem Fall CD befasst. Der CD-Führung wurde schnell klar, dass es für das System CD überlebenswichtig war, sich auf der juristischen Ebene durchzusetzen. Dabei verfolgte sie von Anfang an eine offensive Strategie. Sie beauftragte renommierte Rechtsanwält_innen und betrieb intensive Lobbyarbeit bei lokalen, regionalen und nationalen Gerichten. Rechtsanwalt Sergio Corvalán, der Amnesty International und die Botschaft in diversen CD-Verfahren vertrat, beschrieb in einem Rechtsgutachten 1991, dass der Einfluss der CD bis zum Obersten Gerichtshof und zur Spitze der Diktatur reichte:

»Colonia Dignidad, desde sus orígenes - en especial debido a la comprometida situación procesal y de residencia de Paul Schäfer que llegó a Chile huyendo y con una orden de detención y búsqueda pendiente - dio una gran importancia a la contratacion de una eficiente asesoría legal y al desarrollo de relaciones amistosas y de abierto compromiso con los jueces de la zona de Parral. Con el transcurso de los años estas relaciones alcanzaron a Ministros de la Corte de Apelaciones de Chillán y finalmente también con Ministros de la Corte Suprema. Esta influencia de la CD sobre jueces y funcionarios chilenos, ejercida a través de personeros e interpósitas personas que actúan para ella, se consolidó definitivamente durante el reciente gobierno militar, a través del cultivo logrado de relaciones con el propio general Pinochet, con su esposa Lucia Hiriart de Pinochet y el Ministro de Justicia señor Rosende. ${ }^{8}$

Die juristische Strategie der CD hatte das Ziel, eine Aufklärung der Taten sowie ihrer Hintergründe im Rahmen strafrechtlicher Ermittlungen zu verhindern. $\mathrm{Zu}$ diesem Zwecke wurden auch aufklärerische Akteur_innen eingeschüchtert. Dazu stellte sie Strafanzeigen und reichte Verleumdungsklagen, die auf falschen Beschuldigungen

8 PA AA, AV NA 31604. Bericht vom RA der deutschen Botschaft, Sergio Corvalán, vom 21.03.1991, CZ CD 91/137. »Informe sobre el estado de la tramitación judicial de los recursos interpuestos para impugnar el decreto de cancelacion de la personalidad juridica de la SBED«. 
beruhten, sowie Schutzanträge für Colonos ein. Dabei betonte die CD stets, sich lediglich gegen falsche Anschuldigungen oder ungerechtfertigte behördliche Maßnahmen zu verteidigen. Die CD legte in allen Verfahren sämtliche ihr zur Verfügung stehenden Rechtsmittel ein und betrieb Rechtsstreitigkeiten grundsätzlich durch alle verfügbaren Instanzen. Der sozialistische Abgeordnete Jaime Naranjo bezeichnete dieses Vorgehen 2003 als Guerilla-Krieg in den Gerichten: »la ex Colonia Dignidad ha desarrollado una estrategia, denominada sguerra de guerrillas dentro de los tribunales $\triangleleft$, consistente en llenar a éstos de recursos, uno tras otro. Y no hay celo ni acción. «9 Ein Vertreter des Staatsverteidigungsrates (CDE), der in den 1990er und 2000er Jahren an zahlreichen CD-Verfahren beteiligt war, formulierte es 1995 diplomatischer aus, zog aber in der Sache ebenso das Resümee, die Vielzahl der von der CD eingelegten Rechtsmittel habe die Herbeiführung von Gerechtigkeit beeinträchtigt: "La multiplicidad de juicios ante diferentes Tribunales y la cantidad de recursos interpuestos por los abogados de la ex Colonia Dignidad, ha afectado la expedición de la justicia. «10

Chilenische Medien kommentierten die Einflussnahme der CD auf die chilenische Justiz bereits in den 1960er Jahren. Auch vielen aufklärerischen Akteur_innen war die Nähe der CD zu einigen Richter_innen bekannt. Heinz Kuhn äußerte beispielsweise 1993, die langjährige Richterin am Gericht in Parral, Lydia Villagrán, habe Paul Schäfer und die CD immer geschützt: "Quiero pedir en este careo que S.S. no me cite por el Tribunal de los Ángeles, por cuanto la Juez Lydia Villagrán que estaba en Parral fue designada a Los Ángeles y es amiga de Paul Schäfer y su grupo y protegió siempre a CD. «1

Die CD-Führung war sich ihres Einflusses bewusst. Bei einer Vernehmung 2006 beschrieb Gerd Seewald, wie die guten Kontakte der CD ins Justizministerium während der Diktatur einer juristischen Aufklärung entgegengewirkt hatten:

»Amnesty quiso hacer una inspección ocular en la Colonia y enviar jueces alemanes, por lo que el tema se trató en un nivel superior, se conversó con el señor Ricardo Navarro Beltrán, funcionario de la Ministra señorita Mónica Madaríaga, quien estaba informada de esto.

En algún momento quisimos hacer una reforma de estatutos, y en una oportunidad que me encontré con doña Mónica Madariaga, Ministro de Justicia en ese entonces, me parece que conversé con ella acerca del tema, pero en definitiva no se concretó dicha reforma. ${ }^{12}$

Senado, Diario de Sesiones, Legislatura $348^{a}$, Sesión $41^{\text {a }}$ vom 16.04.2003. Evaluación de estado actual de ex Colonia Dignidad (observaciones del señor Naranjo). Beobachtungen des Senators Naranjo über den Zustand der CD, S. 47-54.

10 Cámara de Diputados, Diarios de Sesiones, Legislatura 332, Sesión 33a, 06.12.1995a en miércoles 6 de diciembre de 1995, Informe de la Comisión Especial Investigadora de la Cancelación de la Personalidad Jurídica de Colonia Dignidad, creada con el objeto de verificar la forma como se dió cumplimiento al decreto supremo que disolvió esa institución, online unter: https://www.camara. cl/camara/media/docs/colonia/01.pdf, S. 61(zuletzt abgerufen am 12.02.2018).

11 PA AA, B 130, Bd. 14503. Careo (Gegenüberstellung) Wolf von Arnswaldt con Heinz Kuhn Fenster y otros vom 26.02.1993.

12 CA Santiago, AZ 2182-98 (»Asociación Ilicitá«), Bd. I, BI. 550. Richterliche Vernehmung von Gerd Seewald vom 06.04.2006. 
Unter dem im Jahr 2000 in der CD sichergestellten Aktenmaterial befinden sich auch eine Reihe vertraulicher Dokumente der chilenischen Justiz. An diese muss die CD über die genannten Kontakte gelangt sein. Für die juristische Strategie der CD dürften sie von großem Wert gewesen sein. Die Ermittler_innen vermuteten, dass diese Dokumente über das Justizministerium an die CD gelangt sein könnten:

»[S]e establece en definitiva, la fuga de información desde el Ministerio de Justicia hacia la Colonia a través del señor »NAVARRO«, el que podría tratarse de don Ricardo Navarro Beltrán, quien [...] ocupaba el cargo de Jefe del gabinete del Subsecretario de Justicia a la fecha, ya que no existe justificación para que los documentos [...] hayan llegado a su poder, sin ser sus destinatarios. ${ }^{13}$

Tabelle 10 enthält eine Zusammenstellung aller mir bekannten Verfahren bei der chilenischen Justiz, die sich mit dem Fall CD befassen oder befasst haben. Da es sehr viele Verfahren gab und diese an keiner Stelle systematisch erfasst wurden, ist es sehr wahrscheinlich, dass noch weitere Verfahren existierten. Der erste Teil der Tabelle führt strafrechtliche Untersuchungen und zivilrechtliche Auseinandersetzungen auf. Der zweite Teil nennt Schutzanträge (recursos de protección und recursos de amparo), spezielle in der chilenischen Verfassung verankerte Rechtsmittel. Sowohl die CD als auch Aufklärer_innen machten vielfach von diesem Rechtsinstrument Gebrauch. Im Anschluss an die Tabelle beschreibe ich die wichtigsten Untersuchungskomplexe der chilenischen Justiz seit 1966.

13 CA Santiago, AZ 2182-98 (»Asociación Ilícita«), Bd. I (Parral), BI. 463ff, hier Bl. 501. PDI Prefectura Regional Talca. Polizeibericht 02/00510/vom 08.01.2001. 


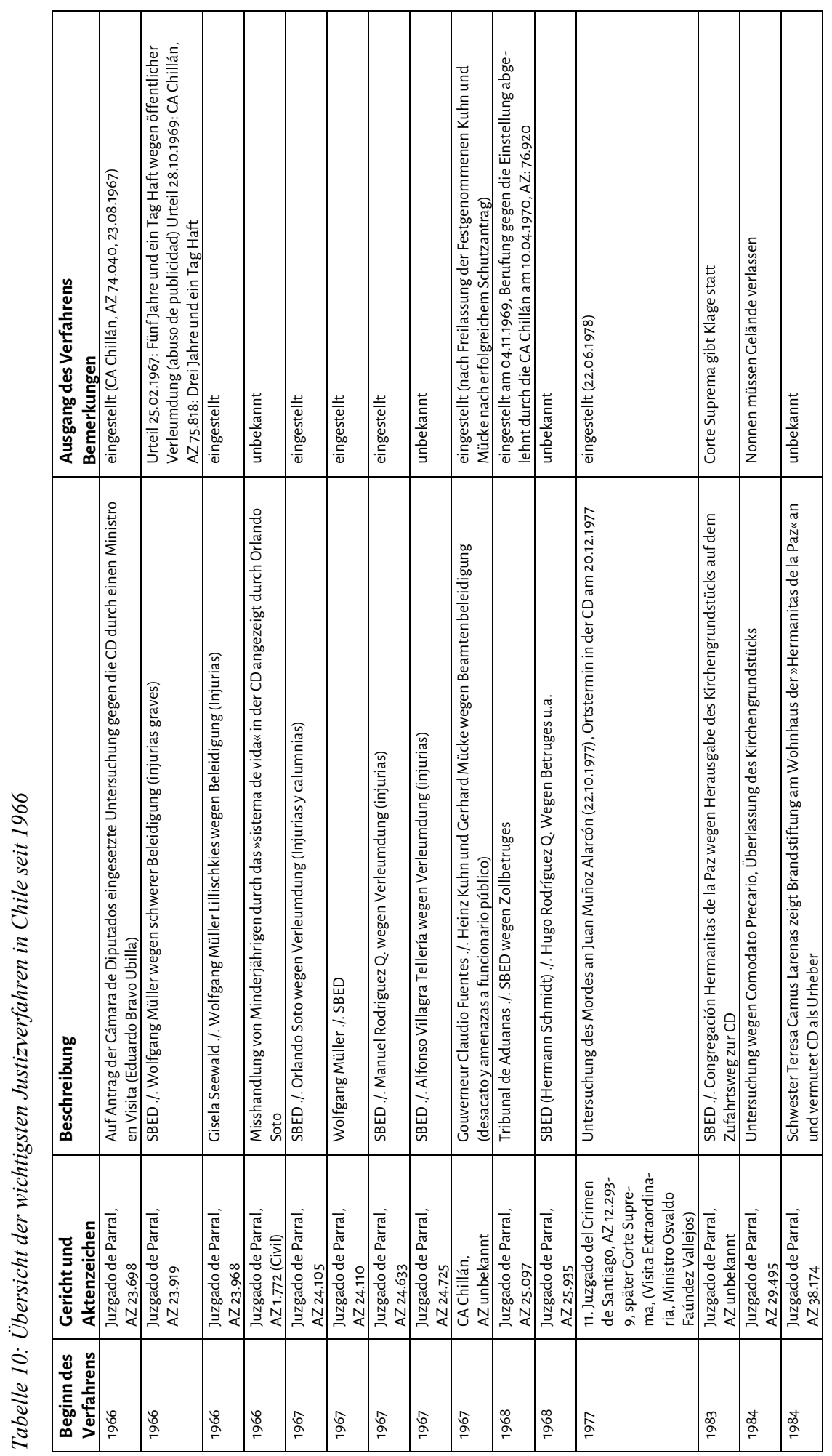




\begin{tabular}{|c|c|c|c|c|c|c|c|c|c|c|c|c|c|c|c|}
\hline 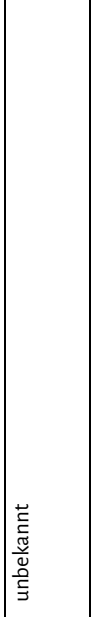 & 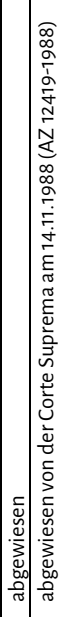 & 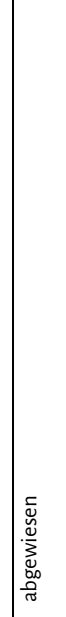 & 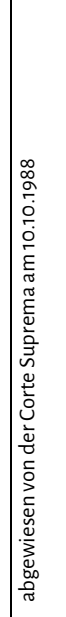 & 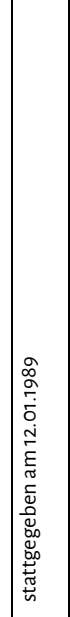 & 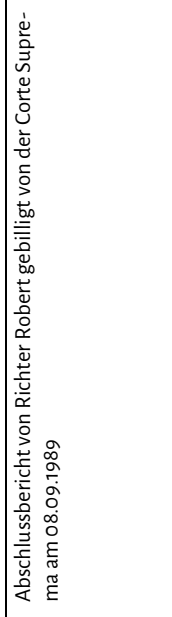 & 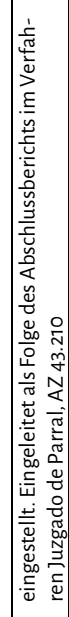 & 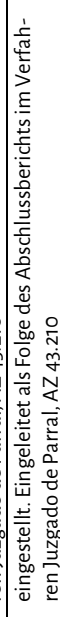 & 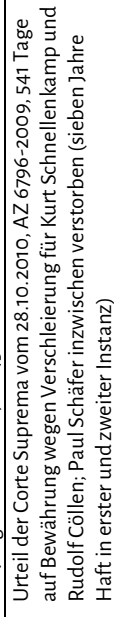 & 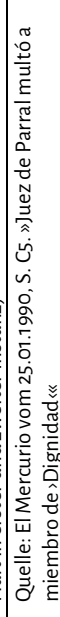 & & & & 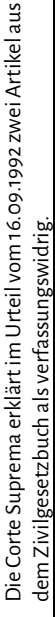 & 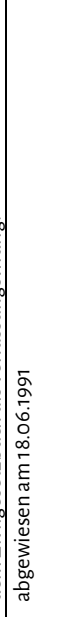 & 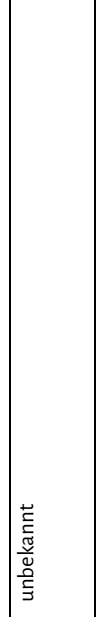 \\
\hline 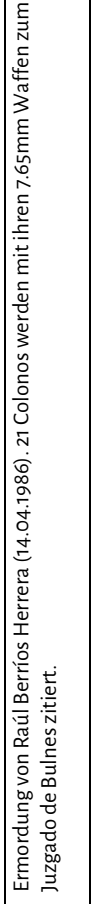 & 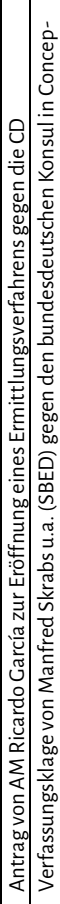 & 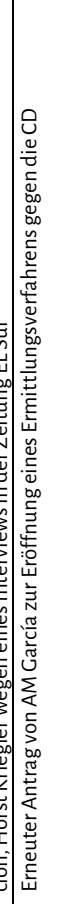 & 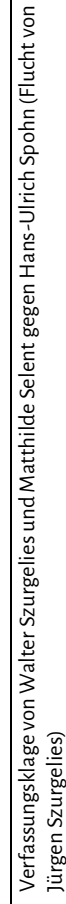 & 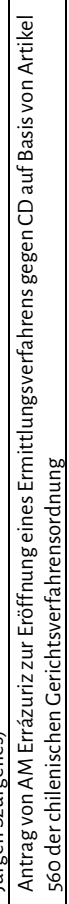 & 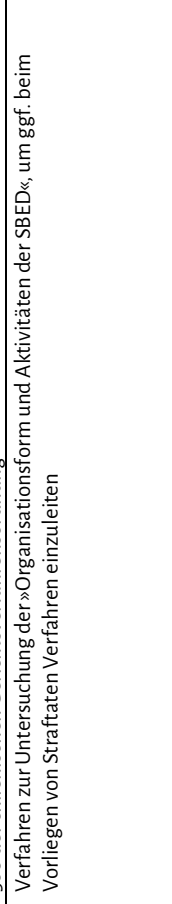 & 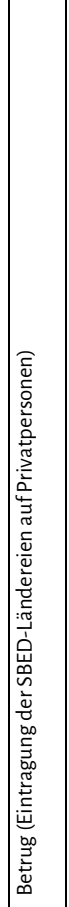 & 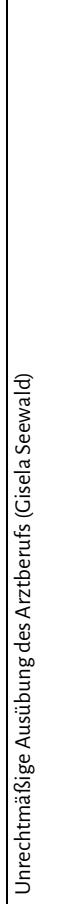 & 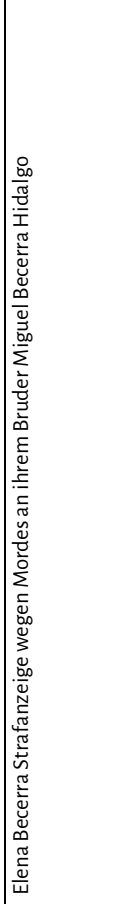 & 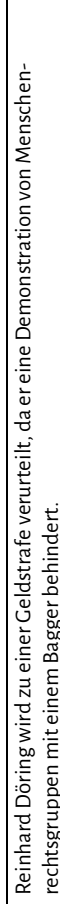 & | & 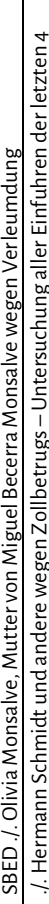 & 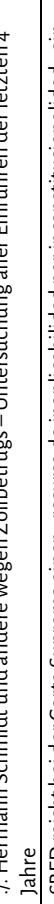 & 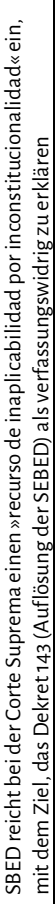 & 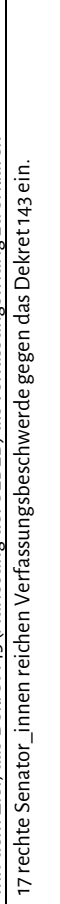 & 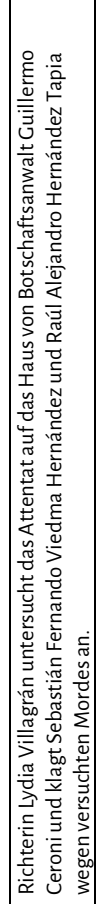 \\
\hline 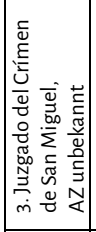 & 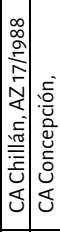 & 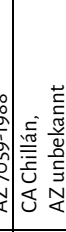 & $\hat{n}$ & 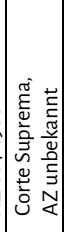 & 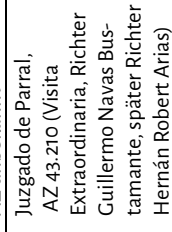 & 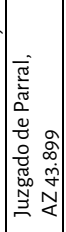 & 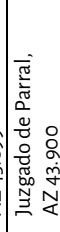 & 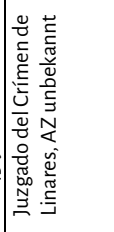 & 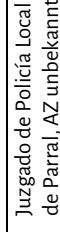 & 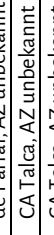 & & 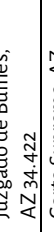 & 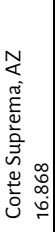 & 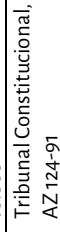 & 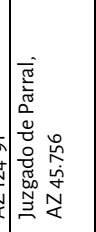 \\
\hline 怘 & 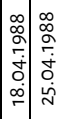 & 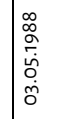 & 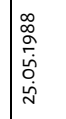 & 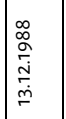 & $\underset{\circ}{\infty}$ & 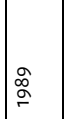 & $\stackrel{\infty}{\circ}$ & $\stackrel{\infty}{\circ}$ & \begin{tabular}{|l}
$\alpha$ \\
$\sigma$ \\
$\sigma$ \\
$\bar{\sigma}$ \\
$\alpha$ \\
$\sigma$ \\
$\sigma$
\end{tabular} & & & & & 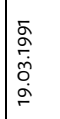 & ફे \\
\hline
\end{tabular}




\begin{tabular}{|c|c|c|c|c|c|c|c|}
\hline & 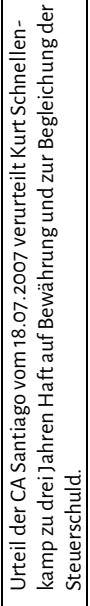 & & & 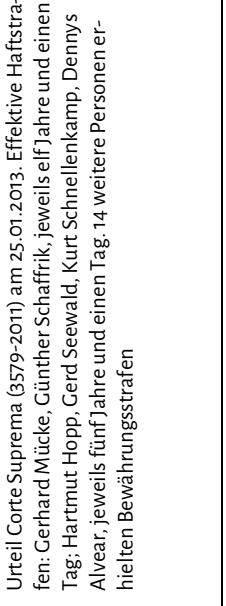 & 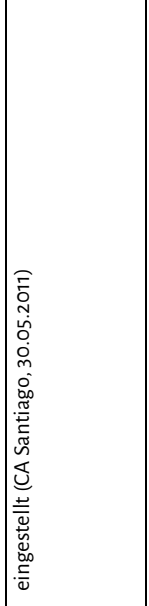 & 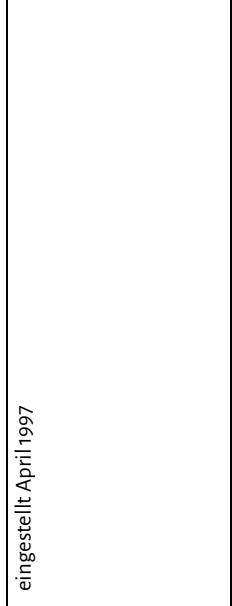 & 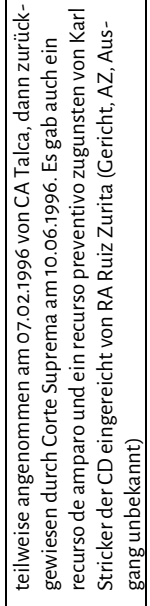 \\
\hline 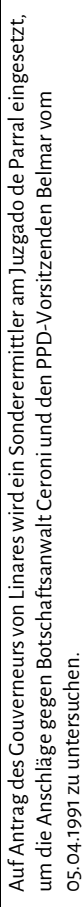 & 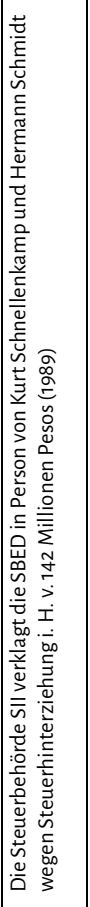 & & 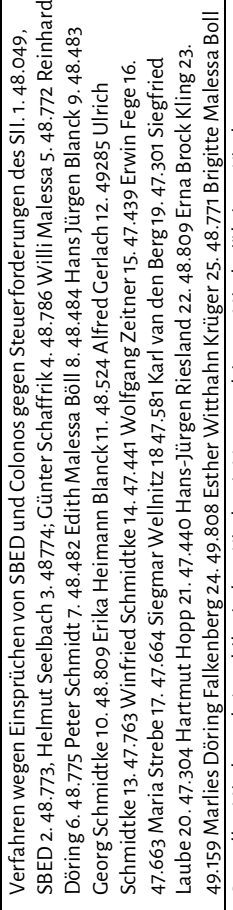 & 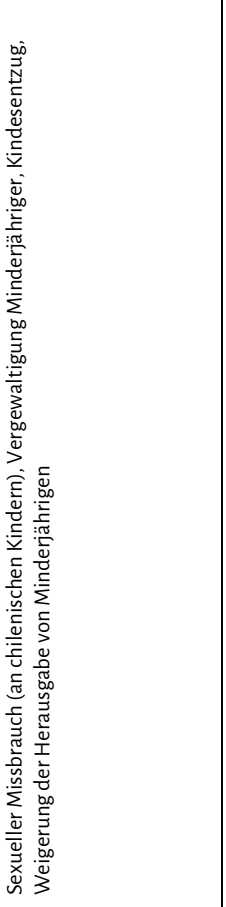 & 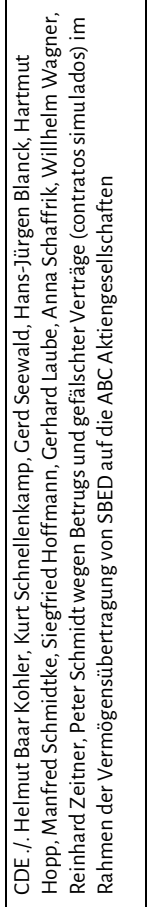 & 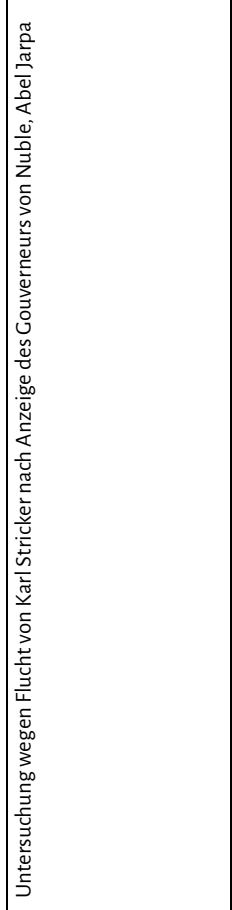 & 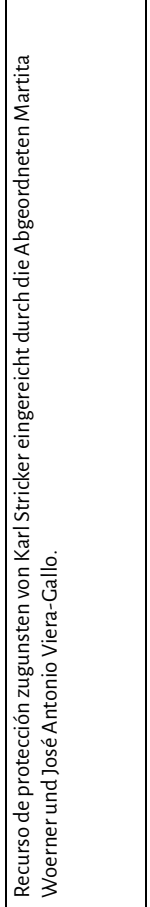 \\
\hline 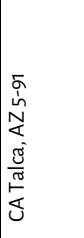 & 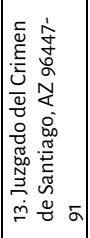 & & 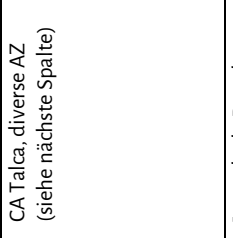 & 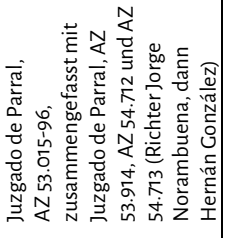 & 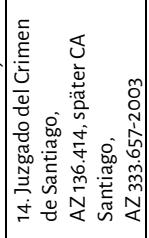 & 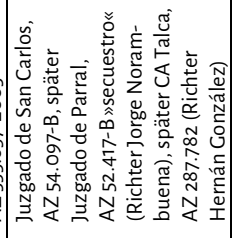 & 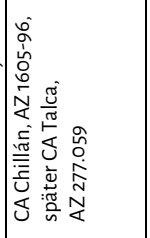 \\
\hline $\begin{array}{l}\tilde{\delta} \\
\sigma \\
\dot{j} \\
0\end{array}$ & 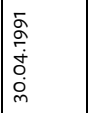 & & $\begin{array}{l}\bar{\lambda} \\
\alpha \\
\alpha\end{array}$ & बू & ๙ু & 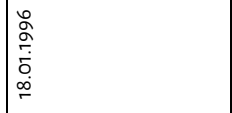 & $\begin{array}{l}\alpha \\
\alpha \\
\sigma \\
\sigma \\
\sigma \\
\sigma\end{array}$ \\
\hline
\end{tabular}




\begin{tabular}{|c|c|c|c|c|c|c|c|c|}
\hline & 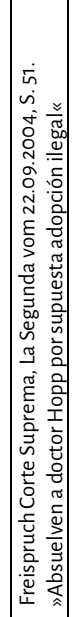 & 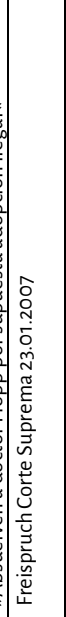 & 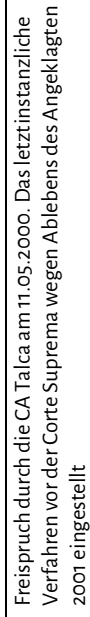 & 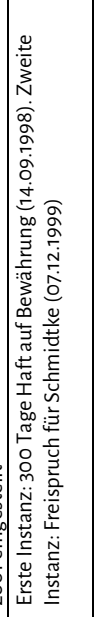 & 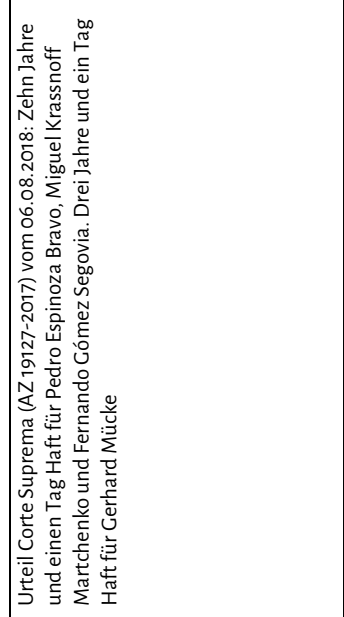 & 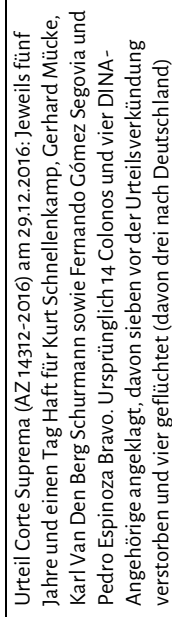 & 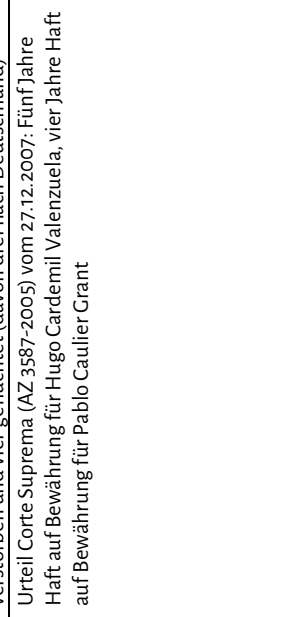 & 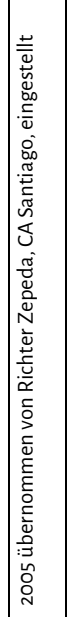 \\
\hline 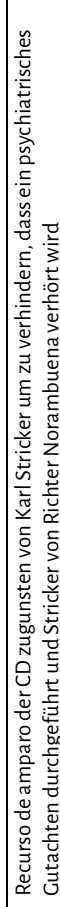 & 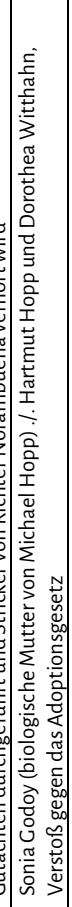 & 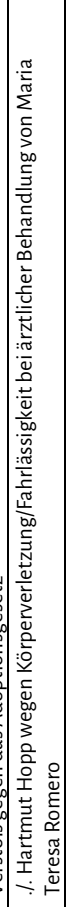 & 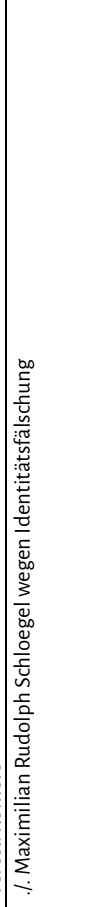 & 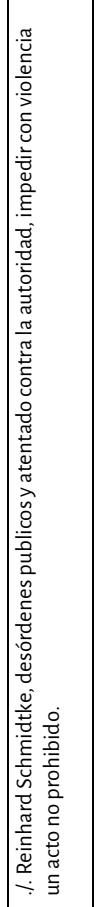 & 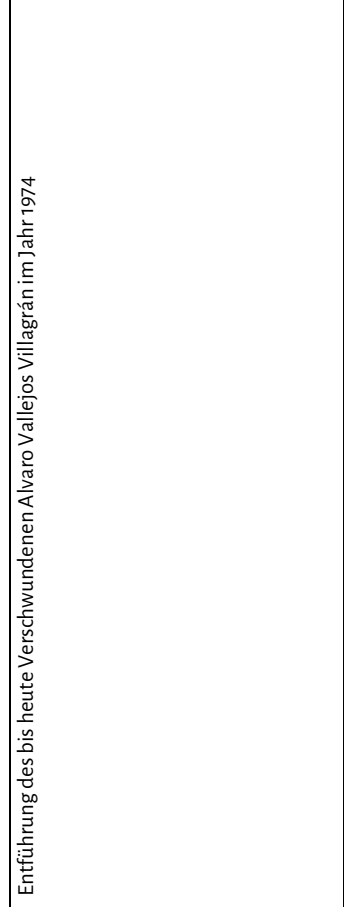 & 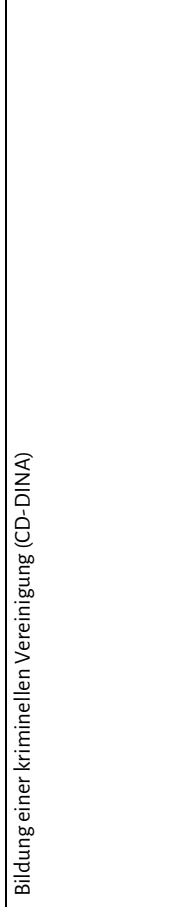 & 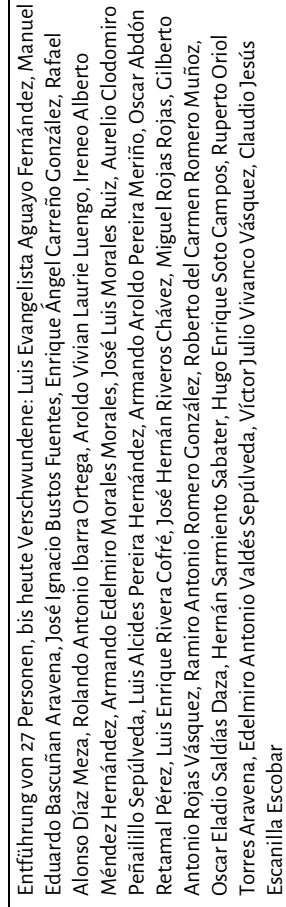 & 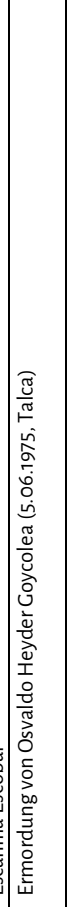 \\
\hline 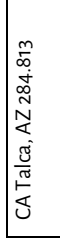 & 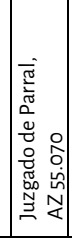 & 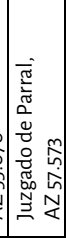 & 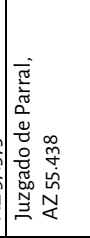 & 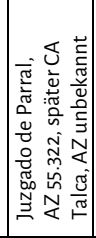 & 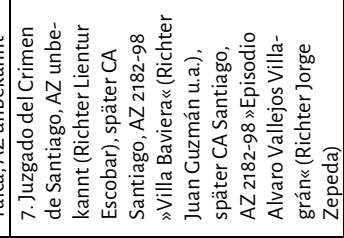 & 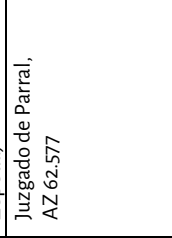 & 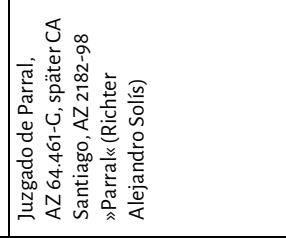 & 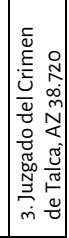 \\
\hline $\begin{array}{l}0 \\
0 \\
0 \\
0 \\
0\end{array}$ & 合 & | & 命 & مू & $\begin{array}{l}\infty \\
\alpha \\
\sigma \\
\tilde{\sigma} \\
\tilde{j} \\
\end{array}$ & 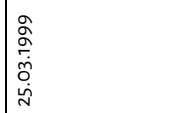 & | & 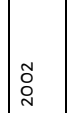 \\
\hline
\end{tabular}




\begin{tabular}{|c|c|c|c|c|c|c|c|c|c|c|c|}
\hline 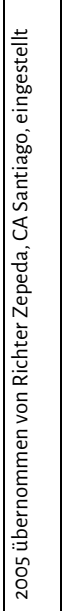 & 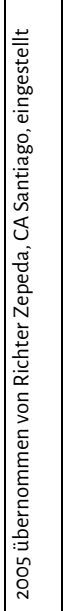 & 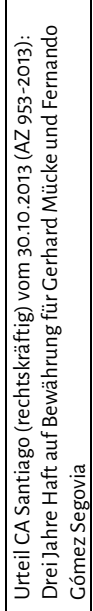 & 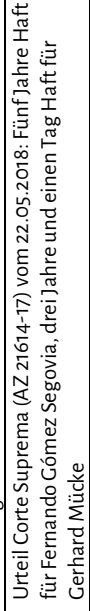 & 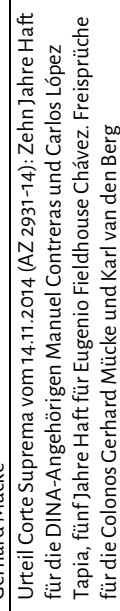 & 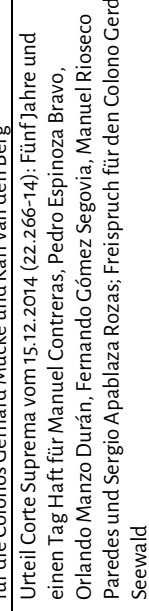 & 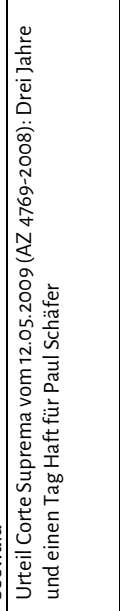 & 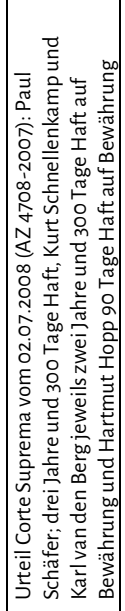 & 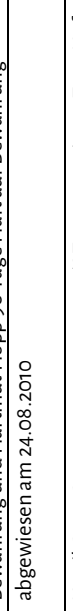 & 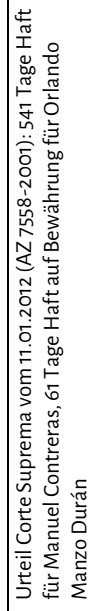 & 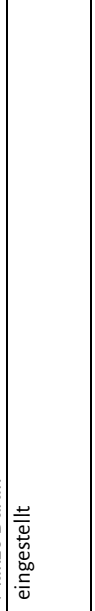 & 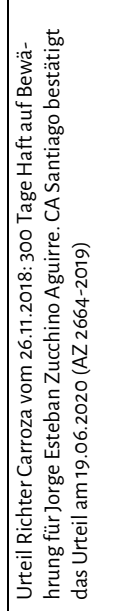 \\
\hline 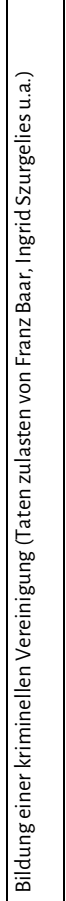 & 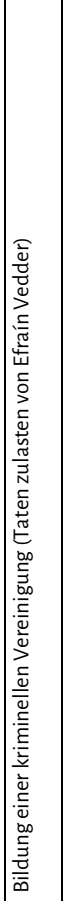 & 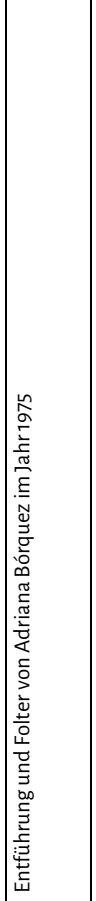 & 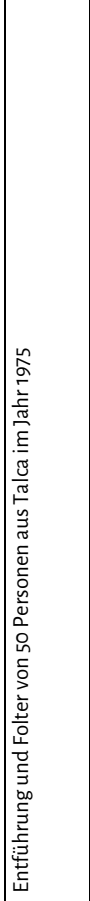 & 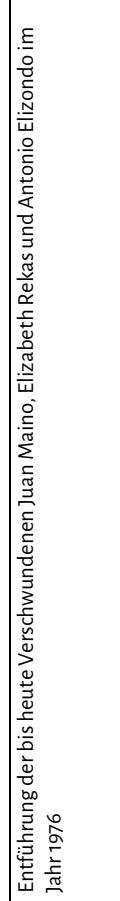 & 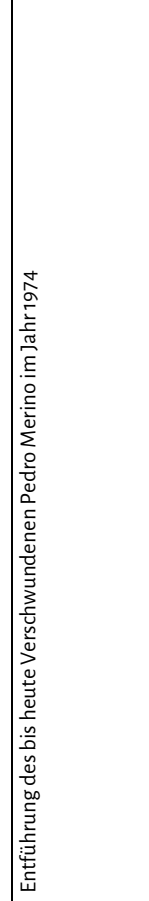 & 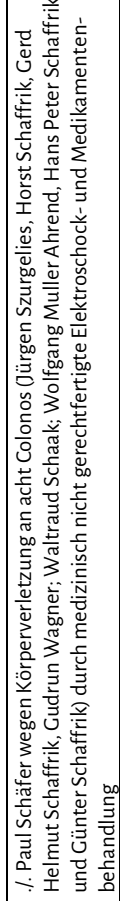 & 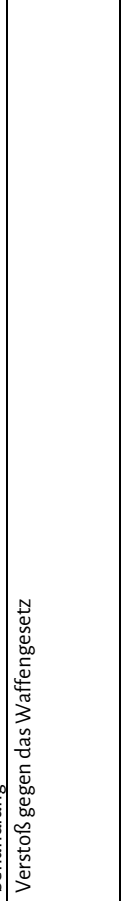 & 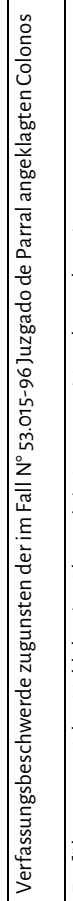 & 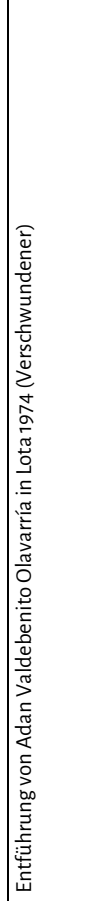 & 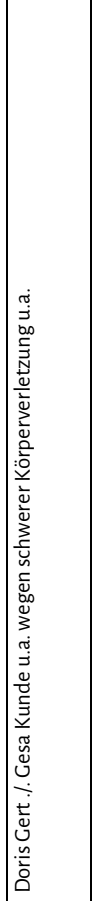 & 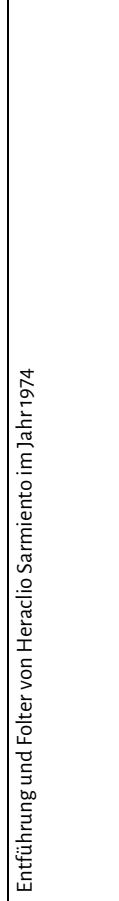 \\
\hline 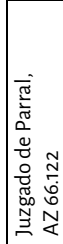 & 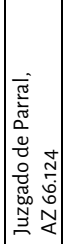 & 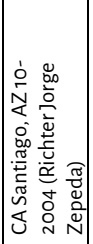 & 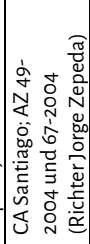 & 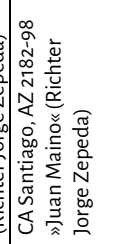 & 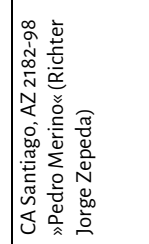 & 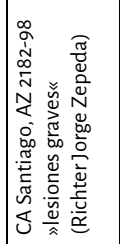 & 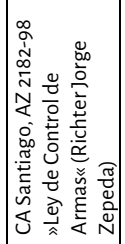 & 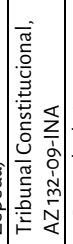 & 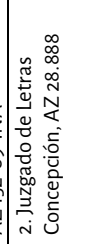 & 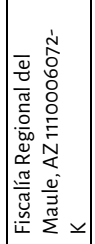 & 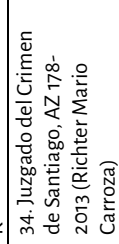 \\
\hline 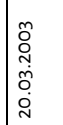 & $\begin{array}{l}\tilde{O} \\
\stackrel{0}{0} \\
\hat{o} \\
\dot{m} \\
\dot{m}\end{array}$ & ঃ & | & $\begin{array}{l}\text { No } \\
\text { on }\end{array}$ & 峉 & ס. & 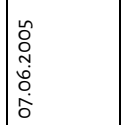 & 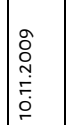 & $\overline{\mathrm{N}}$ & $\overline{\mathrm{N}}$ & 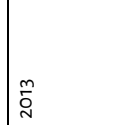 \\
\hline
\end{tabular}




\begin{tabular}{|c|c|c|c|c|c|c|c|c|c|c|c|c|c|c|c|c|}
\hline 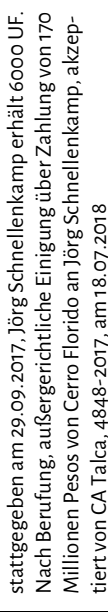 & 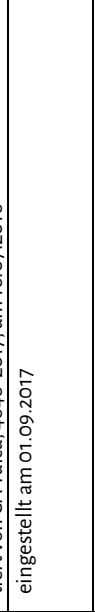 & 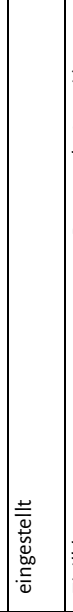 & 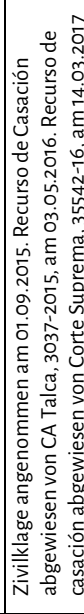 & 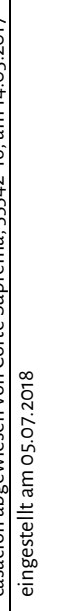 & 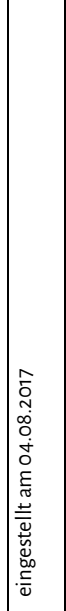 & 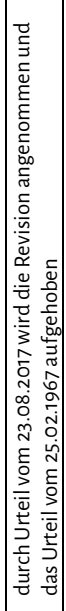 & 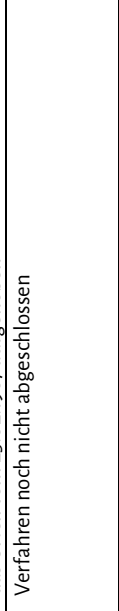 & 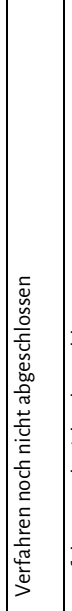 & 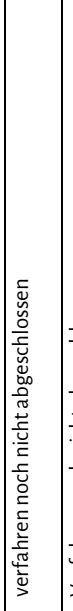 & 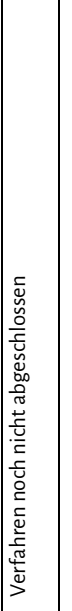 & & 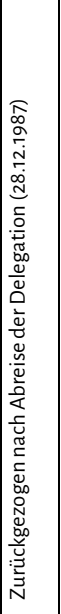 & 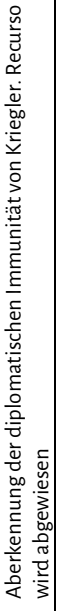 & 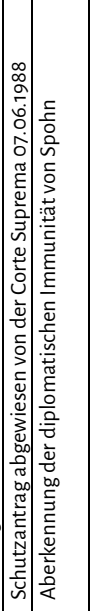 & 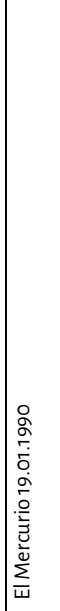 & 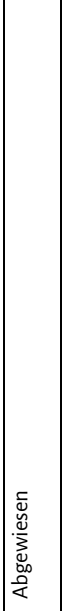 \\
\hline 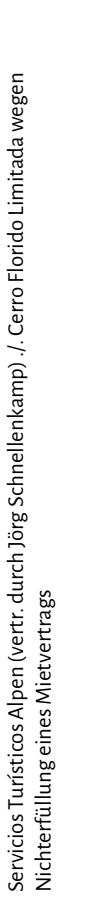 & 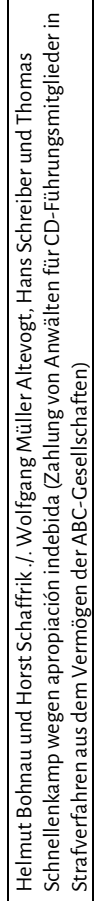 & 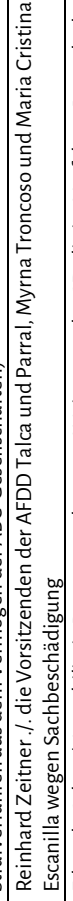 & 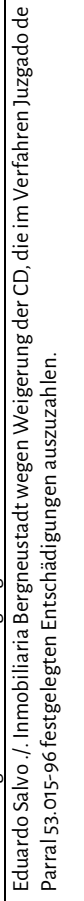 & 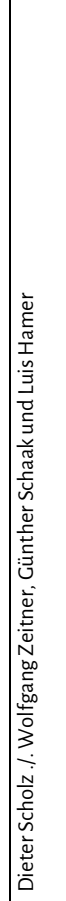 & 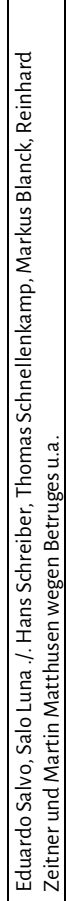 & 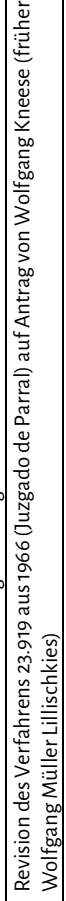 & 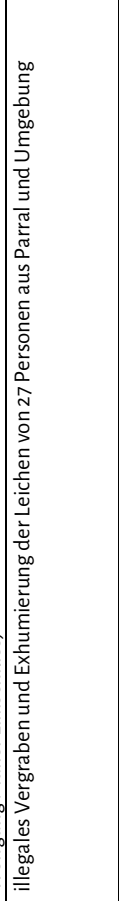 & 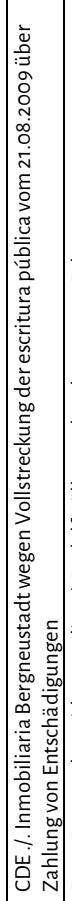 & 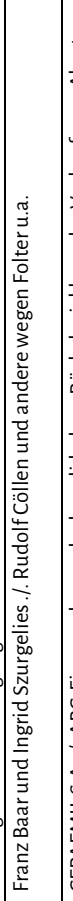 & 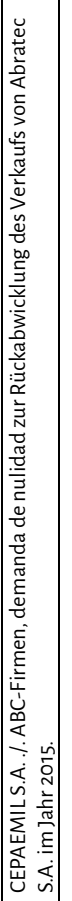 & $\begin{array}{l} \\
\\
\\
\end{array}$ & 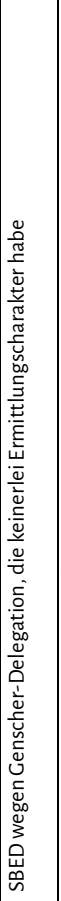 & 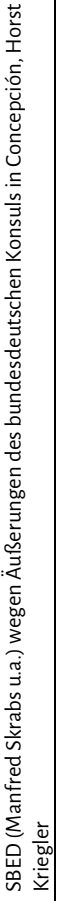 & 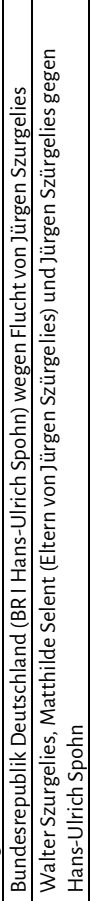 & 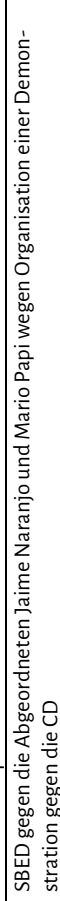 & 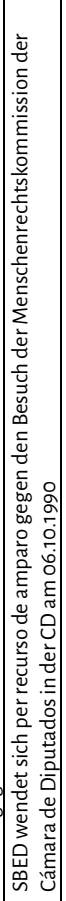 \\
\hline 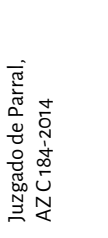 & 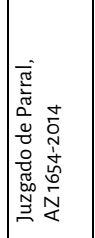 & 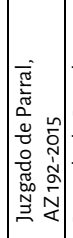 & 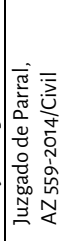 & 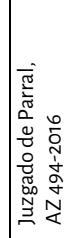 & 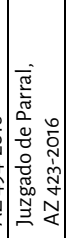 & 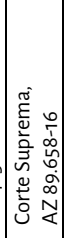 & 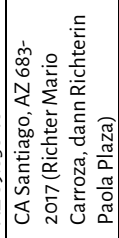 & 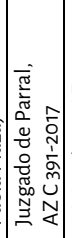 & 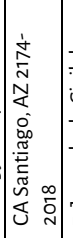 & 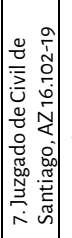 & 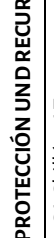 & 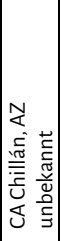 & 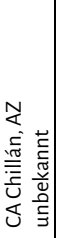 & 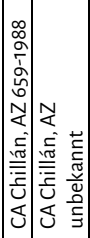 & 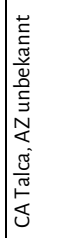 & 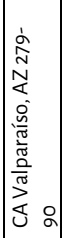 \\
\hline $\begin{array}{l}\text { 离 } \\
\text { Oे }\end{array}$ & 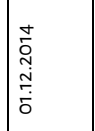 & 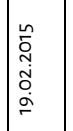 & 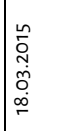 & 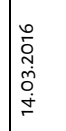 & 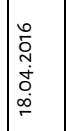 & $\bar{N}$ & i & 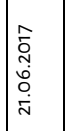 & 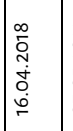 & 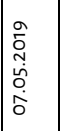 & 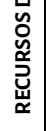 & 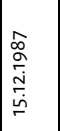 & 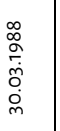 & 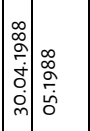 & 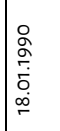 & 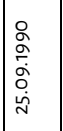 \\
\hline
\end{tabular}




\begin{tabular}{|c|c|c|c|c|c|c|c|c|c|c|c|c|c|}
\hline 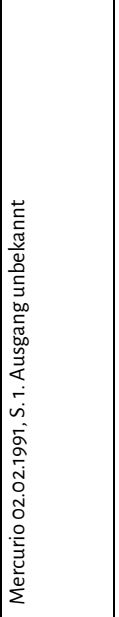 & 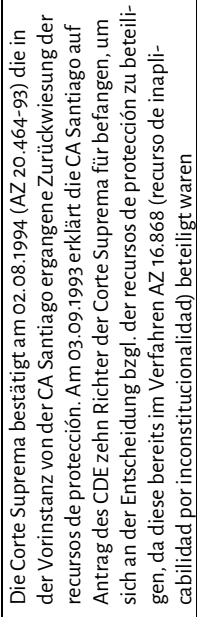 & 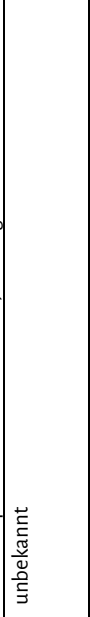 & 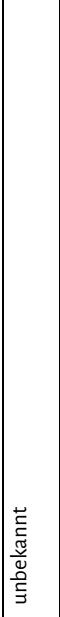 & 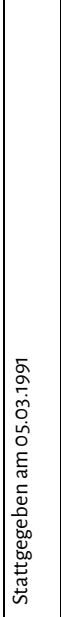 & 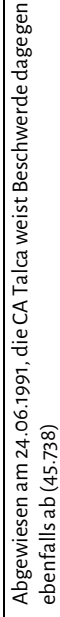 & & 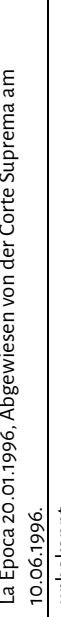 & 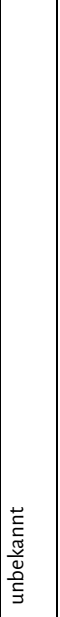 & & 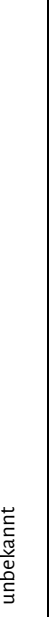 & 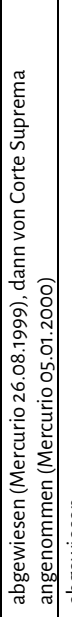 & 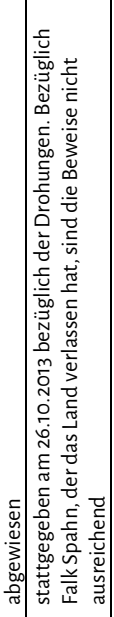 & 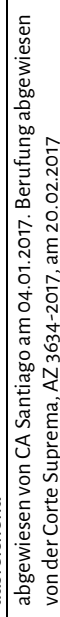 \\
\hline 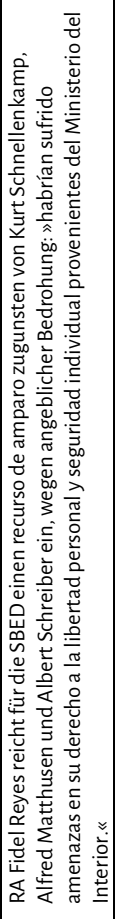 & 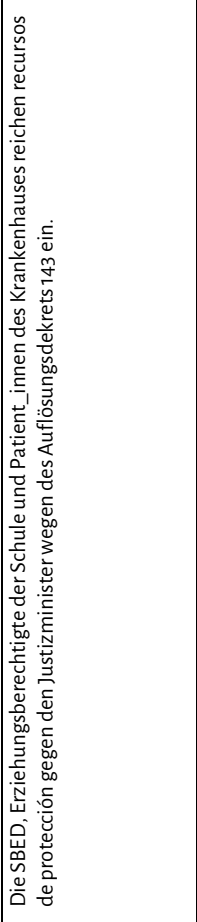 & 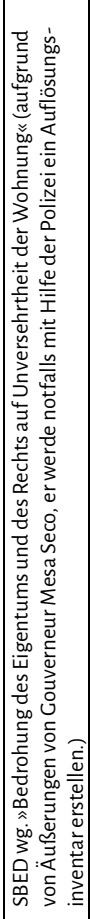 & 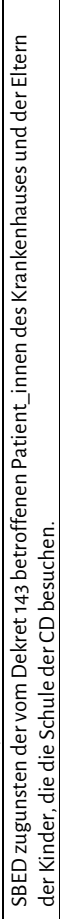 & 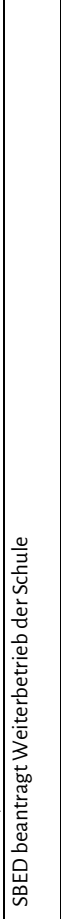 & 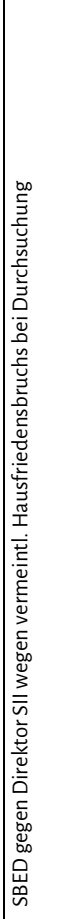 & & 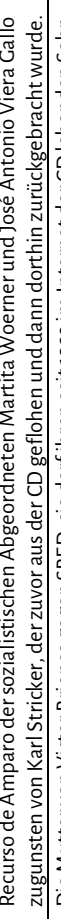 & 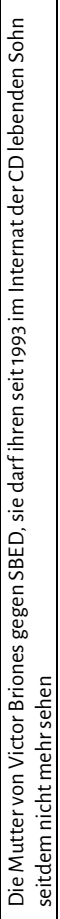 & 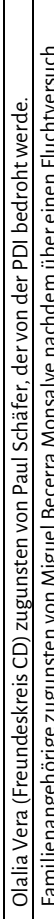 & 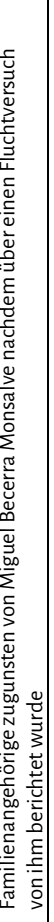 & 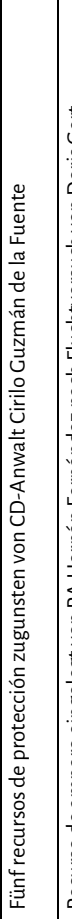 & 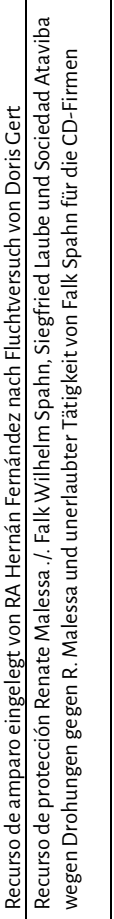 & . \\
\hline 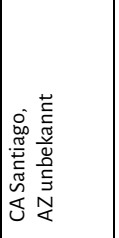 & 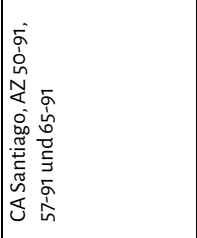 & 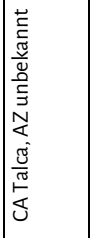 & 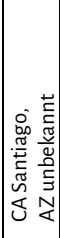 & 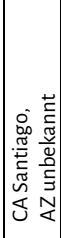 & 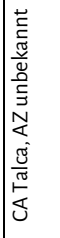 & & 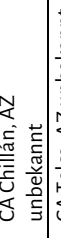 & 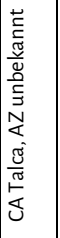 & 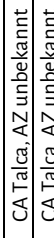 & & 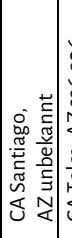 & 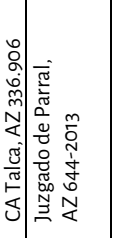 & \\
\hline $1 \%$ & $\frac{2}{2}$ & 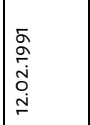 & 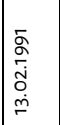 & $\begin{array}{l}\text { ò } \\
\dot{\nu}\end{array}$ & 2 & & & $\begin{array}{l}\alpha \\
0 \\
0 \\
0 \\
0\end{array}$ & & & $\sqrt[n]{2}$ & 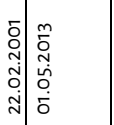 & 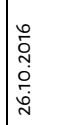 \\
\hline
\end{tabular}




\subsubsection{Verfahren nach der Flucht von Wolfgang Müller (1966-1969)}

Am 26. Februar 1966 gelang Wolfgang Müller Lilischkies (heute Kneese) nach zwei erfolglosen Versuchen die Flucht aus der CD (vgl. Abschnitt 4.1.3). ${ }^{14}$ Müller berichtete der deutschen Botschaft und den chilenischen Medien ausführlich über die Zustände im Innern der CD und bestätigte auch, dass sich Paul Schäfer in der CD aufhielt. ${ }^{15}$ Nur wenige Wochen später, am 28. März 1966, gelang Wilhelmine Lindemann die Flucht aus der CD. Die Cámara de Diputados bat daraufhin die chilenische Justiz einstimmig um die Einsetzung eines "ministro en visita extraordinaria « am Gericht in Parral, um die Vorgänge in der CD zu untersuchen. ${ }^{16}$ Die Corte Suprema stimmte dem zu und wies die CA Chillán an, ${ }^{17}$ die wiederum Richter Eduardo Bravo Ubilla nach Parral abordnete. ${ }^{18}$ Gegenstand der Ermittlungen waren Müllers Aussagen zum Missbrauch durch Paul Schäfer, zur Freiheitsberaubung (an seiner Mutter Vera Lilischkies sowie an Wilhelmine Lindemann), sowie Berichte über den möglicherweise gewaltsamen Tod von Ursula Schmidtke und weiterer Colonos.

Die CD ging rasch in die juristische Gegenoffensive: Die SBED stellte kurz darauf Strafanzeige gegen Müller wegen Sodomie und Diebstahl. Hinzu kamen Strafanzeigen gegen Müller von Gisela Seewald wegen injurias (Beleidigung) ${ }^{19}$ und von Hermann Schmidt wegen abuso de publicidad (öffentlicher Verleumdung). ${ }^{20}$ Als Rechtsbeistand für die CD fungierte Luis Ortíz Quiroga. Die entsprechenden Verfahren führte Richter Hernán Olate Melo am Juzgado de Parral.

Wolfgang Müller, den die Botschaft in einem deutschen Altersheim in Santiago untergebracht hatte, wurde im April 1966 festgenommen. Der Vorwurf der Sodomie beruhte auf der Behauptung von Hartmut Hopp und Willi Malessa, Müller sei gegenüber ihnen sexuell übergriffig geworden. Der Vorwurf des Diebstahls bezog sich auf die Entwendung eines Pferdes der CD, eines deutsch-spanischen Wörterbuchs von Albert Tymm, eines Dolches von Rudolf Cöllen sowie eines Paars Schuhe von Heinrich Hempel. Müller gestand den Diebstahl, rechtfertigte sich jedoch damit, dass er Pferd,

Vgl. Basso, Carlos. „Wolfgang Kneese: el joven que le ganó un partido de ajedrez al diablo«, in: CIPER (Website), 28.08.2017, online unter https://ciperchile.cl/2017/08/28/wolfgang-kneese-el-jov en-que-le-gano-un-partido-de-ajedrez-al-diablo/.

PA AA, AV NA 31591. Vermerk Goldschmitt über Gespräch mit dem Direktor der chilenischen Kriminalpolizei Oelckers vom 02.03.1966. Coldschmitt schrieb: „Der deutsche Konsul Coldschmitt schreibt in einem Vermerk über ein Gespräch mit dem Leiter von Investigaciones Oelckers: »Müller behauptet, daß sich ein gewisser Paul Schäfer auf dem Fundo aufhalte. Dieser werde unseres Wissens von Interpol wegen des Verdachts der Unzucht mit Kindern gesucht (Paul Schäfer wird im Fahndungsbuch - Festnahmen - IntF ausgeschrieben) [.] An Paul Schäfer schien Herr Oelckers wenig interessiert zu sein, nachdem ihm einer seiner Angestellten [.] mitteilte, Schäfer sei vor Jahren aus Chile ausgereist. «

16 Cámara de Diputados, Diarios de Sesiones, Legislatura extraordinaria periodo 1965-1966, Sesión $71^{\text {a }}$ vom 12.04.1966, S. 6919ff. Investigacion de hechos ocurridos en la colonia Alemana »Dignidad«, ubicada en Parral, provincia de Linares - oficios. 
Wörterbuch, Dolch und Schuhe für seine Flucht benötigte. Richter Olate Melo urteilte, dass dem minderjährigen Müller das nötige Urteilsvermögen für den Diebstahl fehle und wies den Gesundheitsdienst SNS im Juli 1966 an, ihn bis zu seiner Volljährigkeit in einer Jugendeinrichtung unterzubringen. ${ }^{21}$

Zudem ließ Olate Paul Schäfer zur Fahndung ausschreiben. ${ }^{22}$ Als öffentlich bekannt wurde, dass gegen Schäfer bereits in der Bundesrepublik ein einschlägiges Ermittlungsverfahren anhängig war, behauptete die CD zunächst, Schäfer sei schon seit Jahren nicht mehr in der Siedlung gewesen. ${ }^{23}$ Als dies rasch widerlegt wurde, ${ }^{24}$ behauptete sie, Schäfer sei Anfang April 1966 in die Berge geflüchtet, möglicherweise um sich selbst zu töten: er habe eine Schusswaffe mitgenommen und einen Abschiedsbrief hinterlassen. ${ }^{25}$ Da die Presseberichterstattung über den Fall nicht nur in Chile, sondern auch in der Bundesrepublik sowie in anderen Ländern immer breiter wurde, reagierte das AA zunehmend besorgt und forderte die Botschaft auf, umgehend zu berichten, um "Behauptungen entgegenzutreten, die deutschem Ansehen abträglich « seien. ${ }^{26}$ Auf einer Pressekonferenz der Bundesregierung teilte der Sprecher des AA am 20. April 1966 mit:

»Ausser gegen Paul Schäfer, der in Chile flüchtig ist und gegen den auch von deutscher Polizei wegen früherer Verfehlungen Haftbefehl vorliegt, hat sich bis jetzt kein Verdacht strafbarer Handlungen ergeben. Insbesondere liegen bisher keine Anhaltspunkte für Behauptung vor, in Siedlung befänden sich prominente frühere Nazis. Ermittlungen wuerden fortgesetzt. Deutsche Botschaft steht in enger Fühlungnahme mit chilenischer Kriminalpolizei. Bisherige Untersuchungen haben des weiteren gezeigt, dass Siedlung positive landwirtschaftliche Arbeit leistet, die auch von chilenischer Seite anerkannt wird. ${ }^{27}$

Am 22. April 1966 ließ Richter Bravo auf dem Friedhof der CD die sterblichen Überreste von Ursula Schmidtke, Reinhard Vedder, August Friedrich, Johanna Gruber und Anna Hartmann exhumieren. Ein Ergebnis dieser Untersuchungen ist mir allerdings nicht bekannt. $^{28}$

Die Botschaft kommunizierte derweil mit Emilio Oelckers, dem Direktor der PDI, und beobachtete die Untersuchungen von Richter Bravo diskret, ohne sich dazu öffent-

CA Santiago, AZ 2182-98 (»Asociación Ilícita«), Bd. I (2) (Parral), Bl. 920f. Beschluss Richter Olate Melo (Juzgado de Parral) vom 22.07.1966.

PA AA, B 85, Bd. 598. Bericht Botschafter Nostitz an das AA vom 12.04.1966, GZ V6/914/66. äußert darin, die CD habe Schäfer bereits 1961 ausgeschlossen, als Missbrauchsvorwürfe bekannt wurden.

El Mercurio vom 13.04.1966, S. 21. »Repercusiones en Alemania del caso de la Colonia >Dignidad««. Der Artikel berichtet, Paul Schäfer habe sich in den vergangenen Jahren als Paul Schneider ausgegeben. Vgl. auch Kölner Stadtanzeiger vom 14.04.1966. »Polizei umstellt 〉Berg-Paradies« sowie Bonner Generalanzeiger vom 18.04.1966. »Ist Paul Schäfer in Chile?«. 
lich zu äußern. Nach Bonn berichtete sie: »Um sich nicht dem möglichen Vorwurf der Intervention oder Parteinahme auszusetzen, hat die Botschaft von einem Besuch beim Gericht in Parral oder in der Kolonie jedoch abgesehen. ${ }^{29}$ Als Bravo die Botschaft bat, ${ }^{30}$ ihm ihre Kenntnisse über die SBED und deren Aktivitäten mitzuteilen, antwortete diese trocken, nicht die deutsche Botschaft in Chile, sondern die chilenische Botschaft in Deutschland habe der SBED beim Aufbau ihrer Siedlung geholfen:

»[E]sta Embajada no tiene en su poder antecedentes relacionados con la instalación en Chile y actividades desarrolladas por la SBED. Como es de conocimiento de esta Embajada, la colonia >Dignidad se ha radicado en Chile con ayuda de la Embajada de Chile en Bonn. La SBED sólo ha tenido contacto con el Departamento Consular de esta Embajada en asuntos de carácter consular. Esta Embajada a su vez había tomado contacto con la Dirección General de Investigaciones después de la fuga del menor Wolfgang Müller de la colonia, lo que, seguramente, es de conocimiento oficial del señor Ministro en visita. ${ }^{31}$

Das Schreiben verdeutlicht die Haltung der bundesdeutschen Diplomaten, der chilenischen Seite die volle Verantwortung für eine Aufklärung zuzuweisen und eine eigene (Mit-)Zuständigkeit zu negieren.

Bereits zuvor hatte die Botschaft dem chilenischen Außenministerium eine weitere Verbalnote ${ }^{32}$ übersandt, zusammen mit einer Reihe von Schreiben besorgter Angehöriger von Colonos. ${ }^{33}$ Dazu führte die Botschaft aus, sie selbst habe keine Möglichkeit, Nachforschungen anzustellen, bäte aber Richter Bravo, den Fall zu untersuchen:

»Por no tener la posibilidad de efectuar las averiguaciones necesarias, ni tomar contacto con los miembros de la colonia - El Directorio no contesta a cartas de esta Embajada y en casos de tener que presentarse en el pasado a esta Embajada personas de la colonia, llegaban solo acompañadas por un miembro del Directorio o se presentaba, en representacion de aquellas personas un miembro del Directorio - esta Embajada estaría muy agradecida si por intermedio de este Ministerio se podría rogar al señor Ministro en visita don Eduardo Bravo Ubilla, Parral, efectuar las averiguaciones del caso. ${ }^{34}$

29 PA AA, B 85, Bd. 598. Botschaftsbericht 1026/66 an das AA vom 02.05.1966.

$30 \mathrm{AGH}$, Bestand RFA, Notas Verbales 1966. Verbalnote 07044 des chil. Außenministeriums an die deutsche Botschaft vom 07.05.1966.

31 AGH, Bestand RFA, Notas Verbales 1966. Verbalnote Nr. 166/66 der deutschen Botschaft an das chilenische Außenministerium vom 21.06.1966.

$32 \mathrm{AGH}$, Bestand RFA, Notas Verbales 1966. Verbalnote Nr. 160/66 der deutschen Botschaft an das chilenische Außenministerium vom 07.06.1966.

33 Aufgezählt werden folgende Angehörigenschreiben: carta del señor Otto Brock referente a Ema Brock de Hühne; carta del señor Johannes Hühne referente a Wolfgang Hühne y Michael Hühne, carta del señor Fritz Joswig referente a Ruth Joswig y Brunhilde Joswig, carta de la señora Luise Witthahn referente a Elisabeth Witthan y Dorothea Witthan, carta de la señora Elisabeth Herrmann referente a Helene Bohnau, Nathaniel Bohnau, Edeltraud Bohnau, Günter Bohnau, carta de la señora Cerda Schwöll referente a Ursula Schwöll, carta de la señora Ursula Bruntzlow referente a Wilhelmine Brunzlow de Lindemann.

$34 \mathrm{AGH}$, Bestand RFA, Notas Verbales 1966. Verbalnote Nr. 160/66 der deutschen Botschaft an das chilenische Außenministerium vom 07.06.1966. 
Unterdessen sprach in der Bundesrepublik Hugo Baar, der die PSM in Siegburg vertrat, beim $\mathrm{AA}^{35}$ sowie bei der chilenischen Botschaft in $\mathrm{Bonn}^{36}$ vor und übergab dabei vermeintlich entlastende Schriftstücke.

Richter Bravo stellte seine Untersuchungen bereits wenige Wochen später, am 26. Juli 1966 ein. Die Gründe für die schnelle Verfahrenseinstellung sind mir nicht bekannt.

Am 23. August 1967 stellte die CA Chillán endgültig alle Ermittlungen im Kontext der Untersuchung von Richter Bravo Ubilla ein. ${ }^{37}$ Die SBED wertete dies als endgültigen Freispruch von vermeintlichen Verleumdungen, die Müller 1966 erhoben hatte und schaltete in mehreren Medien Zeitungsanzeigen, in denen sie ihre Befriedigung darüber ausdrückte, dass sie nun von allen Vorwürfen der im Zuge der ab 1966 vorgebrachten »Verleumdungskampagne « freigesprochen sei. ${ }^{38}$

Richter Olate führte sein Verfahren gegen Wolfgang Müller wegen »abuso de publicidad« jedoch weiter. Bei diesem Verfahren ging es um mehrere Äußerungen Müllers gegenüber chilenischen Medien, in denen er die internen Verhältnisse in der CD beschrieb. Am 28. Februar 1967 verurteilte er Müller wegen wiederholter schwerer Verleumdung zu fünf Jahren und einem Tag Haft. ${ }^{39}$ Das Strafmaß war für den Tatbestand der Verleumdung unüblich hoch. Richter Olate begründete es damit, dass Müller durch wiederholte beleidigende und verleumderische Aussagen den Ruf der CD schwer beschädigt habe. Müller flüchtete wenige Tage vor dem Urteilsspruch nach Argentinien und reiste von dort aus weiter in die Bundesrepublik. ${ }^{40}$ Die CA Chillán setzte am 28. Oktober 1969 das Strafmaß in zweiter Instanz auf drei Jahre und einen Tag Haft herab. ${ }^{41}$ Erst 2017 stellte die Corte Suprema auf Antrag von Wolfgang Kneese (damals Müller) die Unrechtmäßigkeit der Verurteilungen von 1967 und 1969 fest und hob sie auf. ${ }^{42}$

CD-Anwalt Ortíz Quiroga kommentierte für die CD den Einstellungsbeschluss vom 23. August 1967 sowie die Urteile gegen Müller. Die CD reichte die genannten Urteile und Kommentare bei diversen nachfolgenden Verfahren als vermeintlich entlastende Dokumente ein, beispielsweise im Deutschen Bundestag 1988 und bei der Staatsanwalt-

PA AA, B 85, Bd. 540. Visitenkarte Hugo Baar-PSM und handschriftlicher Vermerk über Vorsprache und Übergabe von Schriftstücken vom 24.06.1966.

$36 \mathrm{ACH}$, Bestand RFA, Oficios Reservados 1966. Schreiben estrictamente confidencial Nr. 174-22, Botschafter Perez de Arce an den Staatssekretär vom 15.04.1966. Perez de Arce berichtet über einen Besuch von Hugo Baar und Wilhelm Zeitner in der Botschaft vom Vortag. Hugo Baar habe auch im September 1965, kurz nach Amtsantritt des Botschafters in Bonn, die Botschaft besucht und einen Diavortrag über die CD gehalten.

PA AA, AV NA 31693. CA Chillán, AZ 23.698. Beschluss vom 23.08.1967 bzgl. Verfahren Juzgado de Parral.

38 Diario llustrado vom 27.08.1967, S. 3. »Inserción - Sobreseimiento definitivo de la Sociedad Benefactora y Educacional Dignidad« sowie El Mercurio vom 04.09.1967, S. 11. »Sobreseimiento definitivo de la Soc. Benefactora y Educacional Dignidad «.

39 Juzgado de Parral, AZ 23.919. Urteil vom 25.02.1967.

40 Basso, Carlos. »Wolfgang Kneese: el joven que le ganó un partido de ajedrez al diablo«, in: CIPER (Website), 28.08.2017, online unter https://ciperchile.cl/2017/08/28/wolfgang-kneese-el-joven-que -le-gano-un-partido-de-ajedrez-al-diablo/. 
schaft Bonn 1988. ${ }^{43}$ Noch 2011 nahm die StA Krefeld diese Dokumente als Beweismittel zu ihren Akten. ${ }^{44}$

Nach dem Einstellungsbeschluss der CA Chillán kontaktierte Ortíz Quiroga regelmäßig die Botschaft und legte sogenannte Informationsdossiers seiner Mandant_innen vor. In einigen Fällen bat er die Botschaft, zugunsten der CD tätig zu werden, so etwa bei Auseinandersetzungen zwischen der CD und Hector Tarrico, dem Intendenten von Linares, sowie Claudio Fuentes, dem Gouverneur von Parral. Die Botschaft führte daraufhin ein Gespräch mit dem chilenischen Innenministerium. Botschaftsmitarbeiter End vermerkte hierzu:

»Herr Dr. Spang und ich suchten gestern den Unterstaatssekretär im Innenministerium, Krauss, auf trugen ihm den Fall >Dignidad` vor. Wir wiesen daraufhin, daß der Rechtsvertreter der >Dignidad〈, Ortiz, die Botschaft gebeten habe, bei der Regierung Schritte zu unternehmen, um den Couverneur von Parral [...] zu veranlassen, seine negative Einstellung gegenüber der Kolonie zu revidieren. Herr Krauss war über den Fall >Dignidad ‘ bestens informiert und bezeichnete sich als Freund des Rechtsanwalts Ortiz. Die Regierung beurteile die kolonisatorische Arbeit der Dignidad guenstig und sei der Meinung, daß der Couverneur falsch gehandelt habe. Auch aus anderen Gruenden sei gegen ihn ein Disziplinarverfahren im Gange. Herr Krauss zeigte für die Haltung der Botschaft volles Verstaendnis und fuehrte auf Befragen aus, daß er keine Bedenken habe, wenn die Botschaft dem Außenministerium eine informative Verbalnote ueber diesen Sachverhalt zuleite. ${ }^{45}$

Die Botschaft schickte daraufhin eine Verbalnote an das chilenische Außenministerium, in der sie sich die »Besorgnis« von Ortíz Quiroga zu eigen machte. ${ }^{46}$ Der Vorgang verdeutlicht, wie gut in dieser frühen Phase das Unterstützungsnetzwerk der CD bereits funktionierte. Über den der Christdemokratie nahestehenden Anwalt Luis Ortíz Quiroga hatte die CD eine unüblich harte Verurteilung Wolfgang Müllers erreicht. Durch die Lobby- und Kontaktarbeit des Anwalts in hohen Kreisen der chilenischen Regierung und bei der bundesdeutschen Botschaft erreichte die CD nun ein weiteres Ziel: Die Botschaft setzte sich für sie ein in ihrer Auseinandersetzung mit hohen Amtsträgern der Regionalregierung. Während die Botschaft zuvor bemüht war, den Anschein einer neutralen Haltung zu vermitteln, wurde sie nun auf dem Wege der stillen Diplomatie zugunsten der CD tätig.

43 StA Bonn, AZ 50 ]s 285/85, Bd. III, Bl. 164ff. Stellungnahme Hartmut Hopp anläßlich der Anhörung des Unterausschusses des Deutschen Bundestages am 22.02.1988 nebst Anlagen. Dies reichte RA Gatzweiler für seine Mandanten Paul Schäfer, Gisela Seewald und Hartmut Hopp bei der StA Bonn ein.

StA Krefeld, AZ 3 ]s 753/2011, Bd. II. Bl. 164-542. Stellungnahme Hartmut Hopp anläßlich der Anhörung des Unterausschusses des Deutschen Bundestages am 22.02.1988 nebst Anlagen. 


\subsubsection{Untersuchung der Ermordung von Juan René Muñoz Alarcón (1978)}

Am 23. Oktober 1977 wurde Juan René Muñoz Alarcón auf einem Brachgelände in Santiago tot aufgefunden. ${ }^{47}$ Laut Autopsiebericht wies seine Leiche zehn Stichwunden auf. ${ }^{48}$ Eine Zeitung berichtete in einer Randnotiz, dass Muñoz »überfallen wurde mit dem Ziel, ihn auszurauben oder im Laufe einer Rauferei ermordet wurde« ohne weitere Ausführungen zum Tathergang oder zur Person zu machen. ${ }^{49}$ Wenige Monate zuvor hatte Muñoz mehrere Male die Vicaría de la Solidaridad (Solidaritätsvikariat der katholischen Kirche $)^{50}$ besucht und dort eine Art Lebensbeichte auf Band gesprochen. ${ }^{51}$ Darin erklärte er, ein ehemaliges Mitglied der Partido Socialista (sozialistische Partei, PS) zu sein. 1973, noch vor dem Putsch, habe er sich jedoch wegen Meinungsverschiedenheiten von der Partei abgewandt ${ }^{52}$ und begonnen, mit Allende-Gegner_innen zusammenzuarbeiten. Nach dem Putsch vom 11. September 1973 verhaftete die Militärjunta massenhaft politische Gegner_innen und hielt diese u.a. im Nationalstadion in Santiago gefangen. Muñoz berichtete, von Sicherheitskräften ins Stadion gebracht worden zu sein, um mit einer Kapuze auf dem Kopf ehemalige Genoss_innen unter den Verhafteten zu identifizieren. Er habe viele von ihnen verraten und sei daher für ihren Tod verantwortlich. Anschließend sei er unter der Bedingung, weiter mit den Putschisten $\mathrm{zu}$ kollaborieren, freigelassen worden. Muñoz sagte, während er spreche, d.h. im Mai oder Juni 1977, seien über 100 Personen in der CD inhaftiert, darunter Anführer verschiedener linker Parteien:

47 Archiv Al, Bestand CD. Dokumentation zum Fall Muñoz Alarcón vom 09.08.1978. Enthält die Akten des Verfahrens: 11. Juzgado del Crimen, AZ 12.293 »Homicidio de Juan René Muñoz Alarcón«, Bl. 85. Oficio Nr. 124, PDI an 11. Juzgado del Crimen o.D.

48 Archiv Al, Bestand CD. Dokumentation zum Fall Muñoz Alarcón vom 09.08.1978. Enthält die Akten des Verfahrens: 11. Juzgado del Crimen, AZ 12.293 »Homicidio de Juan René Muñoz Alarcón«, Bl. 13. Dokument »Muerte de Juan René Muñoz Alarcón« o. A., o. D. Laut diesem Bericht wurde die Leiche im Gerichtsmedizinischen Institut von seinem Bruder erkannt. »Este relató que se presentaba un balazo en la cabeza, quemaduras de cigarrillo en la frente, las muñeca con huellas esposas y el cuerpo se encontraba completamente apuñalado."

49 PA AA, ZW 111131. Bericht Botschaft an AA Nr. 694/78 Betr.: Verschwundene Personen in Chile hier: Aussage des früheren Mitglieds des Zentralkomittees der Sozialistischen Partei Chiles, Juan René Muñoz Alarcón, mit Anlage: Las Últimas Noticias vom 25.10.1977. Kopie des Zeitungsartikels, ohne Überschrift u. Seitenangabe.

50 Die 1976 in Nachfolge des Comité Pro Paz gegründete Vicaría de la Solidaridad bestand bis 1992 als Institution der katholischen Kirche in Chile. Das Vikariat bot den Opfern von Menschenrechtsverletzungen der Militärdiktatur juristische und soziale Unterstützung. Nach 1992 wurde es in eine Stiftung (Fundación Vicaría de la Solidaridad) umgewandelt, die u.a. ein Archiv betreibt.

51 PJS, Sammlung Gesprächsnotizen. Notiz des Gesprächs des Verfassers mit Alvaro Varela Walker in Santiago vom 23.11.2012. Muñoz machte seine Aussagen in Anwesenheit des angehenden Rechtsanwalts Alvaro Varela Walker. Die Sekretärin des Vikars Cristián Precht transkribierte die Aufnahmen später. Bei einem späteren Besuch im Vikariat autorisierte Muñoz die Verschriftlichung durch seine Unterschrift.

52 Die Zeitschrift Lateinamerika Nachrichten veröffentlichte 1978 eine Reihe von Details über Muñoz' Rolle vor dem Putsch sowie über seine Abkehr von der PS. Vgl. Lateinamerika Nachrichten Nr. 7/1978, S. 5. »Ein DINA-Agent packt aus«. 
»[S]e me llevó a la Colonia Dignidad, al interior de Parral, mas o menos a unos 40 kms. Ahí funciona un centro de adiestramiento de la Inteligencia Nacional regido por alemanes [...]. Ahí se me preparó para interrogar gente y hacer tareas de contrainteligencia. [...] Posteriormente se me ha ocupado en tarea de cazar gente, de interrogarla, de torturarla y de matarla. [...]. He participado en la desaparicion de algunas personas que están en la Colonia Dignidad. Hay 112 personas en estos momentos en la Colonia Dignidad. Algunos antiguos dirigentes de los diferentes partidos de la UP. En Santiago, acá en Peñalolen en Colina está el resto. Son alrededor de 145. El resto están todos muertos. ${ }^{53}$

Muñoz sagte aus, dass die CD, Peñalolén und Colina die einzigen Orte seien, an denen noch Verschwundene festgehalten würden. Auch Carlos Lorca, damaliger Chef der PS, der 1975 von der DINA festgenommen wurde, werde innerhalb der CD festgehalten. Muñoz schätzte, dass all diese Gefangenen keine Chance hätten, zu überleben. Sie würden vom Regime lediglich am Leben gehalten, um den Rest der noch im Untergrund lebenden linken Aktivist_innen ebenfalls festnehmen zu können. Seiner Erklärung fügte Muñoz eine Liste mit Namen von 81 Personen an, die ihm zufolge noch am Leben seien und in der CD festgehalten wurden. ${ }^{54}$

Neben den Informationen zur Colonia Dignidad und den Verschwundenen enthält Muñoz' Bericht eine Fülle von Informationen zu den chilenischen Geheimdiensten, vor allem zur DINA, und zu ihrer Operationsweise. Die Mitarbeiter_innen des Solidaritätsvikariats waren sich deshalb anfangs unsicher und befürchteten ein Täuschungsmanöver des Geheimdienstes. Schließlich übergaben sie aber im November 1977 die Transkripte an die Justiz. Die Corte Suprema ordnete daraufhin am 2. Dezember 1977 Richter Osvaldo Faúndez Vallejos als Ministro en Visita ab, um den Fall zu untersuchen. ${ }^{55}$

Nach dem Putsch fingierten die Militärs eine Festnahme von Muñoz, um zu verhindern, dass er als Kollaborateur verdächtigt wurde. ${ }^{56}$ Im Oktober 1973 brachte der spätere DINA-Chef Manuel Contreras ihn in die CD. ${ }^{57}$ Muñoz Ehefrau und Mutter der sechs gemeinsamen Kinder, von der er seit 1971 getrennt gelebt hatte, sagte gegenüber

53 PA AA, ZW 111131. 11. Juzgado del Crímen de Santiago, AZ 12.293, »Homicidio de Juan René Muñoz Alarcón«. Bl. 14-26. Neunseitiges Transkript der Erklärung von Juan René Muñoz Alarcón vom Mai oder Juni 1977.

54 Ebd. Anlage Liste »Casos de Desaparecidos«.

55 Zuvor hatte Richter Tomás Dahm Guiñez am 11. Juzgado del Crímen de Santiago (AZ 12.293, »Homicidio de Juan René Muñoz Alarcón«), wegen Muñoz' Tod als einfachem Mord ermittelt.

56 Vgl. Azócar Valdés, Juan. Lorca - de la reforma universitaria a la lucha antidictatorial. Santiago, 2011, S. 238. Einem schwedischen Filmjournalisten sagte Muñoz in den ersten Monaten nach dem Putsch, er sei als Cefangener im Nationalstadion gezwungen worden, mit einer Kapuze auf dem Kopf Cenoss_innen zu identifizieren, habe die Militärs jedoch angelogen. Die Umstände dieser Filmaufnahme sind unbekannt. Vgl. Sandquist, ]an. »Santiago de Chile - våldtagen stad « [»Santiago de Chile - vergewaltigte Stadt ], Sveriges Television 1973, online unter https://www.youtube.co $\mathrm{m} /$ watch? $\mathrm{v}=14 \mathrm{f} 5 \mathrm{wWDoyg} 8$.

57 CA Santiago, AZ 2182-98 (»Asociación Ilícita«), Bd. I (2), BI. 575. Richterliche Vernehmung von Gerd Seewald vom 19.08.2005. Seewald sagte hier jedoch aus, Manuel Contreras habe Juan Muñoz Alarcón im Dezember 1973 persönlich in die CD gebracht. 
Richter Faúndez aus, im Oktober 1973 von ihrem Mann und CD-Angehörigen namens »Albert« und »Ingrid« in die CD gebracht worden zu sein:

»En el mes de octubre del año 1973 Juan llegó a la casa con un señor alemán llamado Albert y una señorita de nombre Ingrid, me conversó si deseaba ir a la Colonia Dignidad de la Ciudad de Parral. Le dije que lo iba a pensar [...] A los dias 5 días después regresó con las mismas personas que había venido la primera vez y se llevó en un auto a mis cinco hijos. A los días llegó a mi casa una camioneta tipo Station Wagon que nos llevaron a Parral junto a mi hijo menor.

Una vez instalada en dicha Colonia le pregunté a mi esposo quien era la señorita Ingrid y el señor alemán, respuesta que eludió haciéndome ver que era conveniente que yo y mis hijos estuvieramos allí, que nada nos iba a faltar. A Juan lo veía solamente de día ya que en la noche lo venía a buscar el señor Alemán, su nombre es Albert, y regresaba en la madrugada. ${ }^{58}$

Neben seiner Ehefrau sagte auch Muñoz' aktuelle Partnerin, mit der er seit $1971 \mathrm{zu}-$ sammenlebte, aus. Ein Sohn von Muñoz habe ihr berichtet, dass er gemeinsam mit seinen Eltern und Geschwistern zwei Wochen lang in der CD gewesen war. ${ }^{59}$ Für den 20. Dezember 1977 setzte Sonderrichter Faúndez einen Ortstermin in der CD an. In Anwesenheit von SBED-Präsident Hermann Schmidt sowie den »Zeugen Albert Schreiber Rauschenberger und Ingrid Pöhlchen Wittchen ${ }^{60}$ besuchte er die Siedlung. In seinem Bericht gab er Schmidts Ausführungen zur sozialen Arbeit der CD, insbesondere des Krankenhauses, wieder. Er vermerkte, dass sich auf der Besuchsliste des Krankenhauses keiner der Namen vermeintlicher Gefangener aus Muñoz' Bericht wiederfinde. Am 16. Juni 1978 stellte Faúndez das Verfahren endgültig ein. ${ }^{61}$ Er stellte fest, die Vorwürfe gegen die CD seien unbegründet und wandte gleichzeitig das Amnestiegesetz ${ }^{62}$ an.

Bis zu diesem Zeitpunkt hatte das Solidaritätsvikariat den Fall aus Angst nicht publik gemacht, weshalb auch die Öffentlichkeit keinerlei Notiz davon genommen hatte. In den Tagen nach der Einstellung des Verfahrens berichteten die Süddeutsche Zei-

58 11. Juzgado del Crímen, AZ 12.293, »Homicidio de Juan René Muñoz Alarcón«, BI. 87. Vernehmung von Olivia Guajardo Barahona (Ehefrau von Juan Muñoz Alarcón), o. D.

59 Ebd.

60 In der Aussage von Muñoz' Ehefrau von ist von »dem deutschen Herrn Albert und einem Fräulein namens Ingrid« die Rede. Ob es sich bei »Ingrid« auch um eine deutsche Colona handelt, ist nicht sicher. Juan Azócar vermutet, es könne sich bei »Ingrid« um die deutschstämmige DINA-Agentin Ingrid Olderock handeln. Vgl. Azócar Valdés, Juan. Lorca - de la reforma universitaria a la lucha antidictatorial. Santiago, 2011, S. 238.

61 PA AA, ZW 111130. Bericht Nr. 694/78 vom 30.06.1978, GZ RK 544.80/36, Betr.: Verschwundene Personen in Chile; hier: Aussage des früheren Mitglieds des Zentralkomitees der Sozialistischen Partei Chiles, Juan René Muñoz Alarcón.

62 Das von der Militärjunta erlassene Gesetzesdekret Nr. 2191 vom 19.04.1978 sah eine Generalamnestie für alle zwischen dem 11.09.1973 und dem 10.03.1978 von den Streitkräften und Sicherheitsorganen begangenen Verbrechen vor. 
tung $^{63}$ und El Mercurio ${ }^{64}$ aus unterschiedlichen Perspektiven darüber. ${ }^{65}$ Das Auswärtige Amt bat daraufhin Botschafter Strätling um einen Bericht, den dieser am 30. Juni 1978 übersandte. Er fügte Muñoz' Bericht bei, den er wenige Tage zuvor vom Solidaritätsvikariat erhalten habe. Bezugnehmend auf Muñoz' Liste mit 81 Namen vermeintlich in der CD festgehaltener Verschwundener schrieb Strätling:

»Unter den als lebend aufgeführten Personen befindet sich auch Ricardo Lagos Salinas, an dessen Schicksal die sich zur Zeit in Santiago aufhaltenden Abgeordneten der SPD-Fraktion des Deutschen Bundestages sich interessiert gezeigt haben und die von dem Inhalt des besagten Protokolls offenbar bereits durch die Vicaría de la Solidaridad unmittelbar Kenntnis erhalten hatten. [...] 6. Der Wahrheitsgehalt der Ausführungen von Muñoz läßt sich mit den einer diplomatischen Vertretung im Ausland zu Cebote stehenden Mitteln nicht überprüfen. Die gilt insbesondere für die gegen die Colonia Dignidad erhobenen Beschuldigungen, die sich im Kern mit einigen Vorwürfen aus der Vergangenheit decken, denen ich bereits Ende 1976 nachgegangen war, ohne daß diese allerdings erhärtet werden konnten. Selbst wenn die Behauptungen in Teilen oder als Ganzes den wahren Sachverhalt treffen sollten, so dürfte es äußerst schwierig sein, eine Aufklärung von außen her zu erreichen. ${ }^{66}$

Die Worte von Strätling sind widersprüchlich. Einerseits klang durch, dass er es zu dem Zeitpunkt doch für möglich hielt, dass es eine Zusammenarbeit zwischen CD und DINA gab. Andererseits bezweifelte er, diese als Botschaft aufklären zu können und schlug dahingehend auch keine weiteren Schritte vor.

Der erwähnten SPD-Delegation gehörten die Abgeordneten Herta Däubler-Gmelin, Hajo Hoffmann und Ernst Waltemathe an. Diese hatten vom Solidaritätsvikariat nicht nur Muñoz' Bericht, sondern die gesamte Ermittlungsakte von Richter Faúndez erhalten. Nach der Rückkehr der Delegation in die Bundesrepublik übergab Waltemathe die Akte an Helmut Frenz, den damaligen Generalsekretär von Amnesty International. Dieser leitete sie inklusive einer Übersetzung der wichtigsten Passagen an Klaus von Dohnanyi, Staatssekretär im Auswärtigen Amt, mit der Bitte um ein Gespräch weiter. ${ }^{67}$ Fünf Wochen später antwortete von Dohnanyi:

»Der Bericht des sogenannten `Kapuzenmannes` Muños Allarcón ist dem Auswärtigen Amt bekannt. Die darin enthaltenen Behauptungen über die angebliche Existenz eines Folterlagers in der COLONIA DICNIDAD sind in ähnlicher Weise bereits früher von anderen Personen erhoben worden. Unsere Botschaft in Santiago ist den damaligen

63 Süddeutsche Zeitung vom 18.06.1978. »Spitzel der Militärjunta Chiles sagt aus«. Einsehbar in PA AA ZW 111131.

64 El Mercurio vom 19.06.1978. »Cerrado Sumario por Homicidio de un ex-dirigente del PS«. Einsehbar in PA AA ZW 111131.

65 Während die Süddeutsche Zeitung konkret auf Muñoz' Rolle als »Kapuzenmann« im Nationalstadion eingeht und seine Aussagen zur CD zusammenfasst, erwähnt der Mercurio lediglich, dass Richter Faúndez die CD zu einem Ortstermin besucht hat.

66 PA AA, ZW 111130. Bericht Nr. 694/78 vom 30.06.1978, CZ RK 544.80/36, Betr.: Verschwundene Personen in Chile; hier: Aussage des früheren Mitglieds des Zentralkomitees der Sozialistischen Partei Chiles, Juan René Muñoz Alarcón. 
Anschuldigungen gegen die Kolonie nachgegangen, ohne jedoch die Wahrheit der Behauptungen feststellen zu können. [...] Wie sie in Ihrem Schreiben erwähnen, ist die Behauptung von Amnesty International, in der COLONIA DICNIDAD habe sich ein Folterlager des Geheimdienstes DINA befunden, Gegenstand eines Verfahrens vor dem Landgericht Bonn. Angesichts dieser Tatsache ist es erforderlich, alles zu unterlassen, was auch nur den Anschein eines Eingriffs in ein schwebendes Verfahren erwecken könnte. Ich würde es daher vorziehen, wenn wir uns zu einem Gespräch über den Prozeßgegenstand nach Abschluß des Verfahrens treffen würden. ${ }^{68}$

Die Antwort von Staatssekretär von Dohnanyi verdeutlicht die distanzierte Haltung des AA gegenüber Amnesty International und deren Aufklärungsbemühungen. Der erwähnte Besuch Strätlings hatte zwei Jahre zuvor stattgefunden, nun machte AI das AA auf neue konkrete Hinweise über die CD-DINA Zusammenarbeit aufmerksam und statt auf die Bitte um ein Gespräch einzugehen, verwies von Dohnanyi auf das Bonner Zivilverfahren, in dem AI Beklagte war.

Der Bericht von Juan René Muñoz Alarcón gilt bis heute als wichtiger Beleg für die Rolle der CD im Repressionsapparat der chilenischen Militärdiktatur. Er zeigt, dass die $C D$ von Beginn an eine zentrale Funktion bei der geheimdienstlichen Informationsgewinnung und -verarbeitung, aber auch als Haft-, Folter- und Ermordungsstätte hatte.

Anfangs war nicht nur das Solidaritätsvikariat skeptisch, was Muñoz' Glaubwürdigkeit betraf. Auch andere Menschenrechtsorganisationen hegten Zweifel an den detailreichen Schilderungen des Kollaborateurs. ${ }^{69}$ Botschafter Strätling äußerte seine diesbezüglichen Zweifeln in seinen Berichten ans AA ebenfalls. ${ }^{70}$ Bis heute haben sich jedoch viele von Muñoz' Angaben als korrekt erwiesen. $\mathrm{Zu}$ dieser Bestätigung trugen Aussagen von Colonos vor Gericht, aber auch Auswertungen von Fichas aus dem CDGeheimarchiv bei. Gerd Seewald etwa berichtete bei seiner richterlichen Vernehmung 2006, DINA-Chef Contreras habe Muñoz in die CD gebracht:

»El primer contacto con lo militares debe haber sido en diciembre de 1973, cuando Manuel Contreras Ilegó [a Colonia Dignidad] junto a Muñoz Alarcón, este en calidad de detenido. En esa ocasión estaba Paul Schäfer presente. «"

68 Archiv Al, Bestand CD. Schreiben von Dohnanyi an Frenz vom 31.10.1978, CZ 331-531.45 CHL.

69 Heller, Colonia Dignidad: von der Psychosekte zum Folterlager, S. 144, schreibt: »Amnesty international nannte auch die Aussage des DINA-Agenten Muñoz als Beweismittel im Prozeß vor dem Bonner Landgericht. Hinter vorgehaltener Hand war allerdings von Menschenrechtsorganisationen zu hören, daß Muñoz zwar als DINA-Agent in der Siedlung gewesen sei, daß aber einige seiner Angaben nicht recht zu glauben seien.«

70 PA AA AV NA 31580. Bericht der Botschaft an das AA Nr. 101/79 vom 26.01.1979 (Pol/Rk 543). Darin schreibt Strätling: »Auch der Militärregierung kritisch gegenüberstehende Persönlichkeiten haben es gegenüber der Botschaft rundweg abgelehnt, zu den Muñozschen Beschuldigungen Stellung zu nehmen. So wird er auch von den Christdemokraten als allzu >schillerndeく Persönlichkeit betrachtet (Abwendung von der Sozialistischen Partei, Verdingung bei der DINA, Abwendung von der DINA), als daß diese ihn als unbedingt glaubwürdigen Zeugen ansehen würden.«

71 CA Santiago, AZ 2182-98 (»Asociacion Ilícita«), Bd. I (2), Bl. 549. Richterliche Vernehmung von Gerd Seewald vom 06.04.2006. Seewald irrt hier bei der Monatsangabe, da die Aussage der Ehefrau von Muñoz als auch die Eintragungen in den Karteikarten den Oktober 1973 als ersten Aufenthalt von Muñoz in der CD festhalten. 
Bei der Fortsetzung der Vernehmung am folgenden Tag beschrieb Seewald, Muñoz' Berichte seien auch in das CD-Geheimarchiv eingeflossen:

»Hay una trascripción en la ficha del mes de octubre de 1973, correspondiente a un informe por escrito, efectuado por Molli (es decir Muñoz Alarcón), detenido y colaborador llevado por Manuel Contreras. Fue de las primeras fichas que confeccioné por sus informes durante el año 1973. ${ }^{72}$

Die in den Fichas wiedergegebenen Spitzel-Berichte, die Juan René Muñoz Alarcón alias »Molli« in nächtlicher Arbeit vor allem über Mitglieder der Sozialistischen Partei

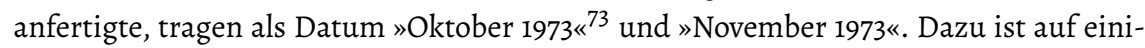
gen Karten auch der 20. Juni 1973 als Berichtsdatum angegeben ${ }^{74}$. Das bedeutet, dass Muñoz die Putschisten bereits mehrere Monate vor dem Staatsstreich mit Informationen versorgte. Wann diese Information in das CD-Geheimarchiv aufgenommen wurden, ist nicht bekannt. Die Eintragungen zu Muñoz selbst bestehen aus 18 Fichas. Sie legen nahe, dass dieser vor dem Putsch bei Attentaten rechtsextremer Gruppen gegen Mitglieder der Allende-Regierung eine wichtige Rolle gespielt haben könnte. ${ }^{75}$

Rätselhaft ist weiterhin, dass Muñoz in seinem Bericht an das Solidaritätsvikariat behauptet, die von ihm aufgezählten Gefangenen seien zum damaligen Zeitpunkt noch am Leben. Die meisten dieser Menschen wurden bereits 1974 und 1975 festgenommen. Aus Sicht der Täter_innen sind kaum Gründe vorstellbar, sie so lange am Leben zu halten, wenn sie ohnehin umgebracht werden sollten. Gleichzeitig gibt es bis heute unbestätigte Hinweise, dass sich in (der Nähe) der CD ein Arbeitslager befand, in dem Gefangene sehr lange festgehalten wurden (vgl. Abschnitt 4.2.3).

Auch die US-Botschaft in Santiago interessierte sich für den Fall Muñoz, wie aus einem Bericht des damaligen Botschafters Saul Landau an das State Department hervorgeht. ${ }^{76}$ Muñoz nannte in seinem Bericht an das Solidaritätsvikariat auch Kontaktpersonen der CIA in Chile:

»Otro hombre [...] muy importante es Daniel Galleguillos, esposo de Silvia Pinto. Ambos son los encargados de la $\mathrm{Cl}$ A aquí en este país, quien los dirige a ellos es James John Blayton de la Embajada Norteamericana y la secretaria chilena del embajador Sheila Fortno, con un colaborador inmediato que es un ex socialista tal como yo, quien cuenta con toda la confianza del Partido Socialista en este momento y es un traidor, llamado

72 CA Santiago, AZ 2182-98 (»Asociacion Ilícita«), Bd. II, BI. 671. Richterliche Vernehmung von Gerd Seewald vom 07.04.2006.

73 Allein die Berichte vom Oktober tragen fortlaufende Nummern von 1 bis 63.

74 Vgl. CD-Geheimarchiv. Fichas »Mario Guerra« und »Simón López«.

75 CD-Geheimarchiv, Ficha »]uan René Muñoz Alarcón (2)«. Hier ist beispielsweise unter dem Datum 20.06.1973 und dem Kürzel »Molli-Danilo« vermerkt: »A MUNOZ le han encargado de matar a LEICHTON y hacer volar el auto de ELIANA BOCCA«.

76 DB der US-Botschaft in Santiago an das State Department vom 16.12.1977. CZ Santiago 10081. Subject: The strange case of Juan Munoz: Ambassador's social secretary questioned, online unter htt ps://foia.state.gov/documents/pinochet/94C5.pdf. 
Hugo Vicencio. Es el responsable de la caída de Exequiel Ponce y de todos los que han caído últimamente. ${ }^{77}$

Richter Faúndez hatte Sheila Fortuno, Mitarbeiterin der Botschaft, vorgeladen, welche Botschafter Landau zufolge sagte, sie kenne Muñoz nicht. Eine anschließende Recherche in den Akten der US-Botschaft habe jedoch ergeben, dass Muñoz zwei Mal in der Botschaft gewesen sei, am 29. Mai 1973 sowie am 15. Januar $1976 .{ }^{78}$ Bei seinem ersten Besuch hatte Muñoz Fortuno berichtet, er werde von der Sozialistischen Partei verfolgt und fürchte um sein Leben. Beim zweiten Besuch verwies Fortuno ihn an den Regional Security Officer Blystone, dem er dann von einer geplanten Entführung des Botschafters berichtete. Ferner habe Muñoz um Asyl gebeten, was ihm jedoch verweigert wurde. Später habe Fortuno sich dann an beide Begegnungen erinnert, von denen auch Protokolle angefertigt worden seien. Der Botschaftsbericht endet mit den Worten:

"Since Ms. Fortuno answered the court to the best of her knowledge at the time, we see no reason to volunteer the additional information we have on Muñoz. Should the court again ask Ms. Fortuno to testify, we will address the issue of the embassy's responsibility to protect the confidentiality of its information and of persons meeting with our personell. Until such time, we plan to let the matter rest. « ${ }^{79}$

Ein weiterer ungeklärter Aspekt aus Muñoz' Bericht ist die Erwähnung eines Sozialisten namens Hugo Vicencio.

Mit Hugo Vicencio ist vermutlich Jaime López Arellano gemeint, ein Mitglied der Sozialistischen Partei, das 1975 verdeckt für die DINA arbeitete und vermutlich die Informationen lieferte, die zur Festnahme des Zentralkomitees der Partei führten, darunter Carlos Lorca, Exequiel Ponce und Ricardo Lagos. López, der sich in den Jahren nach dem Putsch mehrfach in der DDR aufhielt und in einer Beziehung mit der späteren chilenischen Präsidentin Michelle Bachelet lebte, wurde Ende 1975 von der DINA verhaftet und in die Villa Grimaldi verbracht. Seitdem galt er als Verschwundener. Diverse Informationen legen jedoch nahe, dass er mit der DINA kollaborierte und möglicherweise eine neue Identität erhielt. ${ }^{80}$

Die Episode Muñoz verdeutlicht, dass in den Jahren der Existenz der DINA (19731977) bereits diverse Informationen über die CD-DINA Verbindungen im Raum standen und auch bundesdeutschen (und US-)Diplomat_innen zur Kenntnis gelangten. Ein ähnlich gelagerter Fall war der des DINA-Agenten Miguel Becerra, der ebenfalls aussteigen wollte und 1974 von der CD ermordet wurde (Vgl. Abschnitte 4.2.1 und 4.2.3).

PA AA, ZW 111131. 11. Juzgado del Crímen, AZ 12.293 (»Homicidio de Juan René Muñoz Alarcón«), Bl. 14-26. Bericht Juan René Muñoz Alarcón von 1977.

78 DB der US-Botschaft in Santiago an das State Department vom 16.12.1977. CZ Santiago 10081. Subject: The strange case of Juan Munoz: Ambassador's social secretary questioned, online unter htt ps://foia.state.gov/documents/pinochet/94c5.pdf.

79 Ebd.

80 Vgl. Azócar, Juan. El enigma Jaime López, in: The Clinic vom 13.01.2015, online unter https://www.th eclinic.cl/2015/01/13/el-enigma-jaime-lopez/sowie CA Santiago, AZ 47.518 (»Comité Central Partido Socialista«). Urteil vom 17.12.2018. 


\subsubsection{Untersuchungen durch die Richter Navas und Robert (1989)}

Am 4. Januar 1989 übersandte der chilenische Außenminister Hernán Felipe Errázuriz der Corte Suprema die Berichte von Hugo Baar ${ }^{81}$ sowie Lotti und Georg Packmor ${ }^{82}$ und beantragte die Abordnung eines Ministro en Visita zur Untersuchung möglicher Straftaten der $\mathrm{CD} .{ }^{83}$ Er bezog sich dabei auf die chilenische Gerichtsverfahrensordnung, ${ }^{84}$ die dieses Instrument vorsieht für Fälle, die möglicherweise internationale Verstimmungen auslösen. ${ }^{85}$ Am 13. Januar 1989 informierte Errázuriz Bundesaußenminister Genscher, dass die Corte Suprema seinem Antrag stattgegeben habe. ${ }^{86}$ Zum ermittelnden Richter am Gericht in Parral wurde Richter Guillermo Navas Bustamante von der CA in Chillán ernannt. ${ }^{87}$ Er erhielt den Auftrag, die Vorwürfe in den vom Außenministerium überreichten Dokumenten zu prüfen und gegebenenfalls Strafverfahren einzuleiten. Doch am 15. März 1989 wurde Navas überraschend durch einen Beschluss der Corte Suprema von seiner Funktion entbunden und durch Richter Hernán Robert Arias von der CA Talca ersetzt. ${ }^{88}$ Ende Juli 1989 legte Robert der Corte Suprema seinen Untersuchungsbericht vor. ${ }^{89}$ Darin schrieb er, keine Beweise für Freiheitsberaubungen oder Körperverletzungen gefunden zu haben. Allerdings eröffnete er zwei Strafverfah-

81 PA AA, B 83, Bd. 2384. Bericht Hugo Baar an die deutsche Botschaft vom 02.04.1985.

82 PA AA, B 83, Bd. 2384. Bericht Georg und Lotti Packmor an die deutsche Botschaft vom 15/17.03.1985.

83 PA AA, AV NA 31595. Schriftsatz RA Pacheco an die Corte Suprema vom 16.08.1989. Anlage Petición de Ministro Errazuriz por Oficio Reservado No. 00080 y 00081 , invocando el artículo 560 No. 1 del Codigo Organico de Tribunales Oficios Reservados 00080 und 00081 vom 04.01.1989.

84 Diario Oficial vom 09.07.1943. Ley 7421 que aprueba Código Orgánico de Tribunales, § 560 I.

85 Die Bezugnahme auf diesen Paragraphen war ein Novum, er war niemals zuvor zur Anwendung gekommen. Unklar ist, ob Errázuriz einen neuen Antrag direkt bei der Corte Suprema gestellt hatte oder ob er Berufung gegen eine vorherige Ablehnung der CA in Chillán eingelegt hatte.

86 PA AA, AV NA 31596. DB 32 vom 16.01.1989, CZ Pol'RK 543.00 an 330, Betr: CD Hier: Brief des chilenischen $A M$ an BM Censcher.

87 Vgl. La Segunda vom 12.01.1989, S. 28, „Suprema nombró Ministro en Visita para el caso de Colonia Dignidad «.

88 PA AA, AV NA 31601. DB144 vom 15.03.1989, GZ Pol/Rk 543.00. Betr: Colonia Dignidad hier: Wechsel des Untersuchungsrichters. Offiziell wurde dieser Schritt mit einer Neuordnung der Gerichtsbezirke begründet, nachdem nunmehr die CD nicht mehr in den Gerichtsbezirk Chillán, sondern in den Bezirk Talca fiel. Die Botschaft schrieb dazu per Drahtbericht nach Bonn: »1. Am 15.03. um 13 Uhr beschloß das Oberste Gericht, Richter Navas vom Appelationsgericht Chillán durch Richter Hernán Robert Arias vom Appelationsgericht Talca zu ersetzen. [.] 2. Der Beschluß stützt sich auf das Gesetz Nr. 187776 vom 18.01.1989, mit dem verschiedene Gerichtsbezirke Chiles an die bestehenden Verwaltungsbezirke Chiles angepasst wurden. Darunter fiel auch der Cerichtsbezirk Parral, der bisher zum Bezirk der CA Chillán gehörte, obwohl die Kommune Parral von Talca (Region Maule) aus verwaltet wird (jetzt Gerichtsbezirk der CA Talca). Der vom Obersten Cericht verfügte Wechsel des Untersuchungsrichters ist zwar nach verbreiteter Auffassung rechtlich möglich, war aber nicht zwingend, da Einsetzung Navas vor Änderung der Cerichtsbezirke erfolgte.«.

89 Juzgado de Letras de Parral, AZ 43.210. Informe sobre Investigación a Colonia Dignidad, Ministro en Visita Extraordinaria Hernán Robert Arias, Ministro I. CA Talca. o. D. Von Richter Robert am 31.07.1989 der Corte Suprema übergeben. Enthalten in: CA Santiago, AZ 2182-98 (»Asociación Ilícita «) Bd. I (2) (Parral), Bl. 585-676. 
ren gegen Colonos: Eines wegen Betruges, ${ }^{90}$ aufgrund der Übertragung von Vereinsvermögen der SBED an einzelne Colonos und eines wegen unerlaubter Berufsausübung gegen Gisela Seewald. ${ }^{91}$ Diese hatte ihren deutschen Arzttitel nie in Chile anerkennen lassen. Die Corte Suprema nahm Roberts Bericht am 8. September 1989 an und übertrug gleichzeitig die beiden Verfahren an Richterin Lydia Villagrán am Gericht in Parral, eine der CD sehr wohlgesonnene Richterin. ${ }^{92}$ Beide Verfahren wurden später eingestellt.

\section{Die Vorgeschichte}

Das AA hatte die Berichte von Hugo Baar sowie Lotti und Georg Packmor von 1985 lange Zeit den chilenischen Behörden vorenthalten. Sie hatte sie lediglich der Staatsanwaltschaft Bonn zur Verfügung gestellt, die ein Ermittlungsverfahren wegen »Freiheitsberaubung, Körperverletzung usw. «gegen Paul Schäfer eingeleitet hatte. ${ }^{93}$ Auf dem Wege der stillen Diplomatie versuchte das AA zwischen 1985 und 1987, die chilenische Militärregierung von der Notwendigkeit juristischer Untersuchungen gegen die CD zu überzeugen. Unter anderem kontaktierte die Botschaft Rodolfo Stange, den deutschstämmigen General der Carabineros. Dieser gab jedoch vor, in der Sache nichts unternehmen zu können. ${ }^{94}$ Im Oktober 1987 bat Botschafter Kullak-Ublick das AA um Erlaubnis, dem chilenischen Außenminister Hernán García die beiden Berichte zur Verfügung stellen zu dürfen. Das AA lehnte dies unter Hinweis auf die Vertraulichkeit der Dokumente ab. ${ }^{95}$ Die Weigerung der CD, in den darauffolgenden Wochen die gesetzlich vorgege-

90 Juzgado del Crimen de Parral, AZ 43.899.

91 Juzgado del Crimen de Parral, AZ 43.900.

92 PJS, Sammlung CD. Barbara Hayes Frabasile. Colonia Dignidad: Una historia de horror, sexo y poder. Unveröffentlichtes Manuskript, Santiago, 2005, S. 275. Laut Jaime Naranjo, ehemaliger Senator und heutiger Abgeordneter der PS, mietete die Richterin Villagrán eine Wohnung in Parral, die der CD gehörte.

93 StA Bonn, AZ 50 ]s 285/85.

94 PA AA, AV NA 31577. Bericht Botschaft an AA Nr. 1095/85 vom 3.10.1985, GZ DsaK, Abg. 9.10.1985. Botschafter Holzheimer übersandte Ceneral Stange bereits am 30.05.1985 eine Kopie des Packmor-Berichts. Nach mehreren weiteren Kontakten mit Stange berichtete Holzheimer am 03.10.1985 nach Bonn: »Bei einem Cespräch am 3.10 hat der Chef der Polizei, Ceneral Stange, mitgeteilt, daß die Bemühungen seiner Organe, Verantwortlichen in der Colonia Dignidad strafbare Handlungen nachzuweisen, völlig vergeblich gewesen seien. Man sei auf einer Mauer des >Nichtwissens und des Schweigens gestoßen. General Stange erklärte, daß nunmehr nur eine Anzeige mit entsprechenden Anhaltspunkten zum Erfolg führen könne.«

95 Kullak-Ublick hatte am 23.10.1987 an das AA gekabelt: »Außenminister García rief mich am 22.10 vor seiner Abreise nach Europa persönlich wegen des Falles CD an. Der Vorgang läge auf seinem Tisch. Er hat mich zu einem Gespräch unmittelbar nach seiner Rückkehr am Freitag 30. Oktober gebeten. Ich gehe davon aus, dass AM dieses Thema mit gleicher Effizienz in die Hand nehmen wird wie seinerzeit den Fall Brinkmann, den er in enger Anlehnung mit mir zu Ende brachte. Aus diesem Grund bitte ich, keine weiteren Schritte zu unternehmen, bevor dieses grundsätzliche Gespräch zwischen Aussenminister und mir stattgefunden hat. «PA AA, AV NA 31583. DB 396 vom 23.10.1987. In einem weiteren DB vom selben Tage fügt er an: »Für mein Gespräch mit Aussenminister García am 30. Oktober erbitte ich Autorisation, dass ich ihm die Protokolle der Ehepaare Baar und Packmor ganz oder teilweise zugängig machen kann. Die Schwere der Aussagen in diesen Protokollen ist Basis für die von uns eingeleiteten administrativen, rechtlichen und politischen Schritte. «PA AA, AV NA 31583. DB 397 vom 23.10.1987. Das AA antwortet ihm am 27.10: »Botschaft wird gebeten, in obiger Angelegenheit wie folgt zu verfahren: Protokolle Baar und Packmoor kön- 
benen Regeln bei konsularischen Vorgängen zu akzeptieren sowie das Scheitern der im Dezember 1987 von Genscher entsandten sogenannten »Hubschrauberdelegation« führten im AA zu so starken Verstimmungen, dass dieses einer Übergabe der Berichte schließlich zustimmte. Am 21. Dezember 1987 übersandte Botschafter Kullak-Ublick die Unterlagen offiziell an García. ${ }^{96}$

Im Januar 1988 bat Außenminister Genscher auf dieser Grundlage seinen chilenischen Kollegen García, gerichtliche Untersuchungen zum Fall CD einzuleiten. ${ }^{97}$ Im Februar wurden dem chilenischen Außenministerium eine Reihe staatsanwaltlicher Vernehmungsprotokolle und weitere Dokumente übergeben. ${ }^{98}$ Begleitend dazu veröffentlichte die Botschaft eine Pressemitteilung. Darin wurden Vorwürfe der 1984/85 aus der CD geflohenen Personen benannt:

»Con relación a diversas publicaciones de prensa publicadas en los últimos dias sobre la Colonia Dignidad y su relacion con la embajada de la República Federal de Alemania esta Misión Diplomática señala lo siguiente: [...] La Embajada supone que aproximadamente 300 ciudadanos alemanes viven en la Sociedad (CD). La obligacion legal de esta Embajada conforme a la legislacion nacional alemana y el derecho internacional es el de prestar ayuda y apoyo tanto a los ciudadanos alemanes mencionados anteriormente como a todos los demas ciudadanos alemanes residentes en Chile. [...]

Después de que en los años 1984/85 dos matrimonios abandonaron la Colonia, acusando gravemente a la dirección de la la CD, la opinión pública alemana se ha mostrado especialmente preocupada por el destino de las personas ahí residentes. Sobre todo,

nen so nicht weitergeleitet werden, da nicht bekannt ist, ob sich deren Haltung wegen Angst vor Repressalien gegen in CD lebende Familienangehörige geändert hat. Herr Baar hatte am 13.8.1985 im AA erklärt, sein Bericht sei in erster Linie für die dt. Behörden bestimmt. Daher sollten nur die in den Protokollen -erhobenen Vorwürfe - in ihrem wesentlichen Gehalt ohne Quellenangabe zur Begründung unseres Wunsches auf Unterstützung einer Untersuchungsdelegation durch die chil. Regierung benutzt werden.«PA AA, AV NA 31583. DE 233 vom 27.10.1987, GZ: 330.504.00 CHL. Bei seinem Gespräch mit AM García am 30.10 übergab Kullak-Ublick lediglich eine Liste der aus den Berichten hervorgehenden Tatbestände und kabelte nach Bonn: »Nachdem Übergabe der Protokolle von Baar und Packmor an Außenminister gemäß Bezugserlass nicht zuggestimmt worden ist, übergab ich bei Besprechung am 30.10 folgende Aufstellung von Vorwürfen, die in Deutschland aktenkundig sind und unmittelbares Handeln von uns erfordern: Freiheitsberaubung, sexueller Mißbrauch von Minderjährigen, vorsätzliche Körperverletzung an Erwachsenen und Kindern, Mißhandlung und Folter, Medikamentenmißbrauch, Kinderarbeit, Verletzung des Briefgeheimnisses, Betrug, Urkundenfälschung, Trennung der Familien, Eltern von ihren Kindern, Männer von ihren Frauen.«PA AA, AV NA 31583. DB 407 vom 30.10.1987.

96 PA AA, AV NA 31578. Schreiben Botschafter Kullak-Ublick an AM García vom 21.12.1987.

97 PA AA, AV NA 31593. Vermerk Konsul Haller vom 11.02.1988, GZ RK 543.00, Betr: Kolonia Dignidad; hier Stellungnahme zu den Empfehlungen der Sachverständigenkommission.

98 PA AA, AV NA 31578. Schreiben Kullak-Ublick an AM García vom 17.02.1988. Am 17.02.1988 übersandte Kullak-Ublick Außenminister García folgende Vernehmungsprotokolle aus dem Verfahren StA Bonn, AZ 50 ]s 285/85: Hugo Baar, Vernehmung vom 29.08.1985 in Cladenbach und vom 27.10.1987 in Bonn; Ceorg und Lotti Packmor, Vernehmung vom 04.11.1985 in Gronau; desweiteren ein Schreiben von Waltraud Baar an Botschafter Holzheimer vom 25.05.1985 (alles in spanischer Übersetzung). 
los familiares en Alemania han solicitado al Gobierno de la RFA informaciones relacionadas al bienestar de sus parientes. [...]

La declaraciones hechas por los dos matrimonios que habían abandonado la CD en los años 1984/85, comprometen, junto con la direccion de Colonia, especialmente al ciudadano alemán Paul Schäfer, residente allí. Actualmente, ante el Juzgado de primera instancia de Bonn está pendiente un sumario en contra del señor Paul Schäfer, con el fin de comprobar su responsabilidad en diferentes casos de detención ilegal continua y daño corporal contra personas y otros delitos cometidos contra ciudadanos alemanes residentes en la $C D$.

Las declaraciones hechas por los dos matrimonios que abandonaron la $C D$ en los años 1984/85 fueron entregadas al Cobierno chileno, tratándose de delitos cometidos en territorio chileno y bajo la jurisdicción chilena. El Cobierno de la RFA tiene la esperanza que las autoridades chilenas pertinentes inicien una investigacion con el fin de aclarar las acusaciones presentadas en contra del directorio de la CD y contra Paul Schäfer. «99

García holte zunächst die Meinung des Staatsverteidigungsrates (CDE) ein. ${ }^{100}$ Im März 1988 beantragte er bei der CA Chillán die Einleitung eines Verfahrens wegen des Vorwurfs der Freiheitsberaubung sowie der Verletzung der Privatsphäre. ${ }^{101}$ Das Gericht lehnte dies jedoch aus formalen Gründen $a b .{ }^{102}$ Die CD lancierte sofort eine juristische Gegenoffensive: Mitglieder der SBED stellten beim selben Gericht einen Schutzantrag

99 PA AA, AV NA 31590. Nota de Prensa de la Embajada de la República Federal de Alemania en Santiago, o. D. [Ende Februar 1988]. Später berichtete die Botschaft nach Bonn, dass die SBED am 01.03.1988 eine Pressemitteilung in Reaktion auf die Pressemitteilung der Botschaft herausgegeben habe. PA AA, AV NA 31590. DB 91 vom 04.031988.

100 PA AA, AV NA 31683. Oficio Secreto no. 2 del Presidente Subrogante del CDE al sr. Director Juridico del Ministerio de Relaciones Exteriores vom 19.02.1988 sowie Oficio Secreto no. 03 del Presidente del CDE al sr. Director de Política Bilateral del Ministerio de Relaciones Exteriores vom 02.03.1988. Im ersten Schreiben argumentiert der CDE, dass eine Strafanzeige Ausgangspunkt jeglicher gerichtlicher Untersuchungen in Chile sein müsse. Diese könne entweder von den Betroffenen selbst, von ihren Angehörigen oder von der Bundesregierung eingereicht werden. Im zweiten Schreiben präzisiert der CDE, dass im Falle einer Einschränkung verfassungsmäßig garantierter Rechte, wie Freiheitsberaubung oder Verletzung der Privatsphäre durch Verletzung des Postgeheimnisses ein Offizialverfahren eingeleitet werden solle.

101 PA AA, AV NA 31578. Oficio Reservado No 02126 del Ministro de Relaciones Exteriores al Sr. Presidente de la Corte de Apelaciones de Chillán vom 10.03.1988. García übersandte dem Cericht in Anlage alle von der Botschaft zur Verfügung gestellten Aussagen und Schriftstücke von Hugo Baar sowie Ceorg und Lotti Packmor.

102 PA AA, AV NA 31578. Acuerdo Pleno de Minstros de la Corte de Apelaciones de Chillán (Guillermo Herrera Navarrete, Guillermo Cocio Paredes, Guillermo Navas Bustamante, Sonia Araneda Briones) vom 18.04.1988. Darin heißt es, die Richter lehnten es ab, sich zur Sache zu äußern, da die übergebenen Schriftstücke formal keinerlei Beweiswert aufwiesen: »El análisis de las comunicaciones y anexos recibidos revela que se trata de copias informales de declaraciones que habrían sido prestadas por cuatro personas en uno o más procesos penales seguidos en el extranjero y referidos a hechos ocurridos en fechas imprecisas. Por ende, antecedentes truncos, carentes de firmas y formalmente de valor para impetrar alguna accion a su respecto, por manera tal que su materialidad impide a esta Corte entrar a pronunciarse al tenor de lo requerido por el senor Ministro don Ricardo García Pérez.« 
gegen Horst Kriegler, den bundesdeutschen Konsul in Concepción. ${ }^{103}$ Kriegler hatte in einem Interview angedeutet, möglicherweise verletze die CD persönliche Freiheiten. ${ }^{104}$

Im April 1988 übersandte García der CA Chillán die Berichte, Aussagen und Vernehmungsprotokolle von Baar und den Packmors erneut, diesmal in legalisierter Form. Das Gericht wiederholte jedoch seine negative Entscheidung und stellte das Verfahren erneut ein. ${ }^{105}$ Im Oktober 1988 startete García seinen letzten Anlauf, um eine Verfahrenseröffnung zu erreichen. Dabei berief er sich auf die chilenische Gerichtsverfahrensordnung (siehe oben) und beantragte die Einsetzung eines ministro en visita. ${ }^{106}$ Außerdem fügte er den Unterlagen weitere Zeug_innenaussagen hinzu. ${ }^{107}$ Am 21. Oktober wurde García als Außenminister von Hernán Felipe Errázuriz abgelöst. Unterdessen lehnte die CA Chillán am 13. Dezember 1988 auch Garcías dritten Antrag ab. ${ }^{108}$

103 Am 30.03.1988 stellten Manfred Skrabs und andere Colonos über den CD-Anwalt Fernando Saenger bei der CA Chillán einen Schutzantrag. PA AA, AV NA 31681. CA Chillán, Recurso de Protección Manfred Skrabs u.a. vom 20.03.1988. Zum Fortgang dieses Schutzrekurses vgl. auch: Lauterpacht, E./Greenwood, C. J. (Hg.) International Law Reports, Vol. 89, Cambridge, 1992, S. $60 f$.

104 In einem Interview in El Sur »Afirma consul alemán-Caso Dignidad no es político « vom 17.03.1988 sagte Kriegler, es gehe nicht um Politik, aber die deutsche Regierung müsse das Wohlergehen deutscher Staatsangehöriger sicherstellen: »Yo creo que el asunto no es político. Se trata de una preocupación propia de la tarea que deben cumplir los representantes del gobierno alemán que deben interesarse por lo que sucede con los ciudadanos alemanes [...] Hay una preocupacion porque existen indicios de que esos ciudadanos no viven en plena libertad, que - posiblemente hayan situaciones en lo que respecta al trato de salud y derechos humanos. «Die CD antwortete mit einem Leserbrief an die Zeitung El Sur, den 233 Colonos unterschrieben. Darin bestätigen die Unterzeichnenden, aus eigenem Willen in der CD zu sein und dort alle Freiheiten zu genießen: »Miembros de Dignidad contestan al consul. 1. Es y ha sido mi propio y personal deseo y voluntad el vivir y trabajar como miembro activo de la SBED en su fundo: 2.Durante mi permanencia en el fundo de la Sociedad he tenido la mas absoluta libertad en todo sentido 3.Tengo absoluta libertad para salir del fundo cuando yo lo desee 4. Deseo que la presente Declaracion Jurada sirva como testimonio fehaciente de que siendo yo un ciudadano libre, tengo dentro de la Sociedad los normales derechos y deberes que corresponden a todos los hombres libres del mundo. « Artikel und Leserbrief enthalten in: PA AA, AV NA 31681.

105 PA AA, AV NA 31683. CA Chillán, AZ 17-1988. Beschluss vom 03.05.1988.

106 PA AA, AV NA 31587. DB 597 vom 09.11.1988, GZ: pol rk 543.00. Betr. CD hier: weiteres Vorgehen.

107 Es handelte sich um die Aussagen von Heinz Kuhn, Wolfgang Kneese und Botschafter KullakUblick bei der StA Bonn. PA AA, AV NA 31589. Schriftsatz RA Fernando Saenger, von RA Pacheco der Botschaft übersandt am 11.01.1989.

108 El Mercurio vom 15.12.1988, S. C6, »Abogado de >Colonia Dignidadর: Fallo está ajustado a hechos y derecho«. Auch der im Januar 1989 zum Ministro en Visita ernannte Guillermo Navas stimmte gegen die Einleitung einer Untersuchung. Bei Salinas/Stange, Los amigos del »Dr.« Schäfer, S. 202 wird angedeutet, die Zusammensetzung der CA Chillán könnte verantwortlich dafür gewesen sein, dass kein Verfahren eröffnet wurde: »Tres veces consecutivas, durante todo el año 1988, la corte de Chillán rechazó las solicitudes del gobierno alemán. Los ministros de la corte señalaron que los antecedentes presentados eran struncos, carentes de firmas, correspondían a testimonios hechos en el extranjero y en fechas imprecisas ‘. ¿Por qué los denunciantes no testificaron ante tribunales chilenos?, preguntaron los magistrados. La misma composición de la corte de Chillán era una buena respuesta a la pregunta. Su presidente, el juez Guillermo Herrera, había sido juez en Parral y era claro simpatizante de la colonia, ál igual que el ministro Guillermo Navas. Fernando Saenger, abogado integrante de la Corte de Apelaciones de Concepción, era también representante del en- 
Außenminister Genscher schrieb daraufhin am 19. Dezember 1988 seinem Amtskollegen einen Brief. Darin brachte er seine Bestürzung über die Entscheidung des Gerichts zum Ausdruck und bat darum, die erforderlichen Maßnahmen für Ermittlungen durch die nächsthöhere gerichtliche Instanz zu treffen. Genscher fügte an:

»die Bundesregierung und die deutsche Öffentlichkeit erwarten, dass die chilenische Justiz die notwendigen und möglichen Schritte für die Einleitung eines strafrechtlichen Verfahrens gegen die Führung der CD unternimmt. Wie mir bekannt ist, enthält das chilenische Recht klare Regelungen, die auch die Auswirkungen von Rechtsverfahren auf die auswärtigen Beziehungen in Rechnung stellen. ${ }^{109}$

Der neue chilenische Außenminister Errázuriz antwortete Genscher am 13. Januar 1989:

»Es wird darauf hingewiesen, dass die Regierung Chiles durch dieses Ministerium den Wünschen Ihrer Regierung bezüglich der Colonia Dignidad angemessen entsprochen hat.

Mit gestrigem Datum hat der Oberste Gerichtshof dem Gesuch der Einsetzung eines >Ministro en Visita< entsprochen. Diesem unterliegt die Untersuchung und Bewertung der Vorfälle und Vorwürfe. In diesem Gerichtsverfahren, mit dem sich dieses Ministerium weder befasst noch zu dem es Partei ergreift, wird die Intervention der Anwälte, die ihre Botschaft ernannt hat, entscheidend sein. « $^{110}$

Bei einem Gespräch mit Octavio Errázuriz, dem Generaldirektor des Außenministeriums, erfuhr Botschafter Holzheimer, dass Außenminister Hernán Felipe Errázuriz persönlich zur Corte Suprema gegangen sei, um den Berufungsantrag zu begründen. Dies sei einmalig in der jüngeren chilenischen Geschichte. Zum ersten Mal sei daraufhin $\$ 560$ der chilenischen Gerichtsverfahrensordnung zur Anwendung gekommen. Nun liege das Verfahren in der Hand des Sonderrichters, die chilenische Regierung habe nun keinen Einfluss mehr darauf. Die deutsche Seite könne jedoch, so Holzheimer, "noch manches $\mathrm{zu}$ einer gründlichen Untersuchung beitragen, z.B. indem wir neue Zeugen herbeischaffen oder einen der bisherigen Zeugen dazu bringen, Klage anzustrengen. «111

\section{Das Untersuchungsverfahren}

Der politische Hintergrund für die hier geschilderten Ereignisse ist das Referendum vom 5. Oktober 1988. Gemäß der Verfassung von 1980 hatte Pinochet über eine mögliche dritte Amtszeit abstimmen lassen. Die Abstimmung endete mit einem Nein, das Ende der Militärdiktatur war damit absehbar. Die chilenische Justiz leitete das Verfahren, das vor allem die politische Rechte als Einmischung in die inneren Angelegenheiten

clave en diversos procesos. ¿Por qué los denunciantes no testificaron en Chile? Porque era como testificar dentro de la propia Colonia Dignidad.« 
Chiles betrachtete, nur widerwillig ein. Sie leitete eine Untersuchung ein, deren genauer Auftrag von Anfang an nicht klar definiert war. Formal betrachtet handelte es sich nicht um ein Strafverfahren, sondern um ein Verwaltungsverfahren, im dem geklärt werden sollte, ob die Voraussetzungen für die Einleitung eines Strafverfahrens vorlagen. Während die Bundesregierung eine umfassende Untersuchung sowie die anschließende Einleitung eines Strafverfahrens erwartete, beharrte die chilenische Regierung auf der Unabhängigkeit der Justiz, wissend dass diese der Untersuchung weitgehend ablehnend gegenüberstand. Der zur Untersuchung abgeordnete Richter Guillermo Navas hatte als Mitglied der CA Chillán zuvor die Eröffnung eines Verfahrens gegen die CD mehrfach abgelehnt. Außenminister Errázuriz wies Genscher gleich zu Beginn des Verfahrens darauf hin, dass sich die Regierung aus dem Verfahren heraushalten würde, da sie den Fall CD nicht als »schlüssig belegt « betrachtete. ${ }^{112}$ Gleichzeitig forderte er die Bundesregierung auf, selbst Strafanzeige zu stellen bzw. Geschädigte dazu zu bringen, Nebenklage einzureichen. ${ }^{113}$ Auch Máximo Pacheco, Rechtsanwalt der Botschaft, verwies frühzeitig auf die Dringlichkeit von Strafanzeigen durch Botschaftsangehörige, Angehörige von Colonos oder chilenische Geschädigte. ${ }^{114}$ Solche Strafanzeigen - von der Bundesregierung gestellt oder von Geschädigten, die politische Rückendeckung von der Bundesregierung erhielten - hätten einen großen Druck auf die CD und die chilenische Justiz ausgelöst. Gleichzeitig hätte sich die Bundesregierung dadurch in eine offene Auseinandersetzung mit der CD begeben, was ihrer Leitlinie, der chilenischen Seite die Verantwortung für die Aufklärung zuzuweisen, zuwiderlief.

Das AA wollte keinesfalls selbst Teil des Verfahrens werden, erwog jedoch zeitweise die Möglichkeit, Anzeigen bzw. Nebenklagen von geflüchteten Colonos zu unterstützen. $\mathrm{Zu}$ diesem Zweck ließ die Botschaft von RA Sergio Corvalán eine Musterklage anfertigen. ${ }^{115}$ Corvalán forderte für die Übernahme eines Mandats eine Mitübernahme durch RA Pacheco und eine Einbeziehung der Botschaft. Die Botschaft berichtete hierzu ans AA: »Motiv für diese Forderung ist die nicht unverständliche Furcht, im Fall von Repressalien auf sich alleine gestellt zu sein und der Wunsch nach Absicherung. " ${ }^{116}$ Letztlich wurde Corvalán nicht beauftragt. Die potenziellen Nebenkläger_innen hatten Angst vor einer Reise nach Chile sowie vor Verleumdungsklagen der $C D$. Zudem verlangten sie vom AA eine vollständige Kostenübernahme, ${ }^{117}$ wozu dieses nicht bereit war. ${ }^{118}$

Die Rahmenbedingungen für das Untersuchungsverfahren waren dementsprechend ungünstig: Während beide Regierungen sich formal aus dem Verfahren heraushielten, sollte ein einzelner Richter aus den Reihen des Justizapparates der chilenischen Diktatur, der sich in den Jahren zuvor stets der CD wohlgesonnen gezeigt hatte, die Vorwürfe untersuchen. Carlos Camus, Bischof von Linares und erklärter Gegner der Diktatur sowie der $\mathrm{CD}$, erklärte, dass er ohne einen demokratisch verfassten

114 PA AA, AV NA 31596. Schreiben Pacheco an Knackstedt vom 17.01.1989.

115 PA AA, AV NA 31601. DB 133 vom 10.03.1989, GZ Pol/Rk 543.00. Stellungnahme zur Musterklage Schaffrik gegen Schäfer.

116 Ebd.

117 Archiv AI, Bestand CD. Schreiben Waltraud Baar an die Botschaft vom 09.02.1989.

118 PA AA, AV NA 31601. DE 74 vom 31.03.1989, GZ 330-504.00. 
Rechtsstaat in Chile keine Möglichkeiten zur Aufklärung der Geschehnisse in der CD sah:

\begin{abstract}
»Desgraciadamente yo soy muy escéptico. No creo que en estas condiciones se pueda conocer la verdad. Pienso que mientras no tengamos en Chile un gobierno democrático con plena libertad y donde tengamos plena separación de los poderes del Estado y los Jueces puedan actuar en conciencia, va a ser imposible descubrir la verdad de lo que ocurre en Colonia Dignidad [...] no es que desconfíe del ministro en visita, pero pienso que él está muy limitado y debe tener mucho miedo. Se me ocurre que es imposible que él pueda hacer frente a una organización tan poderosa donde con tantos medios y tanto apoyo él se encuentra solo tratando de averiguar la verdad. Tendría que ser un héroe y es muy difícil encontrarlo hoy en día. ${ }^{119}$
\end{abstract}

Auch die Botschaft war von Beginn an skeptisch und zweifelte an dem Aufklärungsinteresse der chilenischen Justiz. Sie beauftragte RA Pacheco, sie im Untersuchungsverfahren zu vertreten. Wie bereits bei den Rechtshilfeersuchen aus dem Zivilverfahren des LG Bonn ${ }^{120}$ wurde Pacheco dabei von RA Corvalán und RA Guillermo Ceroni unterstützt. Formal war die Bundesrepublik jedoch nicht Teil des Verfahrens. RA Ceroni äußerte gegenüber der Presse die Hoffnung, die Einsetzung von Untersuchungsrichter Navas würde zur Einleitung von Strafverfahren führen, in denen dann Opfer, aber auch die Bundesrepublik zu Nebenklägerinnen werden könnten. ${ }^{121}$ Kurz nach Beginn der Ermittlungen von Navas berichtete Botschafter Knackstedt nach Bonn:

»Befremdet haben hier die Äusserungen des Untersuchungsrichters vor der Presse. Er erklärte u.a. dass er nicht verstehen könne, dass die ehemaligen Angehörigen der CD, die sich in D befinden, ihre Anschuldigungen nicht in Chile vorgebracht hätten. Hier wäre ihnen, wie vielen anderen, die Beschuldigungen vorgebracht hätten, vermutlich nichts passiert. Und als persönliche Bemerkung fügte er hinzu, diese Einstellung der geflüchteten CD-Bewohner sei >um das wenigste zu sagen, eine Beleidigung dem chilenischen Staat gegenüber mit allen seinen Institutionen, Gerichten und Gesetzen.< Untersuchungsrichter Navas hat auch betont, dass er die Ermittlungen so behutsam wie möglich führen wolle, um den Namen einer swohltätigen Cemeinschaftı, die ja die Kolonie sei, nicht unnötig zu belasten. [...] Wir sind über die Äußerungen [...] besorgt. Obwohl der Richter gegenüber RA Pacheco geäussert hatte, dass er sich zunächst einen Cesamtüberblick verschaffen wolle, bevor er in die eigentlichen Ermittlungen eintrete, tritt er schon mit Erklärungen gegenüber der Presse hervor, die Verständnis gegenüber Dignidad erkennen lassen. [...] Es scheint mir von großer Wichtigkeit, dass einer oder mehrere der ehemaligen CD-Bewohner Klage erheben. Mit Kurier habe ich eine Liste mit potentiellen Klägern sowie ein Vollmachtsformular für RA Pacheco übersandt. « ${ }^{122}$

119 La Epoca vom 22.01.1989, S. 13. »Obispo Camus, escéptico ante el caso de Colonia Dignidad«.

120 LG Bonn, AZ $30123 / 77$.

121 Ebd.

122 PA AA, AVNA 31596. DB 37 vom 19.01.1989, GZ Pol'RK 543.00. 
Die chilenische Presse berichtete ausführlich darüber, Navas habe bereits vor seiner Abordnung die $C D$ »als Freund « besucht. ${ }^{123}$ Auch chilenische Menschenrechtsorganisationen kritisierten Navas`Abordnung und unterstellten ihm eine Nähe zur CD. ${ }^{124} \mathrm{El}$ Mercurio schrieb Navas die Äußerung zu, mögliche Menschenrechtsverletzungen der CD aus den 1970er Jahren seien bereits verjährt und daher nicht Gegenstand seiner Untersuchungen. ${ }^{125}$

Navas begann seine Ermittlungen mit Befragungen einer großen Anzahl von Colonos. Diese betonten in ähnlich lautenden Aussagen, freiwillig und gerne in der CD zu leben und dort auch keinerlei Misshandlungen ausgesetzt zu sein, von Verbrechen besäßen sie keine Kenntnis. ${ }^{126}$ Lediglich eine CD-kritische Aussage wurde zu den Akten genommen. Sie stammt von Heinz Kuhn, der die Vorwürfe aus den Baar- und PackmorBerichten weitgehend bestätigte. Interessanterweise gibt es zwei stark divergierende Darstellungen von Kuhns Aussage: Zum einen das Vernehmungsprotokoll vom 31. Januar 1989, ${ }^{127}$ das Teil der chilenischen Verfahrensakten ist und zum anderen ein Erinnerungsprotokoll, welches Kuhn selbst nach seiner Vernehmung anfertigte, ${ }^{128}$ das Teil der Botschaftsakten ist. Das offizielle Vernehmungsprotokoll enthält nur einen Bruchteil der Aussagen, die Kuhn laut seinem Erinnerungsprotokoll getätigt hatte. Dies legt nahe, dass das offizielle Vernehmungsprotokoll durch Auslassungen beschönigt wurde.

Am 25. Februar 1989 traf sich Botschafter Holzheimer in Begleitung von RA Pacheco mit Untersuchungsrichter Navas im Gericht von Parral. Anschließend berichtete er nach Bonn ${ }^{129}$ : „Vor der Tür des Amtsgerichts standen mehrere Mitglieder der CD, die mich fotografierten. Ich fotografierte sie meinerseits, woraufhin sie verschwanden.« Holzheimer betonte zu Beginn des Gesprächs nochmals die Wichtigkeit der Untersuchung für die Bundesregierung und die bundesdeutsche Öffentlichkeit. Er sprach Navas das Vertrauen aus. Über das anschließende Gespräch berichtete Holzheimer:

»Navas nahm meine Ausführungen mit ernstem Gesicht zur Kenntnis und sagte, dass ihn vor allem meine Ausführungen zur besonderen Sensitivität der deutschen Öffentlichkeit zu Menschenrechtsverletzungen beeindruckt hätten. Hier in Chile, besonders in der Provinz, könne man sich davon nur schlecht ein Bild machen. Der Anwalt der CD,

123 El Mercurio vom 22.01.1989, S. D 10-11. »Al fin del camino«.

124 Die Comisión de Derechos Humanos de Linares stellte die Unabhängigkeit des neu ernannten Sonderrichters Guillermo Navas infrage. Dieser habe zuvor als Privatperson die CD besucht und danach geäußert, er habe eine »excelente impresión«, einen ausgezeichneten Eindruck von der CD. Vgl. La Epoca vom 22.01.1989, S. 13. »Obispo Camus escéptico ante el caso de Colonia Dignidad «. Vgl. El Mercurio vom 22.01.1989, S. C5.»Afirma abogado Fernando Saenger: Antigua visita a Colonia Dignidad no descalifica al juez."

126 Die Akten dieses Untersuchungsverfahrens sind - vermutlich weitgehend vollständig - archiviert. Es handelt sich um die Bände PA AA, AV NA 31586, 31588, 31686, 31687, 31689, 31690, 31691, 31692 und 31693.

127 PA AA, AV NA 31588. Verfahren Juzgado de Parral, AZ 43.210, Bd. I, BI. 614 vta- 620 vta. Vernehmung von Heinz Kuhn Fenster vom 31.01.1989.

128 PA AA, AV NA 31645. 17-seitiges Transkript einer Tonaufnahme Heinz Kuhns vom 01.02.1989. Das Transkript beginnt mit den Worten »Aquí habla Heinz Kuhn Fenster«.

129 PA AA, B 130, Bd. 13694. DB 101 vom 25.02.1989, GZ Rk 543.00, VS-V TGB NR 11044/89 (entsperrt im April 2016). 
Saenger, habe ihm unsere Verfolgung der CD-Leitung als ein innenpolitisches Manöver geschildert, das BM Censcher gegen MP Strauss und die CSU führe, die der Colonia Dignidad freundschaftlich verbunden sei. Ich stellte das mit deutlichen Worten richtig und sagte ihm, hier seien sich alle Parteien in Deutschland völlig einig. An den >Manövern< sei kein wahres Wort, wie auch die angebliche Freundschaft der CSU ein Trick Schäfers sei. Richter Navas wies mich dann darauf hin, dass er sein Mandat enger gefasst sehe als wir. Er müsse vor allem feststellen, ob Verbrechen vorliegen und dann evtl. Anklage erheben. ${ }^{130}$

Der Botschafter insistierte auf einer Untersuchung sämtlicher Bereiche möglicher Menschenrechtsverletzungen an Colonos und zog folgendes Fazit:

»Der erste persönliche Kontakt [...] gab uns Gelegenheit, dem enormen politischen Druck, dem der Richter ausgesetzt ist, entgegenzuwirken [...] Dazu mussten wir die Stellung der Bundesrepublik Deutschland in die Waagschale werden. (Hier konnte ich auch auf die Unterredung BM mit AM Errázuriz vom Vortag verweisen.). Ich meine, dass dies zu einem guten Teil gelungen ist. Man muss sich zwar vor zu schnellem Optimismus hüten, ich wage aber die Voraussage, dass das Untersuchungsergebnis nicht völlig negativ ausgehen wird wie etwa die Antwort der Richterin Villagrán auf das RHE vom November 1988. Dies wäre bei der besonderen politischen Unterwürfigkeit der chilenischen Justiz unter politische Vorgaben schon ein gutes Ergebnis. « ${ }^{131}$

Nur wenige Wochen später, am 15. März 1989, musste Navas die Ermittlungen abgeben. Richter Hernán Robert Arias von der CA Talca wurde nach Parral abgeordnet, um sie fortzuführen. Die formale Begründung für diesen überraschenden Schritt war eine Neuordnung der Gerichtsbezirke. Demnach fiel die CD nunmehr in den Zuständigkeitsbereich der CA Talca anstelle der CA Chillán. Die Botschaft bewertete dieses Manöver nach Rücksprache mit RA Pacheco in einem Bericht ans AA negativ. ${ }^{132}$ Der neue Richter sei inkompetent und von schwacher Persönlichkeit. Zudem würden ihm Sympathien für die CD nachgesagt. Seine Ernennung gehe vermutlich auf den Druck durch Justizminister Hugo Rosende zurück und habe das Ziel, das Verfahren zügig und ergebnislos - abzuschließen. ${ }^{133}$ Diese Einschätzung, die vor allem auf den Eindrücken Pachecos beruhte, sollte sich jedoch in den folgenden Monaten ändern, in denen deutlich wurde, wie engagiert Robert seine Ermittlungen betrieb.

Derweil ging die CD in die Offensive: Am 30. März 1989 reichte die SBED beim Verwaltungsgericht Köln Klage gegen die Bundesrepublik Deutschland ein. ${ }^{134}$ Das AA solle "jegliche Einflußnahme auf Regierung und Behörden der Republik Chile, mit dem Ziel, strafrechtliche Ermittlungsverfahren gegen die Klägerin einzuleiten unterlassen«. Das Gericht solle feststellen, dass die von Genscher entsandte Hubschrauberdelegation im

\footnotetext{
130 Ebd.

131 Ebd.

132 PA AA, AV NA 31601. DB 166 vom 03.04.1989.

133 Ebd.

134 VG Köln, AZ 8 K 2497/89.
} 
Dezember 1987 rechtswidrig war. ${ }^{135}$ Am 7. April 1989 beantragte CD-Anwalt Fernando Saenger bei der chilenischen Regierung, den bundesdeutschen Botschafter Knackstedt zur persona non grata zu erklären und auszuweisen. ${ }^{136}$ Als Begründung nannte er den von Knackstedt ausgeübten Druck auf die chilenische Justiz. Die Botschaft berichtete nach Bonn, die CD schlachte das von ihr initiierte Verfahren pressemäßig in großem Stil aus:

»Saenger erscheint jetzt laufend in Presse und Fernsehinterviews und erklärt, dass die Unhaltbarkeit der deutschen Anschuldigungen erwiesen sei und nun die Auseinandersetzung gegen die BR auf deutsches Territorium getragen werde. Des Weiteren kündigte er weitere Schritte vor deutschen Gerichten gegen Baar und Packmor und erneut eine Beschwerde vor dem Europäischen Menschenrechtsgerichtshof in Strassburg gegen die BR an.

Die Botschaft hat dem wegen der von uns zu beachtenden Regeln im Augenblick nichts entgegenzusetzen. In der chil. Öffentlichkeit entsteht der Eindruck, dass die Kolonie jetzt die Überhand gewinnt. Ich wäre dankbar, wenn das AA Presseerklärung zu dem jüngsten Schritt der Kolonie abgeben und zugleich unseren Standpunkt in Sachen CD erneut bekräftigen könnte. « ${ }^{137}$

Die Botschaft gab schließlich am 26. April 1989 eine Pressemitteilung heraus. Darin bekräftigte sie das Interesse der Bundesregierung, die schwerwiegenden Vorwürfe gegen die CD-Führung vollständig aufzuklären. ${ }^{138}$

Unterdessen schritten Roberts Ermittlungen voran. Der Richter erwies sich als deutlich engagierter als Navas. Er führte innerhalb weniger Wochen acht Ortstermine in der CD durch und vernahm 155 Colonos. Dazu gehörte auch Paul Schäfer, der vergeblich versucht hatte, sich durch Vorlage ärztlicher Atteste einem Verhör zu entziehen. Bei einem ausführlichen Gespräch mit den Anwälten der Botschaft am 25. April $1989^{139}$ übte Robert heftige Kritik an der fehlenden Zusammenarbeit seitens der Bundesregierung, er sei »extrañado, desilusionado y molesto por la falta de colaboración que él había tenido del Gobierno de la RFA en esta investigación. « ${ }^{140}$ Die deutsche Seite habe sehr energisch auf die Einsetzung eines Untersuchungsrichters gedrängt, im weitern Verlauf jedoch keine weiteren Dokumente, Beweismittel oder Zeug_innen zur Verfügung gestellt. Er habe wiederholt um Informationen etwa zu

135 Das VG Köln wies die Klage im Dezember 1992 ab. VgI. PA AA, AV NA 31653. Urteilsprotokoll VG Köln, AZ 8 K 2497/89 vom 02.12.1992 sowie PA AA, Bd. AV NA 31.AV NA 31603. Klageerwiderung der RAe der Bundesregierung vom 29.08.1989

PAAA, AV NA 31601. DB 179 vom 07.04.1989 sowie AdsD, NL Waltemathe, Bestand CD, Ordner 27. Pressemitteilung von MdB Waltemathe vom 11.04.1989: »Colonia Dignidad schlägt um sich - sie beantragt jetzt, Botschafter Dr. Knackstedt zur >unerwünschten Person`zu erklären. «Eine vierköpfige Delegation mit MdB von CSU, CDU, SPD und Grünen, darunter auch Waltemathe, hatte vom 01.-06.04.1989 Chile besucht und dort Gespräche zum Thema Colonia Dignidad geführt u.a. mit dem Außenminister und einem Staatssekretär aus dem Innenministerium.

138 PA AA, AV NA 31601. Nota de Prensa de la Embajada RFA vom 26.04.1989.

139 PA AA, AV NA 31601. Schreiben RA Pacheco an Botschafter Knackstedt vom 28.04.1989.

140 Ebd. 
Fluchtversuchen oder Rentenzahlungen gebeten, ohne die gewünschten Antworten zu erhalten. Insbesondere habe er die Bundesregierung ersucht, eine Vernehmung von Georg und Lotti Packmor sowie Hugo und Waltraud Baar in Chile zu ermöglichen. Dazu habe er zugesagt, diese bei ihrem Aufenthalt in Chile angemessen schützen zu lassen.

Bundesregierung und Botschaft hatten in den vorangegangenen Monaten erörtert, wie verschiedene Geschädigte der CD dazu bewegt werden könnten, durch Strafanzeigen oder eine Nebenklage am Verfahren beteiligt zu werden. Die Geschädigten, darunter die Ehepaare Baar und Packmor, scheuten eine Reise nach Chile, da sie dort Repressalien durch die CD oder deren Verbündete befürchteten. Neben der Angst um ihre körperliche Unversehrtheit nahmen sie an, die CD würde sie mit Verleumdungsklagen überziehen (ähnlich wie bei Wolfgang Müller 1966) und sie so an einer Wiederausreise hindern. Auch RA Corvalán, der einen großen Teil der inhaltlichen Arbeit in dem Fall leistete, befürchtete Repressalien. Schließlich erstellte Corvalán eine Musterklage, die Angehörige von Helmut Schaffrik einreichen sollten, der in der CD misshandelt worden war. ${ }^{141} \mathrm{Da}$ die Botschaft jedoch vor Corvaláns Honorarforderungen zurückschreckte und dieser wiederum den Eindruck hatte, die zu seinem persönlichen Schutz erforderliche politische Rückendeckung sei nicht vorhanden, trat er von der Annahme eines möglichen Mandats zurück. ${ }^{142}$ Er schlug daraufhin auch den Auftrag für eine weitere Musterklage aus. Das AA, das mit der Botschaft mehrfach die Kosten des Verfahrens erörtert hatte, stand nun ohne Anwälte da, die entsprechende Strafanzeigen oder Klagen hätten formulieren können. Während sich die Ereignisse überschlugen, war die Kommunikation zwischen Zentrale und Auslandsvertretung gemessen am dringenden Handlungsbedarf völlig unzureichend. Die drei Anwälte der Botschaft drängten jedoch weiter darauf, Strafanzeigen einzureichen. Bei einem Gespräch mit einer Delegation von Bundestagsabgeordneten äußerten sie im April 1989:

»Besonders wichtig sei, dass auch die Familienangehörigen aktiv würden. Am besten wäre es, wenn diese Strafanzeigen vor der chilenischen Justiz stellten. Die Kostenfrage müsste allerdings geregelt werden. An dieser Stelle bedauerte RA Corvalán, dass sich die Bundesregierung offenbar nicht stärker engagieren könne. « ${ }^{143}$

Am 2. Juni meldete Botschafter Holzheimer nach Bonn, dass Robert plane, Mitte des Monats der Corte Suprema seinen Abschlussbericht vorzulegen. Er führte aus:

»Die Ermittlungsakten umfassen inzwischen über 2.000 Seiten (ohne Beiakten). Mehr als vierhundert Zeugen sind vernommen worden. Ein Fachkenner bewertete die vereidigten Aussagen der CD-Mitglieder wie folgt: >uniform wie Aussagen bei Verhör von Mitgliedern eines Regiments. Das strafrechtliche Ergebnis ist auf den ersten Blick dünn. Richter Robert meinte zu Pacheco, eine Anklageerhebung sehe er nicht. ${ }^{144}$ 
Nachdem die Rechtsanwälte der Botschaft Robert gegenüber gegen einen Abschluss der Ermittlungen plädiert hatten, wurde dieser um einige Woche verzögert. Dies erlaubte es den Botschaftsanwälten Pacheco, Corvalán und Ceroni, noch eine Reihe von Schriftsätzen einzureichen. Diese enthielten Informationen und Ermittlungsanregungen u.a. zum Fluchtfall Jürgen Szürgelies sowie zur Adoption von Matthias Gerlach (vgl. Abschnitt 4.2.1). Letztlich blieb dies aber folgenlos. Um nochmals auf Untersuchungsrichter Robert einzuwirken, gab die Botschaft im Juni 1989 bei Eduardo Novoa Monreal, einem renommierten Verfassungsrechtler und ehemaligen Präsidenten des CDE, ein Rechtsgutachten in Auftrag. Dieses Gutachten sollte klären, ob auf Basis der Verfahrensakten die Eröffnung von Strafverfahren nach chilenischem Recht begründet werden könnte. Das Gutachten betonte, viele Fragen im CD-Kontext blieben ungeklärt:

»Quien revise detenidamente la investigacion tan dilatada, aunque en muchos aspectos poco precisa, llevada a cabo por los Sres. Ministros en Visita que la tomaron a su cargo, habrá de quedar con la sensación clara de que hay aspectos fundamentales de los hechos que no han sido descubiertos aún. Existen demasiadas cosas extrañas y muy graves anomalias en lo que se observa como la vida en Villa Baviera y en las actividades que desarrollan quienes manejan la Sociedad Dignidad. Algo muy importante sigue oculto.

Más allá de mi juicio como jurista - que espero haber emitido en forma completa pienso que no es posible acallar dicha sensacion, porque ella es ineludible para todo el que se proponga enfocar cabalmente el problema. Por sobre la acumulación de innumerables testimonios, documentos y piezas del expediente, por sobre el despliegue de argumentos jurídicos persiste un secreto sin cuya revelacion no se alcanzará la verdad definitiva. La tarea queda pendiente; ella cae fuera de mi cometido. ${ }^{145}$

Letztendlich bestätigte der Verfassungsrechtler damit, dass eine reguläre juristische Befassung mit dem Fall CD während der Diktatur faktisch unmöglich war. Mit dem »Geheimnis« meinte er den Schutz, den die CD seitens der Militärjunta genoss. Das Papier wurde dem Richter aus strategischen Überlegungen "privat « übergeben. ${ }^{146}$ In einem Gespräch mit RA Pacheco vertrat Novoa Monreal die Einschätzung, dass lediglich starker politischer Druck auf die Diktatur seitens der Bundesregierung zu Fortschritten bei der Aufklärung führen könnte und äußerte damit eine versteckte Kritik an der Bundesregierung:

»Considera que la investigación realizada por los Ministros fue incompleta, descaminada e ineficaz; particularmente por lo que toca al primero [Guillermo Navas]. Los Ministros no supieron o quisieron realizar una investigación que dejara de manifiesto hechos que tenían clara connotación criminal. [...] Es cierto que hubo serios inconvenientes para una investigacion exitosa, que provinieron principalmente de una abierta resistencia a colaborar en ella por parte de los dirigentes alemanes y de la falta de cooperacion de organos auxiliares de la justicia y de organismos administrativos. Pero ante ésto los Ministros investigadores debieron ponerlo en conocimiento de la Corte

145 PA AA, AV NA 31600. Informe en Derecho von Eduardo Novoa Monreal vom 26.06.1989.

146 Ebd. 
Suprema, cosa que no aparece que hayan hecho. [...] don Eduardo Novoa ha llegado a la conclusión que esta investigación no cumplirá los objetivos, ni siquiera para fines de alta política, porque Colonia Dignidad tiene en Chile, mucho poder y grandes vinculaciones con el Cobierno, el cual ha influído ante los Tribunales de Justicia para que esta investigación judicial no cumpla su objetivo. [...]don Eduardo Novoa considera que si el Cobierno Alemán mantiene su interés en esta investigación y desea que ella se pronlongue y profundice hasta que se conozca la verdad sobre CD, no queda otro camino que actuar políticamente de manera conducente. $\ll^{147}$

In der Botschaft und bei RA Pacheco herrschte inzwischen die Ansicht vor, dass bis zum Antritt der demokratisch gewählten Regierung im März 1990 keine tatsächlichen Fortschritte mehr zu erwarten seien. Deshalb sollten die wichtigsten Zeug_innen bis zu diesem Zeitpunkt "aufgehoben « werden. ${ }^{148} \mathrm{AA}$ und Botschaft rechtfertigten ihre Entscheidung, Strafanzeigen weder einzureichen noch zu unterstützen, also durch taktische Überlegungen.

Wenige Tage vor Bekanntwerden des Abschlussberichts schlug die Botschaft dem AA vor, zum Zeitpunkt der Veröffentlichung des Berichts eine Protestnote (Demarche) an das chilenische Außenministerium zu senden, in der Hoffnung, damit eine Verlängerung und Vertiefung der Ermittlungen über den Amtsantritt von Präsident Aylwin am 11. März 1990 hinaus zu erreichen. Dazu sollte eine Pressekonferenz ohne eine offizielle Meinungsäußerung seitens der Botschaft abgehalten werden, bei der ein Anwalt den Bericht kommentieren sollte. Zudem sollte auch Präsidentschaftskandidat Aylwin eine Presseerklärung abgeben; dieser sei dazu bereit und habe bereits einen entsprechenden Text vorbereitet. Botschafter Knackstedt zog gegenüber dem AA ein ungewohnt deutliches Fazit der Beeinflussung des Ermittlungsverfahrens durch die Militärregierung. Darin erwähnte er auch die Zusammenarbeit zwischen CD und DINA, während er sein eigenes Auftreten als positiv und resolut darstellte:

»Das Regime deckt die CD (Zusammenarbeit mit Geheimpolizei DINA 1973-1976), die Colonia hat hochplatzierte Beschützer (u.a. Justizminister Rosende, ein PinochetIntimus). Die Pinochet-Diktatur hat die Justiz völlig korrumpiert, wie wir aus langer eigener Erfahrung wissen und wie Opposition und MR-Organisationen seit langem behaupten und bestätigen. Das Oberste Gericht hat stets die Interessen des Regimes in allen politisch relevanten Stellen unter dem Deckmantel von Rechtsförmlichkeit geschützt, es ist dem Regime willfährig. [...] Dennoch waren unsere Bemühungen nicht umsonst. Die Schwierigkeiten unter dem Pinochet-Regime, Schäfer und seine Helfer zu überführen, waren unverkennbar. Aber wir haben erreicht:

- Niemand kann an unserem Engagement für Achtung der Menschenrechte in diesem Fall zweifeln.

- Die chil. Öffentlichkeit ist in hohem Masse und in breitesten Kreisen sensibilisiert. [...] 
Die Opposition und Präsidentschaftskandidat Aylwin, wahrscheinlich der nächste Präsident des Landes, sind in die Pflicht genommen worden. ${ }^{149}$

Am 31. Juli 1989 übergab Richter Robert Arias schließlich seinen Abschlussbericht an die Corte Suprema, wo er vorerst unter Verschluss blieb. Zwei Tage später leitete Robert am Gericht in Parral eigenverantwortlich zwei Strafverfahren ein, eines wegen Unterschlagung $^{150}$ und eines wegen unerlaubter Berufsausübung ${ }^{151}$. Die Botschaft sprach in einem Bericht ans AA von einem Erfolg sowie einer »für uns positiven Entscheidung «. ${ }^{152}$

\section{Der Untersuchungsbericht}

Richter Robert Arias stellte in seinem 90-seitigen Untersuchungsbericht ${ }^{153}$ fest, zwar habe es Hinweise auf die Straftatbestände des Betrugs und der unerlaubten Berufsausübung gegeben (vgl. die daraufhin eingeleiteten Strafverfahren). Bezüglich der Vorwürfe der Freiheitsberaubung und der Verletzung des Postgeheimnisses in den Berichten von Hugo Baar und dem Ehepaar Packmor, die der Anlass für die Aufnahme seiner Untersuchungen gewesen waren, stellte Robert jedoch fest, dass die vorliegenden Beweise nicht ausreichten, um strafrechtliche Ermittlungen einzuleiten. Sämtliche 255 befragten Colonos - praktisch alle Bewohner_innen der CD zwischen 15 und 70 Jahren - hätten unisono geantwortet, sie befänden sich freiwillig in der CD und seien mit ihrem dortigen Leben zufrieden. Vorwürfe über Körperverletzungen wiesen sie zurück. Es gäbe auch keine Postkontrolle oder -zensur. Die Berichte Hugo Baars und der Packmors sowie die Vernehmung von Heinz Kuhn seien, so Robert, allein nicht ausreichend, um einen Tatverdacht zu begründen. Der einzige weitere Hinweis auf ein Vorliegen von Freiheitsentzug seien die Aussagen zweier Elternteile von chilenischen Kindern, die in der CD lebten. Der Vater von Hernán Escobar und die Mutter von Sergio Campos hatten bei ihrer Vernehmung berichtet, ihre Kinder seien nach der Geburt im CD-Krankenhaus aufgrund gesundheitlicher Probleme in der CD geblieben. Anschließend sei es ihnen nur in Anwesenheit anderer Colonos gestattet worden, ihre Kinder zu besuchen. ${ }^{154}$

Nichtsdestotrotz stellte Robert in seinem Bericht eine Reihe von Unregelmäßigkeiten und ungewöhnlichen Vorgängen fest. So verstoße die SBED gegen eine Reihe von Regularien im Vereinsrecht. Insbesondere seien die Vermögenswerte und Ländereien der $C D$ auf einzelne Personen eingetragen und nicht Teil des Vereinsvermögens.

149 PA AA, AV NA 31596. DB 365 vom 25.07.1989.

150 Juzgado de Letras de Parral, AZ 43.899-89. Dieses Verfahren gründete auf der Tatsache, dass Grundstücke und bewegliches Vermögen der CD auf Einzelpersonen eingetragen waren, während die SBED aufgrund ihrer Cemeinnützigkeit zahlreiche Steuer- und Zollprivilegien genoss (vgl. Abschnitt 3.2).

151 Juzgado de Letras de Parral, AZ 43.900-89. Grund für dieses Verfahren war der Verdacht, dass Gisela Seewald, die Ärztin des CD-Krankenhauses, ihren deutschen Artzttitel niemals in Chile hatte legalisieren lassen.

152 PA AA, AV NA 31596. DB 380 vom 04.08.1989.

153 Juzgado de Letras de Parral, AZ 43.210. Informe sobre Investigación a Colonia Dignidad, Ministro en Visita Extraordinaria Hernán Robert Arias, Ministro I. CA Talca. o. D. Von Richter Robert am 31.07.1989 der Corte Suprema übergeben. Enthalten in: CA Santiago, AZ 2182-98 (»Asociación Ilícita «) Bd. I (2) (Parral), Bl. 585-676. 
Die Vereinsmitglieder arbeiteten allesamt unentgeltlich, was nicht den Arbeitsgesetzen entspreche. Zudem verließen sie die Siedlung nur selten. Da die CD keine interne Buchhaltung führe, könne nicht festgestellt werden, ob die regelmäßigen erheblichen Überschüsse aus der Geschäftstätigkeit der Vereinsmitglieder tatsächlich gemeinnützigen Zwecken zugutekämen. Auch sei die Behauptung unwahr, das CD-Krankenhaus erbringe unentgeltliche Gesundheitsleitungen. Die Kosten für diese Leistungen würden zu $100 \%$ von der Gesundheitsbehörde erstattet, zusätzlich erhalte die CD vom Staat Medikamente und Milch.

Am 8. September 1989 billigte das Plenum der Corte Suprema Roberts Abschlussbericht und resümierte, die Untersuchung habe keine Taten nachgewiesen, die die internationalen Beziehungen gefährden könnten: »La investigación praticada no estableció la existencia de hechos o delitos que puedan afectar tales relaciones internacionales. « ${ }^{155}$ Die Corte Suprema entschied auch, die Straftatbestände der beiden von Richter Robert eingeleiteten Strafverfahren seien nicht Teil des Untersuchungsmandats gewesen und überwies diese zurück ans Gericht in Parral. Damit fielen sie in die Kompetenz der CD-freundlichen Richterin Lydia Villagrán. Die Verfahren wurden später ergebnislos eingestellt. Die Bundesregierung zog nach der Entscheidung der Corte Suprema ein nüchternes Fazit:

»Das Oberste Chilenische Cericht hat am 08.09.1989 eine Entscheidung gefällt, mit der eine Verfolgung der Angehörigen der $>C D$ < zu Last gelegten Straftaten im Wesentlichen vermieden wird. Damit schwindet die Hoffnung, daß es in absehbarer Zeit gelingt, die deutschen Staatsangehörigen in dieser Siedlung gegen schwere Straftaten von Seiten der Leitung wie Freiheitsberaubung, Körperverletzung und andere schwere Delikte durch die Behörden Chiles schützen zu lassen. «156

Am Folgetag veröffentlichte die Bundesregierung über die Botschaft ihre bis dahin deutlichste Pressemitteilung in der Sache. ${ }^{157}$ Mit Blick auf die ersten demokratischen Wahlen seit 1970, die für den 14. Dezember 1989 angesetzt waren, gab die Bundesregierung ihre bisherige Strategie der diplomatischen Zurückhaltung im Fall CD auf und setzte nun ganz auf einen Machtwechsel in Chile. In der Pressemitteilung hieß es, die Bundesregierung sei bestürzt über den Beschluss der Corte Suprema, der eine strafrechtliche Verfolgung von Colonos verhindere, obwohl ihnen schwere Taten zur Last gelegt würden. Die Entscheidung spiegele die Haltung des chilenischen Regimes wider, das versuche, die Aufklärung schwerer Anschuldigungen gegen Colonos - wie Folter und Freiheitsberaubung - zu verhindern. Da auch die Opfer deutsche Staatsbürger seien, müsse die Bundesregierung davon ausgehen, dass das chilenische Regime nicht die Absicht habe, deutsche Staatsbürger zu schützen. Dieser schwerwiegende Vorgang bedeute eine ernsthafte Beeinträchtigung der deutsch-chilenischen Beziehungen. Die

155 PA AA, AV NA 31644. Juzgado de Parral, AZ 43.210. Beschluss der Corte Suprema zum Untersuchungsbericht von Richter Hernán Robert Arias, vom 08.09.1989.

156 PA AA, AV NA 31600. Schreiben StS Jürgen Sudhoff an Dr. Cero Pfennig, Vorsitzender des Petitionsausschusses des Bundestags vom 26.09.1989.

157 PA AA, AV NA 31600. Embajada RFA - Declaración del Ministerio de Relaciones Exteriores de la RFA vom 09.09.1989. 
Bundesregierung behalte sich daher alle angemessenen Schritte vor, sowohl im Rahmen der bilateralen Beziehungen als auch vor internationalen Gremien. Auf Weisung von Außenminister Genscher werde zudem Gerhard Henze, der Lateinamerikabeauftragte des AA, der sich zu der Zeit in Chile aufhielt, nach Bonn zurückgeordert. In einem Schreiben an die UN-Menschenrechtskommission vom September 1989 wählte Genscher deutliche Worte:

»Solange die chilenische Regierung nicht alles tut, um die schweren Vorwürfe gegen die führenden Mitglieder der `Colonia Dignidad` aufzukären, Menschenrechtsverletzungen zu verhindern und die Mitglieder vor einer unmenschlichen Behandlung zu schützen, ist die Bundesregierung der Ansicht, daß die chilenische Regierung eine schwere Mitverantwortung an den berichteten Folterungen, Mißhandlungen und an der Verweigerung persönlicher Freiheitsrechte trägt.

Ich verweise in diesem Zusammenhang auf die Berichte der ad-hoc-Arbeitsgruppe der Menschenrechtskommission zur menschenrechtlichen Situation in Chile [...], die Ihnen vorliegen. ${ }^{158}$

Genschers Schreiben zitiert explizit zwei Berichte des United Nations Economic and Social Council (ECOSOC) von $1976 .{ }^{159}$ Dies ist interessant, da diese die Zusammenarbeit der CD mit der DINA thematisieren. Bis dahin hatte das AA es stets streng vermieden, sich zu dieser Verbindung öffentlich zu äußern.

Der Pressesprecher des chilenischen Außenministeriums entgegnete, das AA selbst habe nicht alle "internen Instanzen« in Chile ausgeschöpft, beispielsweise habe es vor chilenischen Gerichten nie eine Anzeige (denuncia) erstattet oder Strafklage (querella) eingereicht. Die chilenischen Gerichte seien nach wie vor offen für jegliche neuen Beweismittel. ${ }^{160}$ Im Übrigen sei es unpassend, eine Entscheidung des höchsten chilenischen Gerichts von politischer Seite zu kritisieren. Parallel dazu unternahm die CD eine lokale Machtdemonstration und führte auf dem Hauptplatz von Parral eine Art Siegesfeier durch. ${ }^{161}$

Im Auswärtigen Amt formulierte das für Chile zuständige Referat 330 am 18. September 1989 einen Vorschlag für den Außenminister ${ }^{162}$ zum weiteren Vorgehen. Die StA Bonn sollte erneut um Auskunft zum Stand ihres Ermittlungsverfahrens gebeten werden, verbunden mit der Frage, wann Haftbefehl gegen Schäfer ergehen sollte. Zudem sollte die Botschaft einen Bericht für die StA Bonn erstellen, um zu verhindern, dass das Ermittlungsverfahren eingestellt würde. Dabei sollte argumentiert werden, dass der zu erwartende Machtwechsel in Chile Zeug_innen zur Aussage ermutigen würde, die bislang aus Angst zurückhaltend waren. Zudem sollte bei der chilenischen Regierung ein neuer Antrag auf Einsetzung eines Untersuchungsrichters gestellt werden.

158 PA AA, AV NA 31600. Schreiben BM Genscher an den Vorsitzenden der UNMenschenrechtskommission Marc Bossuyt vom 22.09.1989.

United Nations Economic and Social Council (ECOSOC). E/CN.4/1188 vom 04.02.1976 sowie United Nations Economic and Social Council (ECOSOC). Bericht A/31/253 vom 08.10.1976.

161 Ebd.

162 PA AA, AV NA 31600. BM-Vorlage vom 18.09.1989. GZ Ref. 330. 
Dazu sollten bisher nicht genutzte Beweismittel vorgebracht werden. Mit den Betroffenen und ihren Angehörigen würde das AA weiter über die Möglichkeit von Strafanzeigen sprechen. Die von den potenziellen Anzeigesteller_innen verlangte Übernahme der Verfahrenskosten durch das AA belaufe sich allerdings auf 50.000 US-Dollar pro Verfahren. Maßnahmen, die konkreten (auch wirtschaftlichen) Druck auf die chilenische Seite ausgeübt hätten, empfahl das Referat dem Minister nicht. Am 14. September hatte das Direktorium der Weltbank einen Kredit für Chile einstimmig genehmigt, auch Präsidentschaftskandidat Aylwin hatte bei einem Gespräch mit Genscher keinerlei Einwände gegen eine Zusammenarbeit internationaler Finanzorganisationen mit der chilenischen Diktatur erhoben.

Die Vorlage macht deutlich, dass das AA zwar in seiner Presseerklärung deutliche Worte gefunden hatte, sich jedoch weiterhin nicht zu weitreichenden Maßnahmen durchringen konnte. Dies wäre etwa eine Verweigerung der Zustimmung zum Weltbankkredit gewesen. Auch ein direktes juristisches Eingreifen durch eigene Strafanzeigen oder die Unterstützung der Strafanzeigen von Opfern vermied das AA weiterhin. Die gegenüber der chilenischen Diktatur getroffene Feststellung, die Entscheidung der chilenischen Justiz belaste die bilateralen Beziehungen, blieb daher folgenlos. Hoffnung versprach allein der erwartete Machtwechsel in Chile. Allerdings war schon zu diesem Zeitpunkt absehbar, dass ein Wahlerfolg des demokratischen Lagers keine drastischen Verschiebungen der tatsächlichen Machtverhältnisse innerhalb der chilenischen Institutionen bewirken würde. Die Hoffnung, dass sich die Verhältnisse nach den Wahlen rasch in Richtung einer umfassenden Aufarbeitung der CD-Verbrechen durch chilenische Behörden verschieben würden, war vor allem das Wunschdenken des AA. Nichtsdestotrotz setzte das Amt voll auf diese Karte: Bei einem gemeinsamen Frühstück am 18. September 1989 in Bonn sprach Genscher Präsidentschaftskandidat Aylwin auf die $\mathrm{CD}$ an. Die Bundesregierung, so Genscher, sei empört, dass Straftaten der CD-Führung an den Colonos noch immer nicht verfolgt und geahndet würden. Mit Abscheu habe er von dem Versuch der Vertuschung in der CD Kenntnis genommen. Genscher unterstrich, dass eine zukünftige demokratische Regierung in Chile sich unverzüglich der schutzbedürftigen Deutschen in der CD annehmen, den Status der CD untersuchen und die Verantwortlichen zur Rechenschaft ziehen müsse. In einem Vermerk über das Gespräch heißt es weiter:

»Aylwin führte zu CD aus: BR könne sicher sein, daß sich eine demokratische Regierung bemühen werde, dieses Problem zu lösen. Er habe bereits 1968 auf die Notwendigkeit einer tiefgreifenden Prüfung der Siedlung hingewiesen. CD sei ein Staat im Staat, chilenische Gesetze würden mißachtet und übertreten. Er habe nie große Hoffnungen in die jetzt durchgeführten Untersuchungen gesetzt. Es sei offensichtlich gewesen, daß die Richter nicht mit der Unterstützung der Politiker rechnen konnten. CD werde von Pinochet und ihm nahestehenden Personen geschützt. Eine demokratische Regierung müsse eine umfassende Untersuchung durchführen lassen, um das Problem der deutschen Siedlung zu lösen. ${ }^{163}$

163 PA AA, AV NA 31600. Gesprächsnotiz vom 20.09.1989 über das Gespräch Genscher-Aylwin vom 18.09.1989. 
Es ist unklar, ob beide Seiten tatsächlich glaubten, der Regierungswechsel in Chile würde durch das resolute Auftreten der Behörden zu einer unmittelbaren Veränderung der Verhältnisse in der CD führen, oder ob es sich lediglich um diplomatische Willensbekundungen zweier sich freundlich gesonnener Politiker handelte. Da beide wußten, dass Pinochet auch nach einer verlorenen Wahl über großen Einfluß verfügen würde, liegt Letzteres nahe.

Zusammenfassend ist festzustellen, dass der Untersuchungsbericht von Richter Robert Arias zwar keineswegs eine umfassende Untersuchung der Vorgänge in der CD darstellte. Jedoch ging Richter Robert mit seinen Feststellungen bis an die Grenzen des während der Militärdiktatur Möglichen und gab vor allem mit seinen Fesstellungen zu administrativen Verfehlungen der CD der Nachfolgeregierung Alywin wichtige Werkzeuge an die Hand, um nach der Rückkehr zur Demokratie eine Auflösung der SBED zu betreiben. Der Ausgang der Untersuchung war vor allem vorgezeichnet, da die Bundesregierung das Verfahren nicht durch eigene Strafanzeigen bzw. entsprechende Kostenübernahmen und Sicherheitsgarantien für Nebenkläger_innen unterstützte. Die CD konnte selbst wenige Monate vor dem Ende der Diktatur ihre ausgezeichneten Beziehungen zur Militärjunta und ihrer Justiz in die Waagschale werfen und hatte wegen der zahnlosen Haltung der Bundesregierung dabei leichtes Spiel.

Besonders sicher fühlen konnte sich die CD, da die Justiz in NRW auf Basis derselben Zeug_innenaussagen und Berichte operierte, die auch chilenischen Richter_innen vorlagen. Die deutsche Justiz - die in keiner Wiese von der chilenischen Militärjunta abhängig war - konnte sich selbst nach fünf Jahren Ermittlungen nicht zu einer Anklageerhebung durchringen. Sie befand noch nicht einmal Haftbefehle gegen Schäfer, Hopp oder Gisela Seewald für notwendig. Solche Haftbefehle hätte ein energischeres Vorgehen der chilenischen Seite rechtfertigen können. Während die deutsche Diplomatie 1988/1989 vor dem Hintergrund des absehbaren Endes der Diktatur und des Navas/Robert-Verfahrens schrittweise von ihrer vorherigen Politik der offenen Sympathie gegenüber der CD (1973 bis 1979) bzw. der schweigenden Duldung der CD (1979 bis 1985) Abstand nahm, verblieb die Staatsanwaltschaft Bonn bis 2010 bei einer Haltung, die faktisch Straflosigkeit für die CD-Führung bedeutete und auch Auswirkungen auf juristische Ermittlungen der demokratischen Regierungen nach 1990 hatte.

\subsubsection{Verfahren wegen sexuellen Missbrauchs an Chilenen (1996-2013)}

Von 1990 bis 1996 gab es keine strafrechtlichen Ermittlungen in Chile, die der CDFührung hätten gefährlich werden können. Was die Diktaturverbrechen anging, hatte die fragile chilenische Demokratie durch Präsident Patricio Aylwin von Beginn an klargestellt, dass eine strafrechtliche Aufarbeitung nur »en la medida de lo posible « ${ }^{164}$, also »im Rahmen des Möglichen" stattfinden werde. Aber die neue chilenische Regierung versuchte, der $C D$ auf dem Verwaltungswege beizukommen. Dies gestaltete sich allerdings mühselig (vgl. Abschnitt 3.2.3) und änderte nichts am kriminellen Status Quo der CD. Nur einige progressive Medien berichteten in diesen Jahren vom kriminellen

164 Vgl. Veit Straßner, Die offenen Wunden Lateinamerikas - Vergangenheitspolitik im postautoritären Argentinien, Uruguay und Chile, Wiesbaden 2007, S. 243. 
Wirken der CD, meist im Zusammenhang mit der Diktatur. In der rechten Opposition und den ihr nahestehenden Medien genoss die CD weiterhin volle Unterstützung. Erst die massiven Vorwürfe gegen Paul Schäfer wegen sexuellen Missbrauchs auch an chilenischen Kindern sollten daran etwas ändern.

Im Juni 1996 gelang es Jacqueline Pacheco, der Mutter des 12-jährigen Cristóbal Parada Pacheco, der im sogenannten Intensivinternat der CD lebte, ihren Sohn aus der CD zu holen (vgl. zu diesem Fall ausführlich Abschnitt 4.2.4). Sie erstattete Strafanzeige gegen Schäfer wegen sexuellen Missbrauchs. Inzwischen hatte die CD-freundliche Richterin Lydia Villagrán das Gericht in Parral verlassen und ein junger neuer Richter, Jorge Norambuena, nahm Ermittlungen auf. ${ }^{165}$ Am 14. August 1996 erließ er einen Haftbefehl gegen Schäfer. ${ }^{166}$ Wenig später wurde Richter Hernán González an der CA Talca als Ministro en Visita mit dem Fall betraut, der sich schnell ausweitete, da nun auch weitere Eltern chilenischer Kinder Strafanzeigen gegen Schäfer stellten. Die CD versuchte die Ermittlungen zu behindern und Kinder, die zuvor in der CD gelebt hatten, zu verstecken. Ab November 1996 führte die chilenische Polizei mehrfach Razzien in der CD durch, um Schäfer habhaft zu werden. Nach der Flucht von Tobias Müller und Salo Luna aus der CD im Juli 1997 (vgl. Abschnitt 4.1.3) nahm die mediale Aufmerksamkeit enorm zu und Schäfer beschloss, die CD zu verlassen. Er begab sich in den Untergrund nach Argentinien, wo er erst 2005 gefasst wurde.

Das von Richter González geführte Verfahren wegen sexuellen Missbrauchs an chilenischen Kindern führte $2004 \mathrm{zu}$ Urteilen gegen über zwanzig Kompliz_innen Schäfers ${ }^{167}$ und $2006 \mathrm{zu}$ einer erstinstanzlichen Verurteilung von Schäfer zu 20 Jahren Haft. ${ }^{168}$ Gegen die Begleiter_innen Schäfers im argentinischen Untergrund ergingen nach deren Rückkehr nach Chile 2007 und 2009 Urteile. ${ }^{169}$ Wie üblich legte die CD Rechtsmittel ein. Die CA Talca fällte ihr Urteil im Revisionsverfahren $2011 .^{170}$ Mit der Entscheidung der Corte Suprema vom 25. Januar 2013 war der Rechtsweg ausgeschöpft. ${ }^{171}$ In letzter Instanz wurden insgesamt 14 Colonos und sieben chilenische Unterstützer_innen wegen der Vergewaltigung von unter 12-Jährigen in vier Fällen, sexuellem Missbrauch in 16 Fällen, sowie der Entführung und Nicht-Herausgabe von Kindern zu Haftstrafen zwischen 541 Tagen und elf Jahren verurteilt. Bei 15 Verurteilten wurde die Strafe zur Bewährung ausgesetzt. Fünf Personen traten ihre Haftstrafen im Februar 2013 im Gefängnis von Cauquenes an. Der sechste, Hartmut Hopp, verließ unter Verletzung einer Ausreisesperre im Mai 2011 Chile und flüchtete über mehrere Zwischenstationen in die Bundesrepublik. Im August 2011 reichte das European

165 Juzgado de Parral, AZ 53015-96.

166 PA AA, AV NA 31637. CA Talca, Urteil vom 14.10.1996 zum Schutzantrag von RA Saenger und RA Ortega Jarpa gegen Nelson Mery, Luis Henriquez sowie Richter Jorge Norambuena.

167 Jugzado de Parral, AZ 53015. Urteil vom 14.11.2004. Ministro en Visita Hernán Conzález.

168 Jugzado de Parral, AZ 53015. Urteil vom 24.05.2006. Ministro en Visita Hernán González.

169 Jugzado de Parral, AZ 53015. Urteile vom 06.09.2007 (Peter Schmidt und Rebeca Schäfer) und vom 22.07.2009 (Friedhelm Zeitner, Matthias Gerlach, Renate Freitag). Ministro en Visita Hernán Conzález. 
Center for Constitutional and Human Rights (ECCHR) bei der zuständigen Staatsanwaltschaft Krefeld Strafanzeige gegen Hopp ein. Im Oktober 2011 folgten weitere Strafanzeigen ${ }^{172}$ der Berliner Rechtsanwältin Petra Schlagenhauf im Namen diverser Geschädigter wegen Mordes, Körperverletzung und sexuellen Missbrauchs. 2013, nach dem Urteil der Corte Suprema, das Hopp zu 5 Jahren Haft wegen Beihilfe zum sexuellen Missbrauch verurteilte, beantragte die chilenische Justiz die Auslieferung Hopps. Die Bundesrepublik lehnte dies unter Verweis auf das Auslieferungsverbot in Art. 16 GG ab. Einem zweiten Auslieferungsersuchen fügte die chilenische Justiz 2014 subsidiär, d.h. nachrangig, einen Antrag auf Haftvollstreckung in der Bundesrepublik bei. Die StA Krefeld befürwortete diesen Antrag 2016 und leitete ihn zur Entscheidung ans Landgericht Krefeld weiter. Dieses erklärte im August 2017 das chilenische Urteil gegen Hopp von 2013 als in Deutschland vollstreckbar. ${ }^{173}$ Hopp legte dagegen Beschwerde beim OLG Düsseldorf ein. Dieses hob daraufhin den Beschluss des LG Krefeld im September 2018 wieder auf. ${ }^{174}$ Weitere Rechtsmittel waren gegen diese Entscheidung des OLG nicht möglich. Dementsprechend massiv kritisierten Menschenrechtsaktivist_innen und -anwält_innen den Beschluss. ${ }^{175} 2019$ stellte die StA Krefeld auch ihre eigenen Ermittlungen ein. Eine Beschwerde gegen die Einstellung und ein Antrag auf Erzwingung einer Anklageerhebung scheiterten 2021.

Das 1996 eröffnete Verfahren wegen sexuellen Missbrauchs (mit den dazugehörigen Nebenverfahren) war es, was die Colonia Dignidad zu Fall brachte ${ }^{176}$, zumindest in ihrer vorherigen Form. Das Verfahren veranlasste Paul Schäfer 1997 zur Flucht und führte deutlich später, $2005 \mathrm{zu}$ seiner Verhaftung. Bis zu seinem Lebensende 2010 befand sich Schäfer in Haft. Als das Urteil gegen ihn im Januar 2013 rechtskräftig wurde, war er allerdings bereits verstorben. Die Urteile gegen seine Mittäter_innen, Helfer_innen und Kompliz_innen führten zur Inhaftierung von Gerhard Mücke, Kurt Schnellenkamp, Gerd Seewald, Dennys Alvear und Günther Schaffrik. Das Verfahren hatte damit mit Abstand die weitreichendsten strafrechtlichen Folgen aller Verfahren für Täter_innen der CD.

Dies wurde möglich, da die Transición langsam voranschritt und auch die Figuren, die die CD während der Diktatur maßgeblich beschützt hatten, abtreten mussten: 1995 wurde der ehemalige DINA-Chef Manuel Contreras inhaftiert, 1998 Augusto Pinochet

172 StA Krefeld, AZ 3 ]s 753/11.

173 LG Krefeld, AZ 21 StVK 218/16. Beschluss vom 14.08.2017, online unter: https://www.justiz.nrw.de/ nrwe/lgs/krefeld/lg_krefeld/j2017/21_StVK_218_16_Beschluss_20170814.html.

174 OLC Düsseldorf, AZ III-3 AR 158/17. Beschluss vom 20.09.2018, online unter: https://www.olg-duesseldorf.nrw.de/behoerde/presse/Presse_aktuell/20180925_PM_Colonia_Dignidad/20180920Beschluss-III-3-AR-158-17-.pdf (zuletzt abgerufen am 29.09.2018).

175 Vgl. European Center for Constitutional and Human Rights (ECCHR). Rechtliche Stellungnahme zum Beschluss des Oberlandesgerichts Düsseldorf in Sachen Hartmut Hopp/Colonia Dignidad, Oktober 2018, online unter https://www.ecchr.eu/fileadmin/user_upload/Stellungnahme_zum_Be schluss_OLG_Ddorf_im_Fall_Hartmut_Hopp_Colonia_Dignidad.pdf.

176 Löhning, Ute. »Wer brachte die Colonia Dignidad zu Fall?«, ursprünglich in: WDR 5. Neugier genügt - das Feature vom 12.02.2019, online unter https://www.swr.de/swr2/programm/SWR2-Leben-Siebrachten-die-Colonia-Dignidad-zu-Fall,broadcastcontrib-swr-28808.html. 
in London festgenommen. Auch die verwaltungsrechtlichen Maßnahmen der chilenischen Regierung brachten die CD Stück für Stück in Bedrängnis. Vor allem aber war das Thema sexueller Missbrauch ein Lagerübergreifendes, anders als die Menschenrechtsverbrechen der Diktatur. Die Verfahren zu letzteren Verbrechen mit Bezug zur CD nahmen erst nach der Festnahme von Paul Schäfer 2005 an Fahrt auf.

\subsubsection{Verfahren wegen Menschenrechtsverbrechen (seit 2005)}

Am 16. Oktober 1998 wurde Augusto Pinochet in London festgenommen. Der spanische Richter Baltazar Garzón, der gegen Pinochet wegen Verbrechen gegen die Menschheit ermittelte, hatte einen internationalen Haftbefehl erwirkt. Pinochets Verhaftung beendete de facto den Konsens der chilenischen Transición, Diktaturverbrechen nur in Ausnahmefällen zu untersuchen. Sie begründete damit einen Fortschritt in der strafrechtlichen Aufarbeitung der Verbrechen der Diktatur. ${ }^{177}$ Bis dahin hatte die chilenische Justiz nur wenige Urteile wegen Diktaturverbrechen gefällt. Häufig wurden Verfahren unter Verweis auf das noch während der Diktatur erlassene Amnestiegesetz (Vgl. Abschnitt 4.2.3) eingestellt. Nun reichten Opfer der Diktatur in großem Umfang Strafanzeigen ein. Diktaturverbrechen wurden vermehrt als Verbrechen gegen die Menschheit eingestuft, die weder unter die Amnestie fielen, noch verjährten. Auch die Gerichte gaben dem zunehmend statt. So gab beispielsweise Richter Juan Guzmán von der CA Santiago einer Klage der KP-Generalsekretärin Gladys Marín wegen ihres verschwundenen Ehemannes statt und begann zu ermitteln. Unter dem Aktenzeichen 2182-98 wurden Ermittlungen zu zahlreichen Einzelverbrechen zusammengefasst, die in einzelne »Episoden« unterteilt wurden. Einige davon betrafen auch die CD. So ging es beispielsweise in der Episode »Villa Baviera« anfangs um das Verschwindenlassen und die Ermordung des MIR-Aktivisten Alvaro Vallejos Villagrán. Die Ermittlungen zu CD-Verbrechen wurden durch die Abgeschlossenheit der Siedlung und die Weigerung der CD-Führung, Ermittlungen auf dem CD-Gelände uneingeschränkt zuzulassen, stark beeinträchtigt. Mehrere von Guzmán angeordnete Razzien brachten so nur einen begrenzten Erkenntnisgewinn. Im März 1999 stellte der CDE Strafanzeige gegen die CD wegen Bildung einer kriminellen Vereinigung. ${ }^{178} 2003$ sprach Richter Solís an der CA Santiago ein erstinstanzliches Urteil wegen der Entführung von 27 Personen in Parral in den Monaten nach dem Putsch 1973. ${ }^{179}$ Aussagen von Angehörigen der Mordopfer sowie diverse andere Aussagen hatten auf eine Beteiligung der CD verwiesen. Dennoch wurde kein einziger Colono angeklagt.

Durch die Festnahme Schäfers im März 2005 änderte sich die Situation. Seitdem wurden tiefergehende Ermittlungen ohne Beschränkung des Zugangs zur Siedlung möglich. Am 17. März 2005 wurde Schäfer im Verfahren »Alvaro Vallejos« erstmals

177 Vgl. Ruderer, Stephan. Das Erbe Pinochets. Vergangenheitspolitik und Demokratisierung in Chile 1990-2006, Göttingen 2020, S. $213 \mathrm{ff}$.

178 CA Santiago, AZ 2182-98, Episode »Asociación Ilícita ex Colonia Dignidad«, im Folgenden häufig kurz »Asociación Ilícita«. 
wegen eines Diktaturverbrechens angeklagt. ${ }^{180}$ Am 8. April übertrug die CA Santiago eine Reihe von Verfahren mit vermutetem oder bereits festgestelltem Bezug zur CD an Richter Jorge Zepeda am selben Gericht. Zepeda hatte bislang die Verfahren (Episoden) "Juan Maino« und »Antonio Llidó« geführt. Folgende Verfahren wurden an Zepeda übertragen bzw. von ihm eröffnet:

Tabelle 11: An Richter Jorge Zepeda übertragene bzw. von ihm eröffnete Verfahren

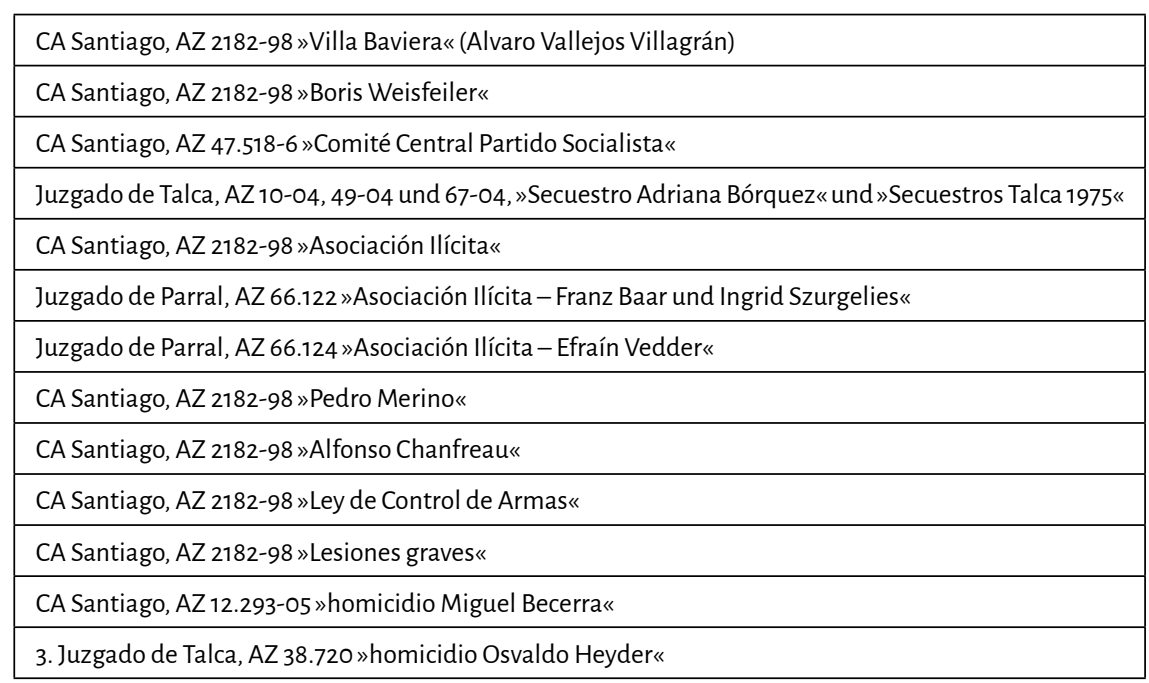

Zepeda, der trotz der hohen Zahl von Verfahren nur von einem einzigen Mitarbeiter (actuario) unterstützt wurde, verfolgte die Ermittlungen mit hohem Engagement. Das Ganze vollzog sich vor dem Hintergrund eines hohen Medieninteresses. In den ersten Monaten seiner Tätigkeit überschlugen sich die Ereignisse: Im Mai 2005 fanden Beamte der PDI bei Grabungen in der CD Motorenteile, vermutlich aus Fahrzeugen, die Verschwundenen gehört hatten. Im Juni und August wurden bei weiteren Grabungen ein Waffenarsenal und das Geheimarchiv der CD entdeckt (vgl. Abschnitt 2.2.5 und 4.2.2). 2005 und 2006 führte Zepeda im Rahmen verschiedener Verfahren Hunderte Vernehmungen durch und gab der PDI Ermittlungsanweisungen. Zudem ließ er die CD-Führungsmitglieder Gerhard Mücke, Karl van den Berg, Hartmut Hopp und Kurt Schnellenkamp jeweils mehrere Monate lang in Untersuchungshaft nehmen. Unter diesem Druck fingen einige Colonos an zu reden und berichteten über die Inhaftierung von Gefangenen in der CD sowie über Folter und Erschießungen. Allerdings beschränkten sie sich bei ihren Aussagen meist auf eine allgemeine Beschreibung der Tatvorgänge oder ihrer Umstände. Sie vermieden es, ihre eigene Mitwirkung zu thematisieren und nannten auch nur selten andere konkrete Täter_innen beim Namen. Bei meiner Analyse der umfangreichen Ermittlungsakten sowie der dazugehörigen Vernehmungen habe

180 CA Santiago, AZ 2182-98 (»Alvaro Vallejos Villagrán«), Bd. 8ª BI. 2596ff. Auto de Procesamiento vom 17.03.2005. Zuvor war in diesem Verfahren im Jahr 2000 bereits Gerhard Mücke angeklagt worden. 
ich den Eindruck gewonnen, dass es sich dabei um eine koordinierte Verteidigungsstrategie gehandelt haben muss, die vermutlich unter Mitwirkung der Rechtsbeistände der CD zustande kam. Nahezu alle Vernommenen schoben die Primärverantwortung für sämtliche Verbrechen auf Paul Schäfer und gaben an, dieser habe den Informationsfluss über einzelne Vorgänge und Verbrechen derart beschränkt und gesteuert, dass sie zwar bestimmte Tätigkeiten verrichteten (z.B. das Ausheben einer Grube), ohne jedoch den Gesamtzusammenhang oder geschweige denn den Zweck zu kennen (z.B. die Erschießung von Gefangenen und das anschließende Vergraben ihrer Leichen). In meinen Gesprächen mit Richter Jorge Zepeda konnte ich den Eindruck gewinnen, dass auch er die Vermutung einer zumindest weit überwiegenden Alleintäterschaft Schäfers teilte. ${ }^{181}$ Nachdem die Mitglieder der CD-Führung 2006 wieder aus der Untersuchungshaft entlassen wurden, ging auch die Aussagebereitschaft vieler Colonos wieder deutlich zurück: In den Verfahrensakten finden sich nur wenige Aussagen von Colonos aus der Zeit nach 2007, zumindest nur wenige, die sachdienliche Hinweise zur Aufklärung von Verbrechen beinhalten. Auch das Engagement Zepedas bei den Ermittlungen ließ spürbar nach: Zum einen war er unter Zeitdruck, Urteile zu fällen, zum anderen wurde er bei seinem Vorgehen immer wieder durch die von den CD-Anwält_innen eingelegten Rechtsmittel gebremst.

Zepeda fällte seine Urteile zwischen 2006 und 2016. Er verurteilte Paul Schäfer vor dessen Tod im April 2010 wegen des unerlaubten Besitzes und der Herstellung von Waffen (2006), wegen Mordes an Miguel Becerra (2008) sowie wegen schwerer Körperverletzung an Colonos (2009). Außer Schäfer verurteilte Zepeda nur wenige Colonos und auch meist nur zu Bewährungsstrafen. Rudolf Cöllen, Karl van den Berg, Kurt Schnellenkamp und Gerhard Mücke wurden in verschiedenen Verfahren zu Bewährungstrafen verurteilt. Im Verfahren wegen Bildung einer kriminellen Vereinigung wurden Mücke und van den Berg rechtskräftig zu je fünf Jahren Haft ohne Bewährung verurteilt. Im Verfahren wegen der Verschwundenen Juan Maino, Elizabeth Rekas und Antonio Elizondo verurteilte Zepeda Mücke und van den Berg wegen Beihilfe zu je fünf Jahren Haft ohne Bewährung. Die nächsthöheren Instanzen hoben dieses Urteil jedoch wieder auf und sprachen beide frei. In beiden Verfahren entzog sich Hartmut Hopp einer Verurteilung durch Flucht nach Deutschland. Die einzigen rechtskräftigen Urteile wegen Folterungen oder Verschwindenlassen im Zusammenhang mit der CD, die zu einer tatsächlichen Haftstrafe führten, ergingen gegen Gerhard Mücke. Dieser war in den Verfahren wegen des Verschwindenlassens von Alvaro Vallejos Villagrán, der Entführung von Adriana Bórquez und der Entführung von 50 Personen aus Talca 1975 jeweils zu drei Jahren Haft verurteilt worden.

2016 wurde Jorge Zepeda zum Vorsitzenden Richter an der CA Santiago ernannt und gab infolgedessen die Verantwortung für die CD-Verfahren an seinen Kollegen Mario Carroza ab. Dieser wurde 2021 zum Richter am Obersten Gerichtshof ernannt, die Verfahren wurden an Richterin Paola Plaza übertragen. Diese ermittelt noch heute u.a.

181 PJS, Sammlung Gesprächsnotizen. Notiz eines Gesprächs des Verfassers mit Jorge Zepeda vom 16.10.2012. 
aufgrund 2017 eingereichter Strafanzeigen wegen unerlaubten Vergrabens und Exhumierung von Leichen (inhumación y exhumación ilegal). ${ }^{182}$

Die von Jorge Zepeda geleiteten Ermittlungen waren lediglich erfolgreich, was die Aufklärung über die CD-Verbrechenskomplexe und die entsprechenden Tathintergründe betrifft. Dank der gerichtlichen Feststellungen kann heute der Charakter der CD als krimineller Organisation, die in Zusammenarbeit mit der chilenischen Diktatur schwerste Verbrechen beging, nicht mehr angezweifelt werden. Einschränkend muss jedoch gesagt werden, dass Zepeda viele Tatvorwürfe nur oberflächlich oder exemplarisch ermittelte. Damit enttäuschte er die Hoffnung vieler Angehöriger von Opfern auf Wahrheit und Gerechtigkeit. In keinem einzigen Fall von Verschwindenlassen gelang es Zepeda, einen materiellen Täter zu identifizieren oder rechtskräftig festzustellen, dass die CD der »destino final «, also der Todesort der Verschwundenen war. Immerhin gelang es im Fall von Pedro Merino und Alvaro Vallejos durch die Urteile, zweifelsfrei festzustellen, dass diese in der CD festgehalten worden waren.

\subsection{Parlamentarische Vorgänge in Chile}

Seit den 1960er Jahren waren die Verbrechen der Colonia Dignidad auch Gegenstand parlamentarischer Vorgänge - in Chile ebenso wie in der Bundesrepublik. Vor allem in Chile, um das es nun gehen soll, war es dabei mehrfach sogar die CD selbst, die im Rahmen ihrer offensiven Verteidigungsstrategie die Initiative ergriff und sich an Abgeordnete oder parlamentarische Instanzen wandte. Im Folgenden beschreibe und analysiere ich die wichtigsten parlamentarischen Vorgänge im chilenischen Oberhaus, dem Senado (Senat) sowie dem Unterhaus, der Cámara de Diputados zwischen 1968 und 1999.

\subsubsection{Aberkennung der Immunität von Héctor Taricco und Claudio Fuentes 1968}

Durch die Fluchten von Wolfgang Müller (heute: Wolfgang Kneese) und Wilhelmine Lindemann aus der Siedlung im Jahr 1966 und die darauffolgenden Untersuchungen und gerichtlichen Verfahren war das Thema CD 1966 und 1967 in der chilenischen Öffentlichkeit sehr präsent. Die CD startete eine juristische (Gegen-)Offensive, um ihr Narrativ, es handele sich um eine von Missgunst und niederen Motiven getragene "Verleumdungskampagne«, zu befördern. Dazu gehörte die - schließlich erfolgreiche - Beantragung der Aberkennung der Immunität für zwei wichtige Vertreter von Regionalbehörden, die besonders energisch eine Untersuchung der CD vorangetragen hatten.

Am 9. Januar 1968 beantragte SBED-Präsident Hermann Schmidt bei der CA Chillán die Aberkennung der Immunität für den Intendenten der Provinz Linares, Héctor Taricco Salazar, und den Gouverneur von Parral, Claudio Fuentes Avello. Die SBED warf den beiden Politikern Amtsanmaßung, Unverhältnismäßigkeit und willkürliche Verhaftung von zwei Mitgliedern der SBED vor: Gerhard Mücke und Heinz Kuhn. Im August 1967 hatte Taricco angeordnet, eine von der CD bewachte Schranke auf einem Weg, 
der durch das CD-Gelände führt, zu entfernen. ${ }^{183} 45$ Landarbeiter_innen, die mit ihren Familien von Parral aus betrachtet hinter der CD wohnten und ein Wegerecht zur Durchquerung des CD-Geländes besaßen, hatten sich über willkürliche Ausweiskontrollen, lange Wartezeiten und die herablassende Behandlung durch die Wachposten der CD beschwert. Mücke und Kuhn erschienen im Büro von Gouverneur Fuentes, um sich über dessen unangekündigte Inspektion der CD am Vortag zu beschweren. ${ }^{184}$ Sie lieferten sich ein Wortgefecht mit Fuentes, woraufhin dieser die beiden Colonos verhaften ließ.

Im Februar 1968 befasste sich der Verfassungsausschuss des chilenischen Senats mit dem Antrag auf Aberkennung der Immunität. Er empfahl einstimmig, die Immunität von Taricco und Fuentes nicht aufzuheben. ${ }^{185}$ Ein Bericht des Ausschusses drückte sogar Sorge aus über gewisse Informationen über »den tatsächlichen Charakter, Ziele, Ausrichtung und Aktivitäten« der SBED, die in diesem Zusammenhang zu Tage getreten seien. Der Ausschuss empfahl eine Weiterleitung des Berichts an die Cámara de Diputados, die gegebenenfalls einen Untersuchungsausschuss einrichten sollte. ${ }^{186}$

Trotz dieser einstimmigen Empfehlung des Ausschusses hob der chilenische Senat am 28. Februar 1968 in geheimer Sitzung die Immunität von Taricco und Fuentes auf. ${ }^{187}$ Eine Ablehnung des SBED-Antrags hätte einer Zwei-Drittel-Mehrheit bedurft, die nicht zustande kam. Gleichzeitig beschloss der Senat, sämtliche zusammengetragenen Erkenntnisse zur SBED an die Cámara de Diputados weiterzuleiten, um dort eine Untersuchung einzuleiten.

183 La Tercera de la Hora vom 06.08.1967, S. 2. »Incidentes en >Dignidad por retiro de la barrera«.

184 Beide kamen nach einem kurzen Aufenthalt im Gefängnis von Chillán wieder frei, nachdem CDAnwalt Luis Ortíz Quiroga bei der CA Chillán einen Schutzantrag gestellt hatte, der positiv beschieden wurde. Vgl. Vea vom 17.08.1967, S. S12f. »Cada dia más oscuro caso >Dignidad«« sowie El Diario Ilustrado vom 10.12.1967, S. 4. »Sobreseidos dos miembros de la Colonia >Dignidad««.

185 Senado, Diario de Sesiones, Legislatura extraordinaria 1967-1968, Sesión 61 a vom 27.02.1968, S. 2416-2436. Informe de la Comision de Constitucion, Legislacion, Justicia y Reglamento, recaido en la peticion de desafuero formulada por don Hermann Schmidt Ceorgi, en representacion de la Sociedad Benefactora Y Educacional »Dignidad«, en contra del señor Intendente de Linares, don Héctor Taricco Salazar y del gobernador de Parral, don Claudio Fuentes Avello.

186 Ebd. Demnach hätten die Behörden über einen Großteil der Colonos keine Kontrolle. Auch eine Überprüfung der Einhaltung der Arbeits- und Sozialversicherungsgesetzgebung sei in der Vergangenheit nicht möglich gewesen. Mindestens ein Colono [Paul Schäfer] sei illegal eingereist und werde von Interpol gesucht. Das Landgut der CD sei nicht Eigentum der SBED, sondern gehöre den Einzelpersonen Hermann Schmidt und Rudolf Cöllen. Es sei unklar, wem die Überschüsse aus der Bewirtschaftung des Gutes zufielen. Der Vereinszweck sei laut Satzung die Hilfe für bedürftige chilenische Kinder und Jugendliche durch Errichtung eines Jugendheimes, einer Schule und Werkstätten. Dies sei anscheinend nicht geschehen. Trotzdem erhielt die SBED eine Zollbefreiung für ihre Einfuhren. Aus Deutschland sei - wenn auch nicht auf offiziellem Wege - zu hören, dass es sich bei der Privaten Sozialen Mission, der Mutterorganisation der SBED, um eine Sekte handele.

187 Senado, Diario de Sesiones, Legislatura extraordinaria 1967-1968, Sesión 62 a vom 28.02.1968, S. 2471 . 


\section{Die Rede des Senators Patricio Aylwin}

Nach der Abstimmung ergriff der christdemokratische Senator (und spätere Präsident) Patricio Aylwin, in dessen Wahlkreis sich die CD befand, das Wort. ${ }^{188}$ Seine Rede erscheint rückblickend besonders relevant, da sie bereits 1968 vieles von dem thematisierte, was noch Jahrzehnte später gegen die CD vorgebracht wurde. Der Jurist Aylwin berichtete von seinen Besuchen in der CD sowie von seinen Analysen der in Parral anhängigen Gerichtsverfahren. Er sehe zwar einige positive Aspekte, die auch von der CD und ihren Unterstützer_innen vorgebracht würden, wie etwa die Arbeit des Krankenhauses für die lokale Bevölkerung. Gleichzeitig gäbe es jedoch eine Reihe von Lügen und zumindest erklärungsbedürftigen Aspekten: »Hay mentiras comprobadas; hay situaciones irregulares; hay actitudes injustificadas «, so Aylwin. ${ }^{189}$ So sei beispielsweise fraglich, ob die Gruppe nach Chile ausgewandert sei, um eine Strafverfolgung von Schäfer zu verhindern, gegen den in der Bundesrepublik wegen »homosexualidad con menores ${ }^{190}$ ermittelt werde. Satzungsgemäßes Ziel der SBED sei die wohltätige Arbeit für Kinder und Jugendliche, die durch das Erdbeben bei Valdivia 1960 ihre Eltern verloren hätten. Viele Jahre nach Aufnahme ihrer Arbeit habe die SBED jedoch vor allem Kinder und Jugendliche aus der Bundesrepublik nach Chile geholt und fast keine chilenischen Kinder aufgenommen. Auch seien Waisenheim, Schule und Werkstätten für chilenische Kinder nicht wie angekündigt errichtet worden. Dass die bundesdeutsche Botschaft sich für diese Fragen nicht interessiere, sei ebenfalls verdächtig, erklärte Aylwin:

»Estas incógnitas, no aclaradas hasta el momento por los dirigentes de >Dignidad〈, son agravadas por la circunstancia más o menos notoria de que la Embajada de Alemania no demuestra ningún interés especial por esa colonia, lo que no deja de ser sospechoso. ${ }^{191}$

Als gemeinnütziger Verein erhalte die SBED Zoll- und Steuervergünstigungen vom chilenischen Staat. Die Einnahmen ihrer wirtschaftlichen Aktivitäten kämen jedoch lediglich den Colonos zu Gute und würden eben nicht wohltätigen Zwecken zugeführt. Viele der Minderjährigen seien Kinder von Colonos. Wirtschaftliche Tätigkeit mit dem Ziel, die eigenen Kinder zu ernähren, sei jedoch keine wohltätige Arbeit. Selbst der Mercedes von Paul Schäfer sei zollbefreit eingeführt worden. Der Grundbesitz sei nicht auf den Verein, sondern auf einzelne Mitglieder eingetragen. ${ }^{192}$ Unter den 235 Bewohner_innen

188 Senado, Diario de Sesiones, Legislatura extraordinaria 1967-1968, Sesión 62 a vom 28.02.1968, S. 2505-2511. Investigación de actividades de la »Sociedad Benefactora y Educacional Dignidad.« Aylwins Rede wurde vermutlich mithilfe seines Freundes Héctor Taricco verfasst. Aylwin greift auf zahlreiche Passagen einer Verteidigungsschrift zurück, die Taricco und Fuentes dem Kongressausschuss übergeben hatten. PJS, Sammlung CD. Informe al Senado de Hector Taricco Salazar y Claudio Fuentes Avello vom 14.02.1968.

189 Senado, Diario de Sesiones, Legislatura extraordinaria 1967-1968, Sesión $62^{\text {a }}$ vom 28.02.1968, S. 2505-2511. Investigación de actividades de la »Sociedad Benefactora y Educacional Dignidad«, hier S. 2506. Ebd., S. 2507.

191 Ebd.

192 Konkret auf Hermann Schmidt und Rudolf Cöllen. 
der CD seien 228 deutsche Staatsangehörige. 95 Colonos seien minderjährig, doch nur sieben in Chile geborene Kinder besäßen die chilenische Staatsbürgerschaft. Aylwin fragte, warum der chilenische Staat einen Verein unterstützen sollte, der überwiegend ausländische Kinder nach Chile brächte, wo es doch genug chilenische Kinder gäbe, die in ärmlichen Verhältnissen lebten und hilfsbedürftig seien. Zudem sei es mysteriös, so der Senator, dass Colonos wie Wolfgang Müller und Wilhelmine Lindemann aus der CD geflohen seien, wenn diese doch ihren Mitgliedern angeblich Schutz biete. Die CD habe Müller nach seiner Flucht wegen Sodomie ${ }^{193}$ angezeigt, er sei wegen Beleidigung verurteilt worden. Im Fall von Wilhelmine Lindemann sei ihr Ehemann binnen 48 Stunden aus der Bundesrepublik angereist, um sie mit zurück nach Deutschland zu nehmen, während ihre gemeinsamen Kinder in der CD geblieben seien. Nach Müllers Flucht sei der von Interpol gesuchte Paul Schäfer auf mysteriöse Weise verschwunden. Gleichzeitig gebe SBED-Präsident Hermann Schmidt in Gerichtsverfahren $\mathrm{zu}^{194}$ dass er Schäfer unter dem Namen Paul Schneider in der CD versteckt gehalten habe sowie auf Nachfragen der Botschaft dessen dortige Anwesenheit geleugnet habe. Einer Verfügung des Gerichts in Parral ${ }^{195}$ zufolge gäbe es Gründe zur Annahme, dass sich Paul Schäfer der Sodomie schuldig gemacht habe. Wegen des Untertauchens von Schäfer seien die Ermittlungen jedoch zeitweilig eingestellt worden.

Aylwins zentrale Kritik lautete, die chilenischen Gesetze, hätten in der CD praktisch keine Gültigkeit: Die Schule und das Krankenhaus hätten keine Genehmigung, sie unterlägen nicht der zuständigen behördlichen Kontrolle. Auch der private Friedhof der $\mathrm{CD}$ umginge behördliche Regelungen. Auch die Arbeitsgesetzgebung gelte in der CD de facto nicht, Inspektoren würde der Zutritt verweigert. Jegliche Nachfragen würden entweder ausweichend oder mit Lügen beantwortet, ${ }^{196}$ die CD sei eine Gemeinschaft, die sich systematisch von der Außenwelt abschotte. Ihre Mitglieder lernten kein Spanisch und träten in der Umgebung nur gruppenweise auf. Es sei mysteriös, dass kein einziger Colono das Bedürfnis verspüre, andere Ortschaften in der Gegend kennenzulernen oder zu vereisen. Möglicherweise sei dies den Colonos aber auch verboten, was die Fluchtfälle Müller und Lindemann nahelegten. All diese Fragen und Unregelmäßigkeiten, so der Senator, bedürften einer umfangreichen Aufklärung. Aylwin schloss seine Rede mit der Warnung vor einem Gebiet auf chilenischen Boden, in dem chilenisches Recht ausgehebelt würde:

»Me parece que este episodio ha tenido la virtud de que, al pretender iniciar un proceso contra las autoridades que quieren cumplir las leyes chilenas en territorio nacional, será la cabeza de proceso para establecer la verdad acerca de lo que ocurre en una

"Sodomía« im Spanischen bedeutet Analverkehr. In Chile stand homosexueller Analverkehr bis 1999 unter Strafe.

194 Juzgado de Parral, AZ 23.698.

195 Juzgado de Parral, AZ 23.698. Verfügung vom 26.06.1966.

196 In der Senatssitzung vom 05.03.1968 beantragten die christdemokratischen Senatoren Aylwin und Fuentealba, offizielle Anfragen des Senats an die Minister für Bildung, Finanzen, Gesundheit und Arbeit zu richten, um diese Sachverhalte aufzuklären. Senado, Diario de Sesiones, Legislatura extraordinaria 1967-1968, Sesión 63 $3^{\mathrm{a}}$ vom 05.03.1968, S. 2543. 
parte de nuestro suelo patrio, que pretenden convertir en república independiente, sujeta a sus propias leyes, violando las normas de hospitalidad chilena. ${ }^{197}$

Aylwins Rede 1968 war die Geburtsstunde des Diskurses von der CD als Staat im Staate, in dem die chilenische Gesetzgebung nicht gelte oder zumindest nicht durchgesetzt werde. 1990 sollte Aylwin als erster demokratisch gewählter Präsident nach der Militärdiktatur die Gelegenheit bekommen, seine Fragen und Feststellungen wieder aufzugreifen.

\section{Die Rede des Senators Jaime Barros}

In der darauffolgenden Senatssitzung ${ }^{198}$ ergriff überraschenderweise der kommunistische Senator Jaime Barros das Wort, um die CD zu verteidigen - zumindest solange Chile nicht sozialistisch sei, so Barros: »Mientras en Chile no haya un régimen socialista, me quedo con Dignidad tal como está. «"199 Barros unterstellte den Gegner_innen der CD Rassismus und warf der Presse eine Hetzkampagne vor. Er monierte, dass der Verfassungsausschuss des Senats keine Colonos angehört habe. Barros behauptete, sich selbst eine objektive Meinung von der CD gebildet zu haben - freilich ohne diese je besucht zu haben. ${ }^{200}$ Er verwies darauf, dass die CA Chillán nach Müllers Anschuldigungen die entsprechenden Colonos vollständig freigesprochen habe. Ganz im Jargon der CD nannte er Müller einen »Sittenlosen« und Lindemann eine »Verrückte«. Diese Episode verdeutlicht, dass es der CD immer wieder gelang, quer durch die politische Landschaft Fürsprecher_innen zu gewinnen und diese dazu zu bringen, sich vehement für die CD einzusetzen. Dies stiftete politische Verwirrung, beschädigte die Glaubwürdigkeit der Kritik an der CD und stützte deren stets wiederkehrenden Verteidigungsdiskurs, alle Vorwürfe seien erlogen und entweder durch Neid und Kränkung motiviert oder das Produkt von Geisteskranken.

\subsubsection{Untersuchungsausschuss der Cámara de Diputados 1968}

Der für den Fortbestand der CD wichtigste parlamentarische Vorgang in Chile war der 1968 von der Cámara de Diputados eingesetzte Untersuchungsaussschuss. Durch intensive Lobbyarbeit unter Mitwirkung ihrer Rechtsanwälte und anderer Unterstützer_in-

197 Senado, Diario de Sesiones, Legislatura extraordinaria 1967-1968, Sesión 62 ${ }^{\mathrm{a}}$ vom 28.02.1968, S. 2505-2511. Investigación de actividades de la »Sociedad Benefactora y Educacional Dignidad.«, hier S. 2511.

198 Senado, Diario de Sesiones, Legislatura extraordinaria 1967-1968, Sesión 63 ${ }^{\mathrm{a}}$ vom 05.03.1968, S. 2543-2548, Actividades de la Sociedad Benefactora y Educacional Dignidad - observaciones del señor Barros.

199 Ebd., S. 2547.

200 Als »objektive« Quellen nennt Barros u.a. die Berichterstattung von Fernando Murillo Viaña in der linken Abendzeitung Las Noticias de Última Hora vom Februar 1968. Hermann Schmidt und Albert Schreiber hatten die Redaktion der Zeitung besucht und dort sämtliche Anschuldigungen gegen die CD als Verleumdungen dargestellt. Vgl. Las Noticias de Última Hora vom 16.02.1968, S. 7. »Dirigentes de Colonia Dignidad responden a acusaciones en su contra«. Bei dieser Gelegenheit luden CD-Führungsmitglieder Murillo Viaña in die CD ein, der daraufhin in einer mehrteiligen Serie in Las Noticias de Última Hora die Arbeit der CD lobte und die Sichtweise der CD wiedergab. 
nen erreichte die $C D$, dass der Untersuchungsaussschussbericht sie weitgehend entlastete. In den folgenden Jahrzehnten führte die CD diesen »Freispruch« immer wieder als Beleg für eine vermeintlich gegen sie vorgebrachte »Verleumdungskampagne« an.

Nur kurz nach den geschilderten Vorgängen im Senat, am 7. März 1968 beschloss die Cámara de Diputados die Einrichtung eines 13-köpfigen Untersuchungsausschusses. ${ }^{201}$ Dieser hatte einen sehr allgemein gefassten Untersuchungsauftrag, »diversos hechos y actividades de la Sociedad Benefactora y Educacional >Dignidad««, d.h. diverse seit der Flucht von Wolfgang Müller 1966 bekannt gewordenen Vorwürfe gegen die CD aufzuklären. Über die Medien forderte der Ausschuss die Bevölkerung auf, ihm Hinweise zum Untersuchungsgegenstand zukommen zu lassen. Auch bei Ministerien und Behörden bat der Untersuchungsausschuss um Informationen, selbst in der Bundesrepublik: Am 20. März 1968 wurden zwei Mitarbeiter der chilenischen Botschaft beim AA vorstellig und baten um Auskünfte zur Privaten Socialen Mission. Das AA berichtete der Botschaft darüber:

»Den Angehörigen der chilenischen Botschaft wurde erklärt, daß das Auswärtige Amt selbst nur wenig über die Muttergesellschaft wisse. [...] Was die Frage der Untersuchung selbst anlange, so handele es sich um eine chilenische Angelegenheit, deren Durchführung wir den zuständigen chilenischen Stellen überlassen müssten. Eine Klärung der Zustände in der Kolonie liege im Interesse des Fortbestandes der guten deutsch-chilenischen Beziehungen. Unseres Erachtens wäre eine Untersuchung nur dann sinnvoll, wenn sie im Rahmen einer größeren Aktion von deutschsprechenden Beamten durchgeführt würde, wenn die Befragungen der Kolonieangehörigen einzeln und in Abwesenheit der Leitung der Kolonie oder anderer Angehöriger erfolge und wenn denjenigen Angehörigen der Kolonie, die diese verlassen wollten, ausreichender Schutz gewährt würde. Dieser Schutz müsse einmal gegenüber Rückführungsversuchen der Leitung bestehen, zum anderen aber auch die Schaffung einer neuen Existenzgrundlage zum Gegenstand haben. ${ }^{202}$

Anfang Mai 1968 besuchten die Mitglieder des Untersuchungsausschusses Catillo, Parral und die CD. Dort wurden sie von einem Chor mit Blumensträußen empfangen. ${ }^{203}$ Botschaftsrat Spang begleitete die Ausschussmitglieder. ${ }^{204}$

Nach 18 Sitzungen sowie der Anhörung dutzender Zeug_innen veröffentlichte der Ausschuss im November 1968 einen Abschlussbericht, ${ }^{205}$ der die CD zu großen Teilen

201 Cámara de Diputados, Boletín de Sesiones, Legislatura extraordinaria periodo 1967-1968, Sesión $40^{\mathrm{a}}$ vom 05.03.1968, S. 3741. Se acuerda la designación de una Comisión Especial para investigar los hechos producidos en la Colonia »Dignidad« de Parral, provincia de Linares.

202 PAAA, B 82, Bd. 991. Schreiben AA an Botschaft vom 27.03.1968, GZ V 5-88/6228.

203 El Siglo vom 04.05.1968, S. 3, »Dignidad«.

204 PA AA, AV NA 31581. Aufzeichnung vom 10.07.1970, CZ RK V 4-88. Darin wird Spangs Teilnahme erwähnt. Einen Bericht von Spang über diesen Besuch konnte ich jedoch im PA AA nicht finden.

205 Cámara de Diputados, Boletín de Sesiones, Legislatura Extraordinaria periodo 1968-1969, Sesión $12^{\mathrm{a}}$ vom 26.11.1968, S. 1133-1160. Informe de la Comisón Especial designada para investigar las actividades de la »Sociedad Benefactora y Educacional Dignidad« de Parral. Unter den ca. 80 namentlich im Ausschussbericht genannten Zeug_innen waren zahlreiche Führungsmitglieder und Anwälte der CD, ihr wohlgesonnene Journalist_innen sowie langjährige Unterstützer_innen, je- 
entlastete. Er stellte fest, die SBED habe sich weitestgehend satzungskonform verhalten. Sämtliche Mitglieder verfügten über rechtmäßige Aufenthaltstitel. Auch halte sich die CD - zumindest was die in der CD beschäftigten externen chilenischen Arbeitnehmer_innen anging - an die Arbeitsgesetzgebung. Ansonsten sei die CD ein gemeinnütziger Verein, die Überschüsse aus der Geschäftstätigkeit und der unentlohnten Arbeit der Mitglieder flössen in die wohltätige Arbeit. Das Bildungs-, Justiz- und Wirtschaftsministerium sollten eine Form finden, die Arbeit der Schule in der CD zu legalisieren. Das Krankenhaus der CD leiste eine vorbildliche Arbeit und behandele die Bevölkerung kostenlos. ${ }^{206}$ Zwar habe die Leiterin des Krankenhauses (Gisela Seewald) ihren Artzttitel in Chile noch nicht anerkennen lassen, Kolleg_innen bescheinigten ihr jedoch umfangreiche medizinische Kenntnisse. Zudem müssten einige Artikel der Vereinssatzung angepasst und es müsse genauer definiert werden, wie gemeinnützige Vereine bei Zolleinfuhren zu behandeln seien.

Bei der CD, so der Bericht des Untersuchungsausschusses, handle es sich nicht um eine Sekte. In der Siedlung herrsche vielmehr Religionsfreiheit. Viele Colonos seien christlich-evangelikalen Glaubens, es gäbe jedoch auch Katholiken und nicht-praktizierende Juden. Kritisiert wird im Bericht lediglich, dass der Grundbesitz nicht im Besitz des Vereins, sondern auf die Privatpersonen Hermann Schmidt und Rudolf Cöllen eingetragen sei. Dies solle geändert werden.

Schäfers Rolle in der CD und seine Anwesenheit in der Siedlung erwähnt der Bericht mit keinem Wort. Ganz allgemein formuliert heißt es allerdings apologetisch, manche Anschuldigungen seien »keine Stellungnahme wert, da sie absolut irreal ${ }^{207}$ seien. Stattdessen enthält der Bericht eine pauschale Journalist_innenschelte: Er kritisiert scharf die angebliche "Sensationsberichterstattung« der Medien, bei der Unwahrheiten verbreitet würden, oftmals ohne jegliche Belege und ohne dass die Berichtenden die CD je besucht hätten. Oftmals seien Beschreibungen in der Presse derart fantastisch, dass sie »jeglichem normalen Menschenverstand« widersprächen. Dies sei mit einer ethischen Ausübung des Journalistenberufs unvereinbar, so die Abgeordneten.

Die Cámara de Diputados nahm den Abschlussbericht des Untersuchungsausschusses am 27. November 1968 mit großer Mehrheit an. ${ }^{208}$ Lediglich kommunistische Abge-

doch nur eine Handvoll Kritiker_innen der CD. Einer von ihnen war Ruperto Torres Aravena, der am 13.10.1973 in Catillo verhaftet wurde und seitdem als verschwunden gilt. Vermutlich wurde Torres in der CD ermordet. Seine Entführung war Gegenstand des Verfahrens CA Santiago, AZ 2182-98 »Episodio Parral«.

206 Die - auch von der CD wiederholt vorgetragene - Behauptung, die umliegende Bevölkerung werde in ihrem Krankenhaus kostenlos behandelt, ist nur aus Sicht der Patient_innen korrekt. Die CD erhielt für den Betrieb des Krankenhauses umfangreiche Subventionen und rechnete die Behandlungen mit der Gesundheitsbehörde ab. Es gibt Hinweise darauf, dass die CD diese Abrechnungen regelmäßig fälschte, um höhere Zahlungen zu erschleichen. Dieser mutmaßliche systematische Betrug dürfte eine wichtige Einkommensquelle für die CD gewesen sein. Er wurde durch die Justiz nie eingehend untersucht.

207 Cámara de Diputados, Diarios de Sesiones, Legislatura extraordinaria periodo 1968-1969, Sesión $12^{\text {a }}$ vom 26.11.1968, S. 1131-1161. Informe de la Comisión Especial designada para investigar las actividades de la Sociedad Benefactora y Educacional »Dignidad «, de Parral, hier S. 1150.

208 Cámara de Diputados, Boletín de Sesiones, Legislatura extraordinaria periodo 1968-1969, Sesión $13^{\mathrm{a}}$ vom 27.11.1968, S. 1285-1288. La Cámara vota las conclusiones del informe de la Comisión Espe- 
ordnete sollen gegen die Annahme gestimmt haben. ${ }^{209}$ Wie es zu einer solch deutlichen Übereinstimmung des Ausschusses mit der Linie der CD-Führungsmitglieder kommen konnte, ist nicht eindeutig belegbar. Die Fülle von Unterstützer_innen der CD unter den angehörten Zeug_innen und Sachverständigen, die große Anzahl eingereichter Schriftstücke der CD sowie die tatkräftige Unterstützung der CD durch Rechtsanwälte aus renommierten Kanzleien ${ }^{210}$ zeugen jedoch von einer professionell geplanten sowie mit großem Einsatz an Personal und Ressourcen durchgeführten Lobbystrategie.

Für die CD war der Bericht des Untersuchungsausschusses ein riesiger Triumph. Nach den Anschuldigungen u.a. Aylwins kam der Bericht einem Freispruch auf ganzer Linie gleich - und so nannte es auch die CD selbst immer wieder. Die zum Teil sehr pauschalen Bewertungen der Abgeordneten bestätigten den Opferdiskurs der CD, den diese in den darauffolgenden Jahrzehnten stets bemühen sollte: Demnach waren jegliche Vorwürfe gegen die CD bloße Erfindungen von Neider_innen, psychisch Kranken oder sensationslüsternen Journalist_innen. Die CD präsentierte den Abschlussbericht des Untersuchungsausschusses von 1968 noch Jahrzehnte später als vermeintlichen Beleg für die Unwahrheit der gegen sie erhobenen Anschuldigungen.

\subsubsection{Besuch des Menschenrechtsausschusses in der Colonia Dignidad 1990}

In den Jahren der Allende-Regierung (1970-73) befasste sich das chilenische Parlament nicht mit der Colonia Dignidad und die Militärdiktatur (1973-1990) löste das Parlament auf. Der Amtsantritt des ersten wieder demokratisch gewählten Präsidenten Patricio Aylwin im März 1990 löste auf vielen Seiten Hoffnungen aus, dass die seit Jahrzehnten im Raum stehenden Verbrechen der CD nun mit Nachdruck untersucht würden.

Bereits wenige Monate nachdem das neue Parlament seine Arbeit wieder aufgenommen hatte, stattete der Menschenrechtsausschuss der Cámara de Diputados am 6. Oktober 1990 der CD einen angekündigten Besuch ab. ${ }^{211}$ Die CD hatte zuvor durch einen Schutzantrag bei der CA Valparaíso ${ }^{212}$ versucht, den Besuch zu verhindern. Dabei

cial encargada de estudiar las actividades de la Sociedad Benefadora y Educacional »Dignidad«, de Parral. Über die Schlussfolgerungen des Ausschussberichts wurde einzeln abgestimmt. Viele davon wurden mit 37:8 Stimmen angenommen.

209 Dies meldete zumindest die Botschaft nach Bonn. PA AA, B 82, Bd. 991. Schreiben AA an Botschaft vom 27.03.1968, GZ: $V$ 5-88/6228. Es gab keine namentliche Abstimmung, jedoch hatten sich in der vorherigen Debatte nur kommunistische Abgeordnete gegen die Annahme des Berichts ausgesprochen.

210 CD-Anwalt Luis Ortíz Quiroga, der die CD auch gegenüber dem Ausschuss vertrat und von diesem angehört wurde, gilt bis heute als einer der renommiertesten Rechtsanwälte Chiles. Er ist Christdemokrat und arbeitete 1968 in der Kanzlei von Mariano Puga Vega. Dieser war Vorsitzender der Liberalen Partei, Kongressabgeordneter und Botschafter Chiles in den USA. Ein Kollege von Ortíz in der Kanzlei Puga war damals Máximo Pacheco Gómez, christdemokratischer Bildungsminister (1968-1970) und späterer Rechtsanwalt von Amnesty International sowie der Botschaft in Verfahren gegen die Colonia Dignidad.

211 PA AA, AV NA 31638. Protokoll über den Besuch des Menschenrechtsausschusses in der CD vom 06.10.1990, verfasst von Kommissionssekretär José Vicencios Frías.

212 PA AA, AV NA 31638. CA Valparaíso, AZ 279-90. Recurso de protección vom 25.09.1990, eingereicht von RA Fidel Reyes für die SBED. 
argumentierte sie, ein Parlamentsausschuss habe keinerlei Kontrollbefugnisse auf Privatgelände. Der Antrag wurde jedoch abgelehnt und der dreistündige Besuch der zwölf Abgeordneten fand statt. Die Delegation wurde vom Vorstand der SBED ${ }^{213}$ sowie von CD-Anwalt Fidel Reyes empfangen. Die Abgeordneten stellten dem Vorstand eine Reihe von Fragen, die Hartmut Hopp und RA Reyes allesamt ausweichend beantworteten. ${ }^{214}$ So bat etwa der Abgeordnete Jaime Naranjo (PS) darum, Miguel Becerra Monsalve, den Sohn des 1974 von der CD ermordeten DINA-Agenten Miguel Becerra Hidalgo, sprechen zu dürfen. Dessen Mutter hatte sich seit 1974 vergeblich um die Herausgabe ihres Sohnes bemüht. Naranjo erhielt die Antwort, dass Becerra Monsalve sich derzeit leider in Bulnes befinde und außerdem bereits volljährig sei. Er habe bereits vor der Justiz ausgesagt und wolle die CD nicht verlassen. Ausschusspräsidentin Maria Maluenda (PPD) fragte nach dem 1975 verschwundenen ehemaligen sozialistischen Abgeordneten Carlos Lorca und ergänzte, Zeug_innen hätten Lorca in der CD gesehen. Hopp antwortete, Lorca sei "nicht in der CD gestorben ${ }^{215}$ und für diese Fragen sei die Justiz zuständig. Der Besuch des Ausschusses endete mit einer Begehung des CD-Krankenhauses und des Flugplatzes. Die anschließende Einladung der CD zum Tee nahmen lediglich die drei Ausschussmitglieder der rechten Parteien an.

Der Besuch des Menschenrechtsausschusses kann rückblickend als erstes Kräftemessen nach der Rückkehr zur Demokratie betrachtet werden. Im Dezember 1990, einige Wochen nach seinem Besuch in der CD richtete der Ausschuss ein umfassendes Schreiben ${ }^{216}$ an Präsident Aylwin und forderte diesen auf, die Auflösung der SBED per Dekret zu veranlassen (vgl. den folgenden Abschnitt 5.2.4).

\subsubsection{Untersuchungsausschuss der Cámara de Diputados 1995}

Im Februar 1991 wurde von der Alywin-Regierung die 1961 von der CD gegründete Rechtsperson, die Sociedad Benefactora y Educacional Dignidad (SBED), per Dekret aufgelöst. ${ }^{217}$ Die CD ging umgehend juristisch gegen das Dekret vor und verhinderte so die Auflösung der SBED über mehrere Jahre. Am 5. Januar 1995 beschloss die Cámara de Diputados die Einsetzung eines Untersuchungsausschusses ${ }^{218}$ mit dem Ziel, die Umsetzung des Regierungsdekrets Nr. 143 vom 31. Januar 1991 zur Auflösung der SBED

213 Laut diesem Schutzantrag (ebd.) gehörten dem Vorstand der SBED damals an: Hermann Schmidt (Präsident), Kurt Schnellenkamp (Vizepräsident), Hans-Jürgen Blanck (Sekretär), Hartmut Hopp (Direktor) und Albert Schreiber (Direktor).

214 PA AA, AV NA 31638. Protokoll über den Besuch des Menschenrechtsausschusses in der CD vom 06.10.1990, verfasst von Kommissionssekretär José Vicencios Frías.

215 Ebd.

216 PA AA, AV NA 31620. Cámara de Diputados, Comisión de Derechos Humanos Nacionalidad y Ciudadanía, Oficio 117 vom 12.12.1990 an Präsident Aylwin.

217 Diario Oficial N³3.896 vom 16.02.1991. Ministerio de Justicia, Decreto 143 vom 31.01.1991. »Declara disuelta y cancela personalidad jurídica y destina bienes de entidad que indica."

218 La Epoca vom 06.01.1995, S. 22. »Cámara acordó comisión por caso Dignidad «. 38 Abgeordnete des Parteienbündnisses Concertación stimmten der Zeitung zufolge für die Einsetzung des Untersuchungsausschusses, 18 Abgeordnete der rechten Opposition stimmten dagegen. 
und die rechtmäßige Anwendung der chilenischen Gesetzgebung in der CD zu überprüfen. Die CD hatte die Umsetzung des Auflösungsdekrets durch alle verfügbaren Rechtsinstanzen angefochten. Bereits im Vorfeld des Dekrets hatte die CD-Führung vorgesorgt und ihr Vermögen zwischen 1988 und 1990 auf verschiedene Aktienholdings übertragen, so dass von der SBED praktisch nur eine leere Hülle blieb (vgl. Abschnitt 3.2.3). Auch das Auflösungsdekret lief so praktisch ins Leere. Dennoch konnte die SBED formal weiterhin als Trägerin der (externen) Schule und des Krankenhauses der CD fungieren, bis der Rechtsweg gegen das Dekret ausgeschöpft war. Dies war mit der Entscheidung der Corte Suprema vom 6. September 1994 der Fall. ${ }^{219}$ Nur wenige Wochen später jedoch gründete die CD einen neuen Verein namens Organización Comunitaria de Desarrollo Social Perquilauquén, ${ }^{220}$ der nun die Trägerschaft von Schule und Krankenhaus übernahm. ${ }^{221}$ Gleichzeitig versuchte die CD, durch einen Hungerstreik Druck auf die Regierung auszuüben. Dabei erhielt sie Unterstützung durch rechte Abgeordnete. Anfang Dezember 1994 schloss die CD Krankenhaus und Schule, während Unterstützungsgruppen und sogenannte Patientenkomitees Demonstrationen und Besetzungen durchführten und deren Wiedereröffnung forderten. ${ }^{222} \mathrm{Zu}$ Beginn des Schuljahres im März 1995 nahm die Schule ihren Betrieb wieder auf. Auch die Wiedereröffnung des Krankenhauses wurde für Anfang Mai 1995 angekündigt, ${ }^{223}$ obwohl der Servicio de Salud del Maule (die Gesundheitsbehörde der Region) keine entsprechende Genehmigung erteilt hatte. Am 7. Mai $1995^{224}$ verkündigte die CD die sofortige Wiedereröffnung des Krankenhauses. Dabei gelang es ihr, als Fürsprecher_innen bei einer großen Unterstützungsveranstaltung nicht nur Abgeordnete der Rechten, wie Hernán Larraín und Sergio Correa (beide UDI), sondern auch Felipe Letelier von der

219 Die CD hatte gegen das Dekret 143 drei Schutzanträge bei der CA Santiago gestellt, die diese am 17.03.1993 ablehnte. Die daraufhin eingelegte Berufung wies die Corte Suprema am 02.08.1994 zurück (AZ 20464-93). Auch der Einspruch gegen diese Entscheidung wurde am 06.09.1994 von derselben Kammer zurückgewiesen. Somit waren alle Rechtsmittel ausgeschöpft und das Dekret 143 wurde endgültig rechtskräftig.

220 Die Vereinsgründung wurde im November 1994 beim Justizministerium beantragt. Per Dekret vom 23.05.1995 wurde der Verein ins Vereinsregister eingetragen. Als Präsident fungierte Eduardo Fuentes, langjähriger Vertrauter der CD-Führung und Präsident der »CD-Freundeskreise«. Zu den Gründungsmitgliedern zählte auch der Abgeordnete der UDI, Ignacio Urrutia Bonilla, der auch einen Direktorenposten innehatte. CA Santiago, AZ 2182-98 (»Asociación Ilícita«), Bd. III (Ministro), BI. 1326. PDI, Informe Policial 1003/00510 vom 03.07.2006, Anexo 30, Dokument »Colonia Dignidad - historia« O. A., o. D. nennt Decreto Exento Nº633 vom 23.05.1995 als Tag der Eintragung ins Vereinsregister.

221 Nachdem die letzten Rechtsmittel gegen das Dekret Nr. 143 erschöpft waren, wurden die Schule und das Krankenhaus am 06.12.1994 geschlossen.

222 Zum verkündeten Schließungstermin besetzten Schüler_innen und Patient_innen die Schule und das Krankenhaus. Eine Unterstützungsgruppe besetzte im Februar 1995 zudem die Kathedrale in Talca und forderten eine Wiedereröffnung beider Einrichtungen.

223 El Mercurio vom 23.04.1995, S. 6C. »Dijo Doctor Hartmut Hopp: ^Hospital de »Dignidad« será reabierto en Mayo.«

224 Während El Mercurio die Zahl der Teilnehmer_innen mit 3500 angab, schrieb La Tercera von 6000. Vgl. El Mercurio vom 08.05.1995, S. 4C. »Con masivo acto: Reabrieron hospital de la ex-Colonia Dignidad« sowie La Tercera vom 08.05.1995, S. 6, »Reabrió sus puertas hospital de Dignidad«. 
Regierungspartei PPD zu gewinnen. Letelier sprach sich in Abweichung von der Linie der Regierung öffentlich vehement für die Wiedereröffnung des Krankenhauses aus. ${ }^{225}$

Auch den Termin für die Wiedereröffnung des Krankenhauses hatte die CD strategisch gewählt: Denn am darauffolgenden Tag, dem 8. Mai 1995, sollte die von der Regierung aufgelöste SBED ihre Vermögenswerte und -gegenstände an die Methodistische Kirche übergeben. Als Victor Chávez, der Gouverneur von Parral, sich zu diesem Zweck in Begleitung der Polizei zur CD begab, stand er vor verschlossenem Tor. Auf der anderen Seite, in der CD, protestierten Unterstützer_innen der CD. Die Polizei brach das Tor auf und es kam zu Rangeleien. Chávez verhandelte stundenlang mit CDAnwalt Fidel Reyes, um letztlich unverrichteter Dinge wieder abzureisen. Gleichzeitig erklärte Eduardo Vega, Direktor der regionalen Gesundheitsbehörde, das Krankenhaus wegen fehlender Betriebserlaubnis für geschlossen. ${ }^{226}$ Die CD strebte dagegen mit einen Schutzantrag umgehend bei der CA Talca eine sofortige Aussetzung der Schließung an. ${ }^{227}$ Zwar wurde der Aussetzungs-Antrag (orden de no innovar) eine Woche später abgelehnt, ${ }^{228}$ am 14. Juni entschied jedoch die Corte Suprema, das Krankenhaus könne bis zu einer Entscheidung in der Hauptsache über den Schutzantrag geöffnet bleiben. ${ }^{229}$ Diese Entscheidung der Judikative stellte aus Sicht der chilenischen Regierung einen Affront dar: Erneut hatte die CD das Auflösungsdekret von 1991 de facto ausgehebelt und gleichzeitig demonstriert, dass sie durch eine juristische Offensive - unterstützt von einigen Richter_innen an der Corte Suprema - in der Lage war, sich über Entscheidungen der Regierung hinwegzusetzen.

Präsident Eduardo Frei hatte erst im März 1995 bei seinem Staatsbesuch in der Bundesrepublik nach Gesprächen mit Bundeskanzler Kohl und Außenminister Kinkel erklärt, seine Regierung werde keinerlei Neugründungen von Organisationen mit Verbindungen zur CD zulassen. ${ }^{230}$ Trotz dieser Aussage des Staatspräsidenten wur-

225 La Segunda vom 09.05.1995, S. 44. »Diputado F. Letelier (PPD): >Respaldo al hospital de Villa Baviera«. Dies blieb nicht die einzige Abweichung Leteliers von der Parteilinie Am 22.09.1995 besuchte er erneut die CD, diesmal zusammen mit einer Delegation des Cesundheitsausschusses der Cámara de Diputados. Als einziges Delegationsmitglied der Regierungsfraktionen erklärte er gegenüber der Presse: »Wenn von Versöhnung und nationaler Einheit die Rede ist, müssten die sozialen und politischen Aspekte getrennt und anerkannt werden, dass dieses Krankenhaus Hilfe und Medizin anbietet für die Sektoren, die in jener Zone am meisten unter Mittelknappheit leiden«. Die Botschaft berichtete dem AA über einen entsprechenden Artikel in der Zeitung El Mercurio vom 24.09.1995. Der Bericht der Botschaft endet mit der Feststellung: »Ein Punkt für die ex-CD!«PA AA, AV NA 31666. DB 505 vom 27.09.1995.

226 El Mercurio vom 09.05.1995, S. 9C. »También fue clausurado hospital: Descerrajamiento e incidentes hubo en la ex-Colonia Dignidad«.

227 La Tercera vom 12.05.1995, S. 4. »Recurso de protección por hospital«.

228 Die Entscheidung fällte die zweite Kammer der CA Talca unter Richter Hernán Robert Arias, der 1989 das Untersuchungsverfahren gegen die CD geleitet hatte, vgl. La Tercera vom 18.05.1995, S. 7. »Petición ordenaba no innovar: Rechazan recurso por Villa Baviera«.

229 La Segunda vom 14.06.1995, S. 21. »Por oficio ayer: Corte Suprema decretó la reapertura del hospital de Villa Baviera«.

230 Vgl. El Mercurio vom 16.03.1995, S. C2. »Aseguró Frei a Kohl: No habrá personalidad jurídica para ningún ente vinculado con Dignidad«. Senator Hernán Larrain von der rechten UDI erklärte daraufhin, Freis Äußerungen »parece[n] haber sido producto de la presión de un gobierno extranjero en materias propias e irrenunciables de la soberanía nacional. [.] Añadió que la autoridad bien 
de die Gründung des SBED-Nachfolgevereins Organización Comunitaria de Desarrollo Social Perquilauquén am 23. Mai 1995 offiziell anerkannt. Die Einsetzung des Untersuchungsausschusses kann in diesem Kontext als verzweifelter Versuch der Regierung interpretiert werden, trotz der Blockade der Justiz eine endgültige Schließung der CD $\mathrm{zu}$ bewirken.

\section{Arbeit und Ergebnisse des Untersuchungsausschusses der Cámara de Diputados}

Der 15-köpfige Untersuchungsausschuss des chilenischen Unterhauses konstituierte sich am 2. März 1995. Der Ausschuss bat diverse Ministerien und Behörden um die Zusendung von Berichten und hörte insgesamt 22 Personen an. Carlos Cáceres und Hernán Felipe Errázuriz, während der Diktatur Innen- bzw. Außenminister, kamen der Vorladung nicht nach. ${ }^{231}$ Auch der deutsche Botschafter Werner Reichenbaum ließ sich entschuldigen. ${ }^{232}$ Stattdessen erschien Botschaftsanwalt Máximo Pacheco vor dem Untersuchungsausschuss.

Der Einsetzungsbeschluss der Cámara de Diputados hatte die Notwendigkeit des Untersuchungsausschusses u.a. mit der weitverbreiteten öffentlichen Wahrnehmung begründet, wonach die CD ein Staat im Staate sei. ${ }^{233}$ Dies untergrabe das Vertrauen in die staatlichen Institutionen und den Rechtsstaat. Da dieselben Personen, die die SBED geleitet hätten, nun einen Nachfolgeverein gegründet hätten, müsse überprüft werden, ob die Missstände, die zur Auflösung der SBED geführt hatten, von den dafür zuständigen Behörden inzwischen abgestellt bzw. sanktioniert worden seien.

Der Abschlussbericht des Untersuchungsausschusses kam zu dem Schluss, die für die Umsetzung des Auflösungsdekrets zuständigen Behörden und Institutionen seien ihrem Auftrag zwar im Allgemeinen nachgekommen, an der Lebensweise und dem Wirken der CD habe sich jedoch faktisch wenig geändert:

»Llama poderosamente la atención que habiendo transcurrido más de 4 años desde que se canceló la personalidad jurídica a la mencionada Corporación, todos los territorios, se encuentran aún inscritos a nombre de sociedades comerciales que ocupan como trabajadores a los mismos colonos que desempeñaban los mismas labores que los que realizaban en la Colonia Dignidad. En nada han variado las restricciones a la

sabe que la continuación de la obra de Dignidad es solicitada por muchas personas, entre otras, por destacadas figuras del quehacer nacional que garantizan el fiel cumplimiento de los objetivos perseguidos por la sociedad benefactora«. El Mercurio, 17.03.1995, S. 4C. »Senador Hernán Larraín: Dichos de Frei sobre Colonia Dignidad son incomprensibles«.

231 El Mercurio vom 18.03.1995, S. 6C. »Ex-Ministros declinaron exponer acerca de su gestión sobre Dignidad «.

232 El Mercurio zufolge dürfen deutsche Diplomaten generell nicht vor Untersuchungskommissionen ausländischer Parlamente erscheinen, vgl. El Mercurio vom 28.05.1995, S. 2C. »Comisión ha reunido datos sobre presuntas ilegalidades de la ex-Colonia Dignidad«. Reichenbaum erklärte gegenüber der Presse, die Bundesregierung verfolge das Untersuchungsverfahren sehr aufmerksam und erwarte mit großem Interesse das Ergebnis. Vgl. El Mercurio vom 27.04.1995, S. 4C. »Embajador germano Werner Reichenbaum: Alemania espera resultado de informe sobre Dignidad «.

233 Cámara de Diputados, Boletín de Sesiones, Legislatura 330ª , Sesión 31ª vom 03.01.1995, S. 33-36. Creación de Comisión investigadora de cumplimiento del decreto supremo que disolvió la ex »Colonia Dignidad«. 
libertad individual de desplazamiento de los habitantes de la ex Colonia y a la inviolabilidad de la correspondencia. Esos territorios de la ex-Colonia Dignidad siguen cercados por alambradas que sirven de pretexto a quienes sostienen que sus habitantes no pueden abandonarlos libremente. A la luz de las informaciones recogidas por esta Comisión, se puede afirmar que la forma de vida de la agrupación que existía bajo la vigencia de la personalidad jurídica cancelada, no ha sufrido alteraciones sustanciales, [...] existen un apreciable número de situaciones irregulares de la ex Colonia Dignidad que se mantienen después del Decreto $\mathrm{N}^{\circ} 143$ del año 1991, que afectan los derechos de las personas que habitan en sus territorios. Esta es, además, la preocupación expresada por la Comisión investigadora del Parlamento Alemán.«²34

Der Ausschuss stellte fest, die soziale Realität in der CD weiche immer noch von den Grundprinzipien der chilenischen Rechtsordnung ab. Er forderte die Regierung auf, eine erneute Prüfung durchzuführen und innerhalb eines Jahres u.a. zu berichten

- ob die Familien- und Cemeinschaftsorganisation in der CD der chilenischen Verfassungs- und Rechtsordnung entspräche;

- ob die Informations- und Kommunikationsfreiheit und die Wahrung des Briefgeheimnisses gewährleistet seien;

- ob das Recht auf Freizügigkeit und Bewegungsfreiheit in der CD gewährt sei;

- ob die Gesetzgebung zur allgemeinen Schulpflicht (acht Grundschuljahre) für die Minderjährigen in der CD eingehalten werde. ${ }^{235}$

Weiterhin sollte die Regierung die Einhaltung der Wehrpflicht und die rechtmäßige Eintragung von Waffen und des Flugplatzes in der CD untersuchen. Sollte festgestellt werden, dass in der CD Rechte nicht eingehalten würden, sollte das Innenministerium neue Maßnahmen prüfen, wie etwa eine Ausweisung von Paul Schäfer aufgrund des Verstoßes gegen ausländerrechtliche Bestimmungen. ${ }^{236}$

Des Weiteren forderte der Ausschussbericht die Regierung auf, über den Staatsverteidigungsrat (CDE) als Vertreter des Fiskus zu überprüfen, ob die Übertragung des CD-Vermögens von der gemeinnützigen SBED auf kommerzielle Aktiengesellschaften als Betrug anzusehen und entsprechend anfechtbar sei. Außerdem sollte der CDE die Vielzahl an Verfahren, bei denen er die Interessen des Staates vertrat, energischer betreiben. Schließlich forderte der Bericht die Regierung auf, zur Bündelung und Be-

234 Cámara de Diputados, Boletín de Sesiones, Legislatura 332 a , Sesión 33ª vom 06.12.1995. Informe de la Comisión Especial Investigadora de la Cancelación de la Personalidad Jurídica de Colonia Dignidad, creada con el objeto de verificar la forma como se dio cumplimiento al decreto supremo que disolvió esa institución, auch online unter https://www.camara.cl/camara/media/docs/colonia/01. pdf, S. 85 (zuletzt abgerufen am 12.02.2018). Die Feststellung des Ausschusses bzgl. der Position des Bundestages (S. 85) ist nicht korrekt: Zwar gab es dort am 22.02.1988 im Unterausschuss für Menschenrechte und Humanitäre Hilfe eine öffentliche Anhörung zum Thema Colonia Dignidad, der Ausschuss besaß jedoch keinerlei Befugnisse, die mit denen eines Untersuchungsausschusses vergleichbar wären. Aus der Anhörung folgte auch keinerlei Positionierung oder Bericht des Deutschen Bundestages. 
schleunigung der anhängigen Justizverfahren im Zusammenhang mit der CD die Einsetzung eines Ministro en Visita zu beantragen.

Der Untersuchungsausschuss hatte den Entwurf des Abschlussberichtes am 8. November 1995 mit acht Ja-Stimmen bei drei Gegenstimmen gebilligt. Die ablehnenden drei Mitglieder rechter Parteien legten zwei Minderheitenvoten vor. Das eine, das alle drei Abgeordneten unterzeichneten, war von Anwälten der CD verfasst worden. ${ }^{237}$ Es stellte fest, dass die Justiz die CD stets freigesprochen habe, wie etwa im Bericht von Untersuchungsrichter Robert 1989 (vgl. Abschnitt 5.1.3) und kritisierte, dass entlastende Dokumente, wie der Bericht des Untersuchungsausschusses von 1968 (vgl. Abschnitt 5.2.2) im aktuellen Fall nicht berücksichtigt worden seien. Das zweite Minderheitsvotum des Abgeordneten Valentín Ferrada (RN) kritisierte darüber hinaus auch die deutsche Diplomatie. Obwohl die deutsch-chilenischen Beziehungen immer freundschaftlich und respektvoll gewesen seien, hätte das AA eine Haltung an den Tag gelegt, die den Respekt gegenüber Chile vermissen lasse. ${ }^{238}$

Am 6. Dezember 1995 legte der Untersuchungsausschuss seinen Abschlussbericht dem Parlament vor. ${ }^{239}$ Am 18. Januar 1996 beriet das Plenum der Cámara de Diputados darüber und nahm den Bericht mit 47 Stimmen der Regierungskoalition gegen 23 Stimmen der rechten Opposition an. ${ }^{240}$ Am Tag der Abstimmung wurde ein weiterer Fluchtversuch aus der CD bekannt. ${ }^{241}$ Es handelte sich um die erste bekannt gewordene Flucht nach dem Ende der Diktatur. Der Colono Karl Stricker hatte den PerquilauquénFluss durchquert und war auf Forstarbeiter getroffen, die die Polizei alarmierten. Den Beamt_innen gegenüber gab Stricker an, die CD verlassen zu wollen. Nach einer Vernehmung beim Gericht in San Carlos soll er jedoch seine Meinung geändert haben und in die CD zurückgekehrt sein. ${ }^{242}$ Die CD stellte Strafanzeige gegen die Kriminalpolizei wegen »willkürlicher Verhaftung« von Karl Stricker. ${ }^{243}$ Die Abgeordneten Marta Woerner (PPD) und José Antonio Viera-Gallo (PS) stellten bei der CA Chillán einen Schutzantrag zugunsten von Stricker. ${ }^{244}$ Die Anwälte der CD legten dem Gericht daraufhin eine von Stricker unterzeichnete Erklärung vor, in der dieser bestätigte, in der CD bleiben $\mathrm{zu}$ wollen: »no tengo intenciones de irme a vivir a ninguna otra parte, ya que estoy

237 PA AA Bd. AV NA 31646. DB 646 vom 04.12.1995.

238 Ebd.

239 Cámara de Diputados, Boletín de Sesiones, Legislatura 332 a , Sesión 33 ${ }^{\text {a }}$ vom 06.12.1995, S. 31-88. Informe de la Comisión Especial Investigadora de la Cancelación de la Personalidad Jurídica de Colonia Dignidad, creada con el objeto de verificar la forma como se dio cumplimiento al decreto supremo que disolvió esa institución, auch online unter https://www.camara.cl/camara/media/do cs/colonia/01.pdf (zuletzt abgerufen am 12.02.2018).

240 Cámara de Diputados, Boletín de Sesiones, Legislatura 332 a , Sesión 44 a vom 18.01.1996, S. 21-52. Informe de la Comisión Especial Investigadora sobre la cancelación de la personalidad jurídica de Colonia Dignidad, hier S. 51.

241 Stehle, Jan. La muerte de Karl Stricker y la amnesia de Otto Dörr, in: CIPER (Website), 10.04.2018, online unter https://ciperchile.cl/2018/04/10/colonia-dignidad-la-muerte-de-karl-stricker-y-la-amn esia-de-otto-dorr/.

242 Vgl. u.a. La Nación vom 20.01.1996, S. 8: „Curiosa fuga de colono de Dignidad«.

243 La Tercera vom 21.01.1996, S. 18. »Dignidad: Denuncian detención arbitraria«.

244 La Epoca vom 20.01.1996, S. 21. »Gobierno alemán realiza gestiones por colono Karl Albert Stricker - diputados presentan recurso de amparo y piden ministro en visita«. 
satisfecho del lugar donde estoy y donde he cultivado relaciones de amistad con los demás habitantes. ${ }^{245}$ Der Psychiater und Unterstützer der CD, Otto Dörr, stellte zudem ein Attest aus, in dem er Stricker eine schwere Depression bescheinigte und von seiner Vernehmung abriet. ${ }^{246}$ Die Anwälte der CD gaben diese Bescheinigung zu den Verfahrensakten und der Schutzantrag wurde abgelehnt.

\subsubsection{Untersuchungsausschuss der Cámara de Diputados 1997}

Am 29. April 1997 setzte die Cámara de Diputados einen weiteren Untersuchungsausschuss ein. Dieser sollte die Umsetzung der Empfehlungen des vorangegangenen Untersuchungsausschusses durch die chilenischen Behörden überprüfen. Gleichzeitig wurde der Familienausschuss des Parlaments ersucht, Hinweisen auf Verletzungen der Kinderrechte in der ehemaligen CD nachzugehen. Der Untersuchungsausschuss legte seinen Abschlussbericht am 13. August 1997 vor. ${ }^{247}$ Am 20. August 1997 nahm die Cámara de Diputados ihn an. ${ }^{248}$ Der Familienausschuss nahm eine eigene Untersuchung auf, die ihren Abschlussbericht am 15. Oktober 1997 vorlegte. ${ }^{249}$

\section{Kontext und Hintergrund der Einsetzung des Untersuchungsausschusses}

Im Beschluss zur Einsetzung eines erneuten Untersuchungsausschusses hieß es, die CD sei trotz der formellen Auflösung ihrer Rechtsperson als "faktische Vereinigung « nach wie vor aktiv gewesen. Gleichzeitig habe die Justiz gegen diverse Colonos wegen schwerer Straftaten ermittelt, unter anderem Mord, Freiheitsberaubung, Verletzung von Kindesrechten und des Rechts auf Familie. Mehrere Familien hätten die Entführung ihrer Kinder durch die CD angezeigt. Kinder seien in der CD ihrer Freiheit beraubt und daran gehindert worden, bei ihren Eltern zu wohnen. ${ }^{250}$ Zudem sei Paul Schäfer seit August 1996 justizflüchtig gewesen.

Die Einsetzung des zweiten Untersuchungsausschusses geschah in einer Zeit der intensiven Medienberichterstattung über die CD. Nach einer Strafanzeige gegen Paul

245 El Mercurio vom 21.01.1996, S. C11 „Colono de V. Baviera rechaza amparo legal«.

246 Stehle, Jan. La muerte de Karl Stricker y la amnesia de Otto Dörr, in: CIPER (Website), 10.04.2018, online unter https://ciperchile.cl/2018/04/10/colonia-dignidad-la-muerte-de-karl-stricker-y-la-amn esia-de-otto-dorr/.

247 Cámara de Diputados, Informe de la Comisión Investigadora encargada de velar por el cumplimiento de las recomendaciones aprobadas por la $\mathrm{H}$. Cámara de Diputados, en relación con la ex Colonia Dignidad vom 13.08.1997, online unter https://www.camara.cl/camara/media/docs/colonia 102.pdf(zuletzt abgerufen am 12.02.2018). Protokoll der Abstimmung: Cámara de Diputados, Boletín de Sesiones, Legislatura 334 ${ }^{a}$, Sesión $63^{\text {a }}$ vom 29.04.1997, S. 31-37.

248 Cámara de Diputados, Boletín de Sesiones, Legislatura 335ª , Sesión 35ª vom 20.08.1997, S. 19-48. Informe de la Comisión investigadora sobre la ex Colonia Dignidad.

249 Cámara de Diputados, Boletín de Sesiones, Legislatura 336ª , Sesión 10ª vom 21.10.1997, Informe de la Comisión de Familia recaido en el Proyecto de Acuerdo que le encomienda investigar situaciones de posibles violaciones a los derechos de los niños y niñas en la ex Colonia Dignidad, auch online unter https://www.camara.cl/camara/media/docs/colonia/o3.pdf(zuletzt abgerufen am 12.02.2018), S. $67 \mathrm{ff}$. 
Schäfer wegen sexuellen Missbrauchs an chilenischen Kindern im Juni $1996^{251}$ hatte die Justiz Ermittlungen aufgenommen, es folgte eine Reihe weiterer Anzeigen. Schäfer hatte sich einer Vernehmung mehrfach entzogen und es wurde auch öffentlich intensiv über seinen Aufenthaltsort spekuliert. Zum Zeitpunkt der Einsetzung des Untersuchungsausschusses war der damalige Bundesjustizminister Edzard Schmidt-Jortzig zu einem offiziellen Besuch in Chile. Auf Nachfragen chilenischer Medien drückte er sein Vertrauen in die chilenische Justiz aus, »den Fall Schäfer« zu »lösen«. ${ }^{252}$ Der langjährigen Linie des AA folgend fügte er an, die Bundesrepublik sei bereit, Chile dabei zu unterstützen. Für ein Gerichtsverfahren gegen Schäfer in der Bundesrepublik läge das nötige Beweismaterial jedoch bis zum damaligen Zeitpunkt nicht vor. Auf die Frage, ob Deutschland eine Auslieferung Schäfers beantragen werde, antwortete Schmidt-Jortzig, es gäbe gegenwärtig keinen Anlass, in das chilenische Verfahren einzugreifen. ${ }^{253}$ Zwei Wochen später, am 14. Mai 1997, legten fünf Rechtsanwälte Schäfers ihr Mandat nieder, da dieser sich weigerte, sich der Justiz zu stellen. ${ }^{254}$ Kurz darauf verlas Hartmut Hopp gegenüber der Presse einen Brief Schäfers. Darin kündigte dieser an, sich nicht stellen $\mathrm{zu}$ wollen, da die Justiz ihm »keine Garantien « gebe und er um sein Leben fürchte. ${ }^{255}$ Er sei einer Kampagne und dem "Psychoterror« von Medien, Kriminalpolizei und Anzeigenden ausgesetzt. ${ }^{256}$ Als Reaktion rief Chiles Präsident Eduardo Frei Schäfer persönlich auf, sich der Justiz zu stellen, die Verfassung biete ihm alle Garantien für ein rechtsstaatliches Verfahren. ${ }^{257}$

Auch als der Untersuchungsausschuss seine Arbeit beendete, war das mediale Interesse für die CD immens. Im Juni 1997 war die chilenische Polizei bei der Suche nach Schäfer mit einem Großaufgebot in die Siedlung eingedrungen. Am 15. Juli gelang Tobias Müller und Salo Luna die Flucht aus der CD. Beide reisten mit Unterstützung der Botschaft nach Deutschland aus. Am 12. August, dem Tag bevor der Ausschuss seinen Bericht vorstellte, wurde Hartmut Hopp nach einer Verfolgungsjagd festgenommen. ${ }^{258}$ Hopp hatte zuvor mehrmals Vorladungen der Justiz ignoriert und war stattdessen am 31. Juli nach Argentinien ausgereist, um seinen Adoptivsohn Michael, seine Ehefrau Dorothea sowie Friedhelm Zeitner und Schäfers Adoptivtochter Rebeca außer Landes zu bringen. Nach Hopps Festnahme ordnete Richter Jorge Norambuena ihm an, dessen Adoptivsohn nach Chile zurückzubringen, was jedoch nicht geschah.

Am 14. August berichtete Mónica Madariaga, die während der Diktatur Justizministerin in Chile war, in den Medien ausführlich über ihre eigenen, aber auch über die

251 Juzgado del Crimen de Parral, AZ 53.015.

252 Las Ultimas Noticias vom 30.04.1997, S. 12. »La Justicia de Chile resolverá el caso Schäfer«.

253 El Mercurio vom 30.04.1997, S. C9. »Ministro de Justicia Alemán: Elogian a la Justicia por Caso Dignidad «.

254 La Segunda vom 14.05.1997, S. 2. »Líder de Colonia Dignidad, Schaefer, se quedó sin abogados«.

255 Las Ultimas Noticias vom 16.06.1997, S. 3. »Schäfer resistirá«.

256 La Segunda vom 15.05.1997, S. 1. »]efe de la Colonia alega ssicoterror«.

257 El Mercurio vom 17.05.1997. S. 15C. »Frei insta a Schäfer a que se entregue«.

258 Vgl. u.a. La Nación vom 13.08.1997, S. 1. »Hopp en prisión« sowie La Segunda vom 12.08.1997, S. 1. »Detenido el Dr. Hopp«. 
Verbindungen führender Mitglieder der UDI zur CD. ${ }^{259}$ Dies war das erste Mal, das eine (ehemals) hochranginge Politikerin die Kontakte des rechten politischen Lagers zur CD öffentlich thematisierte. So berichtete sie, die UDI habe die CD als Trainingszentrum genutzt. Parteigründer Jaime Guzmán habe dort Schulungen abgehalten, auch Senator Hernán Larraín sei eng mit einigen Colonos befreundet gewesen. Hartmut Hopp habe sie (Madariaga) und ihre Mutter in der CD medizinisch behandelt. Sie habe auch mehrere Male mit Schäfer, Hopp und anderen Colonos zu Abend gegessen. Nach ihrem Abtritt als Ministerin habe die CD jedoch den Kontakt zu ihr abgebrochen.

\section{Arbeit und Ergebnisse des Untersuchungsausschusses}

Der von José Antonio Viera Gallo (PS) geleitete Untersuchungsausschuss traf sich insgesamt neun Mal, davon ein Mal gemeinsam mit dem Untersuchungsausschuss des Familienausschusses. Er überprüfte sämtliche Empfehlungen des Untersuchungsausschusses von 1995 und erörterte deren Umsetzung. Neben Minister_innen und Staatssekretär_innen sowie Vertreter_innen von CDE und Polizei hörte der Ausschuss auch die im Juli 1997 aus der CD geflüchteten Tobias Müller und Salo Luna, den Ex-Colono Heinz Kuhn sowie Pastor Adrián Bravo aus Parral an. Die ebenfalls vorgeladenen Hartmut Hopp und Fernando Saenger (Anwalt der CD) ließen sich entschuldigen. Eine »Gemeinschaft der Familien von Dignidad« protestierte in einem Schreiben an den Ausschuss gegen die vermeintlichen »Lügen und Falschbeschuldigungen« des Innenstaatssekretärs Belisario Velasco. Der Ausschuss forderte diverse Behörden auf, schriftlich zu berichten.

Der Untersuchungsausschuss von 1995 hatte dem CDE vorgeschlagen, Untersuchungen, an denen er selbst beteiligt war, zu beschleunigen sowie sich an weiteren Verfahren zu beteiligen. Außerdem sollte die Rechtmäßigkeit der Vermögensübertragungen von der SBED auf die ABC-Aktiengesellschaften überprüft werden, auch auf möglichen Steuerbetrug hin. Der CDE gab bei der Anhörung durch den Ausschuss an, an diversen Strafverfahren sowie an einer Reihe von Verfahren wegen Wirtschaftsdelikten beteiligt zu sein. Diese Verfahren würden mit Nachdruck vorangetrieben, dazu habe der CDE mit Daniel Martorell eigens einen Anwalt abgestellt.

Martorell schilderte dem Ausschuss vor allem seine Eindrücke aus einem noch laufenden Verfahren wegen des Vorwurfs der betrügerischen Übertragung des SBEDVermögens auf die ABC-Aktienholding. ${ }^{260}$ Dabei werde gegen 73 Colonos ermittelt, das Verfahren laufe sehr langsam. Zeitweise seien sogar die Verfahrensakten beim Gericht »verloren« gegangen und erst nach einer Beschwerde wieder aufgefunden worden. Auch seien Ermittlungsanregungen des CDE nicht umgesetzt worden. Ein umfassendes Sachverständigengutachten habe die Vorwürfe der betrügerischen Übertragung gestützt. $^{261}$

Vgl. La Tercera vom 14.08.1997, S. 3. »Mónica Madariaga afirma que dirigentes UDI fueron adoctrinados en Villa Baviera« sowie Las Ultimas Noticias vom 14.08.1997, S. 5. »Madariaga y su paso por Dignidad «.

260 14. Juzgado del Crimende Santiago, AZ 136.414.

261 Cámara de Diputados, Informe de la Comisión Investigadora encargada de velar por el cumplimiento de las recomendaciones aprobadas por la H. Cámara de Diputados, en relación con la ex 
Das Bildungsministerium berichtete, es gäbe nur sieben Colonos im schulpflichtigen Alter, ${ }^{262}$ diese würden von ihren Eltern unterrichtet. Eine Inspektion habe ergeben, dass entgegen anderslautender Informationen in der CD keine funktionierende Schule existierte. Bisher habe es keine Anträge auf staatliche Anerkennung von Schulzeugnissen aus der CD gegeben. Die nach Auflösung der SBED nun von der Organización Comunitaria de Desarrollo Social Perquilauquén getragene und staatlich subventionierte Schule außerhalb des CD-Geländes werde nicht von Colonos besucht. Trotz der herrschenden Schulpflicht habe das Bildungsministerium aufgrund der Bildungsgesetzgebung wenig rechtliche Handhabe, die Schulpflicht durchzusetzen. ${ }^{263}$ Bei der Volkszählung 1992 war die Datenerhebung in der CD nicht von offizieller Seite, sondern von Colonos selbst durchgeführt worden. Daher bat der Ausschuss nun das Instituto Nacional de Estadísticas (Nationales Institut für Statistiken, INE), in der CD eine neue Erhebung durchzuführen. Das INE weigerte sich jedoch mit der Begründung, dass Volkszählungen per Regierungsdekret nur alle zehn Jahre vorgesehen seien. ${ }^{264}$ Das Servicio de Registro Civil e Identificación (Zivilregister) berichtete dem Ausschuss, dass 65 Colonos in der CD geboren wurden. In 17 Fällen sei die Geburt erst bis zu zehn Jahre später eingetragen worden, und zwar mangels Geburtsurkunden durch sogenannte »Geburtszeugen«. Das sei zwar rechtlich möglich, in dieser Häufung jedoch ungewöhnlich. Vermutlich handle es sich also um (betrügerisch) adoptierte chilenische Kinder. Bei den nachvollziehbaren Adoptionsvorgängen falle auf, dass die Verfahren oftmals nur zwei Monate gedauert hätten, im Gegensatz zu den sonst üblichen mindestens sechs Monaten. ${ }^{265}$

Bereits der erste Untersuchungsausschuss hatte festgestellt, dass trotz der Auflösung der SBED in der Siedlung weiterhin »eine soziale Realität vorherrsche, die von den grundlegenden Prinzipien unseres Rechtssystems abweicht «. ${ }^{266}$ Vom zweiten Ausschuss befragt, sah der Innenminister dann kaum Veränderungen. So widerspräche das Familienleben in der CD Grundsätzen der chilenischen Verfassung. Eheschließungen könnten nur nach Erlaubnis von CD-Führungsmitgliedern stattfinden und Kinder wüchsen getrennt von ihren Eltern auf. Soziale Beziehungen unter Colonos würden unterbunden, Beziehungen zu externen Personen seien praktisch inexistent. Es gäbe keinen freien Zugang zu Medien und Briefkontakte mit der Außenwelt unterlägen der Zensur. Selbst innerhalb der Siedlung herrsche keine Bewegungsfreiheit. Bewaffnete Sicherheitstrupps überwachten jegliche Bewegung. Auch die Schulpflicht werde umgangen. Kinder würden gezwungen, von klein auf zu arbeiten. Die einzige positive Änderung nach der Auflösung der SBED sei, dass die ABC-Gesellschaften schließlich

Colonia Dignidad vom 13.08.1997, online unter https://www.camara.cl/camara/media/docs/colonia 102.pdf(zuletzt abgerufen am 12.02.2018), S. 7 ff.

262 In Chile besteht Schulpflicht für die Klassen 1 bis 8.

263 Cámara de Diputados, Informe de la Comisión Investigadora encargada de velar por el cumplimiento de las recomendaciones aprobadas por la H. Cámara de Diputados, en relación con la ex Colonia Dignidad vom 13.08.1997, online unter https://www.camara.cl/camara/media/docs/colonia 102.pdf(zuletzt abgerufen am 12.02.2018), S. 14. 
Arbeitsverträge mit den Colonos abgeschlossen hätten, die der Kontrolle des Arbeitsministeriums unterlägen. ${ }^{267}$

Der Ausschuss hatte vier Rechtsprofessor_innen um ihre Einschätzung gebeten, welche Möglichkeiten bestünden, um dem Zwangssystem in der CD auf dem Rechtsoder Verwaltungsweg ein Ende zu setzen. Die Jurist_innen stimmten darin überein, dass dies durch eine Ausweisung der deutschen CD-Führungsmitglieder geschehen könne bzw. durch eine Entziehung ihrer Aufenthaltserlaubnis. ${ }^{268}$

Genau dies empfahl der Ausschuss der Regierung dann auch. Der Corte Suprema empfahl er, neben Hernán González noch einen zweiten Richter als Ministro en Visita zu bestellen. Dieser solle gebündelt alle Vorwürfe untersuchen, wegen derer Gónzalez noch nicht ermittelt hatte, etwa wegen Zollbetrugs, Steuerhinterziehung und betrügerischer Vermögensübertragung. Außerdem sollten dem Familienausschuss der Cámara de Diputados sämtliche verfügbaren Unterlagen zu sexuellem Missbrauch sowie zu Verletzungen von Familien- und Kinderrechten zugeleitet werden. Weiterhin empfahl der Ausschuss der Regierung, das Ley Orgánica Constitucional de Enseñanza (Bildungsgesetzgebung) so zu verändern, dass die Grundschulpflicht effektiv kontrolliert werden könne. Das Verteidigungsministerium wurde ersucht, regelmäßig den Bestand an Schusswaffen in der CD zu kontrollieren. ${ }^{269}$

\section{Die Untersuchungen des Familienausschusses 1997}

Der Familienausschuss, der die Situation der Kinder- und Familienrechte in der CD untersuchen sollte, tagte zwölf Mal und stellte seinen Abschlussbericht am 15. Oktober 1997 vor. ${ }^{270}$ Auch dieser Ausschuss richtete Anfragen an unterschiedliche Behörden und hörte eine Reihe Zeug_innen an, darunter Mitglieder der PDI und der Carabineros, Vertreter_innen der Kinder- und Jugendbehörde SENAME, Opferanwalt Hernán Fernández, verschiedene Expert_innen für Sekten, Pastor Adrián Bravo, die aus der CD Geflüchteten Tobias Müller und Salo Luna sowie den Ex-Colono Heinz Kuhn.

Zur Schulbildung in der CD stellte der Ausschuss fest, die von der Organización Comunitaria de Desarrollo Social Perquilauquén getragene und staatlich subventionierte Schule außerhalb der Siedlung habe die chilenischen Bildungsgesetze weitgehend eingehalten. Die "Deutsche Schule Villa Baviera«, die interne Schule der CD, sei hingegen keine Schule im eigentlichen Sinne, sondern sei ein informelles System ohne klare Zeit-und Lehrpläne: "sistema tutorial, informal, con curriculum flexible, sin un horario estructurado y sin una distribución del tiempo organizada sistemáticamente«. ${ }^{271}$ Die chilenischen Gesetze böten keine ausreichende Handhabe, um die Schulpflicht effektiv durchzusetzen. Schon in sich widersprüchlliche Informationen über diese Schule,

267 Ebd., S. 21.

268 Ebd., S. 26.

269 Ebd., S. $27 f$.

270 Cámara de Diputados, Boletín de Sesiones, Legislatura 336ª , Sesión 10ª vom 21.10.1997, Informe de la Comisión de Familia recaido en el Proyecto de Acuerdo que le encomienda investigar situaciones de posibles violaciones a los derechos de los niños y niñas en la ex Colonia Dignidad, auch online unter https://www.camara.cl/camara/media/docs/colonia/03.pdf, (zuletzt abgerufen am 12.02.2018). 
die angeblich sieben Kinder besuchten, habe es ausschließlich von der CD-Führung gegeben. Eine Inspektion durch den Leiter der Bildungsbehörde der Provinz Linares habe keine Anzeichen für einen Internatsbetrieb ergeben. Allerdings habe die Kriminalpolizei in der CD eine Liste von Schüler_innen des sogenannten »Intensivinternats« der CD gefunden. Darunter haben sich auch die Namen von fünf Minderjährigen befunden, deren Erziehungsberechtigte in den vorangegangenen Monaten Strafanzeigen wegen sexuellen Missbrauchs eingereicht hatten, und die nun nicht mehr in der CD lebten. ${ }^{272}$ Die Leiterin des Zivilregisters (s.o.) berichtete von zwölf Adoptionsvorgängen, die sämtlich vom Juzgado de Letras in Parral abgewickelt worden waren, und zwar oftmals im Sammelverfahren und mit deutlich kürzerer Bearbeitungszeit als üblich. Daneben seien zwei Namensänderungen von Volljährigen festgestellt worden. ${ }^{273}$

Gestützt auf die Zeug_innenaussagen stellte der Ausschuss fest, dass Kinder in der $C D$ von klein auf von ihren Eltern getrennt und nach Geschlecht segregiert wurden. Sie seien in Gruppen eingeteilt, von anderen Colonos überwacht und in Anwesenheit von Paul Schäfer geduscht worden, den sie als »Sprinter« Tag und Nacht begleiten mussten. Sie hätten keinerlei Kontakte zur Außenwelt und seien von Schäfer indoktriniert worden: "no conocen otra realidad que les permita valorar el régimen de vida al que se encuentran sometidos. Además, son concientizados por Paul Schäfer - desde que nacen acerca de las bondades de su entorno inmediato y de la maldad reinante en el exterior. « ${ }^{274}$ Die Kinder hätten keinen freien Zugang zu Informationen über die Außenwelt, selbst externe Briefkontakte würden überwacht. Angesichts all dieser Tatsachen sei es verwunderlich, dass die Mehrzahl der Kinder, Jugendlichen und Erwachsenen in der CD angäben, mit dieser Lebenssituation zufrieden zu sein.

Der Ausschuss ließ sich von einer Reihe Expert_innen aus den Bereichen Soziologie, Kinderpsychologie und Kriminologie den Sektencharakter der CD erläutern. Die hermetische Struktur der Gruppe, so die Fachleute, erlaube eine enorme Beeinflussung, eine bedingungslose Akzeptanz der Führungsfigur Paul Schäfer sowie eine Ausschaltung von Kritik oder Zweifeln. Die so abgeschottet lebenden Kinder hätten keine Möglichkeit, ihre eigene Lebensrealität mit der in der Außenwelt zu vergleichen. Schon deshalb werde der sexuelle Missbrauch von den Mitgliedern der Gruppierung häufig nicht als Unrecht empfunden. Unter den Colonos herrsche die Wahrnehmung vor, Schäfer würde nicht wegen seiner Verbrechen an Kindern verfolgt, sondern durch eine an sich böse Außenwelt. Wichtig sei daher der Versuch, so der Experte Humberto Lagos, diesen »absoluten ideologischen Zaun« durch eine schrittweise Annäherung und Kommunikation mit den Colonos während der Razzien der Kriminalpolizei zu durchbrechen. ${ }^{275}$

272 Ebd., S. 18.

273 Es handelt sich um die Namensänderung von Francisco del Carmen Morales Norambuena, der den Namen Franz Baar Kohler erhielt und die Namensänderung von Juan Patricio Chávez Catalán zu Johannes Neufeld Drescher. Vgl. Cámara de Diputados, Boletín de Sesiones, Legislatura 336a , Sesión 10 vom 21.10.1997, Informe de la Comisión de Familia recaido en el Proyecto de Acuerdo que le encomienda investigar situaciones de posibles violaciones a los derechos de los niños y niñas en la ex Colonia Dignidad, auch online unter https://www.camara.cl/camara/media/docs/col onia/o3.pdf, S. 30 (zuletzt abgerufen am 12.02.2018). 
Auch der kurz zuvor aus der CD geflüchtete Tobias Müller sprach sich für eine solche langsame Annäherung aus. Die Schlussfolgerungen im Abschlussbericht betonen die Bedeutung der Kenntnis von Natur und Funktionsweisen der Ex CD:

»Lo más relevante del trabajo de esta Comisión fue avanzar en la comprensión de la verdadera naturaleza del fenómeno social, psicosocial y cultural que se anida en la ex Colonia Dignidad, constituida por una secta semireligiosa y militarista que se caracteriza, antes que nada, por su subordinación fanática y total a un líder carismático y pederasta. ${ }^{276}$

Der Ausschuss stellte fest, die Schulpflicht werde bereits seit 30 Jahren nicht garantiert. Dies sei besonders verwerflich angesichts der Tatsache, dass Chile 1990 der Internationalen Konvention über Kinderrechte beigetreten sei. Die CD stelle Schulzeugnisse aus, die rechtlich keinerlei Gültigkeit hätten, aber betrügerischerweise den Namen des Bildungsministeriums führten. Dies sei strafbar und müsste sanktioniert werden. Der Ausschuss stellte auch fest, dass die Lebensumstände in der CD das Recht der Kinder auf körperliche und seelische Unversehrtheit verletzten. Ausdruck dessen seien auch die zahlreichen Strafanzeigen und Ermittlungsverfahren wegen sexuellen Missbrauchs. Es sei aber die Pflicht des Staates, die Kinder entsprechend zu schützen, sowohl nach der chilenischen Verfassung als auch nach der Internationalen Konvention über Kinderrechte. ${ }^{277}$ Auch zahlreiche Hinweise auf Unregelmäßigkeiten bei Adoptionsverfahren stellte der Ausschuss fest. Mindestens eines dieser gerichtlichen Verfahren habe mutmaßlich zu einer betrügerischen Adoption geführt. Beim Zivilregister seien nur zwölf Adoptionsverfahren aktenkundig, während die tatsächliche Anzahl der adoptierten Kinder vermutlich viel höher gewesen sei. Auch diese Verstöße müssten näher untersucht werden. ${ }^{278}$

Der Familienausschuss fasste zusammen, dass sich an den Lebensbedingungen in der CD seit Auflösung der SBED nichts geändert habe; diese seien nach wie vor »objektiv schädlich « für alle Colonos, insbesondere aber für die dort lebenden Kinder. Dies gelte insbesondere für den sexuellen Missbrauch Schäfers an Jungen, doch auch der "Schleier des Schweigens" auf der Situation der Mädchen und Frauen in der CD sei »besorgniserregend und verdächtig «. ${ }^{279}$ Der Staat und Gesellschaft in Chile seien dazu verpflichtet, die Zustände in der CD zu überwinden sowie die Opfer zu rehabilitieren und zu entschädigen.

Der Ausschuss hielt auch vielfache Belege für die Existenz von Unterstützungsnetzwerken der CD fest - sowohl auf gesellschaftlicher als auch auf behördlicher Ebene. Diese seien für die straflose Weiterexistenz der CD nach der SBED-Auflösung verantwortlich:

»Creemos que ello explica, en importante medida, el prolongado período en que esta secta ha podido subsistir en el territorio nacional sin que se haya impedido o limitado su accionar, ni se le hayan aplicado las sanciones jurídicas correspondientes, sino hasta 
el decreto de disolución dictado recién en 1991, y que, incluso, a pesar de éste, haya podido seguir actuando con posterioridad a dicha época. $\ll^{280}$

Dies zeige, so die Kommission, dass der chilenische Staat nicht über angemessene und wirksame Werkzeuge verfüge, um Vorgänge wie in der CD zu verhindern und Bürger_innen, insbesondere Kinder, angemessen zu schützen.

In seinen Empfehlungen ${ }^{281}$ hielt der Ausschuss es für unbedingt nötig, die körperlichen und geistigen Misshandlungen der Kinder in der CD zu verhindern. Hierfür bedürfe es einer umfassenden und koordinierten Strategie des Staates, die zu einer faktischen (nicht nur formalen) Auflösung der CD führen müsse, allein mit juristischen Maßnahmen sei dieser nicht beizukommen. Eine multidisziplinäre therapeutische Interventionsstrategie solle polizeiliche und juristische Maßnahmen begleiten und insbesondere Kindern besonderen Schutz zukommen lassen. Die Kommission des Familienausschusses schloss sich auch der Forderung des Untersuchungsausschusses nach Ausweisung der Führungsmitglieder der CD an.

Dem Bildungsministerium empfahl die Kommission, die Einhaltung der Schulpflicht notfalls mithilfe von Gerichten durchzusetzen. Der Organización Comunitaria de Desarrollo Social Perquilauquén solle die Trägerschaft für die externe Schule entzogen werden. Das Justizministerium solle die betrügerischen Adoptionsverfahren untersuchen. Um das Unterstützungsnetzwerk der CD zu bekämpfen, solle das Innenministerium jegliche Hinweise auf entsprechende Tendenzen bei staatlichen Behörden oder Bediensteten nachgehen. Schließlich solle die Gesetzgebung dahingehend überarbeitet werden, dass derartige Gruppierungen wie die CD in Chile zukünftig nicht mehr entstehen könnten.

Insgesamt fand der Bericht an Deutlichkeit kaum zu überbietende Worte für die unhaltbaren menschenrechtswidrigen Zustände in der CD, die der chilenische Staat jahrzehntelang geduldet hatte, worüber zu diesem Zeitpunkt auch in der chilenischen Öffentlichkeit allgemeine Bestürzung vorherrschte. Gleichzeitig klang der Bericht an vielen Stellen geradezu hilflos, wie eine Art Kapitulationserklärung gegenüber einer kriminellen Gruppierung, die den Staat unterwandere und sich nicht an dessen Gesetzgebung halte.

\subsubsection{Untersuchung der Ausschüsse für Menschenrechte und Familie 1999}

Am 19. Mai 1998 beauftragte die Cámara de Diputados ihre Ausschüsse für Menschenrechte und Familie, gemeinsam zu untersuchen, inwiefern staatliche Behörden zum Fortgang der juristischen Untersuchungen im Fall CD beigetragen haben. ${ }^{282}$ Grundlage für diesen Beschluss war die Feststellung, die CD existiere auch sieben Jahre nach der Auflösung der SBED faktisch weiter. Besorgniserregend sei, dass Paul Schäfer noch immer nicht gefasst sei. Richter Hernán González habe zwar große Anstrengungen

280 Ebd., S. 54.

281 Ebd., S. $53 \mathrm{ff}$.

282 Cámara de Diputados, Boletín de Sesiones, Legislatura 337 a , Sesión $23^{\mathrm{a}}{ }^{\mathrm{a}}$ vom 19.05.1998. S. 29ff. Proyecto de Acuerdo »Fiscalización de de actuaciones de organismos públicos respecto de ex Colonia Dignidad«. Beschlossen mit 38 Ja und fünf Nein Stimmen bei zwei Enthaltungen. 
unternommen, werde jedoch nicht von allen staatlichen Behörden ausreichend unterstützt. So hätten beispielsweise die Carabineros ihm die für eine Überwachung des CDGeländes notwendigen Polizeikräfte erst mit vier Monaten Verspätung zur Verfügung gestellt.

\section{Hintergrund und Kontext}

Seit November 1996 war die chilenische Polizei über ein Dutzend Mal mit richterlichem Durchsuchungsbefehl in die CD eingedrungen, um den Haftbefehl gegen Schäfer zu vollstrecken oder Beweise über die Existenz eines Haft- und Folterzentrums während der Militärdiktatur zu sichern. Die meist von Carabineros und PDI gemeinsam durchgeführten Maßnahmen waren jedoch wenig erfolgreich. Schäfers Aufenthaltsort war nach wie vor unklar, was Ermittler_innen und Polizei unter Druck setzte. Die CD nutzte regelmäßig eine Fülle juristischer Mittel gegen vermeintliche Rechtsverstöße im Zuge der Ermittlungen und Razzien. In der öffentlichen Wahrnehmung wurde die Unfähigkeit, Schäfer festzunehmen mit der Existenz der Schutznetzwerke der CD erklärt. In diesem Zusammenhang kritisierten Opfervertreter_innen und Abgeordnete der Regierungsparteien insbesondere die Rolle der Carabineros. Sie verwiesen auf die hinderliche "historische Beziehung « ${ }^{283}$ zwischen Carabineros und CD.

Unterstützer_innen der CD hoben auch immer wieder die angeblich wichtige soziale Arbeit der CD hervor, insbesondere die Schule und das Krankenhaus. Letzteres war aufgrund staatlicher Eingriffe mehrfach geschlossen und nach juristischer Gegenwehr der CD jeweils wiedereröffnet worden.

Ende November 1997 ordnete Richter Hernán Gónzalez eine Großrazzia der Carabineros in der CD an, um Schäfers Versteck dort zu finden. General Jaime Rieutord, Polizeibefehlshaber der Region Maule, weigerte sich die richterliche Anordnung umzusetzen und antwortete Gónzalez erst einen Monat später, die Razzia sei aus »operativen Erwägungen nicht angebracht «. ${ }^{284}$ Obwohl eine solche Weigerung ein nie dagewesener Affront gegenüber der Justiz war, nahm González die Antwort hin. Im März 1998 ordnete er erneut eine Durchsuchung der CD an, die auch umgesetzt wurde. Am 24. März 1998 begaben sich Dutzende Polizeikräfte in die CD und blieben 40 Tage vor Ort.

Gleichzeitig nutzten die Unterstützer_innen der CD, vor allem in Reihen der rechten Oppositionsparteien, die Situation immer wieder, um eine vermeintlich fehlende Verhältnismäßigkeit der staatlichen Maßnahmen anzuprangern oder die Legitimität der Ermittlungen insgesamt anzuzweifeln. Hernán Larraín (UDI), damals Senator für die Region Maule und heutiger Justiz- und Menschenrechtsminister (Stand Mai 2021), versuchte beispielsweise nach einer Razzia 1998 öffentlich, die Durchsuchungen in der $\mathrm{CD}$ zu delegitimieren:

283 Jaime Naranjo, Abgeordneter der PS für die Region Maule, in: La Nación vom 27.01.1999, S. 9. »Acusan a Carabineros«.

284 Cámara de Diputados, Diarios de Sesiones, Legislatura 340 ${ }^{a}$, Sesión $27^{\text {a }}$ vom 10.08.1999. Informe de las Comisiones Unidas de Derechos Humanos, Nacionalidad y Ciudadanía, y de Familia, encargadas de estudiar y fiscalizar cómo los distintos órganos públicos competentes han colaborado para el éxito de las investigaciones judiciales relativas a la ex Colonia Dignidad, auch online unter http s://www.camara.cl/camara/media/docs/colonia/o4.pdf, (zuletzt abgerufen am 12.02.2018), S. 20. 
»Con centenares de efectivos de investigaciones, con decenas de automóviles, con metralletas, con violencia innecesaria, eso obviamente forma parte de un montaje, de una campaña. No se hace. El país tiene problemas de seguridad gigantescos en otras partes [...]. ¿Alguien me quiere decir que es porque hay la denuncia de un menor sobre abuso en contra de una persona determinada? ${ }^{285}$

Im März 1999 stellte der CDE eine Strafanzeige gegen CD-Führungspersonen und ehemalige DINA-Agent_innen wegen Bildung einer kriminellen Vereinigung. ${ }^{286}$ Dies sollte sich als später, aber wichtiger Schritt der Regierung erweisen, um verschiedenen Strafverfahren im Fall CD einen Rahmen zu geben.

\section{Arbeit und Ergebnisse der gemeinsamen Ausschüsse}

Menschenrechts- und Familienausschuss des Parlaments bildeten mit all ihren Mitgliedern am 19. Mai 1998 die sogenannten Comisiones Unidas (gemeinsamen Ausschüsse). Diese trafen sich zu 14 Sitzungen, richteten Anfragen an Behörden und hörten diverse Zeug_innen an. Vertreter_innen der Ausschüsse wurden auch vom Innenminister, vom Präsidenten der Corte Suprema, von der Präsidentin des CDE sowie von den ermittelnden Richtern Hernán González und Juan Guzmán empfangen. Andere, wie der Verteidigungsminister sowie einige Polizeigeneräle erschienen trotz Ladung nicht vor dem Ausschuss. Dem Verteidigungsminister unterstanden damals sowohl die Carabineros als auch die PDI. Abgeordnete der damaligen Regierungsfraktionen sprachen gegenüber den Medien in diesem Zusammenhang von einem "red de protección« (Schutznetzwerk) der CD-Führung, das für dessen Straflosigkeit verantwortlich sei. ${ }^{287}$

Im Folgenden möchte ich auf einige Aspekte der Anhörungen der Vertreter des CDE (Pedro Pierry und Daniel Martorell), der PDI (Nelson Mery und Luis Henríquez) sowie des Innenministeriums (Belisario Velasco) eingehen. Deren Aussagen sind außergewöhnlich deutlich, was die von der Justiz kritisierten Missstände im behördlichen Umgang mit dem Fall CD angeht.

Pedro Pierry, Vizepräsident des CDE, nannte zahlreiche straf- und zivilrechtliche Verfahren zur CD, an denen der CDE zum damaligen Zeitpunkt beteiligt war und stellte fest, dass zum ersten Mal in der Geschichte Chiles ein zur Fahndung ausgeschriebener Straftäter mit bekanntem Aufenthaltsort ${ }^{288}$ nicht inhaftiert werde. Seiner Meinung nach sollte die Regierung die CD-Führungspersonen aus Chile ausweisen. Zudem sollte die Justiz eine umfangreiche Durchsuchung der CD anordnen, für die der Staat alle notwendigen Mittel zur Verfügung stellen müsse. Daniel Martorell, der für die CDVerfahren abgestellte Rechtsanwalt des CDE, erläuterte seine Tätigkeit. Die CD schöpfe

285 El Desconcierto. »Es un montajes: El día en que Hernán Larraín defendió a Paul Schäfer tras operativo policial«, 06.06.2018, online unter https://www.eldesconcierto.cl/2018/06/06/video-es-un-m ontaje-el-dia-en-que-hernan-larrain-defendio-a-paul-schafer-tras-operativo-policial/.

286 CA Santiago, AZ 2182-98 (»Asociación Ilícita«), Bd. I (Parral), Bl. 3-37. Strafanzeige des CDE vom 11.03.1999.

287 Vgl. Las Ultimas Noticias vom 19.01.1999, S. 13. »A Roberto Dávila - Pidieron agilizar proceso contra Paul Schaefer«.

288 Die Fahnder_innen gingen zu diesem Zeitpunkt davon aus, dass sich Schäfer weiterhin in der CD aufhielt. 
in der Regel sämtliche verfügbaren Rechtsmittel aus. Gegen jede einzelne richterliche Anordnung werde Beschwerde eingelegt, er selbst habe bereits 25 bis 30 solcher Beschwerden und Schutzanträge bearbeiten müssen. Zwar könne sich die CD mit diesen Rechtsmitteln nur selten durchsetzen, verfolge aber, so Martorell, wohl eher die Strategie, die juristischen Verfahren zu bremsen und in die Länge zu ziehen. ${ }^{289}$ Dass Schäfer noch immer auf freiem Fuß sei, habe nicht nur einen, sondern vielfältige Gründe, fuhr Martorell fort. Dazu gehöre, dass die chilenische Gesetzgebung keine ausreichenden Instrumente habe, um einer hoch ausgerüsteten Organisation wie der CD das Handwerk zu legen. Die CD agiere mit Überwachungsanlagen, Tunnels und gepanzerten Türen und sei darauf ausgerichtet, ihre Aktivitäten zu verstecken, erlärte Martorell, »nuestro país, que es subdesarrollado o en vias de desarrollo se está enfrentando a una organización desarrollada, donde existe un sujeto con características muy especiales, que ha destinado toda su vida a esconderse. ${ }^{290}$ Dagegen verfüge die chilenische Kriminalpolizei nicht einmal über einen Hubschrauber, insgesamt seien die den Ermittler_innen zur Verfügung stehenden technischen Ressourcen »lächerlich«. ${ }^{291}$ Erschwerend käme die soziale Fassade der CD hinzu - etwa mit ihrem Krankenhaus, und noch immer zögen wichtige Persönlichkeiten der chilenischen Gesellschaft die Vorkommnisse in der CD in Zweifel. Das muss als deutliche Kritik des CDE-Anwaltes Matorell an den zahlreichen Unterstützer_innen der CD in der Justiz und in rechten Parteien verstanden werden. Martorell berichtete, er habe am Zustandekommen von 30 Interpol-Haftbefehlen gegen Schäfer mitgewirkt. Die Verfahren seien so umfangreich, da gleichzeitig gegen etwa 15 Personen aus der CD-Führung wegen Beihilfe oder Verschleierung ermittelt werde. Keinesfalls handle es sich um eine politisch motivierte Verfolgung der CD, wie deren Unterstützer_innen gerne behaupteten. Vielmehr ginge es um die Verfolgung schwerer Verbrechen, für deren Existenz sich in den Akten umfangreiche Beweise fänden.

Innenstaatssekretär Belisario Velasco berichtete von 75 Verfahren zur CD, die bei der Justiz zum damaligen Zeitpunkt anhängig waren. Die Regierung sei fest entschlossen, voranzukommen, werde jedoch immer wieder von »komplexen Situationen« behindert. So hätten sich beispielsweise 18 Senatoren rechter Parteien gegen die Auflösung der SBED ausgesprochen und Gegenmaßnahmen gefördert. Velasco beschrieb Abwehrstrategien, die die Verfahren verzögerten:

»[H]ubo numerosos recursos ante los tribunales, es decir se estuvo durante años con atrasos y dilaciones; también se rechazan recursos presentados en favor de niños adoptados y la Corte se ampara en la ley de adopción, en circunstancia que existe una ley de menores y la Convención Internacional sobre los derechos de los niños. Hay opiniones y acciones de sectores que han perjudicado las investigaciones. Hubo editoriales y artículos de prensa en que se dijo que era absurdo utilizar a 100 carabineros y que

289 Cámara de Diputados, Diarios de Sesiones, Legislatura 340ª , Sesión $27^{\mathrm{a}}$ vom 10.08.1999. Informe de las Comisiones Unidas de Derechos Humanos, Nacionalidad y Ciudadanía, y de Familia, encargadas de estudiar y fiscalizar cómo los distintos órganos públicos competentes han colaborado para el éxito de las investigaciones judiciales relativas a la ex Colonia Dignidad, auch online unter http s://www.camara.cl/camara/media/docs/colonia/04.pdf, (zuletzt abgerufen am 12.02.2018), S. $6 \mathrm{ff}$.

290 Ebd., S. 8.

291 Ebd., S. 8. 
se inviertieran cien millones de pesos, para buscar a un pobre anciano, que ha violado a unos pocos niños. Hay una defensa cerrada de sectores, que denomina ifuerzas fácticasく, que los protegen en distintos niveles [...] Comenta que ni Alemania lo pudo detener. Sólo hace dos meses que se está pidiendo por parte de ese país la extradición de Schaefer. Los problemas que hay son difíciles, pero se han ido solucionando. ${ }^{292}$

Neben den Problemen auf politischer, juristischer und medialer Ebene, beschrieb Velasco auch offensichtliche Hinweise darauf, dass die CD auch aus Polizeikreisen lange Zeit umfangreich unterstützt wurde: »Ya que han estado en permanente contacto, hay relaciones fluidas, en que se crean amistades, lo que al final se convierte en una red de protección. ${ }^{293}$ So sei SBED-Präsident Hermann Schmidt plötzlich angeblich verstorben, nachdem Anklage gegen ihn erhoben wurde. Auch Schäfer sei schon zwei Mal, 1967 und 1987, angeblich verstorben. Ganze Ermittlungsakten seien bei der Justiz angeblich verschwunden. ${ }^{294}$ Problematisch sei auch, dass die Befehlsgewalt über Carabineros und PDI beim Verteidigungsministerium liege. Allerdings werde das »Schutznetz« der CD immer dünner, je mehr Beweise gegen sie gefunden und bekannt würden. Velasco berichtete, sein Ministerium habe Kontakt zu den Regierungen Deutschlands und der USA aufgenommen, um technische Unterstützung beim Auffinden unterirdischer Anlagen auf dem CD-Gelände zu erhalten.

Auch Nelson Mery, Chef der PDI und Luis Henríquez, Leiter der PDI in der Region Maule, hörte die Kommission an. Nach Merys Einschätzung halte sich Schäfer auf dem Gelände der CD auf. Er, Mery, arbeite mit Interpol, dem BND und den Geheimdiensten einiger südamerikanischer Länder zusammen. Die Ermittlungen erstreckten sich über Chile hinaus nach Argentinien, Brasilien, Paraguay und Deutschland. Henríquez war überzeugt, dass man es mit einer kriminellen Organisation zu tun habe, für deren Bekämpfung der bestehende Rechtsrahmen nicht ausreiche. Die PDI werde kritisiert, weil sie nicht in der Lage sei, Schäfer festzunehmen. Jedoch werde ihre Arbeit seit 90 Tagen durch eine Aussetzungsanordnung (»orden de no innovar«) der CA Talca blockiert. Dies nehme jedoch niemand wahr. Bei Durchsuchungen ordneten Richter häufig an, es dürften nur wenige Beamt_innen eingesetzt werden. Zudem dürfe die PDI häufig erst am Tag nach dem Eindringen der uniformierten Polizei selbst die CD betreten. ${ }^{295}$ Manuel Ugarte, Generaldirektor der Carabineros und Jaime Rieutord, General der Carabineros für die Region Maule, wiesen die Vorwürfe gegen ihre Institution vor der Kommission zurück. Ihr gesamtes Vorgehen sei mit dem ermittelnden Richter Hernán González abgesprochen.

Rechtsanwalt Hernán Fernández, Rechtsbeistand zahlreicher Opfer der CD, erhob schwere Vorwürfe gegen Justiz und Carabineros und stellte einen direkten Zusammenhang zwischen dem behördlichen Versagen und der Schutzlosigkeit der Opfer her: 
»[E]ste caso es un ejemplo dramático de incumplimiento de resoluciones judiciales, de ineficacia de la ley, de falta de colaboración en la administración de justicia, que se traduce en la vulnerabilidad de las víctimas, es decir, en desprotección de niños. «"296

Fernández führte aus, die Umgebung der Siedlung sei eine abgelegene, ländliche Gegend, in der die Opfer dem systematischen Agieren der CD schutzlos ausgeliefert seien. Viele Opfer kämen aus einfachen Familien, die den Unterstützungsstrukturen der CD, etwa den sogenannten Patientenkomitees des Siedlungskrankenhauses, naheständen. Die lokalen Carabineros stünden mit Führungsmitgliedern der CD im engen Kontakt. Es seien nicht Polizeikräfte, sondern Fahrzeuge und Motorräder der CD, die in der Gegend Tag und Nacht patrouillierten. Er selbst sei bereits mehrfach von CD-Fahrzeugen verfolgt worden. Taxifahrer hätten ihn aus Angst auf halber Strecke aufgefordert, auszusteigen. Auch Kinder, die den sexuellen Missbrauch in der CD zur Anzeige brächten, und deren Familien würden bedrängt, ihre Aussagen zu widerrufen und niemand sei in der Lage, sie zu beschützen. ${ }^{297}$ Die Carabineros, so Fernández, fertigten unvollständige Ermittlungsberichte für die Gerichte an und widersetzten sich richterlichen Anordnungen. Beamt_innen, die Ermittlungen gegen die CD blockierten, würden sogar noch befördert. Die PDI arbeite zwar effizienter, verfüge aber nicht über ausreichende personelle und materielle Mittel, zudem werde sie von der CD bedrängt. Im Zusammenwirken von Gerichten, Carabineros und PDI komme es immer wieder zu Widersprüchen. So würden beispielsweise Schutzanträge wegen vermeintlicher Formfehler abgelehnt oder CD-Anwälte erhielten verfrühte Akteneinsicht. González« Ermittlungen seien zum Scheitern verurteilt, da er sich allein auf die Suche nach Schäfer konzentriere und nicht die kriminelle Organisation als Ganzes untersuche.

Die Kommission schloss sich dieser grundlegenden Kritik von Fernández in ihren Schlussfolgerungen an. Die beteiligten staatlichen Institutionen hätten den kriminellen Charakter der CD bisher nicht umfassend verstanden. ${ }^{298}$ Dies hätten die beiden vorangegangenen Untersuchungsausschüsse bereits festgestellt, weshalb es keine Rechtfertigung für dieses Versäumnis gäbe. Es sei auch nicht akzeptabel, dass die Justiz erst im März 1999 ein Verfahren wegen Bildung einer kriminellen Vereinigung aufgenommen hätte und dieses bislang noch keinerlei Konsequenzen gehabt habe. Die Kommission übernahm auch die Position, dass seit den 1960er Jahren in Staat, Politik und Medien ein »wahrnehmbares Schutznetzwerk« der CD bestehe, das die Aufklärung und Ahndung von Straftaten effektiv behindere. Ausgehend von diesen Prämissen bewertete die Kommission in ihrem Abschlussbericht die Rolle der einzelnen untersuchten Behörden. Dabei kritisierte sie in unüblicher Deutlichkeit die Carabineros und warf ihnen eine schwere Behinderung der Justiz vor:

»Carabineros de Chile no actuó con la debida diligencia y faltó a sus deberes [...] Esta conducta de Carabineros constituye la más clara expresión de falta de voluntad en el 
cumplimiento debido y cabal de sus funciones públicas en la materia y el más evidente y grave entorpecimiento que ha obstruido a la acción de la justicia, en este caso. ${ }^{299}$

Die Kommission drückte darüber hinaus ihre Besorgnis über die Situation der chilenischen Missbrauchsopfer aus, die aus einfachen ländlichen Familien stammten. Sie seien ständigen Bedrohungen ausgesetzt und würden nicht angemessen von den Polizeikräften geschützt.

Die PDI habe hingegen nach Einschätzung der Kommission ihre Arbeit erfüllt und zu Ermittlungsfortschritten beigetragen, verfüge jedoch teilweise nicht über ausreichende technische Mittel (Hubschrauber, Georadar- und Satellitentechnologie). ${ }^{300}$ Dem CDE dankte die Kommission ausdrücklich für die Strafanzeige wegen Bildung einer kriminellen Vereinigung. Allerdings hätte dies bereits viel früher geschehen müssen.

Im Anschluss an diese Schlussfolgerungen empfahl die Kommission eine permanente Beobachtung der Behörden durch den Menschenrechtsausschuss der Cámara de Diputados. Dieser solle dem Parlament halbjährlich über seine Erkenntnisse berichten. Außerdem solle der Verteidigungsminister sicherstellen, dass die Carabineros zukünftig den Anordnungen der Justiz komplett Folge leisteten. Der Bericht schloss - wie bereits der Bericht der Untersuchungskommission von 1997 - mit einem bestimmten, jedoch unkonkreten Aufruf, die Gesetzgebung anzupassen, um kriminellen Organisationen wie der CD besser beikommen zu können.

Am 21. Juli 1999 nahmen der Ausschuss für Menschenrechte und der für Familie den Abschlussbericht der Untersuchungskommission ${ }^{301}$ einstimmig an. ${ }^{302}$ Doch erst ein Jahr später, am 19. August 2000, stimmte die Cámara de Diputados darüber ab. Das Parlament nahm den Bericht mit 41 Ja-Stimmen, bei 18 Nein-Stimmen und einer Enthaltung an. ${ }^{303}$ Sämtliche Nein-Stimmen kamen von Abgeordneten der rechten Oppositionsparteien. Die Empfehlungen der Ausschüsse wurden jedoch nicht umgesetzt, vor allem nicht die weitere Beobachtung und Kontrolle verschiedener Behörden hinsichtlich ihrer Kooperation bei den Ermittlungen.

\subsection{Juristische Aufarbeitung der Verbrechen in der Bundesrepublik}

Die Mehrzahl der Verbrechen der Colonia Dignidad wurde auf chilenischem Staatsgebiet begangen. Dennoch kam es, wie in der Einleitung zu diesem Kapitel geschildert,

299 Ebd., S. 28.

300 Ebd., S. 28.

301 Cámara de Diputados, Boletín de Sesiones, Legislatura 340a , Sesión 27ª vom 10.08.1999, S. 124-169. Informe de las Comisiones Unidas de Derechos Humanos, Nacionalidad y Ciudadanía, y de Familia, encargadas de estudiar y fiscalizar cómo los distintos órganos públicos competentes han colaborado para el éxito de las investigaciones judiciales relativas a la ex Colonia Dignidad, auch online unter https://www.camara.cl/camara/media/docs/colonia/o4.pdf(zuletzt abgerufen am 12.02.2018).

302 Vgl. La Tercera vom 22.07.1999, S. 12. »Informe de Comisiones Unidas de Familia y Derechos Humanos de la Cámara de Diputados: `Carabineros frustró captura de Schäfer«.

303 Cámara de Diputados, Boletín de Sesiones, Legislatura $342^{a}$, Sesión 18ª vom 19.07.2000, S. 20-34. 
nach dem Personalitätsprinzip auch in der Bundesrepublik Deutschland zu Ermittlungsverfahren wegen Verbrechen der Colonia Dignidad, die sich häufig über mehrere Jahre hinzogen.

In den 1950er Jahren, noch vor der Übersiedlung der Gruppierung nach Chile, wurde eine Reihe von Missbrauchstaten Schäfers an Jungen bekannt, ohne dass die Familien der Opfer, bzw. die kirchlichen Jugendeinrichtungen bei denen Schäfer gearbeitet hatte, Strafanzeige gestellt hätten. Ende 1960, Anfang 1961 gingen bei der Staatsanwaltschaft Bonn die ersten Anzeigen ein, woraufhin Ermittlungen eingeleitet wurden. ${ }^{304}$ Schäfer erlangte vermutlich Kenntnis davon und setzte sich nach Belgien bzw. Luxemburg 305 $a b$, noch bevor die Staatsanwaltschaft ihn vorlud. Von Belgien aus reiste er Anfang Januar 1961 weiter nach Chile. ${ }^{306}$ Ein auf Anfrage der Botschaft erstellter Bericht der StA Bonn vom Juli 1985 gibt Aufschluss über die Ermittlungen, vor denen Schäfer samt seiner Gemeinde nach Chile geflüchtet war:

»Gegen den am 4.12.1921 in Bonn geborenen Paul Schäfer bestand seiner Zeit der Verdacht, sich an drei noch nicht 14-jährigen Jungen in sexueller Hinsicht vergangen zu haben. Deswegen war bei der Staatsanwaltschaft Bonn unter dem Aktenzeichen 14 Js 173/61 jug. ein Ermittlungsverfahren anhängig. Die aufgrund eines gegen Paul Schäfer erwirkten Haftbefehls eingeleiteten Fahndungsmaßnahmen blieben jedoch ohne Erfolg. Da in der Zwischenzeit neue Erkenntnisse nicht gewonnen werden konnten, wurde die Ausschreibung des Beschuldigten zur Festnahme am 23. Juli 1970 gelöscht, weil sie im Hinblick auf Verschlechterung der Beweislage (nur auf Kinderaussagen gestützter Tatverdacht) unverhältnismäßig erschien. Der Haftbefehl wurde am 13.10.1970 auf Antrag der Staatsanwaltschaft Bonn aufgehoben.

Mit Verfügung vom 14.5.1974 wurde das Verfahren wegen zwischenzeitlich eingetretener Verfolgungsverjährung eingestellt und der noch niedergelegte Suchvermerk zurückgenommen. Ein aus dem Verfahren 14 JS 173/61 jug. Ausgetrennter Vorgang 14 Js 1940/65 StA Bonn - ist am 9.12.1966 gemäß \$170 II StPO eingestellt worden. Die Akten beider Verfahren sind bereits seit längerem vernichtet. « 307

In den folgenden Jahrzehnten kamen weitere Straf- und Zivilverfahren hinzu. Tabelle 12 zeigt eine Übersicht der mir bekannten strafrechtlichen Ermittlungsverfahren im Zusammenhang mit den CD-Verbrechen. Daraus ergibt sich ein deutliches Bild: Alle der 13 aufgeführten Verfahren wurden ohne Anklageerhebung eingestellt. Die Einstel-

304 StA Bonn, AZ 14 Js 173/61.

305 Laut Fröhling, Unser geraubtes Leben, S. 148 verbrachte Schäfer einige Monate in Luxemburg. Mehrere Ex-Colonos, die damals Jungen waren, berichteten, dass Kurt Schnellenkamp sie nach Belgien brachte, wo sie von Schäfer für den Fall einer Befragung durch die Kriminalpolizei instruiert wurden. Vgl. CA Santiago, AZ 2182-98 (»]uan Maino«), Bd. 5a, BI. 2173. Polizeiliche Vernehmung von Willi Malessa vom 29.09.2005.

306 Vgl. Fröhling, Unser geraubtes Leben, S. 146ff.

307 PA AA, AV NA 31577. Schreiben von OStA Irsfeld (StA Bonn) an den Justizminister NRW vom 19.07.1985. Betr. Ermittlungsverfahren gegen Verantwortliche der Sekte »Christliche Soziale Mission« in Siegburg wegen des Verdachts auf Freiheitsberaubung u.a.; hier: Anfrage der Deutschen Botschaft in Santiago de Chile über Paul Schäfer. 
lungen erfolgten meist nach $\$ 170$ II StPO, das heißt die Staatsanwaltschaft sah keinen hinreichenden Tatverdacht für eine Anklage.

Neben Strafverfahren gab es in der Bundesrepublik auch eine Vielzahl zivil-, verwaltungs- und sozialrechtlicher Verfahren mit Bezug zur CD. Die Zivilverfahren gehen allesamt auf Initiative der CD zurück. Wie auch in Chile ging die CD auch in der Bundesrepublik stets mit hoher Vehemenz und unter Einsatz vieler Ressourcen juristisch gegen ihre Gegner_innen vor, sei es, um diese einzuschüchtern oder um das eigene Überleben zu sichern. Tabelle 13 führt die mir bekannten Verfahren auf. 


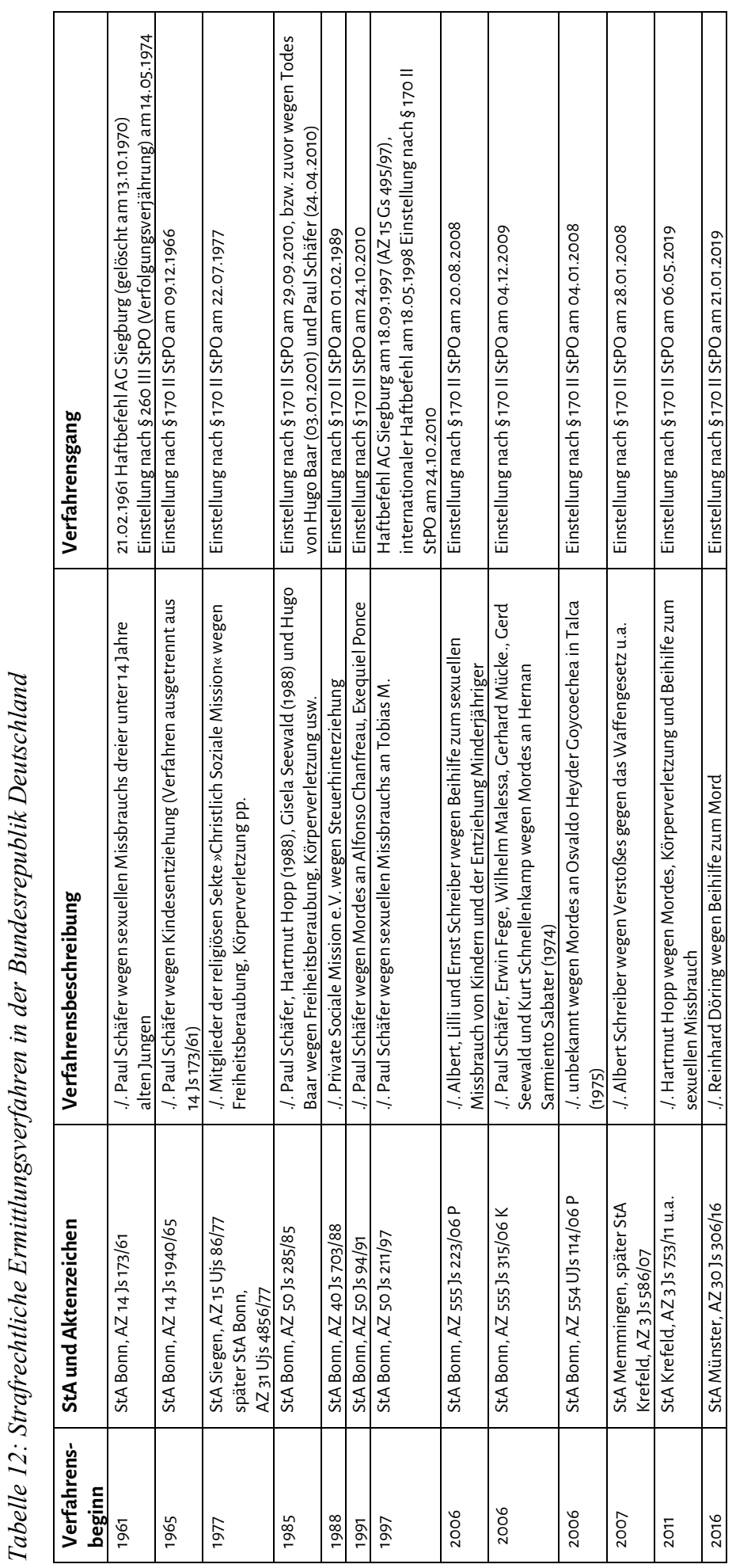




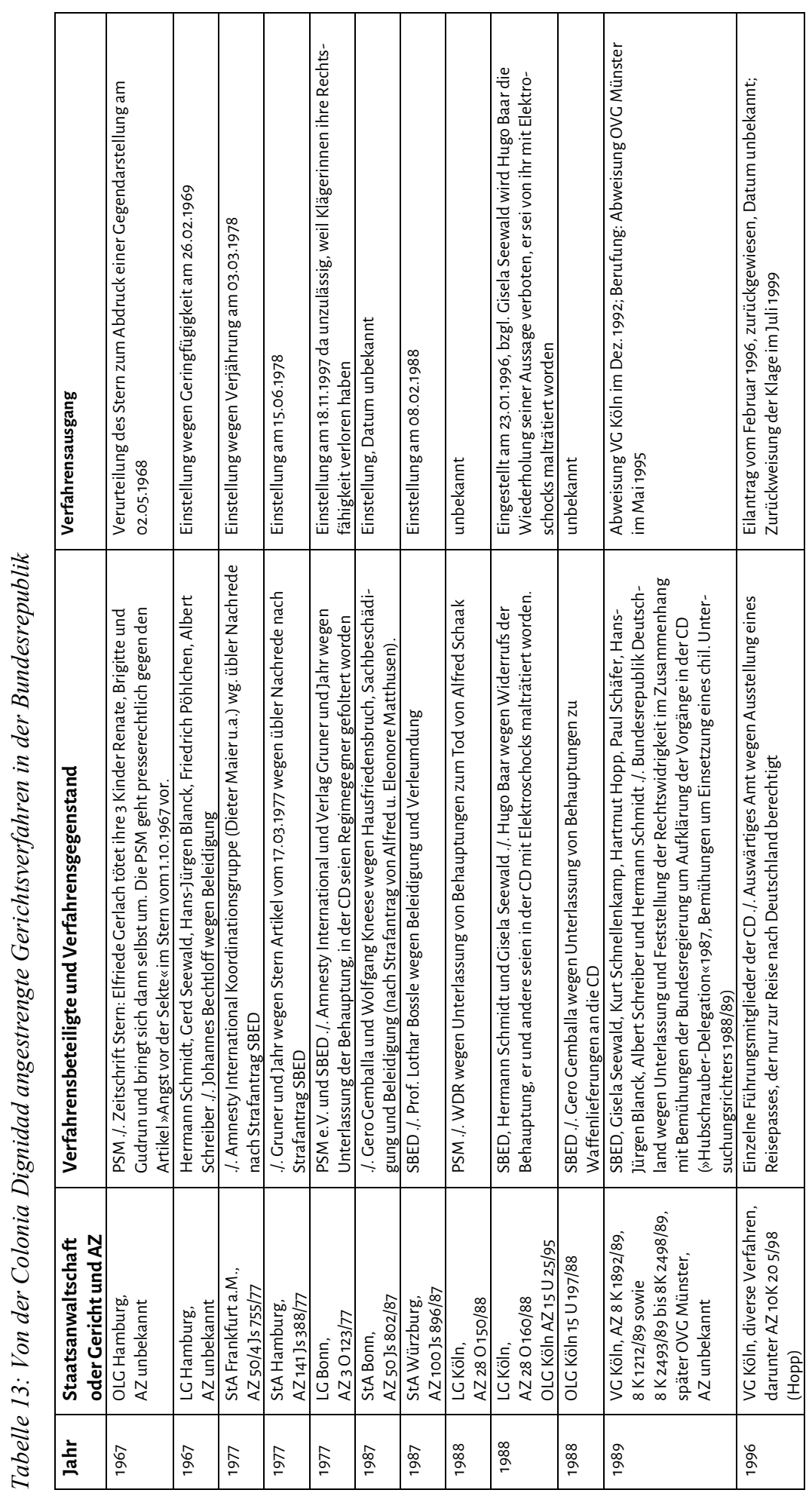


Daneben führte die CD ab Ende der 1980er Jahre eine große Anzahl von Verfahren vor bundesdeutschen Sozialgerichten. Diverse Rentenversicherungsträger hatten die Auszahlung von Renten an in der CD lebende Berechtigte eingestellt, da diese nicht, wie erforderlich, persönlich in der Botschaft bzw. bei eigens in der Nähe der CD organisierten Rentensprechtagen vorgesprochen hatten. $\mathrm{Zu}$ Recht befürchteten die Versicherungsträger deshalb, dass die Zahlungen nicht den Anspruchsberechtigten persönlich zu Gute kämen. Die CD verklagte diese Träger auf Fortsetzung der Rentenzahlungen, die in der Tat in die Kassen der CD flossen (vgl. Abschnitt 3.2.3). Bei einer Hausbesprechung der BfA im August 1989 wurde festgestellt, dass damals 36 Klagen auf Rentenauszahlung anhängig waren. Viele dieser Verfahren zogen sich über mehrere Jahre, und gingen bis hin zu Landessozialgerichten oder dem Bundessozialgericht. ${ }^{308}$ Weitere sozial- und verwaltungsrechtliche Verfahren drehten sich vornehmlich um die Auszahlung von Renten sowie die Ausstellung von Pässen für einzelne Colonos. Diese Verfahren waren zweifellos Teil der Strategie der CD, mittels juristischer Verfahren für eine Aufrechterhaltung der Zahlungen an die Gruppierung zu sorgen. Auf eine detaillierte Auflistung verzichte ich an dieser Stelle, auch weil diese Verfahren kaum etwas zur Aufklärung über die Verbrechen der CD beigetragen haben.

Wie bereits dargelegt zogen sich die bundesdeutschen Behörden in der Regel auf die Position zurück, dass für die Aufklärung der Verbrechen der CD in erster Linie die chilenische Justiz zuständig ist. So wurde trotz zum Teil jahrelanger Ermittlungen, etwa der Staatsanwaltschaften Bonn, Memmingen und Krefeld, niemals Anklage gegen mutmaßliche Täter aus der CD erhoben, geschweige denn deren Auslieferung beantragt. Selbst Schäfer wurde von der bundesdeutschen Justiz nur zeitweise per Haftbefehl gesucht: Zwischen 1961 und 1970 sowie zwischen 1997 und 2005 - nicht aber beispielsweise während der Jahre der chilenischen Militärdiktatur.

Die bundesdeutsche Diplomatie gab 1985 die Berichte des Ehepaars Packmor und von Hugo Baar an die Bonner Staatsanwaltschaft weiter und verhinderte im Verlauf des daraufhin eröffneten Ermittlungsverfahrens mehrfach eine schnelle Einstellung des Verfahrens. Gleichzeitig gab sie ihre Kenntnisse über Verbrechen in anderen Phasen des Falls CD allerdings nicht proaktiv an die NRW-Justiz weiter. Als Begründung wurde intern auf eine chilenische Primärzuständigkeit verwiesen, wie folgender Bericht eines deutschen Botschaftsrats aus dem Jahr 1997 zeigt, also zu einem Zeitpunkt als sich Paul Schäfer noch in der CD befand:

»Cegen eine Weitergabe dieser Informationen an die deutschen Ermittlungs- und Strafverfolgungsbehörden mit dem Ziel der Einleitung von Verfahren vor deutschen Gerichten gegen PS [Paul Schäfer, JS] wegen sexuellen Missbrauchs Minderjähriger bestehen im jetzigen Zeitpunkt folgende Bedenken:

1. Hauptproblem bei dem Vorhaben, den Strafanspruch gegen PS durchzusetzen, ist

- nicht

- mangelnde Kenntnis oder Beweisbarkeit der Tatbestände

- mangelnde Rechtsvoraussetzung für strafrechtliche Verfolgung.

Zur Beweislage haben die Anzeige vom Juni 96 und die darauffolgenden sich z.T. 
Überstürzenden Ereignisse erstmals Tatsachen ans Licht gebracht, die vor jedem Gericht der Welt für eine Verurteilung Schäfers ausreichen müssten. [...]

2. Kernproblem ist vielmehr, - der Person Schäfers habhaft zu werden - und dies ungeachtet der Tatsache, dass über den Ort seines Aufenthaltes kaum Zweifel bestehen. Es ist schwierig bis fast unmöglich, PS aus dem um seine Person gelegten, gegen den Rest des chil. Staates und der Welt mit einem Ring von Sicherheitsvorkehrungen abgesicherten Celände gegen seinen Willen ohne Schäden und gravierende Personenrisiken - lebend - herauszuholen. Dies soll nach derzeitiger Einschätzung, nicht zuletzt angesichts rd. 40 registrierter Waffen auf dem Celände, eine militärisch-logistische Planung grossen Umfangs unter massivem Polizeieinsatz, evtl. Mit Landung aus der Luft und anschl. Durchkämmung von Katakomben, erfordern. Z. Zt. ist nicht erkennbar, ob und wann der chilenische Staat zu einer derartigen Aktion bereit und in der Lage ist. Was sam Tag danach und in der Folgezeit mit den Insassen der Kolonie geschehen kann, ist ausführlich erörtert worden (Ref. 330, 106).

3. Verschärft wird das Problem durch folgende Punkte:

- Chile befindet sich in einem Wahljahr,

- es besteht eine heikle Balance (Projekte Verfassungs- und Justizreform) der regierenden Konzertation mit rechten Oppositionsparteien, welche immer noch mit PS-Anhängern durchsetzt sind; [...]

4. Bekannt werdende Ermittlungen in Deutschland, Übersendung von RHE u.Ä. mit dem Ziel der Eröffnung eines (Parallel-)Verfahrens gegen PS könnten in dieser Situation dem labil austarierten chilenischen Selbstwertgefühl einen weiteren Dämpfer versetzen und der rechten Opposition (`Einflußnahme aus dem Ausland`) in die Hände spielen. $\ll^{309}$

Die Argumentation seitens der bundesdeutschen Diplomatie lautete also, Chile müsse selbst tätig werden; jegliche bundesdeutsche Unterstützung dabei sei aufgrund der vermeintlich fragilen chilenischen Demokratie abträglich. Dies führte auf der deutschen Seite zu einer Untätigkeit, die bis zur Festnahme von Paul Schäfer eine Stagnation bei der Aufklärung und weiteres Leid für Opfer bedeutete. Am Tag nach der Festnahme Paul Schäfers in Buenos Aires im Jahr 2005 verkündete Bundesaußenminister Joschka Fischer durch eine Pressemitteilung des AA:

»Die Festnahme von Paul Schäfer ist eine gute Nachricht. Dank der hervorragenden Zusammenarbeit zwischen den deutschen, chilenischen sowie argentinischen Strafverfolgungsbehörden haben die intensiven Bemühungen der Bundesregierung, den Leiter der sogenannten `Colonia Dignidad zu fassen und zur Rechenschaft zu ziehen, zu einem Erfolg geführt.

Mit der Festnahme Paul Schäfers wird eine umfassende Aufklärung und Ahndung aller krimineller Handlungen in der ehemaligen >Colonia Dignidad ‘ möglich. Paul Schäfer werden von den chilenischen und deutschen Behörden zahlreiche Straftaten u.a. Freiheitsberaubung und sexueller Missbrauch von Minderjährigen, zur Last gelegt. « 310

309 PA AA, AV NA 32987. DB 126 an Ref. 511 vom 19.03.1997.

$310 \mathrm{AGH}$, Bestand RFA, Telex 2005. Pressemitteilung Auswärtiges Amt vom 11.03.2005, »Bundesaußenminister Fischer begrüßt Festnahme von Paul Schäfer«. 
Belege für eine »hervorragende« Mitarbeit deutscher Strafverfolgungsbehörden bei der Festnahme von Paul Schäfer sind mir nicht bekannt. Eine »umfassende Aufklärung und Ahndung aller kriminellen Handlungen« der ehemaligen CD waren zwar vor und nach Schäfers Verhaftung und Außernminister Fischers Erklärung durchaus möglich. Faktisch gingen von deutschen Justizbehörden jedoch auch nach Schäfers Verhaftung keine ambitionierten Aufklärungsmaßnahmen aus.

Den prekären chilenischen Aufklärungsbemühungen war zudem abträglich, dass sich einige der in Chile angeklagten Colonos der chilenischen Justiz entzogen und nach Deutschland flüchteten. Die chilenischen internationalen Festnahmeersuchen liefen ins Leere und meist eröffnete die deutsche Justiz in der Folge auch keine eigenen Ermittlungsverfahren. Mir bekannte Fälle sind die von Albert, Ernst und Lilli Schreiber (chilenische internationale Haftbefehle ca. 1999), Reinhard Döring (2005), Hans Jürgen Riesland (2005) und Hartmut Hopp. Im Fall Albert Schreiber und Hartmut Hopp richtete die chilenische Justiz Auslieferungsersuchen an die Bundesrepublik, die mit Verweis auf Art. 16 GG abgelehnt wurden. Im Fall Hartmut Hopp kam hinzu, dass das OLG Düsseldorf in letzter Instanz ein chilenisches Haftvollstreckungsersuchen für eine rechtskräftige chilenische Haftstrafe wegen Beihilfe zu Missbrauch und Vergewaltigung ablehnte. Gegen Albert Schreiber eröffnete die StA Memmingen ein Ermittlungsverfahren, das nur pro-forma geführt wurde. Die Bundesrepublik wurde in zunehmendem Maße zum sicheren Hafen für (mutmaßliche) Täter_innen der CD und deutsche Justizbehörden wirkten einer Aufklärung der Verbrechen eher entgegen, anstatt sie zu befördern.

\subsubsection{Zivilverfahren gegen Amnesty International vor dem LG Bonn (1977-1997)}

Am 22. April 1977 beantragte die CD über ihre Rechtspersonen in Chile und der Bundesrepublik, SBED und PSM, beim Landgericht Bonn den Erlass einer einstweiligen Verfügung gegen die deutsche Sektion von Amnesty International (AI) sowie den Verlag Gruner \& Jahr. Beiden wurde die Verbreitung der Behauptung untersagt, die CD sei ein Folterlager des chilenischen Geheimdienstes DINA. Anschließend hatte das LG Bonn im Hauptverfahren zu klären, ob die CD als Folterlager der DINA bezeichnet werden durfte.

Daraus entwickelte sich eines der längsten Zivilverfahren der bundesdeutschen Rechtsgeschichte, ${ }^{311}$ das erst nach über 20 Jahren endete: Erst ab November 1997 durfte AI wieder konstatieren, dass die CD als Folterlager der DINA gedient hatte - allerdings nicht, weil das Gericht die Richtigkeit dieser Aussage bestätigt hatte, sondern weil die Klägerinnen im juristischen Sinne nicht mehr existierten: Die SBED war von der chilenischen Regierung aufgelöst worden und der PSM hatte das Amtsgericht Siegburg 1995 auf eigenen Antrag die Rechtsfähigkeit entzogen, da die Mitgliederzahl des Vereins auf unter drei gefallen war. ${ }^{312}$ Aufgrund »fehlender Parteifähigkeit« der Klägerinnen erklärte das LG Bonn die Klage am 18. November 1997 daher für unzulässig.

311 Vgl. Lüthke, Karsten. Der unendliche Prozess. Colonia Dignidad gegen amnesty international, in: amnesty international (Hg.), 40 Jahre für die Menschenrechte, Neuwied 2001, S. 76-85, hier S. 76.

312 Vgl. Gesterkamp, Harald. »Ein Ende des unendlichen Prozesses « in: Al-Journal 10/1997, S. 6-12, hier S. 12. 
AI blieb durch diese Entscheidung auf den Gerichtskosten in Höhe von über 150.000 DM sitzen. ${ }^{313}$ Zwar wies das Gericht die Klage auf Kosten der Klägerinnen ab, da diese aber formal nicht mehr existierten, konnten auch die Kosten nicht mehr bei ihnen eingetrieben werden.

Zudem war das Urteil inhaltlich ernüchternd, da eine »sichere abschließende Beurteilung der strittigen Vorwürfe« auch mehrere Jahre nach Ende der chilenischen Diktatur nach Meinung des Gerichts »nicht möglich « war. ${ }^{314}$ Der ehemalige AI-Mitarbeiter Karsten Lüthke kommentierte die Entscheidung so:

»Die Kolonie hatte nur auf Zeit gespielt und war offensichtlich damit zufrieden, dass amnesty die Foltervorwürfe wegen der entgegenstehenden 20 Jahre alten einstweiligen Verfügung nicht wiederholen durfte, während alle Welt wusste und sagte, dass in der Kolonie gefoltert wurde. [...] Das inhaltliche Urteil über das Folter- und Schreckensregime des Cenerals Pinochet und über das brutale Privatgefängnis des Paul Schäfer hatte die Geschichte längst gefällt. « ${ }^{315}$

\section{Vorgeschichte des Zivilverfahrens}

Im Februar und Oktober 1976 hatte der United Nations Economic and Social Council (ECOSOC) die CD in zwei Berichten als Haft- und Folterstätte der DINA bezeichnet. ${ }^{316}$ Diesem Vorwurf gingen verschiedene Journalist_innen, aber auch die ChileKoordinationsgruppe von Amnesty International in Frankfurt a.M. nach. Am 17. März 1977 veröffentlichte der Stern einen Artikel über die CD mit dem Titel »Das Folterlager der Deutschen«. Nur wenige Tage später, am 21. März, stellte Amnesty International bei einer Pressekonferenz in Siegburg die 60-seitige Broschüre »Colonia Dignidad Deutsches Mustergut in Chile - Ein Folterlager der DINA« vor. Der Zeitpunkt der Veröffentlichung war zwischen AI und dem Stern koordiniert. In der Frankfurter AI-Gruppe hatten sich zwei Mitglieder die mehrmonatige Recherchearbeit aufgeteilt: Jürgen Karwelat hatte die Vorgeschichte der CD in der Bundesrepublik erforscht, während Dieter Maier den Verbindungen der CD zum chilenischen Geheimdienst nachgegangen war. Maier hatte ausführliche Gespräche mit ehemaligen politischen Gefangenen geführt, die 1975 in der CD gefoltert worden waren, dies überlebt hatten und denen es gelungen war, Chile zu verlassen.

Die erwähnten ECOSOC-Berichte basierten ebenfalls auf Aussagen vieler dieser Personen. Die AI-Broschüre gab die Berichte von drei Folterüberlebenden detailliert wieder: Erick Zott, Luis Peebles und Adriana Bórquez. Die MIR-Mitglieder Erick Zott und Luis Peebles waren im Februar 1975 von der DINA in die CD gebracht und dort etwa 12 Tage lang gefoltert und verhört worden. Die KP-Anhängerin Adriana Bórquez war

\footnotetext{
313 Lüthke, Der unendliche Prozess, S. 84.

314 LC Bonn, Pressemitteilung vom 18.11.1997 zur Beendigung des Verfahrens 30 123/77.

315 Lüthke, Der unendliche Prozess, S. 84f. Walter spricht sogar von 165.000 DM. Walter, Klaus H. CoIonia Dignidad, die unendliche Geschichte, in: Deutsches Institut für Menschenrechte et al. (Hg.). Jahrbuch Menschenrechte 2007, Frankfurt a.M. 2006, S. 183-188, hier S. 186.

316 United Nations Economic and Social Council (ECOSOC). E/CN.4/1188 vom 04.02.1976 sowie United Nations Economic and Social Council (ECOSOC). Bericht A/31/253 vom 08.10.1976.
} 
im April 1975 gemeinsam mit 50 weiteren politischen Gefangenen in die CD verschleppt worden, wo sie 24 Tage lang festgehalten und unter Folter verhört wurde.

\section{Verfahrensgenese}

Etwa einen Monat nach den Veröffentlichungen von AI und Stern beantragten SBED und PSM über den Bonner Rechtsanwalt Felix Busse eine einstweilige Verfügung. AI sollte die Behauptung untersagt werden, die CD sei ein Folterlager der DINA. Auch die Broschüre sollte AI nicht weiter verbreiten dürfen. Die Dringlichkeit einer Eilentscheidung wurde damit begründet, dass AI für den 22. April in Siegburg eine weitere Veranstaltung geplant hatte, auf der diesmal die Zeug_innen aus der AI-Broschüre sprechen sollten. Die Mitglieder der CD in Siegburg, so die Argumentation von Busse, hätten dadurch »ungeheuerliche Diffamierungen in größter Öffentlichkeit zu befürchten. «17 Das LG Bonn untersagte die Veranstaltung mittels einer einstweiligen Verfügung und stellte diese dem Christlichen Verein Junger Männer (CVJM), in dessen Räumen in Siegburg die Veranstaltung stattfinden sollte, wenige Stunden vor Beginn der Veranstaltung zu. ${ }^{318}$ AI entschied sich daraufhin, die Veranstaltung ins Siegburger Servatius-Haus zu verlegen, wo sie u.a. in Anwesenheit von CD-Anwalt Busse schließlich stattfand. ${ }^{319}$ Helmut Neumann, der von AI sowie Gruner \& Jahr beauftragte Rechtsanwalt, reichte umgehend Widerspruch gegen den Erlass der einstweiligen Verfügung ein. Dabei berief er sich u.a. auf die beiden ECOSOC-Berichte.

Am 12. Mai 1977 kam es zu einer ersten Anhörung vor dem LG Bonn. Dabei waren der 1975 in der CD inhaftierte Ivan Treskow sowie der in der CD-Führung für rechtliche Fragen zuständige Hans-Jürgen Blanck als Zeugen geladen. Treskow beschrieb minutiös, wie er nach seiner Festnahme in die CD gebracht und dort mehrere Tage lang verhört sowie mit Elektroschocks und Medikamenten gefoltert worden war. Anschließend sei er in andere Haftanstalten in Santiago und im Norden Chiles verlegt worden. Die Verhöre in der CD hätten zwei Deutsche angeleitet, die von anderen mit »Doktor « und »Major « angesprochen worden seien. ${ }^{320}$ Während der Folter sei per Funk auf Spanisch und Deutsch kommuniziert worden, so Treskow.

Hans-Jürgen Blanck erklärte, er könne mit Sicherheit sagen, dass es in der CD nie eine Zusammenarbeit mit dem chilenischen Geheimdienst gegeben habe »oder gar eine Zusammenarbeit, die zu Folterungen oder zu irgendwelchen rechtswidrigen Versuchen an Menschen geführt haben. Solche Ereignisse haben sich nicht abgespielt. « ${ }^{321}$ Blanck gab jedoch zu, dass Augusto Pinochet die Siedlung 1974 besucht und dass die CD ihm »mal unseren Mercedes 600 anlässlich eines Staatsbesuches leihweise zur Verfügung gestellt $\ll^{322}$ hatte.

Vgl. Harald Cesterkamp. »Ein Ende des unendlichen Prozesses« in: Al-Journal 10/1997, S. 6-12, hier S. 7

318 LG Bonn, AZ 3 O 103/77.

319 Vgl. Harald Gesterkamp. »Ein Ende des unendlichen Prozesses« in: Al-Journal 10/1997, S. 6-12, hier S. 7.

320 »Doktor« war ein Spitzname von Paul Schäfer. Mit »Major« war möglicherweise der DINA-Agent Fernando Gómez Segovia gemeint, dessen militärischer Rang »mayor« war.

321 Archiv AI, Bestand CD. LC Bonn, 3 O 104/77. Sitzungsprotokoll vom 12.05.1977, S. 17.

322 Ebd., S. 26. 
Am 23. Mai bestätigte das LG Bonn seine einstweilige Verfügung. ${ }^{323}$ In der Begründung hieß es, AI habe mit der Veröffentlichung der Broschüre üble Nachrede im Sinne des $\$ 186$ StGB begangen. Für das Gericht sei es unerheblich, ob die Zeugen ${ }^{324}$ gefoltert worden seien. $\mathrm{Zu}$ klären sei für das Gericht nur, ob diese Folterungen ohne jeglichen Zweifel in der CD stattgefunden hätten. Dies hätten die Zeugen nicht belegen können, die ja sie bei ihrem Transport Kapuzen tragen mussten. Ihre Beschreibungen der Wegstrecke in die CD seien widersprüchlich gewesen. Auch die Tatsache, dass die Folterer Deutsch sprachen, belegte nicht, dass sie sich in der CD befunden hätten, da in Chile viele Deutschstämmige lebten.

Diese Abwägungen verdeutlichten die Haltung der Richter, die eine mögliche Rufschädigung des in Chile tätigen Vereines für schwerwiegender hielten als den konkret dargelegten Vorwurf massiver Menschenrechtsverletzungen. Die Argumentationsweise der Richter basierte auf deren Einschätzung, dass Folterüberlebende oder AI möglicherweise aus ideologischen Motiven eine falsche Beschuldigung gegen die CD erhoben haben könnten, um dieser zu schaden. Da ähnliche Falschbeschuldigungen bis dahin nicht vorgekommen waren, liegt nahe, dass die Richter selbst aus ideologischen Motiven handelten und der Version der CD größeren Glauben schenkten als der der Aufklärer_innen.

AI legte beim OLG Köln Berufung gegen der Erlass der einstweilige Verfügung ein. Am gleichen Tag reichten SBED und PSM beim LG Bonn Klage gegen AI und Gruner \& Jahr ein. ${ }^{325}$ Das einstweilige Verfügungsverfahren wurde bis zur Entscheidung im Hauptverfahren ${ }^{326}$ zurückgestellt. Das Verbot, die Broschüre weiter zu verbreiten und weiterhin festzustellen, dass die CD ein Folterlager der DINA sei, blieb solange in Kraft.

Im Hauptverfahren vernahm das LG Bonn von Juni 1978 bis Ende 1979 sieben von AI benannte ehemalige politische Gefangene als Zeug_innen. ${ }^{327}$ Diese berichteten über ihre Verschleppung, Inhaftierung und Folter in der CD. Sie führten eine Reihe weiterer Belege an, um restliche Zweifel auszuräumen, dass es sich bei dem Folter- und Haftort tatsächlich um die CD handelte. Außerdem sagte als Zeuge für AI auch HansGünter Matthusen aus, ein Beamter der Kriminalpolizei, dessen Angehörige in der CD lebten. ${ }^{328}$ AI thematisierte im Verfahren auch die umfangreichen Aussagen des im Oktober 1977 ermordeten Juan René Muñoz Alarcón über das Gefangenenlager in der CD (vgl. Abschnitt 5.1.2).

Am 30. Oktober 1979 kam es zu einer Aussage von Samuel Fuenzalida Devia, einem ehemaligen DINA-Agent, der Chile verlassen und in der Bundesrepublik um politisches

323 Archiv Al, Bestand CD. LC Bonn, 3 O 104/77. Anlage zum Verkündungsprotokoll vom 23.05.1977.

324 Bis zu diesem Zeitpunkt des Verfahrens war Iván Treskow als Zeuge vernommen worden. Luis Peebles und Erick Zott hatten eidesstattliche Versicherungen zu den Akten gegeben.

325 Archiv Al, Bestand CD. Rechtsanwälte Felix Busse und Wolfgang Miessen in Vertretung von PSM und SBED an das LG Bonn, 3. Zivilkammer. Klage gegen Al auf Unterlassung vom 23.05.1977.

326 LG Bonn, AZ $30123 / 77$.

327 Dies waren Iván Treskow, Luis Peebles, Erick Zott, Adriana Bórquez, Gerardo Sánchez, Manuel Bravo und Eduardo Garcés.

328 Hans-Günter Matthusens Bruder Alfred - ein Führungsmitglied - und ihr Vater Johannes lebten in der CD. Zu den Bemühungen von Hans-Günter Matthusen seinen Vater Johannes aus der Siedlung zu holen, vgl. Abschnitt 5.3.4. 
Asyl gebeten hatte. Fuenzalida berichtete, dass viele seiner Kollegen bei der DINA die CD kannten. Intern würde diese als »Los Alemanes« (die Deutschen) bezeichnet. Er gab an, als DINA-Agent 1974 zwei Mal in der CD gewesen zu sein. Im Juni oder Juli jenes Jahres habe er den Befehl erhalten, gemeinsam mit seinem Vorgesetzten Fernando Gómez Segovia (dem Kommandanten der BIR-Sur in Parral) den Gefangenen Alvaro Vallejos Villagrán von der klandestinen Haftanstalt Cuatro Alamos in Santiago in die CD zu bringen. In der Gefangenenkartei der DINA-Haftanstalt Villa Grimaldi, wo Fuenzalida stationiert war, sei neben Vallejos Name der Zusatz »Puerto Montt « aufgeführt gewesen. Dazu führte Fuenzalida aus:

»Der Begriff >Puertomont` war ein Schlüsselwort. Er wurde dafür verwendet, wenn ein Gefangener nicht mehr überleben sollte. Dabei bedeutete dieser Begriff zugleich, daß der Betreffende sauf dem Landweg zu beseitigen sei. Wie das im einzelnen vor sich ging, weiß ich nicht, da ich nie jemanden umgebracht habe. Es gab da noch einen weiteren Zusatz, nämlich das Wort >Monedar. Dieser Zusatz bedeutete, daß der Betreffende auf dem Luftweg oder auf dem Wasserweg beseitigt werden sollte, zum Beispiel durch Herauswerfen aus dem Flugzeug oder durch Versenken in einem beschwerten Sack im Meer. «29

Fuenzalida berichtete weiter, dass sein Vorgesetzter und er den Gefangenen Vallejos in der CD Gerhard Mücke und Paul Schäfer übergeben habe. Diese hätten ihn weggeführt. Einige Zeit später sei Schäfer ins Esszimmer im Zippelhaus der CD gekommen, in dem die DINA-Mitarbeiter derweil bewirtet wurden. Er sei mit seiner Hand einmal quer über seinen Hals gefahren und habe »fertig! « gesagt. Fuenzalida schloss daraus, dass Vallejos ermordet worden war. ${ }^{330}$

Die Aussage von Samuel Fuenzalida fand in bundesdeutschen Medien große Beachtung $^{331}$. Einige Tage nach Fuenzalidas Anhörung sandte das AA der Botschaft einen umfassenden Bericht des International Press Service (IPS) und bat die Botschaft um eine Stellungnahme »zu dem übersandten IPS-Bericht und zur Person des Zeugen Fuenzalida. ${ }^{332}$ Die Botschaft antwortete, Fuenzalidas Aussage enthalte »h. E. [hiesigen Erachtens, JS] hinsichtlich der Colonia Dignidad keine wesentlich neuen Elemente, die

329 PA AA, AV NA 31580. LG Bonn, 3 O 123/77. Abschrift der öffentlichen Sitzung vom 30.10.1979. Anlage zum Schreiben von ai-Generalsekretär Helmut Frenz ans AA vom 23.11.1979, S. 7.

330 Alvaro Vallejos Villagrán ist der einzige Verschwundene im Zusammenhang mit der CD, der im Bericht der chilenischen Wahrheitskommission von 1991 namentlich erwähnt wird, vgl. Corporación Nacional de Reparación y Reconciliación. Informe de la Comisión Nacional de Verdad y Reconciliación. Bd. 2. Santiago 1996, online unter https://www.memoriachilena.gob.cl/archivos2/pdfs/MCo053680.pdf, hier S. 469f. 2018 verurteilte die Corte Suprema nach einem jahrzehntelangen Verfahren fünf ehemalige DINA-Agenten, darunter Fernando Gómez Segovia, wegen »secuestro calificado de Alvaro Vallejos Villagrán« zu jeweils 15 Jahren und einem Tag Haft. Cerhard Mücke wurde als »cómplice del delito de secuestro calificado« zu drei Jahren und einem Tag Haft verurteilt. Vgl. Urteil der Corte Suprema vom 07.08.2018 im Verfahren AZ 19127-17.

Vgl. z.B. Frankfurter Rundschau vom 03.11.1979. »Ex-Agent: Gefangene auf deutschem Gut gefoltert und getötet« sowie Westfälische Nachrichten vom 01.11.1979. »Ex-Ceheimdienstler aus Chile enthüllt vor dem Bonner Landgericht: Politischer Gefangener in deutscher Siedlung getötet. « 
nicht schon im Rahmen früherer Zeugenaussagen in dieser oder ähnlicher Form vorgetragen worden wären. «333 Um weitere Information zur Person Fuenzalidas werde man sich bemühen. Am folgenden Tag verfasste RK Referent Dieter Hertrampf einen Vermerk »zur Person des Zeugen Fuenzalida«:

»Herr [Alfred, ]S] Matthusen hat mir heute einige wenige Angaben [...] zum Zeugen Fuenzalida gemacht. Danach hat der in Chile lebende Vater sich vor einigen Jahren von seinem Sohn losgesagt, da dieser begonnen habe, mit dem MIR zu sympathisieren und sich dessen Cedankengut zu eigen zu machen.

Die Colonia Dignidad habe kürzlich auch bei der CNI angefragt um festzustellen, ob es mit der von Fuenzalida behaupteten Mitgliedschaft in der damaligen DINA seine Richtigkeit habe. CNI habe zwar bestätigt, daß Fuenzalida bis 1973 Militärdienst abgeleistet habe, Unterlagen über eine formelle Zugehörigkeit zur DINA, so habe CNI behauptet, gäbe es jedoch nicht. [...] In der Colonia Dignidad wird die Ansicht vertreten, Fuenzalida erhoffe sich durch seine Angaben einen >Asylgrund « zu verschaffen, da er sich offenbar bisher illegal in der Bundesrepublik aufhalte. «334

Dieser Vorgang verdeutlicht, dass die Verbindungen zwischen der Botschaft und der CD-Führung äußerst eng waren. Ebenso zeigt er, dass die Botschaft über die engen Verbindungen zwischen CD und dem Geheimdienst (CNI war die Nachfolgeorganisation der DINA) unterrichtet war. Keine gewöhnliche »wohltätige« Organisation konnte in Chile Anfragen dieser Art an den Geheimdienst richten und zudem umgehend eine Antwort erhalten.

Die CD-Anwälte im Verfahren am LG Bonn versuchten in ähnlicher Weise die Glaubwürdigkeit Fuenzalidas und anderer Zeug_innen zu erschüttern. Sie verfassten dazu ausführliche Schriftsätze und bemühten sich, vermeintliche Widersprüche in den Aussagen aufzuzeigen, etwa bezüglich der Beschreibung des Weges zur CD oder der Kellerräume, in denen gefoltert worden war. So bezweifelte RA Busse etwa, dass Fuenzalida überhaupt bei der DINA gewesen sei. Er präsentierte Bescheinigungen des chilenischen Verteidigungsministeriums, nach denen er lediglich ein einfacher Wehrpflichtiger gewesen war. Zum Schicksal des Gefangenen Vallejos führte Busse aus, dessen Vater Manuel Vallejos habe angegeben, dass sich sein Sohn noch im Mai 1975 »bester Gesundheit «35 erfreut und seine Eltern besucht habe. »Tatsächlich ist Loro Matías alias Alvaro Vallejos 1975 wieder verhaftet und 1976 wieder freigelassen worden und ist ins Ausland ins Exil gegangen.«336

Neben Felix Busse vertrat ab 1979 - auf Betreiben des Waffenhändlers Gerhard Mertins - auch Rechtsanwalt Ludwig Klassen die CD in diesem Verfahren. ${ }^{337}$ Als Zeug_innen benannten sie Colonos, mit der CD befreundete Gutsbesitzer ${ }^{338}$ aus der Umgebung

333 PA AA, AV NA 31580. DB 295 vom 28.11.1979, CZ Rk 543.

334 PA AA, AV NA 31580. Vermerk RK-Referent Hertrampf vom 29.11.1979, Betr: Colonia Dignidad, hier: zur Person des Zeugen Fuenzalida. Ebd. PJK, Ordner Prozessakte. Schreiben RA Helmut Neumann an RA Winfried Fedder vom 22.01.1980. Unter anderem die Grundbesitzer Guillermo Soto, Enrique Fuentes und Guillermo Marín. Archiv Al, Bestand CD. LG Bonn, 3 O 123/77. Schriftsatz RA Busse vom 27.06.1977. 
sowie Botschafter Erich Strätling. Strätling hatte im November 1976 die CD besucht und anschließend die chilenische Luftwaffe beauftragt, Luftbilder von der CD anzufertigen. ${ }^{339}$ Die Bilder sollten Aufschluss über die unterkellerten Räumlichkeiten in der CD gegeben. Laut CD-Anwalt Busse gäbe es dort nur in vier Gebäuden Kellerräume, in denen jedoch lediglich Vorräte aufbewahrt würden - darunter auch der sogenannte Kartoffelkeller. ${ }^{340}$

\section{Das Rechtshilfeersuchen}

Im Februar 1979 schrieb der Staatsminister im AA, Klaus von Dohnanyi an seinen Parteikollegen, den Bundestagsabgeordneten Ernst Waltemathe (SPD):

»Das Auswärtige Amt hat alles im Rahmen des völkerrechtlich Möglichen unternommen, um Einzelfälle aufzuklären, die an es herangetragen wurden. Die Verdachtsmomente haben sich jedoch nicht bestätigt. Die Botschaft wäre überfordert, wenn man sie mit Untersuchungen kriminalistischen Charakters beauftragte. Das wäre auch völkerrechtlich unzulässig. Der vom Bonner Landgericht für 1979 offenbar ins Auge gefaßte Lokaltermin in der >Colonia Dignidad erscheint als der einzig gangbare Weg, weitere sachdienliche Untersuchungen anzustellen [...] Es bleibt zu hoffen, daß das anhängige Cerichtsverfahren die allseits gewünschte Klärung über die Vorgänge in der Siedlung bringt. $^{341}$

Am 22. Januar 1980 fasste das LG Bonn einen umfangreichen Beschluss: Vom 11. August bis zum 15. September desselben Jahres sollten Vertreter_innen des Gerichts nach Chile reisen, dort eine Ortsbesichtigung vornehmen und 30 Zeug_innen vernehmen. Die Anwälte der CD wandten sich gegen dieses Vorhaben. Sie reichten ein Rechtsgutachten des Würzburger Juraprofessors Dieter Blumenwitz ein, der bereits beratend an der Ausarbeitung der 1980 in Kraft getretenen chilenischen Verfassung beteiligt gewesen war. Das 40-seitige Gutachten vom Oktober 1980 kam zu dem Schluss:

»Nach den Normen des internationalen und des chilenischen Rechts kann die von der 3. Zivilkammer des LG Bonn mit Beweisbeschluß vom 22.01.1980 beabsichtigte Beweisaufnahme in Chile in Cegenwart des Kollegiums der 3. Zivilkammer des Landgerichts Bonn nicht durchgeführt werden. ${ }^{342}$

Am 15. Dezember 1981 fasste das LG Bonn einen neuen Beweisbeschluss: Die Beweiserhebung in Chile sollte nun auf dem Wege der Rechtshilfe erfolgen, das heißt ohne die Anwesenheit der Bonner Richter_innen. Damit übergab das LG Bonn faktisch die Beweiserhebung der Justiz der chilenischen Diktatur.

PA AA, S 5 - Karten und Pläne, 299. »Zwei Luftaufnahmen der Colonia Dignidad von der chilenischen Luftwaffe und zwei Pausen« vom 19.11.1976.

340 Archiv AI, Bestand CD. LG Bonn, 3 O 123/77. Schriftsatz RA Busse vom 27.06.1977.

341 Archiv AI, Bestand CD. Schreiben StS von Dohnanyi (AA) an MdB Waltemathe vom 08.02.1979, CZ 331-321.39 CHL.

342 Archiv Al, Bestand CD. Gutachterliche Stellungnahme von Prof. Dr. Dieter Blumenwitz vom 24.10.1980, G VIII-15-80. 
Rechtshilfeersuchen (RHE) sind äußerst bürokratische Verfahren: Das RHE eines deutschen Gerichts - hier des LG Bonn - geht zunächst an das jeweilige Landesjustizministerium (hier NRW) und wird von diesem ans Bundesjustizministerium weitergeleitet. Dieses leitete das Ersuchen ans AA weiter, das das Ersuchen in die Sprache des Ziellandes übersetzt und an die zuständige Auslandsvertretung schickt. Die Botschaft beurkundet dann das RHE und sendet es an das Außenministerium des Ziellandes. In Chile entscheidet die Corte Suprema über die Annahme eines RHE. Im Falle einer positiven Entscheidung leitet er das Ersuchen an das zuständige lokale Gericht weiter, das dann die im RHE erbetenen Maßnahmen durchführt - bevor die Ergebnisse auf dem umgekehrten Wege über alle Zwischenstationen wieder zurückgemeldet werden. Aufgrund dieser Vielzahl an Stationen und Schritten sind RHE sehr anfällig für Verzögerungen. Dies gilt umso mehr, wenn eine oder gar mehrere der zu durchlaufenden Stellen eine solche Verzögerung beabsichtigen.

Am 6. Mai 1982 erstellte das LG Bonn ein 56-seitiges Rechtshilfeersuchen. Die chilenischen Behörden wiesen dieses im Oktober 1982 wegen fehlerhafter Übersetzungen sowie nochmals im März 1984 wegen fehlender Legalisierungen zurück. Per Verbalnote erkundigte sich die Botschaft im September 1985 beim chilenischen Außenministerium nach dem Bearbeitungsstand des RHE. Die Anfrage wurde mehrere Monate lang nicht beantwortet, woraufhin Botschafter Holzheimer im Februar 1986 nach Bonn meldete: »In der Tat müssen wir damit rechnen, dass angesichts der guten Beziehungen und des Ansehens, das die Colonia Dignidad bei den Spitzen der chilenischen Regierung geniesst, die Erledigung des Ersuchens durch Hindernisse gleich welcher Art zumindest verzögert werden wird. ${ }^{343}$ Der Direktor der Rechtsabteilung des chilenischen Außenministeriums habe gegenüber einem Botschaftsmitarbeiter darauf hingewiesen, »dass die Angelegenheit auch eine >politische Seite habe, die den Gang der Dinge seines Erachtens nicht gerade fördere. «44

Von der Erstellung bis zur Umsetzung des RHE vergingen über fünf Jahre. Erst am 26. März 1987 konnte AI als Beklagte ${ }^{345}$ in Santiago das Beweisverfahren einleiten. ${ }^{346}$ AI beauftragte hierfür die Rechtsanwälte Máximo Pacheco, Sergio Corvalán und Guillermo Ceroni. Im Dezember 1987 beschloss das Erste Zivilgericht von Santiago die Durchführung der Beweisaufnahmen. Es begann mit der Vernehmung von Zeug_innen und setzte einen Ortstermin in der CD für den 28. April 1988 an. Das war über neun Jahre, nachdem das LG Bonn das erste Mal einen solchen Ortstermin erwogen hatte.

343 HISArch, Bestand CD, Ordner 15. Bericht der Botschaft ans AA (Ref. 330) vom 11.02.1986, $330 \mathrm{Nr}$. 154/86 Rk 543.

344 Ebd.

345 Der Verlag Gruner \& Jahr war inzwischen »intern« aus dem Verfahren ausgeschieden, nachdem er bereits länger unzufrieden gewesen war bezüglich der Dauer und Kosten des Verfahrens. Al und Verlag einigten sich, dass Gruner\& Jahr das Verfahren formal nicht verlassen würde, um nach außen keine Spaltung zu signalisieren. Rückwirkend ab 1982 übernahm Al die bisherigen Kosten des Verfahrens sowie das vollständige Risiko für künftige Kosten und Schadensersatzansprüche. Vgl. Archiv Al, Bestand CD. Schreiben RA Neumann an RA Hagen (Gruner \& Jahr) vom 21.03.1983 sowie Antwort RA Hagen vom 22.03.1983. 
Die Leitung der Delegation für den Ortstermin in die CD fiel der Richterin Lydia Villagrán vom Gericht in Parral zu, die für ihre CD-freundliche Haltung bekannt war. Für die CD nahmen Hartmut Hopp und Hans-Jürgen Blanck, sowie die CD-Anwälte Waldo Ortúzar und Julio Sagües teil. Für AI waren Walter Rövekamp, Generalsekretär der bundesdeutschen AI-Sektion sowie die genannten chilenischen Rechtsanwälte anwesend. Rövekamp hatte sich mit den Anwälten und der AG Colonia Dignidad von $\mathrm{AI}^{347}$ akribisch auf den Termin vorbereitet und fertigte anschließend ein ausführliches Protokoll an. ${ }^{348}$ Die Delegation inspizierte in den Folgetagen an insgesamt drei Nachmittagen die Zufahrtswege zur CD. Zwei Mal (am 4. und 5. Mai 1988) wurde die Siedlung selbst in Augenschein genommen und ca. 15 Gebäude besucht. ${ }^{349}$

Am 5. August 1988 wurden die Colonos Hermann Schmidt, Hans-Jürgen Blanck, Ingrid Pöhlchen, Wolfgang Müller Altevogt und Albert Schreiber im Gericht in Parral vernommen. Dabei bestätigte Schreiber, dass sich Juan René Muñoz Alarcón 1973 einige Tage in der CD aufgehalten hatte. ${ }^{350}$ Der ebenfalls vorgeladene Paul Schäfer ließ sich aus gesundheitlichen Gründen entschuldigen und bat um eine Vernehmung im CD-Krankenhaus. Ein Attest von Hartmut Hopp bescheinigte ihm eine Herzkrankheit. Trotz Protesten der AI-Anwälte wurde dem stattgegeben. Die etwa vierstündige Vernehmung Schäfers brachte jedoch keine neuen Erkenntnisse, da Schäfer alles leugnete. Dieter Haller, RK-Referent der Botschaft, schloss seinen Drahtbericht ans AA mit den treffenden Worten: »Die eigentliche Bedeutung dieser neuen Runde in der Auseinandersetzung zwischen CD und AI liegt in der Tatsache, dass Paul Schäfer zum ersten Mal in der 26-jährigen CD-Geschichte in Chile gezwungen wurde, vor einem chilenischen Gericht auszusagen.«351

Die Umsetzung des RHE sollte der letzte Teil der Beweisaufnahme in dem Marathonverfahren bleiben. Die etwa 850 Seiten starken Gerichtsakten des Lokaltermins und der Zeug_innenvernehmungen aus Chile erreichten das LG Bonn im Februar 1989. Im Sommer 1990 gab das Gericht die Übersetzung der Akten in Auftrag. Darauf folgte ein jahrelanger Disput zwischen den Verfahrensbeteiligten um die Übersetzung und Interpretation einzelner Textstellen. Erst im November 1994 gab es einen weiteren Prozesstermin. Dabei beantragte AI, zu prüfen, ob die Klägerin überhaupt noch existiere. Mit seinem Urteil vom 18. November 1997 stellte das LG Bonn fest, dass dem nicht so war

347 Die AG Colonia Dignidad von Al bestand aus einigen Vorstandsmitgliedern, Rechtsanwält_innen und engagierten Basismitgliedern, wie Dieter Maier und Jürgen Karwelat. Die AC traf sich unregelmäßig und tauschte auch brieflich Informationen zum Thema CD aus. Vgl. Archiv Al, Bestand CD. Adressliste der AG Colonia Dignidad vom März 1988. Nach internen Differenzen verlangte der Vorstand von AI Mitte 1989, dass sämtliche nicht hautptamtlichen Mitglieder die AG verlassen. Einige der Geschassten trafen sich daraufhin weiterhin u.a. Maier, Karwelat sowie Werner Stangier. Archiv AI, Bestand CD. Schreiben ]. Karwelat an Helmut Neumann vom 14.01.1990.

348 Archiv Al, Bestand CD. »Akte zum Ortstermin«, o. D.

349 Archiv AI, Bestand CD. Schreiben AA an BM] vom 13.06.1988, CZ 512-521 E-509/1.

Schreiber konnte die Anwesenheit von Muñoz in der CD nicht leugnen, da er 1977 in einem anderen Verfahren bereits vor der Corte Suprema ausgesagt hatte, dass dieser 1973 in der CD gewesen war. PA AA, AV NA 31611. DB 398 von Dieter Haller (Botschaft, RK-Referent) an AA, Referat 330 vom 08.08 .1988 . 
und stellte das Verfahren ein. Damit vermied das Gericht eine inhaltliche Entscheidung in der Sache.

Amnesty International war nach dem Urteilsspruch nicht zum Feiern zumute. Das Verfahren hatte sich über 20 Jahre hingezogen und war ohne eine eindeutige Beurteilung der Sachlage geendet. Dass das Gericht trotz der großen Anzahl der präsentierten Zeug_innen die in der AI-Broschüre vorgebrachten Vorwürfe selbst 1997 als nicht erwiesen ansah, kann als Kapitulation der bundesdeutschen Justiz vor der CD gewertet werden. Die chilenische Wahrheitskommission hatte bereits Jahre zuvor die Beteiligung der CD an Folter- und Mordhandlungen der chilenischen Diktatur beschrieben und sie damit offiziell bestätigt. ${ }^{352}$ Das Verfahren hatte also nicht zur Aufklärung der Taten der CD beigetragen, sondern zu einem zwei Jahrzehnte andauernden Schwebezustand geführt, in dem die CD behaupten konnte, der Vorwurf der Zusammenarbeit mit der chilenischen Diktatur bei Folter und Mord sei nicht bewiesen. Das wiederum ermöglichte es der CD, ihren Unterstützer_innen gegenüber die Legende zu pflegen, sämtliche derartigen Vorwürfe seien lediglich bösartige, politisch bzw. ideologisch motivierte Verleumdungsversuche ihrer Gegner_innen. Aus Sicht der CD war das Verfahren somit ein voller Erfolg.

Der Rechtsstreit zwischen AI und CD hatte für ein Zivilverfahren eine enorme politische Dimension. Letztlich hatte das LG Bonn zu klären, ob deutsche Staatsangehörige in der CD maßgeblich an systematischer Folter und Mord durch Organe der chilenischen Militärdiktatur beteiligt waren. Spätestens seit sich die chilenische Seite einer Beweiserhebung vor Ort durch Vertreter_innen des LG Bonn verweigerte, war das Verfahren zum Scheitern verurteilt. Es war naiv, zu glauben, die chilenischen Justizbehörden, die integraler Bestandteil der Militärdiktatur waren, hätten ein ernsthaftes Interesse daran gehabt, zur Aufklärung der Vorwürfe gegen die CD beizutragen.

Die 20-jährige Hängepartie in Form der juristischen Auseinandersetzung zwischen zwei privaten Parteien ohne gerichtliche Klärung begründete die Leitlinie des AA, Zurückhaltung zu üben, um nicht in ein laufendes Verfahren einzugreifen.

Bereits kurz nach dem Antrag der CD auf Erlass einer einstweiligen Verfügung vom April 1977 schrieb Johannes Marré, Leiter der politischen Abteilung des AA, in einer Vorlage für Außenminister Genscher:

»Bisher liegen eindeutige Beweise weder für noch gegen die behauptete Existenz eines Folterzentrums und Häftlingslagers in der >Colonia Dignidad ‘vor. Die Berichte der ad-hoc Arbeitsgruppe der Menschenrechtskommission [der UN ECOSOC, JS] beziehen sich auf Zeugenaussagen, nennen aber weder die Anzahl noch die Namen der Zeugen, 'Stern < und Amnesty International berufen sich auf die Aussagen von zwei namentlich genannten Exilchilenen und einer ungenannten Exilchilenin. Die Beweise für deren Behauptungen, in der >Colonia Dignidad ‘ gefoltert worden zu sein, wirken nicht sehr überzeugend.

352 Corporación Nacional de Reparación y Reconciliación. Informe de la Comisión Nacional de Verdad y Reconciliación. Bd. 2. Santiago 1996, online unter https://www.memoriachilena.gob.cl/archivos2/pdfs/MCo053680.pdf, hier S. $469 f$. 
Nach dem Motto sin dubio pro reo < dürfte es angebracht sein, äußerste Zurückhaltung zu üben. «353

Staatssekretär Walter Gehlhoff fügte handschriftlich hinzu:

»Wir haben ein objektives Interesse an der Aufklärung der Vorwürfe, können diese Aufklärung aber keinesfalls selber vornehmen. Wir sollten uns auch nicht in die Auseinandersetzung zwischen >Colonia Dignidad einerseits und Amnesty International sowie >Stern andererseits hineinziehen lassen. «354

Bereits zwei Tage zuvor hatte Marré Gehlhoff unterrichtet. Dabei hatte er den direkten Kontakt der Botschaft zu führenden Personen der CD eingeräumt und aus seiner Meinung zu dem Bericht von AI - zu der kein direkter Kontakt bestand - keinen Hehl gemacht:

»Ein Beauftragter der Kolonie hat der Botschaft Santiago eine Anzahl Unterlagen, die für die Erstattung der Strafanzeigen dienten, übergeben. [...] Diese Unterlagen scheinen sorgfältig erarbeitet worden zu sein. [...] Die Verfasser gehen hierbei methodisch, fast wissenschaftlich vor; sie verzichten auf Polemik ebenso wie auf Dialektik; ihre Sprache ist nüchtern, fast spröde und die Argumentation begrifflich klar.

Die Unterlagen können als eine ernstzunehmende Replik mit Beweiswert auf die von Amnesty International eingeleitete Kampagne gegen die deutsche Siedlung in Chile angesehen werden. [...] Die Stellungnahme der »Colonia Dignidad« zum Inhalt der Amnesty International Broschüre [...] analysiert die Al-Methode (Verwendung unbewiesener Behauptungen, Abwertung von Tatsachen, Auslassungen u.a.); [...] sie unterstreicht beeindruckend die Widersprüche der Zeugenaussagen; und sie kann neben Personenbeschreibungen auch Behauptungen geographischer, topographischer und administrativer Art als falsch nachweisen. [...] Eine kritische Durchsicht der von der »Colonia Dignidad« übermittelten Unterlagen führt zu dem Schluß, daß die Existenz eines Folterzentrums im Bereich der Siedlung äußerst zweifelhaft erscheint. « 355

Gesprächsanfragen von AI beantwortete das AA in der Folge mit Verweis auf das schwebende Gerichtsverfahren negativ. Im Oktober 1978 schrieb beispielsweise Staatsminister Klaus von Dohnanyi an AI-Generalsekretär Helmut Frenz:

»Wie sie in ihrem Schreiben erwähnen, ist die Behauptung von Amnesty International, in der COLONIA DIGNIDAD habe sich ein Folterlager des Geheimdienstes DINA befunden, Gegenstand eines Verfahrens vor dem Landgericht Bonn. Angesichts dieser Tatsache ist es erforderlich, alles zu unterlassen, was auch nur den Anschein eines Eingriffs in ein schwebendes Verfahren erwecken könnte. Ich würde es daher vorziehen, wenn wir uns zu einem Cespräch über den Prozessgegenstand nach Abschluß des Verfahrens treffen würden. ${ }^{356}$ 
Mit ähnlicher Begründung lehnte das AA auch Gespräche mit den chilenischen Zeugen ab. ${ }^{357}$ Das zivilrechtliche Verfahren vor dem LG Bonn diente nicht nur dem AA als Legitimation für seine abwartende Haltung, sondern hatte de facto auch eine verzögernde Wirkung auf strafrechtliche Ermittlungen der bundesdeutschen Justiz im Fall CD. Beispielsweise wurde das Ermittlungsverfahren bei der Staatsanwaltschaft Bonn gegen Paul Schäfer ${ }^{358}$ (vgl. Abschnitt 5.3.4) 1987 ausgesetzt »bis das Ergebnis des Ortstermins des Zivilprozesses der CD gegen AI und Gruner und Jahr bekannt ist. «359

Trotz des ernüchternden Ausgangs des 1977 von SBED und PSM eingeleiteten Zivilverfahrens ermöglichte dieses Amnesty International, die in der CD begangenen schweren Menschenrechtsverletzungen an chilenischen Oppositionellen in der bundesdeutschen Öffentlichkeit zu thematisieren. In Chile war die Aufklärung von Menschenrechtsverletzungen durch die chilenische Justiz während der Diktatur nicht möglich. Nach dem Ende der Diktatur wurden jedoch sämtliche Aussagen der von AI im Verfahren präsentierten Zeug_innen bestätigt, entweder von der chilenischen Wahrheitskommission oder durch strafrechtliche Verfahren.

\subsubsection{Zivilverfahren gegen Hugo Baar vor dem LG Köln (1988-1995)}

Am 14. März 1988 reichte Rechtsanwalt Norbert Gatzweiler im Namen der SBED sowie der Colonos Hermann Schmidt und Gisela Seewald beim Landgericht Köln Klage gegen Hugo Baar ein. ${ }^{360}$ Die Klage verlangte vom Gericht, Baar anzuordnen, die nach seiner Flucht aus der CD getätigten Aussagen zu widerrufen, in der CD würden medizinisch nicht gerechtfertigte Behandlungen mit Psychopharmaka und Elektroschocks durchgeführt. Baar hatte in seinem Bericht an die Botschaft vom 2. April $1985^{361}$ unter anderem angegeben, er sei am 10. Januar 1975, unter dem falschen Vorwand eines Besuches der CD durch Pinochet, von Paul Schäfer aus Deutschland nach Chile in die CD gelockt und dort mit Elektroschocks und Psychopharmaka misshandelt worden. Ähnliche Misshandlungen hätten Peter Rahl, Wolfgang Müller [Ahrend] und Sergio Contreras erleiden müssen.

Laut Gatzweiler habe Baar den Bericht nicht nur an das AA, sondern auch an Medien wie Spiegel, Stern und WDR weitergegeben. Die Behauptungen, so Gatzweiler, seien unwahr. Zudem sei Baar alkohol- und drogensüchtig. ${ }^{362}$

\section{Verfahrensgenese}

Die Klage ging beim LG Köln nur wenige Wochen nach einer Anhörung des Unterausschusses für Menschenrechte und humanitäre Hilfe des Deutschen Bundestages am

357 PA AA, ZW 111130. Schreiben von BM Genscher an den Franz Möller, MdB, vom 03.05.1977.

358 StA Bonn, AZ 50 JS 285/85.

359 PA AA, AV NA 31583. StS-Vorlage von Referat 330 vom 10.09.1987. Nach Weisung vom 18.08.1987.

HISArch, Bestand CD. LC Bonn, AZ 28 O 160/88. Klageschrift Rechtsanwalt Gatzweiler vom 13.04.1988. Mir stand nur ein geringer Teil der Verfahrensunterlagen zur Verfügung. Diese stammen größtenteils aus HISArch, Bestand CD. 
22. Februar 1988 ein. Dort hatte auch Hugo Baar ausgesagt und verschiedene seiner bereits 1985 gegenüber der Botschaft geäußerten Vorwürfe gegen die CD-Führung wiederholt. $^{363}$

Am 7. November 1988 vernahm das LG Köln Ursula Kuhn (geb. Klemkow), die geschiedene Ehefrau von Heinz Kuhn. Sie hatte in den 1960er Jahren im Krankenhaus der CD gearbeitet und gemeinsam mit ihrem Mann 1968 die Siedlung verlassen. Ursula Kuhn bestätigte, dass sie zwischen 1963 und 1966 wiederholt an der Vergabe von Elektroschocks an Helmut Schaffrik beteiligt war. Grund für diese Misshandlungen sei gewesen, dass Schaffrik sich "gegen die Anordnung von Herrn Schäfer auflehnte«, so Ursula Kuhn. ${ }^{364}$ Auch ihr Ehemann Heinz Kuhn habe ihr berichtet, dass er Ende der 1960er Jahre Elektroschocks ausgesetzt wurde, nachdem bekannt geworden war, dass er mit ihr zusammen die Siedlung verlassen wolle.

Am 9. Januar 1989 stellte das LG Bonn ein Rechtshilfeersuchen an die kanadische Justiz. ${ }^{365}$ Die kanadische Justiz sollte die 1985 aus der CD geflüchtete und nun in Kanada lebende Lotti Packmor zum Sachverhalt befragen. Dies geschah am 2. Mai 1989 im deutschen Generalkonsulat in Toronto. ${ }^{366}$ Dabei bestätigte Packmor die Darstellungen, die sie nach ihrer Flucht 1985 gegenüber der Botschaft gemacht hatte. ${ }^{367}$ Unmittelbare Belege für Elektroschock- und Medikamentenmisshandlungen in der CD habe sie jedoch nicht. Zwar habe sie 1975 Hugo Baar und Anfang der 1980er Jahre Peter Rahl in einem geistesabwesenden Zustand sowie in beklagenswerter körperlicher Verfassung erlebt, was auf eine derartige Misshandlung schließen lasse. Mit eigenen Augen gesehen habe sie diese Misshandlungen jedoch nicht. ${ }^{368}$

Am 14. Juli 1989 stellte des LG Bonn ein weiteres Rechtshilfeersuchen an die chilenische Justiz. ${ }^{369}$ Diese wurde darin gebeten, neun Zeug_innen in der CD zu vernehmen. ${ }^{370}$ Die in der CD lebenden Zeug_innen bestritten allesamt, dass in der CD Misshandlungen durch Elektroschocks oder Medikamente stattgefunden hätten.

363 PA-DBT 3127, 712 - UA 2 - 2451. Stenographisches Protokoll der 10. Sitzung des Unterausschusses für Menschenrechte und Humanitäre Hilfe vom 22.02.1988. Auch online unter http://coloniadigni dad-prot.blogspot.com/.

364 HISArch, Bestand CD, Ordner 1. LG Köln, AZ 28 O 160/88. Vernehmung von Ursula Kuhn durch das AG Eutin am 07.11.1988.

365 StA Bonn, AZ 50 ]s 285/85, Bd. XI, Bl. 148ff. Protokoll der Vernehmung von Lotti Packmor im Ceneralkonsulat Toronto vom 02.05.1989.

366 Ebd. Bei der Vernehmung waren Generalkonsul Leopold von Hassel sowie CD-Anwalt Norbert Gatzweiler anwesend.

367 Vgl. PA AA, B 83, Bd. 2384. Transkription des Tonbandberichts von Lotti Packmor an die Botschaft vom 17.03.1985.

368 StA Bonn, AZ 50 ]s 285/85, Bd. XI, Bl. 148ff. Protokoll der Vernehmung von Lotti Packmor im Ceneralkonsulat Toronto vom 02.05.1989.

369 PA AA, AV NA 32991. LC Bonn, AZ 28 O 160/88. RHE vom 14.07.1989.

370 Ebd. Die zu vernehmenden Zeug_innen waren ]ürgen Szurgelies, Peter Rahl, Wolfgang Müller Ahrend, Karl van den Berg, Paul Schäfer, Sergio Contreras, Maria Strebe, Ingrid Böckler und Ingrid Klunk. Vgl. El Mercurio vom 25.01.1990, S. C5. »]uez de Parral multó a miembro de Dignidad«. 
Über den weiteren Gang dieses Zivilverfahrens gegen Hugo Baar ist mir nur wenig bekannt. Am 11. Januar 1995 sprach das LG Köln sein Urteil. ${ }^{371}$ Die CD legte dagegen Berufung ein. Gut ein Jahr später verkündete das OLG Köln sein Urteil im Berufungsverfahren. ${ }^{372}$ Bezüglich der SBED wurde die Klage verworfen, da die Existenz des Vereins nach dessen Auflösung durch die chilenische Regierung nicht mehr ausreichend belegt werden konnte. Bezüglich Hermann Schmidts wurde die Berufung zurückgewiesen, da dieser seine Anspruchsberechtigung und seine individuelle Betroffenheit nicht hinreichend hatte darlegen können. Bezüglich Gisela Seewalds verurteilte das Gericht Hugo Baar dazu, es unter Androhung eines Ordnungsgeldes von 200.000 DM oder sechs Monaten Haft zu unterlassen,

»wörtlich oder sinngemäß folgenden Behauptungen aufzustellen und/oder zu verbreiten:

Er sei in einem der Cästezimmer im Waldhaus der Klägerin zu 1) [SBED] von der der Klägerin zu 3) [Gisela Seewald] mit Elektroschocks mißhandelt worden; die Herren Peter Rahl, Wolfgang Müller und Sergio Contreras seien im Krankenhaus der Klägerin zu 3) mit Elektroschocks behandelt worden, obwohl eine medizinische Indikation hierzu nicht bestanden habe. «73 $^{373}$

Baar, so das OLG, habe seinen Bericht an die Botschaft vom April 1985 auch an den Journalisten Gero Gemballa weitergeleitet. Dieser habe 1988 Auszüge daraus in seinem Buch zur Colonia Dignidad veröffentlicht. ${ }^{374}$ Die darin enthaltenen Vorwürfe gegen Gisela Seewald, als Ärztin des CD-Krankenhauses medizinisch nicht indizierte Elektroschockbehandlungen beim Beklagten sowie bei drei weiteren Personen durchgeführt $\mathrm{zu}$ haben, seien geeignet, Seewalds Berufsehre in hohem Maße zu verletzen. Von der Richtigkeit der Aussagen Baars ging das Gericht nicht aus. Im Urteil hieß es: »Der Senat vermochte sich nach der Vernehmung des Beklagten als Partei nicht von der Wahrheit der von ihm aufgestellten Behauptungen zu überzeugen. «75 Baar habe sich bei seiner Vernehmung in einem »angegriffenen geistigen Gesundheitszustand « befunden. Auch sei zu berücksichtigen gewesen, dass Baar sich laut ärztlicher Bescheinigung bei einem Arzt für Neurologie und Psychiatrie in Behandlung befand und nach eigenen Angaben Psychopharmaka einnahm. Zu den Vorwürfen von Ursula Kuhn sagte das OLG, diese bezögen sich auf die 1960er Jahre und seien damit verjährt. Eine Vernehmung von Heinz Kuhn und Wolfgang Kneese sei aus demselben Grund entbehrlich gewesen. Letztlich, so das Gericht, habe die Misshandlung durch Elektroschocks in der CD nicht zweifelsfrei nachgewiesen werden können:

»Die Beschreibung des Cesundheitszustandes der vom Beklagten namentlich benannten Personen während ihrer Krankenhausaufenthalte und danach sowie ihre Isolierung

371 LG Bonn, AZ 28 O 160/88. Urteil vom 11.01.1995. Der Urteilstext liegt mir nicht vor. Das Urteil wird erwähnt im Urteil der nächsten Instanz: Archiv AI, Bestand CD. OLG Köln, AZ 15 U 25/95. Urteil vom 23.01.1996.

Archiv Al, Bestand CD. OLG Köln, AZ 15 U 25/95. Urteil vom 23.01.1996.

373 Ebd.

374 Gemballa, Colonia Dignidad. Ein deutsches Lager in Chile. 
durch das Krankenhauspersonal ebenso wie der - unbestrittene - Umstand, daß die Herren Rahl und Müller auf sog. Herrenversammlungen zusammengeschlagen wurden, begründen zwar ebenfalls den Verdacht auf weitergehende Mißhandlungen der Bewohner der Colonia Dignidad; aber auch sie reichen zum vollen Nachweis von Elektroschockbehandlungen nicht aus. «376

\subsubsection{Ermittlungen der StA Siegen und Bonn (1977)}

Am 17. März 1977 war - etwa zeitgleich mit der Broschüre von Amnesty International ${ }^{377}$ - im Stern ein Artikel zur Rolle der CD als Folterlager der chilenischen Militärdiktatur erschienen (vgl. Abschnitt 5.3.1). ${ }^{378}$ Die beiden Veröffentlichungen sowie die in ihnen erhobenen Vorwürfe gegen die CD lösten ein starkes mediales Interesse aus. In den nachfolgenden Wochen wandten sich u.a. Angehörige von Colonos sowie verschiedene politische und kirchliche Gruppen mit Zuschriften an die Justiz oder das Auswärtige Amt. So warfen beispielsweise die Jungdemokraten, die damalige Jugendorganisation der FDP, der Botschaft sowie dem AA in einer Pressemitteilung Untätigkeit in Sachen CD-Verbrechen vor. Bundesaußenminister Genscher, bis 1985 langjähriger Bundesvorsitzender der FDP, reagierte darauf mit der Weisung ans AA, ihn über dieses Thema zu unterrichten. Die für Lateinamerika zuständige Abteilung 3 des AA berichtete ihm daraufhin:

»Obwohl auch die jüngsten Berichte der Botschaft Santiago weiterhin keinen Hinweis auf die Richtigkeit der Vorwürfe ergaben, prüft Abteilung 5 derzeit in Verbindung mit dem Bundesjustizministerium, ob die zuständige deutsche Strafverfolgungsbehörde ein Ermittlungsverfahren gegen deutsche Staatsangehörige in der Siedlung einleiten kann; 379

Die Ministervorlage der Abteilung 3 schloss mit der Stellungnahme:

»Der auch von den Deutschen Jungdemokraten gegen die >Colonia Dignidad erhobene Vorwurf, sie unterhalte ein Folterzentrum, hat sich bisher nicht beweisen lassen. Das Ergebnis der eingeleiteten Schritte bleibt abzuwarten. Die Kritik der deutschen Jungdemokraten am Auswärtigen Amt und den Botschaftsangehörigen in Santiago ist unbegründet. «80 $^{380}$

Etwa zeitgleich nahm die Staatsanwaltschaft Siegen von Amts wegen Ermittlungen gegen unbekannt wegen des Verdachts der Freiheitsberaubung und Nötigung zum Nachteil von Wolfgang Müller Altevogt auf. ${ }^{381}$ Der Siegener Sozialpädagogikstudent war im Mai 1975 recht überstürzt nach Chile ausgewandert, auch die Lokalzeitung Siegerländer Rundschau hatte darüber berichtet. ${ }^{382}$ Müller Altevogt, dessen Mutter bereits in der CD

382 Vgl. Lateinamerika Nachrichten. Colonia Dignidad-Der doppelte Skandal, S. 9. 
lebte, befand sich zum Zeitpunkt seiner Ausreise kurz vor seinem Studienabschluss. Er hinterließ seiner Wohngemeinschaft einen Abschiedsbrief, in dem es hieß:

»Ich werde eine Reise antreten, d.h. wenn Ihr diese Zeilen lest bin ich schon nicht mehr da. Die Reise wird schließlich, mit Aufenthalten in den USA, evtl. Kanada, Brasilien, in Chile enden. Eine Rückreise ist nicht geplant. Ihr werdet sicherlich an meinem Verstand zweifeln. Ich kann Euch gut verstehen. Steht doch der Studienabschluß vor der Tür; [...]. Glaubt bitte nicht, ich hätte bei meiner Entscheidung unter irgendeinem Zwang gestanden. Ich habe mich ganz bewußt, unter Berücksichtigung aller Konsequenzen für diese Sache entschieden. Welche Gründe mich zu diesem Entschluß geführt haben? Euch würde keiner genügen, deshalb fange ich erst gar nicht an aufzuzählen.« ${ }^{383}$

Besorgte Kommiliton_innen und Dozent_innen vermuteten, Müller Altevogt sei gegen seinen Willen nach Chile gebracht worden. Nach den Presseberichten vom März 1977 über Folterungen an Gefangenen erschien Müller Altevogt am 29. April in Begleitung von seiner Mutter und zwei Geschwistern in der Botschaft in Santiago und ließ sich von einem Konsularmitarbeiter ein Schreiben an die Staatsanwaltschaft Siegen beglaubigen. Darin versicherte er, dass seine Ausreise vollkommen freiwillig zustande gekommen sei:

"Sehr verwundert mich, dass man nach ganzen 2 Jahren aus meiner friedlichen Abreise einen Menschenraub konstruiert. Der Zeitpunkt dieses Antrages bei der Staatsanwaltschaft drängt mir die Vermutung auf, dass man mich zum Spielball politischer Intrigen benutzen will. [...] Ich bin glücklich, zusammen mit meiner Mutter und meinen Geschwistern in der Freiheit, die wir hier geniessen, zu leben. ${ }^{384}$

Nach Erhalt dieses Schreibens stellte die StA Siegen das o.g. Verfahren bezüglich Müller Altevogt ein. ${ }^{385}$ Allerdings hatte sie ihre Ermittlungen in Folge der Berichte von AI und Stern über Folterungen an politischen Gefangenen in der CD zuvor auf eine Reihe weiterer Colonos ausgeweitet. Diese Ermittlungen gab die StA Siegen nun an die StA Bonn $a b{ }^{386}$ Die StA Bonn führte die Ermittlungen noch einige Wochen weiter, stellte sie aber am 22. Juli 1977 ebenfalls ein. ${ }^{387}$ Sie begründete die Einstellung einerseits mit der angeblichen Unglaubwürdikeit der Belastungszeug_innen und andererseits mit Berichten der Botschaft, die die CD entlasteten. Die StA Bonn führte dies in ihrer Einstellungsverfügung aus:

»Es handelt sich um die Ermittlungen gegen Mitglieder der religiösen Sekte >Christlich Soziale Mission in Siegburg wegen Freiheitsberaubung, Körperverletzung pp. [...] die Ermittlungen haben jedoch keinen hinreichenden Tatverdacht hinsichtlich des Vorliegens der behaupteten Straftaten gegeben. - Die einzigen Anhaltspunkte hierfür bieten die Aussagen der Zeugen Müller (Hamburg) und Zott. Die Angaben des Müller

383 PA AA, AV NA 31577. Schreiben Müller Altevogt an seine Wohngemeinschaft vom 20.05.1975.

384 PA AA, ZW 111131. Schreiben von Müller Altevogt an die StA Siegen vom 25.04.1977.

385 PA AA, ZW 111131. StA Bonn, AZ 15 U]s 86/77. Einstellungsverfügung vom 16.5.1977.

386 StA Bonn, AZ U]s 4856/77.

387 PA AA, B 83, Bd. 1177. StA Bonn, AZ 31 U]s 4856/77. Einstellungsverfügung vom 22.07.1977. 
haben sich aber schon im Rahmen der Ermittlungen der StA Siegen wegen Straftaten zum Nachteil des W. Müller (Siegen) als zweifelhaft erwiesen. Denn dort ist ein von der deutschen Botschaft in Santiago de Chile beglaubigtes Schreiben des Müller (Siegen) eingegangen, durch das die insoweit erhobenen Vorwürfe widerlegt wurden.

Aber auch im Übrigen bestehen gegen die Claubwürdigkeit und den Beweiswert der Aussagen von Müller und Zott Bedenken. So hat Müller angegeben, in der Kolonie bestünden unterirdische Anlagen der chilenischen Ceheimpolizei. Demgegenüber hat die deutsche Botschaft in Santiago, die in die Ermittlungen eingeschaltet wurde, mitgeteilt, daß die Kolonie ein lokales medizinisches Zentrum bilde, in dem inzwischen ca. 13.000 Personen behandelt worden seien, ohne daß irgendwann die Existenz geheimer Anlagen aufgefallen sei. Auch seien von Botschaftsangehörigen, die die Kolonie regelmäßig besuchten, solche Einrichtungen niemals entdeckt worden. Schliesslich habe die chilenische Luftwaffe auf Ersuchen der Botschaft Luftbilder des gesamten Koloniegeländes hergestellt, die von Spezialisten der deutschen Luftwaffe ausgewertet worden seien. Auch hierbei seien keinerlei Anhaltspunkte für die Existenz unterirdischer Anlagen festgestellt worden.

Durch diese Angaben wird die Glaubhaftigkeit der Bekundungen über die Existenz geheimer Einrichtungen in der CD erheblich erschüttert. Denn es erscheint äußerst unwahrscheinlich, daß in einem Anwesen mit derart regem Publikumsverkehr geheime Anlagen, die auch bei genauer Untersuchung selbst durch Militärexperten nicht entdeckt werden, unterhalten werden können. [...] Überdies hat die Botschaft berichtet, der auch in Chile vereinzelt geäußerte Verdacht, in der Kolonie würden Bewohner und Regimegegner gewaltsam festgehalten und mißhandelt, beruhe regelmäßig auf $\mathrm{Ce}$ rüchten, die auch gutunterrichtete Informanten nicht bestätigen könnten [...] Schließlich habe sie selbst aufgrund der Gerüchte mehrfach Ermittlungen angestellt. Hierbei habe sie nicht nur die Leitung, sondern auch einfache Bewohner der Kolonie befragt. Personen, bei denen konkrete Verdachtsmomente dafür bestanden, daß sie gegen ihren Willen festgehalten wurden, seien auch in Einzelgesprächen - ohne Zuziehung eines Mitgliedes der Sektenleitung - befragt worden. Hierbei habe sich der Verdacht regelmäßig nicht bestätigt.

Auch diese Feststellungen sprechen dagegen, daß in der >Colonia Dignidad die in den o.a. Berichten behaupteten Straftaten begangen worden sind. Denn es erscheint nicht glaubhaft, daß innerhalb einer so großen Cemeinschaft alle Personen zwangsweise auf dem Gut zusammengehalten werden können, ohne daß dies bei Einzelgesprächen der Botschaft mit den Betroffenen aufgedeckt oder jedenfalls einem parlamentarischen Untersuchungsausschuß mit seinen weitreichenden Kompetenzen aufgefallen wäre. Auch daß, wie in den Presseberichten z.T. behauptet wurde, die Mehrzahl der Ausschußmitglieder bestochen worden sein soll, kann als reine Spekulation ohne sachliche Anhaltspunkte die Bedeutung der Untersuchung des Parlamentarausschusses für die hiesigen Ermittlungen nicht vermindern.

Zusammenfassend läßt sich sagen, daß die Aussagen des Müller (Hamburg) durch den Bericht der Botschaft über die in Chile selbst durchgeführten Ermittlungen widerlegt sind. Die Angaben des Zott sind schon insoweit kaum verwertbar, als dieser nur vermutet, daß sich die behaupteten Mißhandlungen in der >Colonia Dignidad ereignet haben. Im Übrigen können sich Anhaltspunkte für die behaupteten Straf- 
taten lediglich aus einem Bericht der deutschen Sektion von samnesty international ergeben, der von dem Zeugen Karwelat, der im Auftrag der Gruppe die Zustände in der Kolonie verfolgt, im Laufe der Ermittlungen zu den Akten gegeben worden ist. Auch die in diesem Bericht enthaltenen Aussagen beruhen aber im Wesentlichen auf Schlußfolgerungen und Mutmaßungen, die die auf konkreten Beobachtungen beruhenden Ergebnisse der Ermittlungen der Botschaft nicht erschüttern können. Insgesamt haben also die Ermittlungen die Vermutung, in der >Colonia Dignidad würden fortgesetzt Straftaten zum Nachteil unbekannter Personen begangen, nicht bestätigt. Ein hinreichender Tatverdacht läßt sich - insbesondere nach dem o.a. Ergebnis der Ermittlungen der deutschen Botschaft in Santiago nicht begründen.

Damit entfällt auch ein hinreichender Tatverdacht gegen die Mitglieder der Sekte Christlich Soziale Mission in Siegburg. ${ }^{388}$

Welche Unterlagen und Stellungnahmen das AA bzw. die Botschaft der StA Bonn übermittelt hat, ist allerdings nicht bekannt.

\subsubsection{Ermittlungen der StA Bonn (1985-2010)}

Während der im Abschnitt 5.3.1 behandelte Rechtsstreit der CD mit AI eines der längsten Zivilverfahren der bundesdeutschen Rechtsgeschichte war, handelt es sich bei dem im Mai 1985 eingeleiteten Ermittlungsverfahren der Staatsanwaltschaft Bonn ${ }^{389}$ um eines der langwierigsten Strafverfahren in der Geschichte der Bundesrepublik. Wegen des Verdachts auf »Freiheitsberaubung, Körperverletzung usw.« wurde zunächst gegen Paul Schäfer ermittelt. Nach einer Anhörung im Deutschen Bundestag 1988 wurden die Ermittlungen auf Hartmut Hopp, Gisela Seewald und Hugo Baar ausgeweitet. Nach dem Tod von Paul Schäfer wurde das Verfahren im September 2010 nach \$170 Abs. 2 eingestellt.

\section{Verfahrensvorgeschichte - Der Bericht von Lotti und Georg Packmor}

Am 27.02.1985 floh das Ehepaar Lotti und Georg Packmor aus der Colonia Dignidad und versteckte sich bei dem ehemaligen CD-Bewohner Heinz Kuhn und seiner Familie in Los Ángeles (Südchile). Zwei Wochen später suchten sie in der Kanadischen Botschaft in Santiago Zuflucht. Der Deutschen Botschaft misstrauten sie, aus Gründen die Georg Packmor in seinem Bericht vom 15.03.1985 erläuterte:

»Herrn Matthusen fällt die Aufgabe zu, vom Fundo aus die Produkte in Santiago an die Supermärkte oder Privatpersonen abzusetzen. Und da ist es von Anfang an die Deutsche Botschaft gewesen, die seit dem ersten geschäftlichen Kontakt, der nach außen gepflegt wurde, ständiger Kunde geworden ist.

So wurde z.B. die Deutsche Botschaft jeden Montag mit Produkten der Deutschen Kolonie versorgt. Ob oder nicht gegen Bezahlung, entzieht sich meiner Kenntnis. Bezeichnend war es nur wieder einmal vor einigen Monaten, aber das nicht zum ersten

388 PA AA, B 83, Bd. 1177. StA Bonn, AZ 31 U]s 4856-77. Einstellungsverfügung vom 22.07.1977.

389 StA Bonn, AZ 50 JS 285/85. 
Mal, daß Paul Schäfer vor allen Fundobewohnern beim Mittagstisch vorne vor der Bühne aussagte mit anzuhaltender Faust: >Die Botschaft habe ich so in meinen Händen. Damit wollte er ganz bestimmt nur Angst säen, damit in Zukunft niemand versucht, einmal auszubüchsen und dann bei der Botschaft Schutz zu suchen. In Wirklichkeit konnte er Recht haben insofern, daß er in der Botschaft einen sehr guten Kunden- und Freundeskreis hatte. $\ll^{390}$

Nach einem Gespräch von Botschafter Holzheimer mit dem Kanadischen Botschafter übernahm die Bundesdeutsche Botschaft die Betreuung der beiden Flüchtigen am 15.03.1985. Noch am selben Tag, sowie am 17.03.1985, sprachen beide im Deutschen Altersheim von Santiago einen Bericht über ihr Leben in der CD auf Tonband. Darin berichteten sie von den Verhältnissen in der Siedlung und thematisierten Missstände und Verbrechen wie beispielsweise Körperverletzung, Freiheitsberaubung, die Trennung der Familien oder auch die an Colonos begangenen Misshandlungen durch Elektroschocks und Psychopharmaka. Georg Packmor berichtete:

»Die Beziehungen der Bewohner untereinander sind gleich null. Wenn man vergleichen darf, wie ein Paar Ochsen vor einen Karren gespannt [...] und sieht, bald bekommt der eine oder der andere die Peitsche. Und Klagen untereinander gibt es nicht, denn schon vor vielen Jahren ist schon bekannt, einigen und anderen nicht, daß sie abgehört werden.

Aufgrund seiner religiösen Vorträge sektiererischer Weise bearbeitet er [Paul Schäfer, JS] [...] die armen Seelen und treuen Mitarbeiter in der Form, daß sie sich anschließend [...] nach seinen Predigten einer Gehirnwäsche unterziehen, bzw. ihm alles berichten und beichten, was sie in ihrem Leben falsch gemacht haben können oder mit ihrem lieben Nachbarn, sei es die eigene Frau oder Mutter oder ihrem Kinde, gesprochen haben.

Das bringt dann als Folge Auswüchse bis hin zu Folterungsmaßnahmen, oder, wie häufig vorkommt in den letzten Jahren, daß Menschen der Kolonie mit Brechdurchfall ins Krankenhaus eingeliefert werden, um dann in den Schockkammern Zimmer 14 oder 9 Monate lang oder sogar Jahre in einigen Fällen verbringen müssen, weil sie nicht mehr Schäfer hörig waren oder ihm gefährlich werden. Diese Menschen laufen heute herum wie geistige Vollinvaliden und es wäre Sache des Servicio de Salud, diese Fälle eingehend zu untersuchen, die Menschen herauszuholen aus dem Fundo und auf neutralem Boden unter Spezialisten zu untersuchen und die Schäden, die Schäfer an ihnen angerichtet hat mit einer kleinen Gruppe. «391

390 PA AA, B 83, Bd. 2384. Transkription des Tonbandberichts von Georg Packmor an die deutsche Botschaft vom 15.03.1985, S. 4. Botschafter Holzheimer schrieb dazu in seinem Bericht ans AA: »Was die Ausführungen von Herrn Packmor bezüglich der Belieferung der Botschaft mit Produkten aus der Colonia Dignidad anbelangt, so ist festzustellen, daß ohne meine Kenntnis ein inzwischen versetzter Beamter des mittleren Dienstes die Produkte in seinem Privathaus entgegennahm und verteilte. Ich habe, unmittelbar nachdem ich von dieser Praxis erfahren habe, allen Mitarbeitern strikte Weisung erteilt, von jeglicher geschäftlicher Beziehung mit Vertretern der Colonia Dignidad in den Räumlichkeiten der Botschaft Abstand zu nehmen. $P A$ AA, B 83, Bd. 2384. Bericht Botschafter Holzheimer an AA vom 27.03.1985.GZ: Ber. Nr. 352/85 Rk 543.00. 
Georg und Lotti Packmor berichteten über konkrete Fälle von Colonos, die mit Elektroschocks malträtiert wurden. Sie erläuterten auch, wie die für die »Nachbehandlung für die geschockten Patienten oder auch für die Dauerbehandlung« verabreichten Psychopharmaka Luminal und Memprobato betrügerisch von der chilenischen Gesundheitsbehörde bezogen wurden (vgl. Abschnitt 4.1.8). Lotti Packmor berichtete zudem von den Misshandlungen an kleinen Jungen im »Neukra«, von Schlägen, Stromstößen mit Viehtreibern und Spritzen in die Hoden, um die »sexuellen Regungen« der Kinder zu unterdrücken.

Der Bericht thematisierte ebenfalls, ohne viele Details zu nennen, die engen Kontakte der CD-Führung zu DINA und Militärjunta. Hartmut Hopp sei der Kontaktmann »den Obrigkeiten gegenüber, der DINA, Militär, Polizei, Ministro de Justicia, Richter, Universitäten und vielen anderen.« Der DINA-Chef Manuel Contreras sei regelmäßig im Fundo gewesen, Lotti Packmor habe für ihn kochen müssen. Und Junta-Mitglied General Mendoza sei zu einer Grillparty in die CD gekommen.

Botschafter Holzheimer zeigte sich von dem Zeugnis der Packmors bewegt und leitete die 31 Seiten umfassende Transkription des Tonbandberichts mit deutlichen Worten an das Auswärtige Amt weiter. Er vertrat die Auffassung, die chilenische Seite müsse über den Vorfall unterrichtet werden und schlug vor, seinerseits den deutschstämmigen Carabineros-General Rodolfo Stange zu konsultieren.

»Damit könnte h. E. auch der Boden dafür vorbereitet werden, daß das Rechtshilfeersuchen des Landgerichts Bonn eine positivere Aufnahme findet, als dies bislang der Fall zu sein scheint. Wichtiger wäre allerdings, daß die in vielem an ein Konzentrationslager gemahnenden Lebensbedingungen wie die Behandlung mit Psychopharmaka und Elektroschocks geändert werden und Herrn Schäfer nicht weiter Celegenheit gelassen wird, Kinder bei sich schlafen zu lassen (siehe Fahndungsersuchen in der Vergangenheit). $\aleph^{392}$

Lotti Packmor berichtete, ihr Adoptivsohn Matthias Packmor sei einer der Lieblings"Sprinter« von Paul Schäfer und schlafe auch regelmäßig bei ihm. Die Packmors gaben an, Matthias befinde sich gegen ihren Willen in der CD und unterzeichneten eine Ermächtigung in der Botschaft, in der sie darum baten »alle Schritte zu unternehmen, damit unserem Adoptivsohn Matthias Packmor Peters [...] die Ausreise von obengenannten Fundo, auf dem er festgehalten wird, möglich gemacht wird «. ${ }^{393}$ Die Botschaft unternahm jedoch keine konkreten Schritte (vgl. dazu ausführlich Abschnitt 4.2.1) und Georg und Lotti Packmor reisten einige Wochen später ohne ihren Adoptivsohn in die Bundesrepublik aus.

»Ein die Abwicklung der Ausreise aus Chile noch überlagerndes Problem konnte allerdings nicht mehr gelöst werden. Die Eheleute Packmor hinterließen in der Colonia Dignidad ihren 14-jährigen Adoptivsohn Matthias. Wie stark seitens der Eltern der Wunsch ist, ihren Sohn zu sich zu holen, vermochte die Botschaft nicht eindeutig

392 StA Bonn, AZ 50 ]s 285/85, Bd I., Bl. 3ff. Bericht Nr. 352/85 Botschafter Holzheimer an AA vom 27.03.1985, CZ: Rk 543.00. 
festzustellen. Sie hat die Eheleute jedenfalls umfassend über die notwendigen juristischen Schritte unterrichtet, die sie ggf. ergreifen müssen. «394

In ihrem beigefügten Tonbandbericht hatte Lotti Packmor ihren Wunsch hingegen klar benannt: Matthias sei einer der Lieblings-»Sprinter« von Paul Schäfer und schlafe auch regelmäßig bei ihm. »Wir wollen unser Kind aus Schäfers Händen haben. Wir wollen unser Kind unbedingt und unter allen Umständen zu uns nehmen und nicht länger bei diesem Tyrann wissen. ${ }^{395}$ Bei einer Vernehmung bei der Staatsanwaltschaft Gronau am 04.11.1985 äußerte Georg Packmor:

»Wir haben auch bei der Deutschen Botschaft in Chile eine Ermächtigung hinterlassen, die Herausgabe des Matthias zu betreiben. Obwohl wir auch im Besitz der Ceburtsurkunde des Matthias sind usw., hat sich jedoch noch nichts getan. Das heißt also, daß sich der Matthias gegen unseren Willen im Fundo befindet. « 396

Diese Ermächtigung, in der die Eheleute Packmor die Botschaft bitten, »alle Schritte zu unternehmen, damit unserem Adoptivsohn Matthias Packmor Peters [...] die Ausreise von obengenannten Fundo, auf dem er festgehalten wird, möglich gemacht wird«, befindet sich bei den Botschaftsakten ${ }^{397}$.

Konsul Haller sprach daraufhin mit dem Chef von Interpol, der ihm erklärte, die Packmors müssten eine notarielle Erklärung abgeben und darin ihr Einverständnis zur Ausreise unter Angabe des Reiseziels geben. Ferner brauche der Sohn einen chilenischen Reisepass, den er unter Vorlage des Personalausweises und der notariellen Erklärung erhalten könne.

Weitere konkrete Schritte der deutschen Vertretung sind mir nicht bekannt. Matthias wurde einige Monate später von einem weiteren Ehepaar in der CD adoptiert. Als Matthias Gerlach wurde er im März 2005 gemeinsam mit Paul Schäfer in Argentinien entdeckt.

\section{Der Bericht von Hugo Baar}

Nur wenige Tage nachdem er den Bericht von Georg und Lotti Packmor ans AA übermittelt hatte, erreichte Botschafter Holzheimer ein weiterer umfangreicher Bericht über die Situation in der CD: Hugo Baar, vormals enger Vertrauter von Schäfer und Mitbegründer der Gruppierung, war bereits im Dezember 1984 aus der CD geflohen. Ebenso wie die Packmors traute auch Baar der Botschaft nicht und floh mit Unterstützung Heinz Kuhns nach Argentinien. Von dort aus reiste er über Kanada in die Bundesrepublik und schickte der Botschaft einen 33-seitigen Bericht. ${ }^{398}$ Dieser enthält einen

Ebd.

StA Bonn, AZ 50 ]s 285/85, Bd. 1, Bl. 6-35. Transkription des Tonbandberichts von Lotti Packmor in der Deutschen Botschaft vom 17.03.1985, S. 21f.

StA Bonn, AZ 50 ]s 285/85, Bd. 1, Bl. 108. Vernehmung von Georg Packmor im AC Cronau vom 04.11.1985.

PA AA, AV NA 31577. Ermächtigung von Georg und Lotti Packmor vom 22.03.1985.

PA AA, B 83, Bd. 2384. Bericht Hugo Baar an die deutsche Botschaft vom 02.04.1985. 
Anhang über »Mitarbeiter und besondere Vertraute des Herrn Schäfer« und Charakterisierungen von 13 Mitgliedern der CD-Führungsebene. ${ }^{399}$

Hugo Baar schildert in seinem Bericht sein Wirken für die Gruppe, seit seiner ersten Begegnung mit Paul Schäfer im Jahr 1954. Er war als Vorsitzender (1956-1980) des Vereins Private Sociale Mission bis 1975 in der Bundesrepublik geblieben und hatte von Siegburg aus die Interessen der Siedlung vertreten. Im Januar 1975 sei er von Schäfer unter dem falschen Vorwand eines Pinochet-Besuchs in der Siedlung nach Chile gelockt worden, wo er nach eigenen Angaben in der Siedlung eingesperrt und mit Elektroschocks und Medikamenten malträtiert wurde. Danach habe Schäfer ihn »endgültig total ausgeschaltet «, indem er ihm verbot, seelsorgerisch tätig zu sein und ihm befahl, dies in der Herrenrunde zu verkünden und per Brief nach Siegburg zu schreiben.

In dem Bericht begründete Baar seine Flucht aus der CD mit dem »Verschweigen (Verheimlichen), daß es sich bei den Mitgliedern der Sociedad Dignidad und der Privaten Socialen Mission um überzeugte Christen handelt. ${ }^{400}$ Selbst gegenüber Freunden, die aus Deutschland zu Besuch kamen ${ }^{401}$ habe Schäfer auf Fragen nach dem Glauben der Colonos nur ausweichend reagiert.

Baar erläuterte in seinem Bericht, wie Schäfer über die "Seelsorge« die Gruppe vollständig beherrsche: Niemand dürfe mit anderen sprechen, alles dürfe nur Schäfer berichtet werden, der über dieses Informationsmonopol die Gruppe kontrolliere und uneingeschränkt herrsche. Baar berichtete mit detaillierten Beschreibungen und Einzelfallschilderungen über die Unfreiheit in der Siedlung, die Trennung der Familien, die enorme Arbeitsbelastung, von der auch Kinder und Jugendliche betroffen sind und die an einzelnen Colonos begangenen schweren Misshandlungen. ${ }^{402}$ Im Abschnitt "Bemerkungen zur Person Schäfer« beschrieb Baar, jede Nacht müsse ein 10-15-jähriger, als »Sprinter« bezeichneter, Junge bei Schäfer schlafen. »Dies weiss und akzeptiert jedermann im Fundo, denn niemand wagt es von Herrn Schäfer schlecht zu denken. «03

Hugo Baar hatte zum Zeitpunkt des Verfassens des Berichts nicht endgültig mit der CD gebrochen und verteidigte mehrfach die aufrichtigen, von christlichen Motiven geprägten Beweggründe vieler Colonos, nach Chile auszureisen und dort die Gemeinschaft aufzubauen. Er schloss seinen Bericht mit der Feststellung, die CD habe zwei Gesichter:

399 Dies waren im Einzelnen: Kurt Schnellenkamp, Albert Schreiber, Hartmut Hopp, Hans-Jürgen Blanck, Gerd Seewald, Gerhard Mücke, Alfred Matthusen, Rudolf Cöllen, Karl van den Berg, Erika Blank geb. Heimann, Dorothea Hopp geb. Witthahn, Hildegard Möhring, Gisela Seewald geb. Gruhlke.

400 PA AA, B 83, Bd. 2384. Bericht Hugo Baar an die deutsche Botschaft vom 02.04.1985.

401 Baar nennt an dieser Stelle folgende Personen: Reinhard Günther, Kanzler der Universität Würzburg; Prof. Lothar Bossle und Prof. Dieter Blumenwitz (beide Universität Würzburg); Dr. Georg Waltner (persönlicher Referent des Bayrischen Innenministers); Dr. Kothny (Botschafter a. D.) und Wolfgang Vogelsgesang (Münchner Stadtrat, CSU).

402 PA AA, B 83, Bd. 2384. Bericht Hugo Baar an die deutsche Botschaft vom 02.04.1985, Abschnitt »Mißhandlungen«, S. 16-21. Hier berichtet Baar von brutalen Prügelstrafen und »psychatrischen Behandlungen« mit Elektroschocks und Psychopharmaka an seiner Tochter Dorothea Baar sowie an Peter Rahl, Wolfgang Müller Ahrend, Jürgen Szurgelies und Sergio Contreras. 
»Das Verhalten nach außen, den Freunden und Besuchern gegenüber, vor allem aber gegenüber den Behörden, unterscheidet sich wie Tag und Nacht von der Wirklichkeit auf dem Fundo, wenn kein Besuch da ist. [...] Durch Zweierlei hat sich Dignidad abgesichert:

-durch das raffinierte System von Zäunen, Sicherheitsanlagen, Wachhunden etc. -durch ein ebenso geschicktes System von Kontakten zu zuständigen Behörden bis hin zu den obersten Regierungsstellen, sowie auch durch Kontakte zu Persönlichkeiten des öffentlichen Lebens aus der Bundesrepublik.

Ich bin im Dezember 1984 aus dem Fundo weggegangen, nicht, weil ich es verlassen wollte, sondern weil ich keine Möglichkeit mehr sah, von innen her eine Änderung herbeizuführen. Ich bin der Überzeugung, daß Freiheit und Menschenwürde der Bewohner des Fundo >El Lavadero< nur mit Hilfe von außen wiederhergestellt werden können.«404

Botschafter Holzheimer leitete den Bericht Baars am 28. Mai 1985 weiter ans AA. ${ }^{405}$ Baar hatte zuvor sein Einverständnis gegeben, den Bericht »amtlich zu verwerten«. Holzheimer berichtete dem AA dazu:

»Die Aufzeichnung gibt einen guten Einblick in die Zusammenhänge und Entwicklung der Siedlergemeinschaft sowie in deren Innenleben. Die Schilderungen sprechen für sich. Sie erhellen die bereits im Bericht der Eheleute Packmor beschriebene Rolle von Paul Schäfer, der, ohne ein offizielles Amt innerhalb der Cemeinschaft innezuhaben, diese in brutaler und gleichzeitig sublimer Weise führt und ein sinneres` Regime errichtet hat, das in vieler Hinsicht an ein Arbeits-oder Konzentrationslager erinnert. Die Erläuterungen von Herrn Baar machen aber auch deutlich, von welch lauteren Motiven die überwiegende Mehrheit der Colonia Dignidad-Angehörigen bestimmt sind. [...] Die Botschaft vertritt die Auffassung, daß das Verhalten von Paul Schäfer nicht mehr länger untätig hingenommen werden kann. Sie regt an, die Niederschrift von Herrn Baar den deutschen Ermittlungsbehörden zugängig zu machen. Die Botschaft wird sich ihrerseits über General Stange von den Carabineros de Chile bemühen, die chilenischen Behörden in Kenntnis zu setzen. Die bisher vorliegenden Erkenntnisse legen die Vermutung nahe, daß die Probleme in Zusammenhang mit der Colonia Dignidad vor allem ein Problem um die Person von Paul Schäfer ist. « ${ }^{406}$

\section{Der Verlauf des Verfahrens}

Am 15. April 1985 schrieb das Referat 330 des AA an die Botschaft:

»In Abstimmung mit Referat 511 wird die Botschaft ermächtigt, die chilenische Seite in ihr geeignet erscheinender Weise unsere Erkenntnisse über die Lebensbedingungen

404 Ebd., S. 26.

405 StA Bonn, 50 ]s 285/85, Bd. I, Bl. 43f. Bericht Botschafter Holzheimer an AA (Referat 330) vom 28.05.1985. GZ: Bericht 672/85, rk 543.

406 Ebd. 
in der >Colonia Dignidad`mitzuteilen. Das Auswärtige Amt wird seinerseits auch das BKA unterrichten. $\ll^{407}$

Noch im April 1985 leitete das AA die Berichte der Packmors und Baars ans Bundesministerium der Justiz weiter. ${ }^{408}$ Dieses leitete sie wiederum Anfang Mai weiter an das Landesministerium der Justiz in NRW. ${ }^{409}$

Ende Mai 1985 eröffnete die Staatsanwaltschaft Bonn auf Grundlage der PackmorBerichte ein Ermittlungsverfahren gegen Schäfer. ${ }^{410}$ Nach Eingang des Baar-Berichts Anfang Juli 1985 wurde Baar zur Vernehmung vorgeladen. Die dazugehörige Verfügung der Staatsanwaltschaft zeigt die Komplexität des Verfahrens, aber auch den Blick der Ermittler_innen auf den Fall:

»Insbesondere kommt es innerhalb des Ermittlungsverfahrens auf diejenigen Sachverhalte an, die in nicht rechtsverjährter Zeit geschehen sein sollen. Tatbestände, die mehr als fünf Jahre zurückliegen, dürften allenfalls indiziell von Bedeutung sein. Hinsichtlich des Verdachts der fortgesetzten Freiheitsberaubung müßte durch die Befragung des Zeugen Baar intensiver geklärt werden, inwieweit sich die Mitglieder der Sekte überhaupt durch die freiheitsbeschränkenden Maßnahmen eingeengt fühlen. Es hat zumindest den Anschein, daß viele von ihnen aus Überzeugung freiwillig im Lager bleiben.

Angesichts der sehr schwierigen Beweislage, die in diesem Ermittlungsverfahren von Anfang an zu erwarten ist, dürfte es zweckmäßig sein, zur Herbeiführung einer wahrheitsgemäßen Aussage des Zeugen Baar dessen richterliche Vernehmung zu beantragen. ${ }^{411}$

Am 29. August 1985 wurde Hugo Bar vor dem Amtsgericht Biedenkopf (Gladenbach) vernommen. Er wiederholte die Beschreibungen der nach 1980 erfolgten Misshandlungen und Freiheitsberaubungen aus seinem Bericht und fügte einige weitere Fallschilderungen hinzu. ${ }^{412}$ Zur Frage, wie die Colonos die Freiheitsberaubung empfinden, antwortete Baar:

»Die Angehörigen der Gesellschaft bleiben im Fundo aus Angst, Druck und im Clauben, sie würden sich versündigen, wenn sie das Fundo verlassen. Dies wird ihnen von dem Beschuldigten [Paul Schäfer, ]S] eingeimpft. Aus diesen Gründen sind auch meine Kinder dort geblieben und schreiben uns nicht einmal.«

407 PA AA, AV NA 31577. Schreiben AA an Botschaft vom 15.04.1985, GZ: 330-504.00, Betr: CD hier: Fall der Eheleute Packmor.

408 PA AA, AV NA 31577. Bericht Sachstand vom 13.11.1985 von Ref. 511 an Ref. 012 im Vorfeld des Gesprächs von BM Genscher mit Brigitte Erler (Ceneralsekretärin Al) am 28.11.1985.

409 PA AA, B 83, Bd. 2386. StS-Vorlage von Ref. 511 des AA vom 04.12.1987.

410 StA Bonn 50 ]s 285/85.

411 StA Bonn, AZ 50 Js 285/85, Bd. I, Bl. 88. Verfügung vom 22.07.1985.

412 Neben den an Peter Rahl, Wolfgang Müller Ahrend, Dorothea Baar, Jürgen Szurgelies und Sergio Contreras begangenen Misshandlungen erwähnte Baar die Fälle von Franz Baar und Rainer Schmidtke. 
Auf Nachfrage fügte Baar hinzu: »Die Mitglieder der Gesellschaft nehmen im Fundo um ihres Glauben Willens alles hin, sie fühlen sich aber trotzdem in ihrer Freiheit und im Leben beschränkt. « ${ }^{413}$

Baars Ehefrau Waltraud hatte sich in der Zwischenzeit ebenfalls von der CD abgesetzt: Am 10. April 1985 war sie auf Anweisung der CD-Führung zusammen mit Peter Rahl und Hartmut Hopp nach Deutschland gereist, vermutlich, um ihren Mann zur Rückkehr zu bewegen. Für Peter Rahl sollte ein psychiatrisches Gutachten besorgt werden, um die als "psychiatrische Behandlung« getarnten Misshandlungen an ihm zu legitimieren. Hugo Baar, der vorab vertraulich aus Chile von der Ankunft seiner Frau informiert wurde, überraschte jedoch Hopp noch vor der Passkontrolle am Frankfurter Flughafen und überzeugte seine Frau, mit ihm zu kommen. Am 25. Mai schrieb Waltraud Baar Botschafter Holzheimer und setzte ihn von ihrer Flucht in Kenntnis. ${ }^{414}$ Sie teilte Holzheimer auch mit, dass sich Peter Rahl in der Bundesrepublik aufhalte. Bereits einen Monat vorher hatte Georg Packmor die Botschaft über die Einreise von Peter Rahl und Hartmut Hopp in die Bundesrepublik informiert. ${ }^{415}$ Dass Rahl, der laut den Berichten des Ehepaars Packmor und von Hugo Baar in der CD schwer misshandelt worden war, in der Bundesrepublik weilte, nutzten die Strafverfolgungsbehörden nicht für eine Vernehmung. Einige Zeit später kehrten Rahl und Hopp unbehelligt in die CD zurück.

Am 2. Oktober 1985 war der deutschstämmige General Rodolfo Stange zum Chef der Carabineros und damit zum Mitglied der Militärjunta ernannt worden. Am folgenden Tag berichte Botschafter Holzheimer dem AA:

»Bei einem Cespräch am 3. Oktober 1985 hat der Chef der Polizei, Ceneral Stange, mitgeteilt, daß die Bemühungen seiner Organe, Verantwortlichen in der Colonia Dignidad strafbare Handlungen nachzuweisen, völlig vergeblich gewesen seien. Man sei auf eine Mauer des >Nichtwissens $<$ und des Schweigens gestoßen.

General Stange erklärte, daß nunmehr nur eine Anzeige mit entsprechenden Anhaltspunkten zum Erfolg führen könne. Ob die Familie Baar oder Familie Packmor zu Anzeigen bereit sind, müßte von dort aus eruiert werden. Hier sind zur Zeit keine Ansatzpunkte vorhanden. ${ }^{416}$

Nach dieser Aussage von Stange wandte sich das AA an Hugo Baar und bat ihn, seinerseits Kontakt mit Stange aufzunehmen, um mit ihm eine Strafanzeige gegen die CD zu erörtern:

»Die Botschaft Santiago de Chile hat berichtet, daß ein Vertreter der Botschaft mit dem Chef der chilenischen Polizei, Ceneral Stange, über die `Colonia Dignidad` gesprochen

413 StA Bonn, AZ 50 ]s 285/85, Bd. I, BI. 94. Vernehmung von Hugo Baar am AC Biedenkopf, Zweigstelle Gladenbach vom 29.08.1985.

414 StA Bonn, AZ 50 ]s 285/85, Bd. I, Bl. 166ff. Schreiben von Waltraud Baar an Botschafter Holzheimer vom 25.05.1985. Das Schreiben wurde erst nach Waltraud Baars Vernehmung als Zeugin am 27.10.1987 zu den Akten genommen.

415 PA AA, AV NA 31577. Vermerk Dullmeier (Botschaft) vom 25.04.1985, GZ: rk 543.

416 StA Bonn, AZ 50 ]s 285/85, Bd. I, Bl. 109. Bericht Nr. 1095/85 von Botschafter Holzheimer an AA vom 03.10.1985. 
habe. Ceneral Stange habe erklärt, daß eine Anzeige mit entsprechenden konkreten Hinweisen erforderlich sei, damit die chilenischen Behörden tätig werden können. Sie haben mir telefonisch mitgeteilt, daß Sie Herrn General Stange persönliche kennen und grundsätzliche bereit seien, mit ihm in Verbindung zu treten. Ich möchte Sie bitten, in diesem Sinne auch mit der Familie Packmor zu sprechen. « ${ }^{417}$

Weder das Ehepaar Baar noch das Ehepaar Packmor war jedoch bereit, Strafanzeige gegen die CD zu stellen, da sie hierzu wieder nach Chile hätten reisen müssen. Vermutlich wäre für eine Anzeige das Gericht in Parral zuständig gewesen, zu dem die CD in besonders enger Beziehung stand. Neben einer Reise in das Einflussgebiet der CD hätten sich die Anzeigenden auch Gegenanzeigen der CD ausgesetzt - mit unkalkulierbarem Ausgang und hohen Kosten.

Vorgeblich hatte die Botschaft das Ziel, die Vorwürfe gegen die CD, zu denen auch ihre Kooperation mit dem Repressionsapparat der chilenischen Militärdiktatur gehörte, aufzuklären. Dass sie hierzu ausgerechnet einen der höchsten Vertreter jener Militärdiktatur konsultiert, mag verwundern. Im Fall CD in den Jahren der Pinochet-Diktatur war dies jedoch keineswegs unüblich. Vielmehr müssen die Beziehungen der Botschaft gerade zu den deutschstämmigen Generälen Stange und Fernando Matthei als durchaus vertrauensvoll bezeichnet werden (vgl. Abschnitt 6.3.1).

Doch nicht nur die Botschaft, auch die CD-Führung stand mit Stange in Kontakt. Hartmut Hopp berichtete darüber in einer Vernehmung 2007:

»Cuando Baar y Packmor se fueron de la Colonia y debido a los rumores que ellos estaban generando, arribamos a la conclusión que era conveniente que sostuviéramos una reunión con el Ceneral Stange, a fin de entregarle nuestra versión de los hechos. De esta manera se verificó dicha reunión con el Ceneral Stange, a la que concurrí pero no sucedió nada posteriormente. ${ }^{418}$

Am 4. November 1985 wurden Georg und Lotti Packmor am Amtsgericht Gronau richterlich vernommen. Sie wiederholten weitgehend die Schilderungen aus ihrem Bericht. Zumindest den Akten zufolge folgten nach dieser Vernehmung erst mal keine weitere Ermittlungsschritte. Erst nachdem der Fall CD im Herbst 1987 medial wieder größere Beachtung fand, wurden die Ermittlungen fortgeführt. Zwischen Oktober 1987 und Mai 1989 vernahm die Staatsanwaltschaft insgesamt 28 Zeug_innen. Darunter waren Heinz Kuhn, Hugo und Waltraud Baar und Wolfgang Kneese, die detailreich über die Verhältnisse in der CD aussagten und zahlreiche konkrete Beispiele von Freiheitsberaubungen und Körperverletzungen schilderten. Mehrere Angehörige von Colonos schilderten, wie die CD es erreicht hatte, dass Colonos mit der Gruppierung nach Chile ausgewandert waren und den Kontakt zu ihren Familien abgebrochen hatten.

417 PA AA, AV NA 31577. Schreiben Krapp (Referat 511, AA) an Hugo Baar vom 17.10.1985.

418 CA Santiago, AZ 2182-98 (»Asociación Ilícita«), Bd. IV (Ministro), BI. 1858. Vernehmung von Hartmut Hopp vom 23.01.2007. 


\section{Vernehmungen von Diplomaten}

Sechs bundesdeutsche Diplomaten schilderten der Bonner Staatsanwaltschaft ihre Erfahrungen mit der CD-Führungsriege. Besonders ausführlich schilderten Dieter Haller, Hans Filusch sowie Botschafter Horst Kullak-Ublick sowie dessen Frau Ingeborg ihre Eindrücke von einem Konsularsprechtag in der CD am 7. November 1987. Seit der Flucht der Ehepaare Baar und Packmor hatte sich das AA um die Abhaltung eines solchen Konsularsprechtags in der Siedlung bemüht. Es wollte dadurch einen Eindruck von den Verhältnissen in der CD gewinnen. Bis dahin beschränkte sich der Kontakt zu Colonos fast ausschließlich auf die CD-Führungsriege. Beim ersten Versuch am 18. Februar 1987 verweigerte die CD Konsul Haller und zwei weiteren Botschaftsangehörigen den Zutritt. Die Botschaft schlug daraufhin dem AA vor, Amtshandlungen für Colonos nur noch nach deren direkter Vorsprache in der Botschaft vorzunehmen. Haller erklärte hierzu in seiner Vernehmung:

»Bereits im Frühjahr 1985 hat die Botschaft das Prozedere der konsularischen Betreuung der in CD lebenden Deutschen ebenfalls überprüft. Bis zu jenem Zeitpunkt wurden konsularische Angelegenheiten im Wege eines sogenannten Sammelverfahrens erledigt. Dies hieß im konkreten, daß über Vollmachtserteilung die in CD lebenden Deutschen einen Vertreter des CD-Vorstands mit der Erledigung ihrer persönlichen Rechtsangelegenheiten beauftragten. Dieses Verfahren hat die Botschaft abgestellt und eine individualisierte Betreuung eingeführt. Dies bracht u.a. mit sich, daß in einer Reihe von Rentenangelegenheiten in CD lebende Rentenempfänger ihre Lebensbescheinigungen nicht mehr vor einer Amtsperson des Gastlandes erlangen konnten, sondern nur noch durch eine persönliche Vorsprache in den Amtsräumen der Botschaft. In allen die CD-Angehörigen betreffenden Rechtsangelegenheiten hat die Botschaft die entsprechenden Personen jeweils zur persönlichen Vorsprache vorgeladen. Diese Maßnahme sollte den in CD lebenden Deutschen die Möglichkeit der persönlichen Kontaktaufnahme mit Angehörigen der Botschaft ermöglichen. In der Zeit Frühjahr 1985 bis Oktober 1985 [sic! korrekt ist Oktober 1987, JS] hat mit Ausnahme von wenigen Vorstandsmitglieder[n] der CD kein einfaches Mitglied der $C D$ die Botschaft persönlich aufgesucht. Dies hatte zur Folge, daß die überwiegende Mehrheit der Paßdokumente der in CD lebenden Deutschen ungültig waren. Dies hatte ebenfalls die Konsequenz, daß verschiedene deutsche Rentenbehörden wegen der Nichtvorlage von formalisierten Lebensbescheinigungen zahlreiche in CD lebenden Rentenempfänger[n] die Einstellung der Rentenzahlungen drohten. Ich vermute, daß diese Tatsache letztendlich die Leitung der CD bewogen hat, der Botschaft am 7. November 1987 die Türen zu öffnen. « ${ }^{419}$

Am 7. November 1987 wurde die Botschaftsdelegation von Hartmut Hopp, Hermann Schmidt, Albert Schreiber, Hans-Jürgen Blanck und Paul Schäfer empfangen. Später stießen noch Kurt Schnellenkamp und Gerhard Mücke dazu. Haller berichtete vom Ablauf des Besuchs in seiner Vernehmung Folgendes: 
»Die Gesprächsführung lag seitens des CD-Vorstandes eindeutig in den Händen der Herren Hopp und Paul Schäfer [...] Die Herren geleiteten uns durch eine kleine Empfangshalle, in der sie uns stolz auf eine persönliche Widmung mit Bild des Ministerpräsidenten von Bayern Franz Josef Strauß hinwiesen. [...] Auf unserem Rundgang durch das Lager hatten wir Gelegenheit zu mehreren kurzen Gesprächen mit einzelnen Personen an deren jeweiligen Arbeitsplätzen. [...] Auf einer Bühne wartete ein Männerchor. Herr Paul Schäfer bat uns Platz zu nehmen, sowie den Chor, uns etwas zum besten gegeben. Nach dem Chorvortrag stand Herr Botschafter auf und bedankte sich in einer kurzen Stegreifrede. Der Chor löste sich auf und es kam zu einem Zwiegespräch zwischen Botschafter und dem Chor. Eigenartig daran war, daß auf Fragen der >Chor im Chor antwortete. [...] In einer spontanen Antwort auf eine Frage des Botschafters, an die ich mich nicht mehr erinnere, erklärte einer der jungen Männer: ১Wir denken hier nicht.< [...] An der Physionomie der jungen Männer fielen mir zunächst ihre starren und ausdruckslosen Augen auf. Bereits während des Chorvortrags starrten einige junge Männer auf einen imaginären Punkt an der Decke des Saales. [...] Im Anschluß an das Mittagessen gingen Herr Filusch und ich zurück in die Kantine, wo die dort noch Anwesenden noch auf uns warteten. Am Eingang richten wir uns einen Tisch ein. Im wesentlichen stellten wir Lebensbescheinigungen aus und bearbeiteten Rentenanträge. [...] Bei dieser Celegenheit fragten wir stets nach dem persönlichen Befinden. Auch die zum Teil sehr betagten älteren Mitglieder gaben stets stereotype Antwort: Es ginge ihnen gut, sie hätten hier ihre Familie und würden gut versorgt. [...] Mehrere CDMitglieder baten darüberhinaus um die Beglaubigung ihrer Unterschrift auf diversen Schriftstücken. [...] Es handelte sich dabei u .a. um gleichlautende eidesstattliche Erklärungen, in der einzelne CD-Mitglieder die Freiwilligkeit ihres Aufenthalts in der CD versicherten. [...] wir haben die CD-Mitglieder allerdings nicht bezüglich der Autorenschaft dieser Schriftstücke befragt. [...] Ich persönlich vermute, daß diese Erklärungen vorformuliert wurden, da ihre Stereotypität den uns mündlich von den Chormitgliedern gegebenen Aussagen ähnlich waren. Bei der Beurteilung dieser Frage lasse ich mich auch davon leiten, daß die CD-Leitung Herrn Botschafter Kullak-Ublick 1987 eine Erwiderungsschrift auf das Baar-Protokoll überreichte. Darin werden eine Reihe von angeblichen Zeugenaussagen zusammengefasst, die die Person von Herrn Hugo Baar in einem schlechten Licht darstellen und sehr diffamieren. An dieser Schrift fällt allerdings ihr durchgängig gleicher Stil und Diktion auf. Ich hege die Vermutung, daß sie aus einer Feder stammt. Aus meiner allgemeinen Einschätzung der persönlichen Situation der CD-Mitglieder halte ich es für unwahrscheinlich, daß alle Personen, die um die Beglaubigung ihrer Unterschrift baten, intellektuell zur Aufsetzung eines solchen Schriftsatzes fähig waren. Die Verweigerung der Vornahme der Unterschriftsbeglaubigung, die eine mögliche Reaktion am 7. 11. dargestellt hätte, habe ich auch deshalb verworfen, um den mit großer Mühe gespannten Gesprächs- und Kontaktfaden zur CD-Leitung nicht unnötig zu belasten. [...]

Nach der Flucht des Ehepaars Packmor ist mir aufgefallen, daß die Leitung der Kolonie gegen das Ehepaar Packmor schwere Vorwürfe erhoben hat. Diese Vorwürfe umfassen sowohl angebliche strafrechtliche Tatbestände als auch Verfehlungen im persönlichen Bereich. Mir ist ebenfalls aufgefallen, daß auch im Fall von Hugo Baar die Leitung der Kolonie mit schweren Vorwürfen gegen seine Person reagiert hat. Inwieweit diese Vor- 
würfe zutreffen, entzieht sich meiner Kenntnis. Ich habe jedoch den Eindruck, daß die Reaktion der Kolonieleitung gegenüber Dissidenten sich auch bereits in der Vergangenheit wiederholt hat und insofern stereotype Züge trägt. Im April 1986 oder 1987 erinnere ich mich, daß in einem von einem chilenischen Gericht untersuchten Mordfall 21 Mitglieder der CD, die ausweislich des bei den chilenischen Behörden geführten Waffenregisters jeweils eine Pistole Kal. 7,65mm besaßen, zur waffentechnischen Untersuchung gebeten wurden. Dieser Aufforderung des chilenischen Gerichts kamen die CD-Mitglieder nach Presseberichten nicht nach. [...] Ich habe Kenntnis von Dokumenten, die ausweisen, daß Paul Schäfer im Jahre 1975 ein damals 8-jähriges chilenisches Mädchen adoptiert hat. Ich habe mich sehr gewundert, daß Alleinstehende in Chile Kinder adoptieren können. Bei der Durchsicht der Dokumente ist mir auch aufgefallen, daß Herr Paul Schäfer als Berufsbezeichnung entweder den Titel Professor und/oder Dr. angibt. Ich kann der Staatsanwaltschaft die Unterlagen, die sich im Besitz der Botschaft befinden, jederzeit übermitteln. Ich erwähne dies deshalb, weil nach Eigendarstellung der Mitglieder der Kolonieleitung des häufigeren chilenische Kinder adoptiert werden. Dies erscheint mir unverständlich vor dem Hintergrund, daß, nach Erkenntnissen der Botschaft, Ehepaare nicht zusammenleben können. In der chilenischen Presse finden sich sowohl positive sowie auch negative Meinungen über die CD. Positiv wird in der Regel stets die Disziplin und Effizienz gewürdigt. Negativ werden die möglichen Straftatbestände erwähnt, die Gegenstand dieses Ermittlungsverfahrens sind. Immer wieder wird darüberhinaus in der kritischen Berichterstattung über die CD der Vorwurf erhoben, daß im Innern der Kolonie Minderjährige sexuell mißbraucht würden. Die Begründetheit dieser wie auch anderer Vorwürfe könnte meines Erachtens durch medizinische Gutachten überprüft werden. « 420

Zum Abschluss des Konsularsprechtags fand ein Gespräch zwischen Botschafter KullakUblick und Konsul Haller einerseits sowie Paul Schäfer, Hartmut Hopp und Hermann Schmidt andererseits statt. Kullak-Ublick schilderte dies in seiner Vernehmung 1988 folgendermaßen:

»Bei diesem Gespräch stellte Herr Schäfer die menschliche und soziale Bedeutung der $C D$ aus seiner Sicht dar. Die hier versammelten Menschen seien freiwillig hier. Jeder könne tun und lassen, was er wolle. Ich selbst hätte mich überzeugen können, wie man mit jedem in der Kolonie ein persönliches Cespräch führen könne, es gebe keine Einschränkungen oder Begrenzungen.

Auf seine eigene Person zu sprechen kommend äußerte Herr Schäfer, daß über ihn vieles geschrieben worden sei, was böswillig zusammengesetzt und wiedergebeben worden sein. Personen die die Kolonie verlassen hätten, seien Menschen gewesen, die sich nicht in die Gemeinschaft einordnen wollten oder, wie im Falle von Herr Baar, nicht mehr zurechnungsfähig gewesen seien, oder wie im Falle von Herr Packmor, sogar noch Unterschlagungen begangen hätten. Derartige Kronzeugen gegen die Kolonie könnten nicht ernstgenommen werden.

Im weiteren stellte Herr Schäfer dar, daß in dieser Cemeinschaft alles abgestimmt werde, so daßjeder an der Entscheidungsfindung beteiligt sei. Hierüber gebe es Protokol- 
le, die man notfalls auch zur Verfügung stellen könnte.

Bei diesem Gespräch war es offensichtlich, daß Herr Schäfer in Herrn Hopp seinen eigentlichen Vertrauten und Vertreter hat. Der eigentliche Vorstand der Kolonie saß dabei und hat nicht ein einziges Wort gesagt.

Nach diesem Monolog von Herrn Schäfer ergriff ich dann das Wort und antwortete etwas wie folgt: Ein Rundgang durch die Cemeinschaft sei ein eindeutiger Beleg, daß in der CD nur ein Wille herrsche und das sei der von Herrn Schäfer persönlich. Die stereotypen Antworten, die mir zuteil geworden seien, seien für mich ein Beleg dafür, daß alle Menschen unter einem übergeordneten Willen stünden und daß sie nicht einmal die innere Freiheit zu einer eigenen Meinung mehr aufbringen könnten.

Es täte mir leid, in Cegenwart des hier versammelten Vorstandes offen sagen zu müssen, daß der ganze Vorstand nur aus Marionetten bestünde, die Herr Schäfer geschaffen habe, um sie nach außen vorzuzeigen. Keiner dieser Personen habe den ganzen Tag über irgendeine Aussage gemacht, sie alle hätten sich lediglich den Aussagen und dem Willen von Herrn Schäfer angeschlossen. [...] Ich fügte dann hinzu, daß Herr Schäfer in meinen Augen durch die Abgeschiedenheit im Bereich von CD selbst keinen Kontakt mehr zur Außenwelt habe und die Umstände, unter denen wir am Ende dieses Jahrhunderts leben, gar nicht mehr beurteilen könne. Diese Art einer Cemeinschaft sei ein Anachronismus in dieser Zeit. Herr Schäfer spüre gar nicht, daß das Wasser ihm bereits bis zum Hals stünde, denn unsere Zeit könne eine solche Einrichtung, wie sie hier sei, nicht mehr tolerieren. Ich könne meinerseits lediglich an ihn plädieren, das gesamte System von CD zu überdenken, eine Öffnung einzuführen, den jungen Menschen die Möglichkeit zum Kontakt nach außen zu geben und die ganze Cemeinschaft zu öffnen. Auf diese Ausführungen, die Herr Schäfer sichtlich bewegt entgegennahm, reagierte er ziemlich gereizt. Für ihn gehe es um Sieg oder Niederlage. Er setze auf Sieg. « ${ }^{421}$

"Das ist Theresienstadt", soll Konsul Haller als erstes gesagt haben, nachdem die Botschaftsdelegation nach neun Stunden Besuch in der CD am 7. November 1987 wieder im Auto saß. ${ }^{422}$ »Technisch haben wir eine große Aufbauarbeit und Leistung gesehen, menschlich eine Tragödie«, resümierte Ingeborg Kullak-Ublick, die Ehefrau des Botschafters. $^{423}$

In den Vernehmungen und Berichten über den Konsularsprechtag schilderten die Diplomaten der Bonner Staatsanwaltschaft detailgetreu die inneren Verhältnisse und Strukturen der CD und stützten die Aussagen der Baars und Packmors. Konsul Haller

421 StA Bonn, AZ 50 ]s 285/85, Bd. II, Bl. 139ff. Vernehmung Horst Kullak-Ublick vom 01.03.1988.

422 Als Haller in seiner Vernehmung auf diese Äußerung angesprochen wurde, bedauerte er diese, da ein Vergleich mit den einzigartigen Verbrechen des Nationalsozialismus letztere verharmlose. Er habe diese Äußerungen, die er in seinem Bericht ans AA wiederholte, jedoch unter dem noch frischen Eindruck seines Besuchs in der CD getätigt. Insbesondere der Chorvortrag habe ihn an Berichte über einen Besuch des Internationalen Roten Kreuzes in Theresienstadt erinnert. Der SPIEGEL griff die Äußerung Hallers in seinem Bericht über den Konsularsprechtag auf, vgI. SPIEGEL Nr. 49/1987 vom 30.11.1987, S. 32 »Metropolis und Theresienstadt. Bonner Diplomaten besuchten die berüchtigte Colonia Dignidad «.

423 StA Bonn, AZ 50 ]s 285/85, Bd. II, Bl. 183. Bericht Ingeborg Kullak-Ublick »Ein Besuch in der Colonia Dignidad am 07.11.1987«. Anlage zum Vernehmungsprotokoll von Ingeborg Kullak-Ublick vom 04.03.1988. 
bekam jedoch bei seiner Vernehmung den Eindruck, dass die Bonner Staatsanwält_innen die Glaubwürdigkeit der Geflüchteten in Zweifel zogen und somit der Version der CD-Führung Glauben schenkten. In einem Bericht an das AA über seine Vernehmung bei der Staatsanwaltschaft äußerte sich Haller im März 1988 skeptisch über die Bemühungen der Bonner Ermittlungsbehörden:

»Am Rande der Vernehmung erörterte ich mit dem Staatsanwalt Fragen des Fortgangs des Verfahrens. Ich hatte den Eindruck, dass die Staatsanwaltschaft die Baar- und Packmor-Berichte in ihrer strafrechtlichen Bedeutung und in ihrem Cesamtzusammenhang unterschätzt, bzw. die Glaubwürdigkeit darin enthaltener Aussagen in Zweifel zieht. Darauf deutet z.B. eine Bemerkung des Staatsanwalts, dass das Ehepaar Packmor evtl. aus egoistischen Motiven handeln könnte, um frühere geldliche Einlagen in CD wieder zurückerstattet zu bekommen. «24

Er resümierte:

»Ich meine, dass die Staatsanwaltschaft Bonn über weitere Möglichkeiten verfügen müsste, die Ermittlungen dynamischer voranzutreiben. Die Baar-PackmorBerichte geben hierzu vielfältige Ansatzpunkte, ebenso die Anhörung im BTUntersuchungsausschuss, deren Ergebnisse durch die Präsenz des Staatsanwalts am 22.02.1988 in das Verfahren eingeflossen sind. $^{425}$

Auch Kullak-Ublicks Vorgänger, Botschafter Hermann Holzheimer (1983-1986) bezeichnete die CD als »Konzentrationslager«. Bei seiner Vernehmung im Mai 1988 führte er aus:

»Wenn ich von KZ gesprochen habe, so meine ich dies aus der objektiven Betrachtung des Außenstehenden. Auch das äußere Erscheinungsbild, über das mir Besucher, wie Kolonieangehörige berichtet haben, nämlich Stacheldraht, Überwachungskameras, bewaffnete Streifen mit Hunden müssen gerade in uns Deutschen ungute Erinnerungen wecken. Sicher ist es so, daß subjektiv wohl die wenigsten gegen ihren Willen in $\operatorname{der} C D$ wohnen und arbeiten und daß es sich sehr wohl um Menschen handelt, die sich hohen, vielleicht vorwiegend religiösen Zwecken verschrieben haben, aber auch dies ist eine rein subjektive Betrachtungsweise. Die objektive Sicht kann nicht umhin, gravierende Mängel gegenüber dem Normalleben zu entdecken. Die Menschen leben in einer Art Scheinparadies und sehen die wirklichen Realitäten erst, wenn sie vom Baume der Erkenntnis gegessen haben, sprich einen Blick nach außen werfen konnten und Vergleiche möglich werden.

Woran es bis dato immer fehlte, war eine beweiskräftige Aussage und eine Person, die willens war, sich als Zeuge zur Verfügung zu stellen. Die Angst vor der Macht der CD, nicht nur in Chile, sondern auch in der BRD und in dritten Ländern war etwas, was mich außerordentlich in Erstaunen setzte. Mit der für die Botschaft auf Band gesprochenen, dann abgeschriebenen und vom Ehepaar Packmor Seite für Seite gezeichneten umfassenden Aussage, war erstmals ein Instrument vorhanden, mit dem es aussichtsreich

424 PA AA, AV NA 31590. DB 106, Haller an AA, vom 11.03.1988.

425 Ebd. 
war, die Behörden zu befassen. Ich hatte mir dabei größere Hoffnungen auf ein Tätigwerden in Deutschland gemacht, da die Packmors dort auch aussagebereit waren. In Chile konnten und wollten sie vor Cericht nicht zur Verfügung stehen. Sie hatten aber keine Einwendung gegen das Verwenden ihrer schriftlichen Aussage auch in Chile. « ${ }^{426}$

Holzheimer erwähnte in seiner Aussage die Existenz umfangreicher Dokumentenbestände zur CD in der Botschaft. Die StA Bonn bat daraufhin das AA darum, ihr die "die CD betreffenden Akten zur Verfügung zu stellen «. ${ }^{427}$ Das AA übersandte der StA daraufhin 42 Schriftstücke mit 243 Seiten, die in Band 10 der Ermittlungsakten eingingen. ${ }^{428}$

Auch der ehemalige Botschafter Erich Strätling (1976-1979) wurde im Rahmen des Ermittlungsverfahrens vernommen. Er berichtete dabei von seinem Besuch in der CD am 15. November 1976. Dies sei sein einziger Besuch in der Siedlung gewesen. Anlass hierfür sei der ECOSOC-Bericht vom Oktober 1976 gewesen, der die CD als Folterzentrum bezeichnete. Ihm und seiner Ehefrau sei in der CD eine »Art Show mit Lieder- und Musikvorträgen « präsentiert worden, bei der alle Colonos anwesend waren. Danach habe ein Rundgang in Begleitung einer großen Gruppe von Colonos stattgefunden. »Ich habe alle Wohn- und Wirtschaftsbauten angesehen, bin in allen Häusern in den Kellern gewesen, habe die Generatorstation und den Fuhrpark besichtig und habe keine Auffälligkeiten entdeckt. «29 Einige Tage später, so berichtete Strätling, habe er von der $\mathrm{CD}$ ein Fotoalbum geschenkt bekommen und nach seinem Besuch »nicht das Gefühl gehabt, dass dort unter Umständen kriminelle Dinge geschehen könnten. « ${ }^{430}$

Nach seiner Rückkehr, so Strätling, habe er zudem General Leigh, Oberbefehlshaber der Luftwaffe und Mitglied der Militärjunta, gebeten, Luftaufnahmen der CD anzufertigen. Diese seien dann vom Bundesverteidigungsministerium ausgewertet worden. Auf den Aufnahmen wurden keine versteckten Gebäude oder Bewachungsmaßnahmen festgestellt. Am 27. Februar $1977^{431}$ habe er daraufhin - nach Rücksprache mit Johannes Marré, Leiter des Chile-Referats im AA, folgende Presseerklärung veröffentlicht:

»Angesichts der kürzlich in der Presse erschienenen Berichte über die angebliche Unterbringung chilenischer politischer Häftlinge in der von Deutschen bewohnten landwirtschaftlichen Niederlassung Colonia Dignidad bei Parral teilt der Botschafter der Bundesrepublik Deutschland mit: Nach der Veröffentlichung des Allana-Berichts der Ad-hoc-Kommission der Vereinten Nationen Ende vergangenen Jahres habe ich der

426 StA Bonn, AZ 50 ]s 285/85, Bd. VI, Bl. 106ff. Vernehmung von Hermann Holzheimer vom 18.05.1988.

427 StA Bonn, AZ 50 ]s 285/85, Bd. VI, Bl. 125f. Schreiben OStA Holstein (StA Bonn) an AA vom 19.05.1988.

428 Darunter waren Berichte über diverse Fluchtfälle u.a. von Wolfgang Müller (heute Kneese), Peter Packmor, Heinz Schmidt und Horst Münch sowie Hilfsersuchen an die Botschaft von Nathanael Bohnau und Brigitte Baak.

429 StA Bonn, AZ 50 ]s 285/85, Bd. II, Bl. 227ff. Vernehmung von Erich Strätling vom 15.03.1988.

430 StA Bonn, AZ 50 ]s 285/85, Bd. II, Bl. 237ff. Eidesstattliche Erklärung von Erich Strätling vom 26.02.1988.

431 Tatsächlich wurde diese Erklärung am 26.03.1977 abgegeben, wenige Tage nach Erscheinens des Stern-Artikels und der AI-Broschüre. VgI. El Mercurio vom 27.03.1977, S. 33. »Embajador de la RFA: No hay chilenos detenidos en la Colonia >Dignidad « 
Siedlung Colonia Dignidad am 15.11.1976 einen Besuch abgestattet, um die im Bericht erhobenen Behauptungen zu prüfen.

Bei diesem Besuch haben sich keine Anhaltspunkte für die Richtigkeit dieser Behauptungen ergeben. Auch eine Auswertung von Luftaufnahmen des gesamten Cebietes der Colonia Dignidad durch deutsche Stellen hat keine Bestätigung der Behauptung erbracht, daß sich in oder bei der Colonia Dignidad ein Lager mit sbesonders ausgestatteten unterirdischen Anlagen befindet. « ${ }^{432}$

\section{Vernehmungen von Ex-Colonos und Angehörigen}

Auch weitere Ex-Colonos wie Heinz Kuhn oder Wolfgang Kneese bestätigten gegenüber der Staatsanwaltschaft die Vorwürfe der Ehepaare Baar und Packmor. Auch Personen, die seit vielen Jahren versuchten, ihre Angehörigen aus der CD zu holen, wie Reinhold Freitag oder Günter Bohnau, gaben Hinweise auf Freiheitsberaubungen und das Zwangssystem der CD. Dazu gehörte auch Ida Gatz, die in den 1950er Jahren zu Schäfers Gruppierung gehört, sich dann aber gegen eine Ausreise nach Chile entschieden hatte. Sie berichtete bei ihrer Vernehmung, schon damals vom sexuellen Missbrauch durch Schäfer gewusst zu haben. Renate Greissner berichtete von ihren Bemühungen, ihren Sohn Tobias Müller aus der CD herauszuholen. ${ }^{433}$

Einen Kontrapunkt setzten die Aussagen der Brüder Hans-Günther und Alfred Matthusen. Hans-Günther Matthusen gehörte zu den Aufklärer_innen, während Alfred Matthusen dem engeren CD-Führungskreis angehörte. Er hatte jahrelang als Vertreter der CD in Santiago das Stadthaus in der Calle Campo de Deportes 817 geleitet. Nach dem Tod Alfred Schaaks 1985 wurde er als Repräsentant der PSM nach Siegburg abgeordnet. Bei seinen Vernehmungen verteidigte Alfred Matthusen die CD und wies sämtliche Vorwürfe als Verleumdungen zurück. Im April und Mai 1988 hatte die StA Bonn Räumlichkeiten der PSM sowie der Schaak oHG durchsucht und dabei Schriftverkehr beschlagnahmt. So hatte er beispielsweise im März 1988 an Gerd Seewald geschrieben:

»Wir haben im Rahmen der >großen Säuberung`hier bei uns ein Teil Briefe vernichtet, und andere außer Haus geschafft, denn wir wußten ja nicht, und wissen es immer noch nicht, ob irgend jemand der Einfall kommt, hier mal, mit richterlichem Befehl, rumzuschnüffeln.«434

$\mathrm{Zu}$ diesen Schreiben befragt, erklärte Matthusen, er habe aufgrund der Verleumdungen und Kampagnen der Presse sowie der Drohanrufe einen Ordner mit Privatpost seiner Familie vernichtet. ${ }^{435}$

Sein Bruder, Hans-Günther Matthusen, hatte Schäfer bereits Ende der 1940er Jahre kennengelernt, jedoch 1954 eine Ausbildung zum Polizisten begonnen und war nicht mit

432 StA Bonn, AZ 50 ]s 285/85, Bd. II, Bl. 237ff. Eidesstattliche Erklärung von Erich Strätling vom 26.02.1988.

433 Die gemeinsame Flucht von Tobias Müller und Salo Luna aus der CD im Juli 1997 gab Schäfer vermutlich den endgültigen Impuls für seine Flucht nach Argentinien wenige Tage später.

434 StA Bonn, AZ 50 JS 285/85, Bd. VI, Bl. 152. Vernehmung von Alfred Matthusen vom 25.05.1988.

435 Ebd. 
nach Chile ausgewandert. Als seine Mutter ihm 1961 von den Ausreiseplänen berichtete, war er Schäfer gegenüber bereits misstrauisch. Im Fahndungsbuch sah er, dass Schäfer per Haftbefehl gesucht wurde. Als er seine Mutter damit konfrontierte, kam es zum Streit. Die Mutter bezeichnete Hans-Günther als Lügner und Ketzer und reiste mit ihrem Mann Johannes und ihrem anderen Sohn Alfred nach Chile.

1969 schrieb Johannes Matthusen seinem Sohn Hans-Günter einen Brief. Darin berichtete er, er werde in der CD wie ein Gefangener behandelt und bat seinen Sohn, ihn herauszuholen. Daraufhin wandte Hans-Günter Matthusen sich an die Botschaft. Er schrieb:

»Mit einem Brief [...] teilte mir mein Vater mit, daß er schon jahrelang dort - er meint in der Siedlung der Sekte - gegen seinen Willen festgehalten wird. Man läßt ihn weder nach Deutschland zurück noch zu einer dortigen Behörde, bzw. zu der Deutschen Botschaft, damit er seine Rückführung beantragen kann. Seiner Frau oder seinem Sohn Alfred kann sich mein Vater nicht anvertrauen, da diese fanatischen Mitglieder der Sekte sind und darum mit noch mehr Schwierigkeiten rechnen muß. [...] Im Auftrage meines Vaters bitte ich Sie um folgendes: Bestellen Sie meinen Vater unter irgendeinem Vorwand - Verlängerung des Passes oder der Aufenthaltsgenehmigung - in die Botschaft. Geben Sie ihm bitte die Gelegenheit, sich mit einem Ihrer Herren allein zu unterhalten. Die Anwesenheit eines Sektenmitgliedes einschließlich seiner Frau oder seines Sohnes müßte dabei verhindert werden. [...] Ceben Sie bitte meinem Vater Celegenheit, daß er in freier Willensentscheidung seinen Aufenthaltsort selbst bestimmen kann. ${ }^{436}$

Bereits im April 1968 hatte die chilenische Kriminalpolizei die Botschaft darüber unterrichtet, dass einzelne Colonos die CD verlassen wollten und dabei u.a. den Namen Johannes Matthusen genannt. ${ }^{437}$ Dennoch antwortete die Botschaft Hans-Günter Matthusen nicht. Erst nachdem dieser im September 1969 das AA angeschrieben hatte, erhielt er einige Wochen später folgende Antwort:

»Wie die Deutsche Botschaft in Santiago mitteilt, hat Herr Johannes Matthusen am 1.10.1969 in der Rechts- und Konsularabteilung der Botschaft vorgesprochen. Er war in Begleitung eines jungen Mannes, bei dem es sich um einen seiner Söhne gehandelt haben soll.

Aus der Tatsache, daß Herr Matthusen anläßlich seiner Vorsprache nicht um Heimführung oder um eine vertrauliche Rücksprache mit einem Beamten sprach, kann geschlossen werden, daß er - zumindest im Augenblick nicht rückkehrwillig ist. « 438

Enttäuscht von der bundesdeutschen Diplomatie reiste Hans-Günther Matthusen im Februar 1971 auf eigene Faust nach Chile und in die CD. Der Reise ging eine vorsichtige, vertrauensbildende Annäherung an die PSM voraus. Nach mehreren Besuchen in

436 PA AA, ZW 111131. Schreiben Hans-Cünther Matthusen an Botschaft vom 29.05.1969.

437 StA Bonn, AZ 50 ]s 285/85, Bd. VIII, O. BI.Nr. Schreiben Botschaft an AA vom 03.04.1968, GZ: V 5-85$657 / 68$.

438 PA AA, ZW 111131. Schreiben AA an Hans-Günther Matthusen vom 27.10.1969, GZ: V 6-88/7451. 
Siegburg gaben ihm Hugo Baar und Alfred Schaak grünes Licht für einen Besuch seiner Angehörigen. In der CD nutzte er eine Gelegenheit, um unbeaufsichtigt mit seinem Vater zu sprechen. Dieser bekräftigte seinen Wunsch, zusammen mit seinem Sohn in die Bundesrepublik zurückzukehren. Als er seinem Bruder, Alfred Matthusen, erklärte, seinen Vater mitnehmen zu wollen, reagierte dieser ablehnend. In seiner Vernehmung erklärte Hans-Günther Matthusen dazu, dass er seinem Bruder gegenüber gesagt habe

»daß ich mich unbedingt morgen mit meinem Kontaktmann von Interpol in Santiago in Verbindung setzen würde, weil anderenfalls spätestens übermorgen mindestens eine Kompanie Carabinieros im Fundo sein und mich suchen würde. Daraufhin wurde mein Bruder sichtlich blasser und lief davon. Nach ca. 1/2 Stunde kam er zurück und erklärte, daß die gewünschte Fahrt nach Santiago morgen stattfinden könne.«439

Johannes Matthusen war einer der wenigen Colonos, die die CD verlassen konnten, ohne fliehen zu müssen. Vor ihm war dies Vera Müller (Mutter von Wolfgang Müller, 1966), Wilhelmine Lindemann (1966) und Theresia Wagner (geb. Woehri) sowie deren Kindern (1968) gelungen. In jedem dieser Fälle hatte es des Drucks durch Behörden bedurft. Die beiden letztgenannten Frauen mussten sogar als Faustpfand Kinder in der CD zurücklassen. Dies sollte der CD garantieren, dass sie sich nicht öffentlich negativ über die Verhältnisse in der CD äußerten. All diese Fälle ereigneten sich in den 1960er Jahren, als sich die Freundeskreise und Schutznetzwerke der CD bei Behörden noch im Aufbau befanden.

\section{Vernehmungen von CD-Unterstützern}

Die CD bat diverse Unterstützer und aktive Gruppenmitglieder als Entlastungszeugen auf. Die einzigen externen Unterstützer, die als Zeugen die CD vollständig in Schutz nahmen, waren der Münchner CSU-Stadtrat Wolfgang Vogelsgesang und der Waffenhändler Gerhard Mertins. Vogelsgesang berichtete der Staatsanwaltschaft von vier mehrtägigen Besuchen in der CD zwischen 1978 und 1982. ${ }^{440}$ Er überreichte den Ermittler_innen entsprechende Zeitungsartikel. ${ }^{441}$ Seine Argumentation glich der Verteidigungsstrategie der CD: Er habe in der CD glückliche Menschen erlebt, die zum großen Teil regelmäßig die CD verlassen würden. Bei der Umzäunung handle es sich um Viehgitter. Der Lebensstil in der CD sei zwar nicht wie der seiner Familie, jedoch habe er die Siedlung mit dem Gefühl verlassen, »daß hier nichts Rechtswidriges geschehe ${ }^{442}$ Zudem habe er die CD-Führung immer wieder auf die in der Öffentlichkeit erhobenen Vorwürfe angesprochen. SBED-Präsident Hermann Schmidt und andere CD-Führungsmitglieder konnten ihm jedoch »eindrucksvoll nachweisen, daß an den

439 StA Bonn, AZ 50 ]s 285/85, Bd. VIII, BI. 68. Vernehmung von Hans-Günther Matthusen vom 12.08.1988.

440 StA Bonn, AZ 50 ]s 285/85, Bd. IV, BI. 43ff. Vernehmung von Wolfgang Vogelsgesang vom 24.03.1988.

441 Bayernkurier vom 05.01.1980, »Eine deutsche Siedlung am Fuße der Anden - Zu Besuch in der sozialen >Colonia Dignidad«; Deutschland-Magazin Nr. 3/1980, S. 32f. »Anatomie einer Hetzkampagne«

442 StA Bonn, AZ 50 ]s 285/85, Bd. IV, BI. 43ff. Vernehmung von Wolfgang Vogelsgesang vom 24.03.1988. 
Vorwürfen nichts Wahres sein könne«. ${ }^{443}$ Auf die Frage der Staatsanwaltschaft, ob er selbst beobachtet habe, wie Kinder "gezüchtigt « ${ }^{444}$ wurden, antwortete Vogelsgesang:

»Ich gehe davon aus, daß bekannt ist, daßich vier Kinder habe und die im Laufe der Jahre auch gelegentlich Ohrfeigen von mir bekamen. Deshalb kann ich noch lange nicht davon sprechen, daß in meiner Familie eine autoritäre Erziehung stattgefunden hatte. Meine Kinder haben einen ordentlichen Beruf eingeschlagen. Als mehr sehe ich die ein oder zwei Ohrfeigen, die Herr Schäfer in meiner Anwesenheit Jugendlichen verabreichte, nicht an. $\ll^{445}$

Der Waffenhändler Gerhard Mertins meldete sich am 27. Februar 1989 von sich aus bei der Bonner Staatsanwaltschaft. Er sei unlängst in der CD gewesen und könne darüber berichten. Nur wenige Tage später wurde Mertins vernommen. Er gab an, die CD bereits fünf oder sechs Mal besucht zu haben. Anfang der 1970er Jahre sei er gebeten worden, Informationen über die CD einzuholen. Daraufhin hatte er 1972 den Polizeichef in Parral aufgesucht. Später, vermutlich nach dem Militärputsch, habe er mit DINA-Chef Contreras gesprochen und ihn »um Aufklärung « ${ }^{446}$ gebeten. Dabei sagte Contreras,

»daß man schon in der Oppositionszeit unter Allende den Eindruck gehabt hätte, daß die Deutschen in der CD als konservativ zu bezeichnen waren. Es gab aber zu keinem Zeitpunkt eine Notwendigkeit in direkter form sich dieser Institution zu bedienen. Nur Dr. Hopp war ihm seinerzeit bekannt, der mal bei ihm war, um irgendwelche Einzelheiten bei der Errichtung eines Hospitalgebäudes zu besprechen (Hilfsersuchen wahrscheinlich finanziell). «47

Bei einem späteren Besuch, so Mertins, habe er mit Botschafter Strätling über die CD gesprochen. Als er diese dann besuchte, habe er einen sehr positiven Eindruck gewonnen und nichts gesehen, was die im Raum stehenden Vorwürfe bestätigt hätte. Auch andere Quellen belegen, dass Mertins und die CD-Führung mindestens seit Mitte der 1970er Jahre in Verbindung standen. So berichtete Hugo Baar 1990 gegenüber Mitarbeitern der chilenischen Wahrheitskommission, dass Paul Schäfer anlässlich einer Reise nach Deutschland 1975 gemeinsam mit Kurt Schnellenkamp und Albert Schreiber mit Gerhard Mertins Kontakt aufnahmen. ${ }^{448}$

Auf die Frage des Staatsanwalts, wer ihn um die Einholung von Informationen über die CD gebeten habe, erklärte Mertins:

»Ich habe eine Reihe von Jahren die Interessen des Deutschen Verteidigungsministeriums bezugnehmend auf Überschußmaterial im Export vertreten und habe viele Jahre jeweils zweimal jährlich eine Rundreise zu allen Agenturen, die aufgebaut wurden,

443 StA Bonn, AZ 50 ]s 285/85, Bd. IV, BI. 43ff. Vernehmung von Wolfgang Vogelsgesang vom 24.03.1988.

444 Ebd.

445 Ebd.

446 StA Bonn, AZ 50 ]s 285/50, Bd. XI, BI. 69ff. Vernehmung von Gerhard Mertins vom 01.03.1989.

447 Ebd.

448 PJS, Sammlung CD. Protokoll der Anhörung von Waltraud und Hugo Baar am 02/03.11.1990 durch Vertreter_innen der Comisión Nacional de Verdad y Reconciliación. 
unternommen. Informationen die politisch wertvoll waren, habe ich zur Auswertung den entsprechenden deutschen Dienststellen übermittelt. Und hierbei wurde der $\mathrm{Na}$ me CD erwähnt. Ich meine sogar, daß eine Institution der Bundesregierung dahinter stand, die um nähere Aufklärung über behauptete Vorgänge in der CD nachsuchte. «49

In seiner Vernehmung bei der StA Bonn gab Mertins auch an, Botschafter Kullak-Ublick gut zu kennen. Er habe ihn bereits vor seinem Amtsantritt in Chile im AA besucht, und zwar gemeinsam mit Kurt Schnellenkamp, und ihn »in die Problematik der CD von meiner Warte eingeführt «. ${ }^{450}$ Ein weiteres Mal habe er Kullak-Ublick zufällig getroffen, als dieser nach der gescheiterten sogenannten »Hubschrauber-Delegation« im Dezember $1987 \mathrm{zu}$ Außenminister Genscher zitiert worden war. Damals, so Mertins, habe KullakUblick bezüglich der CD den Standpunkt vertreten, »Änderungen sind nötig aber die positiven Eindrücke sind überwiegend «. 451

Folgende tabellarische Übersicht führt die relevantesten der von der Staatsanwaltschaft Bonn in den Bänden I-XII durchgeführten Zeug_innenvernehmungen auf:

449 StA Bonn, AZ 50 ]s 285/50, Bd. XI, BI. 74. Vernehmung von Gerhard Mertins vom 01.03.1989.

450 StA Bonn, AZ 50 ]s 285/50, Bd. XI, Bl. 69ff. Vernehmung von Gerhard Mertins vom 01.03.1989

451 Ebd. 
Tabelle 14: Auflistung der Zeug_innenaussagen im Verfahren StA Bonn, AZ 50 Js 285/85

\begin{tabular}{|c|c|c|}
\hline $\begin{array}{l}\text { Datum der } \\
\text { Vernehmung }\end{array}$ & Name & Eigenschaft \\
\hline 29.08 .1985 & Hugo Baar & Ehem. Colono, geflüchtet 1984 \\
\hline 04.11 .1985 & $\begin{array}{l}\text { Ceorg und Lotti } \\
\text { Packmor }\end{array}$ & Ehem. Colonos, geflüchtet 1985 \\
\hline 19.10 .1987 & Heinz Kuhn & Ehem. Colono, geflüchtet 1968 \\
\hline 27.10.1987 & Hugo Baar & s.o. \\
\hline 26.02 .1988 & Dieter Haller & $\begin{array}{l}\text { BRD-Diplomat (Konsul Botschaft Santiago 1984-1988, } \\
\text { Ständiger Vertreter Santiago 2000-2003) }\end{array}$ \\
\hline 29.02 .1988 & Hans Filusch & $\begin{array}{l}\text { BRD-Diplomat (Sachbearbeiter Rechts- und Konsular- } \\
\text { wesen Botschaft Santiago ab September 1987) }\end{array}$ \\
\hline 01.03 .1988 & Horst Kullak-Ublick & BRD-Diplomat (Botschafter Santiago 1986-1988) \\
\hline 04.03 .1988 & Ingeborg Kullak-Ublick & Ehefrau des Botschafters \\
\hline 23.03 .1988 & Lothar Bossle & Professor Universität Würzburg \\
\hline 24.03 .1988 & Wolfgang Vogelsgesang & Münchner Stadtrat (CSU) \\
\hline 08.04.1988 & Gero Gemballa & Journalist \\
\hline 18.04 .1988 & Wolfgang Kneese & Ehem. Colono, geflüchtet 1966 \\
\hline 03.05 .1988 & Waltraud Tymm & Colona \\
\hline 10.05 .1988 & Esther Laube & Colona \\
\hline 18.05.1988 & Hermann Holzheimer & BRD-Diplomat (Botschafter Santiago 1983-1986) \\
\hline $\begin{array}{l}25.05 .1988 \& \\
21.06 .1988\end{array}$ & Alfred Matthusen & Colono \\
\hline 16.06 .1988 & Ernst Waltemathe & $\operatorname{MdB}(S P D)$ \\
\hline 16.06 .1988 & Freimut Duve & $\mathrm{MdB}(\mathrm{SPD})$ \\
\hline 27.06 .1988 & Günther Bohnau & Angehöriger \\
\hline 06.07.1988 & Ida Gatz & Ehem. Mitglied der CD (vor Ausreise in D) \\
\hline 06.07.1988 & Reinhold Freitag & Angehöriger \\
\hline 12.08 .1988 & $\begin{array}{l}\text { Hans-Günter } \\
\text { Matthusen }\end{array}$ & Angehöriger \\
\hline 06.09.1988 & Rita Seelbach & Colona \\
\hline 27.09.1988 & Hugo Baar & s.o. \\
\hline 04.11 .1988 & Renate Greissner & Angehörige \\
\hline 01.02 .1989 & Hans-Ulrich Spohn & Dt. Diplomat (Botschaftsrat 1987-1990) \\
\hline 09.02 .1988 & Walter Rövekamp & Generalsekretär Amnesty International \\
\hline 01.03 .1989 & Gerhard Mertins & Waffenhändler \\
\hline 19.04.1989 & Waltraud Baar & Ehem. Colona (geflüchtet 1985) \\
\hline 02.05 .1989 & Lotti Packmor & Ehem. Colona (geflüchtet 1985) \\
\hline
\end{tabular}




\section{Rechtshilfeersuchen}

Zwischen März 1988 und Januar 1991 richtete die StA Bonn insgesamt fünf Rechtshilfeersuchen an die chilenische Justiz, sowie ein weiteres 1990 an die belgische Justiz. Ziel war die Vernehmung von Zeug_innen sowie die Überlassung von Dokumenten.

1988 beantragte der chilenische Außenminister Hernán García mehrfach die Eröffnung eines Ermittlungsverfahrens gegen die CD (vgl. Abschnitt 5.1.3). Nach Garcías erstem Antrag stellte die StA Bonn am 30. März 1988 erstmals ein Rechtshilfeersuchen (RHE) an die chilenische Justiz. ${ }^{452}$ Darin bat sie um Übermittlung von Erkenntnissen aus chilenischen Verfahren bezüglich der CD. Die chilenische Justiz beantwortete es gut ein Jahr später per Verbalnote mit dem Hinweis, dass in Chile kein straf- oder zivilrechtliches Verfahren gegen die Beschuldigten anhängig sei. ${ }^{453}$ Unterdessen hatte die StA Bonn am 15. Juli 1988 ein weiteres, diesmal sehr detailliertes RHE nach Chile gesandt. ${ }^{454}$ Darin wurde beantragt, 35 Zeug_innen sowie die Beschuldigten Paul Schäfer und Gisela Seewald zu den Vorwürfen der Freiheitsberaubung und der Körperverletzung in den Baar- und Packmor-Berichten zu befragen. Die StA Bonn beauftragte für das RHE zudem Botschaftsanwalt Máximo Pacheco Gómez, sowie seine Kollegen Sergio Corvalán und Guillermo Ceroni. Der Christdemokrat Pacheco, der zuvor u.a. Bildungsminister (1968-1970) gewesen war und seine Kollegen vertraten bereits Amnesty International im Rahmen eines Rechtshilfeersuchens des Bonner Landgerichts im dortigen Zivilverfahren der CD gegen AI.

Die Vernehmungen führte die mit der CD verbundene ${ }^{455}$ Richterin Lydia Villagrán am Gericht in Parral durch. Sie vernahm im November und Dezember 1988 insgesamt 32 Colonos. Pacheco schrieb in seinem Abschlussbericht an die StA Bonn, die Befragungen seien oberflächlich und fehlerhaft durchgeführt worden. Teilweise habe die Richterin an einem Tag bis zu sieben Zeug_innen vernommen und dabei keinerlei Rückfragen gestellt. Die Colonos hätten allesamt gleichlautende eidesstattliche Versicherungen eingereicht, nach denen sie sich freiwillig in der CD befänden und es ihnen dort gut gehe. Am 11. Dezember 1988 vernahm Villagrán auch Paul Schäfer, laut Protokoll »verheiratet, Lehrer, noch nie strafrechtlich verfolgt « ${ }^{456}$ Auf die Frage, ob Menschen gegen ihren Willen in der CD festgehalten würden, antwortete Schäfer:

452 StA Bonn, AZ 62 AR 515/88 Ausl.R.

453 StA Bonn, AZ 50 ]s 285/85, Bd. 11, Bl. 133f. Bericht Botschaft an AA vom 11.04.1989, GZ: Nr. 403/89, pol-rk 543.

454 StA Bonn, AZ 62 AR 974/88 Ausl.R.

455 Vgl. PJS, Sammlung CD. Hayes Frabasile, Barbara. Colonia Dignidad: Una historia de horror, sexo y poder. [unveröffentlichtes Manuskript], Santiago 2005, S. 275. In einem Interview mit der Journalistin Barbara Hayes berichtete der sozialistische Abgeordnete Jaime Naranjo, Richterin Villagrán habe sogar ein Haus der CD in Parral gemietet: »Incluso están las pruebas de que la ex Colonia le arrendaba una casa a la jueza de Parral de aquel entonces. Una jueza que le arriende una casa a Colonia Dignidad es absurdo y sólo pudo ocurrir aquí.«Andere Colonos berichteten zudem, dass die Mutter von Richterin Villagrán 1988 im Neukra behandelt wurde, zum gleichen Zeitpunkt, als die Richterin im Rahmen des RHE des LG Bonn einen Ortstermin in der CD durchführte, vgl. PJS, E-Mail von Bernd und Waltraud Schaffrik an Dieter Maier vom 19.02.2012.

456 StA Bonn, AZ 50 ]s 285/85, Bd. XII, O. BI.Nr. (Übersetzung von BI. 307-309). Vernehmung von Paul Schäfer durch Richterin Villagrán vom 11.12.1988. 
»Das ist zum Lachen. [...] Ich bin seit sechsundzwanzig Jahren hier in Chile, etwas Derartiges hat es während meines Zugegenseins und während der Zeit meines Hierseins nicht gegeben. Das ist eine krankhafte Beleidigung. ${ }^{457}$

Fragen von RA Pacheco an Schäfer ließ die Richterin nicht zu. Nach Ende der Vernehmungen empfing sie Pacheco und seinen Kollegen Guillermo Ceroni zu einem Gespräch. Hierüber berichtete Pacheco der Botschaft:

»Con respecto al interrogatorio de Paul Schäfer me manifestó que le había parecido un hombre muy inteligente, astuto y que había dado respuestas generales y no compromitentes. [...] Con respecto a Jürgen Szurgelies me manifestó la Juez que a ella le había parecido un joven extraño, que le había dicho que jamás había pretendido huir de CD, sino que a él le agradaba salir a caminar y que ese día se había perdido. [...] En relación con el interrogatorio de los demás inculpados y testigos le había parecido que no estaban bajo la influencia de sedantes o fármacos, que daban razón de sus dichos y que con sus declaraciones no daban mayores antecedentes que, en su concepto, pudieran servir en el proceso criminal que se sigue en la Fiscalía de Bonn. [...] Me manifestó que ella se había formado la impresión que en >CD< se desarrolla una forma de vida muy particular y extraña a los hábitos y costumbres chilenas, pero que las personas que viven allí aceptan voluntariamente esta modalidad de existencia y viven como en sun mundo de fantasía « « 458

Da mir nur die Bände I bis XII der Verfahrensakten vorlagen, ist der Umgang mit den weiteren Rechtshilfeersuchen mir leider nicht bekannt. Vermutlich handelte es sich dabei jedoch um punktuelle Nachfragen und Präzisierungen sowie Bitten um Vernehmung weiterer Zeug_innen oder um Überlassung von Akten aus chilenischen Justizverfahren. Auch der weitere Gang des Verfahrens zwischen 1989 und 1994 ist mir aufgrund der Aktenlage leider nicht bekannt. Ich gehe jedoch davon aus, dass ein Großteil der Ermittlungen und Vernehmungen von Zeug_innen 1987 und 1988 stattfand. ${ }^{459}$

\section{Die Verfahrenseinstellung}

Am 26. Januar 1994 bat die Staatsanwaltschaft Bonn das AA um Zustimmung zur Einstellung des Ermittlungsverfahrens. ${ }^{460}$ Grundlage hierfür ist Absatz 90 I der Richtlinien für das Strafverfahren und das Bußgeldverfahren (RiStBV). Darin heißt es:

»Hat eine Behörde oder eine Körperschaft des öffentlichen Rechts die Strafanzeige erstattet oder ist sie sonst am Ausgang des Verfahrens interessiert, soll ihr der Staatsanwalt, bevor er das Verfahren einstellt oder die Zustimmung des Cerichts zu einer Einstellung einholt, die Gründe mitteilen, die für die Einstellung sprechen, und ihr Celegenheit zur Äußerung geben.«

458 PA AA, AV NA 31596. Schreiben RA Pacheco an Botschafter Knackstedt vom 26.12.1988.

459 Die Einstellungsverfügung von 1994 erwähnt zumindest nur wenige Ermittlungsschritte, die später als 1988 stattfanden. PA AA, AV NA 31606. StA Bonn, AZ 50 ]s 285/85. Einstellungsverfügung vom 26.01.1994. 
Die Verfahrensakten - »18 Bände ohne Beweisunterlagen « ${ }^{461}$ - schickte die StA nicht mit ans AA. Die Begründung für die Einstellung fasste die StA in ihrer 50-seitigen Einstellungsverfügung folgendermaßen zusammen:

»Soweit der Tatbestand der Freiheitsberaubung unter dem Cesichtspunkt der vorgetragenen ständigen psychischen Beeinflussung durch Paul Schäfer überprüft worden ist, haben die Erhebungen ebenfalls nicht zu der Annahme eines hinreichenden Tatverdachts geführt.

Zwar ist davon auszugehen, daß Paul Schäfer - ohne daß von ihm ein offizielles Amt in der Organisation bekleidet wird - durch seinen Willen im Wesentlichen die Ceschicke der >Colonia Dignidad ‘ bestimmt und nichts geschieht, was nicht zuvor mit ihm abgesprochen ist und seinen Vorstellungen entspricht.

Indes hat keiner der heutigen Bewohner der $>\mathrm{CD}$ < Hinweise gegeben, aufgrund derer zu schließen ist, daß er in der Person Paul Schäfers und in dessen Verhalten eine Einengung seiner persönlichen Freiheit sieht. Auch wenn in Bezug auf die Glaubhaftigkeit der Bekundungen der Mitglieder der $>\mathrm{CD}$ < Bedenken anzumelden sind, deutet manches darauf hin, daß diese Menschen bewußt und freiwillig etwas auf sich genommen haben, was andere als Isolation, Zwangsarbeit und letztlich als Entmündigung bewerten könnten.[...] Wie oben bereits angedeutet, können die Erklärungen der Bewohner der $>C D<$, soweit diese sowohl in vorliegender Sache vernommen worden sind, als auch soweit sie sich in Schreiben an die Staatsanwaltschaft gewandt haben, nicht vorbehaltlos als wahr übernommenen werden. Einiges deutet darauf hin, daß entsprechende Aussagen vorgefertigt wurden und dann zu den Akten gereicht worden sind, zumal sie teilweise wortwörtlich übereinstimmen und sich nur dadurch voneinander abheben, daß sie die jeweilige Unterschrift einer anderen Person aufweisen. Indes konnten dennoch keine begründeten Anhaltspunkte festgestellt werden, wonach diese Zeugen in irgendeiner Form zu der Abgabe der jeweiligen Erklärung gezwungen worden sind bzw. es liegen auch keine konkreten Hinweise vor, daß die dort gemachten Aussagen nicht ihrem tatsächlichen freien Willen entsprechen. ${ }^{462}$

Das für Chile zuständige Referat 330 des AA, das Referat 511 der Rechtsabteilung des AA (»Nothilfe für Deutsche im Ausland«) und die Botschaft wandten sich in ihren Stellungnahmen vehement gegen eine Einstellung des Verfahrens. Das Länderreferat argumentierte, die Bewertung der belastenden Zeug_innenaussagen als beispielsweise wirr oder uneindeutig gehe auf vermeintliche Widersprüche in den Aussagen oder dem Verhalten der Zeug_innen zurück. Die Aussagen müssten jedoch stärker im Kontext anderer relevanter Erkenntnisse bewertet werden, die das Verfahren nur scheinbar nicht berührten. Die Glaubwürdigkeit der belastenden Aussagen, so das Länderreferat des AA, erscheine

»in einem anderen Licht, wenn man sie vor dem Hintergrund verbürgter Fakten bewertet: So ist z.B. Schäfer von einem Gefolterten eindeutig als jemand identifiziert worden, 
der bei Folterungen zugegen war (s. F. Paul Heller, >Colonia Dignidadく, Kap. >Die Folterschuleく, eine Auseinandersetzung der Staatsanwaltschaft mit dieser Publikation wäre nützlich). $«^{463}$

Zudem sei im Einstellungsbeschluss keine kritische Auseinandersetzung mit den Aussagen der Beschuldigten erkennbar. So sei bekannt, dass Paul Schäfer bewiesenermaßen ein notorischer Lügner sei. Das Referat kritisierte auch offen die Art und Weise, wie die Zeug_innen in der CD befragt wurden:

»Hinzu kommt, daß die durch die verschiedenen Rechtshilfeersuchen erlangten Aussagen auf z.T. Fragwürdigen Methoden beruhen (z.B. hat die zuständige Richterin von Parral das RHE der Staatsanwaltschaft Bonn vom 30.03.1988 mit vorab verteilten, in der $C D$ ausgefüllten Fragebögen erledigt, deren Inhalt dann nur kurz vor ihr bestätigt wurde.)

Damit soll nicht unbedingt das Ergebnis des Einstellungsbeschlusses kritisiert werden. Doch, eine kritische Würdigung der >Hauptzeugen « gegen die CD und eine unkritische Würdigung der Schutzbehauptungen der Beschuldigten würde mit Sicherheit von der $\mathrm{CD}$ als >Persilschein « der deutschen Justiz öffentlichkeitswirksam >vermarktet « und als großer Sieg gefeiert werden. ${ }^{464}$

Man könne nicht beurteilen, so das Länderreferat, wann die Staatsanwaltschaft aus Gründen der Rechtsstaatlichkeit genötigt sei, das Verfahren einzustellen. Politisch sei jedoch damit zu rechnen, dass die chilenische Regierung eine Verfahrenseinstellung als Signal dafür betrachte, dass die deutsche Seite dem dringenden Verdacht von Menschenrechtsverletzungen in der $C D$ nicht konsequent nachgehe. Es sei aber das Interesse des AA, das Gegenteil zu vermitteln:

»Unsere Bemühungen, die chilenische Regierung zu Anstrengungen zur Aufarbeitung der menschenrechtswidrigen Aktivitäten der CD anzuhalten, verlören bei ihr an Claubwürdigkeit und erlitten damit einen Rückschlag. Die Chancen, die chilenische Seite für eine Ausweisung Schäfers zu gewinnen, würden sich unter diesen Umständen vermindern.

Hieraus ergibt sich, daß eine Verfahrenseinstellung wichtige Belange der Bundesrepublik Deutschland tangiert und daher erst ins Auge gefaßt werden sollte, wenn sie auch nach eingehendster Prüfung aus rechtlichen und tatsächlichen Gründen unabdingbar ist. ${ }^{465}$

In diesem Sinne »unabdingbar« sei die Einstellung des Verfahrens aber aus Sicht des AA noch nicht. Die Stellungnahme der Botschaft fiel ähnlich deutlich aus. Sie kritisierte,

»daß die StA Bonn zwar die Aussagen der Zeugen kritisch würdigt, die Aussagen der Beschuldigten und der von diesen angeführten Zeugen jedoch in der Regel unkritisch übernimmt. Die Tatsache beispielsweise, daß diese Zeugenaussagen z.T. wörtlich über-

463 PA AA, AV NA 31606. Schreiben AA (Ref 330 über Dg 33) an AA (Referat 511) vom 08.02.1994.

464 Ebd.

465 Ebd. 
einstimmen und vorgefertigt waren (S. 45), läßt nach Ansicht der Botschaft erhebliche Zweifel am Wert dieser Aussagen aufkommen.« 466

Weiter schrieb die Botschaft, eine Einstellung aufgrund nicht hinreichenden Tatverdachts erwecke

»den fatalen Eindruck, die CD sei zwar eine >Cemeinschaft, die mit den hiesigen Vorstellungen von einem menschlichen Zusammenleben nicht oder nur wenig in Einklang zu bringen< ist (S. 51), jedoch im Übrigen makellos. Eine Einstellung mit der vorliegenden Begründung stellte für die CD einen >Persilschein ‘ dar, der sie von den gekannten Vorwürfen reinwüsche. Sie könnte damit gegenüber den chilenischen Behörden ihre Stellung noch weiter stärken und die ohnehin schwierigen Verfahren der chilenischen Behörden gegen sie weiter erschweren. Unser jahrelanges Beharren auf einer `Verfolgung`der CD würde mit so einer Einstellungsverfügung fast ad absurdum geführt. « ${ }^{467}$

Die Kritik des AA führte dazu, dass das Verfahren zunächst nicht eingestellt wurde. Schließlich wurde das Verfahren erst Ende September 2010 eingestellt - über 25 Jahre nach Beginn der Ermittlungen und über 15 Jahre nach der Einstellungsverfügung von 1994. ${ }^{468}$ Der Einstellungszeitpunkt lag wenige Monate nach dem Tod Schäfers und wenige Monate vor der Flucht Hartmut Hopps nach Deutschland. Ob die Ermittlungen zwischen 1994 und 2010 tatsächlich fortgesetzt wurden und falls ja, wie engagiert dies geschah, ist mir nicht bekannt, erscheint mir aber zumindest zweifelhaft. Wahrscheinlicher ist, dass die tatsächliche Einstellung durch Einwände des AA mehrfach aufgeschoben wurde, die Ermittlungen jedoch de facto schon seit 1994 weitgehend ruhten.

\subsubsection{Ermittlungen der StA Bonn wegen Diktaturverbrechen in der Colonia Dignidad (1991-2010)}

Aufgrund mehrerer Strafanzeigen leitete die Staatsanwaltschaft Bonn zwischen 1991 und 2006 eine Reihe von Ermittlungsverfahren wegen Mordes mit Bezug zur CD ein. Viele Informationen bekam die StA dabei vom Menschenrechtsaktivisten Dieter Maier. Sämtliche dieser Verfahren wurden jedoch wegen mangelnden Tatverdachts (\$ 170 II StPO) eingestellt.

\section{Das Verfahren wegen Mordes an Alfonso Chanfreau, Exequiel Ponce und Alvaro Vallejos}

Alfonso Chanfreau, Exequiel Ponce und Alvaro Vallejos wurden 1974 in Santiago entführt und gelten bis heute als verschwunden. Zwischen den drei Fällen gibt es keinen direkten Bezug, ${ }^{469}$ das einzige gemeinsame Merkmal sind Hinweise, dass die Verschwundenen

466 PA AA, AV NA 31606. Bericht Botschaft an AA (Referat 511) vom 08.03.1994, GZ: Nr. 301/94.

467 PA AA, AV NA 31606. Bericht Botschaft an AA (Referat 511) vom 08.03.1994, GZ: Nr. 301/94.

468 Die Einstellung erfolgte am 29.09.2010, »weil Tathandlungen in nicht rechtverjährter Zeit nicht zu belegen waren.«Landtag Nordrhein-Westfalen. Drucksache 15/3025 vom 18.10.2011. Antwort JM zu KIAnfr 1110, Drs 15/2782. Ermittlungen der NRW-Justiz zur Colonia Dignidad (Teil 1), S. 2.

469 CA Santiago, AZ 2182-98 (»Alfonso Chanfreau«). Erstinstanzliches Urteil vom 22.05.2013. Darin werden die Fichas von Alvaro Vallejos Villagrán im CD-Geheimarchiv erwähnt. Diese enthalten 
nach ihrer Entführung von DINA-Agent_innen in die CD verbracht wurden. Chanfreau war Aktivist der MIR und besaß sowohl einen französischen als auch einen chilenischen Pass. Mehrere ehemalige politische Gefangene berichteten, dass Chanfreau in die CD gebracht wurde. ${ }^{470}$ Exequiel Ponce war Führungsmitglied der Sozialistischen Partei. Der DINA-Agent Juan Muñoz Alarcón (Vgl. Abschnitt 5.1.2) sagte 1977 aus, Ponce sei noch am Leben und werde gemeinsam mit etwa 120 Gefangenen in der CD festgehalten. Alvaro Vallejos wurde 1974 von den DINA-Agenten Fernando Gómez Segovia und Samuel Fuenzalida in die CD gebracht. ${ }^{471}$ Sein Fall war bereits Gegenstand des Zivilverfahrens der CD gegen AI vor dem LG Bonn (vgl. Abschnitt 5.3.1).

In den chilenischen Strafverfahren wurden jeweils mehrere DINA-Agent_innen verurteilt, aber keine Colonos. Lediglich im Fall Alvaro Vallejos wurde 2018 mit Gerhard Mücke ein CD-Führungsmitglied rechtskräftig verurteilt. Paul Schäfer wurde zwar als Beschuldigter geführt, verstarb jedoch noch vor dem erstinstanzlichen Urteil. In Frankreich war Schäfer in einem Verfahren wegen des Mordes an Chanfreau angeklagt, erlebte aber auch hier den Urteilsspruch nicht mehr. ${ }^{472}$

1991 stellte der Frankfurter Rechtsanwalt Armin Golzem bei der Staatsanwaltschaft Bonn Strafanzeige wegen der Ermordung von Chanfreau und Ponce. ${ }^{473}$ Die StA Bonn nahm daraufhin ein Ermittlungsverfahren auf ${ }^{474}$ und richtete am 30. Juli 1993 ein Rechtshilfeersuchen an die chilenische Justiz mit der Bitte um Überlassung von Unterlagen aus dem entsprechenden chilenischen Strafverfahren und den Bezugsdokumenten der chilenischen Wahrheitskommission von 1991. ${ }^{475}$ Nach fast zwanzig Jahren wurde das Verfahren mit dem Tod von Paul Schäfer am 24. April 2010 eingestellt. ${ }^{476}$

\section{Das Verfahren wegen Mordes an Hernan Sarmiento}

Der Medizinstudent Hernán Sarmiento Sabater wurde am 28. Juli 1974 in Parral festgenommen, nachdem er seinen Bruder Heráclio im Gefängnis besucht hatte. Heráclio Sarmiento kam einige Zeit später frei und bekam in der Bundesrepublik politisches

die Transkription eines Verhörs von Vallejos vom 30.07.1974 in der CD. Nach Alfonso Chanfreau gefragt macht Vallejo Angaben zu dessen Aufenthaltsort.

470 Vgl. u.a. Archiv FUNVISOL. Erklärung von Ramón Rojas González vom 28.07.1975; Archiv FUNVISOL, Richterliche Vernehmung von León Gómez vom 21.08.1990 sowie CA Santiago, AZ 2182-98 (»Alfonso Chanfreau«). Erstinstanzliches Urteil vom 22.05.2013, S. 6. Aussage von Pedro Matta Lemoine.

471 CA Santiago, AZ 2182-98 (»Alvaro Vallejos Villagrán«). Urteil vom 07.05.2015. Vgl. auch PA AA, AV NA 31580. LC Bonn, 3 O 123/77. Abschrift der öffentlichen Sitzung vom 30.10.1979. Darin: Vernehmung von Samuel Fuenzalida.

472 Cour D'Assises de Paris, AZ 07/0027. Urteil vom 17.12.2010, online unter https://www.fidh.org/IMC /pdf/Arret_de_condamnation_17dec2010.pdf.

473 Die Ermittlungen wurden später auch auf Alvaro Vallejos Villagrán ausgedehnt. PA AA, AV NA 32992. StA Bonn, AZ 62 AR 1034/93. Rechtshilfeersuchen vom 30.07.1993.

474 StA Bonn, AZ 50 ]s 94/91.

475 PA AA, AV NA 32992. StA Bonn, AZ 62 AR 1034/93. Rechtshilfeersuchen vom 30.07.1993. Die Corte Suprema vergab das AZ 30.375-94.

476 Landtag Nordrhein-Westfalen. Drucksache 15/3025 vom 18.10.2011. Antwort JM zu KIAnfr 1110, Drs 15/2782. Ermittlungen der NRW-Justiz zur Colonia Dignidad (Teil 1), S. 2. 
Asyl. Hernán Sarmiento hingegen gilt bis heute als verschwunden und wurde vermutlich in der CD ermordet. Gerd Seewald, der das CD-Geheimarchiv führte, bestätigte 2006 in einem chilenischen Gerichtsverfahren, dass der Gefangene in die CD gebracht wurde: „Sarmiento llegó detenido desde Parral«. ${ }^{477}$ In einer späteren Vernehmung äußerte er die Vermutung, Sarmiento und Laurie könnten in der CD ermordet worden sein: »También creo que pudieron haber sido muertos y enterrados en Colonia, Hernán Sarmiento Sabater y Haroldo Laurie Luengo, los que provenían de Parral.«478

Am 12.08.2006 stellte Heraclio Sarmiento bei der Staatsanwaltschaft Bonn Strafanzeige wegen Mordes an seinem Bruder Hernán. Er berief sich dabei auf einen Presseartikel, der einige Wochen zuvor in La Nación erschienen war ${ }^{479}$ und über die Erschießungen von Gefangenen in der CD und das Verbrennen der Leichen mit Fosfor berichtete. Der Artikel zitierte auch aus Verhören von Gerd Seewald durch die chilenische Justiz, in der dieser Hernán Sarmiento als Mordopfer nannte. Die Strafanzeige richtete sich gegen die in dem Artikel zitierten CD-Führungsmitglieder Paul Schäfer, Kurt Schnellenkamp, Gerd Seewald, Gerhard Mücke, Erwin Fege und Willi Malessa. Die Staatsanwaltschaft Bonn nahm daraufhin entsprechende Ermittlungen auf. ${ }^{480}$ Auch die Botschaft hatte dem AA über den Artikel berichtet und befunden, dass nun endgültig nicht mehr geleugnet werden könne, dass die Diktatur mit der CD bei der Ermordung von politischen Gefangenen zusammengearbeitet habe. ${ }^{481}$ Das AA leitete den Bericht ans Bundesministerium der Justiz (BMJ) weiter, von dort aus gelangte er über das Justizministerium NRW an die StA Bonn und schließlich in die Ermittlungsakte. Die ermittelnde Staatsanwaltschaft bereitete daraufhin ein RHE vor und bat die Botschaft um Angaben zu den Aufenthaltsorten der Beschuldigten und zu den in Chile laufenden oder bereits geführten Ermittlungen in der Sache. Die Botschaft übersandte sieben Monate später einen Bericht. Am 13. August 2007 stellte die Staatsanwaltschaft Bonn bei der chilenischen Justiz offiziell ein Rechtshilfeersuchen. ${ }^{482}$ Die chilenische Justiz übersandte daraufhin ein Urtei ${ }^{483}$ sowie Protokolle der Vernehmungen der Beschuldigten aus diversen Verfahren bei der CA Santiago. In einer Verfügung ${ }^{484}$ stellte die Staatsanwaltschaft daraufhin bewertend fest, dass es Ende 1974 auf dem CD-Gelände zu Erschießungen von etwa 20 Personen gekommen sei. Jedoch sei die Identität der Opfer nicht mehr festzustellen, da die Leichen 1978 ausgegraben und verbrannt wurden. Hinweise auf eine direkte Beteiligung der Beschuldigten an diesen Tötungshandlungen ergäben sich nicht. Die Staatsanwaltschaft schrieb: »Die Beschuldigten Paul Schäfer, Gerhard Mücke, Erwin Fege, Wilhelm Malessa und Rudolph Cöllen haben allerdings

477 CA Santiago, AZ 2182-98 (»Asociación llícita«), Bd. I (2), Ministro, Bl. 575. Richterliche Vernehmung von Gerd Seewald vom 19.08.2006.

478 CA Santiago, AZ 2182-98 (»Boris Weisfeiler«), Bd. Cuaderno Reservado, BI. 223. Richterliche Vernehmung von Gerd Seewald vom 13.04.2007.

479 La Nación vom 23.07.2006. „Quemados con fósforo químico«.

480 StA Bonn, AZ 555 ]s 315/06 K.

481 StA Bonn, AZ 555 ]s 315/06, Bd. I, BI. 26ff. Bericht Botschaft vom 26.06.2006, Nr. M 349/2006.

482 StA Bonn, AZ 666 AR 281/07.

483 CA Santiago, AZ 2182-98 (»Episodio Parral«).

484 StA Bonn, AZ 555 ]s 315/06 K, Bd. I, BI. 244ff. Verfügung der StA vom 08.06.2009. 
insofern >mitgewirkt‘, als dass der Ablauf der Erschießungen - zumindest objektiv ermöglicht und erleichtert wurde. $\aleph^{485}$

Trotz dieser Mitwirkung gäbe es jedoch keine konkreten Hinweise auf eine vorsätzliche Förderungshandlung nach $\$ \$ 211,27$ StGB. Es könne nicht davon ausgegangen werden, dass die Beschuldigten - insbesondere Mücke und Fege - in die Abläufe eingeweiht gewesen seien. Allenfalls Schäfer, so die StA, dürfte Kenntnis vom Umfang der Erschießungen gehabt haben. Da auch die chilenische Justiz keine Verfahren gegen an den Erschießungen beteiligte Militärangehörige führe, sei zudem zweifelhaft, ob diese Umstände jemals aufgeklärt werden könnten. Damit bleibe lediglich ein Tatverdacht wegen Strafvereitelung gegen Mücke, Fege, Malessa und Cöllen. Dieser sei allerdings mittlerweile verjährt. Allein eine Vernehmung von Reinhard Döring käme in Betracht, da dieser nach Angaben von Dieter Maier bei der Zuschüttung von Gräbern mitgewirkt haben soll. ${ }^{486}$

Döring wurde am 8. September 2009 vernommen. ${ }^{487}$ Er gab an, damals Kontakt zu Fahrer_innen der DINA gehabt zu haben und Gefangene bewacht zu haben. Zudem habe er Waffen und Motoren vergraben. Von Erschießungen oder der Beseitigung von Leichen wisse er jedoch nichts. Nachdem ihm Mückes in einem chilenischen Presseartikel $^{488}$ wiedergegebene Aussage über die Beseitigung von Leichen vorgehalten wurde, räumte Döring jedoch ein, etwas davon mitbekommen sowie Rudolf Cöllen und Willi Malessa gesehen zu haben. Nach Chanfreau, Ponce und Vallejos befragt, antwortete Döring, er habe einzig den Namen von Vallejos in der Zeitung gelesen. Da solle eine Leiche am Zaun gewesen sein, mehr wisse er jedoch nicht. ${ }^{489}$

Nach mehr als drei Jahren Ermittlungen mit der Auswertung von Presseartikeln und chilenischen Aussagen sowie der Vernehmung von zwei Zeugen wurde das Verfahren am 04. Dezember 2009 wegen mangelnden Tatverdachts ( $\$ 170$ II StPO) eingestellt. Die Staatsanwaltschaft schrieb dem Anzeigenerstatter Heraclio Sarmiento, die Ermittlungen hätten ergeben, dass sein Bruder am 28. Juli 1974 von chilenischen Polizeikräften entführt worden sei - wie es auch aus dem chilenischen Urteil hervorgeht. ${ }^{490}$ Zudem gäbe es Hinweise, dass er in die CD gebracht und dort möglicherweise festgehalten und verhört worden sei. Was jedoch anschließend mit ihm geschehen sei, bleibe ungeklärt. Die Staatsanwaltschaft erklärte: »Ob ihr Bruder durch Fremdeinwirkung ums Leben kam, ob hierfür Militärangehörige verantwortlich sind und wann dies erfolgt sein könnte, ist anhand der vorliegenden Beweismittel nicht näher aufzuklären. « 491 Auch gebe es keine Anhaltspunkte dafür, dass Hernán Sarmiento auf dem CD-Gelände erschossen wurde. Eine Verantwortlichkeit von Colonos sei daher nicht auszumachen. Ohnehin gäbe es keine Anhaltspunkte für eine Tatbeteiligung von Colonos an möglichen Erschießungen. Zwar seien Beihilfehandlungen denkbar, diese könnten jedoch nicht als

485 Ebd.

486 Ebd.

487 StA Bonn, AZ 555 ]s 315/06 K, Bd. I, Bl.292ff. Vernehmung von Reinhard Döring vom 08.09.2009.

488 La Nación vom 23.07.2006. »Quemados con fósforo químico«.

489 Ebd.

490 CA Santiago, AZ 2182-98 (»Episodio Parral«). Urteil vom 03.08.2003.

491 StA Bonn, AZ 555 ]s 315/06. Schreiben der StA Bonn an den Anzeigenerstatter vom 04.12.2009 (anlässlich der Verfahrenseinstellung). 
vorsätzliche Förderungshandlungen verstanden werden, da von einer vorrangigen Verantwortlichkeit der Militärs auszugehen sei.

Die Einstellungsverfügung vom Dezember 2009 verdeutlicht, dass die Staatsanwaltschaft Bonn eine Strafverfolgung bei Verschwundenenfällen grundsätzlich als aussichtslos einstuft: Im entsprechenden chilenischen Verfahren seien lediglich Verurteilungen wegen Entführung (»secuestro calificado«) ergangen, nicht jedoch wegen Mordes. Ausreichende Daten über den Tod des Entführten lägen nicht vor, weshalb Tötungsdelikte nicht in Betracht gezogen worden seien. Auch habe die chilenische Justiz gar nicht gegen Militär- oder DINA-Angehörige wegen Mordes ermittelt. Die StA könne nicht beurteilen, »ob dies darauf beruht, dass objektive Beweismittel - Leichenfunde, Aufzeichnungen der Militärs - nicht vorliegen oder dem sonstige prozessuale oder ggf. politische Gründe entgegen stehen «. ${ }^{492}$ Im Kern sah die Staatsanwaltschaft Bonn also die Verantwortung für entsprechende Ermittlungen bei der chilenischen Justiz. Diese begann mit umfassenden Ermittlungen wegen Diktaturverbrechen in der Tat erst 1998. Im Fall von Verschwundenen, deren Leichen unauffindbar sind, ermittelt und verurteilt sie nicht wegen Mordes, sondern wegen Entführung (»secuestro calificado«). Aufgrund des systematischen Kontexts der Diktaturverbrechen und allem darüber bisher bekannten, geht die chilenische Justiz davon aus, dass sich an die Entführung der bis heute Verschwundenen eine Mordhandlung anschloss. Nach chilenischem Recht werden diese Verbrechen als Verbrechen gegen die Menschheit eingestuft und verjähren nicht. Gleichzeitig haben die beschuldigten Colonos in chilenischen Verfahren - wahrscheinlich nach Absprache - jegliche Beteiligung an Mordhandlungen stets bestritten. Bei dieser Rechtsauslegung können Ermittlungen deutscher Staatsanwaltschaften, die sich weitgehend auf Rechtshilfeersuchen mit der Bitte um Überlassung chilenischer Verfahrensakten beschränken, nur schwerlich zu einer weiteren Aufklärung der Verbrechen beitragen.

\section{Das Verfahren wegen Mordes an Osvaldo Heyder}

Hauptmann Osvaldo Heyder Goycolea, Mitglied des SIM, wurde am 5. Juni 1975 erschossen in seinem Auto aufgefunden. Laut Gerüchten aus Militärkreisen soll er Selbstmord begangen haben. Später wurde offiziell verbreitet, er sei von linken Extremist_innen umgebracht worden. Vieles deutet jedoch darauf hin, dass er von der DINA ermordet wurde. Möglicherweise wurden die beteiligten DINA-Agent_innen dabei von Colonos unterstützt. In Chile wurde ab 2002 ein Strafverfahren in dem Fall geführt, ${ }^{493}$ das mehrfach eingestellt und wieder eröffnet wurde. Vor der letztmaligen Verfahrenseinstellung richtete die chilenische Justiz im Februar 2007 ein Rechtshilfeersuchen an die deutsche Justiz, ${ }^{494}$ da sie erfahren hatte, dass auch in Deutschland diesbezüglich ermittelt wurde.

492 StA Bonn, AZ 555 ]s 315/06, Bl. 318ff. Einstellungsverfügung vom 04.12.2009.

493 3. Juzgado del Crimende Talca, AZ 38.720. Das Verfahren wurde aufgrund einer Strafanzeige von Adriana Heyder gegen unbekannt vom 25.02.2002 eröffnet.

494 Corte Suprema, AZ 3737-06. Das Rechtshilfeersuchen wurde den deutschen Behörden per Verbalnote Nr. 012/07 vom 05.02.2007 übermittelt. Die StA Bonn vergab zu diesem Vorgang das AZ 663 AR 162/07. 
Am 15. August 2006 hatte die in Deutschland lebende Schwester Heyders bei der Staatsanwaltschaft Bonn Strafanzeige wegen Mordes gegen Unbekannt gestellt. Sie gab an, dass die Mörder_innen ihres Bruders oder zumindest deren Helfer_innen vermutlich Colonos gewesen seien. Sie verwies auf eine Aussage des ehemaligen politischen Gefangenen Erick Zott, der während seiner Inhaftierung Kontakt zu Heyder hatte. Zott hatte in den 1990er Jahren einem Gespräch von AI-Generalsekretär Walter Rövekamp mit Hugo Baar beigewohnt. 2002 gab Zott eine eidesstattliche Erklärung zu diesem Gespräch ab. ${ }^{495}$ Der inzwischen verstorbene Baar habe darin gesagt, er sei Mitte der 1970er Jahre für die Waffenkammer der CD zuständig gewesen. Im Winter 1975 - passend zum Zeitpunkt des Mordes an Heyder - habe er zwei Colonos, die an einem Attentat auf einen Heeresoffizier in Talca beteiligt waren, eine Waffe ausgehändigt. Später hätte man ihm die Waffe zurückgegeben, die beiden Colonos hätten sich zeitweise im Süden Chiles versteckt. ${ }^{496}$

Die Staatsanwaltschaft Bonn nahm nach der Anzeige Ermittlungen auf. ${ }^{497}$ Sie vernahm neben der Anzeigenerstatterin die Ex-Colonos Klaus Schnellenkamp und Winfried Schmidtke. Das Verfahren wurde am 4. Januar 2008 nach $\$ 170$ II StPO eingestellt. $^{498}$

\subsubsection{Ermittlungen der StA Bonn wegen sexuellen Missbrauchs (1997-2010)}

Im Juli 1997 gelang dem Colono Tobias Müller mithilfe des Chilenen Salo Luna die Flucht aus der CD (vgl. Abschnitt 4.1.3). Nachdem die beiden unter großer Medienanteilnah$\mathrm{me}^{499}$ nach Deutschland ausgereist waren, vernahm die Staatsanwaltschaft Bonn sie und leitete ein Ermittlungsverfahren ein. ${ }^{500}$ Einige Wochen später erließ das Amtsgericht Siegburg einen Vollstreckungshaftbefehl gegen Paul Schäfer. ${ }^{501}$ Die Staatsanwaltschaft Bonn schrieb Schäfer über Interpol zur Fahndung aus. ${ }^{502}$ Dies war der erste bundesdeutsche Haftbefehl gegen Paul Schäfer seit Februar 1961. Nach Schäfers Tod im April 2010 wurde das Verfahren eingestellt. ${ }^{503}$

495 PJS, Sammlung CD. Declaración Jurada Erick Zott vom 23.10.2002 im chilenischen Konsulat in Wien. Dieses Dokument wird auch zitiert in: Basso Pietro, Carlos. »La extraña muerte del militar que enfrentó a la DINA«, in: El Mostrador vom 05.06.2015, online unter https://www.elmostra dor.cl/pais/2015/06/05/la-extrana-muerte-del-militar-que-enfrento-a-la-dina/.

496 Ebd.

497 StA Bonn, AZ 554 U]s 114/06 P.

498 Landtag Nordrhein-Westfalen. Drucksache 15/3025 vom 18.10.2011. Antwort JM zu KIAnfr 1110, Drs 15/2782. Ermittlungen der NRW-Justiz zur Colonia Dignidad (Teil 1), S. 2.

499 Vgl. Pieper, Dietmar/Helene Zuber. »Die Pistole lag immer griffbereit. Tobias Müller und Salo Luna über Tyrannei und sexuellen Mißbrauch in der Colonia Dignidad«, in: Der SPIECEL Nr. 33/1997 vom 11.08.1997, S. 124-127.

500 StA Bonn, AZ 50 ]s 211/97.

501 AC Siegburg, AZ 15 CS 495/97. Vollstreckungshaftbefehl gegen Paul Schäfer vom 18.09.1997 wg. sexuellem Missbrauch von Minderjährigen in acht Fällen (StGB § 1761.1 und § 53).

502 CA Santiago, AZ 2182-98 (»Ley de Control de Armas«). Urteil vom 28.08.2006, S. 74. Vgl. auch La Segunda vom 03.10.1997, S. 17. »Fiscalía de Bonn ordenó detención de Paul Schaefer«.

503 Landtag Nordrhein-Westfalen. Drucksache 15/3025 vom 18.10.2011. Antwort JM zu KIAnfr 1110, Drs 15/2782. Ermittlungen der NRW-Justiz zur Colonia Dignidad (Teil 1), S. 2. 


\subsubsection{Ermittlungen der StA Memmingen, Krefeld und Bonn (2005-2008)}

Wenige Tage nach der Festnahme Paul Schäfers im März 2005 erließ Richter Jorge Zepeda über Interpol einen internationalen Haftbefehl gegen Albert Schreiber wegen Entführung und Verschwindenlassen von Juan Maino, Elizabeth Rekas und Antonio Elizondo. ${ }^{504}$ Schreiber und seine Ehefrau Lilli (geb. Nill) sowie ihr Sohn Ernst Schreiber wurden zudem wegen Kindesentführung international zur Fahndung ausgeschrieben. ${ }^{505}$ Die drei hatten von 1997 bis 1999 das Missbrauchsopfer Rodrigo Salvo entführt und an verschiedenen Orten Chiles versteckt. Damit wollten sie verhindern, dass die chilenische Justiz Missbrauchstaten an Salvo nachweisen könne. Später setzten die Schreibers sich nach Deutschland ab. 2006 wurde Albert Schreiber von Richter Zepeda zusätzlich wegen Bildung einer kriminellen Vereinigung angeklagt.

2005 leitete die Staatsanwaltschaft Memmingen ein Verfahren gegen Albert Schreiber ein, ${ }^{506}$ vermutlich wegen des Haftbefehls von Zepeda. Sie richtete ein Rechtshilfeersuchen an die chilenische Justiz ${ }^{507}$ und erhielt von dieser Dokumente zu den Verfahren gegen Schreiber. 2006 zog Schreiber nach Krefeld, vermutlich schloss er sich mit seiner Frau und seinem Sohn der religiösen Gruppierung Freie Volksmission Krefeld an. ${ }^{508}$ Im Januar 2006 beantragte Richter Jorge Zepeda die Auslieferung Schreibers aus Deutschland ${ }^{509}$, was unter Verweis auf das grundgesetzliche Auslieferungsverbot abgelehnt wurde. ${ }^{510}$ Am 30 . September 2006 organisierten Menschenrechtsaktivist_innen eine sogenannte $»$ Funa ${ }^{511}$ vor dem Sitz der Freien Volksmission in Krefeld, um die bisherige Straflosigkeit von Schreiber öffentlich aufzuzeigen. ${ }^{512} 2007$ übernahm die Staatsanwaltschaft Krefeld das Verfahren, ${ }^{513}$ stellte es jedoch bereits im Januar 2008 nach $\$ 170$ II StPO wieder ein..$^{514}$

2006 leitete die Staatsanwaltschaft Bonn ein strafrechtliches Ermittlungsverfahren gegen Albert, Lilli und Ernst Schreiber wegen Beihilfe zum sexuellen Missbrauch von

504 CA Santiago, AZ 2182-98 (»Ley de control de armas«), Bd. III, BI. 770. CA Santiago, AZ 2182-98 (»]uan Maino«), Anordnung von Richter Zepeda vom 17.03.2005.

505 CA Talca, AZ 53.015-96.

506 StA Memmingen, AZ mir unbekannt. Das Verfahren wurde 2007 nach einem Umzug Schreibers nach Krefeld an die StA Krefeld abgegeben, AZ 3 ]s 586/07.

507 Die Corte Suprema vergab nach Eingang des Memminger RHE das AZ 4057-2006.

508 La Tercera vom 25.09.2006, S. 14. »Prófugo de ex-Colonia Dignidad es miembro de secta en Alemania«.

509 La Nación vom 26.01.2006, S. 7. »Cursan extradición de asesor clave de Schäfer«.

510 La Tercera vom 27.09.2006, S. 18. »Alemania abre juicio contra principal prófugo de ex-Colonia Dignidad«.

511 »Funar« ist umgangssprachliches chilenisches Spanisch für »Offenlegen« oder »Bloßstellen«. Eine Funa in Chile ist eine Protestveranstaltung von Menschrechtsaktivist_innen und Angehörigen von Opfern zur Thematisierung von Straflosigkeit. Dabei werden am Wohnort oder der Arbeitsstätte der Täter_innen Nachbarn und Passanten über die Tatvorwürfe aufgeklärt, während von Staat und Justiz Aufarbeitung und Cerechtigkeit gefordert wird.

512 La Segunda vom 02.10.2006, S. 8. » Funa a distancia«.

513 StA Krefeld, AZ 3 ]s 586/07.

514 Landtag Nordrhein-Westfalen. Drucksache 15/3025 vom 18.10.2011. Antwort JM zu KIAnfr 1110, Drs 15/2782. Ermittlungen der NRW-Justiz zur Colonia Dignidad (Teil 1), S. 2 f. 
Kindern und Entziehung Minderjähriger ein. ${ }^{515}$ Im Mai 2007 richtete sie ein Rechtshilfeersuchen an die chilenische Justiz mit der Bitte um Überlassung der dortigen Verfahrensakten. ${ }^{516}$ Sie vernahm die drei Beschuldigten und stellte fest, dass das Ehepaar Schreiber eine Pflegevereinbarung für Rodrigo Salvo unterzeichnet hatte, der in das sogenannte Intensivinternat der CD aufgenommen und dort regelmäßig von Schäfer missbraucht worden war. Laut Staatsanwaltschaft war jedoch nicht nachweisbar, dass die Unterzeichnung der Pflegevereinbarung in Kenntnis des Missbrauchs oder gar zu dessen Zweck geschah. Ob auch der Straftatsbestand der Entführung von Salvo untersucht wurde, ist mir nicht bekannt. Im August 2008 stellte die Staatsanwaltschaft Bonn auch dieses Verfahren wegen mangelnden Tatverdachts ( $\$ 170$ II StPO) ein. Albert Schreiber verstarb wenig später, Anfang September 2008 in Krefeld. Seine Frau und sein Sohn Ernst leben bis heute dort.

\subsubsection{Ermittlungen der StA Krefeld (2011-2019)}

In dem Krefelder Ermittlungsverfahren ab 2011 ging es zentral um Hartmut Hopp, der aufgrund seines Vertrauensverhältnisses zu Paul Schäfer eine herausragende Stellung in der Struktur der CD innehatte, als Verbindungsmann zur DINA galt und als Leiter des Krankenhauses verantwortlich war für die Beschaffung und die Handhabung von Medikamenten in der CD. In Chile war er 2011 in zweiter Instanz wegen Beihilfe zum sexuellen Missbrauch an 26 chilenischen Kindern zu 5 Jahren Haft verurteilt worden. ${ }^{517}$

Wenige Monate später, im Mai 2011, floh Hopp vor der chilenischen Justiz in die Bundesrepublik. Zum Zeitpunkt seiner Flucht liefen in Chile zwei weitere Strafverfahren gegen Hopp: wegen Entführung bzw. Verschwindenlassens von Juan Maino, Elizabeth Rekas und Antonio Elizondo ${ }^{518}$ und wegen Bildung einer kriminellen Vereinigung. ${ }^{519}$ Eine weitere 90-tägige Haftstrafe wegen Waffenproduktion und -handel in der CD hatte Hopp bereits durch Anrechnung seiner mehrmonatigen Untersuchungshaft 2005/2006 verbüßt. Trotz eines Ausreiseverbots wegen der laufenden Verfahren verließ Hopp Chile Anfang Mai 2011 und kam Mitte des Monats in Deutschland an. Er berichtete einem Arbeitskollegen, er habe Chile auf »extra-offiziellem Wege« verlassen - auf dem Landweg über Argentinien und Paraguay. ${ }^{520}$ Hopp ließ sich mit seiner Ehefrau Dorothea in Krefeld nieder. Die chilenische Justiz erließ umgehend einen internationalen Haftbefehl.

Bis heute gehört das Ehepaar Hopp der in Krefeld ansässigen Freien Volksmission Krefeld des freikirchlichen Predigers Ewald Frank an. Hopps Adoptivsohn Michael und dessen Frau Bärbel Schreiber wohnten bereits in Krefeld. Bärbel Schreiber bestätigte

\footnotetext{
515 StA Bonn, AZ 555 ]s 223/06 P.

516 El Mercurio vom 22.05.2007, S. C10. »Alemania pide a Chile datos sobre Schreiber«.

517 CA Talca, AZ 28-2005. Urteil vom 06.01.2011. Die Corte Suprema bestätigte das Strafmaß gegen Hopp im Januar 2013 in Hopps Abwesenheit. Corte Suprema, AZ 3579-2011. Urteil vom 25.01.2013.

518 CA Santiago, AZ 2198-98 (»]uan Maino«).

519 CA Santiago, AZ 2182-98 (»Asociación Ilícita«).

520 CA Santiago, AZ 2182-98 (»Asociación Ilícita«), (Ministro) BI. 2940. E-Mail von Hartmut Hopp an Gonzalo Díaz vom 16.05.2011.
} 
Hopps Ankunft in Deutschland gegenüber der chilenischen Presse. ${ }^{521}$ Auch in Krefeld erregte die Nachricht Medieninteresse. ${ }^{522}$ Anwohner_innen organisierten Demonstrationen und Unterschriftensammlungen gegen Hopps Anwesenheit. ${ }^{523}$. Verschiedene Vermieter_innen kündigten Hopps Wohnung, nachdem sie von seiner Vergangenheit erfahren hatten. ${ }^{524}$ Die Medien thematisierten auch, dass die Hopps Sozialleistungen bezogen, obwohl sie möglicherweise Zugriff auf versteckte Gelder der CD hatten. ${ }^{525}$

Artikel 16 II GG schließt eine Auslieferung deutscher Staatsangehöriger an Staaaten außerhalb der EU grundsätzlich aus. ${ }^{526}$ Daher war abzusehen, dass ein Auslieferungsantrag ins Leere laufen würde, und deshalb wurde auch der internationale Haftbefehl gegen Hopp in Deutschland nicht vollstreckt. Dennoch stellte Chile Ende 2011 ein Auslieferungsersuchen, ${ }^{527}$ das jedoch erwartungsgemäß negativ beschieden wurde.

Am 24. August 2011 stellte das European Center for Constitutional and Human Rights (ECCHR) bei der StA Krefeld Strafanzeige gegen Hartmut Hopp »wegen aller in Frage kommender Delikte, insbesondere Beihilfe zum schweren sexuellen Missbrauch von Kindern und Mord in drei Fällen «. ${ }^{528}$ Zusätzlich stellte die Berliner Rechtsanwältin Petra Schlagenhauf weitere Strafanzeigen gegen Hopp im Namen mehrerer Geschädigter und beantragte die Eröffnung von Strafverfahren. ${ }^{529}$ Die Staatsanwaltschaft Krefeld leitete daraufhin strafrechtliche Ermittlungen gegen Hopp wegen Mordes, Beihilfe zum

521 Ramírez, Pedro/Francisca Skonic. »La fuga de Hopp a Alemania enciende alerta sobre los millones que ocultó Schäfer«, in: CIPER (Website), 23.05.2011, online unter http://ciperchile.cl/2011/05/23/la -fuga-de-hopp-a-alemania-enciende-alerta-sobre-los-millones-que-oculto-schafer.

522 Vgl. u.a. Diehl, Jörg. »Dr. Unerwünscht. Colonia-Dignidad-Arzt in Krefeld«, in: Spiegel Online vom 26.08.2011, online unter https://www.spiegel.de/panorama/justiz/colonia-dignidad-arzt-in-krefeld -dr-unerwuenscht-a-782465.html.

523 Vgl. u.a. Westdeutsche Zeitung vom 26.08.2011. »Am Samstag soll Demo vor H. neuer Wohnung stattfinden«, online unter: https://www.wz.de/nrw/krefeld/colonia-dignidad-am-samstag-soll-eine -demo-vor-h-neuer-wohnung-stattfinden_aid-30517465.

524 Vgl. u.a. Westdeutsche Zeitung vom 24.08.2011. »Colonia Dignidad: Wohnstätte kündigt H. - BKA Fragt in Chile an «, online unter https://www.wz.de/nrw/krefeld/colonia-dignidad-wohnstaette-kue ndigt-h-bka-fragt-in-chile-an_aid-30517481.

525 Vgl. u.a. Westdeutsche Zeitung vom 18.08.2011. »Ceflüchteter Sektenarzt lebt in Krefeld von Sozialhilfe«, online unter: https://www.wz.de/nrw/krefeld/colonia-dignidad-gefluechteter-sekten-arz t-lebt-in-krefeld-von-sozialhilfe_aid-30517537 sowie Westdeutsche Zeitung vom 18.08.2011. »Sektenarzt zieht nach Linn«, online unter https://www.wz.de/nrw/krefeld/sektenarzt-zieht-nach-linn_ aid-30517581.

526 Eine Ausnahme gilt lediglich für Staaten der Europäischen Union.

527 Richter Jorge Zepeda von der CA Santiago stellte das Auslieferungsersuchen im Rahmen des Verfahrens AZ 2182-98 wegen der Entführung von Juan Maino, Elizabeth Rekas und Antonio Elizondo. Die Corte Suprema befürwortete die Übermittlung des Auslieferungsersuchens an die deutsche Seite am 17.11.2011 (AZ 7.791-2011). Das Auslieferungsersuchen wurde dem AA am 12.01.2012 per Verbalnote 4-2012 des chilenischen Außenministeriums übermittelt.

528 Vgl. European Center for Constitutional and Human Rights (ECCHR). Stellungnahme zu der Rolle von Hartmut W. Hopp innerhalb der Colonia Dignidad - Seine Kollaboration mit dem PinochetRegime und Verbrechen an Bewohnern der Colonia Dignidad. Berlin, Oktober 2011, online unter: https://www.ecchr.eu/fileadmin/Pressemitteilungen_deutsch/Stellungnahme_Colonia_Dignid ad_Hopp_-_2011-10-06.pdf

529 StA Krefeld, AZ 3 ]s 753/11, Bd. 1, Bl. 86ff. Strafanzeige RA'in Petra Schlagenhauf vom 06.10.2011. 
sexuellen Missbrauch und gefährlicher Körperverletzung durch medizinisch nicht indizierte Vergabe von Psychopharmaka ein. ${ }^{530}$ Nach den Ermittlungen der StA Bonn (vgl. Abschnitt 5.3.4) war dies das zweite Verfahren seitens der (bundes)deutschen Justiz gegen Hopp. Hopp wurde von Rechtsanwalt Helfried Roubicek vertreten, der ihm vom Unternehmensberater Falk Spahn vermittelt worden sein soll ${ }^{531}$ und der sich auf seiner Webseite wiederholt zum Ermittlungsverfahren äußerte. ${ }^{532}$

\section{Verlauf der Ermittlungen}

In einer Einlassung vom Dezember 2011 bestritt Hopp jegliche Beteiligung an strafbaren Handlungen. ${ }^{53}$ Außer seiner Tätigkeit als Arzt und Leiter des CD-Krankenhauses von 1985 bis 1997 habe er keinerlei leitende oder repräsentative Funktionen für die CD ausgeübt. Vom sexuellen Missbrauch durch Paul Schäfer habe erst 2002 erfahren. Er behauptete, er hätte »auf jeden Fall allumfassende Strafanzeige gestellt«, hätte er zuvor Kenntnisse von diesen »abscheulichen Taten« gehabt. ${ }^{534}$ Das chilenische Urteil gegen ihn sei nicht auf rechtsstaatlichem Wege zustande gekommen, erklärte Hopp. Zum Zeitpunkt des Verschwindens von Juan Maino, Elizabeth Rekas und Antonio Elizondo sei er gar nicht in der CD gewesen, sondern habe in Santiago Medizin studiert. Über Hinrichtungen von Gefangenen in der CD habe er erst seit 2006 erfahren. Zum Vorwurf der Körperverletzung gab Hopp an, auch vor 2002 keinem Colono Medikamente verabreicht zu haben, um ihn oder sie »gefügig « zu machen, »da dazu im Übrigen in der inzwischen freiheitlich und offen organisierten CD gar keine Veranlassung bestand «. 535

Im Februar 2012 wurde Hopp erstmals als Beschuldigter vernommen. Er leugnete erneut jegliche Beteiligung an den ihm vorgeworfenen Taten und benannte insgesamt 33 Entlastungszeug_innen - allesamt Colonos teils mit Wohnsitz in Deutschland, teils in Chile. Die Staatsanwaltschaft vernahm 2012 eine Reihe dieser Zeug_innen, aber auch einige Zeug_innen die Hopp belasteten. 2013 richtete sie ein Rechtshilfeersuchen an die chilenische Justiz. ${ }^{536}$ Dieses beschränkte sich de facto weitgehend auf die Übersendung chilenischer Gerichtsurteile. Im Herbst 2017 erinnerte die StA Krefeld die chilenische Justiz an die Beantwortung der noch offenen Fragen aus dem RHE. ${ }^{537}$ Gleichzeitig bat das Justizministerium NRW die chilenischen Behörden um die Genehmigung einer Teilnahme von Vertreter_innen deutscher Justizbehörden an den in Chile laufenden Ermittlungen sowie einer Besprechung mit Hernán González, dem zuständigen Richter

530 StA Krefeld, AZ 3 ]s 753/11.

531 Vgl. Schildmann, Daniela. »50 Jahre und kein Ende in Sicht«, in: Lateinamerika Nachrichten Nr. 450/2011, Dezember 2011, S. 26-28.

532 Vgl. https://www.strafverteidiger-ostsee.de/presse/eigene-pressemeldungen.html. Die Website ist seit 2019 nicht mehr verfügbar.

533 StA Krefeld, AZ 3 ]s 753-2011, Bd. III, Bl. 491ff. (Erste) Einlassung zur Sache von Hartmut Hopp vom 29.11.2011.

534 Ebd.

535 Ebd.

536 StA Krefeld, AZ 4 AR 53/13. Bei der chilenischen Justiz trägt das RHE das AZ Corte Suprema, AZ 4854-2013.

537 Corte Suprema AZ 42464-2017. Schreiben des Ministeriums der Justiz des Landes NRW an die chilenische Justiz vom 10.10.2017, GZ: 9352E-III.213/13. 
an der CA Talca (vgl. Abschnitt 5.1.4) »zum Stand der Ermittlungen in Chile und zu den Parallelen zu den deutschen Ermittlungsverfahren «. ${ }^{538}$ Im April 2018 reiste eine Delegation der deutschen Justiz nach Chile, um mit den dortigen Kolleg_innen Möglichkeiten einer Kooperation bei der Aufklärung von CD-Verbrechen zu erörtern. ${ }^{539}$ Auch Verhandlungen zur Vereinfachung des Rechtshilfeverkehrs soll es gegeben haben. ${ }^{540} \mathrm{Ob}$ eine entsprechende Vereinbarung tatsächlich unterzeichnet wurde, ist nicht bekannt.

Erschwert wurde das Verfahren durch die Verjährungsproblematik: Bei den Ermittlungen wegen Beihilfe zum sexuellen Missbrauch konnten nur sechs Taten berücksichtigt werden, die übrigen Taten zwischen 1993 und 1997 waren nach deutschem Recht verjährt. Die Verjährung setzte zum Tatzeitpunkt zehn Jahre nach Eintreten der Volljährigkeit eines Opfers ein. Das chilenische Urteil hatte sich auf Taten an 27 Opfern bezogen. Auch für die Ermittlungen wegen gefährlicher Körperverletzung galt eine Verjährungsfrist von zehn Jahren, weshalb nur nach 2001 begangene Taten in Betracht kamen. Einzig die Ermittlungen wegen Mordes waren nicht von Verjährungsfristen betroffen, da Mord nach deutschem Recht nicht verjährt.

Beim Tatkomplex sexueller Missbrauch ermittelte die StA Krefeld wegen Beihilfetaten des früheren Leiters des CD-Krankenhauses Hopp, für die dieser in Chile bereits verurteilt worden war. Nach Auswertung des chilenischen Urteils erklärte die StA, dass bei den noch nicht verjährten Taten des Haupttäters Paul Schäfer »im Hinblick auf die Stellung und Funktion des Beschuldigten Dr. Hopp in der CD zureichende tatsächliche Anhaltspunkte für verfolgbare Straftaten in Form der Beihilfe gegeben« seien. ${ }^{541}$ Eigene Ermittlungen unternahm die StA Krefeld vorerst jedoch nicht. Grund hierfür war vermutlich das seit 2013 anhängige Vollstreckungsersuchen aus Chile (vgl. Abschnitt 5.3.9). Wäre dieses erfolgreich gewesen, hätte Hopp nicht wegen derselben Taten erneut strafverfolgt werden können.

Erst 2018 kam es im Rahmen des Krefelder Rechtshilfeersuchens zur Vernehmung von fünf chilenischen Missbrauchsopfern durch die Richterin von Parral. Die fünf Betroffenen wurden dabei nach konkreten Beihilfehandlungen durch Hartmut Hopp befragt. Drei der Befragten machten konkrete Angaben über den Erhalt von Medikamen-

538 Ebd.

539 Die Delegation bestand aus zwei Vertretern des BM] (Nicolaus Alvino und Dirk Mierow), zwei Staatanwält_innen aus NRW (OStA Axel Stahl, StA Krefeld sowie OStAin Monika Volkshausen, LM] NRW) sowie aus Anette Werth, stellvertretende Leiterin der Abteilung für internationales Strafrecht des AA. Die Delegation führte Cespräche mit den Richter_innen Mario Carroza, Hernán Conzález und Alejandra Castro sowie mit einer Gruppe von Rechtsanwält_innen, die Ceschädigte der CD vertreten. Vgl. Knobbe, Martin, „Deutsche Staatsanwälte ermitteln in Chile«, in: Spiegel Online vom 21.04.2018, online unter https://www.spiegel.de/panorama/justiz/coloniadignidad-deutsche-staatsanwaelte-ermitteln-in-chile-a-1204100.html sowie Dannemann, Victoria. Colonia Dignidad: Chile y Alemania impulsan colaboración judicial, in: Deutsche Welle (Website), 25.04.2018, online unter https://p.dw.com/p/2weeB.

540 Gegenstand war vor allem der Einsatz von Kommunikationsmitteln wie Videokonferenzen zur Koordinierung der Ermittler_innen und der Vernehmung von Zeug_innen. Vgl. Deutscher Bundestag. Drucksache 19/3380 vom 11.07.2018. Antwort der Bundesregierung auf die Kleine Anfrage der Fraktion DIE LINKE - Drucksache 19/2955 - Stand der Aufarbeitung der Verbrechen der Colonia Dignidad, S. 2. 
ten, die sie vor den Taten betäuben und gefügig machen sowie Erinnerungen an die Tat unterdrücken sollten. Neben seiner herausragenden Stellung in der Struktur der CD aufgrund seines Vertrauensverhältnisses zu Paul Schäfer war Hopp als Leiter des Krankenhauses verantwortlich für die Beschaffung und die Handhabung von Medikamenten in der CD.

Beim Tatvorwurf der gefährlichen Körperverletzung durch Medikamentenvergabe vertrat RAin Schlagenhauf die Eheleute Gudrun und Wolfgang Müller Ahrend, die beide in der CD ohne jegliche medizinische Indikation jahrzehntelang mit Psychopharmaka misshandelt worden waren. Wolfgang Müller musste zudem 2002 unter Einfluss von Medikamenten Dacharbeiten verrichten und brach sich dabei das Sprunggelenk. Im Krankenhaus litt er unter schweren Entzugserscheinungen, da er die Psychopharmaka, von denen er zu dem Zeitpunkt abhängig war, plötzlich nicht mehr erhielt. Neben Wolfgang Müller vernahm die Staatsanwaltschaft vier weitere Zeug_innen, welche die Praxis der systematischen Misshandlung mit Medikamenten in der CD detailreich schilderten. Die StA vernahm aber auch sieben von Hopp benannte Entlastungszeug_innen. Hopps Verfahrensbeistände reichten zudem eine eidesstattliche Erklärung der CD-Ärztin Gisela Seewald ein. Diese gab an, die Misshandlungen mit Elektroschocks und Psychopharmaka auf Anweisung Schäfers praktiziert zu haben. Hopp habe auf Anweisung Schäfers nichts davon erfahren dürfen. ${ }^{542}$ Im Juni 2013 verstarb Gisela Seewald in Chile.

Die Ermittlungen wegen Mordes bezogen sich auf die 1976 entführten und verschwundenen Juan Maino, Elizabeth Rekas und Antonio Elizondo. In den entsprechenden chilenischen Verfahren war Hopp bezüglich dieser Personen wegen »secuestro calificado«, also Entführung in besonders schweren Fällen angeklagt. RAin Schlagenhauf vertrat hier einen Angehörigen von Elizabeth Rekas. In ihrer Strafanzeige führte sie aus, dass die drei Verschwundenen 1976 Indizien und Aussagen zufolge in die CD verbracht worden waren, wo die DINA gemeinsam mit der CD-Führungsriege ein Gefangenenund Folterlager betrieb. Schlagenhauf reichte eine Reihe von Dokumenten und Aussagen aus chilenischen Verfahren ein, die die Existenz dieses Lagers sowie Hopps Rolle in der CD-Führung belegten. Sie benannte als Zeugen einen ehemaligen Leibwächter von DINA-Chef Contreras, der u.a. aussagte, dass Contreras bei Besuchen der CD stets von Hopp empfangen worden sei. Für das DINA-Hauptquartier in Santiago habe Hopp über eine Zugangskarte der höchsten Stufe verfügt, die einen Zutritt ohne Beschränkungen ermöglichte. Die Staatsanwaltschaft vernahm diesen Zeugen nicht - auch die meisten anderen von der Nebenklage benannten Zeug_innen wurden nicht vernommen.

\section{Die Verfahrenseinstellung}

Am 6. Mai 2019 stellte die Staatsanwaltschaft Krefeld ihre Ermittlungen nach \$170 (2) StPO ein. Sie erklärte dazu:

»Nach umfangreichen und langwierigen Ermittlungen, die in Kooperation mit den chilenischen Strafverfolgungsbehörden geführt worden sind, konnte nach Ausschöpfung

542 StA Krefeld, AZ 3 ]s 753-2011, Bd. III, BI. 655ff. Eidesstattliche Versicherung von Gisela Seewald vom 09.02.2012. 
aller erfolgversprechender Ermittlungsansätze ein für eine Anklageerhebung erforderlicher hinreichender Tatverdacht unter keinem rechtlichen Cesichtspunkt begründet werden. ${ }^{543}$

So habe der Beschuldigte jegliche Tathandlung bestritten. Die Ermittlungen hätten zu keinerlei Beweisen oder Ansatzpunkten geführt, die zu einer Verurteilung nach den Anforderungen des deutschen Straf- und Strafverfahrensrechts hätten führen können. So könne beispielsweise die Beteiligung an einem Mord strafrechtlich nicht alleine durch Hopps Stellung innerhalb der CD nachgewiesen werden. Weiter argumentierte die StA, es sei »eher fernliegend «, dass der damals 32-jährige »Student der Medizin« Hopp »von dem mehr als 20 Jahre älteren Paul Schäfer« in Hinrichtungen »eingeweiht worden wäre ${ }^{544}$ Weder für Hopps Kenntnis von den Morden noch für seine Beihilfe zu diesen lägen Beweismittel vor, so die StA. Eine Zurechnung nach den Grundsätzen, wie sie der Bundesgerichtshof für die in den Betrieb der nationalsozialistischen Konzentrationslager eingeordneten Personen entwickelt, käme nicht in Betracht. Der Nebenklägerin, RAin Schlagenhauf, teilte die StA in ihrer Einstellungsverfügung ferner mit:

»Eine Vernehmung der zahlreichen Ihrerseits benannten Zeugen ist mangels Erfolgsaussicht nicht veranlasst, da weder vorgetragen noch sonst ersichtlich ist, dass sich aus den Bekundungen der Zeugen zur Überführung des Beschuldigten geeignete Erkenntnisse ergeben könnten. ${ }^{545}$

Bezüglich der Vorwürfe zur Beihilfe zum sexuellen Missbrauch bezog sich die StA Krefeld auf den Beschluss des OLG Düsseldorf zum Haftvollstreckungsersuchen. Dieses hatte wenige Monate zuvor die Vollstreckung des chilenischen Urteils gegen Hopp abgelehnt (vgl. Abschnitt 5.3.9). Auch Vernehmungen von fünf der Geschädigten in Chile 2018 seien im Hinblick auf einen Tatbeitrag Hopps "gänzlich unkonkret " gewesen, so die StA. Diese Feststellung überrascht insofern, als einige Geschädigte in ihren Aussagen beispielsweise schilderten, wie Hopp veranlasste, dass ihnen vor den Missbrauchstaten Medikamente verabreicht wurden, die Schläfrigkeit und Gedächtnisverlust bewirkten, aber auch, dass Hopp am Eingang zu Schäfers Zimmer stand, als die Geschädigten dort hineingeführt wurden, um missbraucht zu werden. ${ }^{546}$

Hinsichtlich der Vorwürfe der gefährlichen Körperverletzung erklärte die Staatsanwaltschaft, sie habe keine rechtswidrigen Verabreichungen von Medikamenten durch Hopp feststellen können. Auch hätten die Anzeigenden keine »hinreichend konkreten Angaben« gemacht, "welche Medikamente sie in welcher Dosierung während des tatrelevanten Zeitraums wann genau von dem hier Beschuldigten oder auf dessen Ver-

543 StA Krefeld, Pressemitteilung vom 06.05.2019, online unter https://www.sta-krefeld.nrw.de/behoerde/presse/Presseerklaerung-zu-3-]s-753-11-Ermittlungverfahren-gegen-Hartmut-H.pdf.

544 StA Krefeld, AZ 3 ]s 753-2011. Einstellungsverfügung vom 06.05.2019 an Rechtsanwältin Schlagenhauf.

545 Ebd.

546 StA Krefeld, AZ 3 ]s 753-2011, Sonderband III. Aussagen von J. P. (20.02.2018), E. U. (02.03.2018) und J. C. (20.02.2018). 
anlassung erhalten haben wollen. $"{ }^{547}$ Auch sei nicht feststellbar, dass die etwaige Vergabe von Psychopharmaka ohne medizinische Indikation und damit rechtswidrig erfolgt sei.

Menschenrechtsanwält_innen und Expert_innen reagierten bestürzt und fassungslos auf die Verfahrenseinstellung sowie auf die Begründung der Staatsanwaltschaft. ${ }^{548}$ In einer gemeinsamen Presseemitteilung erklärten das Forschungs- und Dokumentationszentrum Chile-Lateinamerika (FDCL) und das European Center for Constitutional and Human Rights (ECCHR):

»Die Entscheidung der Staatsanwaltschaft Krefeld reiht sich ein in eine lange Kette des Nichthandelns. Die Betroffenen sind fassungslos, ihr Vertrauen in die deutsche Justiz ist erschüttert. In Deutschland und in Chile leben etliche Betroffene und Zeugen der Verbrechen, die in der Colonia Dignidad begangen wurden. Sie sind bereit auszusagen, etwa zur Rolle von Hartmut Hopp bei Folter und Mord an Gegnern des PinochetRegimes auf dem Gelände der Sektensiedlung. Doch die Staatsanwaltschaft Krefeld hat diese Zeugen schlicht ignoriert. ${ }^{549}$

Hopp hingegen empfand das Urteil als Sieg. Er erklärte, sein Glaube an Gerechtigkeit und Rechtsstaatlichkeit in Deutschland habe sich bestätigt:

»Ich finde es abscheulich, was in der Colonia Dignidad an Grausamkeiten geschehen ist, die von mir und der großen Mehrheit der ehemaligen Bewohner der Colonia Dignidad aufgrund des dort herrschenden System niemals vermutet wurden. Meine Cedanken sind bei den Opfern und deren Familien, für die ich zusammen mit meinen engsten Angehörigen bete und auf Trost für sie hoffe. ${ }^{550}$

Rechtsanwältin Petra Schlagenhauf legte Beschwerde gegen die Verfahrenseinstellung ein, die im Dezember 2020 von der Generalstaatsanwaltschaft Düsseldorf zurückgewiesen wurde. ${ }^{551}$ Ein daraufhin von Rechtsanwältin Schlagenhauf eingereichter Antrag auf gerichtliche Entscheidung (Klageerzwingung) wurde vom OLG Düsseldorf im April

547 StA Krefeld, AZ 3 ]s 753-2011. Einstellungsverfügung vom 06.05.2019 an Rechtsanwältin Schlagenhauf. Hervorhebung im Original.

548 Vgl. Burghardt, Peter, »Freiheit der Schergen«, in: Süddeutsche Zeitung vom 08.05.2019, S. 6 sowie Dannemann, Victoria. Colonia Dignidad - Opfer kritisieren deutsche Justiz, in: Deutsche Welle (Website), 08.05.2019, online unter https://p.dw.com/p/3lApz.

549 Forschungs- und Dokumentationszentrum Chile-Lateinamerika (FDCL). Pressemitteilung »Colonia Dignidad: Vertrauen der Betroffenen in deutsche Justiz erschüttert.«, 07.05.2019, online unter https://www.fdcl.org/pressrelease/2019-05-07-colonia-dignidad-vertrauen-der-betroffenen-i n-deutsche-justiz-erschuettert/.

550 PJS, Pressemitteilung Rechtsanwalt Helfried Roubicek vom 07.05.2019.

551 GStA Düsseldorf. Pressemitteilung 6/20 vom 09.12.2020. Beschwerdeentscheidung hinsichtlich der Einstellung des bei der Staatsanwaltschaft Krefeld geführten Ermittlungsverfahrens gegen den Beschuldigten Hartmut H. wegen Beihilfe zum Mord u.a., online unter https://www.gsta-due sseldorf.nrw.de/behoerde/presse/Pressemitteilung-Nr_-6_20-091220.pdf. 
2021 abgelehnt. ${ }^{552}$ Das ECCHR richtete eine Fach- und Dienstaufsichtsbeschwerde an den Justizminister von Nordrhein-Westfalen, Peter Biesenbach. ${ }^{553}$

Bei Betroffenen und Menschenrechtsaktivist_innen herrschten Bestürzung und Unverständnis ob der langen Verfahrensdauer und der ergebnislosen Einstellung der Ermittlungen. Zweimal - im März 2013 und im Juni 2018 fanden Protestaktionen, sogenannte »Funas«, vor Hopps Wohnung in Krefeld statt. ${ }^{554}$

Das hier beschriebene Verfahren war vermutlich die letzte Ermittlung bundesdeutscher Justizbehörden wegen Verbrechen der Colonia Dignidad. Es wies starke Parallelen zu den Ermittlungsverfahren der Staatsanwaltschaft Bonn (vgl. Abschnitte 5.3.3 bis 5.3.7), insbesondere zwischen 1985 und 2010 auf: Dazu gehören der Verweis auf lang zurückliegende und teilweise verjährte Taten, die lange Verfahrensdauer, das Fehlen eigenständiger Ermittlungen und der Vorwurf an die Opfer, die vorgeworfenen Taten nicht hinreichend konkret belegen zu können. Eine Vernehmung von in Chile lebenden Geschädigten oder Zeug_innen ${ }^{555}$, die auf dem Wege der Rechtshilfe oder bei Vorladung und freiwilligem Erscheinen in der Botschaft durchaus möglich gewesen wäre, blieb weitgehend aus. Zugleich wurden die von der Verteidigung eingereichten entlastenden eidesstattlichen Erklärungen sehr wohlwollend gewertet. Auch das energische Auftreten des Anwalts von Hopp scheint auf die StA gewirkt zu haben. Weitere Aspekte sind die Anhörung einer hohen Zahl entlastender Zeug_innen sowie die geringe Glaubwürdigkeit, die den Belastungszeug_innen zugeschrieben wurde. Die Ermittlungen zeugen von Ignoranz gegenüber dem Hintergrund der CD und der CDVerbrechen, aber auch gegenüber der chilenischen Justiz, inklusive der fehlenden Berücksichtigung von Dokumenten, Aussagen und Kontextinformationen aus anderen juristischen Verfahren. Anstatt eigenständige Ermittlungen durchzuführen, Hinweisen nachzugehen und Zeug_innen zu befragen, beschränkte sich die StA Krefeld vor allem auf die Übersetzung und Durchsicht chilenischer Gerichtsurteile. Trotz politischen Drucks und entsprechender Willensbekundungen aus der Politik ${ }^{556}$ entschied sich die

552 OLG Düsseldorf, AZ III Ws 19/21 - 3]s753/11 StA Krefeld. Beschluss vom 01.04.2021.

553 ECCHR. Fachaufsichtsbeschwerde gegen die Entscheidungen von OStA'in Alexander (Staatsanwaltschaft Krefeld) im Ermittlungsverfahren gegen Hartmut Hopp wg. Mord u.a. (Aktz. 3 ]s 753/11) sowie von OStA Müller (CStA Düsseldorf) im Beschwerdeverfahren (Aktz. 4 Zs 1733/19) sowie Dienstaufsichtsbeschwerde gegen OStA Klaus Schreiber (StA Krefeld) vom 28.01.2021.

554 Zur Protestaktion in Krefeld am 24.03.2013 vgl. Burghardt, Peter, »Der Sektenarzt von nebenan«, in: Süddeutsche Zeitung vom 25.03.2013, S. 6 sowie Beucker, Pascal, »Keine Ruhe für Dr. Hopp«, in: die tageszeitung vom 25.03.2013, S. 4. Zur Protestaktion in Krefeld am 16.06.2018 vgl. Löhning, Ute, »Der Sektenarzt aus Krefeld«, in: die tageszeitung vom 17.06.2018, online unter https://www.taz.de/Colonia-Dignidad-in-Chile/!5511389/ sowie Westdeutsche Zeitung vom 25.06.2018, »Hopp soll sein Schweigen brechen«.

555 Einzige Ausnahme war die Vernehmung von fünf chilenischen Missbrauchsopfern sowie des CoIonos Willi Malessa im Rahmen des RHE der StA Krefeld 2018.

556 Deutscher Bundestag. Drucksache 18/12943 vom 27.06.2017. Antrag der Fraktionen CDU/CSU, SPD und BÜNDNIS 90/DIE GRÜNEN. Aufarbeitung der Verbrechen in der Colonia Dignidad. Darin forderte der Bundestag im Juni 2017 die Bundesregierung auf, »die ihr zur Verfügung stehenden Maßnahmen zu ergreifen, um die strafrechtlichen Ermittlungen in Deutschland und in Chile voranzutreiben.«(ebd., S. 4). 
Justiz in Nordrhein-Westfalen gegen eine Vertiefung und Bündelung der Ermittlungen in Form von Strukturermittlungen durch BKA und Generalstaatsanwaltschaft.

\subsubsection{Chilenisches Vollstreckungsersuchen zu Hartmut Hopp (2014-2018)}

Nach Hopps Flucht nach Deutschland 2011 reiste die Rechtsanwältin Petra Schlagenhauf mehrfach nach Chile. Sie erklärte Vertreter_innen von Regierung und Justiz - darunter den ermittelnden Richtern Jorge Zepeda und Hernán González -, dass eine Auslieferung deutscher Staatsangehöriger z.B. nach Chile per Grundgesetz ausgeschlossen sei. Zugleich wies sie auf das Internationale Rechtshilfegesetz (IRG) hin. Dieses sieht ein Exequaturverfahren vor, nach dem bei rechtskräftigen Urteilen aus dem Ausland die Haft in Deutschland vollstreckt werden kann. Hierfür muss eine Reihe von Voraussetzungen erfüllt sein, die die $\$ \$ 48$ und 49 des IRG regeln. So muss Chile der deutschen Justiz ein Haftvollstreckungsersuchen übermitteln und darin darlegen, dass das entsprechende Urteil durch ein rechtsstaatliches Verfahren zustande gekommen ist, in dem der Verurteilte Zugang zu einer angemessenen Verteidigung, zu rechtlichem Gehör sowie einem Verfahren durch mehrere unabhängige Instanzen hatte. Am 25. Januar 2013 wurde das Urteil gegen Hartmut Hopp wegen Beihilfe zum sexuellen Missbrauch rechtskräftig. ${ }^{557}$ Schlagenhauf riet der chilenischen Seite daraufhin, ein solches Vollstreckungsersuchen zu übermitteln. Im August 2013 sandte das AA zudem dem chilenischen Außenministerium ein sogenanntes Non-Paper, das auf die Möglichkeit eines Haftvollstreckungsersuchens nach IRG hinwies. ${ }^{558}$

Im Juli 2014 stellte die chilenische Justiz ein entsprechendes Ersuchen, in Ergänzung zum bereits laufenden Auslieferungsantrag. ${ }^{559}$ Die Justiz von NRW eröffnete daraufhin ein Exequaturverfahren nach $\$ \$ 48 \mathrm{ff}$. IRG, um die Rechtmäßigkeit der Vollstreckung in Deutschland zu überprüfen. An dieser Überprüfung waren keine Opfervertreter_innen beteiligt. Die StA Krefeld übernahm darin faktisch die Vertretung der antragstellenden chilenischen Justiz. Die chilenische Regierung verzichtete auf ihre Möglichkeit, einen Verfahrensbevollmächtigen in Deutschland zu benennen, obwohl chilenische Menschenrechtsorganisationen sie mehrfach dazu aufgefordert hatten. ${ }^{560}$ Ver-

557 Corte Suprema, AZ 3579-2011, Urteil vom 25.01.2013.

558 Ein Non-Paper ist ein Dokument der zwischenstaatlichen Kommunikation mit inoffiziellem Charakter, ohne Briefkopf, das auf informellem Wege übermittelt wird. Vgl. Auslieferungsvorgang Hopp, Corte Suprema, AZ 4146-2013. Schreiben Ministerio de Relaciones Exteriores (Dirección de Asuntos Jurídicos) an Corte Suprema vom 08.08.2013, RREE (Dir]ur) OF.PUB. Nr. 009715. Anlage »Non Paper«.

559 Poder Judicial. Noticias del Poder Judicial vom 03.07.2014. „Corte Suprema solicitó a Alemania que Harmut Hopp cumpla condena por abusos sexuales en ese país«, übernommen von https://www.biobiochile.cl/noticias/2014/07/03/corte-suprema-solicita-a-alemania-que-harmu t-hopp-cumpla-condena-por-abuso-sexual-en-ese-pais.shtml.

560 So trafen beispielsweise Vertreter_innen der Asociación por la Memoria y los Derechos Humanos Colonia Dignidad (AMCD) in Berlin den chilenischen Außenminister Heraldo Muñoz und forderten ihn auf, einen Prozessbevollmächtigten für das Vollstreckungsverfahren zu benennen. Muñoz versprach eine Prüfung dieser Möglichkeit. Vgl. Asociación por la Memoria y los Derechos Humanos Colonia Dignidad (AMCD). »El canciller Heraldo Muñoz se reúne con AMCD en Berlín«, 30.10.2014, online unter https://asociacioncoloniadignidad.wordpress.com/2014/10/30/el-canciller-heraldo-mu 
fahrensbeteiligte waren somit ausschließlich Hopp bzw. sein Rechtsbeistand sowie die Staatsanwaltschaft. Nur diese Beteiligten konnten ihre Sichtweise in das Verfahren einbringen und Zugang zu den Akten erhalten.

Im Juni 2016 beantragte Axel Stahl, der Krefelder Oberstaatsanwalt, Haftvollstreckung. ${ }^{561}$ Er sah die im IRG dargelegten Voraussetzungen als erfüllt an. Das LG Krefeld folgte seiner Argumentation mit seinem Beschluss im August 2017. Es erklärte:

»Die Voraussetzungen der Zulässigkeit der Vollstreckung der ausländischen Entscheidung nach $\S 48,49$ IRG liegen vor. Insbesondere ist das ausländische Erkenntnis unter Beachtung der wesentlichen Verfahrensgarantien im Sinne von $\S 49$ Abs. 1 Nr. 2 IRC ergangen. ${ }^{562}$

Dabei argumentierte das LG, dass kein Verstoß gegen wesentliche Verfahrensgarantien feststellbar sei. Das chilenische Verfahren entspreche den Grundprinzipien des fairen Verfahrens und den wesentlichen Standards der Europäischen Menschenrechtskonvention. Der Verurteilte habe rechtliches Gehör bekommen, und über eine angemessene Verteidigung verfügt. Das Gericht sei unabhängig gewesen. Hopps Haftstrafe (knapp über fünf Jahre ohne Bewährung) wurde durch den Beschluss in eine deutsche Haftstrafe umgewandelt.

Hopps Anwalt Roubicek legte dagegen Beschwerde beim OLG Düsseldorf ein. Am 20. September 2018 gab das OLG Düsseldorf als letzte Instanz dieser Beschwerde überraschend statt und verwarf die Vollstreckung des Urteils. ${ }^{563}$ Es argumentierte, Hopps Verhalten, für das er in Chile verurteilt worden war, sei nach deutschem Recht nicht strafbar. Hopp könne auch nicht allein aufgrund seiner Zugehörigkeit zur CD-Führung der Beihilfetätigkeit für schuldig befunden werden. Im Unterschied zur jüngeren deutschen Rechtsprechung bei der Mittäterschaft in NS-Konzentrationslagern, die alleine dem Zweck des Massenmordes gedient hätten, habe die CD dem OLG zufolge "gerade nicht ausschließlich kriminellen Zwecken« gedient. Vielmehr sei sie »ursprünglich als Wohltätigkeits- und Erziehungsgesellschaft gegründet worden«. »Entsprechend dieser Zwecksetzung«, so das OLG, »erhielten dort Kinder aus der Umgegend Schulunterricht. Für die Landbevölkerung wurde erstmals ein Krankenhaus vorgehalten. «" ${ }^{564}$ Das Gericht lieferte keine Begründung dafür, weshalb es die inzwischen durch zahlreiche Verfahren widerlegte Selbstdarstellung der CD übernahm. Es fuhr fort, dass Hopp im chilenischen Urteil keine konkreten Handlungen nachgewiesen werden konnten, die den deutschen Straftatbestand der Beihilfe zum sexuellen Missbrauch erfüllen. Daraus

noz-se-reune-con-amcd-en-berlin/ sowie Peter Burghardt, »Deutsche Abgründe«, in: Süddeutsche Zeitung vom 29.10.2014, S. 7.

561 Spiegel Online vom 07.06.2016. "Sektenarzt soll in Deutschland in Haft«: https://www.spiegel.de/panorama/justiz/colonia-dignidad-sektenarzt-soll-in-deutschland-in-haft-a1096367.html.

562 LG Krefeld, AZ 21 StVK 218/16. Beschluss vom 14.08.2017. II, 20-21, online unter https://www.justiz. nrw.de/nrwe/lgs/krefeld/lg_krefeld/j2017/21_StVK_218_16_Beschluss_20170814.html.

563 OLC Düsseldorf, AZ III-3 AR 158/17. Beschluss vom 20.09.2018, online unter https://www.olg-duesseldorf.nrw.de/behoerde/presse/Presse_aktuell/20180924_PM_Colonia_Dignidad/20180920Beschluss-III-3-AR-158-17-.pdf (zuletzt abgerufen am 29.09.2018). 
schloss das OLG, Hopps Verhalten müsse als »neutral« und somit »strafrechtlich nicht zu beanstandende sozialadäquate Handlung ${ }^{565}$ beurteilt werden.

Während sich das LG Krefeld also auf die im IRG vorgesehene Prüfung der Einhaltung rechtsstaatlicher Verfahrensstandards beschränkte, bewertete das OLG Düsseldorf die Tatsachen, die der Verurteilung Hopps durch chilenische Gerichte zugrunde lagen, nach deutschem Recht. Damit missachtete das OLG nach Ansicht von Fries/Schüller den Charakter des Exequaturverfahrens als reinem Akt der Rechtshilfe. ${ }^{566}$ Zugleich ermöglichte das OLG aber auch keine ergänzende Beweisaufnahme, sei es durch chilenische Behörden oder durch das Gericht selbst. ${ }^{567}$

Die Bewertung der CD durch das OLG löste bei Menschenrechtsanwält_innen, Expert_innen und Medienvertreter_innen Fassungslosigkeit aus. Die Rechtsanwälte Wolfgang Kaleck und Andreas Schüller sprachen von einem »Justizskandal ${ }^{568}$ die Süddeutsche Zeitung bezeichnete es als ein »verstörendes Urteil« und einen »Tiefpunkt im Umgang mit den Verbrechen « der CD. ${ }^{569}$ Die Feststellung, die CD habe nicht ausschließlich kriminellen Zwecken gedient, sondern soziale und gesundheitsfürsorglichen Ziele verfolgt, klinge für die Opfer der CD wie ein Hohn, so die Zeitung. Petra Schlagenhauf resümierte, der Beschluss reihe sich in eine lange Reihe von Entscheidungen der deutschen Justiz ein, welche die tatsächlichen Verhältnisse in der CD unzutreffend beurteile, und die de facto herrschende Straflosigkeit für die Täter fortsetze. Sie sagte: »Wer davon ausgeht, dass es in der CD überwiegend normal und sozialadäquat zuging, hat nichts verstanden. ${ }^{570}$

Der Beschluss des OLG Düsseldorf war nicht anfechtbar. Es ist davon auszugehen, dass er die wenig später getroffenen Entscheidungen anderer Staatsanwaltschaften in Nordrhein-Westfalen, ihre noch laufenden Ermittlungen in Sachen CD einzustellen (vgl. Abschnitte 5.3.8 und 5.3.10), maßgeblich beeinflusst hat. Dass die CD noch 2018 höchstrichterlich als Wohltätigkeitsorganisation eingestuft wurde, dürfte sich sehr demotivierend auf die mit CD-Verbrechen befassten Staatsanwaltschaften ausgewirkt haben.

Ebd., S. 15.

Fries, Mirka/Andreas Schüller. Sozialadäquates Verhalten, in: Freispruch. Mitgliederzeitung der Strafverteidigervereinigungen 14 (2019), S. 41-46.

67 European Center for Constitutional and Human Rights (ECCHR). Rechtliche Stellungnahme zum Beschluss des Oberlandesgerichts Düsseldorf in Sachen Hartmut Hopp/Colonia Dignidad, Oktober 2018, online unter https://www.ecchr.eu/fileadmin/user_upload/Stellungnahme_zum_Beschlu ss_OLG_Ddorf_im_Fall_Hartmut_Hopp_Colonia_Dignidad.pdf.

568 Kaleck, Wolfgang/Andreas Schüller. Colonia Dignidad, ein deutscher Justizskandal, in: Legal Tribune Online, 17.10.2018, online unter https://www.Ito.de/recht/hintergruende/h/colonia-dignidadjustizskandal-nrw-chile-pinochet-hopp-sekte/.

569 Burghardt, Peter, »Verstörendes Urteil«, in: Süddeutsche Zeitung vom 27.09.2018, S. 4.

Forschungs- und Dokumentationszentrum Chile-Lateinamerika (FDCL). Pressemitteilung »Beschluss des OLC Düsseldorf lehnt Vollstreckung der chilenischen Verurteilung von Hartmut Hopp ab. Justizversagen im Fall Colonia Dignidad nimmt kein Ende.«, 26.09.2018, online unter https://www.fdcl.org/pressrelease/2018-09-26-beschluss-des-olg-duesseldorf-lehnt-vollstrecku ng-der-chilenischen-verurteilung-von-hartmut-hopp-ab/. 


\subsubsection{Ermittlungen der StA Münster (2016-2019)}

Im September 2005 erließ die chilenische Justiz einen internationalen Haftbefehl gegen Reinhard Döring wegen Entführung und Verschwindenlassens von Juan Maino, Elisabeth Rekas und Antonio Elizondo. ${ }^{571}$ Döring hatte sich 2004 nach Deutschland abgesetzt. Da er als Deutscher nicht nach Chile ausgeliefert werden konnte, wurde er nicht festgenommen. Allerdings gab es auch keine Ermittlungen deutscher Strafverfolgungsbehörden gegen Döring. Jahre später - im September 2009 - vernahm die StA Bonn Döring als Zeugen im Rahmen eines anderen Ermittlungsverfahrens. ${ }^{572}$ Dabei gab Döring an, von Kontakten der CD zur DINA gewusst und DINA-Chef Contreras in der CD gesehen zu haben (vgl. Abschnitt 5.3.5). Er habe sich jedoch lediglich mit den Fahrern der DINA-Führungsmitglieder unterhalten. Er sei auch selbst an der Bewachung von Gefangenen beteiligt gewesen und habe »für die Ernährung gesorgt «. Auf die Frage nach der Anzahl der Gefangenen antwortete er: "Das waren wohl so 10 bis 15. Das hat sich gesteigert. Am Anfang waren es vielleicht drei oder vier. Dann kamen auch wieder welche weg. ${ }^{573}$ Unter den Gefangenen sei »Milovic, ein Pole« gewesen. Dabei handelte es sich um den mazedonischstämmigen Mile Mavrovski, der 1974 zwölf Monate in der CD inhaftiert war, wo er verhört und gefoltert wurde. ${ }^{574}$ Mit Erschießungen von Gefangenen oder der Beseitigung von Leichen habe er, Döring, jedoch nichts zu tun gehabt.

Am 21. Juli 2016 erneuerte die chilenische Justiz ihr Festnahmeersuchen und die Staatsanwaltschaft Münster eröffnete ein Ermittlungsverfahren gegen Döring. ${ }^{575}$ Die Öffentlichkeit, aber auch Geschädigte und deren Vertreter_innen wussten zunächst nicht von diesen Ermittlungen. Im April 2018 erstattete das European Center for Constitutional and Human Rights (ECCHR) Strafanzeige gegen Döring wegen Beihilfe zum Mord an Juan Maino, Elizabeth Rekas und Antonio Elizondo. Gestützt auf chilenische Urteile und Ermittlungsergebnisse legte es dar, dass zwischen 1973 und 1976 in der CD mindestens 20 Personen erschossen wurden, deren Leichen später beseitigt wurden. Zur Rolle Dörings wurden auch Sachverhalte genannt, die über dessen Aussage von 2009 hinausgingen. So soll Döring an gemeinsamen Kursen sowie militärischen Operationen von DINA- und CD-Angehörigen mitgewirkt haben. Die Anzeige erwähnte auch eine Aussage des in Österreich lebenden Ex-Colonos Wilhelm Wagner. ${ }^{576}$ Dieser hatte beteuert, 1974 oder 1975 gemeinsam mit Döring zwei Fahrzeuge (vermutlich der DINA) mit Gefangenen in ein Waldstück gefahren zu haben. An einer bestimmten Stelle seien Döring und er ausgestiegen. Die Fahrzeuge seien noch ein Stück weiter in den Wald gefahren, dann sei eine heftige Schusssalve zu hören gewesen. Wenig später seien die

571 CA Santiago, AZ 2182-98 (»]uan Maino«).

572 StA Bonn, AZ 555 ]s 315/06.

573 StA Bonn, AZ 555 ]s 315/06 K, Bd. I, BI. 292f. Vernehmung von Reinhard Döring vom 07.09.2009.

574 CA Santiago AZ 2182-98 (»]uan Maino«), Bd. 6a, BI. 2440ff. Richterliche Vernehmung von Mile Mavroski vom 04.01.2006.

575 StA Münster, AZ 30 ]s 306/16.

576 CA Santiago, AZ 2182-98 (»Lesiones graves«), Bd. I, BI. 33ff. Richterliche Vernehmung von Wilhelm Wagner vom 22.09.2005. 
zivil gekleideten DINA-Agenten ohne die Gefangenen zurückgekehrt und mit Wagner und Döring wieder zurück ins Dorf der Siedlung gefahren. ${ }^{577}$

Die Anzeigenden des ECCHR führten aus, dass Dörings Handlungen als Beihilfe zum Mord zu bewerten seien. Er habe gewusst, dass gemordet wurde und in welchem Rahmen dies geschah. Zudem sei Döring Teil eines inneren Kreises von Vertrauten um Paul Schäfer gewesen, der innerhalb eines Systems der Verbrechensbegehung bestimmte Aufgaben ausgeführt habe. ${ }^{578}$

Da eine Reise von Vertreter_innen des BMJV, des Justizministeriums NRW und des Krefelder Staatsanwalts Axel Stahl nach Chile kurz bevorstand, regte das ECCHR an, in Chile auch zu diesem Fall Verfahrensakten zu erheben und sich um Aussagen in Chile ansässiger Zeug_innen zu bemühen. Mit weiteren Schriftsätzen wurden Dokumente und Auszüge aus chilenischen Ermittlungsakten übermittelt und 26 Zeug_innen benannt. Die StA Münster reagierte nicht auf die Anregungen der Anzeigenerstatter_innen.

Am 22. Januar 2019 stellte die StA Münster das Ermittlungsverfahren nach $\$ 170$ II StPO ein. Aus ihrer Pressemitteilung, ${ }^{579}$ aber auch aus der Einstellungsverfügung, die dem ECCHR zuging, ist nicht erkennbar, dass die Staatsanwaltschaft während des Verfahrens irgendwelche eigenen Ermittlungsschritte unternommen hat. Die StA gab an, im November 2017 ein Rechtshilfeersuchen an die chilenische Justiz gerichtet zu haben und aus Chile eingegangene Dokumente ausgewertet zu haben. Von einer Vernehmung Dörings oder von Zeug_innen hatte die StA abgesehen, da Döring bereits bei seiner Vernehmung 2009 angegeben hatte, von Erschießungen nichts gewusst zu haben. Auch die chilenischen Ermittlungen hätten keine Belege für konkrete Tötungshandlungen erbracht, sondern nur die Entführung von Personen sowie die Exhumierung und Verbrennung von 40 bis 50 Leichen belegt. Die Möglichkeiten der Beweisführung seien aufgrund des hohen zeitlichen Abstands und der nachträglichen Vernichtung von Spuren sehr begrenzt. Schon den chilenischen Ermittler_innen sei es nicht gelungen, den genauen Todeszeitpunkt, den Todesort oder die Täter_innen festzustellen. Die StA führte aus: "Allein die (vielleicht zutreffende) Vermutung, die Vermissten könnten wegen ihrer politischen Einstellung und damit eventuell aus niedrigen Beweggründen im Sinne des $\$ 211$ StGB getötet worden sein, reicht für eine Strafverfolgung nicht aus. ${ }^{580}$ Auch wenn Döring Teil der von Paul Schäfer ausgehenden Befehlskette gewesen sei, bedeute dies nicht zwangsläufig, dass er in Einzelheiten der konkreten Verbrechen eingeweiht war und von den Exekutionen wusste. Dörings eigene Aussage, er habe von nichts gewusst, ließe sich nicht widerlegen, so die StA. Auch Wagners Aussage zum Transport der Gefangenen sei kein Beleg für eine Beihilfehandlung. Vielmehr deute die Tatsache, dass Wagner und Döring vor den Erschießungen aus den Wägen ausstiegen, darauf hin, dass Döring weder wusste noch wissen durfte, was Zeck des Transports war. ${ }^{581}$

578 StA Münster, AZ 30 ]s 306/16. Strafanzeige des ECCHR gegen Reinhard Döring vom 12.04.2018.

579 StA Münster. Presseerklärung vom 22.01.2019, online unter https://www.sta-muenster.nrw.de/beh oerde/presse/Archiv/Archiv_2019/Pressemitteilung-vom-22_01_2019.pdf. 
Auch argumentierte die StA Münster, dass es im Unterschied zu jüngeren Entscheidungen zur Mittäterschaft in NS-Konzentrationslagern nicht die vordringliche oder gar einzige Aufgabe der Colonos gewesen sei, gemeinsam mit der DINA Tötungsverbrechen zu begehen. Auch hätten die Tötungen in der CD im Verborgenen, außerhalb der eigentlichen Siedlung und zur Nachtzeit stattgefunden. Die Einlassung des Beschuldigten, er habe von Tötungen nichts gewusst, lasse sich daher allein aus den äußeren Umständen der Geschehnisse nicht widerlegen. Direkte Kontakte mit der DINA hätten sich auf die führenden Vertreter der CD beschränkt, zu denen Döring aber nicht gezählt habe. So habe Döring angegeben, dass er selbst von Schäfer missbraucht worden und in der CD lediglich als Baggerführer tätig war. Dies spreche gegen eine Führungsmitgliedschaft Dörings, so die StA. ${ }^{582}$

Das ECCHR kritisierte die Einstellung des Verfahrens scharf. ${ }^{583}$ So seien benannte Zeug_innen nicht vernommen worden. Die deutsche Justiz müsse sich fragen, wie es sein könne, dass die Täter der CD über Jahrzehnte unbehelligt in Deutschland leben konnten.

\subsection{Der Fall Colonia Dignidad im Deutschen Bundestag}

Als Legislative setzt der Deutsche Bundestag die gesetzlichen und institutionellen Rahmenbedingungen für Menschenrechtspolitik der Bundesrepublik. Dabei ist seine Einflussnahme auf die unmittelbare Gestaltung der Menschenrechtspolitik »angesichts der klassischen Kompetenzverteilung im parlamentarischen Regierungssystem relativ gering, aber durchaus gegeben. ${ }^{584}$ Neben Gesetzesinitiativen kann sie darin bestehen, dass Abgeordnete Vorgänge innerhalb oder außerhalb des Parlaments öffentlich thematisieren, beispielsweise durch Presseerklärungen, Anhörungen oder Delegationsreisen. Zudem besitzt der Bundestag zur parlamentarischen Kontrolle des Regierungshandelns sogenannte Interpellationsrechte, wie Fragestunden, schriftliche Fragen oder Kleine bzw. Große Anfragen an die Bundesregierung. Der Bundestag hat auch schon Untersuchungsausschüsse mit Bezug zu internationalen Menschenrechtsfragen eingesetzt. $^{585}$

Der Fall CD war für den Bundestag lange Zeit ein randständiges Thema, das nur vereinzelt aufgegriffen wurde, meist in Phasen hoher medialer Aufmerksamkeit aufgrund besonderer Ereignisse (vgl. Tabelle 1, Abschnitt 2.2.2). Vielfach handelte es sich

582 Ebd., S. 4.

583 European Center for Constitutional and Human Rights (ECCHR). Pressemitteilung vom 22.01.2019. »Colonia Dignidad: Deutsche Justiz bleibt untätig«, online unter https://www.ecchr.eu/nc/pressem itteilung/colonia-dignidad-deutsche-justiz-bleibt-untaetig/.

584 Voß, Silke, Parlamentarische Menschenrechtspolitik. Die Behandlung internationaler Menschenrechtsfragen im Deutschen Bundestag unter besonderer Berücksichtigung des Unterausschusses für Menschenrechte und humanitäre Hilfe (1972-1998), Düsseldorf 2000, S. 267.

585 So beispielsweise zur Lieferung von U-Boot-Bauplänen an das Apartheidsregime in Südafrika (1986-1990) oder zur Rolle der Bundesregierung nach dem Luftangriff der Bundeswehr in Kunduz, Afghanistan (2009). 
um Fragen oder Kleine Anfragen, größere Aktivitäten wie eine Anhörung 1988 sowie zwei Entschließungsanträge 2002 und 2017 waren äußerst selten.

Die erste dokumentierte Beschäftigung von Bundestagsabgeordneten mit dem Fall CD sind zwei Schreiben von 1966, wenige Monate nach Wolfgang Müllers Flucht aus der CD, die auch hierzulande große mediale Beachtung fand (vgl. Abschnitte 4.1.2 und 4.1.3). Die Abgeordnete Annemarie Griesinger (CDU) schrieb am 7. November an Außenminister Gerhard Schröder, »Wie auch in anderen Orten haben sich in meiner Heimat die Fragen gemehrt, wie es wohl in der deutschen Kolonie Dignidad bei Santiago de Chile zugehen mag. ${ }^{586}$ Sie fragte nach Angehörigen einer besorgten Bürgerin aus ihrem Wahlkreis und bat um »Prüfung der Verhältnisse« in der CD. ${ }^{587}$ Nach dem Wechsel an der Spitze des Bundesaußenministeriums antwortete Willy Brandt der Abgeordneten Griesinger am 6. Dezember 1966. Er berichtete, dass die chilenische Justiz inzwischen einen Sonderrichter eingesetzt habe, um die Verhältnisse in der CD zu untersuchen. Das AA habe daher Bedenken gegen die Entsendung eines Botschaftsmitarbeiters in die CD. Da die Ermittlungen des Richters "zur Zeit noch nicht abgeschlossen sind, könnte ein solcher Schritt die Botschaft dem Vorwurf aussetzen, sich in ein schwebendes Verfahren einzumischen. ${ }^{588}$ Die Botschaft habe jedoch bereits in mehreren Fällen Schreiben von Angehörigen an den chilenischen Sonderrichter weitergeleitet, mit der Bitte sie den betreffenden Colonos unter vier Augen vorzulegen. Das AA riet der Abgeordneten, im Falle der Bürgerin ihres Wahlkreises ähnlich zu verfahren.

Im selben Monat richtete Alfred Guhl aus Hamburg eine Petition an den Bundestag mit dem Betreff "Das Deutsche Ansehen im Ausland gefährdet «. ${ }^{589}$ Er bat den Petitionsausschuss, die Bundesregierung darum zu ersuchen, »endlich alle geeigneten Maßnahmen zu treffen, um den Urheber der gesamten Misere, Paul Schäfer, alias Paul Schneider, schnellstmöglich der deutschen Gerichtsbarkeit zuzuführen! «590 Ferner sollte die Bundesregierung ein Disziplinarverfahren gegen die zuständigen Beamten der Botschaft Santiago einleiten, da Botschafter von Nostiz die »rein deutsche Strafrechtsangelegenheit >Dignidad und Müller in die Hände der chilenischen Justiz übergeben hat «. Weiterhin habe die Botschaft nichts dazu beigetragen, »der chilenischen Justiz sodann zu helfen die Verbrechen in »Dignidad « aufzuklären, bzw. Menschen, die in >Dignidad noch heute festgehalten werden zur Freiheit zu verhelfen. ${ }^{591} \mathrm{Ob}$ und gegebenenfalls wie sich der Petitionsausschuss zu dieser Eingabe verhalten hat, ist mir nicht bekannt.

Es gab aufklärerische Interventionen einzelner Abgeordneter - meist auf Anregung entweder von Angehörigen oder von Menschenrechtsaktivist_innen, die direkt an die Abgeordneten herangetreten waren. Anfragen zu einzelnen Colonos leiteten Abgeordnete meist per Privatdienstschreiben ans AA oder das Bundeskanzleramt weiter. Meh-

586 PA AA, B 85, Bd. 540. Schreiben Criesinger, MdB an Bundesaußenminister Schröder vom 07.11.1966.

587 Ebd.

588 PA AA, B 85, Bd. 540. Bundesaußenminister Brandt an Griesinger (MdB) vom 06.12.1966. Durchschlag als Reinkonzept. Abgesandt am 07.12.1966.

589 PA AA, B 85, Bd. 540. Schreiben Ing. Alfred Cuhl an den Petitionsausschuss vom 19.11.1966.

590 Ebd.

591 Ebd. 
rere Abgeordnete stellten Fragen oder Kleine Anfragen zu den Erkenntnissen der Bundesregierung zu bestimmten Vorgängen in und um die CD. Ab den 1980er Jahren entstanden viele schriftliche Fragen und Kleine Anfragen unter Mitwirkung oder gar auf Initiative von Dieter Maier (seit 1988) und wenigen weiteren Aufklärer_innen.

Nur wenige Abgeordnete verfolgten den Fall CD über längere Zeit und setzten besondere aufklärerische Akzente. Einer von ihnen war Ernst Waltemathe (SPD), der sich seit 1977 und bis zu seinem Ausscheiden aus dem Bundestag 1994 intensiv für eine Aufklärung des Falls CD einsetzte. Er engagierte sich für einzelne Opfer, traf CD-Aussteiger_innen und thematisierte den Fall CD bei mehreren Delegationsreisen nach Chile. Waltemathe führte einen intensiven Schriftverkehr mit dem AA, übersandte diesem Dokumente und stellte kritische Fragen. Im April 1977 organisierte und leitete er eine Anhörung zum Fall CD im Bonner Bundeshaus. ${ }^{592} 1978$ versuchte er gemeinsam mit seinem Fraktionskollegen Hajo Hoffmann die CD zu besuchen, wurde jedoch nicht eingelassen. ${ }^{593} 1988$ sagte Waltemathe als Zeuge im Ermittlungsverfahren der Staatsanwaltschaft Bonn aus. ${ }^{594}$ Seine Mitarbeiterin Wendy Tyndale reiste nach Chile, um Informationen zum Fall CD zu sammeln. Sie hielt engen Kontakt zu AI sowie $\mathrm{zu}$ anderen Menschenrechtsorganisationen. Waltemathes Nachlass, der auch mehrere Aktenordner zur CD enthält, ist Teil des Archivs der sozialen Demokratie (AdsD). Der Abgeordnete Lothar Mark (SPD) thematisierte den Fall CD zwischen 1998 und 2009 regelmäßig, auch in seiner Funktion als Lateinamerikabeauftragter der SPD-Fraktion. Er hielt Kontakt zu Opfergruppen und wandte sich wiederholt mit Anliegen an die Bundesregierung. Sein größter politischer Erfolg auf diesem Gebiet war der erste Beschluss des Bundestages zum Fall CD 2002 (vgl. Abschnitt 5.4.2). Im September 2005, wenige Monate nach Schäfers Festnahme, tagte auf Initiative von Mark ein »Runder Tisch Ex-Colonia Dignidad« im Bundestag. An diesem nahmen neben Ministerialvertreter_innen auch Betroffenenvertreter_innen und Menschenrechtsaktivist_innen teil. ${ }^{595}$ Unmittelbare Ergebnisse sind mir nicht bekannt. Auch einzelne Abgeordnete der Grünen (insbesondere Hans-Christian Ströbele und Ludger Volmer, später Staatsminister im AA) und der PDS bzw. Linkspartei (insbesondere Ulla Jelpke und Jan Korte) arbeiteten seit Ende der 1980er Jahre mit Menschenrechtsaktivist_innen zusammen und formulierten zahlreiche Fragen oder Kleine Anfragen zum Fall CD.

Der Großteil der parlamentarischen Interventionen zielte auf eine Aufklärung der Vorwürfe gegen die CD. Diese kamen zum weit überwiegenden Teil von Abgeordneten der SPD, der Grünen und der PDS/Linken. Es gab jedoch auch einzelne Abgeordnete, die die CD unterstützten. Der Grund hierfür dürften zum einen grundsätzliche

592 Die Anhörung fand am 22.04.1977 statt und wurde in enger Abstimmung mit Al organisiert. Teilnehmer_innen waren die SPD-Abgeordneten Däubler-Gmelin, Erler, Heyenn, Marschall, Hansen, Steger, Kuhlwein und Waltemathe. Angehört wurden Jürgen Karwelat, Dieter Maier, Helmut Frenz (alle Al), Pastor Bauz aus Siegburg, Hans-Cünter Matthusen, Wolfgang Kneese, Adriana Bórquez, Erick Zott sowie eine Gruppe Studierender aus Siegen, die zum Fall Wolfgang Müller Altevogt berichtete. Vgl. PJS, Sammlung CD. Protokollarische Mitschrift »Hearing in Bonn mit Bundestagsabgeordneten«, 22.04.1977. PA AA, AV NA 31580. Ernst Waltemathe: Abschrift des Reisetagebuchs vom 11.12.1978. StA Bonn, AZ 50 ]s 285/85, Bd. VI, BI. 20off. Vernehmung Ernst Waltemathe vom 16.06.1988. PJS, Sammlung Lothar Mark. Protokoll Runder Tisch Ex-Colonia Dignidad vom 07.09.2005. 
Sympathien für die ihrer Außendarstellung nach wohltätige und streng konservative christliche Siedlung von Deutschen in Südamerika sein, und zum anderen die beständige Lobbyarbeit der CD bei konservativen Abgeordneten. Es gab diverse Verbindungen oder zumindest eine gewisse Nähe zwischen konservativen Politiker_innen und der CD. Adolf Herkenrath (CDU) beispielsweise, von 1964 bis 1989 Bürgermeister von Siegburg und von 1980 bis 1994 Bundestagsabgeordneter, verteidigte die CD jahrzehntelang öffentlich und besuchte sie sogar. ${ }^{596}$ Ein Beispiel dafür, dass die Kontakte der CD sogar bis in hohe Kreise von CDU und CSU reichten, ist ein Vorgang aus dem Jahr 1987: Friedrich Bohl, parlamentarischer Geschäftsführer der CDU/CSU-Bundestagsfraktion und später langjähriger Chef des Bundeskanzleramts, bat am 15. Oktober StM Helmut Schäfer im AA um einen Sachstandsbericht bezüglich einer Dienstaufsichtsbeschwerde gegen Dieter Haller, den RK-Referenten der Botschaft. Diese Beschwerde hatte die CD am 20. August 1987 gestellt. ${ }^{597}$ Bohls Anfrage ist insofern als Unterstützung für die CD $\mathrm{zu}$ verstehen. Vermutlich kam sie auf Bitten CD-unterstützender Kreise innerhalb der Union zustande. Bekannt wurde das Schreiben durch einen Artikel im Spiegel. ${ }^{598}$ Bohl machte StM Helmut Schäfer für die Veröffentlichung verantwortlich und beschwerte sich bei diesem über den vermeintlichen Vertrauensbruch. Bohl schrieb: „Für den offensichtlich im Bereich des Adressaten mitlesenden Spiegel-Informanten: ich kenne Herrn Paul Schäfer nicht, geschweige denn habe ich etwas mit ihm zu tun. ${ }^{599}$ StM Schäfer entschuldigte sich daraufhin bei Bohl, nahm jedoch Haller gegen die Vorwürfe der CD in Schutz. ${ }^{600}$

Tabelle 15 in Abschnitt 5.4.4 listet alle mir bekannten in offiziellen Dokumenten (Bundestagsdrucksachen oder Plenarprotokollen) erfassten Aktivitäten des Bundestages zum Fall CD auf. Nicht erfasst sind darin Initiativen einzelner Abgeordneter, wie Schreiben an die Bundesregierung, Anhörungen oder sonstige Veranstaltungen in Räumlichkeiten des Bundestags, sowie die Beschäftigung mit dem Fall CD in fraktionsinternen Arbeitsgruppen. Auch die Thematisierung der CD in den diversen Ausschüssen des Bundestages ist nicht erfasst. Diese können zwar im Parlamentsarchiv eingesehen werden, unterliegen jedoch teilweise Zugangsbeschränkungen. ${ }^{601} \mathrm{Bei}$ einigen Ausschüssen, etwa beim Rechtsausschuss oder beim Ausschuss für Menschenrechte und Humanitäre Hilfe können die Protokolle in der Regel ab der darauffolgenden Legislaturperiode eingesehen werden - sofern keine Einstufung als Verschlusssache

5961997 wurde Herkenrath in einem Interview gefragt, ob er schon einmal die CD besucht habe. Er antwortete: "]a, ich bin von der Botschaft angemeldet worden. Mir wurde wohl das Besuchsprogramm der Siedlung mit Krankenhaus und Vorführungen geboten. Ich war beeindruckt von der Landwirtschaft. Man konnte sich mit den Leuten unterhalten. Sie hatten aus der Wüste ein fruchtbares Land gemacht und waren genauso fröhlich wie die Menschen hier.« Kölner Stadtanzeiger. Sonderdruck»Kolonie der Qualen«, August/September 1997, S. 24. Mit »den Menschen hier« meint Herkenrath die Vertreter_innen der PSM in Siegburg.

597 PA AA, AV NA 31593. Schreiben Bohl, MdB an StM Schäfer vom 15.10.1987, GZ 0603W/9/H.

598 Der Spiegel Nr. 49/87 vom 30.11.1987, S. 32. »Metropolis und Theresienstadt«.

599 PA AA, AV NA 31593. Schreiben Bohl, MdB an StM Schäfer vom 02.12.87, GZ 0606W/4/H.

600 PA AA, AV NA 31593. Schreiben StM Schäfer an Bohl, MdB vom 01.02.1988, GZ StM, 194/88.

601 Geschäftsordnung des Deutschen Bundestages (CO-BT), Anhang 2-Richtlinien für die Behandlung der Ausschussprotokolle gemäß § 73 III GO-BT. 
vorliegt. Bei anderen Ausschüssen, etwa beim Auswärtigen Ausschuss, sind die Protokolle hingegen vollständig gesperrt und dadurch erst nach 30 Jahren einsehbar. Silke Voß schreibt hierzu:

»Die aus der Unzugänglichkeit der Sitzungsprotokolle des Auswärtigen Ausschusses für die Wissenschaft resultierende schwierige Quellenlage ermöglicht also hier keine präzise Bewertung seiner tatsächlichen Einflussnahme auf die Außenpolitik der Bundesregierung. In weitgehender Übereinstimmung kommen bisherige Untersuchungen zu dem Ergebnis, daß die parlamentarischen Einflußmöglichkeiten auch durch den Auswärtigen Aussschuß eher gering sind. « ${ }^{602}$

Im Folgenden stelle ich zunächst die drei wichtigsten Aktivitäten des Bundestages zur CD dar: Die Anhörung im Unterausschuss für Menschenrechte 1988 (5.4.1), den Entschließungsantrag von 2002 (5.4.2) sowie den Entschließungsantrag von 2017 (5.4.3). Im Anschluss daran werden die weiteren Aktivitäten des Parlaments in Sachen CD dargestellt (5.4.4).

\subsubsection{Anhörung im Unterausschuss für Menschenrechte und humanitäre Hilfe 1988}

Die am 22. Februar 1988 vom Unterausschuss für Menschenrechte und Humanitäre Hilfe durchgeführte öffentliche Anhörung zum Thema »Befinden sich deutsche Staatsangehörige unfreiwillig und unter menschenrechtsverletzenden Bedingungen in der Colonia Dignidad in Chile?« war ein herausragendes Ereignis in der bundesdeutschen Beschäftigung mit der $\mathrm{CD} .{ }^{603}$ Es war die erste öffentliche Anhörung des Unterausschusses, der sich im Juni 1987 konstituiert hatte. ${ }^{604}$ Der Vorsitzende Friedrich Vogel (CDU) machte zu Beginn der Anhörung deutlich, dass es sich nicht um einen parlamentarischen Untersuchungsausschuss ${ }^{605}$ handelte. Das bedeutete u.a., dass sämtliche Teilnehmer_innen freiwillig erschienen und aussagten.

Neben den parlamentarischen Mitgliedern des Unterausschusses nahmen Vertreter_innen des AA, des BMI, des Bundespräsidialamtes und des Bundesrates teil. Die Liste der Sachverständigen bzw. Auskunftspersonen liest sich wie ein »Who-is-Who« des Falls CD: Auf Seiten der CD und ihrer Unterstützer_innen erschienen Hartmut Hopp, Wolfgang Vogelsgesang (CSU) und der Fabrikant Friedrich Peymann. Als Kritiker_innen der CD waren die geflohenen Colonos Wolfgang Kneese, Hugo Baar sowie Lotti und

602 Voß, Parlamentarische Menschenrechtspolitik, S. 87.

603 PA-DBT 3127, 712 - UA 2 - 2451. Stenographisches Protokoll der 10. Sitzung des Unterausschusses für Menschenrechte und Humanitäre Hilfe vom 22.02.1988, auch online unter http://coloniadigni dad-prot.blogspot.com/.

604 Der Ausschuss war dem Auswärtigen Ausschuss untergeordnet. Erst 1998 wurde ein eigenständiger Ausschuss für Menschenrechte und humanitäre Hilfe geschaffen. VgI. Voß, Parlamentarische Menschenrechtspolitik, S. 100.

605 Parlamentarische Untersuchungsausschüsse verfügen über eine Reihe besonderer Rechte, die in Artikel 44 GG formuliert sind. Dazu gehört die Beweiserhebung nach Regeln der Strafprozessordnung. Cerichte und Verwaltungsbehörden sind zur Rechts- und Amtshilfe für BundestagsUntersuchungsausschüsse verpflichtet. 
Georg Packmor anwesend. Diese trugen ihre bereits 1985 formulierten Darstellungen der menschenrechtswidrigen Verhältnisse in der CD detailliert vor. Außerdem ergriffen das Wort gegen die CD: der Journalist Gero Gemballa, Helmut Frenz, langjähriger Generalsekretär von Amnesty International, und Günter Bohnau, ein Angehöriger mehrerer Colonos. Lothar Bossle, Würzburger Professor und langjähriger Unterstützer der $C D$, plädierte für eine »Herauslösung von Herrn Schäfer« aus der CD, ${ }^{606}$ d.h. konkret für ein Auslieferungsersuchen und eine Verurteilung Schäfers durch ein Gericht in der Bundesrepublik. Erich Strätling und Hermann Holzheimer, ehemalige Botschafter in Chile, erschienen trotz Einladung nicht. Strätling begründete sein Fernbleiben damit, dass der Abgeordnete Freimut Duve (SPD) ihn der Komplizenschaft mit Schäfer beschuldigt habe. ${ }^{607}$ Holzheimer entschuldigte sich, er könne aus eigener Sachkenntnis keine Angaben zur CD machen. ${ }^{608}$

Hopp versuchte als Vertreter der CD eine 26-seitige Stellungnahme vorzutragen, wurde dabei aber immer wieder durch emotionale Zwischenrufe von Wolfgang Kneese und anderen unterbrochen. Hopp behauptete, dass sich alle Colonos freiwillig in der CD aufhielten und sämtliche Anschuldigungen gegen die CD Teil einer Verleumdungskampagne seien. Als Hopp den Anwesenden Hugo Baar seiner angeblichen Alkohol- und Drogenabhängigkeit sowie eines außerehelichen Verhältnisses mit der ebenfalls anwesenden Lotti Packmor bezichtigte, unterbrach der Vorsitzende Vogel ihn. ${ }^{609}$ Schließlich beendete Vogel Hopps Vortrag, weil dieser zu lange dauerte. Hopp übergab seine Stellungnahme daraufhin in schriftlicher Form dem Unterausschuss, zusammen mit einem 250 Seiten starken Anhang. ${ }^{610}$ Der Anhang enthielt Gerichtsurteile ${ }^{611}$ und Berichte von Untersuchungsausschüssen ${ }^{612}$, die die CD entlastet hatten; ausführliche Statistiken über die vermeintlich soziale Arbeit des CD-Krankenhauses sowie von diversen Colonos unterzeichnete, verleumderische Berichte über Hugo Baar sowie Lotti und Georg Packmor. Die Frage des Vorsitzenden, ob eine Kommission des AA die CD besichtigen

606 PA-DBT 3127, 712 - UA 2 - 2451. Stenographisches Protokoll der 10. Sitzung des Unterausschusses für Menschenrechte und Humanitäre Hilfe vom 22.02.1988. S. 10/90 sowie S. 10/151.

607 StA Bonn, AZ 50 ]s 285/85, Bd. II, BI. 18. Verfügung StA Gawlik vom 23.02.1988 über Anhörung im Bundestag am Vortag. Strätling reichte sogar beim LC Bonn eine einstweilige Verfügung ein, um Duve folgende Äußerungen zu untersagen: 1. Strätling habe sich als ehemaliger Botschafter der BRD in Chile häufig schützend vor die CD gestellt; 2 . Strätling habe dem deutschen Freundeskreis der CD angehört oder gehöre diesem noch an; 3. Strätling habe möglicherweise schwere kriminelle Handlungen gedeckt oder indirekt unterstützt. Das LC Bonn wies Strätlings Antrag auf einstweilige Verfügung am 24.03.1988 zurück. Vgl. PJS, Sammlung CD. LC Bonn, AZ 7 O 92/88, Anlage zum Verkündungsprotokoll vom 24.03.1988.

608 PA-DBT 3127, 712 - UA 2 - 2451. Stenographisches Protokoll der 10. Sitzung des Unterausschusses für Menschenrechte und Humanitäre Hilfe vom 22.02.1988, S. 10/3.

609 Ebd., S. 10/2f.

610 StA Bonn, AZ 50 JS 285/85, Bd. III, BI. 164ff. Schreiben RA Gatzweiler an StA vom 18.03.1988 mit Stellungnahme Hopp vom 22.02.1988 und Anlagen.

611 U. a. das Urteil gegen Wolfgang Kneese wegen Verleumdung 1967, vgl. Abschnitt 5.1.1.

612 U. a. den Bericht des Untersuchungsausschusses der Cámara de Diputados von 1968, vgl. Abschnitt 5.2.2. 
könne, beantwortete Hopp knapp mit »Nein«. Er beantwortete auch keine Fragen der Mitglieder des Unterausschusses. ${ }^{613}$

Die Anhörung fand sowohl in Deutschland als auch in Chile ein großes Medienecho. Darüber hinaus beeinflusste sie die strafrechtlichen Ermittlungen der Staatsanwaltschaft Bonn (vgl. Abschnitt 5.3.4). Ulrich Gawlik, der ermittelnde Staatsanwalt, war bei der Anhörung anwesend und gab am nächsten Tage einen 17-seitigen Vermerk zu den Akten. ${ }^{614}$ Noch am selben Tage wurde das Ermittlungsverfahren, das bislang nur Schäfer als Beschuldigten geführt hatte, auf Hartmut Hopp, Gisela Seewald und Hugo Baar ausgeweitet. ${ }^{615}$ In den folgenden Wochen vernahm die Staatsanwaltschaft fast alle Auskunftspersonen der Anhörung. Hopp war für den 25. Februar 1988 als Beschuldigter vorgeladen, reiste jedoch zuvor eilig nach Chile und ließ über seinen Anwalt erklären, seine Großmutter in der CD sei erkrankt. ${ }^{616}$

Das Unterlassen einer Vernehmung von Hopp durch die StA Bonn war daraufhin Thema im Rechtsausschuss des Bundestages. Am 2. März 1988 unterrichtete die Bundesregierung den Rechtsausschuss über den Sachstand zur CD und fügte dazu den schriftlichen Bericht des nordrhein-westfälischen Justizministers an:

»Anlaß zu Maßnahmen, die ein Verbleiben des Herrn Dr. Hopp in der Bundesrepublik Deutschland hätte gewährleisten können, hatte die Staatsanwaltschaft Bonn nach dem Stand des Ermittlungsverfahrens nicht. Der Verfahrensstand erlaubt auch keine Beurteilung, ob die Erhebung einer Anklage gegen den Beschuldigten Schäfer oder andere Mitglieder der CD in Betracht kommt. ${ }^{617}$

Der Abgeordnete Burkhard Hirsch (FDP) bezeichnete diese Erklärung als »eine der törichsten Erklärungen, die er in dieser Sache bisher gehört habe ${ }^{618}$ Es sei schon seit Langem erörtert worden, dass Hopp als Mittäter in Betracht komme und deshalb hätte vernommen werden müssen. Der bei der Rechtsausschusssitzung anwesende Vertreter des BMJ, Jürgen Schnigula, erklärte daraufhin »[s]eines Wissens sei eine Art stillschweigende Übereinkunft der Art getroffen worden, daß Herrn Hopp im Gegenzug für die Bereitschaft, als Zeuge [bei der Bundestagsanhörung, JS] auszusagen, die Ausreise aus der Bundesrepublik zugesagt worden sei.« ${ }^{619}$ Diese Aussage stand im Widerspruch zu den in den Ermittlungsakten dargelegten Versuchen der Staatsanwaltschaft, Hopp vorzuladen. Sollte diese "stillschweigende Übereinkunft" tatsächlich getroffen worden sein, so stellte sie eine amtliche Zusicherung Hopp gegenüber dar, dass er sich einer

613 PA-DBT 3127, 712 - UA 2 - 2451, Stenographisches Protokoll der 10. Sitzung des Unterausschusses für Menschenrechte und humanitäre Hilfe des Auswärtigen Ausschusses vom 22.02.1988, S. 10/106f.

614 StA Bonn, AZ 50 ]s 285/85, Bd. II, Bl. 17ff. Vfg. StA Gawlik vom 23.02.1988 über die Anhörung im Bundestag vom Vortag.

615 StA Bonn, AZ 50 ]s 285/85, Bd. II, Bl. 3. Vfg. StA Gawlik vom 23.02.1988.

616 StA Bonn, AZ 50 ]s 285/85, Bd. II, Bl. 66. Vfg. StA Gawlik vom 25.02.1988.

617 PA-DBT, 0538 6.88. Anlage zum Protokoll des Rechtsausschusses Nr. 19 vom 02.03.1988: Schreiben des Justizministers des Landes Nordrhein-Westfalen an den Bundesminister der Justiz vom 01.03.1988.

618 PA-DBT, 0538 6.88. Protokoll des Rechtsausschusses Nr. 19 vom 02.03.1988. S. 19/31.

619 Ebd. S. $19 / 32$. 
staatsanwaltschaftlichen Vernehmung entziehen könnte. Rechtsgrundlagen für ein solches Verfahren sind mir nicht bekannt.

Die Anhörung im Unterausschuss für Menschenrechte und Humanitäre Hilfe war einerseits eine eindrückliche Darlegung des Falls CD, in der wichtige Kritiker_innen und Geschädigte der CD zu Wort kamen. Andererseits war sie jedoch eine vereinzelte und vor allem rechtlich und politisch folgenlose Veranstaltung. Auswirkungen hatte sie wie geschildert allein durch die Anwesenheit von Staatsanwalt Gawlik. Der Unterausschuss sowie der Rechtsausschuss des Bundestags werteten die Anhörung in den nachfolgenden Wochen aus und luden hierzu Vertreter_innen der Bundesregierung sowie der Landesregierung von Nordrhein-Westfalen ein. ${ }^{620}$ Dabei schlug der Ausschussvorsitzende Vogel vor, dass das AA und das LMJ NRW nach Ablauf einer bestimmten Zeit erneut zum Thema CD berichten sollten. Ob dies geschehen ist, ist mir nicht bekannt.

\subsubsection{Entschließungsantrag 2002}

Auf Initiative des Abgeordneten Lothar Mark (SPD) fasste der Bundestag 2002 erstmals einen Beschluss zum Thema Colonia Dignidad. Der Entschließungsantrag, dem sich die Regierungsfraktionen von SPD und Grünen sowie die Oppositionsfraktion der FDP anschlossen, trug den Titel »Hilfe für die Opfer der Colonia Dignidad ${ }^{621}$ Er forderte die Bundesregierung u.a. auf:

»1. dem Fall Colonia Dignidad, wie angekündigt, eine höhere Priorität einzuräumen. Der aktuelle politische Wandel in Chile sollte für eine verstärkte Zusammenarbeit beider Länder auf Regierungsebene zur Aufklärung der Vergehen und unverzüglichen Hilfe für die Bewohner der Kolonie genutzt werden. Die Bundesregierung sollte den vergangenheitsbezogenen Aufarbeitungsprozess in der chilenischen Cesellschaft ausdrücklich begrüßen und ihn unterstützen; [...] 3. im engen Dialog mit der chilenischen Seite Möglichkeiten der personellen und technologischen Unterstützung bei der Aufklärung des CD-Komplexes zu eruieren. Gedacht werden könnte an die zeitlich befristete Entsendung von Experten des Bundeskriminalamtes zur Unterstützung der chilenischen Behörden und Justiz; 4. einen Fonds zur Finanzierung der notwendigen Hilfsund Reintegrationsmaßnahmen einzurichten, aus dem ausreisewillige Koloniebewohner bei einer eventuellen Rückkehr nach Deutschland unterstützt und betreut werden können. Die Klärung der Eigentumsverhältnisse der CD sollte Entschädigungszahlungen aus diesem Vermögen - auch zu Existenzgründungen in Chile-erleichtern; 6. nach 12 Monaten über ihre Aktivitäten zu berichten.«

Am 16. Mai 2002 wurde der Antrag mit den Stimmen von SPD, Grüne, FDP und PDS angenommen - die CDU/CSU-Fraktion enthielt sich. ${ }^{622}$ Allerdings wurden die meisten

PA-DBT 3127, 712-UA 2-2451, Protokoll der 11. Sitzung des Unterausschusses für Menschenrechte und humanitäre Hilfe des Auswärtigen Ausschusses vom 09.03.1988, 3. Auswertung der öffentlichen Anhörung zur Colonia Dignidad. 
der zitierten Maßnahmen nicht umgesetzt. Auch der geforderte Bericht der Bundesregierung erfolgte nicht. Allerdings diente der Beschluss zwischen 2009 und 2013 als Legitimation für die Bereitstellung von Bundesmitteln für »Projekte zur Förderung der Integration der Villa Baviera (soziale und wirtschaftliche Anbindung) in die Region und in die chilenische Gesellschaft«. ${ }^{623}$

\subsubsection{Entschließungsantrag 2017}

Im Februar 2016 fand in der Gedenk- und Bildungsstätte Haus der Wannsee-Konferenz (GHWK) in Berlin ein Seminar zum Thema CD statt. Es fiel zeitlich zusammen mit dem Kinostart des Spielfilms »Colonia Dignidad - es gibt kein Zurück««. ${ }^{624}$ Seit dieser Zeit nahm sich der Abgeordnete Klaus Barthel (SPD) des Themas CD in besonderem Maße an. Als Vorsitzender der Deutsch-Südamerikanischen Parlamentariergruppe des Bundestags organisierte er eine Reihe von Veranstaltungen für Bundestagsabgeordnete mit Anwält_innen, Menschenrechtsaktivist_innen sowie Vertreter_innen von CD-Opferverbänden. ${ }^{625}$ An diesen Veranstaltungen nahmen erstmals auch Abgeordnete der Unionsfraktion teil. ${ }^{626}$ Nach der Rede von Außenminister Steinmeier zur CD am 26. April 2016 brachte Barthel einen ersten Entwurf für einen Entschließungsantrag des Bundestags zum Fall CD in Umlauf. Als der damalige Bundespräsident Joachim Gauck im Juli 2016 auf Staatsbesuch in Chile war, war Barthel Teil der Reisedelegation.

Im November 2016 besuchte erstmals eine Delegation mit Mitgliedern aller Fraktionen des Bundestages die CD. ${ }^{627}$ Die Delegation bestand aus sieben Mitgliedern des Ausschusses für Recht und Verbraucherschutz. ${ }^{628}$ Sie fuhr zu Beginn ihres Besuchs in ein Waldstück auf dem CD-Gelände, der sogenannten Fosa-4, wo nach Stand der chilenischen Ermittlungen ein Massengrab bestand, in dem politische Gefangene nach

623 Bundeshaushalt Kapitel 0502, Titel 687-43. VgI. z.B. Deutscher Bundestag. Drucksachte 16-9900 vom 08.08.2008. Haushaltsgesetz 2009, S. 26. Die bereitgestellten Mittel betrugen etwa. 250.000 Euro pro Jahr. Sie wurden eingesetzt für psychosoziale Betreuung einiger Colonos und Bildungsprojekte; etwa $60 \%$ der Mittel flossen über die Gesellschaft für Internationale Zusammenarbeit (CIZ) in Maßnahmen zur Beratung und Förderung der wirtschaftlichen Aktivitäten der Gesellschaften der ehemaligen $C D$.

624 Gallenberger, Florian [Regie]. »Colonia Dignidad - es gibt kein Zurück«, Spielfilm, 110 min, Kinostart in Deutschland am 18.02.2016.

625 Dazu gehörten u.a. ein Treffen der Parlamentariergruppe am 25.02.2016 mit 15 Vertreter_innen von Opfer- und Menschenrechtsorganisationen, die zuvor am erwähnten Seminar in der GHWK teilgenommen hatten sowie ein fraktionsoffenes Treffen des Gesprächskreises Lateinamerika der SPD-Fraktion mit einer Reihe von CD-Opfern sowie Menschenrechtsaktivist_innen am 16.02.2017 im Bundestag.

626 Besonderes Engagement zeigte hierbei Michael Brand, ehemaliger Vorsitzender des Ausschusses für Menschenrechte und Humanitäre Hilfe (2013-2017) sowie Vorsitzender der Arbeitsgruppe Menschenrechte und Humanitäre Hilfe der Unionsfraktion.

627 Vgl. Amerika21, Nachrichten und Analysen aus Lateinamerika (Website) vom 04.11.2016: „Delegation des Bundestags besucht Colonia Dignidad in Chile«, online unter https://amerika21.de/2016/1 1/163580/bundestag-colonia-dignidad.

628 Die Delegation setzte sich zusammen aus der Ausschussvorsitzenden Renate Künast (Grüne) sowie den Ausschussmitgliedern Mathias Bartke (SPD), Christian Flisek (SPD), Stefan Harbarth (CDU), Jan-Marco Luczak (CDU) Harald Petzold (Linke) und Volker Ullrich (CSU). 
ihrer Erschießung verscharrt wurden. Die Abgeordneten hielten dort gemeinsam mit Angehörigen von Verschwundenen eine Gedenkzeremonie ab. Anschließend machten sie einen Rundgang durch die CD und sprachen mit derzeitigen und ehemaligen Colonos. Vor ihrer Rückreise nach Santiago traf sich die Delegation mit Vertreter_innen der Angehörigen von Verschwundenen (AFDD) aus der Region. Diese Einbeziehung von Angehörigenorganisationen, die sich für chilenische Opfer der Diktatur einsetzen, war ebenfalls ein Novum. Das AA hatte sich bislang stets auf Kontakte zu Geschädigten mit deutscher Staatsangehörigkeit beschränkt. Nach ihrer Rückkehr nach Deutschland kündigte Künast an, dass die Delegation dem Bundestag Maßnahmen vorschlagen werde. ${ }^{629}$ Ursprünglich sollte es einen parteiübergreifenden Antrag mit Unterstützung aller Delegationsmitglieder geben. ${ }^{630}$ Das Vorhaben scheiterte jedoch, der Antrag »Aufarbeitung der Verbrechen in der Colonia Dignidad und Hilfe für die Opfer«, den Künast am 30. März 2017 in den Bundestag einbrachte, wurde nur von 91 Abgeordneten der Grünen und der Linken getragen. ${ }^{631}$ Die Regierungsfraktionen aus CDU/CSU und SPD erarbeiteten einen eigenen Antrag, dem sich auch die Grünen anschlossen und der am 27. Juni ins Plenum eingebracht wurde. ${ }^{632}$ Darin wurde die Bundesregierung u.a. aufgefordert:

»2. eng mit dem chilenischen Staat bei der umfassenden Aufklärung der [...] Verbrechen zusammenzuarbeiten;

3. die ihr zur Verfügung stehenden Maßnahmen zu ergreifen, um die strafrechtlichen Ermittlungen in Deutschland und in Chile voranzutreiben;

4. im Wege der deutsch-chilenischen Zusammenarbeit [...] die historische Aufarbeitung der Vergangenheit der CD voranzutreiben. [...]

5. den Prozess der Aufarbeitung der Vergangenheit im Rahmen einer Gedenkkultur [...] zu unterstützen. Die gemeinsame Errichtung einer nach wissenschaftlichen Kriterien gestalteten Begegnungs- und Gedenkstätte, die unter anderem die Menschenrechtsarbeit fördern soll, [...] bis zum 30.06.2018 zu prüfen. Das Wissen über die Entwicklung und Struktur der Sekte soll durch ein wissenschaftlich begleitetes oral history Projekt befördert werden;

6. bis zum 30.06.2018 dem Deutschen Bundestag ein Konzept für Hilfsleistungen zur Beratung vorzulegen und dessen Finanzierung zu prüfen. Die Einrichtung eines Hilfsfonds ist darin als eine Möglichkeit in Betracht zu ziehen. [...]

7. allen früheren Bewohnern der CD, die Opfer der Sekte wurden psychosoziale Betreuung zu gewährleisten und Unterstützung bei der Klärung ihrer rechtlichen, sozialen

629 Süddeutsche Zeitung vom 07.11.2016, S. 6, »Traumatisiert sind alle«.

630 Knobbe, Martin/Christoph Schult, »Terrorsekte Colonia Dignidad: Bundestagsabgeordnete fordern >rückhaltlose Aufklärung«, in: Spiegel Online vom 31.03.2017, online unter https://www.spiegel.de/politik/deutschland/colonia-dignidad-abgeordnete-fordern-rueckhaltlose-aufklaerung-a1141426.html.

631 Deutscher Bundestag. Drucksache 18/11805 vom 30.03.2017. Antrag einzelner Abgeordneter der Fraktionen SPD, BÜNDNIS 90/DIE GRÜNEN und LINKE. Aufarbeitung der Verbrechen in der Colonia Dignidad und Hilfe für die Opfer.

632 Deutscher Bundestag. Drucksache 18/12943 vom 27.06.2017. Antrag der Fraktionen CDU/CSU, SPD und BÜNDNIS 90/DIE GRÜNEN. Aufarbeitung der Verbrechen in der Colonia Dignidad. 
und wirtschaftlichen Situation zukommen zu lassen. Hierfür sollen Anlaufstellen in Deutschland und an der Botschaft in Santiago de Chile eingerichtet werden.

8. die Klärung der Besitzverhältnisse der CD/Villa Baviera voranzutreiben, auch mit dem Ziel, dass Mittel aus dem Vermögen konkret den Opfern zugutekommen.« ${ }^{633}$

Der Inhalt der Anträge von Künast und den Regierungsfraktionen war ähnlich. Letztlich bestand die Regierungskoalition auf dem eigenen Antrag, wohl auch um zu verhindern, dass ein von der Opposition und insbesondere von der Linken miteingebrachter Antrag verabschiedet würde. Nur zwei Tage später wurde der Antrag der Regierungskoalition nach einer Debatte im Plenum einstimmig angenommen. ${ }^{634}$ Es war das erste Mal, dass über Parteigrenzen hinweg eine gemeinsame Haltung zum Fall CD vorgebracht wurde.

Im Juli 2017 unterzeichnete die Bundesregierung eine Absprache mit der chilenischen Regierung über die Einsetzung einer Gemischten Kommission auf Regierungsebene. ${ }^{635}$ Folgende Ziele für die Zusammenarbeit wurden vereinbart: Die Errichtung eines Gedenkortes sowie eines Dokumentationszentrums; die Feststellung, Sicherung und Auswertung von Spuren und Dokumenten von auf dem CD-Gelände begangenen Verbrechen sowie eine Überprüfung der Vermögenswerte der CD und der aus ihr hervorgegangenen Gesellschaften. ${ }^{636}$ Die Gemischte Kommission beauftragte die Deutsche Gesellschaft für internationale Zusammenarbeit (GIZ), eine Machbarkeitsstudie zur Untersuchung des CD-Vermögens anzufertigen. Diese legte die GIZ in der ersten Jahreshälfte 2018 vor. ${ }^{637}$ Die ABC-Gesellschaften hatten eine Verschwiegenheitserklärung zur Bedingung für Einblick in ihre Bücher gemacht, worauf die GIZ einging. Im Juni 2018 lud Niels Annen, Staatsminister im AA, Bundestagsabgeordnete zu einem Gespräch über die Studie ein. Auch sie mussten eine Verschwiegenheitsverpflichtung unterzeichnen, bevor sie über den Inhalt der Studie informiert wurden. Sie durften diese nur in der Geheimschutzstelle des Bundestages einsehen. Weiteres ist mir über die Studie nicht bekannt.

Am 29. Juni 2018 unterrichtete die Bundesregierung den Bundestag über ihre Maßnahmen infolge des Entschließungsantrags von 2017. Sie präsentierte ihren Entwurf eines Hilfskonzeptes für die Opfer der CD. ${ }^{638}$ Dieser sah die Finanzierung sogenannter Unterstützungsmaßnahmen vor, die den Opfern indirekt zugutekommen sollte. Individuelle Hilfen, insbesondere Geldzahlungen an Einzelpersonen waren hingegen nicht vorgesehen. Der Entwurf löste bei Opfern sowie bei einigen Abgeordneten Entrüstung

633 Ebd., S. $3 f$.

634 Deutscher Bundestag. Plenarprotokoll 18/243 vom 29.06.2017, S. 25042Dff.

635 PJS, Sammlung AA. Absprache zwischen der Regierung der Republik Chile und der Bundesrepublik Deutschland über die Einsetzung einer chilenisch-deutschen Cemischten Kommission zur Aufarbeitung der »Colonia Dignidad« und Integration der Opfer in die Gesellschaft vom 12.07.2017.

636 Ebd.

637 Deutscher Bundestag. Drucksache 19/3380 vom 11.07.2018. Antwort der Bundesregierung auf die Kleine Anfrage der Abgeordneten Jan Korte, Heike Hänsel, Andrej Hunko und der Fraktion die LINKE - Drucksache 19/2955 - Stand der Aufarbeitung der Verbrechen in der Colonia Dignidad, S. 4.

638 Deutscher Bundestag. Drucksache 19/3233 vom 29.06.2018. Unterrichtung durch die Bundesregierung. Entwurf der Bundesregierung für ein Hilfskonzept für die Opfer der Colonia Dignidad. 
aus. ${ }^{639}$ Am 10. Oktober 2018 konstituierte sich die »Gemeinsame Kommission zur Umsetzung des Hilfskonzepts für die Opfer der Colonia Dignidad«, bestehend aus Vertreter_innen von Bundestag und Bundesregierung. ${ }^{640}$ Im Mai 2019 stellte die Kommission ihr Hilfskonzept für die Opfer der CD vor. ${ }^{641}$ Dieses sah nun doch individuelle Einmalzahlungen in Höhe von bis zu 10.000 Euro vor. Daneben soll ein "Fonds Pflege und Alter« eingerichtet werden. Das Konzept betont, dass es sich um freiwillige Hilfen und nicht etwa um rechtlich bindende Entschädigungen handelt: Unterstützungsmaßnahmen für die Opfer der >Colonia Dignidad erfolgen ausschließlich aus moralischer Verantwortung und ohne Anerkennung einer Rechtspflicht. ${ }^{642}$ Zudem sind chilenische Opfer der im Kontext der Diktatur begangenen CD-Verbrechen von den Hilfszahlungen kategorisch ausgeschlossen:

»Empfänger sind die deutschen Bewohner der `Colonia Dignidad « und die chilenischen Staatsangehörigen, die als Kinder in der >Colonia Dignidad lebten (z.B. zwangsweise adoptiert), soweit sie seinerzeit dort ihren tatsächlichen Lebensmittelpunkt hatten, ohne dem Täterkreis zugerechnet zu werden. « ${ }^{643}$

Zur Umsetzung des Hilfskonzepts wurde die Internationale Organisation für Migration (IOM) beauftragt. Die Gemeinsame Kommission bewilligte im März 2020 erste Anträge auf Hilfen.

\subsubsection{Weitere Aktivitäten des Bundestages}

Tabelle 15 listet sämtliche Aktivitäten des Bundestages im Zusammenhang mit der CD auf. Neben den behandelten Anträgen umfasst dies 14 Kleine Anfragen (1988-2021), 26 schriftliche oder mündliche Fragen (1977-2019) sowie zwei Eingaben an den Petitionsausschuss.

639 Süddeutsche Zeitung vom 03.07.2018, S. 5. »Kein Geld für Colonia-Opfer«.

640 Der Bundestag benannte als Vertreter_innen für die Kommission die Abgeordneten Volker Ullrich (CSU), Michael Brand (CDU), Matthias Bartke (SPD), Karl-Heinz Brunner (SPD), Konstantin Kuhle (FDP), Friedrich Straetmanns (LINKE), Renate Künast (Grüne) und Waldemar Herdt (AFD). Vgl. Deutscher Bundestag. Plenarprotokoll 19/46 vom 05.07.2018, S. 4795Af. Die Vertreter_innen der Bundesregierung in der Cemeinsamen Kommission stammen aus AA, BMF, BMC, BMAS, BMFS] und Bundeskanzleramt. Federführend ist seitens der Bundesregierung das AA, die Lateinamerikabeauftragte des AA leitet in der Regel die Sitzungen der Cemeinsamen Kommission.

641 Deutscher Bundestag. Drucksache 19/10410 vom 21.05.2019. Unterrichtung durch die Bundesregierung, Hilfskonzept für die Opfer der Colonia Dignidad der Gemeinsamen Kommission von Deutschem Bundestag und Bundesregierung.

642 Ebd., S. 2.

643 Ebd., S. 4. 


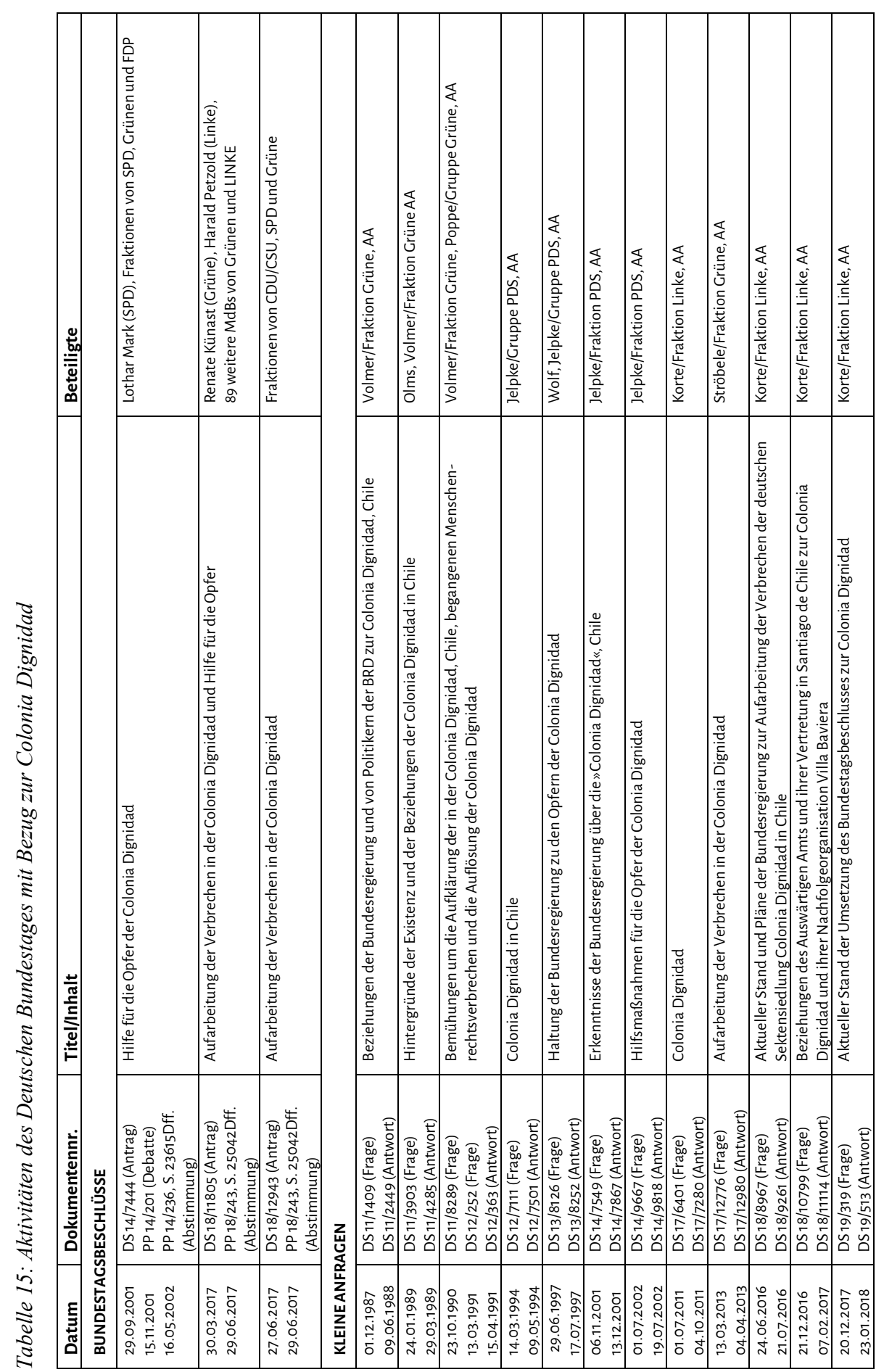




\begin{tabular}{|c|c|c|c|c|c|c|c|c|c|c|c|c|c|c|c|c|c|c|}
\hline 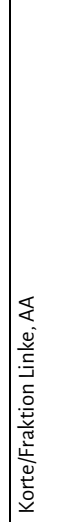 & 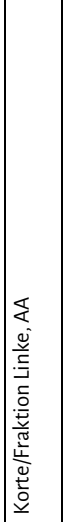 & & 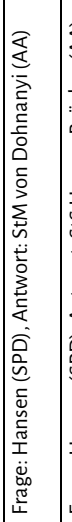 & 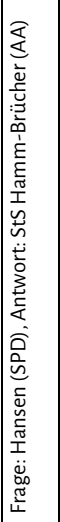 & 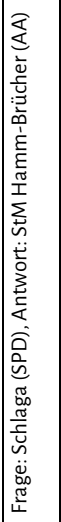 & 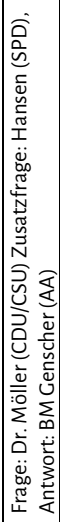 & 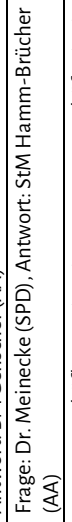 & 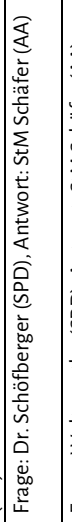 & 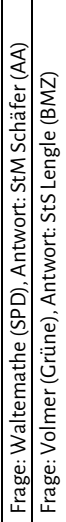 & 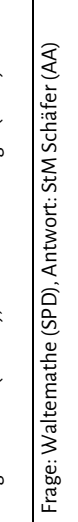 & 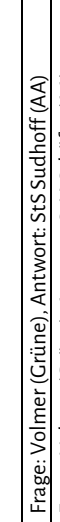 & 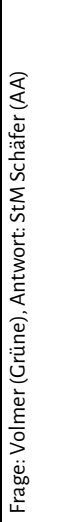 & 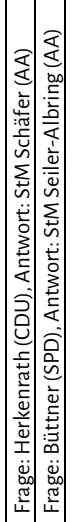 & 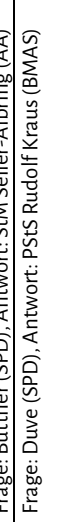 & 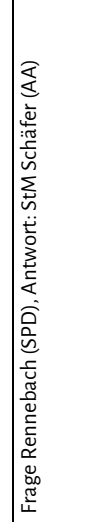 & 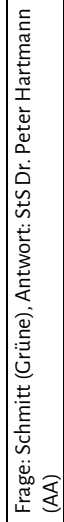 & & 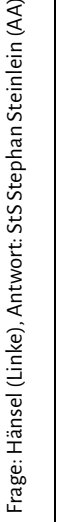 \\
\hline 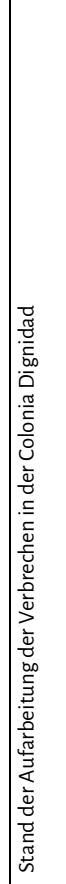 & 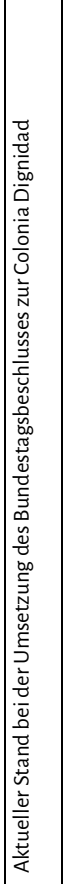 & & 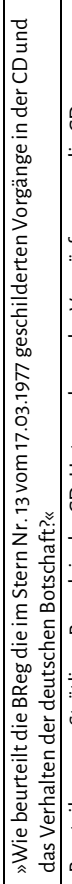 & 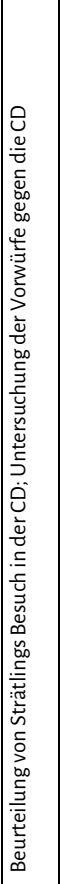 & 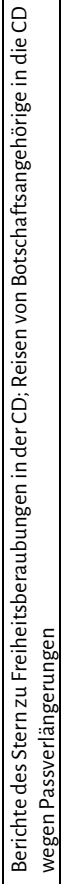 & 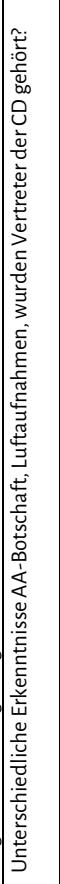 & 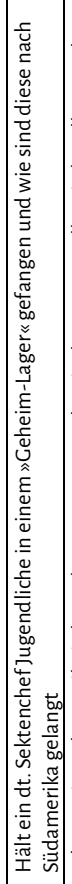 & 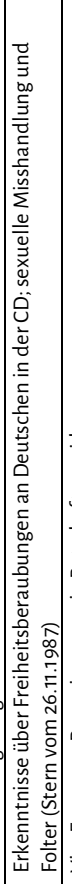 & 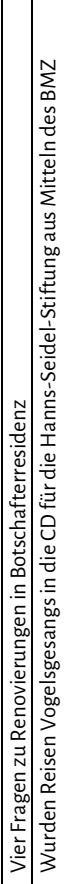 & 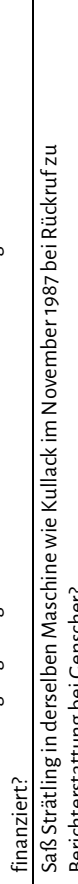 & 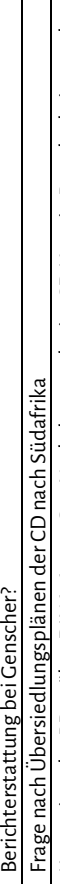 & 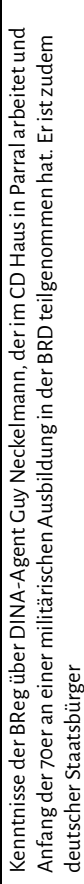 & 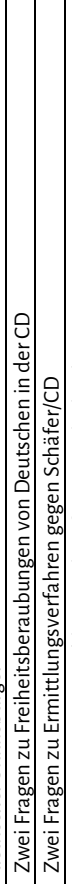 & 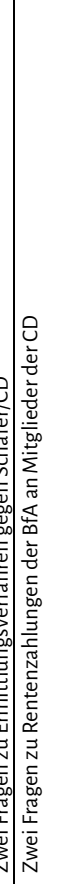 & 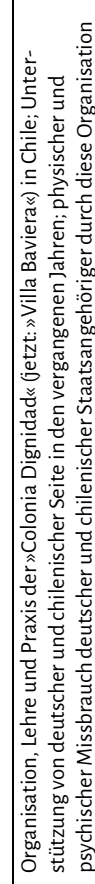 & 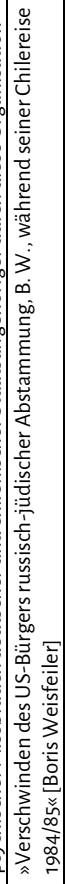 & & 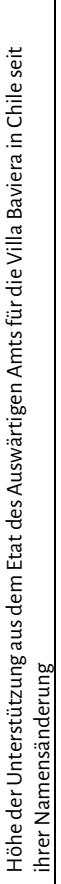 \\
\hline 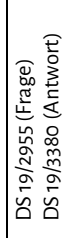 & 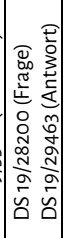 & 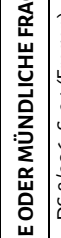 & 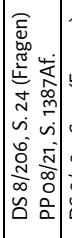 & 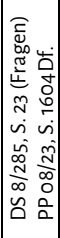 & 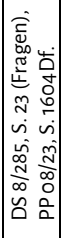 & 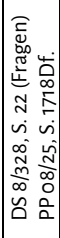 & $\begin{array}{l}n \\
\vdots \\
0 \\
0 \\
0 \\
\infty \\
\infty \\
0 \\
0\end{array}$ & 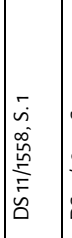 & 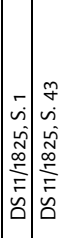 & $\begin{array}{cc}m \\
m \\
s=3\end{array}$ & 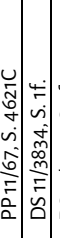 & 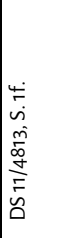 & 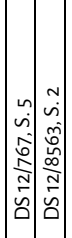 & 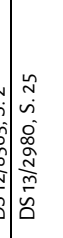 & 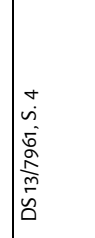 & 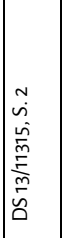 & & व \\
\hline 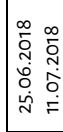 & 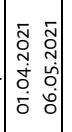 & 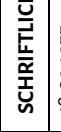 & 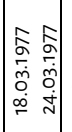 & 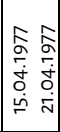 & $\mid$ & 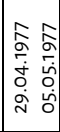 & 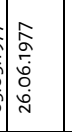 & 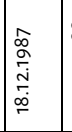 & 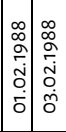 & 10 & $\begin{array}{c}0 \\
\\
\\
0 \\
0\end{array}$ & & 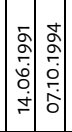 & לִ & - & 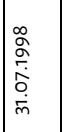 & & ș. \\
\hline
\end{tabular}




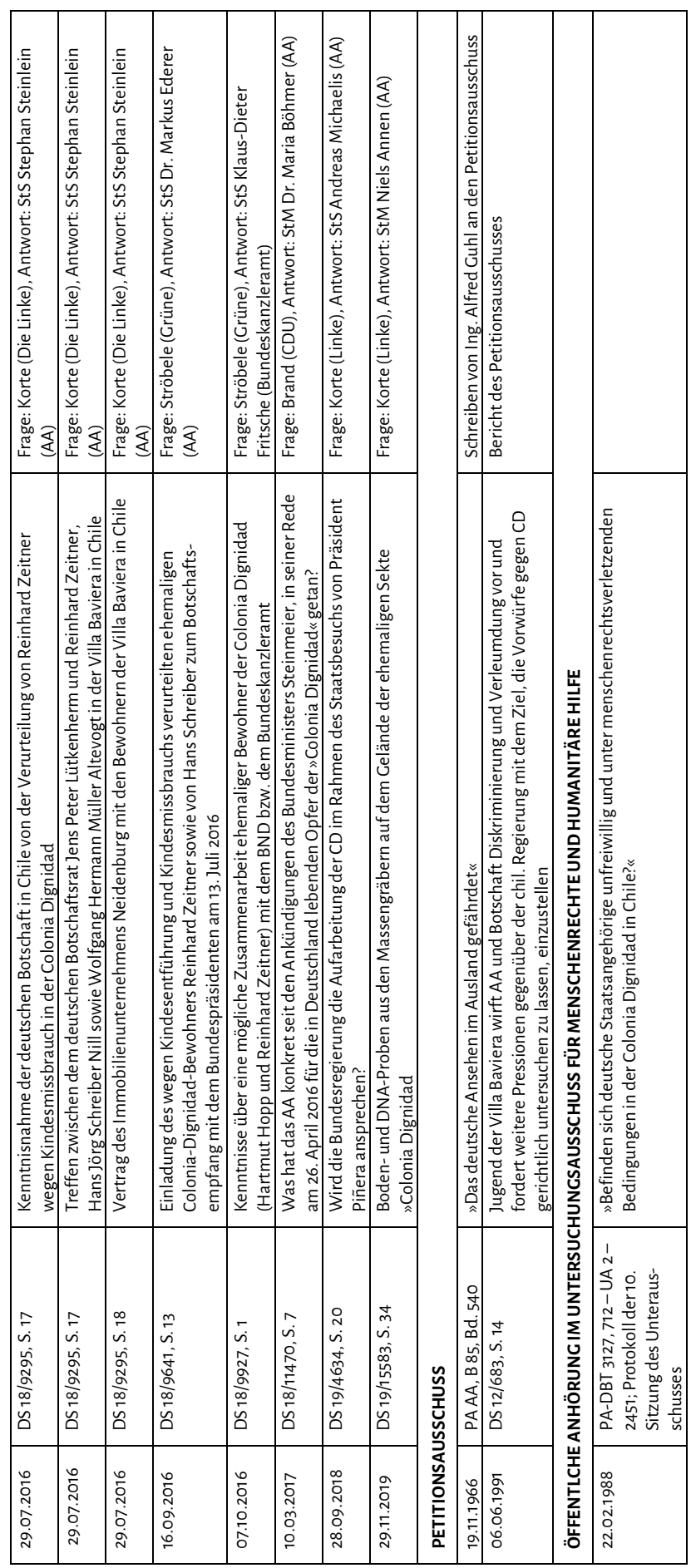


Nach Hartmut Hopps Flucht in die Bundesrepublik 2011 stellte die Linkspartei auch eine Reihe von Kleinen Anfragen im Landtag von Nordrhein-Westfalen. ${ }^{644}$ Sie zielten auf die Ermittlungen der Staatsanwaltschaft Krefeld (vgl. Abschnitt 5.3.8) und der StA Bonn (vgl. Abschnitte 5.3.3 bis 5.3.7).

Der Bundestag war regelmäßig mit dem Fall CD befasst. Dies blieb jedoch lange Zeit weitgehend folgenlos für die politische und juristische Aufklärung. Die in Tabelle 15 aufgeführten Fragen und Kleinen Anfragen beantwortete die Bundesregierung meist wortkarg, oftmals unter Verweis auf anhängige Justizverfahren und auf die Verantwortung chilenischer Stellen. So hieß es noch im April 2016, zwei Wochen vor der Rede von Außenminister Steinmeier zur Colonia Dignidad: »Die Bundesregierung ist der Auffassung, dass der Schutz der Menschenrechte auf chilenischem Territorium vorrangig den dort zuständigen Stellen obliegt. ${ }^{645}$

Auch wenn die Bundesregierung in der Regel antwortete, über keinerlei Erkenntnisse zu bestimmten Vorgängen zu verfügen, konnten durch die Fragen doch mitunter einzelne Sachverhalte bestätigt werden, die Menschenrechtsaktivist_innen oder Journalist_innen zuvor recherchiert hatten. So bestätigte die Bundesregierung beispielsweise 1988 auf eine Kleine Anfrage, dass das Bundesvermögensamt 1961 »im Auftrag des Bundesministers der Verteidigung Immobilien in Lohmar-Heide bei Siegburg von Paul Schäfer erworben ${ }^{646}$ hatte. In der Antwort auf eine Frage des Abgeordneten Waltemathe (SPD) zur Renovierung der Botschaftsresidenz in Santiago während der Amtszeit von Botschafter Strätling (1976-1979) musste das AA einräumen, dass daran Handwerker der CD beteiligt waren. Das Amt rechtfertigte dies damit, dass die Handwerker »alle deutsche Befähigungsnachweise besitzen und für ihre Qualitätsarbeit bekannt

644 Landtag Nordrhein-Westfalen. Drucksache 15/2782 vom 18.09.2011. Kleine Anfrage 1110, Conrads, Anna LINKE. Ermittlungen der NRW-Justiz zur Colonia Dignidad (Teil 1); Landtag NordrheinWestfalen. Drucksache 15/2783 vom 18.09.2011. Kleine Anfrage 1111, Conrads, Anna LINKE. Ermittlungen der NRW-Justiz zur Colonia Dignidad (Teil 2); Landtag Nordrhein-Westfalen. Drucksache 15/2784 vom 18.09.2011. Kleine Anfrage 1112, Conrads, Anna LINKE. Ermittlungen der NRW-Justiz zur Colonia Dignidad (Teil 3); Landtag Nordrhein-Westfalen. Drucksache 15/2785 vom 18.09.2011. Kleine Anfrage 1113, Conrads, Anna LINKE. Vermögensverhältnisse des früheren Vize-Chefs der CoIonia Dignidad; Landtag Nordrhein-Westfalen. Drucksache 15/2786 vom 18.09.2011. Kleine Anfrage 1114, Conrads, Anna LINKE. Illegale Finanzströme und Geldwäsche bei Vereinigungen rund um die Colonia Dignidad sowie Landtag Nordrhein-Westfalen. Drucksache 15/2787 vom 18.09.2011. Kleine Anfrage 1115, Conrads, Anna LINKE. Approbation des früheren Vize-Chefs der Colonia Dignidad Hartmut $\mathrm{H}$.

645 Deutscher Bundestag. Drucksache 18/8127 vom 15.04.2016. Schriftliche Fragen mit den in der Woche vom 11. April 2016 eingegangenen Antworten der Bundesregierung, S. 12. 2013 hatte die Bundesregierung auf eine Kleine Anfrage ähnlich geantwortet: »Der Schutz der Menschenrechte auf chilenischem Territorium obliegt den dort zuständigen Stellen. Eine Mitverantwortung der Bundesrepublik Deutschland für die in der Colonia Dignidad begangenen Straftaten besteht nicht." Deutscher Bundestag. Drucksache 17/12980 vom 04.04.2013. Antwort der Bundesregierung auf die Kleine Anfrage der Abgeordneten Hans-Christian Ströbele, Tom Koenigs, Ingrid Hönlinger, weiterer Abgeordneter und der Fraktion BÜNDNIS 90/DIE GRÜNEN - Drucksache 17/12776 - Aufarbeitung der Verbrechen in der Colonia Dignidad, S. 3.

646 Deutscher Bundestag. Drucksache 11/2449 vom 09.06.1988. Antwort der Bundesregierung auf die Kleine Anfrage der Fraktion der DIE GRÜNEN - Drucksache 11/1409-Beziehungen der Bundesregierung und von Politikern der Bundesrepublik Deutschland zur Colonia Dignidad, Chile, S. 2. 
sind «. ${ }^{647}$ Diese Antwort war pikant, da der Bundesregierung zum damaligen Zeitpunkt bekannt war, dass die CD sehr versiert bei der Installation verdeckter Mikrofone und Abhöranlagen war.

Bereits einen Tag nach dem Erscheinen der Zeitschrift Stern am 17.03.1977 fragte der SPD-Abgeordnete Karl-Heinz Hansen: »Wie beurteilt die Bundesregierung die im Stern Nr. 13 vom 17. März 1977 geschilderten Vorgänge in der »Colonia Dignidad« in Chile und das Verhalten der deutschen Botschaft? «. ${ }^{648}$ Staatsminister von Dohnanyi antwortete in der Bundestagssitzung am 24. März:

»Die Bundesregierung bittet um Verständnis dafür, dass auf diese Frage heute keine endgültige Antwort erteilt werden kann. Die Bundesregierung hatte Hinweise über gewisse Zustände und hatte deswegen den Botschafter gebeten, sich um Aufklärung zu bemühen. Die erneut - wie es scheint - nicht unbegründet gegen die >Colonia Dignidad in Chile erhobenen Vorwürfe sind jedoch so schwerwiegend, dass eine eingehende Untersuchung unbedingt erforderlich ist. Bei der Kürze der zu Verfügung stehenden Zeit konnte eine abschließende Stellungnahme nicht vorgelegt werden. Die erneut eingeleitete Prüfung wird aber intensiv fortgeführt. Über das Ergebnis wird die Bundesregierung so bald wie möglich berichten. ${ }^{649}$

Ein Jahr später antwortete Staatsministerin Hamm-Brücher jedoch auf die Frage des Abgeordneten Meinecke, ob in der CD Jugendliche von einem Sektenchef festgehalten würden:

»Die Bundesregierung verfügt über keine Erkenntnisse, daß [...] >ein deutscher Sektenchef Jugendliche in Geheimlagern in Chile gefangen hältı. Auch haben sich Gerüchte nicht bestätigt, daß Jugendliche gegen ihren Willen in der >Colonia Dignidad ‘ festgehalten werden. [...] Unsere Botschaft in Santiago hat sich wiederholt mit ähnlichen Vorwürfen befaßt. Ihre Ermittlungen haben keinen Beweis für die Richtigkeit der Beschuldigungen erbringen können. « 650

Zum Teil klangen die Antworten der Bundesregierung auch recht hilflos, wie etwa in diesem Fall von 1994:

»Im übrigen betont die Bundesregierung erneut, daß sie seit Jahren nichts unterläßt, um die schweren, auch strafrechtlichen Vorwürfe vor allem gegen die Führung der Colonia Dignidad aufzuklären und die Verantwortlichen zur Rechenschaft zu ziehen. Die Bundesregierung ist ebenso konsequent bemüht, das Recht der CD-Angehörigen auf Freizügigkeit und menschenwürdige Lebensumstände durchzusetzen. Sie hat bisher

647 Deutscher Bundestag. Drucksache 11/1825 vom 05.02.1988. Schriftliche Fragen mit den in der Woche vom 1. Februar 1988 eingegangenen Antworten der Bundesregierung, S. 2.

648 Deutscher Bundestag. Drucksache 8/206 vom 18.03.1977. Fragen für die Fragestunden der Sitzungen des Deutschen Bundestages am Mittwoch, dem 23. März 1977 am Donnerstag, dem 24. März 1977, S. 24.

649 Deutscher Bundestag. Plenarprotokoll 8/21 vom 24.03.1977, S. 1387Af.

650 Deutscher Bundestag. Drucksache 8/2009 vom 26.06.1977. Fragen für den Monat Juli 1978 mit den dazu erteilten Antworten, Teil III, S. 2. 
5. Die juristische und parlamentarische Aufarbeitung der Verbrechen der Colonia Dignidad

wie die chilenische Regierung und andere ausländische Regierungen in ähnlichen Fällen ihr Ziel noch nicht erreicht. Sie wird ihre Bemühungen beharrlich fortsetzen. « ${ }^{651}$

651 Deutscher Bundestag. Drucksache 12/7501 vom 09.05.1994. Antwort der Bundesregierung auf die Kleine Anfrage der Abgeordneten Ulla Jelpke und der Cruppe der PDS/Linke Liste - Drucksache 12/7111 - Colonia Dignidad in Chile, S. 2. 



\section{Fünf historische Phasen des Falls Colonia Dignidad}

Die Kernfrage dieser Arbeit ist, was bundesdeutsche Behörden über die Verbrechen der Colonia Dignidad wussten und wie sie auf dieses Wissen reagiert haben, also was sie unternommen bzw. unterlassen haben. Die Antwort auf diese Frage fällt für verschiedene historische Phasen durchaus unterschiedlich aus. In diesem Kapitel stelle ich daher eine Unterteilung des Falls CD in fünf historische Phasen vor. Diese soll die Verbrechen der CD sowie die Reaktionen von Politik und Justiz in ihren jeweiligen historischen und gesellschaftspolitischen Kontext einordnen. Diese fünf Phasen sind die Genese des »Projekts Schäfer« in der Bundesrepublik bis 1961 (6.1), der Aufbau der CD in Chile von 1961 bis 1973 (6.2), die CD während der chilenischen Militärdiktatur (6.3), die Phase der chilenischen Transición von 1990 bis zu Schäfers Verhaftung 2005 (6.4) sowie die verspätete Transición der CD von 2005 bis heute (6.5).

Vor der Beschreibung der fünf Phasen möchte ich auf einige Punkte eingehen, die für eine Analyse des Falls CD grundlegend sind: Dies ist erstens die Bilateralität und das Problem der - je nach Perspektive - doppelten oder ungeklärten Verantwortung Deutschlands und Chiles. Zweitens thematisiere ich die Wechselwirkungen zwischen der politischen und der juristischen Ebene in beiden Staaten, die im Einzelnen bereits in Kapitel 5 deutlich geworden sein dürften. Drittens möchte ich auf die Rolle und Wahrnehmungen von Deutschstämmigen in der chilenischen Gesellschaft sowie auf die Asymmetrie der deutsch-chilenischen Beziehungen eingehen.

\section{Ein bilateraler Fall und die Zuständigkeit zweier Staaten}

Die Colonia Dignidad war von Anfang an ein bilateraler Fall, der hinsichtlich der zwischenstaatlichen Kommunikation und Zusammenarbeit sowohl Chile als auch die Bundesrepublik Deutschland vor Herausforderungen stellte und bis heute stellt: Eine Gruppe vorwiegend deutscher Staatsangehöriger ${ }^{1}$ wanderte nach Chile aus und ließ sich van den Berg war Niederländer. Die Mehrzahl der nach Chile ausgewanderten Colonos verfügt bis heute nur über die deutsche Staatsangehörigkeit. Die in Chile geborenen Colonos haben meist einen deutschen und einen chilenischen Pass. Von Colonos adoptierte Chilen_innen behielten nur die chilenische Staatsbürgerschaft. 
dort für mehrere Jahrzehnte nieder. Paul Schäfer, der Anführer der Gruppe, wurde zu diesem Zeitpunkt in der Bundesrepublik per Haftbefehl gesucht. Die Aktivitäten der Gruppierung auf chilenischem Staatsgebiet unterlagen der chilenischen Gesetzgebung. Zugleich waren die deutschen Staatsangehörigen in der Gruppierung auf konsularische Dienstleistungen der zuständigen ${ }^{2}$ bundesdeutschen Auslandsvertretung angewiesen - beispielsweise zur Verlängerung von Personaldokumenten oder zur Ausstellung sogenannter Lebensbescheinigungen für den Rentenbezug. Die Gruppierung gründete in Chile einen Verein (SBED) und wurde wirtschaftlich aktiv. In der Bundesrepublik betrieb sie weiterhin den Verein PSM sowie Unternehmen, um die Logistik der Gruppe in Chile zu unterstützen (vgl. Abschnitt 3.2.1). Einige CD-Führungsmitglieder reisten regelmäßig zwischen den Dependancen der CD in beiden Ländern hin und her.

Die CD beging jahrzehntelang systematisch und kontinuierlich schwere Verbrechen, vor allem auf dem CD-Gelände, also auf chilenischem Staatsgebiet. Nach dem Territorialprinzip oblag deren Strafverfolgung den chilenischen Strafverfolgungsbehörden. Nach dem Personalitätsprinzip sind bei Straftaten, die von deutschen Staatsangehörigen oder zulasten von deutschen Staatsangehörigen begangen werden, jedoch gleichzeitig auch bundesdeutsche Strafverfolgungsbehörden zuständig - unabhängig vom Tatort. Deshalb gab es sowohl in Chile als auch in der Bundesrepublik eine Vielzahl juristischer Verfahren. Die Staatsanwaltschaften und Gerichte beider Länder kommunizierten per Rechtshilfeersuchen miteinander (vgl. Abschnitte 5.1 und 5.3).

Zugleich stand der Fall CD mit unterschiedlicher Intensität auch immer wieder auf der innenpolitischen und außenpolitischen Agenda beider Staaten. Über sehr lange Zeiträume und bis heute ist der Fall CD auf bilateraler Ebene Gegenstand von Staatsbesuchen und politischen Gesprächen. Die Auslandsvertretungen beider Staaten kommunizierten über Verbalnoten mit der Regierung des jeweils anderen Landes.

Dabei haben sich die politischen Verhältnisse in Chile und der Bundesrepublik zum Teil grundlegend gewandelt. In beiden Ländern herrschten formal demokratische Verhältnisse, mit Ausnahme der chilenischen Diktatur von 1973 bis 1990. Nach dem Militärputsch vom 11. September 1973 bildete die CD eine Allianz mit der Diktatur. Auch konservative Kreise in der Bundesrepublik sympathisierten mit der Militärjunta in Chile, die das Land zu Zeiten des Kalten Kriegs nach dem von Allende verkündeten demokratischen Weg zum Sozialismus wieder fest ans westliche Lager binden sollte. Gleichzeitig sympathisierten viele Progressive in der Bundesrepublik eher mit Allende und zeigten nach dem Putsch ihre Solidarität mit politisch verfolgten Chilen_innen.

Die Medienberichterstattung über die CD war in beiden Ländern umfangreich, allerdings gab es einige, meist eher kurze Phasen hoher medialer Aufmerksamkeit (vgl. Tabelle 1 in Abschnitt 2.2.2) sowie längere Perioden geringen Interesses. In Phasen erhöhter Aufmerksamkeit nahmen auch die Regierungen beider Länder verstärkt Kenntnis von der CD sowie von den von ihr verübten Straftaten und Gesetzesverstößen. Gleichzeitig betrieb die CD-Führung über Jahrzehnte in beiden Ländern eine intensive Lobbyarbeit, pflegte Unterstützungsnetzwerke und verfolgte eine offensive juristische 
Strategie. Dabei wurden nicht selten auch Journalist_innen oder staatliche Stellen zum Spielball der CD.

Eine zentrale These dieser Arbeit lautet, dass der geschilderte bilaterale Charakter des Falls CD bzw. die formal doppelte, de facto aber ungeklärte Zuständigkeit staatlicher Stellen eine wichtige Voraussetzung dafür war, dass die CD ihre Verbrechen über einen so langen Zeitraum perpetuieren konnte.

Auf politischer Ebene führte die ungeklärte Zuständigkeit dazu, dass sich Chile und die Bundesrepublik gegenseitig die Verantwortung für den Fall CD und die daraus abzuleitenden Handlungsschritte zuwiesen. Die grundsätzliche Auffassung, die hauptsächliche Verantwortung liege bei der jeweils anderen Seite, führte zu einer gegenseitigen Blockade und oftmals zu einem Aussitzen der Probleme. Jegliches Ergreifen von Initiative konnte als Eingeständnis von Verantwortung gewertet werden und wurde daher in der Regel zumindest herausgezögert, wenn nicht ganz vermieden. Dieses ermöglichte es früher der CD, ihre Verbrechen fortzusetzen und bremst bis heute die politische und juristische Aufarbeitung dieser Verbrechen.

Auf juristischer Ebene gab es eine weitere Hürde: Da Deutschland und Chile bis heute kein Rechtshilfeabkommen geschlossen haben, war die Kommunikation zwischen den Justizapparaten beider Länder stets auf hochformalisierte und langwierige Rechtshilfeersuchen angewiesen (vgl. Abschnitt 5.3.1). Hatte eine Seite kein Interesse an der Gewährung effektiver Rechtshilfe, vergingen mitunter Jahre, bis eine Anfrage beantwortet wurde, was beim Fall CD häufiger vorkam. Zudem führten unterschiedliche Rechtskulturen zu Verständigungsschwierigkeiten. Die CD und die von ihr beauftragten Rechtsanwält_innen konnten allerdings in beiden Ländern agieren und sich untereinander austauschen. Sie pflegten ständig ihre Kontakte sowie den Informationsaustausch mit Ermittler_innen und Richter_innen in beiden Ländern, was ihnen oftmals einen immensen Informationsvorteil sowie ein entsprechendes Ansehen bei Staatsanwaltschaften und Gerichten verschaffte.

\section{Wechselbeziehungen zwischen Politik und Justiz}

Grundlegend für ein Verständnis des Falls CD sind neben seinem bilateralen Charakter die Wechselbeziehungen zwischen politischer und juristischer Ebene in beiden Ländern. Es gilt, ein komplexes, bilaterales Gefüge unterschiedlicher Institutionen und Akteur_innen zu analysieren. Dennoch liegt mein Hauptaugenmerk auf der Frage, was Behörden in der Bundesrepublik - insbesondere das Auswärtige Amt sowie Staatsanwaltschaften und Gerichte in Nordrhein-Westfalen - wann über die Verbrechen der CD gewusst haben und wie sie angesichts dieses Wissens reagiert und gehandelt haben.

Das Auswärtige Amt vertritt die - politisch definierten - Interessen der Bundesrepublik Deutschland nach außen und pflegt die Außenbeziehungen des Staates. ${ }^{3}$ Die Auslandsvertretungen der Bundesrepublik, also die Botschaften und Konsulate, sind als Teil des Auswärtigen Dienstes gegenüber dem AA weisungsgebunden. Zu ihren Aufgaben gehört es, im Ausland lebenden deutschen Staatsangehörigen Schutz und Beistand 
zu leisten. ${ }^{4}$ Das bedeutet für den Fall CD, dass deutsche Diplomat_innen in Chile einerseits gegenüber Colonos (deutscher Staatsangehörigkeit) Schutz- und Beistandsverpflichtungen hatten und haben. Andererseits sollte die bundesdeutsche Außenpolitik im Zusammenhang mit dem Fall CD auch die »Interessen der Bundesrepublik« vertreten. Zumindest auf diskursiver Ebene gehört dazu der Menschenrechtsschutz.

In der Bundesrepublik ist es Aufgabe von Staatsanwaltschaften und Gerichten, Straftaten nachzugehen, diese aufzuklären und zu sanktionieren. Bei sogenannten Offizialdelikten (wie z.B. Mord, schwere Körperverletzung oder Freiheitsberaubung) müssen zuständige Behörden nach $\$ 160$ StPO von sich aus Ermittlungen aufnehmen, sobald sie Kenntnis von entsprechenden Straftaten erhalten. Dies kann durch Anzeigen von Betroffenen oder Dritten, aber auch durch Hinweise auf Straftaten in Medien erfolgen. Charakteristisch für den Fall CD ist, dass die Behörden von Straftaten meist nicht direkt durch Betroffene erfuhren (dies versuchte die CD-Führung durch vielfältige Maßnahmen zu verhindern), sondern durch Berichte oder Anzeigen von Angehörigen von Colonos, von Menschenrechtsaktivist_innen oder durch andere Behörden. So leitete beispielsweise das Auswärtige Amt entsprechende Informationen an Justizbehörden in der Bundesrepublik weiter. Die Botschaft in Santiago ist dabei in mehrfacher Hinsicht ein zentraler Akteur: erstens als Instanz der Informationserhebung und -aufbereitung vor Ort, zweitens durch ihre direkten Kontakte zu chilenischen Behörden und Politiker_innen, drittens durch ihre Kontakte zur CD-Führung und viertens als Anlaufstelle für geflüchtete Colonos.

\section{Deutsche in Chile und Asymmetrie in den deutsch-chilenischen Beziehungen}

»Die Anerkennung, die die Kolonie in manchen Kreisen Chiles findet [...] ist Ausdruck der Bewunderung, die man der deutschen Arbeit und Perfektion entgegenbringt, und die, gerade weil sie in Abkapslung praktiziert wird, chilenische Belange eigentlich nicht berührt. Die Haltung der chilenischen Seite gegenüber der Kolonie wäre in dem Augenblick völlig anders, in dem Chilenen in das Leben und die Zwänge der Kolonie einbezogen würden. So ist die Kolonie >Dignidad « ein Stück Auslandsdeutschtum, das uns auch weiterhin mehr belasten als nützen wird. ${ }^{5}$

Paul Schäfer und seine Anhänger_innen kamen ab 1961 in ein Land, in dem Deutsche hohes Ansehen genossen. Deutschstämmige Migrant_innen waren in mehreren Perioden nach Chile gekommen, insbesondere zwischen 1850 und $1950 .{ }^{6}$ Im 19. Jahrhundert waren viele deutsche Immigrant_innen Teil einer von privaten Siedlungsgesellschaften zusammen mit der chilenischen Regierung vorangebrachten Anwerbekampagne zur Besiedlung von Gebieten südlich des Flusses Biobío, in denen die indigenen

5 PA AA, ZW 111129. Bericht Botschaftsrat Werner Kaufmann-Bühler »Aufzeichnung des RKReferenten der Botschaft Santiago über den Besuch der Deutschen Kolonie ১Dignidadı am 19.06.1972《.

6 Vgl. z.B. Blancpain, Jean-Pierre. Los Alemanes en Chile (1816-1945). Santiago 1985, sowie: De la Cerda, María Soledad. Chile y los hombres del Tercer Reich, Santiago 2000. 
Mapuche lebten. ${ }^{7}$ Neben einer Zurückdrängung der Mapuche versprach man sich von den deutschen Siedlern Modernisierungseffekte. Ende der 1930er Jahre flüchteten etwa 13.000 deutsche Jüdinnen und Juden nach Chile. ${ }^{8}$ Nach Ende des Zweiten Weltkriegs kam eine unbekannte Zahl ehemaliger Nationalsozialisten nach Chile. ${ }^{9}$ Heute haben von den etwa 18 Millionen Chilen_innen Schätzungen zufolge zwischen 150.000 und 500.000 deutsche Vorfahren. ${ }^{10}$ Dies ist der höchste Anteil aller lateinamerikanischen Länder. Viele positive Stereotype über die deutschstämmige Bevölkerung haben sich bis heute erhalten. ${ }^{11}$ Auch viele Deutschstämmige betrachten sich selbst als »arbeitsam«, »pünktlich« und »ordentlich« - nicht selten in Abgrenzung von der Mehrheit der Chilen_innen. ${ }^{12}$

Viele Nachfahren deutscher Immigrant_innen beziehen sich bis heute auf dieses Erbe. In Chile gibt es zahlreiche deutsche Auslandsschulen, ein deutsches Lehrerbildungsinstitut, deutsche Institutionen und Vereine. ${ }^{13}$ Viele Deutschstämmige in Chile verfügen über ein höheres Einkommen, gehören den »Führungsschichten des Landes ${ }^{14}$ an und sind politisch konservativ eingestellt. ${ }^{15}$ Viele Deutschstämmige begrüßten den Putsch und die Militärdiktatur ab 1973. Auch in der Wirtschaftselite des Landes finden sich zahlreiche Familien mit deutschen Vorfahren.

Neben diesen familiären Traditionen gibt es in einigen Bereichen auch politische Einflüsse aus Deutschland. So prägten preußische Militärberater seit Ende des 19. Jahr-

Diese militärische Besetzung und die darauffolgende Besiedlung mit chilenischen und europäischen Kolonist_innen beschrieb die offizielle chilenische Geschichtsschreibung lange Zeit euphemistisch als »Pacificación de la Araucanía« (»Befriedung Araukaniens«), vgl.: Lorena Mazuré Loos. Perspektiven der deutsch-chilenischen Minderheit in Chile auf Colonia Dignidad. [Diplomarbeit], Wien 2009, online unter http://othes.univie.ac.at/4235/1/2009-03-16_0448041.pdf, S. 26.

8 Vgl. Wojak, Irmtrud. Exil in Chile: Die deutsch-jüdische und politische Emigration während des Nationalsozialismus (1933-1945), Reihe Dokumente, Texte, Materialien des Zentrums für Antisemitismusforschung an der TU Berlin, Bd. 16, Berlin 1994.

9 Vgl. de la Cerda, Chile y los hombres del Tercer Reich und Wojak, Exil in Chile.

10 Es gibt keine statistische Erfassung, sondern nur unterschiedliche Schätzungen. Während Singer 1998 von 150.000 Deutschstämmigen in Chile ausging, schätzte Gloël die Zahl 2015 auf 500.000. Barrenechea liegt mit seiner Schätzung auf 300.000 von 1984 in der Mitte. Vgl. Singer, Christine. Deutsche Auswanderer zwischen Mythos und Realität - Zur Sonderstellung der deutschen Minderheit in Chile. [unveröffentlichte Magisterarbeit], Konstanz 1998, online unter http://kops.uni-k onstanz.de/bitstream/handle/123456789/11487/204_1.pdf; Gloël, Matthias. »Deutsche Kolonisten in Chile - Ursprünge und Gegenwart«, in: Humboldt-Magazin, Mai 2015, online unter https://www.g oethe.de/ins/cl/de/kul/mag/20815303.html sowie Barrenechea, Carlos. Bundesrepublik und Chile. Die politischen und wirtschaftlichen Beziehungen der Bundesrepublik Deutschland zur Republik Chile während der Regierungen Frei, Allende und Pinochet, Köln 1984.

11 Dufner, Georg. Partner im Kalten Krieg. Die politischen Beziehungen zwischen der Bundesrepublik Deutschland und Chile, Frankfurt a.M. 2014, S. 10.

12 Ziebur, Ulrike. Die soziolinguistische Situation von Chilenen deutscher Abstammung, in: Linguistik Online 7 (2000) Nr. 3, online unter https://doi.org/10.13092/lo.7.987.

13 Dazu gehören Krankenhäuser, Kirchen, freiwillige Feuerwehren, der Deutsch-Chilenische Bund und die von ihm herausgegebene deutschsprachige Wochenzeitung »Der Condor sowie eine deutsch-chilenische Industrie- und Handelskammer.

14 Loos, Perspektiven der deutsch-chilenischen Minderheit, S. 15.

15 Ziebur, Die soziolinguistische Situation. 
hunderts die Organisation des chilenischen Heeres. ${ }^{16}$ Chilenische Offiziere wurden zur Ausbildung nach Deutschland geschickt. ${ }^{17}$ Eine Reihe hoher chilenischer Militärangehöriger hatte deutsche Vorfahren. Der Historiker Maldonado Prieto sieht den deutschen Einfluss als einen der wichtigsten Faktoren für das Aufkommen und die Weiterentwicklung faschistischen Gedankengutes in Chile an. ${ }^{18}$

Auch wirtschaftlich spielt Deutschland bis heute eine wichtige Rolle für Chile, es ist Chiles wichtigster Handelspartner in der EU. ${ }^{19}$ Allerdings spielt Chile für die deutsche Wirtschaft eine geringe Rolle. Ein Blick auf das Bruttoinlandsprodukt (BIP) zeigt das ökonomische Ungleichgewicht zwischen beiden Ländern. In der Bundesrepublik war das BIP pro Kopf 2018 dreimal so hoch wie in Chile. ${ }^{20}$ Dabei hat Chile gegenüber der Bundesrepublik schon stark aufgeholt. Bei Ankunft der ersten Colonos in den 1960er Jahren war Chile noch ein Entwicklungsland, heute ist es Mitglied der Organisation für wirtschaftliche Zusammenarbeit und Entwicklung (OECD), in dem sich die Länder mit besonders hohem Pro-Kopf-Einkommen zusammenschließen.

Nicht nur das wirtschaftliche, auch das politische Gewicht beider Länder ist unterschiedlich. Die Bundesrepublik als das größte und oftmals entscheidende Mitglied der EU hat auf internationaler Ebene einen sehr viel höheren Einfluss als Chile. Dies betrifft auch multilaterale Entscheidungen, die Auswirkungen auf Chile haben können, wie etwa internationale Kredite. Der Fall CD ist daher vor dem Hintergrund asymmetrischer bilateraler Beziehungen zwischen Chile und der Bundesrepublik zu betrachten.

Nach diesen eher grundsätzlichen Bemerkungen zum Charakter des Falls CD sowie der deutsch-chilenischen Beziehungen möchte ich nun der Entwicklung des Falls sowie dem Umgang der bundesdeutschen Behörden mit diesem in den genannten fünf historischen Phasen nachgehen. Dabei beschreibe ich für jede dieser fünf Phasen die jeweilige politische Konstellation in beiden Ländern sowie die wichtigsten Ereignisse des Falls CD, um vor diesem Hintergrund die Reaktionen der bundesdeutschen Behör-

16 Diese sogenannte Preußifizierung begann 1884 mit der Verpflichtung des preußischen Offiziers Emil Körner als Militärberater in Chile. 1900 wurde Körner Ceneralinspektor der chilenischen Armee. Er gestaltete die Lehrpläne der Militärschule mit und war an der Gründung der Kriegsakademie des Heeres beteiligt. 1895 schickte das chilenische Heer erstmals Ausbildungsoffiziere zur Fortbildung ins Deutsche Reich. Vgl. Rinke, Stefan. Eine Pickelhaube macht noch keinen Preußen: preußisch-deutsche Militärberater, »Militärethos« und Modernisierung in Chile 1886-1973, in: Carreras, Sandra/Günther Maihold (Hg.). Preußen und Lateinamerika. Im Spannungsfeld von Kommerz, Macht und Kultur, Münster 2004, S. 259-284.

17 Zu den deutschstämmigen chilenischen Militärangehörigen, die Bundeswehrlehrgänge absolvierten und danach während der Militärdiktatur (1973-1990) eine wichtige Rolle spielten - teilweise auch in Verbindung mit der CD - zählen Eduardo Guy Neckelmann Schütz, Bruno Siebert Held und Christian Ackerknecht. BArch BW 2/11237. Schreiben von Oberstleutnant von Pilgrim an OTL i. C. Loyo, Militärattaché der Botschaft vom 19.02.1971.

18 Maldonado Prieto, Carlos. La Prusia de América del Sur. Acerca de las relaciones militares chilenogermanas, 1927-1945, in: Estudios Sociales 73 (1992), S. 75.

19 Auswärtiges Amt, »Deutschland und Chile: Bilaterale Beziehungen« vom 02.03.2020, online unter https://www.auswaertiges-amt.de/de/aussenpolitik/laender/chile-node/bilateral/201114.

20 International Monetary Fund. World Economic Outlook Database, Oktober 2019, online unter: htt ps://www.imf.org/external/pubs/ft/weo/2019/02/weodata/index.aspx. 
den einzuordnen und zu bewerten. Hierzu gehe ich auch auf das jeweilige Agieren bzw. die Strategien der CD ein.

\subsection{Phase I (bis 1961): Die Genese einer totalitären Gruppierung}

Colonia Dignidad war das Projekt Paul Schäfers. Dieser betrieb die Gründung seiner Gruppierung von Beginn an, um seine Sexualverbrechen begehen zu können. Andere, sekundäre Verbrechen dienten dazu, diese Verbrechen zu ermöglichen bzw. deren Verfolgung zu verhindern (vgl. Abschnitt 4.1.1). Bereits in der Früh- oder Gründungsphase, also noch vor der Auswanderung nach Chile, schuf Schäfer in der Bundesrepublik eine pseudoreligiöse Gruppierung. Schon damals bemühte er sich um den Aufbau einer sozialen Fassade, die dazu diente, seine Missbrauchstaten zu decken. Das freikirchliche Umfeld, aus dem Schäfer die Mitglieder der Gruppierung rekrutierte, sowie die gesellschaftliche Situation der Nachkriegs-Bundesrepublik waren für dieses Projekt ein fruchtbarer Nährboden.

Diese erste Phase des Aufbaus der Gruppe ist zugleich ein Prozess der Entwicklung von einer kriminellen Einzelperson hin zu einem kriminellen System, das Schäfer einerseits die ständige Verfügbarkeit von Opfern für seine Sexualverbrechen und andererseits eine Verschleierung und damit Straffreiheit für seine Taten sicherte. Dieses in der Bundesrepublik etablierte und erprobte System wurde später in Chile zur Blaupause für die Colonia Dignidad. Diverse Zeugnisse belegen schon für diese frühe Phase die systematische Anwendung jener kriminellen Mechanismen, die in dem für die CD noch günstigeren Setting in Chile später noch weiter perfektioniert werden sollten. Die integralen Bestandteile dieser kriminellen Gemeinschaft um Schäfer waren neben dem sexuellen Missbrauch Freiheitsberaubung, Kindesaneignung, Körperverletzung, Postzensur, Überwachung sowie unentgeltliche Arbeit (vgl. Abschnitt 4.1).

Diese Entwicklung fand in der Adenauer-Ära statt, also in einer Periode der Nachkriegszeit, die politisch von Restauration und gesellschaftlich von Autoritarismus und speziell von den Nachwirkungen von Krieg und Nationalsozialismus geprägt war. Demokratie existierte vielfach nur formal. Einstellungen und Handlungsmuster hatten sich seit 1945 nicht plötzlich grundlegend gewandelt. In einer zum Teil unbestimmbaren Mischung aus unterdrückter Enttäuschung, Ernüchterung, Schockiertheit und Desorientierung waren viele Deutsche auf der Suche nach neuen Sinnstiftungen. Bei den Anhänger_innen Schäfers handelte es sich meist um tiefreligiöse Menschen, die aus einfachen Verhältnissen stammten und sich nach einem charismatischen Anführer mit vermeintlich einfachen Erklärungsmustern sehnten. Dabei fanden sie mit Schäfer den Propagandisten eines manichäischen Weltbildes: Auf der einen Seite standen Gott, die ihm treu Ergebenen und von ihm Auserwählten und auf der anderen der Teufel sowie die vom Glauben Abgefallenen. ${ }^{21}$ Friedrich Paul Heller formulierte dies so: 
»Eine Welt, die nach dem Verbrechen von Auschwitz und der Kriegsniederlage Hitlerdeutschlands nicht mehr deutbar war, gewann aus der Perspektive einer isolierten religiösen Gemeinschaft ihren Sinn zurück. $\ll^{22}$

\section{9-1954: Schäfer als Leiter evangelischer Jugendgruppen}

Ende der 1940er, Anfang der 1950er Jahre leitete Paul Schäfer verschiedene Jugendgruppen in evangelischen Kirchengemeinden, zunächst als ehrenamtlicher Gruppenleiter, später auch als Angestellter diverser Gemeinden und Heime (vgl. Abschnitt 3.1.1). Dabei versuchte er wiederholt, seine Jungengruppen von den Gemeinden und ihren Leitungen abzuschotten. Er organisierte Bibelstunden an ungestörten Orten und lud Jungen zu persönlichen Gesprächen zu sich ein. Aufgrund seines Charismas konnte Schäfer schnell das Vertrauen der Jungen erlangen, geriet aber fast ebenso schnell in Konflikt mit deren Eltern sowie den Gemeindeleitungen. Seine Radikalisierung in Richtung evangelikaler Kreise sowie seine Methode der Abschottung führten wiederholt zu Gerüchten und Auseinandersetzungen, die mehrfach mit einer Entlassung Schäfers endeten. Die ebenfalls im Raum stehenden Vorwürfe über sexuellen Missbrauch durch Schäfer wurden allerdings dem Zeitgeist jener Jahre entsprechend meist unter den Teppich gekehrt.

\section{4-1956: Herausbildung der Gruppierung um Schäfer}

Nach mehrfachen Entlassungen wandte sich Schäfer von der evangelischen Kirche ab und suchte die Nähe zu freikirchlichen baptistischen Kreisen. Aus diesen rekrutierte er auch seine Gefolgschaft - unabhängig von kirchlichen Institutionen. Schäfer verfügte dabei nicht über einen festen Ort. Er predigte in diversen freikirchlichen Gemeinden und organisierte Zeltfreizeiten und Zusammenkünfte an verschiedenen Orten. Er besuchte mit seinen Anhänger_innen auch Massenveranstaltungen, z.B. des USamerikanischen Endzeitpredigers William Branham, über die sich neue Kontakte ergaben oder sich zusätzliche Personen der Gruppierung um Schäfer anschlossen.

1954 bzw. 1957 lernte Schäfer die baptistischen Prediger Hugo Baar und Hermann Schmidt kennen. Er überzeugte beide von seinem Projekt und brachte die beiden da$\mathrm{zu}$, in ihren jeweiligen baptistischen Gemeinden in Gronau und Hamburg Spaltungen herbeizuführen. Zahlreiche Gläubige aus beiden Gemeinden wurden nun zu Anhänger_innen Schäfers. Bei diesem Prozess wurden auch Familien gespalten und Ehepartner_innen voneinander getrennt. Dabei spielte Hugo Baar eine wichtige Rolle. Wer sich für die neue Gruppierung entschied, musste sich vollständig von seinen vorherigen Familien- und Gemeindestrukturen lossagen und jeglichen Kontakt zu diesen abbrechen. Die Gruppe isolierte sich zunehmend. Bei der Darstellung nach außen legte Schäfer zunehmend Wert auf ein wohltätiges Image, nach innen festigte er seine Position als totalitärer Herrscher. Bei seinen Anhänger_innen, die sich nach intensiven spirituellen Erfahrungen sehnten, erzeugte Schäfers pseudoreligiöse, vermeintlich an urchristliche Bibelauslegungen angelehnte Lehre Faszination und Ehrfurcht. Praktisch bedeutete die Auflösung jeglicher familiärer Bindungen und Vertrauensbeziehungen zugunsten einer diffusen Gemeinschaftsidentität aber die Unterwerfung aller unter den Willen Schäfers. 


\section{6-1960: Formierung der Schäfer'schen Gruppierung in Siegburg}

Wer sich der Gruppierung anschloss, wurde von Schäfer als »Freund der Wahrheit ${ }^{23}$ bezeichnet. Schäfer selbst betrachtete sich als personifizierten Ausdruck der Wahrheit. Sich dieser Wahrheit anzuschließen bedeutete nicht nur einen vollständigen Bruch mit der Außenwelt, die Schäfer als Bedrohung darstellte, sondern auch die Aufgabe des eigenen Willens und die Unterwerfung unter den allein von Schäfer definierten Gemeinschaftswillen. Die persönliche Beichte bei Schäfer war einerseits eine symbolische Reproduktion dieser Unterwerfung und diente zugleich ihrer Kontrolle. Bei gruppeninternen »Verhandlungen« wurde vermeintliches Fehlverhalten gegenüber der Gruppierung festgestellt und sanktioniert.

Dabei schottete sich die Gruppierung zunehmend von der Außenwelt ab. Dies bedeutete einerseits, dass sich die Mitglieder der Gruppierung immer weniger zu anderen Lebensbedingungen in Beziehung setzten. Andererseits entzog Schäfer die Vorgänge innerhalb der CD auch einer möglichen Kontrolle oder Sanktionierung durch staatliche Behörden. Die Mitglieder nahmen die Außenwelt immer stärker als feindlich wahr. Das schloss auch Angehörige von Mitgliedern ein, die der Gruppierung kritisch gegenüberstanden.

Der Rhein-Sieg-Kreis, die Region, in der Schäfer aufgewachsen war, sollte zum festen Ort für die Gruppierung werden. Ab 1956 war die nur 20 Kilometer von Bonn entfernte Kleinstadt Siegburg ihr Dreh- und Angelpunkt. Als formaler Träger wurde der Verein Private Sociale Mission (PSM) gegründet. Die Gruppierung erwarb in Heide (Lohmar) bei Siegburg ein Grundstück und baute sich ein als Jugendheim bezeichnetes Domizil (vgl. Abschnitt 3.1.1). Bis 1975 war Hugo Baar Vorsitzender der PSM, anschließend Alfred Schaak sowie nach dessen Tod 1985 Alfred Matthusen. Die PSM blieb auch nach der Auswanderung eines Großteils der Gruppe nach Chile als Dependance der CD in der Bundesrepublik bestehen - bis Ende der 1980er Jahre (vgl. Abschnitt 3.2.1).

Das Gelände des »ugendheims« wurde dabei systematisch abgeriegelt, der Einblick von außen erschwert. Jegliches Verlassen des Geländes durch Gruppenmitglieder wurde kontrolliert, auch mittels modernster Technik. ${ }^{24}$ Nur selten durften Jugendliche das Heim ohne Begleitung verlassen. ${ }^{25}$

\section{Die Siegburger Jahre als Blaupause für die Colonia Dignidad}

Rückblickend betrachtet erscheint die Siegburger Zeit der Gruppierung als Blaupause für die spätere Colonia Dignidad. Hier entwickelte und praktizierte Schäfer mithilfe einer ihm treu ergebenen Führungsgruppe sein Zwangssystem, hier erprobte er Unterdrückungs- und Verbrechensmuster, die oftmals als pseudoreligiöse Rituale getarnt waren. Aus jenen Jahren existieren Berichte über kollektive Prügelorgien, Einsperren und Fluchtversuche, Medikamentenvergabe zur Ruhigstellung und Elektroschocks 
zur Auslöschung der Erinnerung und systematischen sexuellen Missbrauch sowie Drohungen unter vorgehaltener Pistole, nichts darüber zu berichten.

In den Siegburger Jahren wurden auch die ökonomischen Grundlagen für den Fortbestand der Gruppierung geschaffen. Die sogenannten »Kreuzler«, die nach Siegburg gezogenen Mitglieder, mussten nahezu unbezahlt in den Betrieben von Alfred Schaak und Heinz Kuhn arbeiten (vgl. Abschnitt 3.2.1). Dieses »Kreuzverhältnis« - unentgeltliche Arbeitsleistung gegen Gemeinschaft, Kost und Logis - bezeichnete Schäfer als »unsere Lebensordnung «. ${ }^{26}$ Externe Mitglieder mussten ein Zehntel ihres Einkommens an die Gruppierung abführen. Viele Mitglieder brachten zudem ihre privaten Vermögen (z.B. Erbschaften) in die Gruppierung ein. Wer die Gruppierung verlassen wollte, war laut Schäfer ${ }^{27}$ ein »Abtrünniger« und hatte keinerlei Ansprüche geltend zu machen. Neben Einkommen, Vermögen und Arbeitskraft überließen viele Mitglieder der Gruppierung auch die Verfügungsgewalt über ihre eigenen Kinder.

\section{Die Führungsgruppe als tragendes Element des Schäfer'schen Projekts}

Bereits in Siegburg umgab Schäfer sich mit einer Reihe bedingungslos loyaler Personen, von denen viele über mehrere Jahrzehnte hinweg als Teil der CD-Führungsgruppe die Geschicke der Gemeinschaft mitbestimmen und ihre kriminellen Strukturen aufrechterhalten sollten. Nach 2005 schoben viele dieser Jerarcas (Hierarchen) sämtliche Verantwortung auf Schäfer ab und behaupteten, von dessen charismatischer Ausstrahlung quasi geblendet gewesen zu sein, von Verbrechen aber nur zu kleinen Teilen gewusst oder erst viel später erfahren zu haben. Doch es gibt zahlreiche Belege dafür, dass Schäfer die Gruppierung zwar dominierte, es aber die ihn umgebende Führungsgruppe war, welche die Verbrechen im Wesentlichen plante und umsetzte, insbesondere die gruppeninternen Zwangsstrukturen. Die Jerarcas wussten auch von jenen Verbrechen, an denen sie selbst nicht beteiligt waren. Dafür sowie für ihre bedingungslose Loyalität gegenüber Schäfer gestand dieser ihnen individuell »maßgeschneiderte« Privilegien zu. Diese Arbeitsteilung ermöglichte es Schäfer, sich nach innen und außen $\mathrm{zu}$ inszenieren und je nach Notwendigkeit als mächtiger und omnipräsenter Herrscher aufzutreten oder sich monate- wenn nicht jahrelang vor der Öffentlichkeit zu verstecken. Selbst wenn er im Versteck war, zog Schäfer im Hintergrund die Fäden. Es gelang ihm, die auf Zwang, Manipulation und Gewalt basierende Gruppenstruktur sowie die wohltätige Fassade nach außen aufrechtzuerhalten und seine alltäglichen Sexualverbrechen zu verschleiern. Die Zwangsmaßnahmen im Innern der Gruppierung, etwa Prügelstrafen, übernahmen die Jerarcas, während Schäfer sich als eine Art Richter oder graue Eminenz im Hintergrund hielt und nur intervenierte, wenn Dinge nicht seinen Vorstelllungen entsprechend liefen. Bei bestimmten Gewaltritualen wurden möglichst viele Gruppenmitglieder angehalten zuzuschlagen. So wurden aus individuellen Taten Gemeinschaftsverbrechen, von denen sich kein Einzelner distanzieren konnte.

Im Kontakt der Gruppierung nach außen trat Schäfer - höchstwahrscheinlich in weiser Voraussicht - bereits in den Siegburger Jahren von der ersten Reihe zurück und

PJS, Sammlung CD. Schreiben Schäfer an die Colonos vom Oktober 1998 zu »Heiratsbegehren oder Heiratswut«. 
übernahm formal kein Amt mehr. Das ermöglichte es ihm z. B., bei Bedarf unterzutauchen, ohne die Gruppierung und ihre Strukturen zu gefährden. De facto aber dirigierte und inszenierte er die Gruppierung nach Belieben.

\section{Der ungestörte Aufbau des Systems CD}

Während die Gruppierung den Grundstein für das spätere System der CD legte, waren weder aufklärerische Akteur_innen noch staatliche Stellen in nennenswertem Maße präsent. In den 1950er Jahren fand die Gruppierung nur in wenigen Artikeln in der Lokalpresse Erwähnung. Öffentliche Berichte über Missstände gab es nicht. Auch mehrere Mitglieder, die Ende der 1950er Jahre die Gruppierung im Streit verließen, ${ }^{28}$ erhoben keinerlei öffentliche Anschuldigungen. Jedoch wurden sie selbst zum Ziel von Einschüchterungsmaßnahmen der Gruppenführung.

In der ersten Jahreshälfte 1960 reisten Paul Schäfer, Hermann Schmidt und Hugo Baar durch verschiedene Länder, um ein mögliches Auswanderungsziel für die Gruppierung ausfindig zu machen. Dabei fiel die Wahl, nicht zuletzt aufgrund entsprechender Empfehlungen von Arturo Maschke, dem chilenischen Botschafter in Bonn, auf Chile.

Der erste öffentlichkeitswirksame Auftritt der Gruppierung war die offizielle Einweihung ihres »Jugendheims« im September 1960. Hierzu lud sie neben Lokalpolitiker_innen auch Bundespolitiker_innen sowie Mitglieder der Bunderegierung ein. Franz Josef Würmeling, Bundesminister für Familie und Jugend, schickte eine Vertreterin. Diese gewann einen positiven Eindruck vom »sozialen Anliegen ${ }^{29}$ der PSM. Das Ministerium empfahl wenige Monate später die PSM dem bundesdeutschen Botschafter in Chile, Hans Strack. ${ }^{30}$

Auch Maschke nahm an der Feier teil. Zuvor hatte er zwei Mitgliedern der Gruppierung eines Handwerkerauftrag erteilt. ${ }^{31}$ Der chilenische Konsul Guillermo Osorio beschrieb später seinen "großartigen Eindruck« von der Organisation. Das Jugendheim sei ein »Wirksamkeit-, Ordnung- und Sauberkeitsvorbild «. ${ }^{32}$ Die beiden zitierten Beispiele zeigen, wie erfolgreich die Lobbyarbeit der Gruppierung bereits in frühen Jahren war. Abgesehen von der gewünschten Unterstützung für ihre Auswanderungspläne beschränkte sich der Kontakt der Gruppierung zu Behörden in dieser Frühphase auf ein Mindestmaß.

28 Beispielsweise Johannes Bechtloff, Willi Georg und Getrude Kraftt.

29 PA AA, B 85, Bd. 598. Abschrift Schreiben BM für Familien- und Jugendfragen an Botschafter Strack vom 16.05.1961, GZ: 15 - 8050 - Heide, gez. i. A. von Schönfeld.

30 Ebd.

31 CA Santiago, AZ 2182-98 (»Asociación Ilícita«), Bd. I (Parral), BI. 296. Schriftsatz der CD-Anwälte Cesar Valero Nader, Mario Ruiz Zurita und Mario Ruiz Zurita vom 20.10.2000.

32 PJK, Ordner Hummel. Schreiben Konsul Osorio an den chilenischen Außenminister vom 29.11.1960, No. 105/65. Auf die Frage, weshalb die Wahl auf Chile fiel, geben mehrere Colonos übereinstimmend an, der chilenische Botschafter Arturo Maschke sei hier maßgeblich gewesen. El Mercurio vom 15.05.1977, Revista del Domingo S. 8-11. »El Remezón Dignidad - diálogo con dudas«, zitiert aus einem Gästebucheintrag von Maschke aus dem Jahr 1965 in der CD, der bestätigt, er habe der Gruppe nahegelegt ihre Arbeit nach Chile auszudehnen. 
Zumindest den Quellen, die ich einsehen konnte zufolge verfügten nur wenige Behörden 1961 bereits über weitergehende Informationen zu Schäfers Gruppierung. $\mathrm{Zu}$ ihnen gehörte das Innenministerium Nordrhein-Westfalen. Dieses informierte am 25. Mai 1961 an das Bundesverwaltungsamt, das die Auswanderungspläne der Gruppierung untersuchte:

»Bei den Gründern des Vereins handelt es sich um eine abgesplitterte Gruppe der Baptistengemeinde Gronau/Westf. Das Crundstück, auf dem das Missionshaus mit Nebengebäuden usw. errichtet wurde, ist auf den Namen des Evangelisten Paul Schäfer, geb. am 4. Dez. 1921 in Bonn [...] eingetragen. Gegen Schäfer besteht Haftbefehl des Amtsgerichts Siegburg wegen Verdachts der Unzucht mit Abhängigen. Sch. Ist flüchtig; er hält sich seit Anfang des Jahres im Ausland auf. [...] Die Auswanderungspläne bezogen sich auf eine vorgesehene Neugründung in Chile, deren Initiator Schäfer war. In letzter Zeit ist von Auswanderungsplänen nichts mehr bekannt geworden. Es ist sehr schwierig, über die Vereinigung ein klares Bild zu erhalten, da jedes bisher daraufhin angesprochene Mitglied nur ausweichende Antworten gab. «33

Als Anfang 1961 erste Strafanzeigen gegen Schäfer wegen sexuellem Missbrauch von Minderjährigen gestellt wurden und einige Wochen später Haftbefehl erging, war Schäfer mit einer kleinen Vorhut bereits nach Chile gereist. Die Übersiedlung eines Großteils der Gruppe nach Chile war in Vorbereitung und erstreckte sich über die nächsten beiden Jahre.

\subsection{Phase II (1961-1973): Aufbau in Chile, erste Skandale und Allende-Regierung}

Als Paul Schäfer und Hermann Schmidt Anfang Januar 1961 in Chile ankamen, regierte dort Jorge Alessandri als Präsident. Damals lebten in Chile knapp 8 Millionen Menschen (heute knapp 18 Millionen). Etwa ein Viertel von ihnen war in der Landwirtschaft beschäftigt. Die chilenische Gesellschaft war von großer sozialer Ungleichheit geprägt. Insbesondere im ländlichen Raum herrschten postfeudale Strukturen: Das Land gehörte einigen wenigen Großgrundbesitzern. Deren Ländereien bewirtschafteten in einfachen Verhältnissen lebende Landarbeiter_innen, die nur sehr begrenzt Zugang zu Bildung, Gesundheitsversorgung und anderen staatlichen Institutionen (wie etwa der Justiz) hatten. Dies galt auch für die Región del Maule, in der sich die Gruppierung ansiedelte.

Die drei Regierungen zwischen 1958 und 1973, die jeweils mit relativ geringem Stimmenvorsprung an die Macht kamen, repräsentierten drei politische Blöcke und unterschiedliche Interessengruppen in Chile. Dementsprechend reagierten sie mit unterschiedlichen Reformen auf den wachsenden sozialen Unmut. Die »konservative und wirtschaftsfreundliche ${ }^{34}$ Regierung von Jorge Alessandri (1958-1964) wurde von Unter-

33 PJK, Ordner Hummel. Schreiben Innenminister NRW an Bundesverwaltungsamt vom 25.05.1961.

34 Angell, Alan. Chile Since 1958, in: Bethell, Leslie (Hg.), Chile since independence, Cambridge 1993,

S. 129-202, S. 129. 
nehmer_innen und Landbesitzer_innen getragen. Die Democracia Cristiana (christdemokratische Partei, DC) unterstützte sie. Von 1964 bis 1970 stellte die DC mit Eduardo Frei Montalva den Präsidenten. Die Wahlen 1970 gewann die Unidad Popular (UP), ein breites linkes Bündnis mit Salvador Allende an der Spitze.

Das Beispiel der Landreformen zeigt die unterschiedlichen Vorgehensweisen der drei Regierungen. Während die Landreform unter Alessandri nur brachliegende Agrarflächen erfasste, setzte das Landreformgesetz der Frei-Regierung von 1967 eine Obergrenze von 80 Hektar für bewässerte Anbauflächen im Einzelbesitz fest. Unter Frei und Allende wurden etwa 5000 Landgüter enteignet. Diese machten zusammen etwa 60 Prozent der landwirtschaftlichen Anbaufläche Chiles aus. ${ }^{35}$ Vor der staatlichen Enteignung hatten Landarbeiter_innen mehrere Fundos besetzt. Der Staat entschädigte die enteigneten Eigentümer_innen und verteilte das Land über die Corporación de Reforma Agraria (CORA) um. Für die Colonia Dignidad, deren mehrere Tausend Hektar Land auf einige wenige Eigentümer_innen eingetragen waren, stellte dies durchaus eine Bedrohung dar.

Auch in der Bundesrepublik hat sich die politische Situation seit dem Beginn der 1960er Jahre mehrfach verändert. Bis 1966 regierte im Bund die CDU. Sie stellte mit Konrad Adenauer und Ludwig Erhard den Bundeskanzler sowie mit Heinrich von Brentano und ab 1961 mit Gerhard Schröder den Außenminister. 1966 kam es zur Großen Koalition unter Kurt Georg Kiesinger (CDU), Außenminister wurde Willy Brandt. 1969 wurde Brandt Bundeskanzler einer sozialliberalen Koalition. Die FDP übernahm mit Walter Scheel das Außenministerium. Sein Nachfolger Hans-Dietrich Genscher (ebenfalls FDP) war bis 1992 im Amt. ${ }^{36}$

Chile spielte für die Außenpolitik der Bundesrepublik nie eine entscheidende Rolle. Dennoch fanden regelmäßig Staatsbesuche statt, beispielsweise besuchten Bundespräsident Lübke und Außenminister Brandt Chile 1964 bzw. 1968. Chiles Präsident Frei reiste 1965 in die Bundesrepublik. Auch auf politischer Ebene gab es wichtige Beziehungen, allen voran zwischen den christdemokratischen Parteien beider Länder. ${ }^{37}$

\subsubsection{1-1966: Aufbau der Siedlung und Vernetzung mit lokalen Eliten}

Der Großteil der ausgewanderten Mitglieder der Gruppierung um Paul Schäfer kam in Chile 1961 und 1962 an. Einige Führungsmitglieder um Paul Schäfer und Hermann Schmidt hatten dort bereits Land gekauft und einen Verein, die SBED, gegründet (vgl. Abschnitt 3.2.3). An dem selbst für chilenische Verhältnisse entlegenen Ort begann ein »Totalaufbau«: ${ }^{38}$ Felder wurden urbar gemacht und ein Dorf errichtet. Trotz diverser

35 Rector, John L. The history of Chile, Westport (CT) 2003.

36 An der Spitze des AA standen von 1969-1998 Außenminister der FDP, mit einer kurzen Unterbrechung durch Helmut Schmidt (SPD) 1982.

37 Dufner zufolge war die Verbindung zwischen der bundesdeutschen CDU bzw. der CDU-nahen Konrad-Adenauer-Stiftung und der DC »bis zum Staatsstreich von 1973 wahrscheinlich die intensivste überseeische Kooperation der bundesdeutschen Christdemokratie«. Dufner, Partner im Kalten Krieg, S. 110.

38 Der Begriff stammt aus einem Schreiben der Colona Frida Bosch vom 08.03.1970, zit. bei Heller, Lederhosen, Dutt und Giftgas, S. 17. 
Vorfälle in den ersten Jahren der CD (z.B. den Fluchtversuchen von Wolfgang Müller 1962 und 1963) beschränkten sich die Botschaft und das AA darauf, die Siedlung zu beobachten. Auch die chilenischen Medien nahmen von der CD kaum Notiz.

Die CD-Führung betrieb allerdings von Anfang an aktive Lobbyarbeit. Hermann Schmidt und einige andere besuchten in den Monaten nach ihrer Ankunft in Chile mehrfach die Botschaft. Dabei warben sie um Unterstützung für die CD und versuchten, das durch den Haftbefehl gegen Schäfer und diverse Anfragen von Angehörigen entstandene Misstrauen auszuräumen. Zeugnis hiervon legt eines der ersten Schriftstücke zum Fall CD ab, das ich im Archiv des AA finden konnte. Es zeigt den Modus operandi, der von der CD in den darauffolgenden Jahrzehnten praktiziert wurde. Das Schreiben $^{39}$ der PSM vom Juni 1962 war an das Direktorium der SBED - also ihre chilenische Schwesterorganisation - gerichtet. Der Inhalt des Schreibens war jedoch vermutlich für die Botschaft oder andere Behörden bestimmt. Die PSM berichtete darin über einen vermeintlichen »Verleumdungsfeldzug« einer »bestimmten Gruppe von Leuten« gegen die CD in Chile. Kopf dieser Gruppe seien zwei Prediger einer Sekte, der Baptisten, aus Gronau und Hamburg. Die beiden Prediger führten eine von Habgier und Neid getriebene Rachekampagne gegen die Gruppierung um Schäfer. Johannes Bechtloff, einer der beiden, habe einige Zeit bei der PSM mitgewirkt, sei jedoch als »Faulenzer« enttarnt worden, der darauf spekuliert habe, über die Gruppe in Chile eigene Geschäfte machen zu können. Auch auf bereits existierende Gerüchte über sexuellen Missbrauch ging das Schreiben ein:

»Wir wissen heute, daß von dieser Seite auch die handfesten Gerüchte und Verleumdungen über angebliche sittliche Verfehlungen einiger Herren kamen. Diese Bezichtigungen sollen anscheinend jetzt alle Mitarbeiter und das ganze Werk in üblen Ruf bringen und die Arbeit untergraben. Diese Menschen scheuen also nicht vor den niedrigsten und gemeinsten Verleumdungen zurück, um das Bewußtsein ihrer menschlichen Niederlage zu kompensieren oder sich für angebliche Nachteile zu rächen. « ${ }^{40}$

Dieses Dokument wurde Botschafter Strack bei einer persönlichen Vorsprache im September $1962^{41}$ übergeben und sollte auch Zweifel ausräumen, die durch das erste Bonner Ermittlungsverfahren gegen Schäfer und die Medienberichterstattung zum ersten Fluchtversuch von Wolfgang Müller (heute Kneese) aufgeworfen worden waren. ${ }^{42}$ Es verdeutlicht, wie die CD möglicherweise anstehenden Nachforschungen und Untersuchungen bereits präventiv begegnete durch Gegeninformation oder juristische Angriffe.

39 PA AA, B 85, Bd. 598. Schreiben Jugendheim Heide/PSM (gez. Hugo Baar, Alfred Schaak) an das Direktorium der SBED vom 11.06.1962.

40 Ebd.

41 So Strack in einem Bericht ans AA. PA AA, B 85, Bd. 598. Bericht Strack an AA vom 25.01.1963, GZ: AA 502-81.05-124/63.

42 PA AA, B 85, Bd. 598. Bericht Strack an AA vom 25.01.1963. Der Bericht enthielt als Anlage ein Schreiben des Jugendheimes Heide/PSM vom 11.06.1962 sowie Presseartikel zum Fluchtversuch von Wolfgang Müller. 
Nach einiger Zeit wurde der Kontakt der Jerarcas zur Botschaft jedoch dünner. Im April 1963 besuchten erstmals zwei Vertreter der Botschaft die CD, ${ }^{43}$ nachdem es viele Anfragen besorgter Angehöriger von Colonos gegeben hatte. Ihr Bericht klingt ernüchternd: Sie seien zwar von den Führungsmitgliedern der CD mit »ausgesuchter Höflichkeit« behandelt worden, ein Kontakt zu einfachen Colonos sei jedoch unterbunden worden. Es sei daher nicht gelungen, »den Schleier des Geheimnisses der Privaten Sozialen Mission zu lüften. « ${ }^{44}$ Zwar stehe fest, so der Bericht, dass die Colonos gewillt seien, »unter persönlichen Opfern ein wohltätiges Werk zu errichten «, ${ }^{45}$ aber es sei ebenso offensichtlich, dass sie etwas zu verbergen hätten. Die Botschaftsangehörigen vermuteten, dass es sich bei der CD um eine Sekte handle, deren Mitglieder den Kontakt zu ihren Familien abbrechen müssten und sich ganz dem »Heimleiter Hermann Schmidt unterworfen hätten. Die Vorwürfe gegen Paul Schäfer erschienen ihnen hingegen unvorstellbar. Sie schrieben: »Unzutreffend dürfte dagegen die Annahme sein, auf dem Gut herrschten unsittliche Zustände. Eine derart mustergültige Ordnung und Disziplin [...] wäre in diesem Fall nicht zu erreichen. ${ }^{46}$ Die Beamten sprachen bei ihrem Besuch Schmidt direkt auf Schäfer an. Darauf entgegnete dieser, Schäfer habe die CD mit unbekanntem Ziel verlassen. Der Bericht ergänzt, die Botschaft habe im Nachhinein erfahren, dass die chilenische Polizei Schäfer in die USA abgeschoben habe ${ }^{47}$. Dieser wenig plausible Vorgang - die Abschiebung eines bundesdeutschen Staatsbürgers aus Chile in die USA - wurde jedoch nicht weiter ausgeführt.

Der Bericht der Botschaft ist bemerkenswert ambivalent: Einerseits betont er den vermeintlich wohltätigen Charakter der $C D$, andererseits vermutet er schwere Missstände und Verbrechen. Diese Ambivalenz war für das Handeln der Botschaft gegenüber der CD viele Jahre lang prägend: Zahlreiche Hinweise auf diverse Missstände und Verbrechen wurden von Diplomat_innen immer wieder durch Verweis auf das ordentlich geführte »Mustergut « und das höfliche Verhalten der CD-Führungsfiguren relativiert. So standen letztlich zwei Narrative nebeneinander, die eigentlich nicht zueinander passten: Das von der Mustersiedlung und das von der geheimnisvollen kriminellen Sekte. Im Ergebnis führte die Ambivalenz zwischen diesen beiden Deutungsmustern $\mathrm{zu}$ einer abwartenden und beobachtenden Haltung der Diplomatie. Konkrete Handlungsansätze, die zu einer Behebung der Missstände hätten beitragen können, gab es grundsätzlich nicht.

Als die beiden Botschaftsbeamten die CD besuchten, war Schäfer tatsächlich nicht dort. Er befand sich unter falschem Namen für sechs Monate in einer Klinik in Santiago. Bei einem Jagdunfall in der CD im Januar 1963 hatte er einen Schuss in die Magengrube erhalten und rang mit dem Tod (Vgl. Abschnitt 4.2.2). Während er nur wenige Kilometer von der Botschaft hospitalisiert war, berichtete die Botschaft an das AA, sie habe nun 
Schäfers Aufenthaltsort identifiziert, er befinde sich in Buenos Aires. ${ }^{48}$ Diese Angabe war höchstwahrscheinlich nicht das Produkt eigener Nachforschungen, sondern die Übernahme einer von der CD lancierten Desinformation. Die Vollstreckung des Haftbefehls gegen Schäfer in der Bundesrepublik wurde nicht weiter betrieben - zumindest ist darüber nichts bekannt. Anscheinend begnügte sich die Staatsanwaltschaft damit, dass Schäfer die Bundesrepublik verlassen hatte. 1974 wurde der Haftbefehl gegen Schäfer gelöscht. ${ }^{49}$

Auch über eine Befassung chilenischer Behörden mit der CD in jenen Anfangsjahren ist wenig bekannt. In den Akten finden sich nur einige Unterstützungsschreiben von Amtsinhaber_innen aus der Region um die CD. ${ }^{50}$ Die CD genoss bei chilenischen Behörden erstaunliches Wohlwollen, so wurde die SBED rasch als gemeinnützige Körperschaft anerkannt, auch die Befreiung von Steuern und Einfuhrzöllen erfolgte sehr schnell. Ein Grund hierfür mag gewesen sein, dass die CD regelmäßig wichtige Persönlichkeiten und Entscheidungsträger_innen in die CD einlud. Dort bewirtete sie ihre Gäste fürstlich und präsentierte die Fassade von Wohltätigkeit und Aufbauleistung. Der spätere Sprecher der Militärjunta, Federico Willoughby, berichtete, dass er bereits 1961 mit dem Vizepräsidenten der Landreform-Behörde (Corporación de la Reforma Agraria - CORA) die CD besuchte:

»Todos regresamos con una visión positiva de esa colonia, pensando en la colonización alemana de Vicente Pérez Rosales en la zona sur, que había producido un adelanto y aún perduraba. $\ll^{51}$

\subsubsection{6-1968: juristische und politische Erfolge der CD-Strategie}

Die erfolgreiche Flucht von Wolfgang Müller aus der CD 1966 (vgl. Abschnitt 4.1.3) wurde für die CD zur Zäsur. Die Medienberichterstattung machte den Fall CD innerhalb weniger Wochen zum Thema in ganz Chile. Auch internationale und deutsche Medien griffen den Fall auf. Dadurch wiederum gerieten Botschaft und AA in Erklärungsnot, ein Muster das sich in den darauffolgenden Jahrzehnten oftmals wiederholte. Zwar sprachen Müllers Berichte über die Zustände in der CD, über Freiheitsberaubung, Körperverletzung und sexuellen Missbrauch für sich und waren deutlich genug, dennoch fügten viele Medien ihnen zum Teil wilde Spekulationen hinzu: Prominent war dabei die Beschreibung der CD als eine von ehemaligen Nazis oder gar SS-Offizieren

48 PA AA, B 85, Bd. 598. Bericht der Botschaft vom 04.06.1963, Nr. 502-81.05-697/63.

49 PA AA, AV NA 31577. Schreiben von Oberstaatsanwalt Irsfeld an den Justizminister von NordrheinWestfalen vom 19.07.1985.

50 Beispielsweise eine Bescheinigung des Couverneurs von Parral, Enrique Fuentes, die vermutlich zur Vorlage bei chilenischen Behörden gedacht war. Fuentes schreibt darin: »El suscrito estima que por tratarse de una sociedad benefactora cuya labor irá en bien de los niños vagos y huérfanos de esta zona, es acreedora a que se le otorgue el máximo de franquicias para que empiece cuanto antes a desarrollar su elevado cometido. «PA AA, B 85, Bd. 598. Schreiben »Certificado No. 17« von Enrique Fuentes Vásquez, Cobernador del Departamento de Parral, vom 17.01.1962.

51 Federico Willoughby, ehemaliger Sprecher der Militärjunta, über einen Besuch in der Colonia Dignidad 1961 [vermutlich 1962, JS]. Vgl. Willoughby-MacDonald, Federico. La Guerra. Historia íntima del poder en los últimos 55 años de política chilena 1957-2012, Santiago 2012, S. 138. 
geführte, konzentrationslagerähnliche Siedlung, in der sich möglicherweise gesuchte NS-Kriegsverbrecher versteckt hielten. Dieses Zerrbild, das zum Teil noch heute verbreitet wird, war der CD-Führung durchaus dienlich. Zum einen verschaffte es der CD Sympathien in rechtsextremen Kreisen, die es auch innerhalb des chilenischen Militärs gab. Zum anderen konnte das Bild einfach widerlegt werden und zusammen mit der Skandalisierung der realen CD-Verbrechen als Verleumdung abgetan werden.

Nachdem nur wenige Wochen nach Müller auch Wilhelmine Lindemanns die Flucht aus der CD gelang, verstärkte sich die Medienberichterstattung noch, auch auf internationaler Ebene. Medien in Israel und Frankreich berichteten über ein von Deutschen geführtes »Konzentrationslager in Chile ${ }^{52}$. Das AA befürchtete nun, dass solche Berichte »dem deutschen Ansehen abträglich ${ }^{53}$ sein könnten und wurde aktiv. Es erklärte, die chilenische Polizei untersuche die Vorwürfe gegen die CD eingehend. Außer gegen Paul Schäfer habe sich bislang jedoch kein Hinweis auf Straftaten ergeben. Insbesondere gäbe es keine Hinweise darauf, dass sich prominente Nazis in der CD aufhielten. Zudem bemühte sich das AA, ein positives Bild von der CD zu zeichnen. Seine Stellungnahme schloss mit den Worten: »Bisherige Untersuchungen haben desweiteren gezeigt, dass Siedlung positive landwirtschaftliche Arbeit leistet, die auch von chilenischer Seite anerkannt wird. ${ }^{54}$

Als Reaktion auf die umfangreiche Medienberichterstattung erhielt das AA nun zahlreiche Anfragen von besorgten Angehörigen von Colonos. Mehrere Aussteiger_innen der PSM übersandten Berichte über die Ursprünge der Gruppe. Parallel dazu wurde in Chile ein besonderer Richter eingesetzt, um die von Wolfgang Müller vorgebrachten und von zahlreichen Medien verbreiteten Vorwürfe gegen die CD zu untersuchen. Die Botschaft erwog, Botschaftsbeamte zur CD zu schicken, um Untersuchungen anzustellen. Das AA lehnte dies jedoch ab, da es nicht in die laufenden chilenischen Untersuchungen eingreifen wollte. Die Botschaft schlug vor, über einen Anwalt das Gespräch mit dem Untersuchungsrichter zu suchen, doch das AA entgegnete, es sei »nicht erkennbar, warum an einer Verurteilung wegen angeblicher Unzucht mit Minderjährigen ein politisches Interesse besteht «. ${ }^{55}$ Während die Botschaft dem landesinternen Druck ausgesetzt war, pochte das AA auf die Zuständigkeit Chiles und wies die Botschaft an, nicht in laufende chilenische juristische Untersuchungen einzugreifen. ${ }^{56}$

Währenddessen ging die CD bereits in die Offensive: Sie übersandte dem AA psychiatrische Gutachten, die belegen sollten, dass Wolfgang Müller psychisch krank sei und forderten die Herausgabe des Minderjährigen an Hermann Schmidt, seinen bevollmächtigen Betreuer. Gleichzeitig stellte sie über den christdemokratischen Rechtsanwalt Luis Ortíz Quiroga Strafanzeige gegen Wolfgang Müller wegen Sodomie und Diebstahl. Parallel dazu beauftragte die CD auch in der Bundesrepublik Rechtsanwälte, die

52 PA AA, B 85, Bd. 598. FS Nr. 250 der Botschaft Tel Aviv ans AA vom 15.04.1966 sowie PA AA, B 85, Bd. 598. FS Nr. 575 der Botschaft Paris ans AA vom 15.04.1966.

53 PA AA, B 33, Bd. 465. FS der Botschaft ans AA vom 20.04.1966, CZ: I B 2-82.60/91.08/66.

54 PA AA, B 33, Bd. 465. Text der Erklärung des AA-Sprechers auf der Presskonferenz vom 20.04.1966, GZ: L 4-84.SL91.08. 
das AA mit langen Schriftsätzen beschäftigten. Hugo Baar, Vorsitzender der PSM, besuchte das AA und die chilenische Botschaft in Bonn persönlich, um die Vorwürfe gegen die CD zu entkräften und sie als Verleumdungskampagne darzustellen. Auch in Chile betrieben CD-Anwälte intensive Lobbyarbeit. Ortíz besuchte die Botschaft sowie einen Staatssekretär im Innenministerium, mit dem er befreundet war und fordere beide auf, aufklärerische Initiativen zu bremsen (Vgl. Abschnitt 5.1.1.).

Aufgrund der Anzeige der CD leitete das Juzgado de Parral ein Strafverfahren gegen Wolfgang Müller ein. Durch ihr beständiges Einwirken auf die Justiz erreichte die $C D$, dass Müller wegen Verleumdung zu fünf Jahren Haft verurteilt wurde. Es gelang ihm jedoch, sich einer Inhaftierung durch Flucht in die Bundesrepublik zu entziehen. Das AA kommentierte dieses Unrechtsurteil gegen Müller ${ }^{57}$ nicht. Für die CD war das Urteil ein grandioser Erfolg. Sie hatte nun die Bestätigung eines chilenischen Gerichts für ihre Behauptung, dass sämtliche Vorwürfe gegen die CD lediglich Teil einer Verleumdungskampagne seien. Zugleich zeigt sich im Fall Wolfgang Müller ein Muster, dass sich noch vielfach wiederholen sollte: Während die CD unter Rückgriff auf ihre Unterstützungsnetzwerke schnell, bestimmt und offensiv agierte, verhielt sich das AA beobachtend und abwartend. Das praktische Ergebnis war eine Stärkung des Systems $C D$, dem seine Opfer nun noch schutzloser ausgeliefert waren.

Die Vorwürfe gegen die CD waren in Politik und Medien Chiles trotz des Urteils weiter präsent. Die CD ging resolut gegen weitere Kritiker_innen vor. Nachdem einige regionale Amtsträger Untersuchungen und Maßnahmen gegen die CD eingeleitet hatten, verlangte die CD die Aufhebung der Immunität zweier Politiker, Hector Taricco und Claudio Fuentes (vgl. Abschnitt 5.2.1) - und war damit sogar erfolgreich. Als Reaktion auf eine von Taricco und Fuentes initiierte Untersuchung zollrechtlicher Verstöße ergriff die $C D$ eine ungewöhnliche, aber erfolgreiche Maßnahme: Colonos inszenierten einen Hungerstreik und die CD-Führung erreichte, dass der Staatsekretär aus dem Innenministerium zu Verhandlungen in die CD kam. Kurz darauf wurde die Einstellung der Untersuchungen vermeldet.

Den größten politischen Erfolg aber konnte die CD im November 1968 verbuchen: Die Cámara de Diputados hatte einen Untersuchungsausschuss eingerichtet, der den verschiedenen Vorwürfen gegen die CD nachgehen sollte. Am Ende sprach der Ausschuss die CD jedoch von jeglicher Verantwortung frei (vgl. Abschnitt 5.2.2). Dieser politische Triumph festigte die Macht des Systems CD entscheidend. Sowohl auf juristischer als auch auf politischer Ebene hatte der chilenische Staat nach Untersuchungen festgestellt, dass die Vorwürfe gegen die CD keinerlei Substanz hätten.

\subsubsection{8-1973: Die zahnlose Botschaft und die Allianz der Colonia Dignidad mit den Putschisten}

Seit 1966 war sowohl den chilenischen als auch den deutschen Behörden klar, dass sich Paul Schäfer (der in beiden Ländern per Haftbefehl gesucht wurde) entgegen anderslautender Beteuerungen durch die CD-Führung weiterhin in der CD aufhielt. Dennoch

57 Die Corte Suprema hob das Urteil 2017 auf. Kneese wurde damit vollständig rehabilitiert. Vgl. Corte Suprema, AZ 89658-2016. Urteil vom 23.08.2017. 
ergriff keine Behörde ausreichende Maßnahmen für eine Festnahme. Das AA verwies regelmäßig auf die Zuständigkeit chilenischer Stellen und die chilenische Seite zeigte so gut wie kein Interesse. Die Botschaft wusste über die Verhältnisse im Innern der CD inzwischen Bescheid. Dennoch agierte sie nicht resolut und sandte der chilenischen Seite widersprüchliche Signale. Mal bat sie die chilenische Regierung um eine Untersuchung der im Raum stehenden Vorwürfe gegen die CD, mal machte sie sich die Empörung des CD-Anwalts über die vermeintlich ungerechtfertigten Vorwürfe zu eigen. ${ }^{58}$

Unterdessen erreichten die Botschaft zwei weitere deutliche Hilferufe aus der CD. Nathanael Bohnau sprach im Februar 1968 in der Botschaft vor, berichtete von Freiheitsberaubungen und Misshandlungen und bat um Hilfe für seine Rückkehr in die Bundesrepublik. Kurz darauf war er wieder in der CD und widerrief sein Hilfsersuchen schriftlich. Dieses Vorgehen praktizierte die CD in den darauffolgenden Jahrzehnten bei Fluchtfällen und Hilferufen immer wieder. 1969 flüchtete Heinz Schmidt in die Botschaft, wurde aber dort u.a. von seinem Adoptivvater, SBED-Präsident Hermann Schmidt zur Rückkehr gedrängt. Spätestens Ende der 1960er Jahre konnte die Botschaft nach einer Reihe solcher Ereignisse keinerlei Zweifel mehr am kriminellen Handeln der CD haben. Neben der Art der systematisch begangenen Verbrechen mussten ihr auch die sich immer wieder gleichenden Verteidigungs- und Verschleierungsstrategien der CD bekannt sein. Ganz in diesem Sinne stellte die Botschaft im Juli 1970 fest:

»Festzustehen scheint, daß die Freiheit der Mitglieder eingeengt ist, daß Briefkontrolle und ein Verbot, die Kolonie frei zu verlassen, besteht. Besonders belastet hat die KoIonie, daß eines ihrer Vorstandsmitglieder, Paul Schäfer, wegen Unzucht mit Abhängigen vorbestraft und im Fahndungsbuch ausgeschrieben ist. [...] Alle Personen, die der Kolonie entkommen konnten, berichteten von Mißhandlungen, homosexuellen Praktiken und einem internen Strafsystem, das aus Prügelstrafen und haftähnlicher Abschließung besteht [...]. Die Ausbrecher wurden alle regelmäßig als schizophren hingestellt. ¿59 $^{59}$

Bemerkenswert ist jedoch, dass die Botschaft die CD in demselben Dokument trotzdem weiterhin verharmlosend als Vereinigung bezeichnete, die »religiöses Sektierertum mit wohltätigen Bestrebungen ${ }^{60}$ verbinde. Auch entwickelte die Botschaft keinerlei Bereitschaft, um über eine bürokratische Betrachtung von Einzelfällen hinaus aktiv zu werden.

In den Jahren der Allende-Regierung besuchten Botschaftsangehörige die CD nur ein einziges Mal, im Juni 1972. Anlass dafür waren laut Botschaftsrat Werner Kaufmann-Bühler die eben geschilderten Fälle Bohnau und Schmidt. Deren Hilfsersuchen waren jedoch schon von 1968 bzw. 1969. Insgesamt spiegelt auch KaufmannBühlers mit 24 Seiten sehr umfangreicher Bericht von dem Besuch die ambivalente Haltung der Botschaft wider: Auf der einen Seite stellte er die CD als sektenhafte Gruppierung mit wohltätigen Absichten, allerdings auch kriminellen Auswüchsen dar. Letztere erörterte Kaufmann-Bühler minutiös. Obwohl der Botschaftsrat in der 
CD auch schwere Straftaten wie Freiheitsberaubungen konstatierte, leitete er daraus keinerlei Handlungsbedarf ab. Kaufmann-Bühler stellte im letzten Satz seines Berichts vorausschauend fest: "So ist die Kolonie >Dignidad ein Stück Auslandsdeutschtum, das uns auch weiterhin mehr belasten als nützen wird. « ${ }^{61}$

Für die Betroffenen hatte die unterlassene Hilfe durch die Botschaft schwerste Konsequenzen: Bohnau starb 1987 in der CD, ohne dass er jemals die Chance gehabt hätte, das Gelände wieder verlassen zu können. Heinz Schmidt wurde Jahrzehnte lang im sogenannten Krankenhaus der CD eingesperrt und mit Elektroschocks und Psychopharmaka misshandelt. Er erlitt dadurch schwere körperliche und psychische Schäden.

Während der Amtszeit von Salvador Allende (1970-1973) verschwand die CD weitgehend aus der öffentlichen Wahrnehmung, auch die sozialistische Regierung ließ sie weitgehend in Ruhe. Möglicherweise scheute sie einen Konflikt mit der Bundesregierung, die Allende kritisch gegenüberstand und sich wiederholt für den Schutz deutscher Unternehmen in Chile vor staatlichen Eingriffen eingesetzt hatte. Auch die CD mit ihren großen Ländereien fürchtete eine Enteignung und suchte Unterstützung bei der Botschaft, wie Botschaftsrat Kaufmann-Bühler 1972 ausführte:

»Die Existenzbedrohung der Kolonie hat den Vorstand veranlaßt, sich um ein gutes Verhältnis zur Botschaft zu bemühen. Gleich nach dem Amtantritts Allendes wurden die Pässe der 250 Mitglieder zur Erneuerung bzw. Verlängerung vorgelegt. Mehrere Botschaftsangehörige wurden eingeladen, die Kolonie zu besuchen. Bei Beginn der Versorgungsschwierigkeiten in Chile bot die Kolonie der Botschaft an, sie mit Lebensmitteln zu versorgen. Hinter alledem steht die Sorge, vielleicht in nicht allzu ferner Zeit, den Schutz der Botschaft in Anspruch nehmen zu müssen «. ${ }^{62}$

Die Botschaft sicherte der CD im Rahmen ihrer »beschränkten Möglichkeiten « ${ }^{63}$ Unterstützung zu für den Fall, dass diese von Enteignungen betroffen sein sollte. Parallel dazu begann die CD, sich zu bewaffnen und militärische Abwehrpläne zu entwickeln. Sie organisierte Treffen mit rechtsgerichteten Großgrundbesitzern aus der Region, bei denen militante Aktionsstrategien gegen linksgerichtete Befürworter_innen einer Landreform erörtert wurden. Die CD lud auch militante Gegner_innen der Allende-Regierung ein, stellte ihnen Waffen zur Verfügung, führte militärische Trainings durch und beteiligte sich an Sabotageaktionen in der Region. Neben den Aktivisten der rechtsradikalen Gruppierung Patria y Libertad (Heimatland und Freiheit) gingen in der CD auch hochrangige Militärs ein und aus, die zum Kreis der späteren Putschisten gehörten. In Santiago nahmen CD-Führungspersonen an Treffen teil, die zur Vorbereitung des Putsches vom 11. September 1973 dienten. Vieles weist also darauf hin, dass die CD bei den Vorbereitungen zum Pusch eine wichtige Rolle spielte.

61 PA AA, ZW 111129. Aufzeichnung von Kaufmann-Bühler, RK-Referent der Botschaft über den Besuch der CD am 19.06.1972, vom 05.10.1972, S. 24.

62 PA AA, ZW 111129. Aufzeichnung von Kaufmann-Bühler, RK-Referent der Botschaft über den Besuch der CD am 19.06.1972, vom 05.10.1972, S. 8. 


\subsection{Phase III (1973-1990): Die Colonia Dignidad während der chilenischen Militärdiktatur}

Die Militärdiktatur in Chile von 1973 bis 1990 kann als Epoque d'Or der Colonia Dignidad bezeichnet werden. In dieser Zeit hatte sie keinerlei Strafverfolgung zu befürchten. Darüber hinaus führte die enge Allianz zwischen der CD und der Diktatur zu einer Ausweitung ihrer Verbrechen. Wie weiter oben ausgeführt war die CD bereits vor dem Putsch an den Vorbereitungen für eine Machtübernahme der Militärjunta beteiligt. Nach dem Putsch wurde sie zu einem Schlüsselakteur des Repressionsapparates der Diktatur. Die Entscheidung der CD-Führung, aktiv an den Menschenrechtsverbrechen der Diktatur mitzuwirken, bedeutete eine neue Qualität von Verbrechen. Die CD wurde zu einem politisch-militärischen Akteur, der die Macht der Diktatur half abzusichern. Laut den heute verfügbaren Quellen wurden in der CD während der Diktatur Dutzende - vermutlich über Hundert - Menschen ermordet und Hunderte weitere gefoltert. Aus der kriminellen Gemeinschaft heraus, deren Verbrechen hauptsächlich dem eigenen Fortleben dienten, entwickelte sich eine kriminelle Vereinigung, welche die Diktatur aktiv stützte, um ihre eigene Position zu stärken. Die CD arbeitete zwar eng mit der Militärjunta zusammen, blieb jedoch stets ein eigenständiger Akteur, der auch eigene Interessen verfolgte. Bei den Machtkämpfen innerhalb der Junta, insbesondere in den ersten Jahren der Diktatur, ${ }^{64}$ positionierte sich die CD in absoluter Loyalität zu Pinochet und seinem Machtgaranten: Dem mit staatsterroristischen Methoden agierenden Geheimdienst DINA, der Oberst Manuel Contreras unterstand. ${ }^{65}$

Dabei fungierte die CD als geheimes Folter- und Tötungslager, als Schulungsstätte für DINA-Agent_innen, als Waffen- und Technologieliefererant sowie als Rückzugsort für DINA-Offiziere und ausgewählte Repräsentant_innen der Diktatur (vgl. Abschnitt 4.2.3). Auch bei den Auslandsoperationen der DINA spielte sie eine noch näher zu erforschende Rolle, ebenso bei der Produktion von Nervengiften. Die CD bahnte für bundesdeutsche Stellen und vermutlich auch Geheimdiensten Kontakte zur DINA an. So unterhielt sie beispielsweise enge Verbindungen zum Waffenhändler Gerhard Mertins, der auch für den BND tätig war.

Unterstützend für die Militärdiktatur war auch das Spitzel- und Informationsnetzwerk, das die CD aufbaute. Dieses zielte nicht nur auf die Verfolgung des Widerstands linker Gruppen, sondern auch auf die Überwachung verschiedenster Akteur_innen auf ihre Gesinnung und Loyalität zu Pinochet. Dazu gehörten auch Angehörige von Militär und Geheimdiensten.

Die CD als etwas geheimnisvolle deutsche Siedlung, der vermeintlich »urdeutsche« Eigenschaften wie Fleiß und Disziplin, aber auch eine Nähe zur NS-Ästhetik zugeschrieben wurden, übte durchaus eine Faszination auf diktaturtreue Kreise aus. Das in den 1960er Jahren von diversen Medien perpetuierte Narrativ von der CD als einer

64 Vgl. Heller, Pinochet.

65 Der damalige Pressesprecher der Diktatur, Federico Willoughby, beschrieb die DINA 2012 folgendermaßen: »Lo que pareció ser la creación de un organismo militar de seguridad interna, inteligencia y contraespionaje, funcional al gobierno, se volvió un poder paralelo, un instrumento encubierto de Pinochet, de cuyas acciones no tenía que dar cuenta.« Willoughby, La Guerra, S. 341. 
von ehemaligen Nazis geleiteten Gruppe löste bei Rechtsradikalen innerhalb und außerhalb des Militärs entsprechend wohlwollende Reaktionen aus.

International galt Chile schon während der Allende-Regierung vielen als Beispiel für die Polarisierung im Kalten Krieg. Mit quasi umgekehrtem Vorzeichen wurde nun auch die Militärdiktatur vielfach vor allem als Teil eines weltweiten Kampfes wahrgenommen. Dementsprechend inszenierten sich Pinochet und die Junta als Speerspitze der »freien Welt« und Kämpfer gegen das »Krebsgeschwür des Kommunismus«. ${ }^{66} \mathrm{Pi}$ nochet nutzte die starke Polarisierung und den weit verbreiteten Antikommunismus als Legitimation, um Gegner_innen der Diktatur, aber auch Konkurrenten und Gegenspieler innerhalb des Militärs zu ermorden. Jegliche Berichte über bzw. Kritik an Menschenrechtsverletzungen tat er als marxistische Verleumdungen ab.

Die CD bediente sich desselben Narrativs: Jegliche Vorwürfe über Verbrechen und Menschenrechtsverletzungen betrachtete sie als Teil einer marxistischen Kampagne mit dem Ziel, die CD bzw. die Militärregierung zu diskreditieren. Zumindest in den ersten Jahren der Diktatur gelang es der CD mit diesem Diskurs, Vorwürfe einer Zusammenarbeit zwischen CD und Diktatur zu minimieren und diese Kooperation dadurch de facto zu decken. Auch mit Vorwürfen über sexuellen Missbrauch, Freiheitsberaubungen oder Körperverletzungen war die CD während der Diktatur kaum konfrontiert. Das lag in erster Linie an der engen Zusammenarbeit der CD mit der Diktatur: Erstens war eine Flucht aus der CD in diesen Jahren nahezu unmöglich und zweitens standen die Medien - aber auch die Justiz - unter der Kontrolle der Militärjunta. Die CD hatte so jahrelang kaum etwas zu befürchten.

Das Lagerdenken im Kontext des Kalten Krieges führte dazu, dass die Legitimationsstrategie der Militärjunta und der CD auch in der Bundesrepublik verfing. Die bundesdeutschen Behörden erhielten zwar zahlreiche, zum Teil sehr deutliche Hinweise auf eine Zusammenarbeit zwischen CD und DINA, schenkten diesen aber entweder keinen Glauben oder reagierten nicht darauf. Stattdessen wuchs die Unterstützung für die CD in der Bundesrepublik sogar noch. Vor der Diktatur gab es in der Bundesrepublik kaum öffentliche Unterstützung für die CD. Nun aber gelang es der CD, zahlreiche Fürsprecher_innen aus rechten Kreisen, auch aus der CDU und vor allem der CSU zu mobilisieren. Zahlreiche, zum Teil hochrangige Persönlichkeiten wirkten meist über informelle Kontakte auf Behörden in der Bundesrepublik ein, um aufklärerische Initiativen gegen die $\mathrm{CD}$ zu verhindern bzw. diese als linke Meinungsmache abzutun. Besonders wirkungsvoll waren dabei die Würzburger Professoren Lothar Bossle und Dieter Blumenwitz sowie der auch für den BND tätige Waffenhändler Gerhard Mertins. Bossle war ein Vertrauter von Franz-Josef Strauß und hatte direkten Zugang zu Augusto Pinochet. Er half, Geschäfte zwischen deutschen Unternehmen und der chilenischen Diktatur anzubahnen. Blumenwitz wirkte an der Ausarbeitung der chilenischen Verfassung von 1980 mit und verfasste Rechtsgutachten für die CD, die er mehrfach besuchte (vgl. Abschnitt 5.3.4). Mertins lieferte über die CD Waffen an die chilenische Diktatur (vgl.

66 Bei der Vorstellung der Militärjunta gegenüber der Presse nach dem Putsch sagte Juntamitglied Gustavo Leigh: »Tenemos la certeza, la seguridad que enorme mayoría del pueblo chileno está con nosotros, está dispuesto a luchar contra el marxismo, está dispuesto a extirparlo hasta las últimas consecuencias. « Zitiert nach Huneeus, Carlos. El régimen de Pinochet, Santiago 2016. 
Abschnitt 4.2.2), vermittelte der CD Rechtsanwälte für Verfahren in der Bundesrepublik und sprach sich in Verfahren für die CD aus.

Da sich der öffentliche Diskurs über die CD und die Militärdiktatur, aber auch das Vorgehen der bundesdeutschen Behörden während der Diktatur zum Teil stark verändert haben, ist es sinnvoll, diese Phase in mehrere Zeitabschnitte zu unterteilen: In den Jahren 1973-1984 ist die Logik des Kalten Krieges vorherrschend und die Behörden machen sich durch ihr Nicht-Handeln faktisch zu Komplizinnen der CD. Ab 1985 führen die Berichte der aus der CD geflüchteten Ehepaare Baar und Packmor zu einer graduellen Sensibilisierung der bundesdeutschen Diplomatie, während die bundesdeutsche Justiz eher passiv bleibt. In den folgenden Abschnitten werden jeweils folgende Zeiträume behandelt: Die »harte Phase« der Militärdiktatur von 1973-1979 (Abschnitt 6.3.1), die Jahre des Schweigens von 1979-1984 (Abschnitt 6.3.2), die Flucht der Baars und Packmors sowie die steigende Aktivität der bundesdeutschen Diplomatie 1985-1987 (Abschnitt 6.3.3) und schließlich das engagierte, aber ergebnislose Vorgehen des AA von 1988-1990 (Abschnitt 6.3.4).

\subsubsection{3-1979: Die "harte Phase« der Diktatur - Kalter Krieg und Unterstützung für die Colonia Dignidad}

Nachdem die CD bereits bei den Putschvorbereitungen eine wichtige Rolle gespielt hatte, wirkte sie seit dem 11. September 1973 vom ersten Tag in Schlüsselpositionen an der Stärkung der Militärregierung und ihres Repressionsapparats mit. Paul Schäfer und Hartmut Hopp nahmen an Sitzungen der Militärs teil, Colonos beteiligen sich an Festnahmen von Oppositionellen und die CD versorgte Militärregierung und Geheimdienste mit Funk- und Überwachungstechnik - und hörte dabei vermutlich von Beginn an die interne Kommunikation wichtiger Stellen mit (vgl. Abschnitt 4.2.3). Die CD errichtete unterirdische Anlagen in der Residenz von Diktator Pinochet ${ }^{67}$ und auch die Residenz des bundesdeutschen Botschafters wurde von Handwerkern der CD renoviert ${ }^{68}$ und vermutlich verwanzt.

Die direkte Mitwirkung der CD an der Tötung von vermutlich über hundert Oppositionellen sowie an der Folter von mehreren hundert Linken konzentriert sich nach den bisher verfügbaren Aussagen und Dokumenten auf die Jahre 1973-1976. Die Aktenlage für diesen Zeitraum ist - zumindest was die Korrespondenz zwischen Botschaft und AA betrifft - sehr dünn. Lediglich einzelne Dokumente geben Hinweise auf die Existenz eines Haftlagers in der CD, dies führte offensichtlich jedoch nicht zu einer ausführlichen Berichterstattung der Botschaft an das AA. Als Resultat der diplomatischen Tradition der Entsendung von ideologisch affinem Personal wirken die Botschaftserichte gegenüber der Vorphase zunehmend konservativ und CD-freundlich.

Laut Akten war der erste Besuch von Botschaftsangehörigen in der CD nach dem Putsch im November 1974. Zu diesem Zeitpunkt waren in der CD bereits Dutzende Ge-

67 PA AA, B 130, Bd. 13631. Bericht Hallensleben (AA) an Botschafter Holzheimer vom 10.12.1986, GZ: 330-504.00 CHL 735'86 geh.

68 Deutscher Bundestag. Drucksache 11/1825 vom 05.02.1988. Schriftliche Fragen mit den in der Woche vom 1. Februar 1988 eingegangenen Antworten der Bundesregierung, S. 1f. 
fangene erschossen und deren Leichen verscharrt worden. Am 20. August 1974 hatte Pinochet persönlich, gemeinsam mit DINA-Chef Contreras und weiteren hochrangigen Funktionären der Diktatur die CD besucht. ${ }^{69}$ Der Bericht von RK-Referent Klaus Platz über seinen Besuch im November 1974 erwähnt dies kurz. Platz habe in Erfahrung bringen können, dass die CD sehr gute Beziehungen zur Militärjunta unterhalte und mit ihr sympathisiere. Darüber hinaus thematisiert Platz die Beziehungen zwischen CD und Militär bzw. DINA in seinem Bericht nicht. Auch den von ihm bemerkten "relativ hohen Funkmast ${ }^{70}$ kommentiert er nicht weiter. Der acht Seiten lange Bericht beschreibt vorwiegend die Siedlung und erörtert die Vorwürfe gegen die CD aus den späten 1960er Jahren. Dabei hält Platz fest, dass das eigentliche ideelle Ziel der CD die Unterhaltung des Krankenhauses sei. Er habe »das Krankenhaus, das Kraftwerk, eine Geflügelfarm, die Gärtnerei, Bäckerei und ein Hirschgehege« besichtigt und sei anschließend »zu einer Kaffeetafel gebeten« worden und habe »einer - möglicherweise eigens arrangierten - Chorprobe beigewohnt. ${ }^{71}$ Platz erkundigte sich auch bei Hermann Schmidt, wann der »wegen Homosexualität und Unzucht mit Minderjährigen vorbestrafte« Paul Schäfer die CD verlassen habe. Schmidt entgegnete ihm, dass Schäfer die CD bereits vor langer Zeit verlassen habe und übergab Platz einen »dicken Aktenband« über »die Arbeit der Kolonie, die ihr gegenüber erhobenen Vorwürfe und deren Unhaltbarkeit ${ }^{72}$. Wahrscheinlich war Paul Schäfer bei diesem Gespräch auch unter seinem Decknahmen Schneider anwesend. ${ }^{73}$

Platz fragte auch nach Heinz Schmidt, der 1969 in die Botschaft geflüchtet war und durfte ihn sprechen - allerdings nur im Beisein seiner Adoptiveltern. Schmidt machte auf Platz einen »heiteren, ausgeglichenen und freundlichen Eindruck« und erklärte, er sei psychisch krank und entsprechend in Behandlung.

69 CA Santiago, AZ 12293- 2005 (»homicidio Miguel Becerra Hidalgo«). Urteil vom 27.11.2008, S. 8.

70 Am 20.02.1974 hatte Verteidigungsattaché Weidhöfer Botschafter Luedde-Neurath informiert: „Cemäß telef. Information Marineverbindungsoffizier am 20.2.1974 reisen zwei Marineoffiziere, Fregattenkapitän Pedro Castro u.a. heute nach Dignidad, um hier eine Kommunikationsinspektion durchzuführen, da angeblich Schwierigkeiten bei Radio, Funk etc. -Verbindungen bestehen. Information geschieht deshalb, da es sich in Dignidad um deutsches Interessensgebiet handelt." PA AA, AV NA 31581. Vermerk Weidhöfer (Verteidigungsattaché) an Botschafter Luedde-Neurath vom 20.02.1974. PA AA, AV NA 31581. Aufzeichnung Platz (RK-Referent) über seinen Besuch in der CD am 21.11.1974 vom 03.12.1974.

72 Diesen Aktenband konnte ich im PA AA nicht finden.

73 RK-Referent Platz schrieb an anderer Stelle des Berichts von einem Colono namens »Schneider «. Nach dem er die CD angeblich 1966 verlassen hatte, gab sich Paul Schäfer wiederholt als Paul Schneider aus (Schneider war der Mädchenname seiner Mutter). Die Botschaft erreichten immer wieder Berichte, nach denen sich Schäfer sehr wohl weiterhin in der CD befinde. Nach einem Besuch der FEPROLI-Messe 1978 vermerkte Botschaftsrat Schirnding über einen Dialog mit Schäfer: "Sowohl bei der Führung durch den Pavillon als auch beim Mittagessen konnte ich feststellen, daß Herr >Schneider sich unter den anwesenden Mitgliedern der Kolonie unangefochtener Autorität erfreute. [...] Nach einem etwa dreistündigen Aufenthalt in dem Pavillon verabschiedete ich mich. Als ich Herrn sSchneider hierbei mit seinem Namen anredete, versprach ich mich versehentlich, worauf `Herr Schneider « sagte: >Sie können mich auch Schäfer nennen, beide Namen sind richtig. « PA AA, AV NA 31580. Vermerk Botschaftsrat Schirnding vom 02.01.1979, GZ: RK 543. 
Platz schien zwar über die Vorwürfe aus den 1960er Jahren informiert und durchaus gewillt gewesen $\mathrm{zu}$ sein, auch kritische Nachfragen zu stellen. Insgesamt sagte er jedoch, sein Besuch in der CD habe »mit Ausnahme einer etwas gespannten Stunde im Zusammenhang mit meinen Fragen nach Heinz Schmidt und Paul Schäfer, in angenehmer und freundlicher Atmosphäre ${ }^{74}$ stattgefunden. In der CD werde »wertvolle humanitäre Arbeit für die arme Landbevölkerung der Umgegend « geleistet. Zudem sei, so Platz, die CD »in der Vergangenheit zum Opfer mindestens teilweise ungerechtfertigter Beschuldigungen und Verleumdungen geworden «. ${ }^{75}$ Dennoch sei es »keineswegs ausgeschlossen «, dass es in der CD auch zu Straftaten bis hin zu Freiheitsberaubungen gekommen sei, vieles an der CD bleibe "nach wie vor undurchsichtig «. ${ }^{76}$

Aus Platz' Sicht gäbe es aufgrund der Vorgänge zwischen 1966 und 1968 sowie des Besuchs von Kaufmann-Bühler im Jahr 1972 weiterhin ein gewisses Misstrauen der CDFührung gegen die Botschaft. Platz schlug vor, dies durch regelmäßige Besuche der Botschaft in der CD abzubauen.

Der Tenor des Berichts knüpft an die ambivalente Haltung der Botschaft aus der Phase vor dem Militärputsch an: Die Botschaft hält es zumindest für möglich, dass in der CD Verbrechen an Colonos begangen werden. Die enge Verbindung zwischen CD und Diktatur erwähnt Platz zwar, hinterfragt sie jedoch nicht. Obwohl ihm Vieles suspekt erscheint, überwiegt in Platz' Urteil das Bild der CD als wohltätiger Akteurin sowie der Gastfreundschaft der CD-Führung.

Auch die Haltung der bundesdeutschen Diplomatie im Fall Schäfer erscheint widersprüchlich. Seit 1966 hatte die Botschaft mehrfach Informationen über Schäfers fortgesetzte Anwesenheit in der CD erhalten. Der bundesdeutsche Haftbefehl gegen Schäfer hatte bis Juli 1970 Bestand, im Mai 1974 wurde das Ermittlungsverfahren gegen ihn endgültig eingestellt. Am 23. April 1975 begab sich Schäfer in die Botschaft in Santiago, um einen Reisepass zu beantragen, ${ }^{77}$ den er am Folgetag erhielt. Damit reiste er in die

74 PA AA, AV NA 31581. Aufzeichnung Platz (RK-Referent) über seinen Besuch in der CD am 21.11.1974 vom 03.12.1974.

75 Ebd.

76 Ebd.

77 Schäfers vorheriger Reisepass war am 23.12.1960 in Siegburg ausgestellt worden, Von Dezember 1970 bis April 1975 verfügte Schäfer vermutlich über keinen gültigen deutschen Reisepass. Bei seinem Passantrag vom 24.04.1975 gab Schäfer als Wohnadresse Román Diaz 512 an, eine Wohnung, die die CD in Santiago besaß. PA AA, AV NA 31582. Antrag auf Ausstellung eines Reisepasses, beantragt von Paul Schäfer am 24.04.1975. Es folgte eine Passverlängerung am 29.10.1980 in Santiago, bei der Schäfer als Wohnort Santiago de Chile angab. Letztmalig wurde Paul Schäfer 1985 ein Reisepass ausgestellt, der aufgrund des bereits bestehenden Ermittlungsverfahrens bei der StA Bonn (AZ 50 ]s 285/85) auf eine 2-jährige Laufzeit beschränkt wurde. Als letzter Reisepass Schäfers ist ein Pass des Karibikstaates St. Kitts und Nevis auf den falschen Namen Paul Berger bekannt, der ihm von Hartmut Hopp, Peter Schmidt und Rebeca Schäfer von einer Reise nach St. Kitts und Nevis mitgebracht wurde. Rebeca Schäfer erhielt ebenfalls einen Reisepass von St. Kitts und Nevis. Um diese Pässe zu erhalten, mussten die Passbewerber eine Immobilie erwerben. Wer sich später diese Immobilie angeeignet hat ist nicht bekannt. Vgl. CA Santiago, AZ 2182-98 (»Asociación Ilícita«), Bd. IV (Ministro), Bl. 1661f. Richterliche Vernehmung von Rebeca del Carmen Schäfer Schneider am 20.10.2006. 
Bundesrepublik. Am 9. Juni 1975 beantragte er in Siegburg einen weiteren Pass, den er am folgenden Tag ausgehändigt bekam. ${ }^{78}$

Nach dem Besuch von RK-Referent Platz gingen bei der Botschaft einzelne Hinweise auf die Existenz eines Folterlagers in der CD ein. In den Akten findet sich beispielsweise ein Schutzantrag von Fernando Treskow zugunsten seines Sohnes Iván. ${ }^{79}$ Laut Treskow wurde sein Sohn am 23. April 1975 in Chillán entführt und auf ein Landgut verschleppt, auf dem Deutsch gesprochen wurde. Vermutlich handle es sich dabei um die $\mathrm{CD}^{80}$ (vgl. dazu Abschnitt 5.3.1).

$\mathrm{Zu}$ dieser Zeit gab es auch bereits vereinzelte Medienberichte über die CD. So kabelte die chilenische Botschaft in Paris im Juli 1975 an das chilenische Außenministerium:

»1. France Soir, fecha 28 presente, [...] afirma: a.) Médicos Alemanes, ex-nazis, realizarían experiencias en prisioneros chilenos en Colonia Dignidad, en Parral b.) Dichos médicos inyectaríar drogas fin conseguir revelaciones c c.) En este lugar y en un campo cercano a Paine habría 2 mil prisioneros, que la Junta no desearía reconocer. d.) Finalmente, artículo hace referencia $M$. René Chanfreau, chileno-frances desaparecido. 2. Sugerimos a US. poner en conocimiento chileno-alemanes de Colonia Dignidad acusaciones formuladas por dicho vespertino. Vásquez. ${ }^{81}$

Auch bei Geheimdiensten anderer Staaten kursierten inzwischen Informationen über die Verbindungen zwischen CD und DINA. Ein Bericht der Hauptverwaltung Aufklärung (HVA) des DDR-Ministeriums für Staatssicherheit vom November 1975 etwa enthält den Hinweis:

»Die DINA unterhält enge Beziehungen mit den Nazis aus der Kolonie >Dignidad〈, ca. $350 \mathrm{~km}$ suedlich von Santiago in der Provinz Linares gelegen, und ueber diese mit Nazikriegsverbrechern wie Walther Rauff, Handelspartner/Teilhaber der Gebrueder Custavo und Sergio Leigh Guzman in der Fisch- und Konservenfabrik >Camelior. Rauff gilt als einer der Gruender und Leiter der DINA. ${ }^{82}$

78 Hier gab Schäfer als Wohnort »El Mallin/Esquel« in Argentinien an. Vermutlich gab er an, seinen vorherigen Pass verloren zu haben. Vgl. Bärbel Künz (2010), Dokumentenanhang Nr. 26, Passantrag Schäfer.

79 PA AA, AV NA 31581. CA de Santiago, Schutzantrag von Fernando Treskow zugunsten von Iván Treskow, handschriftlich datiert 04.06.1975.

80 Weitere Dokumente aus Aktenband PA AA, AV NA 31581 beziehen sich beispielsweise auf den Verschwundenen Alfonso Chanfreau (Vgl. Eidesstattliche Erklärung von Ramon Rojas González vom 28.07.1975) und den Sohn des in der CD-stationierten und im Juli 1974 ermordeten DINAAgenten Miguel Becerra (Vgl. Vermerk RK 543 vom 30.09.1976).

81 PJS, Sammlung Dieter Maier. Chilenische Botschaft Paris an Santiago, Telex Abierto Nr. 251 vom 28.07.1975. Luis Peebles berichtete auf einem Seminar zu CD in Santiago 2014, er habe im August 1975 auf einer Pressekonferenz in Paris von seinen Foltererfahrungen in der CD berichtet: Luis Peebles. La experiencia de un sobreviviente de tortura en Colonia Dignidad in: Hevia/Stehle (Hg.), Colonia Dignidad - Diálogos sobre verdad, justicia y memoria, 2015, S. 199-204, hier S. 201.

82 BStU, MfS-HVA Nr. 1035, BI. 55. Übersicht zur Dirección de Inteligencia Nacional. Bei Walter Rauff handelt es sich um den während der NS-Diktatur im Reichssicherheitshauptamt tätigen Erfinder der mobilen Gaswägen, der sich 1958 in Chile niederließ und 1984 verstarb. Zu seiner möglichen Tätigkeit für die DINA, vgl. Schneppen, Heinz. Walther Rauff: Organisator der Gaswagenmorde. Eine Biografie, Berlin 2011, S. $168 f f$. Colonos haben mir im Cespräch bestätigt, dass sich Rauff mehr- 
1974 und 1975 waren mehrere Folterüberlebende ins Exil gelangt und hatten von ihren Erfahrungen berichtet. Daraufhin führte ein Bericht des UN-Wirtschafts- und Sozialrates ECOSOC vom Februar 1976 die CD erstmals öffentlich als geheimen Haftort der DINA auf. ${ }^{83}$

Am 29. März 1976 besuchte RK-Referent Petersmann zusammen mit Amtsrat Alfons Roth für zwei Tage die CD. Die Vorwürfe aus dem ECOSOC-Bericht und überhaupt die Verbindungen der CD zur Militärdiktatur erwähnt Petersmann in seinem Bericht von dem Besuch jedoch nicht. ${ }^{84}$ Die in dieser Zeit am Eingang der CD postierten Wachen der DINA waren für den Besuch vermutlich abgezogen worden. ${ }^{85}$ Auch Themen, die bei vorherigen Botschaftsbesuchen in der CD eine Rolle gespielt hatten, wie etwa der Fluchtversuch von Heinz Schmidt oder die Suche nach Paul Schäfer, wurden nun nicht mehr angesprochen. Der Bericht gibt lediglich die Sichtweise der CD wieder: Die "Gastgeber « (also die CD), berichteten demnach von »mannigfache[n] Schwierigkeiten [...] aufgrund von - wie sie es sehen - Verleumdungen«, die nun aber »überwunden« seien. ${ }^{86}$ Petersmann macht sich das Selbstbild der CD zu eigen. Er schreibt, dort werde »tatsächlich sehr wertvolle humanitäre Arbeit für die Menschen der Umgebung geleistet«. Dies sei »möglicherweise in der Vergangenheit von der Öffentlichkeit nicht genügend gesehen und gewürdigt worden. ${ }^{87}$ Abschließend stellt der Bericht fest, es sei »aufbauend auf den langjährigen Kontakten zwischen der Kolonie und Herrn [...] Roth« gelungen, »eine gewisse Vertrauensbereitschaft der Leitung der Kolonie gegenüber dem neuen RK-Referenten herzustellen «. ${ }^{88}$ Alfons Roth war von 1970-1976 an der Botschaft. Mir gegenüber gab er an, in diesem Zeitraum die CD etwa fünf Mal besucht

fach in der CD aufgehalten habe. Paul Schäfer habe aus Anlass seines Besuches geäußert: »Heute rauff ich mir die Haare«.

83 United Nations Economic and Social Council (ECOSOC). E/CN.4/1188 vom 04.02.1976. Report of the ad hoc working group established under resolution 8 (XXXI) of the Commission On Human Rights to inquire into the present situation of human rights in Chile, online unter http://daccess-ods.un.o rg/access.nsf/get?open\&DS=E/CN.4/1188\&Lang=E.

84 PA AA, AV NA 31581. Vermerk vom 01.04.1976»Betr: Besuch des RK-Referenten der Botschaft und von Herrn AR Roth in der Kolonie »La Dignidad« bei Parral am 29/30.03.1976."

85 Mehrere Zeug_innenaussagen in chilenischen Verfahrensakten belegen die Existenz der DINAWachposten am Eingang zur CD. Eine erste Erwähnung der Colonia Dignidad in offengelegten US-Behördenakten findet sich im April 1976: Ein interner CIA Bericht vom 13.04.1976 erwähnt die CD als Haftlager der DINA. Über einen Besuchsversuch einer CIA-Quelle wird berichtet: »[Name geschwärzt] attempted to visit the fenced-in colony during a vacation trip in the area with a Chilean Navy officer. They were not permitted access beyond the guardhouse reception area and were requested to wait for an interview by a DINA Army Major who was dispatched to the colony from the nearby town of Parral. Within hours following the interview, DINA's director, Colonel Manuel Contreras, called the chief of staff of the Chilean Navy to inquire about the visitors i interest in the colony. No further action was taken. It is interesting that the colony is not listed on any official map of Chile. «US. Department of State, Freedom of Information Act, Virtual Reading Room. Bericht des CIA Directorate of Operations vom 13.04.1976. Views of government and church officials on human rights abuses.

PA AA, AV NA 31581. Vermerk vom 01.04.1976 »Betr: Besuch des RK-Referenten der Botschaft und von Herrn AR Roth in der Kolonie »La Dignidad« bei Parral am 29/30.03.1976.« 
$\mathrm{zu}$ haben. ${ }^{89}$ In den Akten konnte ich jedoch über andere Dienstreisen von Roth außer der vom März 1976 nichts finden. AI-Generalsekretär Walter Rövekamp beschrieb Roths Rolle 1988 folgendermaßen:

»In der Zeit vor Strätling war [...] Roth die wichtigste Kontaktperson [...] Roth hat mit seiner Frau und seinen beiden Töchtern oft Wochenenden in der Kolonie verbracht. Er war eng mit Mat[t]husen und Hopp befreundet. [...] Roth hat Konsularangelegenheiten in der $C D$ erledigt. In einer deutschsprachigen Zeitung (Condor?) hat er einen CD-freundlichen Artikel verfasst. «

Diese Hinweise auf die freundschaftlichen Beziehungen zwischen Roth und einigen CD-Führungsmitgliedern legen nahe, dass es Kontakte zwischen Botschaftsangehörigen und der CD gab, deren Intensität über die offiziellen Kontakte weit hinausging, über die sich aber nichts in den Akten findet.

Im Mai 1976 trat Erich Strätling seinen Posten als Botschafter in Santiago an. Seine Entsendung spiegelt die Politik des AA wider, Botschafter_innen zu entsenden, die anschlussfähig an die politische Situation im Gastland sind. Strätling, ein extrem konservativer Diplomat, war zuvor Botschafter im Apartheidsstaat Südafrika gewesen. Im Juli 1976 berichtete Strätling erstmals dem AA wegen der vermeintlichen Verbindungen zwischen CD und DINA. ${ }^{91}$ SBED-Präsident Schmidt habe ihm kürzlich den Brief einer chilenischen Richterin an die CD übergeben. Dieser sei an den »Jefe de Campamento de Prisioneros Políticos Colonia Dignidad de Parral « adressiert gewesen. ${ }^{92} \mathrm{Da}$ es ein solches Gefangenenlager offiziell nicht gab und da der Brief von der CD selbst der Botschaft übergeben wurde, liegt die Vermutung nahe, dass es sich bei diesem Vorgang um ein Ablenkungsmanöver der CD und/oder der DINA handelte, um den Feststellungen des UN-Berichts vom Februar 1976 strategisch zu begegnen. In dem Brief fragte die Richterin nach dem Verbleib des Verschwundenen Rodrigo Ugas für den ein Schutzantrag gestellt worden sei. Die Botschaft richtete daraufhin eine Verbalnote an das chilenische Außenministerium mit der Bitte um Aufklärung des Vorgangs. ${ }^{93}$ Ans AA schrieb Strätling, der Vorgang rufe »Gerüchte in Erinnerung «"94 - gemeint waren damit die Vorwürfe gegen die CD, die u.a. in dem UN ECOSOC-Bericht vom Februar 1976 veröffentlicht worden waren. Diese »Gerüchte« seien verschiedentlich auch gegenüber

89 PJS, Sammlung Gesprächsnotizen. Notiz eines Gesprächs mit Alfons Roth vom 30.03.2011 in Ebernhahn.

90 Archiv Al, Bestand CD. Aufzeichnung von Walter Rövekamp vom 11.01.1988 über Gespräch von Rövekamp mit Peter Clever über dessen Zusammenkunft mit dem Ehepaar Packmor.

91 PA AA, AV NA 31581. Botschaftsbericht Nr. 923/76 vom 16.06.1976 [korrekt ist 16.07.1976, JS], CZ: RK 543. Der Bericht bezieht sich auf Vorgänge bis Mitte Juli 1976, er wurde von Strätling handschriftlich mit »16/7« abgezeichnet.

92 PA AA, AV NA 31581. Verbalnote Nr. 106/76 vom 02.06.1976.

93 Das chilenische Außenministerium antwortete, das Schreiben entbehre jeglicher Grundlage. Lauf Information des Innenministeriums gebe es in Chile nur drei Haftorte für politische Häftlinge: Puchuncaví, Tres Alamos und Cuatro Alamos. Der »verschollene« Rodrigo Ugas sei niemals in Chile inhaftiert gewesen. Vgl. PA AA, AV NA 31581. Botschaftsbericht Nr. 1135/76 vom 27.08.1976. 
Botschaftsmitarbeitern geäußert worden. Kürzlich habe die DINA einen deutschen Studenten festgenommen bei dem Versuch, die CD zu besuchen. Strätling schlug vor, das Thema »ohne Publizität weiterzuverfolgen « ${ }^{95}$.

Diese Weiterverfolgung ohne Publizität sollte zu einem regelmäßig praktizierten Vorgehen der Botschaft bei Menschenrechtsfragen während der Diktatur werden. Dabei spielte der Kontakt zu hochrangingen deutschstämmigen Militärs eine wichtige Rolle. Besonders vertrauensvolle Gesprächspartner der Botschaft waren der Luftwaffengeneral Fernando Matthei und der General der Carabineros, General Rodolfo Stange. Beide waren während der Diktatur Mitglieder der vierköpfigen Militärjunta um Diktator Pinochet ${ }^{96}$ und beide wurden von der Botschaft regelmäßig kontaktiert, wenn Vorwürfe gegen die CD im Raum standen. Am 9. April 1976 besuchte Botschaftsrat Leopold von Hassel den frisch als Gesundheitsminister vereidigten Matthei. ${ }^{97}$ Dieser hatte von Hassel bereits 1975 um ein Gespräch über die Menschenrechtslage gebeten, da er »nicht eines Tages für Dinge verantwortlich gemacht werden [wolle], die er nicht billigen könne ${ }^{98}$ Laut von Hassel berichtete Matthei mit »beachtliche[r] Offenheit «, dass die DINA Misshandlungen und Folterungen vornehme. Er und die anderen Regierungsmitglieder hätten jedoch keinerlei Möglichkeit, das Handeln der DINA unmittelbar zu beeinflussen, diese unterstehe ausschließlich Pinochet. Die Luftwaffe sei von Anfang an gegen die Errichtung der DINA gewesen und habe ihre Mitarbeiter aus der DINA zurückgezogen, sobald Menschenrechtsverletzungen bekannt geworden seien. ${ }^{99}$ Die Luftwaffe versuche auch beständig, auf Pinochet einzuwirken, um die Verbrechen einzudämmen. Dies zeige auch Ergebnisse. Schließlich lobte Matthei die verständnisvolle Haltung der Bundesrepublik gegenüber der Diktatur in Menschenrechtsfragen. Diese und die USA seien »die einzigen, die Chile nicht nur Vorwürfe machten, sondern auch Verständnis zeigten und positive Entwicklungen zur Kenntnis nähmen. Ein Staat, der sich so verhalte, könne in Chile viel eher etwas erreichen als Staaten, die ständig nur einseitige Kritik übten.«100

Ebd.

Fernando Matthei Aubel war von 1976-1978 chilenischer Gesundheitsminister und von 1978-1990 Mitglied der vierköpfigen Militärjunta. Rodolfo Stange Oelckers war ab 1985 Direktor der Carabineros und 1985-1990 Mitglied der Junta. Auch nach dem Ende der Militärdiktatur blieb er bis 1995 Direktor der Carabineros.

PA AA, ZW 103473. Bericht Botschaftsrat von Hassel an AA vom 09.04.1976, GZ: Pol 383 Nr. 465/76. Betr.: Lage der Menschenrechte in Chile, hier: Cespräch mit dem Minister für das Cesundheitswesen General Matthei.

Ebd.

Ob die Luftwaffe tatsächlich Mitarbeiter aus der DINA zurückgezogen hat, ist mir nicht bekannt, allerdings waren Mitglieder des Luftwaffengeheimdienstes SIFA an der Errichtung des sogenannten »Comando Conjunto « beteiligt, die ähnlich wie die DINA extralegale Hinrichtungen durchführte. Das Comando Conjunto war federführend an der Zerschlagung des Zentralkomitees der KP beteiligt, deren Mitglieder entführt und ermordet wurden. Vgl. Memoriaviva (Website), »Comando Conjunto« online unter: https://www.memoriaviva.com/criminales/organizaciones/comando_conj unto.htm.

PA AA, ZW 103473. Bericht Botschaftsrat von Hassel an AA vom 09.04.1976, GZ: Pol 383 Nr. 465/76. Betr.: Lage der Menschenrechte in Chile, hier: Cespräch mit dem Minister für das Cesundheitswesen General Matthei. 
Auf den »Fall der 119« Verschwundenen angesprochen, antwortete Matthei, dies sei »ein ganz trübes Kapitel, in das kaum Licht zu bringen sei ${ }^{101}$ Er selbst habe dazu vergeblich recherchiert. Von Hassel bezeichnete Matthei in seinem Bericht als »integre Persönlichkeit, die meint was sie sagt « ${ }^{102}$. Dass die Luftwaffe die DINA ablehne, dürfte zutreffen, so von Hassel. Allerdings könnten hier neben moralischen Überlegungen auch Rivalitäten eine wichtige Rolle spielen sowie die Sorge um das internationale Ansehen Chiles infolge des Agierens der DINA. Mattheis Aussagen zeigten aber auch die Machtlosigkeit der anderen Regierungsmitglieder gegenüber der DINA und Pinochet. Von Hassels Bericht über sein Treffen mit Matthei endet mit dem Fazit:

»Man fragt sich, aus welchem Grunde ein Mann wie General Matthei trotz seiner deutlichen Mißbilligung der Menschenrechtsverletzungen durch die DINA in einer Regierung mitarbeitet, die ungeachtet ihrer Machtlosigkeit gegenüber der Ceheimpolizei letzten Endes doch für ihre Tätigkeit mitverantwortlich ist. Wahrscheinich ist es die Überzeugung, daß trotz allem unter den gegebenen Umständen eine Militärregierung die einzige Möglichkeit für Chile darstellt, und durch die Mitarbeit integrer Persönlichkeiten letzten Endes doch eine Besserung von Mißständen innerhalb des Systems erreicht werden kann. Es mag ein ähnlicher Cewissenskonflikt sein wie derjenige, in dem sich manche Persönlichkeiten während des Nationalsozialismus befanden, die trotz innerer Ablehnung glaubten, zur Mitarbeit verpflichtet zu sein, um Schlimmeres zu verhüten. Man muß hoffen, daß Leuten wie General Matthei mehr Erfolg beschieden sein wird als diesen Menschen. ${ }^{103}$

Von Hassels Überlegungen sind aus mehreren Gründen relevant für das Vorgehen der bundesdeutschen Diplomatie im Fall CD während dieser ersten Phase der Diktatur. Dieses Gespräch und sein Inhalt verdeutlichen einerseits ein Vertrauensverhältnis zwischen Matthei und von Hassel. Andererseits zeigt es die Ambivalenz des Botschaftsrats, der einerseits die Äußerungen von Matthei dahingehend interpretiert, dass sie zur strategischen Besänftigung des Diplomaten dienen sollten, angesichts des durch die DINA Verbrechen erlittenen Imageverlustes der Junta. Andererseits lässt von Hassel durchaus Sympathie für Matthei und seine Argumentation durchklingen, dass die Militärregierung im Kern das richtige Projekt vertrete, jedoch Missstände - ein äußerst verharmlosender Ausdruck für den Staatsterrorismus der DINA - behoben werden müssten.

Am 8. Oktober 1976 legte der UN-Wirtschafts- und Sozialrat (ECOSOC) der UNGeneralversammlung einen umfangreichen Bericht zur Menschenrechtslage in Chile vor. Darin wurde die CD nicht nur - wie im erwähnten ECOSOC-Bericht vom Februar 1976 - als Haft- und Folterstätte aufgelistet. Darüber hinaus erwähnte der Bericht tet wurde, die Aktivist_innen hätten sie aufgrund von internen Disputen gegenseitig umgebracht. Vgl. Sepúlveda, Lucía. 119 de nosotros. Santiago, 2005.

PA AA, ZW 103473. Bericht Botschaftsrat von Hassel an AA vom 09.04.1976, CZ: Pol 383 Nr. 465/76. Betr.: Lage der Menschenrechte in Chile, hier: Gespräch mit dem Minister für das Cesundheitswesen Ceneral Matthei. 
Details über die Folterpraktiken, die in der CD angewandt wurden. Grundlage hierfür waren Berichte von Folterüberlebenden, die nun im Exil lebten. ${ }^{104}$ Als Reaktion auf den Bericht besuchte Strätling am 15. November 1976 die CD. ${ }^{105}$ Das vorab informierte Innenministerium begrüßte Strätling zufolge den Besuch, »da in Dignidad nichts zu verbergen sei ${ }^{106}$ Strätlings Bericht von seinem Besuch betont - wie beinahe sämtliche Berichte vorheriger Botschaftsbesuche - den wohltätigen Charakter der CD und schildert ausführlich die Führung durch das Krankenhaus und diverse weitere Bereiche der CD. Strätling fand, »alle Einrichtungen der Siedlung« müssten »als mustergültig bezeichnet werden «. ${ }^{107}$ Auch in der Umgebung genieße die CD hohes Ansehen. Von »Geheimnistuerei« könne keine Rede sein. Im Folgenden tat Strätling die Vorwürfe gegen die $C D$ im Wesentlichen als ungerechtfertigt $a b$ und schlug zu deren angeblicher Klärung Luftaufnahmen des chilenischen Militärs vor:

»Da - aus welchen Cründen auch immer - die Kolonie Dignidad in der Vergangenheit des Öfteren verdächtigt und verleumdet worden ist - Prozesse sind zugunsten der Kolonie ausgegangen, ein parlamentarischer Untersuchungsausschuss hat Vorwürfe als nicht gerechtfertigt bezeichnet -, halte ich es nicht für ausgeschlossen, dass die Behauptungen in dem oben genannten Report auf Quellen aus früheren Zeiten beruhen. Die Bereitschaft der Leitung der Kolonie, sich einer Inspektion zu unterziehen, die Zustimmung des Innenministeriums, die Offenheit der Atmosphäre im dortigen Cebiet sprechen gegen die Behauptungen der Existenz eines geheimen Folterzentrums. Meine eigenen Beobachtungen bestätigen diese Auffassung. Da ich jedoch nicht den gesamten Grund begehen konnte, habe ich ein Angebot der chilenischen Luftwaffe angenommen, Luftbilder anzufertigen, um etwaige weitere Einrichtungen aufzufinden. $\ll^{108}$

Strätlings Besuch unterschied sich von den vorherigen dahingehend, dass er offensichtlich der CD-Führung keinerlei kritischen Nachfragen stellte und auch keine fragwürdigen Vorgänge aus der Vergangenheit erwähnte. Stattdessen entlastete Strätling die CD vollständig und übernahm fast vollständig die Selbstdarstellung der CD, wonach sämtliche Vorwürfe gegen sie unbewiesen seien und sowohl das Gerichtsverfahren in den 1960er Jahren als auch Untersuchungsausschuss der Cámara de Diputados 1968 diese entkräftet hätten.

Allerdings waren nicht alle Mitarbeiter_innen der Botschaft so frei von Zweifeln wie die Einschätzungen Strätlings. Dies zeigt ein Bericht des stellvertretenden USBotschafters Charles Stout an das State Department. Stout sprach drei Tage nach Strät-

104 United Nations Economic and Social Council (ECOSOC). Bericht A/31/253 vom 08.10.1976. Abs. 371 .

105 PA AA, B 83, Bd. 1177. DB 381 vom 16.11.1976, GZ: pol 383.25-5.

106 Ebd.

107 Ebd.

108 Strätling leitete die von der chilenischen Luftwaffe gefertigten Aufnahmen an das Bundesministerium der Verteidigung weiter. Das Verteidigungsministerium schrieb dem AA, es habe keinerlei versteckten Gebäude oder Zugänge auf den Bildern finden können. Bei den Zäunen handele es sich um einfache Stacheldrahtzäune zur Weidenabgrenzung. »Obwohl alle Anzeichen für eine Farm mit Tierhaltung sprechen, konnte kein Vieh auf den Weiden festgestellt werden. «PA AA, B 83, Bd. 1177. Schreiben BM der Verteidigung an AA vom 21.02.1977, GZ: FÜ S II 5-AZ 02-91-08. 
lings Besuch in der CD mit von Hassel, um sich von diesem Strätlings Eindrücke schildern zu lassen. Stout schildert von Hassels Haltung gegenüber der CD folgendermaßen:

»I asked, whether the Embassy was satisfied with the examination. Von Hassell said no, that there were too many strange things about the colony - its own character aside. They had very modern installations and equipment. Where did the money come from? They were in close touch with a mother house in Cermany, and the origins of the operation were obscure. They have a complex and costly communications system. And they plan to buy a jet aircraft capable of international travel. I mentioned some indications we had come across of close connections with DINA. Von Hassell said that they did not know for sure, but such connections could be explained by the fact that the colony's land includes some 18 passes to Argentina. There could be a natural security interest in keeping track of what happened in the colony. But there could be other reasons. [...] Relations with the COC [Covernment of Chile] appear good. The colony is giving president Pinochet a Mercedes 600 in appreciation of his understanding attitude. Von Hassell agreed with my comment that if anything sinister was going on, it could be hidden in the colony. ${ }^{109}$

Der Bericht von Stout belegt, dass andere Mitarbeiter_innen in der Botschaft Berichte über eine Kooperation zwischen CD und DINA durchaus als plausibel bewerteten.

\section{Die Enthüllungen von Amnesty International und Stern}

Im März 1977 erschienen die Broschüre von Amnesty International sowie ein Artikel im Stern über die CD als »Das Folterlager der Deutschen ${ }^{110}$ (vgl. Abschnitt 5.3.1). Die Botschaft hatte dem AA bereits im Dezember 1976 über entsprechende Recherchen der Stern-Journalisten Hero Buss und Kai Herrmann berichtet. Es sei "nicht auszuschließen«, dass der geplante Bericht im Stern »unrichtige oder irreführende Angaben« enthalten werde. ${ }^{111}$ Wie Buss wenig später mitteilte, wurde er daraufhin am 4. Februar 1977 auf dem Weg von Parral zur CD von der DINA verhaftet und am nächsten Morgen nach Argentinien abgeschoben. ${ }^{112}$

Am Tag nach Erscheinen des Stern-Artikels übermittelte Strätling seine Einschätzung ans AA: Er bestätigte, dass es in den 1960er Jahren wiederholt Vorwürfe gegen die CD wegen Freiheitsberaubungen gegeben habe. Auch die wiederholten Vorwürfe gegen Paul Schäfer wegen »sittlicher Verfehlungen« bestätigte Strätling. Den Berichten über Folterungen in der CD im Rahmen einer Zusammenarbeit der CD mit der DINA, so Strätling, sei er mit allen ihm zur Verfügung stehenden Mitteln nachgegangen, könne sie aber nicht bestätigen. Sie beruhten »auf Aussagen, die nicht eigene sichere

109 US. Department of State, Freedom of Information Act, Virtual Reading Room. Memorandum of Conversation, Gesprächsnotiz.1976 von Charles R. Stout, Acting DCM [Deputy Chief of Mission] Santiago mit Henning Leopold von Hassell, German DCM, vom 22.11.1976.

110 Herrmann, Kai. »Das Folterlager der Deutschen«, in: Stern Nr. 13/1977 vom 17.03.1977, S. 26-33.

111 PA AA, B 83, Bd. 1177. Bericht Botschaft an AA Nr. 1742 vom 21.12.1976, GZ: Pol/Pr 320.46/01.

112 PA AA, AV NA 31580. Schreiben Botschaft an die Staatsanwaltschaft bei dem Landgericht Hamburg vom 28.07.1977. 
Wahrnehmungen, sondern Vermutungen, Mutmaßungen und Schlußfolgerungen wiedergeben ${ }^{113}$ Selbst Kontaktpersonen der Botschaft aus Menschenrechtskreisen hätten es lediglich als Gerücht bezeichnet, dass die CD bzw. die DINA in der CD ein Gefangenenlager betreibe. Auch das chilenische Außenministerium habe nach einer Anfrage der Botschaft die Existenz eines Gefangenenlagers dementiert. Er selbst habe mit mehreren einfachen Colonos gesprochen, zudem würden sich derlei Einrichtungen bei dem starken Publikumsverkehr in der CD nicht verheimlichen lassen, so Strätling. Auch der Vorwurf des Stern, dass die Botschaft die CD protegiere, sei »entstellend « und entbehre jeder Grundlage. ${ }^{114}$ In Wahrheit seien die Verbindungen der Botschaft zur CD jahrelang völlig abgebrochen, was sich jedoch als unzweckmäßig erwiesen habe. Deshalb habe die Botschaft in der letzten Zeit bis zu zwei Mal pro Jahr einen Beamten in die CD entsandt, um einen Einblick zu erhalten. Da ein solcher Einblick nur begrenzt sei, so Strätling, könne die Botschaft keine »Ehrenerklärung« abgeben und sämtliche Vorwürfe als haltlos bezeichnen. Allerdings hätten sich die im ECOSOC-Bericht geäußerten Vorwürfe trotz der genannten Nachforschungen nicht belegen lassen. Gegen Ende seines Berichts kündigt Strätling an, dass die CD »noch heute« Strafanzeige gegen die verantwortlichen Redakteure des Sterns »wegen übler Nachrede« stellen wolle. ${ }^{115} \mathrm{Am}$ 26. März gab Strätling zusätzlich eine Pressemitteilung heraus, in der er die CD von den Vorwürfen entlastete:

»Angesichts von kürzlich in der Presse erschienenen Berichten über die angebliche Unterbringung chilenischer politischer Häftlinge in der von Deutschen bewohnten landwirtschaftlichen Niederlassung und wohltätigen Einrichtung >Colonia Dignidad ‘ bei Parral teilt der Botschafter der Bundesrepublik Deutschland folgendes mit: Nach der Veröffentlichung des Allana-Berichts der Ad-hoc Kommission der Vereinten Nationen Ende vergangenen Jahres habe ich der Siedlung Colonia Dignidad am 15. November 1976 einen Besuch abgestattet, um die im Bericht erhobenen Behauptungen zu prüfen. Bei diesem Besuch haben sich keine Anhaltspunkte für die Richtigkeit dieser Behauptungen ergeben. Auch eine Auswertung von Luftaufnahmen des gesamten Gebiets der $C D$ durch deutsche Stellen hat keine Bestätigung der Behauptung erbracht, daß sich in oder bei der CD ein Lager mit sbesonders ausgestatteten unterirdischen Anlagen< befindet. ${ }^{116}$

Die chilenische Presse, in jenen Jahren aufgrund von Zensur vollständig diktaturfreundlich, wertete das als eine vollständige Entlastung der CD durch den Botschafter. Die Zeitung El Mercurio druckte am Folgetag die spanische Übersetzung der Erklärung ab und berichtete unter der Überschrift »Declaración del Embajador de la RFA: No hay chilenos detenidos en la Colonia Dignidad «. ${ }^{117}$

\footnotetext{
113 PA AA, B 83, Bd. 1177. DB 89 vom 18.03.1977, GZ: pol 385.25 05. Betr.: Stern-Artikel vom 17.03.77.

114 Ebd.

115 Ebd.

116 Ebd.

117 El Mercurio vom 27.03.1977, S. 33. »Embajador de la RFA: No hay chilenos detenidos en la Colonia >Dignidad«.
} 
Das Medienecho in der Bundesrepublik auf die Veröffentlichungen von Stern und AI war groß. Diverse Angehörige von Colonos wandten sich mit Fragen ans AA. Auch Bundestagsabgeordnete interessierten sich für den Fall und richteten Schreiben bzw. schriftliche Fragen an die Bundesregierung. Auf die Frage eines SPD-Abgeordneten, wie die Bundesregierung die im Stern geschilderten Vorgänge und das Verhalten der Botschaft einschätze, antwortete Staatsminister Klaus von Dohnanyi:

»Die Bundesregierung bittet um Verständnis dafür, daß auf diese Frage heute keine endgültige Antwort erteilt werden kann. Die Bundesregierung hatte Hinweise über gewisse Zustände und hatte deswegen den Botschafter gebeten, sich um Aufklärung zu bemühen. Die erneut - wie es scheint - nicht unbegründet gegen die >Colonia Dignidad in Chile erhobenen Vorwürfe sind jedoch so schwerwiegend, daß eine Eingehende Untersuchung unbedingt erforderlich ist. [...] Über das Ergebnis wird die Bundesregierung so bald wie möglich berichten. ${ }^{118}$

Anders als Botschafter Strätling, erachtete das AA die Vorwürfe als möglicherweise zutreffend. Das AA erörterte die Entsendung eines Beamten, der bereits zuvor mit dem Fall CD betraut gewesen war: Werner Kaufmann-Bühler, Botschaftsrat in Chile von 1970 bis 1973. Die Idee wurde jedoch wieder verworfen. ${ }^{119}$ Das AA stand nun durch die Anfragen von Medien und Abgeordneten unter Druck, die im Stern beschriebene wohlwollende Haltung der Botschaft zur CD zu erklären. Das für Lateinamerika zuständige Referat bat Raban von Mentzingen vom Bundespresseamt, der wenige Monate zuvor noch als Pressereferent der Botschaft tätig gewesen war, um eine alternative Stellungnahme zu den Anschuldigungen im Stern. Gegenüber Strätling war dies ein Affront. Von Mentzingen, der einen gewerkschaftlichen Hintergrund hatte, berichtete dem AA ausführlich von diversen Hinweisen auf eine Kooperation zwischen CD und DINA, die die Botschaft in den vergangen Monaten erhalten hatte. ${ }^{120}$ Er sei sich bewusst, schrieb er, dass er sich mit seiner Aufzeichnung »in einem gewissen Gegensatz zur Berichterstattung der Botschaft befinde«. Diese verfüge »sicher über Informationen [...], die Zweifel an der Integrität der Kolonie aus dem Weg räumen. ${ }^{121}$

118 Deutscher Bundestag. Plenarprotokoll 8/21 vom 24.03.1977, S. 1387Af. Antwort des Staatsministers von Dohnanyi (AA) auf die mündliche Frage des Abgeordneten Hansen (SPD).

119 PA AA, B 83, Bd. 1177. Verworfene StS-Vorlage vom 24.03.1977. Vorschlag: Entsendung eines Beamten der Zentrale nach Chile zur Untersuchung der Vorgänge um die »Colonia Dignidad« i. V. m. PA AA, B 83, Bd. 1177. Stellungnahme D 5, 500-500 CHL vom 28.03.1977. D 5 teilte mit, Ref. 500 könne VLR Kaufmann-Bühler nicht entbehren, da er in der Vorbereitung einer Seerechtskonferenz unabkömmlich sei. Die in der StS-Vorlage vorgeschlagene Entsendung eines Beamten nach Chile zur Untersuchung der CD-Vorgänge wurde daraufhin verworfen.

120 PA AA, AV NA 31581. Aufzeichnung Pressereferent von Mentzingen vom 05.04.1977. Betr.: Colonia Dignidad, hier: Gerüchte über die dortige Existenz eines Lagers für politische Gefangene.

121 PA AA, AV NA 31581. Schreiben von Mentzingen (Bundespresseamt) an Fischer (AA) vom 05.04.1977. Strätling erhielt das Schreiben von Mentzingens vom AA, mit der Bitte um Stellungnahme. Strätling antwortete: »In der Sache ergibt sich aus den Ausführungen Herrn von Mentzingens nach Ansicht der Botschaft nichts Neues. Ein Beweis dafür, daß in der Colonia Dignidad politische Gefangene untergebracht waren und dort gefoltert wurden, ist dadurch nicht erbracht worden. So mysteriös auch manches erscheinen mag, was mit der Colonia Dignidad in Zusammenhang steht, so dürfen doch Gerüchte und unbewiesene Behauptungen nicht ausreichen, um eine 
Zur selben Zeit kam es im AA zu Kompetenzstreitigkeiten zwischen der Abteilung 3 (Lateinamerika) und der Abteilung 5 (Recht). Das AA war unentschieden, ob der Fall CD vorrangig als politische oder als strafrechtliche Angelegenheit zu behandeln sei. Nach einer Aufforderung von Außenminister Genscher schlug Abteilung 3 vor, Abteilung 5 solle die Federführung übernehmen, da die zentrale Frage die Erörterung von Strafverfolgungsmaßnahmen gegen deutsche Staatsangehörige im Ausland sei. ${ }^{122}$ Abteilung 5 teilte diese Auffassung jedoch nicht. ${ }^{123}$

Während die deutsche Diplomatie sich sozusagen selbst blockierte, ging die CD in die juristische und politische Gegenoffensive: Beim Landgericht Bonn beantragte sie im April 1977 eine einstweilige Verfügung gegen AI und Gruner \& Jahr, den Verlag des Stern. Dem gab das Gericht am 22. April 1977 statt (vgl. Abschnitt 5.3.1). Zusätzlich erschienen, ebenfalls im April 1977, Hartmut und Dorothea Hopp in der Botschaft und übergaben Strätling eine Erklärung des SBED-Vorstands. Diese verkündete mit pathetischen Worten ${ }^{124}$, dass sich 225 Colonos im Hungerstreik befänden, aus Protest gegen die »Pressegreuel und hemmungslosen Verleumdungen ${ }^{125}$

Wenige Tage später trafen sich die CD-Führungsmitglieder Hans-Jürgen und Erika Blanck (geb. Heimann) mit dem CDU-Bundestagsabgeordneten Franz Möller. Dieser bat Außenminister Genscher in einem Schreiben, sich der Sache anzunehmen, um ernste Folgen für die Hungerstreikenden zu vermeiden. Das Ehepaar Blanck habe ihm glaubhaft versichert, dass die Aussagen der Zeug_innen in der AI-Broschüre nicht stimmten. Das AA könne jederzeit eine Kommission nach Chile senden, um dies in der CD zu überprüfen. ${ }^{126}$

Strätling traf sich mit General Matthei, der nun Gesundheitsminister war. ${ }^{127}$ Am 27. April 1977 flog Matthei in die CD und bewog die Hungerstreikenden zur Aufgabe. Noch am selben Abend berichtete er in Santiago Strätling persönlich. Dieser meldete ans AA:

»Der deutschstämmige Minister, der fließend Deutsch spricht, war sowohl von der Zuständigkeit als auch von der Persönlichkeit her der bestgeignetste Mann für diese Auf-

Gemeinschaft von deutschen Staatsangehörigen im Ausland pauschal moralisch zu verurteilen. Nach rechtsstaatlichen Crundsätzen muß vielmehr davon ausgegangen werden, daßjeder als unschuldig zu gelten hat, solange ihm das Cegenteil nicht nachgewiesen ist. Die Botschaft begrüßt es daher, daß die Anschuldigungen gegen die Colonia Dignidad nunmehr hiesigen Informationen zufolge Gegenstand eines Verfahrens vor einem deutschen Cericht sind und damit eine objektive Prüfung der Vorwürfe gewährleistet erscheint. «PA AA, ZW 111130. Bericht Strätling Nr. 510/77 vom 03.05.1977, CZ: Pol 543.

PA AA, ZW 111129. Vorlage AA, Abteilung 3 an AA, Abteilung 5 vom 28.04.1977. PA AA, ZW 111129. Vorlage AA, Abteilung 5 an AA, Abteilung 3 vom 29.04.1977. In der Erklärung hieß es u.a.: »[...] Das Abendland zweifelt nicht: wenn Wahrheit und Scham stürzen, bricht das letzte Cefüge vor dem mörderischen Untergang zur ewigen Sklaverei. [...] Uns Opfern millionenfachen Rufmordes erscheint unser Weiterleben billig.«PA AA, ZW 111129. DB 119 vom 22.04.1977, GZ: RK 543. Ebd. PA AA, ZW 111130. FS Nr. 608 des Bundestages ans AA vom 27.04.1977. Inhalt: Schreiben MdB Franz Möller an AM Genscher. 
gabe. Die Mitteilung über die Beendigung des Hungerstreiks wurde gestern Abend bei einem großen Empfang bekannt und löste beim Staatspräsidenten [Pinochet] und beim Innenminster offensichtlich große Erleichterung aus. [...] Minister Matthei [...] war beeindruckt von der sektiererischen Hartnäckigkeit, mit der die Mitglieder der Generalversammlung ihren Standpunkt vertreten hätten. [...] Hauptwortführer sei Paul Schäfer gewesen, der sich mit seinem Namen vorgestellt habe. Diese Mitteilung hat mich insofern überrascht, als Schäfer das Memorandum an den Außenminister nicht mitunterzeichnet hatte. ${ }^{128}$

Die Offensive der Colonia Dignidad zeigte nachhaltige Wirkung: Am 29. April 1977 schickte die Lateinamerika-Abteilung des AA Genscher eine Ministervorlage. ${ }^{129}$ In der Zusammenfassung heißt es:

»Die Existenz eines Haftlagers und Folterzentrums im Bereich der >Colonia Dignidad erscheint zweifelhaft. Die Zweifel verstärken sich nach der kritischen Lektüre der Unterlagen, die der Kolonievorstand für seine gerichtlichen Schritte erarbeitet und in Fotokopie der Botschaft in Santiago übergeben hat (Anlage 5). Ein überzeugender Nachweis, daß in der Kolonie kein Folterzentrum besteht, wird sich jedoch nur durch eine gründliche Inspektion an Ort und Stelle führen lassen. Die Kolonie hat sich zu einer solchen Untersuchung durch eine unabhängige internationale Kommission - etwa Internationales Rotes Kreuz - bereit erklärt.

Wir sollten weiterhin Zurückhaltung üben und uns jedweder Stellungnahme zu den Vorwürfen strikt enthalten. Hierzu berechtigt und verpflichtet uns die rechtliche Situation, nachdem in der Bundesrepublik Deutschland ein Rechtsstreit zwischen den Hauptbeteiligten - Colonia Dignidad und Amnesty International - anhängig gemacht worden ist. ${ }^{130}$

Am 4. Mai 1977 übersandte das AA der Botschaft einen Durchdruck dieser Vorlage, die allerdings einen anderen Wortlaut hat. Hier heißt es in der Zusammenfassung:

»Bisher liegen eindeutige Beweise weder für noch gegen die behauptete Existenz eines Folterzentrums und Häftlingslagers in der >Colonia Dignidad « vor. [...] >Stern< und Amnesty International berufen sich auf die die Aussagen von zwei namentlich nicht genannten Exilchilenen und einer ungenannten Exilchilenin. Die Beweise für deren Behauptungen, in der >Colonia Dignidad ‘ gefoltert worden zu sein, wirken nicht sehr überzeugend.

Nach dem Motto sin dubio pro reo < dürfte es angebracht sein, äußerste Zurückhaltung zu üben. Auf jeden Fall sollten das Ergebnis der Prüfung der Landesjustizverwaltung

128 PA AA, ZW 111130. DB 130 vom 28.04.1977, GZ: pol-rk 543.

129 PA AA, ZW 111129. Ministervorlage AA, Abt. 3 vom 29.04.1977. Betr. Deutsche Siedlung »Colonia Dignidad in Chile«, mit handschriftlicher Stellungnahme von Staatssekretär Gehlhoff.

130 Ebd., Hervorhebungen im Original. 
Nordrhein-Westfalen und die von der `Colonia Dignidad` angekündigten rechtlichen Schritte [...] abgewartet werden. $\ll^{131}$

Staatssekretär Gehloff leitete die Vorlage vom 29.04.1977 mit folgender handschriftlicher Stellungnahme an Außenminister Genscher weiter:

»Wir haben ein objektives Interesse an einer Aufklärung der Vorwürfe, können diese Aufklärung aber keinesfalls selber vornehmen. Wir sollten uns auch nicht in die Auseinandersetzung zwischen >Colonia Dignidad einerseits und Amnesty International sowie >Stern $<$ andererseits hineinziehen lassen. ${ }^{132}$

Die Auffassung, es handle sich bei den Verbrechen der CD quasi um eine Auseinandersetzung zwischen zwei Privatparteien, kann als Leitlinie der bundesdeutschen Außenpolitik beschrieben werden. Das AA negierte jegliche politische Verantwortung für die Aufklärung der CD-Verbrechen und schrieb die Verantwortung für deren Aufklärung ausnahmslos den Strafverfolgungsbehörden zu. Diese ermittelten allerdings nicht intensiv selbst und stellten ihre Ermittlungen sogar unter Verweis auf angeblich entlastende Hinweise von AA und Botschaft ein. Außerdem war der CD allein auf juristischer Ebene nicht beizukommen, insbesondere nicht während der chilenischen Diktatur, deren Ende zum damaligen Zeitpunkt noch lange nicht absehbar war. Diese Haltung hatte fatale Folgen: Sie legitimierte de facto das fehlende Eingreifen bundesdeutscher Behörden angesichts systematischer Menschenrechtsverbrechen. Dies war besonders fatal, da die CD während der Diktatur in Chile vollkommen unter dem Schutz staatlicher Stellen stand, also auch hier keinerlei Verfolgung der Verbrechen zu erwarten war. Auch in den 1960er Jahren hatte das AA gegenüber der CD eine Politik der äußersten Zurückhaltung gepflegt. Diese war das Ergebnis eines politischen Erörterungsprozesses sowie oftmals des Handelns einzelner Diplomaten. Doch nun wurde die Nichteinmischung zu einer Handlungsleitlinie auf höchster Ebene des AA, vom Minister direkt gebilligt und mitverantwortet.

In Chile blieb die CD von der Justiz aus den genannten Gründen nahezu vollkommen unbehelligt. Doch auch von den Justizverfahren in der Bundesrepublik hatte die CD nicht viel zu befürchten, eher im Gegenteil (vgl. Abschnitt 5.3). Wenige Tage nach dessen Erscheinen leitete das AA den Stern-Artikel sogar ans Bundesjustizministerium weiter und bat um strafrechtliche Prüfung der darin enthaltenen Vorwürfe. ${ }^{133}$ Die Folge waren zwei Ermittlungsverfahren.

Der Stern hatte u.a. über die plötzliche Ausreise des Studenten Wolfgang Müller Altevogt in die CD 1975 berichtet. Die Staatsanwaltschaft Siegen ermittelte in diesem Fall zwei Monate lang wegen Freiheitsberaubung, stellte das Verfahren dann aber ein (vgl. Abschnitt 5.3.3). In der nur zwei Seiten dünnen Einstellungsverfügung hieß es, Müller Altevogt habe mitgeteilt, dass es ihm in der CD gut gehe und dass die Darstellung

PA AA, ZW 111130. Schreiben AA an Botschaft vom 03.05.1977. Durchschlag als Konzept. Hervorhebungen im Original. Das Schreiben gibt ebenfalls die auf der Ministervorlage festgehaltene handschriftliche Anmerkung von StS Gehlhoff wieder. 
des Stern verleumderisch sei. ${ }^{134}$ Die Staatsanwaltschaft Bonn stellte Ermittlungen wegen des im Stern erhobenen Vorwurfs der Existenz eines Haft- und Folterlagers in der $\mathrm{CD}$ an. Auch diese wurden nach wenigen Monaten eingestellt. Die StA argumentierte, die einzigen Anhaltspunkte für die Vorwürfe des Stern seien Aussagen von Wolfgang Kneese und des Folterüberlebenden Erick Zott. ${ }^{135}$ Diese seien aber nicht glaubwürdig. Die Botschaft habe der StA mitgeteilt, dass es in der CD ein Krankenhaus mit Publikumsverkehr gäbe, »ohne daß irgendwann die Existenz geheimer Anlagen aufgefallen sei ${ }^{136}$ Auch Luftaufnahmen hätten keinerlei Belege für die Existenz unterirdischer Anlagen erbracht. Botschaftsangehörige, die die Siedlung regelmäßig besuchten, hätten »solche Einrichtungen « ebenfalls »niemals entdeckt«, so die StA. ${ }^{137}$ Während also die Botschaft dem AA zuvor mehrfach berichtet hatte, keine Ermittlungsbefugnis zu haben und das AA argumentierte, keine Aufklärung vornehmen zu können, begründete die Staatsanwaltschaft Bonn ihre Einstellung mit den Ermittlungen der Botschaft. Ihre Stellungnahme schloss mit den Worten:

»Zusammenfassend lässt sich sagen, daß die Aussagen des Müller (Hamburg) [Wolfgang Müller Lilischkies, heute Kneese, JS] durch den Bericht der Botschaft über die in Chile selbst durchgeführten Ermittlungen widerlegt sind. Die Angaben des Zott sind schon insoweit kaum verwertbar, als dieser selbst nur vermutet, daß sich die behaupteten Mißhandlungen in der `Colonia Dignidad « ereignet haben. Im übrigen können sich Anhaltspunkte für die behaupteten Straftaten lediglich aus einem Bericht der deutschen Sektion von samnesty internationak ergeben [...] Auch die in diesem Bericht enthaltenen Aussagen beruhen aber im wesentlichen auf Schlußfolgerungen und Mutmaßungen, die die auf konkreten Beobachtungen beruhenden Ergebnisse der Ermittlungen der Botschaft nicht erschüttern können. [...] Ein hinreichender Tatverdacht läßt sich -insbesondere nach dem o.a. Ergebnis der Ermittlungen der deutschen Botschaft in Santiago - nicht begründen. ${ }^{138}$

Trotz der Leitlinie des AA, sich aus der Auseinandersetzung zwischen CD und AI bzw. Stern herauszuhalten, war der Bericht Strätlings nun ausschlaggebend für die Argumentation der Staatsanwaltschaft zur Einstellung des Verfahrens. Wie Strätlings entlastender Bericht zur StA Bonn gelangte, ist mir nicht bekannt. Die Einstellungsverfügung macht jedoch deutlich, dass die Staatsanwaltschaft keine eigenständigen Ermittlungen durchführte, sondern sich ausschließlich auf die Aussagen anderer verließ, insbesondere auf die Strätlings.

Dass die chilenische Diktatur für die CD die Epoque d'Or war, verdankte sie nicht nur dem Schutz durch die Militärjunta in Chile. Das Handeln der bundesdeutschen Diplomatie sowie der Staatsanwaltschaften in NRW hatte de facto ähnliche Folgen: Eine wirksame Aufklärung der CD-Verbrechen blieb aus, stattdessen unterstützten staatliEbd. 
che Stellen der Bundesrepublik de facto die Verteidigungsstrategie der CD und ließen dieser damit bei ihren Verbrechen weiterhin freien Lauf.

Unterstützung erhielt die CD in den darauffolgenden Jahren auch von diversen rechtskonservativen Politikern und Persönlichkeiten aus der Bundesrepublik, die die CD besuchten. Damit bestärkten sie die CD und ihre Behauptung, bei den Vorwürfen von AI und Stern handle es sich ausschließlich um eine ideologisch motivierte Verleumdungskampagne aus dem linkspolitischen Spektrum.

Entgegen der zeitweiligen Distanz, die Strätling bemängelt hatte, waren die persönlichen Kontakte zwischen CD und Botschaft während seiner Amtszeit regelmäßig und eng. Sogar Renovierungsarbeiten in der Botschafterresidenz im Sommer 1977 wurden von Handwerkern der CD durchgeführt. ${ }^{139}$ Mitarbeiter_innen der Botschaft reisten in die CD, um sammelweise neue Reisepässe für Colonos zu übergeben. Ein Vermerk über solch einen Besuch im Juli 1977 zeigt die Vertrautheit, aber auch die unkritische, nahezu bewundernde Haltung der Botschaftsangehörigen für die CD:

»Ein genüßlicher Duft, der mich an die herrlichen Erbsensuppen meiner Soldatenzeit erinnern ließ, lag in der Luft und ließ einem das Wasser im Munde zusammenlaufen. [...] Die Aushändigung der Pässe ging sehr diszipliniert vor sich. [...] Die jungen Mädchen, alle mit hellen, fröhlichen Augen und einem offenen Lachen im Gesicht, begrüßten uns mit einem höflichen Knicks, der dem englischen Hof alle Ehre gemacht hätte. Die jungen Männer [...] verneigten sich bei der Begrüßung. Bei einigen bemerkten wir sogar einen leichten Hackenzusammenschlag! [...] Nach dem wiederum reichlichen Frühstück besuchten wir nun das Prachtstück der ganzen Kolonie, nämlich das Krankenhaus [...] Unseren eigenen Cedanken nachhängend verließen wir tief beeindruckt die Stätte wahren Samaritertums. ${ }^{140}$

Diese Praxis der Sammel-Ausstellung von Reisepässen (und Lebensbescheinigungen für die bundesdeutschen Rentenversicherungsträger) ohne persönliche Vorsprache der Betroffenen in der Botschaft machte es einfachen Colonos unmöglich, vertrauliche Gespräche mit der Botschaft zu führen. Die Botschaft stärkte dadurch die Willkür und Kontrolle der CD-Führung über sämtliche Menschen in der CD.

1978 versuchte die von der ECOSOC eingesetzte Ad-Hoc-Arbeitsgruppe zur Situation der Menschenrechte in Chile die Colonia Dignidad zu besuchen, was diese als »erniedrigend « ablehnte. ${ }^{141}$ Nachdem es in der Jonestown-Sekte in Guayana ${ }^{142}$ einen Massenselbstmord gegeben hatte, forderte das AA die Botschaft im November 1978 auf, zum Fall CD zu berichten. Es sei "mit einem wachsenden Interesse der deutschen Öffentlichkeit an der Tätigkeit von Sekten « und daher auch an der CD zu rechnen. ${ }^{143}$ Strätling antwortete dem AA, er sähe keine Veranlassung, von seiner bisherigen Beurteilung der CD

139 PA AA, AV NA 31582. DE 14 vom 14.01.1988, GZ: Vw 220.05'01.

140 PA AA, AV NA 31581. Vermerk Hiemann, Botschaft vom 11.07.1977. Betr.: Dienstreise in die Kolonie »Dignidad«am 04./05.07.1977.

PA AA, ZW 615483. Dokument 6: Übersetzung von United Nations Ceneralversammlung, 33. Sitzung, Punkt 12, A 33/331 vom 25.10.1978, S. $11 \mathrm{ff}$. 
abzuweichen. ${ }^{144}$ Zwar sei die CD durch die Ermordung des DINA-Agenten Juan Muñoz Alarcón in »das Blickfeld negativer Publizität « ${ }^{145}$ geraten, die diesbezüglichen Untersuchungsverfahren hätten die CD aber entlastet. Auch gegenüber Besucher_innen aus der Bundesrepublik habe die CD 1978 "nicht immer eine glückliche Hand bewiesen ${ }^{146}$, da sie ideologische Maßstäbe angesetzt habe. So habe sie dem CD-kritischen Bundestagsabgeordneten Waltemathe (SPD) einen Besuch verweigert. Andererseits hätten konservative, der $C D$ wohlgesonnene Politiker_innen die CD zum Teil tagelang besuchen dürfen. Unter ihnen seien der Münchner CSU-Stadtrat Vogelsgesang, der ZDF-Moderator Löwenthal und Dieter Huber, Berater von Franz-Josef Strauß, gewesen. Letzterer habe die CD mit einer 35-köpfigen Delegation von CSU-Mitgliedern besucht. Diese sei »liebenswürdig aufgenommen ${ }^{147}$ worden, hätte keinerlei Folterkammern gefunden und sich in der chilenischen Presse lobend über die soziale Arbeit der CD geäußert. In Bezug auf die Kontakte der CD zur Botschaft berichtete Strätling weiter:

»Um den rund 300 deutschen Staatsangehörigen die 400km lange Reise nach Santiago zu ersparen, wurde die frühere Praxis fortgesetzt, wonach die Ausstellung deutscher Reisepässe [...] durch Einschaltung des in Santiago ansässigen »Verbindungsmannes« der Colonia Dignidad, Herr Alfred Matthusen, erleichtert wird, der die nötigen Dokumente im RK-Referat der Botschaft vorlegt. $\ll^{148}$

Botschafter Strätling schloss mit der Feststellung, die Botschaft sei den Anfragen durch Angehörige von Colonos aus der Bundesrepublik mit besonderer Sorgfalt nachgegangen. Schließlich stünde bei diesen explizit oder implizit der Vorwurf im Raum, die betreffenden Personen würden gegen ihren Willen in der CD festgehalten. Hierfür, so Strätling, hätten sich jedoch keine Anhaltspunkte ergeben. ${ }^{149}$

Im Zeitraum zwischen dem Militärputsch im September 1973 und der Abberufung Strätlings als Botschafter im Mai 1979 gab es mit den Berichten der ECOSOC sowie von Amnesty International und diversen Medien handfeste Belege für von der CD begangene Menschenrechtsverletzungen im Kontext der Diktatur. Gleichzeitig gab die Botschaft jegliche kritische Distanz zur CD auf und übernahm nahezu vollständig deren Selbstdarstellung. Grund hierfür ist vermutlich die zur CD gefühlte ideologische Nähe von Strätling sowie vielen Botschaftsangehörigen, aber auch von Vertreter_innen des AA. Im Lagerdenken des Kalten Krieges lehnten sie die vermeintlich ideologisch motivierten und als Verleumdungskampagne wahrgenommenen Vorwürfe gegen die CD ab und solidarisierten sich - ob bewusst oder unbewusst - gegen diese Kritik mit der CD. Darin befand sich die Botschaft auf einer Linie mit dem überwiegenden Teil der einflussreichen deutschstämmigen Community in Chile. Diese unterstützte die Militärjunta offen und vehement. Dies wiederum korrespondierte mit der Unterstützung 
der chilenischen Diktatur, aber auch der CD durch rechtskonservative Kreisen in der Bundesrepublik, insbesondere aus Reihen der CSU. Diese Haltung führte zu einer Ausblendung jeglicher menschenrechtlich gebotener Handlungsansätze.

Unklar bleibt letztlich, inwieweit Strätling tatsächlich über die Verbindungen zwischen CD und DINA sowie über die Mitwirkung der CD an schweren Menschenrechtsverbrechen informiert war. Aus dem CD-Geheimarchiv geht hervor, dass Strätling in mindestens einem Fall sogar Informationen über eine konkrete, in der CD gefolterte Person an CD-Führungsmitglieder weitergab. ${ }^{150}$ Auch wenn der Grund für Strätlings Solidarisierung mit der CD möglicherweise nur seine ideologische Nähe zur CD und keine konkrete Mitwisserschaft über Verbrechen war, legitimierte sein Handeln zumindest das Eintreten anderer Verbündeter für die CD, wie etwa beim Waffenhändler Mertins (Vgl. z.B. Abschnitt 4.2.2).

\subsubsection{9-1984: Jahre des Schweigens - Bekannte Fakten und mächtige Netzwerke}

In den Jahren nach der Abberufung Strätlings ebbte die mediale Aufmerksamkeit für das Thema $C D$ ab. Medien berichteten nur noch sporadisch, Angehörige waren von der fehlenden Unterstützung durch das AA enttäuscht. Auch zu strafrechtlichen Ermittlungen gegen die CD kam es in dieser Zeit nicht. Das Zivilverfahren der CD gegen AI zog sich in die Länge (vgl. Abschnitt 5.3.1). Das LG Bonn hörte zahlreiche Folterüberlebende an und vernahm den in die Bundesrepublik geflüchteten DINA-Aussteiger Samuel Fuenzalida Devia. Das Gericht bemühte sich um einen Ortstermin in der CD, was die chilenische Justiz aber verhinderte. Hierbei bekam sie Unterstützung vom Würzburger Jura-Professor Blumenwitz. Dessen Gefälligkeitsgutachten für die CD-Anwälte erklärte die aktive Präsenz bundesdeutscher Richter in Chile für unzulässig. Auch Rechtshilfeersuchen des LG Bonn wurden in Chile jahrelang nicht bearbeitet. Das formal laufende, de facto aber stillstehende Verfahren wurde zunehmend zu einem Propagandainstrument der CD. Es ermöglichte der CD jahrelang zu behaupten, dass die Vorwürfe gegen die CD von der Justiz nicht erhärtet werden konnten. Aufklärerische Akteur_innen verloren aufgrund des sich immer länger hinziehenden Verfahrens allmählich die Hoffnung. Währenddessen betrieb der informelle CD-Freundeskreis in der Bundesrepublik um Gerhard Mertins intensive Lobbyarbeit zugunsten der CD. ${ }^{151} \mathrm{Da}$ in dieser Phase kaum neue Fluchtfälle oder Hilferufe aus der CD publik wurden, gab es auch keine neuen Hebel, um die Aufklärung der CD-Verbrechen voranzutreiben.

\subsubsection{5-1987: Die allmähliche Sensibilisierung der bundesdeutschen Diplomatie}

Nachdem es jahrelang recht still um die CD gewesen war, brachten erst die Fluchten von Hugo Baar im Dezember 1984 sowie von Lotti und Georg Packmor im Februar 1985

150 Vgl. CD-Geheimarchiv, Ficha Luis Enrique Peebles Skarnic. Siehe dazu Abschnitt 2.2.5.

151 Vgl. u.a. HISArch, Bestand Colonia Dignidad, Ordner 2. Schreiben Mertins an die Siegburger Presse vom 07.11.1979. 
aus der CD den Fall wieder auf die politische Tagesordnung. Mit Baar war erstmals ein ehemals hochrangiges Mitglied der CD-Führung aus der CD geflohen, das Ehepaar Packmor hatte zur loyalen mittleren Führungsebene gehört. Alle drei wurden bei ihrer Flucht von Heinz Kuhn unterstützt, einer weiteren ehemaligen CD-Führungsperson. Kuhn lebte seit 1968 im südchilenischen Los Ángeles und hatte weiter engen Kontakt mit der CD-Führung gepflegt, bis er sich 1984 von Schäfer abwandte. Insbesondere Baar und Kuhn waren der chilenischen Diktatur grundsätzlich zugeneigt. Beide verfügten über diverse Kontakte in gesellschaftliche Kreise, die einer Skandalisierung von Menschenrechtsverbrechen aus linkspolitischen Motiven vollkommen unverdächtig waren.

Sowohl Baar als auch das Ehepaar Packmor schilderten die Zustände innerhalb der $C D$, deren Zwangssystem und die von ihr begangenen Verbrechen ebenso ausführlich wie detailliert. Da sich ihre Berichte direkt an die bundesdeutsche Diplomatie richteten, musste diese reagieren. Diese gab ihre »äußersten Zurückhaltung« in den folgenden Jahren schrittweise auf und änderte sowohl intern als auch gegenüber chilenischen Gesprächspartner_innen ihre Haltung gegenüber der CD. Dabei blieb sie aber stets ihrer Linie treu, anhand von Menschenrechtsfragen keine Brüskierung der chilenischen Diktatur zu riskieren: Das Handeln der bundesdeutschen Diplomatie beschränkte sich daher formal auch weiterhin auf den Einsatz für deutsche Staatsangehörige. Die Diktaturverbrechen thematisierte sie weiterhin nicht.

Die Jahre von 1985 bis 1987 waren von einer Interessenallianz dreier Männer geprägt, von Botschafter Holzheimer, dem Würzburger Soziologieprofessor Lothar Bossle sowie dem geflüchteten CD-Mitgründer Hugo Baar. Alle drei pflegten gemeinsam ein Narrativ, dass sich etwas verkürzt wie folgt beschreiben lässt: Die CD ist ein im Kern wohltätiges und sinnvolles Projekt, das erhalten werden muss. Die Menschenrechtsverbrechen gegen deutsche Colonos - die nun unzweifelhaft anerkannt werden - gingen allein von Paul Schäfer aus. Daher müsste dieser aus der Siedlung »entfernt« und durch eine andere Führungsfigur, etwa Hartmut Hopp, ersetzt werden. Bei alldem gelte es aber einen Skandal zu vermeiden, etwa durch eine zusätzliche Thematisierung der Kooperation zwischen CD und DINA. Dies würde nur Angriffsfläche für linke Kräfte bieten und außerdem die Militärregierung diskreditieren.

Bossle besuchte kurz nach der Flucht der Packmors 1985 zum wiederholten Male die CD. Bossle war ein Freund der chilenischen Militärdiktatur ${ }^{152}$, verfügte über beste Kontakte zu Führungskreisen der $\mathrm{CDU} / \mathrm{CSU}^{153}$ und half während der chilenischen Diktatur bundesdeutschen Unternehmen in Chile Geschäfte anzubahnen. ${ }^{154}$ Über ein

152 Vgl. Bossle, Lothar. Allende und der europäische Sozialismus, Stuttgart 1975.

153 Bossle hatte enge Verbindungen zu Franz-Josef Strauß und arbeitete als Berater für Helmut Kohl. Vgl. Köhler, Otto. »Doktorspiele in Würzburg. Professor Bossle und sein soziologisches Familienunternehmen an der Julius-Maximilians-Universität«, in: Die Zeit Nr. 45 vom 04.11.1988, online unter https://www.zeit.de/1988/45/doktorspiele-in-wuerzburg.

154 Hopp bezeichnete Bossle bei einem Telefonat mit Mertins als einen Vertreter der Firma Hochtief, die sich in Chile um Aufträge bewerbe. PJS, Sammlung Luis Narváez. Bericht der JIPOL/PDI vom 13.10.2006: Procesamiento y Análisis de la información en idioma alemán remitida por el Ministro Jorge Zepeda Arancibia el 14 de septiembre de 2005. Documento 69. Protokoll eines Telefonats zwischen »Struppi« (Hartmut Hopp) und »Rettich« (Gerhard Mertins) vom 15.11.1987. 
am 20. März 1985 mit Bossle geführtes Telefonat gab Botschafter Holzheimer folgendes wieder:

»Die Mitglieder der CD leben sim Familienverband wie Kommunisten und denken wie Reaktionäre.< Das Musizieren spielt eine besondere Rolle, es gibt einen Männerchor und ein Damenorchester. Zur Einweihung der selbstgebauten Schule am 20. März '85 werden Herr Rudek, Präsident des Deutschen Schulverbands Santiago, und Herr Thümmler, Vertreter der Deutschen Bank in Santiago die Colonia Dignidad besuchen. Prof. Lothar Bossle wird im November d. J. Wieder nach Chile zurückkehren und wird versuchen, mit anderen Vertretern der Wirtschaft (u.a. Herr Flachskamp-Hoechst) einen weiteren Besuch in der Colonia Dignidad zu organisieren, die er persönlich bereits viermal aufgesucht hat. ${ }^{155}$

Hermann Holzheimer, seit 1983 Botschafter, hatte an der Universität Würzburg studiert. Am 27. März 1985 leitete Holzheimer den Bericht des Ehepaars Packmor ans AA weiter und kommentierte ihn mit deutlichen Worten:

»Wichtiger wäre allerdings, daß die in vielem an ein Konzentrationslager gemahnenden Lebensbedingungen wie die Behandlungen mit Psychopharmaka und Elektroschocks geändert werden und Herrn Schäfer nicht weiter Celegenheit gelassen wird, Kinder bei sich schlafen zu lassen (siehe Fahndungsersuchen in der Vergangenheit). $\ll^{156}$

Holzheimers ausführliche Einschätzung zum Bericht Hugo Baars ${ }^{157}$ hat einen ähnlichen Tenor. Der Bericht zeige, »dass Paul Schäfer die Gemeinschaft in brutaler Weise führe und ein sinneres« Regime errichtet hat, das in vieler Hinsicht an ein Arbeits- oder Konzentrationslager erinnert $«{ }^{158}$ Doch gleichzeitig findet der Botschafter in seinem Kommentar auch positive Worte für die CD: Baars Bericht mache »aber auch deutlich, von welch lauteren Motiven die überwiegende Mehrheit der Colonia DignidadAngehörigen bestimmt sind . ${ }^{159}$ Schließlich, so Holzheimer, gehe es um Schäfer: »Die bisher vorliegenden Erkenntnisse legen die Vermutung nahe, daß die Probleme im $\mathrm{Zu}$ sammenhang mit der Colonia Dignidad vor allem ein Problem um die Person von Paul Schäfer ist. ${ }^{160}$

Auch auf symbolischer Ebene markierte Holzheimer die Distanz zur CD. Einem Botschaftsmitarbeiter, der bisher Lebensmittel der CD an seine Kolleg_innen vertrieben hatte, untersagte Holzheimer beispielsweise, dies weiter zu tun. ${ }^{161}$ Holzheimer schlug

155 PA AA, AV NA 31577. Vermerk Botschafter Holzheimer über ein Telefonat mit Bossle vom 20.03.1985. Die private Schule der CD wurde im Rahmen einer feierlichen Zeremonie am 20.03.1985 von der Diktatorengattin Lucía Hiriart de Pinochet eingeweiht. Vgl. La Nación vom 21.03.1985, S. 6. »Primera dama inauguró escuela en Dignidad«.

156 PA AA, B 83, Bd. 2384. Bericht Botschafter Holzheimer ans AA, Referat 330 vom 27.03.1985, GZ: Ber. $352 / 85$ rk 543.00.

157 PA AA, AV NA 31577. Bericht Botschafter Holzheimer ans AA Nr. 672/85 vom 28.05.1985, GZ: RK 543.

158 Ebd.

159 Ebd.

160 Ebd.

161 PA AA, AV NA 31583. Vorlage AA, Referat 330 für StS Sudhoff, AA, vom 10.09.1987. 
vor, die Berichte Baars und der Packmors an die bundesdeutsche Justiz weiterzuleiten, was auch geschah. Die Staatsanwaltschaft Bonn eröffnete daraufhin im Mai 1985 ein Ermittlungsverfahren gegen Schäfer wegen »Freiheitsberaubung, Körperverletzung usw.« (vgl. Abschnitt 5.3.4). In Chile entschied Holzheimer jedoch in Abstimmung mit dem $\mathrm{AA}$, die Berichte nicht an die Justiz weiterzuleiten, sondern an General Rodolfo Stange, mit dem er ohnehin in regelmäßigem Austausch stand. Am 30. Mai 1985 schrieb Holzheimer an Stange:

»Verehrter, lieber Herr Ceneral, im Anschluß an unser Gespräch vom 30. April 1985 darf ich Ihnen anbei die Ablichtung einer weiteren Aussage in Sachen Dignidad übersenden. [...]. Die Professoren Blumenwitz und Bossle, beides zuverlässige Freunde Chiles und bislang auch sehr beeindruckt von den Leistungen in Dignidad, haben mir nach Kenntnis der Berichte der Familien Packmor und Baar ihre tiefe Besorgnis über die Entwicklung in der Kolonie mitgeteilt, aber auch ihre Bereitschaft, helfend beizustehen. Wie wir bei dem seinerzeitigen Cespräch glauben auch sie, daß die Herausnahme Schäfers dringend geboten sei, daß danach aber ein Heilungsprozeß beginnen könne. Für diese schwierige Phase würden sie ihre fachliche und menschliche Unterstützung anbieten. Ich würde mich freuen, wenn ich gelegentlich von Ihnen hören würde. « ${ }^{162}$

Aufschlussreich sind Holzheimers Formulierungen. Die Rede von »zuverlässigen Freunden Chiles« entspricht dem Vokabular der Diktatur, die die gesamte Welt in Freund und Feind unterteilte. Der Zusatz »zuverlässig« bedeutete, dass die beiden Genannten überzeugte Unterstützer der Diktatur waren, die diese auch mit konkreten Handlungen unterstützten. Der Begriff »Heilungsprozess« verdeutlicht Holzheimers Sicht auf die CD: In seinen Augen war dies eine im Kern gesunde Gruppierung, aus der man nur einen Fremdkörper (Schäfer) herauslösen müsse. Holzheimer bat Stange »helfend bei[zu]stehen«, also behilflich zu sein, um das Problem auf informellem Wege über seinen Einfluss auf die Militärjunta zu lösen.

Baar, grundsätzlich ein Anhänger der Militärdiktatur, nahm nach seiner Ankunft in der Bundesrepublik nach der Vermittlung von Holzheimer ${ }^{163}$ rasch Kontakt zu Bossle auf, der die CD mehrfach besucht hatte. Baar und Bossle waren sich einig, dass eine Veröffentlichung der Berichte linken Kreisen in die Hände spielen konnte - was beide verhindern wollten. Baar untersagte daraufhin dem AA eine Weitergabe seines Berichts an Bundestagsabgeordnete, insbesondere an aufklärerische Akteur_innen wie Ernst Waltemathe (SPD). Ihm dürfte klar gewesen sein, dass ein Bekanntwerden seines Berichts zu einer erneuten öffentlichen Thematisierung der CD geführt hätte. ${ }^{164}$

Parallel dazu führten auch Bossle und Holzheimer einen regen Briefwechsel, in dem es ebenfalls darum ging, die Wogen zu glätten. So heißt es in einem Brief Bossles an Holzheimer vom 15. Mai 1985:

162 PA AA, AV NA 31577. Schreiben Botschafter Holzheimer an Stange vom 30.05.1985.

163 PA AA, AV NA 31577. Schreiben Baar an Botschafter Holzheimer vom 24.05.1985.

164 PA AA, AV NA 31577. Schreiben Waltemathe, MdB an StM Möllemann vom 03.09.1985 und ebd., Bericht Botschaft an Ref. 511 (AA) Nr. 1085/85 vom 30.09.1985, Rk 543.00 (Durchschlag als Konzept, abgesandt am 3.10.85). 
»Man muß unter allen Umständen vermeiden, daß daraus ein erneuter Skandal entsteht. Genauso aber dringlich erscheint es mir nach dem Studium der beiden Berichte wie aus der Unterhaltung mit Herrn Baar, daß jede Lösung des Problems mit einer Entfernung von Herrn Schäfer aus der Colonia Dignidad beginnt. « $^{165}$

Im Juli 1985 reiste Holzheimer in die Bundesrepublik. Unter anderem hielt er an seiner Alma Mater, der Universität Würzburg einen Vortrag, den Bossle organisiert hatte. ${ }^{166}$

Im August 1985 wurde Rodolfo Stange Teil der vierköpfigen Militärjunta. Im Oktober berichtete Holzheimer ans AA, Stange habe ihm mitgeteilt, dass seine Beamte bei Versuchen CD-Mitgliedern strafbare Handlungen nachzuweisen »auf eine Mauer des >Nichtwissens und des Schweigens « gestoßen sein. Nur Anzeigen der Baars und Packmors könnten zum Erfolg führen. ${ }^{167}$

Diese Worte eines Junta-Mitglieds waren eine klare Botschaft an die Bundesregierung: Die CD genoss den vollständigen Schutz der Militärregierung. Da beide Seiten wussten, dass auch die chilenische Justiz die CD protegierte, war der angebliche Rat, den juristischen Weg zu beschreiten, reine Diplomatie. Zudem hätten die Geflüchteten für die vorgeschlagenen Strafanzeigen nach Parral reisen müssen. ${ }^{168}$ Die Baars und die Packmors waren grundsätzlich zu einer Anzeige bereit, sie schreckten jedoch aus guten Gründen davor zurück, sich wieder in den unmittelbaren Einflussbereich der CD $\mathrm{zu}$ begeben. Sie forderten für einen solchen Schritt politische Rückendeckung durch die Bundesregierung sowie eine vollständige Kostenübernahme für die zu erwartenden langen Justizverfahren. Die Bundesregierung war nicht bereit, diese Garantien zu gewähren, wollte aber auch nicht selbst als Klägerin auftreten. In der Folge beschränkte sie sich auf die zahnlose Forderung an die chilenische Regierung, den in ihrem Verantwortungsbereich liegenden Fall aufzuklären.

Auch eine öffentliche Auseinandersetzung mit der Diktatur wollte die Bundesregierung nicht eingehen. Sie beschränkte sich in der Folge auf administrative Mittel. So hatte die CD beispielsweise bisher konsularische Angelegenheiten im Sammelverfahren abwickeln können. Dies betraf vor allem Reisepässe sowie die jährlichen Lebensbescheinigungen für die bundesdeutschen Rentenversicherungsträger. Nun schlug die Botschaft der CD vor, sogenannte Konsularsprechtage abzuhalten, die Entsendung von Konsulatsmitarbeiter_innen in die CD. Die CD lehnte dies erst einmal ab. Am 15. Mai 1985 beantragte Paul Schäfer beim Konsulat in Concepción einen neuen Reisepass. ${ }^{169}$ Das AA wies an, die Laufzeit mit Verweis auf das Bonner Ermittlungsverfahren auf 2 Jahre zu beschränken. Im Dezember 1985 folgte der Erlass, »die Pässe der in der CD

165 PA AA, AV NA 31577. Schreiben Bossle an Botschafter Holzheimer vom 15.05.1985.

167 PA AA, AV NA 31577. Bericht Botschafter Holzheimer an AA Nr. 1095/85 vom 03.10.1985. GZ: Rk 543.00 (Durchschlag als Konzept, abgesandt am 9.10.1985). 
wohnenden Deutschen nur nach persönlicher Vorsprache in der Botschaft zu verlängern «. ${ }^{170}$ Schon bald war ein Großteil der Reisepässe der Colonos abgelaufen. ${ }^{171}$

Im August 1986 löste Horst Kullak-Ublick Holzheimer als Botschafter ab. Es handelte sich erneut um einen sehr konservativen Diplomaten, der über entsprechende politische Kontakte verfügte. Bei einer Vernehmung 1989 sagte der Waffenhändler Gerhard Mertins, er kenne Kullak-Ublick schon »seit einigen Jahren«. Er

»habe ihm vor Dienstantritt seiner neuen Aufgabe in Santiago einen Besuch abgestattet und ihn in die Problematik der CD von meiner Warte eingeführt. Hierbei stellte ich ihm gleichzeitig Kurt Schnellenkamp vor, der gerade in Deutschland besuchsweise weilte. Dieses damalige Gespräch fand im Auswärtigen Amt in Bonn statt. Hierzu wurde vereinbart, daß der Botschafter zu jeder Zeit herzlich willkommen ist und sich jeder Zeit in der CD einfinden kann. Gleichzeitig trug allerdings Schnellenkamp vor, daß das sonst so gute Verhältnis zur Deutschen Botschaft vornehmlich durch Maßnahmen eines Konsularbeamten Haller arglos gestört sei. « ${ }^{172}$

Konsul Haller, der seit 1985 in der Botschaft als RK-Referent tätig war, versuchte einen Konsularsprechtag in der CD durchzusetzen. Haller war durchaus progressiver eingestellt als Holzheimer und Kullak-Ublick. Er pflegte auch Kontakte zu einigen aufklärerischen Akteur_innen. Die CD versuchte daher, auf strategischem Wege Unruhe zu stiften, um die internen Konflikte in der Botschaft anzuheizen. An einem Konsularsprechtag im Februar 1987, den die Botschaft einseitig angesetzt hatte, ließ die CD die drei angereisten Botschaftsangehörigen um Haller schlicht nicht auf ihr Gelände. Noch während die Beamten vor dem Tor der CD warteten, überreichten Vertreter der CD der Botschaft ein Schreiben, in dem sie ihre Ablehnung mit ihrem "gestörten Vertrauensverhältnis zum RK-Referenten « - also zu Haller - begründeten. ${ }^{173}$ Zudem reichte die CD drei Dienstaufsichtsbeschwerden gegen Haller ein ${ }^{174}$ und suchte sich politische Unterstützung (vgl. Abschnitt 5.4.).

170 PA AA, AV NA 31577. Schreiben AA an Botschaft vom 19.12.1985, CZ: 511-531E-2226/77.

171 PA AA, AV NA 31583. Zettel in der Botschaftsakte mit handschriftlichem Vermerk 10/87 »Herrn Haller z. g. K.: nach den hiesigen Paßakten sind die Pässe von 261 CD-Mitgliedern abgelaufen. Lediglich 12 verfügen über gültige Pässe, von denen 7 im Jahre 88 und 5 im Jahre 1990 ablaufen. «

172 StA Bonn, AZ 50 ]s 285/85, Bd. XI, BI. 91. Vernehmung von Gerhard Mertins vom 01.03.1989. Dabei sagte Mertins: »Noch bei einem Besuch in der Bundesrepublik (Berichterstattung an Herrn Censcher) trafen wir uns (Kullak-Ublick und ich) auf dem Flugplatz in Köln, um unsere inzwischen gesammelten weiteren Erfahrungen auszutauschen. >Änderungen sind nötig, aber die positiven Eindrücke sind überwiegend ‘, dies war der Standpunkt, den Kullak-Ublick mir gegenüber vertrat.« Kullak-Ublick wurde am 29.11.1987 von Außenminister Genscher zur Berichterstattung nach Bonn einberufen. Mit ihm im selben Flugzeug saß der ehemalige Botschafter Erich Strätling. Dieser vermeintliche Zufall wurde durch eine Frage des MdB Waltemathe an die Bundesregierung bekannt. Vgl. Deutscher Bundestag. Plenarprotokoll 11/67 vom 10.03.1988, S. 4621Cf. Ebd.

174 HISArch, Bestand CD, Ordner 2 bzw. PA AA, AV NA 31583. Dienstaufsichtsbeschwerden der SBED gegen Konsul Haller vom 20.08.1987, 30.01.1988 und 03.03.1988. 
1987 wurden die Menschenrechtsverletzungen der chilenischen Diktatur zum Gegenstand innenpolitischer Debatten in der Bundesrepublik. ${ }^{175}$ Während die CSU weiterhin auf eine Stützung der Diktatur setzte, nahmen progressivere Vertreter_innen der CDU eine diktaturkritische Haltung ein. Im Juli 1987 besuchte CDU-Arbeits- und Sozialminister Norbert Blüm Chile, ${ }^{176}$ im November folgte ein Chile-Besuch von CDUGeneralsekretär Heiner Geißler. Beide thematisierten bei ihren offiziellen Gesprächen in Chile den Fall CD und forderten auch von Pinochet Aufklärung. Vertreter_innen der CSU wie der Münchner Stadtrat Wolfgang Vogelsgesang traten hingegen weiterhin für die CD ein. Auch Bossle reiste im Oktober 1987 erneut nach Chile und sprach mit Pinochet. ${ }^{177}$ An dem Gespräch nahm auch der CSU-nahe ehemalige Generalbundesanwalt Ludwig Martin teil. Dieser berichtete später:

»Das etwa einstündige Gespräch, das im wesentlichen zwischen Prof. Bossle und Pinochet geführt wurde, drehte sich [...] auch um die Gefahr, daß die menschenrechtswidrigen Zustände in der Colonia Dignidad eine neue Kampagne gegen Chile auslösen könnten. Hierzu vertrat Pinochet die Ansicht, daß Menschenrechtsverletzungen in der $C D$ nicht erwiesen seien und daß es im übrigen Sache deutscher Cerichte wäre, die Täter zur Verantwortung zu ziehen. Zu diesem Punkt mischte ich mich ein und äußerte die Meinung, daß die chilenischen Behörden zum Einschreiten verpflichtet seien, was Pinochet schweigend zur Kenntnis nahm. « ${ }^{178}$

Bossle selbst berichtete später einem Mitarbeiter des Lateinamerikareferats des AA über das Gespräch. Demnach habe Pinochet ihm gesagt, er habe »noch nichts Schlechtes über CD gehört «, aber sobald die Bundesregierung »einen Antrag stelle«, werde die chilenische Regierung reagieren. ${ }^{179}$ Diese Aussage ähnelt den Worten von General Stange im Oktober 1985 und drückten den persönlichen Schutz der CD durch den Diktator aus.

Im Laufe des Jahres 1987 griffen bundesdeutsche Medien das Thema CD zunehmend wieder auf. AA und Botschaft gerieten dadurch unter Druck, ${ }^{180}$ da sie immer noch keinen Konsularsprechtag in der CD hatten durchsetzen können. Der Journalist Gero Gemballa, der für den WDR arbeitete, wurde im August 1987 beim Versuch,

175 Vgl. Der Spiegel Nr. 32/1987 vom 03.08.1987, S. 19ff. »Kein Zentimeter wird zurückmarschiert«, online unter https://magazin.spiegel.de/EpubDelivery/spiegel/pdf/13523259. Der Titel der Ausgabe lautete »Folter in Chile - Krach in Bonn«. Der Artikel beginnt mit der Feststellung: »Die Reise des CDU-Arbeitsministers Norbert Blüm nach Südamerika hat CDU und CSU an den Rand der Spaltung gebracht. Die Christsozialen beschuldigen den CDU-Vize, gegen Kabinettsbeschlüsse zu verstoßen, und verbergen hinter formaler Kritik Grundsätzliches: Ihnen paßt die ganze Richtung nicht, die CDU-Generalsekretär Heiner Geißler und Blüm ihrer Partei geben wollen. CSU-Chef Strauß fürchtet, rechte Wähler zu verlieren, wenn sich die Union nach links profiliert. Kanzler Helmut Kohl taktiert in der Mitte - und wartet ab.« Ebd., S. 19.

176 PA AA, ZW 146532. DB 257 vom 03.08.1987, CZ Pol 300.25. Bericht von Botschafter Kullak-Ublick ans AA über Blüms Gespräch mit Pinochet am 03.08.1987.

177 Laut der Zeitung La Epoca führte Bossle das Cespräch mit Pinochet auf Bitten von Franz-Josef Strauß. La Epoca vom 27.10.1987.

178 PJK. Bericht von Ludwig Martin über dessen Chilereise vom 20.-29.10.1987.

179 PA AA, B 83, Bd. 2388. Vermerk des AA über Besuch Bossles bei Dg 33 vom 22.01.1988, CZ: 330504.00.

180 PA AA, AV NA 31583. Vorlage von Referat 330, AA für StS Sudhoff vom 10.09.1987. 
Filmaufnahmen von der CD zu machen, auf Betreiben der CD festgenommen. ${ }^{181}$ Das Lateinamerikareferat des AA schrieb dazu in einer Vorlage an Staatssekretär Sudhoff, Gemballa sei wieder in der Bundesrepublik und bereite »einen Beitrag vor, in welchem die Verhältnisse in und um CD im Zusammenhang mit dem Interesse an Menschenrechtsfragen in Chile erneut in die Medien gelangen werden«. Mit einer »öffentlichen Diskussion des Themas« müsse "gerechnet werden «. ${ }^{182}$ Weiter hieß es:

»Es ist auch nicht auszuschließen, daß dem AA und der Botschaft Santiago (zu Unrecht) vorgeworfen werden wird, zu lange untätig geblieben zu sein und trotz der Berichte der geflüchteten Packmoor, Baar, Kuhn, des Stern-Berichts und der Hinweise von Amnesty International zu wenig unternommen zu haben. Es gibt Äußerungen von BM Blüm, daß auch er daran denkt, das Thema aufzugreifen « $^{183}$

Auch der chilenischen Regierung sei »an einer verstärkten öffentlichen Diskussion über Menschenrechtsverletzungen in der CD nicht gelegen «, andererseits unternehme diese aber auch »keine wirklichen energischen Schritte gegen $C D \ll .{ }^{184}$ Der Vorschlag, den das Referat zum weiteren Vorgehen machte, hatte jedoch angesichts der der Botschaft und dem AA bekannten Verbindungen zwischen CD und Diktatur wenig Aussicht auf Erfolg:

»Die Botschaft in Santiago sollte angewiesen werden, die zuständigen chilenischen Behörden erneut nachdrücklich zu ersuchen, das Rechtshilfeersuchen mit den Ermittlungen in der CD insbesondere gegen Paul Schäfer auch im eigenen Interesse zu beschleunigen. Außerdem sollten wir sehr rasch nachdrücklich auf eine Untersuchung der Zustände in der CD durch chilenische Behörden und ggf. strafrechtliche Verfolgung der CD-Führung, auf eine Öffnung des Lagers und Unterstützung derjenigen, die es verlassen wollen, drängen. Man könnte auch die Einsetzung einer Kommission des IKRK [Internationales Rotes Kreuz, JS] oder eine internationale Untersuchungskommission vorschlagen. $\ll^{185}$

Dieser Vorschlag war hilflos, da er nichts Neues enthielt: Das Rechtshilfeersuchen des LG Bonn lag seit 1982 unbeantwortet in Chile. Trotz jahrelangem Drängen hatten chilenische Behörden keinerlei strafrechtliche Ermittlungen eingeleitet und dabei immer auf fehlende Strafanzeigen aus Deutschland verwiesen. Auch der Vorschlag einer Untersuchung durch das IKRK war bereits 1977 gescheitert.

Nach langen Verhandlungen mit der CD-Führung besuchte Kullak-Ublick am 7. November 1987 die Siedlung, zusammen mit seiner Frau Ingeborg, Konsul Haller, dem RK-Mitarbeiter Hans-Georg Filusch und einem Personenschutzbeamten namens Schäfer. ${ }^{186}$ Kullak-Ublick bat das AA darum, seinen Bericht vertraulich zu behandeln. Er schrieb:

183

184

185

186

PA AA, AV NA 31583. Memorandum der Carabineros über die Festnahme Gemballas am 27.08.1987 vom 17.09.1987.

PA AA, AV NA 31583. Vorlage von Referat 330, AA für StS Sudhoff vom 10.09.1987.

Ebd.

Ebd.

Ebd.

StA Bonn, AZ 50 ]s 285/85, Bd. I, Bl. 233ff. DB 416 von Botschafter Kullak-Ublick vom 09.11.1987, VS-V, RK 543. 
»Wir sind alle gleichermaßen betroffen über das Cehörte, Cesehene und Beobachtete zurückgekehrt. [...] Wir haben uns 9 Stunden in CD aufgehalten und eine nicht endende Zahl von Einzel- und Gruppengesprächen geführt. Wir haben Erkenntnisse mitgebracht, die den Cesamtkomplex komplizierter und subtiler darstellen, als er sich bisher aus Unterlagen und schriftlichen Darstellungen ergeben hat. Wir wissen, dass unsere Forderungen an die chilenische Seite einen anderen Ansatz haben müssen als dies bisher geschah. ${ }^{187}$

Weiter erklärte Kullak-Ublick in seinem Bericht, die CD sei eine Gründung religiös und sozial engagierter Menschen gewesen, die unter höchstem persönlichen Einsatz und uneigennützig ein blühendes Gemeinweisen aufgebaut hätten. Inzwischen jedoch basiere das System nur noch auf Arbeitsausbeutung. Dabei schoss sich Kullak-Ublick auf die Person Schäfers ein:

»Spiritus Rector ist allein Paul Schäfer. Eine fast dämonische Energie geht von ihm aus [...] Ihm zur Seite als einziger Vertrauter [...] [steht] Hartmut Hopp. [Schäfers] Wille ist so dominierend, [...] sein Despotismus so unbegrenzt, dass alle Mitglieder von CD den Eindruck von Robotern hinterlassen. Menschen, die wie unter Hypnose handeln und leben und keine eigene Persönlichkeit und Identität kennen [...] Eine Gesellschaft von roboterhaften Funktionssklaven. [...] Ein 6-jähriger Junge flüsterte mir ins Ohr >hier ist es nicht schön<. [...] Nach aussen zeigt die Cemeinschaft soziale Leistungen [...] Heutiger Inhalt: Gewinnstreben als Ziel. Ausbeuten der Menschen bis zum Letzten. Soziales Engagement als Feigenblatt nach aussen, zugegebenermaßen auch dieses Effizient. Dieses alles in einem geschickt ausgeklügelten System der Unterordnung, Bespitzelung und drakonischen Selbstverwaltung nach innen. Das schablonenhaft wiederholte Wort >lch bin hier gern, ich bin hier frei, ich will niemals von hier fort ‘ begegnet dem Besucher bei jedem Gespräch. Die dargestellte Freiwilligkeit der Einordnung und Unterordnung sind eine Schutzmauer für den Leitenden. Wie reisst man diese Mauer ein? Wie kommt man an die Persönlichkeit der Menschen, die keine Persönlichkeit mehr haben? Auf dieses Thema angesprochen antwortet Schäfer unverblümt: Hier geht es um Sieg oder Niederlage. Ich setze auf Sieg. [...] Dieser Mann geht nicht unter. Das steht fest. $\ll^{188}$

Aus den Worten von Kullak-Ublick sprach eine Betroffenheit über das aus erster Hand Erlebte. Er schlug häufige und regelmäßige Besuche der Botschaft in der CD vor. Gleichzeitig solle das AA eine Delegation in die CD schicken, der neben Diplomat_innen auch ein Arzt - am besten ein Psychiater - und ein Vertreter der Staatsanwaltschaft angehören solle. Von der Zusammensetzung solle aber niemand wissen, offiziell müsse alles als Delegation des AA firmieren. Der Auftrag der Delegation wäre, so Kullak-Ublick,

»zu formulieren, über welche Normen der internationalen Menschenrechtsprinzipien vorgegangen werden kann, verbunden mit der Tatsache, dass 300 betrogene deutsche Staatsangehörige als Arbeitsinstrumente in einem Arbeitslager gehalten werden, wobei jeder von ihnen auf die Freiwilligkeit seines Daseins verweisen wird. Das Resu- 
mé wäre dann ein Dokument, dass der chilenischen Seite mit der Forderung zum Einschreiten übergeben wird. [...] Dieses Procedere kann nur zum Erfolg führen, wenn es diskret und ohne Öffentlichkeit durchgeführt wird. Wenn uns das Schicksal der 300 Menschen am Herzen liegt, für die als Landsleute wir alle Mitverantwortung tragen, dann darf dieses Thema nicht zu politischen Zwecken instrumentalisiert werden. ${ }^{189}$

Der Verweis auf internationale Menschenrechtsprinzipien war für die bundesdeutsche Diplomatie im Fall CD ein Novum. Kullak-Ublick bot sich an, der anvisierten Delegation vor ihrer Abreise in Bonn zu berichten, um all das $\mathrm{zu}$ »berichten, was schriftlich gar nicht festzuhalten ist. Es ist der Bericht aus einem Geisterhaus. « 190

Auch die anderen Beamten, die an dem Konsularsprechtag teilgenommen hatten, fertigten detaillierte Berichte an. Sie zeigten sich gleichermaßen erschüttert und bemühten NS-Vergleiche, um ihre Eindrücke in Worte zu fassen. Konsul Haller berichtete:

»Die Chormitglieder machen den Eindruck von starren, konditionierten sSingrobotern . Die ausdruckslose Leere ihrer Cesichter, zuweilen auch die unverkennbare Traurigkeit, lassen darauf schließen, daß ihre Lieder nicht in einem ungezwungenen Singspiel eingeübt, sondern ihnen eher mit lautem Peitschenknall eingebläut werden. Der Vortrag des Chores, das steife Herausschmettern russischer und italienischer Melodien erschreckt. Es erweckt auch Vermutungen: So muß Theresienstadt gewesen sein - mit einem Unterschied: Nach dem Musikvortrag war es damals den jüdischen Mitbürgern wohl gestattet, sich gegenseitig auszutauschen oder sich gegenseitig anzuvertrauen. Dies ist in CD verboten. ${ }^{191}$

Botschaftsmitarbeiter Filusch merkte in seinem Bericht an: »Besonders die älteren Krankenschwestern machten auf mich den Eindruck: So muß eine BDM-Führerin ausgesehen haben. ${ }^{192}$ Bei dem Konsularsprechtag beglaubigten die Beamten eine Reihe von Schriftstücken, die ihnen von Colonos vorgelegt wurden, vermutlich um sie bei juristischen Verfahren einzureichen. Die neun in der CD verbliebenen Kinder von Hugo und Waltraud Baar legten Filusch eine eidesstattliche Erklärung vor, die Filusch beglaubigte. Darin hieß es:

»Es ist mein eigener und persönlicher Wunsch und Wille als aktives Mitglied der SBED auf ihrem Landgut zu arbeiten und zu leben. Ich bin von niemandem gezwungen wor-

189 Ebd.

190 Ebd. Kullak-Ublick hatte den Bericht als »Verschlusssache - Vertraulich « eingestuft und als Prolog geschrieben: „Die Geheimhaltung dieses Berichts und der daraus folgenden Konsequenzen ist eine absolute Voraussetzung für unser weiteres Handeln. Ich bitte, dass Inhalt auch im Hause restriktiv behandelt wird.«Trotzdem erhielt der Spiegel, allerdings erst einige Jahre später davon Kenntnis und berichtete darüber: Der Spiegel Nr. 44/1991 vom 25.11.1991, S. 67-69. »Aus einem Geisterhaus«.

191 PA AA, AV NA 31583. Bericht Konsul Haller zum Konsularsprechtag in der CD am 7.11.1987, GZ: RK 543.00. Anlage zum Bericht 1126/87 vom 11.11.1987 der Botschaft Santiago.

192 PA AA, AV NA 31583. Vermerk Filusch über den Konsularsprechtag in der CD am 07.11.1987. 
den an diesem Ort zu bleiben, den ich als mein Zuhause ansehe, und die Menschen, die hier leben, betrachte ich als meine Familie. ${ }^{193}$

Der Konsularsprechtag vom 7. November symbolisiert die allmähliche Sensibilisierung der bundesdeutschen Diplomatie für den Fall CD. Die persönliche Konfrontation mit den tatsächlichen Zuständen innerhalb der Siedlung schienen den anwesenden Botschaftsangehörigen die Augen geöffnet und jegliche noch bestehenden Zweifel über den tatsächlichen Charakter der CD ausgeräumt zu haben. Die bisherige Haltung, Paul Schäfer als Einzeltäter zu charakterisieren, die CD ansonsten aber nicht anzutasten und als sinnvolle, wohltätige Initiative zu behandeln, schien sich nun erledigt zu haben. Nun schien auch die Botschaft motiviert, tatsächlich zu handeln, um schwere Menschenrechtsverletzungen zumindest zukünftig zu verhindern. Doch die Handlungsansätze der Botschaft blieben zunächst unverändert. Sie beruhten weiterhin auf der unbegründeten und schon oft enttäuschten Hoffnung, man könne die Vertreter_innen der chilenischen Diktatur still und heimlich - also ohne große Öffentlichkeit und die damit einhergehende Desavouierung des Regimes - überzeugen, die Verbrechen abzustellen und aufzuarbeiten.

Selbst Mitglieder der Bundesregierung fragten sich nun auch, über welche Kenntnisse der BND zur CD verfügte. Nach seinem Besuch in Chile erkundigte sich CDUGeneralsekretär Heiner Geißler bei Hans-Georg Wieck, Präsident des BND, nach Erkenntnissen zur CD. Wiecks Antwort besteht im Wesentlichen aus einer Auswertung von Presseartikeln. ${ }^{194}$ Der Blick des BND unterschied sich offenbar nicht groß von jenem, den das AA jahrelang gepflegt hatte. Über die CD heißt es: »Die Lebensformen dieser Gemeinschaft sind eigentümlich und mögen im Einzelfall gegen strafrechtliche Tatbestände verstoßen, gehen jedoch im Grunde kaum über das beispielsweise auch über manche der sogenannten >Jugendsekten< Bekannte oder Vermutete hinaus. « ${ }^{195}$ Zur Haltung des BND schrieb Wieck in seinem Anschreiben an Geißler:

»Wir sind natürlich auch bemüht, in Chile aufzuklären und unterhalten lose Verbindungen zu den dortigen Diensten. Es befindet sich aber kein ständiger Verbindungsmann dort. Jüngst hat es wohl zwischen einem meiner Männer und dem Verteidigungsattaché eine etwas kontroverse Diskussion gegeben. Das sollte man nicht überbewerten. ${ }^{196}$

Um welche kontroverse Diskussion es sich dabei handelte ist mir nicht bekannt. Allerdings kam es anscheinend zu einem Disput zwischen bundesdeutschen Behördenmitgliedern, die in ihrer Wahrnehmung der CD scheinbar nicht mehr auf einer Linie lagen.

Geißler war mit der Auskunft offenbar nicht zufrieden. Er hakte mit einem weiteren Fragenkatalog nach, über den der BND intern kommunizierte:

PA AA, AV NA 31577. Beglaubigte Erklärung der Geschwister Baar vom 07.11.1987.

BArch, B 206. Schreiben von Wieck an Geißler vom 07.12.1987. 1. Anlage zu Tagebuch Nr. 1205/87. Das als vertrauliche Verschlusssache (VS-V) eingestufte Schreiben gehört zu den insgesamt elf Seiten (sic!) CD-Akten, die der BND bislang deklassifiziert und ans Bundesarchiv abgegeben hat. BArch, B 206. Schreiben von Wieck an Geißler vom 07.12.1987. 1. Anlage zu TCB Nr. 1205/87. Ebd. 
»Die Beantwortung der vorgelegten Fragen erfolgt im Wesentlichen aufgrund von offenem Material sowie von Hinweisen der PD ADLER und FARN, die jedoch ihrerseits ebenfalls fast ausschließlich auf offenes Material zurück gehen. Weitere Erkenntnisse sind allenfalls durch gezielten Einsatz nachrichtendienstlicher Mittel in Chile selbst zu erlangen; eine Einschaltung von PD CHINCHILLA ist nach hiesiger Beurteilung aufgrund der politischen Dimension der Angelegenheit nicht opportun. ${ }^{197}$

Bei »ADLER«, »FARN« und »CHINCHILLA« handelt es sich augenscheinlich um Decknamen von BND-Mitarbeiter_innen oder -quellen. Bei »Adler« handelt es sich womöglich um Klaus Barbie. ${ }^{198}$ Dieser lebte bis zu seiner Auslieferung nach Frankreich 1983 in Bolivien.

Dass der BND zur CD ausschließlich »offenes Material«, also Medienberichte und dergleichen auswertete, erscheint angesichts anderer Quellen wenig plausibel. So schreibt etwa Dinges, DINA-Agenten hätten 1975 in der Bundesrepublik über die Vermittlung durch Colonos Kontakt zum BND aufgenommen. ${ }^{199}$ Gerhard Mertins, den der BND unter dem Decknamen Uranus mehrere Jahre lang als Quelle führte, ${ }^{200}$ gab 1989 an, die CD Anfang der 1970er Jahre im Auftrag von »entsprechenden deutschen Dienststellen « besucht zu haben. ${ }^{201}$ Günter Wasserberg, Leiter des Referats 512 des AA und 1963 der erste bundesdeutsche Diplomat, der die CD besuchte, ${ }^{202}$ sprach Mertins 1987 auf seine Tätigkeit für den BND an (vgl. hierzu auch Abschnitt 4.2.2). Er vermerkte dazu, Mertins habe nach eigenen Angaben seit Ende der 1960er Jahre im Rahmen eines Auftrags des BND mehrmals die CD besucht und darüber dem BND berichtet. Er habe festgestellt und berichtet »daß sämtliche gegen die Kolonie schon damals erhobenen Vorwürfe unzutreffend seien. ${ }^{203}$ Wasserberg hielt es für »durchaus möglich, daß Herr Mertins [...] vom BND einen entsprechenden Auftrag hatte und diesen unzutreffend unterrichtet hat. ${ }^{204}$ Er regte an, »daß Referat 330, falls noch nicht geschehen, diese Frage mit dem BND aufnimmt. ${ }^{205}$

Für den erwähnten Kontakt zwischen AA und BND gibt es in den mir vorliegenden Akten keine Anzeichen. Sollten Mertins Angaben stimmen, gibt es jedoch beim BND zahlreiche Akten zur CD, die noch nicht freigegeben wurden.

Im Dezember 1987 ordnete Außenminister Genscher die bereits zuvor erörterte Entsendung einer Sachverständigenkommission in die CD an. Diese Entscheidung teilte das AA dem chilenischen Botschafter in Bonn bei einem Gespräch am 7. Dezember mit. Botschafter Riesco reagierte ablehnend und äußerte sein Unverständnis über das Vorgehen der Bundesregierung, an dem sich die chilenische Regierung nicht beteiligen werde. Das AA berichtete der Botschaft zu Riescos Haltung:

BArch, B 206. Schreiben Saalfeld (Leiter Referat 32H des BND) an 90 AC (BND) vom 28.12.1987. 
»Man müsse die Frage stellen, warum das AA auf einem Weg, der keinen Erfolg verspreche, beharrt. Der richtige Weg wäre gewesen, der chilenischen Regierung die Berichte von Baar und Packmor zu übergeben und einen Antrag auf Untersuchung zu stellen. Auch die chilenische Regierung sei an einer Aufklärung der Vorwürfe interessiert. Dies aber nur über chilenische Stellen. Ceneral Stange habe ihm gesagt, er habe nie verstanden, warum Botschafter Holzheimer seinerzeit nach dem Cespräch mit ihm nicht seiner Anregung gefolgt sei und einen schriftlichen Antrag auf Untersuchung von $C D$ durch die chilenischen Behörden gestellt habe. Mit der Entsendung einer Kommission sei das Problem nicht zu lösen. Seit 1981 sei der Bundesregierung bekannt, dass eine deutsche Untersuchungskommission in Chile nicht tätig werden könne. Der Botschafter sagte dann, die chilenische Regierung werde schon deswegen keine besonderen Anstrengungen unternehmen, weil die Besuche von BM Blüm und Ceneralsekretär Geissler die deutsch-chilenischen Beziehungen außerordentlich strapaziert hätten.«06

Reinhardt Schlagintweit, Leiter der Politischen Abteilung des AA, beharrte gegenüber dem chilenischen Botschafter auf der Delegation. Sollte diese scheitern, so habe dies Auswirkungen auf das Ansehen der chilenischen Regierung:

»Eine rasche Aufklärung liege im Interesse beider Seiten. Wenn in CD etwas passiere oder wenn Verantwortliche sich absetzten und dann dunkle Verhältnisse an die Öffentlichkeit dringen, würden die chilenischen Behörden in die Verantwortung gezogen. Würde die deutsche Gruppe jetzt unverrichteter Dinge zurückkehren, so würde man nicht nur auf die Richtigkeit der gegen CD vorliegenden Anschuldigungen schließen, sondern man würde das auch als Komplizenschaft chilenischer Behörden auslegen. Er, D3 [Kürzel für den Leiter der Politischen Abteilung des AA, JS], sei sicher, daß die chilenischen Behörden die Möglichkeit hätten, auf geeignetem Weg auf die CD einzuwirken, damit diese ihre Tore nicht verschließe. ${ }^{207}$

Trotz der deutlichen Ankündigung, dass es keinerlei Unterstützung durch die chilenische Regierung geben würde, hielt das AA an der Entsendung der Delegation fest. Außenminister Genscher bat seinen Amtskollegen García, die Reise der Sachverständigenkommission zu bestätigen. Der Staatssekretär im chilenischen Außenministerium antwortete darauf, man halte die Delegation »aus unabhängigen Persönlichkeiten für sinnvoll«, sehe aber »keine Notwendigkeit zur Beteiligung «. ${ }^{208}$

Die achtköpfige Delegation ${ }^{209}$ mit hochrangigen Vertreter_innen von AA und BMJ sowie einem Polizeipsychologen und einem Bischof hielt sich vom 13. bis 19. Dezem-

206 PA AA, AV NA 31577. DE 268 vom 8.12.1987, GZ 330-504.00.

207 Ebd.

208 PA AA, AV NA 31577. DB 475, RK 543.00 vom 10.12.1987.

209 PA AA, AV NA 31582. Teilnehmerliste der Sonderkommission betreffend Colonia Dignidad, o. D. Die Delegation setzte sich demnach zusammen aus: Johannes Marré, Botschafter a. D., Leiter der Kommission; Emil Stehle, Weihbischof; Wolfgang Salewski, Leiter des Instituts für Konfliktforschung; Jasper Osterloh, DRK Hannover; Gerrit Stein, BM]; OStA Lothar Sent, Justizministerium NRW; Reinhard Schlagintweit, AA sowie LR I Michael Gerdts, AA. 
ber 1987 in Chile auf. ${ }^{210}$ Als die Delegation bereits in Chile war, schrieb Außenminister García Genscher: Falls durch »entsprechende Nachforschungen die Existenz von Handlungen kriminellen Charakters nachgewiesen« würde, so müsse dies »der chilenischen Justiz zur Kenntnis gebracht werden «. ${ }^{211}$ Dies war ein abgekartetes Spiel: Die chilenische Regierung unterstützte die Delegation nicht, wohl wissend, dass diese keinerlei Hoheitsrechte besaß und daher zum Scheitern verurteilt war. Auf sich allein gestellt konnte ein Kräftemessen zwischen der Delegation und der CD mit ihren Anwälten nur zugunsten der $\mathrm{CD}$ ausgehen.

In der Tat hatte die CD juristisch und medial alles in Bewegung gesetzt, um das aus ihrer Sicht widerrechtliche Tätigwerden einer fremden Regierung in Chile zu verhindern. Einen Tag bevor die Delegation in Chile eintraf, teilte Hartmut Hopp Botschafter Kullak-Ublick bei einem Treffen mit, dass die CD beschlossen habe, die Delegation nicht zu empfangen. Hopp begründete dies mit der Darstellung des Konsularsprechtags in den deutschen Medien. Diese habe jegliche Vertrauensgrundlage zerstört. Das AA beschloss, sich über die Absage der CD hinwegzusetzen, um nicht schon im Vorhinein den Eindruck eines Scheiterns der Delegation zu erwecken. Botschafter Kullak-Ublick und Bischof Stehle flogen mit einem Hubschrauber zur CD. Dieser wurde von einem chilenischen Polizeigeneral gesteuert, der General Stange nahestand und über Kontakte zur CD verfügte. Was dann passierte, schildert die Sachverständigenkommission in einem späteren Bericht so:

»Beim Anflug stellte die Besatzung fest, daß die Piste von Fahrzeugen blockiert war. Auch der Hubschrauberlandeplatz war durch zwei Fahrzeuge und, in lebensgefährdender Weise, durch Papplatten unbrauchbar gemacht worden. Dennoch gelang die Landung. Herr Hopp stand vor dem Cebäude und erklärte, eine weitere Mitgliederversammlung habe letzte Nacht um 2.00 Uhr beschlossen, auch dieser Delegation den Zutritt zu verwehren. Es wurde ihr nicht erlaubt, einen Rundgang zu machen oder eines der Gebäude zu betreten. Hopp drohte dem chilenischen Ceneral, er werde wegen Hausfriedensbruch sabgesetzt . Die Gruppe kehrte am gleichen Nachmittag nach Santiago zurück. ${ }^{212}$

Die Delegation war brüskiert und erschrocken darüber, dass die CD entschlossen war, ihren Besuch sogar mit Maßnahmen zu verhindern, die für Passagiere des Hubschraubers lebensgefährlich waren. Am nächsten Tag traf sich die Delegation mit Außenminister García, der vorgab, der gesamten Delegation nun doch einen Besuch der CD ermöglichen zu wollen. Gleichzeitig stellte die CD bei der CA Chillán einen Schutzantrag, um den Besuch der Delegation zu verhindern. Zwei Tage später teilte García Botschafter Kullak-Ublick mit, er habe »Bemühungen unternommen, um eine Änderung der Einstellung der Führung von $\mathrm{CD}$ zu erreichen«, aber »nichts bewirkt «. ${ }^{213}$ García ver-

210 PA AA, AV NA 31637. Abschlussbericht der Sachverständigendelegation über ihren ChileAufenthalt, o. D. [Vermutlich Ende 1987/Anfang 1988].

211 Ebd.

212 Ebd. Die Darstellung dieses Vorgangs durch die CD findet sich im CD-Geheimarchiv, Ficha Carlos Enrique Menne Backmann. 
wies auf die CD-Führung, die auf den Rechtsweg pochte und sah seine Bemühungen als gescheitert an. Die Delegation reiste daraufhin fünf Tage nach ihrer Ankunft unverrichteter Dinge wieder ab. In ihrem Abschlussbericht versuchte sie den Misserfolg zu kaschieren. Ihr Besuch habe bei der chilenischen Regierung »Prozesse ausgelöst, die eine sehr viel kritischere Betrachtung und wohl auch die Behandlung des Problems CD nach sich zogen. ${ }^{214}$ Des Weiteren versuchte sich die Kommission an einer Reform der CD. Es ginge darum,

»den Einfluß von Paul Schäfer zu neutralisieren. Dabei ist zu berücksichtigen, daß $C D$ im Falle eines Gelingens sofort eine neue Führungspersönlichkeit entwickeln oder von außen bestellt bekommen müßte. Für diesen Prozeß kommt das vorhandene Führungspersonal der zweiten Ebene infrage, da es sich um relativ einfache Leute handelt, die führbar sind. ${ }^{215}$

Einzig Konsul Haller widersprach dieser Handlungsempfehlung und verfasste eine eigene Stellungnahme. ${ }^{216}$ Darin stellte er fest, dass die Botschaft es für ausgeschlossen halte, dass der Einfluss von Paul Schäfer neutralisiert werden könne, solange er weiter in der CD lebe. Ziel müsse es daher sein, Schäfer durch Inhaftierung oder Abschiebung aus der CD zu entfernen. Auch die weiteren Führungsmitglieder seien nicht geeignet, die Siedlung zu leiten. Eine Abschiebung Schäfers könne im Interesse der chilenischen Regierung liegen, wenn ihr klar würde, dass Schäfer und die CD eine Belastung für die chilenisch-deutschen Beziehungen darstellen. Haller schrieb, er sehe die politischen Rahmenbedingungen 1988 hierfür als günstig an: Das geplante Plebiszit über die Fortsetzung der Diktatur werde zu innenpolitischen Spannungen führen, weshalb sich der Druck aus dem Ausland auf die Diktatur verstärken werde. Als Strategie gegenüber der chilenischen Regierung und der Öffentlichkeit schlug Haller vor: »unser Interesse an der Situation der Deutschen in CD, die Unhaltbarkeit der dortigen Lebensverhältnisse sowie unser Nicht-Interesse am DINA-Komplex zu verdeutlichen. « ${ }^{217}$

Während die deutsche Diplomatie die Verbindungen zwischen CD und DINA öffentlich noch immer nicht thematisieren wollte, bestätigte sie in privaten Gesprächen, dass sie über ein breites Wissen hierüber verfügte. In einem privaten Schreiben Hallers an den SPD-Abgeordneten Waltemathe vom Juli 1988 etwa heißt es:

»Wir kämpfen, wie Sie wissen, in Sachen CD gegen einen >übermächtigen Gegner«. Unter den gegebenen politischen Rahmenbedingungen blieb uns zunächst nur der justitielle Weg. Wir dürfen eines nicht vergessen - und in diesem Punkt gibt es für mich keine Zweifel mehr - Schäfer hat mit der DINA, zuvor mit `Patria y Libertad ‘ zusammengearbeitet. Er war offenbar aktiv mit seinen Mannen an der Verfolgung von Regimegegnern beteiligt. Nachdem ich Schäfer am 7. November 1987 persönlich erlebt

215 PA AA, AV NA 31593. Abschlussbericht der Sachverständigenkommission, Teil IV »Empfehlungen« [Auszug], o. D. PA AA, AV NA 31593. Vermerk von Konsul Haller vom 11.02.1988, GZ: RK 543. Stellungnahme zu den Empfehlungen der Sachverständigenkommission. 
habe, traue ich ihm auch jedwede Scheußlichkeit zu. Jeder bisherige, auch von anderer Seite unternommene Versuch, die DINA-Aktivitäten aufzudecken bzw. den Unterdrückungsapparat zu entmanteln, wurde stets vom militärischen Establishment abgewürgt. Und was dann noch von ziviler Seite notwendig war, besorgte Justizminister Rosende - einer der größten Falken des Regimes. Dennoch bin ich insgesamt optimistisch. ${ }^{218}$

Während Botschaftsangehörige solche Privatdienstschreiben im Kontext des Themas CD bis dorthin ausschließlich an konservative Politiker oder Persönlichkeiten gerichtet hatten, ist dieser Brief eines der ersten mir bekannten vertrauensvoll formulierten Schreiben eines Diplomaten an einen Politiker, der dem aufklärerischen Lager zugerechnet werden kann.

Nur zwei Tage nach der Abreise der Kommission veröffentlichte die regierungstreue Zeitung El Mercurio eine Reportage mit dem Titel »Lo que no pudo ver la Comisión«. Sie zeigte bunte Bilder glücklicher Colonos bei der Arbeit und beim Musizieren. ${ }^{219}$ Für die Bundesregierung war die ergebnislose Abreise der Kommission eine Niederlage, die sie allerdings in Kauf nahm, um sich nicht öffentlich dem Vorwurf der Tatenlosigkeit aussetzen zu müssen. Für die CD war das Scheitern der Delegation eine Machtdemonstration. Die chilenische Regierung hatte ihre unbedingte Loyalität zu CD bewiesen. Dabei war dies für die chilenische Diktatur nicht ohne Risiken: Noch während die Sachverständigenkommission in Chile weilte, entschied die Bundesregierung als Mitglied der Weltbank mit über die Gewährung eines Kredits an Chile in Höhe von 250 Millionen US-Dollar. Dies brachten auch Medien in Verbindung mit dem Fall CD. ${ }^{220}$ CDU-Generalsekretär Geißler empfahl sogar, die Entscheidung über den Kredit erst nach dem geplanten Plebiszit 1988 zu treffen. ${ }^{221}$ Letztlich wurde der Kredit gewährt auch mit der Stimme der Bundesregierung - noch während die Sachverständigenkommission sich um Zugang zur CD bemühte. Laut Medienberichten hatte Bundeskanzler Kohl dies im Kabinett durchgesetzt, obwohl sich Arbeitsminister Blüm und das Auswärtige Amt für eine Verschiebung des Kredits eingesetzt hatten. ${ }^{222}$

\subsubsection{8-1990: Der ergebnislose Einsatz Genschers}

Aufgrund der Brüskierung durch die CD und des öffentlichen Aufsehens in der Bundesrepublik durch die gescheiterte Delegation entschied sich Genscher, den Fall CD im AA nun zur Chefsache zu machen. Dem Minister erschienen konkrete Maßnahmen zur Abstellung der Verbrechen der CD nun unumgänglich. Der Zeitraum von Ende 1987 bis

218 AdsD, Nachlass Ernst Waltemathe. Ordner 27. Schreiben Konsul Haller an Waltemathe vom 18.07.1988.

219 El Mercurio vom 20.12.1987, S. D4f. »Lo que no pudo ver la Comisión.«.

220 El Mercurio vom 08.12.1987, S. C11. »Investigación en Colonia Dignidad es asunto alemán«.

221 Der Spiegel Nr. 50/1987 vom 07.12.1987, S. 48f. »Blow up«. Online unter: https://magazin.spiegel.d e/EpubDelivery/spiegel/pdf/13524874

222 Wiedemann, Charlotte, »Kohl gibt Chiles Diktator Pinochet Kredit«, in: die tageszeitung vom 17.12.1987, S. 1, 3, online unter https://taz.de/!1855838/. Der Artikel merkt an, das AA habe sich gegen die Bewilligung des Kredits ausgesprochen, obwohl es sich im Vorjahr noch für die Vergabe eines ähnlichen Darlehens eingesetzt habe. 
Ende 1989 ist die einzige Periode in der langen Geschichte des Falls CD, in der das Thema über längere Zeit von einem bundesdeutschen Außenminister persönlich verhandelt wurde.

Anfang 1988 schien ein Ende der Diktatur greifbar. Die von der Junta erlassene Verfassung von 1980 hatte für 1988 ein Plebiszit vorgesehen. Eigentlich sollte es dabei nur um eine weitere Amtszeit für den von der Militärjunta vorgeschlagenen Präsidentschaftskandidaten gehen. ${ }^{223}$ Die Abstimmung war für den 5. Oktober 1988 angesetzt. Seit der Wirtschaftskrise 1983 hatte sich die linke Opposition - die von der brutalen Repression vor allem durch die DINA weitgehend zerschlagen worden war - erstmals wieder getraut, ihren Protest gegen die Diktatur auf die Straße zu tragen. Die Militärregierung geriet immer weiter unter Druck, die in der Verfassung vorgesehene Abstimmung tatsächlich durchzuführen - und zugleich zu erklären, wie eine Rückkehr zu einem demokratisch legitimierten Staatswesen aussehen solle. Die offizielle Rechtfertigung für den Putsch 1973 war stets gewesen, dass die Militärregierung nur eine kurzfristige Unterbrechung der demokratischen Tradition Chiles darstelle, um Allendes vermeintlichen marxistischen Irrweg zu korrigieren und Chile zurück auf den Weg der westlichen Marktwirtschaft zu führen. 1987 gab die Kommunistische Partei ihre aufstandsorientierte Strategie (rebelión popular de masas) auf und setzte fortan auf eine politische Lösung zur Beendigung der Diktatur. Die Sozialistische Partei wandte sich allmählich vom sozialistischen Gedankengut Allendes ab und wandte sich sozialdemokratischen Ideen zu. Regierungen »westlicher« Staaten wie die der USA oder der Bundesrepublik unterstützten in dieser Konstellation zunehmend gemäßigte Kräfte, die einen mit der Militärregierung auszuhandelnden Übergang zur Demokratie anstrebten. Gleichzeitig sollten die KP und zahlreiche Kräfte geschwächt werden, die weiterhin auf einen Bruch mit der Diktatur (ruptura) hinwirkten, wie eine Reihe bewaffneter Bewegungen. ${ }^{224}$

Mit dem Plebiszit war nun das wahrscheinliche Ende der Diktatur absehbar. Damit - so die Hoffnung der bundesdeutschen Diplomatie - würde auch der Schutz für die CD durch höchste chilenische Kreise rasch schwinden. Allerdings ignorierte diese Hoffnung, dass bei einem - auch von der Bundesregierung unterstützten - ausgehandelten Übergang die bisherigen Machthaber niemals zu einem vollständigen Machtverzicht bereit sein würden. Der faktische Fortbestand der Macht der Junta sollte sich als größtes Hindernis für die Aufarbeitung von Menschenrechtsverbrechen erweisen.

Einige Wochen nach dem Scheitern der Hubschrauber-Delegation kam es am 22. Februar 1988 im Bundestag zu einem Show-down von Gegner_innen und Befürworter_innen der CD: Der frisch installierte Unterausschuss für Menschenrechte und humanitäre Hilfe veranstaltete eine öffentliche Anhörung zur Frage: »Befinden sich deutsche Staatsangehörige unfreiwillig und unter menschenrechtsverletzenden Bedingungen in der Colonia Dignidad in Chile?« Hartmut Hopp, der nach Zusicherung freien Geleits angereist war, verkündete, dass sich sämtliche Colonos freiwillig in der CD befänden

223 Ruderer, Stephan. Das Erbe Pinochets. Vergangenheitspolitik und Demokratisierung in Chile 19902006, Göttingen 2020, S. 80ff.

224 Zum Beispiel die Frente Patriótico Manuel Rodríguez (FPMR), das Movimiento Juvenil Lautaro $(M J L)$ und einige aus der Movimiento de Izquierda Revolucionaria (MIR) hervorgegangene Gruppierungen. 
und bezichtigte die aufklärerischen Akteur_innen, darunter die ebenfalls Anwesenden geflüchteten Ex-Colonos Wolfgang Kneese, Georg und Lotti Packmor sowie Hugo Baar der Verleumdung. Nach der Anhörung wurden die Ermittlungen der Staatsanwaltschaft Bonn auf Hartmut Hopp, Gisela Seewald und Hugo Baar ausgeweitet. Darauf reagierte die CD wiederum mit einer Zivilklage gegen Hugo Baar.

Außenminister Genscher versuchte nun, Druck auf den chilenischen Staat auszuüben, um diesen dazu zu bewegen, eigene Untersuchungen gegen die CD einzuleiten, zumindest um die Vorwürfe der Freiheitsberaubung gegen deutsche Staatsangehörige aufzuklären. Jedoch scheute sich das AA weiterhin, selbst Strafanzeigen in Chile zu stellen oder den anzeigewilligen aus der CD Geflüchteten (Hugo Baar und Lotti und Georg Packmor) die von ihnen geforderten Garantien zu gewähren.

Im Januar 1988 bat Genscher erstmals seinen chilenischen Amtskollegen García um Aufnahme einer Untersuchung. Als Grundlage sollten die Baar- und Packmor-Berichte sowie Vernehmungsprotokolle aus dem Ermittlungsverfahren der StA Bonn dienen. Die CA Chillán lehnte eine solche Untersuchung im April 1988 aus formalen Gründen ab. Die $\mathrm{CD}$ antwortete mit Dienstaufsichtsbeschwerden und Schutzanträgen gegen deutsche Diplomaten. ${ }^{225}$

Im April 1988 versuchte der Colono Jürgen Szurgelies aus der CD zu fliehen. Die Botschaft stellte daraufhin erstmals einen Schutzantrag zugunsten des geflüchteten Colonos. ${ }^{226}$ Die CD antwortete wiederum mit einem Schutzantrag gegen den beantragenden Botschaftsrat Spohn. Die Corte Suprema wies den Antrag der Botschaft mit Verweis auf Szurgelies' chilenische Staatsangehörigkeit ab. Gleichzeitig gab sie den Anträgen der CD gegen Kriegler und Spohn statt. ${ }^{227}$ Damit erkannte sie den beiden Botschaftsangehörigen de facto ihre diplomatische Immunität $a b$. Botschafter Günter Knackstedt - der kurz zuvor Kullak-Ublick abgelöst hatte ${ }^{228}$ - berichtete dazu im Juli 1988 ans AA:

»]e seltsamer die Rechtsprechung der Corte Suprema in den beiden Fällen zu bewerten ist, desto klarer wird, dass die Urteile nur politisch zu erklären sind. Die Urteile signalisieren, dass die CD stärker als die deutschen Diplomaten ist und nicht einmal das Institut der diplomatischen Immunität sie vor Angriffen der CD schützt, wenn sie die $C D$ sangreifen $<$ Darin liegt eine Warnung an alle, die in CD eventuell Fluchtgedanken

225 Neben mehrfachen Dienstaufsichtsbeschwerden gegen Konsul Haller, stellte sie am 30. März 1988 einen Schutzantrag gegen den deutschen Konsul in Concepción, Horst Kriegler ein. Dieser hatte in einem Presseinterview geäußert, in der CD würden möglicherweise bundesdeutsche Staatsangehörige in ihren persönlichen Freiheiten verletzt. Zu den von der CD gegen Konsul Kriegler vorgebrachten juristischen Schritten vgl. div. Dokumente in: PA AA, AV NA 31681 und PA AA, AV NA 31584.

226 Zu dem von Botschaftsrat Spohn gestellten Schutzantrag zugunsten von Jürgen Szurgelies vgl. PA AA, AV NA 31682.

227 Lauterpacht, E./Greenwood, C. J. (Hg.) International Law Reports, Vol 89, Cambridge, 1992, S. 48ff., $60 f f$.

228 Botschafter Kullak-Ublick verließ den Posten nach weniger als zwei Jahren vorzeitig. Er soll aufgrund eines Augenleidens um seine Versetzung in den vorzeitigen Ruhestand gebeten haben. Der Spiegel Nr. 18/1988 vom 02.05.1988, S. 260. »Berufliches - Cünther Knackstedt«, online unter http s://magazin.spiegel.de/EpubDelivery/spiegel/pdf/13527844. 
hegen, an die Nachbargelände der CD, Flüchtlingen nicht zu helfen, an alle ev. Zeugen und sonstige Personen, die sich gegen CD wenden (z.B. Kuhn). Alle müssen mit z.B. Verleumdungsklagen rechnen (diese Erfahrung machten bereits Müller/Kneese 1966 und Al/Stern). Das Urteil fordert nicht nur die deutsch-chilenischen Beziehungen, sondern auch die Völkerrechtsgemeinschaft heraus. « ${ }^{229}$

Am 29. Juli 1988 fand hierzu eine Besprechung in Genschers Büro in Bonn statt. ${ }^{230}$ In deren Ergebnis schrieb der Minister seinem Amtskollegen García, dass die Urteile gegen Spohn und Kriegler aus Sicht des AA Verstöße gegen internationales Recht und die Wiener Konvention darstellten. Bisher habe die Bundesrepublik diesbezüglich noch keinerlei Maßnahmen eingeleitet. Allerdings erwarte man nun eine klare Positionierung der chilenischen Regierung zum Schutze der bundesdeutschen Diplomaten und ihrer Arbeit. Weiter schrieb Genscher:

»Todo impedimiento o perjuicio a la labor de nuestras representaciones en Chile viene necesariamente en detrimento de la calidad de nuestras relaciones.

Independientemente de lo anterior le ruego no deje de prestar atencion al problema propiamente dicho, a saber, la suerte de los ciudadanos alemanes y chileno-alemanes que viven en la Colonia Dignidad. Cabe recordar aquí el caso de un jóven, en posesión tanto de la nacionalidad alemana como de la chilena, quien hace escasas semanas trató de abandonar la Colonia. Poco después, evidentemente en contra de su voluntad, fue devuelto al fundo. ${ }^{231}$

Der Hinweis, dass die Rückverbringung von Jürgen Szurgelies in die CD nach seiner Flucht eine offensichtliche Freiheitsberaubung darstellte, war deutlich.

Am 6. August 1988 wurde Paul Schäfer von der Parraler Richterin Lydia Villagrán im CD-Krankenhaus vernommen. Die Vernehmung fand im Rahmen eines Rechtshilfeersuchens des LG Bonn statt (vgl. Abschnitt 5.3.1). Die Botschaft berichtete dazu nach Bonn:

»Vernehmungen haben insgesamt keine neuen Sachverhalte zu Tage gefördert. Ausnahme: Eingeständnis des CD-Leitungsmitglieds Albert Schreiber, dass der sogenannte Kapuzenmann Munoz Alarcon (ihm wird die Identifizierung von zahlreichen im Nationalstadium nach dem Putsch von 1973 gefangengehaltenen politischen Häftlingen zur Last gelegt) sich im Frühjahr 1973 im CD-Lager aufgehalten habe. Sowohl Schmidt als auch Schäfer leugneten jeden Kontakt oder gar Zusammenarbeit mit dem chilenischen Geheimdienst DINA. Schäfer habe sogar zu Protokoll gegeben, dass er von der DINA nur aus der chilenischen Presse gehört habe. [...] Die eigentliche Bedeutung dieser neuen Runde in der Auseinandersetzung zwischen CD und Al liegt in der Tatsache, dass Paul Schäfer zum ersten Mal in der 26-jährigen CD-Ceschichte in Chile gezwungen wurde, vor einem chilenischen Cericht auszusagen. Die Einlassungen von Albert

229 PA AA, AV NA 31583. DB 363 vom 22.07.1988, CZ: pol-rk 543.00.

230 PA AA, AV NA 31582, DE 198 vom 29.07.1988, GZ: 330-504.00. Betr.: Urteile des chil. Obersten Gerichts gegen Spohn und Kriegler.

231 PA AA, AV NA 31582. DE 201 vom 01.08.1988, GZ: 330-504.00, Schreiben BM Censcher an AM Carcía, spanische Übersetzung. 
Schreiber über die Anwesenheit des Kapuzenmannes im CD-Lager könnten ggfs. die Tür zu weiteren Ermittlungen aufstoßen. ${ }^{232}$

Am 8. August übermittelte Genscher Botschafter Knackstedt folgende Weisung:

»1. Jedes Mitglied der CD, das in Zukunft in der Botschaft vorspricht und um Unterstützung beim Verlassen der CD bittet, ist in die persönliche Obhut zu nehmen. Von dem Vorgang ist zunächst ausschließlich das Auswärtige Amt zu unterrichten.

2. BM bittet um Unterrichtung, ob aufgrund des Verdachts gegen bestimmte Ortskräfte, über botschaftsinterne Vorgänge Informationen an Dritte (z.B. chil. Behörden) weitergeleitet zu haben, Ortskräfte entlassen worden sind. Dies sollte ggf. veranlasst werden. Freiwerdende Arbeitsplätze müssten dann mit entsandten Bediensteten besetzt werden. ${ }^{233}$

Die Anordnung hilfesuchende CD-Mitglieder in Obhut zu nehmen und Ortskräfte der Botschaft zu entlassen, die in Verdacht standen, interne Information an die Behörden oder an die CD weiterzuleiten, war deutlich. Ob Ortskräfte tatsächlich entlassen wurden ist mir nicht bekannt. Der nächste erfolgreiche Fluchtfall aus der CD ereignete sich erst im Jahr 1997.

Am 28. August 1988 schrieb Genscher García erneut und drängte auf die Aufnahme einer Untersuchung. Eine weitere Hinauszögerung, so Genscher, würde die deutschchilenischen Beziehungen schädigen. Er verwies dabei auf die in der chilenischen Gerichtsverfahrensordnung vorgesehene Möglichkeit einer besonderen Untersuchung im Falle einer Beeinträchtigung internationaler Beziehungen. ${ }^{234}$ Als sich Genscher und García wenig später zufällig bei der UN-Generalversammlung trafen, bekräftigte Genscher seine Position erneut. ${ }^{235}$ Die chilenische Justiz lehnte jedoch eine Untersuchung erneut $a b$.

Am 5. Oktober 1988 verlor Pinochet das Plebiszit. Damit war das Ende der Diktatur noch greifbarer. Es wurden Wahlen für den Dezember 1989 angesetzt und ein Wahlsieg des demokratischen Lagers erschien greifbar.

Am 21. Oktober 1988 löste Hernán Felipe Errázuriz Außenminister García auf seinem Posten ab. Daraufhin startete Genscher im Dezember 1988 einen dritten Versuch, eine juristische Untersuchung in Chile zu erreichen. Am 12. Januar 1989 gab die Corte Suprema schließlich der Petition von Errázuriz statt und beauftragte Richter Navas am Gericht von Parral, eine verwaltungsrechtliche Untersuchung einzuleiten (vgl. Abschnitt 5.1.3). Ziel sollte aber lediglich eine Prüfung sein, ob die Voraussetzungen für eine strafrechtliche Untersuchung der CD erfüllt waren. Mit diesem einzigartigen Verfahren versuchte die chilenische Justiz den Druck des AA abzuwenden. Dabei war beiden Seiten klar, dass die Wahlen Ende 1989 der Diktatur wahrscheinlich ein Ende setzen

PA AA, AV NA 31611. DB 398 vom 08.08.1988.

PA AA, AV NA 31582. DE 208 vom 08.08.1988, CZ: 330-504.00, Betr. CD - nur für Botschafter. Die darin angeforderte Unterrichtung zu Punkt 2. konnte ich in den Akten des PA AA nicht finden.

PA AA, AV NA 31582. DE 230 vom 29.08.1988. Schreiben AM Genscher an AM García, AZ 105 - 88 3635 Übersetzung, im chilenischen Außenministerium übergeben am 02.09.1988. Genscher verwies darin auf die Artikel 559 und 560 des chilenischen Código Orgánico de Tribunales.

Archiv BPA, Nr. 1462588. BM des Auswärtigen, Pressemitteilung Nr. 1200/88 vom 29.09.1988. 
würden und vorher keine tiefergehenden Ermittlungen mehr zu erwarten waren. Botschaft und AA setzten auf einen Wahlsieg der Concertación, eines breiten Wahlbündnisses u.a. aus sozialdemokratischen und christdemokratischen Parteien mit ihrem Präsidentschaftskandidaten Patricio Aylwin. Sie hofften, durch dieses erste Verfahren die Grundlage für eine tatsächliche juristische Untersuchung der CD-Verbrechen nach der Wahl zu legen. Hierzu beauftragte das AA mit Máximo Pacheco, Sergio Corvalán und Guillermo Ceroni drei erfahrene Rechtsanwälte, die aufgrund anderer Verfahren bereits bestens mit dem Fall CD vertraut waren. Im Juni 1989 berichtete Botschafter Knackstedt nach Bonn:

»Deutlich geworden ist in den Ermittlungen, dass die örtlichen Behörden der CD Persilscheine ausstellen und die Polizei und Kriminalpolizei mit dem Untersuchungsrichter nicht kooperieren, die CD also ein sStaat im Staate « ist und bisher von den chilenischen Behörden entgegen der eigenen Rechtsordnung in keiner Weise kontrolliert wird. Das Verweisen auf die mangelnde Respektierung der chilenischen Rechtsordnung durch die CD ist der chilenischen Öffentlichkeit jetzt sichtbar geworden und hat angefangen Wirkung zu zeigen. Dies wird uns nach der Wiedereinführung der demokratischen Rechtsordnung in unseren Bemühungen, das Problem CD zu lösen, zugute kommen. «36

Die Beziehungen der Botschaft zur Diktatur waren inzwischen geradezu eisig. Erstmals befürchtete die Botschaft nun, aufgrund des Untersuchungsverfahrens selbst vom Diktaturgeheimdienst CNI überwacht zu werden. Botschafter Knackstedt schlug dem AA daher eine konspirativere Kommunikationsform vor:

»Hinweise aus Kreisen des chilenischen Geheimdienstes veranlassen mich, auf die Gefahr des Abhörens der Telefongespräche erneut zu verweisen. Wie wir erfuhren, können hier Telefongespräche mit einem Computer-gesteuerten Gerät abgehört werden, das auf bestimmte Worte wie >Colonia Dignidad « reagiert und dann mit der Aufzeichnung beginnt.

Da aber beim derzeitigen akuten Stand des Untersuchungsverfahrens oft schnell Verständigung notwendig ist, schlage ich vor, gewisse Codeworte zu benutzen. Vorschlag: Colonia Dignidad = Universitaet, Petitionsausschuss = Humboldt-Ausstellung, Richter Navas $=$ Rektor der Universität. Szurgelies $=$ Vorsitzender des Studentenverbandes. Diese Codewörter müsste man in gewissen Zeitabständen wechseln. «337

Der Tonfall bei bilateralen Gesprächen war jedoch nicht durchweg eisig. So berichtete die Botschaft von einem Gespräch von Justizstaatsekretär Klaus Kinkel mit Errázuriz vom Juni 1989:

»Chile lege grossen Wert auf gute Beziehungen zur Bundesrepublik. Die traditionelle Freundschaft solle erhalten bleiben und Chile werde sich darum bemühen. StS Kinkel schloß sich den Wünschen nach einer Vertiefung der Beziehungen an. Er sehe dafür

236 PA AA, AV NA 31601. DB 316 vom 19.06.1989, GZ: Pol-Rk 543. Betr.: Offizialverfahren Richter Robert.

237 PA AA, B 130, Bd. 13694. DB 116 Botschafter Knackstedt an AA vom 02.03.1989, Betreff: CD hier: Abhören der Telefonleitungen. 
vom nächsten Jahr an besonders gute Voraussetzungen. Diese Aussage mache er in Abstimmung mit BM Genscher, der Errazuriz im übrigen Grüsse übermitteln liesse. Nach der Darstellung der innenpolitischen Bedeutung des Falles `Colonia Dignidad ‘ bei uns bat Kinkel den chilenischen AM, das Untersuchungsverfahren voranzutreiben, damit eine Lösung gefunden werden könne. Dies sagte AM Errázuriz zu. Es sei ein schwieriges innenpolitisches Problem, da die CD über außerordentlich starke Unterstützung in vielen chilenischen Kreisen verfüge. Er werde aber in der Sache weiter tätig bleiben. ${ }^{238}$

Wie schon so häufig in dieser Phase gab die chilenische Regierung gegenüber der Bundesregierung vor, zwar selbst an einer Aufklärung interessiert zu sein, dabei aber von mächtigen Stellen - damit ist implizit Pinochet gemeint - blockiert zu werden.

Richter Robert Arias, der inzwischen seinen Kollegen Navas abgelöst hatte, legte Ende Juli 1989 seinen Untersuchungsbericht vor. Darin führte er diverse administrative Unregelmäßigkeiten auf, stellte jedoch lediglich zwei Straftaten fest - Betrug und unerlaubte Ausübung des Arztberufs (vgl. Abschnitt 5.1.3). Der Bericht von Robert wurde am 8. September 1989 von der Corte Suprema gebilligt. Die beiden Strafverfahren wurden nicht von Robert weitergeführt, sondern an die CD-freundliche Richterin Lydia Villagrán am Juzgado in Parral übertragen, die sie kurz darauf eingestellte.

Die CD ging gegen die Untersuchung von Navas und Robert wie üblich auf mehreren Ebenen in die Offensive: Sie inszenierte einen Hungerstreik von Colonos, wandte sich an den Petitionsausschuss des Bundestages und reichte Klagen gegen die Bundesregierung beim Verwaltungsgericht Köln ein (Vgl. Abschnitt 5.3). Die Verfahren zielten darauf ab, die Rechtswidrigkeit der Maßnahmen der Bundesregierung ${ }^{239}$ festzustellen und deren zukünftige Unterlassung anzuordnen. 1995 wurden die Klagen vom OVG Münster abgewiesen.

Am Tag nach der Billigung des Berichts von Richter Robert durch die Corte Suprema rief das AA seinen in Chile weilenden Lateinamerikabeauftragten zurück, bestellte den chilenischen Botschafter ein und gab die deutlichste Pressemitteilung heraus, die mir im Kontext der deutsch-chilenischen Beziehungen während der chilenischen Diktatur bekannt ist:

Die Bundesregierung ist durch die Entscheidung des obersten chilenischen Gerichts, mit der eine Verfolgung der Angehörigen der Colonia Dignidad zur Last gelegten Straftaten im wesentlichen vermieden wird, tief betroffen. Die Bundesregierung sieht darin den Willen der derzeitigen chilenischen Führung, eine Aufklärung der gegen Mitglieder der CD erhobenen schwerwiegenden Beschuldigungen, die sich auf Folterung, Freiheitsberaubung und andere gewichtige Delikte beziehen, zu verhindern. Bei den Opfern handelt es sich um deutsche Staatsangehörige. Die Bundesregierung muss daher davon ausgehen, dass die derzeitige chilenische Führung nicht die Absicht hat, den Schutz deutscher Staatsangehöriger sicherzustellen.

238 PA AA, AV NA 31601. DB 295 vom 08.06.1989. Betr: Besuch von StS Kinkel in Santiago hier: Unterredung mit dem chil. Außenminister.

239 Konkret beantragten die Klägerinnen die Feststellung der Rechtswidrigkeit der von Censcher im Dezember 1987 entsandten Sachverständigenkommission und seines Drängens auf Einsetzung eines chilenischen Untersuchungsrichters. 
Dieser schwerwiegende Vorgang stellt eine ernste Belastung der deutsch-chilenischen Beziehungen dar. Die Bundesregierung fühlt sich von der derzeitigen chilenischen Führung getäuscht. Sie behält sich alle Schritte in internationalen Gremien und in Bezug auf die deutsch-chilenischen Beziehungen vor. ${ }^{240}$

Der Lateinamerikabeauftragte des AA, Gerhard Henze, analysierte die Lage umgehend und entwickelte eine neue Strategie des AA im Fall CD:

»Die Entscheidung des Obersten Gerichts hat bestätigt, dass unter dieser Regierung eine Lösung für die CD nicht mehr zu erwarten ist. Unsere Druckmittel sind beschränkt. Wir haben, zumindest aus chilenischer Sicht, auch nicht viel zu bieten, wie in Cesprächen im Außenministerium deutlich wurde. So sind offensichtlich Interessen, die eine Untersuchung in der CD verhindern wollen, stärker als das Interesse an Guten, aber nicht sehr inhaltsreichen Beziehungen mit uns. [...] Eine Lösung wird auch unter einer neuen Regierung möglicherweise nicht leicht zu erreichen sein. Falls hinter der Verhinderung der Klärung der Vorwürfe enge Verbindungen von Teilen des Militärs mit der CD stehen [...], wird das Interesse an Blockierung der Vorwürfe weiter bestehen.

Verhalten des Obersten Cerichts lässt befürchten, dass der Wunsch nach Blockierung an hoher Stelle besteht. Die neue Regierung wird sich dann fragen müssen, ob sie neben den vermutlich unvermeidbaren Konflikten mit Teilen der Streitkräfte hier noch eine Front eröffnen will. Sie steht außerdem vor dem Dilemma, dass sie Qualität und Unabhängigkeit der Justiz verbessern muss. Druck auf die Justiz im CD-Verfahren würde diesem Ziel widersprechen und könnte ihr den Vorwurf eintragen, damit gegen den Grundsatz der Rechtsstaatlichkeit zu verstoßen.

Unter diesen Umständen bietet sich der Versuch an, das Problem unter der neuen Regierung auf dem Verwaltungsweg zu lösen. Diese Tendenz zeigte sich auch bei meinen Cesprächen mit Vertretern der Opposition. Wir müssen dabei in Kauf nehmen, dass CD-Leiter Schäfer nicht bestraft wird. Hilfe für die Betroffenen ist wichtiger. Dabei wird von uns noch erheblicher Einsatz verlangt werden.

Als administrative Lösung bietet sich an:

- Entzug der Rechtspersönlichkeit für die CD mit einer Reihe von Folgen (u.a. Verlust von Steuer und Zollfreiheit, Einsetzung eines staatlichen Verwalters)

- Ausweisung Schäfers und evtl. Anderer Führungsmitglieder (Möglichkeit wird noch von chilenischem Anwalt geprüft)

Beide Maßnahmen sind wahrscheinlich in Chile gerichtlich anfechtbar. Schon Anordnung könnte aber genügend Druck auf Schäfer schaffen, um ihn freiwillig zum Abzug zu bewegen.

Wir sollten Bitte um entsprechende Maßnahmen durch Parallelschritt bei uns (Entzug der Gemeinnützigkeit, BMF wurde bereits um Prüfung gebeten) unterstützen.

Aylwin sollte bereits bei Besuch in Bonn gebeten werden, Verwaltungsmaßnahmen gegen $C D$ vorzusehen. Ggf. könnte angedeutet werden, dass Wiederaufnahme der Zusammenarbeit bei Fortdauer des CD-Problems erschwert werden könnte. Bitte um Ver- 
waltungsmaßnahme sollte nicht öffentlich bekanntgegeben werden, da sonst diese Lösung erschwert werden könnte. « ${ }^{241}$

In seiner Analyse nahm Henze zahlreiche Entwicklung der nächsten Jahre vorweg und zeichnete ein düsteres Bild von der Zukunft: Auch der Übergang zur Demokratie werde keine großen Fortschritte bei der strafrechtlichen Verfolgung der CD in Chile bringen. Das Grundproblem lag darin begründet, dass die ausgehandelte Transición keine unmittelbaren Veränderungen im chilenischen Justizsystem mit sich brachte. Die personelle Zusammensetzung der oberen Gerichte blieb trotz der formellen Übergabe der Regierungsgewalt von Pinochet an Aylwin weitgehend unverändert. Die Konstatierung Henzes, daher eine Straflosigkeit von Schäfer in Kauf nehmen zu müssen und sich vermehrt den Betroffen zuzuwenden, klingt wie eine Kapitulation vor den Verbrechen der CD. Henze hoffte, dass eine Auflösung der CD auf dem Verwaltungsweg zu einer Ausweisung Schäfers in die Bundesrepublik (bzw. seinem »freiwilligen Abzug«) führen könnte. Gleichzeitig vermutete er wohl, dass das Ermittlungsverfahren der Staatsanwaltschaft Bonn nicht zu einer Anklageerhebung geschweige denn einer Verurteilung führen könnte. Er setzte nun auf»Hilfe für die Betroffenen«, was bislang nicht auf der Agenda des AA stand.

Das AA hatte in der gesamten Phase zuvor die Unterstützung der CD-Opfer stets vermieden, um nach außen Neutralität gegenüber den schwebenden juristischen Untersuchungen zu wahren. Allerdings mied das AA nur den Kontakt zu aufklärerischen Kreisen, die als politisch links galten, tauschte sich jedoch regelmäßig mit Vertreter_innen der Diktatur und des Unterstützungsnetzwerks der CD in der Bundesrepublik aus. Dies verschaffte dem System CD kontinuierlich sowohl einen Informationsvorsprung als auch einen Handlungsvorteil. Aufklärerische Akteur_innen hatten das AA durchaus für dieses Vorgehen kritisiert, das in der Folge ihre Bemühungen um Aufklärung und Aufarbeitung der Verbrechen blockierte. So beklagte sich der Rechtsanwalt Sergio Corvalán, der zunächst für die Botschaft tätig war, im August 1987 bei Staatssekretär Ruhfus vom AA: In Chile kämen Zeug_innen auf sie zu, die Informationen besäßen, die für das Ermittlungsverfahren der Staatsanwaltschaft Bonn relevant seien. Sein Eindruck sei jedoch, dass die Botschaft diesen Zeug_innen kein Gehör schenke und sie auf Distanz halte. AI-Generalsekretär Walter Rövekamp warf der Botschaft sogar vor, vertrauliche Aussagen von aus der CD Geflüchteten an den chilenischen Geheimdienst weitergeleitet $\mathrm{zu}$ haben. ${ }^{242}$

Was Henze in seiner Analyse allerdings nicht erwähnt, sind eigene Handlungsoptionen der bundesdeutschen Seite. Vielleicht lag das daran, dass auch Henze keine Hoffnung in die seit Jahren andauernden und weitgehend ergebnislosen Ermittlungen der Bonner Staatsanwaltschaft mehr setzte. Diese erkannte weiterhin keinen hinreichenden Tatverdacht gegen Schäfer und die weiteren Beschuldigten, weshalb sie auch keinerlei Anklage erhob oder Haftbefehle ausstellte. Die Staatsanwaltschaft hatte seit

241 PA AA, AV NA 31595. DB 921 (aus Buenos Aires) Lateinamerikabeauftragter Henze an AA und Botschaft Santiago vom 11.09.1989, GZ: Pol 322 CHL.

242 PA AA, ZW 159188. Vermerk über Gespräch StS Ruhfus mit RA Corvalán und Al Generalsekretär Rövekamp vom 12.08.1987. 
inzwischen vier Jahren ermittelt und neben den Ehepaaren Baar und Packmor zahlreiche in der Bundesrepublik lebende Ex-Colonos, Unterstützer_innen der CD und Diplomat_innen befragt. Außer den Geflüchteten selbst hatte dabei niemand Hinweise auf selbst beobachtete Verbrechen in der CD gegeben, während zahlreiche CD-Getreue die Anschuldigungen als Verleumdung psychisch Kranker darstellte. Hartmut Hopp reichte ärztliche Gutachten ein, um die vermeintliche psychische Erkrankung und Unzurechnungsfähigkeit von CD-Flüchtigen zu belegen. Hugo Baar bescheinigte er eine »Persönlichkeitsveränderung infolge jahrelangen, ausgeprägten Drogen- und Alkoholmissbrauchs «. ${ }^{243}$ Hopp stellte Baar als den eigentlichen Übeltäter dar. Dieser habe mit »allen unerlaubten und unfairen Mitteln, z.B. Postzensur und Telefonkontrolle, Einschüchterung und Drohungen bis hin zu sexuellen Missbräuchen « ${ }^{244}$ agiert »wie bestimmte Sektenpropheten«, die ihre Position »durch ein rausgeklügeltes System von Psychoterror« aufrechterhalten «. ${ }^{245}$ Dem ebenfalls aus der CD Geflüchteten Jürgen Szurgelies attestierte Hopp, er sei aufgrund eines Hirnschadens geistig zurückgeblieben, er leide unter einer »Verschlechterung des Charakters«, "psychotischen Äußerungen«, »religiösen Wahnsinnsvorstellungen« sowie »dem unwiderstehlichen Wunsch auszureißen«. ${ }^{246}$ Trotz dieser eindeutig parteilichen Stellungnahmen änderte die Staatsanwalt nichts an ihrer Grundhaltung, belastende und entlastende Aussagen als ähnlich glaubwürdig einzustufen.

Das AA - zumindest progressivere Diplomaten wie Konsul Haller - begannen daran zu zweifeln, ob die Bonner Staatsanwaltschaft die Sache richtig einzuschätzen in der Lage war. Haller meldete, nachdem er selbst im März 1988 von der StA Bonn vernommen worden war, ans AA:

»Ich hatte den Eindruck, dass die Staatsanwaltschaft die Baar- und Packmor-Berichte in ihrer strafrechtlichen Bedeutung und in ihrem Gesamtzusammenhang unterschätzt, bzw. die Claubwürdigkeit darin enthaltener Aussagen in Zweifel zieht. Darauf deutet z.B. Eine Bemerkung des Staatsanwalts, dass das Ehepaar Packmor evtl. aus egoistischen Motiven handeln könnte, um frühere geldliche Einlagen in CD wieder zurückerstattet zu bekommen. Zur Erhärtung der Verdachtsmomente regte ich die Vorladung der in den Berichten individualisierten Opfer von Misshandlungen an. ${ }^{247}$

Haller kritisierte ebenfalls die Anbindung des Zivilverfahrens der CD gegen Amnesty International (vgl. Abschnitt 5.3.1) an das laufende Strafverfahren. ${ }^{248}$ Konkret bedeutete dies, dass die StA Bonn die Ergebnisse eines Rechtshilfeersuchens im genannten Zivilverfahren abwartete und sich damit von den prozesstaktischen Überlegungen der

243 StA Bonn, AZ 50 ]s 285/85, Bd. I, BI. 175ff. Ärztlich-Psychiatrisches Gutachten von Hopp zur Persönlichkeitsveränderung von H. B. vom 16.03.1986.

244 Ebd.

245 Ebd.

246 StA Bonn, AZ 50 Js 285/85, Bd. XII. Übersetzung von Bl. 237f. der Ermittlungsakte. Bescheinigung von Hopp über Jürgen Szurgelies vom 30.04.1988. Briefkopf »Cesundheitsministerium, Gesundheitsamt Maule, Hospital >El Lavadero«".

247 PA AA, AV NA 31590. DB 106 Dieter Haller vom 11.03.1988, GZ: RK 543.

248 Die Verbindung beider Verfahren führte jedoch dazu, dass Al als Beklagte im Zivilverfahren Akteneinsicht beim Strafverfahren erhielt. 
Prozessparteien abhängig machte. Das schließt die CD mit ein, die eindeutig auf eine Verschleppung des Verfahrens hinwirkte.

Die bundesdeutsche Diplomatie war gegen Ende der Diktatur gewissermaßen erwacht und hatte einen Handlungsbedarf in Sachen CD erkannt. Dies geschah sicherlich auch aufgrund ihrer direkten Erfahrungen mit der CD beim Konsularsprechtag und dem gescheiterten Delegationsbesuch. Auch erkannten die Diplomaten nun, dass die CD einen vollständigen Schutz seitens der Diktatur genoss und somit juristische Anstrengungen in Chile weitgehend zum Scheitern verurteilt waren. Die Staatsanwaltschaft Bonn hatte diese Erfahrungen nicht und konnte oder wollte diese Einschätzung nicht teilen. Trotzdem drängte das AA Chile weiterhin, Untersuchungen aufzunehmen, während das Bonner Ermittlungsverfahren kurz vor der Einstellung stand. In dieser Situation erkundigte sich das AA beim BMJ nach der Möglichkeit eines Haftbefehls gegen Paul Schäfer, Hartmut Hopp und Gisela Seewald. Das BMJ reichte die Anfrage an den leitenden Oberstaatsanwalt der StA Bonn, Holstein, weiter. Dieser antwortete:

»Ein dringender Tatverdacht als Voraussetzung für die Beantragung eines Haftbefehls gegen die in Chile wohnhaften Beschuldigten Paul Schäfer, Dr. Hartmut Hopp und Frau Dr. Seewald liegen nicht vor. Wie bereits im letzten Bericht mitgeteilt, fehlt es zur Zeit bereits an dem für eine Anklageerhebung erforderlichen hinreichenden Tatverdacht. ${ }^{249}$

Am 18. September 1989 fand im AA eine Hausbesprechung zum Fall CD statt. ${ }^{250}$ Am selben Tag empfing Genscher den aussichtsreichen chilenischen Präsidentschaftskandidaten Patricio Aylwin. ${ }^{251}$ Die Runde ${ }^{252}$ schlug Genscher vor, bei der StA Bonn zu intervenieren, um die drohende Einstellung des Strafverfahrens zu verhindern. Die Botschaft solle hierfür einen Bericht verfassen und darauf hinweisen, dass sich nach den Wahlen im Dezember 1989 Zeug_innen melden könnten, die bisher aus Furcht vor Repressalien nicht aussagen wollten. Des Weiteren habe das AA bereits eine Prüfung der PSM durch das Bundesfinanzministerium angeregt, mit dem Ziel, dem Verein die Gemeinnützigkeit zu entziehen. Gegenüber der chilenischen Regierung solle auf die Einsetzung eines neuen Untersuchungsrichters gedrängt werden. An einem entscheidenden Punkt blieb der Vorschlag jedoch bei derselben Linie wie bisher: Auch diesmal wurden den anzeigewilligen CD-Geflüchteten keine ausreichenden Garantien für ihre

249 PA AA, AV NA 31599. Schreiben Holstein, leitender OtSA Bonn, an Justizminister NRW durch CenStA in Köln vom 12.09.1989. Aufgrund des langen Dienstwegs leitete das BM] das Schreiben erst am 19.10.1989 ans AA weiter.

250 PA AA, AV NA 31600. Ministervorlage von Referat 330, AA vom 18.09.1989. Die Vorlage fasst die Ergebnisse der Hausbesprechung vom selben Tag zusammen und macht Vorschläge für das weitere Handeln.

251 PA AA, AV NA 31600. Gesprächsnotiz über Gespräch zwischen Genscher und Aylwin am 18.09.1989 vom 20.09.1989, CZ: 330-326.36 CHL.

252 PA AA, AV NA 31600. Ministervorlage von Referat 330, AA vom 18.09.1989. An der Hausbesprechung am 18.09.1989 nahmen neben Botschafter Dr. Knackstedt Vertreter_innen der Abteilungen D 3, Dg 51 und Dg 33 sowie der Referate 013, 231, 400, 422, 510, 511 und 611 teil. 
Strafanzeigen in Chile in Aussicht gestellt. Die Kosten, die das AA mit 50.000 US-Dollar pro Verfahren bezifferte, erschienen dem Amt wohl zu hoch. ${ }^{253}$

Auch die Ausübung von Druck über wirtschaftliche Maßnahmen erschienen dem AA vor dem erhofften Wahlsieg des demokratischen Lagers in Chile nicht sinnvoll. Am 14. September 1989 befürwortete die Direktorenrunde des AA einen neuen Kredit der Weltbank für Chile. ${ }^{254}$

Bei dem Gespräch mit Aylwin am 18. September 1989 bat Genscher »daß eine demokratische Regierung sich sofort der schutzbedürftigen Deutschen annehme, den Status von CD untersuche und die Verantwortlichen zur Rechenschaft ziehen lasse. ${ }^{255}$ Aylwin entgegnete, die Bundesregierung könne sicher sein, dass Chile »dieses Problem lösen « und eine umfassende Untersuchung durchführen werde. ${ }^{256} \mathrm{Er}$ verwies darauf, dass er bereits 1968 eine tiefgreifende Prüfung der CD gefordert hatte und erklärte, die CD werde von Pinochet geschützt. Das AA veröffentlichte zu diesem Treffen eine Pressemitteilung, die die chilenische Regierung verärgerte:

»Zur Frage der von Deutschen bewohnten Siedlung in Südchile `Colonia Dignidadく, erklärte Bundesminister Genscher, die Bundesregierung sei empört, dass Straftaten der Führung an Mitgliedern immer noch nicht verfolgt und geahndet würden. Sie habe mit Abscheu von dem Versuch der Vertuschung in der CD Kenntnis genommen. Patricio Aylwin versicherte, dass die Verhältnisse in diesem `Staat im Staate<nach Übergang zur Demokratie mit rechtsstaatlichen Verfahren schonungslos aufgeklärt werden müssten. ${ }^{257}$

Nach Aylwins Wahl gab es zum zweiten Mal in Folge einen vorzeitigen Botschafterwechsel: Wiegand Pabsch löste Knackstedt ab. Im Februar 1990 traf Pabsch den von Aylwin designierten Außenminister Silva Cimma. Er erläuterte den begründeten Verdacht der Bundesregierung, dass die Menschenrechte der in der CD lebenden Deutschen dauerhaft verletzt würden. Er erwarte, dass die Aylwin-Regierung nun so verfahren werde, wie Genscher und Aylwin es im September abgestimmt hatten. ${ }^{258}$

Unterdessen hatte sich die CD schon seit 1988 auf den anstehenden Regierungswechsel vorbereitet: Um einer möglichen Strafverfolgung durch bundesdeutsche Ermittlungsbehörden zu entgehen, stellten 25 CD-Führungsmitglieder, darunter Paul Schäfer, beim chilenischen Innenministerium Einbürgerungsanträge ${ }^{259}$ - die ihnen allerdings verwehrt wurden. Um einer möglichen Auflösung ihres Trägers, der SBED, den Wind aus den Segeln zu nehmen, übertrug die CD ihr gesamtes Vermögen auf eine aus drei Aktiengesellschaften bestehende Holding. Um sich symbolisch von der

253 Ebd.

254 Ebd.

255 PA AA, AV NA 31600. Gesprächsnotiz über Gespräch zwischen Genscher und Aylwin am 18.09.1989 vom 20.09.1989, CZ: 330-326.36 CHL.

256 Ebd.

257 PA AA, AV NA 31600. Information des Pressereferats des AA Nr. 205/1989 vom 18.09.1989.

258 PA AA, AV NA 31599. DB 60 vom 01.02.1990, CZ: Pol-rk 543. Cespräch mit designiertem AM Enrique Silva Cimma.

259 PA AA, AV NA 31600. DB 482 vom 02.10.1989, GZ: Rk-Pol 543. Betr.: Einbürgerung von CDMitgliedern. 
Vergangenheit zu distanzieren und sich für einen Weiterbestand nach dem Ende der Diktatur zu rüsten, benannte sich die CD in »Villa Baviera« um (vgl. Kapitel 3).

\subsection{Phase IV (1990-2005): Die chilenische Transición bis zur Festnahme Schäfers}

Als Kandidat des Parteienbündnisses Concertación de Partidos por la Democracia wurde Patricio Aylwin am 14.12.1989 mit 55\% der Stimmen zum Präsidenten gewählt. Für den Diktatur-nahen Kandidaten Hernán Büchi votierten knapp $30 \%$, der wirtschaftsliberale Francisco Javier Errázuriz kam auf etwa 15 \% der Stimmen.

Mit dem Amtsantritt Aylwins am 11. März 1990 begann in Chile ein langwieriger Demokratisierungsprozess, der in Chile als Transición a la Democracia (Übergang zur Demokratie) bezeichnet wird. Diese Transición hat, wie der im Oktober 2019 ausgebrochene soziale Aufstand in Chile zeigt, Nachwirkungen bis heute und kann noch immer nicht als abgeschlossen bezeichnet werden. So ist die 1980 während der Diktatur erlassene Verfassung noch heute in Kraft. Die Militärjunta gab ihre Macht nur teilweise und unter bestimmten Bedingungen ab. Dazu gehörten einige Regelungen in der Verfassung von 1980: Das einzigartige binominale Wahlsystem begünstigte de facto die Parteien der rechten Opposition (also jene Kräfte, die die Diktatur unterstützten). Ein Fünftel der Mitglieder des Senats wurde nicht gewählt, sondern vom Präsidenten, der Corte Suprema oder dem Consejo de Seguridad Nacional (Staatssicherheitsrat - COSENA) ernannt. Und schließlich blieb Pinochet Oberbefehlshaber des Heeres und drohte, wenn er mit Entwicklungen nicht einverstanden war, mehrmals mit einem erneuten Putsch. De facto kontrollierten die Militärs so die mit ihnen ausgehandelte Transición. Die Regierung Aylwin unterlag daher weitreichenden Handlungsrestriktionen. ${ }^{260}$

\subsubsection{0-1996: Verwaltungshandeln in Chile und deutsche Passivität}

Bereits kurz nach seinem Amtsantritt setzte Aylwin eine Wahrheits- und Versöhnungskommission ${ }^{261}$ ein, die die von der Diktatur begangenen Tötungsverbrechen untersuchen sollte. Die sogenannte Rettig-Kommission legte Anfang März 1991 ihren Bericht vor. $^{262}$ Dieser führte auch die CD als Haft- und Folterlager der DINA auf. ${ }^{263}$ In Bezug auf sogenannte Verschwundene (desaparecidos) konstatierte die Kommission, es gebe diverse Berichte über Personen, deren letzte Spur auf die CD verweise. Einzig im Fall

260 Straßner, Veit. Die offenen Wunden Lateinamerikas. Vergangenheitspolitik im Postautoritären Argentinien, Uruguay und Chile. Wiesbaden, 2007, S. 244ff.

261 Comisión Nacional de Verdad y Reconciliación, wegen des Kommissionsvorsitzenden Raúl Rettig auch als »Rettig-Kommission« bezeichnet.

262 Der Bericht stufte 2.298 Todesfälle während der Diktatur als Menschenrechtsverbrechen oder Folge staatlicher politischer Cewalt ein. Corporación Nacional de Reparación y Reconciliación. Informe de la Comisión Nacional de Verdad y Reconciliación. Bd. 1-3. Santiago 1996.

263 Corporación Nacional de Reparación y Reconciliación. Informe de la Comisión Nacional de Verdad y Reconciliación. Bd. 2. Santiago 1996, online unter https://www.memoriachilena.gob.cl/archivos2/pdfs/MCo053680.pdf, hier S. 470f. 
von Alvaro Vallejos Villagrán könne jedoch weitgehend sicher gesagt werden, dass dieser nach seiner Verschleppung in die $C D$ endgültig »verschwand «. Aylwin versprach im Zuge der Vorstellung des Berichts, sich für »Gerechtigkeit im Rahmen des Möglichen« (justicia en la medida de lo posible) einzusetzen.

Das 1978 verabschiedete Amnestiegesetz machte eine strafrechtliche Aufarbeitung der Diktaturverbrechen zu großen Teilen unmöglich. Das Gesetz bezog sich auf während des Ausnahmezustandes (also zwischen dem 11. September 1973 und dem 10. März 1978) begangene Verbrechen. Ausgenommen von der generellen Amnestie waren lediglich einige Verbrechensbereiche, beispielsweise Verbrechen außerhalb Chiles. So hatten etwa die USA auf die Aufklärung des Bombenattentats gedrängt, das die DINA 1976 in Washington auf Orlando Letelier, einen ehemaligen Minister der Allende-Regierung, verübt hatte. Daraufhin wurden 1977 zwei tatbeteiligte DINA-Agenten in die USA überführt: Michael Townley und Armando Fernández Larios (vgl. Abschnitt 4.2.3). Silva Cimma, designierter Außenminister der Aylwin-Regierung, äußerte bei einem Gespräch mit Botschafter Pabsch im Februar 1990: „Das Thema CD habe für die deutsch-chilenischen Beziehungen eine ähnliche Bedeutung wie der Mordfall Letelier für die chilenisch-amerikanischen Beziehungen. ${ }^{264}$

Im Laufe des Jahres 1990 bereitete die chilenische Regierung ihre Strategie vor, der CD durch verschiedene Verwaltungsakte das Handwerk zu legen. Die deutsche Seite hieß diese Herangehensweise gut. Botschafter Pabsch berichtete dem AA über Gespräche, die er und der Lateinamerikabeauftragte des AA mit der chilenischen Regierung im Juli 1990 geführt hatten. Die chilenische Regierung sei »fest entschlossen«, das »Problem CD endgültig zu lösen. «Der Botschafter teilte die Ansicht, »dass der verwaltungsrechtliche Weg eher Erfolg verspricht als der von Strafverfahren gegen Schäfer, die immer wieder auf die bekannten Beweisschwierigkeiten stoßen. ${ }^{265}$ Nach einem Erfolg verwaltungsrechtlicher Schritte seien dann »resozialisierungs- und psychologischpsychiatrische Betreuungsmaßnahmen für die CD-Insassen« nötig, »wahrscheinlich in erheblichem Umfang «. ${ }^{266}$ Diese könnten nur von deutscher Seite getragen werden. Das AA beschrieb in seiner Antwort an den Botschafter eine Linie, die fortan für seine Politik prägend sein sollte:

»Wir gehen ebenso wie die chilenische Seite davon aus, dass CD als Cemeinschaft fortbestehen wird, da sich, vor allem für ältere Mitglieder, kaum Alternativen bieten. Die Bundesregierung wird dabei ihrer Fürsorgepflicht für Deutsche nachkommen. ${ }^{267}$

Aus dieser Einschätzung wurde eine politische Leitlinie des AA: Das Amt setzte darauf, dass die CD auch nach einer aufgrund des chilenischen Verwaltungshandelns vom AA erwarteten Herauslösung der Führungsebene fortbestehen würde. Das AA wolle infolgedessen seiner »Fürsorgepflicht« für die verbleibenden deutschen Bewohner_innen nachkommen.

264 PA AA, AV NA 31599. DB 60 vom 01.02.1990, CZ: Pol-rk 543. Cespräch mit designiertem AM Enrique Silva Cimma.

265 PA AA, AV NA 31598, DB 376 vom 30.07.1990, CZ: Pol-RK 543. Betr.: CD hier: Gespräche von Dg 33.

266 Ebd.

267 PA AA, AV NA 31598. DE 170 vom 03.08.1990, GZ: Dg33-504. 
Die chilenische Regierung, hingegen, verfügte nicht über eine solche Leitlinie, um die Siedlung zu erhalten. Der Vizepräsident des BND, Paul Münstermann, berichtete im September 1992 Staatssekretär Dieter Kastrup im AA und Staatsminister Bernd Schmidbauer im Bundeskanzleramt über die Pläne des chilenischen Innenstaatssekretärs Belisario Velasco zum Umgang mit den Colonos. ${ }^{268}$ Der BND hatte Velasco während eines Deutschlandbesuches vermutlich abgehört. Münstermann berichtete:

»Nach einem endgültigen (rechtskräftigen) Urteil möchte die chilenische Regierung den Grund, auf dem sich die >Colonia Dignidad befindet, verkaufen und die dadurch gewonnenen Mittel dazu verwenden, die Kolonisten sozial zu integrieren.

Schon jetzt sei abzusehen, daß die Mittel bei weitem nicht ausreichen, um die beabsichtigte Integration erfolgreich durchzuführen. Staatssekretär Velasco hält es deshalb für wünschenswert, wenn die Bundesregierung Mittel bereitstelle, die zur Förderung der sozialen Integration der zu über $90 \%$ deutschstämmigen Kolonisten verwendet werden können. Die chilenische Regierung plant die Ansiedlung der Kolonisten im Süden des Landes, wo bereits viele deutschstämmige Chilenen leben. [...] Staatssekretär Velasco hält eine Umsiedlung der Mitglieder der >Colonia Dignidad in die Bundesrepublik Deutschland für verfehlt, zumal sie ihren sozio-kulturellen Lebensraum in Chile gefunden hätten. ${ }^{269}$

Der Lateinamerikabeauftragte des AA Gerhard Henze schrieb an Botschafter Wiegand Pabsch und leitete ihm das Schreiben des BND weiter. ${ }^{270}$ Henze zeigte sich überrascht und verärgert über den chilenischen Staatssekretär, »um so mehr als wir in Velasco immer einen seriösen Gesprächspartner gesehen hatten und er die Verhältnisse genügend kennen sollte, um auf solche Gedanken zu kommen.« Er bat den Botschafter bei Velasco zu sondieren, ob er wirklich in absehbarer Zeit Möglichkeiten einer »Verwertung « ${ }^{271}$ der CD-Grundstücke sehe und pochte auf der AA-Leitlinie zum Erhalt der CD:

»Aus hiesiger Sicht müssen wir alles tun, um die Colonia Dignidad ohne Schäfer und in einer Form zu erhalten, die eine menschenwürdige Existenz für ihre Bewohner sicherstellt. Wir müssen auch der chilenischen Seite klar sagen, daß die Colonia Dignidad das Ergebnis harter Arbeit dieser Mitglieder ist und daß eine Enteignung von niemand hier verstanden würde. $\ll^{272}$

Am 31. Januar 1991 erließ die Aylwin-Regierung ein Dekret, dass die SBED als Rechtsperson der CD auflöste. ${ }^{273}$ Ihr Vermögen sollte an die methodistische Kirche fallen. Die CD erklärte daraufhin, es könne keinerlei Vermögen, sondern lediglich Schulden übertragen. Die SBED hatte bereits 1988/1989 sämtliche Vermögenswerte an Aktiengesellschaf-

268 PA AA, AV NA 31654. Schreiben BND, der Präsident (gez. Paul Münstermann) an StS Kastrup (AA) und StM Schmidtbauer (Bundeskanzleramt) vom 29.09.1992.

269 Ebd.

270 PA AA, AV NA 31654. Schreiben des Lateinamerikabeauftragten (AA) Henze an Botschafter Pabsch vom 26.10.1992.

271 Ebd.

272 Ebd.

273 Diario Oficial N³3896 vom 16.02.1991. Ministerio de Justicia, Decreto 143 vom 31.01.1991. »Declara disuelta y cancela personalidad jurídica y destina bienes de entidad que indica.« 
ten übertragen. Die neue Regierung zeigte sich davon überrascht. Zudem legte die CD Rechtsmittel gegen das Auflösungsdekret ein, inszenierte einen Hungerstreik und fuhr eine neue Verteidigungsstrategie: Da ihr nun nicht mehr Verbrechen, sondern lediglich administrative Verstöße vorgeworfen wurden, setzte sie voll und ganz auf die vermeintlich wichtige wohltätige Bedeutung des CD-Krankenhauses. Durch dessen Schließung, so die CD, verlören Tausende Landbewohner_innen der Region ihre Gesundheitsversorgung. Die CD organisierte sogenannte Patient_innenkomitees und Jugendwachen, Instanzen, die eine Art Schutzring um die CD bilden sollten. Diese Maßnahmen sollten verdeutlichen, wie sehr die lokale Bevölkerung angeblich die sozialen Vorhaben der CD unterstützte. Abgeordnete der rechten Opposition griffen diese Argumentation auf und ergriffen vehement Partei für die CD. Die Maßnahmen der Regierung, so erklärten sie, seien ausschließlich auf den Druck seitens der deutschen Regierung zurückzuführen. Dies sei ein Eingriff in die chilenische Souveränität. 17 rechte Senatoren ${ }^{274}$ reichten Verfassungsklage gegen das Regierungsdekret ein. Die juristische Auseinandersetzung dauerte mehrere Jahre an. In dieser Zeit gewannen die CD und deren Unterstützer_innen, zu denen auch konservative Medien gehörten, immer wieder die Oberhand. Mithilfe des rechten Lagers, ihres Anwaltsteams und ihrer immer noch aktiven Netzwerke in der Justiz konnte die CD die Umsetzung des Dekrets lange Zeit faktisch verhindern. Als die chilenische Regierung nach mehreren Jahren endlich eine Schließung des Krankenhauses durchsetzen konnte, gründete die CD rasch einen neuen Verein, der dessen Trägerschaft übernahm. In dieser Pattsituation konnte die CD ihre internen Zwangsstrukturen aufrechterhalten. Auch Paul Schäfer konnte seine Missbrauchstaten bis 1997 fortsetzen. Diesen fielen neben Colonos zunehmend auch chilenische Kinder zum Opfer, die über die sogenannten Jugendwachen und Wochenendfreizeiten in die CD kamen und teilweise im sogenannten Intensivinternat der CD lebten (vgl. Abschnitt 4.2.4). Erst nach dem Hilferuf des von Schäfer missbrauchten Jungen Cristóbal Parada im Juni 1996 gelang es, Schäfer seiner Taten zu überführen. Rechtsanwalt Hernán Fernández stellte Strafanzeige gegen Schäfer, am 14. August 1996 erging der Haftbefehl gegen ihn. ${ }^{275}$

Die Bundesregierung, die bereits vor dem Antritt Aylwins im März 1990 Gespräche mit der chilenischen Seite über die Strategie der Verwaltungsmaßnahmen geführt hatte, unterstützte verbal weiterhin die chilenischen Maßnahmen, deren Ausgangspunkt das Auflösungsdekret der SBED gewesen war. Die Leitlinie des AA bestand darin, die chilenische Regierung in ihrem Weg zu bestärken, den sie mit dem Auslösungsdekret beschritten hatte. Zugleich wollte das AA kein großes Aufsehen erregen, um Reflexe der rechten Opposition zu vermeiden. Diese klagte ohnehin immer wieder über den vermeintlichen politischen Druck der Bundesregierung und unterstellte der - von Rechtsaußen betrachtet - linken Bundesregierung in alter Diktatur-Manier eine Verleumdungskampagne.

274 Der chilenische Senat verfügte in jenen Jahren über 47 Senatoren, von denen 38 demokratisch gewählt waren.

275 In Chile war bisher nur einmal 1966, nach der Flucht von Wolfgang Kneese, ein Haftbefehl gegen Paul Schäfer ergangen. Schäfer entzog sich damals der Festnahme bis 1967, als die Ermittlungen eingestellt wurden (Vgl. Abschnitt 5.1.1). 
Nach dem »Erwachen« der bundesdeutschen Diplomatie änderte sich gegen Ende der chilenischen Diktatur ihre Wortwahl bezüglich der CD. Im Dezember 1987 hatte Botschafter Kullak-Ublick erstmals Colonos, die nicht der CD-Führungsebene angehörten, als »Insassen der $C D$ « bezeichnet. Dieser Begriff, der eine Freiheitsberaubung implizierte, wurde nun zum gängigen Terminus bundesdeutscher Diplomat_innen. ${ }^{276}$

In der ersten Hälfte der 1990er Jahre ebbte die mediale Aufmerksamkeit für den Fall $\mathrm{CD}$ in der Bundesrepublik wieder ab. AA und Botschaft verfolgten das Thema jedoch weiter und hielten den Kontakt zur chilenischen Regierung. Anfang 1993 wies Außenminister Klaus Kinkel (FDP), der im Mai 1992 die Nachfolge von Genscher angetreten hatte, an, alles zu tun, »damit Dinge in Ordnung kommen «. ${ }^{277}$ Während der Diktatur hatten AA und Botschaft kaum aktiv zu den Verbindungen zwischen CD und DINA recherchiert. Nun trugen die Diplomat_innen die verfügbaren Erkenntnisse zusammen und analysierten Dokumente aus chilenischen Justizverfahren sowie Informationen von Menschenrechtsaktivist_innen. ${ }^{278}$ Besonderes Engagement zeigten dabei einzelne Diplomaten, die schon jahrelang mit dem Fall CD befasst waren. ${ }^{279}$ Das AA erörterte nun sogar, zur Untersuchung dieser Verbindungen auf einen neuen Antrag auf Einsetzung eines chilenischen Untersuchungsrichters hinzuwirken. ${ }^{280}$ Anfang 1994 berichtete die Botschaft dem AA über Stand und Perspektiven der Aufklärungsbemühungen in Chile. ${ }^{281}$ Botschaftsrat Kliesow war bezüglich der Zielsetzung der Aufklärung sowie der Ahndung der Vorgänge in der CD wenig optimistisch. Er teile zwar den vorsichtigen Optimismus der chilenischen Regierung, denn die Corte Suprema könne ihre Taktik der Rechtsverweigerung in Bezug auf das Auflösungsdekret der chilenischen Regierung, das noch immer nicht rechtskräftig war, nicht auf Dauer durchhalten. Die darauffolgenden Schritte, wie beispielsweise steuerrechtliche Untersuchungen, würden jedoch bestenfalls zur Verurteilung weniger Vertreter_innen des »mittleren Managements « der CD führen, wie etwa von Kurt Schnellenkamp und Alfred Matthusen. Auch eine anschließende Ausweisung der Verurteilten sei möglich. Jedoch, so Kliesow, wären dies zwar

»starke Prestigeverluste der CD und würde eine Schwächung der Organisationsstruktur der CD bedeuten; an Schäfer kämen wir damit nicht ran. Cegen ihn wäre nur, was von chilenischer Seite gebetsmühlenhaft wiederholt wurde, ein auf einen Haftbefehl gestütztes Auslieferungsersuchen wirksam. Insoweit hat die Botschaft ihre Argumente mehrfach vorgetragen und begründet. Nur ein Tätigwerden der deutschen Justiz könnte wirkliche Bewegung in den Fall bringen. Die im Bezugs-Drahterlass [...] genannten Anhaltspunkte und Beweismittel sind zum Teil auch in Deutschland direkt zugänglich,

276 PA AA, AV NA 31598. DB 376 vom 30.07.1990, GZ: Pol-RK 543. Betr.: Gespräche von Dg33.

277 PA AA, AV NA 31606. DE 276 vom 30.12.1993, GZ: 330-504.00 CHL. Darin zitiert: Weisung des BM vom 25.02.1993 (nach Vorlage vom 18.02.1993).

278 PA AA, AV NA 31606. DE 276 vom 30.12.1993, GZ: 330-504.00 CHL.

279 Beispielsweise Hans-Ulrich Spohn, der Ende der 1980er Jahre als Botschaftsrat in Santiago mit dem Fall befasst war und nun in den 1990ern im Lateinamerikareferat des AA tätig war.

280 PA AA, AV NA 31606. DE 276 vom 30.12.1993, GZ: 330-504.00 CHL.

281 PA AA, AV NA 31606. DB 74 vom 07.02.1994, GZ: Pol 504, Betr.: CD hier: Sachstand und Perspektiven. 
insbesondere die Aussage von Fuenzalida, der als einziger Zeuge eine direkte Verbindung zu Schäfer hergestellt hat. ${ }^{282}$

Während das AA seit 1990 die chilenische Strategie des Verwaltungshandelns zwar bestärkte, jedoch keine deutschen behördlichen Maßnahmen voranbrachte, vertrat die chilenische Regierung nun eindringlich die Position, dass der Schlüssel für eine Festnahme Schäfers bei der deutschen Justiz liege. Die Botschaft teilte diese Einschätzung. Während das AA seit 1987 zunehmend stärker erkannte, dass ein Handeln der Bundesrepublik erforderlich war, konnte die Bonner Staatsanwaltschaft bei den Beschuldigten ihres Ermittlungsverfahrens jedoch noch immer keinen hinreichenden Tatverdacht für eine Anklage erkennen.

Die Bonner Staatsanwaltschaft betrachtete die einzelnen Tatvorwürfe nicht im Kontext systematisch geplanter Verbrechen einer kriminellen Vereinigung, sondern als Einzeltaten deren Urheberschaft jeweils durch detaillierte Beweisführung nachgewiesen werden müsse. ${ }^{283}$ Hierfür fehlten jedoch oftmals die Voraussetzungen: Viele Taten waren nach deutschem Recht verjährt. Eine eigene Beweiserhebung in einem weit entfernten Land, mit dem es kein Rechtshilfeabkommen gab, war zudem hochkomplex. Daher erwartete die StA Bonn von der chilenischen Justiz, auf dem Wege einzelner Rechtshilfeersuchen die Übermittlung von Beweisen. Die Zusammensetzung der chilenischen Behörden hatte sich allerdings durch den Regierungswechsel personell kaum verändert. Die chilenische Justiz hielt weiterhin ihre schützende Hand über die CD. Die wenigen progressiven Kräfte bei Justiz und Ermittlungsbehörden bekamen nicht die erwartete Unterstützung. Dazu gehörten auch die fehlende Anklage bzw. Haftbefehle gegen die in Bonn beschuldigten Mitglieder der CD-Führung.

Darüber hinaus erhielt die StA Bonn regelmäßig Schriftsätze und weitere Informationen von der CD und deren Rechtsbeiständen. Diese waren immer wieder neue Darstellungen des Narrativs einer aus persönlichen Motiven geführten Verleumdungskampagne gegen die wohltätige $\mathrm{CD}$. Auch jetzt trug die beständige Lobbyarbeit der CD noch ihre Früchte: Anfang 1994 bat die StA Bonn das AA, der Einstellung des Verfahrens zuzustimmen. In der $C D$, so die Staatsanwaltschaft, deute manches darauf hin, »daß diese Menschen [die Colonos, JS] bewußt und freiwillig etwas auf sich genommen haben, was andere als Isolation, Zwangsarbeit und letztlich als Entmündigung bewerten könnten «. ${ }^{284}$ Die im Verfahren eingereichten vorgefertigten eidesstattlichen Erklärungen der Colonos, in denen sie beteuerten sie seien frei und es gehe ihnen gut, erschienen zwar vorgefertigt, es lägen jedoch keine Anhaltspunkte dafür vor, dass die Colonos zur Abgabe dieser Erklärungen gezwungen worden seien. ${ }^{285} \mathrm{AA}$ und Botschaft

282 Ebd. Zu Samuel Fuenzalida, ehemaliger DINA-Agent der bereits 1979 im Bonner Zivilverfahren ausgesagt hatte, vgl. Abschnitte 4.2.3 und 5.3.1.

283 Diese Sichtweise auf die CD-Verbrechen herrscht bei den Justizbehörden in NRW bis heute vor. Im Unterschied dazu stufte die chilenische Justiz stufte die während der Diktatur begangenen Verbrechen - zumindest ab 1998 rückwirkend - als Verbrechen gegen die Menschheit ein, die in Chile nicht verjähren. Der CDE stellte 1999 Strafanzeige wegen des Verdachts auf Bildung einer kriminellen Vereinigung gegen Mitglieder von CD und DINA (vgl. Abschnitt 3.1.4).

284 PA AA, AV NA 31606. StA Bonn, AZ 50 ]s 285/85. Einstellungsverfügung vom 26.01.1994.

285 Ebd. 
widersprachen der Einstellung des Verfahrens vehement. Sie zeigten sich bestürzt und argumentierten, dass eine derart kritische Würdigung der Hauptzeug_innen, wie $\mathrm{Hu}$ go Baar und dem Ehepaar Packmor, bei einer gleichzeitigen unkritischen Würdigung der Schutzbehauptungen der Beschuldigten einem Persilschein für die CD gleichkomme - mit fataler Wirkung. Die Anstrengungen von AA und Botschaft verlören dadurch an Glaubwürdigkeit. Eine Verfahrenseinstellung, so das AA, tangiere wichtige Belange der Bundesrepublik und solle daher »erst ins Auge gefasst werden«, wenn sie »auch nach eingehendster Prüfung aus rechtlichen und tatsächlichen Gründen unabdingbar« sei. $^{286}$

Die beschriebenen, sich widersprechenden Einschätzungen der CD sollten noch weiter bestehen bleiben. Eine weitere Thematisierung dieser folgenreichen Differenzen geht aus den mir bekannten Akten nicht hervor. Die Bonner Staatsanwaltschaft führte das Verfahren formal noch 15 Jahre lang weiter und stellte es 2010 ein. Auch in anderen Strafverfahren vertraten Staatsanwaltschaften in NRW bis 2019 eine sehr ähnliche Argumentation - sämtliche Verfahren wurden eingestellt, es kam zu keiner einzigen Anklageerhebung geschweige denn Verurteilung. Dies führte, wie vom AA befürchtet, in Chile zu einem Glaubwürdigkeitsverlust der bundesdeutschen Aufklärungsbemühungen. Deutsche Diplomat_innen mussten sich regelmäßig die Frage gefallen lassen, warum die deutschen Strafverfolgungsbehörden im Fall CD so tatenlos blieben.

\subsubsection{7-2005: Schäfers Ende durch Aufklärer_innen im Alleingang}

Nach etlichen Verzögerungen durch juristische Manöver der CD wurde der chilenische Haftbefehl gegen Paul Schäfer im Oktober 1996 rechtskräftig. Nach dem Haftbefehl nährten regelmäßige Razzien in der CD Hoffnungen auf eine Festnahme Schäfers. Botschaft und AA bereiteten sich auf das möglicherweise bevorstehende Zusammenbrechen des Systems CD vor. Im Vorfeld der Razzien bat die chilenische Regierung die deutsche Seite um Unterstützung in Form von Berater_innen und technischer Ausrüstung. Das zuständige Referat im AA schlug vor, Beteiligung oder Beratung bei dem Festnahmevorhaben abzulehnen. ${ }^{287}$ Als Begründung hieß es, die Strukturen der chilenischen Polizei seien zu undurchsichtig - eine diplomatische Formulierung für weiter bestehende Seilschaften der CD in Polizeikreisen - und ein Scheitern würde auch der deutschen Seite angelastet. Das Referat schlug vor, ein Kriseninterventionskonzept zu erarbeiten, um nach einer möglichen Festnahme Schäfers die Betreuung von Colonos zu gewährleisten. Außenminister Kinkel lehnte jegliche Unterstützung, selbst technischer Art, strikt ab. In einem handschriftlichen Vermerk eines Mitarbeiters heißt es, der Außenminister habe "noch einmal nachdrücklich gesagt: allein Sache der chil. Justiz«. ${ }^{288}$ Das zuständige Referat 330 beharrte dennoch auf der Entsendung eines Kriseninterventionsteams. ${ }^{289}$ Den erneuten Vorschlag kommentierte Kinkel handschriftlich wie folgt:

286 PA AA, AV NA 31606. Schreiben AA (Ref 330 über Dg 33) an AA (Referat 511) vom 08.02.1994.

287 PA AA, AV NA 32987. Ministervorlage vom 04.12.1996, GZ: 330.

288 Ebd.

289 PA AA, AV NA 32987. Ministervorlage vom 17.12.1996, GZ: 330. 
»1. Wer gehört genau der Expertengruppe an?

2. Intern d.h. hier in Deutschland können alle Überlegungen und Vorbereitungen geschehen.

3. Jeden Schritt nach draußen behalte ich mir vor.

4. Nun lassen sie uns doch mal abwarten, ob Schäfer festgenommen wird. Dann sehen wir, was zu geschehen hat.

5. Es ist absolut nicht unsere Aufgabe, dabei zu helfen.

6. Ich bin massiv daran interessiert, daß Herrn Schäfer und seinen Leuten das Handwerk gelegt wird. Aber das ist Sache der Chilenen. « 290

Explizite Begründungen, weshalb Kinkel jegliche Unterstützung ablehnte und die Verantwortung allein der chilenischen Seite zuschrieb, konnte ich in den Akten nicht finden. Selbstverständlich war der Ausgang der Festnahmebemühungen unklar, nicht zuletzt aufgrund der engen Verbindungen der CD mit den Carabineros. Gleichzeitig ließ Kinkel mit seiner Haltung diejenigen Richter und Ermittler_innen in Chile, die tatsächlich an einer Beendigung des Systems CD arbeiteten und die deswegen mit erheblichen Widerständen in ihren eigenen Reihen zu kämpfen hatten, de facto im Stich.

Bis in die zweite Jahreshälfte 1997 lebte Paul Schäfer noch in der CD und hätte theoretisch gefasst werden können. Die Flucht von Tobias Müller und Salo Luna aus der CD im Juli 1997 sorgte erneut für enorme mediale Aufmerksamkeit für den Fall CD. Müller und Luna reisten unter großem Medienaufsehen in die Bundesrepublik aus, deutsche Kamerateams begleiteten sie auf dem Flug nach Deutschland. Erstmals berichteten auch deutsche Medien wieder intensiver über den Fall CD. Da die CD in der öffentlichen Wahrnehmung nicht mehr vornehmlich mit Diktaturverbrechen, sondern eher mit dem sexuellen Missbrauch durch Schäfer assoziiert wurde, brach die Unterstützung aus dem rechten politischen Spektrum in Chile zunehmend weg. Unterstützer in Deutschland hatten sich bereits mit dem Ende der chilenischen Diktatur zurückgezogen.

Mitte August 1997 erließ die chilenische Justiz erstmals einen internationalen Haftbefehl gegen Schäfer. ${ }^{291}$ Sechs Wochen später erließ auch die deutsche Justiz Haftbefehl gegen Schäfer und damit erstmals nach 1961 gegen ein CD-Führungsmitglied. ${ }^{292} \mathrm{Meh}$ rere Colonos begaben sich zusammen mit Schäfer nach Argentinien und lebten dort im Untergrund auf einer Finca. Andere wie Winfried Schmidtke oder Dorothea und Michael Hopp gingen in andere südamerikanische Länder oder in die USA. Albert Schreiber, dessen Frau Lilli Nill und ihr Sohn Ernst entführten ein chilenisches Missbrauchsopfer, hielten es zwei Jahre lang in Chile fest und reisten nach der Freilassung des Jungen nach Deutschland aus. Ihre deutsche Staatsangehörigkeit schützte sie vor einer Auslieferung nach Chile, in Deutschland geführte Strafverfahren wurden aufgrund mangelndem Tatverdachts eingestellt. Dem Beispiel Schreibers folgten in den nächsten Jahren zahlreiche Colonos. Sie flohen vor der chilenischen Justiz nach Deutschland, wo sie

290 Ebd.

291 CA Santiago, AZ 2182-98 (»Alvaro Vallejos Villagrán), Bd. 3b, BI. 921. Bericht PDI vom 12.05.1999.

292 AG Siegburg, AZ 15 CS 495/97. Vollstreckungshaftbefehl gegen Schäfer wegen sexuellen Missbrauchs von Minderjährigen in acht Fällen vom 18.09.1997. Email von Interpol Wiesbaden Nr. 24713 vom 16.06.1998 mit. CA Santiago, AZ 2182-98 (»Asociación Ilícita«), Bd. 5 (Ministro), BI. 325 f. 
unbehelligt bleiben. Für chilenische Ermittler_innen und Menschenrechsanwält_innen ist die Haltung der Bundesrepublik in diesen Fällen unverständlich. Im Karibikstaat St. Kitts und Nevis erwarben diverse untergetauchte Colonos Ende der 1990er Jahre auf falsche Namen ausgestellte Pässe. Die chilenischen Ermittler_innen mussten gegen zahlreiche interne Widerstände sowie gegen die einflussreichen Anwält_innen der CD ankämpfen. Ihnen fehlte es an Zeit, Ressourcen und Kompetenzen, diese systematisch organisierten Untergrundaktivitäten der CD zu untersuchen. Hier hätten deutsche Ermittlungsbehörden, das AA oder auch der BND sicherlich unterstützend tätig werden können - über derartige Maßnahmen ist jedoch nichts bekannt. Insgesamt setzten sich ab 1998 eine Reihe von Colonos aus der CD ab, die von diversen CD-Verbrechen wussten. Sie verlangten zum Teil Abfindungen, die einige als Schweigegeld interpretierten. Bis 2005 wandte sich kaum einer dieser Colonos aus eigenen Stücken an die Öffentlichkeit oder an die Justiz. Die einzige Ausnahme war Efraín Vedder, der die Siedlung 2002 verließ und ein autobiografisches Buch verfasste. ${ }^{293}$

Schäfer dirigierte die CD aus dem Untergrund noch bis etwa 2001/2002. Das Zwangssystem der $\mathrm{CD}$ wurde weiter aufrechterhalten. Es gab auch weiterhin Fluchtversuche, die zum Teil vereitelt wurden. ${ }^{294}$ Schäfer hielt Kontakt zu CDFührungsmitgliedern, die nach Argentinien reisten. In der CD entwickelte sich ein Machtkampf um die Führung in der CD zwischen Hartmut Hopp und Hans-Jürgen Riesland. Riesland hielt bis etwa 2001/2002 den Kontakt zu Paul Schäfer in Argentinien. Nach dem Abbruch des Kontakts setzte sich Riesland 2003 in die Bundesrepublik ab. Die CD organisierte sich neu und verabschiedete sich dabei auch von ihren alten formalen Strukturen. 1995 löste die CD ihren Verein PSM und ihre Niederlassung in Siegburg endgültig auf. Nach der schließlich vollzogenen Auflösung der SBED in Chile existierte nun formal keiner der Kläger im Verfahren gegen Amnesty International mehr - im November 1997 stellte das LG Bonn das Verfahren daraufhin nach 20 Jahren ein. Bis zu diesem Zeitpunkt blieb es AI absurderweise untersagt, zu sagen, die CD sei ein Folterlager der DINA gewesen. Allerdings blieb AI durch den Wegfall der Kläger alleine auf den Gerichtskosten in Höhe von über 100.000 DM sitzen.

In Chile bemühten sich aufklärerische Vertreter_innen der Ermittlungs- und Justizbehörden weiterhin vergeblich um eine Festnahme Schäfers - nicht wissend, dass er das Land bereits verlassen hatte. Besonders zwei Abteilungen der Kriminalpolizei (PDI), das Departamento Quinto - Asuntos Internos (Abteilung Fünf - Interne Angelegeheiten) und die Brigada de Derechos Humanos (Menschenrechtsbrigade), ${ }^{295}$ kämpften gegen Widerstände und Blockaden von nach wie vor CD-freundlichen Teilen des Polizei- und Justizapparates. Die Regierungsparteien richteten in der Cámara de Diputados mehrere Untersuchungsausschüsse ein, um diese Blockaden zu untersuchen. Im Ergebnis machten diese Ausschüsse zahlreiche zum Teil weitreichende Empfehlungen, die aber faktisch folgenlos blieben. Im Laufe der Jahre setzte sich in der chilenischen

293 Vedder, Efraín/Ingo Lenz. Weg vom Leben. 36 Jahre Gefangenschaft in der deutschen Sekte Colonia Dignidad, Berlin 2005.

294 Z. B. die Flucht von Doris Gert 2001. Noch 2003 konnten Franz Baar und Ingrid Szurgelies die CD nur mit Hilfe der PDI verlassen. 
Öffentlichkeit der Eindruck von einem Versagen der staatlichen Behörden fest. Die bereits bestehenden Mythen über die vermeintliche Allmacht der CD wurden dadurch weiter befördert. Die Festnahme von Augusto Pinochet in London 1998 hatte einen großen positiven Einfluss auf die Aufarbeitung der Menschenrechtsverbrechen während der Diktatur. Dennoch gelang es der CD auch weiterhin, sich einer Aufklärung der CDVerbrechen sowie einer Durchsetzung geltenden Rechts in der Siedlung weitgehend zu entziehen. Während die prekäre Transición a la Democracia dazu führte, dass sich die Spielräume für eine Aufarbeitung des Falls CD langsam und unvollständig erweiterten, gelang es der CD, sich neu aufzustellen und ihre eigene transición retardada ${ }^{296}$ (verspätete Transición) auf die Zeit nach der Festnahme Schäfers zu verschieben. Das kriminelle System bestand noch weiter fort, und solange das so war, konnte es eine umfassende Aufarbeitung noch gar nicht geben.

In Deutschland führten der Antritt der rot-grünen Bundesregierung und die Ernennung Joschka Fischers zum Außenminister ab 1998 zu keinerlei nennenswerten Veränderungen in der Haltung des AA zum Fall CD, obwohl sich zahlreiche Abgeordnete von SPD und Bündnis 90/Die Grünen in den Jahren zuvor für eine Aufklärung engagiert hatten. Man beobachtete weiterhin die chilenischen Aufklärungsbestrebungen und führte mit der chilenischen Seite Gespräche darüber. Konkrete Maßnahmen zur Beendigung der faktisch straflosen Kontinuität der CD gab es nicht, obwohl sich auch in diesen Jahren noch Fluchtfälle aus der CD ereigneten, wie der von Doris Gert im Jahr 2001. Auch die Bonner Justiz unternahm weiterhin keine konkreten Maßnahmen, um die Beschuldigten in diversen anhängigen Ermittlungsverfahren festzusetzen. Obwohl keine letztendlichen Beweise dafür vorlagen, gingen beide Regierungen nun davon aus, dass sich Paul Schäfer nicht mehr in der CD aufhielt. Dies begründete Hoffnungen auf einen von Innen erwirkten Wandel des CD-Zwangssystems.

Im September 2004 führten Botschaftsangehörige das erste Mal seit 1987 wieder einen Konsularsprechtag in der CD durch. Daran beteiligt waren Wirtschaftsreferent Martin Schäfer und RK-Referent Ulrich Fischer. Ebenso wie ihre Kollegen 17 Jahre zuvor waren sie erschüttert über die menschliche Tragödie, die sie dort vorfanden. In seinem Bericht an das AA schlug Martin Schäfer vor, Maßnahmen der psychologischen und seelsorgerischen Betreuung für Colonos einzuleiten. Außerdem solle die Fahndung nach Paul Schäfer intensiviert werden, was durch politischen Druck auf Chile, Argentinien und Uruguay erreicht, jedoch auch durch eigene Anstrengungen zur Unterstützung der Fahndung geschehen könne. ${ }^{297}$ Für materielle Hilfe, etwa durch Projekte der technischen Zusammenarbeit sei es jedoch noch zu früh, da sie die bewahrenden Kräfte in der CD stärken könnte. ${ }^{298}$ Als Reaktion auf den Konsularsprechttag entwarf das AA eine Planung für den Umgang mit der CD für die kommenden Jahre. ${ }^{299}$ Diese sah in

296 Vgl. Hevia, Evelyn/Jan Stehle (2015): Los estados y los derechos humanos: aproximaciones a cinco décadas de Colonia Dignidad, in: Hevia/Stehle (Hg.). Colonia Dignidad: diálogos sobre verdad, S. 11-20.

297 PJS, Sammlung AA. Bericht Botschaft Santiago/Martin Schäfer an das AA vom 09.09.2004 über den Konsularsprechtag in der CD vom 29-31.08.2004.

298 Ebd.

299 PJS, Sammlung AA. DB 171 vom 12.12.2007. Erster Besuch des deutschen Botschafters seit über 20 Jahren zusammen mit RL 330 und L'in RK. 
einer Phase vor, die Suche nach Paul Schäfer zu intensivieren, wofür vornehmlich Chile zuständig sei. In der darauffolgenden Phase sollten seitens des AA Gelder für psychologische und seelsorgerische Betreuung von Colonos bereitgestellt werden. In einem dritten Schritt sollten sich Deutschland und Chile gemeinsam um die »Sicherung des wirtschaftlichen Überlebens der Opfer und deren Integration in die chilenische Gesellschaft« bemühen. ${ }^{300}$

Nach vielen Jahren der erfolglosen Fahndung hatten viele Aufklärer_innen bereits die Hoffnung aufgegeben, dass der inzwischen bereits 83-jährige Schäfer jemals aufgefunden und für seine Taten belangt werden würde. Am 10. März 2005 gelang es der argentinischen Polizei, angeführt von Kommissar Salvador Bellusci, ${ }^{301}$ Schäfer zu verhaften. Auch dieser Zugriff ging nicht auf chilenische oder deutsche Ermittlungsbehörden zurück, sondern war den Aktivitäten aufklärerischer Akteur_innen zu verdanken, konkret dem Einsatz eines Fernsehteams des chilenischen Senders Canal 13 um die Journalist_innen Carola Fuentes und Gustavo Villarubia sowie dem Engagement des Rechtsanwalts Hernán Fernández. ${ }^{302}$

Fuentes und Villarubia hatten im Januar 2004 Begleiter Schäfers in der Kleinstadt Chivilcoy, etwa $150 \mathrm{~km}$ westlich von Buenos Aires ausfindig gemacht und ihre Finca monatelang observiert. ${ }^{303}$ Fernández reiste mehrfach nach Argentinien und stellte den Kontakt zur argentinischen Kriminalpolizei her. Erst im November wurden vertrauenswürdige Beamte der chilenischen Kriminalpolizei (PDI) informiert. Diese verständigten Richter Joaquín Billard, der bereits zum Fall des Verschwundenen Alvaro Vallejos Villagrán ermittelte. Am 12. November erließ Billard einen internationalen Haftbefehl gegen Schäfer. ${ }^{304}$ Am 10. Februar 2005 teilte der argentinische Kommissar Salvador Bellusci der PDI mit, dass man Schäfer und einige andere sicher lokalisiert habe. ${ }^{305}$ Um einen Zugriff zu erleichtern, solle der Haftbefehl auf Schäfers Begleiter_innen ausgeweitet werden. ${ }^{306}$

Deutsche Ermittler_innen spielten bei den Bemühungen um die Lokalisierung und Festnahme Schäfers keinerlei Rolle. Nach Ausstellung des internationalen Haftbefehls

300 Ebd.

301 Vgl. Bellusci, Salvador. Fin de un mito, Buenos Aires 2008. Darin schildert Bellusci seine Erfahrungen bei der monatelangen Vorbereitung der Verhaftung Schäfers.

302 Vgl. ebd. sowie Villarubia, Gustavo. »Los 13 meses para encontrar a Schäfer«, in: Qué Pasa vom 30.04.2010, online unter https://www.quepasa.cl/articulo/actualidad/2010/04/1-3263-9-los-13-mese s-para-encontrar-a-schafer.shtml/.

303 Villarubia, Gustavo. »Mi vida bajo el régimen de Paul Schäfer«. La historia de uno de los guardaespaldas del líder de Colonia Dignidad [Interview mit Friedhelm Zeitner], in: CIPER (Website), 23.09.2013, online unter https://www.ciperchile.cl/2013/09/23/"mi-vida-bajo-el-regimen-de-paul-sc hafer".

304 CA Santiago, AZ 2182-98 (»Alvaro Vallejos Villagrán«), Bd. 7a, Bl. 2468. Anordnung von Richter Joaquín Billard an das Departamento V der PDI zur Ausstellung eines internationalen Haftbefehls bzgl. Paul Schäfer.

305 Dies waren Schäfers Adoptivtochter Rebeca, Friedhelm Zeitner, Matthias Gerlach, Peter Schmidt und Renate Freitag.

306 CA Santiago, AZ 2182-98 (»Alvaro Vallejos Villagrán«), Bd. 7a, BI. 2522f. Oficio Secreto Nr. 5 der PDI, Brigada Investigadora de Asuntos Especiales y de $\mathrm{DDHH}$, an Richterin Amanda Valdovinos vom 11.02.2005. 
durch die StA Bonn 1997 war Schäfer zwar international zur Festnahme ausgeschrieben, es fand jedoch keine gezielte Fahndung nach ihm statt, ${ }^{307}$ d.h. man wartete mehr oder weniger darauf, dass er zufällig festgenommen würde, etwa bei einem Grenzübertritt. Am selben Tag an dem Billard den Haftbefehl gegen Schäfer erließ, teilte das BKA dem BMI mit, es gäbe zwar Hinweise, dass Schäfer sich nach Argentinien abgesetzt haben könnte, sein Aufenthalt dort sei aber »nicht bestätigt«. ${ }^{308}$ Als RA Hernán Fernández einige Tage vor dem Zugriff im März 2005 den BKA-Verbindungsbeamten in Buenos Aires um Hilfe bitten wollte, wurde ihm mitgeteilt, dieser sei gerade im Urlaub. ${ }^{309}$ Auch andere Anzeichen für eine enge Zusammenarbeit mit argentinischen oder chilenischen Polizeibehörden finden sich nicht. ${ }^{310}$ Zwar gab es von 1961 bis 1970 sowie von 1997 bis 2005 einen formalen Haftbefehl, aber konkrete Maßnahmen oder auch nur ein besonderes Interesse deutscher Strafverfolgungsbehörden an einer Ergreifung Schäfers lassen sich nach jetzigem Kenntnisstand nicht feststellen.

\subsection{Phase V (2005 bis heute): Die verspätete Transición der Colonia Dignidad}

Am 10. März 2005 wurde Schäfer schließlich in Tortuguitas, einem Vorort von Buenos Aires, festgenommen. ${ }^{311}$ Bereits am folgenden Tag wurde er nach Chile abgeschoben mit der offiziellen Begründung, er sei illegal nach Argentinien eingereist. Dies erfolgte aufgrund der beiden internationalen Haftbefehle in Absprache mit der chilenischen und der deutschen Regierung. Die Bundesregierung hatte keinerlei Interesse an einer Auslieferung nach Deutschland, die ebenfalls möglich gewesen wäre. Damit machte sie erneut klar, dass aus ihrer Sicht die Hauptverantwortung für die Aufarbeitung der CD-Verbrechen in Chile lag.

Die Bundesregierung begrüßte die Festnahme Schäfers. Außenminister Fischer behauptete, diese sei der »hervorragenden Zusammenarbeit« zwischen deutschen, chilenischen sowie argentinischen Strafverfolgungsbehörden zu verdanken. Die »intensiven Bemühungen« der Bundesregierung zur Festnahme von Schäfer hätten zu einem Erfolg geführt, der nun eine umfassende Aufklärung und Ahndung der Verbrechen der CD ermöglichen werde. ${ }^{312}$ Die Aussagen der an der Festnahme Beteiligten, aber auch die Tat-

307 PJS, Sammlung IFG BMI. Schreiben BKA an BMI vom 12.11.2004, AZ ZD32-R.

308 Ebd.

309 PJS, Sammlung Gesprächsnotizen. Vermerk über Gespräch mit Rechtsanwalt Hernán Fernández vom 11.12.2014.

310 PJS, Sammlung IFC BMI. Schreiben BKA an BMI vom 12.11.2004, AZ ZD32 - R.

311 Der Zugriff erfolgte während Schäfer Mittagsschlaf hielt, neben seinem Bett sollen eine Bibel und pornografische Zeitschriften gelegen haben. Vgl. Villarubia, Gustavo. »Los 13 meses para encontrar a Schäfer«, in: Qué Pasa vom 30.04.2010, online unter https://www.quepasa.cl/articulo/actualidad /2010/04/1-3263-9-los-13-meses-para-encontrar-a-schafer.shtml/.

$312 \mathrm{ACH}$, Bestand RFA, Telex 2005. Pressemitteilung Auswärtiges Amt vom 11.03.2005, »Bundesaußenminister Fischer begrüßt Festnahme von Paul Schäfer«, vgl. auch Frankfurter Allgemeine Zeitung vom 11.03.2005. » Deutscher Sektenführer Schäfer in Argentinien gefaßt«, online unter: https://www.faz.net/aktuell/politik/ausland/colonia-dignidad-deutscher-sektenfuehrer-scha efer-in-argentinien-gefasst-1208005.html. 
sachen (vgl. letzter Abschnitt) widersprechen dieser Darstellung Fischers. Wie bereits erwähnt findet sich in den verfügbaren Akten keinerlei Hinweis auf eine Mitwirkung deutscher Behörden bei der Festnahme Schäfers. Auch eine strafrechtliche Aufarbeitung der CD-Verbrechen fand zwar seit 2005 in Teilen in Chile statt - aber auch hier ist ein Beitrag deutscher Staatsanwaltschaften oder Gerichte nicht auszumachen. Sämtliche 2005 noch anhängigen oder seitdem eröffneten Ermittlungsverfahren wurden bis 2010 aufgrund mangelnden Tatverdachts eingestellt, eine nennenswerte Beweiserhebung gab es nicht.

In Chile war das Interesse der Öffentlichkeit nach der Festnahme Schäfers groß. Die chilenische Justiz, aber auch die Exekutive bemühten sich, die Erwartungen an eine Aufarbeitung der CD-Verbrechen zu erfüllen. Zahlreiche bereits laufende Strafverfahren wurden bei Jorge Zepeda zusammengeführt, einem eigens dafür abgeordneten Richter an der CA Santiago. Zepeda eröffnete noch weitere Verfahren und nahm mehrere CD-Führungsmitglieder, darunter Hartmut Hopp, Kurt Schnellenkamp und Gerhard Mücke, mehrere Monate lang in Untersuchungshaft, wo sie weitreichende Aussagen machten. Zepeda arbeitete auch mit testigos reservados (Kronzeug_innen) zusammen, deren Identität geschützt wurde und denen vermutlich im Gegenzug für ihre Aussagen Strafverschonung zugesichert wurde. Zepeda vernahm Dutzende Colonos, viele von ihnen gaben Kenntnisse über CD-Verbrechen preis. Allerdings scheint es dabei auch Absprachen unter den Zeug_innen gegeben zu haben. So konnten viele Verbrechenskomplexe (wie z.B. das Verschwindenlassen politischer Gefangener in der CD, vgl. Abschnitt 4.2.3) nachvollzogen werden, aber nicht so, dass einzelne Personen konkreter Taten hätten überführt werden können. Zepedas Ermittlungseifer ebbte jedoch bald wieder ab, tatsächlich ermittelt wurde im Wesentlichen von 2005 bis 2007. Zwischen 2008 und 2015 fällte Zepeda etwa ein Dutzend Urteile wegen der CD-Verbrechen. Darin belegte er verschiedenste Arten von Verbrechen, die nun gerichtlich festgestellte Tatsachen sind und nicht mehr nur Mutmaßungen oder »Anschuldigungen«, wie die CD stets behauptet hatte. Viele Tatkomplexe ermittelte Zepeda jedoch nur oberflächlich und viele Einzelverbrechen überhaupt nicht. In mehreren Verfahren verurteilte er Paul Schäfer als Haupttäter zu einer effektiven Haftstrafe, während andere Angeklagte als Mittäter_innen Bewährungsstrafen erhielten. Die höchsten Strafen wurden von Richter González an der CA Talca verhängt im Verfahren wegen sexuellem Missbrauch. Wegen der Menschenrechtsverbrechen im Kontext der Diktatur saß hingegen bis heute noch kein einziger Colono im Gefängnis. ${ }^{313}$ Heute ist als einziges CD-Führungsmitglied noch Gerhard Mücke inhaftiert. Insgesamt haben mehr als ein Dutzend verurteilte CD-Mitglieder zusammen bislang nicht mehr als 20 Jahre Haft verbüßt. Dank der CD-Anwälte wurden viele schon vorzeitig wieder aus der Haft entlassen. Viele Beschuldigte (aber auch rechtskräftig Verurteilte, wie Hartmut Hopp) setzten sich in die Bundesrepublik ab, wo nicht oder nicht mehr gegen sie ermittelt wird. So wurde beispielsweise gegen Rudolf

313 Als Ausnahme kann hier die Verurteilung von Karl van den Berg und von Cerhard Mücke zu fünf Jahren Haft im Verfahren wegen Bildung einer kriminellen Vereinigung gelten, das sich vornehmlich auf die CD-DINA-Verbindungen bezog. Van den Berg wurde nach etwa eineinhalb Jahren wieder auf freien Fuß gesetzt und kehrte wie die meisten der Verurteilten nach ihrer Haft wieder in die CD zurück. 
Cöllen oder Hans-Jürgen Riesland nie ernsthaft ermittelt. Während Schäfer die letzten fünf Jahre seines Lebens in Haft verbrachte, verstarben Jerarcas wie Albert Schreiber, Alfred Matthusen, Hans-Jürgen Blanck und Gisela Seewald, ohne je für ihre Taten belangt zu werden. Gerd Seewald und Kurt Schnellenkamp verstarben nach kurzer Haft.

Die Bundesregierung sah ihre Verantwortung nach der Festnahme Schäfers vor allem bei den Colonos. Sie konzentrierte ihre Maßnahmen auf die Unterstützung derjenigen Colonos, die sich zu einem Verbleib in der CD entschieden. Ihre Leitlinie war dabei, die CD vor Ort zu erhalten, den Colonos psychosozialen Beistand zu leisten und vor allem ihr wirtschaftliches Überleben zu sichern. Anstatt also eine Auflösung der CD zu erwirken, wurde de facto ihr Fortbestand abgesichert - wenn auch nicht in der bisherigen Form, sondern in einer Art Post-Sektengemeinschaft. Da dies jedoch ohne eine umfassende Aufklärung oder gar Ahndung der zahllosen internen Verbrechen der CD geschah, wurde faktisch die Reproduktion und Transformation von internen Strukturen und Machtverhältnissen der CD erst ermöglicht.

Von 2008 bis 2013 stellte die Bundesregierung insgesamt über eine Million Euro bereit für die psychosoziale und seelsorgerische Betreuung von Colonos sowie für Beratungsdienstleistungen für die Schule und Betriebe der CD. Etwa $60 \%$ der Mittel wurden für die Beratung von Unternehmen der ABC-Holding durch die GIZ verwendet.

Bezüglich der psychosozialen Betreuung hatten mehrere Gutachten aus den Vorjahren argumentiert, dass die Colonos derart traumatisiert seinen, dass ihre Eingliederung in die freie Gesellschaft ihnen möglicherweise schwerfallen könnte. Auch wenn sich in den Akten keine direkten Belege dafür finden, spricht doch vieles dafür, dass diese Einschätzung der Bundesregierung mit ihren politischen Erwägungen gut gelegen kam: Eine Auflösung und Schließung der CD - die die chilenische Regierung mehrfach erwogen hatte - hätte vermutlich zur Folge gehabt, dass die etwa 300 verbliebenen Colonos mehrheitlich nach Deutschland emigriert wären. Dies hätte höchstwahrscheinlich ein großes Medieninteresse hervorgerufen und damit vermutlich auch Fragen nach der Mitverantwortung der Bundesregierung für die jahrzehntelangen Verbrechen der CD aufgeworfen. Die Maßnahmen entsprachen daher der Leitlinie der Bundesregierung, das Thema CD in Chile zu belassen.

In den ersten drei Jahren nach Schäfers Festnahme organisierte die Botschaft etwa 25 Konsularsprechtage in der CD. Das AA initiierte ein psychotherapeutisches Betreuungsprogramm unter Leitung des Psychiaters Niels Biedermann. ${ }^{314}$ Die seelsor-

314 Vgl. Biedermann, Niels/Judith Strasser/Julian Poluda. »Colonia Dignidad« - Psychotherapie im ehemaligen Folterlager einer deutschen Sekte, in: Zeitschrift für Politische Psychologie, 14 (2006) Nr. 1+2, S. 111-127 sowie Bauer, Susanne. Psychologische Behandlungsmöglichkeiten für religiös traumatisierte Menschen am Beispiel der Sekte Colonia Dignidad, in: Utsch, Michael (Hg.). Pathologische Religiosität - Cenese, Beispiele, Behandlungsansätze, Stuttgart 2012, S. 67-105. Niels Biedermann ist seit 2005 im Auftrag der Bundesregierung kontinuierlich als Psychiater in der CD tätig und dürfte damit die externe Person mit den tiefgehendsten Kenntnissen des Innenlebens der CD sein. Biedermann steht in regelmäßigem Kontakt mit der Botschaft und beteiligt sich auch an internen Zirkeln und Arbeitskreisen innerhalb der heutigen CD. 2018 trat er in Erscheinung als verschiedene Menschenrechtsorganisationen zusammen mit dem chilenischen Menschenrechtsanwalt und Ex-Colono Winfried Hempel sowie mir beim Ethiktribunal der chilenischen Ärztekammer Anzeigen gegen den Psychiater Otto Dörr Zegers einreichten. Dörr hatte die CD 
gerische Betreuung der Colonos übernahm der evangelisch-lutherische Pastor Enno Haaks. Dieser hatte es von Beginn an nicht leicht: die meisten Colonos, die Jahrzehnte in dem CD-Zwangssystem gelebt hatten, verbanden mit christlichem Glauben nur einen bestimmten Typ fundamentalistischen Predigens, den sie von Schäfer kannten. Einen religiösen Diskurs, der anschlussfähig daran war, bot ihnen dabei der Prediger Ewald Frank von der Freien Volksmission Krefeld. Frank kam im April 2004 erstmals in die CD und erkannte das aus seiner Sicht bestehende spirituelle Vakuum. In den Folgemonaten reiste er mehrfach nach Chile und taufte über 100 Colonos. Als die chilenische Regierung erkannte, dass Frank auf dem Weg war, sich zu einer neuen religiösen Führungsfigur der CD zu entwickeln, verhängte sie im Oktober 2005 eine Einreisesperre gegen ihn. ${ }^{315}$ Frank intervenierte vergeblich bei der chilenischen Botschaft und beim AA dagegen. Er kontaktierte nach eigenen Angaben den ehemaligen Bundeskanzler Helmut Schmidt. Sein Sohn Werner drohte der chilenischen Vertretung mit einem internationalen Skandal: Sein Vater wisse sehr viel über die Vorgänge in der CD. ${ }^{316}$ In den Folgejahren sandte Ewald Frank seine Vertreter Urs Graff und Helmut Myskies zu Predigten in die CD. Gleichzeitig siedelten sich mehrere Ex-Colonos in Krefeld bzw. in der Umgebung an und besuchten regelmäßig die Predigten in der Freien Volksmission. Darunter waren auch zahlreiche Beschuldigte aus den chilenischen Strafverfahren und sogar CD-Mitglieder, gegen die ein internationaler Haftbefehl vorlag wie Albert Schreiber, Lilli Schreiber, Ernst Schreiber und Hartmut Hopp. Ewald Frank wurde so zu einem wichtigen Referenzpunkt der Post-Sektengemeinschaft der CD. Einige Mitglieder der ehemaligen Führung sowie weitere heute noch in der CD lebenden Colonos

jahrelang öffentlich verteidigt und nach der Flucht des Colonos Karl Stricker 1996 auf Bitten von Hopp Stricker psychiatrisch behandelt. Dabei hatte Dörr auch Stricker Bescheinigungen ausgestellt, welche die CD-Anwälte nutzten, um Strickers Erscheinen vor Cericht zu verhindern (Vgl. Abschnitt 5.2.4). Karl Stricker stürzte 2002 in der CD von einem Dach und verstarb. Bei seiner Obduktion fand der gerichtsmedizinische Dienst (Servicio Médico Legal -SML) Spuren von Psychopharmaka in seinem Körper. Biedermann beteiligte sich an einer Unterschriftenkampagne zugunsten von Dörr. Diese stellte die Anzeigen beim Ethiktribunal als Verleumdungskampagne dar (Vgl. El Mercurio vom 13.05.2018, S. C8. »Inserción - Inaceptable campaña de difamación en contra del Dr. Otto Dörr«). Darüber hinaus gab Biedermann Interviews, in denen er Dörr von jeglicher Verantwortung freisprach (Vgl. Penjean, Lorena. »Niels Biedermann, psiquiatra de los sobrevivientes de Colonia Dignidad: >Nunca, en los trece años que llevo trabajando con los colonos he oído mencionar el nombre del doctor Dörr « [Interview mit Niels Biedermann und Karin Hinzner], in: The Clinic (Website), 02.05.2018, online unter https://www.theclinic.cl/2018/05 /02/niels-biedermann-psiquiatra-los-sobrevivientes-colonia-dignidad-nunca-los-trece-anos-llevo-t rabajando-los-colonos-he-oido-mencionar-nombre-del-doctor-dorr/. Am 10.09.2019 sanktionierte das Ethiktribunal Dörr wegen Verstößen gegen die ethischen Leitlinien der Ärztekammer. Colegio Médico de Chile, Tribunal Nacional de Ética, AZ TNE 008-18, Urteil vom 10.09.2019, online unter: https://www.cooperativa.cl/noticias/site/artic/20190910/asocfile/20190910222606/sentencia_causa _rol_n_008_18_10_09_19_.pdf.

Vgl. La Tercera vom 21.10.2005, S. 25. »Predicador alega que le impidieron la entrada por motivos religiosos«.

Sergio Rodriguez Oro, Anwalt der CD, erwirkte im Dezember 2014 durch einen Schutzantrag eine Aufhebung dieser Einreisesperre. Corte Suprema, AZ 32430-2014.

316 ACH, Bestand RFA, Oficios Reservados 2005. Oficio reservado nro. 437 vom 10.11.2005. Ref: Remite nueva comunicación pastor Ewald Frank. 
sind bis heute Anhänger von Frank. Sie verfolgen die Predigten der Freien Volksmission per Livestream und reisen regelmäßig nach Krefeld. Viele ehemalige Colonos haben sich zudem in Krefeld und Umgebung niedergelassen und besuchen die Freie Volksmission. Franks sektenhafter religiöser Duktus sowie seine pseudoreligiöse Betonung der Vergebung und des Nach-vorne-Schauens stärken bis heute das Schweigekartell der Täter_innen der CD-Verbrechen und wirken sich negativ auf eine Demokratisierung der heutigen $C D$ aus.

Botschaft und AA hatten bereits als Problem identifiziert, dass die in der CD verbliebenen Colonos sich weiterhin als Gemeinschaft betrachteten. Auch verurteilte oder bekannte Täter_innen wurden von ihnen weiterhin akzeptiert, sogar ihre Rechtsbeistände wurden aus der Gemeinschaftskasse bezahlt. ${ }^{317}$ Botschaft und AA betrachteten dies jedoch als nachrangig und zogen keinerlei Konsequenzen daraus. Stattdessen setze das AA seine Förderung einer »Integration der VB/CD in ihr chilenisches Umfeld« fort (vgl. Abschnitt 3.2.3). Nach außen betonte das AA, die »Opfer unter den Colonos $\mathrm{zu}$ unterstützen. Zugleich war sich das AA jedoch bewusst, dass jegliche Unterstützung, insbesondere für die Unternehmen der $\mathrm{ABC}$-Holding, nicht nur den besonders Geschädigten, sondern der gesamten CD und damit auch ehemaligen (Mit-)Täter_innen zugutekam. ${ }^{318}$

Bis heute werden die ABC-Unternehmen von Kindern ehemaliger Führungspersonen geleitet. Sie genossen nach dem Untertauchen Schäfers zahlreiche Privilegien. So durften viele von ihnen ab Ende der 1990er Jahre außerhalb der CD studieren, was vielen anderen Colonos verwehrt wurde. Anschließend bekleideten sie dann Vorstandsposten in den $\mathrm{ABC}$-Unternehmen und führten deren nicht immer durchsichtige Geschäfte weiter. In den Jahren der Projektförderung durch die Bundesregierung bestand regelmäßiger Kontakt der Botschaft zu diesen neuen Jerarcas. Verbände von CD-Opfern und Menschenrechtsaktivist_innen, die in jenen Jahren nicht zu Botschaftstreffen geladen wurden, nahmen dies mit Unverständnis zur Kenntnis. Sie kritisierten dieses Verhalten von Botschaft und AA als Torpedierung der Bemühungen um eine Aufarbeitung der CD-Verbrechen. Bei Opferverbänden und Menschenrechtsorganisationen entstand vielfach der Eindruck, dass es der Bundesregierung tatsächlich eher darum ging, die Vergangenheit zu deckeln und den Status quo in der CD zu stabilisieren. Auch mehrere kritische Colonos, von denen einige inzwischen die $C D$ verlassen hatten, bewerteten das Verhalten des AA als Versuch, die bewahrenden Kräfte innerhalb der CD zu stützen. Dieser Eindruck wurde dadurch bestärkt, dass dieselben Rechtsanwält_innen, die Ende der 1980er Jahre an der betrügerischen Übertragung des CD-Vermögens an die ABC-Unternehmen beteiligt gewesen waren, diese Unternehmen zum Teil immer noch

317 PJS, Sammlung AA. DB 171 vom 12.12.2007. Erster Besuch des deutschen Botschafters seit über 20 Jahren zusammen mit RL 330 und L'in RK.

318 Vgl. El Condor vom 08.08.2008, S. 16. »Botschafter Peter Scholz: > Ein gewaltiges Rad gedreht «. Der 2008 abberufene Botschafter Scholz äußerte sich darin wie folgt: »Wir sind sogar bis zu einer Projektzusammenarbeit vorgedrungen, allerdings nur mit den Opfern. Das ist nicht ganz leicht, weil es keine gewählte Führung der Colonia gibt, da die zum Teil auf freiem Fuß befindlichen verurteilten Täter wieder dort wohnen.« 
vertraten und gleichzeitig noch beschuldigte ehemalige Führungspersonen als Rechtsbeistände in Strafverfahren vertraten.

Die Vorstände der ABC-Unternehmen behaupteten seit 2005 regelmäßig, kurz vor einer Insolvenz $\mathrm{zu}$ stehen. Als Grund hierfür gaben sie u.a. auf den Grundstücken der $\mathrm{CD}$ lastende Pfandrechte an, mit denen die $\mathrm{ABC}$-Unternehmen belegt wurden als Sicherheit für mögliche Entschädigungsforderungen des chilenischen Staates im Falle einer Verurteilung wegen Betruges (vgl. Abschnitt 3.2.3). Die Diplomat_innen glaubten ihnen, ohne die tatsächlichen Verhältnisse des (offenen und versteckten) CD-Vermögens im Detail zu kennen. Auch die Botschaft konstatierte, die CD stehe vor dem wirtschaftlichen Abgrund. Sie gab bei dem Insolvenzverwalter Herman Chadwick ein Gutachten in Auftrag, das diese Einschätzung bestätigte. ${ }^{319}$

Vertreter der chilenischen Regierung und des CDE misstrauten dieser Darstellung und waren der Überzeugung, dass die ABC-Unternehmen, die schon durch betrügerische Geldtransfers entstanden waren, ihre tatsächliche Vermögenssituation weiterhin verheimlichten. ${ }^{320}$ Die Unternehmen hatten durch die Ausgründung zahlreicher Tochterunternehmen die Komplexität der ohnehin bereits höchst intransparenten Unternehmensstruktur noch weiter erhöht. Außerdem hatten mehrere Colonos zusätzlich zahlreiche $\mathrm{ABC}$-externe Gesellschaften gegründet. Für die chilenische Regierung war die Haltung der Bundesregierung ein Ärgernis: Sie sah, dass die chilenischen Strafverfahren nur langsam oder gar nicht vorankamen und die (mutmaßlichen) Täter_innen weiterhin in der Siedlung lebten, während die Bundesregierung gegenüber der chilenischen Regierung auf eine Beendigung der Belegung der ABC-Ländereien mit Pfandrechten drängte. Schließlich setzte sich die Bundesregierung durch: 2009 verhandelte der CDE ein Abkommen zur Aufhebung des Embargos. ${ }^{321}$

Der Einsatz der Bundesregierung für die $\mathrm{ABC}$-Unternehmen und gegen das sogenannte Embargo folgte ihrer Leitlinie, den Fortbestand der CD über die Aufklärung der CD-Verbrechen zu priorisieren. Auch der Bundesregierung war von Anfang an klar, dass diese Unternehmen schon auf betrügerische Weise zustande gekommen waren und dass sie das wirtschaftliche Fundament des Systems CD gewesen waren.

Die neuen Jerarcas wiederum wehrten sich mit allen juristischen Mitteln gegen eine Untersuchung der tatsächlichen Vermögenssituation der CD. Die hierfür notwendigen Rechtsanwält_innen und Berater_innen bezahlten sie aus eben jenem undurchsichtigen Vermögen, zudem möglicherweise auch diverse schwarze Kassen gehörten. Die Bundesregierung sah sich außer Stande, zur Aufklärung der Vermögenssituation der CD beizutragen. Sie verwies auf die Verantwortung der Justiz, wohl wissend, dass die in

319 Ramírez, Pedro. »Crisis en la ex Colonia Dignidad desata pugna por la fortuna que ocultó Schäfer, in: CIPER (Website), 24.03.2009, online unter http://ciperchile.cl/2009/03/24/crisis-en-la-ex-coloni a-dignidad-desata-pugna-por-la-fortuna-que-oculto-schafer/.

320 PJS, Sammlung AA. DB 171 vom 12.12.2007. Erster Besuch des deutschen Botschafters seit über 20 Jahren zusammen mit RL 330 und L'in RK.

321 PJS, Sammlung CD. Vertrag »Transacción e Hipotecas Fisco de Chile - Consejo de Defensa del Estado e Inmobiliaria e Inversiones Cerro Florido Limitada y Abratec S.A.«, unterzeichnet am 21.08.2009 im Notariat Osvaldo Pereira González, Repertorio No 11.335 - 09, Online unter: http: //ciperchile.cl/wp-content/uploads/escritura-publica.pdf. 
dieser Sache nicht tätig werden würde und nach der Einstellung des Verfahrens wegen Betruges (contratos simulados) auch nicht mehr konnte.

In Deutschland waren ausschließlich eng definierte Einzelverbrechen Gegenstand der Strafermittlungen. Dabei wurde die CD zu keinem Zeitpunkt als (wirtschaftlich) kriminelle Struktur betrachtet - also gewissermaßen als Akteur organisierter Kriminalität. Daher wollten und konnten die Staatsanwaltschaften Tatbestände wie Geldwäsche oder zweifelhafte internationale Geldtransfers nicht untersuchen - obwohl ihr Hinweise zu entsprechenden Straftaten vorlagen. In Chile war das Handeln der Justiz weiterhin durch die faktischen Restriktionen der Transición beschränkt. Die Rechtsbeistände der CD bekämpften jegliche Versuche einer juristischen Aufklärung unter Ausnutzung sämtlicher Rechtsmittel.

Während politische Instanzen der Bundesregierung nie Verfahrensbeteiligte in den strafrechtlichen Untersuchungen in Chile wurden und somit ihrer in den 1970er Jahren ausgegebenen Leitlinie einer juristischen Auseinandersetzung zwischen privaten Akteur_innen treu blieben, wurde der chilenische Staat über Strafanzeigen des CDE und des Innenministeriums Verfahrensbeteiligter. Auch hier unterlag er jedoch Restriktionen, die die Transición mit sich brachte, in denen Akteur_innen, die einer Aufarbeitung entgegenwirkten, weiterhin überproportional präsent waren.

In der bereits erwähnten Vereinbarung mit dem CDE zur Aufhebung der Beschlagnahme im Jahr 2009 verpflichteten sich die Vorstände der ABC-Unternehmen zu Entschädigungszahlungen aufgrund von Urteilen gegen einzelne CD-Mitglieder. Die Bedingungen hierfür waren allerdings diffizil: Die Regelung galt nur für Urteile, die bis Ende 2017 rechtskräftig eine Verpflichtung von einzelnen CD-Täter_innen zu Entschädigungszahlungen an Opfer feststellten. Doch selbst dieser eingeschränkten Verpflichtung kamen die ABC-Unternehmen nicht nach. Stattdessen drängten die ABC-Unternehmen über ihre Anwält_innen darauf, die rechtskräftigen Entschädigungsverpflichtungen ${ }^{322}$ auszusetzen, um Zahlungen an Opfer zu verhindern.

Besonders kritisch sehen Opferverbände und Menschenrechtsorganisationen den Umgang mit dem Ort Colonia Dignidad. Lange Zeit wurden die schweren Menschenrechtsverbrechen, die hier stattfanden, vor Ort in keiner Weise thematisiert. Stattdessen wurde die »Villa Baviera« (Bayern-Dorf), wie sich die CD seit den 1980er Jahren nannte, zu einer Tourismusattraktion. Im Anschluss an die bayrisch-volkstümliche Fassade, welche die CD schon über viele Jahre gepflegt hatte, wurde hier folkloristisches Deutschtum präsentiert. Bereits 2004 entstand die Idee von Colonos, den Tourismus als neue Einnahmequelle für die Siedlung zu erschließen. ${ }^{323}$ Bis dahin hatte die CD nur

322 Es handelt sich hier um von der Corte Suprema im Januar 2013 im zivilrechtlichen Teil ihres Urteils zum sexuellen Missbrauch an chilenischen Kindern festgelegten Entschädigungszahlungen in Höhe von umgerechnet etwa 1,25 Millionen Euro. Eine Vollstreckung dieser Entschädigungsverpflichtungen gegen die CD-Unternehmen verhinderten diese bislang (Stand Mai 2021) mit diversen Rechtsmitteln. Corte Suprema, AZ 3579-2011. Urteil vom 25.01.2013. Zur Vollstreckung der Entschädigungsverpflichtung vgl. Verfahren Juzgado de Parral, AZ C 559-2014 i.V.m. ebd. AZ C $391-$ 2017.

323 Las Ultimas Noticias vom 10.12.2004, S. 14. »El gran giro de Villa Baviera como nuevo espacio abierto al ecoturismo«. 
das Restaurant »Casino Familiar« in Bulnes betrieben. Das Vorhaben stieß in Menschenrechtskreisen unmittelbar auf Kritik - diese sahen darin einen Versuch der CD, ihre Geschichte weißzuwaschen. ${ }^{324}$ Im Oktober 2005 setzte die chilenische Regierung Herman Schwember als Beauftragten für die ehemalige CD ein. Der deutschstämmige Schwember, ein ehemaliger politischer Gefangener, ${ }^{325}$ ging seine Aufgabe sehr engagiert an. Er präsentierte der Regierung 2006 einen Arbeitsplan, das Programa Integral de Transición (Integriertes Übergangsprogramm, PIT) ${ }^{326}$ und bestärkte Colonos im April 2006 darin, ein öffentliches Mea Culpa abzugeben. ${ }^{327}$ Wenige Tage später trat Schwember zurück und beklagte die fehlende Rückendeckung der Regierung für seine Tätigkeit. ${ }^{328}$. Einige Wochen danach nahm er seine Arbeit bis Ende 2007 wieder auf. ${ }^{329}$ 2007 eröffnete auf dem CD-Gelände das Restaurant "Zippelhaus«, 2012 folgte das "Hotel Baviera«, dessen Bau die chilenische Regierung unterstützte. ${ }^{330}$ Auch Mitarbeiter_innen der von der Bundesregierung finanzierten Projekte waren am Aufbau dieser touristischen Infrastruktur beteiligt, zwar nicht unmittelbar, aber in der strategischen Beratung der Colonos. ${ }^{331}$ Sie bestärkten diese in ihrem Vorhaben, die Siedlung als »Bayern-Dorf« touristisch zu vermarkten.

Etwa 2009 wurde auf Betreiben der neuen Jerarcas ein Unternehmensberater namens Falk Spahn ${ }^{332}$ für die ABC-Unternehmen tätig. Fortan übte Spahn einen hohen Einfluss auf die Leitung der ABC-Gesellschaften aus. Obwohl er kein formales Mandat besaß, agierte er faktisch als Sprecher für die Unternehmen und vertrat diese bei Gesprächen mit der Botschaft. Gemeinsam mit dem von der Bundesregierung eingesetzten Psychiater Niels Biedermann nahm Spahn auch an Sitzungen von internen Arbeitsgruppen innerhalb der CD teil ${ }^{333}$, in denen die zukünftige Ausrichtung der Siedlung besprochen

Ebd.

El Mercurio vom 09.10.2005, S. D2. »Lazos de Schwember con Colonia Dignidad«.

PJS, Sammlung CD. Delegado de gobierno (Herman Schwember) - Programa Integral de Transición Comunidad de Villa Baviera (ex Colonia Dignidad), März 2006.

El Mercurio vom 19.04.2006, S. 5. »Colonos entregan carta de mea-culpa a Bachelet«. In derselben Ausgabe veröffentlichten einige Colonos eine Anzeige. El Mercurio vom 19.04.2006, S. 7. »Declaración Pública - a nuestros conciudadanos en Chile y Alemania«.

La Tercera vom 25.04.2006, S. 17. »Renuncia el delegado del gobierno ante ex Colonia Dignidad«.

El Mercurio vom 01.06.2008, S. C16. »A raíz de un derrame cerebral falleció ayer Herman Schwember«. Schwembers Buch, in dem er seine Tätigkeit und Erkenntnisse schildert, wurde posthum veröffentlicht. Vgl. Schwember, Herman. Delirios e Indignidad. El Estéril Mundo de Paul Schäfer, Santiago 2009.

331 Laut Hecking wurde das Tourismuskonzept von Anna Schnellenkamp zusammen mit einem Wirtschaftsberater und Niels Biedermann, dem vom AA eingesetzten Psychiater, erdacht. Vgl. Claus Hecking. »Ausspannen im Folterlager« in: Die Zeit Nr. 25/2014 vom 28.06.2014, online unter https ://www.zeit.de/2014/25/colonia-dignidad-chile.

32 Schildmann, Daniela. »50 Jahre und kein Ende in Sicht«, in: Lateinamerika Nachrichten $\mathrm{Nr}$. 450/2011, Dezember 2011, S. 26-28.

Vgl. u.a. PJS, Sammlung CD. Protokoll des AKCom (Arbeitskreis Kommunikation) vom 17.04.2010 und vom 30.05.2010. Das Treffen leitete Wolfgang Müller Altevogt. Weitere Teilnehmer waren Herbert Münch, Gerd Seewald, Jörg Seewald, Falk Spahn, Niels Biedermann, Martin Matthusen, Dennys Alvear, Helmut Baar und Siegfried Laube. 
wurde. 2013 verließ Spahn abrupt Chile, nachdem der Rechtsanwalt und Ex-Colono Winfried Hempel einen Schutzantrag eingereicht hatte. ${ }^{334}$

2010 verstarb Paul Schäfer in der Haft. Die zahlreichen Kommentare zu seinem Tod spiegeln die unterschiedlichen Positionen zum Fall CD zu diesem Zeitpunkt wider. Die spanische Zeitung La Vanguardia betitelte einen Artikel über Schäfers Tod mit »Nazi y Pinochetista « und kommentierte: »Schäfer era criminal y era nazi, [...] Admirador de Hitler y alumno aventajado de la filosofía nacionalsocialista [...] la preservación de la raza aria estaba en manos del líder de la secta. ${ }^{335}$ Das Blatt steht damit exemplarisch für die Perpetuierung bestimmter Mythen über die CD, die sich bis heute fortsetzt. Die spanische Tageszeitung El País schrieb: »Colonia Dignidad sigue existiendo, pero sin el poder de antes, menos aislada del resto del país y con nuevos dirigentes «. ${ }^{336}$ Martin Matthusen, Sprecher der »Villa Baviera«, hingegen bedauerte Schäfers Tod mit den Worten:

» La muerte de cada persona es lamentable, haya hecho lo que haya hecho<, lo que en ese momento >deja de ser importante< [...] hubo muchísimo cambio. Todo lo que existe hoy ya no tiene nada que ver con el sistema jerárquico y autoritario que hubo en ese tiempo«. 337

Auch viele chilenische Medien nahmen Schäfers Tod zum Anlass, um die Gegenwart des Falls CD zu beleuchteten. El Mercurio berichtete über die Aktualisierung der internationalen Haftbefehle gegen die nach Deutschland geflohenen Hans-Jürgen Riesland, Reinhard Döring, Lilli Nill und Ernst Schreiber. ${ }^{338}$ Rechtsanwalt Hernán Fernández, der zahlreiche CD-Opfer vertrat, schlug vor, den Blick der Ermittlungen nun verstärkt auf Schäfers Kompliz_innen zu richten, »para que haya justicia y reparación«. ${ }^{339}$ Als Schäfers Leiche vom Bestattungsinstitut zum Friedhof transportiert wurde, bewarfen Demonstrant_innen den Leichenwagen mit Erde und schrien »Mörder«. ${ }^{340}$ An der Bei-

334 CA Talca, AZ 644-2013.

335 La Vanguardia vom 25.04.2010, S. 43. »Nazi y pinochetista«. Auch chilenische sowie internationale Medien beschrieben Schäfer als »Nazi«, vgl. u.a. El Mostrador vom 2.04.2010, »El nazi Paul Schaefer muere en prisión«, online unter https://www.elmostrador.cl/noticias/pais/2010/04/24/el-nazi-paulschaefer-muere-en-prision/sowie und: BBC Mundo vom 24.04.2010, »Murió ex nazi y fundador de Colonia Dignidad«, online unter https://www.bbc.com/mundo/america_latina/2010/04/100424_ch ile_nazi_paul_schaefer_muerte_lh.

336 El País vom 25.04.2005, »Paul Schäfer, pederasta y criminal nazi«, online unter https://elpais.com/ diario/2010/04/25/necrologicas/1272146401_850215.html.

337 El Mostrador vom 24.04.2010. »El nazi Paul Schaefer muere en prisión«, online unter: https://www .elmostrador.cl/noticias/pais/2010/04/24/el-nazi-paul-schaefer-muere-en-prision/.

338 El Mercurio vom 26.04.2010, S. C7. »Interpol pide renovar órdenes de captura internacional de prófugos ligados a Schaefer«.

339 El Mostrador vom 24.04.2010. »El nazi Paul Schaefer muere en prisión«, online unter: https://www .elmostrador.cl/noticias/pais/2010/04/24/el-nazi-paul-schaefer-muere-en-prision/.

340 Cooperativa.cl (Website) vom 25.04.2010. »Paul Schaefer fue enterrado en el Parque del Recuerdo Cordillera«, online unter https://www.cooperativa.cl/noticias/pais/judicial/villa-baviera/paul-schae fer-fue-enterrado-en-el-parque-del-recuerdo-cordillera/2010-04-25/111905.html. 
setzung nahmen nur fünf Personen teil. ${ }^{341}$ Der chilenische Staatspräsident Sebastián Piñera kommentierte das Ableben Schäfers wie folgt: »Por supuesto que la muerte de Paul Schaefer impide continuar la persecución penal [...] Sin embargo, todos sabemos que hay otra justicia que nunca termina, que es la justicia divina. «42

In der Bundesrepublik wurde Schäfers Tod hingegen kaum kommentiert. Die wichtigste Reaktion war wohl die endgültige Einstellung strafrechtlicher Ermittlungsverfahren durch die Staatsanwaltschaft Bonn im September 2010. Nur wenige Monate später floh Hartmut Hopp unter Umgehung einer Ausreisesperre vor seiner bevorstehenden Inhaftierung aus Chile und siedelte sich in Krefeld an. Dies löste in Chile und Deutschland eine breite Medienberichterstattung aus. Dennoch leitete die Staatsanwaltschaft Krefeld erst nach mehreren Strafanzeigen von CD-Opfern und einer Menschenrechtsorganisation neue Ermittlungen gegen Hopp ein.

In Chile war die Strafverfolgung der CD-Verbrechen erfolgreicher. Im Januar 2013 fällte die Corte Suprema ihr letztinstanzliches Urteil wegen sexuellen Missbrauchs in der CD. Das Verfahren hatte 1996 begonnen. Erstmals mussten nun auch andere Colonos Haftstrafen antreten. Dass nun Täter_innen ins Gefängnis mussten, die weiterhin in der ehemaligen CD gelebt hatten, bestärkte Opferverbände und Menschenrechtsaktivist_innen darin, an diesem Ort, an dem die grausame Vergangenheit der CD nach wie vor tabuisiert wurde, wieder offensiver ein Ende des Folkloretourismus sowie die Umwandlung des Ortes in eine Gedenkstätte zu fordern.

Auch der Bundesregierung wurde nach Hopps Flucht und dem auch in Deutschland gestiegenen Medieninteresse klar, dass ihre ökonomische und psychologische Unterstützung für die ehemalige CD nicht weiter haltbar war - zumindest nicht ohne eine zeitgleiche Auseinandersetzung mit der Vergangenheit der CD. 2013 stellte sie die langjährige Projektförderung für die ABC-Unternehmen ein, nur die Betreuung durch den Psychiater Niels Biedermann wurde fortgesetzt. Auf Antrag der Berliner Gedenkstätte Haus der Wannseekonferenz finanzierte das AA im Dezember 2014 ein Seminar zur Vergangenheit der CD. Die zahlreichen Vorträge am Museo de la Memoria zu Fragen der Diktaturverbrechen in der CD sowie zum Stand der strafrechtlichen Aufarbeitung wurden inzwischen veröffentlicht. ${ }^{343}$ In den folgenden Jahren führten deutsche und chilenische Expert_innen unter Leitung von Elke Gryglewski, der damaligen stellvertretenden Direktorin des Hauses der Wannseekonferenz, jährlich vom AA finanzierte Seminare und Dialogveranstaltungen in Chile und Deutschland durch, bei denen Vertreter_innen von Opferverbänden sowie Betroffene zusammenkamen. Diese Veranstaltungen bilden die Grundlage für die Entstehung einer Gedenk- und Bildungsstätte zumindest in einem Teil der Siedlung. Bei einem dieser Seminare im Februar 2016

341 Dies waren die Colonos Peter Schmidt und Matthias Gerlach, Schäfers Adoptivtochter Rebeca, sein Rechtsanwalt José Luis Sotomayor sowie Rogelio Benavides, Generalsekretär des Partido Nacional Socialista de Chile. Letzterer trug an Schäfers Grab eine Hakenkreuzbinde und zeigte den Hitlergruß. Vgl. El Mercurio vom 26.04.2010, S. C7. »Un solitario funeral y una tumba sin nombre«.

342 El Mercurio de Valparaíso vom 24.04.2010. "Sólo 5 personas asisten al funeral de Paul Schaefer«, online unter https://www.mercuriovalpo.cl/prontus4_noticias/site/artic/20100424/pags/201004242 13757.html.

343 Die Beiträge und Diskussionen dieses Seminars wurden veröffentlicht in Hevia/Stehle (Hg.). CoIonia Dignidad: diálogos sobre verdad, justicia y memoria. 
bekräftigten der Lateinamerikabeauftragte des AA und der chilenische Botschafter in Deutschland ihren gemeinsamen Wunsch nach einer Zusammenarbeit bei Fragen der Aufarbeitung und der Erinnerung an die CD-Verbrechen. Bei dem Seminar wurde in Anwesenheit des Regisseurs Florian Gallenberger der Kinofilm »Colonia Dignidad - es gibt kein Zurück « gezeigt. ${ }^{344}$ An der anschließenden Diskussion beteiligte sich auch der damalige Pressesprecher des AA, Martin Schäfer. Dieser war Anfang der 2000er Jahre als Wirtschaftsreferent an der Botschaft tätig gewesen und hatte auch den Konsularsprechtag im September 2004 mitorganisiert. Vermutlich entstand durch die Filmvorführung die Idee für eine Veranstaltung im AA: Zwei Monate später lud Außenminister Frank-Walter Steinmeier ins Auswärtige Amt und hielt eine Rede zum Umgang des AA mit dem Fall Colonia Dignidad. ${ }^{345}$ Vor der Rede wurde Gallenbergers Spielfilm gezeigt, als »künstlerischen Anstoß, den offenbar auch wir brauchten, um uns des Themas Colonia Dignidad und der Rolle der deutschen Botschaft in Chile noch einmal neu anzunehmen, « wie es Steinmeier formulierte. Der Minister fuhr in seiner Rede fort:

»Nein, der Umgang mit der Colonia Dignidad ist kein Ruhmesblatt, auch nicht in der Ceschichte des Auswärtigen Amtes. Über viele Jahre hinweg, von den sechziger bis in die achtziger Jahre haben deutsche Diplomaten bestenfalls weggeschaut - jedenfalls eindeutig zu wenig für den Schutz ihrer Landsleute in dieser Kolonie getan. Auch später - als die Colonia Dignidad aufgelöst war und die Menschen den täglichen Quälereien nicht mehr ausgesetzt waren - hat das Amt die notwendige Entschlossenheit und Transparenz vermissen lassen, seine Verantwortung zu identifizieren und daraus Lehren zu ziehen. $\ll^{346}$

Steinmeier erklärte die Haltung des AA mit dem Lagerdenken des Kalten Krieges. Auch seien die Menschenrechte in jener Zeit nicht das oberste Ziel der bundesdeutschen Außenpolitik gewesen. Das Umsteuern des Amtes nach 1985 sei kein genereller Kurswechsel gewesen, sondern sei vor allem Einzelpersonen wie dem damaligen Konsul Dieter Haller zu verdanken. Steinmeier lobte ausdrücklich die Rolle aufklärerischer Akteur_innen (Betroffene, Menschenrechtsaktivist_innen, Rechtsanwält_innen), wies jedoch eine politische Verantwortung des AA für die CD-Verbrechen zurück:

»Das Auswärtige Amt ist nicht daran schuld, dass es in Chile einen Militärputsch und 17 Jahre Militärdiktatur gab. Es trägt auch keine Verantwortung für das Unwesen, das Paul Schäfer und seine Spießgesellen trieben, teilweise in Verbindung mit den Militärs und Diktatoren. Aber das Amt hätte entschiedener >Deutschen nach pflichtgemäßem Ermessen Rat und Beistand gewähren«müssen, wie es das Konsulargesetz vorsieht. Und es hätte früher versuchen können, durch diplomatischen Druck die Spielräume der Colonia-Führung zu verengen und juristische Schritte zu erzwingen. [...] Im Spannungsfeld zwischen dem Interesse an guten Beziehungen zum Gastland und dem In-

344 Gallenberger, Florian [Regie]. »Colonia Dignidad - es gibt kein Zurück«, Spielfilm, 110 min, Kinostart in Deutschland am 18.02.2016.

345 Auswärtiges Amt, »Rede von Außenminister Frank-Walter Steinmeier anlässlich der Veranstaltung >Colonia Dignidad im Auswärtigen Amt« vom 26.04.2016, online unter https://www.auswaertiges -amt.de/de/newsroom/160426-colonia-dignidad/280124. 
teresse an der Wahrung von Menschenrechten ging Amt und Botschaft offenbar die Orientierung verloren. $\ll^{347}$

Als Lehre aus der Vergangenheit kündigte der Minister an, für mehr Transparenz zu sorgen. So werde die Schutzfrist der Akten des AA zur Colonia Dignidad im PA AA von 30 auf 20 Jahre verkürzt. Damit wurden Akten bis 1996 für Wissenschaftler_innen und Medien zugänglich. Zudem solle eine Unterrichtseinheit zur CD in die Ausbildung für den diplomatischen Dienst integriert werden. Die CD solle auch Bestandteil des Curriculums von Führungsseminaren des AA werden.

In gewisser Weise war Steinmeiers Rede ein Meilenstein: Erstmals räumte ein deutscher Außenminister Versäumnisse der Bundesregierung beim Schutz der Menschenrechte ein. Grund für dieses Eingeständnis war sicherlich auch ein Generationswechsel: mehrere Mitarbeiter_innen, die in jüngeren Jahren an der Botschaft in Santiago tätig gewesen waren, bekleideten nun hohe Posten beim Amt. ${ }^{348}$

Aus einer anderen Sicht ist zwar vieles an Steinmeiers Rede beachtlich. Letztlich waren die Worte jedoch genau so gewählt, dass sie eine rote Linie nicht überschritten: Das AA bekannte sich nicht zu einer justiziablen Mitverantwortung für die CDVerbrechen, allein schon weil dies höchstwahrscheinlich zahlreiche Entschädigungsklagen zur Folge gehabt und damit einen Präzedenzfall geschaffen hätte. Dementsprechend waren die tatsächlichen Konsequenzen der Rede eher dürftig. Konkrete Unterstützungsmaßnahmen, die Opferverbände erwartet hatten, blieben aus. Die vorzeitig freigegebenen Akten unterlagen besonderen Bedingungen und durften beispielsweise nicht - wie üblich - kopiert oder fotografiert werden. ${ }^{349}$ Die dadurch entstandene Enttäuschung wuchs noch, als Bundespräsident Joachim Gauck drei Monate später auf Staatsbesuch in Chile war. Seine Reise war dominiert vom Thema CD. Gauck bedauerte das Verhalten der bundesdeutschen Diplomatie, fügte jedoch umgehend an, dass daraus keinerlei Entschädigungsansprüche erwachsen dürften. Wörtlich sagte Gauck: »Wir akzeptieren keine Forderungen nach Wiedergutmachung«. Eine deutsche Mitverantwortung für Folter und Mord in der CD während der Diktatur »wäre nun zu viel der Selbstbezichtigung «. ${ }^{350}$ Gauck entschied auch, sich nicht mit Vertreter_innen der CD-Opfer zu treffen. $\mathrm{Zu}$ einem Eklat kam es, als bekannt wurde, dass stattdessen ein verurteilter Täter der CD bei Gaucks Empfang in der Botschafterresidenz anwesend war. $^{351}$

Im November 2016 reiste eine achtköpfige Delegation von Bundestagsabgeordneten nach Chile und besuchte die ehemalige $C D$. Sie legte gemeinsam mit Vertreter_innen

347 Ebd.

348 Der bereits erwähnte Martin Schäfer war Sprecher des AA, der ehemalige Konsul Dieter Haller leitete inzwischen die Wirtschaftsabteilung des AA.

349 Aufgrund der begrenzten Akteneinsicht, die mir das AA gewährt hatte (vgl. Abschnitt 2.3) waren mir viele dieser Akten bereits bekannt.

350 Frankfurter Allgemeine Zeitung vom 14.07.2016, S. 6. »Gauck lehnt Entschädigungen in Chile ab«.

351 Von Bullion, Constanze/Boris Herrmann, »Unerwünschter Cast«, in: Süddeutsche Zeitung vom 16./17.07.2016, S. 9, sowie Burghardt, Peter,»Profil Botschafter Rolf Schulze. Deutscher Botschafter in Chile, den nun ein düsteres Kapitel einholt«, in: Süddeutsche Zeitung vom 20.07.2016, S. 4, sowie Herrmann, Boris, »Peinliche Botschaft«, in: Süddeutsche Zeitung vom 20.07.2016, S. 6. 
von Opferverbänden am Ort der Massengräber auf dem Gelände Blumen nieder. ${ }^{352} \mathrm{Im}$ Juni 2017 verabschiedete der Bundestag einstimmig einen Entschließungsantrag zur Aufarbeitung der CD-Verbrechen, der die Bundesregierung zu konkreten Maßnahmen aufforderte (vgl. Abschnitt 5.4.3). Dazu gehört die Beförderung der Justizkooperation zwischen Deutschland und Chile, die Errichtung einer Gedenkstätte in der ehemaligen $C D$, die Einrichtung eines Hilfsfonds für CD-Opfer sowie die Prüfung des CDVermögens. Michael Brand, menschenrechtspolitischer Sprecher der Unionsfraktion, kommentierte den Beschluss mit den Worten: »Deutschland trägt eine politische Mitverantwortung. «353

Wenige Wochen später vereinbarten die chilenische und die deutsche Regierung die Einsetzung einer Gemischten Kommission zur Colonia Dignidad. ${ }^{354}$ Beide Seiten erklärten, gemeinsam einen Gedenkort und ein Dokumentationszentrum in der ehemaligen CD einrichten, bei der Feststellung, Sicherung und Auswertung von Spuren und Dokumenten zu den CD-Verbrechen zusammenzuarbeiten sowie das Vermögen der ABC-Gesellschaften überprüfen zu wollen. Die Gemischte Kommission solle sich mindestens halbjährlich treffen. Sie beauftragte die GIZ mit einer Machbarkeitsstudie zur Prüfung des CD-Vermögens sowie zwei chilenische und zwei deutsche Expert_innen mit der Ausarbeitung eines Konzepts für eine Gedenk- und Dokumentationsstätte. ${ }^{355}$ Das Gedenkstättenkonzept lag im November 2019 in einer ersten Fassung vor, die Machbarkeitsstudie zum CD-Vermögen bereits im Mai 2018. Um überhaupt Einblick in die Bücher zu erhalten, unterzeichnete die GIZ eine von Juan Pablo Guzmán, dem Anwalt der ABC-Gesellschaften vorgelegte Geheimhaltungserklärung. Guzmán gehörte zu den Architekten jener undurchsichtigen Unternehmensstruktur, die er nun angeblich offenlegen wollte. Ab 1988 hatte er zusammen mit seinem Vater die betrügerische Übertragung des CD-Vermögens auf die ABC-Holding entworfen und durchgeführt. Aufgrund der Geheimhaltungsverpflichtung sind die Ergebnisse der Machbarkeitsstudie nicht bekannt. ${ }^{356}$ Selbst Bundestagsabgeordnete dürfen die Machbarkeitsstudie nur in

352 Amerika21 vom 04.11.2016. Delegation des deutschen Bundestages besucht Colonia Dignidad in Chile: https://amerika21.de/2016/11/163580/bundestag-colonia-dignidad sowie Burghardt, Peter, »Traumatisiert sind alle«, in: Süddeutsche Zeitung vom 07.11.2016, S. 6.

353 Knobbe, Martin. »Colonia Dignidad: >Deutschland trägt eine politische Mitverantwortung«, in: Spiegel Online vom 28.06.2017, online unter https://www.spiegel.de/politik/ausland/colonia-digni dad-cdu-csu-spd-und-gruene-fordern-hilfsfonds-fuer-opfer-a-1154899.html.

354 PJS, Sammlung AA. Absprache zwischen der Regierung der Republik Chile und der Regierung der Bundesrepublik Deutschland über die Einsetzung einer Chilenisch-deutschen Cemischten Kommission zur Aufarbeitung der »Colonia Dignidad« und Integration der Opfer in die Cesellschaft, unterzeichnet am 12.07.2017 vom Lateinamerikabeauftragten des AA, Dieter Lamlé und dem chilenischen Botschafter Patricio Pradel.

355 Die von chilenischer Seite benannten Expert_innen sind Elizabeth Lira, Dekanin der Fakultät für Psychologie an der Universidad Alberto Hurtado und Diego Matte, Leiter des Centro de Extensión der Universidad de Chile. Das AA benannte Elke Gryglewski, Geschäftsführerin der Stiftung niedersächsische Gedenkstätten und Jens-Christian Wagner, Direktor der Stiftung Gedenkstätten Buchenwald und Mittelbau-Dora.

356 Dannemann, Victoria. Un secreto impide conocer a fondo el patrimonio de ex Colonia Dignidad, in: Deutsche Welle (Website), 23.06.2020, online unter https://p.dw.com/p/3eDYd. 
der Geheimschutzstelle des Bundestags einsehen und nicht über ihre Inhalte sprechen. Über weitere Maßnahmen nach Erstellung der Studie ist nichts bekannt.

Im April 2018 reiste eine Delegation des BMJ, des LMJ NRW sowie der gegen Hartmut Hopp ermittelnden Staatsanwaltschaft Krefeld nach Chile. Dort traf sie sich mit chilenischen Richter_innen sowie weiteren Vertreter_innen von Justiz und Regierung. Der Krefelder Oberstaatsanwalt Axel Stahl nahm zudem an einer Zeugenvernehmung teil, die aufgrund eines deutschen Rechtshilfeersuchens stattfand. Als Ergebnis der Reise wurde mit der chilenischen Seite vereinbart, die Justizkooperation zwischen beiden Ländern zu vereinfachen und künftig beispielsweise Zeug_innenvernehmungen per Videokonferenz $\mathrm{zu}$ ermöglichen. Inzwischen fehlt beim Fall CD für diese Kooperation auf deutscher Seite jedoch die Grundlage: Im Oktober 2018 entschied das OLG Düsseldorf, das chilenische Vollstreckungsersuchen gegen Hartmut Hopp abzulehnen. Dies hatte weitreichende Folgen: 2019 stellten die Staatsanwaltschaften Münster und Krefeld die letzten noch laufenden Ermittlungsverfahren gegen Beschuldigte der CD in Deutschland ein (vgl. Abschnitte 5.3.9 und 5.3.10). Sie setzten damit einen (zumindest vorläufigen) Schlusspunkt unter die strafrechtliche Aufarbeitung der CD-Verbrechen durch bundesdeutsche Strafverfolgungsbehörden. Deren Bilanz ist ohnehin eindeutig: So wurden 13 mir bekannte Ermittlungsverfahren in NRW ausnahmslos wegen mangelnden Tatverdachts eingestellt - trotz eindeutiger Verbrechen mit über hundert Toten sowie viele Hunderten gefolterter und missbrauchter Menschen.

Auch in Chile kommen die strafrechtlichen Ermittlungen kaum noch voran. Das derzeit einzige offene Verfahren (Stand Mai 2021) befasst sich mit der Suche nach Überresten oder Spuren von auf dem Gelände der CD während der Diktatur ermordeten und bis heute verschwundenen Personen. Dieses Verfahren wurde 2017 von Richter Mario Carroza eröffnet. Trotz vieler Vernehmungen und einzelner forensischer Arbeiten konnten jedoch keine substantiellen Fortschritte erzielt werden. Im Oktober 2018 bot das AA der chilenischen Seite Hilfe ${ }^{357}$ bei der Untersuchung von in der ehemaligen CD entnommenen Bodenproben auf menschliche Überreste an. 2020 wurden Bodenproben entnommen und in einem schweizer Labor analysiert. Spuren von menschlichen Überresten oder Brandbeschleunigern konnten jedoch nicht festgestellt werden. Richter Carroza wurde Anfang 2021 an den Obersten Gerichtshof befördert. Richtern Paola Plaza übernahm das Verfahren und führte im April 2021 in der ehemaligen Colonia Dignidad Zeugenbefragungen durch. ${ }^{358}$ Weiterhin wurde eine deutsche Firma beauftragt, eine geomagnetische Studie auf dem Gelände durchzuführen. ${ }^{359}$

2021, fünf Jahre nach Steinmeiers Rede, sind bei der tatsächlichen Aufarbeitung der CD-Verbrechen nur wenige konkrete Fortschritte zu verzeichnen. ${ }^{360}$ Die faktische Be-

357 PJS, Sammlung AA. Verbalnote des AA an die chilenische Botschaft vom 08.10.2018.

358 Poder Judicial. Noticias del Poder Judicial vom 22.04.2021. „Caso Colonia Dignidad: Ministra Paola Plaza realiza diligencias en Parral y Villa Baviera«, online unter https://www.pjud.cl/prensa-y-com unicaciones/noticias-del-poder-judicial/55129.

359 El Mostrador (Website) vom 15.02.2021. »AFDD pide incorporar científicos argentinos a búsqueda de fosas en Colonia Dignidad «, online unter https://www.elmostrador.cl/dia/2021/02/15/afdd-pide -incorporar-cientificos-argentinos-a-busqueda-de-fosas-en-colonia-dignidad.

360 Ebert, Matthias. "Colonia Dignidad - Noch heute profitieren einige wenige« In: Tagesschau.de (Website) vom 26.04.2021, online unter: https://www.tagesschau.de/ausland/amerika/colonia-dig 
endigung der Strafverfolgung dieser Verbrechen in der Bundesrepublik ist angesichts dessen ein fundamentaler Rückschritt. Ob es hier - ähnlich wie im Verlauf der strafrechtlichen Aufarbeitung der NS-Verbrechen - in naher Zukunft grundlegende Veränderungen geben wird, die eine Verurteilung zur Mittäterschaft auch ohne den Nachweis einer materiellen Tatbeteiligung ermöglichen, erscheint momentan eher unwahrscheinlich. Staatsanwaltschaften und Gerichte hierzulande haben den Charakter der CD als kriminelle Organisation bislang nie anerkannt, zudem sind viele Täter_innen sehr alt oder sogar verstorben.

Auch die von der Gemischten Kommission anvisierten Maßnahmen ruhen zur Zeit oder kommen kaum voran. Beobachter_innen sehen einen Grund hierfür im Personal der rechten chilenischen Regierung. Hernán Larraín, der hierfür auf chilenischer Seite zuständige Minister für Justiz und Menschenrechte, war seit den 1980er Jahren ein öffentlicher Fürsprecher der CD und ein wichtiger Teil ihres Unterstützungsnetzwerks. ${ }^{361}$

Lediglich der von der Gemeinsamen Kommission beschlossene Hilfsfonds hat inzwischen mit der Auszahlung von individuellen Zahlungen in einer Höhe von bis zu 10.000 Euro für einen Teil der CD-Opfer begonnen. Außerdem hat ein Oral-HistoryProjekt zur Colonia Dignidad, das von der Bundesregierung finanziert wird, 2019 seine Arbeit aufgenommen. ${ }^{362}$

Die ABC-Gesellschaften und das Tourismus-Projekt in der ehemaligen CD werden derweil fortgeführt. Über ihre Geschicke und ihr Vermögen entscheiden nach wie vor die bis heute funktionierenden Strukturen der Post-Sektengemeinschaft, die einer Aufarbeitung der CD-Verbrechen noch immer entgegenwirken.

nidad-aufarbeitung-101.html sowie Löhning, Ute. »Ein Cedenkort fehlt bis heute«, in: die tageszeitung vom 26.04.2021, S. 7, online unter https://taz.de/Verbrechen-der-Colonia-Dignidad/!5762644/. Albert, Catalina. „Colonia Dignidad: víctimas acusan que representante del gobierno en comisión chileno-alemana apoyó régimen de Schäfer« in: CIPER (Website), 17.03.2020, online unter: https://ciperchile.cl/2020/03/17/colonia-dignidad-victimas-acusan-que-representante-del-go bierno-en-comision-chileno-alemana-apoyo-regimen-de-schafer/. 



\section{Zusammenfassung und Fazit}

In diesem Schlusskapitel fasse ich zunächst die wichtigsten Erkenntnisse aus den einzelnen Kapiteln zusammen (Abschnitte 7.1 bis 7.5) und wende mich dann im Fazit (Abschnitt 7.6) der Beantwortung der übergeordneten Fragestellung dieser Arbeit zu. Schließlich gebe ich einen Ausblick auf die zukünftige Aufarbeitung des Falls CD, aber auch zur wissenschaftlichen Forschung zu diesem Thema.

\subsection{Akteur_innen des Falls Colonia Dignidad, Literatur und Quellen (Kapitel 2)}

In diesem Kapitel stelle ich zunächst die zentralen Akteur_innen des Falls Colonia Dignidad vor: Das System CD, die aufklärerischen Akteur_innen und die staatlichen Akteur_innen.

Das System CD umfasst die Führungsmitglieder der CD in Chile und der Bundesrepublik sowie ein Netz von Unterstützer_innen in Verwaltung, Justiz, Polizei, Militär, Geheimdiensten, Politik und Medien. Ziel dieses Systems war es, den Fortbestand der CD zu sichern. Dazu gehörte auch, kritische bzw. aufklärerische Initiativen zu beoder verhindern, meist über Lobbying, Öffentlichkeitsarbeit und juristische Manöver. Dabei griff die CD auf ihr umfangreiches Unterstützungsnetzwerk zurück und war dabei oft erfolgreich. So übernahmen einzelne Medien und Behörden immer wieder die Darstellung der CD, sämtliche gegen sie erhobenen Vorwürfe wegen Verbrechen seien eine Verleumdung und die CD in Wahrheit eine zumindest vom Grundsatz her wohltätige Organisation. Eine Schlüsselrolle spielten zahlreiche von der CD unter hohem finanziellem Aufwand beauftragte Rechtsanwält_innen, die in beiden Ländern mit Verleumdungsklagen und Dienstaufsichtsbeschwerden gegen aufklärerische Akteur_innen vorgingen sowie strafrechtliche Ermittlungen beeinflussten. Die Anwält_innen konnten schnell und flexibel in beiden Ländern agieren. Dadurch verfügte das System CD nicht nur über ein klares Interesse und eine klare Strategie, sondern häufig auch über einen Informationsvorsprung und einen sogenannten first-mover advantage, also den Vorteil, als erster zu handeln und so andere Akteur_innen zum Reagieren zu zwingen. 
Bei den aufklärerischen Akteur_innen handelt es sich meist um Einzelpersonen, mitunter auch um kleinere Gruppen. Darunter waren aus der CD geflüchtete Personen, Rechtsanwält_innen, Journalist_innen und Aktivist_innen, meist aus dem Menschenrechtsmilieu. Beispielhaft seien hier Wolfgang Kneese, Dieter Maier, Hernán Fernández und Gero Gemballa genannt. Auch die aufklärerischen Akteur_innen hatten ein klares Interesse: der CD das Handwerk zu legen, die dort begangenen Verbrechen zu beenden, zu ahnden und aufzuklären. Sie einte die Überzeugung, dass die Menschrechte durchgesetzt werden müssen. Allerdings verfügten sie nicht über eine konzertierte und langfristige Strategie, um dieses Ziel zu erreichen und auch nicht annähernd über ausreichende Ressourcen, um mit den Maßnahmen der CD mithalten zu können. Institutionelle Unterstützung erfuhren die aufklärerischen Akteur_innen in der Regel kaum. Auch beim Zugang zu Informationen waren sie meist von anderen Akteur_innen abhängig und damit im Nachteil. Häufig recherchierten sie Informationen zu Strukturen oder Verbrechen der CD, veröffentlichten diese und versuchten so, Behörden zum Handeln zu veranlassen. Dabei handelten einzelne Akteur_innen oftmals für sich und mitunter mit unterschiedlichen Hintergründen und Ansätzen. Dennoch ist ein großer Teil der bisherigen Aufklärung der Verbrechen der CD ihrer Ausdauer und Beharrlichkeit zu verdanken.

Bei den staatlichen Akteur_innen ist die Interessenlage ungleich schwerer zu bestimmten. Allerdings handelt es sich hierbei auch um höchst unterschiedliche Institutionen wie Regierungen, Ministerien, Parlamente, Gerichte, Staatsanwaltschaften, Verwaltungen und Geheimdienste. Neben diversen chilenischen Behörden spielt für diese Arbeit auf bundesdeutscher Seite vor allem das Auswärtige Amt eine zentrale Rolle, zusammen mit der Botschaft in Santiago. Wichtig waren zudem diverse Justizbehörden in Nordrhein-Westfalen, allen voran die Staatsanwaltschaften Bonn und Krefeld. Diese Behörden nahmen im Fall CD von Anfang an eine abwartende oder ambivalente Haltung ein. Häufig beobachteten sie eher, als dass sie handelten. Den Interessenskonflikt zwischen dem System CD und den aufklärerischen Akteur_innen behandelten sie oftmals als eine private Auseinandersetzung. Anstatt sich eindeutig im Sinne einer Aufklärung der im Raum stehenden Vorwürfe zu engagieren, versteckten sie sich häufig hinter formalen Positionen oder Verfahren. Vielfach folgte vor allem das AA auch einer politisch festgelegten Strategie, in der gute Beziehungen zur chilenischen Regierung schwerer wogen als die Wahrung der Menschenrechte. Die Leitlinie des AA lautete über lange Jahre, dass die Verantwortung für den Fall CD vor allem in Chile läge. Dabei hielt es oftmals mehr Distanz zu aufklärerischen Akteur_innen, als zu dem System CD, dessen Lobbyarbeit mitunter auch hier Erfolge feiern konnte.

Als zweiten Punkt in diesem Kapitel gehe ich auf die vorhandene Literatur, Presseberichterstattung und wissenschaftliche Forschung zum Fall CD ein. Zu Beginn meines Forschungsvorhabens bezogen sich Veröffentlichungen sowie die vorliegenden Informationen über Verbrechen der CD vorwiegend auf Aussagen und Quellen aufklärerischer Akteur_innen. Die Medienberichterstattung verlief seit den 1960er Jahren mit kurzen Phasen erhöhter Aufmerksamkeit und längeren Perioden mit nur vereinzelter Berichterstattung. In den Hochphasen gelang es den Medien, im Interesse der Aufklärung politischen Druck auf staatliche Akteur_innen auszuüben. Jedoch beförderten und reproduzierten Medien zum Teil bis heute auch zahlreiche Mythen über die CD - etwa 
dass diese ein »Nazi-Lager" gewesen sei, in dem sich NS-Kriegsverbrecher versteckt hielten oder dass Paul Schäfer ein solcher gewesen sei.

Im dritten Teil des Kapitels gehe ich auf den problematischen Zugang zu unterschiedlichen, insbesondere behördlichen Quellen zum Fall CD ein und beschreibe meinen Quellenzugang im Kontext meines Forschungsvorhabens. Zur Beantwortung meiner Fragestellung benötigte ich Quellen verschiedener staatlicher Akteur_innen, die bisher nicht zugänglich waren. Besonders relevant waren für mich die Aktenbestände des Auswärtigen Amtes, der Staatsanwaltschaft Bonn sowie der chilenischen Ermittlungen und Gerichtsverfahren.

Die Quellensituation in Chile war während meiner Forschungstätigkeit sehr dynamisch - seit 2008 wurden diverse Urteile zu CD-Verbrechen gefällt, die dazugehörigen Ermittlungsakten enthielten hunderte Aussagen und Dokumente. Ein offizieller Zugang über Gerichtsarchive war noch nicht möglich, aber auf informellem Wege erlangte ich Zugang zu mehreren 10.000 Seiten Ermittlungsakten. 2014 wurde das CDGeheimarchiv bekannt, an dessen Auswertung ich beteiligt war.

In Deutschland verweigerte mir die Staatsanwaltschaft Bonn den Einblick in ihre Bestände, auch hier erhielt ich jedoch über andere Wege Zugang zu einigen Bänden des ab 1985 über 25 Jahre lang geführten Ermittlungsverfahrens. Das AA teilte mir zu Beginn meines Forschungsvorhabens mit, dass der größte Teil ihrer Aktenbestände nicht einsehbar sei. Meine darauffolgenden Bemühungen, dennoch Zugang zu den Akten beim AA sowie bei weiteren Behörden zu erlangen, stelle ich im letzten Abschnitt von Kapitel 2 dar.

Als einzige obere Bundesbehörde gibt das AA seine Akten nicht ans Bundesarchiv $a b$, sondern betreibt ein eigenes Archiv (PA AA). Damit ist es bei der Entscheidung über Aktenzugang sozusagen Richter und Beteiligter zugleich. Ich machte dieselben Erfahrungen wie Historiker_innen, die zuvor den schwierigen Zugang zu Akten des AA kritisiert hatten. In meinem Fall verweigerte das AA den Aktenzugang mit Verweis auf Geheimhaltungserfordernisse (»Schutz des Wohls der Bundesrepublik Deutschland«) und Datenschutznotwendigkeiten (Persönlichkeitsschutz bzw. "Schutz von Opferdaten«). Nach etwa zwei Jahren erhielt ich durch mehrere Vergleiche Einblick in einen wichtigen Teil der AA-Bestände. Eine Fortführung meiner Klagen hätte vermutlich viele weitere Jahre gedauert. Mir wurde zudem klar, dass das AA vor allem einen Präzedenzfall vermeiden wollte, vermutlich um externe wissenschaftliche Untersuchungen weiterhin kontrollieren zu können.

\subsection{Entstehung und Struktur der Colonia Dignidad (Kapitel 3)}

Kapitel 3 behandelt die Entstehungsgeschichte und Struktur der Colonia Dignidad. Der Begriff Colonia Dignidad steht erstens für den physischen Ort in Chile, an dem sich die Gruppierung um Paul Schäfer 1961 niederließ, sowie seine weiteren Niederlassungen in Chile und der Bundesrepublik. Zweitens bezeichnet der Begriff auch die Gruppierung selbst. Drittens ist Colonia Dignidad das Synonym für die kriminelle Vereinigung, die Verbrechen plante und ausführte. Dabei ist Colonia Dignidad (CD) kein neutraler Begriff. Die CD-Führung selbst verwendete den Begriff kaum, da er zunehmend mit 
Verbrechen assoziiert wurde. Um diese Assoziationen loszuwerden, nannte sich die Siedlung ab Ende der 1980er Jahre Villa Baviera (Bayerndorf). Bis heute wohnen noch Colonos, also Bewohner_innen der CD, an diesem Ort und führen die wirtschaftlichen Aktivitäten unter anderem im Tourismus fort. Sie sprechen konsequent von der Villa Baviera, während aufklärerische Akteur_innen bis heute vorwiegend den Begriff Colonia Dignidad verwenden, um auf die nicht aufgearbeiteten Verbrechen hinzuweisen.

Der erste Abschnitt von Kapitel 3 behandelt die Colonia Dignidad als Gruppierung bzw. kriminelle Vereinigung. Die CD kann einerseits als pseudoreligiöse kriminelle Gemeinschaft betrachtet werden, die von internen Verbrechen charakterisiert war. Andererseits kann sie als eine kriminelle Vereinigung beschrieben werden, die vornehmlich nach außen gerichtete externe Verbrechen beging. Erstere umfasste sämtliche Colonos, während zur kriminellen Vereinigung nur diejenigen Colonos gehörten, die direkt an Verbrechen beteiligt waren. Je nach Zähl- und Betrachtungsweise umfasste die CD zwischen 300 und 400 Mitglieder.

Die Geschichte der Gruppierung ist eng mit der Person Paul Schäfer verknüpft. Auch wenn eine Gruppe von Jerarcas, also Führungsmitgliedern, eine wichtige Rolle bei der Aufrechterhaltung der CD und ihrer Strukturen spielte, war es doch Schäfer, der letztlich über Regeln und Politik der CD entschied. Daher kommt keine Analyse der Colonia Dignidad daran vorbei, sich mit seiner Person zu befassen. Entgegen zahlreicher Gerüchte war Schäfer (geboren 1921) kein SS-Mitglied oder Wehrmachtsoffizier. Nach dem Krieg arbeitete er in evangelischen Kirchengemeinden mit Jungengruppen. Er nutze seine starke Anziehungskraft, um die Jugendlichen zu manipulieren und von ihrem sozialen Umfeld zu entfremden. Aus dieser Zeit liegen mehrere Berichte über Schäfers sexuellen Missbrauch von Jungen vor. Die Reaktionen waren jedoch nicht Strafanzeigen, sondern Schweigen und Entlassung.

Schäfer wirkte fortan als Laienprediger und baute eine eigene Gruppierung auf. Anhänger_innen fand er in baptistischen-freikirchlichen Gemeinden. Dort lernte er die baptistischen Prediger Hugo Baar und Hermann Schmidt kennen, die sich mit Teilen ihrer Gemeinden aus Gronau und Hamburg der Schäfer'schen Gruppierung anschlossen. Diese ließ sich ab 1956 in Siegburg nieder, wo sie sich zunehmend von der als feindlich wahrgenommenen Außenwelt abschottete, zu der auch Familienangehörige gehörten, die der Gruppe kritisch gegenüberstanden. Schäfer schuf ein internes Zwangssystem aus charismatischer Führung, bedingungsloser Loyalität, Beichte und Überwachung. Dieses legte den Grundstein für die verbrecherische Struktur der späteren $C D$ in Chile. Auch viele interne Verbrechen an Gruppenmitgliedern wurden schon hier begangen. Dazu zählten Körperverletzungen durch Schläge oder Elektroschocks, Freiheitsberaubungen sowie der regelmäßige sexuelle Missbrauch von Jungen durch Paul Schäfer. Eine Blaupause für die spätere CD war auch die Außendarstellung der Gruppierung in Siegburg. Diese errichtete ein Jugendheim und präsentierte sich als wohltätige Einrichtung. Dies war einerseits eine gelungene Tarnung für die Trennung der Familien und die Missbrauchstaten. Andererseits ermöglichte die soziale Fassade eine Verteidigung gegen eventuelle Vorwürfe von Aussteiger_innen oder Kritiker_innen.

Anfang 1961 reiste Schäfer nach Chile - kurz bevor in der Bundesrepublik ein Haftbefehl gegen ihn wegen sexuellen Missbrauchs erlassen wurde. In den Folgejahren siedelte ein Großteil der Gruppe nach Chile über. Die interne Struktur der dortigen CD war 
geprägt vom Zwang zu harter körperlicher Arbeit sowie einer strikten Geschlechtertrennung sowie parallelen Strukturen für Männer, Frauen und Kinder. Liebesbeziehungen wurden unterbunden und familiäre Strukturen aufgelöst. Kern der patriarchal-hierarchischen Struktur der CD war eine je nach Definition bis zu 70 Personen umfassende Gruppe von Führungsmitgliedern, die in unterschiedlicher Position und unterschiedlichem Ausmaß an Entscheidungen und der Durchsetzung des internen Zwangssystems aus Überwachen und Strafen beteiligt waren. Diese Personen genossen Privilegien. Im Gegensatz zu den meisten Colonos durften sie teilweise heiraten und zur Ausführung bestimmter Aufträge die Siedlung verlassen.

Der zweite Abschnitt von Kapitel 3 stellt die verschiedenen Rechtspersonen und Niederlassungen sowie die Eigentumsstruktur der CD vor. Neben dem Kerngelände der Siedlung bei Parral verfügte die CD in Chile über ein Stadthaus in Santiago, einen Steinbruch und ein öffentliches Restaurant in Bulnes und ein weiteres Haus in Parral, das sie eine Zeit lang der DINA zur Verfügung stellte. In der Bundesrepublik führte die $\mathrm{CD}$ auch nach der Auswanderung nach Chile ihre Siegburger Niederlassung weiter. Bis Anfang der 1990er Jahre lebten dort zwischen 10 und 20 Personen.

Zur CD gehören zudem zahlreiche Rechtspersonen. Als Teil ihrer sozialen Fassade gründete die CD mehrere Vereine - in der Bundesrepublik die Private Sociale Mission (PSM) und in Chile die Sociedad Benefactora y Educacional Dignidad (SBED). Laut der jeweiligen Satzungen dienten diese Vereine gemeinnützigen Zwecken. Die CD erlangte hierdurch steuerliche und zollrechtliche Vergünstigungen. Gleichzeitig boten die Vereine den Rahmen für wirtschaftliche Tätigkeiten der CD. Diese wurden von behördlicher Seite kaum kontrolliert und waren geprägt von Betrug und Verbrechen. Die zahlreichen Unternehmen der CD schufen sich einen Wettbewerbsvorteil durch die sklavenähnliche Arbeit der Colonos. Hinzu kamen Einnahmen aus illegalem Waffenhandel und Minenprojekten sowie Zahlungen bundesdeutscher Rententräger an Colonos. Sämtliche Gelder flossen direkt in die Kasse der CD-Führung. Eine weitere Einnahmequelle war das CD-Krankenhaus. Die CD behauptete zwar, die Gesundheitsversorgung der armen Landbevölkerung unentgeltlich sicherstellen, ließ sich aber in Wirklichkeit ihre Arbeit vom staatlichen Gesundheitssystem bezahlen - wobei sie darüberhinaus auch Leistungen abrechnete, die sie gar nicht erbracht hatte.

Als das Ende der Militärdiktatur langsam absehbar wurde, strukturierte die CD ihr Vermögen um. Sämtliche Vermögenswerte, die bisher auf Einzelpersonen oder die SBED eingetragen waren, wurden auf drei geschlossene Aktiengesellschaften übertragen - die sogenannten $A B C-U n t e r n e h m e n$. Die von der ersten demokratischen Regierung nach der chilenischen Diktatur ab 1990 betriebene Auflösung der SBED blieb damit wirkungslos. Die ABC-Unternehmen führen bis heute die Wirtschaftsbetriebe der »Villa Baviera«. Träger des Krankenhauses und der externen Schule der CD wurde 1995 der neu gegründete Verein Organización Social Comunitaria Perquilauquén. Auch dieser besteht bis heute. Neben den ABC-Unternehmen gründeten Colonos ab den 1990er Jahren eine Reihe weiterer Unternehmen, über deren genaue Tätigkeit wenig bekannt ist. Darüber hinaus gibt es diverse Belege und Anzeichen für versteckte internationale Finanztransaktionen von Colonos. 


\subsection{Interne und externe Verbrechen der Colonia Dignidad (Kapitel 4)}

In Kapitel 4 trage ich den heutigen Kenntnisstand über die Verbrechen der Colonia Dignidad auf Grundlage der mir zugänglichen Quellen zusammen. Dabei unterscheide ich zwischen den internen Verbrechen der kriminellen Gemeinschaft CD, die sich gegen Colonos richteten und den externen Verbrechen der kriminellen Vereinigung CD. In beiden Bereichen stelle ich jeweils unterschiedliche Verbrechenskomplexe dar und gehe auch darauf ein, wer zu welchem Zeitpunkt welche Kenntnisse von den jeweiligen Verbrechen besaß. Die CD ist als ein System zu betrachten, das sich nach innen und außen absicherte, um seine im Kern kriminelle Struktur erhalten zu können. Die Strategie der CD-Führung zur Wahrung dieser verbrecherischen Kontinuität hatte dabei unterschiedliche Dimensionen.

Abschnitt 4.1 behandelt die internen Verbrechen der CD. Im Kern standen Schäfers Sexualverbrechen. Sie waren die Primärverbrechen der CD: Entstehung und Struktur der CD dienten von Anfang an dazu, diese Verbrechen ohne Angst vor Strafverfolgung kontinuierlich und systematisch fortsetzen zu können. Bereits seit der Siegburger Zeit machte Schäfer meist im sogenannten Jugendheim und getrennt von ihren Eltern lebende Kinder zu Opfern seiner Sexualverbrechen. Die CD ermöglichte diese Verbrechen und bot Schäfer den dafür notwendigen Schutz. Es war das primäre Interesse Schäfers, aber auch der Führungsmitglieder, den Fortbestand der CD zu sichern. Während andere interne Verbrechen diesem Zweck dienten und daher als Sekundärverbrechen bezeichnet werden können, war das Primärverbrechen Zweck an sich. Schäfers sexueller Missbrauch zieht sich wie ein roter Faden durch die Geschichte der CD. Immer wenn dieser Zweck gefährdet schien, änderte die CD ihre Strategie - etwa 1961, als die beginnende Strafverfolgung zur Auswanderung der Gruppe nach Chile führte.

Einige Sekundärverbrechen hatten das Ziel, Schäfer Zugang zu Opfern seiner Missbrauchstaten zu ermöglichen. Hierzu gehörte die systematische Aneignung von Kindern. Hierbei handelte es sich um Kinder aus dem Umfeld der Gruppierung, die entweder mit nur einem Elternteil oder gar ohne ihre Eltern nach Chile übersiedelten. Verschiedene Führungsmitglieder übernahmen systematisch das Sorgerecht für die Minderjährigen und adoptierten sie - oftmals auf betrügerische Weise. Abschnitt 4.1.2 schildert beispielhaft hierfür die Fälle von Wolfgang Müller (heute Kneese), Heinz Kuhr (später Schmidt, heute Wagner), der Kinder der Familien Lindemann und Wagner sowie von Tobias Müller. Der Abschnitt zeigt auch, wie bundesdeutsche Behörden diese Vorgänge zur Kenntnis nahmen und Informationen dazu sammelten. Den eingesehenen Quellen zufolge verhielten sie sich jedoch vorwiegend beobachtend und wurden nicht aktiv.

Abschnitt 4.1.3 beschreibt Fluchtversuche und Hilferufe von Colonos als Ausdruck der permanenten Freiheitsberaubung in der CD. Fluchtversuche gab es von 1962 bis Anfang der 2000er Jahre, nur wenige von ihnen waren erfolgreich. Das lag an der Abgelegenheit der Siedlung, den hochtechnologischen Überwachungsanlagen sowie den Aktivitäten der Sicherheitsgruppe, die viele Fluchtversuche vereitelte. In einigen Fällen wurden Flüchtende von Vertreter_innen chilenischer Behörden aufgegriffen. Einige gelangten zur Botschaft in Santiago oder zu einem deutschen Konsulat in anderen Städten. Mehrere Colonos, die die CD verlassen wollten, richteten auch per Brief oder per- 
sönlich Hilfsersuchen an die Botschaft. In den meisten Fällen drängte die CD-Führung diese Personen anschließend, ihr Hilfsersuchen schriftlich zu widerrufen sowie zu erklären, dass es ihnen in der CD gut gehe und sie sich frei fühlten. In einigen Fällen lud die Botschaft Verfasser_innen von Hilfsersuchen in die Botschaft vor, die jedoch in Begleitung von Führungsmitgliedern erschienen, dadurch nicht frei sprechen konnten und ihr Hilfsersuchen widerriefen. Die Botschaft erkannte die Systematik dieses Vorgehens relativ früh, entwickelte jedoch lange Zeit keine wirksame Strategie, um etwa Hilfesuchende allein zu sprechen oder sie bei der Flucht aus der CD zu unterstützen. Für die CD waren erfolgreiche Fluchten eine Gefahr, da die Geflüchteten umfangreich über das Innenleben der CD und die dort begangenen Verbrechen aussagen konnten. Besonders kritisch für die CD waren die erfolgreiche Flucht von Wolfgang Müller 1966, von Hugo Baar 1984 und von dem Ehepaar Georg und Lotti Packmor 1985. Insbesondere die Berichte des ehemaligen Führungsmitglieds Baar sowie der Eheleute Packmor dokumentierten zahlreiche CD-Verbrechen und führten zu einem allmählichen Umdenken der bundesdeutschen Diplomatie. Die Flucht von Tobias Müller 1997 führte letztlich zum Untertauchen Schäfers.

Abschnitt 4.1.4 behandelt die Briefzensur. Ebenfalls um zu verhindern, dass kritische Informationen über die CD nach außen drangen, wurde jeglicher Schriftverkehr von Colonos überwacht und gegebenenfalls zensiert. Viele Colonos internalisierten die Überwachung über die Jahre dergestalt, dass sie nur noch nichtssagende Briefe an Verwandte schrieben. Den Behörden war die permanente Verletzung des Grundrechts auf freie Kommunikation bekannt. Sie wurden von Angehörigen informiert und gebeten, Colonos beim Verlassen der Siedlung zu helfen.

In Abschnitt 4.1.5 beschreibe ich die Missachtung des Rechts auf Schulbildung durch die CD. Die CD verfügte offiziell über zwei Schulen: Eine interne für Colonos, die das chilenische Bildungsministerium nicht als solche anerkannte, sowie seit 1985 die Privatschule Escuela Particular Villa Baviera, die staatlich anerkannt und subventioniert wurde. Letztere wurde von Kindern aus der Umgebung der CD besucht und war so Teil der sozialen Fassade der CD.

»Arbeit ist Gottesdienst « lautete einer von Schäfers Leitsprüchen. Die der Sklaverei ähnlichen Arbeitsverhältnisse in der CD, die ich in Abschnitt 4.1.6 beschreibe, wurden von Schäfer und den Führungsmitgliedern religiös legitimiert. Harte Arbeit jenseits arbeitsrechtlicher Regeln und Gesetze, in einem Umfeld von Unfreiheit, Zwang und Willkür prägte den Alltag der Colonos. Das Arbeitsleben begann für die Colonos bereits im Kindesalter. Sie wurden je nach Belieben der CD-Führung dort eingesetzt, wo diese es jeweils für wichtig erachtete. Der Arbeitstag hatte keine feste zeitliche Begrenzung. Gearbeitet wurde, bis die jeweilige Aufgabe erledigt war. Die Colonos kannten keine Arbeitsverträge, erhielten keinen Lohn, entrichteten keinerlei Sozialversicherungsbeiträge und erwarben so auch keine Ansprüche auf Renten- oder Sozialleistungen. Sämtliche Erträge, die durch die Arbeit erwirtschaftet wurden, flossen in die Kassen der CD-Führung. Den Behörden gegenüber legte die CD hierüber keinerlei Rechenschaft ab.

Die zahlreichen schweren Unfälle in der CD, vielfach mit Todesfolge, sind Gegenstand von Abschnitt 4.1.7. Viele von ihnen ereigneten sich im Kontext des Arbeitslebens in der CD, das keinerlei Arbeitsschutz vorsah. Einige standen im Zusammenhang mit 
Übermüdung oder Vergabe von Psychopharmaka. Die meisten dieser Todesfälle wurden von Behörden gar nicht oder nur oberflächlich untersucht.

Abschnitt 4.1.8 behandelt die Körperverletzungen in der CD, vor allem durch ein System der kontinuierlichen Disziplinierung und Unterwerfung der Colonos mittels physischer Strafen, allen voran durch Prügel, Elektroschocks und zwangsweise verabreichte Psychopharmaka. Prügelstrafen waren die fast zwangsläufige Konsequenz jeglicher (vermeintlicher) Missachtung der von Schäfer definierten Gemeinschaftsregeln oder Moralvorstellungen. Das Prügeln übernahm entweder Schäfer selbst oder verschiedene Funktionsträger_innen. Manchmal wurden regelrechte Prügelrituale veranstaltet, bei denen praktisch alle Colonos dazu gedrängt wurden, andere zu schlagen und Mittäter zu werden. Misshandlungen mit Elektroschocks und die Zwangsverabreichung von Psychopharmaka sollten dazu dienen, die Willenskraft von Colonos zu brechen, ihre Sexualität zu unterdrücken und ihre Erinnerungen auszulöschen. Diese Misshandlungen geschahen meist im Krankenhaus, in das einzelne Colonos teilweise jahrelang eingesperrt wurden. Besonders grausam waren die Verbrechen im sogenannten Neukra (dem Krankenhausneubau) Ende der 1960er, Anfang der 1970er Jahre, bei denen eine Gruppe von Jungen und Mädchen monate-, bzw. jahrelang regelmäßig mit Stromstößen im Genitalbereich, Schlägen und Medikamenten gequält wurde.

Abschnitt 4.2 behandelt die externen Verbrechen der Colonia Dignidad, die außerhalb der CD begangen wurden bzw. durch die nicht zur CD gehörende Personen geschädigt wurden. Ein Großteil dieser Verbrechen steht im Kontext der chilenischen Diktatur von 1973 bis 1990.

Dazu gehört die Aneignung chilenischer Kinder aus der unmittelbaren Umgebung der CD, die Abschnitt 4.2.1 schildert. Bei den meist betrügerischen Adoptionsverfahren unterstützten befreundete Richter_innen und Verwaltungsbeamt_innen die CD. Mir sind insgesamt 21 Fälle einer solchen Aneignung chilenischer Kinder bekannt geworden. Alle diese Kinder blieben dauerhaft in der CD und wurden zu Colonos. In zahlreichen Fällen bemühten sich die leiblichen Eltern um eine Herausgabe ihrer Kinder. Sie wandten sich dazu an Behörden und Medien, blieben aber letztlich alle erfolglos. Einige Colonos wissen bis heute nichts über ihre leiblichen Eltern.

Abschnitt 4.2.2 beschreibt den Waffenbau und Waffenhandel in der CD. Die CD produzierte und lagerte Waffen, handelte mit ihnen, bahnte Waffengeschäfte zwischen Dritten an, experimentierte mit Sprengstoffen und hantierte in einer sogenannten Giftküche mit gefährlichen Chemikalien. Hinweisen zufolge war sie ich Rahmen des Geheimdienstprojekts ANDREA auch an der Entwicklung und Herstellung chemischer und bakteriologischer Waffen beteiligt. Die Waffengeschäfte stehen emblematisch für das Vorgehen der CD-Führungsmitglieder. Diese wussten um den kriminellen Charakter des Systems CD und sahen dieses daher als permanent bedroht an. Sie begannen Ende der 1960er Jahre, die CD auch quasi militärisch abzusichern und sammelten Waffen, um sich gegen eine drohende Landreform wehren zu können. Schon vor dem Militärputsch von 1973 versorgte die CD zunehmend auch Großgrundbesitzer aus der Umgebung der Siedlung mit Waffen, führte militärische Trainings durch und unterstützte militante rechtsextreme Gruppierungen. Die CD begann nun auch, selbst Waffen zu produzieren. Sie war aktiv an den Vorbereitungen zum Militärputsch vom 11. September 1973 beteiligt. Nach diesem entwickelte sie sich zu einem Schlüsselelement 
des Repressionsapparates der Diktatur. Mit ihren Kontakten zu Militärs und Waffenhändlern wurde die CD zum internationalen Waffenumschlagplatz. Eine wichtige Rolle spielte hierbei der CD-Freund und BND-Agent Gerhard Mertins.

Abschnitt 4.2.3. erörtert die Menschenrechtsverbrechen der CD im Kontext der chilenischen Diktatur. Diese gehören zu den schlimmsten Verbrechen der Organisation. Diverse Aussagen ehemaliger politischer Gefangener, aber auch ehemaliger (Mit-)Täter belegen, dass zwischen 1973 und 1977 hunderte politische Gefangene in die CD verbracht und dort gefoltert und verhört wurden. Laut Berichten und Vernehmungen wurden in der CD zudem mehrere Dutzend Menschen - möglicherweise sogar über Hundert ermordet. Ihre sterblichen Überreste wurden bis heute nicht gefunden.

Darüber hinaus versorgte die CD die Repressionsorgane der Diktatur mit Waffen und Kommunikationstechnologie und Know-how. Sie schulte Angehörige des Militärapparats in geheimdienstlichen Methoden, Foltertechniken sowie der Handhabung von Waffen und Sprengstoff. Als Teil ihrer Allianz mit der Diktatur betrieb die CD ein Spionage- und Spitzelnetzwerk, das nicht nur der Bekämpfung der linken Opposition gegen die Diktatur diente, sondern auch die Loyalität von Angehörigen der Militärregierung, der verschiedenen Waffengattungen und ihrer jeweiligen Geheimdienste überprüfte. Die persönlichen Verbindungen der CD-Führung einerseits zur Spitze der DINA, insbesondere zu Manuel Contreras, sowie zu Diktator Pinochet andererseits verdeutlichen die wichtige Rolle der CD in dieser Repressionsallianz. Die umfangreiche Zusammenarbeit der CD mit Organen der Diktatur ist durch zahllose Zeug_innenaussagen, aber auch durch das beschlagnahmte CD-Geheimarchiv dokumentiert, allerdings bis heute nur unzureichend aufgeklärt. 2016 stufte die chilenische Justiz die Allianz zwischen CD und DINA im Nachhinein als kriminelle Vereinigung ein.

Nach dem Ende der Diktatur gründete die CD ab 1991 in Reaktion auf staatliche Versuche, ihr das Handwerk zu legen, zahlreiche sogenannte Komitees. Diese sollten zeigen, wie sehr die lokale Landbevölkerung die CD aufgrund ihrer wohltätigen Arbeit unterstützt. In diesem Kontext gegründete Jugendgruppen nutzte Schäfer zur Rekrutierung von Opfern seines sexuellen Missbrauchs. Wie in Abschnitt 4.2.4 beschrieben, fand dieser im Rahmen sogenannter Wochenendfreizeiten statt, zu denen hunderte chilenische Jugendliche in die CD kamen. Einigen Jungen bot die CD-Führung den Besuch des sogenannten Internado Intensivo (Intensiv-Internats) in der CD an. Jerarcas bemühten sich systematisch um das Einverständnis der leiblichen Eltern hierzu. Allerdings existierte dieses Internat nicht wirklich. Es war nur eine formale Fassade für den alltäglichen Missbrauch an den Jungen. Diese lebten gemeinsam mit gleichaltrigen Colonos mehrere Monate oder gar Jahre lang in der CD. Eine herausgeschmuggelte Nachricht eines dieser chilenischen Jungen an seine Mutter läutete im Juni 1996 das Ende des sexuellen Missbrauchs in der CD ein. Rechtsanwalt Hernán Fernández stellte Strafanzeige, ein Richter erließ Haftbefehl gegen Schäfer, dieser tauchte unter, zunächst in der CD, später in Argentinien und wurde schließlich 2005 gefasst und anschließend verurteilt. Durch die öffentliche Thematisierung von Schäfers Missbrauch begannen auch die CD-Unterstützungsnetzwerke zu bröckeln. Im Gegensatz zu den Diktaturverbrechen führten die Missbrauchsvorwürfe dazu, dass auch rechte Politiker_innen die CD nicht mehr offen unterstützten. 
Abschnitt 4.2.5 widmet sich einer Reihe von Todesfällen im Kontext der CD, zu denen es in unterschiedlichem Ausmaß Spekulationen über eine Fremdeinwirkung durch die CD gab. Fast jeder Todesfall von Personen, die sich mit dem Fall CD beschäftigten und der nicht $\mathrm{zu} 100 \%$ natürlich erschien, nährte Gerüchte über die »lange Hand« der CD. Laut den verfügbaren Quellen wurden trotz dieser Spekulationen zumindest einige dieser Todesfälle nicht untersucht. Bei anderen Fällen wurden die Ermittlungen eingestellt, ohne dass Einzelheiten darüber bekannt wurden. Ich stelle zehn dieser Fälle dar und komme zu dem Schluss, dass in den meisten ein Einwirken der CD sehr unwahrscheinlich ist, da es lediglich vage Vermutungen, aber keinerlei konkrete Belege gibt. Allerdings gibt es in einigen Fällen, etwa beim Tod Alfred Schaaks 1985, zumindest plausible Hinweise. Letztlich kann aber auch dieser Fall nur durch eine weitere Untersuchung geklärt werden.

\subsection{Juristische und parlamentarische Aufarbeitung der Verbrechen der Colonia Dignidad (Kapitel 5)}

Nachdem Kapitel 4 das Ausmaß und die Dimensionen der CD-Verbrechen gezeigt hat, und darauf eingegangen ist, welche Kenntnisse staatliche Stellen in Chile und der Bundesrepublik davon gehabt haben, richtet sich der Blick nun auf den Umgang dieser Stellen mit der CD und den von ihr begangenen Verbrechen. Kapitel 5 analysiert also die Aufarbeitung der Verbrechen in Chile und in Deutschland durch Justiz und Politik, genauer gesagt durch Parlamente, Staatsanwaltschaften und Gerichte.

Die juristische Aufarbeitung der CD-Verbrechen war langwierig und hat bislang erst einen geringen Teil der Einzeltaten untersucht. Während es in Chile erst ab 1996 und verstärkt nach 2005 gelang, diverse Verbrechenskomplexe zu untersuchen und einige Täter_innen dafür zur Rechenschaft zu ziehen, blieben die strafrechtlichen Untersuchungen in der Bundesrepublik bis heute ergebnislos. Die für die Verfahren zuständige Justiz von Nordrhein-Westfalen eröffnete zwar ab 1961 diverse Ermittlungsverfahren. Diese wurden jedoch allesamt mit Verweis auf einen fehlenden hinreichenden Tatverdacht eingestellt. Viele von der chilenischen Justiz gesuchte Beschuldigte haben sich daher in den letzten Jahrzehnten nach Deutschland abgesetzt, um sich den chilenischen Verfahren zu entziehen. Die Bundesrepublik liefert dem Grundgesetz entsprechend keine deutschen Staatsbürger_innen an Staaten außerhalb der EU aus und ist so zum sicheren Hafen für vermeintliche Täter_innen der CD geworden.

Ein Großteil der Verbrechen der CD wurde von deutschen Staatsbürger_innen auf chilenischem Staatsgebiet begangen, Opfer dieser Taten waren Chilen_innen und Deutsche. Aufgrund dessen stellt sich die Frage, welche Justiz für die Strafverfolgung zuständig ist. Nach dem Territorialitätsprinzip war und ist die chilenische Justiz für die Untersuchung und Ahndung sämtlicher auf chilenischem Territorium begangener Taten zuständig. Gleichzeitig kann nach dem sogenannten Personalitätsprinzip bei Taten im Ausland, die von deutschen Staatsangehörigen oder gegen deutsche Staatsangehörige begangen wurden, das deutsche Strafrecht zur Anwendung kommen. Daher haben wir es bei vielen der CD-Verbrechen - zumindest theoretisch - also mit einer doppel- 
ten Zuständigkeit von chilenischer und bundesdeutscher Justiz zu tun. In der Praxis hat die Frage der Zuständigkeit den Fall CD in allen Phasen begleitet.

Das Fehlen eines Rechtshilfeabkommens erschwerte eine Kooperation zwischen den Justizapparaten beider Länder. Die Folge waren langwierige und bürokratische Rechtshilfeersuchen in beide Richtungen. Diese brachten nur selten Fortschritte, führten jedoch oftmals zu einem jahrelangen Stillstand der Ermittlungen. Unterschiedliche Rechtskulturen führten zudem dazu, dass beide Seiten sich regelmäßig über die vermeintliche Untätigkeit der jeweils anderen Seite beschwerten. Auch Auseinandersetzungen über Formalien, etwa über die von Übersetzungen, zogen die Verfahren in die Länge. Diese gegenseitigen Zuweisungen der Verantwortlichkeiten haben die Aufarbeitung der Verbrechen erschwert und teilweise blockiert. Davon profitierten die der Taten Beschuldigten aus den Reihen der CD.

Hinzu kamen auf beiden Seiten wechselnde politische Interessen und Allianzen. Eine Untersuchung und Ahndung der Verbrechen war beispielsweise zwischen 1973 und 1990 aufgrund der engen Zusammenarbeit zwischen der Militärdiktatur und der CDFührung in Chile nahezu unmöglich. Auch in den Jahren dannach verhinderten die im Rahmen der Transición paktierten Machtverhältnisse eine Aufarbeitung der während der Militärdiktatur begangenen Menschenrechtsverbrechen. Erst ab 1996 führten die Ermittlungen wegen des sexuellen Missbrauchs an chilenischen Kindern zu einer Schwächung des CD-Unterstützungsnetzwerks und zu einem zaghaften Fortgang der Ermittlungen. Am Zustandekommen der Festnahme von Paul Schäfer 2005 in Argentinien waren weder chilenische noch deutsche Ermittler_innen beteiligt, sie erfolgte aufgrund privater Ermittlungen von Aufklärer_innen. Überhaupt scheint es seitens beider Staaten nur selten tatsächliche Fahndungen nach per Haftbefehl ausgeschriebenen Tatbeschuldigten im Ausland gegeben zu haben: Zwar wurde Paul Schäfer von der bundesdeutschen Justiz zwischen 1961 und 1970 und ab 1997 per Haftbefehl gesucht. Es wurde jedoch keine Zielfahndung nach ihm durchgeführt. Dies bedeutet, dass die bundesdeutsche Justiz offensichtlich keinerlei Anstrengungen zu seiner Festnahme unternahm und abwartete, ob er sich stellte oder beispielsweise bei einem Grenzübertritt festgenommen wurde - was nicht zu erwarten war. Angesichts der Dimension der ihm vorgeworfenen Verbrechen erscheint dies absolut unangemessen. Auch die chilenische Justiz fahndete nicht eingehend im Ausland und verhinderte nicht, dass diverse Beschuldigte (oder wie im Fall Hartmut Hopp bereits Verurteilte) trotz Ausreiseverbots das Land verlassen und nach Deutschland reisen konnten.

Die CD hat die juristische »Gegenarbeit« immer als zentrales strategisches Element begriffen und »investierte « umfangreich in anwaltliche Vertretung - Teile der Postsektengemeinschaft tut das bis heute. Opfer hatten hingegen nur begrenzten Zugang zu Rechtsanwält_innen, wurden eingeschüchtert und erhielten von behördlicher Seite kaum Unterstützung, um gegen die CD vorzugehen oder sich gegen sie zu wehren. Ab den 1960er Jahren ergriff die CD aktiv die Initiative, um aufklärerische Bestrebungen zu diskreditieren: durch Verleumdungsklagen, Zivilklagen und Lobbyarbeit bei Richter_innen und Justizbeamt_innen. Sie nahm für ihre Strategie dutzende renommierte Anwält_innen in der Bundesrepublik und Chile unter Vertrag, nutzte alle Rechtsmittel aus und verzögerte und verhinderte so die Aufklärung. 
Die Politik versteckte sich hinter der juristischen Ebene, um das Ausbleiben eigener Aufklärungstätigkeit zu rechtfertigen. Insbesondere das AA begriff das Thema lange Zeit als Auseinandersetzung zwischen privaten Akteur_innen und griff nicht in diese ein. 1985 entschied sich das AA erstmals, die Berichte der Geflüchteten Hugo Baar und Georg und Lotti Packmor der Justiz zu übersenden. Dies führte zur Einleitung des Bonner Ermittlungsverfahrens, das - zumindest formell - bis 2010 geführt wurde.

Das Warten auf den Ausgang der oftmals jahrzehntelang schwebenden Verfahren diente den politischen Behörden als Rechtfertigung, um nicht selbst tätig zu werden. Obwohl das AA keine ständige Detailkenntnis über den Fortgang der Ermittlungen der Staatsanwaltschaft Bonn hatte, so kannte sie doch aus den übersandten Einstellungsverfügungen und weiteren Quellen die Grundhaltung der Bonner Staatsanwälte: Diese hielten die Vorwürfe für nicht erwiesen und argumentierten, es könne sich dabei lediglich um gruppeninterne Streitigkeiten handeln. Sie bewerteten detailreiche Schilderungen über Verbrechen von Personen, die aus der CD geflüchtet waren, gleich stark wie unter Druck durch die CD-Führung herbeigeführte eidesstattliche Versicherungen. In diesen bekundeten Menschen, die die Justiz niemals zu Gesicht bekam und die in der CD Verbrechen ausgesetzt waren, sie seien frei und es ginge ihnen gut.

Die Bonner Staatsanwaltschaft begriff die CD nicht als kriminelle Gruppierung. Diese Haltung hatte weitreichende Konsequenzen: Fast drei Jahrzehnte hindurch (1970 bis 1997) gab es keinen Haftbefehl gegen Paul Schäfer und andere Personen aus der Führung der CD. Diese konnten sich frei bewegen und gleichzeitig verkünden, alle Vorwürfe gegen sie seien bösartige Verleumdungen. Der 1997 gegen Paul Schäfer erlassene Haftbefehl kam erst nach einem chilenischen Fahndungsersuchen und hatte keinerlei Konsequenzen, da keine Zielfahndung gegen Schäfer eingeleitet wurde. Gegen die CDMitglieder, die den Untergrund Schäfers in Argentinien organisierten, Kinder entführten, falsche Papiere besorgten und Gelder in verschiedenen Ländern versteckten, wurde von deutscher Seite gar nicht gefahndet. Schäfer konnte sich so in seinem Versteck sicher fühlen, bis Aufklärer_innen ihn auffanden und die argentinische Kriminalpolizei kontaktierten, die ihn festnahm. Bis zur Einstellung des letzten Ermittlungsverfahrens 2019 verfolgte die NRW-Justiz eine Haltung, die CD-Verbrechen als Einzeltaten begriff, die in einem fernen Land begangen wurden und in Teilen bereits verjährt waren. Eigene Ermittlungen zu den Taten waren begrenzt oder unterbleiben ganz. Zwar wurden Rechtshilfeersuchen an die chilenische Justiz gerichtet, deren Urteile und Feststellungen jedoch für die hiesigen Verfahren nicht verwertbar waren. Denn sie kamen in einer anderen Rechtskultur und mit anderem Fokus zustande.

Chile konzentrierte die eigenen Ermittlungen ab 1996 auf die Person von Paul Schäfer und untersuchte im Verfahren um sexuellen Missbrauch in der CD das System, das Schäfer die Verbrechen ermöglichte, indem es ihm die Kinder zuführte. Dieses System organisierte die Entführung sowie Anwerbung von Kindern, die formale Absicherung durch von deren Eltern unterschriebene Einverständniserklärungen, Vollmachten und Sorgerechtsübertragungen - die oft unter Vorspiegelung falscher Tatsachen auf betrügerische Art und Weise zustande kamen. Hinzu kam die Sedierung der Missbrauchsopfer vor und nach den Taten. Die chilenische Justiz verurteilte 21 Personen, darunter 14 Colonos und 7 Unterstützer_innen der CD, wegen dieser Taten. Weitere entzogen sich jedoch der chilenischen Justiz durch Flucht nach Deutschland. Die NRW-Justiz 
erkannte dieses System nicht und stellte alle eigenen Ermittlungen wegen fehlenden hinreichenden Tatverdachts ein. Sie argumentierte, die Beweislage sei für hiesige Verfahrensstandards nicht ausreichend. Gleichzeitig bemühte sie sich kaum darum, eigene Erkenntnisse über die Taten zu erlangen. Strukturermittlungen zur tieferen Durchleuchtung der Gruppierung, ihrer Mitglieder und Zusammenhänge unterblieben. Heute leben diverse CD-Mitglieder in der Bundesrepublik, die nach Erkenntnissen chilenischer Ermittler_innen und Richter_innen beispielsweise im engen Kontakt zu DINAAgent_innen standen, die in der CD Verbrechen begingen. Zu ihren Kenntnissen über Zusammenhänge und konkrete Verbrechen wurden diese Personen jedoch niemals befragt. Da über viele der bundesdeutschen Ermittlungsverfahren nur wenige Informationen zugänglich sind, lassen sich über die Gründe für die Einstellung der Verfahren nur Vermutungen anstellen: Die Staatsanwälte, die für die Ermittlungsverfahren der Staatsanwaltschaft Bonn zwischen 1977 und 2010 zuständig waren, sind teilweise immer noch im Justizapparat von NRW tätig. Jegliche heutige richterliche Feststellung von Verbrechen der CD würde die damaligen Ermittlungen in Frage stellen und ein Eingeständnis dessen bedeuten, dass die NRW-Justiz jahrzehntelang Taten nicht aufklärte und Opfer nicht schützte.

Als Rechtfertigung für ein Unterlassen tiefergehender Ermittlungen von schweren Verbrechen können diese Erklärungsansätze jedoch nicht dienen. Es bleibt jedoch festzustellen, dass die deutsche Justiz bisher keinerlei Ergebnisse bei ihrem Umgang mit dem Fall CD hervorgebracht hat. Während die weiteren behördlichen Ebenen - die chilenische Justiz und die deutsche und die chilenische Politik - sich zumindest in Ansätzen für die Verbrechen der CD zuständig fühlen, war die Mitwirkung der deutschen Justiz an einer Aufklärung der CD-Verbrechen und der Sanktionierung der Verantwortlichen ergebnislos. Bis heute sind keine Ansätze für eine Korrektur dieses Kurses zu erkennen.

Abschnitt 5.1 befasst sich mit der juristischen Aufarbeitung der Verbrechen der CD in Chile. Seit 1966 gab es in Chile dutzende juristische Verfahren und Vorgänge mit Bezug zur CD. Dazu gehören strafrechtliche Untersuchungen, zivil- und verwaltungsrechtliche Verfahren sowie Recursos de Protección und Recursos de Amparo. Während die strafrechtlichen Untersuchungen sich mehrheitlich gegen CD-Mitglieder richteten, nutzte die CD vor allem Recursos de Protección und Recursos de Amparo, um die strafrechtlichen Untersuchungen zu behindern und Verwaltungsentscheidungen anzufechten.

In Chile waren sechs Verfahren, beziehungsweise Verfahrenskomplexe von besonderer Relevanz: Die nach der Flucht von Wolfgang Müller (heute: Wolfgang Kneese) 1966 eröffneten Verfahren bei dem Juzgado de Parral und der CA de Chillán; die bei der Corte Suprema 1977 durchgeführte Untersuchung der Ermordung des DINA-Kollaborateurs Juan René Muñoz Alarcón; die 1989 auf bundesdeutschen Druck angestrengte verwaltungsrechtliche Untersuchung der CD durch die Richter Guillermo Navas und Hernán Robert; die Untersuchung wegen sexuellen Missbrauchs ab 1996 durch die Richter Norambuena und Hernán González; das Verfahren wegen Contratos Simulados (Betruges) und die ab 2005 bei Richter Jorge Zepeda gebündelten Ermittlungen wegen Menschenrechtsverbrechen. Diese Verfahren fanden in den verschiedenen in Kapitel 6 beschriebenen Phasen des Falls CD statt. 
Die Verfahren nach der Flucht von Wolfgang Müller (heute: Kneese) in den Jahren 1966 bis 1969 fanden vornehmlich bei Gerichten in der Nähe der CD statt (Parral, Chillán, Talca). Nachdem infolge der Berichterstattung und politischen Drucks ein Ministro en Visita (besonderer Untersuchungsrichter) eingesetzt wurde, ging die CD in die juristische Gegenoffensive und entwarf ein Verteidigungssystem, das in den folgenden Jahrzehnten in ähnlicher Form immer wieder zum Einsatz kam: Sie stellte Verleumdungsklagen und Gegenanzeigen gegen die Personen, deren Aussagen grundlegend für die gegen die CD gerichtete Untersuchung waren. Gleichzeitig begann sie eine Lobbyoffensive bei Richter_innen und Justizmitarbeiter_innen sowie bei Politiker_innen und Diplomat_innen. Diese Lobbyinitiative hatte das Ziel, sich selbst als Opfer einer Diffamierungskampagne darzustellen. Dieses Verteidigungssystem führte in den nach der Flucht von Wolfgang Müller eröffneten Verfahren zu einem vollständigen juristischen Erfolg: Die Untersuchung gegen die CD wurde eingestellt und der »Verursacher« Wolfgang Müller zu einer exemplarischen Gefängnisstrafe verurteilt. Durch diesen Präzedenzfall konnte die CD in der Folgezeit Unterstützung in den Reihen der chilenischen Regierung und bei bundesdeutschen Diplomaten erreichen.

Während der Militärdiktatur genoss die CD einen weitreichenden Schutz durch die chilenische Justiz. Die 1977 eingeleitete Untersuchung wegen der Ermordung des in der CD stationierten DINA-Kollaborateurs Juan René Muñoz Alarcón wurde rasch eingestellt. Die Verfahrensakten, die AA und AI erhielten, belegten jedoch den Aufenthalt von Muñoz Alarcón in der Siedlung und bestätigten somit die von aufklärerischen Akteur_innen veröffentlichten Informationen über eine Zusammenarbeit zwischen CD und DINA. Tiefergehende Untersuchungen zu CD-Verbrechen waren während der Diktatur in Chile nicht möglich.

Erst 1987 leitete das AA die Berichte der 1984/1985 aus der CD geflüchteten Hugo Baar und Lotti und Georg Packmor formell an die chilenische Justiz weiter. Das AA vermied dabei, selbst Anzeige zu erstatten oder Opfer dabei zu unterstützen, über Klagen eine Untersuchung zu forcieren. Stattdessen drängte das AA die chilenische Seite auf diplomatischem Wege, selbst eine Untersuchung der CD einzuleiten. Nach mehreren Anläufen und erst nach dem 1988 durchgeführten Plebiszit, das das Ende der Diktatur einläutete, gab die Diktatur dem Druck der Bundesregierung nach. Die chilenische Justiz eröffnete jedoch keine strafrechtliche, sondern lediglich eine verwaltungsrechtliche Untersuchung. Der Abschlussbericht von Richter Robert stellte administrative Unregelmäßigkeiten fest und führte zur Einleitung zweier Strafverfahren, die jedoch bald wieder eingestellt wurden. Einerseits führte der Bericht zu dem ersten Beschluss der chilenischen Justiz, der die CD in Ansätzen in Frage stellte und gab der ersten post-diktatorialen Regierung Handreichungen für die Auflösung der SBED. Andererseits wurde eine umfassende strafrechtliche Untersuchung vermieden.

Die CD konnte die Zeit der Untersuchung dafür nutzen, ihre Vermögensstruktur durch die Gründung der ABC-Gesellschaften auf neue Beine zu stellen. Die Vermögensübertragung festigte die Position der $C D$ und die Justiz nutzte die Chance nicht, der CD durch die Feststellung des Betruges die Rechtsgrundlage ihres Handelns zu entziehen. Dies gab der CD die Möglichkeit, sich - auf dem Papier - eine neue formale Struktur zu schaffen, die rechtlich schwer kontrollierbar ist. Diese Struktur der geschlossenen Aktiengesellschaften ABC besteht bis heute. Erst 1996 reichte der CDE 
(Staatsverteidigungsrat) Klage wegen betrügerischer Vermögensübertragung ein (Vgl. Abschnitt 3.2.3). Dieses Verfahren kam nie zum Abschluss, es erreichte lediglich die Beschlagnahmung eines großen Teils der CD-Ländereien und schränkte so die Wirtschaftstätigkeit der ABC-Unternehmen ein. 2009 schloss der CDE einen Deal mit den CD- Unternehmen: Die Beschlagnahmung wurde aufgehoben, im Gegenzug nahmen die Firmen Hypotheken auf eine Reihe von Ländereien auf, die mit 6 Millionen USDollar bewertet wurden. Diese Ländereien sollten für die Auszahlung zivilrechtlicher Titel von Opfern gegen CD-Täter_innen zur Verfügung stehen. Elf Jahre nach dieser Einigung warten Opfer heute jedoch immer noch auf eine Auszahlung seitens der CDUnternehmen, die nach geübtem Muster Rechtsmittel einlegen und die Verfahren in die Länge ziehen.

Erst Strafanzeigen von Eltern chilenischer Kinder, die in den 1990er Jahren in der CD missbraucht wurden, erschütterten ab 1996 die CD in ihren Grundfesten. Das CDUnterstützungsnetzwerk bröckelte. Ein Großteil der Unterstützer_innen stammte aus dem rechten und extrem rechten Lager, die die Diktaturverbrechen der CD bis dorthin in Fortführung einer Logik des Kalten Krieges als linke Verleumdungskampagne oder als notwendige Verbrechen zur Bekämpfung des "Kommunismus« - dargestellt hatten. Die nun in immer weiteren Einzelheiten bekanntwerdenden Missbrauchsverbrechen passten jedoch nicht in diese Logik. Das führte dazu, dass die offen geäußerte Unterstützung für die CD wegbrach. Paul Schäfer wurde zur Fahndung ausgeschrieben und die Ermittler_innen setzten die CD-Führung durch regelmäßige mehrtägige Razzien unter Druck. Obwohl die CD-Netzwerke in der chilenischen Polizei dafür sorgten, dass Razzien aufgeschoben wurden und die CD-Führung meist vor dem Eintreffen der Ermittler_innen gewarnt wurde, sah Paul Schäfer seine Sicherheit in Gefahr und entschloss sich, nach Argentinien zu reisen und dort unterzutauchen. Der durch dieses Verfahren aufgebaute Druck führte viele Jahre später zur Festnahme Paul Schäfers. Diese wurde von Aufklärer_innen quasi im Alleingang herbeigeführt, in dem sie Schäfer in Argentinien ausfindig machten und klug agierten, um eine erneute Flucht Schäfers zu verhindern und den Zugriff der argentinischen Polizei herbeizuführen. Das Verfahren wegen sexuellem Missbrauch kam 2013 durch das Urteil der Corte Suprema zum Abschluss. Dieses bedeutete mehrjährige Haftstrafen für sechs Mitglieder der CD-Führung und Bewährungsstrafen für 15 weitere Personen. Es war damit das bisher umfassendste Strafurteil.

Die Festnahme Schäfers 2005 führte in Chile zu einem überwältigenden Medienaufsehen, in deren Folge zahlreiche juristische Untersuchungen an Fahrt gewannen. Die chilenische Justiz entschied, die Mehrzahl der Strafverfahren, insbesondere zu den CD-Diktaturverbrechen, bei einem einzelnen Richter - Jorge Zepeda Arancibia - zu bündeln. Zepeda stand unter hohem Druck, Ermittlungsergebnisse zu präsentieren und war dabei auf sich alleine gestellt: er verfügte lediglich über einen Sekretär und über wechselnde Polizeiermittler_innen, denen er nicht immer vertraute. Zepeda vernahm dutzende Colonos und nahm einige Führungsmitglieder in Untersuchungshaft. Es gibt Hinweise darauf, dass er mindestens einem Colono auch Strafmilderung oder verschonung im Gegenzug für Aussagen zusicherte. Während Mitglieder der Führungsebene über die CD-Diktaturverbrechen bis dahin geschwiegen hatten, so begannen die Inhaftierten und einige andere nun zu reden: Mehrere Colonos machten weitreichen- 
de Angaben über die Verbringung von politischen Gefangenen in die CD. Dies geschah einerseits, um sie unter Folter zu verhören und um weitere Widerständler_innen zu identifizieren. Einige Dutzend Gefangene wurden den Aussagen zufolge von Militärs oder DINA-Agent_innen in die CD gebracht, um sie dort umgehend zu töten und im Wald zu verscharren.

Ermittler_innen wurden von Colonos zu Orten geführt, an denen Massengräber existiert haben sollen. Forensiker konnten feststellen, dass dort tatsächlich im Zeitraum 1973-1978 Grabungen stattgefunden hatten. Sie konnten jedoch keine Leichen oder biologische Überreste von Menschen finden. Laut Aussagen der CD-Mitglieder wurden mehrere Jahre nach der Erschießung und Vergrabung die Leichen mehrerer Dutzend Ermordeter wieder ausgegraben und verbrannt, um Spuren der Taten zu verwischen. Bei den übereinstimmenden Aussagen der Colonos über diese Taten fehlten entscheidende Details: Informationen über die Identität der Opfer und der materiellen Täter_innen der Mordhandlungen wurden nicht preisgegeben. Alle Colonos, die über die Vorgänge aussagten, gaben an, lediglich an einzelnen Vorgängen beteiligt gewesen zu sein, beispielsweise an dem Verbringen der Gefangenen zum Ort der Erschießung, an dem Zuschütten der zuvor ausgehobenen Gruben oder an dem Verbrennen von Leichen einige Jahre später. Diese Handlungen wertete Zepeda in den meisten Fällen jedoch nicht als Beihilfe oder Verschleierung der Mordtaten. Lediglich bei einem Colono - Gerhard Mücke - kam es zu einer Verurteilung.

Zepeda sprach in den Jahren 2008 bis 2015 mehrere Urteile, in denen er verschiedene Verbrechen feststellte. Die Urteile beziehen sich auf Mord, Entführung und Folter, Körperverletzung durch ungerechtfertigte Medikamentenvergabe und Elektroschocks, Verstoß gegen das Waffengesetz und Bildung einer kriminellen Vereinigung. Die Urteile decken somit einen großen Teil der CD-Verbrechenskomplexe $a b$, jedoch nur einen geringen Teil der Einzeltaten. Sie stellen einen juristischen Wissensstand über die CDVerbrechenskomplexe dar. Eine Sanktionierung der Taten wurde jedoch weitgehend vermieden. Die Anklagen in allen von Zepeda geführten CD-Verfahren, die bis 2010 eröffnet wurden, richteten sich (auch) gegen Paul Schäfer. Dieser verstarb nach fünf Jahren Haft im Jahr 2010. Rechtskräftig verurteilt worden war er in diesem Moment nur in zwei Verfahren zu insgesamt sechs Jahren und 300 Tagen Haft. Vorläufig verurteilt, in erster, bzw. zweiter Instanz, war er in zwei Verfahren zu weiteren 27 Jahren Haft. Infolge der von Zepeda geführten Verfahren wurden zwar mehrere Mitglieder der CD-Führung verurteilt, lediglich in einem Fall führte dies jedoch zu einem Haftantritt (Karl van den Berg). Heute ist nur noch der Colono Gerhard Mücke in Haft.

Abschnitt 5.2. behandelt die Befassung chilenischer parlamentarischer Instanzen mit der CD. Wie auch im Bereich der Justiz konnte die CD bereits in den 1960er Jahren in parlamentarischen Verfahren Erfolge erringen, die sie in den Folgephasen als vermeintliche Entlastung anführte. Zu den wichtigsten Vorkommnissen zählten hier die 1968 vom chilenischen Senat beschlossene Aberkennung der Immunität des Gouverneurs von Parral, Claudio Fuentes, und des Intendenten von Linares, Hector Taricco und der vom chilenischen Abgeordnetenhaus 1968 eingesetzte Untersuchungsausschuss. Letzterer kam zu einem Abschlussbericht, der die CD von einem breiten Spektrum an Vorwürfen entlastete. Diese Entlastung ist lediglich durch die erfolgreiche Lobbyarbeit des Systems CD in politischen Kreisen erklärbar: Abgeordnete wurden in 
die CD eingeladen und der Anwalt der CD Luis Ortíz Quiroga wurde vielerorts vorstellig, um Überzeugungsarbeit zu leisten. Aufklärerische Stimmen außerhalb der Medien waren in der Debatte wenig präsent. Nach Wiederaufnahme des parlamentarischen Betriebs in Chile im Jahr 1990 besuchte die Menschenrechtskommission des Abgeordnetenhauses die CD. Einzelne Abgeordnete der Regierungskoalition unterstützten in den Folgejahren die Regierungsbemühungen um Auflösung der SBED. Sie trafen jedoch auf ein weitgehend geschlossenes Lager im rechten Spektrum, das die CD unterstützte. Das bestimmte Auftreten der Rechten gegen die parlamentarische Regierungsmehrheit zeigte die faktische Machtverteilung während der Transición. Trotz eines energischen Auftretens der Regierung verzögerte sich die Auflösung der SBED und verschiedene Behörden beteiligten sich nicht proaktiv an einer Unterstützung des Regierungshandelns. Gleichzeitig zählte die CD weiterhin auf Unterstützung in Kreisen von Justiz, Polizei und Verwaltung, durch die Regierungsinitiativen immer wieder behindert wurden.

In diesem Kontext setzte das chilenische Abgeordnetenhaus in den Jahren 1995, 1997 und 1999 drei Mal in Folge Untersuchungskommissionen ein, um die verzögerte Umsetzung des SBED-Auflösungsdekrets von 1991 und die fehlende behördliche Unterstützung bei der Aufklärung der CD-Verbrechen zu beleuchten. Die Abschlussberichte dieser Kommissionen wurden mit der Mehrheit des Regierungslagers gegen Stimmen der rechten Oppositionen verabschiedet. Der Tenor der Abschlusserklärungen war deutlich und zeigte gleichzeitig die Ohnmacht des Regierungslagers und des Rechtsstaats gegenüber dem System CD. Die Untersuchungskommissionen stellten fest, dass Regierungsinitiativen systematisch behindert wurden, dass verschiedene Behörden nicht angemessen agierten und dass teilweise der vorhandene Rechtsrahmen nicht ausreichend war, um der CD beizukommen. Die Untersuchungskommissionen blieben ohne unmittelbare Folgen für die CD und die dort herrschenden menschenrechtswidrigen Zustände, die der chilenischen Staat jahrzehntelang geduldet hatte. Die Berichte klangen wie eine Art Kapitulationserklärung gegenüber einer kriminellen Gruppierung, die den Staat unterwandert und sich nicht an dessen Gesetzgebung hielt.

Abschnitt 5.3. beleuchtet das Wirken der bundesdeutschen Justiz im Fall CD. Für die Ermittlungen und Verfahren in Sachen CD war hauptsächlich die Justiz in NRW zuständig. Wie auch in Chile verfolgte die CD in der Bundesrepublik eine offensive Strategie gegen Aufklärer_innen und versuchte, sie mithilfe von Unterlassungs- oder Verleumdungsklagen zum Schweigen zu bringen. Obwohl die Verfahren nur selten zugunsten der $\mathrm{CD}$ ausgingen, so hatten sie den von der $\mathrm{CD}$ gewünschten Effekt, Verfahren in die Länge zu ziehen und die juristische Feststellung von Verbrechen zu vermeiden. Die beiden exemplarisch dargestellten Zivilverfahren zeigen dies.

1977 hatten Amnesty International (AI) und die Zeitschrift Stern Zeug_innenaussagen zusammengetragen, die sowohl externe Verbrechen - im Rahmen der Zusammenarbeit zwischen CD und DINA - als auch interne Verbrechen - Freiheitsberaubung und Körperverletzung - beschrieben. Die nach diesen Berichten eingeleiteten strafrechtlichen Ermittlungen gegen die CD (Abschnitt 5.3.3) wurden von der Bonner Staatsanwaltschaft mit Verweis auf entlastende Erklärungen von Botschafter Strätling und schriftliche Entlastungserklärungen von Colonos rasch eingestellt. 
Ein von der CD initiiertes Zivilverfahren gegen AI und den Verlag Gruner und Jahr hingegen lief über einen Zeitraum von 20 Jahren. Ausgangspunkt dieses Bonner Zivilverfahrens war eine von der CD beantragte einstweilige Verfügung, mit der die Weiterverbreitung der AI-Broschüre unterbunden und die Feststellung, die CD sei ein Folterlager der DINA, untersagt werden sollten. Das LG Bonn stimmte dem Antrag der CD zu und brachte damit aufklärerische Akteur_innen über einen Zeitraum von 20 Jahren zum Schweigen. Durch ein im Anschluss eröffnetes Zivilverfahren konnte die CD den Spieß umdrehen: Die Beweislast über die Existenz der Verbrechen lag nun bei den beklagten Aufklärer_innen. Die Beweiserbringung war jedoch während der Jahre der chilenischen Diktatur - und auch während der ersten Jahre der Transición - nicht möglich. Durch die schützende Hand der chilenischen Justiz war eine formaljuristische Beweisführung über gemeinsam mit der DINA in der CD begangene Foltertaten unmöglich.

Dem Bonner Landgericht lagen jedoch diverse Schilderungen von Folterüberlebenden und einem ehemaligen DINA-Agenten vor, die ein deutliches Bild von der Existenz des Folterlagers zeichneten. Die CD-Anwälte verfolgten die Strategie, das Verfahren mit Diskussionen über Formalia in die Länge und die Glaubwürdigkeit der belastenden Zeug_innen in Zweifel zu ziehen - und sie waren damit erfolgreich. Statt den Opfern Glauben zu schenken, gab die Kammer diesen Diskussionen breiten Raum und ließ so Jahre verstreichen. In diesem und auch in dem 1985 von der Bonner Staatsanwaltschaft eröffneten Verfahren gegen die CD führten Rechtshilfeersuchen, die jahrelang von der chilenischen Seite nicht beantwortet wurden, sogar zu einer Verzögerung der strafrechtlichen Ermittlungen um mehrere Jahre.

Das AA nutzte das Bonner Zivilverfahren, um das eigene Nicht-Handeln zu legitimieren. Es argumentierte damit, dass es sich bei dem schwebenden Verfahren um eine Auseinandersetzung zwischen privaten Akteur_innen handele, deren Ausgang abgewartet werden müsse. Folglich könne man erst nach einer Entscheidung der Bonner Richter weitere Schritte in Erwägung ziehen und müsse bis dahin »in dubio pro reo« äußerste Zurückhaltung üben.

Das Bonner Zivilverfahren ermöglichte der kriminellen Organisation CD die Sicherung der eigenen straflosen Existenz, indem es die Durchsetzung von Menschenrechten auf juristischem Wege verhinderte: Die Bonner Richter_innen untersagten einer Menschenrechtsorganisation und einem Presseorgan 20 Jahre lang die Verbreitung von Informationen über Verbrechen, die in einer Militärdiktatur begangen wurden - und ersuchten auf dem Wege der Rechtshilfe die Justiz selbiger Diktatur um Unterstützung bei der Untersuchung der von ihr mitbegangenen Verbrechen. Ein folgenreiches Paradoxon.

Mit dem zweiten dargestellten Zivilverfahren (Abschnitt 5.3.2) gegen Hugo Baar schüchterte die CD erfolgreich einen ehemaligen Mitstreiter ein, der es "gewagt hatte«, auf die Seite der aufklärerischen Akteur_innen überzuwechseln. Auch dieses - medial kaum wahrgenommene - Verfahren lief über Jahre und ging sogar in Teilen zugunsten der CD aus. Hugo Baar wurde es untersagt, weiterhin zu behaupten, er sei von Gisela Seewald mit Elektroschocks malträtiert worden. Auch hier kehrte die CD die Beweislast um - und die NRW-Justiz unterstützte sie dabei.

Die CD konnte ihre Ziele auf zivilrechtlichen Wege erreichen, da die strafrechtlichen Ermittlungen der NRW-Staatsanwaltschaften systematisch ins Leere liefen. Auch hier 
verfolgte die Justiz die Ansicht, die Taten seien nicht $\mathrm{zu}$ beweisen, nicht einmal ein hinreichender Tatverdacht sei vorhanden.

Die Bilanz der vielen über Jahrzehnte geführten strafrechtlichen Ermittlungen ist ernüchternd: Die 1961 gegen Paul Schäfer wegen Kindesmissbrauchs eingeleiteten Ermittlungen wurden wegen Verfolgungsverjährung 1974 eingestellt. Alle seitdem eröffneten Verfahren - mir sind 12 weitere Verfahren bekannt, die in Abschnitt 5.3.3 bis 5.3.10 dargestellt werden - wurden wegen fehlendem hinreichenden Tatverdacht eingestellt und kamen über das Ermittlungsstadium nie hinaus: In keinem Fall wurde gegen eine_n Beschuldigte_n Anklage erhoben und ein Gerichtsverfahren eröffnet. Verkürzt kann gesagt werden, dass seit der Einleitung des ersten Ermittlungsverfahrens bei der StA Bonn im Jahr 1961 bis zur Einstellung des Ermittlungsverfahrens gegen Hartmut Hopp durch die StA Krefeld im Jahr 2019 die Verbrechen der CD für die NRW-Justiz nicht existierten.

Mit Ausnahme der Jahre 1974 bis 1976 und 1978 bis 1984 ermittelte die NRW Justiz praktisch durchgehend von 1961 bis 2019. Die NRW-Staatsanwält_innen hielten jedoch die verfügbaren Belege und Hinweise auf die Taten nicht für ausreichend, um die Eröffnung eines Gerichtsverfahrens gegen eine_n Beschuldigte_n der CD-Führung zu beantragen. Nur zweimal stellte die NRW-Justiz Haftbefehle gegen CD-Beschuldigte aus, beide ergingen gegen Paul Schäfer: Der erste 1961, als sich Schäfer bereits in Chile befand und der zweite 1997, nachdem die chilenische Justiz bereits ein Fahndungsersuchen nach Schäfer erlassen hatte. Nach meiner Kenntnis fand zu keinem Zeitpunkt eine Zielfahndung nach Paul Schäfer statt. Da dieser rechtlich stets bestens beraten war und sich einer kriminellen Struktur bediente, um sich der Gefahr einer Festnahme systematisch zu entziehen, lief Schäfer seitens der deutschen Justiz zu keinem Zeitpunkt Gefahr festgenommen zu werden. Erst ab 1988 ermittelten die NRW-Staatsanwält_innen auch gegen weitere Beschuldigte - ebenfalls ergebnislos.

Besonders relevant war das 1985 initiierte Ermittlungsverfahren, das nach der Übersendung der Berichte der aus der CD Geflüchteten Baar und Packmor durch das AA an die Bonner Staatsanwaltschaft eingeleitet wurde. Durch die Geflüchteten wurden detaillierte Schilderungen über schwerwiegende Verbrechen verfügbar. Die StA zog diese Aussagen jedoch in Zweifel und maß ihnen kein größeres Gewicht bei als den von der CD eingereichten entlastenden eidesstattlichen Erklärungen von Colonos. Darin mussten diese auf Anweisung der CD-Führung erklären, dass die Vorwürfe nicht zuträfen und dass sie sich frei fühlten, d.h. dass unübliche Einschränkungen ihres Lebens keine Freiheitsberaubung darstellten, da sie selbst gewählt seien. Die Bonner Staatsanwaltschaft kannte sowohl anderslautende Erklärungen als auch den Mechanismus, gleichlautende eidesstattliche Versicherungen einzureichen. Sie stellte dieses Vorgehen jedoch nicht in Frage und bekam die in der CD festgehaltenen Opfer gleichzeitig nie zu Gesicht.

Die Ermittlungen beschränkten sich auf die Anhörung diverser Zeug_innen, die jedoch mit Ausnahme der Geflüchteten selbst, keine Angaben aus eigener Wahrnehmung über die Verbrechen machen konnten. Viele dieser Zeug_innen waren Teil des Systems CD und taten die Vorwürfe pauschal als Verleumdungen ab. Andere, wie zum Beispiel die an dem Konsularsprechtag 1987 beteiligten Diplomaten, zeigten ihre Bestürzung über die in der CD wahrgenommene Traumatisierung der CD-Mitglieder, 
konnten jedoch keine Taten aus eigener Wahrnehmung bezeugen. Da die CD-Führung systematisch den Zugang zu weiteren Opfern der CD verhinderte, konnten auf diesem Wege keine weiteren Belege für Einzeltaten vorgebracht werden. Die vorhandenen Belege wurden als nicht ausreichend bewertet oder als verjährt eingestuft. Die NRWJustiz begriff die CD nie als kriminelle Organisation, die systematisch Verbrechen beging und verschleierte. Dadurch, dass sie immer nur versuchte, Einzeltaten zu belegen ohne die meisten Opfer persönlich vernehmen und begutachten zu können, lief jeder Versuch einer Aufklärung ins Leere. Dazu kam, dass die NRW-Justiz nur prekär und hochformalisiert mit der chilenischen Justiz kommunizierte und deren Beweisführung als nach deutschen Verfahrensstandards nicht ausreichend erachtete. Als nicht ausreichend wertete sie dementsprechend auch die Antworten der chilenischen Justiz auf die über den Weg der Rechtshilfe gestellten Fragen. Das 1985 eingeleitete Ermittlungsverfahren und diverse $a b$ den 1990er Jahren eröffnete Parallelverfahren wurden 2010 mit dem Tod von Paul Schäfer eingestellt.

2011 entzog sich Hartmut Hopp der chilenischen Justiz und flüchtete in die Bundesrepublik. Die nach Strafanzeigen von Aufklärer_innen eröffneten Ermittlungen der Staatsanwaltschaft Krefeld trugen die Struktur der vorangegangenen Verfahren weiter. Die Taten wurden weiterhin als Einzelvorgänge betrachtet, strukturelle Ermittlungen fanden nicht statt. So wurden beispielsweise zu den Mordvorwürfen gegen Hopp nicht die von den Opfervertreter_innen genannten Zeug_innen aus der CD-Führung befragt, von denen sich viele inzwischen in Deutschland niedergelassen hatten. Obwohl diese an der CD-DINA-Kooperation in diversen Formen beteiligt waren und teilweise bei der chilenischen Justiz bereits Aussagen dazu gemacht hatten, hielt es die NRW Justiz nicht für notwendig, tiefergehend und proaktiv den Kontext der Vorgänge zu untersuchen und über Strukturermittlungen den Blickwinkel zu erweitern. Ihr Interesse galt vornehmlich der Frage, welche Beweise für eine materielle (Mit-)Täterschaft von Hartmut Hopp an einzelnen Mord-, Körperverletzungs- und Missbrauchstaten vorlagen. Eigene Ermittlungsschritte hierzu unternahm sie hingegen kaum.

Ähnlich verfuhr die Staatsanwaltschaft Münster in ihrem Ermittlungsverfahren wegen Mordes gegen Reinhard Döring. Sie vernahm keine Zeug_innen, nicht einmal den Beschuldigten selbst. Nach drei Jahren stellte sie das Verfahren ein.

2018 entschied das OLG Düsseldorf, das Ersuchen der chilenischen Justiz auf Vollstreckung einer rechtskräftigen Verurteilung Hartmut Hopps zu 5 Jahren Haft in Deutschland abzulehnen. Dieser Beschluss begrub Hoffnungen der Aufklärer_innen auf eine zumindest symbolische strafrechtliche Aufarbeitung. An diesem Verfahren waren lediglich die StA Krefeld, die formell die antragstellende chilenische Justiz vertrat, sowie der betroffene Hartmut Hopp, bzw. sein Anwalt, beteiligt. Der chilenische Staat hätte sich über einen eigenen Anwalt beteiligen können, tat dies jedoch aus unbekannten Gründen nicht.

Nach dem IRG hätten die Düsseldorfer Richter_innen lediglich prüfen müssen, ob das Verfahren gegen Hopp in Chile formale Rechtsstandards einhielt. Sie folgten jedoch stattdessen der Argumentation des Verteidigers von Hopp, der anmahnte, dass die Beweisführung in Chile hiesigen Verfahrensgrundsätzen nicht entsprochen habe. Anstelle der Argumentation des LG Krefeld als Vorinstanz zu folgen, die die Annahme des Vollstreckungsersuchens befürwortet hatte, argumentierte das OLG Düsseldorf, dass die 
im chilenischen Urteil vorgetragenen Beweise für eine Beihilfe Hopps nach hiesigen Verfahrensgrundsätzen für eine Verurteilung nicht ausgereicht hätten. Die CD, so die Düsseldorfer Richter_innen, habe nicht allein kriminellen Zwecken gedient, sondern habe auch wohltätige Ziele verfolgt. Hopp könne daher nicht qua seiner Funktion als Mitglied der CD-Führung verurteilt werden, es müsse der Einzeltatnachweis geführt werden. Da die CD nicht nur auf die Begehung von Verbrechen ausgerichtet gewesen sei, sondern auch wohltätige Arbeit geleistet habe, stufte die Kammer in ihrem Beschluss das Verhalten von Hopp als neutral und »sozialadäquat« ein. Sogar das sogenannte Intensivinternat - eine real nicht existierende Institution, die nur dem Diskurs der sozialen Fassade diente, um den Missbrauch zu verdecken - sei eine sinnvolle Instanz gewesen.

Diese Auffassung der Düsseldorfer Richter_innen, ist vor dem Hintergrund aller bisher belegten historischen Tatsachen über die CD falsch. Der OLG-Beschluss versagte den Opfern nicht nur in diesem Fall Gerechtigkeit, sondern besiegelte auch die strafrechtliche Aufarbeitung der CD-Verbrechen in Deutschland in Gänze: Wenige Monate nach der OLG-Entscheidung stellten auch die Staatsanwaltschaften in Münster und Krefeld ihre Ermittlungen gegen Reinhard Döring bzw. Hartmut Hopp ein. Auch eine Beschwerde gegen die Einstellung der Ermittlungen gegen Hopp seitens der Opferanwältin sowie ein Antrag auf Erzwingung einer Anklage wurden 2020, bzw. 2021 abgewiesen.

Abschnitt 5.4 stellt die Behandlung des Falls CD seitens des Bundestags dar. Der Bundestag befasst sich seit 1966 bis heute mit dem Fall CD. Jedoch war das Thema lange Zeit randständig. In Phasen hoher medialer Aufmerksamkeit griffen einzelne Parlamentarier_innen es auf, meist in Form von schriftlichen oder mündlichen Fragen oder Kleinen Anfragen an die Bundesregierung. Diese Initiativen zielten auf eine Aufklärung der Vorgänge um die CD ab und kamen meist auf Anregung und unter Mitwirkung von Aufklärer_innen zustande.

Dies blieb jedoch lange Zeit weitgehend folgenlos für die politische und juristische Aufklärung. Die Bundesregierung beantwortete Fragen und Kleine Anfragen meist wortkarg, oftmals unter Verweis auf anhängige Justizverfahren und auf die Verantwortung chilenischer Stellen. Auch wenn die Bundesregierung in der Regel antwortete, über keinerlei Erkenntnisse zu den betreffenden Vorgängen zu verfügen, konnten durch die Fragen einzelne Sachverhalte bestätigt werden, die Menschenrechtsaktivist_innen oder Journalist_innen zuvor recherchiert hatten.

$\mathrm{Zu}$ den größeren Aktivitäten zählen eine Anhörung im Jahr 1988 und zwei Entschließungsanträge 2002 und 2017. Bis zu Letzterem war die Behandlung im Bundestag nie handlungsweisend. 1988 führte der Unterausschuss für Menschenrechte und humanitäre Hilfe eine öffentliche Anhörung durch. Es sollte geklärt werden, ob deutsche Staatsbürger_innen gegen ihren Willen in der CD festgehalten wurden. Als Auskunftspersonen wurden Vertreter_innen aller Akteursgruppen zur Anhörung geladen. Die Vertreter des AA - die ehemaligen Botschafter Strätling und Holzheimer - ließen sich jedoch entschuldigen. Es sprachen auf Seiten der Aufklärer_innen insbesondere die aus der CD Geflüchteten Kneese, Baar und das Ehepaar Packmor. Die CD wurde insbesondere von Hartmut Hopp und dem Münchner CSU-Stadtrat Wolfgang Vogelsgesang verteidigt. 
Die Sitzung führte zu keinen weiteren Initiativen oder Maßnahmen. Ein wichtigstes Resultat war am Folgetag allerdings die Ausweitung des Beschuldigtenkreises im Bonner Ermittlungsverfahren, das bisher nur gegen Schäfer geführt wurde, auf Hartmut Hopp, Gisela Seewald und Hugo Baar. Dazu kam es, da der ermittelnde Bonner Staatsanwalt der Bundestagsanhörung beigewohnt hatte. Trotzdem konnte Hopp nach Chile zurückkehren, ohne von der Staatsanwaltschaft vernommen zu werden.

Erst 2002 befasste sich der Bundestag in seiner Gesamtheit mit dem Fall CD und verabschiedete einen Entschließungsantrag, mit dem er die Bundesregierung zu konkreten Hilfs- und Aufklärungsmaßnahmen aufforderte. Die Umsetzung dieser Maßnahmen unterblieb jedoch weitgehend. 2017, etwa ein Jahr nach der Rede von Bundesaußenminister Steinmeier zur CD, wurde ein weiterer Entschließungsantrag im Bundestag verabschiedet, erstmals einstimmig. Der Antrag forderte die Bundesregierung zu einer Reihe von Maßnahmen zur Aufarbeitung der Verbrechen der CD auf. Während die darin enthaltene Forderung nach Förderung der strafrechtlichen Untersuchungen in Kooperation mit Chile bisher folgenlos blieb, wurden eine Reihe von anderen Maßnahmen eingeleitet, die bislang mit unterschiedlichem Erfolg umgesetzt werden. Die allein von Seiten der Bundesregierung zu erbringenden Maßnahmen, wie die Finanzierung eines Oral History Projekts und die Einrichtung eines Hilfsfonds für einige Opfergruppen, werden bereits umgesetzt. Für die mit der chilenischen Regierung im Rahmen einer Gemischten Kommission diskutierten und gemeinsam einzuleitenden Maßnahmen kam es bislang jedoch noch nicht zu konkreten Resultaten. Dazu gehören die Errichtung eines Gedenkortes sowie eines Dokumentationszentrums; die Feststellung, Sicherung und Auswertung von Spuren und Dokumenten von auf dem CDGelände begangenen Verbrechen; sowie eine Überprüfung der Vermögenswerte der CD und der aus ihr hervorgegangenen Gesellschaften. Hier zeigt sich, wie bei der bilateralen Behandlung des Themas weiterhin Fragen der Zuständigkeit und Verantwortung eine Aufklärung und Aufarbeitung behindern.

\subsection{Fünf historische Phasen des Falls Colonia Dignidad (Kapitel 6)}

Kapitel 6 dient erstens dazu, den Fall CD in fünf historischen Phasen im jeweiligen historischen und gesellschaftspolitischen Kontext zu verorten und zweitens vor diesem Hintergrund das Augenmerk auf das Agieren der Bundesregierung bzw. des AA zu lenken. $\mathrm{Zu}$ Beginn des Kapitels diskutiere ich einige wichtige Charakteristika des Falls CD: Erstens seine Bilateralität oder Zwischenstaatlichkeit, die immer wieder die Frage der Verantwortung beider Staaten aufwarf und somit die Gelegenheit bot, diese der jeweils anderen Seite zuzuweisen. Zweitens die Wechselwirkungen zwischen politischer und juristischer Ebene jeweils innerhalb der beiden Staaten Bundesrepublik Deutschland und Chile. Und drittens die Wahrnehmung der Deutschen bzw. die Rolle der deutschstämmigen Immigrant_innen in der chilenischen Gesellschaft.

Phase I (Abschnitt 6.1) behandelt die Entstehung der Gruppe und ihrer Struktur in der post-nationalsozialistischen bundesdeutschen Gesellschaft der 1950er Jahre. Die Schäfer'sche Gruppe hatte von Beginn an ein Ziel: Sie sollte die Bedingungen für die Primärverbrechen der CD - die sexuellen Missbrauchstaten Paul Schäfers zu der Zeit 
und auch fortwährend weiter in der Zukunft - schaffen und deren dauerhafte Straflosigkeit decken. Das freikirchliche Umfeld, aus dem die Colonos stammten und die Nachkriegs-Bundesrepublik waren für dieses Projekt ein fruchtbarer Nährboden. Diese Phase des Aufbaus ist der Entwicklungsprozess von einer kriminellen Einzelperson zu einer kriminellen Gemeinschaft, die jederzeit Opfer für Schäfers Taten verfügbar machte und die Verschleierung seiner Taten garantierte. Dieses in der Bundesrepublik entwickelte System, in dem die interne Gruppenstruktur und ihre Unterdrückungsmechanismen heranreiften und perfektioniert wurden, bildete den Ausgangspunkt der Colonia Dignidad.

Diverse Zeugnisse aus jenen Jahren belegen, wie in diesem Formationsprozess in den Jahren vor der Auswanderung nach Chile bereits systematisch die meisten der kriminellen Mechanismen Anwendung fanden, die nach der Übersiedlung nach Chile in einem Kontext, der für diese Entwicklungen noch günstiger war, perfektioniert wurden: dazu gehörten Freiheitsberaubung, Kindesaneignung, Körperverletzung, Postzensur, Überwachung und unentlohnte Ausbeutung der Arbeitskraft der Mitglieder. In diesem Sinne stellt Phase I die Keimzelle oder Blaupause für die spätere Colonia Dignidad in Chile dar.

Trotz einer unzweifelhaften Dominanz Schäfers war es doch die ihn umgebende Führungsgruppe, die Verbrechen mit plante und umsetzte. Führungspersonen wussten auch von jenen Verbrechen, an denen sie nicht beteiligt waren. Im Gegenzug für ihre bedingungslose Loyalität erhielten Führungsmitglieder individuell von Schäfer zugestandene Privilegien. Die von den Führungsmitgliedern getragene Implementierung der gruppeninternen Zwangsstrukturen gaben Schäfer die Möglichkeit, sich nach Innen und Außen zu inszenieren und je nach Notwendigkeit als mächtiger Herrscher aufzutreten oder auch über Monate oder Jahre aus Gruppe oder der Öffentlichkeit zu verschwinden. Selbst aus einem Versteck heraus konnte er die Fäden ziehen und die auf Zwang, Manipulation und Gewalt basierende Struktur der kriminellen Gemeinschaft mit der Fassade des vermeintlich wohltätigen Charakters der Gruppe aufrechterhalten, die die Kontinuität seiner Missbrauchstaten verdeckte. Im Inneren der Gruppierung führten die Führungsmitglieder die Verbrechen aus wie beispielsweise die Prügelstrafen, während Schäfer als eine Art Richter oder graue Eminenz in den Hintergrund trat und nur intervenierte, wenn es nicht lief wie er es sich vorstellte. Bei Gewaltritualen innerhalb der Gesamtgruppe wurden alle angehalten zuzuschlagen. So nahmen alle "Schuld« auf sich und die individuellen Taten Einzelner wurden zu Gemeinschaftsverbrechen, von denen keine Distanzierung möglich war, da alle mitbeteiligt waren. Das Preisgeben aller »Sünden« und vermeintlich schlechten Gedanken im Wege der Beichte an Schäfer nahm den Gruppenmitgliedern jeglichen persönlichen Rückzugsraum.

Diese erste Phase unterteile ich in 3 Unterphasen: In den Nachkriegsjahren leitete Paul Schäfer in diversen evangelischen Kirchengemeinden Jungengruppen, die sich durch sein charismatisches Wirken großen Zulaufs erfreuten. Seine religiösen Diskurse radikalisierten sich in Richtung evangelikaler Kreise und seine Methoden der Abschottung und Kontrolle über die Jungen führten zu Gerüchten und Disputen, die wiederholt mit der Entlassung Schäfers aus seinen Anstellungsverhältnissen bei der evangelischen Kirche endeten. Im Raum stehende Vorwürfe über sexuellen Missbrauch wurden tabui- 
siert und unter den Teppich gekehrt, was dem Zeitgeist jener Jahre entsprach, in denen Missbrauchstäter oft straflos wirken konnten.

In den Jahren 1954 bis -1956 begann Schäfer mit der Formierung einer eigenen Gruppe außerhalb der Strukturen der evangelischen Kirche. Er organisierte Zeltfreizeiten und Zusammenkünfte an verschiedenen Orten und suchte die Nähe zu freikirchlichen baptistischen Kreisen, aus denen er die Anhänger_innenschaft rekrutierte. Schäfer lernte die baptistischen Prediger Hugo Baar (1954) und später Hermann Schmidt (1957) kennen, die Spaltungen in ihren baptistischen Gemeinden in Gronau und Hamburg herbeiführten und die ihnen folgende Anhänger_innenschaft in die Schäfer'sche Gruppe überführten. In diesem Prozess wurden Familien gespalten und Ehepaare getrennt.

Ab 1956 bildete sich die Schäfer'sche Gruppierung in Siegburg heraus (1956-60). Dort wurde ein Grundstück erworben und mit dem Bau des als »Jugendheim« betitelten Gruppendomizils begonnen. Einerseits befand sich diese Gruppe im Herzen der Bundesrepublik, andererseits entfernte sie sich von innen betrachtet jedoch mit großen Schritten von der offenen Gesellschaft, die als Bezugsrahmen und Vergleichsinstanz für die Mitglieder in immer weitere Ferne rückte und sie entwickelte sich zur abgeschotteten, enklavenartigen Gruppierung. Die interne Entwicklung der Gruppe blieb der Außenwelt zunehmend verborgen. Diese Abschottung erfolgte ebenfalls gegenüber Behörden, die als Beobachtungs- und Regulierungsinstanz nicht korrigierend wirkten. Wer sich der Gruppierung anschloss, wurde zum »Freund der Wahrheit«, brach mit der Außenwelt, die als Bedrohung dargestellt wurde und unterwarf sich den von Schäfer entworfenen Gemeinschaftsstrukturen und -zwängen. Schäfer war personifizierter Ausdruck der Wahrheit und die Freund_innen der Wahrheit begaben sich in ein System, in dem der eigene Willen zurückgestellt oder ganz aufgegeben wurde zugunsten des von Schäfer definierten Gemeinschaftswillens. Zur ständigen Kontrolle dieser Unterwerfung dienten das Instrument der Beichte gegenüber Schäfer und gruppeninterne Verhandlungen, bei denen vermeintliche Abweichungen vom Wege der Wahrheit als Fehlverhalten gegenüber der Gemeinschaft festgestellt und sanktioniert wurden.

Als formelle Struktur und Fassade wurde der Verein Private Sociale Mission gegründet. Die PSM blieb nach der Auswanderung des Großteils der Gruppe bis Ende der 1980er Jahre die bundesdeutsche Niederlassung der CD.

Nach Außen trat Schäfer bereits in den Siegburger Jahren in weiser Voraussicht aus der ersten Reihe zurück. Während er noch als Eigentümer des Grundstücks in Heide (Lohmar) auftrat, und in der Satzung der PSM als Treuhänder zeichnete, übernahm er künftig keine formellen Ämter der Gruppe mehr. So konnte er bei Bedarf untertauchen, ohne das Gesamtwerk der CD zu gefährden.

Die Siegburger Zeit der Gruppe erscheint heute als Blaupause für die CD: Hier entwarf und erprobte Paul Schäfer mit Hilfe einer treuen Führungsgruppe das Zwangssystem der CD, hier wurden die Unterdrückungs- und Verbrechensmuster erprobt, oftmals getarnt als pseudoreligiöse Rituale und Bestrafungen für die eigene Begriffe erfunden wurden. Sünden und schlechte Gedanken auszusprechen hieß nun »den Teufel blamieren«, Prügelstrafen wurde $\mathrm{zu}$ »Schinkenklopfen« oder »Hurengeister austreiben«. Aus jenen Jahren existieren Berichte über kollektive Prügelorgien, Einsperren und Fluchtversuche, Medikamentenvergabe zur Ruhigstellung und Elektroschocks zur 
Auslöschung der Erinnerung und systematischen sexuellen Missbrauch - sowie Drohungen unter vorgehaltener Pistole, nichts darüber zu berichten.

In diesen Jahren wurden die finanziellen Grundlagen für die Zukunft geschaffen und der Diskurs zur internen Legitimierung der Arbeitsausbeutung entworfen: Externe Mitglieder zahlten den Zehnten ihres Einkommens an die Gruppierung. »Kreuzler«, die nach Siegburg zogen, arbeiteten nur für ein Taschengeld in den von Alfred Schaak und Heinz Kuhn gegründeten Gemischtwarenläden der Schaak und Kuhn OHG und errichteten gleichzeitig außerhalb der Arbeitszeiten unentlohnt das Jugendheim. Viele brachten zudem ihr Vermögen oder Erbschaften in die Gruppenkasse ein. Wer in die Gruppe eintrat, ging ein irreversibles »Kreuzverhältnis« ein, das Schäfer als »unsere Lebensordnung« beschrieb. Wer die Gemeinschaft je einmal verlassen wollte, war laut Schäfer ein »Abtrünniger« und sollte keinerlei Ansprüche geltend machen können. Letztlich übertrugen die Colonos der »Gemeinschaft « alles: Ihren Willen, ihr Vermögen, ihre Arbeitskraft und ihre eigenen Kinder, die manche der wenigen »Abtrünnigen «, die in den darauffolgenden Jahrzehnten aus der CD flüchteten, in der Siedlung zurücklassen mussten. Wer ging, wurde zum Feind, der die Gemeinschaft angeblich zum eigenen Vorteil ausgenutzt hatte und daher bekämpft werden musste.

Als Anfang 1961 die erste Strafanzeige gegen Paul Schäfer wegen sexuellem Missbrauch von Minderjährigen vorgebracht und einige Wochen später ein Haftbefehl erlassen wurde, befand sich Schäfer bereits mit einer Vorhut in Chile. Der Rest der Gruppierung bereitete die Auswanderung vor, die sich über die nächsten beiden Jahre erstreckte.

Die zweite Phase (1961 bis 1973) reicht von der Ankunft in Chile bis zum Beginn der Militärdiktatur. In diese Phase fallen in Chile drei demokratische Regierungen mit unterschiedlichen politischen Vorzeichen, die konservative Regierung von Jorge Alessandri, die Präsidentschaft des Christdemokraten Eduardo Frei und die Regierung des Sozialisten Salvador Allende und der Unidad Popular. Diese Phase beginnt mit der Aufbauphase der CD in Chile (1961 bis 1966), in der die CD die Rechtsperson SBED für ihre soziale Fassade in Chile gründete, Land erwarb und in mühevoller Arbeit die Siedlung errichtete. Obwohl sich von Beginn an Flucht- und unregelmäßige Todesfälle ereigneten, gab es noch kaum überregionales Interesse für die $C D$, die weithin unter dem Radar chilenischer und deutscher Behörden blieb. Aufgrund des deutschen Haftbefehls gegen Schäfer hielt die CD Distanz zur Botschaft in Santiago, wo in diesen Jahren auch eine Reihe von Anfragen von Angehörigen der CD-Mitglieder eingingen. In den ersten Jahren fand nur ein Besuch von Botschaftsangehörigen in der CD statt, der von Misstrauen geprägt war. Nach Eindruck der Botschaftsbeamten war die CD eine Sektengemeinschaft, die einiges zu verbergen hatte, jedoch gleichzeitig eine wertvolle wohltätige Arbeit verrichtete: die soziale Fassade, die auch aufgrund der deutschenfreundlichen Grundhaltung in der chilenischen Gesellschaft verfing, entfaltete von Beginn an seine Wirkung bei chilenischen und bundesdeutschen Behörden. Die CD nutzte diese Anfangsjahre, um auf lokaler und regionaler Ebene Unterstützungsnetzwerke in Politik, Justiz und Verwaltung aufzubauen.

Die erfolgreiche Flucht von Wolfgang Müller 1966 wurde zur Zäsur, durch die die Vorgänge um die Gruppe internationale Aufmerksamkeit erlangten. Die folgenden Jahre (1966 bis 1968) waren geprägt von Untersuchungen durch staatliche chilenische In- 
stanzen sowie von intensiver Lobbyarbeit und offensiven juristischen Bemühungen der CD mit dem Ziel, negative Folgewirkungen dieser Untersuchungen zu verhindern.

Der Fall CD wurde erstmals zum Medienskandal und staatliche Behörden in Chile und der Bundesrepublik mussten sich intensiver damit befassen. Während die chilenische Justiz einen Sonderermittler einsetzte, erkannte auch das AA die Relevanz des Falls. Chilenische Medien berichteten über die internen CD-Verbrechen wie Freiheitsberaubung, Körperverletzung, Ruhigstellung durch Medikamente und sexuellen Missbrauch. Dazu lancierten sie das Bild einer von ehemaligen Nazioffizieren geführten Konzentrationslager-ähnlichen Siedlung, in der sich möglicherweise gesuchte NSKriegsverbrecher versteckt hielten. Dieses Narrativ findet sich teilweise bis heute in Publikationen wieder, wohl auch da es gegenüber der CD-Führung funktional war. Einerseits verschaffte es der CD Sympathien in Kreisen der extremen Rechten, auch im chilenischen Militär. Andererseits war es nicht zu beweisen und einfach zu widerlegen. Auch bundesdeutsche und internationale Medien griffen diese Berichterstattung auf und das AA sorgte sich über die »dem deutschen Ansehen abträglichen« Medienberichte. Bei einer Pressekonferenz wies ein AA-Sprecher Nazi-Verbindungen der CD zurück und betonte gleichzeitig die wohltätige Arbeit der Siedlung.

Die CD reagierte schnell auf die Vorwürfe und professionalisierte ihre Verteidigungsstrategie: Diese basierte von Beginn an darauf, alle Vorwürfe als Verleumdungen abzutun und die Urheber_innen der Vorwürfe mit juristischen Gegenmaßnahmen einzuschüchtern. Durch rasch hinzugezogene renommierte Anwälte erreichte die CD eine schnelle Einstellung der gegen sie eingeleiteten Untersuchung. Die CD zeigte gleichzeitig den Geflüchteten Müller wegen Verleumdung an und erreichte eine Verurteilung des Aufklärers zu 5 Jahren Haft.

Es etablierte sich ein Schema, das über Jahrzehnte einer der Schlüssel zur Straflosigkeit der CD sein sollte: Sobald sich die CD durch Anschuldigungen von Aufklärer_innen in der Defensive befand, drehte sie durch ihr stringentes, schnelles und strategisches Agieren die Situation: Durch offensives juristisches Agieren und intensive Lobbyarbeit erlangte die CD die Deutungsmacht, andere reagierten nur noch. Ende 1968 erreichte die CD, dass der Abschlussbericht der Untersuchungskommission des Abgeordnetenhauses sie weitgehend freisprach. Sowohl die Verurteilung Müllers wie auch der Bericht des Abgeordnetenhauses waren in den nächsten Jahrzehnten die staatlich festgestellten »Beweise« für das CD-Narrativ: Jegliche Berichte über Verbrechen waren demnach Verleumdungskampagnen. Auf staatlicher Ebene wurde die Bilateralität zum Ping-Pong Spiel der Verantwortlichkeiten. Die CD führte Lobbyarbeit bei Behörden beider Staaten durch und agierte als Chamäleon: Einerseits trat sie einladend und zuvorkommend auf, sobald Behörden jedoch misstrauisch wurden und Forderungen an die CD stellten, wechselte die CD die Strategie und ging auf Distanz oder gar in die Offensive - wie beispielsweise im Fall der Durchsetzung der Aberkennung der Immunität des verantwortlichen Gouverneurs Fuentes und Intendenten Taricco im Jahr 1968. Die $C D$ verschaffte sich so eine Aura eines geheimnisvollen und mächtigen Akteurs, gegen den nicht zu gewinnen ist.

Bis Ende der 1960er Jahre erhielt die Botschaft Kenntnis über diverse Fluchtfälle und Hilferufe und erkannte dabei eine Systematik. Trotzdem blieb sie ambivalent, zog sich auf eine formale Ebene zurück und verhielt sich zahnlos. Sie behandelte je- 
des Vorkommnis als Einzelfall und wollte oder konnte der Beharrlichkeit der CD nichts entgegensetzen. Vielen Einzelfällen ging die Botschaft eine gewisse Zeit lang nach und ließ sie dann wieder ergebnislos einschlafen. Es gab wenig Kontinuität und keine klare Linie. Teilweise zeigten auch die Versuche der CD, Botschaftsangehörige zu vereinnahmen durchaus Erfolge.

Zum Ende der 1960er Jahre erfasste die CD Befürchtungen, von einer Enteignung durch staatliche Landreformbestrebungen betroffen zu werden. Sie begann sich massiv zu bewaffnen, zunächst aus Überlegungen der Selbstverteidigung. Die Wahl von Salvador Allende zum Staatspräsidenten verstärkte die Angst vor staatlichen Eingriffen. Die CD baute Allianzen zu Militärs, Großgrundbesitzern und diversen Akteur_innen, die gegen die sozialistische Regierung agitierten, aus. In der Siedlung wurde eine eigenständige Waffenproduktion aufgenommen und die CD stellte rechtsextremen Gruppen wie Patria y Libertad, die die Allende Regierung militant bekämpften, Waffen und Infrastruktur zur Verfügung. Über sich vertiefende Kontakte zu Militärs geriet die CD in die Kreise der zukünftigen Putschisten und schmiedete Allianzen, die sie zu einem maßgeblichen Akteur bei der Vorbereitung des Putsches machten. Aus der kriminellen Gemeinschaft CD entwickelte sich in jener Zeit die kriminelle Vereinigung CD, die mit dem Putsch zu einem Schlüsselakteur im Repressionsapparat der chilenischen Militärdiktatur wurde.

Die dritte Phase beschreibt die Zeit der Militärdiktatur (1973 bis 1990). Sie war die Blütephase des Systems CD. Die CD unterstützte die Diktatur maßgeblich, dafür protegierte das Regime die CD vollständig und ließ sie frei gewähren. Der Schutz kam von höchster Ebene: Die CD pflegte beste Beziehungen zu Diktator Pinochet und seinem Machtgaranten, dem DINA-Chef Manuel Contreras. Da die chilenische Justiz in jenen Jahren faktisch vollständig der politischen Macht subordiniert war, hatte die CD in dieser Phase in Chile keinerlei Strafverfolgung zu befürchten. Die Aufklärung hätte in jenen Jahren lediglich von bundesdeutscher Seite befördert werden können, was zumindest in den »harten Jahren« zu Beginn der Diktatur vollständig ausblieb. Ein Großteil der schwersten Menschenrechtsverbrechen wurde vom Repressionsapparat der Diktatur in den Jahren 1973 bis 1977 begangen. Die DINA setzte sich zum Ziel, jeglichen Widerstand gegen die Militärregierung mit äußerster Brutalität auszulöschen. Sie ging dabei systematisch vor: 1974 galt vor allem der Bekämpfung der Bewegung der Revolutionären Linken (MIR), es folgten die Bekämpfung der Sozialistischen Partei (PS, 1975) und schließlich der Kommunistischen Partei (PC, 1976). Die CD wurde zu einem Schlüsselakteur in diesem Repressionsapparat: Sie stellte der Diktatur ihr Gelände als Folter- und Tötungsstätte für Gefangene, Trainingslager und auch als Rückzugsort für die Spitzen der DINA zur Verfügung. Sie versorgte die Diktatur mit Waffen und Kommunikationstechnologie und unterstützte Militär und Geheimdienst bei der Verfolgung von Oppositionellen und auch bei der Überwachung der eigenen Reihen auf Führungsloyalität. Wie die DINA war auch die CD ein außersystemischer Akteur, der keinerlei Dienstwege oder Formalia beachten musste. Gleichzeitig blieb die CD immer auch ein eigenständiger Akteur, der seine eigene Position auch durch Überwachung ihrer Partner absicherte.

Mit dem Putsch erhielt auch die Verteidigungsstrategie, die jegliche aufklärerische Initiative als Verleumdung deklarierte, einen neuen Hebel: Die CD erweiterte ihre Ver- 
brechenssphäre, die sich bislang auf innere Verbrechen beschränkte, nun durch externe Verbrechen, insbesondere Folter- und Tötungstaten im Kontext der Diktaturrepression. Die Debatte um diese Verbrechen wurde nun im Rahmen des Lagerdenkens des Kalten Krieges geführt. Hatte die CD bislang aufklärerische Initiativen als Verleumdungskampagne von CD-Flüchtigen bezeichnet, so konnten nun Berichte über - interne und externe - CD-Verbrechen als »marxistische« Diffamation abgetan werden. Dies verhalf den Unterstützungsnetzwerken der CD zu neuem Zulauf, insbesondere auch in konservativen Kreisen in der Bundesrepublik. Diese sympathisierten mit der chilenischen Diktatur aufgrund ihres energischen Antikommunismus.

Die Jahre zwischen 1973 und 1979 bezeichne ich als die "harte Phase der Diktatur" (Abschnitt 6.3.1). Der diplomatischen Gepflogenheit folgend, das Botschaftspersonal an die politischen Umstände des Gastlandes anzupassen, entsandte das AA nach dem Militärputsch in erster Linie konservative Botschafter nach Chile. Die CD suchte unter den neuen Rahmenbedingungen wieder verstärkt Beziehungen zu bundesdeutschen Diplomaten und setzte dabei auf persönliche Kontakte zu einzelnen Beamten. In den Jahren nach dem Putsch ist die Aktenlage zur CD äußerst dünn, die Botschaft erreichten jedoch immer wieder einzelne Hinweise auf Beziehungen der CD zur DINA. Berichte über Besuche von Botschaftsmitarbeiter_innen in der CD wurden im Tonfall unkritischer und teilweise sogar sympathisierend und gingen weniger auf Hinweise über interne CDVerbrechen aus den vorangegangenen Jahren ein.

Zwei Berichte des ECOSOC der UN im Jahr 1976 stellten die ersten amtlichen Berichte über die Funktion der CD als Haft- und Folterstätte dar. Der im Mai 1976 von seinem Posten als Botschafter in Pretoria nach Santiago gewechselte Erich Strätling besuchte daraufhin die $\mathrm{CD}$, bezeichnete die Siedlung als mustergültig und bewertete die im Raum stehenden Vorwürfe sehr zurückhaltend. Er ließ von der chilenischen Luftwaffe Luftbilder der Kolonie anfertigen, die vom Bundesverteidigungsministerium ausgewertet wurden. Darauf waren keine Haft- oder Foltereinrichtungen zu erkennen, was für CD faktisch eine Entlastung bedeutete.

Durch die Veröffentlichungen von AI und der Zeitschrift Stern im März 1977 wurden die Vorwürfe über eine CD-DINA Zusammenarbeit breit bekannt. Insbesondere bundesdeutsche Medien berichteten intensiv, was zu parlamentarischen Nachfragen und Anfragen von Angehörigen von CD-Mitgliedern an das AA führte. Botschafter Strätling gab umgehend eine die $\mathrm{CD}$ entlastende Erklärung $\mathrm{ab}$. Während das $\mathrm{AA}$ abwartend reagierte, initiierte die CD sofort eine juristische Gegenkampagne. Sie erreichte beim LG Bonn eine einstweilige Verfügung, die AI und Stern eine Wiederholung der Vorwürfe untersagte und so faktisch eine weitere Berichterstattung darüber unterband. Während die Bonner Staatsanwaltschaft strafrechtliche Ermittlungen mit Verweis auf entlastende Äußerungen Strätlings rasch einstellte, entspann sich beim LG Bonn ein zivilrechtliches Hauptverfahren, das sich mit der Frage befasste, ob die CD ein Folterlager der DINA (gewesen) war. Während das Verfahren, aufgrund der schützenden Hand der chilenischen Justiz, kaum Aussicht hatte für Aufklärung zu sorgen, begründete das AA fortan seine abwartende, lediglich beobachtende, Haltung mit dem schwebenden Gerichtsverfahren. Die politische Ebene übertrug so eine Mitverantwortung für eine Aufklärung auf eine zivilrechtliche Auseinandersetzung zwischen privaten Akteur_innen 
und gab intern von höchster Ebene die Devise aus, die juristische Klärung abzuwarten und - »in dubio pro reo«- äußerste Zurückhaltung zu üben.

Die Leitlinie der äußersten Zurückhaltung hatte zwar auch in den 6oer Jahren das Handeln des AA geprägt, das bereits damals auf eine Primärzuständigkeit Chiles zur Aufklärung verwies. Nun wurde diese Leitlinie jedoch von der Ministerebene gebilligt und war damit nicht mehr Resultat einer Einschätzung einzelner Diplomaten, sondern wurde zur Position der Leitung des AA, die faktisch die Straflosigkeit der CDVerbrechen festschrieb: Da die chilenische Diktatur und Justiz der CD einen umfassenden Schutz boten, konnte auch die bundesdeutsche Justiz über Rechtshilfeersuchen an die chilenische Seite keine Aufklärung erreichen. Es verblieb lediglich die Möglichkeit, auf dem Wege resoluten politischen Drucks eine Aufklärung zu forcieren, was das AA unter Berufung auf die Losung der äußersten Zurückhaltung verwarf.

Die ausgeübte Zurückhaltung fand in der Praxis eine selektive Anwendung. Während sich AA und Diplomaten vor allen Dingen gegenüber aufklärerischen Kreisen reserviert verhielten, pflegte die Botschaft einen regelmäßigen Informationsaustausch mit Vertretern der CD und auch Geschäftsbeziehungen: CD-Handwerker renovierten die Botschafterresidenz und Beamte vertrieben CD-Produkte unter ihren Kolleg_innen. Ferner pflegten Botschafter und Gesandte in der gesamten Phase vertrauensvolle Kontakte zu hochrangingen deutschstämmigen Militärs, wie dem Luftwaffen-General Fernando Matthei und später dem Carabineros-General Rodolfo Stange.

Während der restlichen Amtszeit von Botschafter Strätling erhielt die Botschaft weitere Hinweise auf CD-DINA-Verbindungen und auch Hilferufe von Colonos aus der Siedlung, ohne dass die Botschaft entsprechend handelte.

So waren die Jahre zwischen dem chilenischen Militärputsch 1973 und dem Ende der Dienstzeit von Botschafter Strätling im Mai 1979 ein Zeitraum, in dem die Botschaft trotz diverser Hinweise auf schwere Menschenrechtsverletzungen in der CD jegliche kritische Betrachtung der CD unterließ und die Verteidigungslinie der CD übernahm. Dies geschah vermutlich aus gefühlter ideologischer Nähe zur CD von Botschafter Strätling und vieler seiner Mitarbeiter_innen, die sich einer Logik des Kalten Krieges hingaben und sich mit der vermeintlich einer Verleumdungskampagne ausgesetzten CD solidarisierten. Die Botschaft befand sich dabei auf einer Linie mit dem überwiegenden Teil der einflussreichen deutschstämmigen Community in Chile, die das Gesellschaftsprojekt der Militärjunta offen und vehement unterstützten, ebenso wie rechtskonservative Kreise in der Bundesrepublik, insbesondere aus den Reihen der CSU und ihres Umfelds. Diese von ideologischen Motiven geprägte Haltung führte zu einer Ausblendung jeglicher menschenrechtlich gebotenen Handlungsansätze. Die faktisch praktizierte Politik des Nichthandelns von Botschaft und AA hatte mindestens bis in das Jahr 1985 Bestand. Für Paul Schäfer und die CD-Führung waren diese Jahre, in denen sie weitgehend von strafrechtlichen Untersuchungen verschont blieben, eine Epoque d'Or in denen sie ihre Macht als kriminelle Organisation im Kontext des Repressionsapparats der Diktatur ausbauen und ihre Straflosigkeit verstetigen konnte.

Die Jahre nach dem Ende der Amtszeit von Botschafter Strätling waren »Jahre des Schweigens« für den Fall CD (1979-1984), in denen die Medien das Interesse an der Siedlung weitgehend verloren. In diesem Zeitraum gab es kaum Fluchtfälle oder Hilferufe 
aus der $C D$ und die Berichterstattung der Botschaft über die CD beschränkte sich auf ein Mindestmaß.

Diese Ruhe wurde jäh von den Fluchtfällen Hugo Baar (Dezember 1984) und Georg und Lotti Packmor (Februar 1985) unterbrochen. Ab 1985 und bis Ende 1987 entfernten sich AA und Botschaft von ihrer CD-stützenden Linie und versuchten fortan das Problem $C D$ auf stillem Wege anzugehen. Diesen Zeitraum bezeichne ich als »das langsame Erwachen der bundesdeutschen Diplomatie«. Diese betrachtete das CD-Problem fortan als ein Problem um die Person von Paul Schäfer, die es herauszulösen galt, um das im Kern als unterstützungswürdig erachtete CD-Projekt zu erhalten. Die Geflüchteten hatten in der CD Führungs- bzw. Vertrauenspositionen bekleidet und gaben ihr umfangreiches Wissen über diverse CD-Verbrechen in detaillierten Berichten an die Botschaft weiter. Das AA leitete die Berichte an die Justiz weiter und die Staatsanwaltschaft Bonn eröffnete daraufhin neue Ermittlungen gegen Paul Schäfer. Anders als bei der Flucht von Wolfgang Müller, die medial großes Aufsehen erregte, erfuhren die Medien von dieser Flucht und der Einleitung von strafrechtlichen Ermittlungen nicht unmittelbar. Die Geflüchteten waren ambivalent: insbesondere Hugo Baar wollte zwar eine Veränderung des internen CD-Zwangssystems, jedoch war es ihm gleichzeitig wichtig, einen Medienskandal zu verhindern. Er vermied den Kontakt zu Aufklärer_innen und suchte Rat bei dem Würzburger Professor und Vertrauten von Franz Josef Strauß Lothar Bossle, der in den Jahren zuvor als CD-Unterstützer mehrfach die CD besucht hatte. Dieser zeigte sich bestürzt über die Erzählungen Baars und distanzierte sich in der Folgezeit von Schäfer.

Auch Botschafter Holzheimer zeigte sich erschüttert über die Berichte von Hugo Baar und dem Ehepaar Packmor. Das AA entschied jedoch der chilenischen Seite nicht formell die Berichte zukommen zu lassen - sie tat dies erst Ende 1987. Stattdessen versuchte es Spielräume für eine »stille Lösung« zu eruieren. Holzheimer übergab die Berichte der Geflüchteten dem deutschstämmigen Carabineros-General Stange, der ihm Monate später mitteilte, er sei bei Nachforschungen auf eine Mauer des Schweigens gestoßen und könne nichts weiter unternehmen. Ab diesem Zeitpunkt begann die Botschaft auf dem Verwaltungsweg der CD bisher zugestandene zuvorkommende Behandlung zu verweigern und auf ein persönliches Erscheinen von Antragsteller_innen (für Passverlängerungen, Lebensbescheinigungen zum Rentenbezug etc.) zu bestehen. Sie schlug der CD die Durchführung eines Konsularsprechtages in der Siedlung vor. Zwei Jahre vergingen mit Disputen über diesen Konsularsprechtag, den die CD zu verhindern versuchte, indem sie Konsul Haller mit Dienstaufsichtsbeschwerden überzog. Im Laufe des Jahres 1987 spitzte sich die Situation zu. Bundesdeutsche Medien interessierten sich erneut für den Fall CD und hatten inzwischen auch von der Flucht der Baars und Packmors Kenntnis. Arbeitsminister Blüm und CDU-Generalsekretär Geißler besuchten Chile und kritisierten Pinochet wegen Menschenrechtsverbrechen. Durch das gesteigerte öffentliche Interesse nahm sich die Leitung des AA wieder persönlich des Themas an. Sie drängte auf die Durchführung des Konsularsprechtages in der CD. Gegenüber der chilenischen Regierung pochte das AA auf eine Untersuchung der CD in Bezug auf die Vorwürfe der Verbrechen gegenüber deutschen Staatsbürgern. Die Menschenrechtsverbrechen der CD-DINA hingegen thematisierte die bundesdeutsche Seite nicht. Anfang November 1987 kam es schließlich zum Konsularsprechtag in der 
CD, an dem auch Botschafter Kullak-Ublick teilnahm. Die Botschafts- und Konsularbeamten sprachen mit der CD-Führung einschließlich Paul Schäfer und waren von den Begegnungen mit einfachen Colonos, die sie als willenlose Roboter wahrnahmen, erschüttert. In ihren Berichten an das AA, die auch dem Spiegel geleakt wurden, zogen sie KZ-Vergleiche. Außenminister Genscher machte das Thema CD nun zur Chefsache. Er ordnete die Entsendung einer hochrangigen Delegation aus Mitgliedern von AA, Staatsanwaltschaft, einem Polizeipsychologen und einem Bischof in die CD an. Dies sollte den Handlungswillen der Bundesregierung symbolisieren. Die Delegation wurde jedoch von der CD nicht eingelassen, die CD versuchte sogar die Landung des Hubschraubers von Botschafter Kullak-Ublick und Bischof Stehle durch eine lebensbedrohliche Aktion zu verhindern. Die chilenische Regierung brüskierte Genscher, indem sie das Besuchsansinnen der Delegation nicht unterstützte, die so ergebnislos wieder abreisen musste. Erst ab diesem Zeitpunkt bemerkte das AA die weitreichenden Auswirkungen der Allianz der CD mit der Militärdiktatur.

Die letzten beiden Jahre der Militärdiktatur (1988/1989) bezeichne ich als den Zeitraum des »ergebnislosen Einsatzes Genschers«. Von der bisher verfolgten ergebnislosen stillen Diplomatie schwenkte Genscher auf einen verbalradikalen Konfrontationskurs und forderte die chilenische Regierung zum Handeln auf, um Menschenrechtsverbrechen an deutschen Staatsbürger_innen zu beenden. Gleichzeitig konnte, bzw. wollte das AA keine starken Hebel einsetzen, um den Druck auf die CD-Führung und die chilenische Regierung zu erhöhen. Ein solcher wäre zum Beispiel gewesen, sich gegen die Vergabe von Weltbankkrediten an Chile auszusprechen. Ein weiteres deutliches Signal wäre die Ausstellung von Haftbefehlen gegen Schäfer und einige Führungsmitglieder durch die deutsche Justiz gewesen. Die Staatsanwaltschaft Bonn war jedoch der Auffassung, dass ein Haftbefehl gegen Paul Schäfer nicht gerechtfertigt sei.

$\mathrm{Zu}$ Beginn des Jahres 1988 fand im Bundestag eine Anhörung zum Thema CD statt infolge derer die Staatsanwaltschaft Bonn die 1985 gegen Schäfer eröffneten Ermittlungen auf Hartmut Hopp, Gisela Seewald und Hugo Baar ausweitete. Außenminister Genscher schrieb im Laufe des Jahres mehrere Briefe an seinen chilenischen Kollegen, in denen er mit deutlichen Worten auf eine chilenische Untersuchung der CD drängte. Erst im vierten Anlauf gab die chilenische Justiz im Januar 1989 diesem Ansinnen statt und eröffnete eine Untersuchung, die jedoch nur administrativen Charakter hatte. Inzwischen hatte Pinochet das in der Verfassung vorgesehene Plebiszit über einen Verbleib im Amt des Diktators verloren und es wurden Wahlen für Dezember des Jahres angesetzt. Das Untersuchungsverfahren endete nach vielen Monaten ohne greifbares Ergebnis. Während Botschaftsanwälte und der Untersuchungsrichter die Bundesregierung gedrängt hatten, selbst eine Strafanzeige einzureichen oder zumindest den Geflüchteten weitreichende finanzielle und Sicherheitsgarantien für die Stellung von Strafanzeigen in Chile zu geben, winkte das AA ab. Die Leitlinie die Verantwortung für die Aufklärung der Verbrechen der chilenischen Seite zuzuweisen war prioritär - eine Erhöhung des Drucks zur Unterbindung von Verbrechen nur nachrangig.

So ging mit der Diktatur eine 16-jährige Phase des Falls CD zu Ende, in der AA und Botschaft zu Beginn der CD ihre Unterstützung gegeben hatte und in den letzten Jahren langsam im Diskurs umgesteuert hatte, ohne jedoch ausreichende Maßnahmen für eine Änderung der kriminellen Situation zu ergreifen. Faktisch hatte die CD - dank der 
Unterstützung des AA, beziehungsweise trotz des späten Entzuges dieser Unterstützung - während der gesamten chilenischen Militärdiktatur freie Hand für die Begehung schwerer Verbrechen. Während in der Vorphase die ambivalente Haltung von AA und Botschaft es der CD mit ermöglicht hatte, ihre internen Verbrechen fortzuführen, ermöglichte die Haltung des AA während der Diktatur zusätzlich das straflose Wirken einer kriminellen Organisation, die als Schlüsselakteur des Repressionsapparats des Regimes hunderte Todes- und Folteropfer mit verursachte.

Im letzten Jahr der Diktatur bereitete sich das AA bereits auf die Zeit nach Pinochet vor. Als Strategie zur Lösung des Problems nach den Wahlen sah das AA die Unterstützung der Bemühungen der zukünftigen chilenischen Regierung zur Bekämpfung der CD auf dem Verwaltungsweg: Chile solle der CD die Rechtsperson entziehen und mittelfristig Schäfer ausweisen. Im September 1989 traf Außenminister Genscher den Kandidaten des Mitte-Links-Lagers Patricio Aylwin in Bonn. Während die beiden Maßnahmen erörterten, um der CD auf dem Verwaltungswege beizukommen, war diese ihnen schon wieder einen Schritt voraus. Das Szenario antizipierend, hatte die CD ab 1988 begonnen sich umzustrukturieren, um Besitz und Vermögen der CD einem staatlichen Zugriff ab $1990 \mathrm{zu}$ entziehen. Sie gründete drei geschlossene Aktiengesellschaften (»ABC«) und übertrug darauf alle Vermögenswerte, die sich bis dato im Besitz der SBED sowie einzelner Colonos befanden.

Phase IV umfasst die Jahre der chilenischen Transición ab 1990 bis zur Festnahme Paul Schäfers im März 2005. Sie besteht aus den Unterphasen 1990 bis 1996 (»Chile's Strategie des Verwaltungshandels und deutsche Passivität«) und 1997 bis 2005 (»Schäfers Ende durch Aufklärer_innen im Alleingang«).

Die Rückkehr zur Demokratie in Chile ab März 1990 beruhte auf Absprachen zwischen Pinochet und der gewählten Regierungskoalition Concertación de Partidos por la Democracia. Während der paktierten Transición waren der Demokratie Grenzen gesetzt, insbesondere auch im Bereich der Aufarbeitung der Diktaturverbrechen. Präsident Aylwin setzte eine Wahrheitskommission ein, die auch CD-Verbrechen benannte. Gleichzeitig blieb die Selbstamnestie der Diktatur in Kraft und auch der weiterhin Oberkommandierende des Heeres Augusto Pinochet schützte Täter_innen vor Strafverfolgung. Aylwin verkündete daher 1991, dass eine strafrechtliche Aufarbeitung lediglich »im Rahmen des Möglichen« stattfinden werde.

An der Situation im Inneren der CD änderte sich in dieser neuen Phase zunächst einmal nicht viel. Die Regierung Aylwin beschritt rasch die Strategie des Verwaltungshandelns gegen die CD und löste 1991 per Dekret die SBED auf. Faktisch lief diese Auflösung jedoch ins Leere, da das CD-Vermögen bereits auf die ABC-Gesellschaften übertragen war, die die CD-Strukturen fortführten. Die CD mobilisierte trotzdem ihr Unterstützungsnetzwerk und setzte ihre soziale Fassade in Szene, um das Auflösungsdekret juristisch und politisch zu bekämpfen. Dies tat sie, um Zeit zu gewinnen. Sie erhielt dabei umfangreiche Unterstützung aus dem Lager der rechten Opposition. Unter dem Vorwand der Verteidigung des CD-Krankenhauses zugunsten der armen Landbevölkerung organisierte die CD einen Schutzring um die Siedlung. Die CD richtete eine »ständige Jugendwache« ein, organisierte sogenannte »Patientenkomitees « und lud hunderte Jugendliche in die Siedlung ein. Die CD-Führung nutzte diesen Rahmen 
zudem, um Paul Schäfer einige dieser Jugendlichen als neue Opfer für seine sexuellen Missbrauchstaten zuzuführen.

Das AA unterstützte die Strategie des Verwaltungshandelns der chilenischen Regierung verbal und verfolgte damit weiterhin die Linie, die Verantwortung bei der chilenischen Seite zu verorten. Die Staatsanwaltschaft Bonn bekundete derweil dem AA periodisch ihren Willen, das Ermittlungsverfahren wegen fehlenden hinreichenden Tatverdachts einzustellen. Dies lehnte das AA $a b$, da es eine Einstellung für ein falsches politisches Signal nach Chile hielt. Faktisch verfolgte die Bonner Staatsanwaltschaft jedoch keine eigenen Ermittlungsansätze und hielt die Antworten der chilenischen Seite auf Rechtshilfeersuchen für irrelevant.

Erst die Strafanzeigen durch Eltern chilenischer Jungen, die in den 1990er Jahren in der CD missbraucht wurden, erzeugten tatsächlichen Druck auf die CD-Führung. Im Juni 1996 erging Haftbefehl gegen Schäfer und in den Folgemonaten führten Ermittler_innen Razzien auf dem CD-Gelände durch, um Paul Schäfers habhaft zu werden. Da nun nicht Diktaturverbrechen, sondern der Missbrauch an Chilenen im Zentrum der Berichterstattung standen, wandte sich ein wichtiger Teil der chilenischen Unterstützer_innen von der CD ab. Paul Schäfer beschloss 1997 nach der Flucht von Tobias Müller und Salo Luna aus der Siedlung, die CD zu verlassen und mit einigen Getreuen in Argentinien unterzutauchen. Innerhalb der Siedlung entwickelten sich Auseinandersetzungen um die Führungsnachfolge, insbesondere zwischen Hans-Jürgen Riesland, der den Kontakt zu Schäfer im Untergrund hielt und Hartmut Hopp, der nach außen als Sprecher der CD auftrat. Andere Führungsmitglieder begannen, sich nach Deutschland abzusetzen, da sie das Ende der CD antizipierten und sich hier Straflosigkeit versprachen.

In den Jahren 1994 bis 1995 lösten sich die alten Formalstrukturen der CD - SBED und PSM - endgültig auf, daher endete auch das Zivilverfahren am Bonner Landgericht 1997. Dieses hatte 20 Jahre lang eine wichtige Funktion für die CD gehabt: Aufklärer_innen wurden damit zum Schweigen gebracht und das AA hatte aufgrund des schwebenden Verfahrens seine Leitlinie der äußersten Zurückhaltung gerechtfertigt, was die CD begünstigte.

Die chilenischen Ermittler_innen, die sich um eine Festnahme Schäfers bemühten, mussten gegen Widerstände und Blockaden im alten Justiz- und Polizeiapparat ankämpfen, der immer noch von CD- und Diktaturfreunden durchsetzt war. Auf deutsche Hilfe konnten sie dabei nicht zählen. Außenminister Kinkel verweigerte die von Chile angefragte technische und polizeiliche Unterstützung und äußerte intern, die Festnahmebemühungen seien eine ausschließlich chilenische Angelegenheit. Gleichzeitig diskutierten AA und Botschaft Kriseninterventionskonzepte für den Fall eines »Zusammenbruchs« der CD nach einer Schäfer-Festnahme.

Die Festnahme ließ jedoch noch viele Jahre auf sich warten, da faktisch weder chilenische noch deutsche Behörden sich real darum bemühten. Chilenische Ermittler_innen konzentrierten sich auf Durchsuchungen des CD-Geländes, wo Schäfer noch vermutet wurde. Ermittlungen zur Feststellung von Schäfers Aufenthaltsort im Ausland wurden hingegen seitens Chile nur auf dem Formalwege vorgenommen, Hilfe seitens der deutschen Justiz, BKA oder BND unterblieb. Eine Zielfahndung nach Schäfer wurde nicht durchgeführt, obgleich die Reisen von Mitgliedern der CD-Führung nach Ar- 
gentinien und in andere Länder dafür Ansatzpunkte boten. Wie schon bei jeglichen Aufklärungs-Fortschritten in der Vergangenheit, war es nicht staatlichen Akteur_innen, sondern engagierten Aufklärer_innen zu verdanken, dass Schäfer und seine Vertrauten im März 2005 in Argentinien festgenommen werden konnten. Dass Außenminister Fischer nach dem Ergreifen Schäfers von »intensiven Bemühungen der Bundesregierung « sowie einer »hervorragenden Zusammenarbeit« zwischen deutschen, chilenischen sowie argentinischen Strafverfolgungsbehörden sprach, die zum Ergreifen Schäfers geführt hätten, ist daher nicht nachvollziehbar.

Mit der Festnahme Paul Schäfers beginnt Phase V, »Die verspätete Transición der Colonia Dignidad « - eine Phase, die bis heute andauert. Bereits vor Schäfers Festnahme besuchten im September 2004 erstmals nach 1987 wieder Botschaftsangehörige die CD. Ähnlich wie beim Konsularsprechtag 1987 waren sie von der »menschlichen Tragödie«, die sie vorfanden erschüttert. Sie formulierten eine Strategie der psychologischen und wirtschaftlichen Hilfe für die Colonos, die an vorherige Überlegungen des Amts ab 1989 anknüpften. Bereits damals wurde zur Handlungsleitlinie, sich nach einer - als mittelfristig bevorstehend erwarteten - Festnahme von Schäfer und der CD-Führung für einen Verbleib der Colonos in der Siedlung einzusetzen. Bei den Planungen der Diplomaten 2004 fällt auf, dass sie zwar von einer Unterstützung der Opfer unter den Colonos sprachen, jedoch in ihren Überlegungen nicht ausführten, wie eine Differenzierung der faktischen Täter-Opfer-Gemeinschaft umgesetzt werden könnte.

Die CD war nun nach der Festnahme Schäfers zwar formell eine offene Siedlung, jedoch blieben weitreichende staatliche Eingriffe auf die Gruppe aus. Die Masse der Colonos war nun theoretisch frei, hatte aber weiterhin keinerlei behördliche Anlaufstelle, die ihnen Unterstützung für eine Perspektive zum Beginn eines neuen Lebens außerhalb der Siedlung bot. Daher behielten alte und neue Führungspersonen de facto die Definitionsmacht über das, was in der Siedlung passierte und darüber, wie sie sich nach außen darstellte.

Die interne Struktur und Führung blieb weitgehend erhalten und es begann ein sanfter Übergang von der »alten $C D$ « zu einer neuen Post-Sektengemeinschaft. Es vollzog sich ein allmählicher Generationenwechsel. Die alten Führungsmitglieder standen nun teilweise im Visier von Ermittlungen der chilenischen Justiz und zogen sich aus der ersten Reihe zurück. Deren Kinder, die in den Jahren vor der Schäfer-Festnahme die CD bereits zum Studium verlassen durften, übernahmen gleichzeitig Schlüsselpositionen in den ABC-Gesellschaften.

In gewissem Sinne können hier Parallelen zwischen dem Prozess der chilenischen Transición ab 1990 und dem nun einsetzenden Öffnungs- und Wandlungsprozess der CD gezogen werden, der durch den Fortbestand faktischer Machtverhältnisse Begrenzungen unterlag. Die CD war von dem langsamen Wandlungsprozess in der chilenischen Gesellschaft nach dem Ende der Diktatur ausgenommen, blieb ein geschlossenes System und konnte ihre eigene verspätete Transición erst nach der Festnahme von Paul Schäfer initiieren. Der Ausgangspunkt dieses Prozesses war jedoch ebenfalls kein vollständiger Bruch mit den vorangegangenen Verhältnissen, sondern ging von bestehenden Gegebenheiten aus und unterlag den existierenden Interessenskonstellationen diverser Akteur_innen. Als Ergebnis dieser verzögerten Transición hat sich seit 2005 einiges in der Siedlung verändert. Vieles erfolgt jedoch weiterhin nach Mustern, 
die sich aus den ehemaligen CD-Strukturen fortgetragen haben. Insbesondere betrifft dies die Prozesse der Entscheidungsfindung innerhalb der CD, die von einer begrenzten Personengruppe dominiert werden. Eine Demokratisierung ihrer Strukturen wurde insbesondere durch den Fortbestand der Unternehmensstruktur der CD verhindert.

Die Festnahme Schäfers führte zu einem hohen öffentlichen Interesse und Erwartungen an die Aufarbeitung der CD-Verbrechen. Die chilenische Justiz führte zahlreiche bereits existierende Strafverfahren bei Richter Jorge Zepeda an der CA Santiago zusammen. Zepeda vernahm viele Colonos, eröffnete eine Reihe weiterer Verfahren und nahm einige Mitglieder der CD-Führung in Untersuchungshaft. Einige Colonos machten weitreichende Aussagen über Verbrechenszusammenhänge, schwiegen jedoch meist zur Frage der materiellen Täterschaft und verorteten den Großteil der Verantwortung bei Schäfer. So konnte insbesondere bis heute nicht die Identität der in der CD ermordeten und bis heute verschwundenen Personen festgestellt werden. Zwischen 2008 und 2015 fällte Zepeda etwa ein Dutzend Urteile. Viele Tatkomplexe der CD erfuhren dadurch eine gerichtliche Feststellung, viele Einzeltaten blieben hingegen unaufgeklärt. Viele der Verurteilten erhielten nur geringe oder gar keine effektiven Haftstrafen. Viele Beschuldigte - und auch der verurteilte Hartmut Hopp - entzogen sich der chilenischen Justiz und flüchteten in die Bundesrepublik, wo sie seitdem Straffreiheit genießen. Die NRW-Justiz stellte ein ums andere Mal alle Ermittlungsverfahren ergebnislos ein.

Die chilenische Regierung setzte 2005 einen Regierungsbeauftragten ein, der die Colonos zu einem Mea-Culpa Brief an die chilenische Gesellschaft bewog, der einen Neuanfang ausdrücken sollte. Jedoch hatte der Regierungsbeauftragte keinen klar formulierten Auftrag, er versuchte vor allem menschlich, durch Gespräche mit den Colonos, eine Demokratisierung zu befördern. Die Maßnahmen der chilenischen und deutschen Regierung liefen in dieser Phase (mindestens bis zur Gründung der Gemischten Kommission im Jahr 2017) auf getrennten Gleisen ab. Die chilenische Seite unterlag weiterhin den Rahmenbedingungen der Transición. Die juristischen Bemühungen kamen nur begrenzt voran und auf lokaler und regionaler Ebene erfuhr die CD oftmals die Unterstützung von rechtskonservativen Politiker_innen.

Die Botschaft setzte sich nach der Festnahme Schäfers insbesondere für das wirtschaftliche Überleben der Gruppe ein, ohne jemals einen genauen Überblick über die tatsächlichen Vermögensverhältnisse der Post-Sektengemeinschaft zu erlangen. Die Leitlinie des wirtschaftlichen Überlebens führte zu Handlungsmustern, die bereits aus den frühen Phasen des Falls CD bekannt waren: Die Botschaft kommunizierte fast ausschließlich und regelmäßig mit den Vertreter_innen der ABC-Unternehmensleitungen während die Kontakte zu Aufklärer_innen distanziert blieben. So orientierten sich alle Unterstützungsmaßnahmen in den Jahren nach der Schäfer-Festnahme an der in der Siedlung verbleibenden Post-Sektengemeinschaft, während Aussteiger_innen und andere Opfergruppen kaum Beachtung der deutschen Diplomat_innen fanden. Diese überließen die interne Dynamik der Gruppe dabei den faktischen Kräften innerhalb der Siedlung, ohne wirksam auf eine innere Demokratisierung hinzuwirken. Das ermöglichte auch eine »spirituelle Erneuerung« von Teilen der Gruppe, die nun in dem evangelikalen Prediger Ewald Frank von der Freien Volksmission Krefeld einen neuen religiösen Referenzpunkt fanden. 
In einem Gerichtsverfahren wegen Betruges hatte der CDE Ende der 1990er Jahre eine Beschlagnahme von Ländereien der CD erwirkt. 2007 bis -2008 drängte das AA die chilenische Regierung, sich für die Aufhebung der Beschlagnahme einzusetzen, wozu es 2009 durch eine Einigung zwischen CDE und den ABC-Unternehmen schließlich kam. Über verschiedene Maßnahmen unterstützte die Bundesregierung zwischen 2008 und 2013 die Siedlung mit über einer Million Euro. Die Mittel wurden unter anderem für psychiatrische Unterstützung von Colonos durch Dr. Niels Biedermann sowie für Projekte des Lehrerbildungsinstituts Santiago zur Unterstützung der siedlungseigenen Privatschule aufgewendet.

Ein Großteil der Mittel flossen allerdings über die GIZ (zuvor GTZ) in Maßnahmen zur Unterstützung der Wirtschaftstätigkeit der ABC-Gesellschaften. Dies geschah, obgleich dem AA bewusst war, dass die Siedlung weiterhin eine Täter-Opfer-Gemeinschaft darstellte, die auch weiterhin aus dem Gemeinschaftsvermögen die Rechtsvertretung der Täter_innen finanzierte. Mit dem sich in der Siedlung entwickelnden Tourismuskonzept, das vom AA indirekt gebilligt wurde, stützte das AA das Gemeinschaftsnarrativ der Gruppe, die nun versuchte, einen Teil der langjährigen CD-Fassade - deutsche Kost und Folklore - zu reaktivieren und zu kommerzialisieren. Dies bedeutete einen Affront für die Opfer der Diktaturverbrechen und insbesondere die Angehörigen von Verschwundenen, die regelmäßig beklagten, dass an dem Ort, an dem ihre Familienmitglieder ermordet wurden, nun Bierfeste gefeiert wurden und eine angemessene Darstellung der Verbrechen und eine Erinnerung in Form einer Gedenk- und Bildungsstätte unterblieb. Erst ab 2014 steuerte das AA langsam um und stellte die Fördermaßnahmen ein.

Das Thema CD war seit der Flucht Hartmut Hopps in die Bundesrepublik wieder verstärkt in der deutschen Öffentlichkeit präsent. Expert_innen v.a. aus der Gedenkstättenarbeit begannen einen Dialogprozess zwischen diversen Opfer- und Betroffenengruppen mit dem Ziel einer Transformation der Siedlung durch die Errichtung einer Dokumentations- und Gedenkstätte. Das AA unterstützte diese Aktivitäten finanziell.

Die Rede von Außenminister Steinmeier 2016 war möglich da mittlerweile fast alle mit den CD-Vorgängen der 1960er bis 1980er Jahren befassten Diplomaten verstorben sind. Gleichzeitig befanden sich nun Beamte, die der CD kritisch gegenüberstanden in Führungspositionen, wie der AA-Sprecher Martin Schäfer und der Leiter der Wirtschaftsabteilung Dieter Haller. Die Rede Steinmeiers war einerseits ein Meilenstein, da erstmals eine selbstkritische Haltung bekräftigt wurde. Andererseits waren die Ministerworte sorgfältig abgewogen, um eine rote Linie des AA nicht zu überschreiten: Steinmeier sprach von moralischen Verfehlungen, er übernahm jedoch keine politische Verantwortung für die CD-Verbrechen, was Entschädigungsansprüche begründet hätte. Auch kündigte er keine konkreten Aufarbeitungsschritte an. Letztere wurden in den Folgejahren von Aufklärer_innen und Abgeordneten an die Bundesregierung herangetragen. 


\subsection{Fazit und Ausblick}

Die vorliegende Arbeit beschäftigt sich mit der Frage, wie bundesdeutsche Behörden auf die Verbrechen der Colonia Dignidad reagierten, d.h. wann und in welchem Umfang sie von ihnen wussten, aber vor allem wie sie mit diesem Wissen umgingen. Für diese systematische Rekonstruktion und Analyse des bundesdeutschen staatlichen Handelns im Fall Colonia Dignidad mussten zunächst die Verbrechen der CD selbst bestimmt bzw. der diesbezügliche Kenntnisstand zusammengetragen werden.

Meine Ausgangsthese lautet, dass bundesdeutsche Behörden von den menschenrechtswidrigen Verhältnissen in der CD sowie von den dort begangenen Verbrechen wussten, aber nicht adäquat reagierten. Gemessen am Ziel der Wahrung von Menschenrechten haben sie damit versagt. Sie unternahmen keine ausreichenden Maßnahmen, um darauf hinzuwirken, dass die ihnen bekannten Verbrechen nicht weiterhin begangen wurden. Außerdem trugen bundesdeutsche Behörden auch nur wenig zu einer Aufklärung und Sanktionierung vergangener Verbrechen bei. Meine Vermutung ist zudem, dass staatliche Stellen in Deutschland und Chile das kriminelle Vorgehen der $\mathrm{CD}$ deckten und damit eine Verstetigung des kriminellen Handelns beförderten.

Diese Arbeit zeigt, dass die Colonia Dignidad eine der folgenschwersten kriminellen Organisationen war, die in den letzten Jahrzehnten in Chile und der Bundesrepublik gewirkt hat. Zu den systematisch und zum Teil jahrzehntelang verübten Verbrechen gehören Morde, Folterungen, Freiheitsberaubungen, Körperverletzungen und sexueller Missbrauch. Die von der Gruppierung seit ihrer Gründung in den 1950er Jahren bis zur Festnahme von Paul Schäfer 2005 begangenen systematischen Verbrechen schädigten hunderte, wenn nicht gar tausende Personen.

Darüber hinaus zeigt diese Arbeit, dass bundesdeutsche Behörden seit der Übersiedlung der Gruppe nach Chile in allen historischen Phasen des Falls CD über deutliche Hinweise zu den CD-Verbrechen verfügten, jedoch nicht angemessen einschritten, um diese Taten abzustellen oder deren weitere Begehung zu verhindern. Daher lässt sich kein anderer Schluss ziehen, als dass bundesdeutsche Behörden für diese Verbrechen mitverantwortlich sind. Diese Mitverantwortung betrifft sowohl die Bundesregierung, namentlich das Auswärtige Amt, als auch bundesdeutsche Justizbehörden.

Besonders zu nennen ist hier die Justiz in Nordrhein-Westfalen, die im Fall CD nie angemessen ermittelte. Sogar Ende der 1980er Jahre, als selbst aus dem AA kritischere Töne und Forderungen nach Aufklärung der Verbrechen laut wurden, und auch in den $2010 e r$ Jahren, als umfangreiche Ermittlungen und Urteile der chilenischen Justiz vorlagen, blieben entscheidende Akteur_innen der NRW-Justiz weitgehend inaktiv oder stützten bestehende Argumentationsmuster. Jedenfalls recherchierte und ermittelte die Justiz in NRW zu keiner Zeit aktiv genug, um die Zusammenhänge und Hintergründe des Systems CD auch nur ansatzweise zu durchleuchten. Sie stellte sämtliche Ermittlungsverfahren ohne Anklageerhebung ein. Juristisch gesehen existieren die CD-Verbrechen damit in der Bundesrepublik bis heute nicht, zumindest gibt es offiziell keine Täter_innen. Ohne die Urteile der chilenischen Justiz gäbe es bis heute keinerlei offizielle Anerkennung der CD-Verbrechen als bestätigte Tatsachen.

Die Mitverantwortung der bundesdeutschen Diplomatie, also des AA und der Botschaft in Santiago, betrifft sowohl den unterbliebenen konsularischen Beistand 
für deutsche Staatsangehörige in der CD als auch das Unterlassen von Maßnahmen zur Strafverfolgung der ihr bekannten schweren Menschenrechtsverletzungen in der CD. Menschenrechtliche Fragen, wie sie aufklärerische Akteur_innen immer wieder thematisierten, spielten für die Politik des AA lange Zeit gar keine oder nur eine untergeordnete Rolle.

Die Folgen für die Opfer und ihre Angehörigen sind schwere körperliche und seelische Schäden, die bislang in ihrem vollen Umfang nicht anerkannt wurden. Auch nach Beendigung der Verbrechen förderten bundesdeutsche Behörden deren strafrechtliche und politische Aufarbeitung nicht in ausreichendem Maße und kümmerten sich nur unzureichend um die Opfer. Insbesondere das AA hat durch seine Maßnahmen nach 2005 de facto das Fortwirken alter CD-Strukturen in neuer Form begünstigt.

\section{Akteur_innen im Fall CD}

Die Dynamik des Falls CD wird ersichtlich, wenn man die verschiedenen Gruppen von Akteur_innen mit ihren jeweiligen Interessen und Strategien betrachtet (vgl. Kapitel 2 sowie Abschnitt 7.1). Aufklärerische Akteur_innen bemühten sich in der gesamten Zeit darum, die Verbrechen der CD öffentlich zu machen und ihre Beendigung und Verfolgung zu erreichen, verfügten dabei jedoch nur über limitierte Ressourcen. Das System $C D$ verfolgte stringent das Ziel, jegliche Aufklärung und Unterbindung der Verbrechen zu verhindern. Hierzu mobilisierte sie in hohem Umfang Mittel, Personal und Netzwerke. Für die zahlreichen staatlichen Akteur_innen lässt sich weder ein klares Interesse, noch eine kohärente Strategie identifizieren. Die meisten von ihnen agierten bestenfalls ambivalent, meistens zurückhaltend bis abwartend. Viel zu häufig ließen sie sich vom System CD beeinflussen, so gut wie nie stellten sie sich auf die Seite der Aufklärer_innen und der Opfer. Vielfach bestimmte die CD die Agenda, während Behörden reagierten, anstatt ihrerseits die $C D$ durch eigene Maßnahmen unter Druck zu setzen. Für keine der bundesdeutschen Behörden lässt sich eine konsequente Ausrichtung am Schutz der Menschenrechte bzw. der Betroffenen feststellen.

\section{Chile und Deutschland: Bilateralität}

Beim Handeln staatlicher Akteur_innen muss selbstverständlich zwischen Chile und Deutschland unterschieden werden. Das staatliche Handeln in Chile ist maßgeblich von den politischen Rahmenbedingungen geprägt, vor allem von der Diktatur ab 1973 und der Transición seit 1990, mit eigenen Dynamiken und Auseinandersetzungen. Unumstritten ist inzwischen die enge Zusammenarbeit zwischen der CD und der chilenischen Diktatur. Dies belegen zahlreiche Urteile zu diversen Verbrechenskomplexen. CD und DINA bildeten eine gemeinsame kriminelle Vereinigung. Eine chilenische Verantwortung ist also unbestreitbar, besteht jedoch vornehmlich in der Komplizenschaft zwischen CD und Diktatur. So gesehen waren staatliche Akteur_innen in Chile vor 1990 (Mit-)täter_innen, aber keine (potenziellen) Aufklärer_innen.

Während der Transición nach dem Ende der Diktatur änderten sich die Machtverhältnisse nicht grundlegend. Eine Aufklärung der CD-Verbrechen war nun zwar grundsätzlich möglich, blieb aber prekär, auf bestimmte Bereiche beschränkt und vielfach oh- 
ne Strafen für die Täter_innen. Paradigmatisch hierfür ist Aylwins Formulierung von der Gerechtigkeit im Rahmen des Möglichen - »justicia en la medida de lo posible«.

Im Zentrum meiner Arbeit steht das Agieren staatlicher Akteur_innen in der Bundesrepublik. Eine zentrale These dieser Arbeit lautet, dass die formal doppelte - de facto aber ungeklärte - Zuständigkeit staatlicher Stellen eine wichtige Voraussetzung dafür war, dass die CD ihre Verbrechen über einen so langen Zeitraum perpetuieren konnte. Zum einen verschaffte diese Situation dem System CD einen strategischen Vorteil. Es war insbesondere in Chile außerordentlich gut mit staatlichen Akteur_innen vernetzt, konnte aber auch in der Bundesrepublik agieren und damit schneller und flexibler als staatliche Stellen die Grenzen überwinden bzw. parallel in beiden Staaten agieren. Zum anderen führte die Tatsache, dass die CD sich im fernen Chile befand, bei vielen staatlichen Akteur_innen in der Bundesrepublik dazu, dass sie die Verantwortung per se chilenischen Stellen zuschrieben, ungeachtet der Tatsache, dass es sich bei Täter_innen und Opfern vorwiegend um deutsche Staatsangehörige handelte, wodurch formal betrachtet auch bundesdeutsche Behörden zuständig waren.

Das Agieren bundesdeutscher Behörden erscheint besonders erklärungsbedürftig. Aufgrund ihrer unterschiedlichen Rollen sind das AA und die Botschaft einerseits und die Justizbehörden andererseits getrennt $\mathrm{zu}$ betrachten.

\section{Auswärtiges Amt und Botschaft}

Wie alle Behörden agiert auch das AA nach bestimmten politischen Vorgaben und verfolgt dabei mehr oder weniger klar definierte Interessen. Wie diese Arbeit zeigt, stellt der Schutz von Menschenrechten für das Auswärtige Amt der Bundesrepublik Deutschland dabei - wenn überhaupt - nur eines dieser Interessen dar, hat aber keineswegs die oberste Priorität. In der Praxis verfolgte das AA verschiedene Leitlinien, wie für die historischen Phasen des Falls CD beschrieben (vgl. Kapitel 6 bzw. Abschnitt 7.5). Dabei wurde - grob gesagt - funktionierenden politischen und ökonomischen Beziehungen meist der Vorrang vor einer klaren Haltung in Menschenrechtsfragen eingeräumt. Hin$\mathrm{zu}$ kommt das Interesse des Amtes, sich wie jede andere Institution gegen Kritik von außen abzuschirmen und die Bewertung des eigenen Handelns nicht in die Hände Anderer zu legen. Dies betrifft sowohl das jahrzehntelange Agieren des AA während des Falls CD, also auch dessen Aufarbeitung in den letzten 10 bis 15 Jahren, inklusive der Frage des Aktenzugangs.

Vor diesem Hintergrund neigte das AA auch im Nachhinein dazu, sein Verhalten im Fall CD nicht grundlegend infrage zu stellen, sondern sich - intern wie öffentlich - eher zu rechtfertigen, um so auch die eigene Passivität zu legitimieren. Folgende Argumente spielten dabei zu unterschiedlichen Zeitpunkten eine unterschiedlich große Rolle:

Erstens betonte das AA die Bedeutung "guter Beziehungen « zu Chile - wobei beispielsweise zu Zeiten der chilenischen Diktatur fraglich ist, was genau damit gemeint ist bzw. welchem Zweck diese Beziehungen dienen sollten. Zweitens verwies das AA beständig darauf, dass die Hauptverantwortung für den Fall CD in Chile liege. Drittens schrieb das AA auch innerhalb der Bundesrepublik die Verantwortung für den Fall CD immer wieder anderen $\mathrm{zu}$, indem es auf die Zuständigkeit der Justiz verwies und sich mit Hinblick auf »schwebende Verfahren« mitunter sogar einer Kommentierung ent- 
hielt. Zur Rechtfertigung diente schließlich auch die Behauptung, bei der CD handle es sich im Kern nicht um eine kriminelle, sondern um eine wohltätige Organisation: eine Bewertung, die das AA aus der Selbstdarstellung des Systems CD übernahm.

Für das Handeln des AA in Fall CD gibt es verschiedene mögliche Erklärungen. Eine davon ist, dass das Thema keine hohe Priorität hatte, und das AA deshalb in dieser Frage keine langfristig kohärente Strategie verfolgte. Dafür spricht die Tatsache, dass angesichts der starken personellen Diskontinuität (Botschafter wurden, wie im Auswärtigen Dienst üblich, nach drei Jahren wieder abberufen) vor allem das konkrete Handeln einzelner Personen ausschlaggebend war. Auch scheint es so, als sei das Agieren der Botschaft gegenüber der CD im Sinne einer »Feuerlöscher-Politik« oftmals eher eine kurzfristige Reaktion auf Einzelfälle - teilweise in Reaktion auf eine starke öffentliche Aufmerksamkeit - als Teil einer längerfristigen Strategie. So erkannte die Botschaft beispielsweise relativ früh, wie systematisch die CD hilfesuchende Colonos nötigte, damit diese ihre Aussagen »widerriefen«. Eine wirksame Strategie für den Umgang hiermit entwickelte sie jedoch erst sehr viel später.

Eine weitere mögliche Erklärung lautet, dass es Kongruenzen in der politischen Wahrnehmung gab, die den Umgang des AA und der Botschaft mit der CD prägten. Dazu gehört zum einen die Logik des Kalten Krieges, nach der sämtliche politischen Akteur_innen entweder dem Lager des freien, marktwirtschaftlichen Westens oder aber dem linken Lager des Sozialismus bzw. Kommunismus zuzuordnen waren. Diese Polarisierung prägte gerade in den 1970er und 1980er Jahren auch in der Bundesrepublik vielfach die Wahrnehmung und Einordnung der chilenischen Diktatur, aber auch der CD. Das Personal in AA und Botschaft war zu dieser Zeit überwiegend konservativ eingestellt. Die die von AI und UN gesammelten Berichte über ein Folterlager in der CD wurden nicht selten als linke Propaganda abgetan, während die CD selbst als "ehrenwertes« soziales Projekt gelobt und ihre Vertreter_innen hofiert wurden. Darüber hinaus bestand zumindest phasenweise in bestimmten konservativen Kreisen in der Bundesrepublik, insbesondere der CSU, eine regelrechte ideologische Nähe zur CD und auch zu Protagonist_innen der chilenischen Diktatur. Hierfür stehen exemplarisch die persönlichen Verbindungen etwa von Gerhard Mertins und Lothar Bossle.

Ich versuche in meiner Darstellung für die unterschiedlichen historischen Phasen des Falls CD zu zeigen, was das AA jeweils hätte machen können, um auf eine Beendigung der CD-Verbrechen hinzuwirken. In den späten 1960er Jahren, nach der erfolgreichen Flucht Wolfgang Kneeses, als die Systematik der Freiheitsberaubungen in der CD bekannt waren, hätte die Botschaft sich darum bemühen müssen, dass fluchtwillige Colonos unbegleitet in die Botschaft gelangen und sich in Sicherheit bringen können. Während der Diktatur hätten AA und Botschaft den vorhandenen Berichten von Opfern der Diktaturverbrechen - auch in der CD - Glauben schenken müssen, anstatt auf ein Einsehen der Junta zu hoffen. In den 1980er Jahren, nach den Berichten von Baar und den Packmors, hätte das AA selbst Strafverfahren initiieren oder zumindest den anzeigewilligen Geschädigten umfangreiche Garantien und Unterstützung gewähren müssen. Ende der 1980er Jahre hätte die Bundesregierung beispielsweise durch die Blockierung von Weltbankkrediten zudem realen politischen Druck auf die chilenische Regierung ausüben können. 
Aufklärerische Akteur_innen haben das Handeln und die Prioritäten des AA immer wieder infrage gestellt und auf die deutsche Verantwortung im Fall CD verwiesen. Das AA verhielt sich demgegenüber stets zurückhaltend. Die Mea-Culpa-Rede von Außenminister Steinmeier 2016 war ein Versuch, mit dieser Praxis zu brechen. Allerdings bezog sich dies vor allem auf die Ebene der Rhetorik und der Außendarstellung des Amtes. Was sich der Minister mit seiner Rede über den »verlorenen moralischen Kompass« nicht explizit zu sagen traute, war, dass die Bundesrepublik ihr gutes Verhältnis zur chilenischen Diktatur nicht hatte gefährden wollen und so mitverantwortlich auch für die CD-Verbrechen wurde. Ein solches Eingeständnis hätte unter Umständen einklagbare Entschädigungsforderungen von CD-Opfern begründet und damit einen Präzedenzfall geschaffen. Genau dies will das AA aber bis heute mit allen Mitteln verhindern. Die Steinmeier-Rede betont also einerseits die moralische Verantwortung des AA, schweigt aber andererseits über jegliche politische, rechtliche oder finanzielle Verantwortung.

Die politische Grundsatzentscheidung der Bundesregierung, auch nach 2005 eine vollständige Auflösung der Siedlung zu verhindern und ihre praktischen Maßnahmen, namentlich die wirtschaftliche Förderung der aus der CD hervorgegangenen Unternehmen und der Verzicht auf eine Aufklärung ihrer Vermögenssituation, trugen dazu bei, dass die Machtstrukturen der Post-Sektengemeinschaft stabilisiert und eine kritische Aufarbeitung der Vergangenheit aufgrund des so gestärkten Schweigekartells auch vor Ort massiv behindert wurde.

Zudem spricht das AA bis heute mit Bezug auf die noch vor Ort verbliebenen Colonos oft undifferenziert von »Opfern«. Täter_innen bzw. Mittäter_innen kommen in dieser Sichtweise nicht explizit vor. Die vom AA priorisierte »Hilfe für die Opfer« blendet aus, dass die in der $C D$ verbliebenen tatsächlichen Opfer bis heute tagtäglich mit ihren ehemaligen Peiniger_innen zusammenleben und dass diese undifferenzierte Art der Unterstützung genau diese Struktur einer Täter-Opfer-Gemeinschaft stützt. Zudem wird Opfern, die nicht länger in der CD leben (wollen), keinerlei Unterstützung für den Aufbau eines Lebens außerhalb der Siedlung gewährt, da dieses der Leitlinie des AA, nämlich einer Stabilisierung der Strukturen vor Ort, widerspricht. Erst der 2019 eingerichtete Hilfsfonds weist hier in eine andere Richtung, ist jedoch nicht ausreichend, um schwer geschädigte Menschen nach bis zu 45 Jahren faktischer Gefangenschaft und Misshandlungen nachhaltig zu unterstützen.

\section{Justizbehörden in Deutschland}

Die Untersuchung des Vorgehens bundesdeutscher Justizbehörden war für mich ungleich schwerer als die Analyse des Handelns des AA. Dies liegt in erster Linie daran, dass die Akten zu den beschriebenen Ermittlungs- und Gerichtsverfahren bis heute nicht zugänglich sind. Begründet wird dies mit sogenannten Schutzfristen: Zentrale Verfahren wurden erst innerhalb der letzten zehn Jahre eingestellt, daher werden die dazugehörigen Unterlagen frühestens in ein paar Jahrzehnten zugänglich werden. Voraussetzung hierfür ist allerdings, dass Staatsanwaltschaften und Gerichte diese Akten überhaupt als archivierungswürdig einstufen und an die zuständigen Archive abgeben. Die Verfahrensakten aus den ersten Ermittlungen gegen Paul Schäfer ab 1961 wurden beispielsweise komplett vernichtet. Wenn Verfahren eingestellt werden, gelten die Be- 
schuldigten zudem als juristisch unschuldig, weshalb die Akten aufgrund der darin enthaltenen persönlichen Daten einem besonderen Schutz unterliegen.

Generell gilt, dass Regierungsbehörden zwar der Öffentlichkeit gegenüber rechenschaftspflichtig sind, Gerichte aber nicht. Die Staatsanwaltschaften nehmen eine Zwischenrolle ein: Formal sind sie Teil der Exekutive, de facto aber häufig Teil der Judikative. Für mich hieß das: Auf offiziellem Wege war eine Akteneinsicht zu den in dieser Arbeit erwähnten Verfahren - wie in Kapitel 2.2.4 geschildert - nicht möglich. Bei fast allen Verfahren lagen mir nur punktuelle Informationen vor, über die tatsächlichen Gründe beispielsweise für eine Verfahrenseinstellung kann ich daher in den meisten Fällen nur spekulieren. Die mir vorliegenden Einstellungsverfügungen stammten überwiegend aus dem Archiv des AA. Aus meiner Forschungsperspektive sind die Justizbehörden daher die intransparentesten Akteur_innen.

Nichtsdestotrotz wurde mir im Verlaufe meiner Forschung deutlich, welche zentrale Rolle bundesdeutsche Justizbehörden im Fall CD spielten. Spätestens seit 1985 tragen diese eine Mitverantwortung für die Fortsetzung der CD-Verbrechen, indem sie sich zwar mit der CD befassten, aber keinerlei Beitrag zur Aufklärung der Verbrechen leisteten.

Die Ermittlungen beschränkten sich in der Regel auf Rechtshilfeersuchen, in denen überwiegend Ermittlungsergebnisse und Gerichtsurteile aus chilenischen Verfahren übermittelt wurden, sowie auf die Befragung von Zeug_innen. Zu diesen gehörten zahlreiche aufklärerische Akteur_innen, aber auch zahlreiche Personen, die dem System CD zuzurechnen sind. Während die Aussagen der Aufklärer_innen - darunter auch mehrere Opfer von CD-Verbrechen - vielfach als unglaubwürdig behandelt wurden, übernahmen die Gerichte die Selbstdarstellung der CD zum Teil eins zu eins. Ein frappierendes Beispiel hierfür ist das Urteil des OLG Düsseldorf von 2018, in dem das Gericht argumentierte, die CD sei im Wesentlichen eine wohltätige Organisation gewesen. Im Unterschied etwa zu Botschaftsangehörigen in Chile, die direkt mit Personen konfrontiert waren, die schwer von der CD geschädigt worden waren, bekamen bundesdeutsche Richter_innen und Staatsanwält_innen diese Betroffenen nie zu Gesicht und bemühten sich auch nur selten darum. Zudem betrachteten die bundesdeutschen Justizbehörden die CD-Verbrechen stets nur als Einzeltaten, ohne deren systematischen Zusammenhang zu berücksichtigen. Dies wiegt umso schwerer, als sie diesen in den meisten Fällen aufgrund der Unterlagen, die sie etwa vom AA oder von chilenischen Kolleg_innen erhalten hatten, hätten erkennen müssen.

Zwar haben die Ermittler_innen bei ihrer Arbeit stark auf Unterlagen aus Chile zurückgegriffen, allerdings haben sie diese ausschließlich und sehr streng nach deutschen Rechtsnormen bewertet, ohne Unterschiede der Rechtskultur zwischen Chile und der Bundesrepublik angemessen zu berücksichtigen und für eine Zusammenarbeit konstruktiv nutzbar zu machen. So behandelten die deutschen Strafverfolgungsbehörden zum Beispiel das »Verschwindenlassen«, also die Entführung und Ermordung von Personen inkl. Beseitigung von deren Leichen in der Regel wie gewöhnliche Tötungsdelikte. Als solche waren sie aber kaum verfolgbar, weil es in der Regel weder eine Leiche, noch konkrete Tatverdächtige gab. Die chilenischen Strafverfolgungsbehörden behandelten Fälle von »Verschwindenlassen« ab 1998 verstärkt als Verbrechen gegen die Menschheit. In Deutschland war dies nach der geltenden Rechtsmeinung nicht möglich, da 
eine Einstufung als Verbrechen gegen die Menschheit hier erst nach Ratifizierung des Römisches Statuts des Internationalen Strafgerichtshofs von 2002 möglich war, und auch dies nicht rückwirkend für bereits begangene Taten gilt. Diese Herangehensweise führte dazu, dass bei diesen offensichtlichen Tötungsdelikten ein Mord nach deutschem Recht nicht bewiesen werden konnte - andere Delikte, wie Entführung, die hätten bewiesen werden können, aber längst verjährt waren.

Das Beharren auf einer derartigen Anwendung der deutschen Rechtsordnung ging so weit, dass etwa das OLG Düsseldorf 2018 auf ein Haftvollstreckungsersuchen der chilenischen Justiz - also den Antrag auf Vollstreckung einer von einem chilenischen Gericht nach chilenischem Recht verhängten Haftstrafe in der Bundesrepublik - nicht nur, wie in Exequaturverfahren üblich, dahingehend prüfte, ob es sich um ein faires und rechtsstaatliches Verfahren gehandelt hatte, sondern darüber hinaus den Gegenstand der chilenischen Urteile nach deutschem Recht neu bewertete. Was genau die Gründe hierfür waren, ob es sich um Arroganz, um (post-)koloniale Vorbehalte gegenüber der Justiz eines südamerikanischen Landes oder einfach nur um unterschiedliche Rechtskulturen handelte, lässt sich nur mutmaßen. Von engagiertem Aufklärungswillen oder gar kritischer Hinterfragung früherer Verfahrensweisen der Justiz in NRW bezüglich der Verbrechen der CD war jedenfalls nichts zu erkennen.

In der Folge führte diese Rechtspraxis dazu, dass weiterhin alle Strafverfahren eingestellt wurden, ohne dass Täter_innen der CD auch nur angeklagt wurden. Ermittelt wurde ohnehin nur bei den wenigen Taten, die noch nicht verjährt waren. Doch auch bei diesen argumentierten die Staatsanwaltschaften durchgängig, es bestünde kein hinreichender Tatverdacht. Die letzte Verfahrenseinstellung erfolgte 2019 - damit ist die Strafverfolgung im Fall CD in der Bundesrepublik faktisch beendet. De facto ist Deutschland daher spätestens seit Ende der 1990er Jahre zu einem sicheren Zufluchtsort für Protagonist_innen des Systems CD geworden, die in Chile mit Strafverfolgung rechnen müssen.

Notwendig gewesen wäre meiner Meinung nach eine umfassende Anerkennung des systemischen Charakters der CD-Verbrechen. Juristisch hätte dies bedeutet, die $\mathrm{CD}$ als eine kriminelle Organisation zu behandeln, die systematisch und kontinuierlich Verbrechen beging. Aufgrund der Verjährungsfristen ist dies heute rückwirkend nicht mehr möglich, allerdings haben die zuständigen Behörden immer noch die Möglichkeit, sogenannte Strukturermittlungen einzuleiten.

Aber auch engagiertere Ermittlungen in Einzelfällen, gezielte Fahndungen und die Ausstellung von Haftbefehlen gegen CD-Täter_innen hätten zumindest den Aktionsradius des Systems CD eingeschränkt und ein deutliches Signal an die chilenische Führung gesendet.

In Momenten öffentlicher Aufmerksamkeit für den Fall CD haben Politiker_innen in der Bundesrepublik immer wieder darauf verwiesen, die strafrechtlichen Ermittlungen würden zu einer Aufklärung der CD-Verbrechen führen. Die dadurch genährten Hoffnungen auf eine juristische Aufarbeitung wurden aber ein ums andere Mal enttäuscht. Die bundesdeutschen Justizbehörden haben bis heute keinen nennenswerten Beitrag zu dieser Aufarbeitung geleistet. Daher spricht aus meiner Sicht alles dafür, dass die Justiz eine ähnliche Mitverantwortung im Fall CD trägt, wie sie Steinmeier für das AA 2016 zumindest rhetorisch eingeräumt hat. 
Eine Neuaufnahme von Ermittlungen wäre auch heute noch möglich - insbesondere im Fall der sogenannten Verschwundenen. Das würde den Kriterien der von Deutschland ratifizierten UN-Konvention gegen das Verschwindenlassen gerecht werden. Aufgrund der hier beschriebenen Vorgehensweise der zuständigen Gerichte und Staatsanwaltschaften ist jedoch kaum mit einer Kurskorrektur oder einer selbstkritischen Überprüfung des eigenen Handelns zu rechnen.

\section{Ausblick}

Im Folgenden soll es nicht mehr, wie in den vorherigen Teilen der Arbeit, darum gehen, was passiert ist oder was wahrscheinlich passieren wird, sondern darum, wie ein adäquater Umgang mit dem Fall CD aus meiner Sicht zukünftig aussehen sollte. Notwendig hierfür wäre, den Fall grundsätzlich aus Sicht der Opfer von CD-Verbrechen zu betrachten, ihre Bedürfnisse anzuerkennen und dementsprechend $\mathrm{zu}$ handeln.

Das umfasst erstens eine umfassende Aufarbeitung in einem politisch festgelegten Rahmen, etwa als Wahrheitskommission. Deren Ziel müsste sein, nicht nur, wie etwa die Rettig-Kommission es tat, festzuhalten, welche Verbrechen begangen wurden und deren Opfer zu benennen. Sondern darüber hinaus müsste staatlicherseits festgestellt werden, wer hierfür jeweils die Verantwortung trug. Dies schließt die politische (Mit)verantwortung, in diesem Fall auch der Bundesrepublik Deutschland, explizit mit ein.

Zweitens müssten sämtliche noch existierenden Akten und Quellen zum Fall CD offengelegt werden. Das Interesse der Betroffenen an umfassender Aufklärung muss grundsätzlich Priorität haben gegenüber anderen Interessen staatlicher Akteur_innen. Neben bereits bekannten, aber (noch) nicht zugänglichen Akten umfasst dies beispielsweise auch Verschlusssachen, aber insbesondere die höchstwahrscheinlich umfangreichen Bestände bei Geheimdiensten, allen voran beim BND. Das Beispiel Cryptoleaks bestätigt die Vermutungen aufklärerischer Akteur_innen, dass der BND detaillierte Kenntnisse von zahlreichen Vorgängen und Verbrechen besaß, die bisher zum Teil in Ansätzen bekannt, aber noch nicht durch Quellen belegt sind. Dies ist besonders relevant für den Fall CD, um den sich immer noch zahlreiche bis heute ungeklärte Vermutungen ranken.

Der dritte Punkt betrifft eine ausreichende Entschädigung für die Opfer. Bisher wird vor allem die moralische Verantwortung betont, aber etwa seitens des AA jegliches Eingeständnis vermieden, das einklagbare Entschädigungsforderungen nach sich ziehen könnte. Eine konsequente Ausrichtung an den Interessen der Betroffenen würde hier heißen, für eine Entschädigung zu sorgen, die es Angehörigen aller Opfergruppen ermöglichen sollte, ein Leben in Würde zu führen, unabhängig von den Strukturen der Post-Sektengemeinschaft. Die Maßgabe müsste Hilfe und Entschädigung für die Opfer sein, nicht das Ansehen oder die Interessen eines Staates.

Viertens sollte sich die opferzentrierte Betrachtungsweise des Falls CD auch auf den juristischen Umgang mit den CD-Verbrechen auswirken. Konkret ist damit gemeint, den Charakter der CD als krimineller Organisation, die systematisch Verbrechen beging, angemessen zu berücksichtigen. Eine Parallele dazu findet sich im strafrechtlichen Umgang mit Verbrechen des Nationalsozialismus, bei denen seit 2011 auch Verur- 
teilungen wegen Beihilfe zum Mord erfolgten, ohne dass Angeklagten eine unmittelbare Beteiligung an einer Tötungshandlung nachgewiesen werden konnte.

Fünftens bedeutet dies einen anderen Umgang mit der Colonia Dignidad als historischem Ort. Auf dem Gelände bei Parral sollte ein Gedenk-, Dokumentations- und Lernort eingerichtet werden, der umfassend über die Verbrechen der CD aufklärt. Gleichzeitig sollte das Fortwirken bis heute bestehender CD-Strukturen vor Ort beendet werden. Dazu gehört eine Überprüfung des formellen und informellen Vermögens der CD bzw. der ABC-Gesellschaften. Dieses Vermögen sollte den Opfern zugutekommen.

Auch eine weitere wissenschaftliche Erforschung des Falls CD, die einer solchen opferzentrierten Perspektive folgt, wäre wichtig und notwendig. Diese Arbeit konnte hierzu auf Grundlage der erschlossenen Quellen einen Überblick sowie erste Feststellungen und Einschätzungen liefern. 



\section{Literatur und Quellen}

\section{Literatur}

Albert, Catalina. »Colonia Dignidad: víctimas acusan que representante del gobierno en comisión chileno-alemana apoyó régimen de Schäfer« in: CIPER (Website), 17.03.2020, online unter: https://ciperchile.cl/2020/03/17/colonia-dignidad-victima s-acusan-que-representante-del-gobierno-en-comision-chileno-alemana-apoyo-r egimen-de-schafer/.

Amerika21, Nachrichten und Analysen aus Lateinamerika (Website) vom 04.11.2016: »Delegation des Bundestags besucht Colonia Dignidad in Chile«, online unter ht tps://amerika21.de/2016/11/163580/bundestag-colonia-dignidad.

Amnesty International. Colonia Dignidad: deutsches Mustergut in Chile - ein Folterlager der DINA, Frankfurt a.M. 1977.

Análisis vom 03.08.1987, S. 14ff. »Proyecto Kormoran: El plan secreto alemán.«

Análisis vom 15.10.1990, S. 13. "Raul Urrutia diputado RN: >Dejemos vivir en paz a esta gente «.

Análisis vom 30.07.1985, S. 24. »Colonia Dignidad - Qué abran las cajas!«.

Angell, Alan. Chile Since 1958, in: Bethell, Leslie (Hg.), Chile since independence, Cambridge 1993, S. 129-202.

Araya Escotorín, Marcelo/Pía Lecaros Alvarez. Se busca: Paul Schäfer ¿Salvador o demonio de Colonia Dignidad?, Santiago 1998.

Archivo Nacional de Chile. An pone a disposición de la ciudadanía archivos de Colonia Dignidad vom 31.12.2018, online unter https://www.archivonacional.gob.cl/sitio/C ontenido/Noticias/89326:AN-pone-a-disposicion-de-la-ciudadania-archivos-de-C olonia-Dignidad.

Archivo Nacional de Chile. Exposición + performance »Dignidad«, September 2018, online unter: https://www.archivonacional.gob.cl/sitio/Contenido/Cartelera/87473:Di gnidad.

Asociación Nacional de Miembros y Amigos de la Sociedad Benefactora y Educacional Dignidad. »Mensajero de Dignidad: 30 años Dignidad en Chile«, Santiago 1990.

Asociación por la Memoria y los Derechos Humanos Colonia Dignidad (AMCD). »El canciller Heraldo Muñoz se reúne con AMCD en Berlín«, 30.10.2014, online un- 
ter https://asociacioncoloniadignidad.wordpress.com/2014/10/30/el-canciller-heral do-munoz-se-reune-con-amcd-en-berlin/.

Auswärtiges Amt. Aktenplan 2008, online unter: https:/www.auswaertiges-amt.de/c ae/servlet/contentblob/382696/publicationFile/4259/Aktenplan-Download.pdf (zuletzt abgerufen am 06.01.2013).

Auswärtiges Amt, »Rede von Außenminister Frank-Walter Steinmeier anlässlich der Veranstaltung >Colonia Dignidad〈 im Auswärtigen Amt« vom 26.04.2016, online unter https://www.auswaertiges-amt.de/de/newsroom/160426-colonia-dignidad/280 124 .

Auswärtiges Amt. »Aufgaben des Auswärtigen Dienstes«, 09.12.2019, online unter http s://www.auswaertiges-amt.de/de/aamt/auswdienst/aufgaben-node.

Auswärtiges Amt. "Auslandsvertretungen«, 27.09.2019, online unter https://www.a uswaertiges-amt.de/de/aamt/auslandsvertretungen-node, (zuletzt abgerufen am 06.01.2020).

Auswärtiges Amt. »Das Politische Archiv«, 09.08.2019, online unter: https://www.ausw aertiges-amt.de/de/aamt/politisches-archiv.

Azócar, Juan. El enigma Jaime López, in: The Clinic vom 13.01.2015, online unter https://www.theclinic.cl/2015/o1/13/el-enigma-jaime-lopez/.

Azócar, Juan. Lorca - De la reforma universitaria a la lucha antidictatorial, Santiago 2011.

Banken, Ralf. Hitlers Steuerstaat. Die Steuerpolitik im Dritten Reich, Berlin u.a. 2018. Barrenechea, Carlos. Bundesrepublik und Chile. Die politischen und wirtschaftlichen Beziehungen der Bundesrepublik Deutschlaand zur Republik Chile während der Regierungen Frei, Allende und Pinochet. Köln, 1984.

Basso Pietro, Carlos. »La extraña muerte del militar que enfrentó a la DINA«, in: El Mostrador vom 05.06.2015, online unter https://www.elmostrador.cl/pais/2015/06/ 05/la-extrana-muerte-del-militar-que-enfrento-a-la-dina/.

Basso Prieto, Carlos. El último secreto de Colonia Dignidad, Santiago 2002.

Basso, Carlos, »El escalofriante testimonio del conejillo de Indias de Colonia Dignidad«, in: El Mostrador (Website) vom 27.08.2015, online unter https://www.elmostrador. $\mathrm{cl} /$ noticias/pais/2015/08/27/el-escalofriante-testimonio-del-conejillo-de-indias-decolonia-dignidad-i/

Basso, Carlos. »Wolfgang Kneese: el joven que le ganó un partido de ajedrez al diablo«, in: CIPER (Website), 28.08.2017, online unter https://ciperchile.cl/2017/08/28/wolf gang-kneese-el-joven-que-le-gano-un-partido-de-ajedrez-al-diablo/.

Bauer, Susanne. Psychologische Behandlungsmöglichkeiten für religiös traumatisierte Menschen am Beispiel der Sekte Colonia Dignidad, in: Utsch, Michael (Hg.). Pathologische Religiosität - Genese, Beispiele, Behandlungsansätze, Stuttgart 2012, S. 67-105.

Bauer, Susanne. The Meaning of Music in a German Sect in Chile: Colonia Dignidad. Voices: A World Forum for Music Therapy. [2009], online unter https://www.voices.no/columnist/colbauer200409.php (zuletzt abgerufen am 26.05.2009).

Baumeister, Annette/Huismann, Wilfried. »Colonia Dignidad - Aus dem Innern einer deutschen Sekte«. Dokumentation [arte], Erstausstrahlung am 10.03.2020. 
Bayernkurier vom 05.01.1980, »Eine deutsche Siedlung am Fuße der Anden - Zu Besuch in der sozialen >Colonia Dignidad««.

Beau, Nicolás/Laurent Léger. „Consejero de Pinochet cobró comisiones en Francia por los submarinos Scorpene«, in: CIPER (Website), 10.07.2008, online unter http://ciperchile.cl/2008/07/10/consejero-de-pinochet-cobro-comisiones-en-fr ancia-por-los-submarinos-scorpene.

Becerra, Gonzalo. »Hace agua la galera de Paul Schäfer?«, in: Qué Pasa vom 10.03.1988, S. 13-15.

Bellusci, Salvador. Fin de un mito, Buenos Aires 2008.

Berggur, Bernd. Colonia Dignidad - Umrisse eines deutschen Kolonisationsprojekts in Chile, in: Babylon. Beiträge zur jüdischen Gegenwart, Heft 5/1989, S. 126-132.

Bericht der JIPOL an Zepeda vom 24.01.2006. Procesamiento y análisis de la información remitida por el ministro Jorge Zepeda Arancibia el 14 de septiembre de 2005, conteniendo diferente documentación, online unter: http://londres38.cl/1934/w3-ar ticle-97390.html.

Berliner Zeitung vom 16.04.1966. »Oase für Nazimörder«.

Beucker, Pascal, »Keine Ruhe für Dr. Hopp«, in: die tageszeitung vom 25.03.2013, S. 4.

Biedermann, Niels/Judith Strasser/Julian Poluda. »Colonia Dignidad« - Psychotherapie im ehemaligen Folterlager einer deutschen Sekte, in: Zeitschrift für Politische Psychologie, 14 (2006) Nr. 1+2, S. 111-127.

Bild am Sonntag vom 16.08.1967. »Mutter tötete drei Kinder bei Camping-Spiel«.

Blancpain, Jean-Pierre. Los Alemanes en Chile (1816-1945). Santiago 1985.

Bogolasky, Natalia. "Cables de Wikileaks mencionan polémicos stestigos reservados` en procesos de Colonia Dignidad, in: CIPER (Website), 20.10.2011, online unter https://ciperchile.cl/2011/10/20/cables-de-wikileaks-mencionan-polemico s-"testigos-reservados"-en-procesos-de-colonia-dignidad/.

Bonnefoy, Pascale. Cazar al cazador - detectives tras criminales de lesa humanidad, Santiago 2018.

Bonner Generalanzeiger vom 15.11.2016. »Colonia Dignidad« mit Rentengeld illegal finanziert?«, online unter https:/ga.de/news/politik/ausland/colonia-dignidad-mitrentengeld-illegal-finanziert_aid-43115355.

Bossle, Lothar. Allende und der europäische Sozialismus, Stuttgart 1975.

Branch, Taylor/Eugene M. Propper. Labyrinth, New York 1982.

Bräutigam, Thomas. Rechtsvergleichung als Konfliktvergleich. Das deutsche Informationsfreiheitsgesetz aus Perspektive des US-amerikanischen und finnischen Rechts. [Dissertation] Universität Helsinki, 2008. https://www.doria.fi/bitstream/handle/1 0024/42586/rechtsve.pdf; (zuletzt aufgerufen am 24.02.2011).

Bundesbeauftragter für den Datenschutz und die Informationsfreiheit. 2. Tätigkeitsbericht zur Informationsfreiheit für die Jahre 2008 und 2009, Bonn 2010, online unter https://www.bfdi.bund.de/SharedDocs/Publikationen/Taetigkeitsberichte/T B_IFG/2TB08_09.pdf.

Bundesministerium des Inneren unter Mitwirkung des Bundesarchivs (Hg.): Dokumente zur Deutschlandpolitik. Deutsche Einheit. Sonderedition aus den Akten des Bundeskanzleramtes 1989/90, München 1998. 
Bundesnachrichtendienst. Walther Rauff und der Bundesnachrichtendienst, Mitteilungen der Forschungs- und Arbeitsgruppe Geschichte des BND, Nr. 2, Berlin 2011, online unter https://multimedia.gsb.bund.de/BND/Importer-Downloads/mfg2bnd.p df.

Burghardt, Peter, „Gebunkerte Geheimnisse«, in: Süddeutsche Zeitung vom 05.02.2008, S. 8 .

Burghardt, Peter, »Unser Dorf soll schöner werden«, in: Süddeutsche Zeitung vom 09.11.2011, S. 3.

Burghardt, Peter, »Der Sektenarzt von nebenan« in: Süddeutsche Zeitung vom 25.03.2013, S. 6.

Burghardt, Peter, »Deutsche Abgründe«, in: Süddeutsche Zeitung vom 29.10.2014, S. 7

Burghardt, Peter, »Profil Botschafter Rolf Schulze. Deutscher Botschafter in Chile, den nun ein düsteres Kapitel einholt«, in: Süddeutsche Zeitung vom 20.07.2016, S. 4.

Burghardt, Peter, »Traumatisiert sind alle«, in: Süddeutsche Zeitung vom 07.11.2016, S. 6.

Burghardt, Peter, »Verstörendes Urteil«, in: Süddeutsche Zeitung vom 27.09.2018, S. 4.

Burghardt, Peter, »Freiheit der Schergen«, in: Süddeutsche Zeitung vom 08.05.2019, S. 6.

Burghardt, Peter, »Folklore und Folter«, in: Süddeutsche Zeitung vom 16.03.2020, S. 25. Buschfort, Wolfgang. Projekt zur Geschichte des Verfassungsschutzes, in: Jens Niederhut/Uwe Zuber (Hg.). Geheimschutz Transparent? Verschlusssachen in staatlichen Archiven, Essen 2010, S. 17-26.

Cáceres, Iván. Arqueología y Memoria en Colonia Dignidad: en busca de las materialidades de la represión y la violencia política, in: Evelyn Hevia/Jan Stehle (Hg.) Colonia Dignidad. Diálogos sobre verdad justicia y memoria. Santiago 2015, S. 130-145.

Calloni, Stella. Operación Condor. Pacto Criminal, La Habana 2006.

Cámara de Diputados, Diarios de Sesiones, Legislatura extraordinaria periodo 19651966, Sesión $71^{\text {a }}$ vom 12.03.1966.

Cámara de Diputados, Boletín de Sesiones, Legislatura extraordinaria periodo 19671968, Sesión 40 vom 05.03.1968, S. 3741. Se acuerda la designación de una Comisión Especial para investigar los hechos producidos en la Colonia »Dignidad« de Parral, provincia de Linares.

Cámara de Diputados, Diarios de Sesiones, Legislatura extraordinaria periodo 19681969, Sesión $12^{\text {a }}$ vom 26.11.1968.

Cámara de Diputados, Boletín de Sesiones, Legislatura extraordinaria periodo 19681969, Sesión $13^{\text {a }}$ vom 27.11.1968, S. 1285-1288. La Cámara vota las conclusiones del informe de la Comisión Especial encargada de estudiar las actividades de la Sociedad Benefadora y Educacional »Dignidad«, de Parral.

Cámara de Diputados, Diarios de Sesiones, Legislatura 330 ${ }^{a}$, Sesión $31^{\mathrm{a}}$ vom 03.01.1995, S. 33-36. Creación de Comisión Investigadora de cumplimiento del Decreto Supremo que disolvió la ex »Colonia Dignidad«.

Cámara de Diputados, Diarios de Sesiones, Legislatura 332, Sesión 33 ${ }^{\mathrm{a}}$ vom 06.12.1995, S. 3231--3288. Informe de la Comisión Especial Investigadora de la Cancelación de la Personalidad Jurídica de Colonia Dignidad, creada con el objeto de verificar la forma como se dio cumplimiento al decreto supremo que disolvió esa institución, onli- 
ne unter: https:/www.camara.cl/camara/media/docs/colonia/o1.pdf (zuletzt abgerufen am 12.02.2018).

Cámara de Diputados, Diarios de Sesiones, Legislatura 332 a , Sesión $44^{\text {a }}$ vom 18.01.1996, S. 21-52. Informe de la Comisión Especial Investigadora sobre la cancelación de la personalidad jurídica de Colonia Dignidad.

Cámara de Diputados, Diarios de Sesiones, Legislatura 334ª , Sesión 63 vom 29.04.1997.

Cámara de Diputados, Diarios de Sesiones, Legislatura 335ª , Sesión $35^{a}$ vom 20.08.1997, S. 19-48. Informe de la Comisión investigadora sobre la ex Colonia Dignidad.

Cámara de Diputados, Informe de la Comisión Investigadora encargada de velar por el cumplimiento de las recomendaciones aprobadas por la H. Cámara de Diputados, en relación con la ex Colonia Dignidad vom 13.08.1997, online unter https://www.c amara.cl/camara/media/docs/colonia/02.pdf (zuletzt abgerufen am 12.02.2018).

Cámara de Diputados, Diarios de Sesiones, Legislatura 336 ${ }^{\mathrm{a}}$, Sesión 10 $10^{\mathrm{a}}$ vom 21.10.1997. Informe de la Comisión de Familia recaido en el Proyecto de Acuerdo que le encomienda investigar situaciones de posibles violaciones a los derechos de los niños y niñas en la ex Colonia Dignidad, auch online unter https://www.camara.cl/camara /media/docs/colonia/03.pdf (zuletzt abgerufen am 12.02.2018).

Cámara de Diputados, Diarios de Sesiones, Legislatura 337 $7^{\mathrm{a}}$, Sesión $23^{\mathrm{a}}$ vom 19.05.1998.

Cámara de Diputados, Boletín de Sesiones, Legislatura $340^{a}$, Sesión $27^{a}$ vom 10.08.1999, S. 124-169. Informe de las Comisiones Unidas de Derechos Humanos, Nacionalidad y Ciudadanía, y de Familia, encargadas de estudiar y fiscalizar cómo los distintos órganos públicos competentes han colaborado para el éxito de las investigaciones judiciales relativas a la ex Colonia Dignidad, auch online unter https://www.camar a.cl/camara/media/docs/colonia/04.pdf (zuletzt abgerufen am 12.02.2018).

Cámara de Diputados, Diarios de Sesiones, Legislatura 342 a , Sesión $18^{\mathrm{a}}$ vom 19.07.2000.

Claus Hecking. »Ausspannen im Folterlager« in: Die Zeit Nr. 25/2014 vom 28.06.2014, online unter https://www.zeit.de/2014/25/colonia-dignidad-chile.

Colegio Médico de Chile, Tribunal Nacional de Ética, AZ TNE 008-18, Urteil vom 10.09.2019, online unter: https://www.cooperativa.cl/noticias/site/artic/20190910/a socfile/20190910222606/sentencia_causa_rol_n_008_18_10_09_19_.pdf

Collins, Cath. Human Rights Trials in Chile during and after the >Pinochet Years $\triangleleft$, in: The International Journal of Transitional Justice 4 (2009) No. 1, S. 67-86.

Colonia Dignidad. Ein chilenisch-deutsches Oral History-Archiv (Website), online unter https://www.cdoh.net/.

Comisión Nacional sobre Prisión Política y Tortura. Informe de la Comisión Nacional sobre Prisión Política y Tortura, Santiago 2004.

Comité de Defensa de los Derechos del Pueblo. Labradores de la Esperanza - La región del Maule, Santiago 1992.

Consejo de Monumentos Nacionales (CMN). Noticia: »El CMN aprueba solicitud de declaratoria del sitio de memoria Cuartel de la DINA en Parral como monumento histórico«, 27.12.2018, online unter https://www.monumentos.gob.cl/prensa/notic $\mathrm{ias} / \mathrm{cmn}$-aprueba-solicitud-declaratoria-sitio-memoria-cuartel-dina-parral-comomonumento. 
Conze, Eckart/Norbert Frei/Peter Hayes/Moshe Zimmermann. Das Amt und die Vergangenheit. Deutsche Diplomaten im Dritten Reich und in der Bundesrepublik, München 2010.

Cooperativa.cl, »Miguel Krassnoff fue careado por víctima de torturas«, 05.01.2018, online unter https://www.cooperativa.cl/noticias/pais/dd-hh/judicial/miguel-krassno ff-fue-careado-por-victima-de-torturas/2018-01-05/112217.html.

Corporación Nacional de Reparación y Reconciliación. Informe de la Comisión Nacional de Verdad y Reconciliación. Bd. 1. Santiago 1996, online unter https://www.memor iachilena.gob.cl/archivos2/pdfs/MC0053679.pdf.

Corporación Nacional de Reparación y Reconciliación. Informe de la Comisión Nacional de Verdad y Reconciliación. Bd. 2. Santiago 1996, online unter https://www.memor iachilena.gob.cl/archivos2/pdfs/MCoo53680.pdf.

Corporación Nacional de Reparación y Reconciliación. Informe de la Comisión Nacional de Verdad y Reconciliación. Bd. 3. Santiago 1996, online unter https://www.memor iachilena.gob.cl/archivos2/pdfs/MCo053681.pdf.

Corporación Nacional de Reparación y Reconciliación. Informe de la Comisión Nacional de Verdad y Reconciliación (Informe Rettig), Santiago 1991.

Dannemann, Victoria. Un secreto impide conocer a fondo el patrimonio de ex Colonia Dignidad, in: Deutsche Welle (Website), 23.06.2020, online unter https://p.dw.com /p/3eDYd.

Dannemann, Victoria. Colonia Dignidad - Opfer kritisieren deutsche Justiz, in: Deutsche Welle (Website), 08.05.2019, online unter https://p.dw.com/p/3IApz.

Dannemann, Victoria. Colonia Dignidad: Chile y Alemania impulsan colaboración judicial, in: Deutsche Welle (Website), 25.04.2018, online unter https://p.dw.com/p/2 weeB.

De la Cerda, María Soledad. Chile y los hombres del Tercer Reich, Santiago 2000.

Der Spiegel Nr. 32/1987 vom 03.08.1987, S. 19ff. »Kein Zentimeter wird zurückmarschiert«, online unter https://magazin.spiegel.de/EpubDelivery/spiegel/pdf/135232 59.

Der Spiegel Nr. 49/1987 vom 30.11.1987, S. 32 »Metropolis und Theresienstadt. Bonner Diplomaten besuchten die berüchtigte Colonia Dignidad «.

Der Spiegel Nr. 18/1988 vom 02.05.1988, S. 260. »Berufliches - Günther Knackstedt«, online unter https://magazin.spiegel.de/EpubDelivery/spiegel/pdf/13527844.

Der Spiegel Nr. 40/1990 vom 01.10.1990, S. 97-99, »Der Weg des Teufels«.

Der Spiegel Nr. 44/1991 vom 25.11.1991, S. 67-69. »Aus einem Geisterhaus«.

Deutscher Bundestag. Drucksache 8/2009 vom 26.06.1977. Fragen für den Monat Juli 1978 mit den dazu erteilten Antworten, Teil III.

Deutscher Bundestag. Drucksache 8/206 vom 18.03.1977. Fragen für die Fragestunden der Sitzungen des Deutschen Bundestages am Mittwoch, dem 23. März 1977 am Donnerstag, dem 24. März 1977.

Deutscher Bundestag. Drucksache 11/1825 vom 05.02.1988. Schriftliche Fragen mit den in der Woche vom 1. Februar 1988 eingegangenen Antworten der Bundesregierung.

Deutscher Bundestag. Plenarprotokoll 11/67 vom 10.03.1988.

Deutscher Bundestag. Drucksache 11/2449 vom 09.06.1988. Antwort der Bundesregierung auf die Kleine Anfrage der Fraktion der DIE GRÜNEN - Drucksache 11/1409- 
Beziehungen der Bundesregierung und von Politikern der Bundesrepublik Deutschland zur Colonia Dignidad, Chile.

Deutscher Bundestag. Drucksache 12/683 vom 06.06.1991. Bericht des Petitionsausschusses.

Deutscher Bundestag. Drucksache 12/7501 vom 09.05.1994. Antwort der Bundesregierung auf die Kleine Anfrage der Abgeordneten Ulla Jelpke und der Gruppe der PDS/Linke Liste - Drucksache 12/7111 - Colonia Dignidad in Chile.

Deutscher Bundestag. Drucksache 13/8252 vom 17.07.1997. Antwort der Bundesregierung auf die Kleine Anfrage der Gruppe der PDS (Drucksache 13/8126). Haltung der Bundesregierung zu den Opfern der Colonia Dignidad.

Deutscher Bundestag. Drucksache 14/7444 vom 13.11.2001. Antrag der Fraktionen von SPD, BÜNDNIS 90/DIE GRÜNEN und FDP. Hilfe für die Opfer der Colonia Dignidad.

Deutscher Bundestag. Drucksache 14/8511 vom 13.03.2002. Beschlussempfehlung und Bericht des Auswärtigen Ausschusses (3. Ausschuss) zu BT-DS 14/7444. [beschlossen vom Bundestag am 16.05.2002 bei Enthaltung der CDU/CSU Fraktion]

Deutscher Bundestag. Drucksache 16/11354 vom 12.12.2008. Antwort der Bundesregierung auf die Kleine Anfrage der Fraktion der FDP (Drucksache 16/11079). Freigabe von Akten der Bundesregierung.

Deutscher Bundestag. Drucksache 17/3804 vom 12.11.2010. Kleine Anfrage der Fraktion BÜNDNIS 90/DIE GRÜNEN. Erleichterung des Forschungszugangs zu Archiven des Auswärtigen Amts und anderer Bundesministerien.

Deutscher Bundestag. Drucksache 17/4339 vom 21.12.2010. Antwort der Bundesregierung auf die Kleine Anfrage der Fraktion BÜNDNIS 90/DIE GRÜNEN - Drucksache 17/3804 - Erleichterung des Forschungszugangs zu Archiven des Auswärtigen Amts und anderer Bundesministerien.

Deutscher Bundestag. Drucksache 18/8127 vom 15.04.2016. Schriftliche Fragen mit den in der Woche vom 11. April 2016 eingegangenen Antworten der Bundesregierung.

Deutscher Bundestag. Drucksache 18/10890 vom 18.01.2017. Entschließungsantrag der Fraktion BÜNDNIS 90/DIE GRÜNEN zu der dritten Beratung des Gesetzentwurfs der Bundesregierung (Drucksachen 18/9633, 18/10813). Entwurf eines Gesetzes zur Neuregelung des Bundesarchivrechts.

Deutscher Bundestag. Drucksache 18/11805 vom 30.03.2017. Antrag einzelner Abgeordneter der Fraktionen SPD, BÜNDNIS 90/DIE GRÜNEN und LINKE. Aufarbeitung der Verbrechen in der Colonia Dignidad und Hilfe für die Opfer.

Deutscher Bundestag. Drucksache 18/12943 vom 27.06.2017. Antrag der Fraktionen CDU/CSU, SPD und BÜNDNIS 90/DIE GRÜNEN. Aufarbeitung der Verbrechen in der Colonia Dignidad.

Deutscher Bundestag. Drucksache 19/3233 vom 29.06.2018. Unterrichtung durch die Bundesregierung. Entwurf der Bundesregierung für ein Hilfskonzept für die Opfer der Colonia Dignidad.

Deutscher Bundestag. Drucksache 19/3380 vom 11.07.2018. Antwort der Bundesregierung auf die Kleine Anfrage der Fraktion DIE LINKE - Drucksache 19/2955 - Stand der Aufarbeitung der Verbrechen der Colonia Dignidad. 
Deutscher Bundestag. Drucksache 19/10410 vom 21.05.2019. Unterrichtung durch die Bundesregierung. Hilfskonzept für die Opfer der Colonia Dignidad der Gemeinsamen Kommission von Deutschem Bundestag und Bundesregierung.

Deutscher Bundestag. Drucksache 19/29463 vom 06.05.2021. Antwort der Bundesregierung auf die Kleine Anfrage der Fraktion DIE LINKE - Drucksache 19/28200 Aktueller Stand bei der Umsetzung des Bundestagsbeschlusses zur Colonia Dignidad.

Deutscher Bundestag. Plenarprotokoll 8/21 vom 24.03.1977.

Deutscher Bundestag. Plenarprotokoll 14/236 vom 16.05.2002.

Deutscher Bundestag. Plenarprotokoll 17/132 vom 19.10.2011.

Deutscher Bundestag. Plenarprotokoll 18/243 vom 29.06.2017.

Deutscher Bundestag. Plenarprotokoll 19/46 vom 05.07.2018.

Deutschland-Magazin Nr. 3/1980, S. 32f. »Anatomie einer Hetzkampagne«.

Diario El Centro vom 09.10.2000, S. 2-3. »Dignidad: La verdad del caso archivos«.

Diehl, Jörg. »Dr. Unerwünscht. Colonia-Dignidad-Arzt in Krefeld«, in: Spiegel Online vom 26.08.2011, online unter https://www.spiegel.de/panorama/justiz/colonia-dig nidad-arzt-in-krefeld-dr-unerwuenscht-a-782465.html.

Dinges, John. »Colonia Dignidad«, in: The Rebel vom 06.02.1984, S. 26-35.

Dinges, John. The Condor Years: How Pinochet and his Allies brought Terrorism to Three Continents, New York 2004.

Dinges, John/Saul Landau. Assassination on Embassy Row, New York 1982.

Douglas, Marcela. Hopes and Horror - An ethnographic study of a German community in Chile. [Dissertation]. Troms $\varnothing 2013$, online unter: https://munin.uit.no/handle/10 037/5810.

Dufner, Georg. Partner im Kalten Krieg. Die politischen Beziehungen zwischen der Bundesrepublik Deutschland und Chile, Frankfurt a.M. 2014.

Ebert, Matthias. »Colonia Dignidad - Noch heute profitieren einige wenige« In: Tagesschau.de (Website) vom 26.04.2021, online unter: https://www.tagesschau.de/ausla nd/amerika/colonia-dignidad-aufarbeitung-101.html.

Eckert, Astrid M. Kampf um die Akten. Die Westalliierten und die Rückgabe von deutschem Archivgut nach dem Zweiten Weltkrieg, Stuttgart 2004.

El Cronista, 25.05.1977, S. 16. "Mientras el niño se recupera en Colonia Dignidad - Madre que llora por su hijo, sólo lo hace para sumarse a campaña antichilena«.

El Desconcierto (Website) vom 06.06.2018. " Es un montajeく: El día en que Hernán Larraín defendió a Paul Schäfer tras operativo policial«, online unter https://www.eldesconcierto.cl/2018/06/06/video-es-un-montaje-el-dia-en-quehernan-larrain-defendio-a-paul-schafer-tras-operativo-policial/.

El Diario Ilustrado vom 13.04.1966, S. 6. "Aumenta el desconcierto en el caso de la Colonia >Dignidad «

El Diario Ilustrado vom 16.04.1966, S. 1. »Ordenan detener a todos los jefes de Colonia Dignidad«.

El Diario Ilustrado vom 23.04.1966, S. 6. »Exhumados cadaveres de cementerio de >Dignidad «

El Mercurio vom 11.04.1966, S. 25. »Misterioso desaparecimiento de Paul Schäfer Schneider «. 
El Mercurio vom 07.08.1967, S. 31. »Superado problema relacionado con la Colonia >Dignidad «.

El Mercurio vom 25.02.1968, S. 37. Inserción - La Colonia »Dignidad« a la opinión pública.

El Mercurio vom 27.03.1977, S. 33. »Declaración del Embajador de la RFA: No hay chilenos detenidos en la Colonia >Dignidad «

El Mercurio vom 15.05.1977, Revista del Domingo S. 8-11. »El Remezón Dignidad - diálogo con dudas«.

El Mercurio vom 19.06.1978. „Cerrado Sumario por Homicidio de un ex-dirigente del PS«, Einsehbar in PA AA, ZW 111131.

El Mercurio vom 25.11.1978. »Apreciaciones de 35 Alemanes sobre la Realidad Chilena«.

El Mercurio vom 06.12.1987, S. D4-5. „Dignidad, Puertas adentro«.

El Mercurio vom 15.12.1988, S. C6. »Abogado de »Colonia Dignidad«: Fallo está ajustado a hechos y derecho«.

El Mercurio vom 22.01.1989, S. C5. »Afirma abogado Fernando Saenger: Antigua visita a Colonia Dignidad no descalifica al juez«.

El Mercurio vom 22.01.1989, S. D10-11. »Al fin del camino«.

El Mercurio vom 13.02.1989, S. A1-2. »Cayó avión de la Colonia Dignidad«.

El Mercurio vom 23.04.1992, S. C7. »Cuatro colonos empadronaron a alemanes en Villa Baviera«.

El Mercurio vom 16.03.1995, S. C2. »Aseguró Frei a Kohl: No habrá personalidad jurídica para ningún ente vinculado con Dignidad«.

El Mercurio vom 17.03.1995, S. C4. »Senador Hernán Larraín: Dichos de Frei sobre Colonia Dignidad son incomprensibles«.

El Mercurio vom 18.03.1995, S. C6. „Ex-Ministros declinaron exponer acerca de su gestión sobre Dignidad«.

El Mercurio vom 23.04.1995, S. 6C. »Dijo Doctor Hartmut Hopp: >Hospital de >Dignidad será reabierto en Mayo«.

El Mercurio vom 27.04.1995, S. C4. »Embajador germano Werner Reichenbaum: Alemania espera resultado de informe sobre Dignidad «.

El Mercurio vom 08.05.1995, S. C4. „Con masivo acto: Reabrieron hospital de la exColonia Dignidad «.

El Mercurio vom 09.05.1995, S. C9. »También fue clausurado hospital: Descerrajamiento e incidentes hubo en la ex-Colonia Dignidad«.

El Mercurio vom 28.05.1995, S. C2. »Comisión ha reunido datos sobre presuntas ilegalidades de la ex-Colonia Dignidad«.

El Mercurio vom 21.01.1996, S. C11. »Colono de V. Baviera rechaza amparo legal«.

El Mercurio vom 30.04.1997, S. C9. »Ministro de Justicia Alemán: Elogian a la Justicia por Caso Dignidad«.

El Mercurio vom 17.05.1997, S. C15. »Frei insta a Schäfer a que se entregue«.

El Mercurio vom 18.11.1997, S. C1. »Ex-Colonia Dignidad: Suprema rechazó petición de Cámara«.

El Mercurio vom 08.12.1997, S. C1. »Allanan por tercera vez inmueble de ex-Colonia«.

El Mercurio vom 15.12.2000, S. C9. „Dictó Ministro: Sentencias para Dr. Hopp y su Esposa 
El Mercurio vom 18.02.2002, S. C8. »Investigan muerte de colono alemán«.

El Mercurio vom 19.12.2002, S. C11. »Colono que se cayó del techo estaba sedado - SML detectó hipnosedante en cuerpo de Karl Stricker«.

El Mercurio vom 23.09.2004, S. C10. "La Suprema absolvió a jerarca de la ex Colonia Dignidad $\ll$.

El Mercurio vom 20.06.2005, S. C11. »Juez resolvería hoy destino de los archivos secretos de Villa Baviera«.

El Mercurio vom 26.11.2005, S. C16. »Incautan químicos en Villa Baviera«.

El Mercurio vom 11.03.2006, S. C15. »Hallazgo: Minas antitanques en Villa Baviera«.

El Mercurio vom 29.03.2006, S. C 9. »Dignidad«.

El Mercurio vom 22.05.2007, S. C10. »Alemania pide a Chile datos sobre Schreiber«.

El Mercurio vom 13.05.2018, S. C8. »Inserción - Inaceptable campaña de difamación en contra del Dr. Otto Dörr«

El Metropolitano 04.08.2000, S. 10. »Denuncian que Ejército protegería a Colonia Dignidad«.

El Mostrador (Website) vom 15.02.2021. »AFDD pide incorporar científicos argentinos a búsqueda de fosas en Colonia Dignidad «, online unter https://www.elmostrador. cl/dia/2021/02/15/afdd-pide-incorporar-cientificos-argentinos-a-busqueda-de-fos as-en-colonia-dignidad.

El Mostrador (Website) vom 19.02.2019. "Las conexiones de Hartmut Hopp con los médicos de la UC condenados en el caso Frei«, online unter https://www.elmostra dor.cl/noticias/pais/2019/02/19/las-conexiones-de-harmut-hopp-el-exjerarca-de-c olonia-dignidad-con-los-medicos-de-la-uc-condenados-en-el-caso-frei/.

El País vom 17.11.1992. "La rotunda derrota de Endara confirma la falta de liderazgo en Panama.«

El Periodista vom 25.11.2002, S. 22f. »La muerte de un capitán, la DINA y Colonia Dignidad«.

El Siglo vom 19.01.1967, S. 4. »Periodistas a declarar por >affaire Colonia Dignidad«.

El Siglo vom 06.08.1967, S. 21. »Estalló otro escándalo en Colonia >Dignidad««.

El Siglo vom 04.05.1968, S. 3, »Dignidad«.

El Sur vom 17.03.1988, »Afirma consul alemán - Caso Dignidad no es político«.

Ercilla vom 23.03.1966, S. 20-21. »Policía frustró sensacional rapto. Exclusivo: Comandos alemanes en acción en calles de Santiago«.

Ercilla vom 30.03.1966, S. 3-5. »Tras los muros de la misteriosa colonia alemana«.

Ercilla vom 13.04.1966, S. 3-5. »La justicia tras el misterio de >Dignidad««.

Ercilla vom 20.04.1966, S. 3-5. »Colonia 〉Dignidad〈. Siembra de recelos«:

Ercilla vom 27.04.1966, S. 3-5. »Wolfgang Müller: >Solo contra todos««.

Ercilla vom 04.05.1966, S. 3-5. »Tres niños ponen en jaque a >Dignidad «

Ercilla vom 11.05.1966, S. 3. »Austria pidió repatriación de los Wagner«.

Ercilla vom 01.06.1966, S. 2. Leserbrief »Müller agradece«.

Ercilla vom 01.06.1966. »Nueva etapa en proceso a >Dignidad «

Ercilla vom 20.07.1966, S. 7. »Las 600 fojas del proceso a >Dignidad «

Ercilla vom 01.06.1998, S. 28-29. »Otra muerte misteriosa«.

Ercilla vom 04.03.2002, S. 32. »Extraños accidentes«. 
Escalante, Jorge/Nancy Guzmán/Javier Rebolledo/Pedro Vega. Los crímenes que estremecieron Chile. Las memorias de La Nación para no olvidar, Santiago 2013.

European Center for Constitutional and Human Rights (ECCHR). Stellungnahme zu der Rolle von Hartmut W. Hopp innerhalb der Colonia Dignidad - Seine Kollaboration mit dem Pinochet-Regime und Verbrechen an Bewohnern der Colonia Dignidad. Berlin, Oktober 2011. S. 11, online unter https://www.ecchr.eu/fileadmin/Pressemit teilungen_deutsch/Stellungnahme_Colonia_Dignidad_Hopp_-_2011-10-06.pdf.

European Center for Constitutional and Human Rights (ECCHR). Rechtliche Stellungnahme zum Beschluss des Oberlandesgerichts Düsseldorf in Sachen Hartmut Hopp/Colonia Dignidad, Oktober 2018, online untder https://www.ecchr.eu/filead $\mathrm{min} /$ user_upload/Stellungnahme_zum_Beschluss_OLG_Ddorf_im_Fall_Hartmut_ Hopp_Colonia_Dignidad.pdf.

European Center for Constitutional and Human Rights (ECCHR). Pressemitteilung vom 22.01.2019. „Colonia Dignidad: Deutsche Justiz bleibt untätig«, online unter https://www.ecchr.eu/nc/pressemitteilung/colonia-dignidad-deutsche-justiz-b leibt-untaetig/.

Forschungs- und Dokumentationszentrum Chile-Lateinamerika (FDCL). Pressemitteilung »Beschluss des OLG Düsseldorf lehnt Vollstreckung der chilenischen Verurteilung von Hartmut Hopp ab. Justizversagen im Fall Colonia Dignidad nimmt kein Ende.", 26.09.2018, online unter https:/www.fdcl.org/pres srelease/2018-09-26-beschluss-des-olg-duesseldorf-lehnt-vollstreckung-der-chilen ischen-verurteilung-von-hartmut-hopp-ab/.

Forschungs- und Dokumentationszentrum Chile-Lateinamerika (FDCL). Pressemitteilung »Colonia Dignidad: Vertrauen der Betroffenen in deutsche Justiz erschüttert.«, 07.05.2019, online unter https://www.fdcl.org/pressrelease/2019-05-07-colonia-dig nidad-vertrauen-der-betroffenen-in-deutsche-justiz-erschuettert/.

Foschepoth, Josef. Die Bedeutung der Bundesakten für einen neuen Blick auf die Geschichte der Bundesrepublik Deutschland, in: Mitteilungen aus dem Bundesarchiv 21 (2013), Heft 1, S. 74-79.

Foschepoth, Josef. Staatsschutz und Grundrechte in der Adenauerzeit, in: Jens Niederhut/Uwe Zuber (Hg.). Geheimschutz Transparent? Verschlusssachen in staatlichen Archiven, Essen 2010, S. 27-58.

Frankfurter Allgemeine Zeitung vom 17.11.2010, Leserbrief von Dieter Maier.

Frankfurter Allgemeine Zeitung vom 14.07.2016, S. 6. »Gauck lehnt Entschädigungen in Chile ab«.

Frankfurter Rundschau vom 17.09.2018. »Sibylle Riedmiller in Frankfurt. Im Fluss trieben die Leichen«, online unter https://www.fr.de/frankfurt/sibylle-riedmiller-infrankfurt-im-fluss-trieben-die-leichen-a-1583178.

Freund, Henning. »Colonia Dignidad« - Der Öffnungsprozess einer »geschlossenen Gemeinschaft«, in: EZW Materialdienst - Zeitschrift für Religions- und Weltanschauungsfragen Nr. 5/2008, S. 180-185.

Freund, Henning. Religion als Trauma und Bewältigungshilfe am Beispiel der totalitären religiösen Gemeinschaft Colonia Dignidad, in: Utsch, Michael (Hg.). Pathologische Religiosität - Genese, Beispiele, Behandlungsansätze, Stuttgart 2012, S. 107-136. 
Fries, Mirka/Andreas Schüller. Sozialadäquates Verhalten, in: Freispruch. Mitgliederzeitung der Strafverteidigervereinigungen 14 (2019), S. 41-46.

Fröhling, Ulla. Unser geraubtes Leben - Die wahre Geschichte von Liebe und Hoffnung in einer grausamen Sekte, Köln 2012.

Fröhling, Ulla. »Hussain Siam«, in: Unser geraubtes Leben [Website zum Buch], zuletzt geändert 08.11.2016, online unter https://www.unser-geraubtes-leben.de/diebetroffenen/hussain-siam/index.php.

Gallenberger, Florian [Regie]. »Colonia Dignidad - es gibt kein zurück«, Spielfilm, 110 min, Kinostart in Deutschland am 18.02.2016.

Gemballa, Gero. »Das Dorf der Würde, die Colonia Dignidad in Chile«, Reportage in der ARD-Sendereihe »Unter Deutschen Dächern«, 90 min, Erstausstrahlung am 30.07.1989.

Gemballa, Gero. Colonia Dignidad. Ein deutsches Lager in Chile, Reinbek 1988.

Gemballa, Gero. »Munition für das Folterlager«, in: Der Stern Nr. 8/1988 vom 18.02.1988, S. 236-238.

Gemballa, Gero. Colonia Dignidad: ein Reporter auf den Spuren eines deutschen Skandals, Frankfurt a.M. 1998.

Gemballa, Gero. Freiheit. Und das Gegenteil. Würde. Und das Gegenteil. Die Colonia Dignidad, in: Imbusch, Peter/Dirk Messner/Detlef Nolte (Hg.). Chile heute. Politik, Wirtschaft, Kultur, Frankfurt a.M. 2004, S. 881-887.

Gemballa, Gero/Kai Hermann. »Leben wie im KZ«, in: Stern Nr. 49/1987 vom 26.11.1987.

General-Anzeiger, Rhein-Sieg Zeitung vom 30.12.1987. »Colonia Dignidad-Anhängern ist nichts vorzuwerfen«.

Gesterkamp, Harald. »Ein Ende des unendlichen Prozesses« in: AI-Journal 10/1997, S. 6-12.

Giménez, Daniel/Magadalena Garcés/Xaviera Abdul-Malak. Archivos de Colonia Dignidad, una indagación exploratoria preliminar. [o. O.] 2015, online unter https://ww w.londres38.cl/1934/articles-97466_recurso_1.pdf.

Gloël, Matthias. "Deutsche Kolonisten in Chile - Ursprünge und Gegenwart«, in: Humboldt-Magazin, Mai 2015, online unter https:/www.goethe.de/ins/cl/de/kul/ mag/20815303.html.

González, Correa/Rodrigo Pablo. Comentario a sentencia de la Corte Suprema en el recurso de inaplicabilidad por inconstitucionalidad interpuesta por »Colonia Dignidad«, in: Revista Derecho y Humanidades 1 (1992), S. 251-280.

González, Mónica. »Autos de detenidos desaparecidos en >Dignidad««, in: Análisis vom 28.08.1989, S. 25-29.

Gónzalez, Mónica. „El día en que Manuel Contreras le ofreció al Sha de Irán matar a >Carlos, El Chacal«, in: CIPER (Website), 29.08.2009, online unter https://www.ciperchile.cl/2009/08/06/el-dia-en-que-manuel-contreras-le-ofre cio-al-sha-de-iran-matar-a-"el-chacal"/.

González, Mónica. »Las armas químicas de Pinochet «, in: CIPER (Website), 22.08.2013, online unter http://ciperchile.cl/2013/08/22/las-armas-quimicas-de-pinochet/.

Goñi, Uki. The Real Odessa: How Peron Brought the Nazi War Criminals to Argentina, London 2002. 
Görtemaker, Manfred/Christoph Safferling. Die Akte Rosenburg: das Bundesministerium der Justiz und die NS-Zeit, München 2016.

Goschler, Constantin/Michael Wala. »Keine neue Gestapo«: Das Bundesamt für Verfassungsschutz und die NS-Vergangenheit, Reinbek 2015.

Groß, Heike/Ingo Zöllich. »Es gibt kein Zurück« - Paul Schäfer als Jugendgruppenleiter in Troisdorf, in: Evangelische Kirchengemeinde Troisdorf, Kompass Nr. 677, MärzMai 2018, S. 8-11.

GStA Düsseldorf. Pressemitteilung 6/20 vom 09.12.2020. Beschwerdeentscheidung hinsichtlich der Einstellung des bei der Staatsanwaltschaft Krefeld geführten Ermittlungsverfahrens gegen den Beschuldigten Hartmut $\mathrm{H}$. wegen Beihilfe zum Mord u.a., online unter https:/www.gsta-duesseldorf.nrw.de/behoerde/presse/Pressem itteilung-Nr_-6_20-091220.pdf.

Hammerschmidt, Peter. »With the Backing of the BND«. Die Waffengeschäfte des westdeutschen Auslandsnachrichtendienstes mit lateinamerikanischen Militärdiktaturen - das Beispiel »MEREX«, in: Journal of Intelligence, Propaganda and Security Studies (JIPSS), 6 (2012), S. 26-40.

Hammerschmidt, Peter. Deckname Adler. Klaus Barbie und die westlichen Geheimdienste. Frankfurt a.M. 2014.

Heller, Friedrich Paul. Colonia Dignidad - ein stabiles Zwangskollektiv, in: epdDokumentation Nr. 20/1998, 11. Mai 1998.

Heller, Friedrich Paul. Colonia Dignidad: von der Psychosekte zum Folterlager, Stuttgart 1993.

Heller, Friedrich Paul/Anton Maegerle. Die Sprache des Hasses. Rechtsextremismus und völkische Esoterik - Jan van Helsing, Horst Mahler ..., Stuttgart 2001.

Heller, Friedrich Paul. Lederhosen, Dutt und Giftgas: Die Hintergründe der Colonia Dignidad, 4. erweiterte und aktualisierte Aufl., Stuttgart 2011.

Heller, Friedrich Paul. Pinochet - Eine Täterbiografie in Chile, Stuttgart 2012.

Heller, Friedrich Paul. Die Colonia Dignidad: Ein politischer Skandal bis heute, in: Baer, Willi/Karl-Heinz Dellwo (Hg.). Chile - Salvador Allende und die Unidad Popular, Hamburg 2013, S. 215-235.

Herrmann, Kai, »Das Folterlager der Deutschen«, in: Stern Nr. 13/1977 vom 17.03.1977, S. 26-33.

Hermann, Kai, »Helft, helft bitte. Lasst mich nicht allein«, in: Stern Nr. 53/1987 vom 22.12.1987.

Herrmann, Boris, »Peinliche Botschaft«, in: Süddeutsche Zeitung vom 20.07.2016, S. 6.

Hevia, Evelyn/Jan Stehle. Los estados y los derechos humanos: aproximaciones a cinco décadas de Colonia Dignidad, in: Hevia, Evelyn/Jan Stehle (Hg.). Colonia Dignidad: diálogos sobre verdad, justicia y memoria, Santiago 2015, S. 11-20.

Hevia, Evelyn/Jan Stehle (Hg.). Colonia Dignidad: diálogos sobre verdad, justicia y memoria, Santiago 2015.

Hoffmann, Wolfgang, »Waffen aus Deutschland«, in: Die Zeit Nr. 09/1984 vom 24.02.1984, S. 17, online unter https://www.zeit.de/1984/09/waffen-aus-deutschlan d/.

Hofmeister, Wilhelm. Die deutschen Christdemokraten und Chile, Auslandsinformationen der Konrad-Adenauer-Stiftung (KAS-AI) Nr. 7-04, S. 22-49, Berlin 2004. 
Hollenbach, Michael. „Das Leben nach der Sekte. Ehemalige Mitglieder der Colonia Dignidad in Deutschland«, in: Deutschlandradio Kultur vom 24.05.2014, online unter: https://www.deutschlandfunkkultur.de/traumata-das-leben-nach-dersekte.1278.de.html?dram:article_id=287257.

Hollmann Michael. Verschlusssachen im Bundesarchiv, in: Jens Niederhut/Uwe Zuber (Hg.). Geheimschutz Transparent? Verschlusssachen in staatlichen Archiven, Essen 2010, S. 113-118.

Huneeus, Carlos. El régimen de Pinochet, Santiago 2016.

Instituo Nacional de Derechos Humanos. "¿Cómo puedo obtener la información y/o antecedentes de las fichas de Colonia Dignidad?«, online unter https://www.indh.c 1/preguntas-frecuentes/, (zuletzt abgerufen am 05.12.2019).

International Monetary Fund. World Economic Outlook Database, Oktober 2019, online unter: https://www.imf.org/external/pubs/ft/weo/2019/02/weodata/index.aspx

Jens Niederhut/Uwe Zuber (Hg.). Geheimschutz Transparent? Verschlusssachen in staatlichen Archiven, Essen 2010.

Jens Niederhut/Uwe Zuber. Einleitung, in: Jens Niederhut/Uwe Zuber (Hg.). Geheimschutz Transparent? Verschlusssachen in staatlichen Archiven, Essen 2010, S. 9-16.

Kaes, Wolfgang/Andreas Stanetschek. »Bitte hilf uns hier raus«, in: Bonner Generalanzeiger vom 12.03.2009, online unter https:/www.general-anzeiger-bonn.de/regio n/bitte-hilf-uns-hier-raus_aid-40531101.

Kaleck, Wolfgang/Andreas Schüller. Colonia Dignidad, ein deutscher Justizskandal, in: Legal Tribune Online, 17.10.2018, online unter https:/www.lto.de/recht/hintergrue nde/h/colonia-dignidad-justizskandal-nrw-chile-pinochet-hopp-sekte/.

Kilian, Jürgen. Krieg auf Kosten anderer. Das Reichsministerium der Finanzen und die wirtschaftliche Mobilisierung Europas für Hitlers Krieg, Berlin u.a. 2017.

Kletten, Ingo. Durch Terror zum modernen Staat. Der chilenische Geheimdienst DINA, in: Reemtsma, Jan Phillipp (Hg.). Folter: zur Analyse eines Herrschaftsmittels, Hamburg 1991, S. 37-72.

Kletten, Ingo. Eine lange Nachgeschichte. Der Fall des SS-Standartenführers Walther Rauff nach 1945 in Chile, in: Nürnberger Menschenrechtszentrum (NMRZ) (Blog), [o. O.] 2008, online unter https://www.menschenrechte.org/de/2008/06/03/ss-stan dartenfuhrer-rauff-chile/.

Knobbe, Martin, »Deutsche Staatsanwälte ermitteln in Chile«, in: Spiegel Online vom 21.04.2018, online unter https://www.spiegel.de/panorama/justiz/coloniadignidad-deutsche-staatsanwaelte-ermitteln-in-chile-a-1204100.html.

Knobbe, Martin. »Colonia Dignidad. Deutschland trägt eine politische Mitverantwortung «, in: Spiegel Online vom 28.06.2017, online unter https://www.spiegel.de/pol itik/ausland/colonia-dignidad-cdu-csu-spd-und-gruene-fordern-hilfsfonds-fueropfer-a-1154899.html.

Knobbe, Martin/Christoph Schult, »Terrorsekte Colonia Dignidad: Bundestagsabgeordnete fordern >rückhaltlose Aufklärung«", in: Spiegel Online vom 31.03.2017, online unter https:/www.spiegel.de/politik/deutschland/colonia-dignidad-abgeordnetefordern-rueckhaltlose-aufklaerung-a-1141426.html. 
Köhler, Otto. »Doktorspiele in Würzburg. Professor Bossle und sein soziologisches Familienunternehmen an der Julius-Maximilians-Universität«, in: Die Zeit Nr. 45 vom 04.11.1988, online unter https://www.zeit.de/1988/45/doktorspiele-in-wuerzburg.

Kölner Stadtanzeiger vom 17.06.1980. »Waffenhändler und Bischof miteinander im Clinch .

Kölner Stadtanzeiger. Sonderdruck »Kolonie der Qualen«, August/September 1997.

Kuller, Christiane. Bürokratie und Verbrechen. Antisemitische Finanzpolitik und Verwaltungspraxis im nationalsozialistischen Deutschland, Berlin u.a. 2013.

Künz, Bärbel. Die Colonia Dignidad zwischen kollektiver Freistatt und instrumentalisiertem Zwangskollektiv. [unveröffentlichte Diplomarbeit], Köln 2010.

La Epoca vom 02.03.1988, S. 16. »Pinochet debe intervenir en Dignidad«.

La Epoca vom 22.01.1989, S. 13. »Obispo Camus, escéptico ante el caso de Colonia Dignidad«.

La Epoca vom 05.02.1991, S. 11. „Cuatro sociedades anónimas de colonos son dueñas de los bienes de Dignidad«.

La Epoca vom 10.02.1991, S. 20. »El informe de H.F. Errázuriz sobre Dignidad.«

La Epoca vom 23.02.1991, S. 12. »Eduardo Garcés, un condenado que sobrevivió«.

La Epoca vom 20.03.1991, S. 15. »17 senadores de derecha llevan el caso Dignidad al Tribunal Constitucional«.

La Epoca vom 06.01.1995, S. 22, »Cámara acordó comisión por caso Dignidad«.

La Epcoa vom 20.01.1996, S. 21. »Gobierno alemán realiza gestiones por colono Karl Albert Stricker. Diputados presentan recurso de amparo y piden ministro en visita«.

La Epoca vom 24.10.1996, S. 20. »Investigaciones podrá detener a líder de Dignidad Paul Schäfer«.

La Epoca vom 18.08.1997, S. 14. »Los 36 años de historia del centro asistencial«.

La Epoca vom 03.05.1998, S. 14. »Dignidad: Terminó ocupación policial«.

La Nación Domingo vom 13.03.2005. »Los dólares del tio permanente«.

La Nación Domingo vom 30.07.2006. »El arsenal químico de Colonia Dignidad«.

La Nación vom 19.01.1967, S. 6. »No se han descubierto radios clandestinos en Colonia Dignidad «.

La Nación vom 15.03.1968, S. 2. „¿Dónde están Wilhelmine Erna Lindemann y sus tres hijitos?«.

La Nación vom 21.03.1985, S. 6: »Primera Dama inauguró escuela en Dignidad«.

La Nación vom 20.01.1996, S. 8: »Curiosa fuga de colono de Dignidad«.

La Nación vom 14.03.1997, S. 14. »Hermetismo en caso de niños sustraidos«.

La Nación vom 13.08.1997, S. 1. »Hopp en prisión«.

La Nación vom 17.08.1997, S. 10. »Querella criminal contra Dignidad«.

La Nación vom 27.01.1999, S. 9. »Acusan a Carabineros«.

La Nación vom 16.03.2002, S. 8. »Congelado murió colono de Villa Baviera«.

La Nación vom 04.04.2004, S. 22. »Escapando del tío Paul«.

La Nación vom 30.03.2005, S. 11. »El secreto interrogatorio a Michael Townley«.

La Nación vom 06.07.2005. »Diputado UDI Ignacio Urrutia, socio de sucesora de Colonia Dignidad«.

La Nación vom 26.01.2006, S. 7. »Cursan extradición de asesor clave de Schäfer«. 
La Nación vom 29.03.2006, S. 6. »Abren archivos secretos de la Colonia Dignidad a jueces de $\mathrm{DDHH}$.

La Nación vom 23.07.2006. »Quemados con fósforo químico«.

La Nación vom 30.07.2006. »El arsenal químico de Dignidad«.

La Nación vom 12.09.2007, S. 7. »Muere una de las víctimas de los abusos de Paul Schäfer«.

La Nación vom 22.06.2008. »Los otros secretos de Colonia Dignidad«.

La Nación vom 31.10.2010. "Los horrores que siguen vivos en Villa Baviera«.

La Segunda vom 22.08.1979, S. 25. »Hermann Schmidt: En Dignidad solo hacemos el bien«.

La Segunda vom 09.12.1986. »Asesinato de Comerciante: 21 colonos de Colonia Dignidad declararán en juzgado de Santiago - sin sus armas - con ellas deberán presentarse en tribunal de Bulnes«, einsehbar in PA AA, AV NA 31577.

La Segunda vom 12.01.1989, S. 28, »Suprema nombró Ministro en Visita para el caso de Colonia Dignidad «.

La Segunda vom 09.05.1995, S. 44. »Diputado F. Letelier (PPD): >Respaldo al hospital de Villa Baviera««.

La Segunda vom 14.06.1995, S. 21. »Por oficio ayer: Corte Suprema decretó la reapertura del hospital de Villa Baviera«.

La Segunda vom 14.05.1997, S. 2. "Líder de Colonia Dignidad, Schaefer, se quedó sin abogados«.

La Segunda vom 15.05.1997, S. 1. »Jefe de la Colonia alega ssicoterror«".

La Segunda vom 10.06.1997, Sonderbeilage »36 años de >Dignidad en Chile«, S. 4.

La Segunda vom 12.08.1997, S. 1. »Detenido el Dr. Hopp«.

La Segunda vom 22.03.2005, S. 7. »Predicador apocalíptico convence a parte de los colonos de Villa Baviera«.

La Segunda vom 02.10.2006, S. 8. »Funa a distancia«.

La Tarde vom 12.04.1966, S 1. »Nazis se tomaron Colonia »Dignidad«.

La Tercera vom 25.05.1977, S. 2. »Detectan una extraña maniobra antichilena«.

La Tercera vom 23.03.1980, S. 13. »Denuncia científico de U. de Chile - >Colonia Dignidad pretende explotar mineral de titanio«".

La Tercera vom 08.05.1995, S. 6. »Reabrió sus puertas hospital de Dignidad«.

La Tercera vom 12.05.1995, S. 4. »Recurso de protección por hospital«.

La Tercera vom 18.05.1995, S. 7. »Petición ordenaba no innovar: Rechazan recurso por Villa Baviera«.

La Tercera vom 21.01.1996, S. 18. »Dignidad: Denuncian detención arbitraria«.

La Tercera vom 30.06.1997, S. 6-7. »Las andanzas de Paul Schäfer«.

La Tercera vom 14.08.1997, S. 3. »Mónica Madariaga afirma que dirigentes UDI fueron adoctrinados en Villa Baviera«.

La Tercera vom 22.07.1999, S. 12. »Informe de Comisiones Unidas de Familia y Derechos Humanos de la Cámara de Diputados: >Carabineros frustró captura de Schäfer«".

La Tercera vom 19.06.2005, S. 24. "Archivos hallados en ex Colonia Dignidad contienen antecedentes hasta 1987 .

La Tercera vom 10.07.2005, Reportajes, S. 16, »El fin del secreto mejor guardado de Dignidad 
La Tercera vom 08.01.2006, S. 20. »Ex-colonos buscan transformar casa en museo de la tortura«.

La Tercera vom 01.04.2006, S. 26: »FBI apoya búsqueda de estadounidense desaparecido en ex-Colonia Dignidad« und »Finaliza búsqueda de explosivos«.

La Tercera vom 25.09.2006, S. 14. »Prófugo de ex-Colonia Dignidad es miembro de secta en Alemania«.

La Tercera vom 27.09.2006, S. 18. »Alemania abre juicio contra principal prófugo de ex-Colonia Dignidad«.

La Tercera vom 23.10.2014, S. 18. »PDI busca documentos en Villa Baviera«.

La Tribuna de Los Angeles vom 05.07.1962. »Jóven Alemán refugiado protagoniza espectacular escapada desde Parral«.

Lagos, Jaime/Paul Friedrich Violenstein. Colonia Dignidad - Buscando la salida del laberinto, Santiago 1988.

Landtag Nordrhein-Westfalen. Drucksache 15/2782 vom 18.09.2011. Kleine Anfrage 1110, Conrads, Anna LINKE. Ermittlungen der NRW-Justiz zur Colonia Dignidad (Teil 1).

Landtag Nordrhein-Westfalen. Drucksache 15/2783 vom 18.09.2011. Kleine Anfrage 1111, Conrads, Anna LINKE. Ermittlungen der NRW-Justiz zur Colonia Dignidad (Teil 2).

Landtag Nordrhein-Westfalen. Drucksache 15/2784 vom 18.09.2011. Kleine Anfrage 1112, Conrads, Anna LINKE. Ermittlungen der NRW-Justiz zur Colonia Dignidad (Teil 3).

Landtag Nordrhein-Westfalen. Drucksache 15/2785 vom 18.09.2011. Kleine Anfrage 1113, Conrads, Anna LINKE. Vermögensverhältnisse des früheren Vize-Chefs der Colonia Dignidad.

Landtag Nordrhein-Westfalen. Drucksache 15/2786 vom 18.09.2011. Kleine Anfrage 1114, Conrads, Anna LINKE. Illegale Finanzströme und Geldwäsche bei Vereinigungen rund um die Colonia Dignidad.

Landtag Nordrhein-Westfalen. Drucksache 15/2787 vom 18.09.2011. Kleine Anfrage 1115, Conrads, Anna LINKE. Approbation des früheren Vize-Chefs der Colonia Dignidad Hartmut $\mathrm{H}$.

Landtag Nordrhein-Westfalen. Drucksache 15/2968 vom 11.10.2011. Antwort JM zu KlAnfr 1112, Drs 15/2784. Ermittlungen der NRW-Justiz zur Colonia Dignidad (Teil 3).

Landtag Nordrhein-Westfalen. Drucksache 15/2969 vom 11.10.2011. Antwort JM zu KlAnfr 1113, Drs 15/2785. Vermögensverhältnisse des früheren Vize-Chefs der Colonia Dignidad.

Landtag Nordrhein-Westfalen. Drucksache 15/2970 vom 11.10.2011. Antwort JM zu KlAnfr 1114, Drs 15/2786. Illegale Finanzströme und Geldwäsche bei Vereinigungen rund um die Colonia Dignidad.

Landtag Nordrhein-Westfalen. Drucksache 15/2971 vom 11.10.2011. Antwort JM zu KlAnfr 1115, Drs 15/2787.

Landtag Nordrhein-Westfalen. Drucksache 15/3025 vom 18.10.2011. Antwort JM zu KlAnfr 1110, Drs 15/2782. Ermittlungen der NRW-Justiz zur Colonia Dignidad (Teil 1).

Landtag Nordrhein-Westfalen. Drucksache 15/3026 vom 18.10.2011. Antwort JM zu KlAnfr 1111, Drs 15/2783. Ermittlungen der NRW-Justiz zur Colonia Dignidad (Teil 2).

Larraín Cruz, Rafael (Hg.). Fallos del Tribunal Constitucional pronunciados entre el 23 de diciembre 1985 y el 23 de junio 1992. Santiago 1993, S. 379ff. 
Las Noticias de Ultima Hora vom 16.02.1968, S. 7. »Dirigentes de Colonia Dignidad responden a acusaciones en su contra«.

Las Ultimas Noticias vom 25.10.1977, [Artikel zur Ermordung von Juan René Muñoz Alarcón] ohne Titel, einsehbar in PA AA, ZW 111131.

Las Ultimas Noticias vom 12.09.1980, S. 20. "Qué devuelvan a mi sobrino los de la Colonia Dignidad«.

Las Ultimas Noticias vom 19.12.1987, S. 4. »Mi hijo apareció en colonia Dignidad«.

Las Ultimas Noticias vom 18.04.1997, S. 4. »La increíble historia del >Kito««.

Las Ultimas Noticias vom 30.04.1997, S. 12. »La Justicia de Chile resolverá el caso Schäfer«.

Las Ultimas Noticias vom 26.05.1997, S. 6. »No ve a su hijo hace 23 años«.

Las Ultimas Noticias vom 16.06.1997, S. 3. „Schäfer resistirá«.

Las Ultimas Noticias vom 09.07.1997, S. 5. »Investigan Adopción de hijo de Hopp«.

Las Ultimas Noticias vom 14.08.1997, S. 5. »Madariaga y su paso por Dignidad«.

Las Ultimas Noticias vom 26.08.1998, S. 5. »Restos exhumados son de Schmidt«.

Las Ultimas Noticias vom 19.01.1999, S. 13. »A Roberto Dávila - Pidieron agilizar proceso contra Paul Schaefer«.

Lateinamerika Nachrichten Nr. 7/1978, S. 5. »Ein DINA-Agent packt aus«.

Lateinamerika Nachrichten. Colonia Dignidad - Der doppelte Skandal: Der Prozeß vor dem Bonner Landgericht - eine Dokumentation. Sondernummer, September 1980.

Lateinamerika Nachrichten. Colonia Dignidad. Der Skandal geht weiter, Sonderheft, Dezember 1989.

Lateinamerika Nachrichten. Colonia Dignidad. Sociedad benefactora y educacional dignidad. Gesellschaft für Wohlfahrt und Erziehung...und Freiheitsberaubung und Folter und Geheimdienstkontakte. Lateinamerika Nachrichten, Nr. 166/1988, online unter https://lateinamerika-nachrichten.de/wp-content/uploads/2014/12/LN166_W eb.pdf.

Lauterpacht, E./Greenwood, C. J. (Hg.) International Law Reports, Vol 89, Cambridge, 1992, S. 6of.

Le Figaro vom 14.04.1966. »Un >camp nazi< aurait été découvert au Chili«.

Le Figaro vom 16.04.1966. »Le >camp de concentration< chilien. L'un des dirigeants Hermann Schmidt arrêté et écroué«.

Le Monde vom 14.04.1966. „Une colonie agricole allemande aurait été transformée en camp de concentration «.

Le Monde vom 19.04.1966. "L'affaire du camp de concentracion du Chili«.

Liberona, Carlos/Lucía Sepúlveda Ruiz. Memorias de un labrador de futuro. Carlos Liberona, el amor y la lucha, Santiago 2010.

Löhning, Ute. »Ein Gedenkort fehlt bis heute«, in: die tageszeitung vom 26.04.2021, S. 7, online unter https://taz.de/Verbrechen-der-Colonia-Dignidad/!5762644/.

Löhning, Ute. »Wer brachte die Colonia Dignidad zu Fall?«, in: WDR 5. Neugier genügt - das Feature vom 12.02.2019, online unter https://www.swr.de/swr2/progr amm/SWR2-Leben-Sie-brachten-die-Colonia-Dignidad-zu-Fall,broadcastcontribswr-28808.html. Sendemanuskript online verfügbar unter https://www.swr.de/-/i $\mathrm{d}=24180136 /$ property=download/nid=660174/j2jioo/swr2-leben-20190708.pdf. 
Löhning, Ute, »Der Sektenarzt aus Krefeld«, in: die tageszeitung vom 17.06.2018, online unter https://www.taz.de/Colonia-Dignidad-in-Chile/!5511389/.

Löhning, Ute. »Dahinten, da ist was rot « - Frauen in der Colonia Dignidad, in: Nachrichtenpool Lateinamerika (npla), 30.12.2017, online unter https://www.npla.de/th ema/memoria-justicia/dahinten-da-ist-was-rot-frauen-in-der-colonia-dignidad/.

Londres 38 (Website), »Archivo de la Colonia Dignidad: ¿Dónde están las piezas que faltan?«, 2014, online unter http://londres38.cl/1934/w3-article-96548.html.

Lowy, Maxine. Memoria Latente: Una comunidad enfrentada por el desafío de los derechos humanos en Chile, Santiago 2016.

Lüthke, Karsten. Der unendliche Prozess. Colonia Dignidad gegen amnesty international, in: Amnesty International (Hg.). 40 Jahre für die Menschenrechte, Neuwied 2001, S. 76-85.

Maier, Dieter. Äußerste Zurückhaltung« - die Colonia Dignidad und die deutsche Diplomatie 1961-1978, Nürnberg, 2008, online verfügbar unter: https://www.mensche nrechte.org/wp-content/uploads/2009/11/Colonia_dignidad.pdf

Maier, Dieter. Colonia Dignidad - Auf den Spuren eines deutschen Verbrechens in Chile, Stuttgart 2016.

Maier, Dieter/Jan Stehle. Colonia Dignidad - pieza clave en el aparato represor de la dictadura cívico-militar. Orígenes, historia criminal y preguntas abiertas, in: Hevia, Evelyn/Jan Stehle (Hg.). Colonia Dignidad: diálogos sobre verdad, justicia y memoria, Santiago 2015, S. 27-70.

Maldonado Prieto, Carlos. La Prusia de América del Sur. Acerca de las relaciones militares chileno-germanas, 1927-1945, in: Estudios Sociales 73 (1992), S. 75.

Mazuré Loos, Lorena. Perspektiven der deutsch-chilenischen Minderheit in Chile auf Colonia Dignidad. [Diplomarbeit], Wien 2009, online unter http://othes.univie.ac. at/4235/1/2009-03-16_0448041.pdf.

Memoriaviva (Webseite), »Comando Conjunto« online unter: https://www.memoriaviv a.com/criminales/organizaciones/comando_conjunto.htm.

Merino Vega, Marcia Alejandra. Mi verdad. Más allá del horror yo acuso, Santiago 2001.

Ministerio del Interior, Comisión Nacional sobre Prision Política y Tortura. Informe de la Comisión Nacional sobre Prision Política y Tortura, Santiago 2004.

Molina Sanhueza, Jorge. "Médicos UC reconocen vínculos del Hospital con creador de venenos de la Colonia Dignidad«, in: El Mostrador vom 15.01.2010, online unter https:/www.elmostrador.cl/noticias/pais/2010/o1/15/medicos-uc-reconocen-vi nculos-del-hospital-con-creador-de-venenos-de-la-colonia-dignidad/.

Molina Sanhueza, Jorge. Crimen Imperfecto: Historia del Químico DINA Eugenio Berrios y la Muerte de Eduardo Frei Montalva, Santiago 2000.

Moya, Laura. La represión en el barrio de José Domingo Cañas durante la dictadura (1973-1990). Memoria de los vecinos. Santiago 2013.

Museo de la Memoria y los Derechos Humanos. Archivos de la Memoria en Chile, Region del Maule. Santiago, 2017.

Naranjo, Jaime. Colonia Dignidad en los debates parlamentarios, in: Hevia, Evelyn/Jan Stehle (Hg.). Colonia Dignidad: diálogos sobre verdad, justicia y memoria, Santiago 2015, S. 153-161. 
Narváez, Luis. »Descubren el lugar donde alemanes quemaron a fusilados de Colonia Dignidad«, in: El Dinamo vom 07.05.2018, online unter https://www.eldinamo.cl/ nacional/2018/05/07/descubren-lugar-donde-alemanes-quemaron-a-fusilados-decolonia-dignidad/.

Narváez, Luis. »La profunda huella de Otto Dörr en Colonia Dignidad«, in: El Dinamo vom 10.04.2018, online unter https:/www.eldinamo.cl/nacional/2018/04/ 10/la-profunda-huella-de-otto-dorr-en-colonia-dignidad/ (zuletzt eingesehen am 10.05.2018).

Narváez, Luis. »Testigo Clave vuelve a ex Colonia Dignidad«, in: Televisión Nacional de Chile, edición central, ausgestrahlt am 22.10.2014.

Narváez, Luis. Las fichas de Colonia Dignidad: dificultades de acceso, calidad de fuentes de información y proyecciones, in: Hevia, Evelyn/Jan Stehle (Hg.). Colonia Dignidad: diálogos sobre verdad, justicia y memoria, Santiago 2015, S. 165-178.

Narváez, Luis. Las fichas del horror. Reihe En la Mira. Chilevisión, 87 min, ausgestrahlt am 09.07.2014, online unter https://www.youtube.com/watch?v=eBW-tQOjwoI.

Neues Deutschland vom 04.05.1966. »Bonner Vertretung duldete KZ-Skandal«.

Neues Deutschland vom 15.04.1966. "Nazi-KZ in Chile«.

Neuhoff, Ulrich/Klaus Weidmann. "Die Sekte der Folterer«, Reportage der ARDSendereihe »Die Story im Ersten«, 45 min, Erstausstrahlung am 14.11.2016.

Nützenadel, Alexander (Hg.). Das Reichsarbeitsministerium im Nationalsozialismus: Verwaltung - Politik - Verbrechen. [Unabhängige Historikerkommission zur Geschichte des Reichsarbeitsministeriums 1933-1945], Göttingen 2017.

O. A. [Johannes Wieske]. »Festschrift 50 Jahre in Chile 1961-2011«, o. O. [Parral], o.J. [2011].

O. A. [SBED]. »15 años Sociedad Benefactora y Educacional Dignidad. 1961-1976«» o. O. [Parral], o.J. [1976].

O. A. [SBED]. »Festschrift 15 Jahre in Chile 1961-1976«, o. O. [Parral], o.J. [1976].

Ossendorf, Karlheinz. Colonia Dignidad - Die »Würde« gab es nur im Namen. Die Sekte Private Sociale Mission im Raum Siegburg, in: Geschichts- und Altertumsverein für Siegburg und den Rhein-Sieg-Kreis e. V. (Hg.). Heimatblätter des Rhein-SiegKreises 2009, 77. Jahrgang, Siegburg 2009, S. 240-269.

Penjean, Lorena. "Niels Biedermann, psiquiatra de los sobrevivientes de Colonia Dignidad: >Nunca, en los trece años que llevo trabajando con los colonos he oído mencionar el nombre del doctor Dörr« [Interview mit Niels Biedermann und Karin Hinzner], in: The Clinic (Website), 02.05.2018, online unter https:/www.the clinic.cl/2018/05/02/niels-biedermann-psiquiatra-los-sobrevivientes-colonia-digni dad-nunca-los-trece-anos-llevo-trabajando-los-colonos-he-oido-mencionar-nom bre-del-doctor-dorr/.

Pérez Ricart, Carlos A. MEREX AG o la frontera de lo (i)legal en la política alemana de exportación de armamento. México vía Berlín Working Papers, Nr. 3, Berlin 2014, online unter https://www.ssoar.info/ssoar/handle/document/38508.

Pieper, Dietmar/Helene Zuber. »Die Pistole lag immer griffbereit. Tobias Müller und Salo Luna über Tyrannei und sexuellen Mißbrauch in der Colonia Dignidad«, in: Der SPIEGEL Nr. 33/1997 vom 11.08.1997, S. 124-127. 
Poblete, María Teresa/Fréderic Ploquin. La colonie du docteur Schaefer: Une secte nazie au pays de Pinochet, Paris 2014.

Poder Judicial. Noticias del Poder Judicial vom 22.04.2021. »Caso Colonia Dignidad: Ministra Paola Plaza realiza diligencias en Parral y Villa Baviera«, online unter http s://www.pjud.cl/prensa-y-comunicaciones/noticias-del-poder-judicial/55129.

Poder Judicial. Noticias del Poder Judicial vom 03.07.2018. »Ministro Mesa realiza nuevas diligencias en el marco de causas por asesinatos, apremios y desaparición turista Holandés«, übernommen von https://www.somosnoticias.cl/2018/07/minis tro-mesa-realiza-nuevas-diligencias-en-el-marco-de-causas-por-asesinatos-apre mios-y-desaparicion-turista-holandes/.

Poder Judicial. Noticias del Poder Judicial vom 03.07.2014. »Corte Suprema solicitó a Alemania que Harmut Hopp cumpla condena por abusos sexuales en ese país«, übernommen von https:/www.biobiochile.cl/noticias/2014/07/03/corte-suprema-s olicita-a-alemania-que-harmut-hopp-cumpla-condena-por-abuso-sexual-en-esepais.shtml.

Poder Judicial. Noticias del Poder Judicial vom 28.01.2013, „Corte Suprema dicta sentencia en investigación por abusos sexuales en la ex Colonia Dignidad«, übernommen von: https://www.lasegunda.com/Noticias/Nacional/2013/o1/817731/Cort e-Suprema-dicta-sentencia-en-investigacion-por-abusos-sexuales-en-la-ex-Colon ia-Dignidad.

Quick Nr. 18/1988 vom 27.04.1988, S. 20-27. »Die geheime Kolonie«.

Ramírez, Pedro. "Crisis en la ex Colonia Dignidad desata pugna por la fortuna que ocultó Schäfer.« in: CIPER (Website), 24.03.2009, online unter: https://ciperchile.cl /2009/03/24/crisis-en-la-ex-colonia-dignidad-desata-pugna-por-la-fortuna-que-o culto-schafer/

Ramírez, Pedro. „Crisis en la ex Colonia Dignidad desata pugna por la fortuna que ocultó Schäfer, in: CIPER (Website), 24.03.2009, online unter http://ciperchile.cl/2 009/03/24/crisis-en-la-ex-colonia-dignidad-desata-pugna-por-la-fortuna-que-ocu lto-schafer/.

Ramírez, Pedro. »La negociación que entrega US\$6 millones para indemnizar a las víctimas de Schäfer«, in: CIPER (Website), 28.08.2009, online unter http://ciperchile.cl/ 2009/08/28/la-negociacion-que-entrega-us6-millones-para-indemnizar-a-las-victi mas-de-schafer/. [Escritura pública zwischen dem CDE und den Vertretern von Cerro Florido und Abratec unterzeichnet am 21.08.2009]

Ramírez, Pedro. »Los secretos del código moral que se desplomó en Colonia Dignidad«, in: CIPER (Website), 26.03.2009, online unter http://ciperchile.cl/2009/03/26/los-s ecretos-del-codigo-moral-que-se-desplomo-en-colonia-dignidad/.

Ramírez, Pedro/Francisca Skonic. »La fuga de Hopp a Alemania enciende alerta sobre los millones que ocultó Schäfer«, in: CIPER (Website), 23.05.2011, online unter http://ciperchile.cl/2011/05/23/la-fuga-de-hopp-a-alemania-enciende-alerta-so bre-los-millones-que-oculto-schafer.

Rebolledo, Javier. La danza de los cuervos. El destino final de los detenidos desaparecidos, Santiago 2012.

Rector, John L. The history of Chile, Westport (CT) 2003. 
Redelfs, Manfred. Erfahrungen mit dem Informationsfreiheitsgesetz: Transparenz für Hartnäckige, in: BBE Newsletter Nr. 16/2007 vom 09.08.2007, online unter https://w ww.b-b-e.de/fileadmin/inhalte/PDF/newsletter/nl-2018-16.pdf, (zuletzt abgerufen am 11.02.2011).

Revista Cauce vom 29.10.1984, S. 32-35. »Otra vez >Dignidad<: >A mi hermano lo asesinaron« «.

Revista Cosas vom 01.04.2005, S. 84ff. »Manuel Contreras Valdebenito: Mis días en Colonia Dignidad«.

Rinke, Stefan. Eine Pickelhaube macht noch keinen Preußen: preußisch-deutsche Militärberater, »Militärethos « und Modernisierung in Chile 1886-1973, in: Carreras, Sandra/Günther Maihold (Hg.). Preußen und Lateinamerika. Im Spannungsfeld von Kommerz, Macht und Kultur, Münster 2004, S. 259-284.

Rittel, Heike/Jürgen Karwelat. Lasst uns reden. Frauenprotokolle aus der Colonia Dignidad, Stuttgart 2018.

Rodríguez, Quezada/Hugo Manuel. Colonia Dignidad - ¿Enigma o desafío?, Santiago 1968.

Rohter, Larry. "Chile sect thrives despite criminal charges«, in: New York Times vom 30.12.2002, S. A3.

Rojas, Alvaro. Los secretos de la Colonia Dignidad, Santiago 1988.

Rückert, Horst. Vom Folterzentrum der Militärdiktatur zum Ferienort. Die Geschichte der »Villa Baviera « in Chile, Stuttgart 2017.

Ruderer, Stephan. Das Erbe Pinochets. Vergangenheitspolitik und Demokratisierung in Chile 1990-2006, Göttingen 2020.

Salinas, Claudio/Hans Stange. Los amigos del »Dr.« Schäfer: La complicidad entre el Estado chileno y Colonia Dignidad, Santiago 2006.

Sandquist, Jan. »Santiago de Chile - våldtagen stad « [»Santiago de Chile - vergewaltigte Stadt«], Sveriges Television 19731973, online unter https://www.youtube.com/watc $h ? \mathrm{v}=14 \mathrm{f} 5 \mathrm{wWD}$ oyg 8 .

Sanhueza, Ana María. »La enigmática Rebeca Schäfer«, in: Qué Pasa vom 30.04.2010, online unter https://www.latercera.com/revista-que-pasa/1-3264-9-la-enigmaticarebeca-schafer/.

Schildmann, Daniela. "50 Jahre und kein Ende in Sicht«, in: Lateinamerika Nachrichten Nr. 450/2011, Dezember 2011, S. 26-28.

Schnellenkamp, Klaus. Geboren im Schatten der Angst: Ich überlebte die Colonia Dignidad, München 2007.

Schneppen, Heinz. Walther Rauff: Organisator der Gaswagenmorde. Eine Biografie, Berlin 2011.

Scholz, Michael. Die Öffnung der Archive für Jedermann. Zur Geschichte der öffentlichen Benutzung, in: Brandenburgisches Landeshauptarchiv (Hg.). Brandenburgische Archive - Mitteilungen aus dem Archivwesen des Landes Brandenburg Nr. 10/1997, S. 4-9, online unter http://blha.brandenburg.de/wp-content/uploads/2017/ 06/Brandenburgische_Archive_10_1997.pdf.

Schwarz, Simone. Chile im Schatten faschistischer Bewegungen. Frankfurt a.M., 1997. Schwember, Herman. Delirios e Indignidad. El Estéril Mundo de Paul Schäfer, Santiago 2009. 
Senado, Diario de Sesiones, Legislatura $348^{\mathrm{a}}$, Sesión $41^{\mathrm{a}}$ vom 16.04.2003. Evaluación de estado actual de ex Colonia Dignidad (observaciones del señor Naranjo).

Senado, Diario de Sesiones, Legislatura extraordinaria 1967-1968, Sesión $61^{\mathrm{a}}$ vom 27.02.1968, S. 2416-2436. Informe de la Comision de Constitucion, Legislacion, Justicia y Reglamento, recaido en la peticion de desafuero formulada por don Hermann Schmidt georgi, en representacion de la Sociedad Benefactora Y Educacional »Dignidad«, en contra del señor Intendente de Linares, don Hector Taricco Salazar y del gobernador de Parral, don Claudio Fuentes Avello.

Senado, Diario de Sesiones, Legislatura extraordinaria 1967-1968, Sesión $62^{\mathrm{a}}$ vom 28.02.1968, S. 2471.

Senado, Diario de Sesiones, Legislatura extraordinaria 1967-1968, Sesión $62^{\mathrm{a}}$ vom 28.02.1968, S. 2505-2511. Investigación de actividades de la »Sociedad Benefactora y Educacional Dignidad.«

Senado, Diario de Sesiones, Legislatura extraordinaria 1967-1968, Sesión $63^{\mathrm{a}}$ vom 05.03.1968, S. 2543.

Sepúlveda, Lucía. 119 de nosotros. Santiago 2005.

Sierck, Gabriela M./Michael Krennerich/Peter Häußler (Hg.). Handbuch der Menschenrechtsarbeit, Edition 2006/2007, Berlin 2007.

Silverstein, Ken. Private Warriors, New York 2000.

Singer, Christine. Deutsche Auswanderer zwischen Mythos und Realität - Zur Sonderstellung der deutschen Minderheit in Chile. [unveröffentlichte Magisterarbeit], Konstanz 1998, online unter http://kops.uni-konstanz.de/bitstream/handle/1234567 89/11487/204_1.pdf.

Skonic, Francisca. »Casa de Piedra: el secreto lugar de juerga y tortura de la DINA.«, in: CIPER (Website), 02.11.2007, online unter http://ciperchile.cl/2007/11/02/casa-de-p iedra/.

Spiegel Online vom 07.06.2016. »Sektenarzt soll in Deutschland in Haft«: https://www .spiegel.de/panorama/justiz/colonia-dignidad-sektenarzt-soll-in-deutschland-inhaft-a-1096367.html.

StA Krefeld Pressemitteilung vom 06.05.2019, online unter https://www.stakrefeld.nrw.de/behoerde/presse/Presseerklaerung-zu-3-Js-753-11Ermittlungverfahren-gegen-Hartmut-H.pdf.

StA Münster. Presseerkläreung vom 22.01.2019, online unter https://www.sta-muenst er.nrw.de/behoerde/presse/Archiv/Archiv_2019/Pressemitteilung-vom-22_01_2019 .pdf.

Stehle, Jan. Das Amt und der Aktenzugang. Meine Bemühungen um Aktenfreigabe beim Auswärtigen Amt im Kontext des Berichts der Historikerkommission sowie der Archivierungspraxis des Auswärtigen Amts, in: Hawel, Markus (Hg.). Work in progress. Work on progress. Doktorand_innen-Jahrbuch der Rosa-LuxemburgStiftung, Bd.1, Berlin 2011, S. 119-133, online unter https://www.rosalux.de/fileadm in/rls_uploads/pdfs/sonst_publikationen/JB2011_studienwerk.pdf.

Stehle, Jan. La muerte de Karl Stricker y la amnesia de Otto Dörr, in: CIPER (Website), 10.04.2018, online unter https://ciperchile.cl/2018/04/10/colonia-dignidad-la-muer te-de-karl-stricker-y-la-amnesia-de-otto-dorr/. 
Stern Nr. 40/1967 vom 01.10.1967. »Angst vor der Sekte. Eine verzweifelte Mutter tötete sich und ihre drei Kinder.«

Stern Nr. 50/1987 vom 03.12.1987. »Das Lager des Schreckens«.

Straßner, Veit. Die offenen Wunden Lateinamerikas. Vergangenheitspolitik im Postautoritären Argentinien, Uruguay und Chile. Wiesbaden, 2007.

Süddeutsche Zeitung vom 18.06.1978, »Spitzel der Militärjunta Chiles sagt aus«, einsehbar in PA AA, ZW 111131.

Tagesschau.de. »Colonia Dignidad - Deutsche Renten für die Sekte«, 18.11.2016, online unter https://www.tagesschau.de/ausland/colonia-dignidad-deutsche-renten101.html (zuletzt abgerufen am 26.11.2016).

The Clinic vom 04.07.2014, S. 24-25. »Aparecen las grabaciones secretas de Paul Schaefer al interior de Colonia Dignidad«.

Thun, Konstantin. Menschenrechte und Außenpolitik, Bundesrepublik Deutschland Argentinien 1976-1983, Bad Honnef 2006.

U.S. Department of State. Freedom of Information Act. Chile Declassification Project: Final Release, online unter https://foia.state.gov/Search/PressRelease.aspx?q=state \&type $2=20001113$.

U. S. Department of State. Freedom of Information Act (FOIA). Virtual Reading Room. DB Santiago 10081 an das State Department vom 16.12.1977. »Subject: The strange case of Juan Munoz: Ambassador's social secretary questioned«, online unter: https://www. foia.state.gov.

U. S. Department of State. Freedom of Information Act (FOIA). Virtual Reading Room. Memorandum of Conversation, Gesprächsnotiz.1976 von Charles R. Stout, Acting DCM [Deputy Chief of Mission] Santiago mit Henning Leopold von Hassell, German DCM, vom 22.11.1976, online unter: https://www.foia.state.gov.

U. S. Department of State. Freedom of Information Act (FOIA). Virtual Reading Room. Website, online unter: https://www.foia.state.gov.

United Nations Office of the High Commissioner for Human Rights (OHCHR). International Convention for the Protection of All Persons from Enforced Disappearance, online unter https://www.ohchr.org/EN/HRBodies/CED/Pages/ConventionCED.as px.

United Nations Economic and Social Council (ECOSOC). Bericht A/31/253 vom 08.10.1976. Protection of Human Rights in Chile. Note by the Secretary-General, online unter https://documents-dds-ny.un.org/doc/UNDOC/GEN/N76/193/25/PDF /N7619325.pdf?OpenElement (Englisch), https://documents-dds-ny.un.org/doc/UN DOC/GEN/N76/193/27/PDF/N7619327.pdf?OpenElement (Spanisch).

United Nations Economic and Social Council (ECOSOC). Bericht E/CN.4/1188 vom 04.02.1976. Report of the ad hoc working group established under resolution 8 (XXXI) of the Commission On Human Rights to inquire into the present situation of human rights in Chile, online unter https://documents-dd s-ny.un.org/doc/UNDOC/GEN/G76/021/02/PDF/G7602102.pdf?OpenElement (Englisch), https://documents-dds-ny.un.org/doc/UNDOC/GEN/G76/021/05/PDF/G76 02105.pdf?OpenElement (Spanisch).

Utsch, Michael (Hg.) (2012): Pathologische Religiosität - Genese, Beispiele, Behandlungsansätze, Kohlhammer Verlag, Stuttgart 
VEA vom 10.08.1967, S. 8: »Indignidades en Colonia Dignidad«.

VEA vom 14.04.1966, S. 8f. »Misterio y conjeturas en la colonia alemana de Parral«.

Vedder, Efraín/Ingo Lenz. Weg vom Leben. 36 Jahre Gefangenschaft in der deutschen Sekte Colonia Dignidad, Berlin 2005.

Vega, Pedro. »Revelan espeluznante caso. Niño fue apropiado por ex Colonia Dignidad«, in: La Nación vom 15.08.1997.

Verwaltung des Deutschen Bundestags (Hg.). Datenhandbuch zur Geschichte des Deutschen Bundestags 1994-2003, erstellt von Michael F. Feldkamp unter Mitarbeit von Birgit Ströbel, Berlin, 2005, S. 346, online unter: https:/www.bundestag.de/re source/blob/189498/4b3f91ce2dfodf2fc96b28172930e5fi/Datenhandbuch1994_2003data.pdf.

Vielain, Heinz. Waffenhandel im Staatsauftrag. Was lange in Bonn geheim bleiben musste, Herford 1986.

Villa Baviera (Website). Hotel. [o.J.], online unter https://www.villabaviera.cl/hotel/.

Villarubia, Gustavo. »Los 13 meses para encontrar a Schäfer«, in: Qué Pasa vom 30.04.2010, online unter https://www.quepasa.cl/articulo/actualidad/2010/04/1-32 63-9-los-13-meses-para-encontrar-a-schafer.shtml/.

Villarubia, Gustavo. »Mi vida bajo el régimen de Paul Schäfer«. La historia de uno de los guardaespaldas del líder de Colonia Dignidad [Interview mit Friedhelm Zeitner], in: CIPER (Website), 23.09.2013, online unter https://www.ciperchile.cl/2013/09/23 /"mi-vida-bajo-el-regimen-de-paul-schafer"/.

Vogelsgesang, Wolfgang. »Augenschein in Chile: die Colonia Dignidad am Fuß der Anden ein Musterbeispiel deutscher Aufbauleistung.«, in: Sudetendeutsche Zeitung vom 09.11.1979.

Von Bullion Constanze/Boris Herrmann. »Unerwünschter Gast«, in: Süddeutsche Zeitung vom 16./17.07.2016, S. 9.

von Pottstock Molina, Edmundo Maximilano Carlos. Cancelación de la personalidad jurídica de la corporación sociedad benefactora y educacional Dignidad. [Unveröffentlichte Lizenziatsarbeit], Universidad de Chile, Santiago 1999.

Voß, Silke. Parlamentarische Menschenrechtspolitik. Die Behandlung internationaler Menschenrechtsfragen im deutschen Bundestag unter besonderer Berücksichtigung des Unterausschusses für Menschenrechte (1972-1998), Düsseldorf 2002.

Walter, Klaus H. Colonia Dignidad, die unendliche Geschichte, in: Deutsches Institut für Menschenrechte et al. (Hg.). Jahrbuch Menschenrechte 2007, Frankfurt a.M. 2006, S. 183-188.

Washington Post vom 28.07.1991. "Panama: Dirty business as usual.«

Washington Post vom 18.01.2003, S. A20. »Tracing a mystery of the missing in Chile.« Westdeutsche Zeitung vom 18.08.2011. »Geflüchteter Sektenarzt lebt in Krefeld von Sozialhilfe«, online unter: https://www.wz.de/nrw/krefeld/colonia-dignidad-gefluech teter-sekten-arzt-lebt-in-krefeld-von-sozialhilfe_aid-30517537.

Westdeutsche Zeitung vom 18.08.2011. »Sektenarzt zieht nach Linn«, online unter http s://www.wz.de/nrw/krefeld/sektenarzt-zieht-nach-linn_aid-30517581.

Westdeutsche Zeitung vom 24.08.2011. »Colonia Dignidad: Wohnstätte kündigt H. BKA Fragt in Chile an«, online unter https:/www.wz.de/nrw/krefeld/colonia-dign idad-wohnstaette-kuendigt-h-bka-fragt-in-chile-an_aid-30517481. 
Westdeutsche Zeitung vom 26.08.2011. »Am Samstag soll Demo vor H. neuer Wohnung stattfinden«, online unter: https://www.wz.de/nrw/krefeld/colonia-dignidad-am-s amstag-soll-eine-demo-vor-h-neuer-wohnung-stattfinden_aid-30517465.

Westdeutsche Zeitung vom 25.06.2018. »Hopp soll sein Schweigen brechen«.

Westfälische Rundschau vom 28.12.1979. »Waffenhändler: Colonia Dignidad kein Folterlager .

Widmann, Carlos, »Zucht und Unzucht in der Siedlung >Würde« «, in: Süddeutsche Zeitung vom 08.07.1966, S. 3.

Wiedemann, Charlotte, »Kohl gibt Chiles Diktator Pinochet Kredit«, in: die tageszeitung vom 17.12.1987, S. 1, 3, online unter https://taz.de/!1855838/.

Willoughby-MacDonald, Federico. La Guerra. Historia íntima del poder en los últimos 55 años de política chilena 1957-2012, Santiago 2012.

Wojak, Irmtrud. Exil in Chile: Die deutsch-jüdische und politische Emigration während des Nationalsozialismus (1933-1945), Reihe Dokumente, Texte, Materialien des Zentrums für Antisemitismusforschung an der TU Berlin, Bd. 16, Berlin 1994.

Ziebur, Ulrike. Die soziolinguistische Situation von Chilenen deutscher Abstammung, in: Linguistik Online 7 (2000) Nr. 3, online unter https://doi.org/10.13092/lo.7.987.

Zuber, Uwe. Verschlusssachen in den Archiven der Länder, in: Jens Niederhut/Uwe Zuber (Hg.). Geheimschutz Transparent? Verschlusssachen in staatlichen Archiven, Essen 2010, S. 93-106.

\section{Archivbestände}

A MMDH

Archivo Museo de la Memoria y los Derechos Humanos

AdsD, NL Waltemathe

Archiv der sozialen Demokratie (Archiv der Friedrich-Ebert-Stiftung), Nachlass Ernst Waltemathe, MdB

AGH, Bestand RFA

Archivo General Histórico, Bestand República Federal de Alemania

Archiv Al, Bestand CD

Archiv von Amnesty International, Sektion Deutschland; Bestand Colonia Dignidad

Archiv BPA

Archiv des Bundespresseamtes

Archiv FDCL, Bestand CD

Archiv des Forschungs- und Dokumentationszentrums Chile-Lateinamerika, Bestand Colonia Dignidad 
Archiv FUNVISOL, Bestand CD

Archiv der Fundación de Documentación y Archivo Vicaría de la Solidaridad, Bestand Colonia Dignidad

BArch, B 206

Bundesarchiv, Bestand Bundesnachrichtendienst

BArch, BW 2

Bundesarchiv, Militärarchiv. Bestand Generalinspekteur und Führungsstab Streitkräfte HISArch, Bestand CD

Archiv des Hamburger Instituts für Sozialforschung, Bestand Colonia Dignidad

PA AA, AV NA

Politisches Archiv des Auswärtigen Amts, Bestand Auslandsvertretungen; Band Nr. $31576,31577,31578,31580,31581,31582,31583,31584,31586,31587,31588,31589,31590$, $31592,31593,31595,31596,31597,31600,31601,31603,31604,31605,31606,31611,31620$, $31637,31638,31644,31645,31646,31653,31666,31679,31681,31682,31683,31686,31687$, $31689,31690,31691,31692,31693,32986,32991,32992,33695$

PA AA, B 130

Politisches Archiv des Auswärtigen Amts, Bestand Verschlusssachenregistraturen; Band Nr. 13631, 13694, 14503

\section{PA AA, B 33}

Politisches Archiv des Auswärtigen Amts, Bestand Länderreferat Mittel- und Südamerika; Band Nr. 463, 465

\section{PA AA, B 82}

Politisches Archiv des Auswärtigen Amts, Bestand Rechtsabteilung, Staats- und Verwaltungsrecht; Band Nr. 371, 991

\section{PA AA, B 83}

Politisches Archiv des Auswärtigen Amts, Bestand Rechtsabteilung, Strafrecht, Steuerund Zollrecht; Band Nr. 702, 890,1177,2384, 2386, 2388

\section{PA AA, B 85}

Politisches Archiv des Auswärtigen Amts, Bestand Rechtsabteilung, Arbeits- und Sozialrecht, Nothilfe für Deutsche im Ausland; Band Nr. 540, 598

PA AA, S 5

Politisches Archiv des Auswärtigen Amts, Bestand Karten und Pläne 
642 Der Fall Colonia Dignidad

PA AA, ZW

Politisches Archiv des Auswärtigen Amts, Zwischenarchiv; Band Nr. 103473, 111129, 111130, 111131, 125131, 146532, 159188, 615483

PA-DBT 3127

Parlamentsarchiv des Deutschen Bundestags, Bestand Unterausschuss für Menschenrechte und humanitäre Hilfe

PDM

Privatarchiv Dieter Maier

PHF

Privatarchiv Hernán Fernández

PJD

Privatarchiv John Dinges

PJK

Privatarchiv Jürgen Karwelat

PJS

Privatarchiv Jan Stehle

PWH

Privatarchiv Winfried Hempel 


\section{Politikwissenschaft}

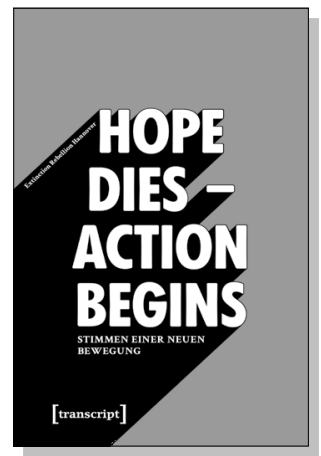

Extinction Rebellion Hannover

"Hope dies - Action begins":

Stimmen einer neuen Bewegung

2019, 96 S., kart.

7,99€ (DE), 978-3-8376-5070-9

E-Book: kostenlos erhältlich als Open-Access-Publikation, ISBN 978-3-8394-5070-3

EPUB: kostenlos erhältlich als Open-Access-Publikation, ISBN 978-3-7328-5070-9

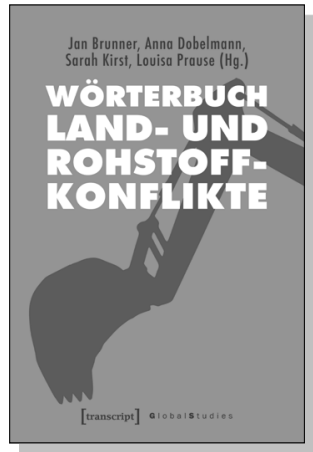

Jan Brunner, Anna Dobelmann, Sarah Kirst, Louisa Prause (Hg.)

Wörterbuch Land- und Rohstoffkonflikte

2019, 326 S., kart., Dispersionsbindung, 1 SW-Abbildung 24,99€ (DE), 978-3-8376-4433-3

E-Book: 21,99€ (DE), ISBN 978-3-8394-4433-7

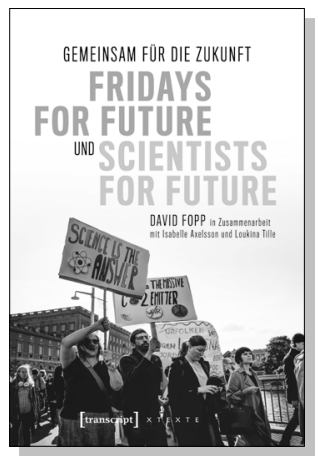

Angela Nagle

Die digitale Gegenrevolution

Online-Kulturkämpfe der Neuen Rechten

von 4chan und Tumblr bis zur Alt-Right und Trump

2018,148 S., kart.

$19,99 €(D E), 978-3-8376-4397-8$

E-Book: 17,99 € (DE), ISBN 978-3-8394-4397-2

EPUB: 17,99 € (DE), ISBN 978-3-7328-4397-8 


\section{Politikwissenschaft}

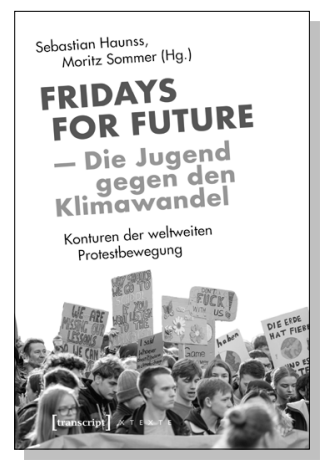

Sebastian Haunss, Moritz Sommer (Hg.)

Fridays for Future -

Die Jugend gegen den Klimawandel

Konturen der weltweiten Protestbewegung

2020,264 S., kart.

$22,00 €(D E), 978-3-8376-5347-2$

E-Book: kostenlos erhältlich als Open-Access-Publikation

PDF: ISBN 978-3-8394-5347-6

ISBN 978-3-7328-5347-2

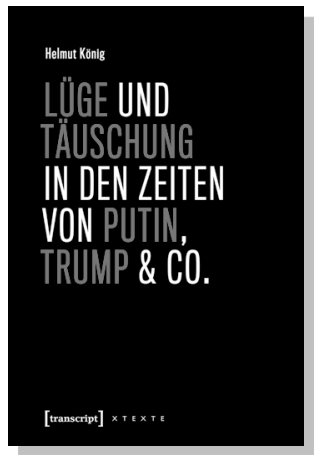

Helmut König

Lüge und Täuschung

in den Zeiten von Putin, Trump \& Co.

2020, 360 S., kart., Dispersionsbindung

29,50€ (DE), 978-3-8376-5515-5

E-Book:

PDF: $26,99 €$ (DE), ISBN 978-3-8394-5515-9

EPUB: $26,99 €$ (DE), ISBN 978-3-7328-5515-5

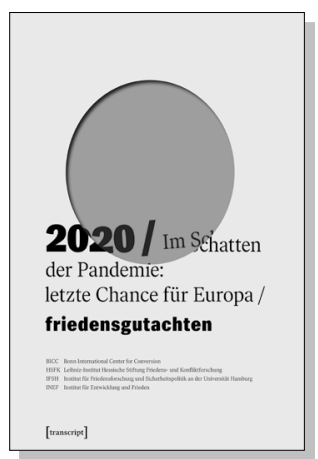

BICC Bonn International Center for Conversion,

HSFK Leibniz-Institut Hessische Stiftung Friedens- und Konfliktforschung, IFSH Institut für Friedensforschung und Sicherheitspolitik an der Universität Hamburg, INEF Institut für Entwicklung und Frieden

\section{Friedensgutachten 2020}

Im Schatten der Pandemie: letzte Chance für Europa

2020, 160 S., kart., Dispersionsbindung, 33 Farbabbildungen $15,00 €(D E), 978-3-8376-5381-6$

E-Book: kostenlos erhältlich als Open-Access-Publikation PDF: ISBN 978-3-8394-5381-0 